

\section{BIOL, DEPT. UNIV. TORONTO.}



BloLi.t
UNIV. TI 
THE

\title{
CAMBRIDGE NATURAL HISTORY
}

\author{
EDITED BY
}

S. F. HARMER, Sc.D., F.R.S., Fellow of King's College, Cambridge ; Superintendent of the University Museum of Zoology

AND

A. E. SHIPLEY, M.A., Fellow of Christ's College, Cambridge ; University Lecturer on the Morphology of Invertebrates

VOLUME VIII

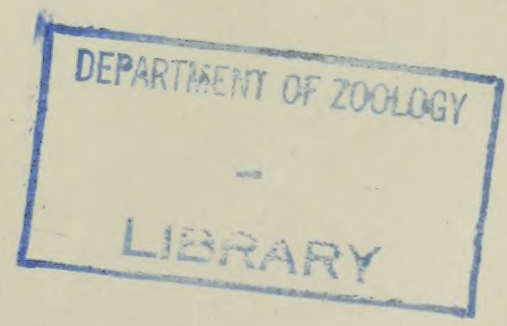


s. 



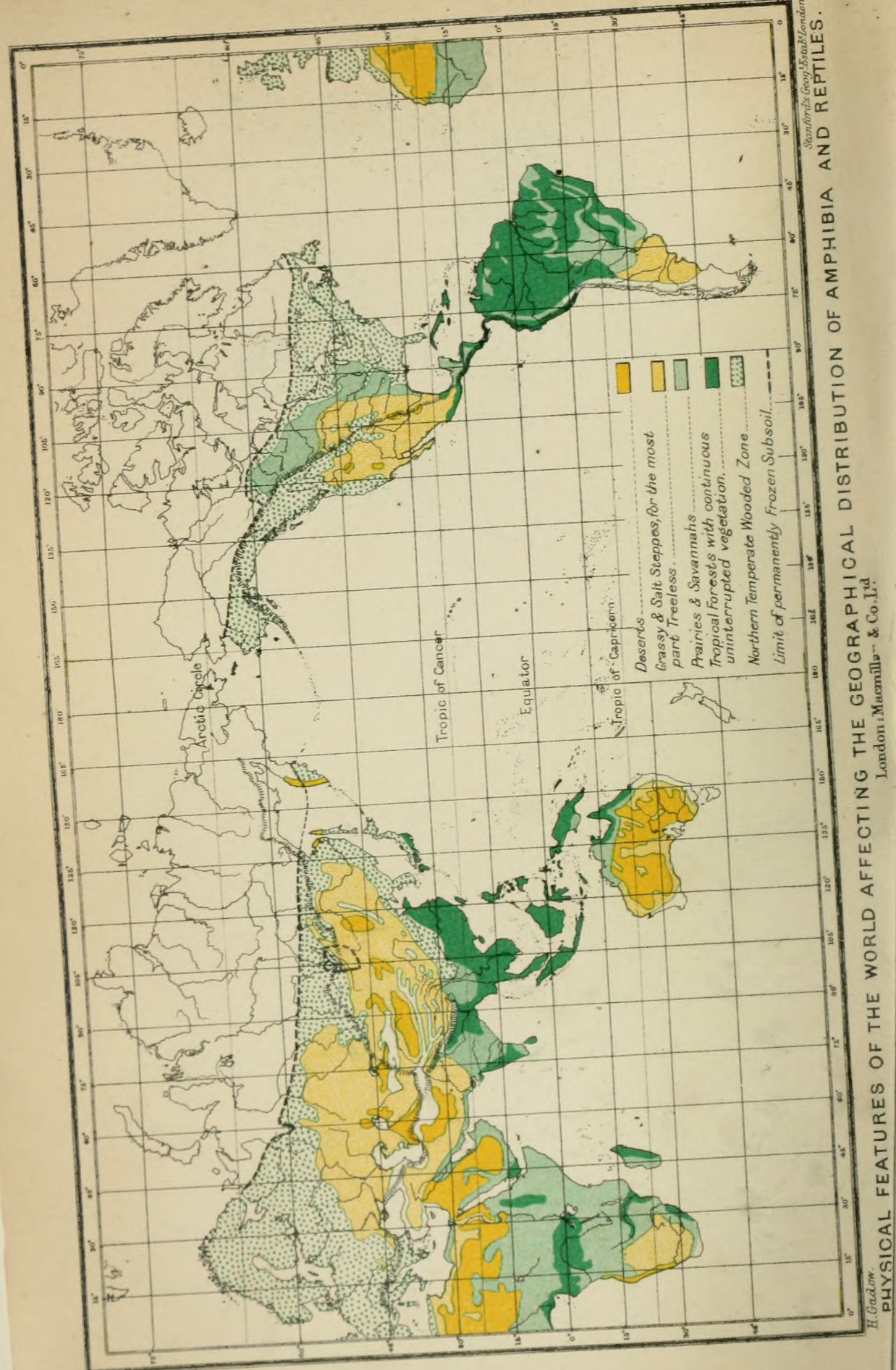




\title{
AMPHIBIA AND REPTILES
}

By Hans Gadow, M.A. (Cantab.), Ph.D. (Jena), F.R.S., Strickland Curator and Lecturer on Advanced Morphology of Vertebrata in the University of Cambridge.
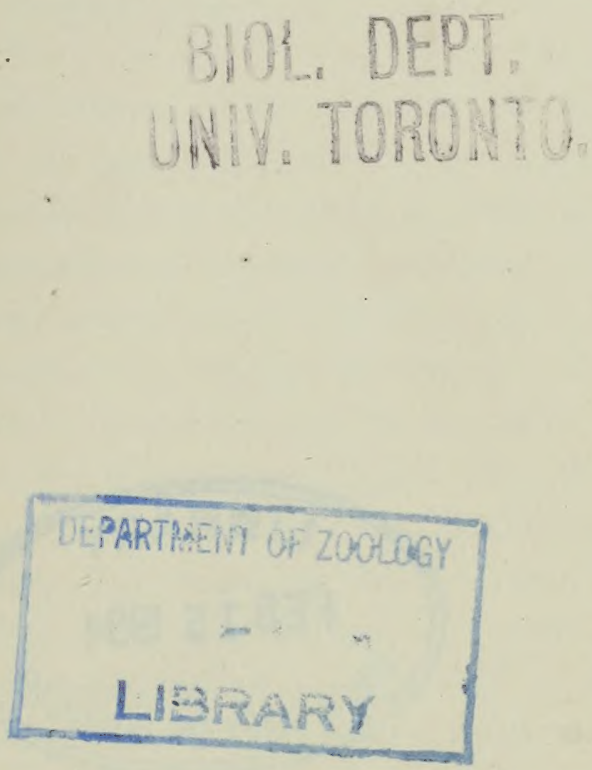

\author{
zononan \\ MACMILLAN AND CO., Limited \\ NEW YORK: THE MACMILLAN COMPANY \\ I 90 I
}


FEB 151994

CASITY of TORON 


\section{PREFACE}

Lrsatecs had hut a poor opinion of the Amphilia and their descrihers, or he would not have called the former " pressima tetraque animalia," nor would he have dismissed the latter with the terse remark: "Amphibiologi omnimn paucissini sunt nullique veri." 'That was, however, nearly 150 years ago; and at the present time there are fewer difticulties in writing a book on Amphibia and Reptiles. Those who care for the study of Amphibia and Reptiles - the Herpetologists, to grive them their scientific title-have never been numerous; lout most of them have been serious students. One reason for the fact that this brauch of Natural History is not very popular, is a prejudice against creatures some of which are clammy and cold to the touch, and some of which may be poisonous. People who delight in keeping Newts or Frogs, Tortoises or Snakes, are, as a rule, consiclered eccentric. But in reality these cold-blocted creatures are of fascinating interest provided they are studied properly. The structure of animals is intimately connected with their life-habits; and this correlation is perhals more alpharent in Amphilia and Reptiles than in any other class. The anatumist who studies internal and external structure is ats much struck with the almost endless rariety in details as he who takes the trouble to olserve the living animal in its native haunts, ar at least umler conditions not too unnatural. He will agree with V. von Scheffel's Toad "that those abore seem to have no 
notion of the beauties of the swamp" - brilliantly coloured

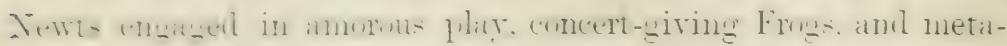

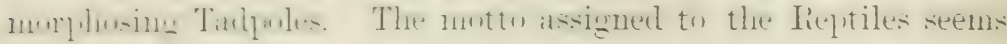

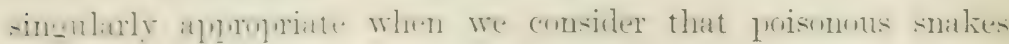

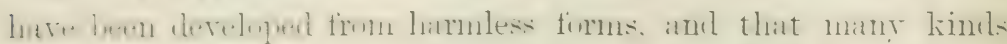
of reptile- hase list linhls. teeth. and eresight in the process of erolution.

The present work is intended to appeal to two kinds of

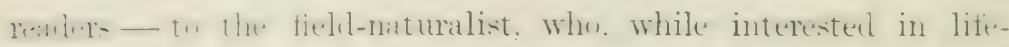

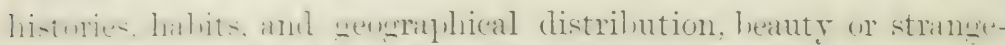

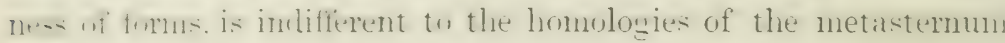

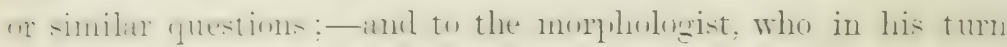
is liable to forget that his specimens were once alive.

A great portion of the book is anatomical and systematic.

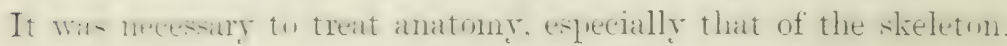
somewhat fully, since it has long been recognised that it is

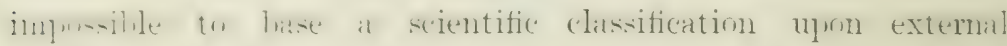

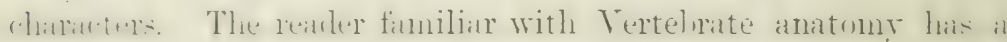

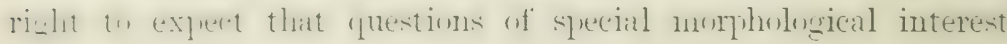
will he drelt upon at length. Those who have no anatomical fountation must be referred to one of the now numerous introductory manuals on the sulject.

The account of the Amphibia is more complete than that of the lieptilia. It was possible to diagnose practically all the recent genera; and this has been especially done in the inum, in orker to show how in an otherwise rery homogeneous group

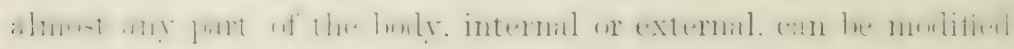
in kaleidoscopic variety. The same could not he done with the lieptilia. Their principal groups, - called sub-classes in the present work, in wrler to emphasise their taxonomic importance in complarison with the main groups of Birds and Mammals, diffir su much from each other that it was rlecirled to refrain 
from attempting a general account of them. Monemser, the number of species of recent lizarls and snakes is so letrildering, the genera of many families heing hut tedinus ramiations of the same theme, that only those forms have been describerl which are the most important, the most striking, or which the traveller is most likely to come acruss. The stulent whu wishes to (no) farther into systematic details must consult the seren rolumes of the Cortulague of Reptiles in the British Musenm (London, 18S9-1S96). Mr. G. A. Poulenger, the anthor of this: magnificent series, has rendered the strstematic treatment of recent Amphibia and Reptiles an easy task. During many rears of the most friendly intercourse I have profited on countless occasions by his ever-ready advice. Although he has kindly read the pronfs of the part clealing with the Amphibia it would be unfair to associate him with any of its shortcomings or with contestahle opinions. for which I alone am responsible.

Cope's large work on the Crocodilians, Lizards, and Snakes of North America (Rep. L.S. Sot. Mus. for 1s9s (1900); has unfortunately appeared too late to les userl in the present work.

The drawings on wood were, with few exceptions, made by Miss M. E. Durham, mostly from living speeimens--a procedure which has to a great extent iletermined the selection of the illustrations.

Since both the metric and the Engliwh sistens of measurements have been employed, it may be well to state for the convenience of the reater that the length of a line of the text is four inches or approximately ten centimeters.

I have frequently and freely quoted accounts of previous authors instear of paraphrasing them. Esprecial thanks are clue (1) Messers. Longmans, Green. and ('o., and to Messrs. Murray, 


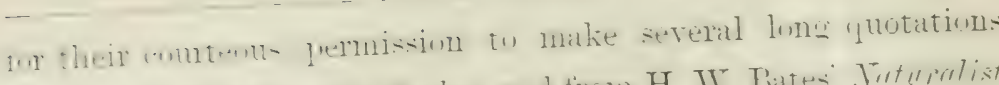

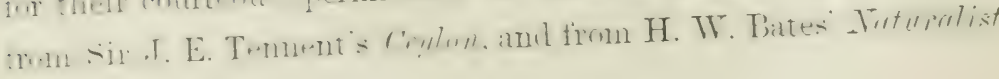
an the River Amrizons.

Lastly, a remark about my Editors. Instead of being a

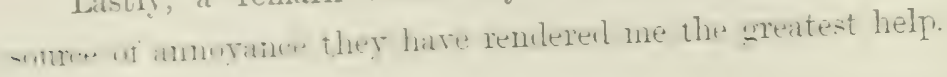

H. GADOW.

Camenidge, Decomber $19,1900$. 


\title{
CONTENTS
}

Preface

Scheme of the Classificatiox ADopted ix this Book

PAOE

\section{PART I. AMPHIBIA}

\author{
('HAPTER I
}

Characteris axd Definition-Positiox of the Class Amphibia is the Phylum Vertebiata-Historical Accourt of the Classification of AMPHIEIA

\section{C'HAPTER II}

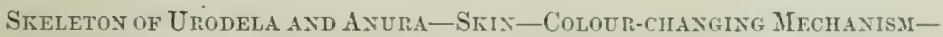
Poison-glands-Spixal Nerves-Respmitafiy Organs-Suppression of Luxgs-Utino-gexital Organs-Fecundation-Numisis Habits

\section{CHAPTER III}

Neotexy-Regeneration-Teyperature-Geographical Distribution .

\section{CHAPTER IV}

Stegocephali or Labyrinthodonts-Lissayphimia-Apoda

('HAPTER T'

LISSAMPHIBIA (CONTINUED)-URODELA . 


\section{PART II. REPTILIA}

CHAPTER VII

PATE

Defistios axi Chanacters-Positios of the Class Remolita ia the

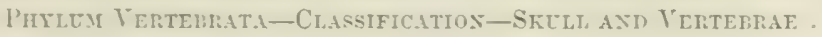

\section{('HAPTER VIII}

Prontptila-Prosatria-Theromoriha $2 \& 5$

CHAPTER IX

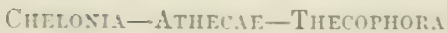

CHAPTER X

DTMosatria-Crocodita

$$
\text { ('HAT'TER XI }
$$

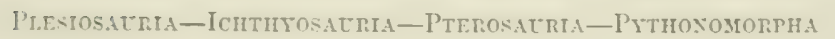
473

\section{r'IHATER XI}

S.THTA-AT"TOSAC゙R. OR LACERTIIA-LIZATRS

\section{CHAPTER XIII}

S.TTTA (CONTINED)-OPHIDA-SNATES 


\section{SCHEME OF THE CLASSIFI(ATION ADOPTEI) \\ IN 'THIS BOOK}

\section{CLASS AMPHIBIA.}

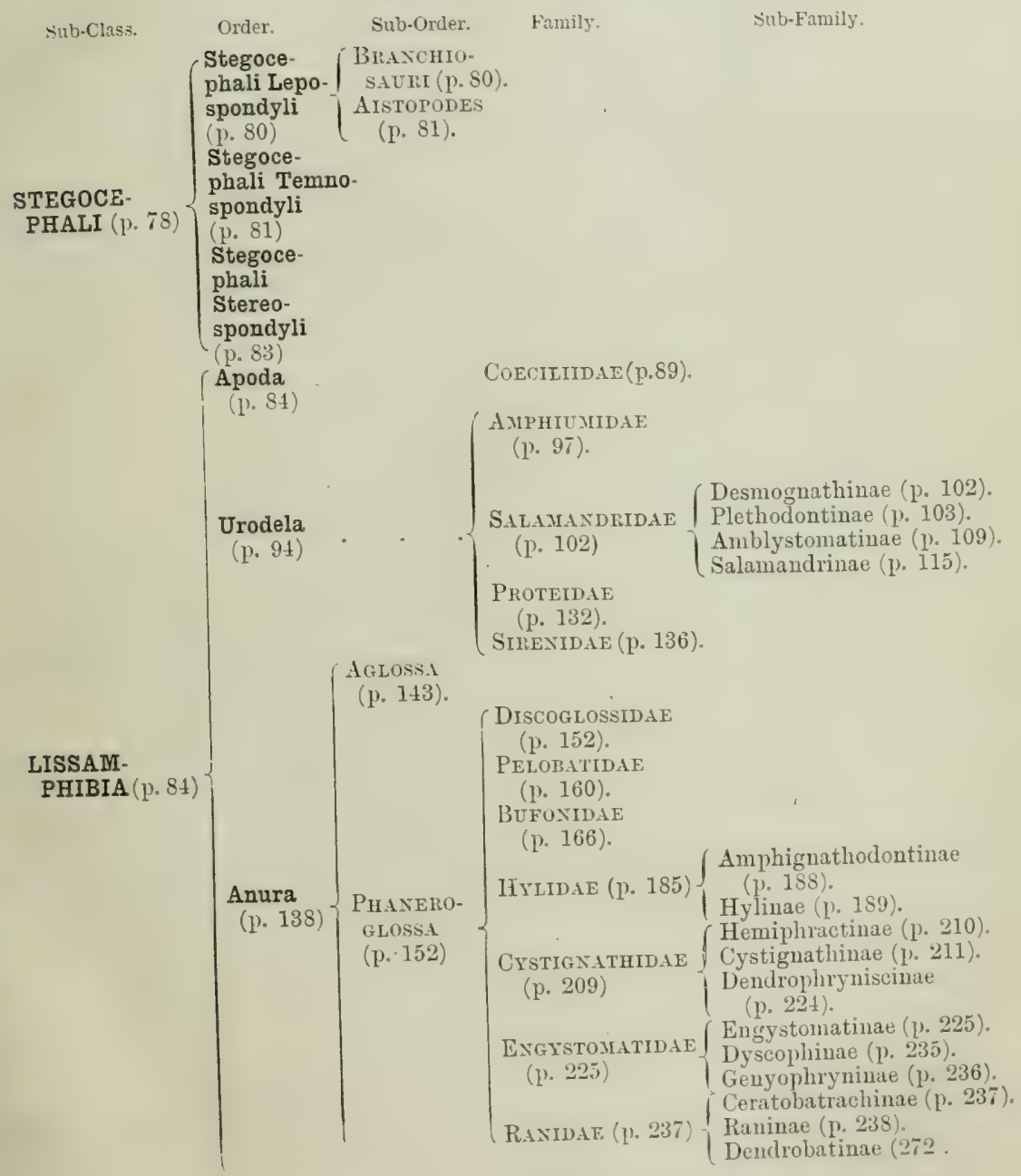




\section{CLASS REPTILIA (p. 27 )}

PROREPTILIA (1, 255). Enyujs (1, 256). C'rieotus (1).25i)

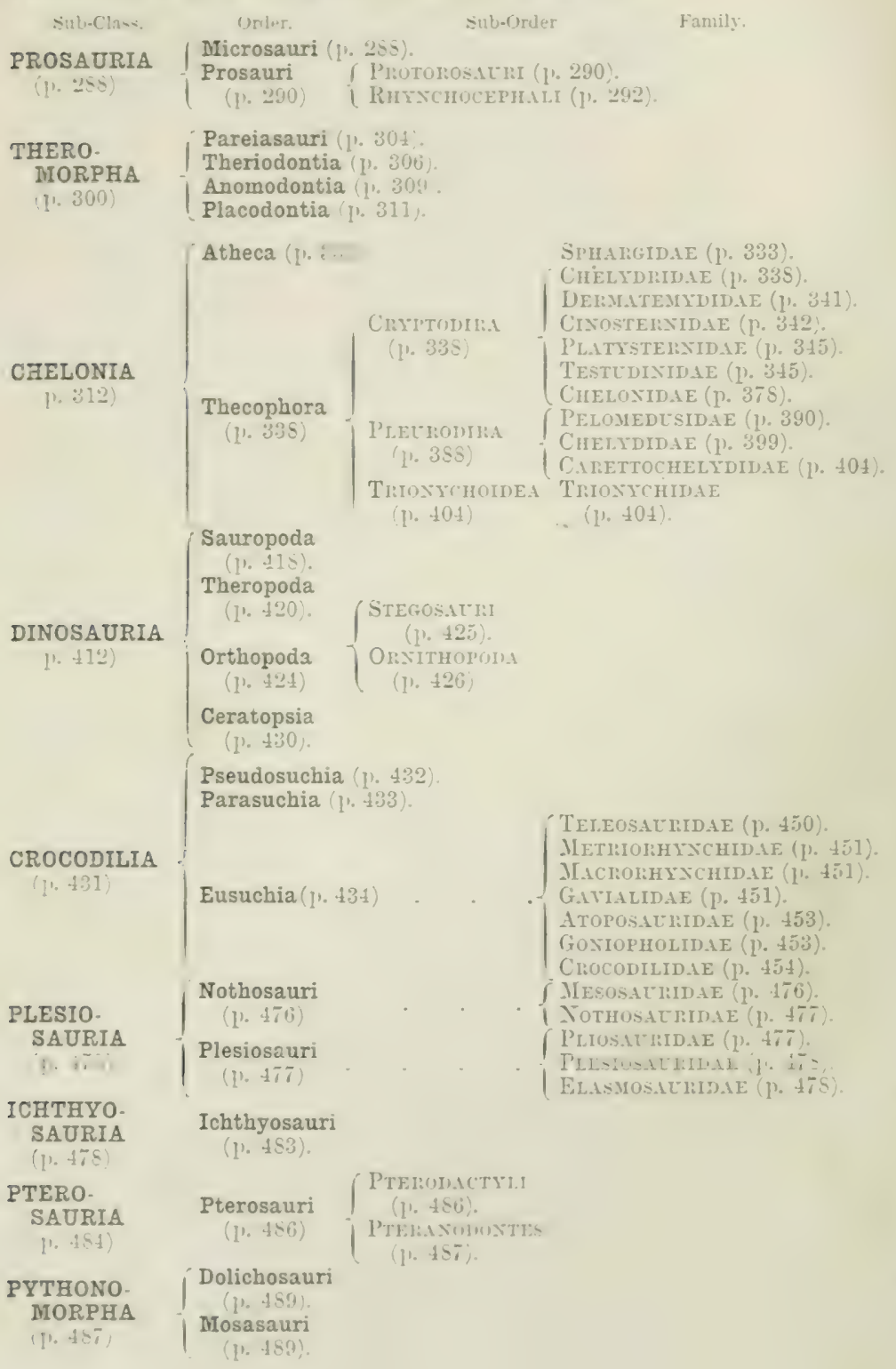

f MEsosatinAE (p. 176).

1 Tothosatrimale (p. 47

(PLIOSATIIDAE (p. 4ti).

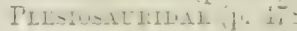

| Ellismositiolde (p. $47 s$ ) 
Sub-Class.

SAURIA

(p. 491)
Order.

Sub-Order.

Family,

Gechoxidate (1). 507)

(p. 502)

\section{Lacertilia}

(p. 491)

Ophidia

(p. 581)

$\left\{\begin{array}{c}\text { GECKONES } \\ (\mathrm{p} .502) \\ \text { LACERTAE } \\ \text { (p. 513) } \\ \text { CHAMAELEON- } \\ \text { TES (p. 56 })\end{array}\right.$

Agajidide (p. 515).

IGUANIDAE (p. 528).

Jexosatridae (p. 536).

ZOXURIDAE (p. 536).

ANGUIDAE (p.537).

Heloderamtidae (p. 510).

LAXTHAXOTIDAE (p.541).

VAIANIDAE (1. 542).

Xastesinde (p.547)

Tejidae (p. 547 ).

LACERTIDAE (1).519).

Gerithosatridae (p. 559).

ScIXCIDAE (p. 559).

AxeltTropidae (p, 564).

DIBAMIDAE (p. 564).

ANIELLIDAE (p. 564).

AMPHISBAEXIDAE (p. 565).

PrgOPODIDAE (p. 56\%).

$\{$ Chamaeleoxtidae (p. 573).

TrPhLOPIDAE (P. 593).

Gladcoxidide (p. 591).

ILXSIIDAE (p).594).

URORELTIDAE (p.595).

- Bordae (p. 596) \{ Pythoninae (1.598).

Xesopeltidae (p. 605).

(1). 605).

- $\begin{gathered}\text { Aglypha } \\ (1 \% 606)\end{gathered}\left\{\begin{array}{l}\text { Acrochordinae } \\ \text { (1.606). } \\ \text { Colubrinae (p. 60\%). }\end{array}\right.$

\&ิ $\quad(1.606) \quad \begin{aligned} & \text { Phachiodontinae } \\ & \text { (1.622). }\end{aligned}$

$=$ Opistho- (p. 623).

$\leqq$ Glypha Elachistodontinae

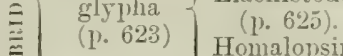

Homalopsinae

(1.625).

\begin{tabular}{c|c} 
Protero- \\
glypha
\end{tabular}$\left\{\begin{array}{l}\text { Elapinae (p). } 626 \\
\text { Hydrophinae. }\end{array}\right.$

Ambirce-

(p. 625) (p.635).

PHAIIDAE

(1. 637).

- Viperidde (Viperinae (p. 638).

(1. 637) T Crotalinae (p, 641). 



\section{PAR T I}

A M PHIBT A 
"s scheint, dass die hier oben keine Ahnung haben von dem Sumpf und Seiner Pracht."

The " plattgedrückte Kröte," SCHEFFEL's Trompeter ron Säkingen. 


\title{
CHAPTER I
}

\author{
AMPHIBIA
}

CHARACTERS ANI DEFINTTION-POAITION OF THE CLASS AMPHIBIA IN THE PHYLUM VERTEBRATA-HISTORICAL ACCOUNT OF THE CIAASSIFICATION OF AMPHIBIA

A Brin is known by its feathers, a Beast by its lairs, a Fish by its fins, but there is no such obvious feature which characterises the Amphibia and the Reptiles. In fact, they are neither fish, flesh, nor fowl. This ill-defined position is indicated by the want of vernacular names for these two classes, a deficiency which applies not only to the English language. All the creatures in question are backboned, creeping amimals. Those which are covered with horny scales, and which from their birth breathe by lungs only, as Crocodiles, Tortoises, Lizards, and Snakes, are the Reptiles. The rest, for instance, Nerts or Efts, Frogs and Toads, are the Amphibia. Their skin is mostly smooth and clammy and deroid of scales; the young are different from the adult in so far as they breathe by gills and live in the water, before they are transformed into entirely lung-breathing, terrestrial creatures. But there are many exceptions. I'outeus and Siren the mud-eel, always retain their gills; while not a few frogs undergo their metamorphosis within the egg, and never breathe by gills. If we add the tropical limbless, burrowing Coecilians, and last, not least, the Labyrinthodonts and other fossil forms, the proper definition of the class Amphibia,-in other words, the reasons for grouping them together into one class, separated from the other backboned animals.requires the examination of many other characters. 
So far as numbers of living species are concerned, the Amplishia are the leas numerous of the Virteluata. There are

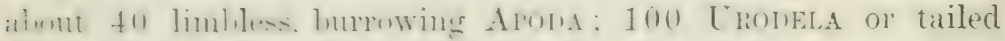

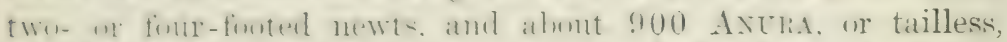

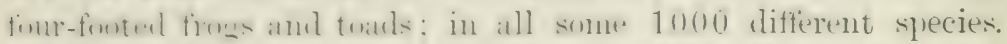

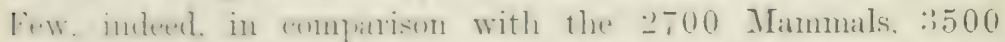
lieptil-.. neatly soou fishes, and almost 10.000 Birds. But we shall see that the Amphilial have not only "had their dity." having flomrished in lyenne ages when they divided the world, so far as Verteblata were concerned, leetween themselves and the lishes. but that they nevere attained a dominant position. Inter-

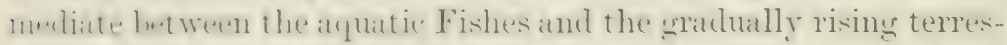
arial lieptiles they hat to fight, so to speats. with a doulde front durin- the strugerle of evolution, until hy now most of them have iecone extinet. The rest persist literally in nonks and corners of the tanenine world and only the Frogs and Toads, the more recont branch of the Amphitian tree have spread over the whole ghon. exhibiting alnus endless variations of the sane narrow. much srecialised plan. The greatest cham of the Anura lies in Hheir narvellons adiptation he prevaling dircumstances: and the nursing habits of some hinds rad almost like fairy-tales.

\section{Characters of the Amphibia. ${ }^{1}$}

1. The vertelıae are $(a)$ acentrous, $(b)$ psendocentrous, or (c) notocentrous.

$\because$ The skull articulates with the atlas by two condyles which are formed by the lateral occipitals. For exceptions see p. 78 .

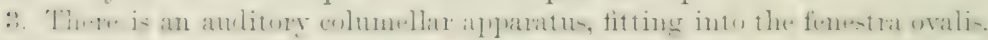

4. The limlss are of the tetrapodous, pentadactyle type.

5. The red blood-corpuscles are nucleated, biconvex, and oval.

6. The heart is (a) divided into two atria and one ventricle, and (h) it has a conus provided with valves.

-. The anrtic arches are strictly symmetrical.

8. Gills are present at least during some early stages of development.

9. The kidneys are provided with persistent nephrostomes.

10. Lateral sense-organs are present at least during the larval stage.

11. The vagus is the last cranial nerve.

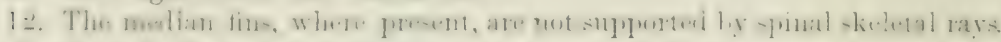

13. Sternal ribs and a costal or true sternum are alsent.

14. There is no paired or unpaired medio-ventral, copulatory apparatus.

1i. J)evelopment takes place without amnion and allantois.

None of these characters is alsolutely diagnostic, except I $(c)$, and this atplies unly to the Anura and most of the Stegocephali.

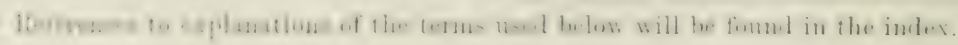


Numbers $1(b), 1(c), 2,3,4$ and 12 separate the Ampliilial frum the Fishes.

Numbers 1, $6(b), 7,8,9,11,13,15$ separate them from the Reptiles, Birds, and Mammals.

Number 2 separates them from the Fishes, Reptiles, and Birts.

Number 5 separates them from the Mammals.

Number 6 (u) seprarates them from the Fishes (exrl. 1)ipmi, Birls and Mammals.

We can, therefore, very easily define all the Amphibia, luth recent and extinct, hy a combination of the characters enumerated above. For instance, lw the combination of numbers : $\because 34$ with either $7,8,9,11,13$ or 15 .

Amplicondylous - Anumniu would be an ahsolutely correct and all-sufficient diagnosis, but it would be of little use in the determination of adult specimens: and the tetrapodous claracter is of no arail for Apoda. Amplierondylous animals rithont an intrueranial hypoylossul nere is a more practical diaguosis.

In the case of firing Crodela and Anura the absence of any scales in the skin affords a more popular character: it is unfortunately not applicable to the Apoda, many of which possess dermal sales, although these are hidden in the imbricating transverse rings of the epidermis: and the frequent oceurrence of typical scales of both ecto- and meso-dermal composition in many of the stegocephali forces us to discard the scales, or lather their absence, as a cliagnostic character of the class Amphibia. The same applies to the mostly soft, moist, or clammy, and very glandular nature of the skin.

The position of the class Amphibia in the Phylum Vertebrata.-There is no doulut that the Amphibia have sprung from fish-like ancestors, and that they in turn have given rise to the Reptilia. The Amphibia consequently hold a rery important intermediate position. It was perhaps not a fortunate imnoriation when Huxley brigaded them with the Fishes as Iilh thyos sidw. thereby separating them more from the sauropside = Reptilia and Ares), than is justifialle, - perhaps more than he himself intended. The comnecting-link, in any case, is formed liy the Stegocephali: all the recent Orders, the Apuda, Irodela, anct Anura, are far too specialised to have any clams to the direct ancestral connections. The line learling from stegocephali to fossil Reptiles, notably to such Proreptilia as Lityous and C'rirotus, and even to the Lepospondylous Prosauria, is extremely gradual, and the steps are almost imperceptille. Naturally, 
assuming erolution to he true there must have lived countless creatures which were a "rudis indigestanne mules." neither" Amploilia nor Iopptilia in the present intensified sense of the systematist. The silne consideration applies eppally to the line

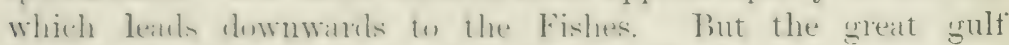
within the Vertebata lis heotwen Fishes and Amphihia, hetween absolutely apluatic creaturts with internal gills and "fins." and

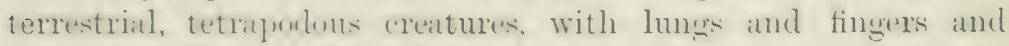

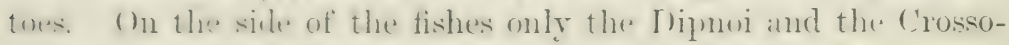
pterygii come into consideration.

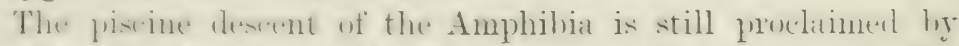
the fullowing teatures - 1) The posiession by the heart of a

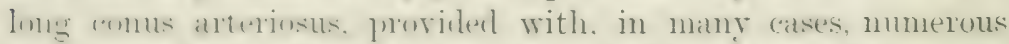
valves. or at least Anmal whe series at the hase, anothere at the

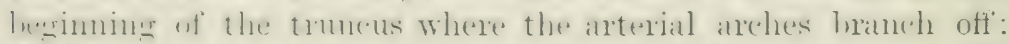
$\therefore$ the strictly symmetrical arrangenuent of these arehes: (:)

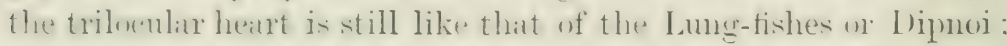
$\left(-\frac{1}{)}\right)$ the occurrence of as many as four or even five branchial sieletal arehes in the latral stage: (5) the glottis is supported hy cartilages which themselves ale derivatives of gusterior visceral

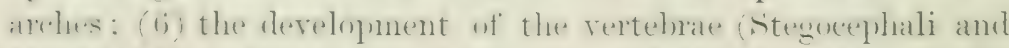

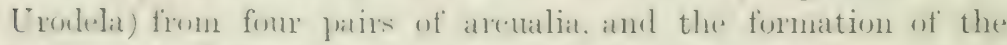
intervertebral joints ly a split aterese the intervertebral ring of

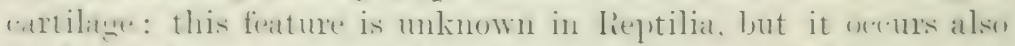

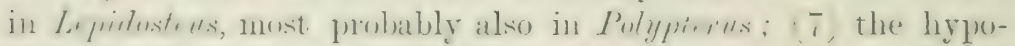
slosil still retains the character of a post-cranial or cerrical

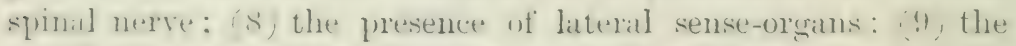

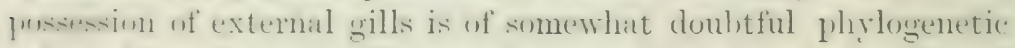

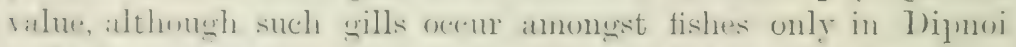

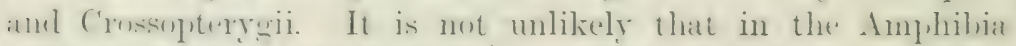

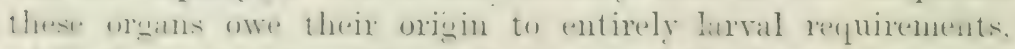
whil. the suretolial month of the larvace of the Anmat and many

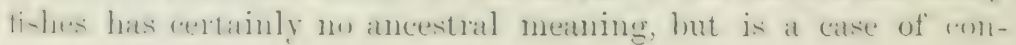
vergent development.

Tle u-nal diagnoses of the Amphiliat contain the statement

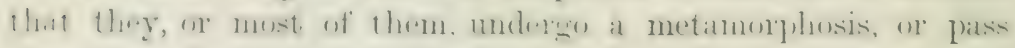
through a litrval stage. The same ipplies to various fishes: while, wh 2lue wher hand, the larral mot ancestrat stanes h.

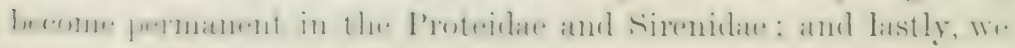
cannot wall speak of larvae in the viviparous Sulamandra atru. 


\section{The evolution of an adequate classification of the Amphibia} has been a long process. Eren their recognition as a class, separate from, and of equal rank with that of, the Reptilia, wats by no means generally accepted until comparatively recent times. A historical sketch of the laborious, often yainful, striving for light, in France and Germany, then in England, and lastly in America, is not without interest.

The term Amphibia was invented by Linnaeus for the third class of animals in his famous "Systema Naturae." It comprises a very queer assemhly, which, even in the 13th edition (1767), stands as follows:-

1. Reptiles Pedati, with the four "genera" Testudo, Draco, Lacerta, and Rana. Lacerte includes Crocodiles, Lizards, and Newts!

2. Serpentes apodes.

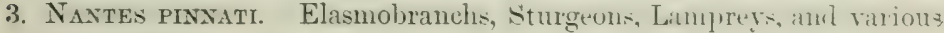
other fishes.

Laurenti, 1768, in a dissertation entitled "Specimen medicun, exhibens Synopsin Reptilium ...." uses Brisson's term, Reptilfs, and divides them into :-

Reptilia salientia, these are the Anura.

Gradientia, namely the Urodela and Lizards.

Serpextia, the Snakes and the Apoda.

Brongniart, 1800, "Essay d'une classification naturelle des Reptiles," 1 dimtinguishes :-

Chelonit, Satrir, Ophidir, B.trachit : the last for the Frogs, Toad; and Newts.

Latreille, 1804, "Noureau Dict. Hist. Nat." xxiv.," accepts the four Orelers of Brongniart's "Reptiles," but clearly separates the fourth Order, "Batrachi," from the rest by the following, now time-honoured, diagnosis: Doigts des pattes n'ayant pas d'ongles; des branchies, du moins pendant un temps; des métamorphoses. But there is not one word about "Amphibia" in opposition to "Reptilia."

Duméril, 1806, "Zoologie analytique" (p. 90, and "Élémens de l'histoire naturelle," 1807, divides the "Reptiles hatraciens," or "Batracii," into Ecaudati and CaUdati; he also introduces the terms "Axoures" and "UrodèLEs" as their equivalents; but since these terms appear in the French form purists do not admit their having any claim to recognition :

Oppel, 1811, "Die Ordnungen, Familien und Gattungen der Reptilien," establishes the term APODA for the Coeciliae, and recognises their affinity to the Ecaudata and Caudata loy removing them from the Snakes.

De Blainville, 1816, "Prodrome d'une nouvelle distribution du règne animal" 3

AMPHIBIENS SQUAMIFL̀RES. [The Reptilia.] $" \quad$ vudrpeltifères s. Ichthyoides. [The Amphibia.]

1 Bull. Soc. Philom. ii. p. 81.

2 Tableun méthodiques, P. 61.

${ }^{3}$ Bull. Soc. Philom. p. 113. 
Merrem, 1820, "Tentamen systematis Amphibiorum."

Pholidota. [The Reptilia.]

BATRACHIA : APODA.

\section{SAITENTIA.}

GRADIENTIA $\left\{\begin{array}{c}\text { Mutabilia [with metamorphosis, e.g. } \\ \text { Newts] } \\ \text { Amphipueusta [Peremibranchiate Uro- } \\ \text { deles] }\end{array}\right.$

F. S. Lenckant, 1821, "Einiges neber die fischartigen Amphibien." 1

Moxorsos. ['The Reptilia.]

Drisos. [The Amphibia] $\left\{\begin{array}{c}\text { with temporary gills: Euadata + Caudata } \\ \text { with permanent gills: "Proteidae," Meno- } \\ \text { poma and Amphiuma. }\end{array}\right.$

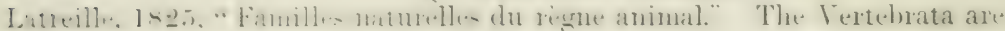
livided into Hacmutherma and Huemacryma. These terms for warmand cold-blooded creatures were later on amended by Owen to Haematotherma and Hacmatocrya. The latter are divided by Latreille as follows:-

Reptidia. Still including the Coeciliae amongst the Snakes.

Ampribi. fladucibrauchiata.

PrSCEN.

Wagler, 1830, "Systema Amphibiorum."

Testudines, Crocodili, Licertae, Serpextes, Axgues, Coeciliae, RaNaE, ICHTHYOd.

RANAE I. AGLOSSA.

. II. PHANERUGLOSSA : 1. Cauda nulla. [The Anura.]

$\because$

2. Cauda distincta. [The Salamandridae.]

ICHTHFod I. ABRANCHIALES. IIenopoma [Criptobranchus] and Amphiuma.

II. BRANCHIALS. [The Perenniloranchiate Urodela.]

.J. Müller, 1831, "Beitrige zur Anatomie ... der Amplibien." :

Granophiona, Derotramata, Proteidaf, SAlamandrisa, BatR.ICHIA.

.T. 13ell, 1836, 'Todkl's "Cyelopredia of Anatomy and Physiology" Art. "Amphibia."

Asprmpsecst.1, the l'eremibranchiate Urodeles; Axours, Urovers: AmRaschis, Monopome and Amphiume; AroDa.

Stannins, 1856. "Handbuch der Znotomie: Anatomie der IVirbelthiere." (2nd (*d.)

Ampribia Muxopsos. The Reptilia.

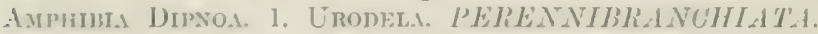

IIEROTREALATA: Amphinmu ancl Menopoma.

UV('T())ESRA:

1 sis, $1 \leqslant 21$.

"'Trevirauus' Zcilschr, f. Jlysiol. 1831, J. 190.

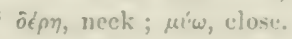


2. BATRAChid. AGLOSSA.

PHANEROGLOSSA: Systomata $=$ Engystomatidae.

Bufoninae. Without manubrium sterni.

Raninae. With manubrium.

Hyloidea. With adhesive fingerdiscs,

GYMNOPHTONA.

Gegenbaur, 1859, "Grundzïge der vergleichenden Anatomie."

Ampнibia as a separate class, equivalent to that of the Reptumi, are divided into the four Orders: PERENNIBRANCHIATA, SALAMANDRINA, BATRACHIA, and GYMNOPHIONA. In the second edition of the "Grundzuige" (1870) they are dirided into URODELA, ANURA, and GYMNOPHIONA.

Huxley, 1864, "The Elements of Comparative Anatomy."

MAMMALS.

SAURoIDS, subsequently changed into SAURopSIDA = Reptilia + Aves.

ICHTHYOIDS, Pisces.

Haeckel, 1866, "Generelle Míorphologie."

Amphibia. A. Phragtamphibia s. Ganocephala = Libyrinthodonta + Peromela [Apoda].

B. Lissamphibia s. Sozobranchia = Sozura $[$ Urodela $]+$ Anurr.

Cope, $1869 .{ }^{1}$

Stegocephalt, Granophidi, Lrodela, Proteidfi, Trachyitomati, ANura.

Huxley, 1871, "A Manual of the Anatomy of Vertebrated Animals."

Amphibia I. Sadrobatrachia [r.d. Hoeven's term] s. Urodela

1. Proteidea.

2. Salamandridae.

II. LABYRINTHODONTA.

III. Grinophiona.

IV. Batrachia s. Anura.

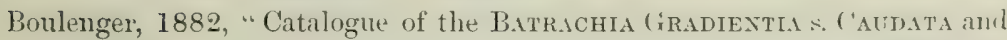

Batrachia APoda," divides the Caudata simply into: SALAMAND.

RIDAE, AMPHII WIINAE, PROTEIDAE, and SIIENITIE.

1882, "Cat. Batrachia Salientia s. Ecaudata," see 1) 140.

Cope, 1890, "Synopsis of the Families of Vertebrata." "

Cluass Batrachia.

Sub-Class I. Stegocephati.

Order 1. Ganocephali: Trimerorhachis, Archegosamms.

2. Rhachitomi : Eryops

3. Embolomeri : Cricotus.

4. Microsauri : Branchiosaurus, Hylonomus, etc. 
Sub-Class II. U URuela.

Orter' 1. Proteidae: Proteus.

2. Psendoniuria. [All the rest of the Urodela + Cueciliidat. ]

3. Trachystomata: Siremidae.

III. SALIKATM.

1. and F. Aarsin, 1890, "Zur Entwicklung*geschichte der Cey"lonesischen Blindwilule, Ichthyophis glutinosa." I

Suh-Clase I. ArChafoßatr.ichi s. Sitrgocephal.

II. Neois.itr.ichi.

Orti.r 1. UROMELLA.

11. Salamandroidera. [T'he Lrodela.]

6. Coeciloidea = Amphiumidae + Coeciliidae. $\therefore$ ANTISA.

The classification arlopted in this volume is as follows:-

l'miss: Amphibia.

Sul-C'lass I. Phuactamplilia.

Orrter I. Stegocephali Lepospondrli.

Sub-ourler 1. Branchiosauri.

Sulb-order 2. Aistoporle:

Orrer II. Stegocephali Temmospondyli.

Oryer III. Stegocephali Stereospondyli.

Suh-Clas: II. Lissamphibia.

Orter I. Apoda.

Order II. Urodelia.

Orter II1. Anum.

Sub-order 1. Agrlosia.

Sub-orler ‥ Phaneroglosit.

1 Surasins Errebnisse . Centon, 1587-1890. 


\section{CHAPTER II}

SKELETON OF URODELA AND ANURA-SKIN-COLOUR-CHANGING MECHANISM - POISON-GLANDS-SPINAL NERVES-RESPIRATORY ORGANS-SUPPRESSION OF LUNGS-URINO-GENITAI ORGANS-FECUNDATION-NURSING HABITS-DEVELOPIEN'T AND METAMORPHOSIS

\section{SKeleton of THE UROdela}

The vertebral column.- The number of vertebrat is smallest in the terrestrial, greatest in the entirely aquatic forms, and is exceptionally large in the eel-shaped Amphiumu. In the following table the sacral vertebra is included in those of the trunk.

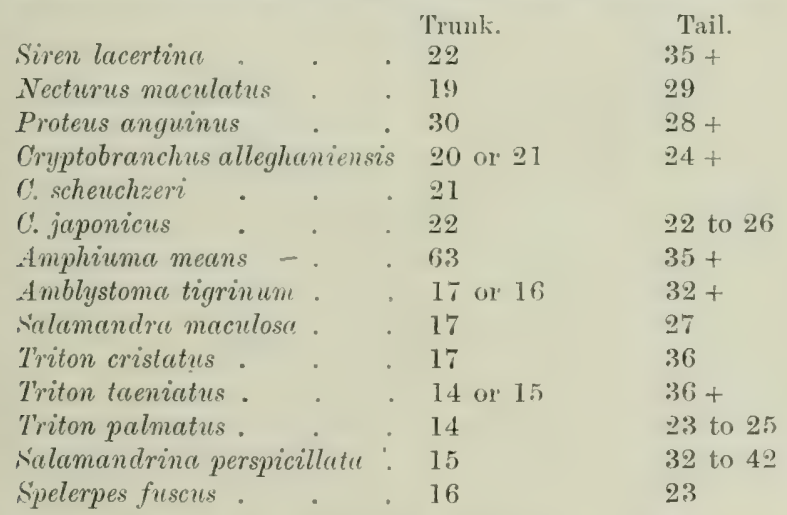

The vertebrat of the Urodela and those of the Apoda differ from those of all the other Tetrapoda ${ }^{1}$ by possessing no special centra or hodies. That part which should correspond with the centrum is formed either by the meeting and subsequent complete ('n-ussification of the two chief dorsal and ventral pairs of arcualia

${ }^{1}$ Credner's term for all Vertebrates higher than fishes. 
tail-veltobrate or entrely hy the gair of chief clursal areualia. There is andsequenty no meno-central sutme. Mroreover, the

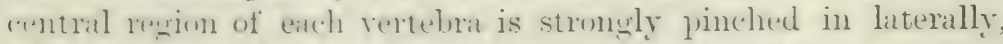
witening cowarts the emels. Another feiture of the vertehral wolumn of the frodelit is the possession of a considerahle amount of intervertelnal cartilate by which the sucessive rertehrae are held together. This cartilage does not ossify, and it either remains rontinums, serving in its entirety and owing to its flexibility as it joint, or it beromes nume or less imperfecely sepratated into a cup

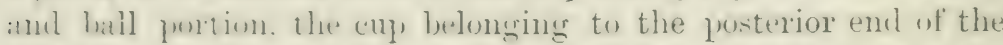
rertehra. surh joints are called opisthocoelons, and ocene in the

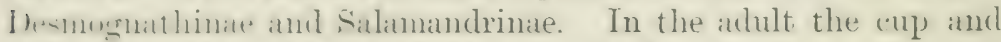
latl frefluenty alleify, and the chordat dorsalis or notochord is

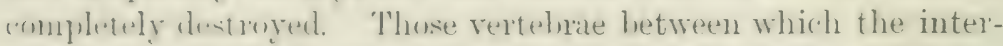

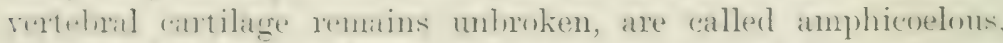
since in them. most whiously in macerated or dried skeletoms. the vertelurate atpleat hollowed wht at either end. In such

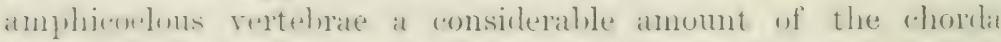
always remains, rumning in an unhroken string thromgh the whele length of the rertehal columm. Towards atult life

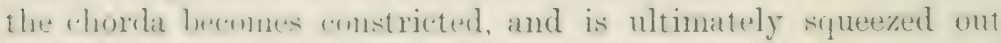
(1) destroyed, in the midhle of the rertema, hy the invasion of

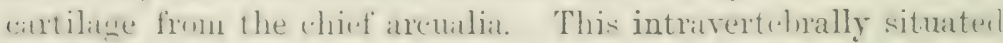

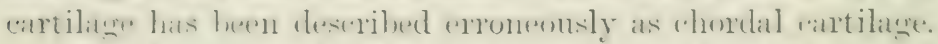

The development of the rertelerae prowerls as follows. First alp lear a pair of basidersaba and it pair of hasiventralia (Fig. 1, 1.

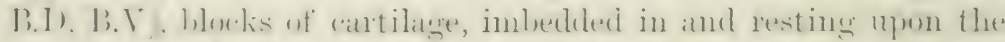

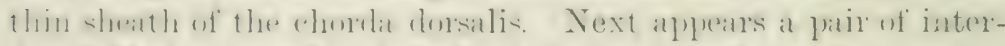

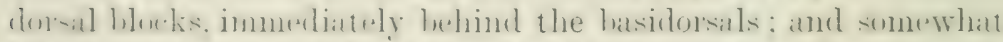

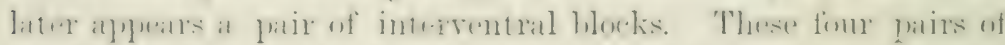

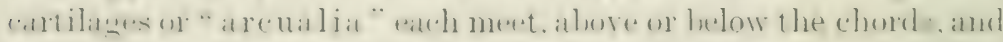

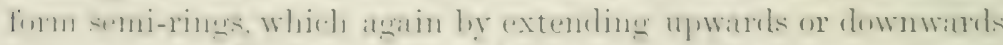

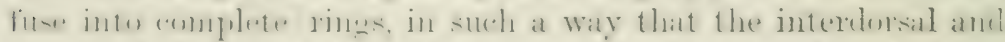

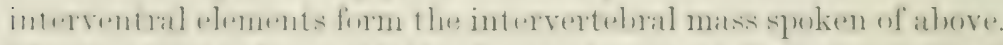

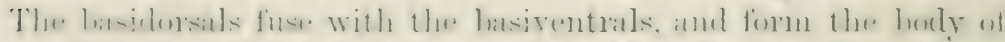

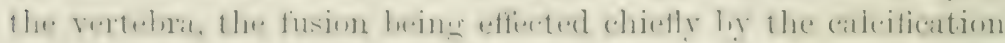

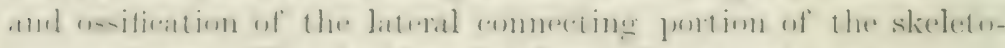

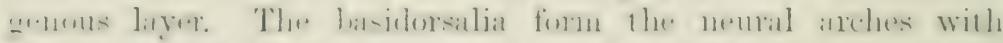

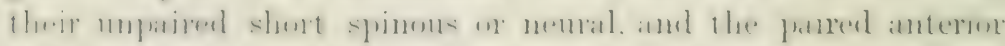
and posterion aygapophysial processes. Concerning the basi- 
rentralia we have to distinguish between the trunk and the tail. In the latter they produce a pair of ventral ontgrowths (1) hatemapophyses, which ultimately enclose the caudal bloor-ressels. In the trumk the hasiventral blocks of cartilage are suppressed: they appear in the early larvie, but disappear during or eren before metamorphosis.

Towards the end of the tail the vertebrate dininish in sire, and their constituent cartilages assume a more and mort
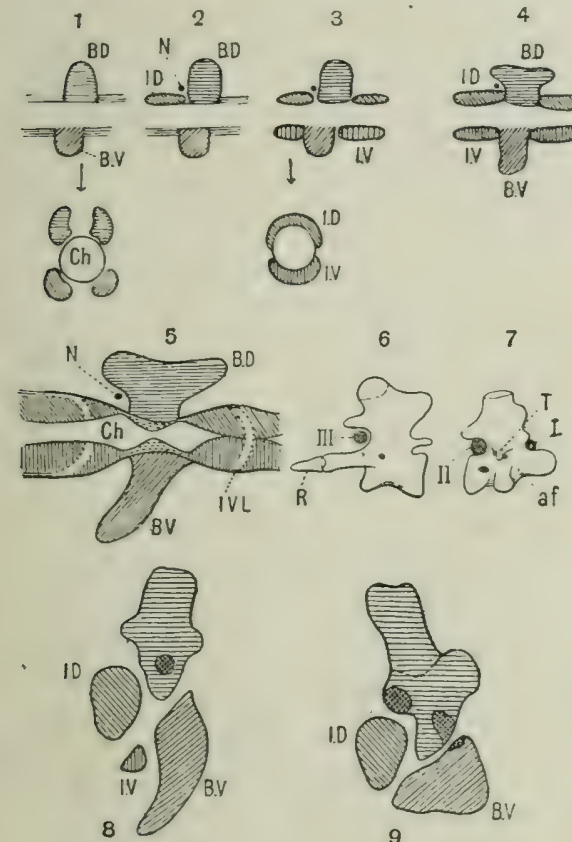

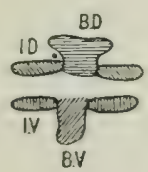

7

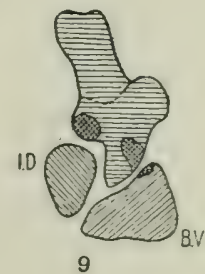

FIG. 1.-1-5, Five successive stages of the development of a caudal vertebra of a newt; $6-7$, the second and the first cervical vertebra of Cryptobranchus; 8-9. side view of the constituent cartilaginous blocks of a caudal vertebra (8) and a trunk-vertebra (9) of Archegosaurus as typical examples of Temnospondylous quadripartite and tripartite vertebrae. The crosshatched parts indicate the articular facets for the ribs. The anterior end of all the vertelirae looks towards the right side. $a f$, In 7 , articulating facet for the occipital condyle ; $B . D$, basidorsal piece or neural arch B. $\boldsymbol{V}$, basiventral piece or reutral arch; $C h$, chorda dorsalis, or notochord; $I . D$, interdorsal piece; $I . I^{\gamma}$, interventral piece : $I . T . L$, intervertebral ligament; $\boldsymbol{N}$, spinal nerve-these are numbered I, II, III in 6 and $7 ; R$. rib; $T$, in 7 , rib-like tubercle on the first rertebra.

indifferent shape, until they become confluent into a continuous rod of cartilage, resembling in this respect the Dipmoi and Holocephali. A periodical revival of this rod, at least of itconnective tissue, appears in the tail-filament of the male Tritun palmatus during the breeding-season.

The first vertebra, called the atlas, because it carries the head, is remarkahle for the possession of an odontoid process. The latter is formed by a pair of cartilages and represents part of a vertebra, the clorsal portion of which seems to have been added to the occipital part of the cranium. 
All the trunk-vertebrate, with the exception of the atlas. arry ribs, at least vestiges thereof. Owing to the early disappearance of the hasiventral cartilages the capitular portions of

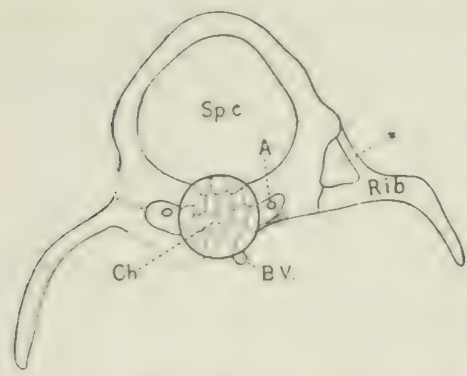

Fig. 2.-Transverse section through a ratuli-vertulut uf a larva of silumandra maculosa, enlarged. The right -ile shows tire actually exintiue state, while on the belt sille the rib and it

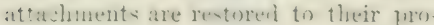
balle original condition. A, Verteliral artery within the true transwerse - anul : li. 1, remuatut of the ha-i-ventral

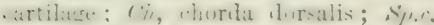
- pinal "anal: ". the fulse transverce canal. the ribs are much reduced, and are mostly represented by strands of connective tissue only. The ribs develop therefore occasionally at some distance from the vertebral column, and that portion of the rib which in the metamorphosed young newt looks like the capitulum is to a great extent really its tuberculum. Witness the position of the vertelial artery, which still inslicates the true foramen transrersarimn. The homolegies of these parts are still more obscrured loy the fact that a new process grows out fim the ril, by which the latter gains a new support upon a knob of the m.mal arch. Thun an additional formen is formel, sometimes confoumberl with the true transverse anal. The meaning which muleties all these modifications is the broadening of the burly, the rils shifting their originally more ventral support towards the dersal sirle. The whole prosess is intensified in the Anuma it is an initial starge of the notocentrous tyle of vertel rare. Thes transverse msified froweses of the alult are often mum:h longer than the vestiges of the rils: themselves, and are somewhat (monphieated structures. They are omplosed first of the rib-berinen

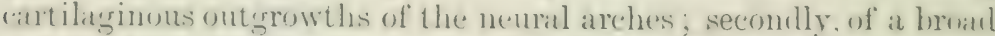
string of connertive tissue whing extends from the ventm-latemal cormer of the perioterdal skeletogenoms layer to the rils.

The shoulder-girdle is extremely simple. It remains almost. -ntirely cartilitginomis and the three (onstituent elements are not separited by sutures. Ossification is extrieted to the hase of the

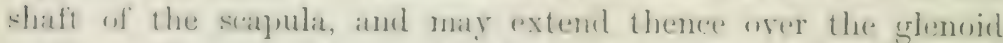

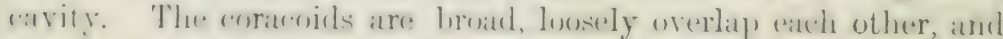
are "lement and mortion" into the triansular or lozenge-shatpent 
cartilaginous sternum, which latter has no connection with the ribs. The precoracoid is a large, flat process, directed forwards. not meeting its fellow; it is absent in Siren.

The humerus articulates with both radius and ulnu, and these two bones of the forearm remain separate. The elements which compose the wrist and hand exhilit an almost ideally simple arrangement, slightly varied by the frequent fusion of two or more neighbouring carpalia into one, and by the reduction of the number of fingers. Most frequently the intermedium and the ulnar carpal element fuse together, and there is more often one centrale instead of two. The wrist and hand of the Urodelia represent, however, no longer the entirely primitive pentadactyle type, owing to the loss of one finger together with its metacarpal and carpal element. Comparison with the Anura makes it probable that the Urodela have lost the pollex, their four fingers being consequently the $2 n d, 3 r d, 4 t h$, and 5 th. Siren has fom or three fingers; Proteus has only three fingrer's and three large compound carpal cartilages. In Amphiuma, with either three or two fingers, the ulnare, intermedium, and carpale are fused together, the radiale with the neighbouring carpale. The number of phalanges in the four-fingered species is generally $2,3,3, .2$ respectively.

The pelvic girdle. - The ilium stands vertically to the vertebral axis, slanting slightly forwards and downwards. It is attached by means of a rib tu only one vertebra, and this ilio-sacral connection is acetabular in its pusition, i.r. it lies in the same transverse plane with the acetabulum, in other words vertically above it. The ventral portion of the pelvis is formed by one large continuous mass, the united pubo-ischia, the anterior or pubic portion of which extends forwards in the shape of a bruad triangle (Nect"rus) or as a slender, stalked, Y-shaped cartilage, the epipulis, which is often morably jointed at its base. "The lateral portion of the pubic cartilage is always perforated by the nervus obturatorius. Ossification is restricted to the ischimm and to the middle of the shaft of the ilium. The acetabular fossi for the femur is closed. The tibia and fibula remain separate. The foot is still more primitive than the anterior extremity, ats the majority of Urodela possess the full complement of five toes, with 2, 2, 3, 3, 2 phalanges respectively. Concrescence of the tarsalia applies most frequently to the fourth and fifth distal 
and to the two centralia: exceptional, for instance, in ('ryptorbitmehns juguniens ale as many as there centralia, hut this is an imliridual. "ren a ome-silled variation, as shown for instance by

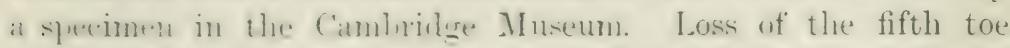

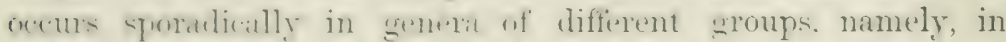

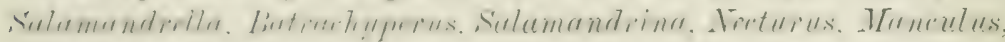
Batrachoseps. In Amphinma the number is reducer to three or two; in Protens to two; and in Siren the hind limbs, with their sirille. art allwather alsent. Lastly. in some species

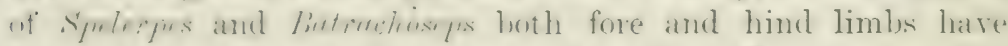

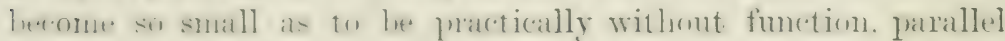

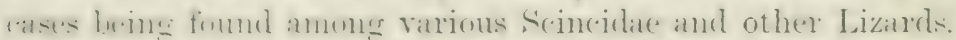

The. hyoid apparatus is still vely flumitive in many.

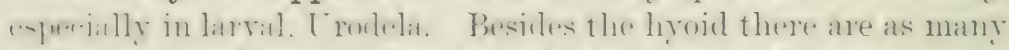

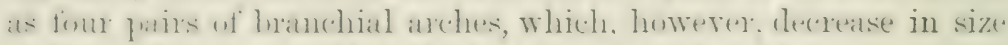

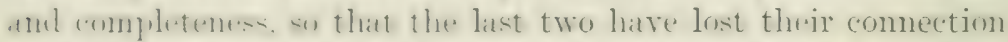

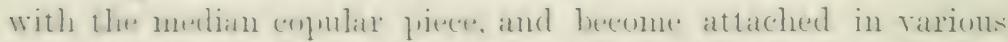

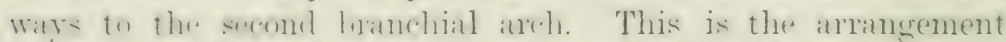
alyatremly in all latvate. lut four pains of hranchials persist in

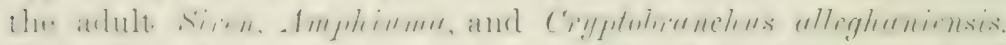

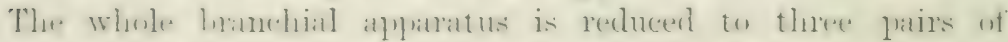
arches in Necturus and Proteus, to two in the adult Crypto-

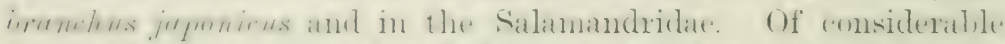
integest is the vestige of a tifth prate of atreles in the latrate of

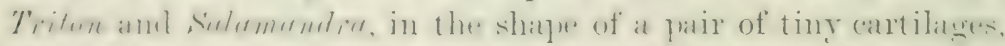
which lie in front and on each side of the opening of the

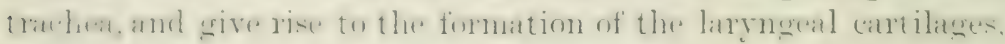
better developed in the higher Vertebrata.

The follwwins are notewerthy characters of 1 les skull of

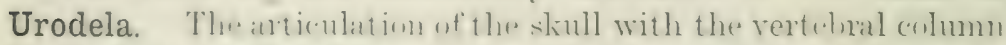

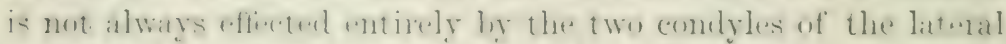

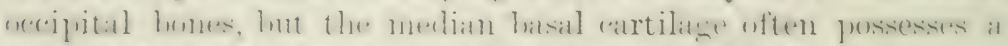

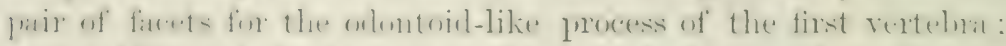

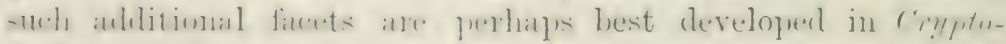
bronclius and in the Salamandrinae.

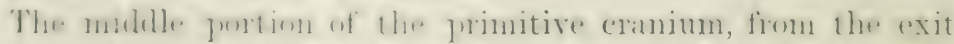

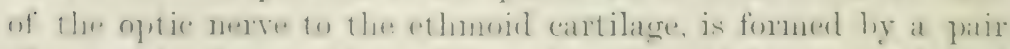

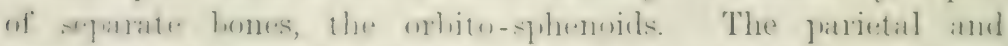

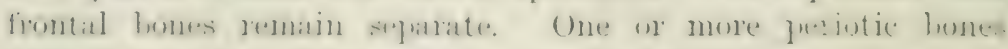
exist, besides the prootic, in the aquatic families. 
A pair of prefrontal bones is present in most Salamandridate. e.g. Salamandra, Triton, Amblystoma, especially in the litrva, and in Cryptobranchus; these bones are absent in Amphiumn, . lerturus, Proteus, and Siren.

The lacrymalia are still separite in some Anllystomatinat.
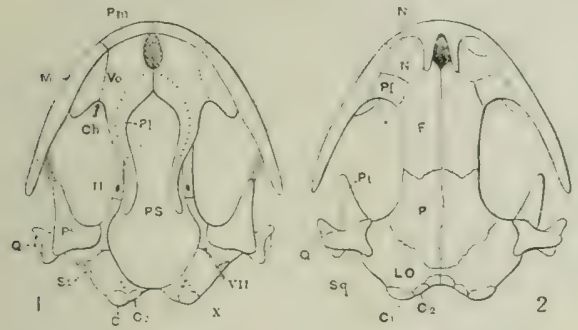

FIg. 3.-Skulls of various Urodela. 1, Salamandra maculose, ventral view, and '2, dorsal view ; 3 , Axolotl stage of Amblystoma; 4, adult stage of Amblystoma; 5, Salamandrine
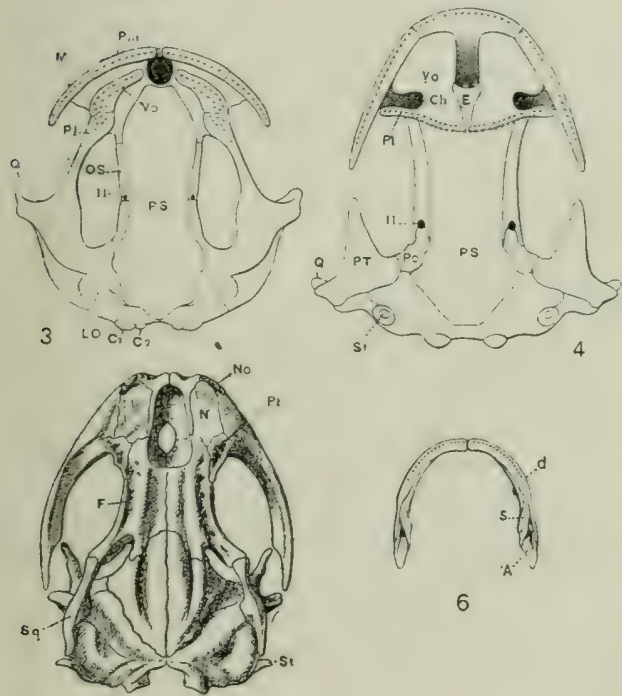
perspicillate (after Wiedersheim); 6, Salamandra maculosa, dorsal view of the lower jaw, $A$, Articulare; $C_{1}, C_{2}$, outer and inner occipital condyles; $C h$, choana or posterior nasal opening ; $d$, dentary ; $E$, ethmoid ; $F$, frontal ; $L O$. lateral occipital ; $\boldsymbol{I} \boldsymbol{I}$, maxillary ; $N$, nasal ; $N^{\prime} 0$, nostril ; $O S$, orbitosphenoid ; $P$, parietal ; $I$ ' $f$, prefrontal ; $P l$, palatine ; $P m$, premaxillary ; $P O$, prootic ; $P S$, parasphenoid; $P t$, pterygoid; $Q$, quadrate ; $S$, angulo-splenial ;

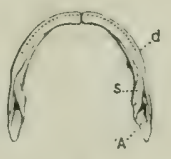
$S q$, squamosal ; $S t$, stapes ; $\mathrm{T} v$, vomer ; II, VII, $X$, exits of the optic, facial, and glosso-vagus nerves.

5

e.s. Ranidens and Hynobius. At pair of nasalia are generally present, but are absent in lertwrus, Proters, and siren. The larasphenoid is furnished with teeth in the Plethodontinae and Desmognathinae.

Separate palatine bones exist in Secturus and $I^{\prime}$ 'oteres, and in the larva of Lmblystome, lut in the adult form they fuse with the vomers, producing the vomero-palatimes charmeteristic of the majority of Urodela. 


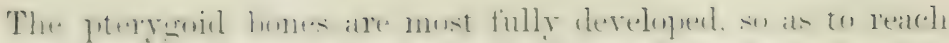

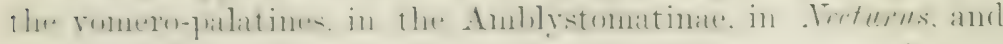
in Protens; they are reduced, so as to leave a gap, in Crypto-

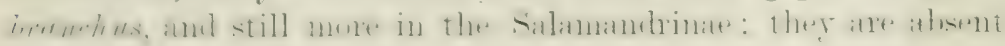
in Amphinma and in siven.

The yuadrates are directed forwards in Acotmus, Proteus, and

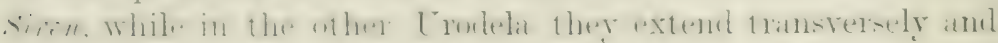

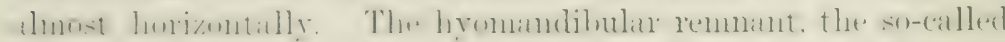

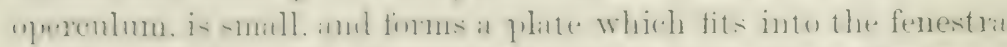

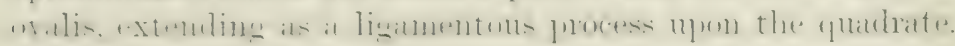

The qualrato-jugal elements are reduced to ligaments. In

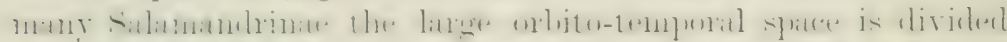

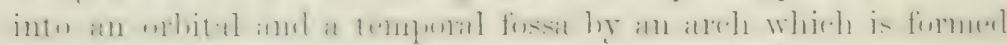
hy the meeting of two corresponding processes from the

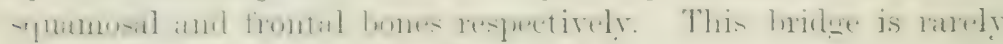

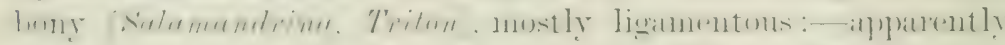

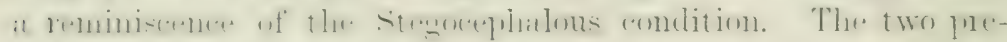
maxillary bones are liable to fuse into one, for instance in cryptobrumehus, generally in adult Tritons. They are most reduced, and are toothless, in Siren.

The two maxillary bones are absent only in Necturus, Proteus,

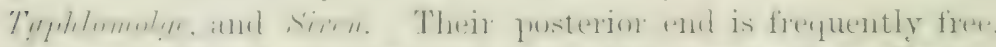

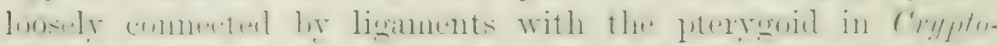

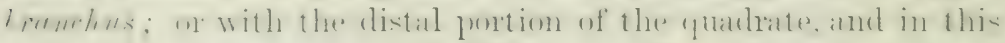

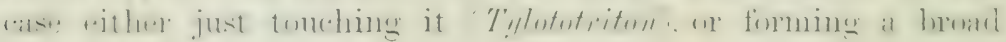
junction (Pachylriton).

Each half of the lower jaw consists of a dentary, articular and angulo-splenial. The splenial remains as a separate

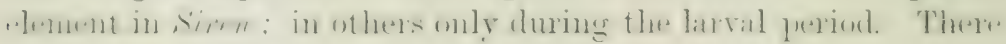
are no mento-Meckelian elements.

\section{Skeletor of tile ANUliA}

The vertebral column.-The distinetive pentiarities of

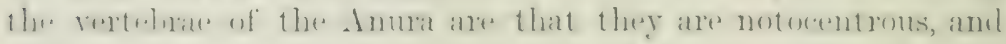
that ahout a dozen of them are modified and fused into an os

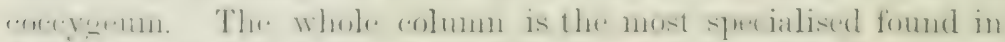

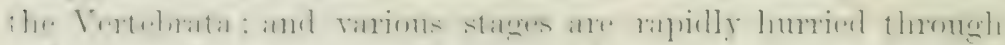

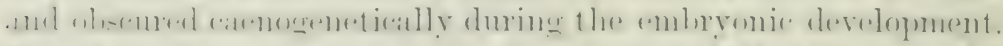

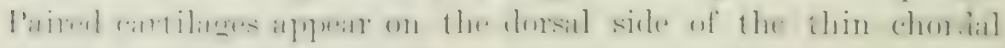
sheath, and whilst tending to enclose the spinal cord in a 
canal, their bases grow head- and tail-wards into what will ultimately become the intervertehral region. This extension of cartilage leads to a fusion with that of the next following prin of arches, so that the axial column at this early stage consists of a right and left longitudinal ridge of cartilage which sends wll dorsal processes, neural arches, in metameric succession. Next, the intervertebral cartilage increases in such a way as to constrict the chorda either laterally (limu) or olliguely from above downwards and inwards (Bufo, Hylı). Tre recognise in this cartilage the interdorsalia. Ventral arenalia are late and much obscured. There is scarcely any cartilage which could represent the interventralia, the intervertebral cartilage being almost. entirely made up of the interdorsalia. These fuse together and form a disc or nodule, which later fuses either with the vertebra in front, and in this case fits into a cup carried by the vertebra next behind (procoelous rertebrae), or the knob is adderl to the front end of the vertehra, fitting into a cup formed ly the tail end of the rertebra next in front (opisthocoelons vertebrae). Much later than the two longitudinal dorsal bands there appears on the rentral side an mpaired band in which appear metamerically repeated swellings of cartilage, likewise unpaired. These swellings become confluent, in a way similar to that which produced the dorsal bands, and form the unpaired ventral band of acartilage, the hypochordal cartilage of some authors. The swellings in this band, equivalent to the basiventralia, become semilunar in a transverse view, their homs tending upwards towards the basidorsal cartilages, but there is $n o$ actual meeting. Both dorsal and ventral elements are, however, joined together and form the chief portion of the rurtebrae, owing to the rapidly proceeding ealcification and lat $\cdot \mathrm{l}$. ()ssification of the all-surrounding "membrana remiens" "I" skeletogenous layer so far as that is not cartilaginous.

Procoelous vertebrae exist in the overwhelming majority of Anura ; opisthocoelous are those of the Aglossa, the Discoglossidate, and of some Pelobatidae. The systematic value of this proor opistho-coelous character has been much exaggrerated. We have seen that the centra of the vertebrae of the Anura are formed entirely by the interdorsal elements, hence the term "motocentrous," and these centra sometimes remain in adult specimens of Polobates as separately ossified and calcified pieces, 
nut finsed with the rest of the verteluate. This imuortant di:-

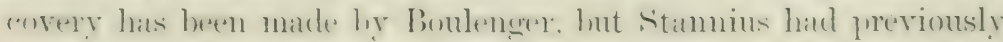

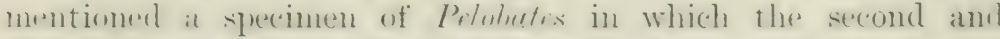

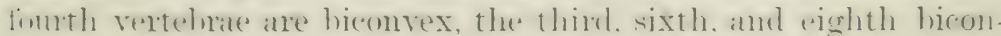

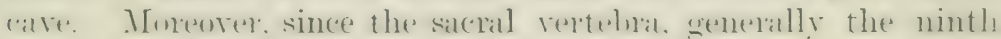
in all the Amura is invariably biconvex, the eighth being

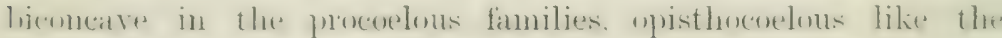
remaining seven vertebrae in the other families, it is not

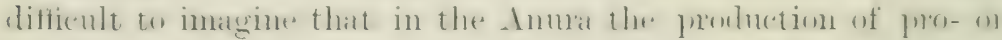

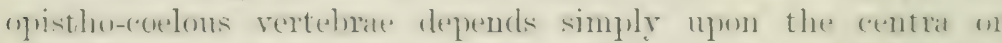
artienlating kmols hapuenine to fuse either with the hime or the

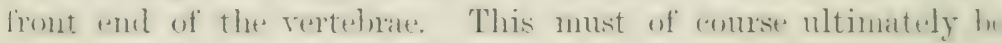
determined by a mechanical problem of motion.

A second type of the vertebrae amongst the Anura is the

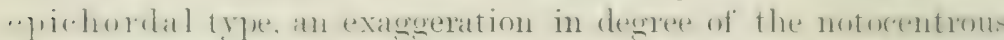

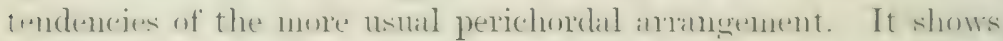
namely. the almote complete smpuressiom of all the rentral

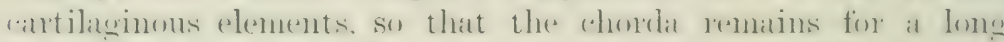
time whe the rentral surface of the axial rolmmo in the shape on!

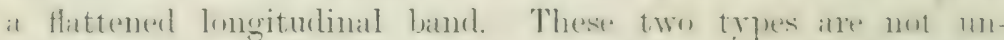

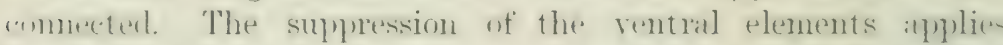

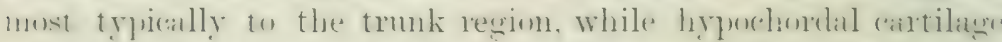
r.xists in the anterior errevical rertelsate, and abose all in the

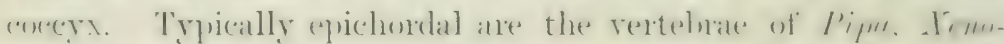
purs, Bombinator, I'elobates, Discoglossus and Alytes. It is

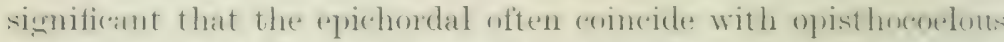

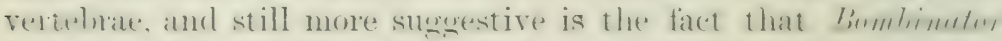

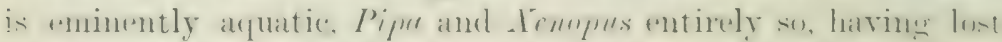

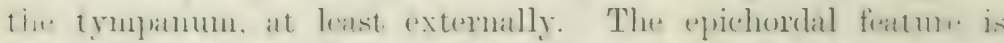

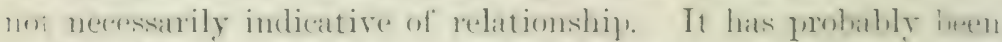

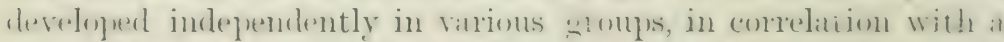

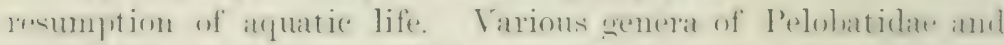

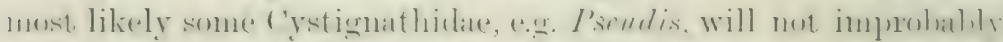

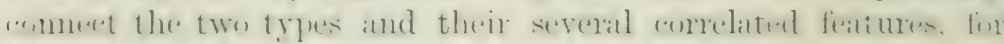
instance, the frequent reduction of the tympanic cavity.

The us renceygenan has letained rather primitive features in

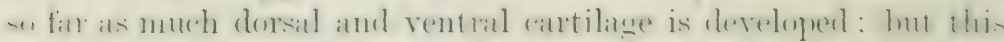

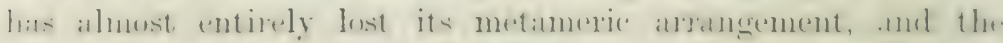

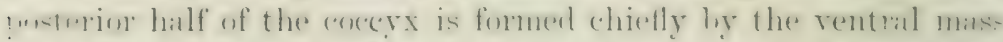

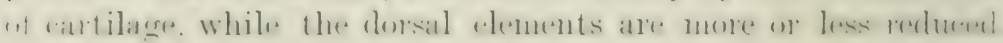


()nly two vertebrate, genterally the tenth and terenth af the

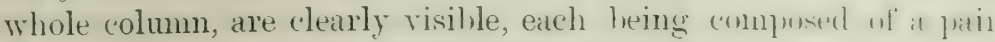
of clorsal and a pair of reutral antilaginous bloxkis. 'T'lu- sarral vertebra articulates with the coccyx by one or two convexities,

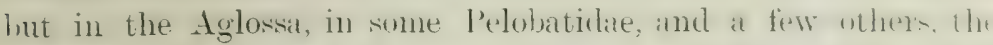
coccyx is fused with the sacral vertebra. Beyoud the first and secomd compenent rertehnate of the embrymic anseys. the artilage is continued in the shape of two dorsal. and me ventral. hands, which soon fuse with each other. Thorsally this artilatere survounds the spinal cord: the latter degenerates towamds the end of the tadpole-stage, learing. howerer, the empty spinal rimal. The chorda, completely surrounded ly cartilitge persists into the post-larval stage, lut is destroyed lomg hefine the creatule attains maturity. Ultimately the whole corex usities.

The tail proper, namely that portion which is alosorbed during the metamorphosis, remains throughout its existence in an apparently primitire condition. The chorda clorsalis and the spmal cord extend through its whole length, surmomulerl hy continuous comnective tissue without any cartilage ; in filct it represents a piece of typical vertebral columm before the apluarance of cartilagts. The reduction of this swimming organ hegins at the hind end.

The vertebral column of the adult. - The first vertebra (we will call it the atlas since it carries the skull) is not, as in the Erodela, provided with an mlontoid process. It articulates hy two cups with the comdyles of the occiput. In some Ammar it (1)-nsifies, rather incompletely, with the second rertelna, resularly

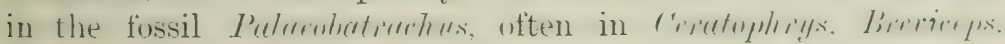
and occasionally in Pelobates, Bufo, Rona, and Lenopms. 'This is, howerer, no justification for looking moun the first vertebra as a complex of two vertelma, although the atlas is frequently very thick and broad, and even carries, in the Aglossa, considerable latelal wings or diapophyses. Those of the trunk-rertelore are often very long, acting thereby as sulstitutes for rilss which axe absent, except on the second, thind, and fomm h retebrae of the Discoglossidat, and on the secomd and thind wi the Aglossa. In the adult Aglossa these ribs fuse with the processes which carry them.

The diapophyses of the sacral vertebra carry no ribs, the ilia being attacherl to them directly. They ane aither rylindrical 


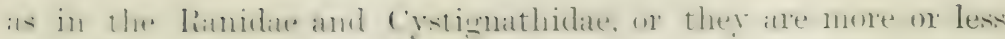
rilated as in all the other families, most strongly in the

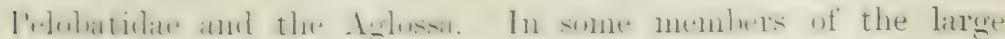
-nh-fanily of the C'ytimathisle the otherwise cylindrical diapophyses are slightly dilated.

The sacrum is formed by the ninth vertebra, but there are

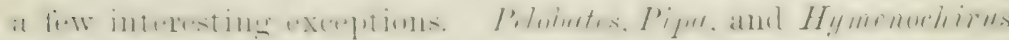

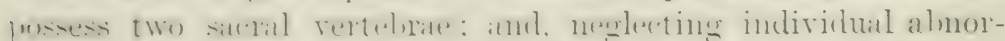
malities. these three generat form the only exception andengst

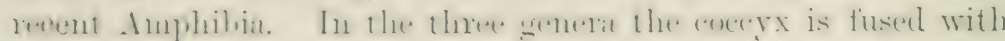

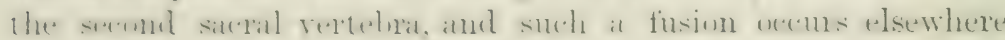

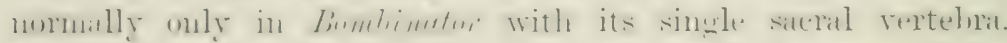

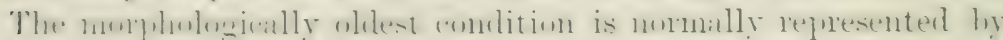
Pclohates, the sacral rertelnae being the tenth and ninth. One
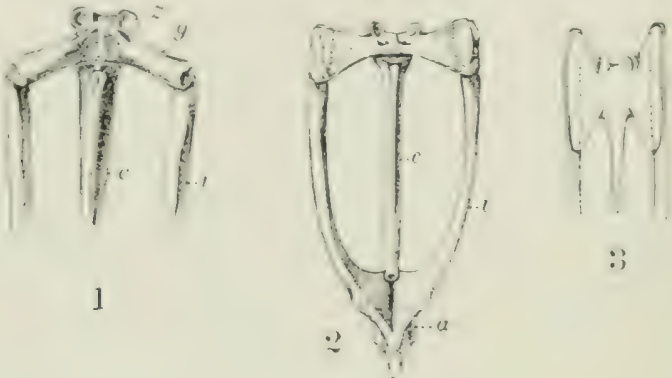

Fil: 4. - Dorsal view of the sacral or ninth vertebra (9), with the attachment of the ilium, of (1) Runa temporeria, (2) Bujoverlyuris, showing the whole coceyx and pelvis, (3) Jelubates fuscus, as examples of cylindrical and of dilated sacral diapophyses. (Alont nat. size.) "1. Acetabulum; $c$, coecyx; $i$, ilium; $z$, anterior zygapophyses.

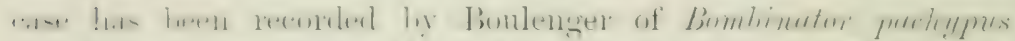

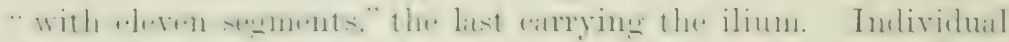

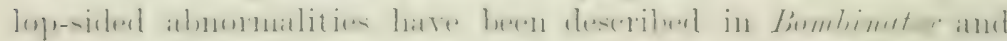

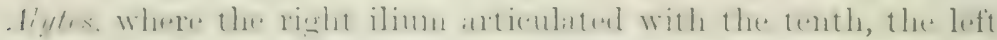
ilium with the ninth vertebra. This shifting forwards of the

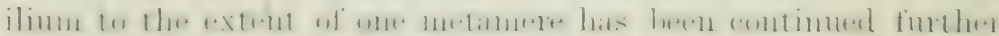

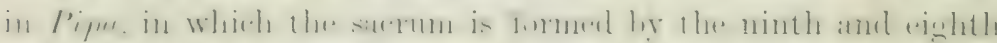

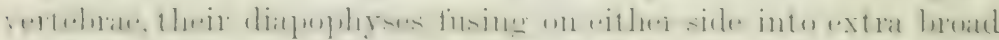

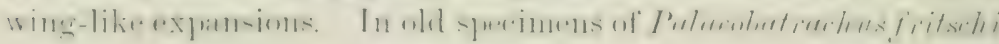
the seventh vertelna is in a transitional condition, the ilium

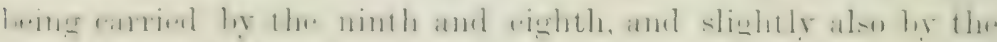
diapophyses of the serenth vertebra; and in $I$. dilmianus the 
diapophyses of all these vertebrae are united into me broal plate to which the ilia are attached. Lastly, in Hymenorlirus the first sacral is the sixth vertebra, and this creature has therehy reduced the pre-sacral vertebrae to the smallest number known.

This shifting forwards of the iliac attachment implies the conversion of original trunk into sacral rertebrate, and the original sacral vertehra itself lecomes ultimately adderl to the mostyle. The second sacral, the tenth of Prlubates, the ninth of Pipa, and the tenth on the right sile of the abnormal Bombinator, are still in a transitional stage of conversion. In I) iscoglossidae the tenth is already a typical post-sacral vertebra, and is added to the coceyx, but it still retains distinct, though short, diapophyses. In the majority of the Anma the tenth rertebra has lost these processes, and its once separate nature is risible in young specimens only. In Bombinator even the eleventh vertebra is free during the larval stages. In fact the whole coccyx is the result of the fusion of about twelve or more rertebrae, which from behind forwards have lost their individuality. Wte conclude that originally, in the early Anura, there was no coceyx, and that the ilium was attached much farther back: and this condition, and the granlual shifting forwards, supply an intelligible canse of the formation of an os coceygem. The fact that the sacral vertehrae of the Anma possess no tracess of ribs as carriers of the ilia, is also very suggestive. The ilia have shifted into a region, the vertelnae of which had alrearly lost their ribs. By reconstructing the vertebral column of the Anura, by dissolving the coceyx into about a dozen vertebrae, so that originally, say the twenty-first vertebra carried the ilia, we bridge over the enormous gap which exists between the Anura and Trodela. That whole portion of the axial continuation behind the coceys, more or less coinciding with the position of the vent, is the transitional tail.

The disappearance of both notochord and spinal cord, and the conversion of the cartilanginums elements into a continuous rod in the case of the os coccygeum, find an analogy in the hinder portion of the tail of Dipnoi and Crossopterygii, and in the tail-end of most Irodela, portions which are not homologous with the os coccygeum. The term urostyle should be restricted to such and similar modifications of the tail-end, and this latter happens to be lost by the Anura during metamorphosis. 
Strictly speaking, or rather in anatomical parlance, the

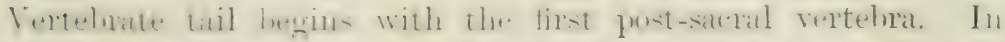

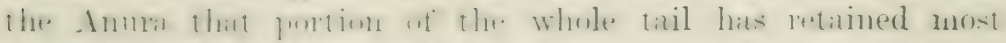

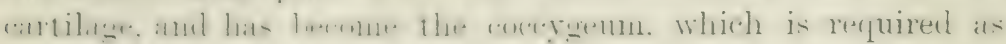
" "backinne" for the often enormous belly. This require-

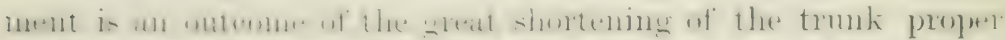

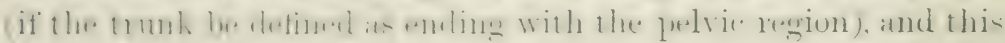

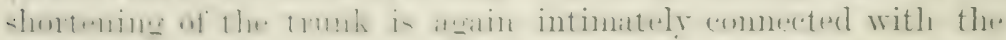

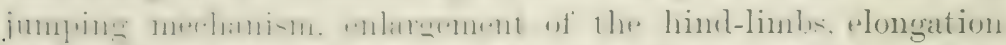

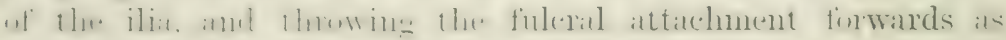

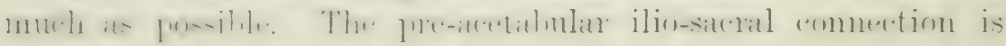
carried to the extreme in the Anum.

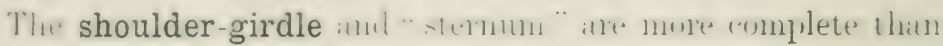
- in the I'indela, there lieing also a pair of clavicles, fused with

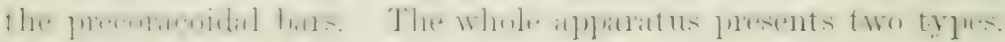
In the areiferous type the coracoids and precoracoids retain a great anount of cartilage in their distal portions, and these

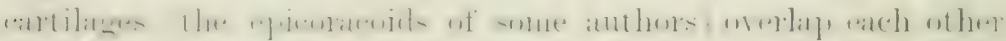

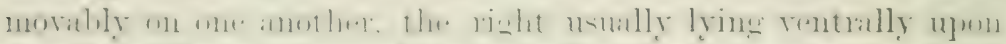

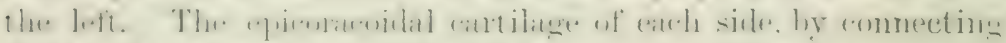

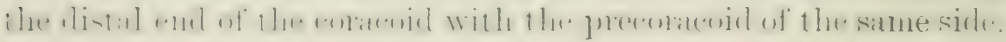
forms an are, hence "arciferous." In the firmisternal type the epicoracoidal cartilages are much reduced, and, instead of

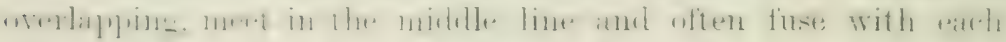
other, forming therely a firm median loar, which connects the ventral ends of the precoracoids with those of the coracoids.

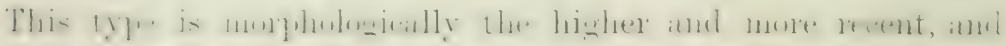
passes in the lanval stage through the arciferous condition. It is restricted to the Ranidae, Engystomatinae, and Aglossi.

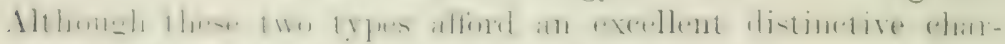
acter for the main divisions of the Anmra, they are to a certain extent commected ly intermeriate forms in such a way, that, for

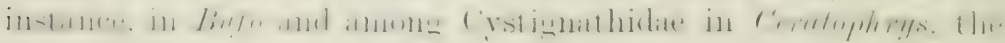
two opposite epiconacoidal cartilages hegin to nuite at the anteriol emul.

Ii many Engystomatinate the precoracoids togrether with the

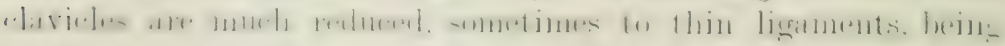
in this case mostly curvel hack and lying closely against the coracoids; or they maty he lost completely. Tery rarely the

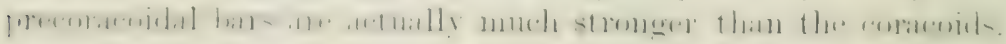


and the median symphysial har of cartilage is lost: this is the? case in Hemisus.

The scapula is always large and curved into transverse, durally broadening blades, the dorsal sreatex furtion wh which, the so-called supra-scapula, does not ossify but calcifies.

It is very doubtful if the Anura possess a true sternum, if hy sternum we understand a medio-ventral alparatus which owes its origin to the rentral portions of ribs. The so-called

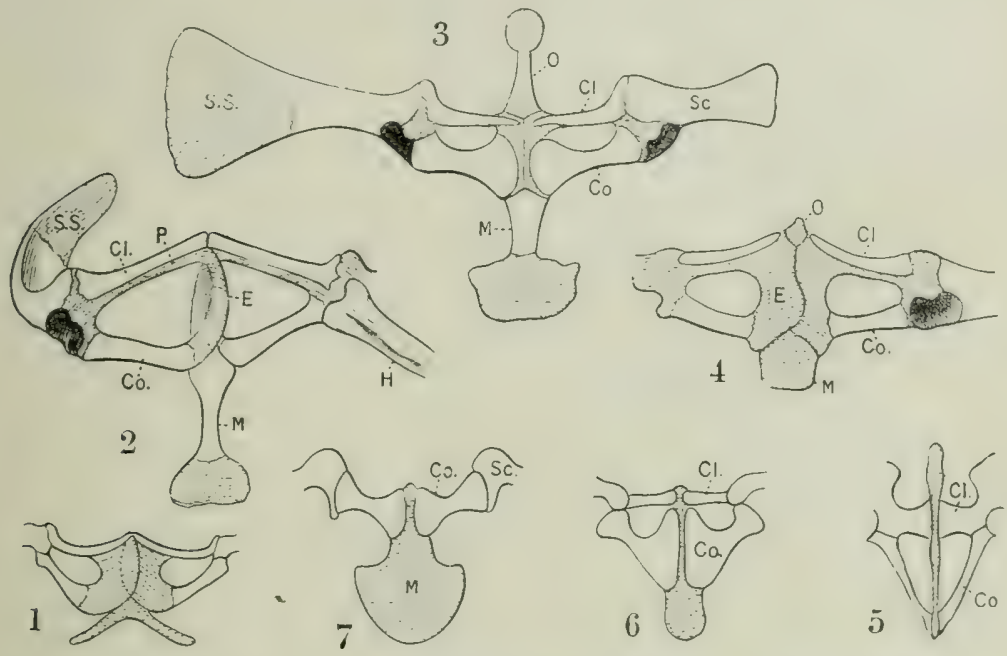

Frc. 5.-Ventral views of the shoulder-girlles of various Anura. (Slightly enlarged.) 1. Bombinator igneus, and 2, Bufo vulgaris, as examples of the areiferous type ; 3 , adult, 4, metamorphosing Rance temporaria, showing change from the arciferous into the firmisternal type ; 5 , Hemisus guttatum; 6, Breviceps gibbosus; 7 , Cucopus systoma. $(5,6,7$, after Boulenger. $)$ Cartilaginous parts are dotted ; ossified parts: are left white. $C l$, Clavicle ; $C o$, coracoid ; $E$, epicoracoidal cartilage : $I I$, humerus : II, metasternum ; O, omosternum : I', precoracoid ; Se, scapula ; S.S. supraseapula.

sternal apparatus of the Anura consists of two pieces. One, interior, variously named episternum, presternum, or onosternum, rests upon the mited precoracoids and extends headwards, heing wither styliform or broadened out. Sometimes it is partly ussitied, with a distinct suture at its lase: this is the caste expecially in the Firmistemia: in many Arcifera the omostemmu remains (artilaginous and is continuous, without a sutmal hreak, with the cartilage of the precoracoids, indicating therely its sentic relation to the shoulder-girdle. Hence omosternum is the 
foreferahle mane. It is frequently much reduced, eren absent. fir instance in mut Intenidate and in the Engrstomatinite.

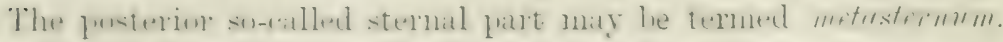
It forms the posterior counterpart of the omostermum. It

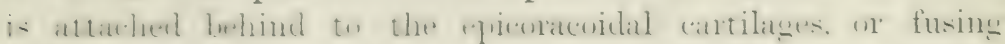
with them forms their posterior continuation. It appears mustly in llue shape of a clyle. which is frepuently assified, and

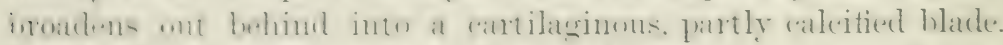

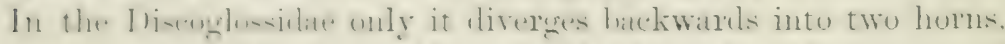

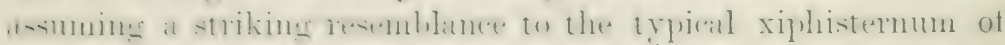
the Amniota. In young Anura the metasternal cartilage is intinately commental with the previcardinm, an indication of it-

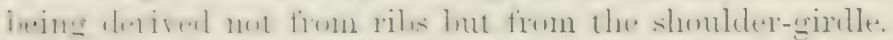

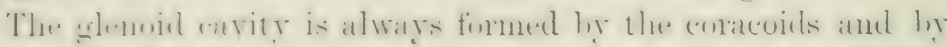

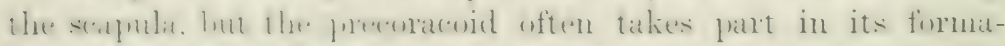

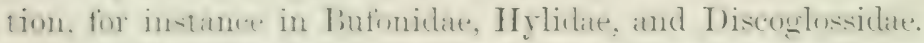

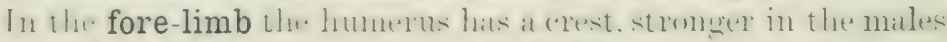

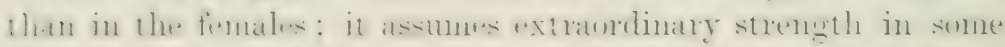

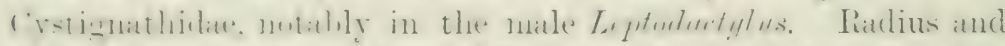

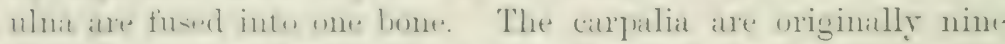

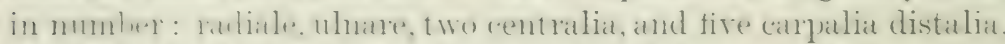

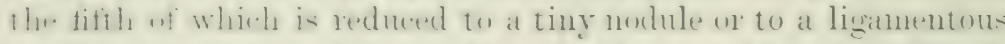

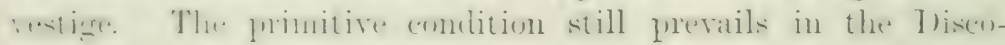
glossidae. In most of the other Anura the fourth and third linal arpulia. in any (ate rery small, fiee with the enlarged

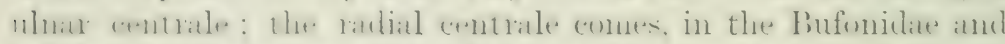

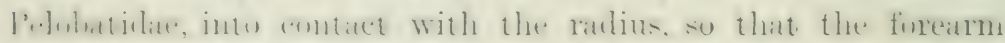

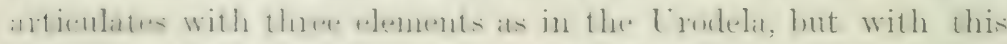

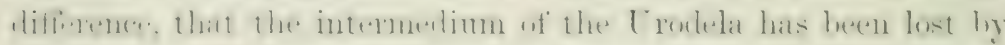
the Anura. There are five metacarpalia and five fingers, but

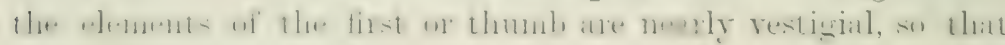
the pollux is reduced to one or two nodules, scarcely visible

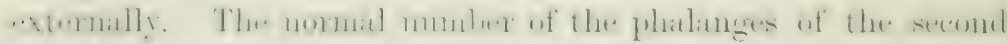

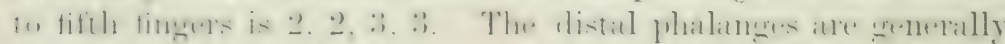

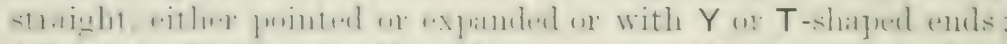

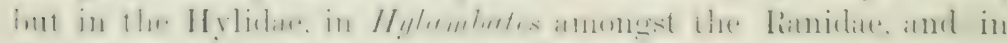

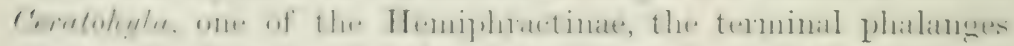

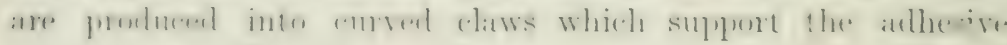
finger-dises. There are, however, many genera of different

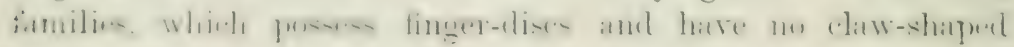


phalanges. The Hylidae, and many of the climbing member's of the Ranidae with adhesive discs, possess an extra skeletal nece intercalated between the last and last but one phalanges of the fingers and toes. This piece, a mere interarticular cartilage in Hyla, is in the following Raninae developed into an additional phalanx, so that their numbers are $3,3,4,4$ in the hand and 3, 3, 4, 5, 4 in the foot: Cassina, Hylambates, Rappia, Megalicalus, Rhacophorus, Chiromantis, Luelus, and Nystionlus. All the other Ranidae are without this additional phalanx, irresuertive of the presence or absence or size of digital expansions.'

The pelvic girdle looks like a pair of tongs (see Fig. 4, 1. 22). The ilium is enomously elongated and is morably attached to the sacral diapophyses. This comnection is always pre-acetabular in position. The ilium and ischinm co-ossify conpletely, and make up nearly the whole of the pelvis: the pulis is very small, and remains cartilaginous mless it calcities. It rarely possesses a centre of ossification, for instance in l'elobutes, where the osseous nodule is exchded from the aretabulum, recalling certain Labyrintholontal, whose ossal pulis likewise do not reach that cavity. The latter is open or perforated in young Anura and remains so in the Discoglossidae, but in the others it becomes closed up as in the Urodela. The ventral halves of the pelvis, besides forming a symphysis, closely approach ach other, just leaving room for the passage of the rectum and the urino-genital ducts.

The hind-limbs are in all cases longer than the fore-limbs. The femur is slender, the tibia and fibula are fused into one bone. The tarsus is much modified by the great elongation of the two proximal tarsalia (there being no intermediun) into an astragalus and a calcaneum, both of which fuse together distally and froximally, or completely as in Peloflytes; in the latter case the limb assumes a unique appeance, since it consists of three sucessive and apparently single bars of nearly exual length. The other tarsal elements, especially the more lateral ones, are practically reduced to pads. The Anura have thereloy acpuired two well-marked joints, one cruro-tarsal, the other tarsonetatarsal; this shows a high stage of specialisation in comprrison with the Urodelous and Sitegocephalous type of still undefined joints. 
The Anura possesses five well-developed toes with normally

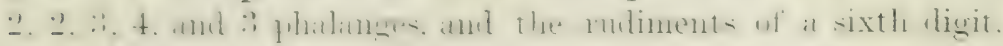
the so-called prehallux, which consists of from two to four pieces, including the one which represents its metatarsal. This prehallux, as a vestige of a once better developed digit, is

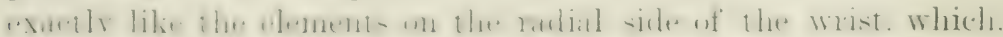

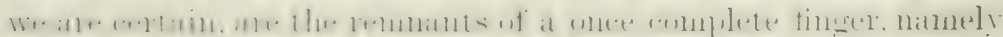

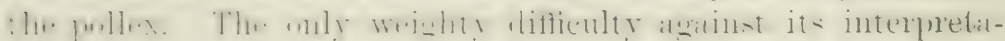
tion as a prehallux lies in the fact that hitherto no six-toed Stegrocephali have been found; but the fact that there are no

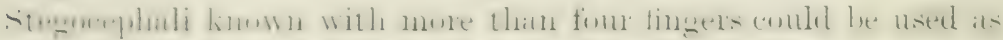
an argument against there being a pollex-vestige in recent Anuma with just as little reason.

The skull of the Amura differs from that of the other recent Amplibia in the fullowing features:-.-

The orhital region of the primitive cranium remains carti-

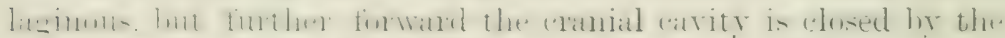

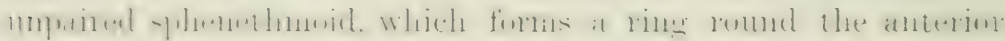
portion of the brain-cavity, hence called "os en ceinture" by

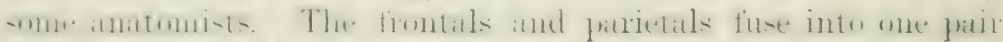

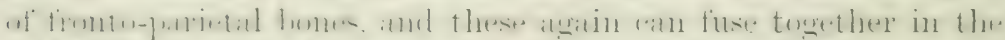

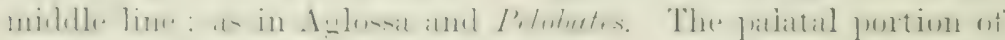

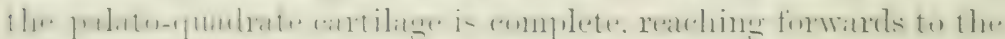
sides of the ethmoid region. The curved arch, formed by this cartilage, is covered by the following bones: (1) the quadrato-

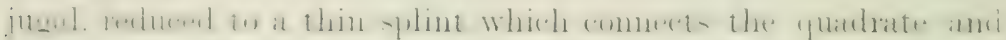
squamosal with the posterior end of the maxilla; (2) the pterygoid, always strong, extending from the distal imner corner of

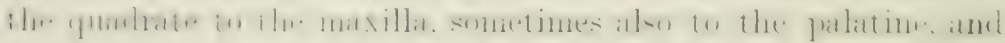
with il hroal, nedian process to the parasphenoid, this process covering ventrally most of the otic region: (3) the palatines, which rany considerably in shape and size; they are placed transversely and meet in the middle line: in Bombinutor and Polorlytes they are alsent.

The quadrates are directed transversely and hackwards, in

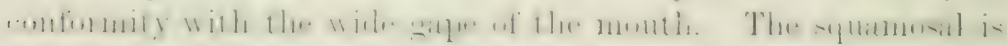

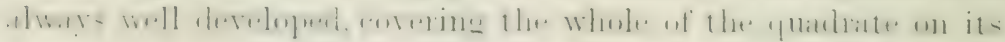
muter side; it has a forwardly directed process which ends freely in linm", meets a corresponding process of the maxilla and forms a bony areh with it in IMismolnssus, Prlotates, and others, or 
is scarcely developed at all, for instance in Bufo. In I'luluetes cultivips the squamosal is very wide and forms a junction with the fronto-parietals, thus producing a broad loridge aceoss the temporal fossa.

The nasal bones are large and meet in the middle line. Frequently they leave a space between them ant the diverging anterior portion of the fronto-parietals, through which gal appears part of the dorsal surface of the ethmoirl cartilage. A tontanelle between the frontals occurs in most Hylidate, many ('ystignathidae, some few Bufonidae, in Prloclytes ammmgst the Pelobatidae, and in the Discoglossidae.

The tympanic cavity is bordered in front, above, and helow by the squamosal and quadrate, hehind by the musculus depressor mandibulae, internally by the otic capsule, and by the cartilage of the cranim between this and the lateral occipital hone The carity communicates, however, hy the wide and short Eustachian tube with the mouth, the passage being hordered anteriorly hy the pterygoid, posteriorly by soft parts. Partly imbedded in these soft tissues is the styloid process or stylohyal. which is attached to the cranium, mostly behind the otic region, and is continued downwards into the anterior horn of the hyoid. The whole partly cartilaginous, ligamentous, and osseous string is, in fact, the entire rentral half of the hyoid arch, while the dorsal half or hyomandibular portion of this, the second visceral arch, is modified intr the columellar or auditory chain. The inner end of this chain, the stapes, is inserted into and around the fenestra ovalis of the otie capsule, while the outer end is somewhat $\mathrm{T}$-shaped, and is loosely attached to or near the upper rim of the tympanic ring and to the middle of the tympanic disc. In many Anura this terminal bar can be seen from the ontside. The middle portion of the columellar chain is ossified, the rest remains cartilaginous. But the whole chain exhihits various modifications in different genera, especially in the number and the extent of the processes sent out by the outer cartilaginous portion: these are attached in various ways to the tympanum and its rims. The tympanic disc is carried loy a cartilaginous ring, which rests against a special process sent out by the quadrate, and is probably itself a differentiation of this element.

In some very aquatic genera the whole tympanic eavity is 
much reduced, for instance in P'clubutes, Bombinator, Liopelmu.

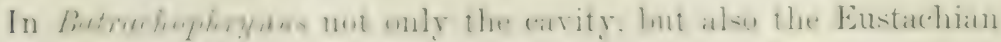
tubes are suppressed. In the Aglossa only the two tubes are

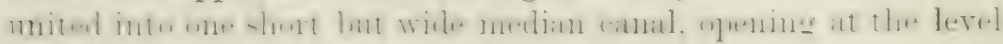
of the pterygoids on the roof of the mouth.

The lawer jaw is remarkable for the possession of mento-

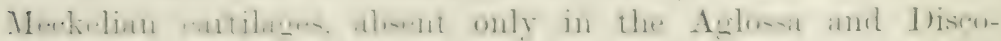

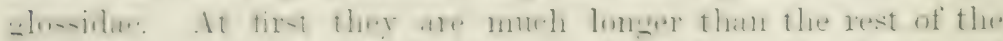

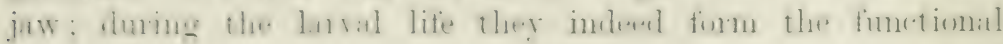
jaw, and they are now corered with horny sheaths instead of teeth. Owing to the absence of teeth on them, these mento-

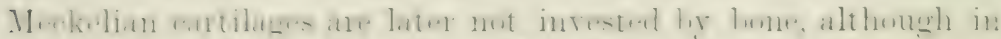

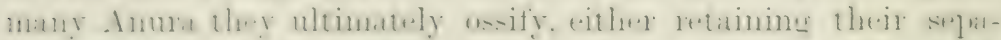

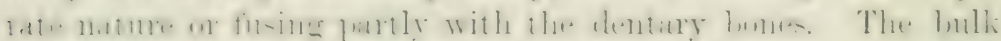

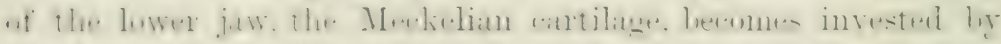

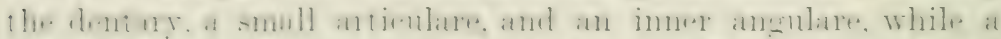

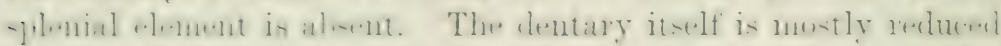

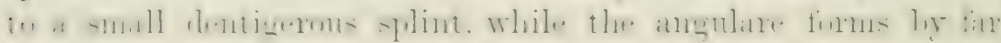
the greater part of the bony jaw.

Teeth are more restricted in their occurrence than in the Lrodela. On the jaws they always stand in one row. With

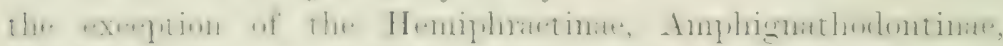

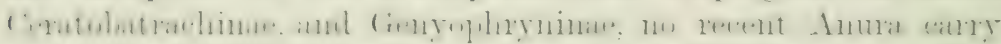

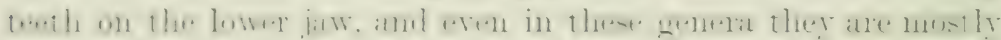

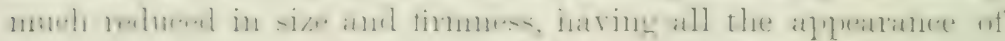

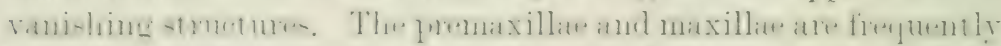

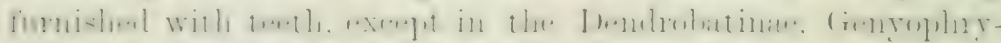

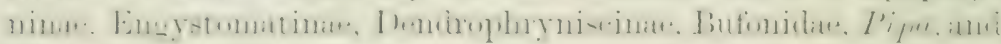
IIymenorhirus. The romers mostly carry a series of teeth on

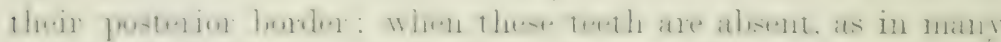
species of linfo, a kind of substitute sometimes occurs on the

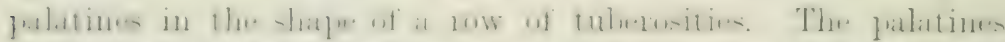

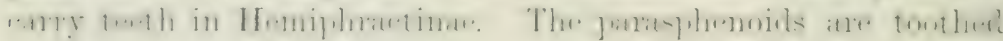
in 'Triprion and Diuglenr, and occusionally in Pelobutes cultripes.

A few Anura possess peculiar substitutes for teeth in the

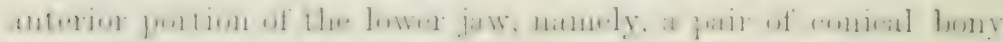
frocesses, sometimes rather long, but always covered by the dense gums, or investment of the jaws; r.y. Lepridobatruehus, reveral Runu, ey. li. mispersu, Ri. lihusiunu, li. limhli, and Cryptotis luris. 
Cranial dermal ossifications are developed in some species of Bufo, still more in the Hemiphractinae, and abore all in IMH-

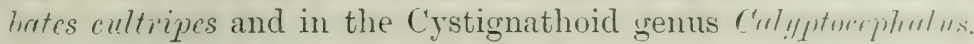

The hyoid apparatus of the Anura is complicated. It is originally composed of the hyoidean and four branchial arehes, with one median, copular piece. The branchial arches form in the early life of the tadpole the elaborate framework of the filtering apparatus mentioned on 1). 44. During metamorphosis the whole filter disappears, owing to resorption of the greater prart of the branchial arches; only their median portions remain, and fuse with the enlarged copular piece and the hyoilean arches into a broad shield-shaped cartilage (rupres linumur). whence several lateral processes sprout ont, the posterior pair of which are generally called thyrohyals or thyroid horms. The true hyoid horns give up their larval lean-to articulation with the quadrate, become greatly elongated, and gain a new attachment on the otic region of the cranim. The transformation of the whole apparatus has been studied minutely by lidewnod, in Pelod.ytes punctatus. ${ }^{1}$

\section{SkIN}

The epidermis of the young larvae of Amphibia is furmished with cilia, which later on are suppressed by the development of a thin hraline layer or cuticula, but cluster's of such cilia remain, at least during the larval life and during the periodical aquatic life of the adult, in the epidermal sense-organs. In the frog, currents are set up by the ciliary action at an earlier stage. and are maintained to a later stage than in the newt. In the latter the tail loses its ciliation, whereas in the frog it remains active almost up to the time of the metanorphosis. In tadpoles of $3-10 \mathrm{~mm}$. nearly the whole surface is ciliated (Assheton): The cilia work from head to tail, causing the little animal, when perfectly quiet, to move forwards slowly in the water. Beneath the cuticula, in the Perennibranchiata and the larvate of the other Crodela, lies a somewhat thicker layer of vertically striated cells, the so-called pseudo-cuticula, which disappear's with the transformation of the upper layers of the Malpighian cells into the stratum corneum. The latter is very thin, consists of one or two layers of flattened cells, and is shed perioclically $h$ all ${ }^{1}$ P.Z.S. 1897 , p. 577. 2 Q.J.M.S. xxxviii. 1896 , p. 465. 
Amphibia in one pieces. In the Lrodela it grenerally breaks

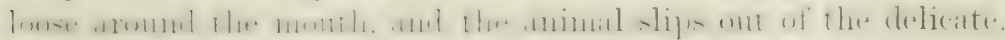
transparent, colomrless "shirt," which during this process of exhsis or moulting becomes inverted. In the Anura it mostly breaks alones the michlle line of the lack, the creature struggles wut of it, polie's it into its mouth, and swallows it. Urodelit also eat this skin. Is a rule the first ecdysis takes place

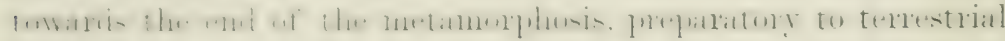
life. Su lone as the animal grows rapidly, the skin has to be

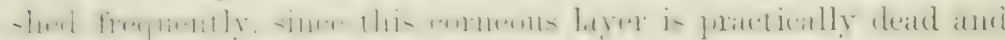
unyielding. Arlult terrestrial Trodela do not seem to moult iften, mostly only when they take to the water in the breeding snason. Anura, on the other hand, moult often on land, at least every few months. The surface of the new skin is then quite moist and slimy, hut it soon dries and hardens.

The Malpighian stratun consists of several lajers, thickest in the Perennihranchiatil; in them it contains mucous cells

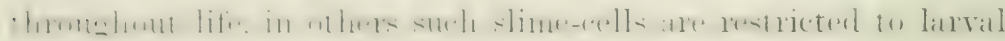
life. Later, recrular slime-chlands are developed, which open (nil the surfice. They are very numerous, and more evenly distributerl, over most parts of the body, than the specifie or

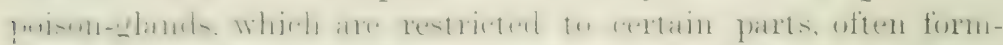
ing large clusters, especially on the sides of the body. They reach their greatest development in the "parotoid glands" of the Anura. Both kinds of glands are furnished with smooth muscle-fibres, which are said to arise from the basal membrane

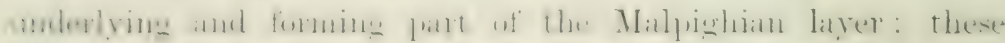
muscle-cells extend later inwowarks into the corium. For the antion of the poison, see p. 37 .

The stratum corneum is mostly thin, but on many parts of

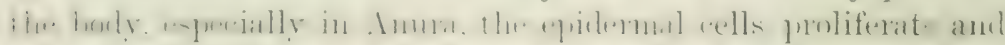

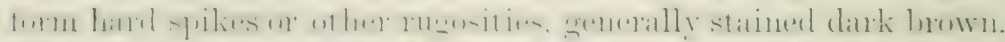

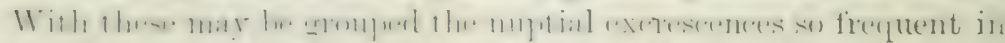

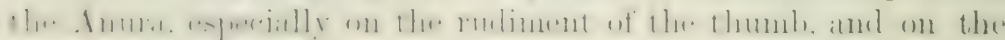
inder surfice of the joints of the fingers and toes. In many

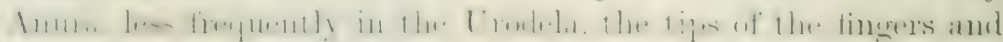
tres are encased in thicker horny shenths, juroducing claws or mails. They are best developed anong newts in Ongehodactulus, anong the Anura in Lenomes and Hymenochirus. The horny covering of the metatarsal tulercles reaches its greatest size in 
the digging spur or spade of Pelotutes. In most of these calses the cutis is elevated into more or less wart-like papillae, corered, of course, by the proliferated and cornified epidermis. In the female of Rana temporaria nearly the whole surface of the body becomes corered with rosy papillae during the breeding season. similar nuptial excrescences are common, and are most noteworthy in the male of the Indian Rana liebigi.

The epidermis also contains sense-organs. They attain their highest development in the larrae: later on ther undergo a retrogressive change. Each of these sense-organs is a little cup-shaped papilla, visible to the naked eye. It is composed of elongated cells which form a mantle around some central cells, each of which ends in a stiff cilium perforating a thin, hyaline membrane which lines the bottom of the cup, and is perhaps the representation of the cuticula. These ciliated cells are connecteri with sensory fibres, the nerve entering at the hottom of the whole organ. The cilia are in direct contact with the water, but the outer rim of the whole apparatus is protected by a short tube of hyaline cuticula-like secretion. These sense-organs are, in the larvae, scattered orer the head, especially near the mouth and around the eyes, whence they extend backwards on to the tail, mostly in three pairs of Iongitudinal rows, one near the rertebral column, the others lateral. They are supplied by the lateral branch of the ragus nerre. They disappear during the metamorphosis, at least in the Anura, with the exception of Ienopus, in which they form conspicuous white objects. The white colour is caused by the tubes becoming choked with the débris of cells or coagulating mucous matter, so that it is doubtful if these organs, which morevrer have sunk deeper into the skin, are still functional. In the terrestrial L'rodela these organs undergo a periodical process of retrogression and rejurenescence. During the life on land they shrink and withdraw from the surface, and their nerres likewise diminish, but in the breeding season, when the newts take again to aquatic life, they revive, are rebuilt and become prominent on the surface. They are an inheritance from the fishes, in which such lateral line organs are universally present.

The cutis of most Amphibia is very rich in lymph-spaces, which, especially in the Anmal, assume enomous proportions, since the so-called subcutaneous comnective tissue forms com- 


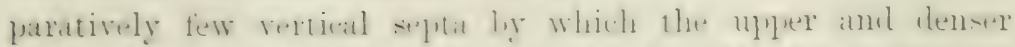

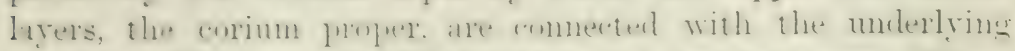

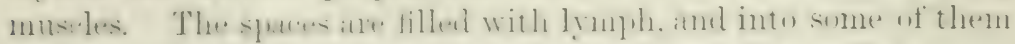

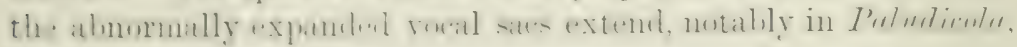
Leptoductylus, and other Cystignathidae, and in Phinodermu.

The entis frepuently forms papillae and prominent folds,

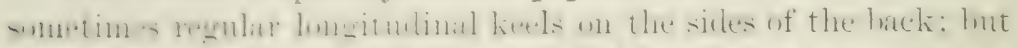

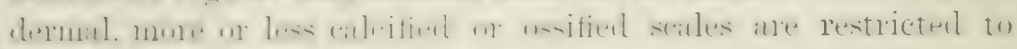
the Stegocephali and to the Apodix, q.x., pp. 79, 87 . We con-

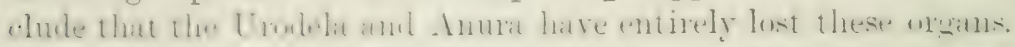

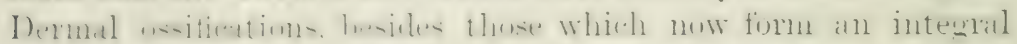

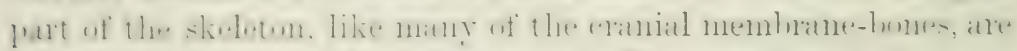

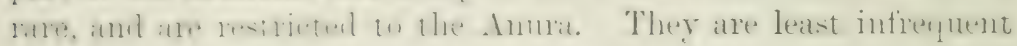
on the head, where the skin is more or less involved in the

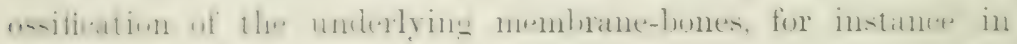
Triprion, Calyptocephalus, Hemiphractus and Pelobates. The think weificatinn in the skin of the hack of several speries of

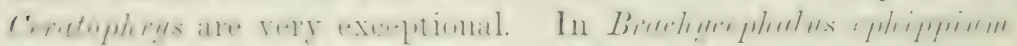

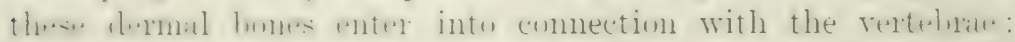

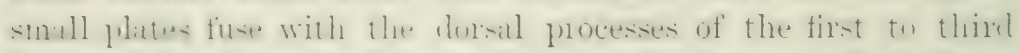

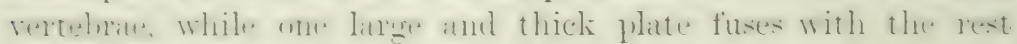

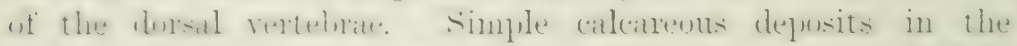

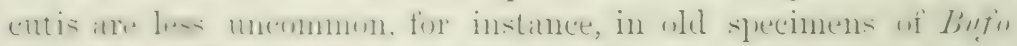

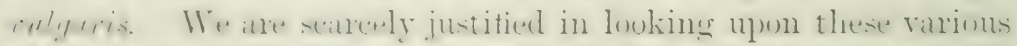

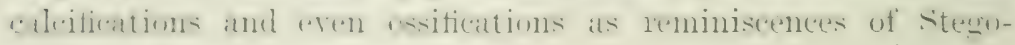
cephalous conditions.

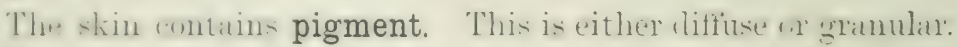

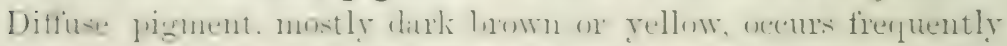

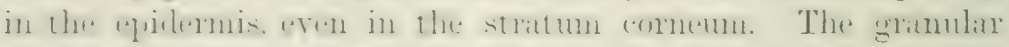

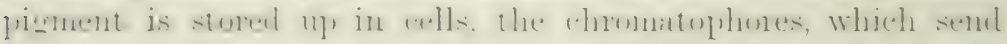

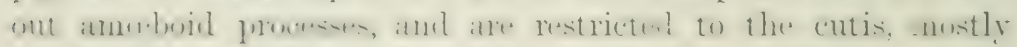
to it upper stratum. Where they malle their first alplearance. Contration of the chronatejpheres withdaws the pionent

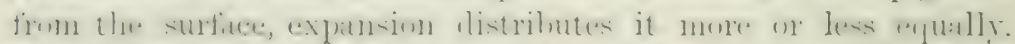

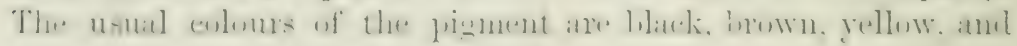
red. Green and blue are merely subjective colours, due to

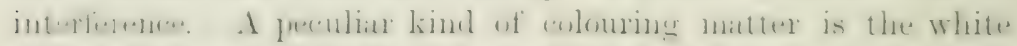

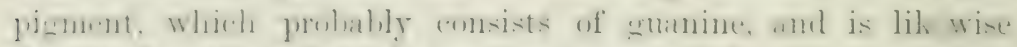

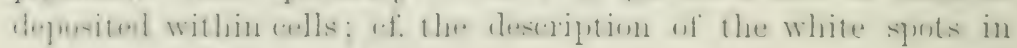
the skin of Hyla cociulea. 
Most Amphibia are capalle of changing colour, the Urortela, however, far less than the Anura, some of which exhibit an extraordinary range and adaptability in their changes.

The mechanism by which the change of colour is prochncer in frogs has been recently studied by Biedermam. ${ }^{1}$ If we eximine the green skin of the common Tree-frog, Hyla arborm, under a low power and direct light, we see a mosaic of green, polygonal areas, separated by dark lines and interrupted hy the openings of the skin-glands. Seen from helow the skin appear's black. Under a stronger power the black layer is seen to be composed of amastomosing and ramified hack pigment-cells. Where the light shines through, the skin appears yellow. The epidemis itself is quite colourless. The mosaic layer is composed of polygonal interference-cells, each of which consists of a basal half which is gramular and colourless, while the upper half is made up of yellow drops. Sometimes the tree-frog appears blackish, and if then the llack pigment-cells are induced to contract, for instance, by warming the frog, it appears silver-grey: in this case the pinment in the yellow drops is no longer diffuse, but is concentrated into a round lump, lorlgerl hetween the interstices of the grimulur portions; the black pigment-cells are likewise balled together. These black chromatophores send out numerous fine lnanches, which occasionally stretch hetween and round the polygonal cells. When each of these is quite surrounded and covered liy the black processes, the frog appears black. On the other hand, when the black pigment-cells withdraw their processes, shrink up, and, so to speak, retire, then the light which passes through the yellow drops is, by interference, broken into green.

Stoppage of the eirculation of the blood in the skin canses the black chromatophores to contract. Carbon dioxide paralysus them and causes them to dilate. This is direct influence without the action of nerves. But stimulation of the central nerve-centres makes the skin turn pale. Low temperatur. causes expansion, high temperature contraction, of the chromatophores. Hence hibernating frogs are much darker than they are in the summer. Frogs kept in dry moss, or such as hare escaped into the room and iry up, tum pale, regardless of light or darkness, probably owing to a central, reflex, nerve-stimulus.

'Tree-frogs turn green as the result of the contact with leares.

1 Atrch. ges. Physiol. 1i. 1892, p. 455. 


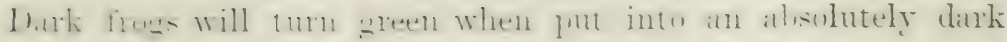
vessel in which there are leaves. This is reflex action, and hlinded sperimens de the sithe. The principal centres of the

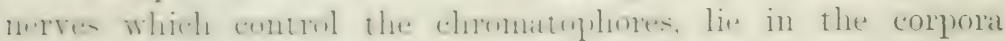
higemina and in the gytic thal:ani of the lonin. When these

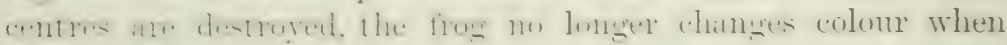
put upon leaves, but if a nerve, for instance the sciatic, be

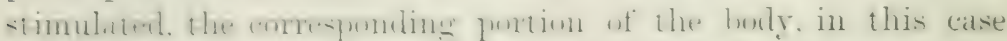

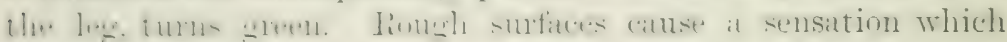

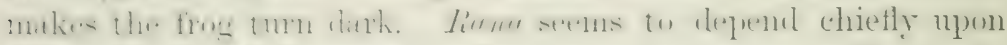

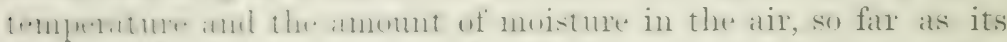

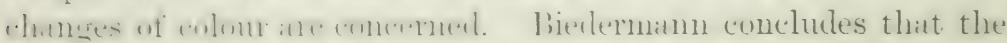

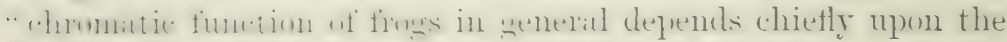
wn-my impresions menved hy the skin. while that of fishes depends upon the eye."

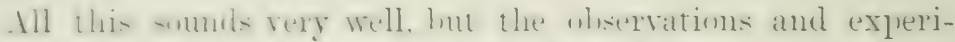

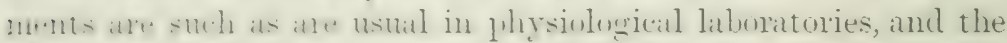

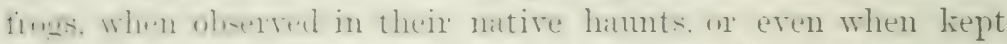

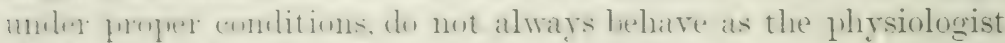
thinks they should. There is no dould that in many cases the changes of colour are not voluntary, but reflex actions. It is quite conceivable that the sensation of sitting on a rough -turfike start a whele train of propeses: moghess means hark, bark is brown, change into brown; but one and the same treefrom does not always assume the colour of the bark when it rests, or even sleeps upon, such a piece. He will, if it suits him, remain grass-green upon a yellow stone, or on a white

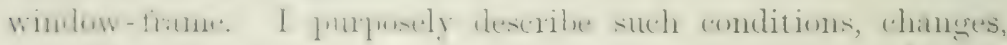

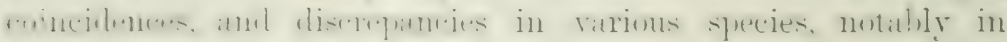
IIylu arborea, H. coerulea, lience temporaria, Bufo viridis, to show that in many cases the creature knows what it is about, and

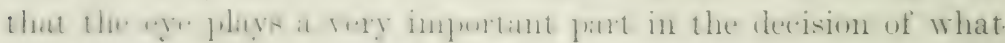
culour is to be produced. The sensory impression receired

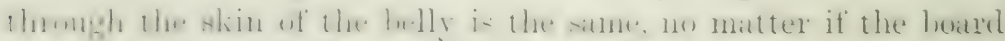

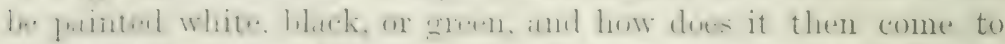

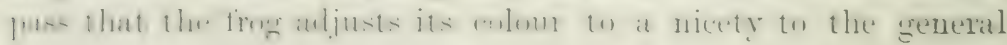
hue or tone of its surroundings !

Boulenger ${ }^{1}$ has given us at summiry of the action of the poison of Amphilia :

I Sut. Sici. i. 1592, 1. $155^{\circ}$ 
It is well known to all who have handled freshly-caught newts, and certain toads, especially Bombinator, that their secretion acts as a sternutatory, and causes irritation of the nose and eyes, the effects produced on us by Bombinator being comparable to the early stages of a cold in the head. Many collectors of Batrachians have learned, to their discomfiture, how the introduction of examples of certain species into the bag containing the sport of their excursion may cause the death of the other prisoners; for although the poison has no effect on the skin of individuals of the same sprecies, different species, however dosely allied, may poison each other by mere contact. But when inoculated the poison acts even on the same individual.

Wiss Ormerod, to personally test the effect, pressed part of the back and tail of a live Crested Newt between the teeth. "The first effect was a bitter astringent feeling in the mouth, with irritation of the upper part of the throat, numbing of the teeth more immediately holding the animal, and in about a minute from the first touch of the newt a strong How of saliva. This was accompanied by much foam and violent spasmodic action, approaching convulsions, but entirely confined to the mouth itself. The experiment was immediately followed by headache lasting for some hours, general discomfort of the system, and half an hour after by slight shivering fits."

Numerous experiments have shown that the poison of toaks, salamanders, and newts is capable, when injected, of killing mammals, birds, reptiles, and even fishes, provided, of course, that the dose be proportionate to the size of the animal. Small birds and lizards succumb as a rule in a few minutes: suineitpigs, rabbits, and dogs in less than an hour.

This poison of Amphibia is not septic, but acts npon the heart and the central nervous system. That of the common toad has been compared, in its effects, to that of Digitalis and Erythrophlaeum. Some anthorities hold that the poison is an acid, others regard it as an alkaloid.

Phisalix ${ }^{1}$ has come to the conclusion that toads and salamanders are possessed of two kinds of glands, different both anatomically and physiologically. These are, first the mucous glands, spread over the greater part of the body, with an alkaloid secretion, which acts as a narcotic; secondly, specific slands, as 


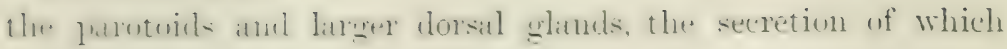
is acid, and acts as a convulsive.

Thr. Imlians of colombia are said to emplor the secretion of

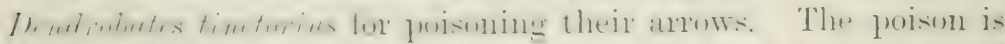

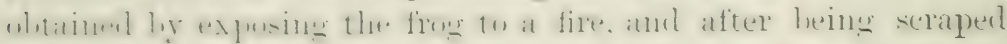

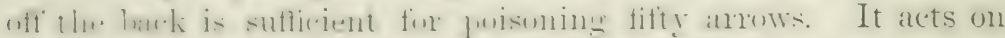

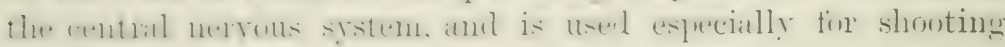
monkeys. Concerning the use of this poison for "dyeing" purrots, see p. 272.

The milly secretion of toads protects them against many

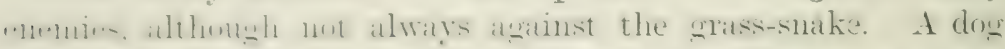

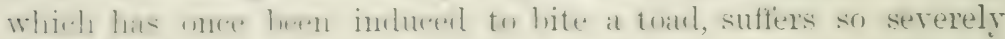
that it will nut tatsily wewat the experintent. The handling of

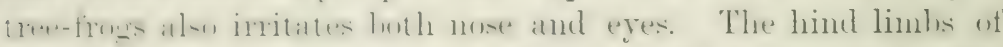
the Water-frog, Runa csculenta, have a rery bitter, acrid taste. In -luni. mut, if mot all, Amphilia are mone or less poisonous. and it is significant that many of the most poisonous, e.g.

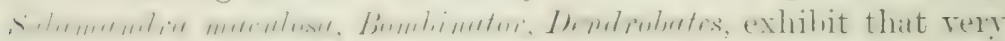

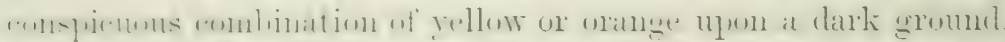
which is se widespreat a sign of proison. ()ther instances of

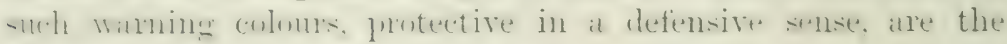
Wasps and Heloderme, the only poisonous lizard.

\section{Neries}

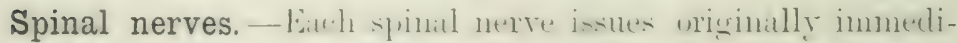

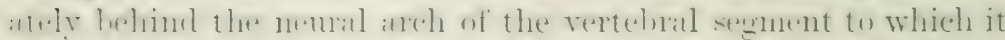

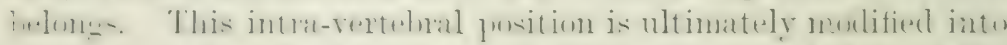

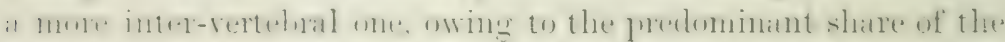

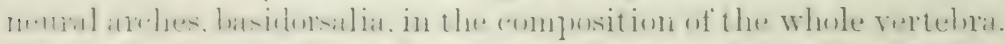

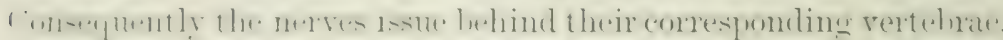

The first spinal nerve, or $\mathrm{N}$. suboccipitalis, is exceptional in sereral respects. It develops a dorsal and a ventral root like

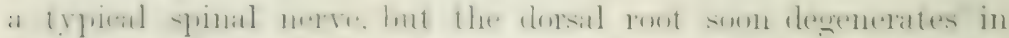

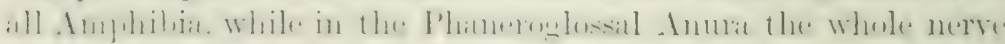
disippears. 'The first spinal nerve reduced to its ventral half

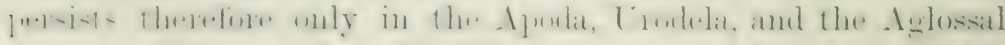

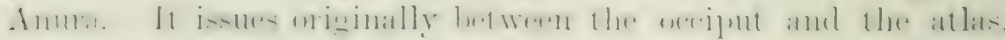

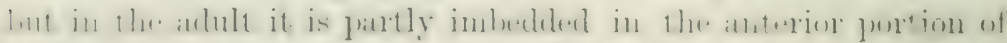

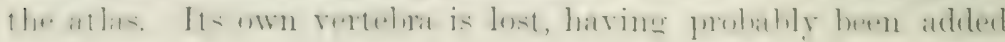
to the cranium. 
In the Lrodela the first spinal nerve either remains separate, or it joins the second spinal, forming with it and with a hranch from the third nerve the cervical plexus, which supplies the muscles of the cervical region. The thind, fourth, and fifth nerves, and sometimes also the sixth, form the lirachial plexus.

In the Aglossal Anura $\mathrm{X}$. spinalis I. mostly sends a fine threarl to the second spinal nerve. the rest supplies chiefly the M. Ievator scapulate, in Pipu the abdominal muscles also. In all the other Anura this $\mathrm{X}$ : spinalis $\mathrm{I}$. is lost: occasional restiges

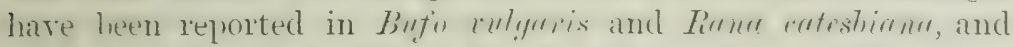
remnants of it may possilly be found in P'elolbatidate and Discoglossiclate. The first actually persisting nerre of the Phameroglossa is consequently $\mathrm{N}$. spinalis II.

The brachial plexus is composed as follows:-Pipa, $\mathrm{N}$. spinalis II. and III.: Frmpus and I'haneroglossa, $\mathrm{X}$. spinalis III. and IV., with a small branch from the second; the next following three nerves, numbers V.. VI. and TII., behave like ordinary trunk nerves.

The pelvie plexus of the I'haneroglusia is formed in Runu ly the VIII. + IX. + X. + XIth nerves, the tenth issung between the sacral rertebra and the coceyx. In Bufo and Hylu the plexus is composed of five nerves, the serenth spinal sending a branch to it. Occatsionally the trelfth nerve contributes a small branch to the posterior portion of the llexus. This and the eleventh nerve leave the cocerx hy separate holes. therely inclicating its composition. The rest of the sprinal cord gives oft no nore recognisable nerves, owing to its reduction during the later stages of metamorphosis: its terminal filanent passes ont of the posterior end of the coceygeal canal.

Concerning the cranial nerves it is necessiry to draw attention to one point only. The last nerve which leaves the cranium of the Amphibia is the ragus or tenth cranial nerve. There is consedpently no eleventh, and no twelfth or hypoglossal, fair of cranial nerves. Their homologues would he the first and second spinal nerves, but the whole tongue of the Amphibia. with its muscles, is supplied by the glossopharyngeal, or ninth cranial pair, and is morphologically not homologous with the tongue of the Amniota. 


\section{REspiratory ORgaNS}

A rerr important and charateristic feature of the Amphibia is the derelopment of two sets of respiratory oreans : Fills and langs. It is as well to grve detinitions of these organs. Lan!/s are holluw evasuations from the ventral wall of the pharyx.

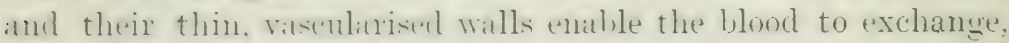

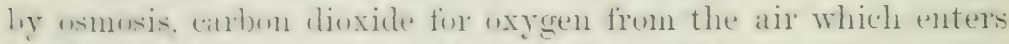
the lunes ly the numb or the nustrils, and the windpipe. The

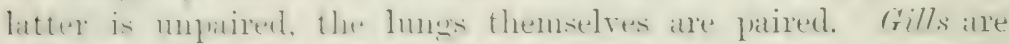

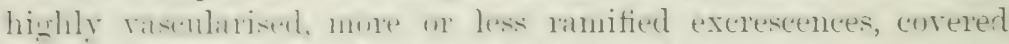

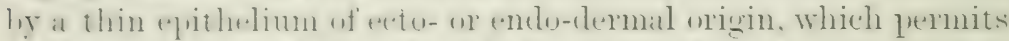

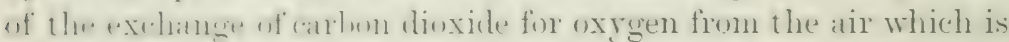

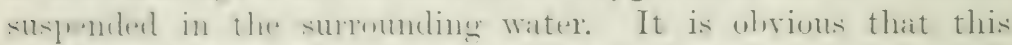

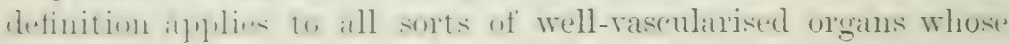

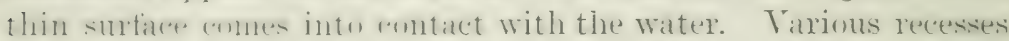

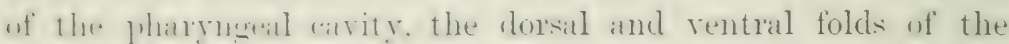

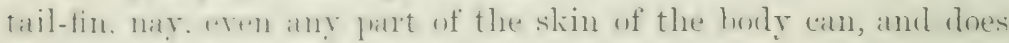

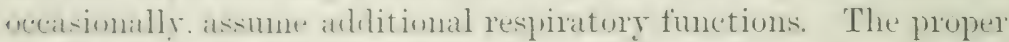
definition wi wills, in Vertelsates, reguires, therefore, the restrictime that they must he heveluged upon and catried lyg visceral arches.

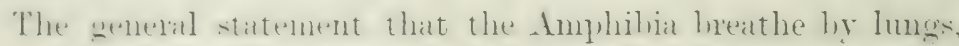

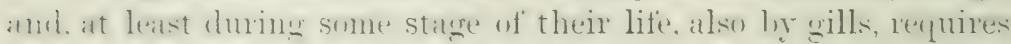

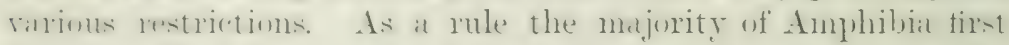

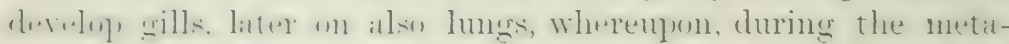

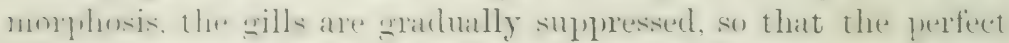
animal breathes by lungs only (see p. 61). But a number of

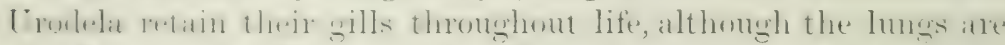

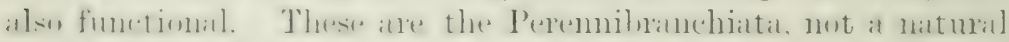

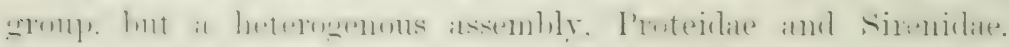
Some species of Amblystoma remain individually P'eremnimanchiate (cf. Axolutl, p. 112). On the other hand, in some

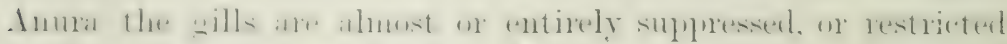

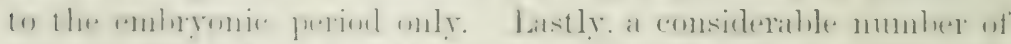

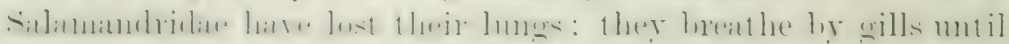
their metamorjhosis, but have in the adult state to resort to respiration by the skin (cf. p. \pm 6 ).

The general plan of the development of the branchial respiratory apparatus is as follows:- The six visceral arches, 
namely, the mandibular, the hyoidean, and the fom hranchial arches, correspond, long before they are cartilaginnus, with fon main arterial arches of the truncus arteriosus. The first, the arteria hyo-mandibularis, belongs to the hyoidean and mamelibular. segments, the second to the first branchial, the third to the secomil hranchial, while the fourth soon splits in two for the thirel and fourth or last branchial arch. On the dorsal side these lnanchial arterial arches combine to form the radix of the dormal aorta. These arehes, especially the three branchials, appear in newts, less clearly in frogs, as transverse ridges on the sides of the future neck. Between the arches the pharynx gratually hulges out in the shape of five lateral gill-pouches; the first between the mandibular and the hyoidean arch, the second leetwen the hyoidean and the first branchial arch, etc. These ponches soon break through to the outside and lrecome gill-clefts, except the first pouch in Urodela. Before the breaking through of the clefts there appears upon the outside of the midlle of the rim of each arch a little knob, which soon ramities and forms an external gill. The knol, owes its origin to the development of a hloodvessel which buts from the arterial arch, ramifies and hreaks n' into capillaries, and returns a little further dorsalwards into the arch. A secondary loop to the outside of the prinary arterial arch is thus formed; and whilst this outer loop sprouts out further, driving before it the likewise proliferating skin, and thus producing the gill, the midlle portion of the primary arch remains in the Urodela as a short cut, but in the Anuxa it partly obliterates, and henceforth acts as the intermal fircut ressel of the gill. When, during metamorphosis, the gills disappear, their intrinsic "fferent and ffirent ressels vanish likewise, and the short cut completes the circuit. In order to do this they have, in the Anura, to form new comnections with the trunks of the afferent vessels.

The arterial arches themselves are modified as follows:- The first pair become the carotids, the second form the right and left aortic arches, while the third and fourth unite amol are transformed into the pulmonary arteries and "ductus Butalli," the liast arterial arch having previously sent a banch into the leveluping lungs. In the Anura the third arch obliterates.

The gills and clefts present various modifications. The [rodela possess three pairs of gills, one each npun the dorwal 
half of the three hanchial arrhes just near the mper comers of the elefts: and the skin of the body is continued upon the stem of eatch eill. pinmenterl like the rest of thes surfiace of the body. such a will is nume or less like a bluke, standing rertically, and is complnated of at stem of comneretive tissue, thick at the hase, and. as a rule, canrring two series of tine lamellate, which, howerer, do not forn two oppusite series. lut hatng downwards, lieing sn to

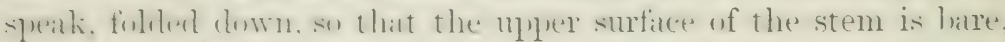
and anries the linnellies an its under side. In the Axolotl some

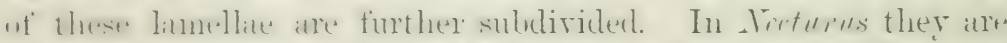

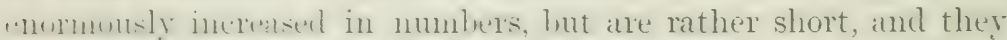
stitnel no longer in two rows. lut are crowderl into one. Those

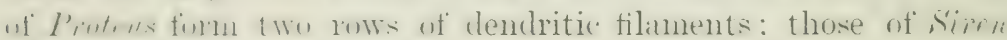
are likewise much ramified.

The larvae of the Urodela have four clefts. In the adult

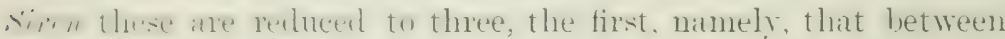
the hyoid and the first branchial arch, being closed up. In

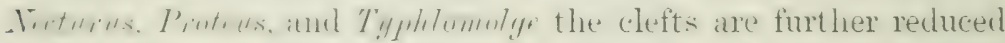
(1) two. wwing to the elosing up of the first and last, only those

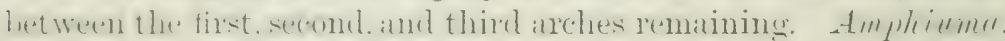

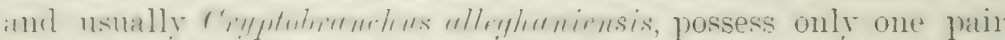
of elefts. while in 1 ' jumnirus and in the solamandridate all the clefts are abolished.

The sills of the Croulelat are alwars uncovered. although a shom operenlum is formed from the posterior margin of the hyobloan areh: the hallees of this fold neet below the throat.

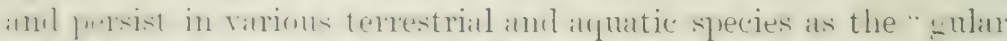

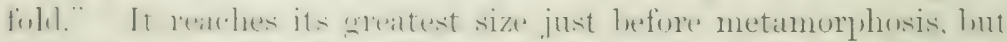

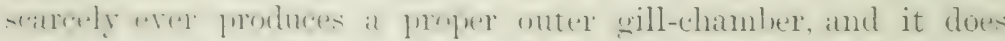

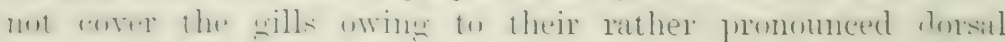

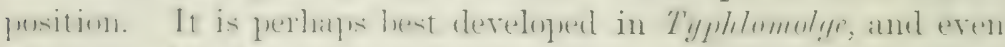

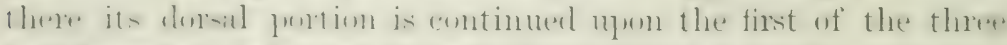

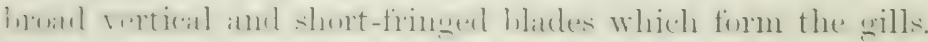

A description of the gills of the Apoda will be found in the systematic part.

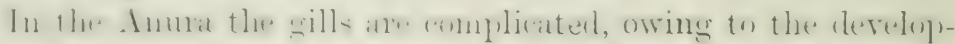

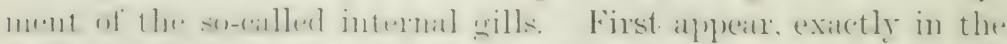

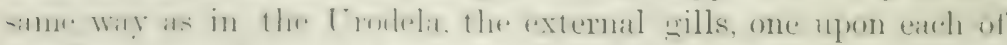

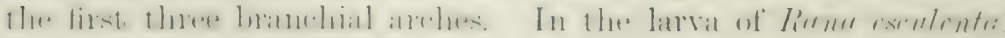

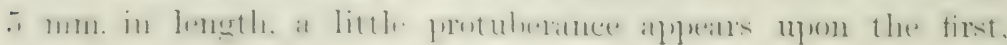


and then upon the second arch. In the $6 \mathrm{~mm}$. larva the first will shows four knols, the second two, the third one linol. They are always delicate and thin, although sometimes pigmented, long, and much-ramified structures. The first pair is always the largest: well developed and persisting a long time in lirnu temporaria; smaller in $R$. esculente and Bufo vulgaris; very short, scarcely fortied, in B. viridis and Hylu witrorm. They are relatively largest in Alytes, while still in the egs. Numerous descriptions of these gills will he found in the systematic prart.

(rreat changes take place alout the time when the fomrth or last lranchial arch and the pulmonary arteries are developed. This oceurs in $I_{i}$, semlenta. when the larval is ahout $9 \mathrm{~mm}$. long. The sprouting of the gills extends gratually downwards along the arches mon their ventral halves, and these new gill-filanents or lonss transform thenselves into nunerous dendritic loundles, resting in several thickset rows upon the hinder margin of the first to the third arch, one row only on the fourth arch, which cimries no extermal gill. These "internal gills" look like red holster's or thick and short-tasselled lunches. Whilst ther are developing the dorsal, alder gills leecome arrested in their growth and disappear, and at the same tine a right and left opereular fold grows out from the head and cover's these new gills, shutting then up in an outer branchial chamber, just like that of 'Teleostei and uther Tectolmanch fishes. This is the reason why these new yills have heen called intemal, and the mistaken notion has sprung up that they are comparable with the true internal gills of tishes. In reality Amphilia have only external gills. Thery are always corered loy ectolemen, are restricted to the ontside of the branchial arches, and are reveloped hefore the formation of the clefts. These gills are in many cases directly continuous with the more dorsally and more superficially placed earlier external gills: but although nearly every one who has studied their development has observed this agreement, the old error still prevails. They are morphologically as little intermal as the true internal gills of Elasmobranch embryos are external gills, because these have beconte so elongated that they protrulle out of the gill-clefts.

The fact that the Amphibia possess only external gills throws important light upon their phylogeny. Not only do the Apoclat, Irodela, and Anura agree much more with each other than 
workld be the cate if the Anuma gussessert hoth internal and external wills, but the Amphiliat reveal themselves also in this

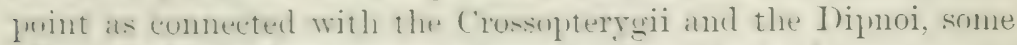
of which fishes alm gussess extermal wills. It is of (onurse quite funilute that the Anphilia have developed these organs in-

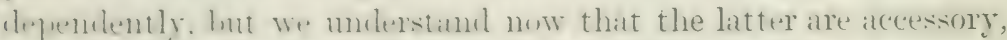
and nut the funitive repiratory wrans: they are dereloped

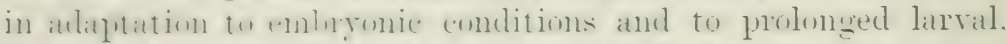

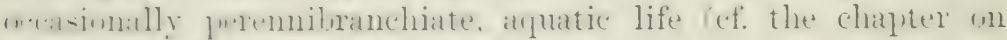
Neoteny, p. (63).

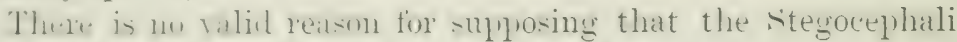
hat trme internal wills. We know their branchial sheleton, and

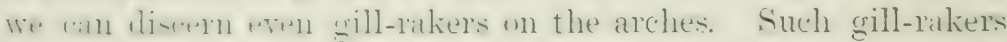

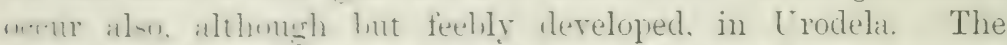

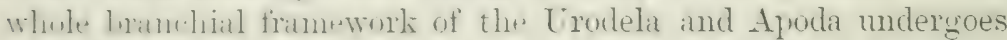

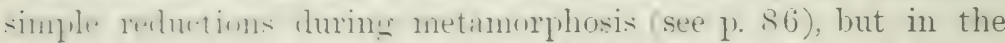
Anuma these arehes are in early tadpole life transformed into a must enpllicaterl hitset-work which acts as a straining apparatus (1) tilur. to frevent any particle of fond or other foreign matter fimu timling its way into the lelionte gills, the current of water fating from the month throm the filter, past the gills and out uf the elefte. Ihming metammphosis this whole elaborate al] the lewitean alpraratus for the support of the generally very

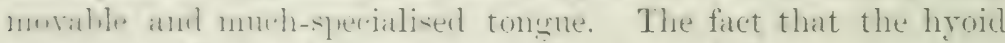

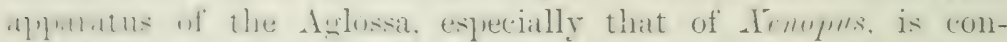
-truthel upun the sinne lines. is a strong indication that these crentures hatre anrised at their tongueless condition through the

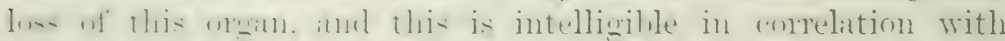
their absolutely aruatic life.

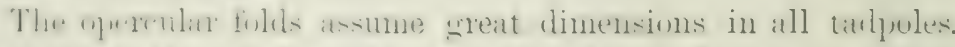

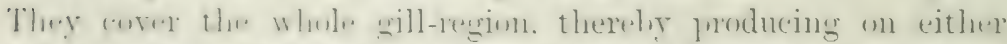

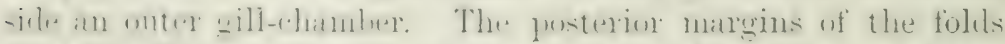

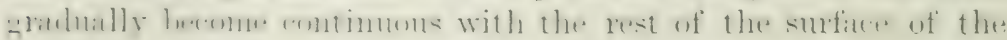
hody. Each gill-chamber opens at first by one lateral canal,

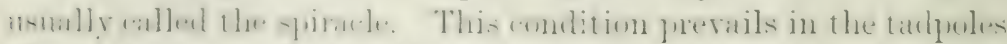

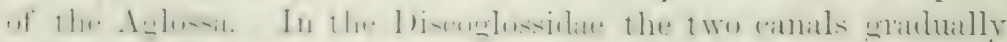

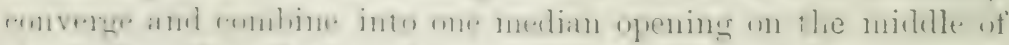

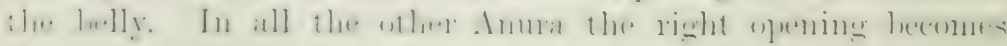
closed, or rather its canal passes over to and joins that of the 
left side, both opening by one short tuhe laterally on the left side, at a variable distance between the eye and the vent. Hence the elegant terms of Amphi-, Medio-, and Laevo-gyrinidie ( $\gamma$ vpivos being the Greek for tadpole).

The external gills lead to a further consideration. Protoptris. possesses a vestigial external gill on the shoulder-girdle. Lefidosiren has them on the gill-arches, besides true piscine interna] gills, and Polypterus has a large biserially fringed external gill (in some cases not disappearing until the fish is adult), which starts from the mandibular arch, at the level of the spiracle or first visceral cleft, and overlaps the operculum externally. The axis of this peculiar organ is possibly based upon the homologues of the spiracular cartilages, which themselves are the branchiostegal rays of the dorsal half of the quadrato-mandibular arch. The branchiostegal rays of the hyoidean arch, at least their material, have given rise to the elaborate opercular apjaratus; and, in conformity herewith, the hyomandibular itself is not known to carry a gill. Quite possibly the large external gill of Polypterus is not serially homologous with other external gills-it may not be a true gill at all, it has perhaps quite a different function-but it, seems to throw light upon a mysterious pair of organs which are common in larval and young Trodela, in the larval Aglossil and in the Apoda. These are the "balancers."

In Triton taeniatus, before hatching, there appear's a little protuberance behind and below the eye; it rests upon the angle of the mandibular arch, and is separated from the first transrerse, externally visible ridge of the first branchial arch by the beginnings of the hyoidean arch. A few days later the arteria hyomandibularis sends a vessel into this knob, forms a vascular coil, and leaves it as a vein which, instead of returning into the arterial arch, passes into the veins of the hody. Its epithelium is not covered with flat, but with culical cells; and sensory cells have not been found in it. These organs attain some size, and are shaped like rods, with thickened ends; they are movable, and are used by the larvae as "balancers," keeping the head from sinking into the slime at the bottom. But they may have other functions besides, and it is not unlikely that they develop, into sensory organs like feelers. They occur in many salamandridae, and are not reduced until, or even after, the metamorphosis, and during this time they shift their place with relation to the eye and the mouth. 


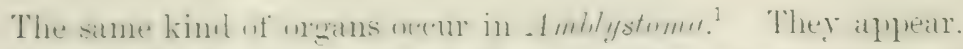

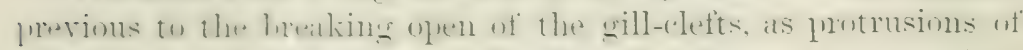

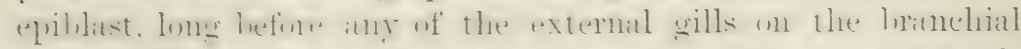

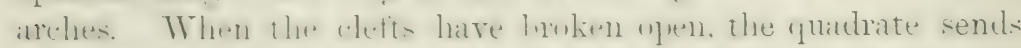

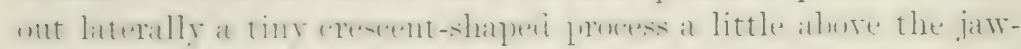

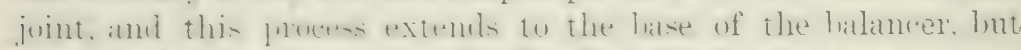

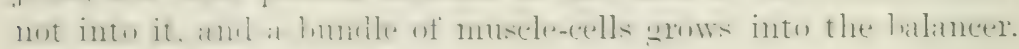
It is easy to recognise the same organ in the extremely long thread-like structures of the larva of Tenopus. In the Apoda

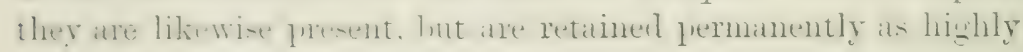
specialised, probably tentacular organs (cf. p. 86, Ajoda).

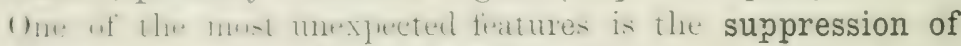

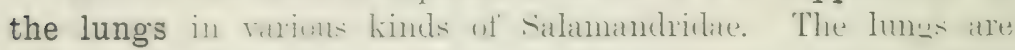

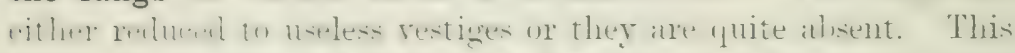
mथurs in anpatic and terrestrial. Anerican and Enmpean forms, and it is motewnthy that the reduction of the lungs dues not

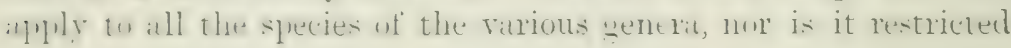
to one sub-family.

The following list is clue to the researches of $\mathrm{H}$. H. Wilder; L. Camerano, ${ }^{3}$ E. Lönnberg, ${ }^{4}$ and G. S. Hopkins ${ }^{5}:-$ All the

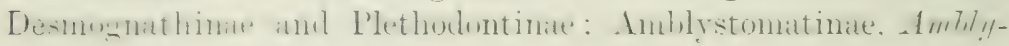
stome opacum; Salamandrinae, Selemendrince perspicillete. In

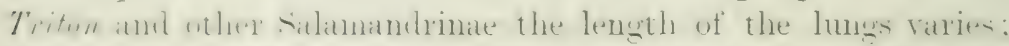

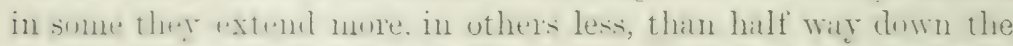

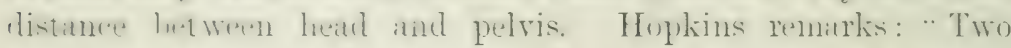

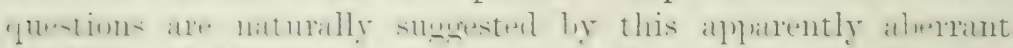

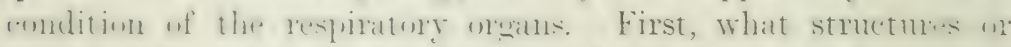

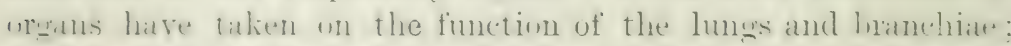
anel secomelly, is there any moditication in the form or strueture of the lwart which in any way nay le correlated with the alust-

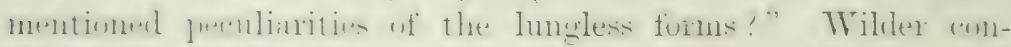

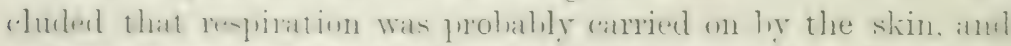

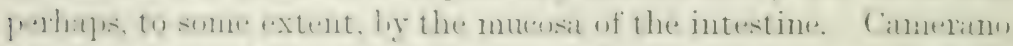

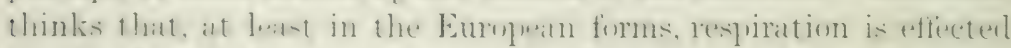

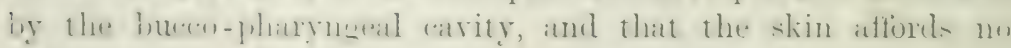
efficient aicl. The left anricle in the lungless forms is much

1 Orr, (nucert. .J. Mier. Sei. xxix. 1889, 1. 316.

" "Lumgenlose Salamandriden," Anut. Anz. 1894, 1. 676; 1896, 1. 182.

\& "Xuove ricerelte anatomo-fisiologiche intorno ai Salamandridi normalmente apncumoni." Torino, 1\$9.1.

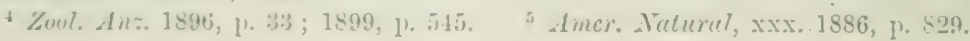


smaller in comparison than the right, and there is no pulmomary vein. The auricular septum has a large aperture, the communication hetween the auricles being larger than even in lirfur.s (which breathes essentially by gills). The sinus venosus, insteat of opening into the right auricle only, opens more freely into the left than into the right, and the latter communicates nore directly with the ventricle than the left, instead of about equally: In short, the heart of these creatures appears almost bilocular, instead of being trilocular, at least functionally.

The lungs of the Urodela are always simple, extrenely thinwalled bags. They are highly developed in the Anura, the wall. being modified into numerous air-cells, whereby the respiratory surface is considerably increased. The lungss are filled with air by the pumping motion of the throat while the mouth is closed, the nostrils heing provided with muscular valves. I muscular apparatus assists the filling of the lungs in the Anura. ${ }^{1}$

Most, if not all, Anura and some Truclela have a voice produced by the larynx, which, especially in the Anura, is provided with a complicated cartilaginous and muscular apraratus and with vocal cords. The voice of the Urodela is at the best a feeble squeak. The females of the Anura are either mute or they produce a mere grunt, but that of many males is very loud, and, moreover, in many species it is intensified by vocal, sacs which act as resonators. These sacs are diverticula of the lining of the mouth-cavity, and bulge out the outer skin and the muscles, chiefly the mylohyoid, of the throat. The

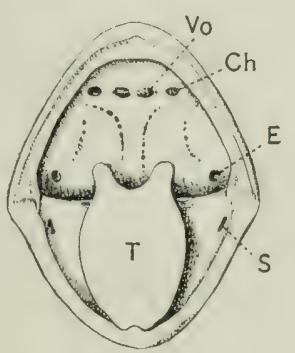

A

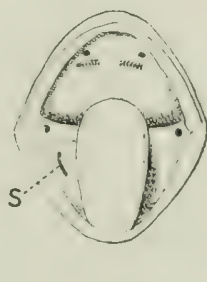

B

FrG. 6.-Interual view of the mouth of $\mathbf{A}$.

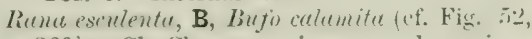
p. 269). Ch, Choana, or inner nasal opening ; $E$, opening of the Eustachian tube; $N$, slit leading into the voul sac; $T$, tomgue: $T$, patches of teeth on the romers.

mostrils and the mouth are firmly closed during the croaking. "The sacs are called internal when they are covered by the umodified gular integument, however much this maly be distended: external when their membrane projects through slits at

1 For the mechanism of the frog's respiration, see Gaupp, Arch. Anat. 1896, 1. 239 . 


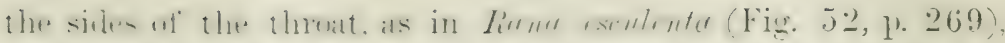
19. when the sling is thinned and converted into a bladder-like

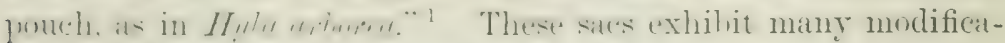

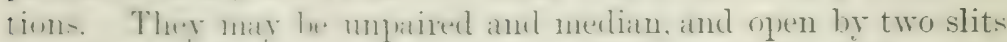
intw the month, on either sile helus the tongue: in bufo one of

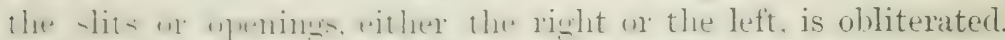

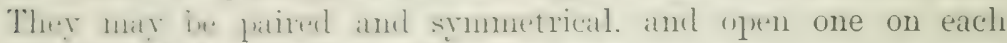
sile w the heal. helow and near the pusterior angle of the jaws.

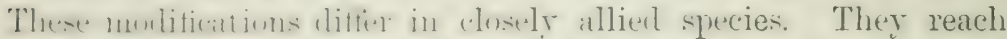

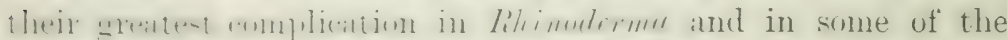

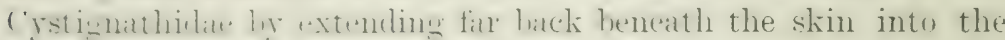
wide lymphatic spaces. In Rluinodermo they are put to the

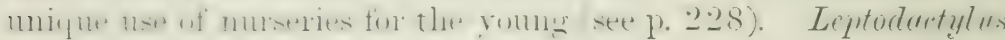
typhomius has a very distinct pair of outer vocal sacs and a

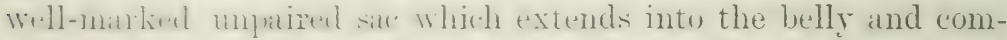

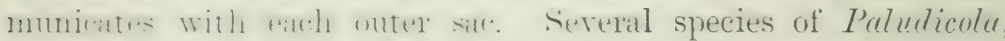

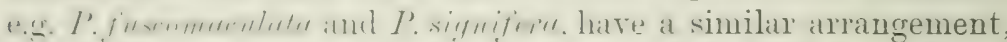

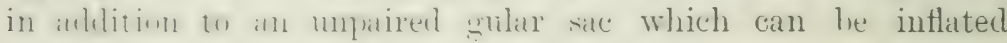
independently of the rest (see Fig. 45, p. 220).

\section{URixo-GENital ORGaNS}

The kithes-and the male senerative slands are still intimately comected with each other. The general plan is as follows:

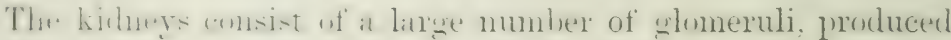

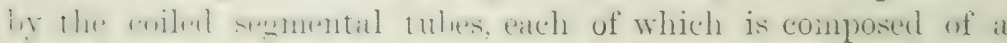

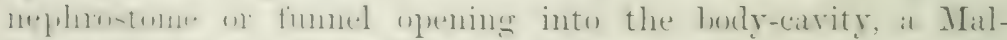
fightian huly and an efferent ramal. The latter combine to form the segrnental duct which opens into the cloaca. The testes,

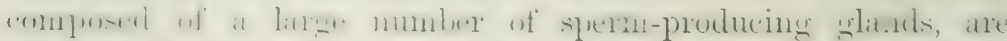

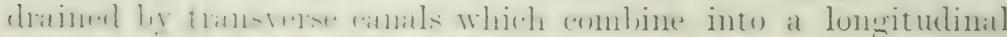

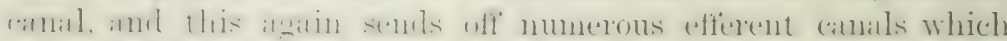

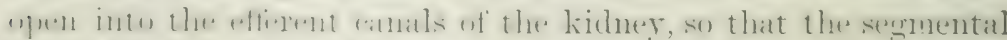

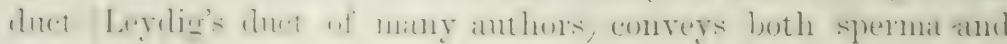
irine.

In the female the network of transverse and longitudinal

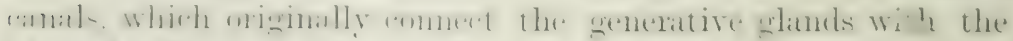

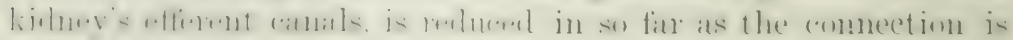

Bonlenger, The T'uilless Latrachians of Euroje, Ray Suc. 1896. 

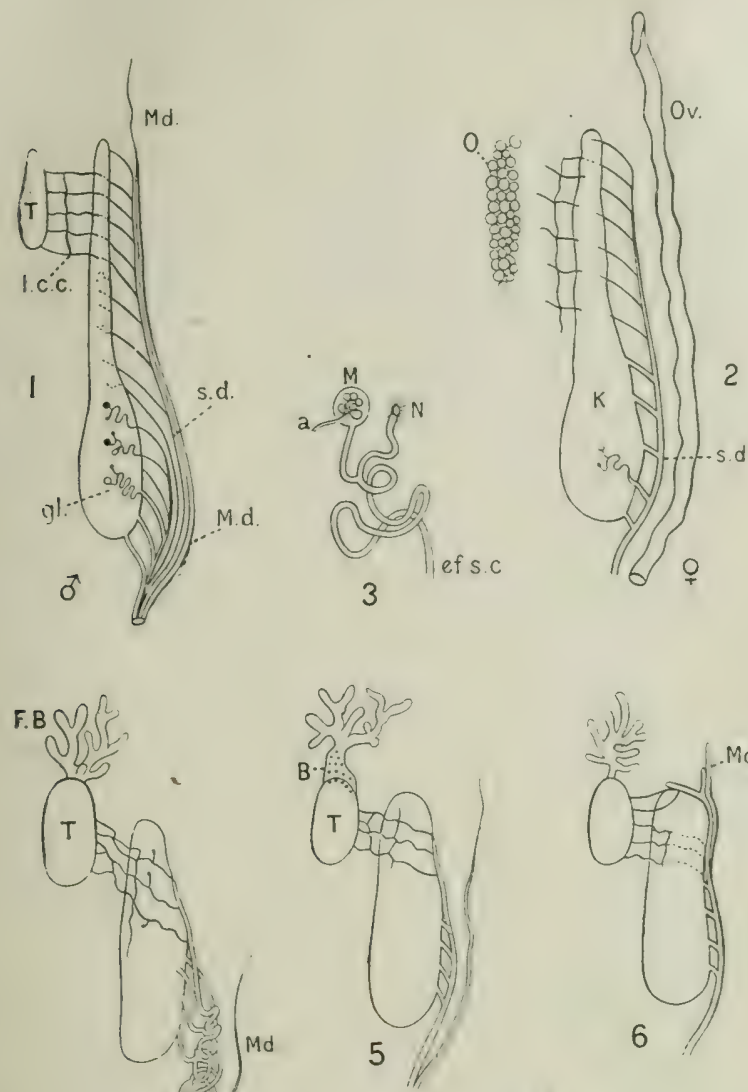

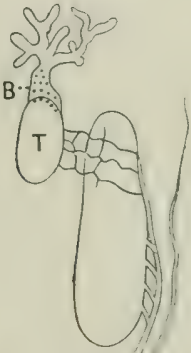

5

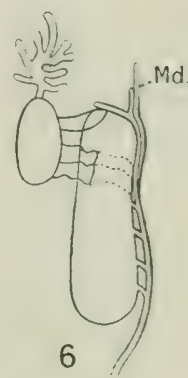

4
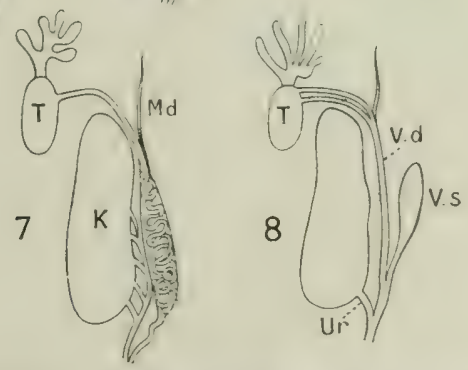

FIG. 7. Diagrammatic representation of molifications of the urino-genital ducts. 1, 2, Male and female Newt; 3 , a tubule of the kidney; 4, male Rana; 5 , male Bufo; 6, male Bombinator ; 7 , male Discoglossus ; 8, male Alytes. $\alpha$, Artery entering, and producing a coil in, the Malpighian body, $\boldsymbol{M} ; \boldsymbol{B}$, Bidder's organ ; of.s.c, efferent segmeutal canal; $F . l$, fat-body; $g l$, glomerulus; $h$, kidney; l.c.c, longitudinal collecting canal; $\boldsymbol{M}$, Malpighian body; $\boldsymbol{M} d$, Millerian duct; $\boldsymbol{N}$, uephrostome ; $O$, ovary ; $O v$, oviduct; $s . d$, segmental duct; $T$, testis ; $U r$, ureter ; $V$.d, vas deferens ; $V^{Y}$.s, vesicula seminalis. 
interrupted and the restiges of the transverse cantals are no longer functional. The enges fall into the holy-carity and ale catloght

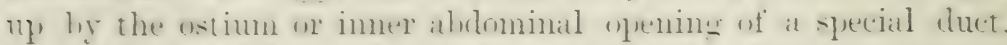
the widnet (Minllerian duet of many authors. Vestiges, nowe or less complete. of these wriluets grersist in the nuales of nost Aimphibia.

This general scheme presents some modifications in the various groups of Amphibia.

The Apmla retain the nun-t prinitive conditions. The kidneys are still long and narmw, and the glomeruli are, at least in the

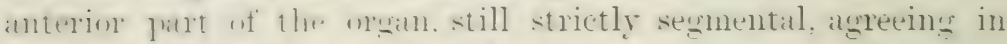

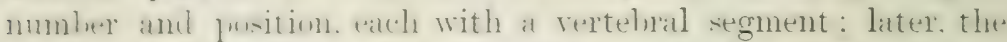
number of the glomeruli is greatly increased, and the fimmer

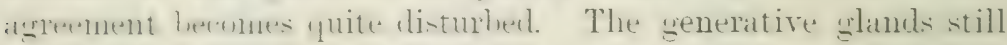

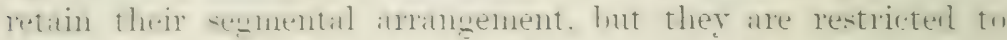
a monch sherter rexion than the kichers. In the male Apolat a

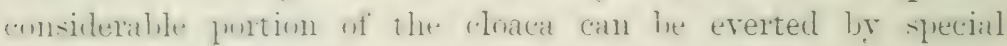

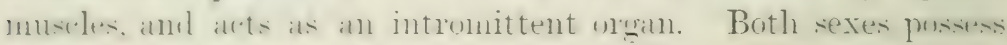
a rentral urinary bladder.

In the lomble buth linhers and testes are much concenthaterl.

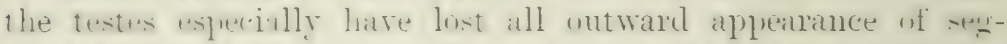
mentitions, and their etferent canals. connecting them with the

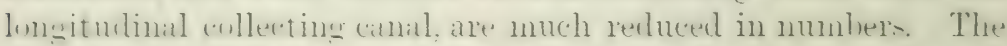
areater portion of the kilheys. at least their anterion half. hats

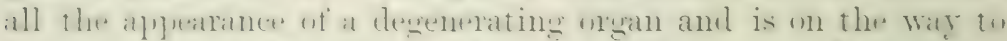
lusing its urinary fonction. althomeh it still posteses Malpighian lunkes and annplete duets: the matn function wif the latter is now the converane of the spermat. In the P'eremniluanchiatit.

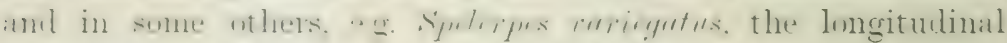

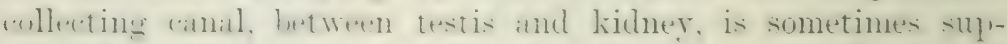

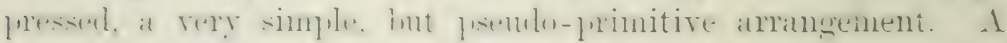
minary bladder is present. The cloaca is not eversible.

In most Anura, e.g. Piene and Bufo (Fig. 7; 4, 5), the same

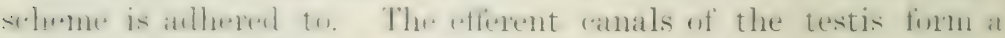

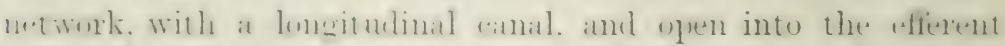

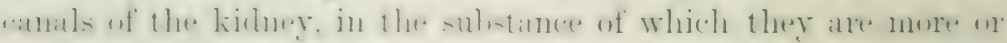

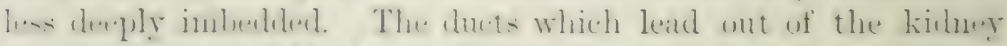

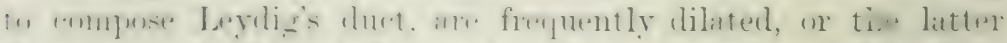

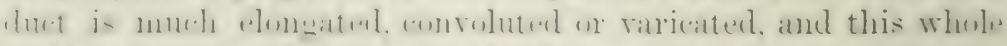

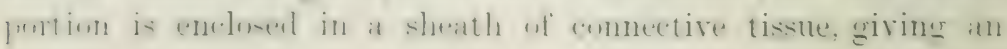


appearance as if the single duct itself were dilated in the greater part of its length ; hence the occasional name of vesicula seminalis. Such means of storing the sperma enable the latter to he ejected suddenly in great quantities.

In Bombinator (6) some of the most anterior seminal canals (h) not perforate the kidney, hut run over it superficially and open directly into a branch of Leydig's duct. This branch, no doult equivalent to a number of segmental canals which have lost their uriniferous function, is curved round the upper end of the permanent kidney, while its forward continuation, ending blindly, is the remnant of its former headward extension. This arrangement of Bombinator is carried further in Discoglossus (7). The testis conveys its sperma through a wide duct directly into Lerdig : canal, without interfering with the kidney, and all the testicular efferent network is lost. The anterior end of Leydig's duct still extends headwards; its middle portion acts solely as a vas deferens, while the lower portion still hehaves like a typical segmental duct, cenveying both sperma and urine. Lastly, in Alytes (8) the functional division of the old segmental duct has been carried to an extreme. The kidney is drained by one canal only, now a true ureter, and this is of course produced by a consolididtion of the multiple exclusively uriniferous canals of the lower half of the kidney. The whole of the segmental duct is now fn the service of the testis, and near its junction with the ureter it forms a large diverticulum or true resicula seminalis.

Remnants of oviducts, or Miillerian ducts, are common in the male Anura: they are best developed in Bufo, much reducel, and individually absent, in Rana. In Bombinator each duct is restricted to its upper or abdominal portion, and is attached (1) the restigial headward extension of Leydig's duct. Lastly in IJiscoglossus and in Alytes all traces of oviducts seem to have vanished, at least in the adult males.

It is interesting to note that in the arrangement of the urinngenital ducts the Discoglossidae are the most alvanced of all Amphibia, instead of showing the most primitive conditions. This is rather unexpected, but is paralleled by the epichordal type of the vertebral column.

The oriducts of the Apoda and Urodela remain more or less straight: in the viviparous species they form uterus-like dilatitions. In the Anura they hecome greatly elongated during the 
Hreeding season and fim many (क) mowhtions. 1. a rule each oviduet oprens separately into the cloacal. lut in IIylu they have one unpaired opening. While in linfu and Alytes the lower parts of both oviducts are themselves confluent.

All Amphilia pusiess Fat-bodies. They consint of richly vilecularioel lymplatic tissue. the meshes of which are filled with lymph-cells. Glulules of fat and wil. In the Aponda these bodies lie laterally to the generative glands, and along the posterior half of the lisineys. In the Trudelat they accompuny the anterion: half of the kidney. In the Anura they are lobate, and are flateen 1 pom the anterior end of the testes or oraries. Their exalct function is still domlifful, but it is intimately connected with that of the senerative glands. The old notion, that they are sinply stores of fat for the nomrishment of the animal during hibernation, is quite untenable. The fat-bolies do not decerase during this period, on the contrary they attain their fullest size in the spring at the time of the rappidly awaking activity of the reproductire organs, and they enable considerable quantities of sperma and of engs to be produced and ripened without detriment to, or utter exhaustion of, the animals, which often spawn hefore they have had time or opportunity to feed. After the glawning seasun the fat-lodies have dwindled down to inconspicuous dimensions.

Lastly, there is in some Anura, hitherto observed in linfo only, a mysterious man, intercalated between the fat-lowly and the testis or mary. This is "Pideler's organ" and it seems to be a rulimentary ovary, or rather that upper, anterior portion of the whole organ which undergoes retrogressive metamorphosis. It clisipleats in old female trads, hut in the males it sometimes asillunes a size equal to, or surpassing that of the testes. The males are in this respect hermaphrodite, and eases are known in which parts of the generative glands have developed testes and egg-benring ovaries.

The spermatozoa of the Aporla and L'rolela have an undulating niemlnane along the tail, while the head-end is either pointed

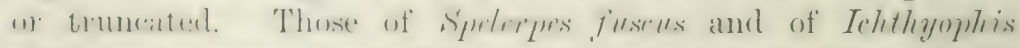

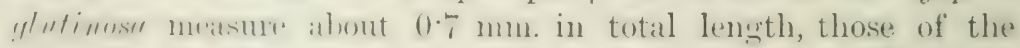

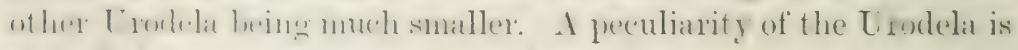
that their spermatorat are massed together in or npon spermato-

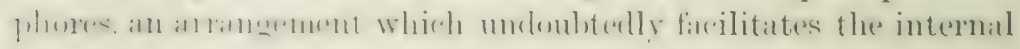




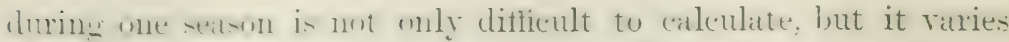

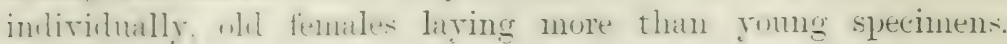

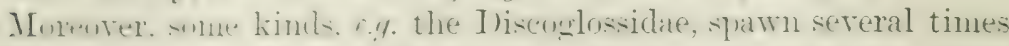

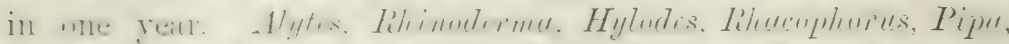
in titel tlune limels which are remarkathe for sperial nursing

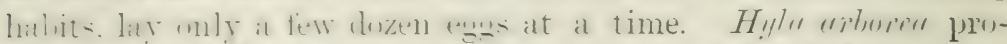

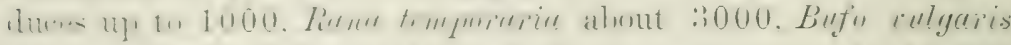
atreratenand more. T. H. Morgan ${ }^{1}$ has observed a Bufo lentiginosus

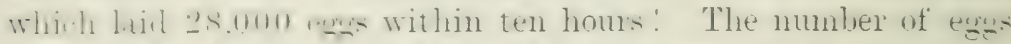

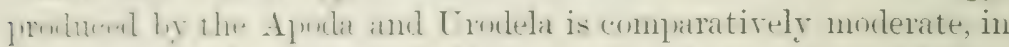

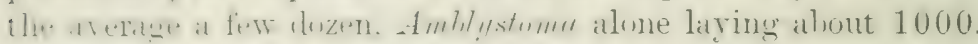

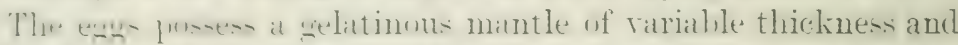
an-i-tency. In Amplimm they are strung together like the

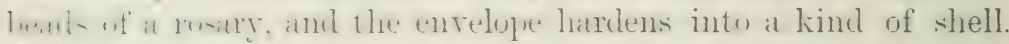
Many Nint and sme Anurat fisten their egges singly on to flume-and wher wherets in the water, with or withont threads of

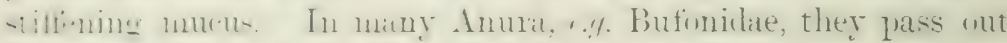

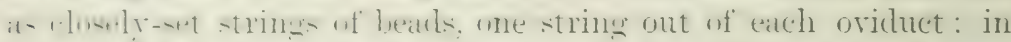

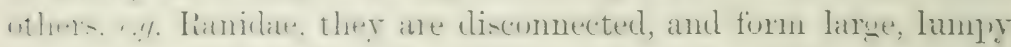

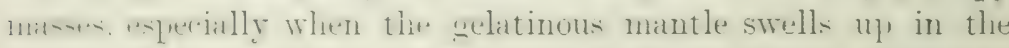

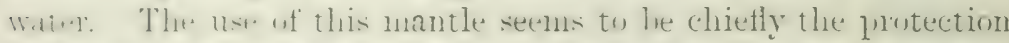

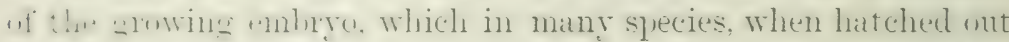

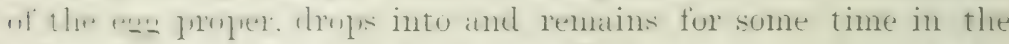

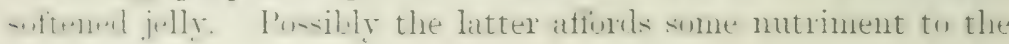
early larva.

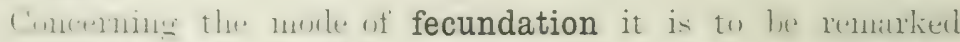

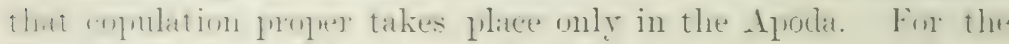

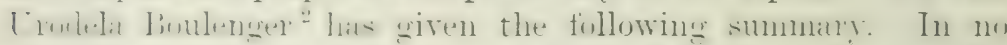

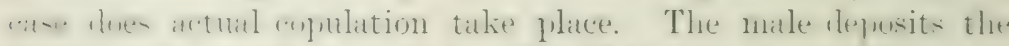

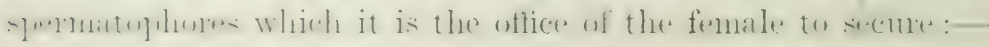

I. No amplexus, but a lengthy courtship in the water; the male is more brilliantly coloured than the female, and ornameuted with dorsal and caudal crests, or other appendages: Triton, cf. also systematic part.

II. Amplexus takes place; there are no marked sexual differences in colour and no ornamental dermal appendage:

A. Amplexus of short duration, partly on land, but deposition of the sperma in the water. Yo accessory sexual characters: Terrestrial Salamanders, namely Selemandra, Chioglosse, Selemendriur. Spelerpes breeds in danp eaves without water. 
B. Amplexus of lengthy duration and in the water.

". The male, distinguished by a greater development of the forelimbs, which are armed with temporary excrescences, clasps the female in the axillary region with the fore-limbs: Triton valtli.

b. The male, distinguished by a greater development of the lindlimbs and a prehensile tail, clasps the female in the lumbar and caudal regions: The Euproctus-groul of newts: Triton asper, T. rusconii, and T. montanus.

The aret of fecundation of most of the other kinds of 'rodelit.

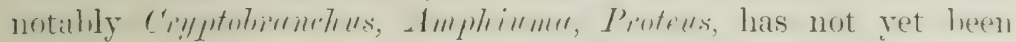
observed.

Embracing of the two sexes is the miversal rule with the Anura, the male creeping on to the back of the female and clasping her firmly with the arms and hands either in the inguinal region, higher up, or under the armpits. See the numerous statements in the systematic part. This often extremely forcible, pressing emhance seens to he necessiry, although the females can deposit the exger without the help of the male, lut in such cases the expulsion takes place at irregnlar intervals insteat of at one time. When the egges appear at last, and this lanprens in many spereies many lours, or eren sonne days, after the begimning of the embace, the male voids the contents of its reminal vesicles orer them. Fertilisation is omsequently external, with the possible exception of Pipa, q.r. p. 152.

Deposition of the eggs and nursing habits.- The majority "f the Amphilia are oviparous, but some Apoda and T'rodelia are viriparous. It is unnecessary to call the latter condition ovo-viviparous, since this is really a distinction without a difference.

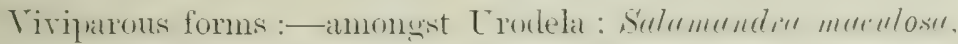
the romm burst the ego-membrane in the act of heing lorm, and are provided with long gills: st. "tho, the young undergon their whole development and metanorphosis within the uterus (sees p. 119); Spelerpes fuscus, the young are likewise born in the perfect condition: anongat Apoda: Typhlomertes inmpressicumder and Dermophis thomensis.

The oviparous Apoda, at least Irhthyopleis and Hypoyeuphis, and at few of the Trodela, as Jesmognuthus and Amphimmu, take catre of their egoss by coiling themselves aromut them in at hole underground.

Nursing habits are rery common amongst the Anura. 


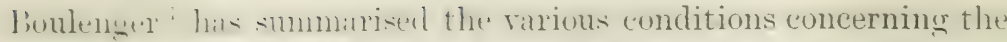
lepontion and rane that is taken of the exyse. in the following

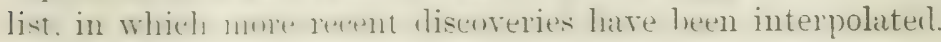

I. The orum is small, and the larra leares it in a comparatively early cmbryonic condition.

A. The eggs are laid in the water:-

u. Without further are or preparations: probably the majority of Anura; ; all European forms, except Alytes.

b. The eggs are lairl in a specially walled-in part of the pond: Hyla faber.

B. The eggs are depusited out of the water:-

a. In holes, or under grats, near the banks of pouls. 'l'he larvae are liheratexl and washed into the water by the next heary rain : Leptodectylus ocellatus, L. mystacinus, Paludicola gracilis, Pseudophryme australis and P. bibromi.

7. On leaves alove the water, the larvae dropping down when leaving the eng: Chiromantis rufrecens, Phy!lomeduse iheringi, Ph. higpochondrialis.

II. The yolk is very large and the roung undergoes the whole or part of the metamorphosis within the egg; at any rate the larra does not assume an independent existence until after the loss of the gills.

A. The eggs are deposited in damp situations, or on leaves. The young excape as: :-

(t. Tadpoles: Arthroleptis seychellensis, Rhacophorus schlegeli, Ph. maculatus.

b. Perfect, air-breathing frogs: Rame opisthodon, Hylodes martinicensis, Hyle nebulose.

B. The eggs are carrient hy a parent.

u. By the male :-

a. Round the lens; the roung leares the egg in the tadpole stage: Alytes.

$\beta$. In the enlarged roal sats; the young leave in the perfect state: Rhinodermu.

b. By the female :-

a. Attached to the belly: Rhucophornes reticulatus.

$\beta$. Attached to the back; the young complete their metamorphosis within the egg: Pipu.

$\%$ In a dorsal pouch which the young leave as tadpoles: Nototreme mursupiatum:- or in the perfect state: Nototremu testudinerm, $\boldsymbol{N}$. cornutum, $\boldsymbol{N}$. oriferum, $\boldsymbol{N}$. fissipes, and Hylu spoldii.

The development and metamorphosis of many species hate leen describerl in the systemattic part. The following is a short

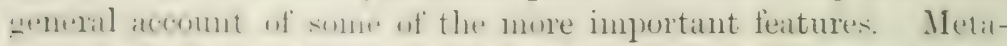
monphosis in the Apmlat and Prodela is restrieted chiefly io the resluetion of the wills, 1 he elesing of the elefts. and the leses of the 
will-chanlex and the fimy matrgins of the tail: hut the change? fiom the tadpole to the final Anurous animal implies an almost entire reorganisation.

In the earliest condition the mbryo consists of a large head and bouly, while the tail is still absent. Behind the loginning of the future mouth appears a transverse crescentic fold, with the convexity looking backwards, which develops into the paired or" mmpaired athesive "pmorntus. This comsists of large complex glands, developed in the Malpighian layer, originally covered by the enticula, which soon disappears, whereupon the sticky secretion enables the larva to attach itself to the gelatinous mantle of the egg, later on to weeds or other objects in the water. The? name of suckers, often applied to this apparatus, conveys a wrong

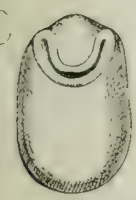

1

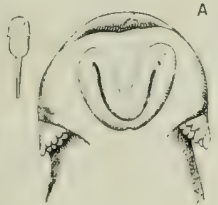

2

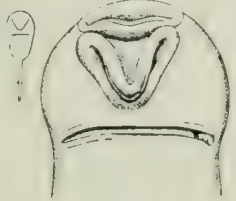

3

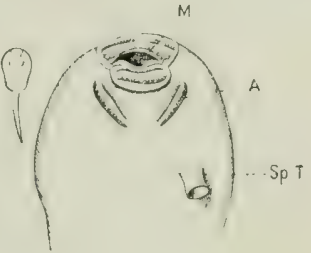

4

Fig. 9. - Four stages of the development of the adhesive apparatus $(.1)$ of Buforulguris : $\mathbf{I}$, Mouth; Sp.T. spiracular tube. In 3 the gills are almost completely hidden by the united right and left opercular folds. 'The small outlined figures indicate the shape and natural size of the tadpoles. '(After Thiele.)

jdea, there being neither muscles nor any suctorial function. T'he shape of this organ undergoes many changes during the early life of the individual, and differs much in the various genera, affording thereby diagnostic characters. ${ }^{1}$ It first a crescent, it divides into a right and a left oval or dise, which either remain asunder and behind the mouth (Limu, Bufin), or they move forwarls to the comers of the month (Hylie) or further back, and unite again more or less completely, as in Discoglossus and Bombinutor. It is mostly of short cluration, and disappears ly the time that the larva, hy the proper levelopment of the gills and the tail and the functional month, changes into the tarlpole. lint in a few species these dises transform themselves into an elaborate ventral dise. Such an organ persists throughout the greater part of the tadpole-stage in certain Oriental species of limno, all of which, when adult, possess fully wobbed tress and 


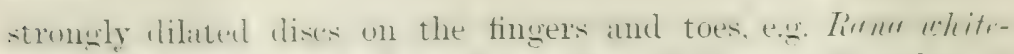

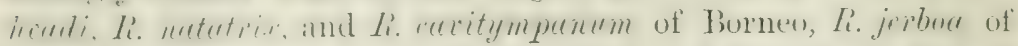

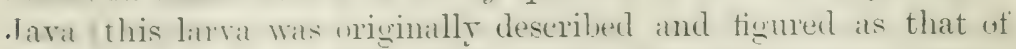

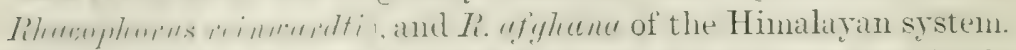
These taulpules at least thuse of li. jerlum, are further remarkible fin having the "spinacular" opening very far lack on the left sile. meitrel to the hase of the tail than to the snout. so as to be well wn of the way when the creature has attached itself hy the adhesive dise.

The numblo of the tatholes of Anura is furnished with horny mmantmis. sulstitutes for teeth. Their development and that of the num he in seneral has been well described by crutzeit.' In the young larvae of Ranc temporaria, one or two days after

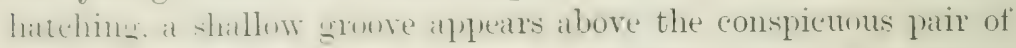

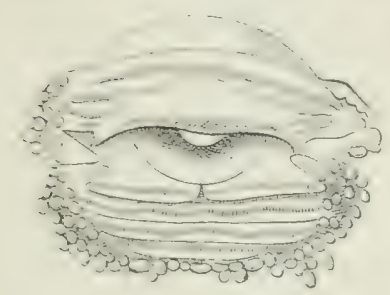

1

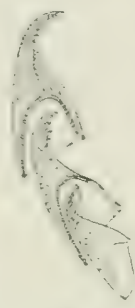

2

Fin, 11. 1, Frout view of the sumuth of a tiulpole of licha temporariu, showing the transverse rows of tiny horny teeth; 2. three successive horuy teeth, much magnified. (After Gutzeit. momb-like tramsierse plates of teeth. The papillate are possibly latedile argans, hut although nerves enter them, nerveendings of a sensory nature have not yet been discovered. On the fourth day the jaws become black, by the tenth day

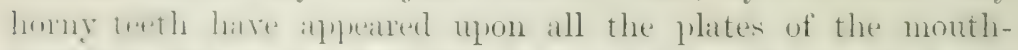

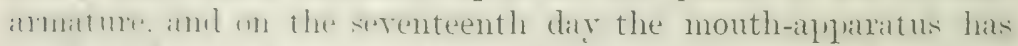

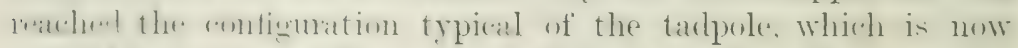

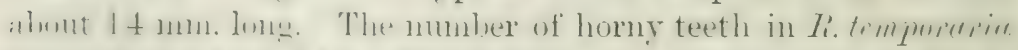

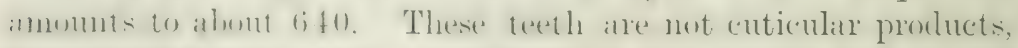

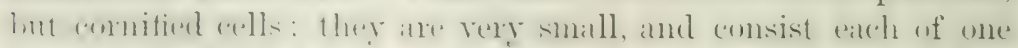

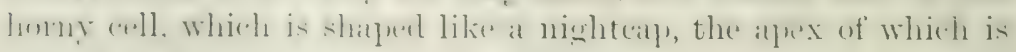
curved back and serrated. The little teeth are shed continu- 
ously, the renewal taking place by successive cells growing into the hases of the older series. 'The shalpe and size difter much in the various genera and species. The comb-like plates, composed of those teeth which surround the lips, seem to be used dhithy for the fixing or hooking of the food, while those which compose the horny beak proper, the armature of the jaws, are used like the radulae of snails. These beaks are likewise composed of a great number of individual teeth, closely pached together in sereral rows, lint the teeth themselves are simple and not serrated.

In Hyla arborea there are in all about 560 teeth. The development of the month does not legin luefore the eleventh day : the horny teeth hreak through, and the jaws get hlack edges, on the eighteenth. In Pelubertes fuscus the number of lom teeth is increased to ahout 1100 . In Buburumoetes tremiatus the horny teeth form series of five lells. which tit into each other like the joints of a rattlesnake's tail.

Gne of the most extrandinary linds of tadpoles is that of

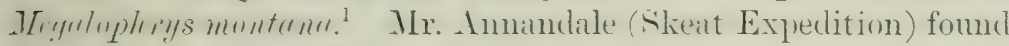
it at Bulkit Besar, Malay l'eninsula, from 2000 to :3000 feet

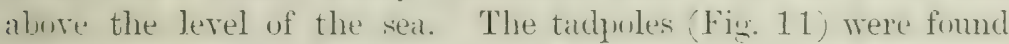
in the hegimning of the month of May 1 s!s? in sandy streans and in pools of rain-water: they fluated in a rertical position, the peculiar membanous fumel-shaped expinsion of the lips acting as surface-floats. The inside of the fumnel is beset with ladiating series of little horny teeth, and the whole alparatus is jussibly used for scraping the under-surfice of the leaves of water-plants in search of food. Total length of the timlpoles 1 inch."

The gills, the formation of the operenlum, and the modificattions of the branchial atrterial arches have heen dercoribed fully on 1, $4: 3$ : those of the hyo-hranchial skeleton on 1) :31. Fusion of the opercular fold with the skin of the neck, across the Inanchial region, canses the head to heone confluent with the trumk (f. Fig. 9, :3, 1, . . T). The body hecomes oral, more or les. gholular. and the alinentary canal is greatly elomgated and stowed away in the shape of a neat, rery regulatr spiral, shining through

1 M. Weber, Ann. Jard. Botan. Buitenzory, Suppl. ii. 1898, 1. 5.

2 For "A Synopsis of the Tadpoles of European Batrachians," see Boulenger, P. Z. S. 1891, pp. 593-62 $\%$, pls. xlr.-xlvii.; also Bedriaga, "Tableaux synoptiques pour servir à la détermination des larves des Batraciens Urodèles," C. I. Ass. Frânȩ. Sci. ii. 1891, 1pp. 540-546. 
the ventral wall of the body; the anus opens at the end of a

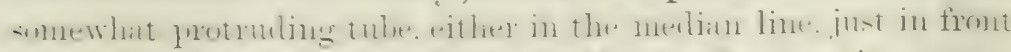

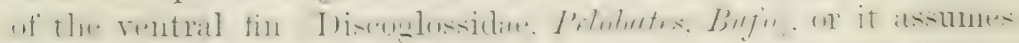

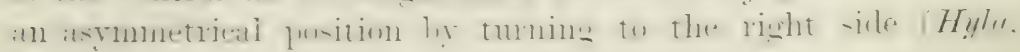
liana).

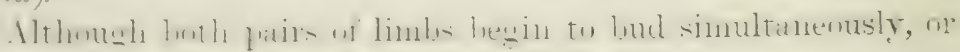

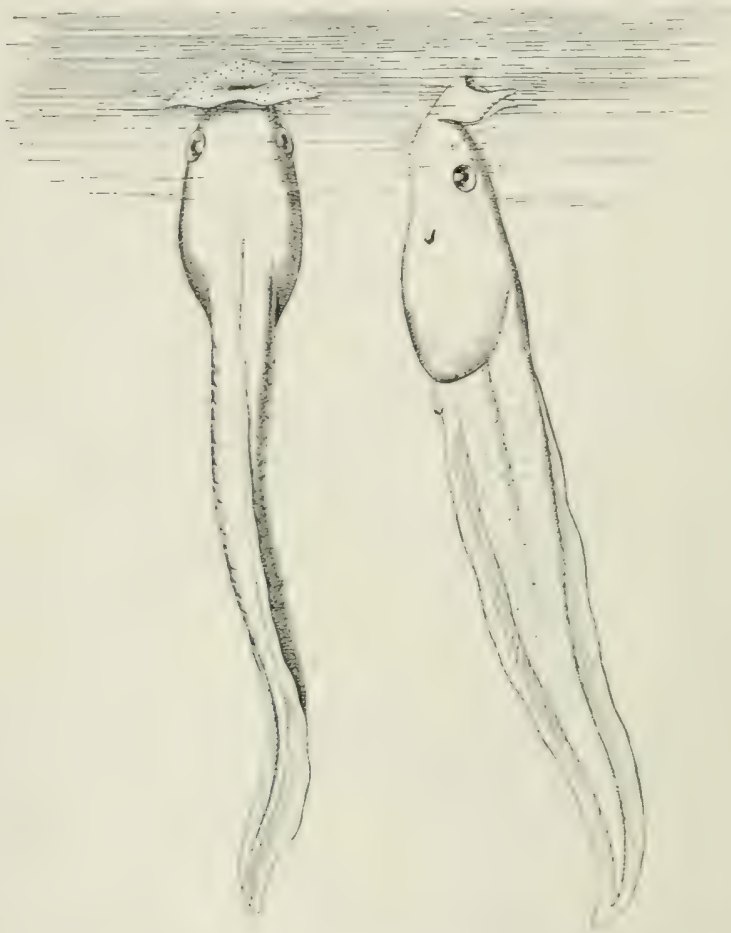

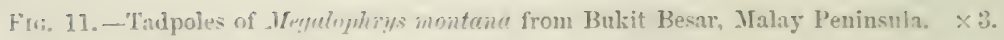

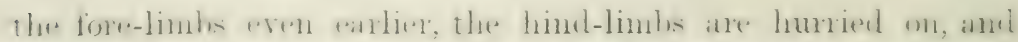

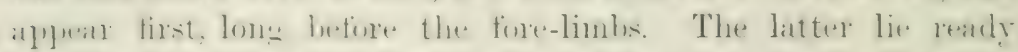

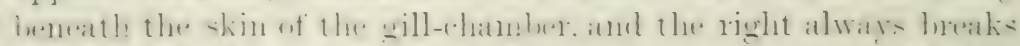

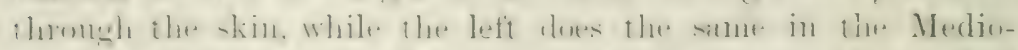

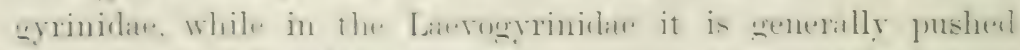

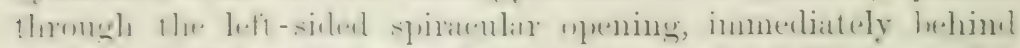

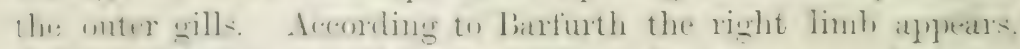

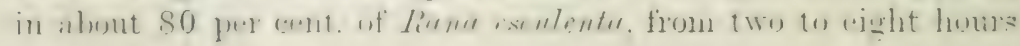
hefore the left. 
Meamwhile the lungs are leing developed, and the tand polt. oceasionally rises to the surface to breathe air. The wills, which, as has been explained elsewhere, are less ancestral than ther are litrval organs, degenerate, and all the organs are modified fin the coming terrestrial life. The fins of the tail are alisortierl, the horny armature of the month and lips is shed in piecess and makes room for the true teeth, the eyes receive lids, and the whole cranium, especially the apparatus of the jaws, undergoes the final modifications - widening and lengthening of the mouth, arresting of the mento-Meckelian cartilages, elongation of the Meckelian cartilages or lower jaw proper, shifting backwards of the suspensorium, and lengthening of its orbital process to form the pterygo-palatine bridge.

The tadpole ceases to feed, the whole intestinal canal is roicled of its contents, and by " histolysis" is thoroughly rebuilt, hecoming wider and shrinking to about one-sixth of its original length, - undoing thereby the spiral-prejaratory for the coarser food, which consists of insects, worns, and other strictly animal, living matter. Hitherto the tadpoles have lived on "mud." confervae, Diatoms, rotting vegetalle and animal matter. The anal tube collapses, hecomes ultimately alssorbed, and a new vent is formerl at and below the root of the tail.

Barfurth ${ }^{1}$ has made interesting observations and experiments with regard to the absorption of the tail and other organs which disappen during the metamorphosis. This is retarded by low temperature; it is accelerated by rest and freedom from mechanical disturbances, as, for instance, concussion of the water. Hunger shortens or hurries on the last stages of metamorphosis, the absorption of the tail taking place in four instead of five days. Amputation of the tail has no retarding intluence; it is followed at once by regeneration, although the tadpole may be on the verge of reducing the tail. Whilst hungering the whole organism draws upon its available store of material, naturally first upon those parts which sooner or later are to become superfluous. This applies eminently to the tail, which represents a considerable anount of "edible" matter", and also to that portion of the skin which still covers the fore-limbs. The elements of the cutis are resorbed, thereby thimming the skin; and consequently. the limbs break through earlier in fasting than in well-fect

1 Arch. mikr. Anat. xxix. 1887, p. 1. 
specimens. Nature herrself seens to apply humger as an atceleterator. MIlle. von Chauvin found that the larvae of Urodela normally fist during the transformation, and according to Barfurth

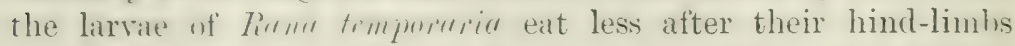
are fully developed. This is, however, also preparatory for the renganisation of the wht, which has to be more or less empty during the shortening process.

The luss of the tail is not due to a sudden dropping off' of this organ - a crude but by no means uncommon belief — but is hrought about ha a very gradual process of resorbtion. When the fore-limbs lewin to break through the skin, the tip of the tail shrinkis and hecomes hlack, owing to an increase, or rather concentration, of the pignent cells. The reduction proceeds from the tip forwarts until on alout the fifth day there remains only a short, conical, blake stmm]. From the heginning of this process of reduction the tail is searcely used for locomotion, the tatpole ruwing with its lexs. or it crawls and hops about, although the tail may still he $20 \mathrm{mmm}$. long. The cells of the epidermis atrophy, shrink, and peed off', while those of the cutis, hool-ressels, nerves, muscles and chorla dorsalis lecome disintegrated, often underwning fitty deneneration. The lencocytes eat up the débris and wher liswolved tissut, and carry it away through the lymplatic ressels. to he nsed ats new huilding material in the rest of the animal.

Barfurth askis very monerly. Why do these tissues degenerate and die! lieranse the vasomotor nerve-fibres cease to renulate the circulation. Ant why dues this trophice influenese of the antral nexwms systems stop! Becatuse the function of the tail

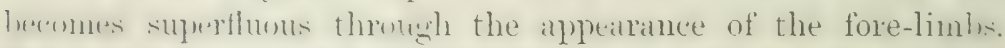

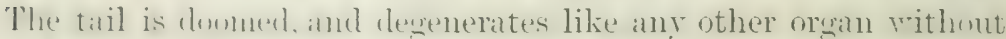
at function. The whole process is, of comrese, a recapitulation of ancestral, phylogenetic evolution. 


\section{CHAPTER III}

NEOTENY - REGEXERATIOX-TEMPERATL LE-CEOGRAPHICAI. DISTRIBUTION

Neoteny.-It has long been known that the larvae of the Spotted Salamander oceasionally attain the size of $80 \mathrm{~mm}$, or about :: inches, whilst the majority undergo metamorphosis when they are only $40 \mathrm{~mm}$. long. Again, larvae of Titum have been found, in the months of April and May, 80 to $90 \mathrm{~mm}$. long, still with tunctional gills, but with the sexual organs fully developed. Te Filippi ${ }^{1}$ found in one locality in Lombardy, besides a few nomal fully metamorphosed specimens of only $30 \mathrm{~mm}$. in length, more than forty specimens, which, although they had attained full size, about 5 a mm., and were sexually mature, still retained their gills. According to him such gill-breathing, otherwise mature specimens, oceur constantly in a small lake in the Tal Formay.o, wn the Italian slope of the Alys, in the province of Ossola. Litter Duméril ${ }^{2}$ astonished the world by his account of the metamorphosis of the Mexican gill-breathing Axolotl into an entirely lung-breathing and terrestrial creature, hitherto called Amh!ystoma, and supposed to be not only a different species, lint to belong to a different family from the Axolotl, which was linown as Siredon uxolotl s. pisciforme, and naturally classed with the Perennibranchiata.

This discovery led to a series of observations and experiments, chiefly conducted by Marie ron Chauvin, instigated thereto ly Koelliker and by Cimerano." It was then found that many, if not most of the European Amphibia, both Lrodela and Anura,

1 Areh. per zool. e per l'anat. comp., Genova, 1861, 1. 206.

$\because$ Ann. sci.nat. (5), vii. 1876.

3 Mem. Acc. Torino, xxxv. 1883, and Atti Acc. Torino, xvii. 1883, 1). 84. See also Woltersdorff, Zool. Garten, 1896, 1. 327. 


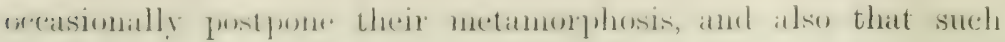

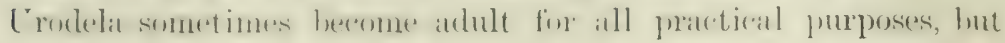
retain their gills.

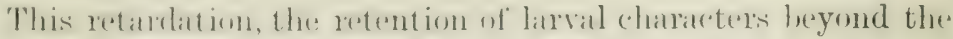

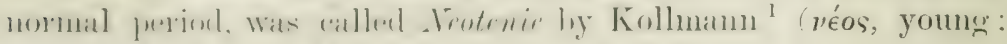

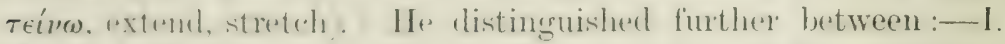

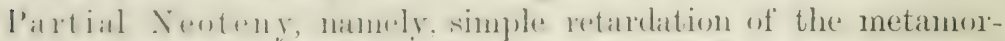

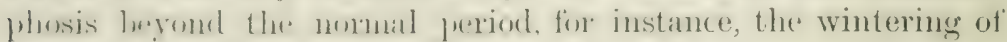
tadpoles of Pelobates fuscus, l'ombinator pachypus, Pelodytes I'unctatus, Alytes obstetricaus, IIylu arborea, liana esculenta, Ri. temporarir, Bufo vulgaris, and B. viridis: II. 'Total Neoteny, whore the andmal retains its gills, hut heomes sexually mature:

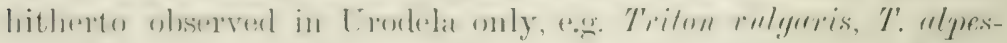
tris, T. cristatus, T'. boscri, T. valtli and Amblystoma. Inter-

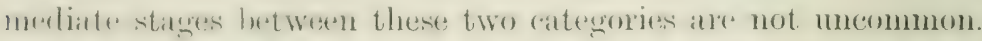

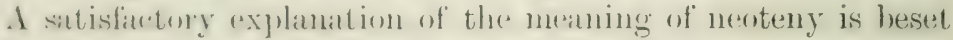

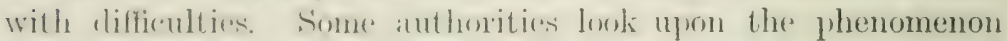

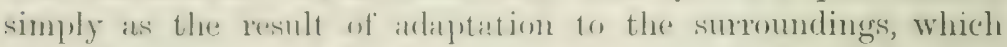
make it alvantargenss for the creature to rotain its larval features. Others think that the smommlimes somelow or other retard or

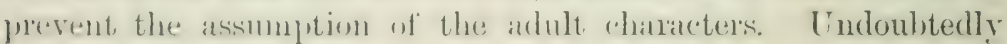
there: are many ratses in which larvale have heen reared in waterhules with sterep walls, so that they rould not change from aquatice to trresstrial libin, and it stamels to reason that abmormally forced amd poolonged nses of the gills and of the tail may stimulate these mgates into further growth at the expense of the limbs and

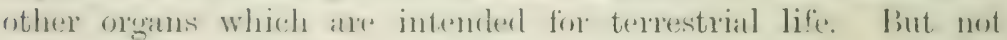

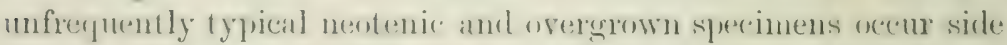
hy side with others which have completed their metamerphosis, and the sillere is true of larvate of newts which were reatred, for

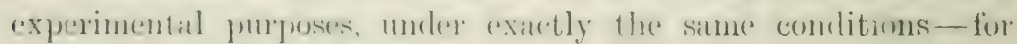
instance, in a high-walled glass vessel.

Wrismann trienl to rxplatin mentemy ats rases of reversion to atavistic ancestral amditions, lut this ideal is lased mpon an

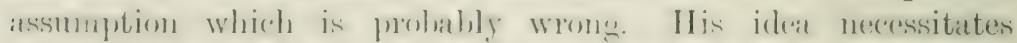
the suppesitim that all the Amphilife were originally gill-

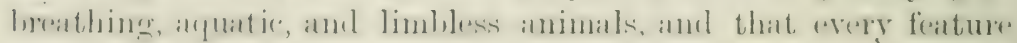

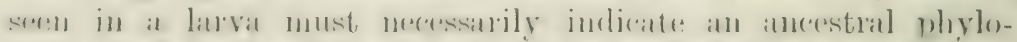

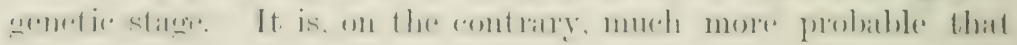


the external gills of the Trodela have been developed in adaplattion to their embryonic and larval, essentially anuatic, life. ( intserguently the possession of such gills would be a secomling, and not, strictly speaking, an ataristic feature. Tomal loss of the the gills, exclusively pulmonary respiration, and preponderating terrestrial life characterise the final adult Amphilian. These' calses of neoteny are therefore instances of more or less complete retardation, or of the retention, of partially larral conditions.

The whole problem is, however, by no means simple. Sirlamondere ation has become viviparous, and the whole metann'phosis takes place within the uterus: in fiat, the roung have an embryonic, but no larval perind, if ly the latter we understand the free swimming and still imperfect stage. Similarly, various Anura-- for instance, Hyludes meitinimsis- pass rapilly through their metamorphosis, and have supuresised the stage of free swimming tallpoles. On the other hand, in many newts, the duration of the larval period is much prolonged, and moreover is very subject to individual viniation. In the Axolotl this litral period is continued until and after sexual maturity is reatched. The extrene condition would then be represented by the Peremnibranchiate genera. It may seem reasonable to lonk upon these as the youngest members of the Trodela, and the loss of the maxillate in the Sirenidae and L'roteidie supports this inlea. But it so happens that the majority of the most nentenic gentera are more primitive in the composition of the skull and the rerteInal column than the typically terrestrial and rapiuly metamorphosing genera. Witness the amphicoelons rertebrate, the completeness of the pterygoids, the separate nature of the palittine hones, and the separate splenials, as mentioned in detail in the description of their skull.

We have therefore to conclude, first, that the rarious l'erennilranchiate genera do not form a natural group, hut are a heterogeneous assembly; secondly, that they have hecome Pereminihanchiate at a phylogenetically old stage-in fict, that they are the oldest, and not the newest, members of the present Trodelir. Al the same time, it would be erroneous to suphose that the first Urodela were aquatic creatures, provided with a finm tail. with small, ill-developed lungs, and with epidermal sense mains. All these features are, on the contrary, directly correlated with apuatic life, and are lanval aequisitions, not ancestral reminimVOL. VIII 


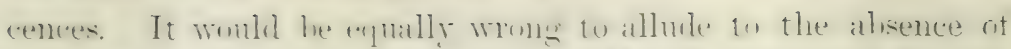

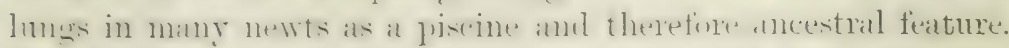

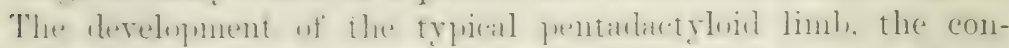
nexion of the pelvic girdle with the rertebral column, the development of the lungs. and alsolute suppresion of interual

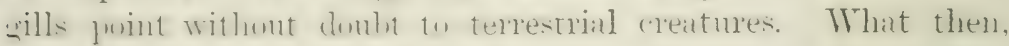
may we ask, were the first Amplibia like? and how about the extermal sils: They were umlentitedly akin to the less

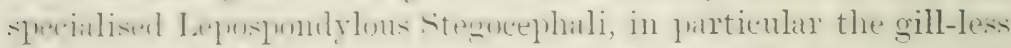

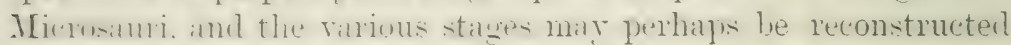
as follows:-

(1) Terrestrial, with two pairs of pentadactyloid limbs; hreathing ly lung only: with a fully developed alpatratus of

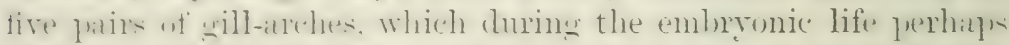
-till anrienl intermal ills: with w without several pairs of gillalefts. limblutim at the demal armour and of the cutanenus scutes had taken place.

(2) Additional respiratory organs were dereloped by the embryo, in the shape of external gills; these were at first re-

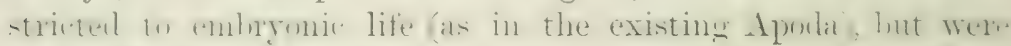

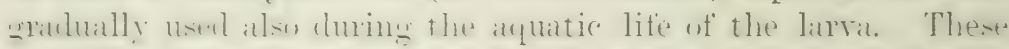

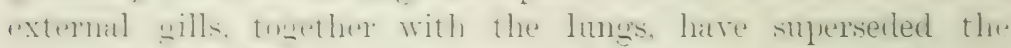
intermal alls, wf wheh there are nuw no traces either in Eronlelit (1) in Anura.

(3a) Some Urodeles, retaking to aquatic life, retained and

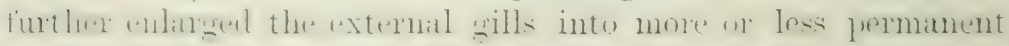
organs (ct. also Siren, p. 136).

(:3b) The majority of Urodela hurried through the larval, aquatic stage, and some-e.g. Salamandra atra-became abso-

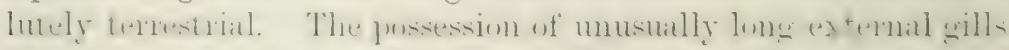

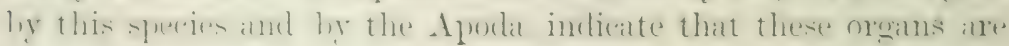
essentially embryonic, not larval, features.

Regeneration . In Amplinhia puseses the ficculty of re-

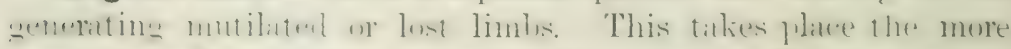

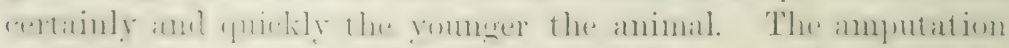

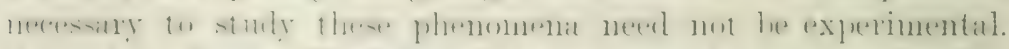

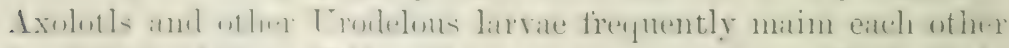

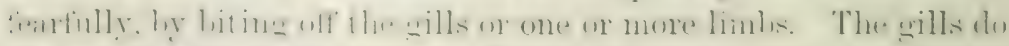

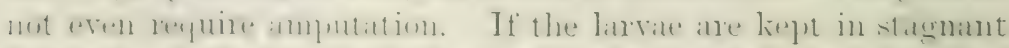

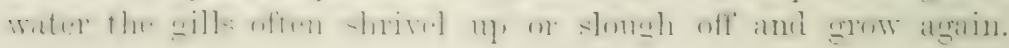


The sane applies to the larrae of viriparmus species, e.g. simlu. mandra atin, which, when cut out of the uterus and put intw water, soon cast off their long, temler gills and produce a strminer set. In an Axolotl, ${ }^{1}$ two year's old, a hand was cut off. After four weeks there was a conical stump; after the sixth week this stump had two points; in the elerenth week three or four fingers were discernihle, and a week later the complete hand. Frequently these creatures reproduce fire instead of the normal four fingers. But the more proximal the cut, the nore lialle is the new limb to reproduce supernumerary fingers, or even extra hands and feet. Complete regeneration of the limb, cut off in the middle of the humerus, took place within five months.

Triton tacniatus, adult, reponduces cut fingers within fire on six weeks, and if the hand be cut above the carpus, new fincerstumps alpear in about one month. Giitte lias olserred that an adult Piruters did not completely repurnduce its whole lew until after eighteen mònths: and, according to Spallanzani, more than one year elapses before the limb, bones, and cartiliges of Tritom regain their normal strength.

The Anura are likewise capalle of regenerating their limbs. the more readily the rounger the specimens. For instance. in " tadpole of Rana temporaria, in which the fore-limbs were still hidden, the hind-limb, cut at the midale of the thish, reproduced nineteen days later a knee, followed by a short twotoed stmmp. Ultimately the whole limh became completed. The tail of tadpoles regenerates very quickly and completely, eren if it he cut off shortly before the final metamorphosis, when the tail would in any ease be reduced. Metamorphosed Anura latre almost entirely lost this faculty, lut not absolutely. I myintt have kept two specimens of Ranc temporaria, which, when already adult, had each lost a hand at the wrist. First there was only the clean-cut stump with at sear, hut within a rear this changed into a four-corpered stump, and two of the protuberances developed a little further, reaching a length of alwut $t$ mm These specimens lived for four years without further changet.

Temperature--Amphihia, like Fishes and Tieptiles, are, ats a rule, classed as cold-blooded animals, in opjosition to the warnbloorlerl Birds and Mammals. This distinction is one of degreet only. The terms poilibothermous and lomothermons moikcios,

1 Barfurth, Avch. Entucickmech. I. 1895, 1. 117. 
Timbiable: öpos. equalile are batsed upon at sommler principle, lut alle likendise liahle to exceptions. Those creatures which, like linds and Minnmals. posess a sperific temperature of their

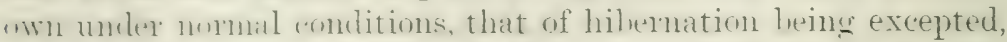
are homothermonls. Cold-hluenled creatures have no specific

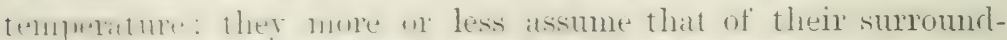
ing. Fron and uewts, fir instance, when living in the water, naturally asmone its temperature. which is, of comse, many

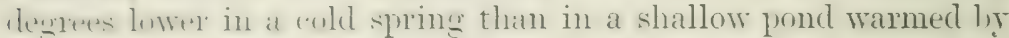
the sun on a hot summer's day. The same applies to the "hangex frond diy to night. Lark-culouren tortoises hasking in the sum are sometines so hot that they ane disagreealile to

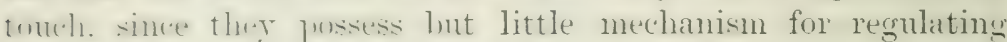
the in leat. The same individual cools down during a chilly

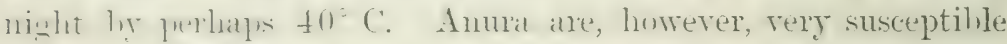
16 heal: must of them die when their temperature rises to about 40 (: Enler such comlitions they die quickly when in the water, but in the air their moist skin counteracts the heat, lowering it he araforation: otherwise it would be impossible for at trespon sit in the glaning sum in a temperature of $120 \mathrm{~F}$. Taitls and others with drier skins seete the sharle, hide under stomes or hury themselves in the colest spots available, and many

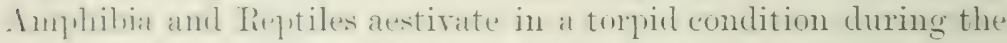
dry and hot season. Many of them can endure a surprising ammun of anle and during hibermation their temperature mat -ink to fireming-point. This power of endurance does not apply 1n all alike: tropical speedes can stand less than those which live: in tempreate and cold regions. In spite of many assertions to

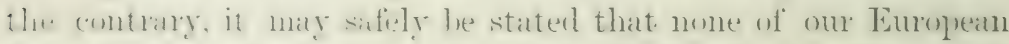

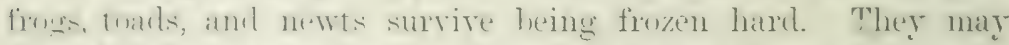

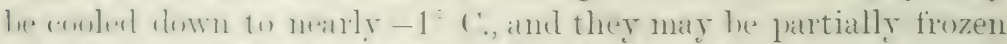

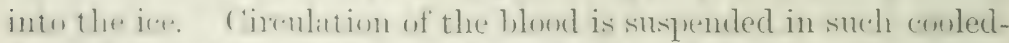

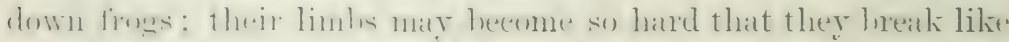

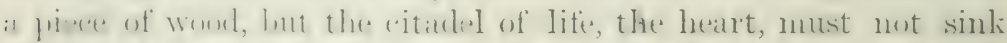

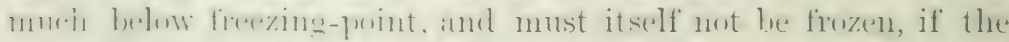

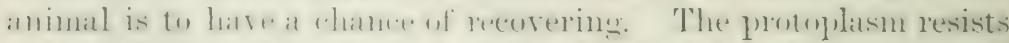
a long time, and on long as sume of it is left moliogen the rest

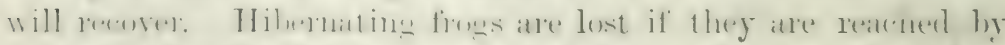

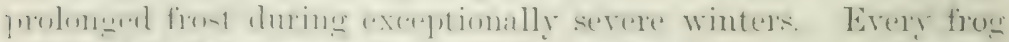

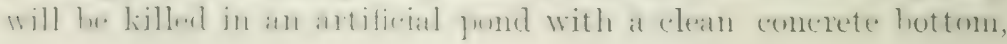


Int if there is sufficient mud, with decaying regetalle matter, the creatures survive, simply because they are not absolutely frozen. A severe winter not infrequently kills off all the ronnger creatures, while the oliter and nore experienced hide themselves more carefully and live to propagate the race.

\section{Geographical Distribution.}

There is a very ably witten chapter on the geographical distribution of the Amphibia by Boulenger in the r'otrlugur of Butrerlice salientir, pp. 104-118. He came to the important conclusion that the geographical distribution of the Amphibia agrees in general with that of the freshwater fishes. Giinther's division into a Northern, Equatorial, ame Sonthern zone is modified only in so firr as the last two are combined into one, "Tasmania and Patagonia not differing in any point regarding the ir Froy Famna from Australia and south America respectively."

Boulenger recognises-

I. 'The Northern zone-(1) Palaearctic, (2) North American, region.

II. The Equatorial Southern zone.

A. Firmisternia division $=$ Cyprinoid division of Günther.

1. Indian region.

2. African region.

B. Areifera division = Acyprinoid division of Giinther.

1. Tropical Auserican region.

$\therefore$ Australian region.

In the chapter on geogralphical distribution in Bronn's Thifrich.

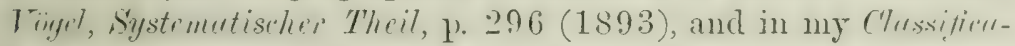
timn of Tertebrotu. (1898), due attention had been paid to the Amphibia as well as to the other classes of Tertelurata. It will he seen in the following pages that my arrangement is well applicable to the Amplibia so far as fundamental principles al't concerned.

It camnot be sufficiently emphasised that any attempt to form the various faunas of the different classes of animals into one scheme must necessarily be a petitio principit. The timehonomed six zoo-geographical regions established by schater and Wallace represent fairly well the main continental dirisions: North America, South America, Africa, Australia, and the large northern continental mass of the Old World, with Incliat as at tropical appendix. There is no correlation and no subordination 


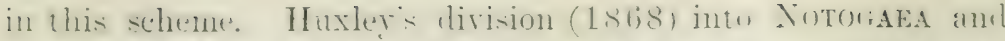

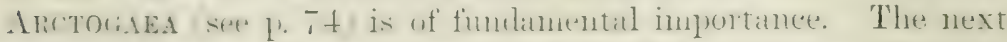

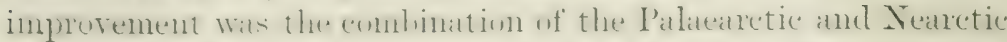

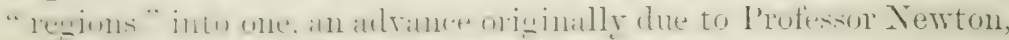

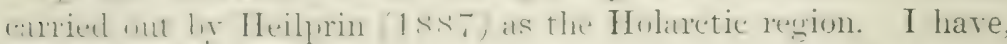

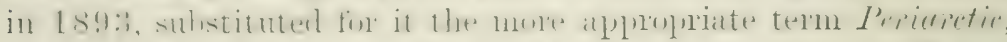

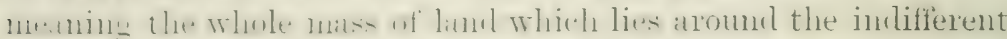

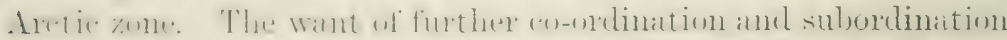

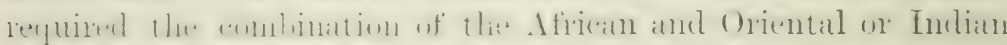

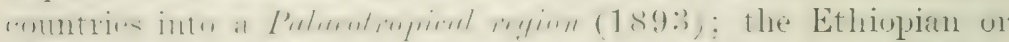

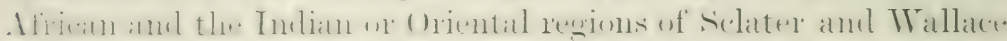
lluenty a

The two primary divisions NotogaEA and Anctogaea are fimdimental. The four secondary divisions, namely the Australian and Teotropienl, Periaretie and Pulaeotropieal regions,

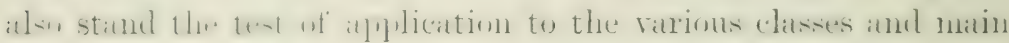
groups of Tertebrata: but naturally, under the present con-

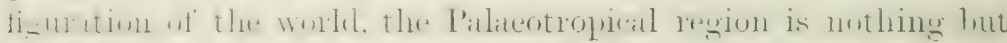
the sontlern montinution of the bastern half of the Pertitretic

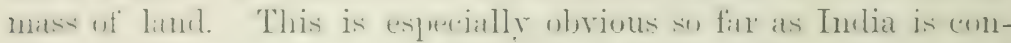
cernecl. There is, however, that broad belt of desert, sand, and

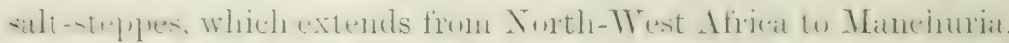

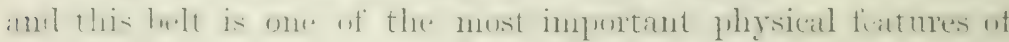

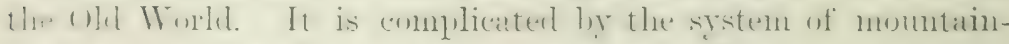

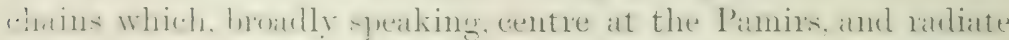

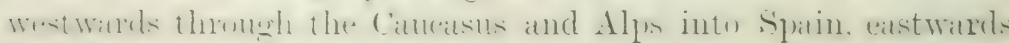

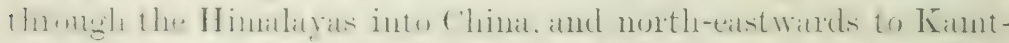

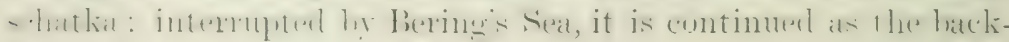
bone of both Americas to P'atagonia.

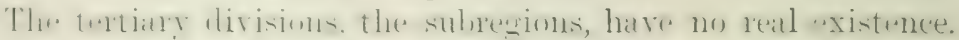

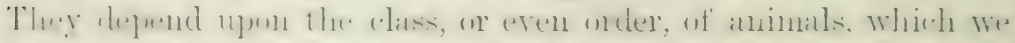

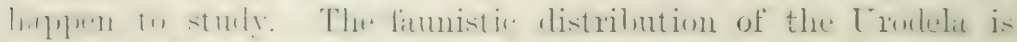
mot that of the Anurat and huth follow sefarate lines of dispersal,

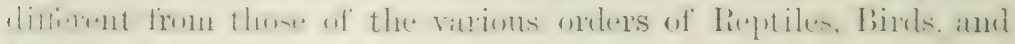
Mammals. This must be so. There is no doubt that the dis-

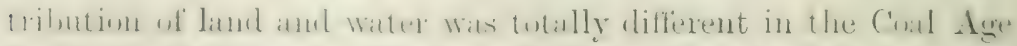

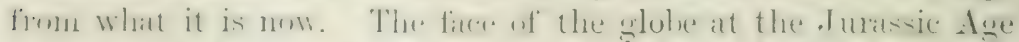

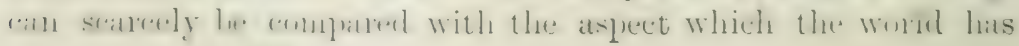
assumed in the Miocene period.

This leads to another consideration, often neglecterl. We 
know that the various classes, orders, fimilies, ete, of animals hilve appeared successively upon the stage. A gromp which atrose in the Coal Age followed lines of dispersal different from one which was not evolved until Jurassic times, and post('retilceous creatures could not arail themselres of what assisted their ancesturs, and rier corsci. The Amphibia are hound alsonlntely to the lind and to fresh water' transportation across salt water is not exchuled, lout must he accidental, and is not a casce of renular "spreating." speaking generally, the older a gromp, the more likely is it to lese wirlely distributed. If it alpears scattered, this mar be due to extinction in intermediate comntries or to submergence of former land-connexions.

There is great danger of arguing in a circle. It is one of the most difticult tasks to decide in casess of great resemblance of groups of animals between their being due to direct altinity or to heterogeneous convergence, "1 pallatlel development. It is the nomphologist who is ultimately responsible for the establishment of famuistic regions, not the sristematist, least of all he who anepts an elalorate classification, and then mechanically, mathematically, hy lists of genera and specier, malss ont the world. let us take an eximple. The Nentropical region and Mada-

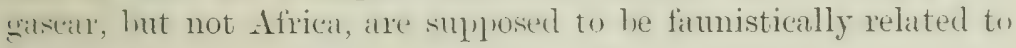
each other. In both namely oceur Bore and Corallus amongst snakes. Thendrobatinate amongst Iianidate, and of the Insectivona Solenocton in Cuba, Centetes in Madagascar. More cases can 116) doubt be fommd which would strengthen this resemblanct. perhaps in support of the startling view that Madagasear and Sonth Americal have rexerved patrt of their finma from the fimous Antarctica. But the value of the Insectivores has heen disposed of by their recognition as an extremely ancient gronl, wis a case of convergence, and the two genera are no longer put into the same fimily as ('entetidate. The Dendrobatinae (Mrnfoll, in Madagatsear, the others in south Anerica) are decidedly not a natural group, but an instance of very recent convergence (ef. 1 . 272 ). Alwut the members of the ancient Boidate we do not feel quite so sure.

It is therefore advisable to eliminate for zoogeographical purposes groups about which there can be any reasonable dumbt, otherwise we may argute that certain genera must constitute a very old family, hecanse they are now restricted to widely 
separated comntries. or on the strength of their distribution we mat conclube that the sentra in question cammot be related to each other, and (lo sut lielong to the silne sul-family or family as the case may be. Such groups are the Engystomatinae

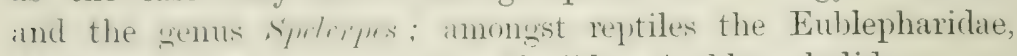
Helolermatidate, Anelytropidate. Tlysidate, Amblycephalidae.

It is customary to represent the rarious regions and subregroms as if they lant lummlaries as fixed as political frontiers. such limitations are puite arlitrary, and what is of more inmportance. Ales ditfere in reality acomeling to the class or order of animals with which we haplexu to deal. Noreorer, there his

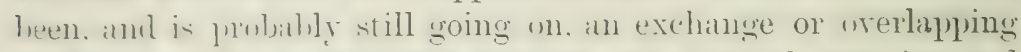

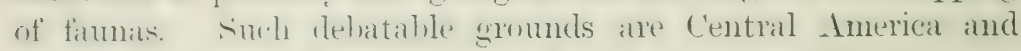
the highlands of North-western south Anerica. The famous

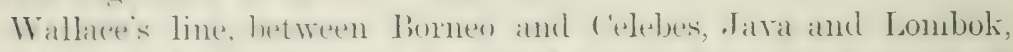
is absolutely malplicable to the Anura. From their point of

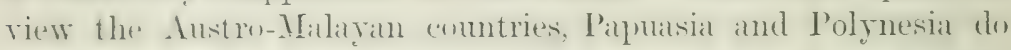

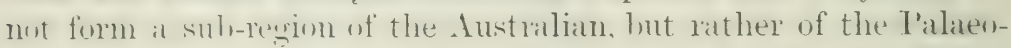

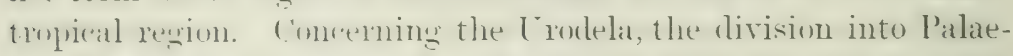

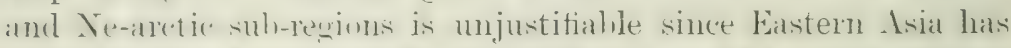

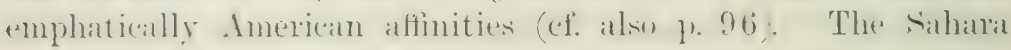
and the rese uf Xorthern Arica are intimately comnected with

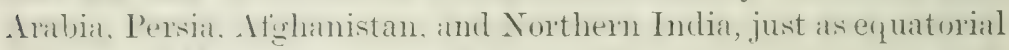

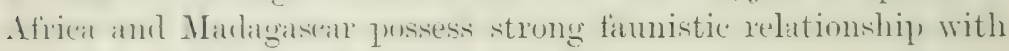
Sonthern India and the Malay islands.

Limiting fuctors of distribution._Common salt is poison to

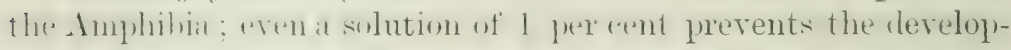

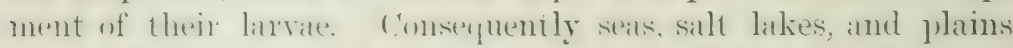

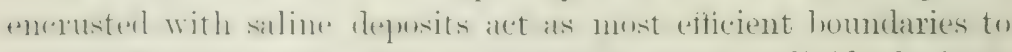

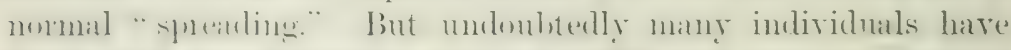

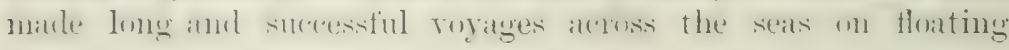
trees. Solutions of lime are likewise detrimental to many

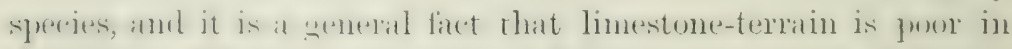

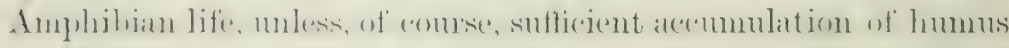

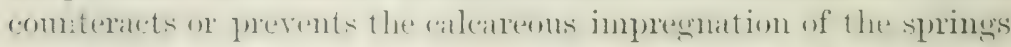
and pools in meadows. Sulcmandre moculose is, for instance,

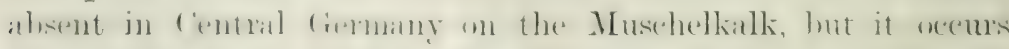

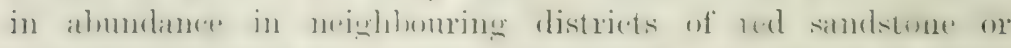
granite; nor can the larvae be reared successfully in very "hard" water. On the other hand, Proteus lives in the sub- 
terramean waters of Carniola, where the whole country is nothing but limestone.

Cold is another powerful limiting factor. The absolute northern limit of Amphibian life coincides rather closely with the somewhat erratic line of $0^{\circ}$ Centigrade of ammal mean temperature, a little to the north of which line the ground remains permanently frozen below the surface. The surfacecrust, which thaws during the summer, engenders an abundance of insects as food-supply, but its freezing down to the icy bottom makes hibernation impossible. There are, of couxse, some exceptions, for instance the occurrence of Urodela in the Schilka river and in the district of Lake Baikal.

Ranges of mountains are far less effective barriers than is generally supposed. In many cases the fauna is the same on either slope, and they act rather as equalising or dispersing factors. especially when they extend from north to south. Witness the Indes, owing to which Ecuador and Peru bear a great resemllance to the Central American fauna, and differ from the tropical parts of South America. The existence of an Amblystome in Siam is another instance.

The more specialised a family the more intimately is it connected with the physical features of the country. Typically arhoreal frogs are dependent on the presence of trees. Some have undoultedly spread into treeless comntries and have changed into prairie-frogs, e.g. Acris. They come out, so to speak, ats something different at the other end, and it is unlikely that these modified descendants redevelop exactly the same features as their ancestors lefore the migration. Baldwin Spencer ${ }^{1}$ met with only six species of frogs in Central Australia, Limnodyunstes, Chiroleptrs, Helrioporus, and Hylu. They are in the main identical with certain forms found in the dry inland parts of New South Wales and Queensland. They are to be regarded as immigrants from the latter regions, which have been able in the majority of cases to adapt themselves to unfarourable climatic conditions by means of a marked derelopment of the burrowing habit, to which in certain eases has been added a capacity for absorbing and holding water.

1 The Horn Scientific Expedition, 1S97, p. 155. 


\section{Faunistic divisions of the Amphibia.}

NOTOGA._-SOUTH WORLD.

Chatraterised hy the Crigtignathidat* and hy the predoni-

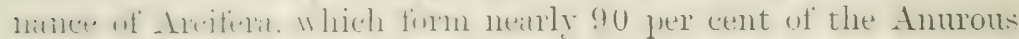
population.

I. Alstrultay regios. - Absence of Apoda and Urodela.

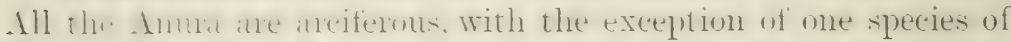

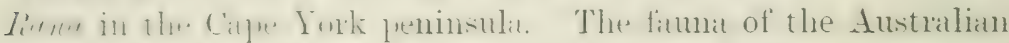

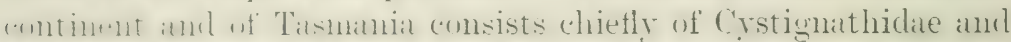

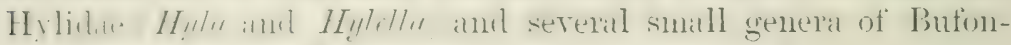

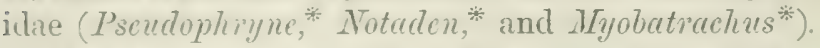

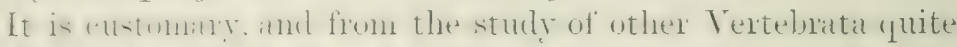
justitialle. 1n divile the Australian resion into sereral sul-

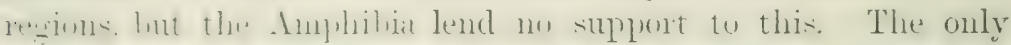

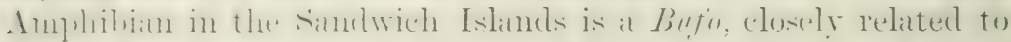

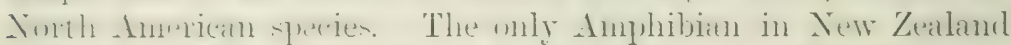

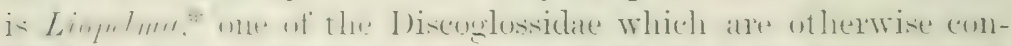

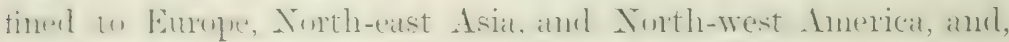

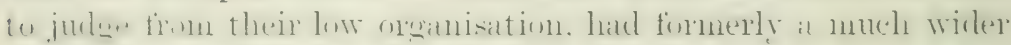

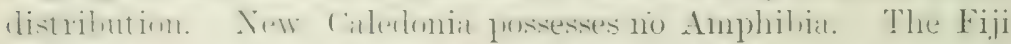

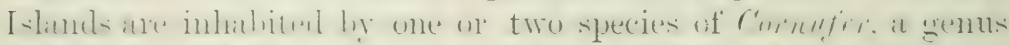
of Rimbilate. The silne getnus is typical of the Austru-Mal layan

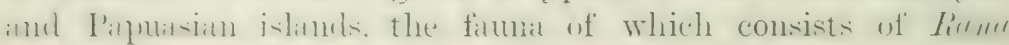

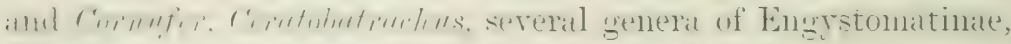
Hylidae, and P'elobatidae.

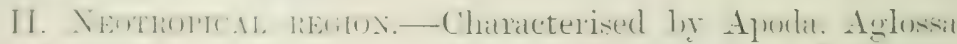

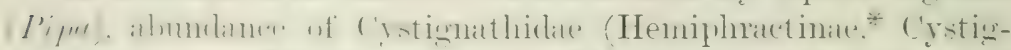

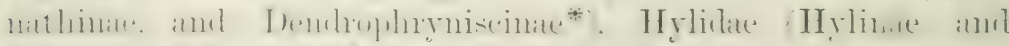

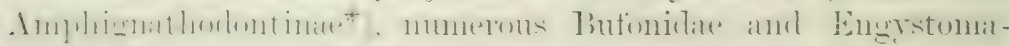
tinae; Dendiotatinac: the Tininae are represented by a few

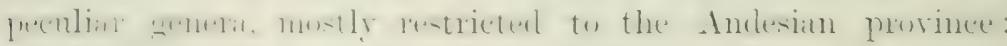
the genus liana oceurs there in a few species only.

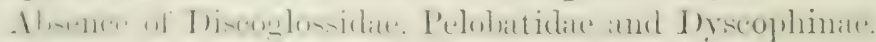

Several species of Crodela, of the genus Spelerpes, extend from Central America into the Andesian province, one necurs in Hayti, and Pethodon platense in Argentina.

This region is by fur the richest in the number of fimilies, - indicates $A$ mphibia which are peculiar to the respective regions or sub-regions. 
generat and species: the total number of the latter being, according to Bonlenger, ahout four-ninths of the known species. The rewim comprises south America, Central Americat, and the Trest Indian islinds. Central America is maturally debatable ground:

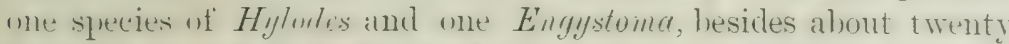
Hylidite, extend into North Anericar proper, while possibly the Ciminate have entered the Neotropieal region from the north. Bufle is ton cosmopolitan to assist on conclusions. The orecurence uf four species of Hylella in sonth Antericar, one in Anstraliat, and me in $\mathrm{N}$ (w) Cinineal indicate that this is not a natural genuls.

From the point of the Amphibia the whole region can be divided into two sub-regions only: (1) The West Indian island with Central Anerical and the north-western Andesian province; (2) the rest of South America.

\section{'ARCTOGAEA-NonTH WohLD.}

Characterised by the absence of Cystignathidae.

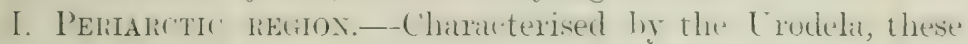
being almost peculiar to the regrion (cf. p. 96). Absence of

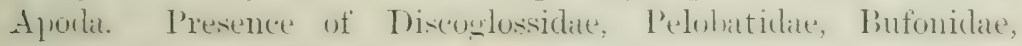
Raninae. Few Hylinae oceur.

The whole region cam be suhdivided into three sub-regions.

1. Western Palaearctic. Prevalence of Salamandrinae

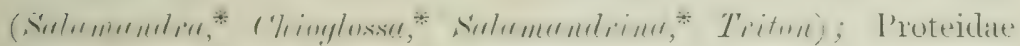
(Proteus anguinus* ); Spelerpes fuseus.*-Discoglossus, Bom-

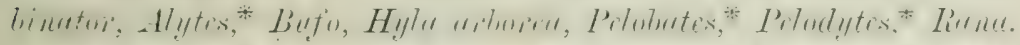

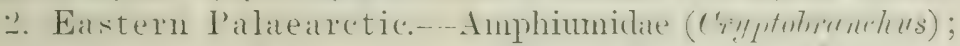

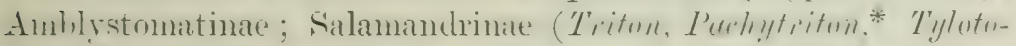

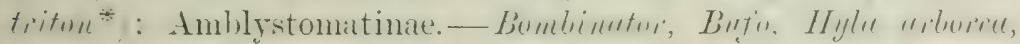
Riune, Rhacophorus.

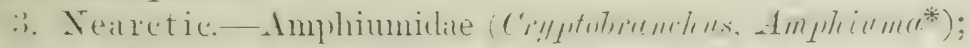

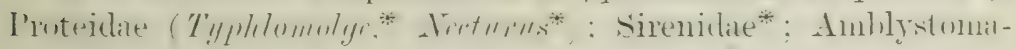

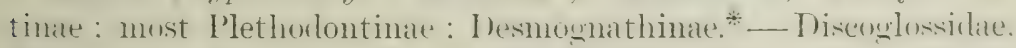

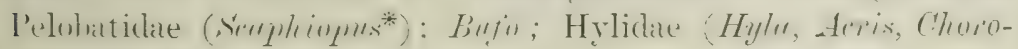
mhilus); Piana.

II. P'ALAEOTHOPICAL REGION-Characterised by the presence

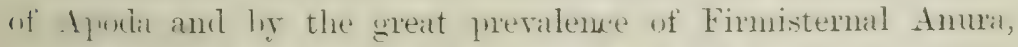
Which anoment to nearly 90 jer cent of the total population.

* inlicates Amphibia which are peculint to the respective regions or sub-regions. 


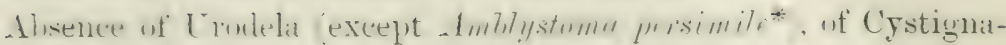
thirlite. and gractically of the Mylislate, only two of which vecur in the Hinalavan distriet. But this great chain of nombains should not he incluterl within the lexion, while the ontlying

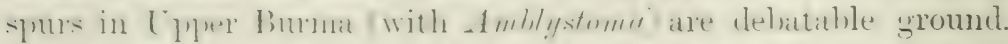
The suludisisinn of this wilely extended resion is leset. with

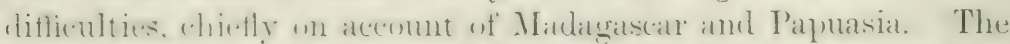

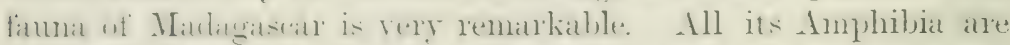
Fimnistemat a mixtme of African and Indian forms. The island

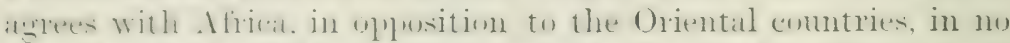

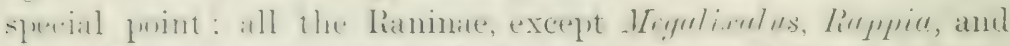

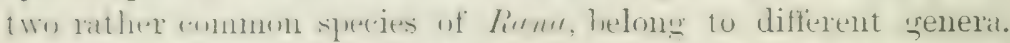

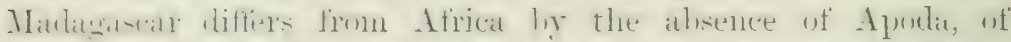
Aglesial and Bufonidae. On the other hand, it agrees with India

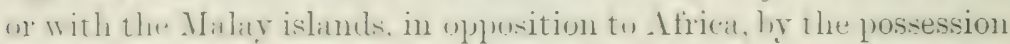
of I r. stomatine genus C'alophrynus.

Africa and India agree with each other, and differ from

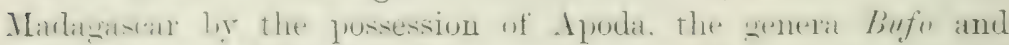

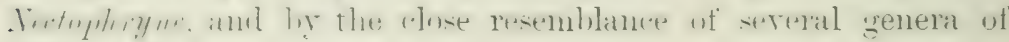
Raninae.

India, the Malay islands, and Papuasia with Melanesia

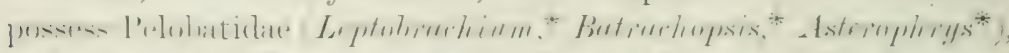

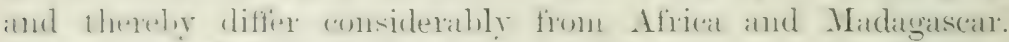

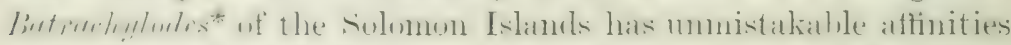

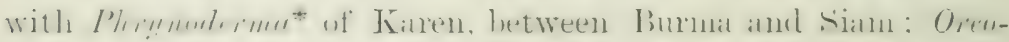

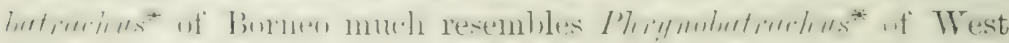
Africal and Cornufer, typical of the Malay and Melanesian

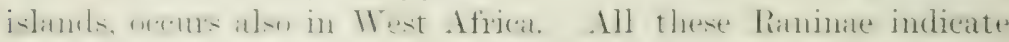

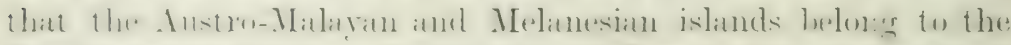

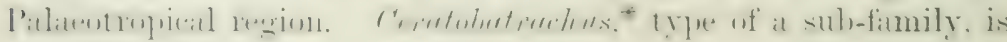
peculiar to Melanesia.

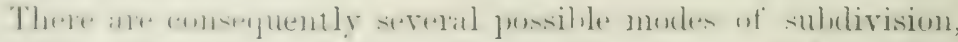

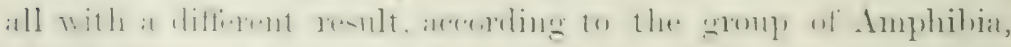
which we may select as of leading importance, r.g. Apoda or Pelobatidae, or Dyscophinae and lihucophorus. The Engy-

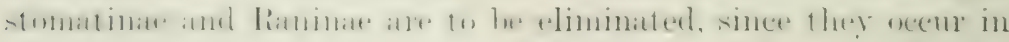
all the comntries in question. We have either to leave the whole region molisident-and it is at significant fird that the 
Indian countries possess not one sub-fitnily of their own-or we must break it up into four provinces, not sub-regions:-

1. Ethiopian, or continental African, with Aglossa and Apoda, no Pelobatidae, no Dyscophinae, few Bufonidae, and many Raninae.

2. Indian and Malayan, with Apoda, no Aglossa, but with Pelobatidae, Dyscophinae, many Bufonidae and Raninae, amongst which Riluecophorus.

3. Malagasy, without either Apoda or Aglossa; with Firmisternal Anuma only, chiefly Dyscophinae, and Rhacophorus and other Raninae.

4. Papuasian, without Apoda, Aglossa, Drscophinae, and Bufonidae, lut with Pelobatidae and Ranidae.

IUSTRIBUTION OF FAMILIES ANI STB-FAMILIES OF THF AMPHIBIA.

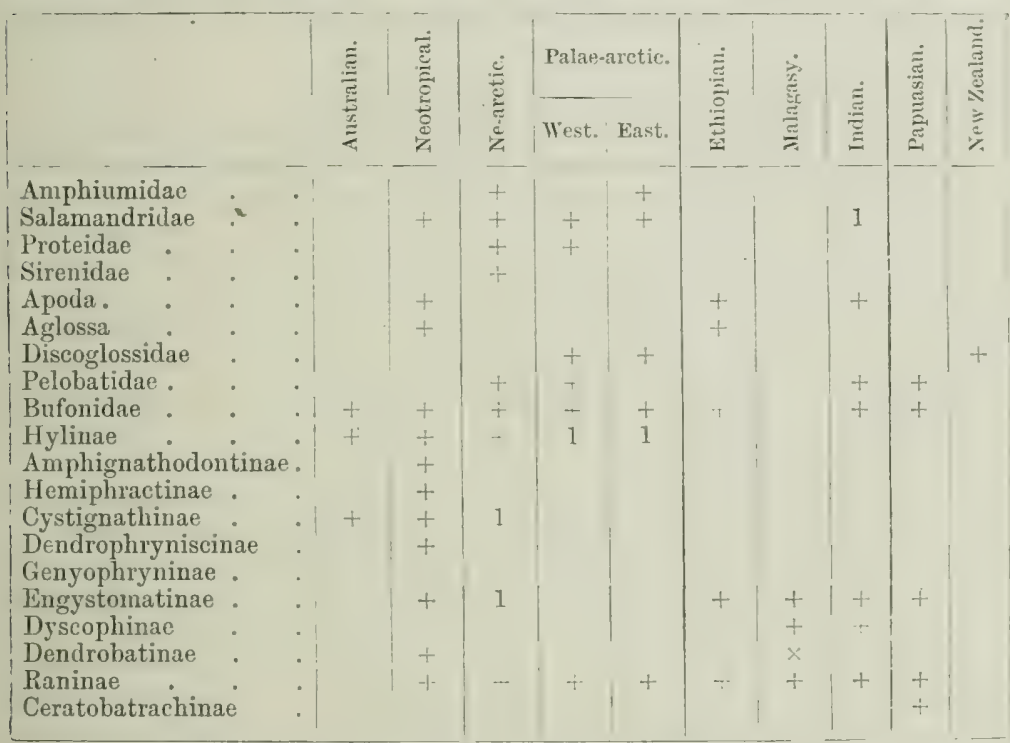

1 signifies the occurrence of only one species of an elsewhere numerous group. $\times$ Mantella, cf. p. 71 and p. 272 . 


\section{CHAP'TER IV}

STEGOCFPHALI OI: LABYRINTHODONTS-LISSAMPHIBIA-APOIA

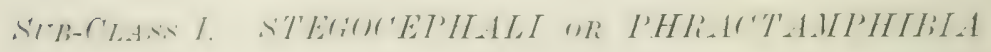

With a considerable amount of dermal armour, especially on the hearl.

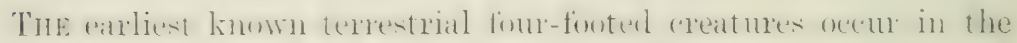

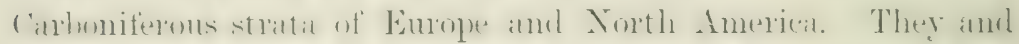
their inmediate allies. which extemel thromgh the l'ermitn into

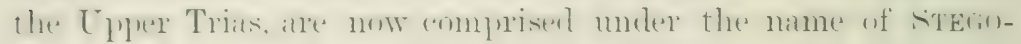
CEPInLI, so called because the whole of the dorsal side of the

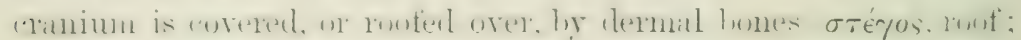

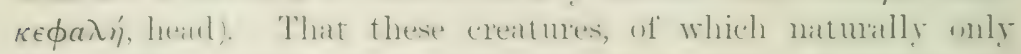
the skeletal parts are lnown, were not fishes, is shown by the typically pentadretyloid limbs; but to recognise them

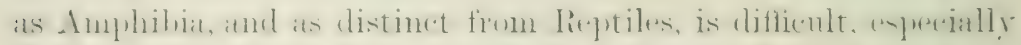

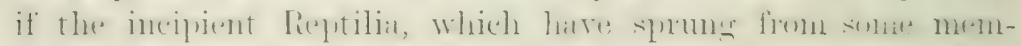
ber's of this Stegocephalous stock, are taken into account.

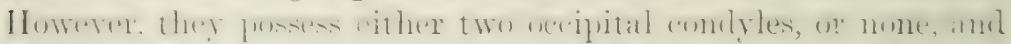

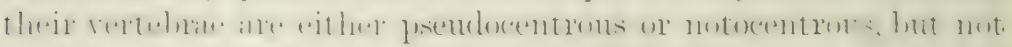

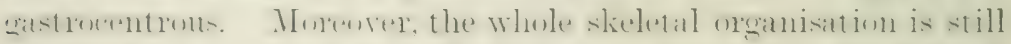

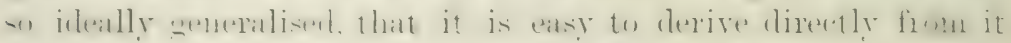
the arrangenent prevailing in the Apoda and Urodelit.

The vertebral column always comprises a well-developed,

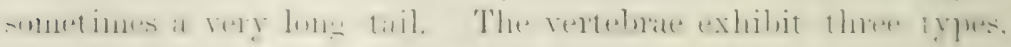
two of which are fundamentally distinct, while the third is a further development of the second.

1. Lepospondylous and psoulocentrous. - The vertebra con-

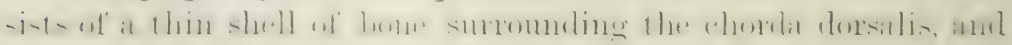
is composed of two pairs of areualia, which meet each other, 
forming a suture, along the lateral side of the rertelua. "lnth partaking in the formation of a transterse process which carries the rib.

2u. Teminospondylous. - The rertehra is composed of three pairs of units; which remain in a separate, unfused state. Two of them are dorsal areualia, one of which tends to form the centrum of the vertebra, which then carries the nemal arch.

21. Stricospondylous. - The three component units fuse hr co-ossification into a solid, amphicoelous vertebra.

The ribs are one- or two-headed, rather strong, but short, rarely reaching half-way round the hody. They ocem on all the vertebrae of the trunk and on most of those of the tail. One pair of ribs comnects one rertebra, the sacral, with the pelvis, of which the ilium and ischium are generally nssified, rarely also a portion of the pubic region.

The shoulder-girdle is very primitive, greatly resembling that of the Crossopterygian fishes. It consists of the following bones:a metian, rhombic, or $T$-shaperl interclavicle, a pair of chilvicles, of cleithra, of coracoids, and of scapulate. The limbs show the typical pentadactyle plan, but eren in these earliest Tetriporla the hand possesses only four fingers, with 2, 2, 3, 2 phalanges respectively. The foot has five toes, with $2,3,4,4,3$, or $2,2,3,4,3$ phalanges.

Many Stegocephali were possessed of a dermal armour, corering rither the whole body or only the under parts. Hence the term I'luactamphibia (фрактós, armoured). The armour consists of a treat number of small cutaneous scales, partly calcifierl, or perhaps ossified, and arranged in many more or less transterse rows. Te can only sumise that these scales were covered hy rorresponding epidermal sheaths. The skull is ideally complete in the rimmber of separate bones which aprear on its surfixce. Besicles the outer nares and the orbits there is always an mmaired, small, interparietal foramen. The whole tempral region is completely roofed over. The following lones are lresent:-nasals, frontals, parietals, supra- and latero-necipitals; licrymals (unless fused with the jugals?), prefrontals, postfrontals, postorbitals, squamosals, and eji-(or opisth-jotics; premaxillaries, maxillaries, jugals, quadrato-jugals, and supra-temporals:" quadrates, pterygoids, palatines, romers, and an unpairecl parasphenoid.-The lower jaw is compused of a pair of dentaries, 
articulars, angulars, and splenials. The dentaries and apparently sometines the splenials, the palitines, maxillate, and roners carry teeth. The eyes possess a ring of sclerotic bones.

\section{Order I. STEGOCEPHALI LEPOSPONDYLI.}

Vertebrae pseudocentrous.

Sub-Order 1. Branchiosauri. -. The young had several pair. of gill-atrhese. which, to julge from their size and fron the

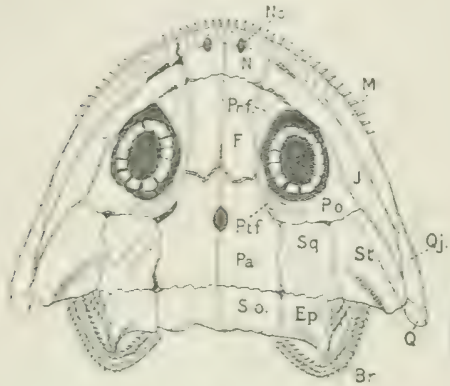

A

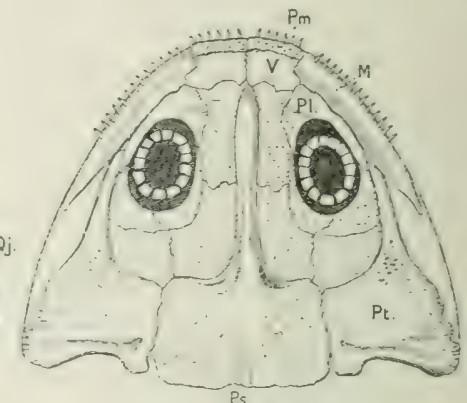

B

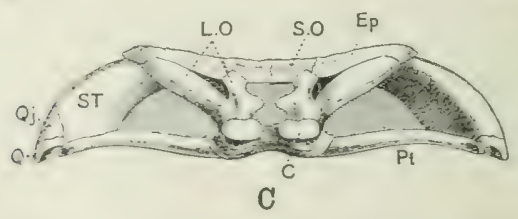

Fig. 12-A, Dorsal ani B, ventral views of the cranium of Brenchioscucrus saluman. dioides, $x$ about 4 . (After Fritsch.) C, Posterior view of the cranium of Trematosaurus, $\times$ about $\frac{1}{2}$. (After Fraas.) $B r$, Branchial arches; $C$, condyle ; $E$, epiotic ; $I$. frontal ; $J$, jugal ; $L . O$, lateral occipital ; $M$, maxillary ; $N$, nasal ; $N O$, nostril; $P a$, parietal ; $P l$, palatine ; $P m$, premaxillary; $P . O$, postorbital ; $I^{\prime} r, f$, prefroutal ;

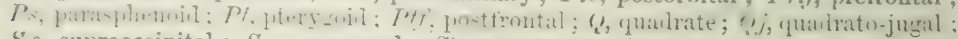
S.o, supraoccipital; $S \%$, squamosal ; St, supratemporal; $\mathbf{V}$, voner.

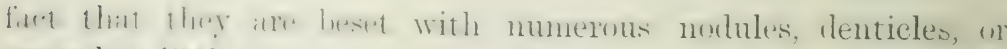

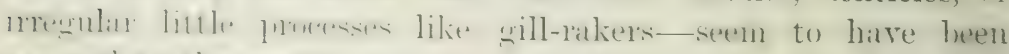

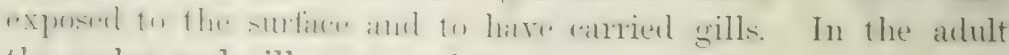
the arches and gills seem to be absent.

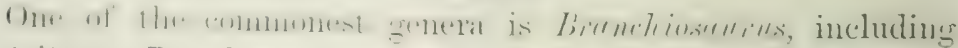
Piotriton. B. salcmandroites of the Lower Red Sandstone of Europe is known in every stage, from larvae of $16 \mathrm{~mm}$. to the till grown animal of ij.t nun. in length. The whole herly wats 
covered with little cutaneous scales. Pelosomrus and perhals Mclunerpeton are allied genera.

The following genera are small newt-like creatures of the Carboniferous age of Europe and North America. In Kerrterpeten of Bohemia, Ireland, and Ohio, the dermal seales were restricted to the under parts; and the ribs were rather long, reaching half way round the body. Gills have not been observed. $K$. crussum, al European species, reached more than one foot in length, two-thirds of which fall to the tail. The ventral side is covered with a most elaborate armour, which consists of about eighty chevron-shaper rows of little scale-shaped nodules. The epiotic bones end in strange processes, carrying a pair of spikes, giving the skull at "horned" appearance, hence the generic name. Urocordylus is an allied genus.

Sub-Order 2. Aistopodes. - Body snake-like and without

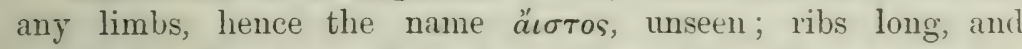
reaching half way round the body; from Carboniferous strata in Ireland and Bohemia, with allied, or perhaps identical forms in Ohio. Dolichosome longissimum possessed more than 150 rertebrae, and was about a yard long. The epioties end in olotuse projections, recalling those of Keruterpeton. These marvellous creatures had strange appendages, extending from behind the sides of the head, which were possibly the supports of external gills; since the upper end of one of the visceral arches, probably the hyoidean arch, is attached to the labyrinthic region, and from this arch starts a bony rod which carries long skeletal filaments. The body seems to have been naked.

Ophiderpeton had a compound rentral shield, while the skin of the back contained granular scutes. Although the Aistopodes have, not without reason, been looked upon as greatly resembling the Coeciliae or Apoda in organisation, especially in that of the vertebral column, the total absence of any other fossils which might bridge over the enormous gulf between the Coal Age and recent times, makes the attempt to lerive the Apolia from these creatures very hazardous.

\section{Order II. STEGOCEPHALI TEMNOSPONDYLI.}

Mostly with rather long ribs and with chiefly ventral armour.

VOL. VIII 
Chelydusunds from the Lower Red sandstune of Bohemia was ; feet long, and possensed a leautiful, complicated, ventral armour, consisting of athont sixty chevon-shaped rows, about three times as numerums as the vertebrae in the corresponding region. splumsumins from the same strata and localities must have heen 2 yards long. 'The trunk-rertebrae of hoth these genera were composed of four pairs of arcualia. Trimerohmele from the Permian of Texas is very imperfectly known, lut its trumkvertelurae. as the name implies, consist of three pairs of separate arcualia, whe of which, the interdorsal pair, tends to form a kind of centrum.

Dissmophus multivintus, also from the Permian of Texas, has been described hy Cope ${ }^{1}$ as a "Batrachian Armadillo," and considered allied to Trimeromhele 'Ten vertelnate are known, of an aggregate length of $9: 3$ mm. : the length of the creature was perliaps one yarl. The neural spines ale elevated, and the apex of each extends in an arch on each side to the ribs. These spinous loranches touch each other, forming a carapace. Above, and concesponding to each of them, is a similar demal and asseous element, which extends from side to side without interruption in the median line, foming a dermal laver of transverse bands which comespond to the skeletal carapace beneath it. This areature lemotely approaches the gemus Zutmolys, Cope, where a dermostenus scute is co-ossified with the ilpex of the neural spine. The systematic position of this genus is at least doubtful.

Archegosaums decheni from the Lower Red of Germany, known hy many well-pnestred specimens, reached a length of 4 ox 5 feet. The trumli vertebrate are tri-partite, those of the tail quadri-partite, like those of the trumk of cholydusanins. Young sperimens show traces of gill-arches. The thoroughly terrestrial walking limbs have four fingers and four toes: the arrangement of the tarsilia, most of which are ossified, lend support to the virw that the morphologiral axis went throwgh femur, fibula, internerlinn, the centralia, the second distal tarsale, and the second toe. 'The dentine and enamel of the teeth are much folderl, and this fouture, which applies to most members of this

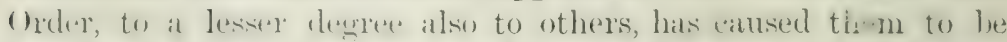

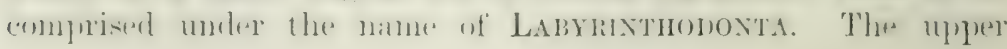


surface of the head shows very characteristically ilranged grooves, which probably contained slime-canals and possibly sensory organs.

Actinodon and Euchiroscurus are closely allied forms, "hiefly from the Lower Red Sandstone of France; Gondurunoscun'us occur's in the Permian of India.

\section{Order III. STEGOCEPHALI STEREOSPONDYLI.}

These are the most highly developed members of the typical Labyrinthodonta, characterised by their much-folded teeth, and by their solid, bi-concave vertebrae. Loxomma oceurs in the Upper Carboniferous of England and in the Lower Red of Bohemia: Tiematosums, Capitosaurus, and Hetopias from the New Red or Lower Trias to the Keuper of Germany. Mrestodonsomrns from the Trias of England and Germany is the most gigantic Amphibian known, with a skull of nearly 1 yard in length.

Labyrinthodon from the Keuper of Warwickshire is one of the latest members of the group. Labyrinthodont creatures have also been described from the Trias of South Africa, e.\%. Rhytirusteus; those from North America are insufficiently preserved.

Many of these and allied genera have left their footprints in slabs of Sandstone, both Lower and New Red, in Europe, Africia, and America. But although their spoors are common enough, only a few can with certainty be referred to Stegocephali, e.\%. Sourichnites salamandroides of the Lower Red of Germany. The spoors of Chirotherimm, common in the New Red of Germany and England, for instance in Cheshire, belong to unknown owners; both the large hind feet (which measure nearly half a foot in length) and the much smaller fore feet, han five digits, the first of which stood off like a thuml. Firefingered Stegocephali are unknown.

There is an almost complete absence of fossil Amphibia from the Upper Trias to the Oligocene. The Stegocephali as such seem to have died out with the Trias. The recent Amphilia, of course, must have had ancestors in the Mesozoic age. There is (me little skeleton, from the Wealden of Belgium, which belongerl to a newt-like creature, called Hylafobatrachus cronyi. Sicarce fragments, described as Migulotitom, are known from the ()ligocene of France, and Triton itself seems to be indicated hy 
remmants in the Lower Miocene of France aml fermany. But fairly complete specinems of large creatures. innch resembling

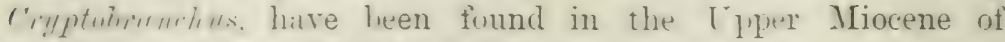
Oeningen. Canton solothurn. Switzerland. The tirst known sinecimen. now at Haarlem, inclicating a total length of :i feet or more. Was descrilued and figured in the year 17.26 ly schenchzer, in a learned dissertation entitled "Homo diluvii testis."

Betrübtes Beingeriist ron einem alten Sünder

Erweiche Herz und Sinn der nenen Bosheitskinder.

Which may be rendered as follows:-

Oh, sad remains of bone, frame of poor Man of sin

Soften the heart and mind of sinful recent kin.

This was the motto attacherl to the illustration, and it remained a warning to mankind until Cuvier leclared the skeleton to be that of sonde large newt. Tschuli named it Andrius solvelhzeri.

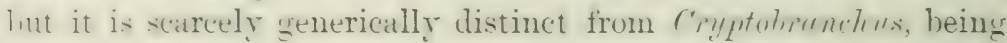
ahno-t interusediate between $C^{\prime}$. allegluniensis and $C$. jupnnicus, see p. 97 .

S'CB-CILASS II. LISSAIIPHIBIA.

Amphibia without dermal armour.

\section{Order I. APODA or LIMBLESS AMPHIBIA.}

The Amphibia Apoda, Coeciliae or Gymmophiona, are a small grmuly of worm-shaped. burrowing creatures, restricted to the Tintrupinal and Paliteotrupical regions, exchding Madagascar. They hate no linhls and no girdles. The tail is extremely shert: the vertebiate are pretudo-centrous, and nust of them "arry rather long rilss, none of which, however, meet to form a -ternum. The whole snake-like lody is covered with a smooth and -ling skin whible forms numerous transierse folds or rings.

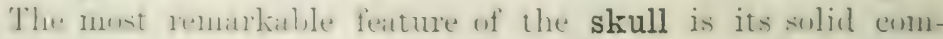

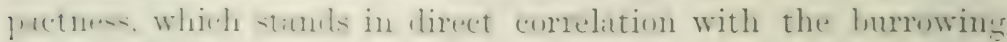
habits of these creatures. The whole dorsal surface of the

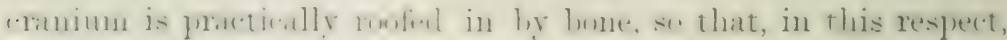

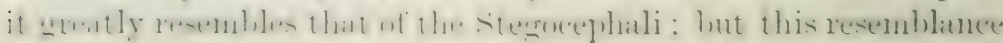

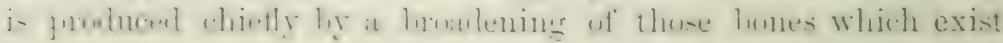


also in the other Lissamphibia, while supratemporals and supuroccipitals are absent. There is, however, a pair of bones which represent either the postorbitals or the postfrontals, perhalps both, of the Stegocephali. The quadrato-jugal arch is enormously developed, and by reaching the parietal, frontal, and postorbitofrontal bones (which latter occur only in Ichthyophis ancl Cracotyphlus.s) and the maxilla, extends over the whole of the orbito-temporal fossa. The squamosal is completely fused with

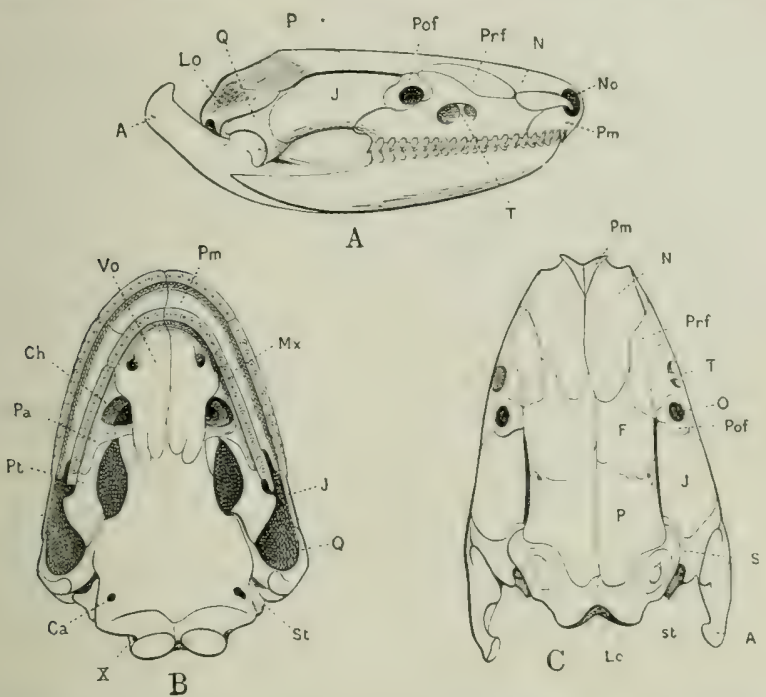

Fig. 13. -Skull of Tchthyophis glutinosa. $\times 3$. (After Sarasin.) A, Lateral, B, ventral, C, dorsal view. $A$, Posterior yrocess of the os articulare ; $C a$, carotid foramen ; $C$, choana or posterior nasal opening; $\boldsymbol{F}$, frontal; $J$, jugal; Lo, lateral occipital; $I x$, maxillary ; $N$, nasal ; $N o$, nostril ; $O$, orbit ; $P$, parietal ; $P(\ell$, palatine ; $P M$, premaxillary; Pof, postfrontal ; Prf, prefrontal ; $P t$, pterygoid ; Q, quadrate ; $s$ squamosal ; $S t$, stapes; $T$, tentacular groove ; $\boldsymbol{V}$, vomer ; $\boldsymbol{X}$, exit of vagus nerve.

the quadrato-jugal. The stapes has the typical stirrup-shape, is even perforated by an artery, and articulates distally with the shaft of the quadrate (as in the snakes). The maxilla is very large and broad. Owing to its hroad junction with the yuadratojugal arch, the prefrontal and frontal, the orlital fossa is reduced to a very small hole, or the maxilla completely covers the eye. Somewhere between the latter and the nares the maxilla is perforated by the tentacular groove. The periotic lomes are represented loy the prootics and epiotics; they fuse with the lateral recipitals and with the parasphenoid. The whole 
orhitu-ethmodal region of the primordial skull is also turned into one mass of bone.

The angular element of the lower jaw forms a thick and latge process which projects upwards and backwards from the mandilular juint. The former possession of a splenial bone is inclicaterl ly the nceurrence of a second series of teeth in the mandililes of Irhthyophis and Troentyphlus. Other genera have restiges of this second row, or it may he completely lost.

The hyoid and branchial appraratus is more primitive than in any other recent Amphibia. In the larva the hyoid and the first and second branchial arches are comnected with each other l,y a neelian connlatr piece. The third branchial arches are free from the lest. Int are fused in the middle line, the fourth are lunely attached to the previons pair. In the adult both fuse into ane transrerse, curved bar, and the second pair of hranchials line their comnexion with the basal longitudinal piece and likewise form a transverse bar.

The verteluate are built upon the pseudocentrous type, are amplicoutums and the chorda is intravertehally destroyed hy arrtilage, at in the majority of the Crodela. The number of rertelrate is great, anounting in some species to lietween 200 and :300, of which a few belong to the tail. The first rertebra is deroid of an udontoid process. The ribs are proximally hifurcated as in the Urodela.

The eyes are practically useless, being either more or less concealed under the skin, or they are covered by the maxillaty bunes. All Coecilians possess a peculiar tentacular sensory alplatatus, which consists of a conical flatp-shatped or shohnlitl soft tentacle: which is lodged in a special groove or andial of the maxillat, hetween the ere and the nose, whence it is

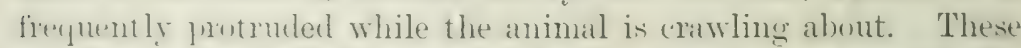
tentarles in the young siphomens lie, according to the Sinrasins, quite (duse (1) the ryes. lint are later transferred neatrer to the nuxe. The oroun ansists of a peculiarly rolled u, and pointerl foll which arises firm the hottom of the sale or pit. Where it

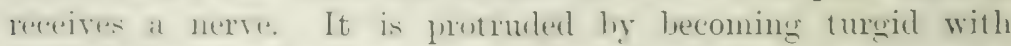
l, lowl, and is retrated ly it strong muscle. Into the lumen of

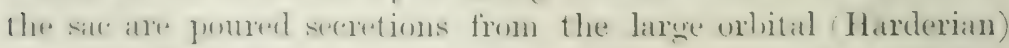

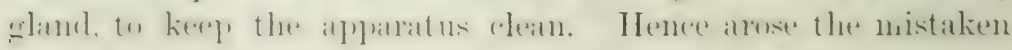


notion of its being a poison-organ. The whole structure is possibly an offshoot of the naso-lacrymal duct.

The skin is most remarkable. In the ripe embryo the epidermis passes smoothly over the surface. Beneath follow two layers of soft cutaneous connectire tissue, bound together by transverse or rertical lamellae, so that ring-shaped compartments are formed, and in these are embedded slime-glands. In the adult each compartment is modified into an anterior glandular belt and a posterior space, from the bottom of which grow several scales. The numler of cutaneous rings agrees originally with that of the vertelnae: but later, and especially in the hinder portion of the trunk, each ring breaks up into two or more secondary segments, and these no longer agree with those of the skeleton. Each scale is beset with numerous smaller scales which consist of hardened cell-secretions infiltrated with calcareous matter. The whole scale is consequently an entirely mesodermal product of the deeper layers of the cutis. The usual statement that the skin forms imbricating lamellae, on the inner side of which appear the scales, is wrong. The "lamellae" can be lifted up only after the general epidermal sheath has heen broken artificially in the constrictions between the rings. No scales exist in the Indian genus (reyenopllis and in the American Siphonops, Typhlonfetes, and Chthmerpeton, a secondary loss which does not indicate relationship. The scales develop, late in embryonic life, and they are reasonably looked upon as inheritances from the Stegocephali. The glands either produce sline, whose function seems to be the lieeping clean of the surface of the body, or they are squirt-glands. The latter kind are also,numerons and are filled with a thid which is squeezed out by muscular contraction, and seems to be poisonous, as it causes sneezing to those who handle or dissect fresh specimens.

The Coecilians live in moist ground and lead a hurrowing life. Their developmental history has only recently heen studied,

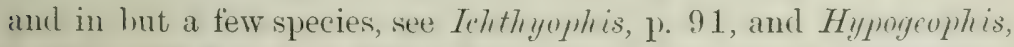
1). 9.2. The female is fertilised internally, copulation taking place by neans of eversion of the cloacal walls in the shape of a tube. The spermatozoa possess an undulating nembrane; the eggs undergo meroblastic division and the embryos have three pairs of long external gills. Some are viviparous.

The snake-like, limbless shape of the borly (Fig. 15) is, ats in 
snakes, complated wible an asymmetrical development of the lunges: the left is recheet. while the right is llawn out into a lome eylindrical sill. The liver is likewise very long, and frartly. comstricterl into a sreat number of lobes. Owing to the great meluction of the rils poregression is effecterl in an almost earthworm-like fitshon ly the leristaltic motion of the skin, assisted by its numerons ring-shaped constrictions.

The sy-tematic pristion of the coeciliate hats beens and is still, a controrersial matter. The sarasins tork up ('npe's sllogestion. that their nearest allies are the Crublelat, expecially Amplimmo, and they went so far as to look nuon Amplimmo as at mentenic form of the " coecilobilea," which they divided into

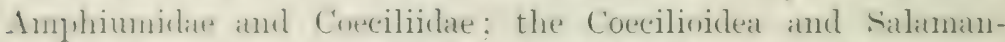
droblea finming the two sub-orders of the Grolela. They based this startling onm-hom dhiefly upon remarkable resemblances

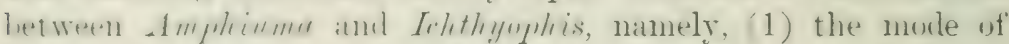
laying the egris on land and coiling themselves around them: 2 the existence of remnants of a tentacular alpraratus in

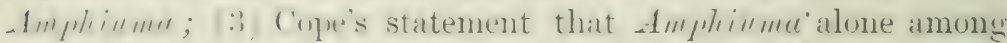

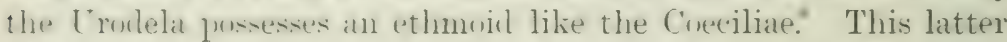
foint is, howerer, eronems: it has since been shown loy Iharison '

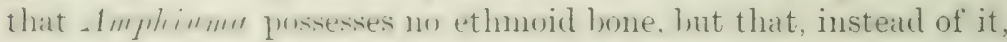
dercemding plates of the firntals join below the premaxilla and function as a natsil septum, with a canal for the olfactory nerves.

We look upon the Apoda with more reason as creatures which of all the Liswanphibia have retained most Stenocephalous chatrater's and at the same time form a highly specialised group

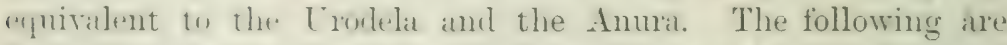

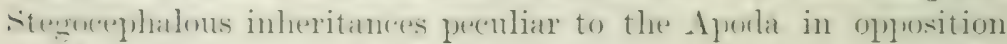
to the other recont Dinphilias retention of cutaneons scales with calcarenus incomstations, sreatly resembling the scales of

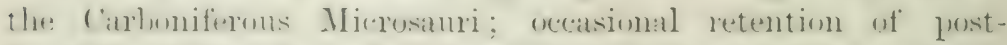
frontal and laterial nasal or laterymal bones, and of at secomel row of treth in the matulihle. To these may he addent the presences of

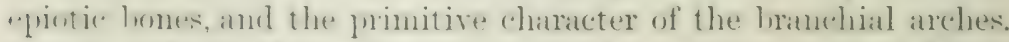
The luss of all these characters womld turn the present dpoula into limbless I rombled. hut this assmuption does not just ify thein inrlusion in this Order. The pusible hommlege of the tentacular apparatus has been discussed elsewhere, p. 45. 
Fossil Apoda are not known: their subterranean life dues not favour preservation.

Only family, Coeciliidae. About forty species are kmum. These have been placed in seventeen genera, mostly on (a)nparatively slight grounds, and several of these generat are probalil
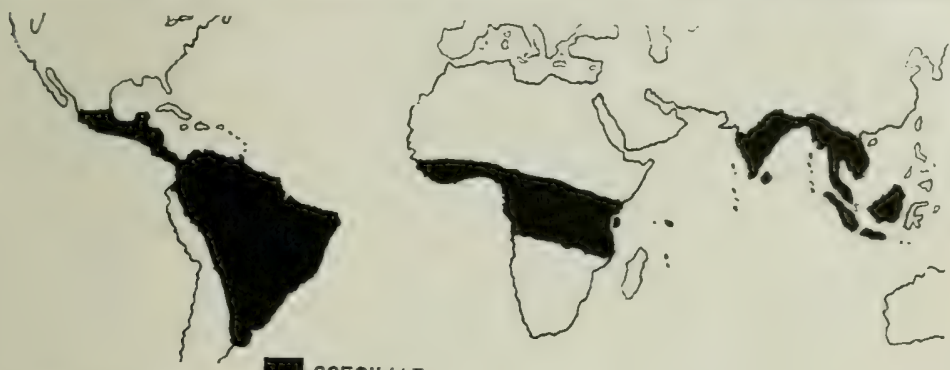

FIG. 14.-Nap showing the distribution of the Coeciliae or Amplibia Apoda.

umnatural, the distinctive characters having undoubtedly heen developed independently in various countries. The have to remember that the recent species are the remainder of a formerly much more numerous group; it is also likely that more will lie discovered in the tropical forests of South America and Sumatrit.

Boulenger ${ }^{1}$ has distinguished them as follows :-

I. Cycloid scales embedded in the skin.

A. Eyes distinct, or concealed under the shin.

a. Two series of teeth in the lower jaw.

u. Quadrato-jugal (squamosal) and parietal bones in contact.

Tentacle between eye and nostril.

Ichthyophis, 2 species, India and Malay islands, p. 90.

" below and behind nostril.

Hypogeophis, 3 species, East Africa and Seychelles, 1). 92.

" below and in front of eye.

Dermophis, 5 species, America and Africa, 1. 93. below the nostril. Coecilia, 6 species, America.

B. Quadrato-jugal separated from parietal.

Tentacle close to the eye. Rhinatrema, 2 species, America.

$"$ below and behind nostril.

" below nostril.

Geotrypetes, I species, West Africa.

Uraeotyphlus, 3 species, West Africa and India.

b. One series of teeth in the lower jaw.

Tentacle in front of the eye.

Cryptopsophis, 1 species, Seychelles.

${ }^{1}$ P. Z. S. 1895, p. 401. 
E. Eyes below the cranial bones. Quadrato-jugal in contact with parietal.

Tentacle near the nostril.

Gymnoplis, 4 species, South America.

Herpele, 2 species, Panama and Gaboon.

II. Without scales.

A. Eres distinct, or concealed under the skin.

1. Two series of teeth in the lower jaw:

u. Quadrato-jugal in contact with parietal.

Tentacle behind nostril ; end of body laterally compressed.

Typhlonectes, 3 species, America, P. 93.

B. Quadrato-jugal separated from parietal.

Tentacle between ere and nostril.

Chthonerpeton, I species, America.

7. One series of teeth.

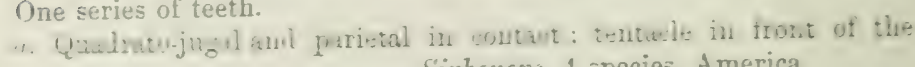
eve

Siphonops, 4 species, America.

B. Quadrato-jugal separated from parietal

Bdellophis, 1 species, East Africa.

B. Eres below the cranial bones.

a. Two series of teeth. Quadrato-jugal and parietal in contact; tentacle behind and below nostril.

Gegenophis, 1 species, Iudia.

7. One series of teeth. Quadrato-jugal separated from parietal.

Scolecomorphus, 1 species, East Africa.

Boulengerula, 1 species, East Africa.

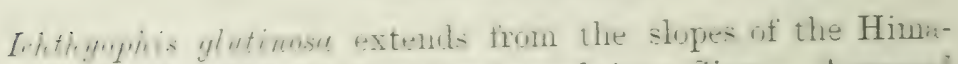

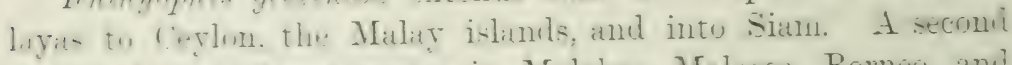

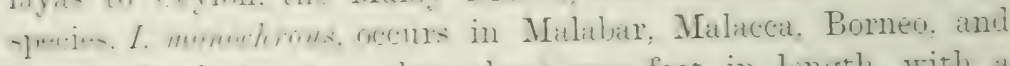

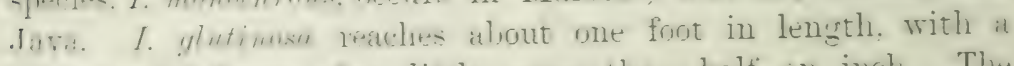

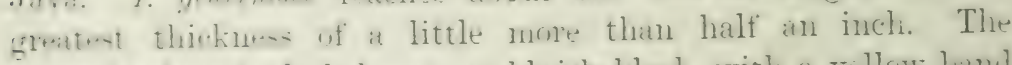

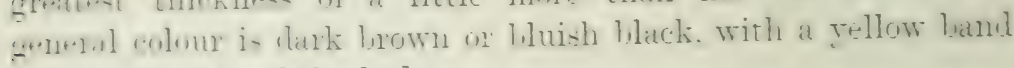
along each side of the body.

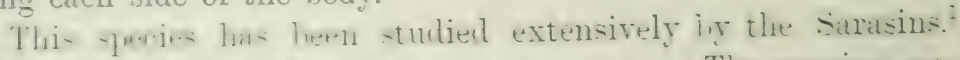

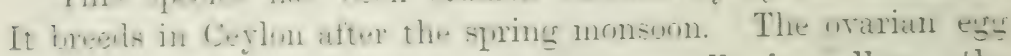
is oval, measuring 9 by $6 \mathrm{~mm}$. The yolk is jellow; the

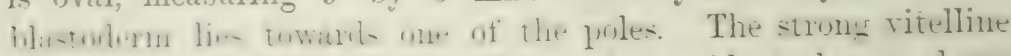

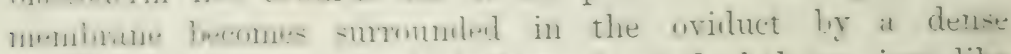

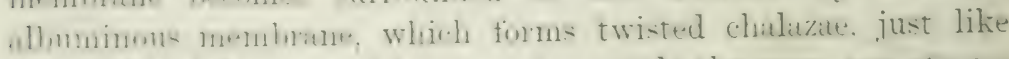

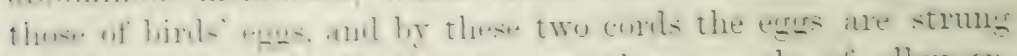

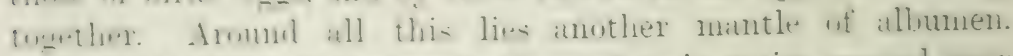

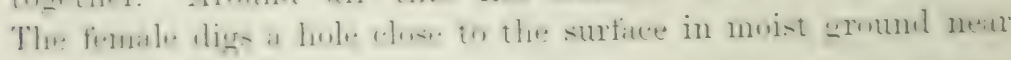

1 P. and F. Sarasin, "Zur Entwichlungsgeschichte der ceylonesiselien Blindwiihle, Ichthyophis glutinosa." Ergchnisse natureiss. Forschungen anf Ccylon, 1557-1590, rol. ii. 
lumning water, and there lays's about two dozen egugs. The rugustring become glued together, entangled into a hmuch. amd thes female coils herself round the hunch and remains in that frosition, probahly to protect the eggs agamst other Inumwing creatures, as hlind snakes (Typllhops and lihimplis.s and certain limbless lizards, with which the gromel literally swams. Ijuring this kind of inculation the egges assume a rommel shatre, and grom to twice their original size, and the mature embryo weigh fom times as much as the newly laid egg.

The exterual gills are delicately fringerl and real, and they more up and down in the fluid of the egg. 'The body of the
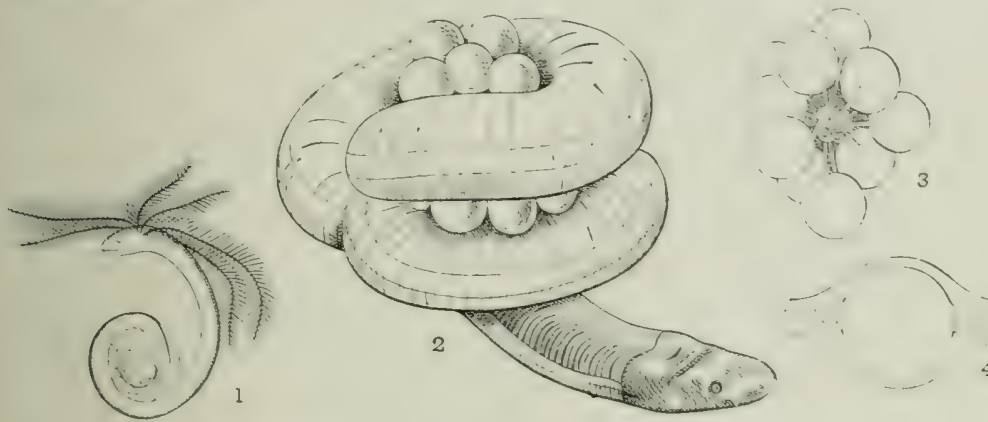

Fig. 15.-Ichthyophis glutinosa $\times$ 1. (After P. and F. Sarasin。) 1, A nearly ripe emhryo. with gills, tail-tiu, and still with a considerable amount of yolk; 2, female guaxhjng her eggs, coiled up in a hole undergronnd; 3 , a bunch of newly laid eggs : 4, a single egg, enlarged, schematised to show the twisted albuminous strings or chalazae within the onter membrane, which surrounds the white of the egg.

embryo is at first white, lont becomes pignented with dark grey. A strong line of lateral stense-orams is formed, and a ring of then lies around the eye and others on other jarts of the head. 'The' short tail derelops a fin. Of the three yairs of yills the thind is the shortest, and is generally tumed dorsilwarks. In emberos uf $f$ cul. in length the lomgest gill measules as much as :- cm. lolk is still present in embryos which have reached the surpusing length of $T$ cm. Then the gills hegin to slumin it little, and at this time onte pair of gill-clefts breals thromgh at the base of the third exterual gill.

When the larvate are hatcherl the gills are lost. The youms larval takes to the water in a gill-less state, and mores about like an eel. At the hotton of the gill-hole on each sicke two arrohes are risible, and there are at this stage neither inmer nor 


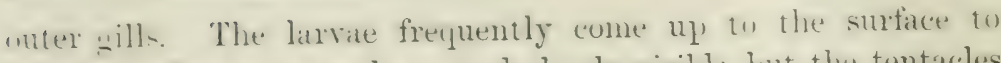
loreathe. The "ress are large and clearly visihle, hut the tentacles are still mmleveloped. The epidermal semse-organs are numerous, amel allual as white spots in the grey shin: ahout fifty extend from the gill-opening to the tip of the tail.

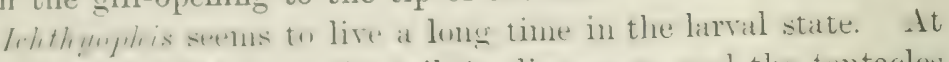
last the gill-cletts cluse. the tail-tin disilpuears, and the tentacles mone to the surtice. The whole shin assumes a totally new strueture and the fish-like larvat turns into a hurowing, sub-

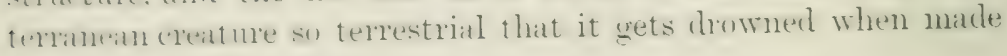
to remain in the water.

Hypogeophis.-According to A. Braner three species of

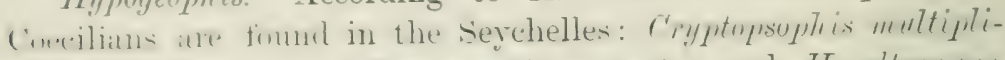

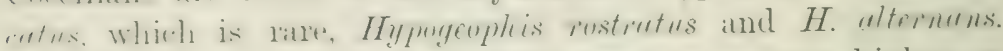
Ther live in moist momul, near the coast in swamps, higher up in lommus. muler groten trexes and rocks, down to the depth of me. fiml. In the island of silhomette, Fianer found them in numlis at labst during the dry season. from May to September. The natives "all them "ress de terre." They seen to propagate during the grater gart if the gear. provited there is sufficient

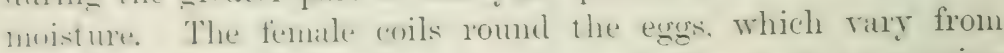

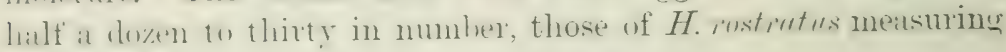
T-S mm., those of $H$. alternans only $4-5 \mathrm{~mm}$.

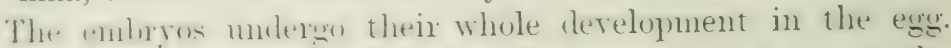

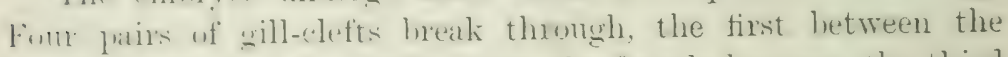

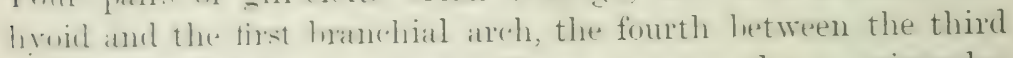

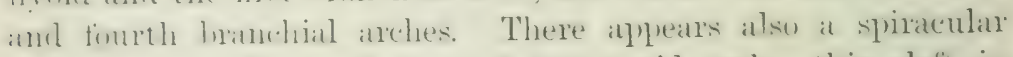

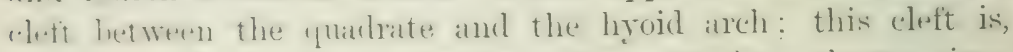

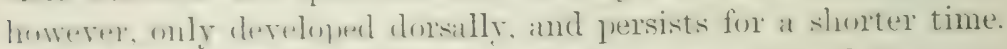

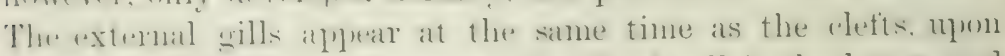

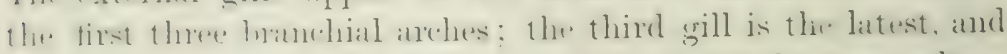
rematus in at vetigial comblition rovered up hy the two nthers. The wills, of which the seromel is the longest, alle mot fis stated

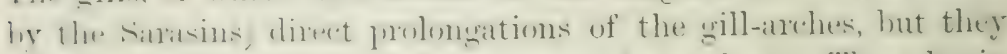

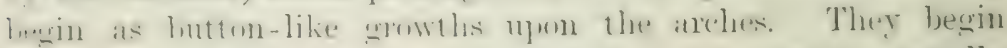

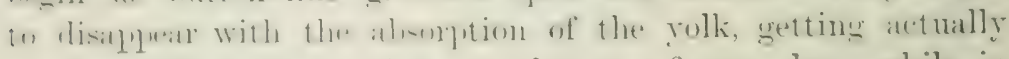
smaller. In embryos of 6 cm. they are 6 mm. long, while in embryos of 6.5 cm. they are reduced to $4.5 \mathrm{~mm}$. in length. The

i "Beitrige zur henutniss der Entwicklungsgeschichte und der Anatomie der ymnophionen," Znul. Jelerb. Anet. x. 1897, 1. 389, and xii. 1899, 1. 475. 
first to disappear is the third gill, of course ly being resorled: and the clefts are closed before the creature leares the egy. Hy/ngeoph is not leading an aquatic larval life possesses no tail-fin in the embryonic state, the gill-holes are closed, and the epidemial sensory organs disappear long before the time of hatching.

Testiges of gills appear also on the hyoid and on the mandibular arch, but on the latter they are of very short duration. Those of the hyoid gradually fuse with the first of the hranchial gills, and these also concentrate with their bases so that they ultimately seem to spring from one common stem. Bratuer remarks that the distinction between internal and external gills seems to be one of degree only; the hyoidean and mandihular gills wamely start from the hinder margin of the arches, just like the internal gills of Torpecto according to Ziegler, while the other gills start from the sides of the branchial arches. He also found a pair of little swellings behind the last gill-cleft, and an umpaired swelling (corresponding with a double one in Ith thyophis) in front of the vent. Not unreasonably he sees in these swelling: the last, very transitional vestiges of the paired limls.

Typhlunectes compressicunde of Guiana and Tenezuela is one of the largest Coecilians, reaching a length of 18 inches, with a body-diameter of $\frac{3}{4}$ inch. The general colour, as in most of these creatures, is olive brown to black. A sort of adhesive dise surrounding the vent occurs in this genus. Peters, who described this species, found in one female six embryos of comparatively enormous size, one of them being $157 \mathrm{~mm}$. (more than 6 inches, long, and $12 \mathrm{~mm}$. thick, and devoid of a tail-fin. Insteal of lateral gill-openings there is a "batg" on each side jo mm. long", upon which is distributed a blood-vessel. The Sarasins have examined the same specimen: The gills are not a hag, but consist of two flat, unbroken membranes which are closely connected with each other. In fact the outer gills of all Amphibia may be said to begin in the shape of small bags, whence sprout secondarily the gill-fringes; but in Typhlonectes they form these flaps instead of growing into the usual three gills. The embryos have no epidermal sense-organs, but plenty of skin-glands. Probably when born they take at once to terrestrial life, the flaps are jossibly shed at birth, and there remains a little cicatrix.

J, monhis thomensis of West Africa (its other relations live in East Africa, South and Central Anerica) is also ririparous. 


\title{
CHAPTER V
}

\author{
LISSAMPHIBIA (CONTINUEL) -URODELA
}

\section{Order II. URODELA or TAILED AMPHIBIA.}

Th: resent tailed Anphihia, Salamanders and Newts in the wider sense, hatre heen somperl into four finnilies which can lie conreniently diagnosed by the following characters:-

Both the upper and lower jaws are furnished with teeth. Fore- and hindlimls are alwatys present.

Maxillary bones present.

Eyes free and devoid of lids . . AMPhicmidae, p. 97.

Eyes with movable lids ${ }^{1}$. . Salamaxdridae, 1). 102.

Maxillary bones absent.

Eyes without lids. Perennibranchiate Proteidae, p. 132.

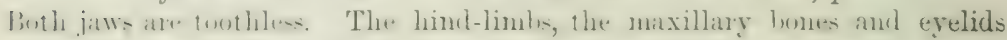
are absent. Perennibranchiate . . Sirenidat, p. 136.

These fom finnilies ane rosely allient to each other, especially the Amphiumidae and the Salamandridae.

The sengraphical alistribution of the Troolela is assentially

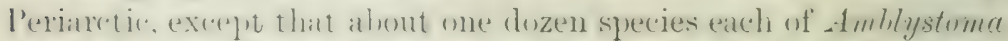

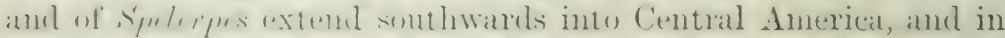
the rase of the latter genus even into the Andesinn parts of South America. Plethodon platense inhabits Argentina.

The Fromblat alford and reasons for dividing the P'eriaretic

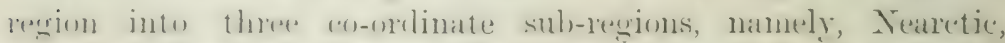
Eisterna and Wisteril lialatenctic. The difference between the

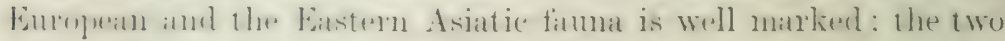

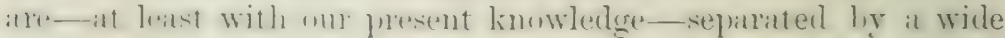

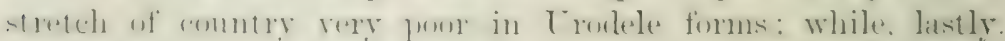

1 The existence of such a form as Typhlotriton, in the adult of which the eyes hecome closed up, makes such short diagnoses of the families defective, although there is no doubt about the Desmognathiue altinities of this genus. See p. 103. 
there are not a few resemblances hetween this Eastern Asiatic and the American fauna. The Crodela thus lend no sulport to the usual division of the Periarctic into a Palaearetic and a Nenretic sub-region. Nor is it possible to divide the Palaearctic into at Eurasian and a Mediterranean province. Tre have in this catse to distiuguish between an American, an Asiatic, and a kuropean

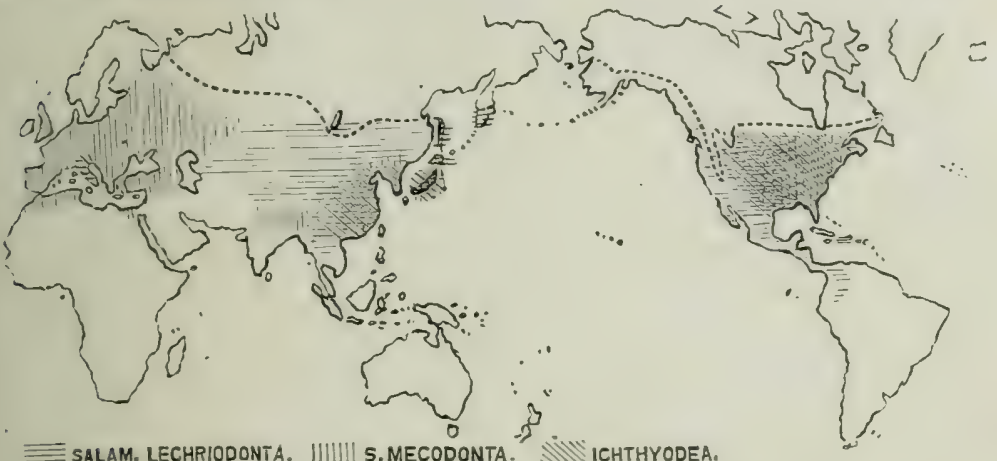

FIG. 16.-Map showing the distribution of the Lrodela. "Ichthyodea " = Anphiumilae + Proteidae + Sirenidae.

finual. The Asiatic or Eastern P'alaearctic sub-region assumes the central position, at least from a merely geographical point of view. It would be unjustifiable to assume a spreading from this centre into Europe, and, on the other hand, into Imerica. The centre existed more prohably in the Arutic circle, now devoid of L'rodela.

So far as mere numbers of species are concerned the huge Asiatic or Eastern Palaearctic region is the poorest, hut it is also the least explored, and China will prohably yield a good many new forms. Te know at present only 15 species, nearly all from the eastern half. These 15 species represent no less thim 11 genera, 8 of which $(=73$ per cent) are peculiar to the sul-1egion. Text comes the Western Palaearctic or Europenn sub-region with about 21 recent species of jo genera, 4 of which are peculiar. America is by far the richest, with no less than (i6 species (36 eastem, about 16 western, and the rest Central American, etc.), belonging to 19 genera, 17 of which $(=90$ per' (ent) are peculiar to the New World. But this richness in spereies is dne mainly to the abundance of the two genera fimblystomu and 'yeleppes, just as Europe is characterised hy its many Tritons.

One of the most striking features of the Asiatic sub-region is 
its ditterence from the Eurojeatn. They have very little in

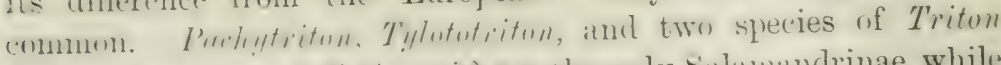

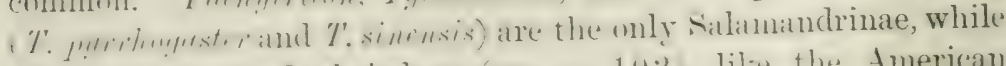
all the rest atre Lechriedunt isen l'. 102. Sike the American

(ifocilaphical Distribution of the Urodela

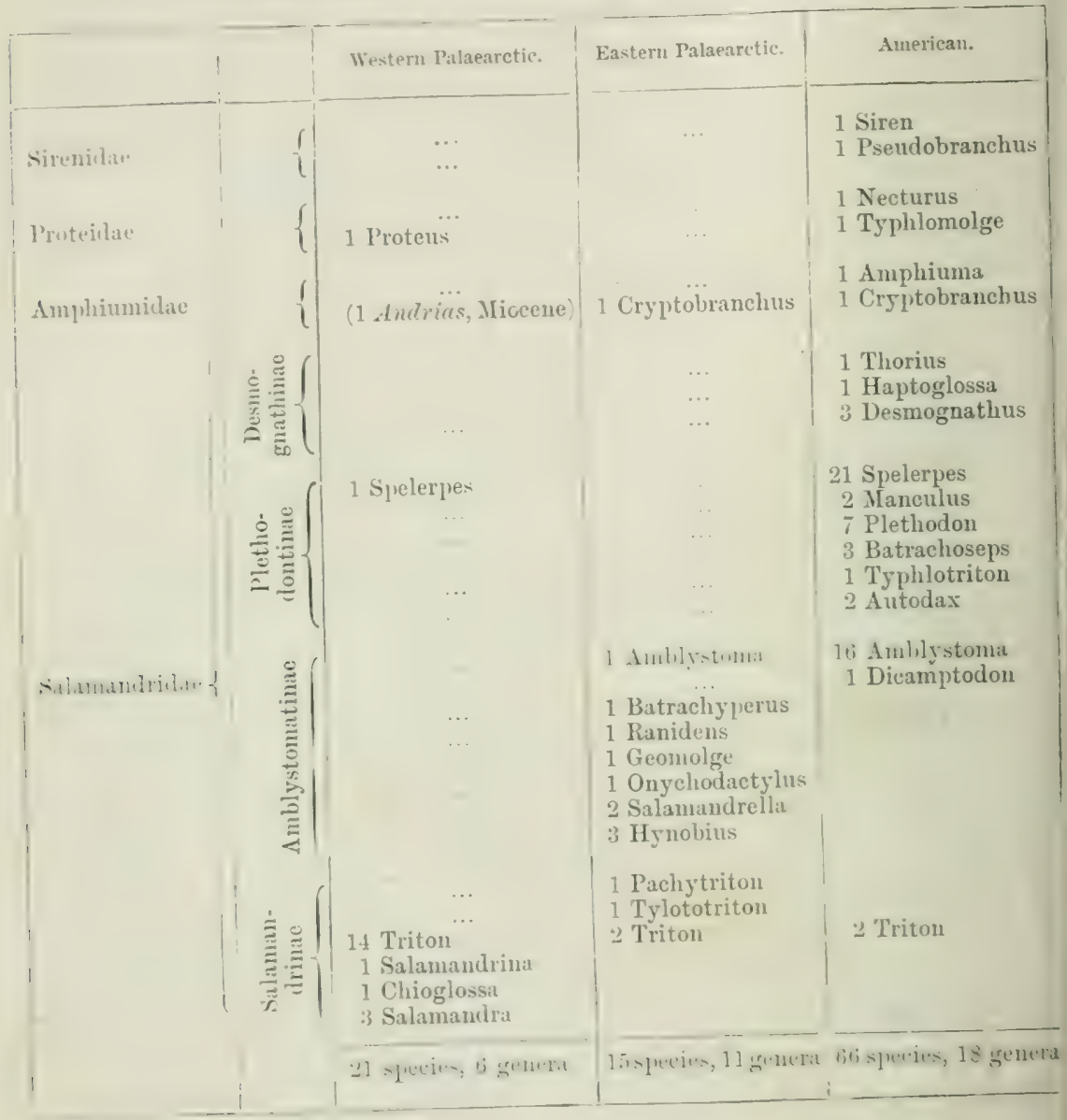

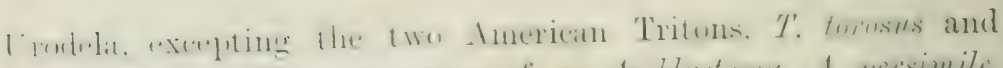

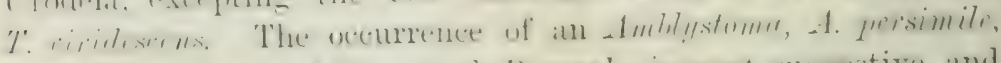

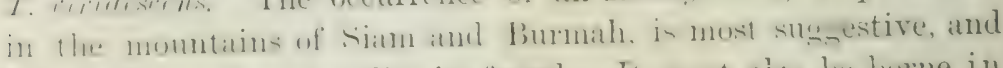

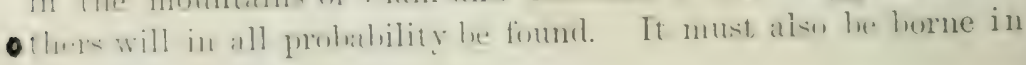


mind that the differences between the genera of Amblystonatinate are in reality very slight: and the same applies to the sul; finnilies themselves. The presence or absence of teeth on the parasphenoid, the possession of amphi- or opistho-cotlons vertebrae, do not mean much, and certainly does not forbid the notion that all the recent Urodela are the offspring of one common generalised stock which inhabited the northern portion of the globe. Nothing is gained by hiding the solitary European species of the essentially American. genus spelerpes under the name of Geutriton. It is a Spelerpes in all characteristic points. Speaking broadly, each of the three principal sub-families of Salamandridat is characteristic of a sub-region; the Salamandrinae of the Western Palaearctic, the Plethodontinae of the American, while the Amblystomatinae are chiefly Asiatic, at least so far as diversity of genera is concerned.

Fam. 1. Amphiumidae.-Without gills in the perfect state. The gill-clefts are in a vanishing stage, being either reduced to one pair of small holes or being altogether absent. The maxillirry bones are present. Teeth occur in both jaws; those of the romer's form transverse rows. The vertebrae are amphicoelous. The fore-limbs and hind-limbs are present, but small. The small eyes are devoid of lids.

This family is now represented by two genera, with only three species, found in the United States and in Eastern Asia.

C'ryptobranchus. - The limbs are functional, with four fingers and five toes. The outer digits and the sides of the limbs are bordered with folds of skin. The head and body are stout and depressed; the tail is short, laterally compressed, and provided with a fin. The skin is very glaudular and slimy, and forms a thick, irregularly-shaped fold along the side of the body.

C. (Hrnopoma) alleghaniensis.-The gill-clefts are normally reduced to one pair, individually to the left cleft, the right closing up. There are, however, four hranchial arches and ressels. The general colour is brown or grey above, sometimes with darker patches, lighter below. The "Hellhender" reaches a length of nearly 18 inches (about $46 \mathrm{~cm}$.), is entirely aquatic, and is apparently restricted to the rivers and streams of the mountainous districts of the Eastern United States. It is very voracious, hving on worms and on fish, being much disliked ly the fishermen, as it takes the angler's bait, and destroys great 

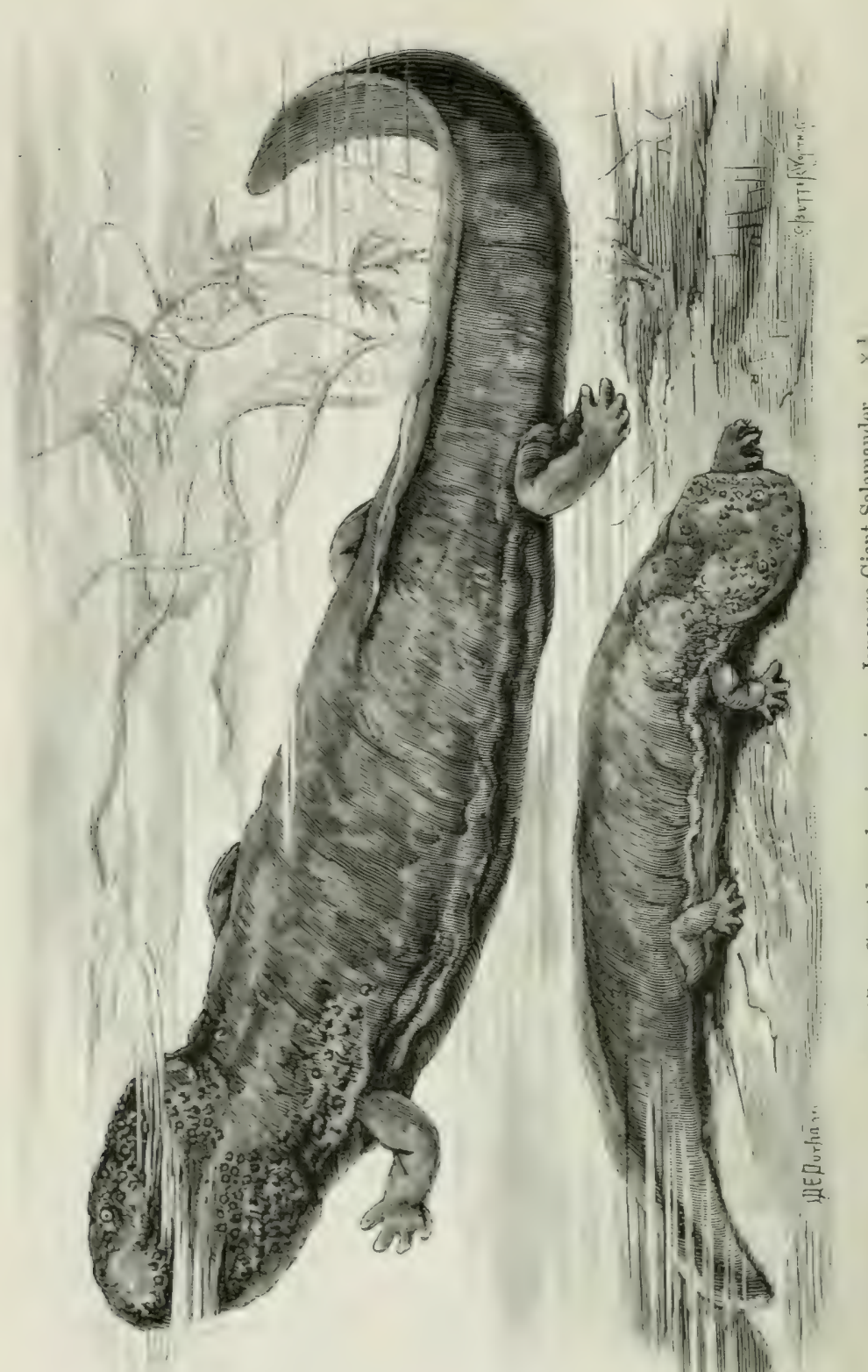

$\therefore$

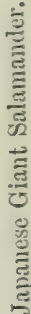

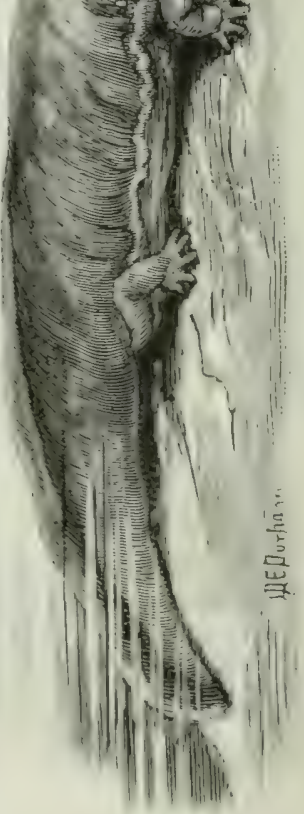

בัב 
quantities of the valuable food-fish Coregonus albus. Although rather common and easily kept, its larrae still remain nmknown.

C. japonicus s. maximus.-The Giant Salamander of Japan differs from its American relation in one essential point only, namely, by the absence of gill-openings and of the modifications of the branchial apparatus connected therewith. It has but three branchial vessels, and the skeletal arches are reduced to two. It lives in Japan and in China, from 600 to 4500 feet above the level of the sea, in small streams of mountain-meadors. It feeds upon fishes, Amphibia, worms, and insects. It is easily fished with the hook and is eaten by the Japanese.

The first living specimen was brought to Europe in $1829 \mathrm{by}$ Th. ron Siebold, its discoverer. It grew within a few years from 1 foot to 3 feet in length, and died in 1881, at least fifty-two years old. Another specimen lived in the Hamburg aquarium for fourteen years, during which time it is said to have grown $36 \mathrm{~cm}$. (more than 14 inches), having attained a length of nearly $\frac{1}{2}$ feet, or $134 \mathrm{~cm}$. The largest specimen known measures 159 $\mathrm{cm}=5$ feet 3 inches.

The life-history of this species is still imperfectly hnown. Japanese picture-books contain drawings of the adult and of larvae, the latter showing three pairs of fringed external gills. Ioung specimens of $16 \mathrm{~cm}$. length have already lost the gills, but still retain a cleft on either side of the neck, in the shape of a horizontal slit, and this is soon after closed up lig the skin.

The best account has recently been given by Sasaki. ${ }^{1}$ Accorting to him the Giant Salamander leads a solitary life, concealenl in dark places, under rocks in swift-flowing, thickly shaded small brooks of clear and cold water.

The animal may be easily captured with a fish-hook, haited with a fish, frog, or several earth-worms, and tied to a string a few feet in length. This is thrust by the aid of a small banlioostick into the salamander's retreat. The string is not tied to the stick, but the point of the loaded hook is forced into one end of it, far enough to keep it in place while this end of the rod is pushed under the rock. When the bait has been thus lirought near the salamander, any bite will be instantly felt through the 
rul. The litter is then withriawn at quictly as possible, the hook and hait leeiner left. As soon as a ferk of the strine is moticenl, a gull is mathe. Which gemerally ems in the capture of the unfortunate animal. If the first pull shomlel firil. the hait is

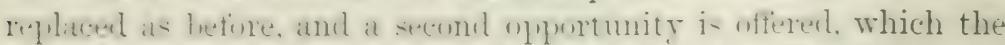
mwary creature accepts as readily as the tirst. The fisherman, having ulatinel whe hite, is sure of ultimate sucess, ats the salatmonder ines not learn hy experience to refinse the proffered monsis. When cafturesl. it enits a pestuliar sliny secretion, having an whore mule like that of the leares of the Japan

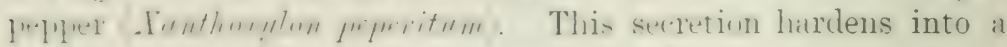
gelatinous mass after a short exposure to the air.

Temminel and schlenel state that the aret of inspimation is arlinarily gerforment once every ti-10 minutes. This is true fin specinens kent in tuls: lint sasaki is inclined to think that they gerfim this atet less fietuently in their native brooks. The eyes ate sis sulall that they are obrinusly of little importame: the salamanters capture their prey not hy jursuing, hut hy wating for its near appordh. wheremun they seize it with their teeth hy a swift lateral nowement of the head. The egg: are said to le latil in August and september, and they form a string resembling a rosiry. Fach esy flots in a clear fluid, inclusel in a bead-shaped crelatinous entelope, and this is connectml with the next hy means of a comparatively small string. The egg measures about $6 \mathrm{~mm}$. by $\pm \mathrm{mm}$, and is yellow erergwhere exrept at the uples prole. where it is whitish. All

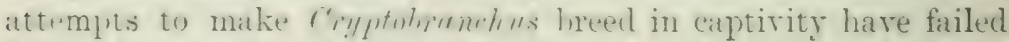
hithertu, owing ne deuht to the difticulty of oldaining the cool temuperature of its momntain streams. Silsiki's smallest specimens neasured 19 to 20 ('m. These hal three pairs of very short lranchial processes from :; to i mm. in lemeth, attached just indide the branchial orifice. Barh process was somewhat flattened and tapering, must of then still with hranchlets. In another speeduen, 2075 cm. in leneth, the gills had almost wholly disappeared, but the branchial slits wres still risible. lowe of 24\% an. length shower no trace of gills, and the liranchial wrifice was completely clusen, lut still marked hy a light streak.

Amphiuma meuns s. tridactylu. The limbs are very much relucenl, and end in two or three little timere or toes. Just in 
front of the fore-limbs lies the pair of small gill-clefts, each gnamed hy two thass of the skin. There are four branchial arches. "The general colour of this eel-shaped creature is hlack, lighter helow. The head is covered with numerous pores, arranged in s.remal rows, which unite in the region of the neck, so that only two rows extend along the sides of the body. It reaches a length of three feet, and lives in swamps or muldy waters.

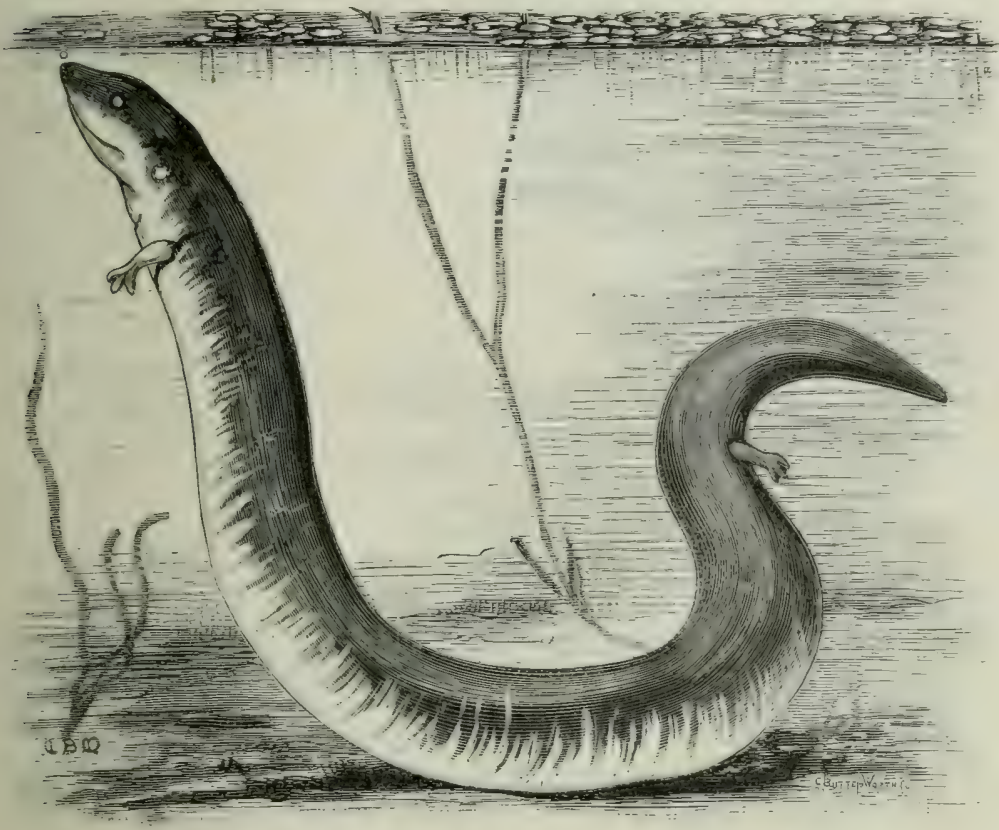

FIG. 18. - Amphiuma means. $\times \frac{1}{6}$.

for instance in the ditches of rice-fields, burrowing occasionally in the mud, feeding on crayfishes, molluses, small fishes, etc. It is ('miined to the south-eastern States of North America, from Cambina to Mississippi. Aceording to Davison, copulation takes place in May. The rather hard-shelled eggs are dejosited in the following August or Septemher, and are connecterl by a twisted (mil. The female lies ahout them in a coil. The embryos, which we hatched in the month of Novemher or Decemher, have wellleveloped external gills. By the following felmumy they have

1 J. Morphol. xi. 1895, p. 375. 
reached a length of from 68 to $90 \mathrm{~mm}$. (ahout :3 inches), living in clamp, lucalities under rocks or rooted stmmps, and have already lost their wills. The legs are said to he relatively longer than they are in the adult.

Fam. 2. Salamandridae Salinuanclers and Newts, - Without frills in the jerferet state. Maxillaries are present. Both jaws are firmished with teeth. The eres are protecterl by movable lids, except in Typhlotiten. Fore-and hind-limbs present, although sometimes rery much reduced.

To this family helong he far the greater number of tailed Amplibial. They have heen, for the sake of convenience, grouped into four sultianilies. the determining characters of which are all intwnal and of complatively slinht inportance. Little better is

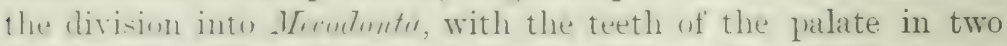
longitulinal rows liverging hehind and inserted nom the inmer

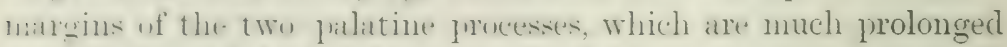

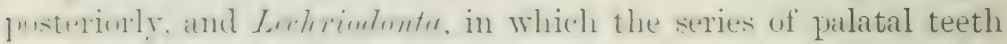
atre restricted to the postering portion of the vomers and form either transverse or posteriorly converging rows.

I. Series of palatal teeth transverse, restricted to the posterior portion of the romers. Parasphenoid beset with dentigerous plates.

Vertebrae opisthocoelous: Desmognathinae, p. 102. amphicoelotis: Plethodontinae, p. 103.

II. Series of palatal teeth transverse or posteriorly converging, restricted

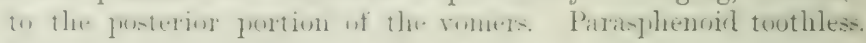
Vertebrae amphicoelons: Amblystomatinae, p. 109.

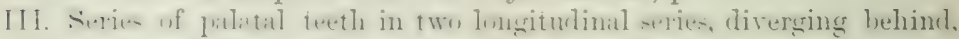
inserted on the inner margin of the long palatine processes. Parasphenoid toothless. Vertebrae amphicoelous: Salamandrinae, \}). 115 .

Sub-Fam. 1. Desmognathinae-Comprising mly three genera, with five species, in North America. Five toes.

If simunumblis.-The tongue is attached alonge the median line. free lwhind, wral in shape. Three speres in the easterm

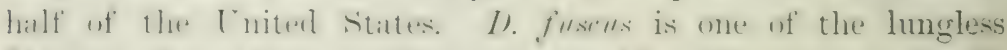
Comlelit, fon which condition see 3 . th. The skin is nearly

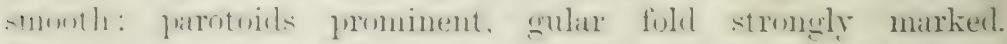

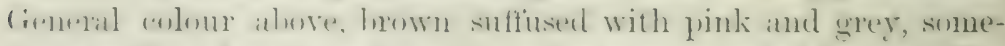
liness with a dark lateral band: under parts mottlesl hrown. The

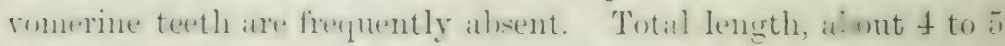
inches. They live, carefully concealed in the daytime, under 
stones in or on the edge of the banks of little mountain streams. The eggs are laid in two long strings, and are wrapped round the hody of the female like a rosary, the female having resorted to a hollow in the mud, below a stone or other suitable place. The outer envelope of each egg tapers out into a short stalk, and the sereral stalks all converge, or are glued together into one common knot, "much like a bunch of toy halloons held in the hand of a street vendor." The egg is said to be meroblastic. The. larrae seem to remain in the egg until they are nearly adult, and they emerge at midsummer, with the gills already much reduced. The complete metamorphosis takes place in the autumn of the same rear. These little newts FIG, 19.- Desmomathus, fuscus: female with egrss can, according to Wilder, ${ }^{1}$

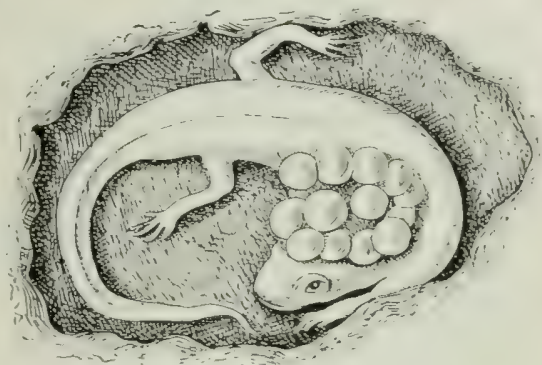
be collected all the year round, in Massachusetts from March to December, except during the time of deep snow. They art? nocturnal and are easily kept.

Thorius pennatulus, from Orizalua, Mexicu, the only species, is noteworthy for its extremely large nostrils, and for the tongue, which is supported hy a central pedicle, free all round, and ending in a thick knoh, which can probably be protruded. The limbs are weak, and the digits are also much reduced. Total length, under 2 inches, or $50 \mathrm{~mm}$.

Typhlotriton spelacus, of the Rock House Cave in Missouri, is lind, the eyes hecoming concealed hy the skin during metmorphosis, when the gills are lost.

Sub-Fam. 2. Plethodontinae.-The five genera of this almost entirely American sul,family (only one species of which, spelerpers fusers, occurs in Europe) can be distinguished as follows:-

I. The tongue is attached by its central pedicle only, is free all round, ends in a soft knob and can be shot out to a considerable distance.

With 5 toes: Spelerpes, p. 104.

With 4 toes: Manculus, p. 106.

1 Amer. Natural. xxxiii. March 1899, p. 231. 
II. The tongue is attached along tle middle line and cannot be protruded out of the mouth.

Jaws with numerous small teeth.

With 5 toes: Plethodon, 1) 106.

With 4 toes: Batrachoseps.

Maxillary and mandibular teeth few in mumber but very large

With 5 toes: Autodar, n. 107.

Spclorpes. - Except in a few species the limbs are well de-

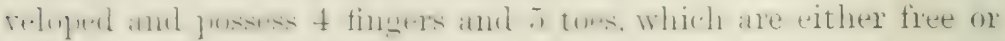
reblued. But in the Colombian S' parripes, still more in $S$.

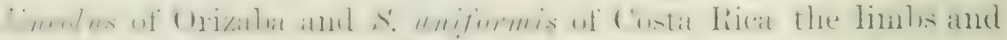

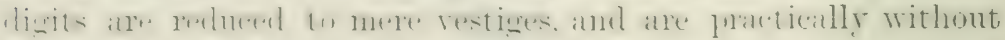

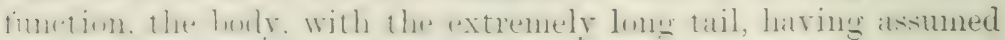

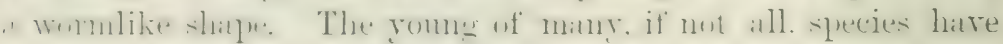
a pair of short balancers below each nostril; ' in the adult

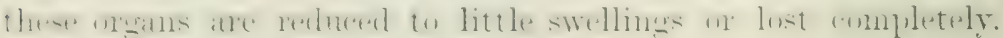
Sereral species are lungless, see p. 46 .

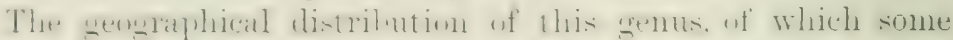

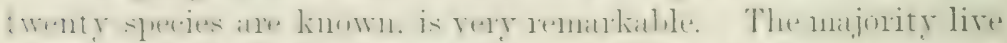

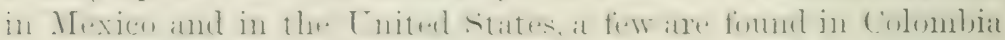
and Northern T'eru (S'. altumuzonious and Plethodon platense

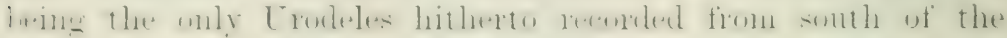
erpuator), one in Hayti (S. infuscatus), two (S. subpalmatus and S. uniformis) in Costa Rica, and S. fuscus in Europe.

S. Tilineatus is a little newt under \pm inches in length-60-95

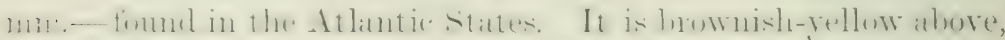

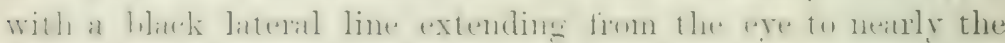
end of the tail. 'The under parts are bright yellow. It lives on

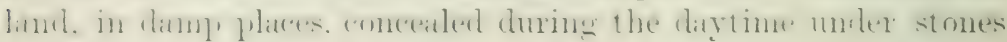
or old trees, whence it emerges after a rain or in the dusk of evening.

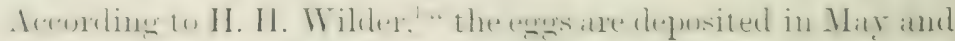

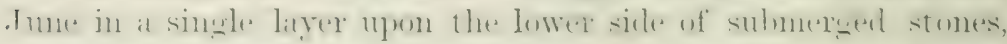
each batch containing 30 to 50 eggs. The stones which are

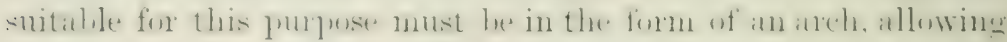

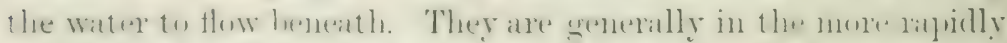

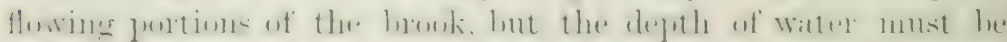

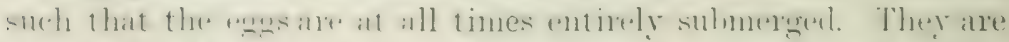

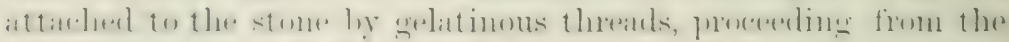

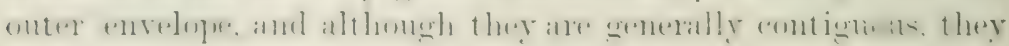


are each attached separately." The eggs are holoblastic. The larvae hatch early and continue for a long time in the lanvil state, probably two or three years.

$\therefore$ prophlyriticus s. sulmoncus.-Yellowish-hrown or purplisharey abore with tiny darker dots and markings. The sides of the hody are salmon-coloured, with a tinge of yellow. The muder. larts are whitish, turning into salmon-pink on the tail. This leatutiful newt reaches about 6 inches in length and has a rely moist, sliny skin, which, combined with the lively motions it the creature, make it as slippery as an eel. It is found in the Alleghany range, from New York to Alabama.

specimens which I am keeping prefer the wettest prot of the cage, where they lie concealed in the moss and mud, leaving their hiding-places at night in search of insects. One of them escaped into the greenhonse and was discovered after nine months. having established its permanent home in a cleft between mossy stones: when the sweepings of a butterfly-net are emptied near its hidingplace it pee'ps out and with a flash of its long, forked, whitecoloured tongue it secures its prey. Oecasionally it gres into a tink, when it swims with rapid, undulating motions, the linh s: heing laid back and remaining inactive: it sometines rises to the surfice to emit and to take in air, but, although mostly resting lialf in the water, upon a rotten stump, it often lies for lwur's at the bottom without stirring. When kept in dry surromelings. the skin soon dries and wrinkles, and the animals show erery sign of suffocation and general disconfort. The respiration if this lungless species by means of rapid morements of the throat is very limited, most of the necessary oxidisation of the hloud being effected through the skin.

$\therefore$ fuscus - This, the only European species, is thoroughly terrestrial. It is found in the mountains bordering the Gulf of (ienva, and in Sarlinia. Its total length remains under four inches. The smooth, rery delicate and easily broken skin is brown above, light below, and speckled with lighter and dirker markings. Below each nostril is a slight swelling, the remmant of the cirri or balancers common to the young of many species. It lives in shady surroundings, under stones, in old trees and in limestone-caves, glued to the walls with spreal-out toes, helly and tail, quietly waiting for insects and spiclers which it catches by flashing out the long tongue. 
Accurding to J. Bere, it lieeps well in conol, moist and wellrentilaterl placess. It lives on flies, small beetles, and maggots: ants are also taken at once, probably owing to their lively morenents. Gut a few minutes later the newts roll about in splisuns and soon die. Towarts the end of March one of Berg's specimens save birth to four young, which were : 6 inm., or nearly

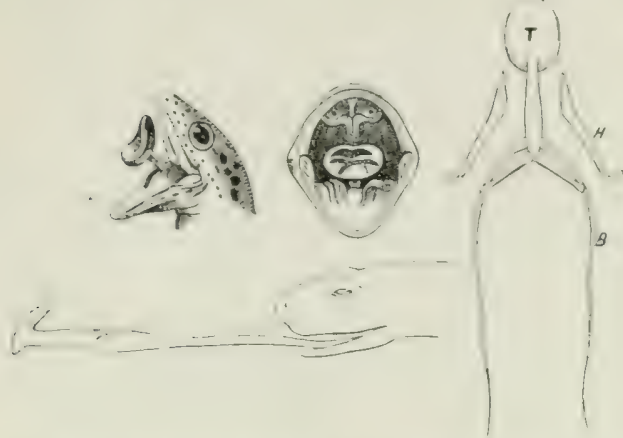

Fig. 20. - Sppelerpes fuscus, showing the position and shape of the partly and fully protruded tongue. The figure on the right side shows the tongne and the skeleton of the hyoid apparatus. $B$, the threadlike, elongated, first branchial arch ; $H$, hyoid, in reality attached by its outer enil to the vicinity of the quadrate; $T$, tongue. About $\times 2$. (After Berg and Wiedersheim.)

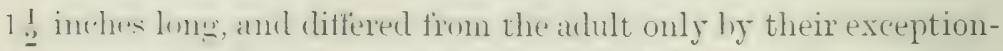
ally-latwe nustrils, therely resembling the Mexican Thorins. The little ones shot out their tongues alwent 10 mun., fexeling on Aphides.

Mrremlus.-The two sprecies of this genus live in Carolina and

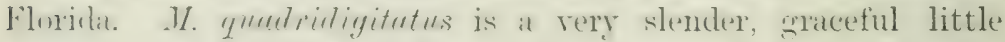
animal. almot :; inches in length, the long and thin tail being considerably larger than the rest of the body. Yellowish, minutely speckled with hown above and on the sides, greyishwhite below. Life entirely terrestrial.

Plethodon.-About seven species in North America. This gonus has given its names to that of the subfanily, which might with more reason be called Spelerpinae.

I. glutinusus is slaty or lilush-lidack, with small whitish speetis, espeedially on the sides of the trunk, where they are large and often comfluent. The skin is smosth and shiny. Total length ilume is inclues, half of which belong to the tail. Hollorook "onsirlerent this ats one of the commonest of the North Anerican IIIWts: and mostly widely distrihuted, from Ohio to the Gulf of Mexion. It usually lives concealed under stomes, but preferes finllen treses, probahly on aecount of the insects upon which it 
preys. When taken in the hand it gives off a great quantity of slime.

P. erythronotus extends into Canada and is much smaller. Brown or grey above, mostly with a broad, reddish-brown hand over the head, back, and tail. The under parts are white, with grey and brown specks.

Autodax s. Anaides.--The large tongue is attached along the median line. The jaws are furnished with few, but surprisingly large, knife-shaped teeth, about ten in the upper and fewer in the lower jaw. The small teeth of the vomers form a chevron-shaped series behind the choanae, those of the parasphenoid stand in one elongated patch. The tail is round; number of toes, five. Three species in Western North America, from California to Oregon.

A. lugubris. - The eyes are very large and prominent. The upper jaw shows a peculiar recess on either side for the reception of the large lower teeth. The skin is smooth, devoid of parotoirl glands, but has a strong gular fold. The upper parts are dark brown or lead-coloured, with whitish dots on the sides; under parts white. Total length some 6 inches, about half of which belongs to the tail. The fingers and toes are very rich in subcutaneous venous sinuses.

The habits of these creatures are in many respects peculiar. Van Denburgh ${ }^{1}$ says of $A$. iecanus " that it usually moves quite slowly, moving one foot at a time, but is capable of motion surprisingly rapid for a salamander. When moring rapidly, it aids the action of its legs by a sinuous movement of its whole body and tail. The latter is prehensile. Several indiriduals, when held with their heads down, coiled their tails around my finger, and, when the original hold was released, sustained themselves for some time by this means alone. One even raised itself high enough to secure a foothold. This animal's tail is also of use in another way. When caught, it will often remain motionless, but if touched, will either rum a short distance with great speed, or quickly raising its tail and striking it forcibly against the surface on which it rests, and accompanying this with a quick motion of its hind-limbs, will jump from four to six inches, rising as high as two or three."

Ritter and Miller ${ }^{2}$ have made extensive observations on the lifehistory of $A$. lugubris. When wishing to pass from the hand to ${ }^{1}$ P. Calif. Ac. (2) v. 1895, p. 776. 2 Amer. Natural. xxxiii. 1899, p. 691. 
the table, the creature will freduently execute a well co-rindinated spring and alight on its feet sume distance anwy insteat of filling wer the extge in the typical salimander-fithindi. This speries is nocturnal and entimely terestrial, and seems to be indifferent even to proxinity to water. lioten stunpss and logs are the habitations preferred, and wherever these werm in the

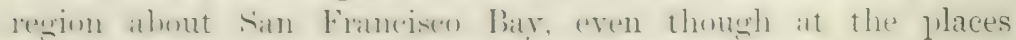
remotest from water, specimens are sure to be found.

The eges are laid in a hollow muler gromol, and the timale

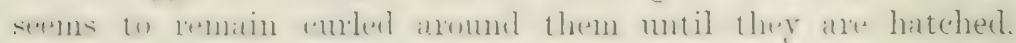
which takes filate in two or three weeks. The specinen obsered

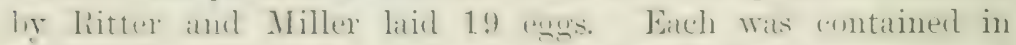

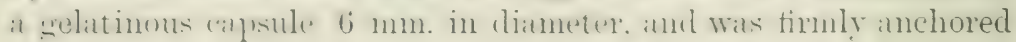
to a clump of earth by a narrow peduncle about $8 \mathrm{~mm}$. long.

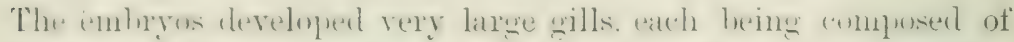

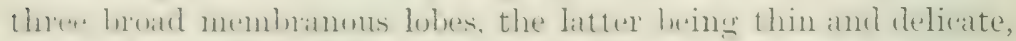
moneh expanderl, highly visculan and whely conthent at their

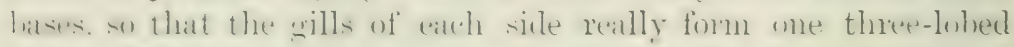
mas. Their dersal surfaces are alplied to the inner surface of

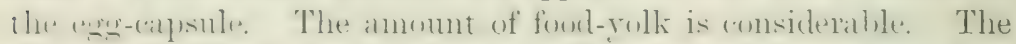
whole latral life is passed through within the ang: Before the

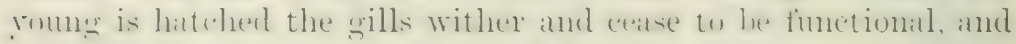
the gill-slits elose 11 . The tail is romel, and shows no indioatim of a fin alt any time during the larval pertoul. Xesly hatched individuals alpeared much distressed when jut into wilter, and were quite unable to swim. They immediately sank to the bottom and remained there until they were removed. The integumentary semse-organs, so woll developed in the andlatic

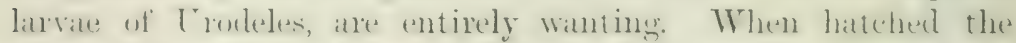
young creature is about : $: 2$ mm. long; its general colom is blakish-ney, finely sprinkled with bluish-silver. lnuring the

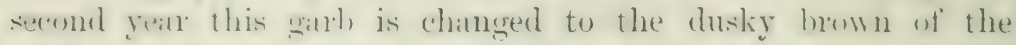

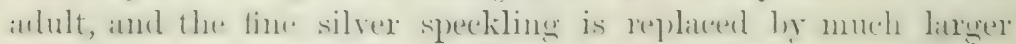
and less numerous yellow spots.

Although one of the most terrestrial of C'roteles, this speectes is hugless, but the skin remains delicattely smooth and nodst thromghout life. Anembling to the olservers quoted, the pharyox plitys an important part in respiration. From $1 \geq 0$ to 1 ș men more viluations are made for the throat in a minate, and in solne cases these movements are prouped into series of alunt 
20 to 25 extremely ripid ribrations, with periods between each two series.

Subfam. 3. Amblystomatinae. - Composed of seren (denely allied genera, the distinguishing characters of which are the grouping of the palatal teeth and the number of the toes, which raries between 4 and $\pi$. The geographical lauge of the subfamily extends over the whole of North America amul Mexico and over the whole of Northern Asia, from Kamtchatla and Japan westwards to the Lral, and southwards into China. The vecurrence of one species, Amblystoma persimile, in the mountains of siam, makes it highly probable that other species and genera exist in the hitherto unexplored intervening countries.

Boulenger gives the following synopsis:-

I. The series of palatal teeth converge backwards, forming a V-shaped figure.

With 5 toes: Hynobius, 3 species in Japan.

With 4 toes: Salamandrella, 2 species Lake Baikal, Ussuri and Schilka rivers, and Kamtchatka, p. 109.

II. The series of palatal teeth form an uninterrupted, doubly arched $V$-shaped figure.

The 4 fingers and 5 toes are furnished with black, horny claws: Onychodactylus japonicus.

III. The series of palatal teeth form two arches, convex forwards, separated by a wide interspace.

The two series are short, confined to the space between the choanae.

With 5 toes: Ranidens sibiricus, Eastern Siberia and N.E. China.

With 4 toes: Batrachyperus sinensis, Moupin in China.

The series are long and converge backwards, 5 toes: Dicamptodon ensatus, California.

IT. The palatal teeth are arranged in a nearly straight, transverse line, or they form an angle which points slightly forwards; they are not separated by a wide median space. With 5 toes: Amblystoma. Some 16 species in North and Central America, one in Siam, p. 110.

Salumundrella keyserlingi.-The mode of propagation of this newt-like species has been observed by Shitkor near Jekaterinburg in the Ural mountains. The eggs were laid at the end of April and were deposited in bags, which were attached to a plant, with one end about an inch below the surface of the witter. The bag measured $15 \mathrm{~cm}$. in length and $2 \mathrm{~cm}$. in width and contained 50 to 60 eggs. The larvae were hatched in $1 \pm$ days in a sunny aquarium; in another with a northern 
aspect the hatching touk $2: 3$ ditys. The latrate were 10 1nm. Jong, and remarkible for the length (1 mmo.) of their halanees.

Amblystumu "furenm. - The general shatre is very much like

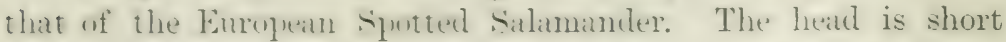
and broad, the swout is rounded. The eyes are very prominent, with a black pupil and a dark-srey iris. The neck has a well-market sular fuld. The tail is thick aml almost romul.

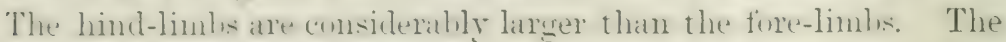
arenemal colonr of the shing, moist skin is a jurplish-lilack with light grey. thanswerse partly conthent hars, giving the creature

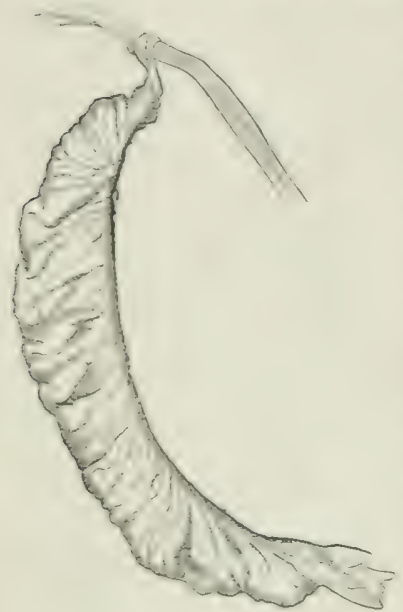

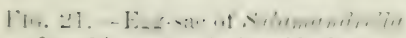
schrenki. $\times \frac{1}{2}$. (After Shitkow.) a pretty appearance; the under parts are paler, bluish-grey. Total length between 3 and $t$ inches, or $9 \mathrm{~cm}$.

This beautiful species inhabits many of the United States east of the Rocky Mountains, from New Jersey to Florida and Texas. In the perfect state it is thoroughly terrestrial and easily liept. My specimens prefer the holes of rotten and moist, moss-covered stumps, or holes beneath stones, which they leave, at night only; in search of earthworms and insects.

A. talpoideum is closely allied, somewhat stouter and almost uniform bromish-back. Aceording to $\mathrm{Hol}$ brook, "it chooses light soil in which it will bury itself in a few seconds like a mole, and there continne

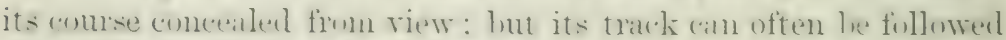
ly the elevation proinged on the surface of the suil. similin to that seen in fields infested by moles."

1. funtertum is huish-hatk, with a row of romelish yellow sputs on eateh side of the loody and tail and upon the linuls.

E. A. Antrews ${ }^{1}$ has mate olservations upen the heesting of this species. Tear Paltimore the ewors are rery abmelant in Marth and exen in Felmatry in small pools in the worls. hut Ilst arlults are then ratrely soen. Even when small pools. but

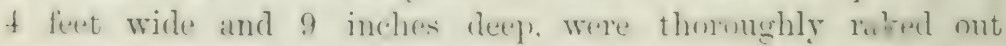


before and after the eggs appeared, no adults were found, so that it is to be inferred that the laying takes place in the night and that the adults leave the water every day to conceal themselves under stones. One female was found moving away from a bunch of eggs early in the morning. This specimen was kept isolated, and laid many eggs, and as these dereloped into normal larvae, the existence of internal fertilisation was proved. Previously to the laying of the eggs white spermatophores were found in the small pools, on the dead twigs and leaves covering the bottom.

A. jeffersonianum.-This very slender and slippery species, reaching a length of 6 inches, is remarkable for its long fingers and toes, and its rather compressed tail. The general colour is brown above, dirty whitish below, generally with numerous, small, light blue and pale brown spots on the sides of the neck, body, limbs, and tail. There are several colour-varieties, one of them with white specks. It is a very active and surprisingly good climber, easily uscaping out of high-walled bell-glasses, hiding in the daytime in dark and moist localities. Its range extends from Indiana and Virginia to Quebec.

A. persimile. This species is remarkable on account of its geographical distribution. It is the only non-American species, inhabiting the higher mountains of Siam and Upper Burmah. There is no doubt about its belonging to the genus Amblystomm, although it had originally been described as a Plethordon. It closely resembles $A$. jeffersonianum in most of its characters, notably in the arrangement of the palatal teeth, general proportions, slender toes, and even in the presence of whitish spots, which are scattered over the sides of its blackish, smooth skin.

A. tigrinum.-This, the commonest species, is conspicuons for its large, depressed head, which is as broad as it is long, its width being enhanced by the unusually large parotoid glands. The mouth is very wide. The large, prominent eyes are golden, and reticulated with brown. The gular fold is strong. The limbs are stout, the fingers and toes short. The trunk is strongly constricted by twelve intercostal grooves. The tail, which is as long as the rest of the body, is somewhat compressed laterally, but bears no trace of a fin. The general colour is more or less dark brown or bluish black, marked with numerous rellow spots and large blotches; the under surface inclines to 
grey. The length of the adult male is about half a foot; the fimales, ats usmal heing larerer, smetimes reath the length of 9 inches. The range is from New Jork to California and to Central Mexico.

The larva of this species is the famous Axolotl. It is

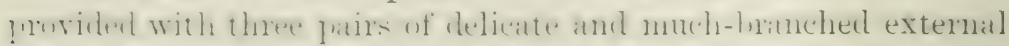

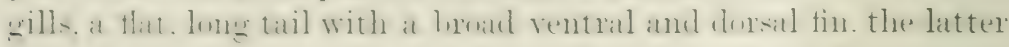
extending along the back almost to the neck. The limbs, although andratatively slenter. are fully developed. and the heal

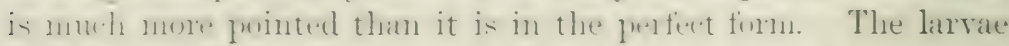
n-1nally reach s or at inches in length: exceptimal specimens

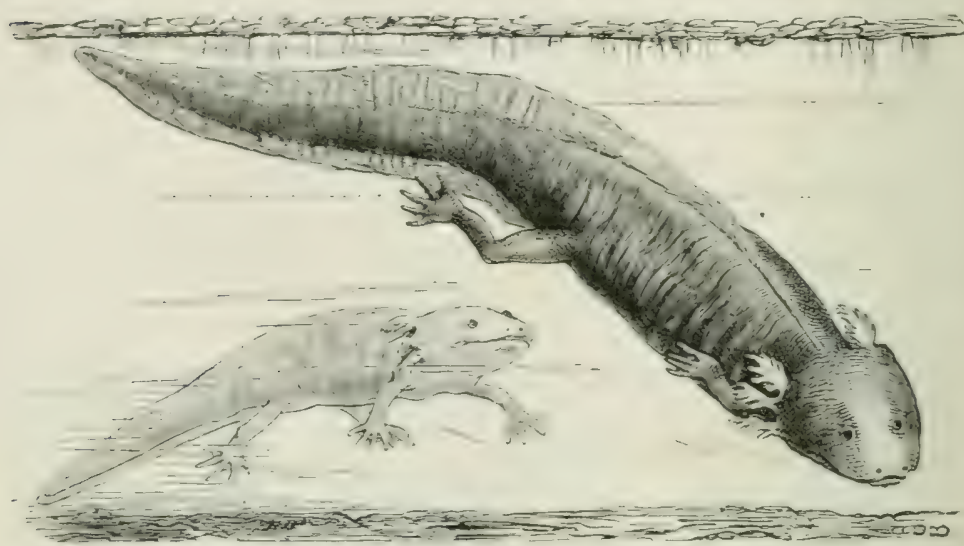

FIG. 2.2. - Axolotls or larwe of Amblystoma tigrinum. $\times \frac{1}{1}$.

larre henen reconded of one foot in length, aml have leeen described as l'riton ingens.

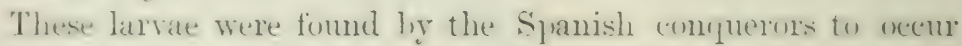
in sreat numbers in the lakes near Mexico ('ity, ant were callent Axulnt ly the natives, a word signifying " lilig in the water:" Thery were, and are still, eaten, either loasterl on boiled, with vinegar or cayenme pepper.

For many years these creatures were looked upon as a

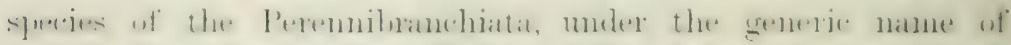
Sircalon (s. axolotl, s. pisciformis, s. mexicanus, etc.), although curier susperted that they were hut the larvate of ath otherwise

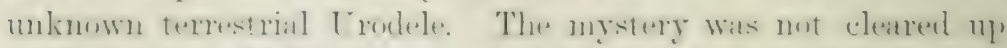

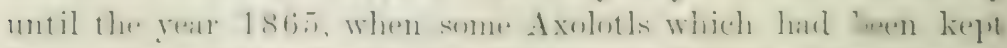

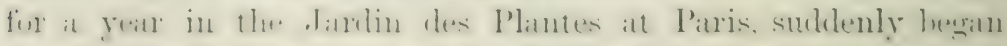


to pair, and laid eggs which within six months dereloped into full-sized Axolotls. This certainly looked as if these creatures were not larvae, but a true Perennibranchiate species. But to the general surprise several of these young Axolotls gradually lost their gills, the clefts closed up, the fins of the back and tail disappeared, the head became broader, the crealtures left the water permanently, and in fact turned into the already well-known terrestrial Amblystome tiginum. The other brothers and sisters of the same brood remained aquatic Axolotls, which thereby revealed themiselves after all as the larval and not as the perfect stage of this remarkable species:

At the suggestion of Kolliker and Weismann, Frl. Marie von Chauvin ${ }^{1}$ undertook, at the University of Freiburg, long and carefully conducted experiments, showing (1) that little Axolotls can comparatively easily be caused to develop further into the perfect Amblystoma if they are induced to breathe air more frequently than usual; shallow ressels, perhaps also insufficiently aerated water, will produce the desired result: (2) that the commencing metamorphosis can again be cheched, the shrinking gills then undergoing fresh development: (3) that they can be forced to remain Axolotls; (4) that the cutting off of the gills has no influence upon their possible metamorphosis, the gills being easily and quickly renewed. The same lady found also that Amblystoma, the perfect form, lives in the water during the pairing time and behaves in the same way as the Axolotls.

The latest observations have been made by Metzdorff." Axolotls, at least those which are kept in captivity in Europe, are ready for propagation several times in the year, either in the spring, from April to June, or in December. The male deposits spermatophores, which in the following night are takeu up ly the female into-the cloaca. On the following day, preferably in the afternoon, she grasps a suitable leaf, for instance that of Tallisneria, with the hind-limbs, and presses it against the rent. The eggs are expelled by strong wriggling movements of the body, and are formed into three or four packets of six to ten exgs each, so that about thirty eggs are laid at one sitting.

${ }^{1}$ Zcitschr. wiss. Zool. xxvii. $18 \pi 7$, p. 522 ; xli. 1891, p. 365; Zoot. Anz. 1882, p. 513.

Zooloy. Garten. 1896, p. 114.

VOL. VIII 
Then she takes a rest hefore proceeding again: the whole process, in which the male takes no further interest. lasting about two days. The most suitalile temperature is one uf $18-200^{\circ} \mathrm{C}$., or about $68^{\circ} \mathrm{F}$. The water must he well aeraterl. Sterile egres turn white on the secomb day. The little larve are hatched in about a fortnight. Eugs which are kept in a higher temperature, from 2-2-24 ('., levelog nure quickly, lut the resulting yomg are smaller: they show alrearly wn the tifth day head, tail, and the besinning of the gills. Accorling to Bedriagat, they live at first upon Infusoria and Jnphlin: when they are 20-25 mm. long they eat Tuhifor rirulurmm; later on they take scrapred meat and are liable, when hungry. to nibble off each wher's gills. hut these are easily reproduced. Trhen $20-25 \mathrm{~cm}$. long, at the age of about six months, they are able to breed. The chief print of interest is the fact that this species of Amblystomu frequently remains throughout life in the larral state, except that it develons cenerative organs. The natural causes of this retention are not completely known. According to Shufeldt, who olserved them unler natural conditions near Fort Wingate in New Miexico, plenty of food, the drying up of the swamps, and the increasing temperature of the diminishing water, hurries on the metamorphosis, while deeprer water retards it. Weismann ${ }^{3}$ suggesterl that the specinens in the Mexican likkes which remainer Axolotls were jrevented from hecoming perfect Amblystomats on aceomet of these lakes, after the disappearance of the surromeling forests, having receded from their former boundaries, which ane now covered with a saline, uninhalitalile crust. This may he an explanation, althomgh Axulotls do not live in lnakkish water. Int Weismamn went farther, and with his well-known dialectic powers has succeeded in spreading the belief not only that the Ixolot is a case of reversion to an ancestrit stater, but that the present Amlilystome insteal of being the progressive, perfect form, is likewise a case of reversion. A reversion from a reversion! The whole line of evolution would then be as follows: Amblystome; its young, owing to atverse ciremustaneses revert to the stage of the l'eremibranchiate ancestors of all lerolelat if some of these Axolotls lose their gills

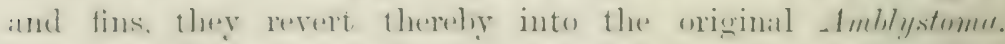

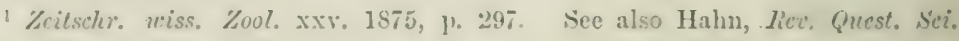
(2), i. 1892, , I. 178. 
Surely a roundabout way of explaining a curious but after all rather simple process of Neoteny; cf. p. 63.

Observations on the metamorphosis of Siredon lichrumids. into Amblystoma marnitium have been made by Marsh, who also gives figures of the larval and adult forms. ${ }^{1}$

Sub-Fam. 4. Salamandrinae.- The six genera of this sulfamily fall into two natural groups: I, True Salamanders, with the palatal teeth arranged in a pair of S-shaped figures, and without a fronto-squamosal, arch. II, Tritons, with the palatal teeth in the shape of a $\wedge$, i.e. the right and left series neet at an angle: the fronto-squamosal arch is present, either bony, or at least ligamentous. Triton ristutus is, however, exceptional, in that the two palatal series often do not meet and that the arch is absent. The number of fingers is universally four, that of the toes is five except in Salamandirina, which has only four.

The geographical distribution of the suh-family, entirely Periarctic, may be said to be the reverse of that of the Amblystomiatinae. Of the twenty-five species namely, only two are American, four are Eastern Asiatic, and of the remaining nineteen, two are Algerian, while the rest live in Europe or in Asia Minor. It is in fact an essentially Palaearctic group.

The six genera can be distinguished as follows:-

I. The palatal teeth are arranged in two S-sbaped curves. Trut. Salamanders.

Tongue short and thick. Salamandra, p. 115.

Tongue long and projectile. Chioglossa, p. 121.

II. The palatal teeth are arranged in a $\wedge$ shape. True Tritons.

With only four toes. Salamandrina, p. 122.

With five toes.

Pterygoids separated from the maxillary and quadrate bones: Triton, p. 122.

Pterygoids touching the maxillae and quadrates. HimaloChinese: Tylototriton, p. 132.

Pterygoids united broadly with the maxillae. Chinese: Pachytriton, p. 132.

Salumandice-Without fronto-squamosal arch. Fire toes. Tail rouml. Three species in Europe and Westem Asia.

S. maculosu.-The spotted or Fire Salamander. (ieneral habit stout. Csual length about 5 to 6 inches; the females are mostly larger than the males; specimens of more than $S$ inches in

${ }^{1}$ Amer. Journ. Sci. (2), xlvi. Nov. 1868, p. 364. 
1.ngth are griants. Hearl as homal as it is long. snout rounded. Limbs and digits stout and short. The skin is smooth, shiny amb full of pures, with a strong gular follt. The parotoid ylamis are large and covered with lange pres. A series of distinct swellings, or cutaneons phonds, eath with a distinct opening. extemls alumer either sile of the batk, amb a shurter series along I the flanks. The general colour of the sintted on Fire-salamander I is hack. with irremular. latge yellow patches on the back and limbs. These markings vary extremely, so much so that scarcely two surinens. collected at randun, are alikis. In some the yelluw patches form two more or less regular hands, in others they are party onfluent: again the yellow may he preponderant on the bark or murh restricted. Ocrasionally the chromerellow is replitced by urange. The muler surface is as a rule hinish prey-lilack. This combination of shiny rellow and black is a good instance of waming colours. The creature is lwismmus. (f. p. B.s. When left in peace. or handled gently, it is perfectly hambless, but when treated with violence, or sulmitted to serere pain, a milky white fluid trutes from the ghands and is, unler violent contrations of the muscular shin and boly, sonetines syuirterl ont in fine jets to the distance of a fimt. IBuming pain and subserpent inflannution result if this puisun gets into the eye. The same applies to the mucous linine of the mouth and throat. A few drops of this poison introduced inter the blesed or inte the stomatch of a small animal anr sutticient to catise its death. Cold-hlooded animals are as susceptible as warm-blooded creatures.

I moce fut two American hull-frogs intu the same outdoor enrhene with a larige number of salamanders. Next morning the hose fross were fombl dead, each haring swallowed a salamander, which they were not acruainted with and hat taken without suspicion.

The Fire-salanamer has a wide range, namely the whole of fintral, sunthern, and Western Europe with the exception of the liritish Isles. It extends sonthwarls into Corsica amb Alegeriar eastwarts through Asia Minum into syria. Where it does oceur it is rather common, provided the terrain is mmuntanums on hilly and anvered with remetation. There it lives under moss or rotten leaves, in the roots of old trees, in the ratks amb elefts of the gmuml, of rucks or of ruins of luildings: 
in default of anything better uncler heaps of stones, or in the holes clug by mice or moles. One chief necessity for its happiness is moisture.

The salamander does not oceur everywhere, but is rather local. On certain kinds of limestone it is raxe or absent: granitic terrain and red sandstone seem to suit it best, for instance the Hartz Mountains, Thuringia, and Heidelberg are favourite localities. But even there we may spend days and weeks and never come across a single specimen. We may turn stones, rake il) the moss and leaves, pry into cracks, and we mearth perhaps at few sorry-looking, listless, dull and dry, half-emaciated creatures. The same place after a thunderstorm will be literally swarming with sleek, lively salamanders, in search of earthworms and all kinds of insects, especially at dusk or during the night. They disilppear in the autumn, in October, to hibernate in the ground, ont of the reach of frost, and they reappear again in April. Liter on they congregate at little springs, always at rumning water, to reach which they have often to make long migrations. This is the only time when these thoroughly terrestrial creatures approach water, in which they easily get drowned.

Although this species is so common its mode of reproduction has been satisfactorily discovered only quite recently. There are some puzzling facts which it took a long time to observe correctly and to interpret. The larvae are born in April, May, or June, while there are no eggs in the oviducts, but in July these are full of fertilised eggs before copulation takes place. This seems contradictory. The explanation is as follows. In July there is an amplexus of the sexes, short, and often on land-a sort of preliminary exciting performance. Both sexes theu descend into the water, but generally remain on land with the fore part of the hody. The male deposits a spermatophore and the female takes part of this into its cloaca. In the case of a virgin female the eggs are fertilised in the oviduct and ripen until the autumn, but the larvae nearly ready for hirth remain within the uterus until the following May, i.e. about ten months. The mother then crawls half into the water, mostly at night, and gives birth to from a few to fifty young, fifteen being perhaps the average. The young are surrounded by the egg-membrane, which either bursts before or shortly after expulsion. This species is consequently viviparous in the proper sense. If she produces a few young only, say from 
Iwo to fire, these are much larger and stronger than those of a linge litter. Occasionally a few achlerl or only partly developed eggs are also expelled.

In the case of old females which have produced offspring betire. the whole process is more complicated. The sperma, taken "1p in oluly, remains in the receptaculum of the cloatca until the Mar a .I une following. is. until the previous larvae have passed mit wit the uterus and are horn. Then the spermatozoa ascend to the upleer ents of the oviduets, where they meet and fertilise the new engs. After these have descemded into and filled the nterus, and are alrealy dereloping into enluryos. (opulation takes place again in July, preparatory for next year's eggs.

The new-lom salamanders hatre thee gairs of long external wills, a longe tail furnished with a hroad dorsal and ventral fin, and four limbs, although these are small. The total length is about $25 \mathrm{~mm}$. or 1 inch. The general colour is hlackish with a pretty metallic golden and greenish lustre. The little creatures are very atctive, and at once eat living or deat animal mattery. In aiplivity they are liable to nibble each nther's wills and tails. During the first six or eight weeks they assume a row of dark spots un the silles: these spots enlarge, and the whole shin bexomes ditrier. Lellow spots alpear next, first aluse the eres am on the thighs, later upon the hack; the nromml-colour at the same time becomes hlack, until at the? beginning of the fourth month they lowk like the parents.

The metammphosis is rery gradual. The tail-fin diminishes first, hut the gills grow until shortly before the little creatures leave the Witter. Darkness, cold, and insufficient food retard the metanmplosis, sometimes until octoher. It is easy to rear them artificially provided they are well fed, kept in a light place, and in chan. well aterated water. If preventerl from leaving the litter, for instanee when liegt in a gless vessel with rertical walls, or if hindered hy a piece of ganze from rising to the surface amb taking in air, they an lee kept as larvate well into the winter.

Very young, perfect little salamanders, of from 1 to 2 inclese in length, are exeessively rare: even speecimens of 3 inches are far from ammon. They probably spend the first two or three years of their life in careful seclusion.

I fill adults can be easily kept for many years in shady 
places provided with moss, rotten stumps and stones, to affind them suitable moist and cool hiding-places, and they readily take earthworms, larvae of leetles, snails, woodlice, etc. But any attempt to keep them in large numbers ends in failure. They (nIIgregate together in clumps, all making for the same cavity ur recess, as if that were the only one in existence (very likely they are right in so far as that place is probably the hest), and they get rapidly enlarging sores, chiefly on the elhows and knees. These are soon infested with fungoid growths, and this disease spreinds like an epidemic and soon carries them off.

$\therefore$ atm. - The Alpine Salimander differ's from the Spotted Salamander by its uniform black colour and smaller size, which arerages between $₹$ and $\bar{y}$ inches. It is restricted to the Alps of Europe, from Saroy to Carinthia, at from 2000 to as much as 9000 feet elevation, living with predilection near waterfalls, the spray of which keeps the neighbourhood moist, or in mossy walls, in the shade of forests near brooks, or uncler that stones on northern slopes. The most interesting feature of this species is that it produces only two young at a time. These are nourished at the expense of the partially dereloped eggs in the uterus, and they undergo their whole metamorphosis hefore they are hom. By far the best and nost complete account of this mole of propagation has been given by G. Schwalbe. ${ }^{1}$ The length of the ripe embryos is ahout $45 \mathrm{~mm}$; they lie mostly bent up, with their heads and tails turned towards the head of the mother. The sills are beautiful, delicate red organs, the first pair being generally directed forwards and rentralwards, the second upwards, the third backwards; they are longest when the creature is about $32 \mathrm{~mm}$. long, while there is still much rolk present. At this stage the gills are so long as to envelop nearly the whole embryo. There is rarely a second embryo in the same uterus, and an extra foetus is generally smaller, frequently a monstrosity not fit to live; it is probable that it is not used as food, but that it is expelled at parturition. The embryo passes through three stages, (1) still enclosed within its follicle and living on its own yolk, (2) free within the vitelline mass which is the product of the other eggs, (3) there is no more vitelline mass, but the embryo is possessed of gills $10-12 \mathrm{~mm}$. in length, and is still growing. I) During the

${ }^{1}$ Zeitschr. Biol, xxxiv. 1896, pp. 310:396. 
second stitge the yolk is directly swallowerl ly the mouth. The walls of the maternal uterus are rather red. 'The exchange of mutritive fhuid takes place thromblo the long external gills, which therehy function in the satne way ats the chorionite villi of the Mammalian eng. Each sill contains at ventral artery and a dursal rein. ratch of which looks like the minhih of a pimate leat: there is also a tine nerre and a wak bundle of striped muscular filures. Each gill-filanent receives a capillary artery which "xtends to the egrithelium of the tipe, where it turns into a capillary vein. The epithelimn of these filiments, which are full of hlool, is ciliaterl, the resulting arrent being directerl from the hase towards the tip. In older lanvate this ciliation becomes restricted to the tips. The boly of the wills is furnished with flat epithelium, these non-ciliater prortions alone are closely ilpuressed to the uterine wall, and it is here that the exchange of ats takes place between mother and larva. The nutrition athes plate through the gills, as they are bathed by the rollimass.

Schwalle also explains the whole question of the reduction of the number of embryos. He says rightly that in s. maculesen, which gives hirth to many young, there are in the oviduct many mes which have only partly developed into emlurys, and these, ferhaps from want of room and nomishment, degenerate into the irresularly shaped whitish-yellow bodies which are occasionally fomml parked in lretween the leveloping embryos. Consequently all those exgs hat heen fertilised near the oraries. St. ot mexhibits a further stiage in so far as must of the egrss, fertilised ahove in the oviduct, degenerate, and only two or three become fully developed. These few embryos live on the degenerating egess, which together froduce the vitelline material spoken of above. The two fullsrown and metamophosed embrys, ach measuring ahout 50 mon. in length, ale expivalent to the numerous new-born larvae of $s$ manculese, espectially if the smaller size of the adult Alpine Salamander is taken into consideration.

Mlle. von (hauvin ${ }^{1}$ has experimented with the monom larrat of this salanameres. She "ut out 2?:) larvate and fut them into water. One of them, already $4: 3 \mathrm{~mm}$. lomg, tonk earthworms cm the next day, and the beantiful lome, red fills became pale and shrunk, and on the third day were cast off close to the 1 Zeitschr. wiss. \%ool. xxix, 18\%, pp. 324 t, pl. xxii. 
body. New gills sprouted out on the same day. first in the shape of three tiny knobs on either side. After three werks they hat become round globes, which gradually spouted out into several branches, far shorter and more chumsy llian the original gills. During the whole time the larvat was lying quietly at the bottom, in the darkest cornex, but. showel at groul appetite. The fin of the tail disappeared and was supplinterl by a stronger one. In the sixth week the skin was shed in Hakes, and this process took fifteen days. This larra lived in the water for fourteen weeks and grew to 6 cm. in length: When the new gills gradually shrank, the compressed and tinny tail assumed a round shape, the skin hecame darker and shinier. and after the larva had again shed its skin, there apleared the dark rugose skin of the typical st. atiu. The gills were reduced to useless appendages-not cast off-and the creature crawled sut of the water. A fortnight later the gill-clefts were closed. A second larva behaved similarly, first casting oft the feathery wills, substituting a new and stronger set, which, however. fourteen days after excision from the uterus, shrank arain, and on the nimeteenth day the gill-clefts were closed. The liudy alsor observed that nearly ripe larvae, when cut out, rusher about in the water and ate, just like the new-hom larvae of the sipotted Salamander.

A third species, st. reucusice, is found in the Caucasus. It rather resembles the Spotted Salamander in coloration, lout has a larger tail and lacks the lateral warts. The male is remarkable for the possession of a soft permanent knob or hook at the top of the root of the tail. This pommel possibly prevents the slipping off during the amorous amplexus, provided the sexes then entwine like certain Tritons.

Chioglossa lusitanier.-The only species of this genus is restricted to the north-westem third of the Iberian peninsula. This graceful, slenderly-proportioned and beautiful sialimanter is apparently very rare and local, having hitherto leen fouml at a few places, namely, near Coimbra, Oporto and Coruña. It lives under moss, and runs and climbs with an agility surprising in a Urodele. The tongue is long, ending in a fork, and is supported hy a median pedicle so that the tip can he quickly furotruded to the distance of more than an inch. The whole length of the animal is about 5 to 6 inches, two-thirds of which leelong to 
the long tail, which is compressed at the end. The skin is smooth and shing. with a gular fold and large parotoids. The general (o)lon is a rich thark hrown, with a pair of hroul reddish-golden bands along the back and tail, the bands being sepatrated by an almost black rertebral line.

The few sperinems which I have been lucky enough to ubserve mate little holes or passatges in the moist moss of their (aige. frepling ont with their heads in wait for little insects, whirh they callsht with thash-like duickness. They seem to be crepuscular.

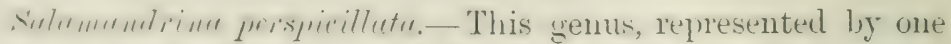
-quedes a native of Liguria and Northem Italy, jossibly extending into Inalnatia, is the only salanumeler which has but four tons. The skin is not shiny and smooth, hut is finely granular and dry, forms no gular fold, and is devoid of parotoid glamis. The tail is more than half the length of the animal. which measures from 3 to 4 inches. The general colour is biak-hown with a hroad $V$-shaped orange-rellow mark extending firm ere to eve over the occiput. A faint irregular rellowish line extends along the mirldle of the back and tail. The throat is hlack, with a diffuserl white patch in the midlle: the belly is white, with black dots: the anal region, the inner siles of the lews and the under side of the tail are carmine-red.

This slenter and pretty salamander is dimmal, and feigns deati when cliscorererl. Only the female goes into the water, in March, to whe the eggis on to submerged rocks or water-plants. The young finish their metanorphosis hy the month of June, and reach full size during the winter, the clinate of their home being suficiently genial to make hibernation scarcely necessary.

I'iton s. Molge. - The tail is strongly compressed and frepuently has a permanent fin. The fronto-squanosal arch is valrialile, it heing either hony as in the South European, Eastem ancl American species, or reduced to a ligament, or lastly ahsent ats in T. rristrtus. The males of all the English Newts, of $T$. rittotus and of $T$. murmoratus, develop a high cutameous crest wh the bark and tail during the breeding season, and this crest acts mot only as a swimming organ amel ormament, lut also ats a sensory organ.

The whole genus comprises some eightern specien, twelve of which are European, although some of these extend into Western 
Asia; T. myrhogaster and T'. sinensis are found in N.E. China, the former also in Japan; $T$. poireti and $T$. hagenmurllere live in Algeria, and only two, T. torosus and T. virideseens, are North American. Some of the species have a limited range; thus I'. montunus is confined to Corsica, T. rusconii to Sardinia, T. Tuseci to the north-west of the Iberian peninsula and $T$. usper to the Pyrenees.

Newts all prefer moisture without heat. During the pairing season they take to the water, mostly to stagnant pools, which sometimes implies long migrations. During this period, which is in some cases rather prolonged, they become thoroughly anuatic and undergo some important changes. The tail-fins are much enlarged; in the males of some species a high cutaneous fold grows out on the back, devoid of muscles, but rich in senseorgans. The whole skin, instead of being dry, possesses numerous mucous glands and, what is of more importance, specialised sensory apparatuses which are arranged chiefly along the lateral lines of the body and part of the tail.

After the breeding season Newts become terrestrial, hicling in cracks, trees, or in the sandy soil. Some species aestivate during the hot and dry season. They hibernate either in the ground, or occasionally in ponds. T'. vulgaris is difficult to keep in the water beyond the pairing season, while this is easily done with $T$. alpestris and $T$. cristatus; ' $T$ '. voltli can live in the water for years. The food consists of all kinds of insects, centipecles, worns, snails, etc., which are searched for chiefly at night. It is astonishing to see a little Triton getting hold of and gradually swallowing a wriggling earthworm almost as thick and as long as itself. When two newts seize the same worm, as these roracious and jealous creatures often do, each gets hold of one end, and swallowing as much as it can, twists and rolls round in a direction opposite to that of its rival, until the worm brealis, or until the jaws of the two newts meet and the stronger of the two draws it out of the weaker one and swallows the whole worm. They do not drink, but soak themselves in the water.

The shin is shed periodically, and rather often ly the rapidly. growing young; by the adult, during the life in the water, rirrely during the sojourn on dry land. The skin breaks round the unouth; assisted by the fingers and by contortions of the 
imly: it is then sliphed hackwards over the trunk and tail, whereupon the mewt seizes the skin with the mouth, lhaws the shirt off" entirely, anul-swallows it. such freshly sheel skins ane

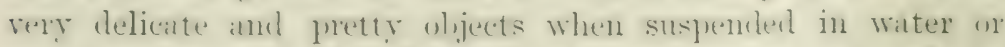
some preserving fluid. The shed skin, consisting only of the ontermost layere of the epidemis, is entire, hut turmenl insisle out. with fingers and toes complete, the anly holes lueing those for the mouth, eyes, and vent.

None of the Tritons are viviparous. The eggs, which are glued singly or in small numbers on to stones or waterflants, are hatched in alwnt a fortnight, somere or later atecording to the species and the prevailing temperature. The larrae are always providet with three pairs of branchenl external gills; the fore-limbs alyear much earlier than the hind-limbs. Most, gerhats all, latrate develop two pariss of threat-like protuluerances (on the sicles of the upuer jiaw, by means of which they attach or anchor themselves on to water-plants shortly after they are hatehed. Thus moored they remain motionless in a slanting fusition, now and then wriggling their tails and shifting their flitee, or sinking to the lottmm. The metammphosis is tinished during the first summer, and the little newts, often partially transparent, leare the water to hicle under stones. Jot unfrequently the metammphosis is retarded and not finished by the antumn. The larvate of $T$. ristutus, especially when reared in pouds with abrupt or orerhanging lanks, so that they cammot leave the watere retain considerable remmats of the gills, still more frefluenty the elefts, although breathing chietly liy the lungs. Sinch individuals reach a length of $: ?$ inches, and are linvate so fin ats the fimng tail and the gills are concerned. They hibrernate in this concdition, and in exceptional cases reach sexual matmity:- at least the females, which develop ripe exps: the males are not known to produce spermatozoa.

Murh has leen written on the amorous games of newts, lint it is only recently that the mode of fecundation has been actually observerl. (iaseo placed the newts in whass resseds suspended from the: ceiling of his laboratory. The antics of the rnamoured male armund the female, rubbing the latter with its heate, or lashing it gently with the tail, and playing arounde in its often leantiful nuptial shess, are meant to excite th: 
fanale. The male then at intervals emits spermatophores. which sink to the bottom, and the female takes them up into its cloaca. For further information see p. $\mathbf{5 4}$.

Tritun ristatus.--.-The Crested Newt has a slightly tuherculin? skin with distinct pores on the head, on the parotoid region am on a line along the side of the trumk. There is a strong gular. fold. The general colour above is dark or black-brown with an olive tinge, interspersed with darker spots; the sides of the body hear irregular white spots. The under parts are rellow. almost always with large black spots. The iris is golden yellow.The nuptial dress of the male is very striking. A high, serrated

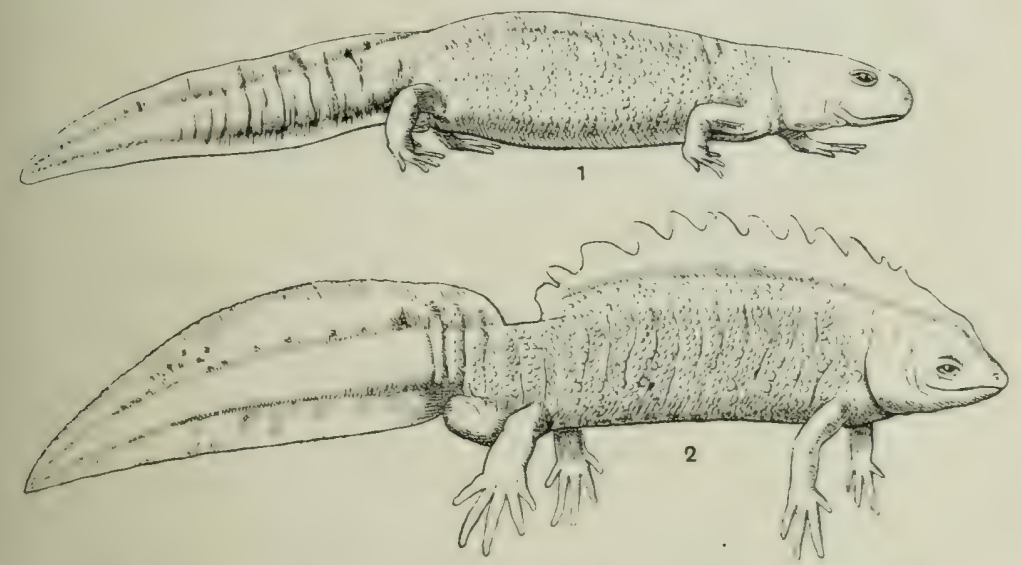

FIr. 23. - Triton cristatus. 1, Feuale ; 2, male in nuptial dress. $\times \frac{2}{3}$.

rest occurs on the head and body ; the upper surface of the head is marbled with black and white; the under parts are orangeyellow with black spots, and the sides of the tail are adomed with a bluish-white band.-The female, always deroid of a crest, generally exhibits a rellow line along the middle of the back. - The arerage length of fully adult sprecimens is ahout $\check{j}-6$ inches or $13-15 \mathrm{~cm}$. : the females are as usual latger than the males: $14 \pm$ and $162 \mathrm{~mm}$. for an English male and female respectively are exceptional records.

Proprasation takes place in April. The newly hatched larrate are yellowish-green, with two black dorsal hands, and with a whitish edge to the tail-fin. By the micllle of July they are anut 5 cm. long, and the white-margined tail now ends in al 
thread $1 \mathrm{~cm}$. in length. The general colom above is light olivehrown, dotted with black: the flanks and helly lave a golden shimmer.

The (rested Newt has a wide distribution, extending from Eugland and Scotland through Central Europe into Trans(aucasial the northern limits are scotland and Sunthern Sweden. Althongh found in Greece and Lombardy, it does not occur in the Therian peninsula nor in the South of France, where it is represented by the next following species.

Tritun mommontus. - The Marbled Newt is of the same size as the Cresterl Newt. Its ground colour is grass-green above, hrown helow, with numerous large and small irregularly shaped marling patches, spots and dots of black. The crest of the neck and trunk is entire, not serrated, adorned with dark rertical lands, and separated from the high dorsal fin of the tail hy a deep indenture or gap. The female has an orange line, slightly sunk in, instend of the crest. This newt is confined to France and the Therian peninsula. In the North of Portugal and in Galicia it is frequently seen in little streams and ponds during the months of March and April. The rest of the year it spends on lant. In France occur hylurids of this species and T. cristatus. They have been described as 'T. blasii.

T. alpestris.-The Alpine Newt is easily distinguished by the rich orange colour of its under parts, which are unspotted, excepting a few dark specks across the throat, below the gular fold. specintens with many rentro-lateral black spots are exceedingly rare. All the upper parts are dark, but vary inclividually. The prettiest specimens are dark purplish grey, with black marblings; other's incline more towards brown ground-tones, the blackish markings then appearing more prominent. The sides are often stiplyled with tiny whitish dots. The iris is golden yellow.The nujelial male hats a low, not rerrated crest, which extends minterupterlly from the nate into the clorsal fin of the tail. The crest is pale rellow, with black rertical bands and spots. The ground-colone of the uprer parts inclines to blue, especially wh the sides. The lower fin of the tail assmess an irregular band of bluish-white confluent patches.

This newt is rather small, females rarely exceeding $100 \mathrm{~mm}$. or 4 inches in length. Its home is chiefly the hilly and mountainoms garts of contral Furope, from Ifollamel to Lombarty, 
Austria-Hungary, and Greece. Although it ascends the Alps to hetween 6000 and 7000 feet, it is also found in the Tethellands, but not in the North German plain.

T. vulgaris (s. taeniatus, S. punctatus).-The Common or Spotted Newt usually reaches 3 inches $(7-8 \mathrm{~cm}$.) in lensth. Boulenger's record-specimen measured 104 mm. It is characterised by the yellow, partly orange under surfitce, which is always spotted with black. The upper parts are olive-green or lorown, inclining to white on the flanks; the black spots of the lack, sides, and especially of the tail, are arranged in nore or less distinct lines, giving a somewhat banded appearance to some females. The breeding dress of the male shows a nonserrated, but "festooned" high and very wary crest, which extends from the neck withont interruption into the likewise wary tail-fin. The tail is adorned with a lateral, glittering bue stripe, interrupted by rertical dark spots. The larvae are marked by a series of yellow dots, which extend over the lateral line and the tail, which latter temporarily possesses a terminal filament like that of the larvae of 'T. cristatus.

The distribution of the Spotted Newt is the same as that of T'. cistatus, namely Europe, with the exception of the Iherian Peninsula and Western Asia.

T. pulmatus s. helveticus. - This is the smallest of all the European newts, rarely reaching more than 3 inches in length. It is distinguished by sereral specific characters. The tuil ends in a thread which is in some males $10 \mathrm{~mm}$. in length, but is only just indicated in the female. The breeding male develops a cutaneons fold along each side of the back, and a low, entire, vertebral 'rest; the toes are fully webbed. The under parts are palt' yellow, inclining to orange towards the middle of the belly, and with a few blackish dots. The lower caudal crest has its edge hine in the male, orange in the female. The general colour of the smooth skin is olive-brown above, with numerous dark spots, which are arranged in more longitudinal streaks on the head.

The Webbed Newt is a native of Westem middle Enope, ranging from Great Britain and Northern Spain to Switzerlancl and Western Germany.

Closely allied to the last species are $T$. buscri of suain and Portugal, T. italicus, T. montadoni of Moldavia, and the 
Beantiful T. rittutes of Asia Mimus. From China and Tapan are known 'T'. pyrrhogaster and 'T'. sinensis.

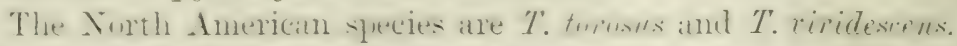
The former. of Western Xorth America, is one of the largest newts. ratching it length of more than six inches. The head is

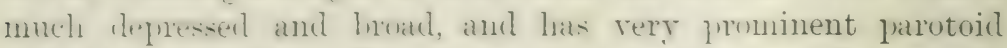
ime wher glands. The limbs are stronge esperially in the makl. The skin of the mpler garts is very granular, uniform ditrk hrown. without a clest. The tail. which is larger than the hemil and borly, is strougly compressed. with a low dorsal and rentral fin. The under parts and the lower edge of the tail ate mifmu rellow or orange rent. The iris is green. A sperinen in my kepping spends most of its time in the cracks

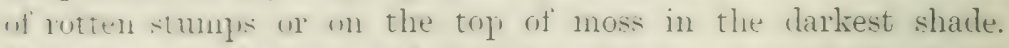
It lives on earthworns hut despises insects. Iike most of the other newts it becomes lively at dusk.

T. viridescens is common throughout the Northern and Eas-ten prirts of the Tniterl states. Larce females are about

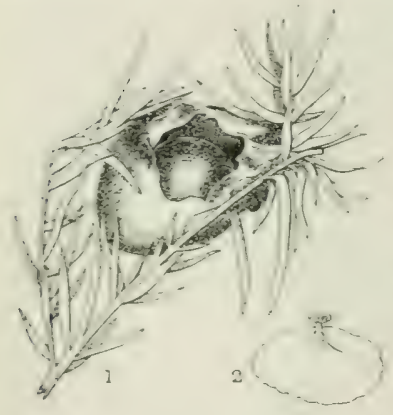

FIf. 24. - Triton viridescens. 1, Egg just after deposition, with the coter mombane openesl. :6: - 2. a - qurmatophore just

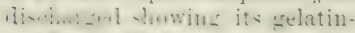
ras - lase vith a projerting spike. whith i war-a tivt of spermatn. zoa. $\times 2 \quad$ (After Jordan.) $11 \mathrm{~cm}$. long, the males $1 \mathrm{~cm}$. less. The general colour above is brown, with a tinge of green; on each side of the trunk, with a row of bright vermilion spots; the under parts are orange, studded with small black dots. Halfgrown specimens are brownish red, with the same lateral red spots as the adult. According to Jordan, ${ }^{1}$ this voracious species lives chiefly on the larvae of insects, on small molluses such as Cyclas and Planorbis, on earthworms and on small Crustacea. It is eminenty alyuatic in the adult stage. The engs are laid from April to June, the period lasting for one individual four to six weeks, or even longer.

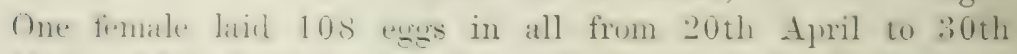
May: .ffor having selecterl a suitalle plant, for instance an Alumberis or a linnch of Fontinal is leatlets, she bestrides the plant anul wathers in the surrounding shouts with her hincl- 
limbs, pressing the leaves closely around the cloaca. She next turns on her side, or occasionally on her back; with forelimbs outstretched and rigid, with hind-limbs and leaves completely hiding the cloaca, she remains perfectly motionless for six to eight minutes. Then she slowly leaves the "nest," which now holds an egg well protected by a tangle of shoots glued together by the gelatinous secretion poured out of the cloaca. Jordan concludes, from the fact that he never found spermatozo: in the oviducts, that the eggs are fertilised just before they are expelled, when passing the receptaculum seminis.

The metamorphosed young pass their life on land under stones and $\operatorname{logs}$ as the so-called red variety, which is merely a stage in the life-history of the species. It seems to take them several years to reach maturity, and to become again typically aruatic. Young, red individuals which I have myself kept, have behaved for more than a year like the young of other newts, spending their time under moss and bark without groing into the water.

The change from the red-spotted stage has been exhaustirely studied by Gage. ${ }^{1}$ He remarks that this species is very common near Ithaca, in an upland forest and along the head-waters of the Susquehammah. The transformation takes place either in the autumn or in the spring, either while the newt is still on land, or after entering the water.

Of two which were kept in a jar with moist wood, one was especially brilliant, but within two weeks it assumed, in the middle of September, the characteristic coloration of the viridescent form. The two specimens were in the jar until the following July, when they were placed where they could enter the water. This they did with great readiness, and they remained submerged for a considerable time at first. The time under water increased in length, until within two or three diys the pharyngeal respiration under water was fully established. On the other hand, viridescent specimens nerer reassume the red garb when kept out of the water.

Red specimens entering the water in the spring, changed into the greenish form within a few weeks, and established the pharyngeal respiration, losing the ciliated oral epithelium. Branchiate larvae and the adult aquatic forms lave non-ciliated 
"pithelimu, and the cilia are retestahlished when a green specimen is forced again to live on land. Ciliation always exists in the reel stage, and in the green stage hefore the newt has talien to the water. The cilia sweep towards the stomach.

The three following somth Enopean species lelong to the Eufremtus grmul, so called on aceount of the mostly conical, backward directed, and vividly coloured vent.

T. asy" s. furenum. - The Pyrenean newt has hitherto heen finme only in the Prrenees, for instance in Lac Bleu and Lac

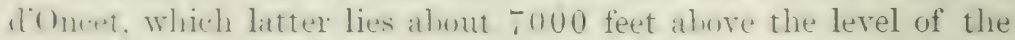
Nai. Aronding to Bedriagat, it prefers latkes which are supplied during the whole smuner with water from glaciers. It is rery showish, only moring to hreathe and when in search of fout. which comsists of worms and insects. The general colour is creenish linwn, dark abore: the under side of the head and lusly are bright wange red in the female, rellow in the male: dark sputs sepratate this bright colour from the Hanlis. The tail has a narrow ventral strige of hright resl and rellow. The chatrat of the fermale is bright red, that of the male dull grey. The total length amounts to about 4 inches or $10 \mathrm{~cm}$.

The pairing time is the end of . June, w later in cold seasons. The male erets holil of the female by forming a noose with it. tail romul her: it lies underneath, the cloacae being pressed tongether so that the spermatozon can be taken in directly. The larvate have latre yellow-sreen spots on the hack and sides, and a bright red ventral tail-fin; when metamorphosed the greenish spots becume more conthent on the back, produciug a invad spinal hand. Larvate which live in deep, water are dark, while those in sunny places are light-coloured and spotted with yellow.

T. montunns in Corsica and T. rnstonnii in sardiniat are allied forms, but the males are distinguished by a spur-like process or dilatation at the end of the fibula.

I. unlti, the Iherian Newt, is olive-lnown ahove, yellowish with hlatkish matrings below. The tail has a rellow or orange ventral line. There is no cesest. A remarkable peculiarity of this species (which it shares nuly with Tylututriton andersomi of the Loo-('Hon Islitnels) is its ribs, which ate very long, sherply lointed, and frequently perforitr. the skis. Before 
jerforation the point of the rib lies in a lymphatic space. This surprising feature has by many authorities been consicleren as abnomal or pathological. Certainly young, and went many aclult, individuals are found in which the skin is not perforated, lut when these are handled the wriggling motions of this strong newt force the points of the ribs through the skin, and they remain sticking out to the extent of several millimetres. The

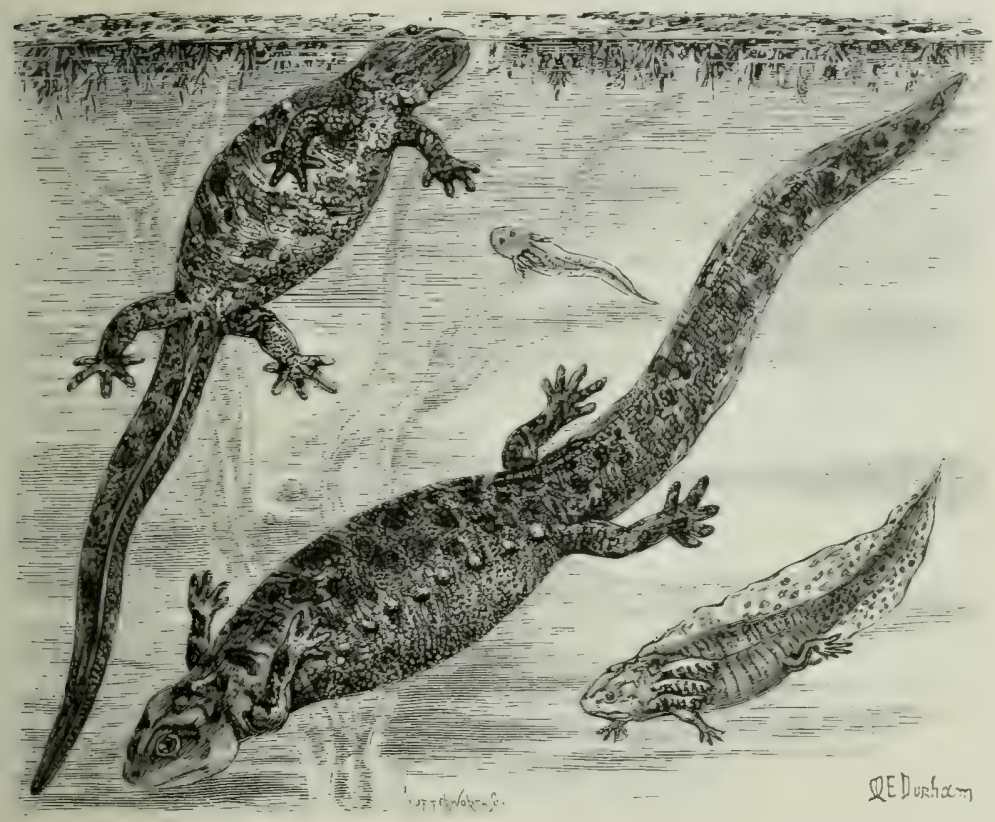

Fig. 25. -Triton waltli. Spanish Newt, adult and larvae. $\times \frac{2}{3}$

wounds heal up, the skin forming a neatly finished-off hole through which the spike projects, not as a formidable, but as a sufficiently awkward, protective weapon.

Large females reach a length of 10 inches. The larvae metamorphose, as a rule, when they are between '2 and : 2 inches loug, but those which have been bred in tanks often reach double this length. These newts are frepuent inhabitants of the rain-water cisterns common in the South of Portugal and Spain, into which they tumble without ever being able to get out again. This species spends most of its time in the water, 
foferring ponds, among the vegetation of which they can he watched lying motionless, with their limbs hanging down and with the head close to the surface; but they are lively during the night. When their ponds dry up they leare them, crawling into the most unexpercted places, to aestivate moler rocks, or even in the walls of old huildings, where they are fomm by ancident only. The ranger extends from Central spain and l'ortugal into Moroceo.

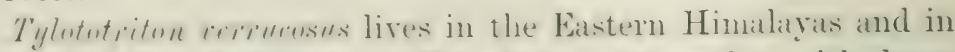
the momntains of Tumntu. The skin is tuleremlar, with large faroterick: ahore uniform black-hrown. pale below: the tail has a ventral fellow or wange line. Tutal length alout if inches. T. andersini of the Lom-Choo Islants is remarkalile for the pointed ribs which perforate the skin.

Preluytriton hrevipes, discovererl in Kiansi, fouthern (hima, has a smooth skin, olive-lowow alowe, with many black dots: the under parts are yellowish, dotted with liack. Tutal length about 7 inches.

Fam. 3. Proteidae.-The three prairs of fringer extermal gills persist throughout life. Both fore- and hind-limbs are present. The eyes are devoid of lirks. The maxillaries are absent. Teeth are present on the premaxillaties, on the vomers, and on the mandible. The vertebrae are amphicoelous.

This family ansists of only three senera. with one sprecies in each.

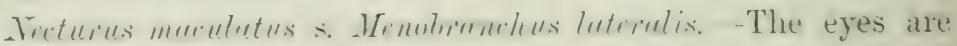
functional, heing covereel by the thin transparent skin. The limbs, although short, are well develoned, and have foum tingers and fonr toes. The whole animal, which reaches the length of one font, is quite sunoth and sliny, lnown with irrenular dark, blackish spots and patches, which freunently form a dark lateral band extending from the month in the tail. The latter, which measures athont one-third of the whole length, is strongly connpressed, carries a thick dorsal and rentral fin, and is romeded ofi at the end. The skin of the throat forms a strongly-marked trunsverse fuld. The thick stalls of the gills are lowwn, while the: numerous and delicate fringes are dark red in life: beneath

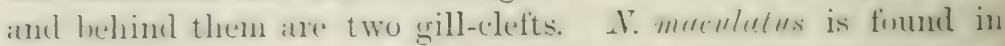

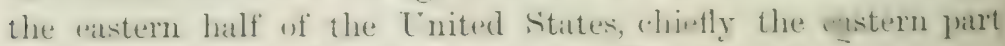
of the hasin of the Mississigli and the Cimadian laties. 
These creatures are rather dull: they remain mostly at the hottom of the water, more or less concealed in the weeds or hetween rocks luring the daytime. Mine, which are kept in il roomy, light-coloured tank, lie motionless, with their gills spreat ont transversely. Every now and then the gills contract suddenly and become jale, whereupon they are filled again with blood. Very rarely they rise to the surface, but tiny airhubliles are let out more freunently, especially when the animals are disturhed. Then the gills collatpse, are lail fiat against the neck, and the creature diarts about with quick, eel-like motions. At night they leave their hiding-places, swim about or creep along the ground with slow, undulating movements, the limbs leing scarcely used, in search of food, which in their wild state consists of rather large ('rustacea, small fishes, worms, insects and frogs. They are most roracious, and absolutely indifferent to cold. The spawning takes place in the months of April and May.

Piotens anguinus.-The fore- and hind-limbs are fully dereloped and possess only three fingers and two toes. The eyes are completely hidden beneath the opaque skin. This peculiar creature is restricted to the subterranean waters of Carniola, Carinthia, and Dalmatia. The vast caves of Adelsberg not far from Trieste are especially celebrated for the occurrence of the "Olm," the German name of this animal. The river l'oik, a moderate mountain-stream, but a large, fierce torrent lluring the rainy season, disappears into the limestone-hills, and rushes through enormous stalactite-grottoes, most of which have heen only partially explored, until several miles farther on it reappears on the surface. There, deep down below the surface, in absolute darkness, in an almost constant temperature of about $50^{\circ} \mathrm{F}$. is the home of Proters.

Their total length is scarcely one foot. The whole body is white, recasionally suffused with a slight Heshy, rosy tinge, while the three pairs of gill-bunches are carmine-red. They are easily lept in captivity, and live for many years, provided three conditions are strictly adhered to, viz. fresh and clean water, an equable low temperature of about $50^{\circ} \mathrm{F} .=10^{\circ} \mathrm{C}$. and darkness. The question of food is not so rery important, since specimens are known to have existed for years, although they refused to take any nourishment. How fir darkmess is an 
absolute necessity is not known. Anyhow, the white shin is almost as susceptible to light as is a photographic plate. If light is not absolutely excluted the white slin heromes in time

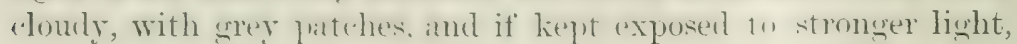
the whole animal turns ultimately jet-black. Mr. Bles has

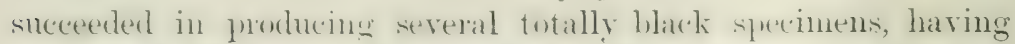
kept them for sereral montls in a white basin under ordinary conditions of light. No experiments have yet been made to find ont if the luare pigment deposited is lost again in darkness. Those which are liept in a tank in an alsolutely dark cellar of the Cambridge Musemm, with germanent water-suplyly, are doing very well. Then approached with a cindle they hedome rest-

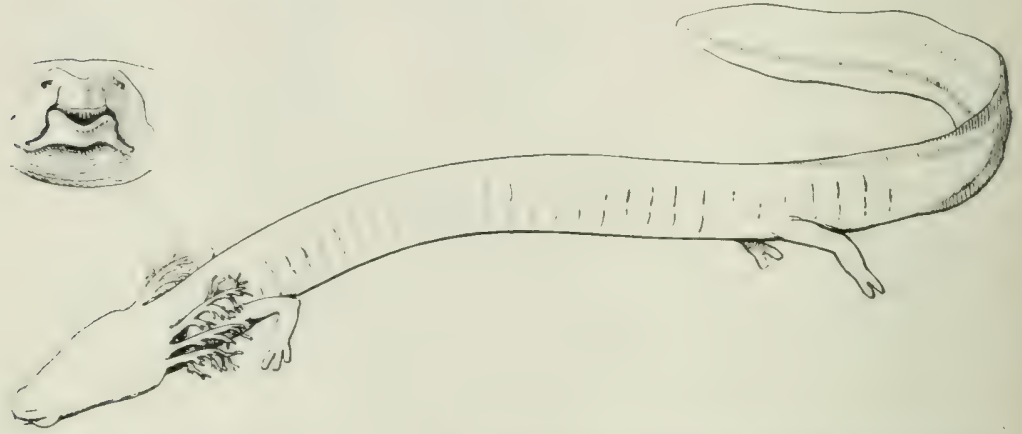

FIs. 26.- l'rotens anguinus. $\times \frac{2}{3}$. Front view of the month in the left upper corner.

less or remain partly hidden in all sirts of seemingly most uncomfortable attitudes, squeezed in hetween the sharp-tedged tiles and drain-pipes with which their lodgings are furnished. But the introduction of a wrigghing worm, a little (rustacean 11 other live bait draws them from their hiding-places, and, guided hy the motions of the grey in the water, possibly dso by the sense of smell, they smap it up and devour it.

If the water is not sulticiently well arerated, they rise to the surface, emit a buble of air, and take a new suphly into their lungs. As a rule they remutin motionless under water, but the

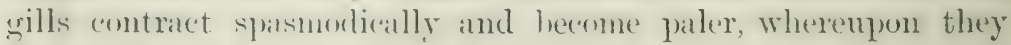
till again with hlood and darken: the contrast between the pure white body and the carnine-rest feathery gills is very leatutiful.

T'ntil recently the morle of propatgation was ynite monown.

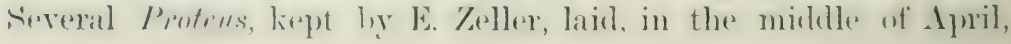


a number of eggs which were then fastened singly on to the under side of projecting stones in the water. The pale rellow yolk measured $4 \mathrm{~mm}$. in diameter and was surruunderi hy it corer of $1 \mathrm{~mm}$. in thickness, besides an onter gelatinous mantl. so that the whole egg measured about $11 \mathrm{~mm}$. The litrat were hatched after 90 days; they were $22 \mathrm{~mm}$. long. and alrealy much like the adult, except that the fin was not restricted to the tail, but extended over the last quarter of the trunk, and that their eyes were still visible. The fore-limlss were already typical in shape, but the hind-limbs were still toeless little stumps. ${ }^{1}$

Typhlomolye rathbuni.-It is of the greatest interest that a subterranean Perennibranchiate newt, in all respects closely allied to Proteus, has recently been discorered in Texas. There can be no doubt that similar conditions of life lave produced these closely resembling forms from Necturus-like ancestors, one in Europe, the other in North America, absolutely independently of each other. The limbs of Typlilomolge are long and very slender, the four fingers and five toes are thin, free and pointed. The head is large, the mouth square. The eyes are completely hidden and the whole animal is colourless and white. The tail is furnished with a dorsal and a rentral fin. The very deep gular fold is nothing but the prir of mited but large opercular flaps. The three pairs of gills are remarkible for their blade-like stalks, while the gill-lamellate proper are short and restricted to the tapering ends. Total length about $75 \mathrm{~mm}$., of which the head measures 15 , the tail $32 \mathrm{~mm}$.

This peculiar creature inhabits subterranean caves in Texas, to judge from the fact that all the specimens hitherto linown have come up with the water of an artesian well $18 \mathrm{~S}$ feet deep, near San Marcos. According to Blackford," " the legs are used for locomotion and the animals creep aloug the bottom of the aunarium with a peculiar movement, swinging the legs in irregular circles at each step. They climb easily orer the rockis piled in the aquarium, and hide in the crevices between them. All efforts to induce them to eat have been futile, as has also been the case with blind cave-fish in captivity, and they are

2 See also M. von Chanvin, Zeitschr. wiss. Zool. xxxviii. 1883, 1) 6 ¡ 1.

2 Nature, Ix. 1899, 1. 389. 
wither adpable of longe filsts or live on intumeriat in the water." It seems more reasmalile to suppoes that these newts live upon

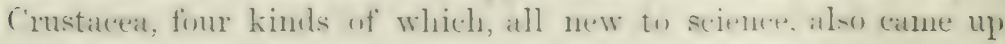
with the water.

Fam. 4. Sirenidae.-The three prairs of fringed external

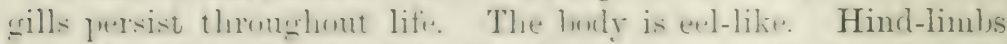
are altonether alsent. While the fore-limbs ate slont and have three or four fingers. The maxillary lwoms are aloent. With the exception of small teeth on the vonere the mouth is torthlus, lut the jaws are fumisherl with hurny shattls. The eves are devoid of lids, but shine through the shim.

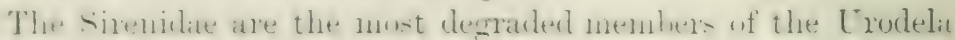

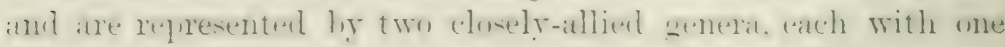

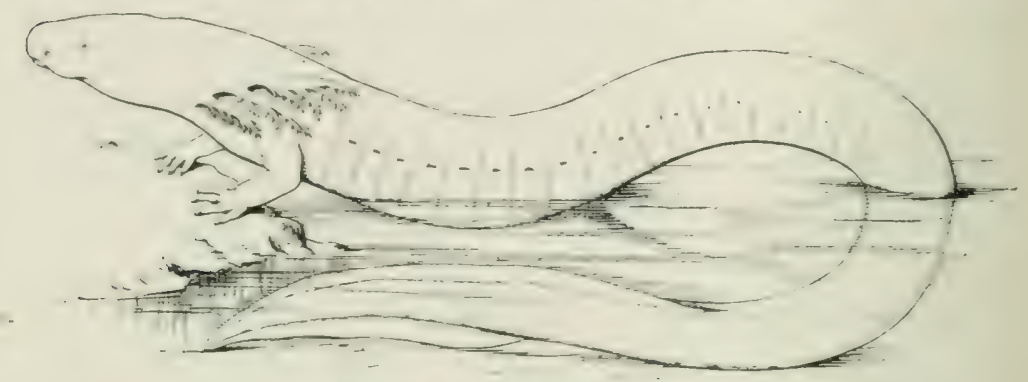

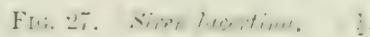

Hrecies, in the sontherastern prats of the United states. Their nun interesting feature, which feals upun the question of

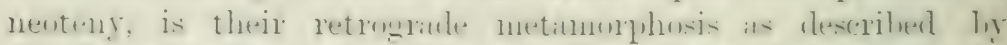

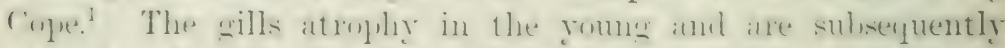

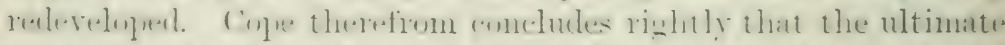
or persistent gills of trien are sinns of maturity and not a larval chatrater. In yomleg speciness of simn of 5 to li inches in

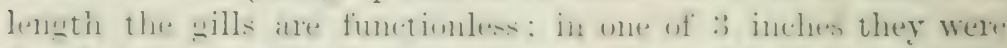

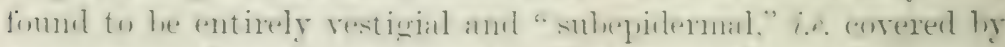

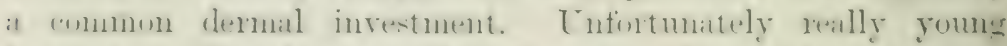
larvate are still unknown. Olel sirens an liwe withont gills, as

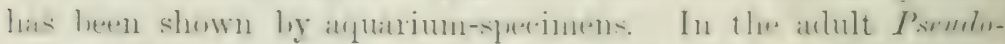

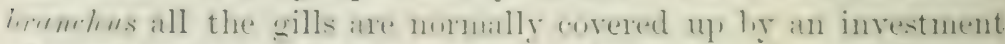
of the skin so as to he quite without funct ion and movelility.

Siren lacertina, the "mud-eel," is distinguished by the 'Amer. Nintural, xix. 1855, p. 1226. 
pussession of three pairs of gill-clefts and by its four fingers. It reaches a length of 70 cm., or about $2 \frac{1}{2}$ feet, of which about one-third is taken up by the tail, which is strongly compressed and finned. The skin is smooth, mostly blackish, lighter lelow; sunetimes with whitish specks all over the body. This creatur. is frequently found in ditches and ponds, where it burrows in the mud. When swimming the limbs are folded back. They are said sometimes to leave the water and to crawl about on the moist ground.

Psindobranchus striates has only one pair of gill-clefts and only three fingers. The slightly granular skin is dusky lrown above, with a broad yellow band on either side and with a paler, narrower stripe below. Total length about 7 inches, 


\title{
CHAPTER TI
}

\author{
LISSAMPHIBIA (CONTIYTED)-ANURA
}

\section{Order III. ANURA or TAILLESS AMPHIBIA.}

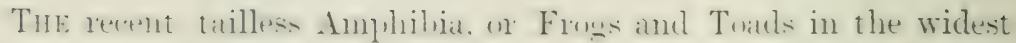
sense, contain such at greal numler of slecies alunt 900 ), with snch a diversity of chatateters. that it is necessary. if only for the sike of mere (onventences. to groulp them into a considerable number of fimilies and sult-finnilies. The dhatacters arailahle for this purpose are few.

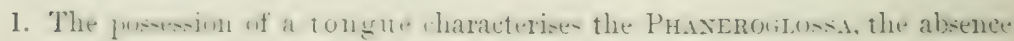
of a tongue the Agrossi.

$\therefore$ The character of the shoulder-girdle-Overlapping of the two halves of the shoulder-girdle on the ventral side characterises the Ancifera, while in the Firmistersia the two ventral halves meet in the middle line and form a firm, median bar. See, for details, p. 24 .

3. The shape of the transverse processes or diapophyses of the sacral

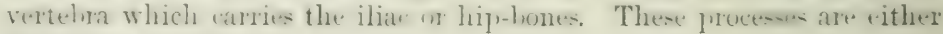
dilated or cylindrical.

4. The presence or alnence of teeth in the upper and lower jaws. This is indicated by a formula in which 0 meaus absence of teeth; max. means

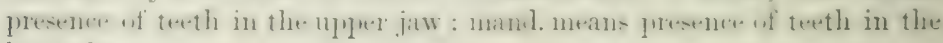
lower jaw.

5. The terminal joints or plualanges of the fingers and toes are sommtimes claw-shaped. See p. 26 .

if. The shape of the centra of the vertebrac-Opisthocoelous, if the

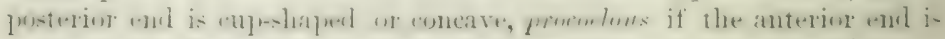
concave and the posterior is conrex. See p. 19.

By meams of these chamacters we can ammere the Anmat in the following key:- 


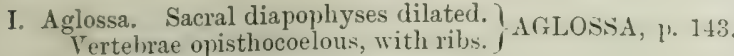

II. Phaneroglossa.

A. Arcifera.

a. Sacral diapophyses dilated.

a. Terminal phalanges not claw-shaped.

Opisthocoelous, with ribs, $\left.\frac{\max .}{0}\right\}$ DISCOGLOSSIDAE, p. 152.

Procoelous, without ribs, $\left.\frac{0}{0}\right\}$ BUFONIDAE, p. 166.

Procoelous, or opisthocoelous,

without ribs, $\frac{\max \text {. }}{0}$

PELOBATIDAE, p. 160.

$\beta$. Terminal phalanges claw-shaped- $\int \frac{\max .}{\operatorname{mand} .} \begin{gathered}\text { Amphignathodon- } \\ \text { tincae, p. } 188 .\end{gathered}$

HYLIDAE $\left(\frac{\max }{0}\right.$ Hylinae, p. 189

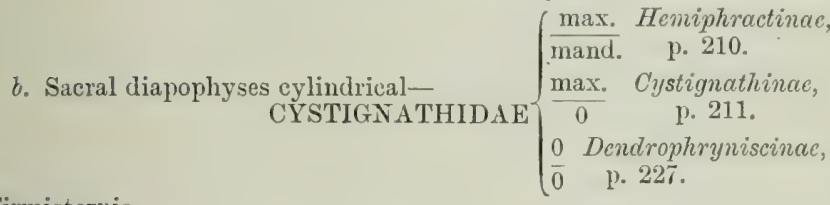

b. Firmisternia.

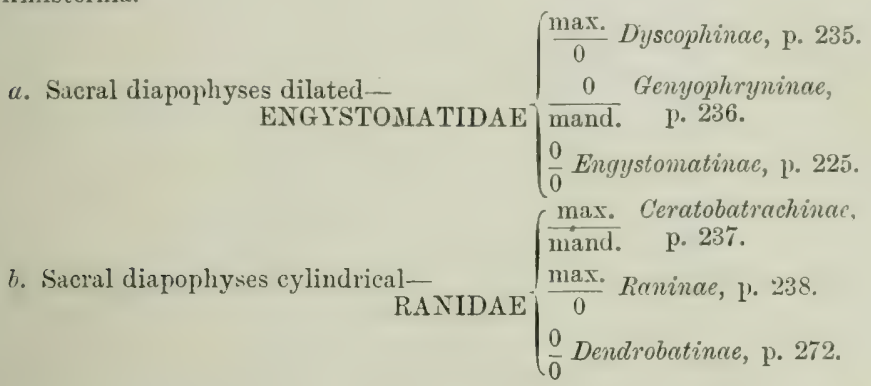

Concerning the evolution of the classification of the Auura, it is interesting to follow the changes of the value attached to the various anatomical characters by systematists. At first the presence or absence of teeth and of adhesive discs on the fingers and toes were considered to be of prime importance for the division of the Phaneroglossa.

Duméril et Bibron, 1841. "Erpétologie générale."

I. Phrmaglosses = Aglossa of Wagler : Pipa and Ienopus.

II. Phanerogrosses. 1. With teeth, «. Without discs: Raniformes.

b. With dises: Hylaeformes.

2. Toothless . . . Bufoniformes.

Stamnius, 1856 (see p. 8), separated the Engystomatidae as "Systomata," and used the presence or absence of the "manubrium sterni" (omosiernum) as a character of distinction between his Bufoninae and Raninae. 
Giunther, 1858, " (atalegrle of the liatmehia salientia." No progress was made by his sclieme, which relied upon the tongue and digits.

Aglossa with Myobatrachus.

Opisthoglossa. a. Oxydactyla. ๖. Platydactyla.

Proteroglossa : Rhinophrynidae.

Cope, 1864. "On the limits and relations of the Raniformes." $1 \mathrm{He}$

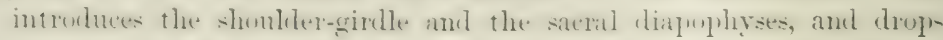
the dises as too adaptive and misleading. He distinguishes between RANIFordes and ARCIFERT.

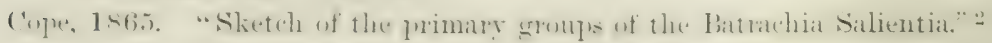
Aglossa.

Bufoniformia (Bufonidae).

Areifera (Discoglossidae, Scaphiopodidae, and Hylidlae).

Raniformia.

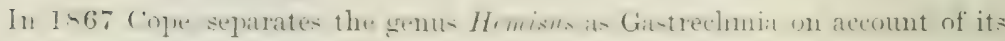
jeeuliar pectoral arch.:3

In 1875, "Clieck-list of North. American Batrachia and Reptilia," Cope elaborates his srstem:

Class Batrachia. Order Anura.

1. Raniformia.

2. Firmisternia. [Dendrobatinae and Engystomatidae.]

3. Gastrechmia : Hemisus.

4. Bufoniformia. [Bufonidae.]

5. Aglossa. Pipu.

6. Odontaglosse. Tenopus.

7. Arcifera. [Crstignathidae, Hylidae, Pelolaticlae and Discoglossidae.]

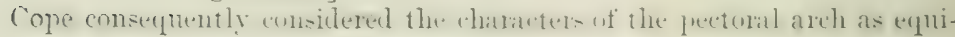
valent to those of the dentition.

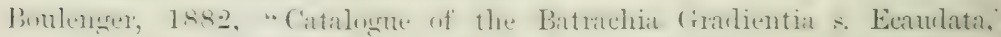
recognises that the pectoral arch is of greater systematic value than the dentition. The latter is used, together with the shape of the sacral cliapophyses, for the separation into families.
I. Phaneroglosia.
A. Eimisternia \{
1. Raniclate.
2. Dendrolatidae.
3. Engystomatidae.
4. Dyscophidae.
э. Cystignathidae.
6. Dendrophnuiscidae.
7. Bufonidate.
1). Arcifern.
8. Hylidae.
9. Pelobatidae.
10. Discoglossidar.
11. Hemiphractidae.
12. Amplignathodontidae.
II. Agloss?
f13. Dactylethridae.
14. Pipidae.

${ }^{1}$ Proc. Ac. Philud. 1564, p. 181.

:The Nutural History Reviev, No. xvii. 1865, 11. 97.

: Joum. Ac. Virt. Hist. Philat. vi. p. 189. 
This emendation of the Arcifera and Firmisternia was accepted by Cope in his synopsis of the families of Tertebrata (Amer. Tatural. xxiii., 1890), except that he still retained his suhorder Gastrechmia.

Since the publication of Boulenger's great work a number of forms have been discovered which, from the characters of their lentition, have necessitated the establishment of certain new families, namely, Ceratobatrachidae and Genyophrynidate and Boulenger was the first to recognise that the taxonomic value of the mere presence or absence of teeth in the jaws had been overestimated. I therefore propose using it as a character distinctive of the sub-families only, thereby reducing the number of families, relying first (leaving the Aglossa aside) upon the firmisternal or arciferous condition of the pectoral arch, secondly upon the dilated or cylindrical shape of the sacral diapophyses, thirdly upon the dentition. Blindly consistent application of these principles would reduce the Phaneroglossa to four fumilies only, namely Ranidae, Engystomatidae, Cystiguathidae and a fourth family comprising all the Arcifera with dilated sacral diapophyses. This would obviously be wrong. The have therefore to resort to other additional characters or rather peculiarities. The opisthocoelous character of the rertebrae and the possession of distinct ribs, together with the disc-shaped tongue, separate the Discoglossidae and justify their retention as a family. The Hylidae are marked off by the claw-shaped terminal phalanges, but the remaining forms, comprising the Bufonidae and Pelobatidae, cannot be separated except by their dentition, and I plead guilty of inconsistency in retaining them as separate families.

After all, our classification may not represent the natural system, and it may be nothing but a convenient key.

When we have eliminated the characters of the rertebrae, the dentition, the claw-shaped phalanges and the adhesive discs, it may well be asked what characters remain. The firmisternal is a further, higher modification of the older, more primitive arciferous condition. The difference between the dilated and cylindrical shape of the sacral diapophyses is in not a few cases rery slight, and there are various, most suggestive exceptions. The presence or absence, size and shape of the onosternum and metasternum are of very limited taxonomic value, not always applicable to all 
the memlers of the same fanily. The fact is, that the Anurat are a very recent and a most aliturive. plastic group. The (arliest known fossils are scarcely older than the Middle Eocene.

Almost every one of the greattre families hats poduced terrestrial, artoreal, anatic, and hurrowing forms. Their habits have molified, and are still shiphing their rarinus organs, first of course those ly which the animals come first and most directly into contact with their surmundings (e\% adhesive discs, dentition. general shape of the bouly, length of limbs, wartiness of

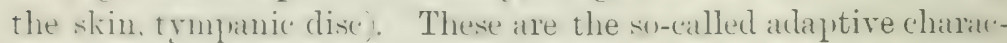
ters. sometimes decried as merely physiological; as if habits. use. and sepuirenents did not likewise influence and ultimately model erery othex organ (e.\% tympanic cavity, Eustachian tubes. rertebrate, ribs, (ocerx, pectoral arch, etc.). There are true Toads, Bufoniclate, which are as smooth, wartless, slender-bodied and longlexged as the most typical of "Frogs": true Ramidate, like Rhacophorus, which hy their green colour, large adhesive discs and arboreal habits may well put any of the Hyliclat to shame. ('erotohyla has developed the claw-shaped terminal phalange: which are otherwise typical of, and peculiar to, the Hylidate, but this genus reveals itself hy various details as a close relation of the other Hemiphractinate: and these fall in with the Cystignathidae on the strength of their cylindrical, not dilated, sacral diapophyses.

In sketching the phylosenetic tree of the families of the Anura we have to proceed with great caution.

There is not much doubt about the Aglossa. They have retainerl some of the most primitive characters, but hatre by now heen so much modified and specialised that they are to be looked upon as an early side-branch.

Anomg the Phaneroglosial the Discoglossidate are with certainty the oldest, hut are now scarce in genera and species, and much specialised. The Pedolatidare (onnect them with the Bufoniclae. The Cystignathidate form a rather ill-clefined assembly which points downwards to the l'elobatidae, upwards to the Hylidate. There is no divergence of opinion about the Finidae being the highest of all the Anuma, and amongst them the Raninate the most typical, the Jendrobatinate the most sperialised. If we assume that moderately dilited sacral diapophyses epresent it more primitive stage than cylindrical processes, we shall natu- 
rally louk to the Engystomatidae as the connecting link leetween the Pinnidae and the Arcifera, through Bufonoid ('reatmes still with teeth in both jaws. If, on the other hand, we tirke the dilatation to he a further derelopment from more or less cylindrical processes, then the Ranidae can le considerent as haring sprung from Cystignathoid creatures, which hate consoliclated their pectoral arch inte the firmistemal andition and in this case the Firmistemia would mot he al natural group, the Engrstomatidate pointing. to the Bufomoid stock. This would, to a great extent, mean a reversion to rope's idea.

Sub-Order 1. Aglossa.- The two diagnustic pexculiarities of the few members of this group are: first, the alsence of i tongue; secondly, the union of the Eustachian tules into one median pharyngeal opening in the posterior portion of the palate.

The pharyngeal opening and the tules themselves are wide, the tympanic carities are present, but the tympanic discs are not distinct from the rest of the skin. The fronto-parietal bones are fused into one mass, a rare feature in the Anura. The nasals are large. Pipa and Hymenochirus have no teeth; Yenopus has teeth on the upper jaw. The vertebrae are opisthocoelous and typically epichordal in their de-

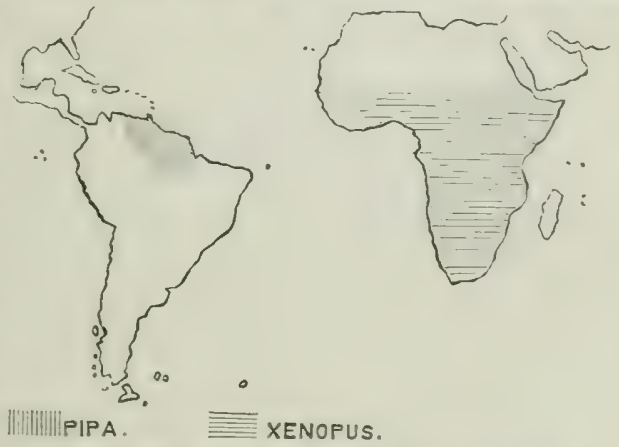

FIG. 28.-Map showing distribution of Aglossa. IIymenochims to be added in Equatorial Afric:t. relopment; the second, third, and fourth carry long ribs, which in old specimens fuse with the supporting dinpophrses. The sacral diapophyses are enormously dilated, and the sacrum is fused with the os coccygeum. The serial number of the sacral vertebrat exhibits a most interesting gradation. In Tenopus the ilium is carried by the diapophyses of the 9 th, in Pipu the 9 th and 8th, in Hymenochirus the 7 th and 6th. In these case's the two diapophyses of each side are fused together into a single broad blade, and their original duplicity is indicated only ly the 
holes for the spinal nerves. Hymenuchirus has consequently only 5 presalcral vertebrae, the verteloral rolumm being shortened to the greatest extent known amongst Vertelnata. For further information see 1. 2.2. The ilia are much brodened vertically, and are firmly attacherl to the sacrum. The shoulder-girdle is sometimes described as of the arciferous type. hut this is quite unjustifiable. The epricoraroinl cartilages in not overlal' each other, but neet, and partly fuse in the mislde. line. The three cenera exhibit some differences. In P'ipu and Hymennrhires the bony jortions of the coracodids are much expanded dorsally, and there is a considerahle amount of epicoracoid cartilage, that of the precoracoid lars extending backwards as a broad-based and blunt onosternum. Semmors is devoid of an omosternum, and the configuration of the whole apparatus is more slender. The metastermum of Fennpus and Hymenumiris broadens out laterally. Hymrnumirims greatly resembles Breviress, a genus of Engystomatinate, in the relative position and size of the varions parts of the shoulder-girdle and sternum.

The tilio-fibula of Hymenuchirus has a wing-like expansion of thin bone on each side, forming a deep' sroove on the outer aspect. The astragalus and calcaneum are united ly a similar bony expansion with wing-like projections.

The lungs are remarkable for the prominent development of trabecular projections and wiches, so that their free lumen is much restricted: they have therehy reached a much higher stage than in any other Amphibia or even many Autusauri. The persistence of an arteria sacialis s. candalis, a ressed absolutely alsent in the adult $R$ anu, is a primitive feature, and the same "plplies to the presence of a true first spinal or suboccipital nerve.

The skin of the back and beily is supplien by two great branches fiom the arteriat anonyma, one arising proximally, the other distally from the suldelavian: herewith is correlated the almost complete absence of the arteria cutanea magnat, which as a branch of the ductus puluns-cutanens plays such a prominemt rible in the other Anura. Only in P'ijm, lut not in Limorus, is the great cutaneous vein reperesented hy a rery small branch. Both these grenerat possess a much more complicated " diaphistanu" tham the other Anura, chicfly owing to at special muscle which arises 
from the anterior end of the ilia and spreads ont finn-like to the oesophagus and to the bases of the lmmg. ${ }^{1}$ This diaphrit. matic arrangement is correlated with the great development of the lungs, and is not a primitive but an alvanced feature. It is reasonahle to suppose that this has caused the reduction of the usual arteria pulmo-cutanea, and that the other two cutaueous arteries have been developed secondarily. The Aglossa are generally considered as the lowest Anura, and only Cope lookerl upon Pipa and Ienopus as two convergent teminal branches. lieddard came to the conclusion that both are closely related to each other, chiefly on account of their peculiar diaphragmatic arrangement. The whole question has entered upon a new stage since the recent discovery of Hymenochirus, which is in many ways intermediate between the two other genera. Moreorer, the inid-Tertiary Palacobatrach ns of Europe is undoubtedly related to them, and we conclude now that all these four genera belong to one group with a distribution formerly much wider than Africa and part of South America. But this does not necessarily mean that the Aglossa are in all respects the most primitive group of living Anura. On the contrary, they possess few decidedly primitive characters, namely, the long typical ribs, the presence of the first spinal nerve, the unimportant persistence of the arteria sacralis, and lastly, the possession in the tadpoles of a right and left opercular "spiracle." The absence of the tongue cannot possibly be an archaic feature, considering its universal presence in all the other Amphibia, including the Apoda, and the suggestive circumstance that this organ is least developed in the entirely aquatic members of the Urodela. In fact, thoroughly aquatic creatures, which seize and swallow their prey under water, require no elaborate tongue: and since we know that the Anura must owe their typical formation to terrestrial life, it follows that those which have again taken to the water and are tongueless, have lost this organ. As I have shown elsewhere, - the epichordal development of the vertebrae is likewise a secondary feature, far from primitive; and the tendency of the shortening of the rertebral column, which has reached its extreme in Hymenorhirns, points to the same conclusion. The alluratus of the shoulder-girdle and stemum is in the last transitional stage from the former arciferous to the typically consolidated firmisternal

1 Beddard, P.Z.S. 1895, 1.. 841.

VOI. VIII

2 Phil. Trans. B. 136, 1896, 1) 1. 
type: In fact there is little left which is primitive, but much that is very specialised and highly developed in the Aglossa, mostly in adaptation to their absolutely ayuat ic life, to which they must howerer have taken very early. They are in a position sonewhat analogous to the Ratitae among Birch, which are likewise an ohe group, although many of their most striking features lnave been acquired secondarily.

Finnms \&. Dorfyluther. The upper jaw is fumished with tereth. The ilia are attached to the ninth rerteha. The pupil is romul. The terminal phatanges are pointed. The fingers are free, the toes hroally weblyed, and the first three are corered with sharply guinted, homy, black-brown nats, at feature which is alluded to by the altermative generic names. At cutaneous tentarch frojects from below the eye and natmally invites comparison with the tentacle of the Apura and of I'rodela. The skin is smonth, rich in mucous glancls, hesides certiain tubeliki apparatuses. possibly sensory. which are scattered over the horly. especially on the heal, and form a comppicuous series of white duts along the dorso-lateral line, from the eye to the rent. The general colsur of the uner parts is olive hrown, mottled darkere while the uncter larts are whitish. The female has threw cutimeuns that ciosing the rent. The male develops black nuptial hathes along the inner side of the fingers. There are several species, all African (Ethiopian).

I. lon ris, ranging from the Caje to Abrsinite is distinguished he the absence of a metatarsal sjum. The tentacle is rery short.

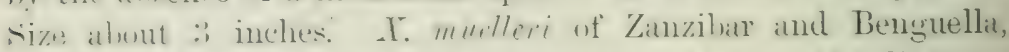

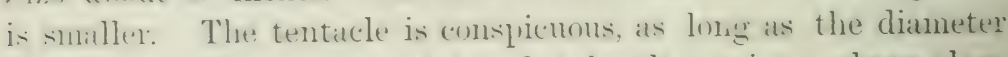
of the ere. The inner metatarsal tuhercle cascles a sharp clatw.

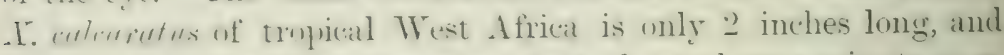
has strong metatarsal "laws, short tentacles and very minute eyes.

The hallits and oripusition of the " Clatwed Tuad" have been

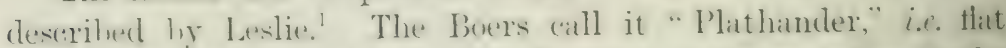
hand. Eutirely annatic, it rests fluting in the water, with the mestrils exposed, and leaves the water only if it has to change the

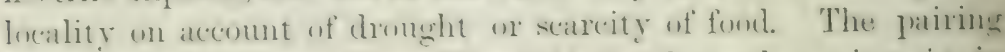
Lakes plice, at least at Port Elizalueth, in the early spromg, ief. in the month of Angust. The mly souml which is conitted is hearel

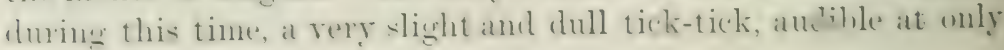

2 I'Z.S. 1890, N. 69. 


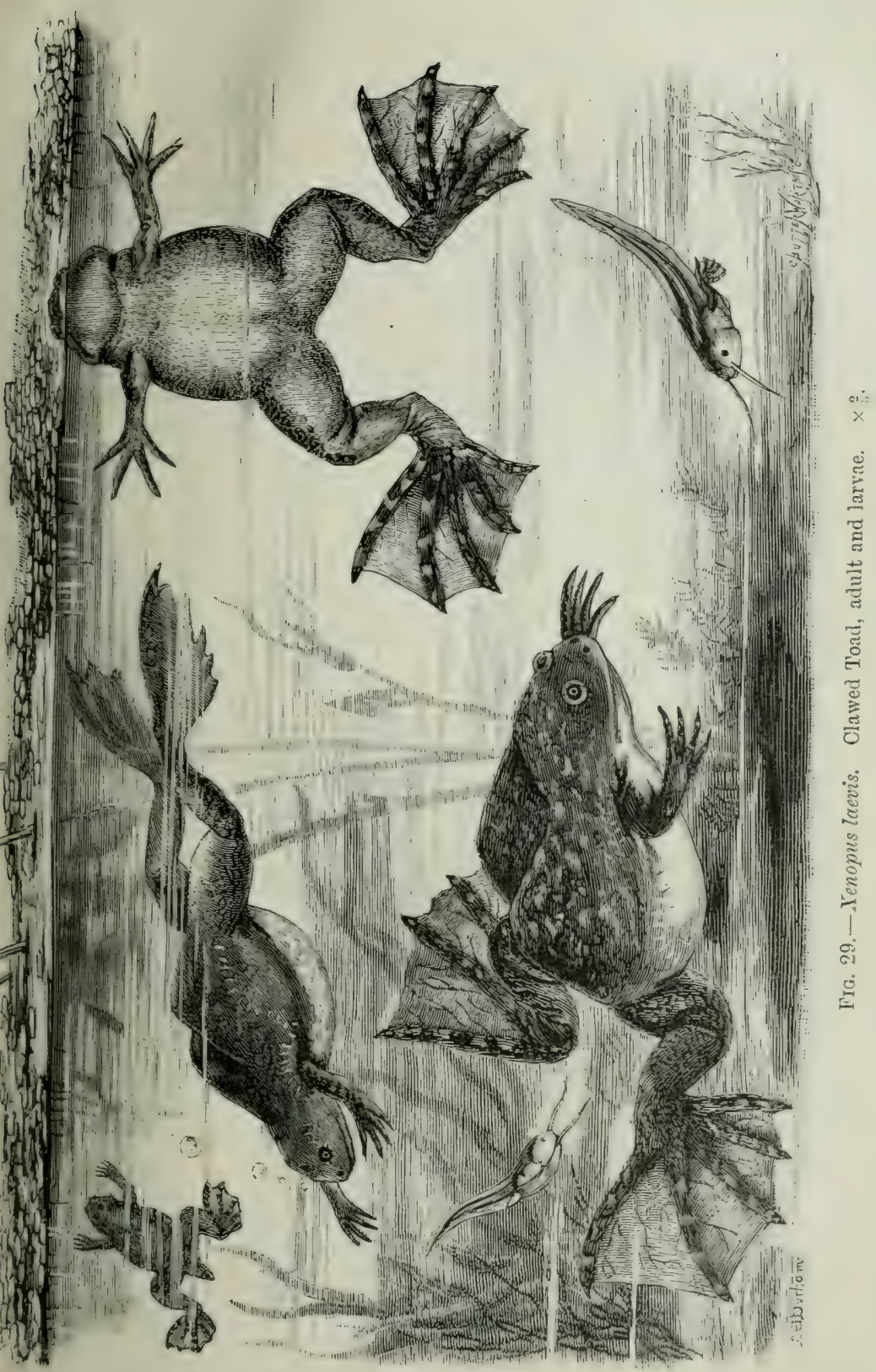




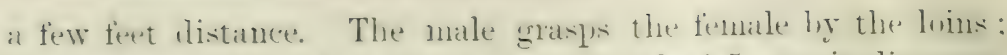
the engs are extruiled singly, measuring only 1.5 mm. in clianteter, hut swell to double that size. They are attached singly tostones or water-plants.

Latterly these creatures have frequently heen hrought were to Englanel. They stamel confinement rery well, eren in a little andurium with sufficient water-weds to heren the water fresh : and they do mot resuire special heat. They greenlily snaty wy worms, strips of liver, or meat, and puke the food in with their hames. A few kejet ly Bonlenger in a glats jar have lived for the last eleren peats in the ordinary temperature of at rom in London.

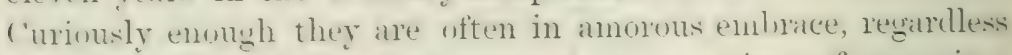
of the seatson. hint they have never shown any signs of spawning.

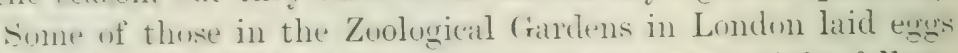
(nil Siturday the 27th of May, and wn the moming of the following Monday the larvae were already hatched. They have heen

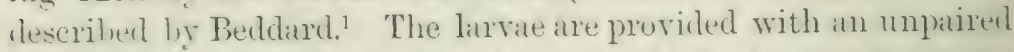
circular, rentral sucker. The tentacles begin to sprout out on the sixth day after hatching, at first not in comnexion with the cranial cartilage, hut soon a catrtilaginous rod runs into the tentache from the ethmoid " just aluse the joint with the mmler jaw." Bunlenger has most reasonalily compared these organs with the "halanceris" of Tirimn and Amblystmmen (cf. p. 46 for the pussilile homologies of the balancers). The tentacles som reach a great length and gire the tadpole a curious appearance. In tadpoles of $I$. calcaratus, $65 \mathrm{~mm}$. long, the tentacles are :30 mun. long, and are inserted just at the angle of the nomtl. By the time that these tarlyoles show their fore-limbs, the fexters are rexheed to $t$ mun. in length, and their relittive position has been slifted to a little above the angle of the gane, and whilst the latter gratually extends further and further batk, the feelers conne to lie, or ratleer renain, below and a little in front of the eyes.

The tanlpoles have no traces of homy teeth. External zills fmeject as low conical or lamellan processes from the first thee hranchial arrhes, hut so-called internal gills are not develuperl.

Anomest a number of 'lawed Tuads immorted in the spring ne lemale hecame swollen with erges, hat as they did not shem

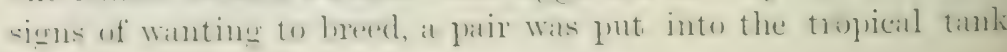


in the C'ambridge Botanic Gardens, a transfer which hat the desired effect. Eggs were laid, and more during the following nights: they hatched out within thirty hours. The whule brond was lost, before any of them were older than a few days, since they were attacked, beyond the possibility of a cure, ly at supulfynin or some similar pest.

Hymmulinas, represented by one species, H. Tuettypi, has heen discorered in the Ituri, German East Africa, and in the French Congo, and has no doubt a much wider distribution. It is scarcely $1 \frac{1}{2}$ inch long, and is easily recognised by the toothless mouth, the half-wehbed fingers (hence the generic nume), the incompletely rebbed toes, the third of which is loncer than the fourth, and the absence of sensory muciferous camils in the skin. The three inner toes are, as in Lemurtus, furnished with small black claws. The skin is rumgh, heset with small gramular tuhereles. The general colour above and below is olive-brown. The vent is, as in Tenopus, produced into a spunt or semi-canal. hut is deroid of dorsal flups of skin.

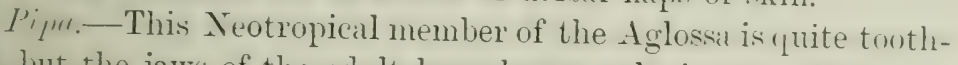
less. hut the jaws of the adult have horny substitutes. The only sprecies is I'. american, the famous Surinam Twad, chiefly knuwn from the Guianas, but undoubtedly extending much further, having recently been reported from the neighthourhood of Pará.

The general shape of this creature is very peculiar. The head is mumbh repressed and triangular; the eyes are rery small : the skin forms several short, irregularly-shaped thaps and tentades on the upper lips and in front of the eye, and at the angle of the month. The tympanm is invisible. The pupil is round. The fingers are very slender and free, ending in star-shiped tips: the tues atre broadly webbed. The whole skin is covered with small tulercles and is dark brown above, while the under parts of the very flat and depressed hody are whitish, sometimes with a dirk bown stripe along the mildle line. In the female the skin of the bick forms growths for the reception of the eggess and in these the yomg undergo their whole metamorphosis.

The most characteristic feature of the skin, ${ }^{1}$ which has exictly the same structure in both sexes, is the papillat, which

${ }^{1}$ Groenberg und Klinckowstroem, "Zur Anatomie der Pipa americana," Zool. Jnh.l. Anat. vii. 1894 , 1. 609. 


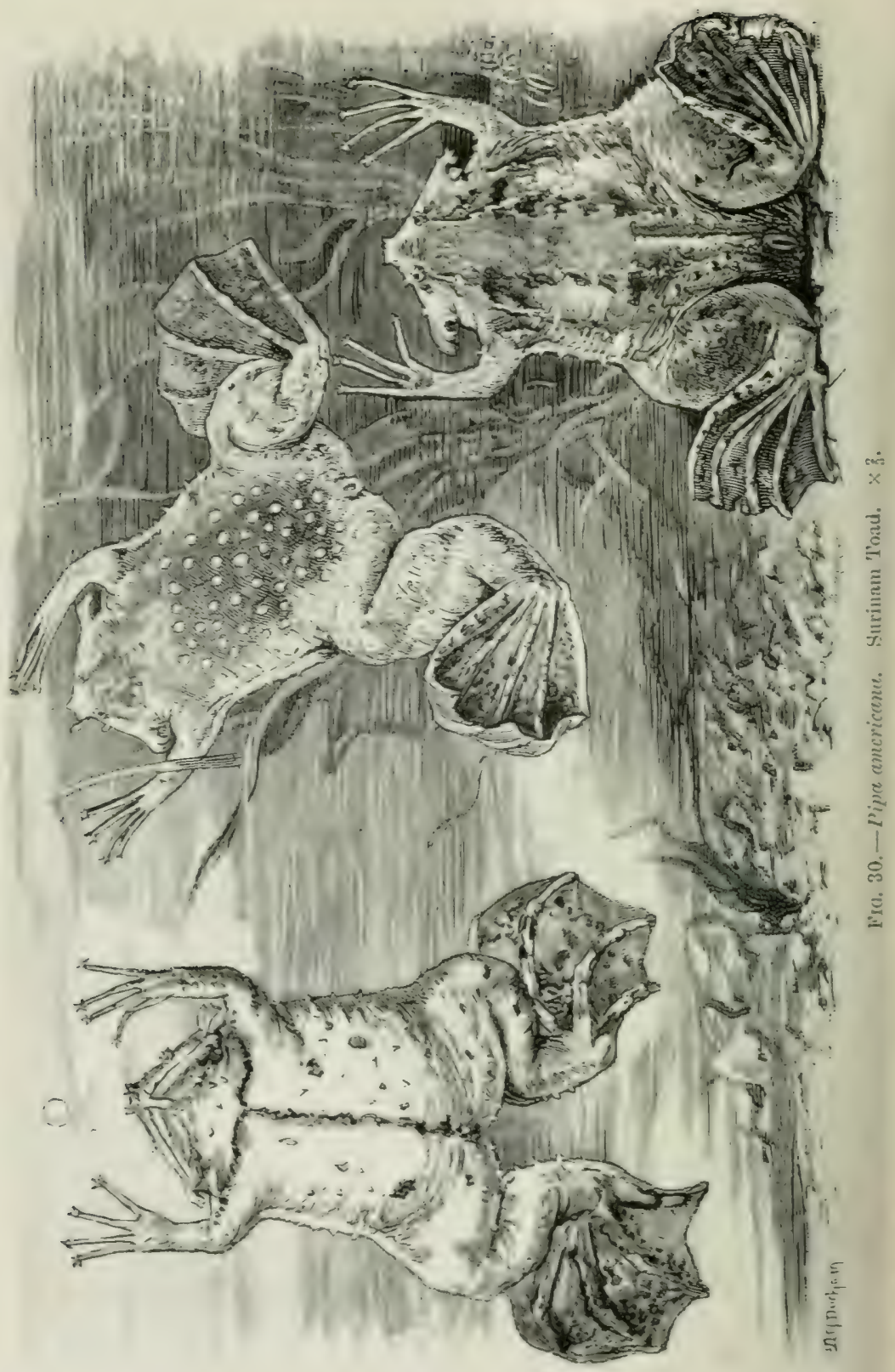


are spreal over the whole surface, except on the webs of the toess, on the cornea and on the star-shaped points of the fingers. Firch papilla carries a little horny spike, and a poison-gland frecuently opens near its base. Larger poison-glands exist on the dorsal and rentral side in four rows, and smaller glands open upon the. sides of the borly, but there are no parotoid complexes. Slimeglands occur all orer the surface. The epidermis consists of the usual layers, namely the Malpighian, the stratum corneun, and the part which is shed periodically. The latter is completely horny, appearing to be structureless like a cuticle, but it is in reality composed of polygonal cells with tlattened nuclei: eatch little spike is one modified horny cell. The whole outermost layer contains black-brown pigment. The upper portion of the cutis is deroid of pigment, then follows a laver of clusters of ramified dark pigment-cells, and lastly the rest of the cutis.

Each of the four fingers ends in a four-armed star, the tips of which again carry four or five sensory papillae. The cartilitge of the terminal phalanges is correspondingly star-shaped.

According to Klinckowstroem these toads, which are entirely arpuatic, are easily collected at the end of the long dry perioul. when they are all confined to the half-dried-up pools. But they do not spawn there. This happens after the rains have inundated the forest, and then it is rery difficult to get the females with eggs on their backs. Each of the eggs, when once they have been glued on to the back, sinks into an inragination of the skin. The initial stages are prohably the same as those caused by the eggs on the belly of Rlucopiliurus ictirulutus (see p. 248). Later, each egg is quite concealed in a cavity with a lid. These cavities are simply pouches of the skin, and are not formed by enlarged glands as has heen suggested hy some anatomists. Each cavity consists of the epidermal pouch and the lid. How the latter is produced is not hnown. According to the authors quoted above, the lid looks like a shiny or sticky layer which has hardened into horn-like consistency. It lies exactly like a lid upon the rim of the pouch itself, and is certainly not in structural or organic continuity with the epidermis. Most probably it is produced l,y the remnant of the egg-shell itself, which, after the larra is hatched, is cast up to and remains on the top of the cup. 
Bartlett ${ }^{1}$ has described the spawning of specinens in the Zoological Gardens in London.

"Alout the 2sth of April 1896 the males hecame very lively, and were comstantly heard uttering their most remarkable metallic, ticking call-nutes. On exannintion we then observed two of the males clasping tightly round the lower fart of the lomlies of the fermales. the himel parts of the males extending lexpond those of the females. On the following morning the keeper arrivel in time to witness the morle in which the exgss were deposited. The oriduct of the female protruded from her body mone than an inch in length, and the hlukler-like protrusion leing retroserterl. passed under the belly of the male on to her won back. The mate appeared to press tightly upon this

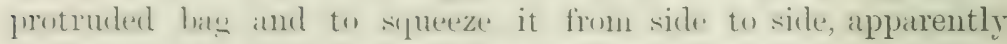

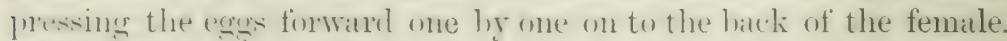
lis this movement the exges were suread with nearly uniform smonthness orer the whele surfice of the lack of the female un which they herame firmly allherent. (In the operation heing completed, the males left their plares on the females, and the enlarged and projected oviduct gradually disappleared from one of the fentales. In the other specinen, the oriduet appears not to have discharged the whole of the eggs."

Foulenger, whn exanined this second specinnen, which died, confirmed this exg-bound comblition. Ile remarks further: "The oripositor formed by the dracat not hy the prolipest uterus), Wats still pontruling and much inflamed. It may be deduced from the observation male ly the keepere, that feedundation must take place before the extrusion of the exgs, and it is probable that the oripositor serves in the first instance to collect the spermatozoil which would penetrate inte the oviducts, the

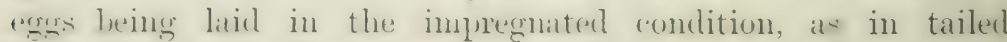
Batrachians.'

\section{Sub-Order 2. Phaneroglossa-Fam. 1. Discoglossidae.}

The tongue has the shipe of a romul dise, allherent hy nearly the whole of its hase, and it rammt he protruled. The vertebra! are opistlocoelous, and in the arguatic seneral ane of the most

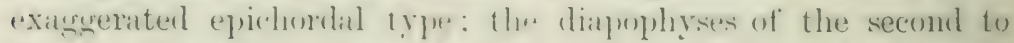
the fourth vertedrate carry shont, free rils, and these of the salcral rertelua are dibled. The metistermun hehind is forked. The 
"lpher jaw and the romers are provided with teeth. The males have no rocal sac. The tadpoles are distinguished hy haring the oprecular spiracle placed in the middle of the thoracic region (see general anatomical part, p. 44).

The few members of this family have a peculiar distribution. liupelmu is confined to New Zealand, where it is the solitary representative of the Amphibia. Aseaplers is found in Torth Americal. The other genera, Discoglussus, Bombinator, and Alytes, are typical of the Palaearctic sub-region, and are, with the exception of Bombinutor', confined to the Wrestern Provinces (cf. Map). Fig. 32, on p. 161).

Iliscoglossus.-The tympanum is indistinct, being more or less concealed by the skin. The pupil is round or triangular. The omosternum is small. The vertebrae are of the epichordal type.

1). pictus, the only species, has a smooth and shiny slin, provided with numerous small mucous glands. The palms of the hauds are provided with three tubereles, of which the innermost is the largest, and is carried by the restige of the thuml. The coloration of this species is very variable. The groundcolour of the upper parts is a rich olive brown with darker, lightedged pratches, which are either separate or confluent in varions ways. forming broad, longitudinal bands, or a few larger asymmetrical patches, separated in some individuals by a lnoad and conspicuous light hrown or yellowish vertebral stripe. An irregular redish band frequently extends from the eyes backwarls along the sides. The under parts are mostly yellowish white. This rariability is purely individual, the most differently nilukerl and rarionsly coloured specimens being found in the sanne lucality and eren amongst the members of one and the same bronl. The male develops various nuptial excrescences, consisting of minute, dark, horny spines, notably on the inuer palmar parl, on the inner side of the first and second finger, on the chin ani throat, and smaller and more scattered spicules on the belly and $\operatorname{legs}$.

This pretty and extremely active little (reature, which measures between 2 and 3 inches in length, is confined to the south-western corner of the Palaearctic suh-region, being fomnd in Algiers and Moroceo, Sicily, Sardinia, Corsica, and the sonthern and western parts of the Therian Peninsula. Curiously 
onmuh it is absent in the Balearic Isles. Thather ayuatic in its lialits, frequenting pols and streams, it is also often found on land.

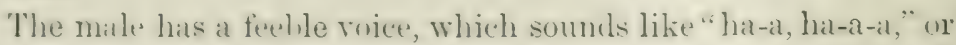
"Wal-Wil-Wal." ut tereed in rapid succession. The lairing season lasts a hong time. in Algeria from . Ianuary to October, hut a much shorter time in the moth of Portugal, where it extends over the spring and sumner months. Ibulenger has mate extensive olservations on many specinems hept in calptivity. The embrace, which nerer lasts long. is lumbir. The egess are small, 1 to $1.5 \mathrm{~mm}$. in dianeter: dark hown alme and grevish below. each sur-

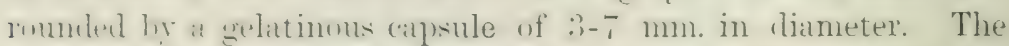

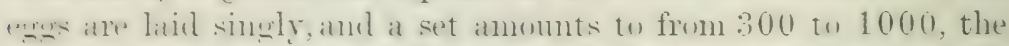
whole mass sinking to the buttom of the poul. Fach female lays sereral tines during the season. The egos are develonest rery litpilly, the larvile excitying sometimes after thinty-six hours. hit nswally from the second to the foruth diy. The external nills are lost on the serenth day, when the tadpoles are $11 \mathrm{~mm}$. long: the hind-limbs aprear on the tenth, and after four weeks the talpeles reach their areatest length. namely from :-5-30 mm. The fore-linbs appear on the thirtieth day, and a few dars later the mast precucious specinens leave the water and hop about. (1) hers. howerer, of the same broul took from two to three months in metamorphosing.

This species lives on insects and woms, and can swallow its prey under water.

Bumlinutur.--The tympanum is absent and the Eustachian tuhes are very minute. The pupil is triangular. The omosternum is alsent. The vertehrat are alsolutely epichordal. The fingers are free, the toes are webled. The upper parts are uniformly dark, and are covered with small porons warts. The general shope of the head and holy is depressed or flattened downwards. The habits are minently anuatic. This genus consists of three species, two of which are European, the third Chinese.

li. igmms. - The muler parts are conspicuously coloured hoish liark with large irregular red or orange-red patches: the upper farts are more wr less dark grey or olive hlack. The iris is wolden, sperkien with hrown. The male hals a pair of internal vacal sates by which the throat can be inflated: muptial ex"rescences alle developed on the inner sirle of the fore-arm and the 
first two fingers. Total length from $1 \frac{1}{2}$ to 2 inches, the males heing generally smaller than the females. This "Fin-lellied toad," the "Unke" of the Germans, is essentially a mative of lakes, ponds, and other standing waters of the plains.

It ranges through the whole of North (iemany, Johemia, and Hungary into Russia, eastwards as far as the Volga. The latter river, the Danube, and the Weser form, roughly sleaking. its boundaries; northwards it extends into Temmark and the southern extremity of Sweden.
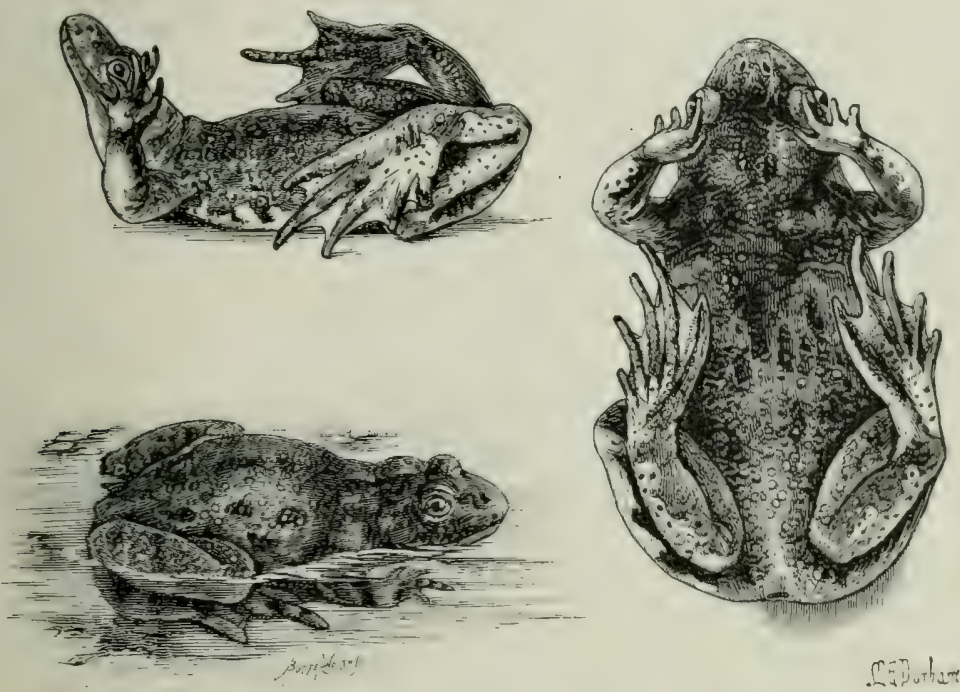

EIG, 31.-Bombinator igneus. $\times 1$. Fire-bellied Toad. 'Two of them in "warning" attitude.

B. pachypus. - The under parts are yellow instead of red. The male is devoid of rocal sacs, but has mutial excrescences on the under surface of most of the toes, in addition to those "In the fore-arm and fingers. The "Yellow-bellied Toad" is the? representative of the red-hellied species in Southern and Trestern Europe, preferring, although not exchusively, the hilly and mountainous districts. It ranges from France and Relgimu through South-Western Germany, continental Italy, and the whole of Austria and Turkey in Europe. Where hoth specles meet, for instance in the hilly districts between the Weser and the Rhine, in Thuringia and in Austria, the predilection of thr yellow-lelliel 
- jectes for the hills, and that of the other fir the phains, is well marked.

While $B$. igneus prefers standing waters with plenty of

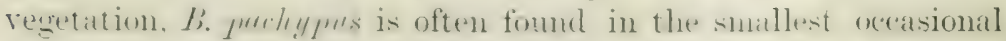
pudiles protureel be recent rain, for instance in the ruts of roaks. Touth species have otherwise much in common. They are essentially anplutic. They hange in the water. with their legs

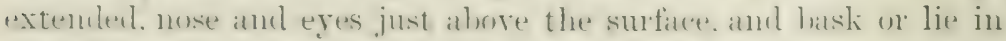
wait for prassing insects the fire-hellied kind prefering to con-

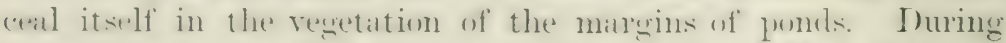
the friring seasmon, in Germany in the month of Mat they are rery lively and perform pecolliatr concerts, one male leswiming with

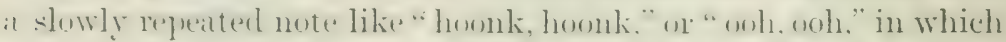
all the other males som join, so that, when thele ale many, an alnust continumes musice is puodured. This somme is not at all

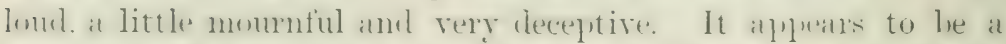
lome way off, certatinly at the othere end of the punt. until hy arreful watehing you see the little creature alnust at your rery feet. But on the shightest disturbance the performance ceases, thery dive helow and histe at the buttom. The rellow-hellied kimbl, when smprised in a shatlow puldles skims orer the mud. disturtse it, and allows it to settle 11 won its flat boxly, so that unthing but the litte whtering eyes will betray its concealuent.

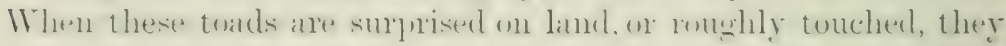
assume a most peculiar attitude, as shown in Fig. 31 . The head is partly thrown back, the limbs are turned upwards with their under surfaeses outwards. and the whole horls is curved up so that as much as possible of the bright yellow or red markings of the under parts is exposed to view. The "reatme remains in this straned pusition mutil all changer seems passerl. In reality this is an exhibition of warning colours, to

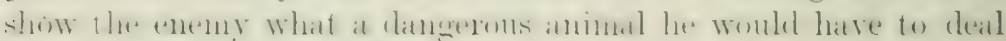
with. 'The secretion of the skin is very poisonous, and the fire-toads are thereby well protected. I know of no creature which will eat or even harm them. I have kept numbers in a

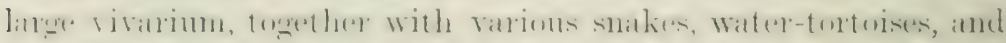

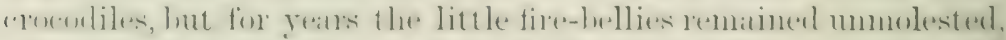

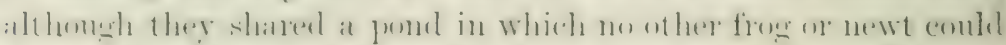

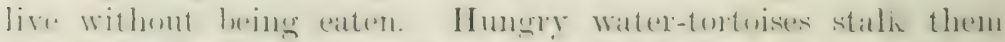

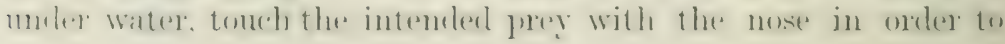


set the right scent, and then they withdraw from the Bombinutur, which has remained motionless, well knowing that quick morements, or a show of escape, would most likely induce the tortoise to a hasty snap, with consequences to he regretted hy lonth.

After they have been handled frequently, they do not readily jerform, hut simply lie still, or hop away. Miss Durhan exjerienced considerable difficulty in inducing her tane specinens to assume and to keep up the correct warning attitude. The statement that they "turn orer on the back" is a fable, grilphically fixed in various illustrated works.

It has been said that these two species are dimrnal and thoroughly ayuatic. They are certainly active in the daytine, sing in full sumshine, and spend most of their time in the water. but they display much more liveliness towards the evening and lluring the night, especially when there is a moon. My fire-toadlive by no means always in the water, but conceal themselves in the daytime under stones, while they are regularly all astir at night in search of worms and all hinds of small insects.

The spawning takes place several times during the spring and summer. The amplexus is lumbar, and the eggs are extrucled singly. They sink to the bottom, or are attacherl to water-plants. The oviposition takes a long time, rerhaps the whole night, and several dozen eggs, not hundreds as in the allied genera, make a set. The egg, with its swollen gelatimous capsule, is large for so small a creature, namely $7-8$ mm. in diameter. The embryos escape after a week, and the talpoles rach two inches in total length. Those of $B$. igneus have it triangular mouth, but in B. purhypus this is elliptical, as in Alytes and Discoylossus. Metamorphosis is completed in the sime autunm; the little toad is then about 1 i) mm. long, and differs from the adult by the absence of the conspicuous coloration of the under parts. In reasonahle conformity herewith it roes not take up the warning attitude. The colour appears gradually during the second rear, but full growth is generally not reached until the third year. They do not hibernate in the water, but hide on land out of the reach of frost.

Alytes. The tympanum is distinct, the pupil vertical, the onosternum is absent. The only two species live in southTrestern Europe. The male attaches the exgs to its hind limbs, and nurses them until they are hatched. 
1. wstetriuns, the " Midwife-tuad," has the weneral appearance of at smonth toatl. The upper parts are rather smooth, sometimes almost shing, in spite of the numerous more or less frominent warts, of which those of the lateral lines, and those above the eatr. are semerally most marked. The colour of the

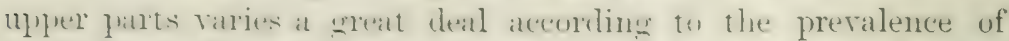

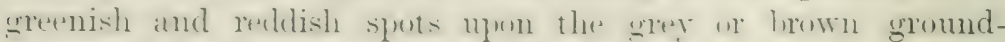
colome. The renl is sometimes, especially in the lireeding males,

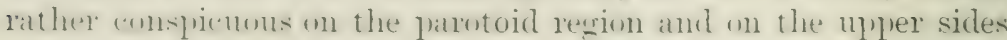
of the body: The under parts are whitish grey. The iris is

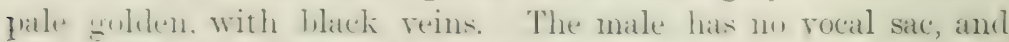
is as a rule smaller than the fenale, the latter reathing a length of two inches.

This spectes ocems in the whole of the therian l'eninsula and in Fance. extending into switzerland and heyond the Phine villey into Thuringial. Altitude above the seit does not seem to hatre any influence upen its range, which reaches from sea-level to the toys of sulatpine momitains. I have fomm great quantities of its talpules in Portugal on the Strat d'Estrella, nearly 6000

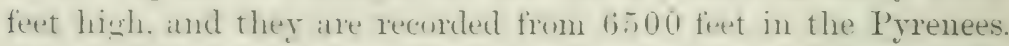
They seren to he nhiquitous in syain and Portugal, not that they are often finmel or seen, hut they are heard ererywhere: hesides, tallunles are sure to le in the clear cold lake's on the tops of the monntain-langes, in the dirty puldles ansed hy the village fountains, and in the smo-heated swanny ditches on the roalsilk with samedy enomeh water on hold the wrigghing mass. Wherever there is water within easy reach, on the lonely momtains, in fertile vallers, in the gardens of the husy towns, yen leatr during the whole night, from March to .lugust, the chulile call-note of the male. somuding like al little bell : but to sere the jerfornere is quite a difterent matter. He sits in front of his hole. dng ont hy himself ar aplungriated from a mouse, in it ratek of the luttom of a wall, umeler stones, or in at similar place into which he withdraws for the day.

The fatring and the gerouliar mole of taking care of the

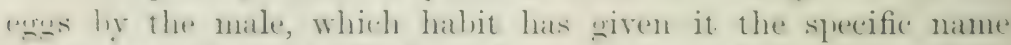

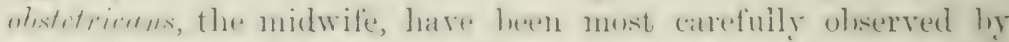

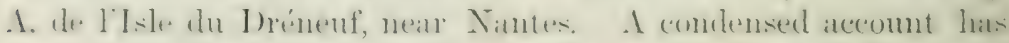
been given by Boulenger. Several males collect around a timale on lambl. not in the water. and the sucessful one grasps 
her round the waist. For nearly half an hour the male lubricates the cloacal region of the female by more than one thousand strokes of his toes, whereupon the female extends the hind-linbs, forming with the bent hind-limbs of the male a receptacle for the eggs, which are then expelled with a sudden noise. The eggs are rellow and large, up to $\bar{j}$ mm. in diameter, and are fiastened together in two rosary-like strings, sereral dozen making one set. Inuring the expulsion of the eggs the male shifts its hody forwards, clasps his fore-limbs round the female's head, and fecundates the eggis. After a rest he pushes first one hind-limb and then the other through the convoluted mass of eggs, which then have the appearance of being wound round the hindlimbs in a figure of 8 . Then the sexes separate and the male withdraws with its precious load into its hole, which it, however, leares during the following nights, in search of food, taking this opportunity to moisten the eggs in the dew, occasionally eren immersing them in the water. After at least three weeks, when the larvae are nearly ready, he betakes himself to the nearest Water, and the larvae burst the thereby softened gelatimous cover of the eggs. Not infrequently the same male rentures upon a second pairing, and adds another load to the olle which already hampers its movements. The eggs being lirge, owing to the great amount of yellow food-yolk, the emhryos are enabled to be hatched in a more advanced stage than in most other Anura. The larva develops only one pair of external gills within the egg. These appear first in the shale of oral hags upom the third branchial arch, which sprout out secondary branches, soon in their turn to be resorhed and repliced by the so-called internal gills before hatehing.

Fischer-Sigwart ${ }^{1}$ gives the following account of the growth of this species. The male took to the water, with its load of twenty to thirty eggs, on the 6 th of June. The larrae escaperl out at once, 16-17 mm. long, the body measuring $5 \mathrm{~mm}$. On the 14 th they had reached $32 \mathrm{~mm}$. in lensth, whereupon they grew very slowly, although they were well fed, in a temperature of alout $50^{\circ} \mathrm{F}$. This same hrood did not metamorphose until Iary of the next year. The growth took place as follows:The hind-limbs appeared on the Sth of September, when the tadpoles were $50 \mathrm{~mm}$. long; by the middle of the next May they 
hand reathed their greatest length, 7 i mm.. the hind-linnls heing 1s mm. long, whilst the fore-legs were just indicated. Un the 21 st of Maly the hind-limbs were $2-7$ nmo. long, and the wholes (reature was practically metamorphoserl, except for the tail. The? latter was resorbed on the 1:3th of Iuly, and the little toants, 25) mm. in length, were actually smaller, certainly far less hulky and heavy, than the tadpoles, which hat recpuired nne year and a quarter for their metamorphosis.

The anly lroods probably finish their development hy the antumm of the same rear, but those which are born later, in July and August, certainly hibernate in the watel. I have fomml very small tadpoles, scarcely $15 \mathrm{~mm}$. longs, on the ('antabrian mountains as late as the end of september, and rather litroe mes in the spring at the time of first pairing: the fict that this takes place during the whole summer explains the occurrence of tadpoles in all stages of development almost the whole rear round.

A. risterusisi has only two palmar tubercles, the midille wh thind one of A. alstrticuns being alsent : the onter finger is short and thick. Insteal of a very long and wide fronto-parietal fontamelle, the fronto-parietal bones diverge only in front sis that there are two fontanelles, a small one in the parietal and a large triangular one in the frontal region. The linhs are relatively shorter and stonter in conformity with the haliis of this species, which prefers to hurrow in sandy localities. otherwise it leads the same kind of life as $A$. olistetrims, and the male carries the exgrs. It has hitherto been found in central Spain and in the middle provinces of Portugal.

Liopelma is intermediate between Alytes and Bumbinatur, angreeing with the latter, in conformity with its essentially arquatic life, in the alsence of at tympanm, while the Eustachian tubes are entirely suppressed. The tongue is disc-shalped, lint is slightly free behind. The gupil is triangular. The male is deroid of a rocal sace. L. hombtotteri is the sole representative of the Amphilia in New Zealimb, where it is apparently rare. The upper parts are corered with smooth tulereles, and are dirli hown with lackish spots: the under parts are whitish. Tutal length only $1 \frac{1}{2}$ inch.

Fam. 2. Pelobatidae. The mpler jaw and, as a rule, the comrers are grovided with tereth. The tomgue is oval, slinhtly 
nicked. and free behind, so that it can be thrown out, except in Astrophrys turpicola of New Guinea, which has a liarw hut entirely adherent tongue. The vertebrae are procoelons, except in Astrophing and the Malay genus Megulophiys, where they are opisthocoelous. The sacral diapophyses are strongly dilated. The onosternum is small and cartilaginous. The metasternum has a bony style, and ends in a cartilaginous, rounded or heart-

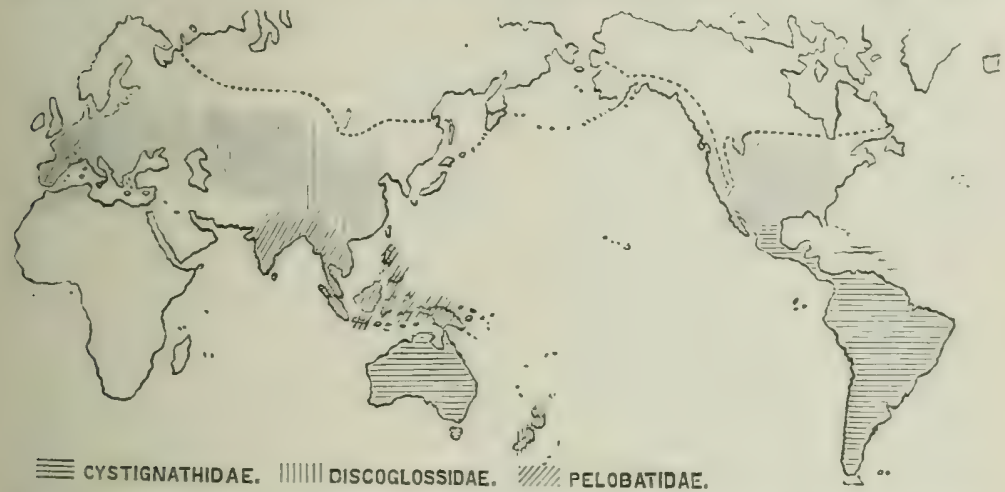

Fiv. 32. - Wap showing distribution of Cystiguathidae, Discoglossidae, and Pelohatidae.

shaped disc, but in Secopleiopus it forms an entirely cartilaginous plate. The tympanic disc is mostly hidden or indistinct, and is quite absent in Pelobates. The Eustachian tubes are very small in Pelolutes, and exceedingly minute in Scaphiopus staynalis of New Mexico. The pupil is vertical. This family contains seren genera with about twenty species, with a rather scattered distribution.

A. Toes extensively webbed, sacrum and coccyx confluent.

a. Metasternum a cartilaginous plate. America Scaphiopus, p. 164

b. Metasternum with a bony style. Europe Pelobates, p. 162.

$B$. Toes nearly free. Metasternum with a bony style.

u. Vertebrae procoelous.

u. Sacral vertebra articulating by one condyle with the coceyx.
Europe
Pelodytes, p. 165.

$\beta$. Sacral vertebra with two condyles. India and Malaya . Leptobrachium, p. 166.

b. Vertebrae opisthocoelous.

fCeylon and Malayan Islands : Megalophrys, p. 60 (Fig. 11).

(New Guineil . Asterophrys. 
Pelulutes "Spade-foot";-The trmplanum is alsent; the toes are wehbed. The inner tarsal tuhercle is latere, and is transformed into a shovel which is covered with a hard, sharp-edged, homy sheath. The skin of the upper surface of the head is partly (n-ossified with the underlying cranial hones, giving them a pitted appearance. The general shape is toad-like.

P. fuscus.- The smooth skin is brown above, with darker mathlings, while the under grats are whitish, lut the coloration varjes ereatly, from pale to dark hrown olive-grey with more (1) less frominent irregular dark, sometines confluent, patches. some specinesls are adomed with numerous red spots. The tarsil spur is yellow or light hrown. The iris is metallic reel or golden. The male has a long oval gland on the upper surface of the unuer arm, and althongh possessed of a roice, has nor rocal saces. The total length of full-grown females is nearly 3 inches, that of males half an inch less.

The "Spade-footed Toad," which occurs throughout the whole of' C'entral Europes extends from Belgium and the midule of France to North-Western Persia, and from the southern emrl of Swerlen to Northern Italy. It juefers sandy localities, in order to dig its deep hole, in which it sits concealed during the daytime. Owing to the looseness of the sand, the hole is filled up so that no trace of its inhabitant is left. The digging is done by means of the spades, and in suitahle lecalities the animal som ranishes, sinking backwards out of sight. Facept in the breeding season, or at night, it is therefore found anly acciclentally. The sand-loving halbits do not, however, prevent it from enjoying moist localities. Several which I have kint for years dig themselves into the wettest moss in preference in the drier prats of their habitation. Being thoromghly motumal, they hunt after nightfall, the food comsisting of all sorts of inserets and of worms. When eaptured they utter a startling slnill ary, and their skin becomes corered with at dernat secretion which smells like garlice, a peeculiarity which hats given them in Germany the name of " Knolnatuchskreite," "sirlic-tead." Although they hecome recy tame, so that they no, longer smell when hamelled, they can he mate ill-tempered by heing pinched or otherwise teased, wherempon they talie up $\therefore$ defiant attitude, and with open month continue to cry for

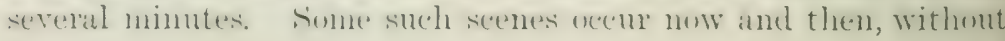


my interference, with the specimens which share their abolte with sereral species of Amblystoma and Spelerpes; there are hearl now and then sudden loud rells, like the squeak of a cat or the Japping of a little dog.

In the spring the Spade-footed Toads take to the water for about a week, and the male's call-note is an erer-repeated clucking sound, which can also be produced under water, with the mouth shut, the air being shifted backwards and forwards through the laryn. The male grasps his mate below the waist; the eggs are combined into one thick string, which is about 18 inches long, and is wound round and between the leaves and stalks of water-plants. The eggs measure $2-2 \cdot 5 \mathrm{~mm}$., and are rery numerous, a large string containing sereral thousands. The larrae are hatched on the fifth or sixth day in a very umipe condition. They are only $4 \mathrm{~mm}$. long, quite black, and still devoid of gills and tail. They attach thenselves to the empty gelatinous egr-membranes, which they possibly live upon. On the following day the tail begins to grow: two days later fringed external gills sprout out and serve for about ten days, when they in turn give way to new, inner gills. The little tadpoles then leave their moorings and become independent. The hind-limbs appear in the ninth week, the fore-limbs in the twelfth. At the age of three months they begin to leave the water. The most remarkable feature is the enormous size of the full-grown tadpole, the body of which is as large as a pigeon's egg; the usual total length, including the tail, amounts to about \pm inches or 100 mmm., but occasionally regular monsters are found. This was the case some thirty years ago, when the Berlin Nuseum received a number of tadpoles, the largest of which measured nearly 7 inches. They were found in the montl of December near Berlin, in a deep claypit with high, steep walls, so that the tadpoles were prevented from leaving the water. Similarly hemmed-in broods probably hibernate in the water under the ice, and such instances have been recorded. Normally they metamorphose into the much smaller toad within the same year.

P. cultripes. - This is the Spade-foot of the whole of Spain and Portugal and of the southern and western parts of France. It is similar in habits to $P$. fuscus, from which it differs but slightly. The tarsal spur is black, and there is a parietosciuanosal bridge which completely roofs over the temporal fossa 


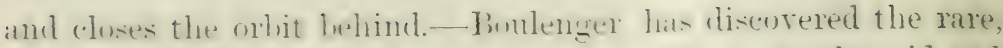
intividual ocenrence of minute teeth on the prasphenoid and

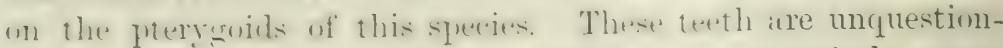
ally the latst reminiscences of a comblitim almust entirely superseded in the recent Anura.

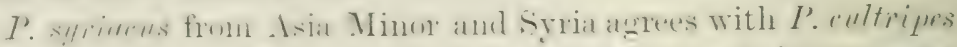
in the aranial configuration, hut has the rellow or brown spur of $P$. fuscus.
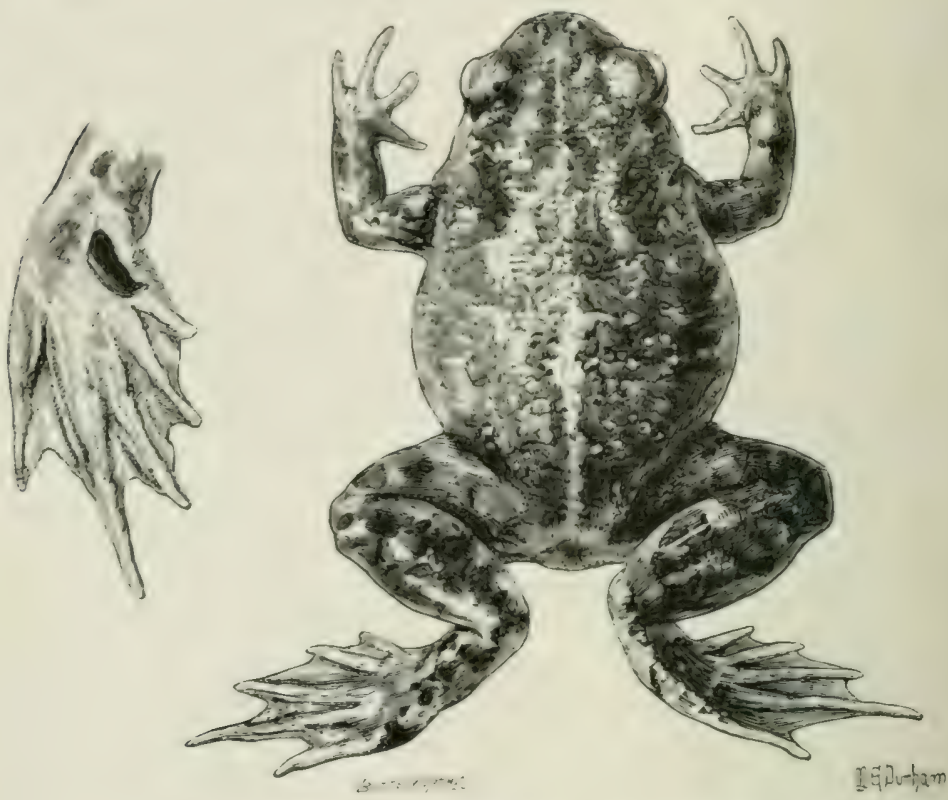

Fig. 33.-Pelobates cultripes, Spade-foot Toad, $\times 1$, and under surface of left foot.

Sinpllingms.--The Spade-font of North Anerima and Mexico differs slightly from those of Europe, chiefly by the presence of a more or less hidilen tympanmm and of a subgular rocal sac, and by the sternum, which forms an entirely cartilaginous plate without a special style. The che relationship of these two genera is finther indiated liy the occurrence of peculiar large glandular monplexes in some of the spereies, pectoral in st. solitrius, tibial

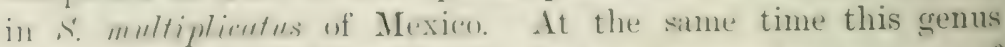

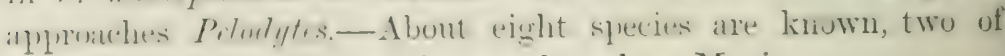
which inhabit the United States, the others Mexico. 
$\therefore$ soliturius is the commonest species of the Southern States. It is brown above, with darker patches; its total length is albout 2 inches. According to Holbrook it excavates small holes half a foot deep, in which it resides, seizing upon such unwary insects as may enter its dwelling. It never leaves the hole except in the evening or after long-continued rains. It appears early in March, and soon pairs; as an instance of hardiness Hollyrook mentions that he has met it whilst there was still snow on the ground. When teased they assume a humble attitude, bending the head downwards with their eyes shut, as illustrated by Boulenger. ${ }^{1}$

Pcluclytes is, like the rest of the genera, devoid of the tarsal diggring spur. The tympanic dise is rather indistinct; the male has a subgular sac. The general appearance of the slender body with long hind-limbs and toes is frog-like. Two species only are known, one in South-Western Europe, the other in the Cancasus.

P. punctutus. - The "Mud-diver" has the upper parts covered with small warts, and is about $1 \frac{1}{2}$ inch in length. Its coloration is variable, and changes much. One day it may appear greenish brown, the next day pale grey; in the daytime perhaps with many bright green spots, and in the evening spotless and unicoloured. The under parts are mostly white, sometimes with a fleshy tinge. The male has a voice like "kerr-kerr" or "creck-creck", uttered during the breeding season, which lasts from the end of February until May, according to the temperature and the more Southern or Northern locality. Occasionally they breed a second time in the summer or autumn. The male (levelops nuptial excrescences, chiefly three rough patches on the inner side of the fore-limbs or on the imner side of the first two fingers, while the belly and thighs are covered with small gramules. In the mode of copulation, the laying of the small and numerous eggs, the hatching of the larvae in a tail- and gillless condition, this genus closely resembles Pelobrtes; but the tadpoles never reach a colossal size, the usual length being 2 inches, and even this is comparatively large for so small a species. It inhabits the greater part of France, most of Portugal, and the southern half of Spain, avoiding, however, the central plateaux and the mountain-ranges. Its habits are essentially nocturnal, 
living in the immediate ricinity of the water. into which it hops witls a long jump in order to hide in the mud. Easily kept, it lireeds regularly in capivity, according to circumstances at almost any time of the year.

$P$. cancusicus has been discovered in the Caucasus at an altitule of 7000 feet. The remaining generat of this family contain mly a few species eatch, and are restricted to SouthTretern Lsia. the Malay and Papulan Islands. The commonest

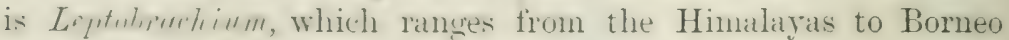
and .Tara. l'upil rertical. Vomerine teeth sometimes absent. Tongue mundish, very slightly nicked behind. Tympanum indistinct. Onnusternum small, cartilaginous. Male with internal rucal same. Tarsus with a roundish tubercle. Some of the species e.s. L. arimense from the Karen Hills, attain to a large siz", nanely, 6 inches: they seem to live on rats and mice, and one specimen contained a young squirrel.

Fam. 3. Bufonidae Turds,-The formula:- - no teeth in the "lner and lower jaws, vertelirae procoelous and without ribs, sacral diapnphyses dilated. - -is sufficiently diagnostic of this cosmopolitan fanily: The generally entertained notion that toads have a rather thick-set, short-limbed, warty appearance. does not apply to all the members of the family. The majority are quite terrestrial, namy are burrowing, the Javanese lertes is ayuatic, the Afro-Indian

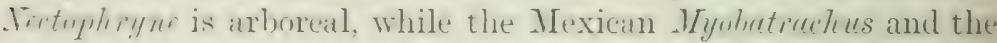
Australian lihimulhrymus eat termites and are correspondingly modified; listly, bufu, jo lum is a slemder. long-legged creature.

Teeth are alnost entirely alisent, except in situden, which has teeth on the romers. The mostermum is mostly absent. except in Enmplstummps and in some sprecies of bufo, while in Intalin it is merely restigial. The metasternum shows more varietr. The trmpanum is usually distinct. but raries even within the sane genus. heing hidden beneath the shin or heing entirely ahsent. The terminal phalanges are modified according to the hahits of the species, but they are nerer claw-shaperl.

The Fufonidate are comnected in varions direetions. The Nentropical Engystemnys greatly resembles the likewise Neotropical Cystignathoid Pulurdirulu, and the Australian P'semlopliryne closely approaches the Australian Cystignathoid ('riniu. It is therefore all the more remarkable that a similar approach, in another direction, namely. towards the Firmisternal family of the Engrsto- 
matidae, is indicated by the Mexican Rhinophrys and the Australian Inyobatrachus. Howerer, since there are no true Engystomatidae in Australia, although several genera occur in Papuasia, these cases may be instances of convergence without necessarily inplying relationship. An unmistakable line of comnexion leads, according to Boulenger, to the Pelobatidae, the link being the Himalayan Cophophryne, with very strongly dilated sacral diapophyses, with a single condylar articulation of the coccyx with the sacral vertebra (as in some Indo-Malayan Pelo-

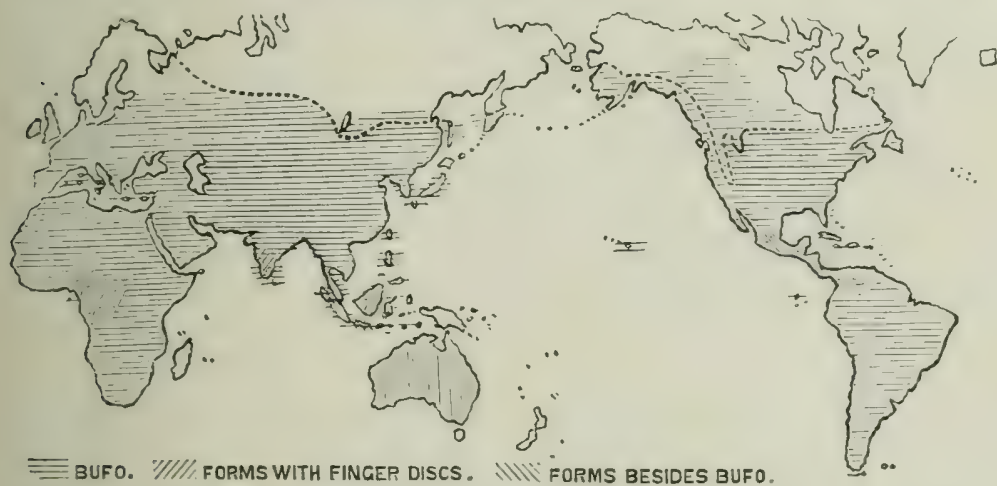

FIG. 34.-Map showing distribution of Bufonidae. The vertical lines indicate the occurrence of Bufonidae, but not of Bufo.

batidae), while this articulation is bicondylar in all the other Bufonidae.

The whole family is divided into eight genera with more than a hundred species, of which only ahout fifteen do not belong to the genus Bufo. The distribution of the family is well-nigh cosmopolitan, with the remarkable exception of Madagascar, Papuasia, and the small islands of the Pacific; Bufo has been wrongly said to inhabit the Sandwich Islands. The greatest number of species, chiefly $B u f(0$, occur in the Neotropical region, the greatest number of genera in Central America, where Bufo is rare, and in Australia, where it is absent.

A. Pupils contracted to a horizontal slit. Typically arciferous.

u. Australian. Tympanum invisible. Fingers and toes not dilated.

1. With vomerine teeth. Both the omo- and meta-sternum are rudimentary. East Australia: . Notaden bennetti.

2. Without vomerine teeth. Omosternum alsent. Metasternum cartilaginous: . 
l. Not Australian.

1. Omosternum narrow and cartilaginous. Metasternum with a bony style ending in a cartilaginous disc. Fingers and toes slightly swollen. Neotropical: . Engystomops, p. 168.

2. Omosternum absent. Metasternum cartilaginous.

a. Fingers and toes webbed; terminal phalanges T-shaped and with adhesive broadened tips. Africa and India :

Nectophryne, p. 169.

B. Fingers free, toes webbed; terminal phalanges simple, not dilated. Tympanum distinct. Java: Nectes, p. 169.

3. Metasternum cartilaginous, sometimes ossified along the middle. Fingers free; toes more or less webbed; tips simple or dilated into very small discs:

Bufo, p. 169.

B. Pupil a vertical slit. The epicoracoid cartilages are narrow and scarcely overlap. Omosternum absent except in Cophophryne. Vomerine teeth absent. Sacral diapophyses strongly dilated. The terminal phalanges are simple and the tips are pointed.

a. Australian. Tympanum distinct. The metasternum is calcified along the middle:

Kyobatrachus, 1) 184.

b. Mexican. Tympanum absent. Metasternum rudimentary :

Rhinophrymus, p. 185.

c. Himalayan. Tympanum absent. Metasternum with a slender bony style:

Cophophryne silikimensis.

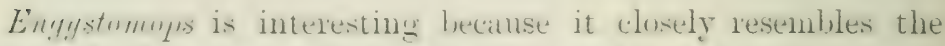

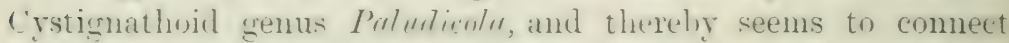
these two tamilies. It differs from I'uludianda chiefly hy the alsence of teeth, hre the moderately dilated satcral diapopligses. and hy the slightly swollen tips of the fingers and toes, the endphatanges of which are, in one species, $E$. $y^{\prime \prime}$ trisi, T- or anchorshaped. The tympanic disc is esther distinct or hidden. The males have a large sulgular vocal sac. The generic name refers to the small head with a pominent snout. Three species are known from Central America and Ecuador.

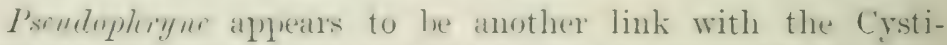

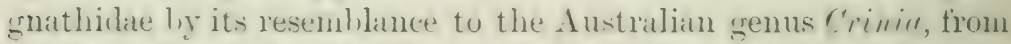
which it differs hy the absence of teeth and by the absence of an omosternum. The sacral diapojolyses are hut molerately dilated. The males have a flat wail shamb on the hinder side of the thighs, and they are provided with a subgular rocal sai: The :) ol 4 species of this gemus which live in Australia, both Eitst amd West. are not mulike fommlinmtur in their general shapes. slort limbs and colorations. The skin of $l$ '. amstomlis and $I$ '. hithoui is covered with small smonth wals and is blackish lirown. while the moler pats are hlakeish with larege gellow 
patches. Total length little more than one inch. Concerning the breeding habits, see p. 223.

Tectophryne.-The sacral diapophyses are strongly clilated. I. "fice, without a tympanum, but with fully-webbed digits and sereral broad, cushion-like or lamellar pads on the fingers and toes, inhabits the Cameroons, 1 . tubereulose of Malabar, and 1. quentheri and 1 . hose $i$ of Borneo, have a risible tympanum and the fingers are webbed at the hase only. These slender and long-legged species are most probably arboreal, as indicated ly the broadened, but truncated, tips of their fingers and toes. 1. huse is about $t$ inches long, $\mathbf{T}$. misen is a little creature of only $\frac{3}{4}$ inch in length. Iertes, hitherto known hy one species. $N$. subasper of Java, is a swimmer and exceeds 6 inches in length. The tympanum is very distinct; the small nostrils look upwards. The toes are long and webber to the tips; the hindlimbs are very long. The sacral diapophyses are strongly diliterl. The skin of the upper parts is very rugose, covered with round warts, and dark brown; the under parts are granular and uniformly light brown.

Bufu.-The great number of species, more than 100 , renders a strict definition of this genus difficult. The tongue is peallshaped, thicker in front, entire, not cut out, but free lehind, so that it can be projected. The fingers are free, the toes nnore or less webbed although never completely so. The terminal phalanges are obtuse and sometimes carry tiny discs. The omosternum is absent or merely restigial. The metastermum is a rather large cartilaginous plate with a waist, which is sometimes incompletely calcified. The sacral diapophyses are moderately dilated. The tympanum is distinct or hidden. The skin of the upper parts is always rich in specific poison-glands, il concentration of which forms in many species rery conspicuous, thickened parotoid glands. The surface of the skin may be smooth, moist and slimy, or rough and warty, sometimes corered with tiny, sharp, horny spikes and quite dry.

The genus is cosmopolitan, with the exception of the whole Anstralian region and Madagascar, from which we may perhatss conclude that its original centre was not in Notogatea, in spite of the diversity of species in the Neotropical region, which now contains about half of all the species known. Next to ('entral Imerica the Indian region is richest in species of $B$ ufo. 


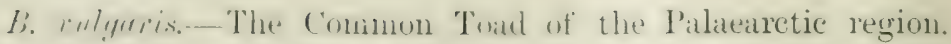
The skin of the upler parts is much wrinkled and beset with numeroms romul warts or proison-glands, the openings of which "atn le serem with the nated eve, especially on the large parotoid complexes. The outermost layer of the episterm, in fact all that gertion which is perindically shed, is elerated into numerous little andified spines. The extent of their develupment varies muth: sonthern sprecinens, espectially those from Portugal, heing gerhatp the bughest. Other's appear quite smooth to the touch, and this is the catse with many English speeinems. The skin uf the muler parts is more aramular and deroid of specific glands. The weneral colour of the uples garts is olive wrey to dark hrown. mure or less mottled: the under parts are whitish, often with a brown, yellow or reddish tinge.

The coldration of this species varies considerahly and is more-

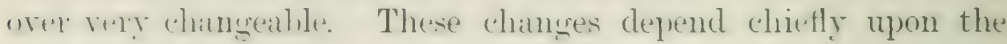
smamomeling and the locality, in which certain styles of coloration

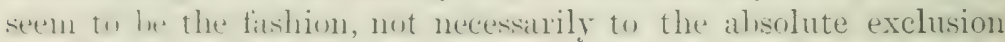
of uthers. Sunne specinens are of a rich brown colour, with or without dark hown spots and patches, and these are sometines confluent. finming irrexular, longitudinal hamb. The gromedcolonu of other indiviluals is olive grey, with or without darker patches, and these paler tones prevail in toads which live on lighteroloural soil. for instance on chalk. I recently fomel men lesteren two dark-colomed slates, and this creature was so hlack that it gave the impression of having soiled itself with coal-dust. One and the same specimen will appear paler or darker according to its mood and the leading tones of its

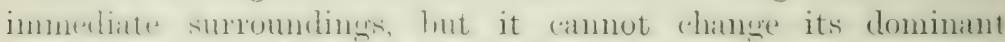

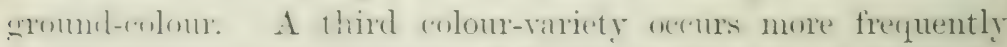

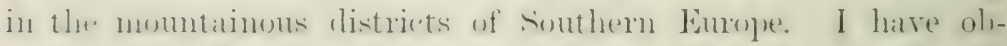
tained the most lamblsome sperimens in the serma Gerez, in North

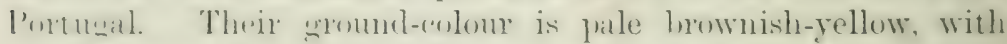
natuy latre and small, rich hrown patches, or if the latter colomir fmoluminates, these patches amb spots ale separated from each

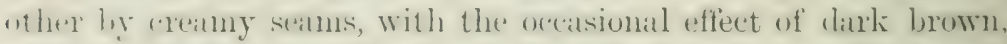
follow-ringerl eyes. Eastern Asiatic specimens often have a lime rellow vertelual line and the moler parts are inclined to be matked with dark spots.

The ixis is red or coppery, mottled with black. The male 
has no vocal sacs, and, besides being smaller than the female, is distinguished by slight nuptial excrescences in the shape of little horny brushes on the inside of the imner palmar tubercle and the three inner fingers. The full size of this toat raries extremely. Taking the standard of everyday experience in England and Central Europe, one would call any female beyond $3 \frac{1}{2}$ inches in length, and any male of more than $2 \frac{1}{2}$ inches, unusually large. But occasionally they grow to a much larger size, especially in the mountains of Southern Europe, provided there is a rich vegetation of meadows and decidnous trees so as to insure a variety of plentiful food. Although Fatio ${ }^{2}$ mentions a toad $153 \mathrm{~mm} .=6$ inches long, and Boulenger succeecled in getting a toad from Paris which measured $132 \mathrm{~mm}$., i.f. almost $5 \frac{1}{4}$ inches, one of my specimens from the Serra Gerez seems to hold the record with a total length from snout to vent of $1: 5 \mathrm{~mm}$. or more than $5 \frac{1}{4}$ inches. Jersey is also famous for its large tcads, possibly on account of the many large greenhouses. These large specimens do not constitute a special race. The nonsters among them are without exception females, often but not always sterile, as I have often found large masses of eggs in them. Food is the chief cause. At least I have observed that the more voracious of some Spanish and Portuguese specimens, which were already 3.- inches long, and therefore entitled to respect, continued to grow rather rapidly, adding about half an inch within a year. Again, if the growth of a promising toad is arrested for a season - not necessarily by starration, but by uncongenial surroundings, sameness, and unvaried nature of food-ther consolidate so to say, or settle down, and no anount of future grood feeding will turn them into exceptionally big specimens. There are no data to tell how old such monsters really are. At least ten years are required by the Southerners to reach four inches. The usual length of life attained by a toad is likewist unknown. Boulenger kept one in a box provided with a sod, "t pan of water and plenty of varied food, but twelve years of close captivity dicl not make any appreciable difference in its appearance. A number of large Spanish and l'ortugnese specimens in my greenhouse were at first rery shy, and tried every possible means of escape or sullen hiding, but gradually they condescended to take food when lifted on to the slate-covered

1 Faune Vertebr. Suisse, iii. 1872, p. 587. 


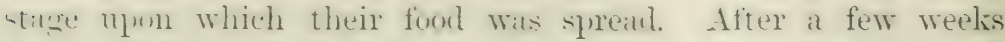
they hat leamed this so thom molly that, towards the usual hom of feenling, they climber most laboriously on to the slates, lying in wait leetween the flower-pots, and coming forward when we entered the house. The rest of the day and night they spent on the smmul, moler stones or plants, each in its indivinlual lair. The bigrest of all, and sereral others, becane si dane that they touk food whilst sitting on the hand, and then they lookerl up for more. The food must be alive and

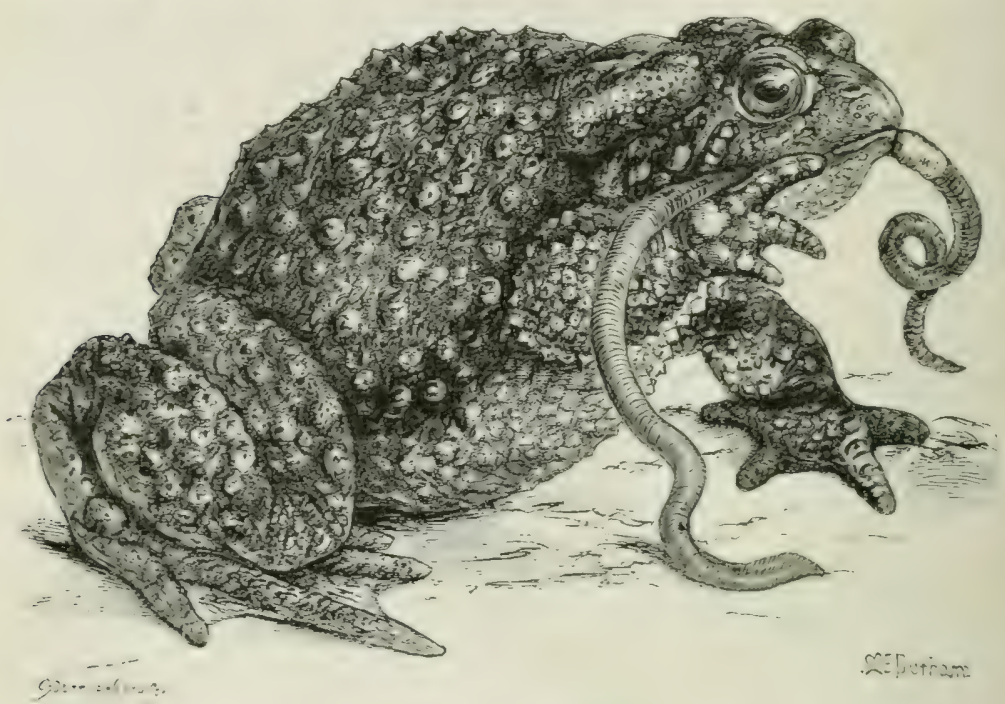

Fig. 35. - Lufo vulgaris. Portuguese specimen. $\times \frac{2}{2}$

show movement. Mealworms, snails, heetles and other small creatlues are first carrefully inspected with hent-down head, and are sumetinnes followed for a few inches: then connes an audible slin], at flish of the rosy tongue and the prey has disajpeared.

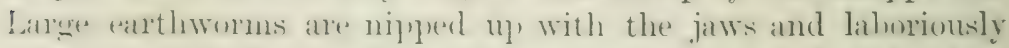
pokenl in with the hamber the fingeres heing so placed as to clean the worme of arlherent soil amel other impuxities. Verg latrge worns atre shaken. twisted, pressed against the ground ant snlperl down with ansulsive movements, but not unfrequently the tipe-tend remains for some minutes stiching out of the tightly shut month. Sereral are taken at one sitting, motil ihe toul is grenterl. () ne of the higrest touk full-grown mice, which 
were not "fascinated by the fiery eyes" but were stalkecl into a corner and then pounced upon immediately when they moreet. The slells of snails can for half a day he felt through the holy; they then dissolve or are disgorged. The dung, which is passert in large, long masses, is often full of fine earthy matter, the content: of the earthworm's intestines, and sometimes it contains the chitinous remains of certain beetles which are supposed to he excessively rare. I know of no instance of slugs being eaten.

The regular hunting-time begins with the evening and is continued throughout bright nights, the toads crawling and hopping about. They are expert climbers of rocks, and succeed in reaching apparently inaccessible places ly shoving themselves up between vertical walls, and taking advantage of any roughnesses for foothold. Every few weeks they shed their shins. Without any preliminary symptoms or loss of appetite or liveliness, the body makes a few twisting motions, the back is now and then curred, and the skin splits down the middle line. Owing to the more forcible contortions of the body it slides down to the right and left of the back, whereupon the toid gets hold of the peeling-off skin with finger's and toes, scraping the head and sides, and conveys the thin, transparent, slightly tinged skin into the mouth, slips out of it hackwards and swallows it. The new surface is then quite wet and shiny, but it soon dries and hardens.

Many toads, for instance the Common Toad and the Pantherine Toad, assume a peculiar attitude when surprised. Instead of blowing themselves up by filling their lungs with air, they raise themselves upon their four limbs as high as possible, but turning the back towards the enemy in a slanting position, either to the right or to the left side, apparently in order to present as much surface as possible, in other words to look their biggest.

Siome of my specimens hibernated regularly for a few months, hurying themselves completely in loose, dry soil, under leaves, or, - a favourite place, - in a heap of cocoa-nut fibre. Others, and this applies also to English specimens transferred from the garden into the greenhouse, are lively all the rear round, but even they withdraw for an occasional sleep of a few weeks at any time of the year.

The whole family of large toads came to a sad end after four years, when they were put into new temporary quarters, a slate- 


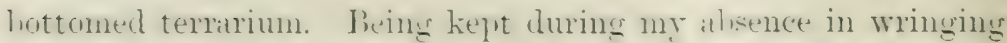
wet moss, which hecane fouled hy their own excretions, they contracted a mysterions distase from which they never recovered. They are rather averese to wet surromelings. and except during the short pairing seasom they live in conl. shanly places, preferably with just a little dampmess. Occasionally they take a soaking lath. One specinem, living in the garden, repraired during the hot and dry summer nights to a standpipe in the garden, enjoying the occasional drips of water.

Comsillering the amount of snails and other noxions creatures destroverd hy then during their rewular nocturnal hunts, toads are eminently useful creatures. Nevertheless, they suffer much through the stupin superstition of people who ought to know hetter. It is difficult to fimel a gentle, alsolutely harmless and useful creature that is more maligned than the Enropean toad. It lurings ill-Inck to the house, the "sliny toad" spits renom, sucks the cows' ullers and after that destroys their power of giving nilk: it poisons the nille in the cellar, and a certain huilder s horse, which was grazing in the eromuls of the Cambritge M[nsemus, and died there frum a latere concrement obstructing its bowels, was solemmly declared to have swallowed one of my tuals. Silly sulustitions, wwing to faulty, or rather entire want of, observation: The toad is not slimy, hut dry: it is often fomel in hulilings, where it keeps down the wodlice; it cannot suck, nor does it drink at all; it does not spit venom, but heeomes corered with milky white and rery strong poison whe'n in acute arony, for instance when trodelen upon: and unless the

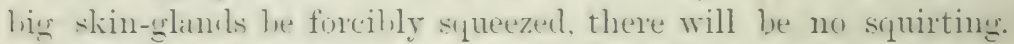
Therefore, leare it alone, or jut dhwn food on iss erening beat, and it will som conte to know and to recognise its friends.

The fommon Trat can exist without fool for a long time, fmoviled the locality is cond and clanl, hut it wastes away almost to skin and lones. In moler to dispore the fersistently cropping ul fable and sensational newsplitereaceomnts of toads having

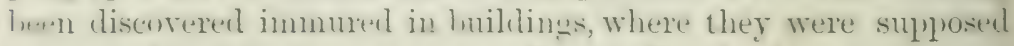
(o) have livel for many years, Frank Puckland put a dozen

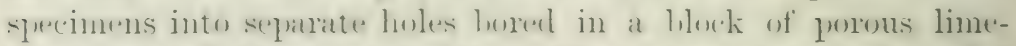
stome, covered them up tiglity with a glass jlate and huried

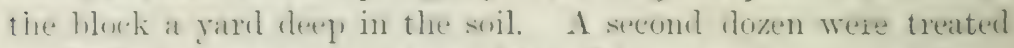
-indiarly, hut were put into a block of dense sandstone. After at 
year and two weeks all the toads enclosed in the latter block were of course found dear and decomposed, but most of those in the porous hlock were still alive, with their eyes open, anc dis not succumb to starvation until eighteen months of confinement. These poor creatures could of course not move about, and were practically undergoing enforced continuous hibernation. (Jtherwise they would soon have wasted away and have died within six months. Those which tumble into deep and dry wells remain rather small, but generally manage to heep alive for rears on the spiclers, woodlice, earwigs and other insects which likewise tumble in.

Toads hibernate far from the water in dry holes or clefts, retiring in the middle of October in Central Europe, and they do not reappear before March. Soon after, and this depends naturally upon the season, they congregate in ponds or ponls, and the males, which far outumber the females, for whom they fight, make a peculiar little noise, something like the whining bleat of a lamb, uttering this sound day and night. The male having, after much wrestling with competitors, secured a female, which is often several times bigger than himself, clasps her tightly; hy pressing his fists into the armpits, and the pair swin or crawl about in this position sometimes for a week hefore the spawning takes place. The number of eggs laid at one sitting is enomous, varying from 2000 to 7000 . They are very small, only $1-5-2 \cdot 0$ mm. in diameter, and are expelled in two doulle rows or strings, one coming out of each oviduct. These strings consist of a soft gelatinous mass, in which the double rows of entirely lyach eygs are imbedded, and they measure in the swollen condition about $6 \mathrm{~mm}$. or $\frac{1}{4}$ inch in diameter, and from 10 to 15 feet in leugth. The strings are wound round and hetween water-plants by the parents, which move about during the laying and fertilising process. According to the coldness or warmth of the season the larvate are hatched in about a fortnight, and for the next few days they hang on to the dissolving gelatinous mass of the egg-strings. They then leave the slime and fasten themselves by means of their suckers to the under side of grasses and water-plants or sticks, with their tails hanging downwards, still in a rudimentary condition, but henceforth progressing rapidly.

Fischer-sigwart ${ }^{1}$ found the time of derelopment as follows:

1 Zool. Garten, 1885, p. 299. 
-The egs we laid on the 6th of March: the larvate left the .elly on the $16 \mathrm{th}$, leing $t$ mm. long. On the ond of April they

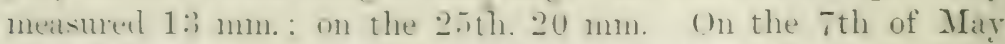
the himb-limbs alupatred. On the 1 sth of Mat the tadpoles hat reached their greatest lenerth, namely $2+1$ mun., and this is a rather small size for so large a spredies. The fore-limbs hroke throngh (n) the -2sth, and the metamorphosis was completed eighty-fire liats after the egos were laild, the creatures learing the water wh the :30th of May. The tallpules showed a preference for rotten pieces of Ayminus. which were fluating in the water. The little baby-toats are surprisingly small, scarcely $15 \mathrm{~mm}$. long, and live in the grass, under stones, in cracks of the ground, and lup abunt in much hetter style than their heavier and more dunsy-lonking parents. Where many hroods have been hatched they can lue net with in myriaks, the ground literally swarming with them, amel as they are natually stirred up by a suclen warm rain, perhaps after a drought, people will occasionally state it as an ubserred and well-ascertained filct that "it has rained toads."

What hecomes of all these hopeful little creatures! Although it take's them fully fire year's to reach maturity, one would expect that the whole country would he swaming with toads: but since this is not the case, there being not more toads now than there were lefore, it follows that their enormous fecundity is only just sufticient to lieter the race going. Achult toads seem to have scarcely any enemies except the Grass snake, which takes them in default of anything hetter. But how ahout the reduction where there are nu snakes! Te know nothing about epilemies which might carry them off, but elderly toads are liable to a horrible disease produced hy various kinds of Hies, notably hy Lucilin

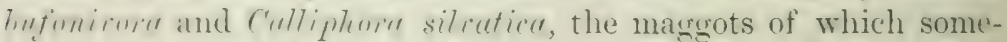
how or other eat their way from the nostrils into the brain and inte the eres. Those which reach the brain at first produce effects similar to thuse of Connerus cerelorulis, the hydatid or hiddde'-worm of sheer. The toad inclines its head towards one side, and cannot crawl straight, lut walks in a circle. By eating away the liain they gradually destroy the host's life. But if mone enter the linin, and a few only find their way into the "ye. they only inpratr or destroy its sight. Such bats show sinns of pain, poling at w stroking the affected eye, which hecomes 
inflamed, and ultimately remains enlarged, with the iris partially or entirely destroyed by the maggot, which does not (levelop further, but dies in the eye-chamber, this being really an unsuitable place for it. The eyesight is of course affected, and is mostly, but not in all cases, lost. Such half-blind individuals - the disease affecting sometimes one eye only-recorer their health, and except for a little awkwardness, behave like normal specinens. This applies to Bufo vulgaris as well as to B. colcumitu. Australian Anura are cursed with a fly of their own, called Batrachomyiu. ${ }^{1}$

D. vulguris inhabits almost the whole of the Palaearctic region; - the whole of Europe, with the exception of Ireland, the Balearic Islands, Sardinia and Corsica. Northwards it extends to Trondhjem, and thence along a line drawn across Russia and Siberia to the Amoor. Its southern limit in Asia is indicated by a line dram from the Caucasus through the Himalayas into China. In Asia Minor and in Persia it is absent. South of the Mediterranean it occurs only in Morocco and Algeria.

B. melanostictus is the common toad of the whole Indian region and of the Malay Archipelago. The epidermis of the fingers and toes is thicker and more cornified than usuld, and is stained black brown, hence its specific name. The male has a sulygular rocal sac. In other respects the Indian species much resembles the more spinous or rough-skinned and brown varieties of the European species. According to S. S. Flower this toad is very common in the Straits Settlements, hiding by day under stones or $\operatorname{logs}$, or in holes, coming out shortly hefore sumset, and remaining abroad till dawn; it may be met with on the roads and in the grass, hopping or crawling ahout in search of ants, bees, and similar food. It utters a rather feeble, plaintive cry when hantleil for the first time. It can change its colour from light yellowish to dark brown. The spawn, which resembles that of $B$. rulyeris, micy be seen in March and April in ponds, in long strings twined ahout the water-weeds. The tadpoles are rery like those of the common English toad in form, size, colonr, and structure of mouth. The largest adult found in Penang measured $115 \mathrm{~mm}$. (about 4 inches) from snout to vent.

1 For further information, ef. Portschinsky, "Biologie des mouches copro. phages et nécrophages, 2 me partie. Étude sur la Lucilia bufonivora, parasite des batraciens anoures."-Horce Soc. cnt. Ross. xxxii. pp. $225-279$ (in Russian). German summary in Zool. Centralll. v. 1898, pp. 855-859.

VOI. VIII 
P. Intiginusess somriemus is the common toad of North Anerical. from Mexico to the (rreat Bear Lake. It is worth noting that this species resembles in its coloration the Eastem races of $B$. rulgriois, in so firl as they generally have a light restedral line, and frequently diark spots on the under surface. The mprel parts are brown and olive, with darker spots, two of which form it cherom helind the eyes. Int the tympanum is linge, and the male his a sulgular vocal sac ; the inner metatarsal tulerele is rery large, and is used as a kind of digging spur. I) ming the paring tine they take to the pools in great numbers, nttering their music, which consists of a prolonged trill, continned ly different individuals, both day and night. Hollmook knew an inclividual which was kept for a long tine, and hecame perfectly time. During the summer months it retired to a corner of the room into a habitation which it harl prepared for itself in a small quantity of earth placed there for its convenience. Towares the evening it wanderes ahout in search of food. Some witer having heen syneezed from a shonge nyon its head one lint day in July, it returned the next liay to the spot, and seened well pleased with the repetition, nor did it fail during the extreme heat if the summer to reprair to it fremuently in search of its shower-bath.

sereral varieties of this wilely distributed sprecies, whose average length is $2 \frac{1}{2}$ inches, have lexen described. The prettiest was called B. quencinus hy Hollurook-according to whom it is mutly foumel in sindy places corered with a small species of mak-which springs up aloundantly where pine-forests have heen destroyed. It is called the "oak-frow," as it spends most of its tine in concealnent under fallen oak-leares, or partially buried in the sand.

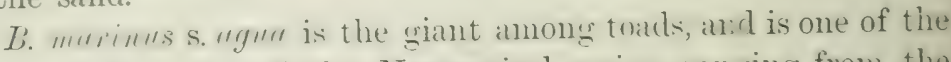
commonest species of the Neotropical rexgion, ranging from the Antilles and Mexion to Argentina. It frequently reaches a length of if inches, with a width of $t$ inches when squatting down in its farourite attitule. The mples parts are sough, owing to the prominent warty ghlands, of which the patrotoid complex is anommons. The general colom alove is clark hown, with sooty dark pratches; below whitish, often with hatckish patches. This

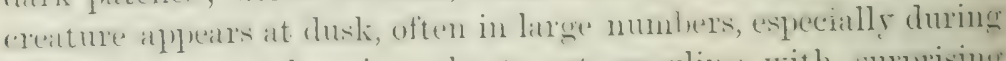

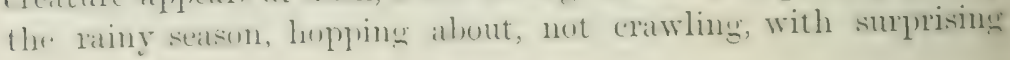


activity. The voice of the male, strengthened by a sulygular sac, is said to be a kind of loud snoring bark. The pairing time begins, according to Hensel, ${ }^{1}$ with the winter rainy season, especially June, and lasts sereral months, until Octoher, hut it is interrupted by the cold, which in the hills of South-Fastern Brazil covers the ponds with ice. Then the tremulous hass voice of the males is heard no longer; they have all withdrawn beneath stones and trees in the neighbourhood of the water. The eggs are laid in strings. The larvae are at first quite lilack and very small, and the young baby-toads are only 1 ''n. in length. They differ considerably from the adult until they are more than 1 inch long; the upper parts are yellowish brown, with darker ocellatel patches, each with a light seam, most conspicuous along the sides of the head and back. The under parts are grey, finely stippled with yellow.

Bulgett ${ }^{2}$ remarks that $B$. marinus feeds on all kinds of insects. "One half-grown specimen sitting by a man's foot picked off fiftytwo mosquitoes in the space of one minute, picking them up with the tongue as they settled. The call of this very common toad consists of three bell-lilie notes; the middle one being the highest. The enormous parotoid glands are discharged like squirts when the creature is roughly handled. When wet weather comes on it hops out from its hiding-rlace to sit in a puddle, with its head out."

In many species of Bufo the crown of the head forms more or less prominent ridges, especially strong in the region between the eyes; for instance, in B. melcustictus and B. lentiginosus. The skin overlying these ridges is liable to be involved in the cranial ossification, and this reaches its greatest extent in the two Cuhan species B. cmpusus and B.peltocephulus. It is a curious coincidence, to say the least, that such dermal ossifications should be best dereloped in Neotropical species, in those rery countries which amongst the Cystignathidae have produced the abnormal grenera I'riprion, Calyptocephalus, and Pternohylu. The most peculiar and odd-looking species is Bufo ceratophrys, a native of Ecuador, which has the upper eyelid produced into a horn-like ippendage, the two sharply-pointed cones standing out transversely, reminding us of several species of the C'ystignathoid semus Ceratophrys; there is also a series of four small pointed 
alpendages on each side of the horly. I'rotertive concealment is possibly the reason of these queer outgrowths.

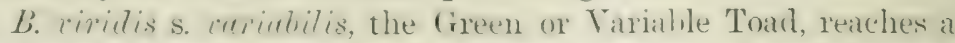
length of alout : inches, and is the prettiest toad of Emope. The skin is distinctly smooth, the numerens porous, large and small warts heing flittened. I'arotoid glands are well dereloped, and a similar pair of glands sometimes occurs on the imner side of the calf, especially in Central Asiatic and in Algerian specinens. The coloration is resy valiable and changealile. The groundcolomer of the upuer parts is creany, with litrge and small, partly contluent and irregularly shiped spots and patches of preen, here and there interspersed with rermilion-red specks, especially along the sides of the back. The under prits ane whitish, sometines spotted with hlack. The iris is hrass-colomed, greenish-yellow, with fine dark dots. The male does not differ from the female in size, but has an internal subgular rocal sac, a conspicuons allosity on the imer side of the first finger, and nuptial brushess on the first three fingers and on the inner palmar tulnercle.

The ehanging of colour affects mainly the intensity of the sreen; the same individual which now looks almost uniformly dull, almost grey, with dusky olive patches, will, if put into grass and sprinkled with water, within a few minutes appear in a tastefully combined garl, of grass-green on a creamy gromod. fome Southern and Eastern specimens hare a creany stripe along the vertebral line, thereby closely resembling $B$. calcamita, from which, howerex, they can always be distinguished ly the little pads below the joints of the toes: these pads being single in $b$. viridis, and double in B. calamite and in B. vulgaris.

The Green Toad spends most of the day in holes, although it is not averse to dayglight, and it roams alout chiefly in the evening. It can jump well, much better and oftener than the Brown Toad. The food consists strictly of insects of all kinds, and most individuals prefer slow starvation to eating an earthworm. Althomeng continuing to live four on five years in captivity, they do not readily become tame: they are indeed no lomger wiln, and when hambled they no longer enit their preculiar insipid smell, but

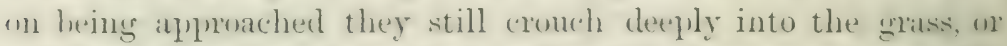
withdraw into their holes, just as they did when recently catuht. The voice is heard during the priring season, and sommes like the slow areaking of a door, or a comblination of a spimning topl and 
rattle. In Germany, during the months of April and May, they take to the ponds, or, improvident like the common frog, to a roadside ditch. The male sits upon the female and grasps her below the arms, his hands on her breast, and in this pesition they remain for days. The eggs are laid in two strings, twisted around water-plants, and are rery numerous. Héron - Foyer has calculated them at 10,000 or more in one set. The emhryos are hatched, like those of the Common Tuad, before the ippearance of the extemal gills and of the tail. In this imperfect condition they remain in the jelly of the egg-strings for a few days, while their extermal gills sprout out like unbranched little stumps, only to disappear again. In about eight weeks the tarlpoles, which reach a length little more than 1 $\frac{1}{2}$ inch or 40 mm., have metamorphosed and leave the water as baby-toads scarcely half an inch in length.

This species has a very wide range, namely, the whole of Midhlle Europe excepting the British Isles, France and the Therian Peninsula; the region between the Elhe and Rhine being its western limit; southwards it extends orer all the Mediterramean islands and the north coast of Africa, eastwards through the whole of Russia, Western and Central Asia, not entering India, but spreading along the Himalayas into China. Stoliczlia mentions its having been found in the Himalayas at an altitude of 15,000 feet, the highest record of any Amphibian, at least in such latitudes.

B. cromita.-The Tatterjack is practically the representative of the Crreen Toad in Western Europe, lut both species occur together in Demmark, Southern Sweden, and nearly the whole of Cermany. Its southern linit is Cribraltar. In the British Isles it occurs in South-TVestern Ireland, in Co. Kerry, and in Fingland and Wales, heing howerer local, and preferring sandy lncalities, where it is found in consiclerable numbers. This predilection is shown by its frequency on the sandy dunes of most of the islands off the German and Inutch coast, where it may be seen running about in glaring sunshine.

Besicles in the coloration, it differs from $B$. viricis in the following points. The little subarticular pads of the toe-joints are jaired, not single, and the hind-limbs are deciledly shorter, so much sn that this species camnot hop. But it runs well, like a mnuse, generally in jerks, stopping every few seconds, and owing 
to this habit it is callerl the "ruming tam " ly the fieldlabourers of Cambrilgeshire. The skin is smooth, but less so than in B. riritis, owing to the slightly more prominent warts; the prarotoids are small: a similar litir of glands lies on the mplen surfice of the fore-itrin and another on the calf. The trmptnum is rather indistinct. The ground-colom of the npper parts is light hrownish rellow, with a green tinge and scattered frenth sputs: must specimens have a nimrow yellow stripe along the vertebral line and over the head. The under parts are white. more or less specklect with hlath. The iris is greenish yellow and speckleml. The male, which is of the same size as the female. -rery large specinens reaching :3 inches in length,hats a large subgular rocal sace, and dereloges nuptial brushes on the first three fingers, but the first lacks the thickened pad of B. rivitis.

The rellow vertelnal line is sometimes absent in specimens from the sonth of France and the Therian P'eninsula; and since these suntherners are at a rule nore handsomely marked, the slextr being mole promonuced and arranged in larger patches. interspersed with red slots, they much resemble $B$. riridis. Bumlenger, who hats paid especial attention to this rertebral streak, which is a not uncommon lesign in rarious species of different finnilies, lats nate the interesting observation that the streak has never heen fomel in Janish and (reman specimens of $B$. viridis, where $B$. calamita occurs also, while it is not nnemmon in $L$. Ciritis of Italy, South-Eastern Europe, Asia. and North Africa, where b. calemitu is not found. Lastly, he remarks that in Eistern Asia, where neither $B$. ririlis nor B. culamitu with such a line occurs, the same character is

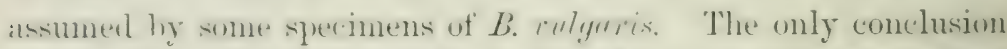
we cann draw from these facts is, that for some unknown reason the streak is a desirable, hut not neessary, possession, but that it is mot kept ly two species in the same country, be rividis dropping it entirely where the typically streated species

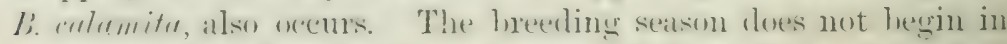
Emeland and Mirlde Eurole until the end of April, in cold springs not hefore May, hut it lists for several months. The males, conerresating in pools in great numbers, make a loud noise, each inclividual uttering a rattling note which lasts a few seconds. 1he repretition distemoling its hoish throat into the shate of at 
globe as large as its head. As the note is taken up, by all the other males, a continuous chorus is established, which on warm and still nights can be heard nearly a mile off. Single croaks are uttered at any time of the day. The embrace, the male digging its fists into the armpits of the female, often takes ylace on land, near the edge of the water, to which they resort in the night for spawning. The egg-strings are slung around waterplants, unless the water is a mere puddle, and are much shorter than those of $B$. viridis, measuring only 5 to 6 feet, and containing altogether 3000 to 4000 eggs. The larvat, when hatched, are very small, imperfect, and blackish: the external gills last a very short time. The young tadpoles live on mud, sulsisting on diatoms and low Algae: they are the smallest tadpoles of all the European kinds, scarcely reaching more than one inch in length, and they metamorphose quickly, the baby-toads leaving the water and rumning about in less than six weeks, when they are only $10 \mathrm{~mm}$., scarcely three-eighths of an inch, in length. Br the end of their second summer they are still only three-quarters of an inch long, and they do not reach maturity until the fourth or fifth year, with a size of $1 \frac{1}{2}$ to 2 inches; still smaller young males hecome mature several years before they are full grown.

Natterjacks stand captivity well and become very tame. Then discovered, they first do their best to run away, instead of hiding or squatting down, and when caught they become corered with a slightly foany lather, the exudation of their glands, which has a peculiar smell, reminding some people of gumpowder, others of india-rubber. They are not rery particular as to food, all sorts of insects and earthworms being taken. Natterjacks are great climbers and diggers. Many of mine have estallisherl themselves in the peat with which the walls of the greenhouse are covered, where they have dug out, or enlarged, holes in which they pass the daytime, just peeping out with their bright eyes; others sit high up, always in dry places, and bisk. In the evening they descend, hunting about on the ground, and occasionally they go into the water, whereupon they become quite flaccid and soft. When taken up and held hetween two finsers, being slightly pressed under the armpits, both sexes utter little jerky notes, as-by the way-most toads and frogs do undèr similar conditions.

In Cambridgeshire they frequent certain clay-pits surrounded 
hy ligh and steep walls of sand, the breeding places of large colonies of sand-martins. During the months of May and June they are found in the shallow water, rumning about on the mud, sometines swimming, in which they are not very proficient, and rarely diving. But they spend most of the time on land. Early in (detuler they climb up and enter the holes of the sand-nartins, or they dig lirge, deep burrows for hibernation, and the old males are the first to disappear.

b. murrituniar s. pontherina.-The "Pantherine Toad" is one of the few African species, and is one of the prettiest of all toads. The skin is almost smooth, although provided with porous glanrls. The parotoids are large, but flat; large glandular complexes on the legs or arms are alsent. The tympanum is rery distinct. The uluer parts are adorned with a delicate pattern of darkenligerl. rich brown or olive patches upon a light, buff-coloured ground: the under parts are uniform white; the male has a sulgular rocal sac. The total length is $:$ to $t$ inches. This leantiful species is one of the gentlest, and it becomes tame enough to lin' "1 food whilst sitting on one's liand. It lives entirely upon insects, prefers shade and dusky light, and utters a sound like "konh-rr." It is a native of North-Westem Africa, Algiers, and Inoreco. Tn the rest of Africa, from Egrpt to the Carpe, Senemanbia to Alysinia, it is represented by $B$. regularis. This slecies has often little spiny tubercles wpon the warts, and necasionilly a light vertemral line: the colour of the upper parts either closely resembles that of the previous species, or it is uniforn light brown, while the under parts are whitish, or variesated with brownish patches. West African specimens are the suallest, only 2 inches long: those of the Cape are the largest, reaching 5 to 6 inches.

The next two genera approach the Fingrstomatinate. amel theresy lead from the arciferous towards the firmisternal ty ne. The "licoracoid cartilages are narrow, and they scarcely orerlitp, sis that hy a further step in this clirection they could easily fusinto the firmisternal comdition. Amother bond hetween these two genera and the Engrstomatinae is their halits, they heing ant-eater's of an extrenty stout appearance, with exclusively short limbs and very small heads.

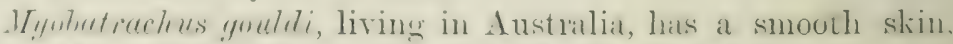
hrown above. lighter beneath, and is about 2 inches loner. 
Rhinophrynus dorsalis of Mexico is remarkable for its tongue, which is elongated, subtriangular and free in front, so that it can be protruded directly-not by reversion as in other toads -and can be used for licking up the termites which seem to he its principal food. The body of this ugly creature is almost eggshaped, and the head is merged into this mass, only the narrow truncated snout protruding. The limbs are very short and stout. The toes are more than half webbed, and there is a large ovil. shovel-like metatarsal tubercle, covered with horn and used for digging. The general colour is brown, with a yellow stripe along the spine and with irregular spots and patches on the flanks and limbs. Total length 2 to $2 \frac{1}{2}$ inches.

Fam. 4. Hylidae (Tree-frogs).-The upper jaw-in Ampli-

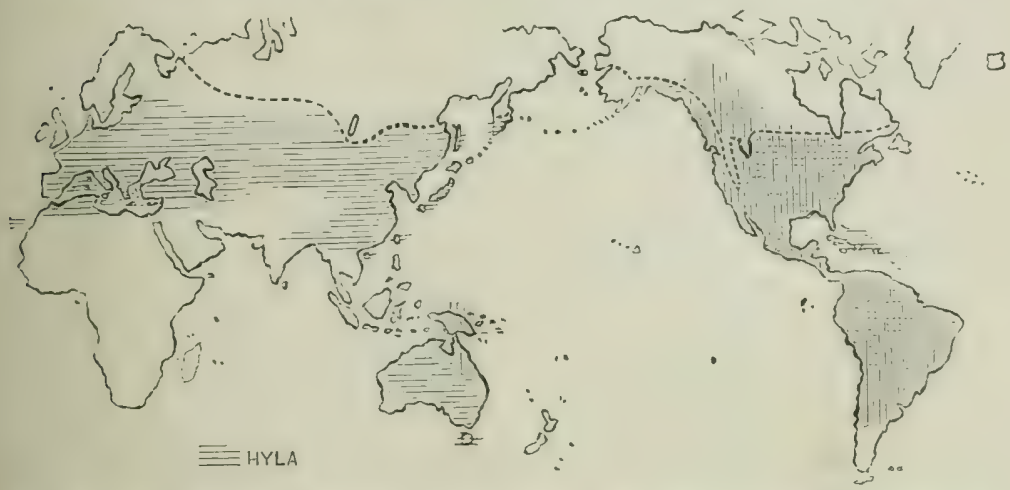

FIG. 36. - Map showing distribution of Hylidae. The vertically shaded countries are inhalbited by $H$ yle and by other genera of Hylidae; the horizontally shaded comntries only by $I I y l a$.

Incthonton the lower jaw also-and the romess carry teeth: Tripion and Dinglene alone have teeth on the parasphenoid also, and the latter genus is further distinguished by possessing palitine teeth. The rertebrae are procoelous and have no rilis: the sacral diapophyses are dilated. The omo- and meta-sternum are cartilaginous, the latter forming a plate with scarcely any basal or style-shaped coustriction. The terminal phalinges are invariably claw-shaped and swollen at the hase, and carry a flittened, roundish, adhesive cushion. The tympanic disc is varialle in appearance, heing either free, or more or less hidden hy the skin. The tongue is also rariable in its shape and in the extent to which it can be protruded. 
Most, if not all, Hylidae are climbers, and many lead an arhoreal life, hut it clues not follow that all the "Tree-frogs" are green.

Their distribution is rery remarkable. To say that this family is cosmopolitan with the exception of the African region, is literally true, but rery misleading. There are in all about 1.50 species, and of these 100 are Notogatem: one-half of the whole number, or 75 , being Neotropical: 23:3 are Central Antrican, 7 Antillean, and about $1 \mathrm{~s}$ are found in North Amexica. One species, Hyla aibure, extends orer nearly the whole Palaearctic sub-region, and two closely allied forms occur in Northern India and Southern China. Conseyuently, with this exception of three closely allied species, the Hylidae are either Anerican or Anstralian. We conclucle that their original home was Notugieal, and that they have spread northwards through C'entral and into North Anerica. The enormous moist and steamy forests of South Anerica naturally suggent themselves as a paradise for tree-frogs, and it is in this country, especially in the Andesian and the adjoining ('entral Anerican sub-regions, that the greatest diversity of generic and specific forms has been producel. It is all the more remarkable that similar forestregions, lilie those of Borneo and other Malay islands, are alisolutely devoid of Hylidae (while there are about a dozen species in P'apuasia), whose place has however been taken for all pactical purposes by correspondingly modified Ranidae, notably the genus Phormilums. Lastly, the fact that tropical evergreen forests of Africal and Madagascar possess no Hylidae, but are inhalbited hy sereral kinds of tree-climbing Rhacophorus, points with certainty to the conclusion that the origin of this large and flourishing fanily of Hylidae was not in Arctogaea.

The versatility and the wide distribution of the Hylidae has naturally produced cases of endergent analogy, and the varions species of one "genus" may be in reality a heterogeneous assembly. Such an instance is probably the grenus Hylellu, wi which four species live in the Andesian and Central American provinces, while the two others ocem in New Grinea and Australia.

The two Torth Anerican genera chorophitus and Leris, aml the Brazilian Thurome, commect the Hylikle with the Cystisnathiclae, in so fin as their finger-elises are rery small, or even 
absent, and their sacral diapophyses are only slightly dilated. On the other hand, it has to be emphasised that the possession of adhesive dises on the fingers and toes does not necessarily constitute a member of the Hylidae. That requires the firithi, combination of an arciferous sternum, with ditated suciul thapophyses and teeth in the upper jaw. Finger-dises are easily dereloped, and still more easily lost. Those of the typical Hylidae are constructed as follows. The terminal phalanx is elongated, claw-shaped, swollen at its base. Between it and the penultimate phalanx lies an interphalangeal cartilaginous disc which projects ventrally below the end-phalanx, thus assisting the formation of the rentral pad, and the turning upwards of the whole disc-like phalanx like the claw of a cat. This peculiar motion can be well observed in Tree-frogs which are at rest upon a horizontal leaf, or, better still, upon a rough stone, when the creatures take good care to adjust their discs into a safe and easy position. The pad or dise itself is furnished with unstriped, smooth muscular fibres, the contraction of which produces one or more longitudinal furrows on the under side. Then the disc is in action or adhering, being flattened to a smooth surface, the end-phalanx sinks into the cushion; when not in action, the cushion swells and the phalanx appears as a slight dorsal ridge. The disc is rich in lrmph-spaces, and its surface contains mucilaginous glānds.

Tarious suggestions have been made to explain the function of these discs. Suction, adhesion, and glueing-on have been resortef to. Suction, through production of a racum, is quite imaginary and does not exist. The question has been thoroughly studied by Schuberg. ${ }^{1}$ Adhesion is due to the molecular attraction of two closely appressed bodies. The less air remains between them the stronger it is. Consequently it' can be increased by the interference of a thin layer of fluid, which as everyday observation shows, possesses both adhesion and cohesion. The more sticky the fluid, the more effective it is, as shown experimentally by Schuberg, who moistened the under surfact of a glass plate, and pressed it against a little dise of glass from which was suspended a weight. A disc of 16 square millimetres, "pproximately equal to the aggregate surface of the 18 discs of a European tree-frog of 4 grammes in weight, carried with water-

1 Arbeiten Instit. Wür $\approx$ burg, x. 1895, p. 57. 
adhesion no less than 14 grammes, with glycerine-solution 20 grammes, - more than sufficient to suspend the frog. The sticky secretion of its glands greatly enhances the adhesive power. Tree-frogs, when hopping on to a rertical plane of clean glass, slide down a little, prohably until the secretion stiffens, or dries into greater consistency. After a few days I find the glass-walls of their recently cleaned cage quite dirty, covered everswhere with their finger-marks. On the other hamd, wet leares or moist glass - walls affird no hold. The athesion of these frogs is assisted in must cases by their suft and moist bellies, just as a dead frog will stick to a pane of glass.

All Hyliblate have a roice, often rery loud, and enhanced lis vocal sacs, which are either internal, swelling out the throat, or external, paired or unpaired.

The rarious Hylidae resort to all kinds of modes of rearing their lnools. Most of them lay many exges. up to one thousand, in the water, not coherent in strings hut in clumps: others lay unly a few, attach them to rarious parts of the hody. or, as in the grenus litutienn. the female receives them in a dorsal prouch. These modifications will be descriled in comnexion with the different species.

Sub-Fam. 1. Amphignathodontinae.-Buth "llpte " jow with teeth.

Ampligumethortun, of which only one species is known, - 1 . guenthrit of Ecuador, angees with Sututremen in all important rharacters except that it possesses teeth in the lowel jaw in andition to these in the unpers. There are further differencess. but they are of degree only. The sacral diapophyses are more strongly dilaterl and the anosternum is alsent. The tympanum is distinet. The pupil is horizontal: the romolist tomone is slighty fres lehinel. The terminal phalanges are chat shaterl and canry latge dises. The temale has a dorsal punti "pering hackwarks. The skin of the heated is involverl in the usiticatton of the cranial hones. The skin of the hack is smomil. slighty tubercular, non-granular below. The midtle of the "lpler eyelid carries a small, prointed, cutanems al'lendage, and

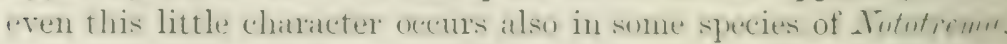
c.\%. in $\Lambda$. longipes and in $\Lambda$. cornutum. The heel carries a triangular little flaty. The ulper parts are olive in spiritspecinens, probalily green in life: the borters of the dorsal pumb 
are black. The sides of the body are adorned with a black, white-edged streak, the limbs are whitish, with black cruss-lart. The total length of the female type-specimen is 3 inches.

Sub-Fam. 2. Hylinae.-Lower jaw toothless.

The Hylinae are divided by Boulenger into 13 genera, which can be recognised by the following key, withont reference to their natural affinities :-

A. The contracted pupil forms a horizontal slit.

a. Tips of the fingers and toes with large discs.

a. With vomerine teeth.

Female without a dorsal pouch . Hyla, p. 189.

Female with a dorsal pouch . Nototrema, p. 202.

B. Without vomerine teeth . . Hylella, p. 203.

b. Tips with very small dises. Tongue free behind.

Tympanum distinct. North America

and Peru . . . Chorophilus, p. 208.

Tympanmm indistinct. North America Acris gryllus, p. 207 .

c. 'Tips simply swollen, not dilated into dises.

Brazil .

Thoropa miliaris, p. 209.

B. The contracted pupil forms a vertical slit. . 'Tropical America.

(.) Tips with large dises.

u. Tongue extensively free behind.

Inner finger and toe opposable . Phyllomedusa, p. 203

Inner finger and toe not opposable. Agalychnis, p. 206 .

B. Tongue scarcely free behind. Ecuador Nyctimantis rugiceps,

With parasphenoid teeth and peculiar p. 206.

helmet-shaped head. Yucatan . Triprion, p. 207.

Ecuador . Diaglena, p. 207.

Withont parasphenoid teeth. Head peculiarly helmet-shaped. Pupil rhomboid. Brazil . . Corythomantis greeningi, p. 207 .

b. Tips without discs. Without parasphenoid teeth, but head peculiar in shape. Mexico Pternohyla fodiens, p. 207 .

Hyla.-The pupil is horizontal. The tympanum is distinct or hidden. The tongue is entire or slightly nicked in its hinder margin, which is more or less free behind. The fingers and toes are provided with typical adhesive dises.

This is the largest genus of all Amphibia, containing about 150 species, and its distribution coincides with that of the whole fimily. Many of the species are very closely allied to each 
other, differing only in small points, for instance in the extent uf the wehs to the fingers and toes, the configuration of the vonerine tereth, the size and alpuearance of the trompanic dise, amb the relative length of the hind-limbs. In some of the West Intian, and in one Brazilian species, $H$. nigromuculutu, the upper surfiare of the heand is rough, owing to the cutis heing involved in the cranial ossification. Buny or perhalps only calcareous depusits in other parts of the skin are rare, but are notably derelopent in $H$. Arsinnutus of Brazil, in which they extend from the head to the sacrum, rendering the skin immovable.

Many are capalle of changing colour to a great extent, and it is at fmindar error to suppose that all tree-frogs are green,

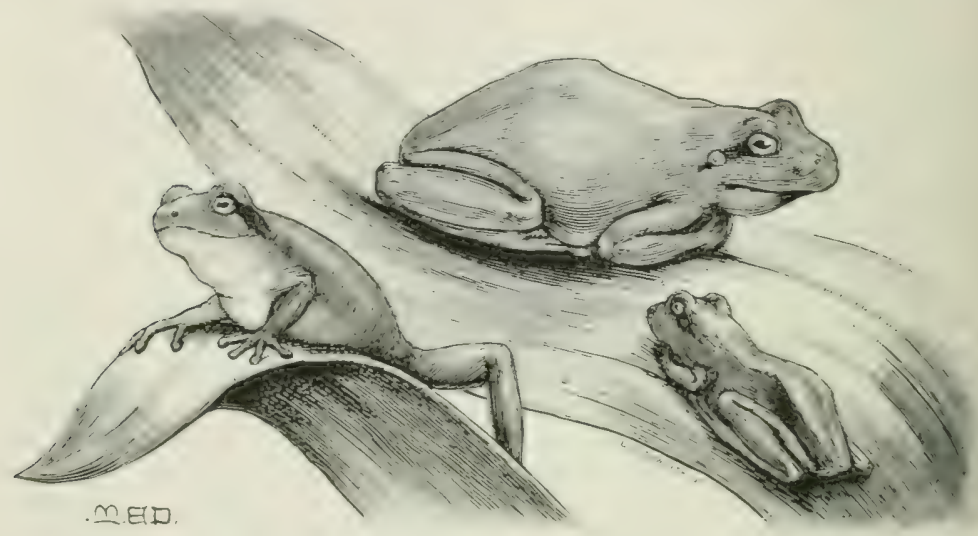

Fig. 37.-Iylla arborea, var. meridionalis. South Europenn Tree-frog. $\times 1$.

although this colour is perhaps the most common in the arboreal kinds.

H. arborea.-The tongue is rather round, slightly nicked lehind, and can be protruded but little. The tympanum is distinct, hut small. The upyer frarts are grass-green, quite smooth and shiny owing to the skin being covered with a film of moisture; the moler parts are yellowish-white and gramular, Hesh(olomerl or rosy on the thighs. Tonal lemgth of latrge females. 2 inches. This, the Tree-frog of Europe, has an enormous range. nanely, from Morocen, France, and the south of Sweden,

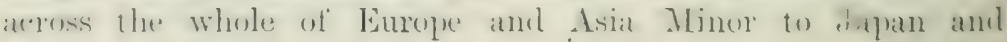
Southern China. 
Several varieties have been described: the tyjucral or Eminum form is ornamented with a narrow black strjpe, which, leginning at the nose, extends backwards along the side of the body to the groin, where it generally forms a hook turned upwards. This: black colour forms the ventral houndary of the green, and is itself narrowly seamed with white on its upper border.

In the south of France, the Iberian Peninsula, Morocco, and the Canary Islands the black lateral stripe is often alisent: this is is the rar. meridionalis. In Spain and Portugal both forms are found in the same localities.

In the Asiatic, chiefly in the eastern specimens, the lateral stripes tend to hreak up into irregular spots, vanishing altogether towards the groins; this var. sfrigmyi s. joponice occurs also on most of the Mediterranean islands.

$H$. whoren can change colour to a great extent, mostly in adaptation to its immediate surroundings, hut ill health and moulting may also influence it. The change is slow. The usual colour is green, brightest on bright, sumny hot days, dull when the sky is orercast, or when it is windy and showery. Day and night have no influence upon the colour-changes. The hue of the green agrees mostly with that of the foliage on which the frog happens to take its rest, for instance a field of Indian corn, birch-trees, or oak-trees. I once received a consignment from Saxony. When the box with moss was unpacked, they were of the dullest greenish-grey: they were put into a wired-off corner of the yard and were given the freshly cut branches of a lime-tree to sit upon. On the following morning I at first looked for nost of the frogs in vain. The leaves had withered and all those fross which sat upon the dark brown branches had put on a light brown garb, mottled with darker patches.

Another specimen, one of sereral which were at liberty in a greenhouse, took to resting on the frame of the window-pane, in a corner where putty, glass, and discoloured white paint met: in the morning it was always of a mottled leaden colour, but luring the nocturnal hunting it was green. In the winter, the window-corner being of course cold, the frog remained stationary for several months, but kept the leaden grey colour, until one day in the early spring it was mottled with green, and soon after it joined its green mates.

Liebe observed a half grown tree-frog which he lept in Ciera 
during the winter in a glats with water-aress. While the temperature was near freezing the fros sat in the water, very lethargic, lareathing perhays once erery quarter of an hour. Its colour wats light green. When the water-cress was cut and removed, the fros darkened and hecame at last yuite a discoloured grey. When the water-cress was jut back, the creature reassumerl the? light yellowish-green (o)lour, remaining in its letharwic condition until it became lively in the spring sunshine.

The Europrean tree-frog spends most of its time in the summer, after the pairing is oser, in trees, often in the very crowns: lut the neightwurhoud of even a small gatch of Indian corn has still greater attractions. There are all sorts of green insects to he cantht, there are fair chances of aming across the commun Cahbage White, a hutterfly which the tree-frog lores, and list unt least the large luscious leaves afford a firm foothold, and the axillae letween stalk and hroul-based leaves are just the places for the fros to slip into, where nobody cam tind it. During the diry they anustly sit still, on the keen look-out for passing insects, which, when they settle within reach, are jumped at: otherwise they have first to be stallied. The jump is quite fearless, resgardless of the height above gromol; thele is the leat upon which the juey sits, and even if this leaf be missed, there are "thers, and one of them is sure to he struck hy some of the dises of either finger's or toes. If the fall is broken by the toes, and the new leaf on hranch is very elastic and hends down, then there are some frantic antices to be gone through until the frog has settled itself again. Then the large blue-lottle, or the butterfly. is deronued at leisure, wings and all being poked in with the assistance of the little hands. But the real hunting-time is the night.

Thuring a shower the frog shifts its position to the uncler side "ft the leaf, or inte a less slippery fusition, and cluring continuous wet it clescends into the grass, or it takes to the water. Its greatest enemy is the (irass sulate, which prefers it to anything (else, not mincling the poisonous secretion of the skin, which is shap enowgh to prome sneezing or eren temporary blimbess when incautiously brought into the human eye.

The male lats an internal vocal salc, which, when infliturl, hulges out the whole throat inte a shobe, nuble larger than the

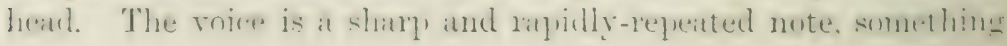


like "epp-epp-epp," or "creck, creck, creck," with mole or less of an a sound. It is uttered at any time of the day, nore frequently at dusk, and of course chiefly during the pairing season. This tree-frog suffers from the reputation of being a good weatherprophet. and it is for this reason often kept in confinement, the orthodox abode being a muslin-covered glass jar, with a hole to put flies through, water and plants at the bottom, and a little ladder to sit upon. The prophesying is of the usual popular unrelialle nature, although the little creature, provided it is a male, often sounds its roice on the approach of a shower, or when there is a thunderstorn in the air. During continuous fine weather it sits on the top of the ladiler, or is glued on near the rim of the glass, while on wet and dull days it is less active, and may keep nearer the ground or in the water. There is a Cremman rhyme which well expresses the prophet's reliability by its ambiguity :-

Wenn die Laubfrösche knarren,

Magst du auf Regen harren.

When the tree-frogs croak, you may wait for rain. Sometimes it does come true.

Tree-frogs are not very intelligent, although they have a keen sense of locality; but they are nice pets, being easily kept, and have a pretty appearance. There is a record of one which lived for twenty-two years in confinement.

The pairing begins soon after the frogs reappear from their hibernation in the ground; in Germany in the month of May. The congregating males make a great noise and take to the water hefore the females, which join them when ready to spawn. The male grasps his mate near the shoulders, and the pair swim about together, sometimes for days, until the eggs are expelled. These are laid in small clumps of 800 to 1000 , which soon swell up and remain at the bottom of the pond. The larvae ire hatched in ten days; two days later the adhesive sucker lelow the throat appears, and after another two days a pair of thread-like external gills are developed. The tadpoles, which reach a length of 2 inches, owing to the long tail, which is nearly three times as long as the body, metamorphose in about twelve weeks, and the baby tree-frogs, scarcely half an inch in length, hicle in the grass for the next two years, until they are ab)ut half grown, not reaching maturity until the fourth year. 
Since many fairs congregate in the same pool, and each produces up to one thomsand esgrs, most of which are hatched, the neighbouring meadows sometimes literally swarm with tiny tree-frogs. Nevertheless the adults are comparatively rare amil are very local.

II. curulinensis s. lutroulis of the South-Eastern states of North America sreatly resembles $H$. "rhorm in general appearance, size, and hallits. Thut the lead is more pointed, and the rivid green of the upper parts is separated from the rellowish white under surface hy a comspicuous, fure white line, giving the little creature a rely smart and neat appearance. According to Hollirouk, it ascends trees, hut most commonly lies upon broadleared water-plants, like - Vympherm, and in fields of Indian corn. Motionless during the daytime, thes emerge in the morning and evening from their hiding-places, and become very lrisk and noisy, often repeating their single note, which is not unlike that of a small hell. When one hegins, hundreds take it up from all parts of the corn-field.

Anong other tree-frogs of the conth-Eastern States may lue mentionerl $H$. siguirella, 1.2 inch in length, which is rery changealle in colour, generally olive above with darker spots and bars on the linhs, and with a white upper lip. It lives in trees, sheltering in the hark. H. femuralis of the same size, withont the white lip, lives high up in the trees of the dense forests of Georgia and Carolina.

H. Arsimlur is one of the most delicately colnured species of Eastern North America, extending northwarls into C'anada. It is alont 2 inches long. Its colour passes within a short time from dark lorown or olive grey to jale delicate grey, almost white, orasionally iretaining a few large darker patches on the hack, and delicate cross-bars on the limbs. A small portion of the sides and the pusterior prart of the belly are hright yellow. The stin is gramular, owing to the presence of small warts which froduce an atcrid secretion. It is sajd to be found in trees, (1) ahout whl stone fences overgrown with lichens, the colour of which it resembles to perfection. It hecomes rery noisy towards the evening, in clomly weather or hefore rain, the voice consisting of a linuid note, teminating almupty, like "l-1-l-l-luk." My (wwn captives fully bear out this statement of Ifolloroos s. Settlent motjonless during the day moun a piece of bark in a shaty 
corner, but occasionally uttering the quaint and rather faint note, they become very lively in the evening, catching insects by long jumps, or investigating the hollows of decaying $110 \mathrm{~s}$ y stumps. Their general colour is then spotless, almost silvery grey. In the day-time they are sometimes suffused with delicate green.

The propagation has been studied by Miss M. H. Hinckley. ${ }^{1}$ They pair in shallow pools, in Massachusetts, in May. On the 10 th of that month eggs were attached singly, and in groups, on the grasses resting upon the surface of the water; first drabcoloured, they became lighter in a few hours. Some lirrae escaped from the gelatinous envelopes on the following day, the others on the third day; they clung to the grasses by means of their prominent suckers. The head and body were creamcoloured, with olive dots, and averaged $\frac{1}{t}$ inch in length. Crills appeared on the fourth day, to disappear again during the four following days, first those of the right, then those of the left, side; the suckers became less conspicuous, and the general colour turned into deep olive-green, with fine golden dots on the upper and lower surfaces. The eyes were of a brilliant tlame-colour. On the eleventh day the suckers or "holders" had disappeared, and the hind-limbs were indicated by small white buds. By June 5th, i.e. the twenty-serenth day, the toes developed the terminal dises; the mottling of gold had given way to a uniform olive or pea-green. Movements of the future arms beneath the skin appeared on the 28 th of June, at the age of seven weeks. The arms, mostly the right one first, were thrust ont on the $2 \mathrm{nd}$ of Tuly; the fins of the tail were absorbed rapidly, and towards the end of the seventh week the nearly transformed creatures hegan to leave the water. The youmg frogs changed colour rapidly, in adaptation to their surroundings, but the fom specimens which survived were never all found to be of the same colour during the next three months. They first lived upon Aphides, later upon flies, and they were alert nocturnally. About the beginning of October they left the fronds of their fernery and nestled away in the damp earth, which they left only when the temperature rose above $60^{\circ} \mathrm{F}$.

$H$. casta of Hayti is the giant of the tree-frogs, reaching it length of 5 inches. In order to support its great weight the

1 Proc. Bost. Soc. Nat. Hist. xxi. 1883, p. 104. 
anthesive dises of the fingers and toes are of a surprising size. ahnut as litroe as a threepremy piece. The skin is covered with small warts, and forms a peculiar fold on the hinder surface of the forr-arm and on the tarsus, and small flats near the rent. The colom is grey above, blatckish on the heat, with a brown lamil letween the eres; the under parts are thesh-coloured, the throat with black spots.

1I. murimu, of the forests of Britich Gruiana, is scarcely less gisantic, and is distinguished hy a forojecting rudiment of the pullex. While the athesive dises are smaller than the tympanum. The skin fimms fulds on the arms and tarsus, like those of $H$. instu, in andition to a triangular tlap at the heel. The general colour is reddish-brown alove, sometimes with a dark rertehal line. the under parts are whitish and corered with large aramules: the throat of the male, which hats an inner vocal sac. is lorowli.

II. furb' of Brazil is closely allied to the last species, hut the skin of its mper parts is quite smonth. There is a small tarsal fold. and one extending from the upper eyelis to the shoulder. It is light hrown above, with clarker markis which form a conspicunos rerteloral line, transterse bars on the hind-limbs, and it few irregular, scattered, vermicular or linear marks on the lexil and buly. The adult, when put into a strong light, will rapielly tum pale; at night the longitudinal stripe on the hack amel the hars on the hind-limbs become very distinct; the umler falls are white, and exhibit a beantiful orange tinge. This is the famous "Ferreiro" or "smith." As will be seen from the following sraphic aceount by In. (roeldi of I'ara, this species drially descrses its name of faller, not only in virtue of its voice. but alsu lecanse of the marvellous nest-building habits recently discovered.

"The Ferreiro is common in the Province Rio de Janeiro, none frefulently still in the mountain regions of the serra dos (1) Patus than in the hot lowland. Its roice is one of the must

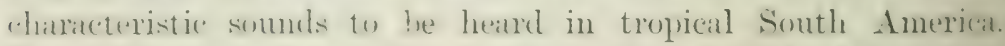
Fancy the nuise of a mallet, slowly and rexularly leaten 10 pun a

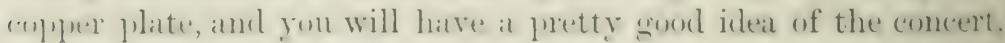
griven generally hy several individuals at the satme time and with slight variations in tone and intensity. When you alperateh the 'P.Z.S. 1895, 1. 89 (with a sketch of a pond, with nests, in Dr. Goeldi's garden). 
spot where the Tree-frog sits, the sound ceases. But keep yniet. and it will be resumed after a few moments. Fou will discurer. the frog on a grass-stem, on a leaf of a low branch, or in the mud. Seize it quickly, for it is a most wonderful jumper, and it will utter a loud and shrill, most startling cry; somewhat similin to that of a wounded cat."

The "sinith" makes rery regular pools, in the shallow water of ponds, or nurseries for the tadpoles surrounded hy a circulitr wall of mud. Dr. Goekdi has watched the building process chuing a moonlit night: "We soon saw a mass of mul rising to the surface carried by a Tree-frog, of which no more than the two hands emerged. Diving again, after a moment's tine, the frog brought up a second mass of mud, near the first. This was repreated many times, the result being the gradual erection of a (ircular wall. From time to time the builder's head and front purt of body appeared suddenly with a load of mud on some "lrosite point. But what astonished us in the highest degrte was the manner in which it used its hands for smoothing the insicle of the mud wall, as would a mason with his trowel. When the height of the wall reached about $t$ inches, the firgy was obliged to get out of the water. The parapet of the wall receires the same careful smoothing, but the outside is neglected. The levelling of the bottom is obtained by the action of the lower surface (belly and throat principally) together with that of the hands."

The male takes no active share in the construction of the nest, but will suddenly climb up the wall of his home, and then "yon the back of his busy mate. The building operation may take one or two nights, and is performed in the most absolute silence; the croakers around are all males clamouring for a mate.

The eggs are laid during one of the following nights, and are hiltihed some four or five days later, the parents keeping hilden in the neighbourhood of the nursery. Heavy rains may destroy the walls, and thus prematurely release the tadpoles.

It is only owing to such keen observers and lovers of mature's fiscinating ways that the breeding habits of some Brazilian Hylidae have become known.

H. netulose, s. luteola also living in Brazil, is yellow above, with brown dots; the sides of the belly and thighs have trans- 
rerse bluish bars, the under parts are whitish. Its size is under 2 inches. Goeldi has often found it in the sheaths of decaring Banama-leares. It glues the lumps of exges on to the edges and to the inside of the withered leaves, where even during the hot hours of the day sufficient coolness and moisture are preserved. These lumps are enreloped in a frothy sulstance, in which the nearly metamorphosed tadpoles can be watched wrigghing. If these are put into water, all will die in a few hours.

H. julyfuenin deposits its exgs in free lumpy masses on waterplants. It is a small creature, little more than 1 inch in length, light wive above, with numerous brown grallel longitudinal mands on the body and limbs. A dark, white-edged band extends from the nose along the sile of the horly. The heel has a short flap of skin. The male has an internal vocal sac.

II. ymldii is a most interesting form, leating to the allied genus litutremu. Boulenger ${ }^{1}$ has described a female which was

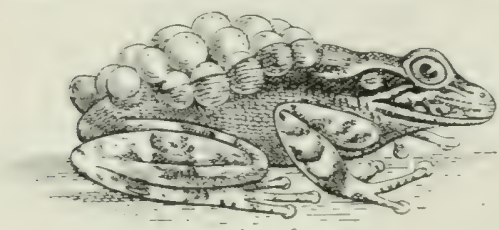

Fra. 35.-IIyla goeldii. $\times 1$. Female with eggs in the incipient dorsal brood-pouch. captured by Goeldi on the 5 th of January, near Para. It is about $1 \frac{1}{2}$ inch long. The whole surface of the back is occupied by a layer of twenty-six pale yellow eggs which are $4 \mathrm{~mm}$. in diameter. The skin of the back is

expanderl inte a feehly reverted foll. which horders and supports the lnits of egess on the sides, thus suggesting an incipient staper

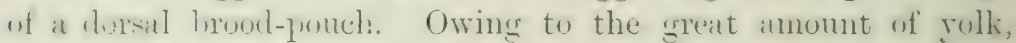
the romes are probatily alile to remain upon the nother until they are nearly metamorphosed.

H. rom inlous s.ynnen is one of the largest Australian green treefross ranging from the south to the very North of Australial. The dises are ats latre as the fully-expesed trmpanum. There is nu projerting rudinent of the pullex, lute a slight cutaneous foll burders the immer sile of the tarsus. The skin is smouth and shing always a little moist, and studeded with numerons rather latre preres on the nale and shoulders: this somewhat thickened rexion forms a pnominent fold which hexins behimb the eyes. The belly and the under parts of the thighs are framular as in most Hrhidas. The male has an internal veral 
sac; and during the breeding season, which seems to occur during our autumn and winter, develops brown rugosities on the immer side of the first finger. The tongue is round, slightly notehed behind and free enough to be protruded a little.

The alternative specific names are most unfortunately chosen, as they apply only to spirit-specimens. During life this treefrog exhibits a considerable amount of colour-changes. The normal colour is bright green above, white below. A conspicuous

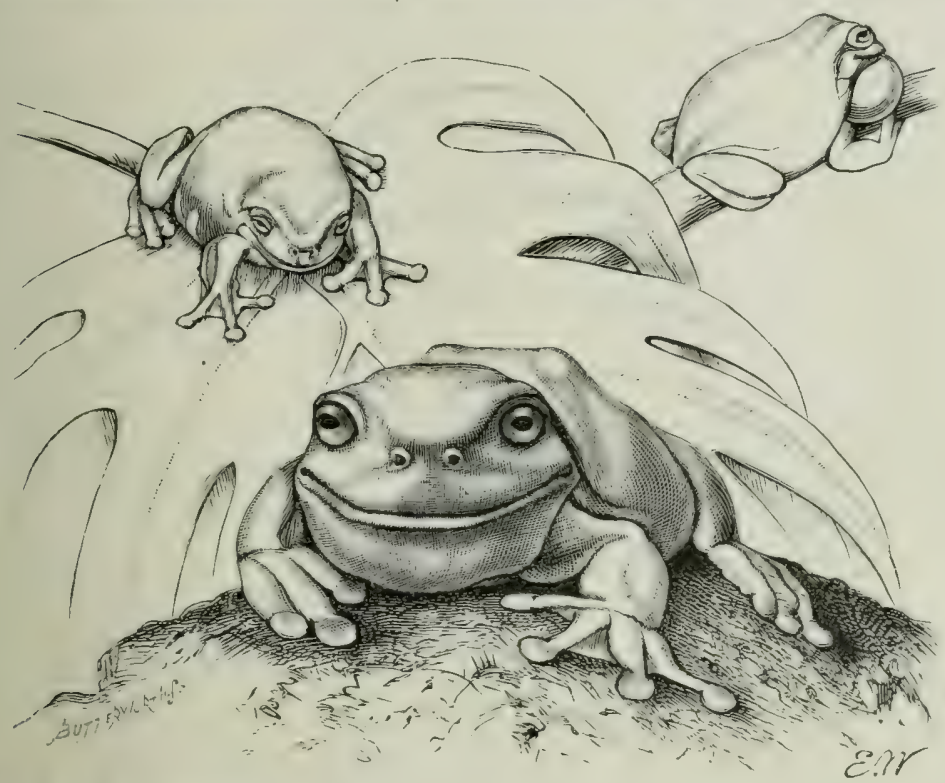

FIG. 39.-Hyla coemelea. Australian Tree-frog (from photographs). Length of the large specimen 4.2 inches. The upper right specimen with vocal sac inflated.

ferture of this species is the frequent occurrence of white specks or spots, which are probably due to the deposition of guanine, a peculiar white colouring matter. The spots appear in any part of the green skin, and are quite irregular in their distribution. Sometimes they remain for weeks in the same place, or they dis"pplear after a few days and others appear. They are in no way comected with the shedding of the skin, nor do they indicate illhealth. H. coerulea lives well in confinement, and becomes tame 'hough to take food from one's fingers, even when sitting upon the hand. Some of mine took to living during the daytime in a small lox, preferring a crowded condition in companionship with Natter- 
ficks. Others squeeze themselves inte the most unconfortable

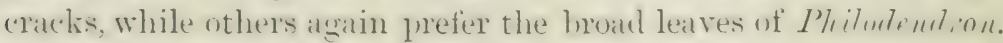
A favourite place for two or three at a time is the funnel-

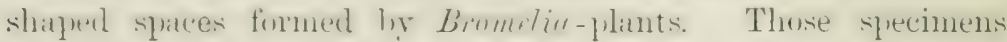
which are hidden in the box or in the hollows of rotten stumps are, alnost without exceptim, dull, very dark hrownish olive. While those on the Iromelias assume exactly the sombre dull wreen of its leares. Lastly, those which sit in the light. exposed places, no matter if upon a leaf, on a white stone, or "1pun a buard, are emerald-sreesn. expecially beatutiful on hot. sumny days:-and ther are not always averse to the full glare of the sun. When syuatting upen at that surface, such ats a broat leat, they tuck the fine-paws muler the head like a cat, and with half open "yelick, the pupil contraceterl to a tiny slit, sol that the wolden iris is exposed, they remain notionless during the day. They take food when offered, hut at night they rean ahout, rither hopping on the ground, or making enormons leaps from leaf to leaf', sometimes deliberately stalking some choice insect, and patiently climbing up a stem, hand over hand. At night their whole aspect is changed. The colour is saturated green, the eyes are transformed into round, projecting sining black heads, and the head is erect. The ludicrously dreany, complacent look has given way to wille-awake alertness. They take all kinds of living ford. When they find an earthworn, they first lowk at it, hending the head sharuly down, lift themselves upon the fore-limbs and then pounce upon it, nipping the prer with the jaws, and then poling it down deliberately with the hands. cuckroaches are simply lapped up, and disappear in the twinkle of an ere. Mealworns, woul-lice, butterflies and moths, flies aml spicters are taken. The stomach of a specimen in the I)resilen Mnsemn, from the Aru Islands, contained some four or five roung freshwater ('rustaceans of the crenus sisurme. They fortmately do not molest smaller frogs of their own kind and of other sperdes. Like many Amphiliat they like a rhange of diet, anci ultinately refuse their fond it it is muvaried. To my smprise my latrest sprecinten, which measures a little more than 4 inches. takes snatils, Helir rirgerfe, half-atdozen at a time, and on the following day, not during the night, vonits the sucked ont shells in a lump, like the peellets of birds of prey. Doring this rather gainful-lowking prowedure the whole tongue and about half an 
inch of the everted gullet are protruded ont of the inmin, and are then slowly withdrawn. After haring roaned almut all nisht, they return to their respective resting-places, where each individual is sure to be found in exactly the same spot. dier after dar. Thes do not mind being looked at, hut if taken ul and put back they aroid that place for perhaps a week, taking shelter somewhere else.

Both sexes have a voice, but that of the female is only a srunting noise, while the male inflates its gular sac and send. forth a sharp craching sound, which can turm into a regular bellowing like the gruff barking of an angry dog. They lellow at any time of the rear, frequently on the alproach of a shuwer ur cluring a thunderstorm. Certain noises will also induce them to bark. The rattling produced by the srringing of the greenhouse, sawing of wond, hammering, the raking of the gravel, or even the scraping of boots on the gravel-path is liable to start one of the males, and the others are sure to chime in.

According to Fletcher, $H$. rocrulen and $H$. wureu lay their erge in romul white frothy patches, which that in the water. rhiefly during the months of August and september: but when the spring months are rery dry, the pairing is delayed until the following January. Sereral other Australian species of Hylu, e.g. $H$. curingi, spawn at any time of the rear if the conditions a farourable. They attach their eggs to suhmerged blades of grass or to twigs.

$H$. rurel is one of the commonest and most beautiful sprecies, occuring throughout Australia and Tasmania, excepting of colirse in the large deserts. It has the appearance and restlessness of a water-frog, is not unlike Rume esrulentu, and grows to about three inches in length. The tympanum is very distin.t, hut rather small. The fingers are without a pollex-rudiment, the tarsus has a fold aloug its inner edge. The allhesive discen are ilecirledly small. The male has two internal rocal sacs, which hulge nut siderays. The shin is smooth and shing. The moler parts are white: the upper parts are, speaking genterally. it mixture of blue and olive, with blue or brown spots, but spiritspecimens give no idea of the beauty which this changrable slecies can assume. Sometimes the same individual is saturated bue and green, with several longitudinal stripes of burnished (npler along the back: a few minutes later the stripes glitter 
like gold, and in wher mouls the whole upler surface is mottled lilue. areen, and lorown. My specinens often went into the water and diel not rlimh. The fornd is salid to consist chiefly of other small frogs in preference to insects.

Nototiema differs from Hyla in so far as the female has a porch on the bath for the retertion of the eggs. This hag is formenl ly an infuling of the skin: it opens batkwards in front of the vent, it has a sphincter and is prermanent, although it distends to latreen timensions when in use. An initial stage of such a pouch

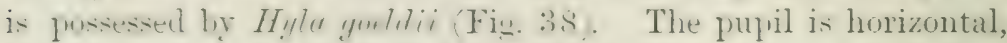

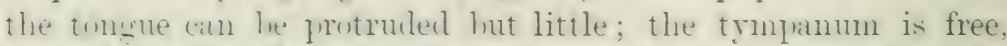
and the athesive dises of the fingers and toes are well developed. These " natrsupial frogs." of which about half-at-dozen species are known. live rhiefty in the tropical forest-region of Sunth America, notably from Peru to Tenezuela.

A. marsupiatum is green with darker blue-green spots, or with longitudinal patches which are each smrmunded by a whitish or rellow sean of little duts. The linnhs have cross-hatrs. Total lentroth alwut $2 \frac{1}{2}$ to 8 inches. The are compratratively snall and numerous. The very small tadpules

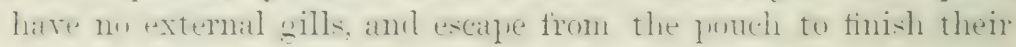
metamorphosis in the rrater.

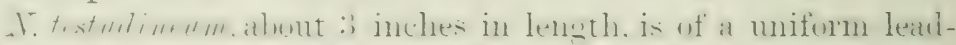

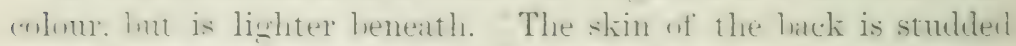

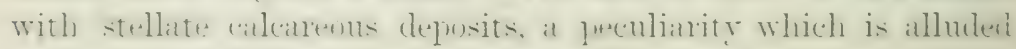
to in the specific name.

1. wirinu is l,rown aluse. with ditrker patches on the sides of the body and with cross-bars on the limbs. The last two

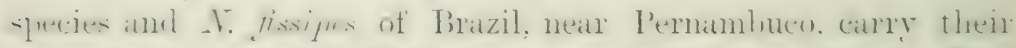

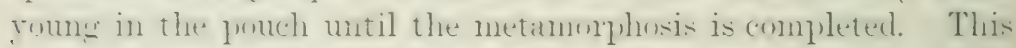

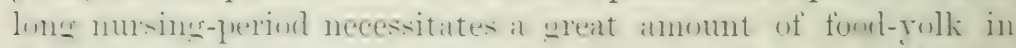
the entes and this enlintentent in turn inplies a considerable molmetion in their mumber. The females loal consists of alent

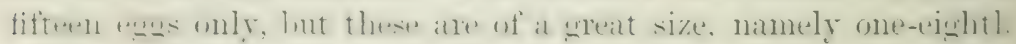
of the length of the mother's body.

1. pygmacum, in Venezuela, is a tiny creature. The female,

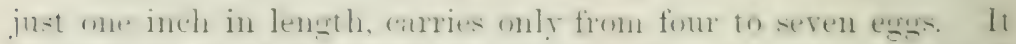

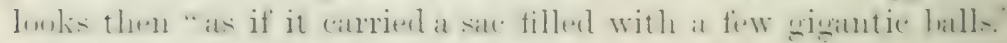
This speeces is further worthy of note an accoment of the apeningof the lnoml-puneh. which is at longitulinal slit. whence a kind 
of thin and slightly elevated ridge or fold of the skin extends on to the neck. The suggrestion, that this seam is burst open, in order to set the full-grown young free, instead of their passing through the existing opening, is searcely credible.

These Neotropical tree-frogs seem to be rare, and females with embryos are of course still more uncommon, so that the best aceount of their structure is still that given by Weinland ${ }^{1}$ of $\mathrm{N}$. oriferum. How the eggs get into the pouch has not yet been observed, but it is most likely with the help of the male, immediately after fertilisation. The pouch forms two blind sacs which extend forwards over the sides of the back. The eggrs are liarge, $1 \mathrm{~cm}$. in diameter, and the enclosed embryos, or rather tadpoles, had a length of $15 \mathrm{~mm}$., with a large amount of yolk still contained in the spirally wound intestine. The first two gill-arches carried each a double thread, which expanded into a fumelshaped membrane, not unlike the flower of a C'onvolvulus, and furnished with a capillary network; the stalk contained muscular filures. These most peculiar structures are of course the much modified external gills. Those of $\Lambda$. testudineum and $N_{\text {. com }}$. mutum are likewise bell-shaped.

Hylclla differ's from Hyla chiefly by the absence of romerine teetl, and consists of about half-a-dozen small species, ahout one inch in length. The fact that two species live in Queensland and New Guinea, while the others are natives of tropical America, suggests that this genus is not a natural but an artificial assembly, an instance of convergent evolution.

I'hyllomedusa, composed of ahout one dozen species of tree-frogn, is characterised hy the vertically contracted pupil, large adhesive discs, and the opposable nature of the inner finger and of the hallux, the last joints of which are like thumbs. The sacral diapophyses are strongly dilated. The range of the genus extends from tropical Central America to Buenos Aires. Most of the species are about 2 inches in length, blue-green to viulet above, with white purple-edged patches on the sides of the body; the under parts uniform white, or with purple or lrown putches. The male has a subgular vocal sac. Some have more or less distinct parotoid glands. Ph. darnicolor of Mexico is unifor'm sreen above, whitish below, and attains a size of more than 3 inches. In Ph. bicolur of Brazil, the slim of the upper

1 Arch. Anat. und Phys. 1854, p. 449. Also Boulenger, P.Z.S. 1898, p. 107. 
prarts is studled with calcareous deposits, and the parotoids are large. It is hlue-green alwre, purplish white helow, the sides of the body and limbs with white purple-edged spots.

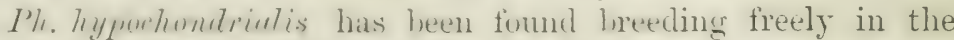
I'araguitan Chaton by budgett. from whose account the following notes have heen extrated. This brilliantly coloured frog is areen alove, which colum may hecome lown-grey or huish at will; leelow, white and granulitr. The flanks are searlet. with hlack transterse bers, and the plantar surfices are deep purplish black. Total length about $1 \frac{1}{2}$ inch.

The " Wollumnkukk," ats it is called by the Indians, from the mall of luth male and fentale at pairing time, is extremely slow in its morements, and is active only at night. At this time, if it is sem liy the aid of a lantern as it slowly climbs orer the low lnshes and grass, it is very conspicuous. In the daytime, howerer, nothing is seen hut the mpere surfice of the houly as it lies on the green leaf of a plant. It has a remarkable power of changing its colour to harmonise with its sumumedinger and can chlect a change from the lrightest green to light chocolate in a few minutes. The skin is also directly sensitive to light; for if the frog is exposed to the sum while in a tuft of grass in such a way that shadows of blates of grass fall across it, on removal it will he found that dark shadows of the grasses remain on the shin, while the general colour has been raised to a lighter sharle. Its food consists largely of young locusts. The sleecies wn each side are divided into five distinct clusters. The creature hats a large salcular diverticulum, which is very heavily giggmented.

In the breeding season-December to February-this beautiful frog collects in considerable numbers in the neighhourhood of fmils. During the night-time they call incessantly to one another, and produce a somd as of a dozen men hreaking stones, well imitated by the native name.

The exors are enclosed in batches in leaves near the margin of the water. diulgett has been ahle to watch the whole process of oriposition and fertilisation. He fomml, at 11 P.M.. a female arrying a male upon her back, wandering alwont in seareh of a suitable leat. It list the female, (limbing up the stom of at plint near the water's edere, reacherl ont and canght hold of the

1 Quert. J. Micr. Sci. xlii. 1899, p. 313. 
tip of an overhanging leaf, and climbed into it. Both male and female held the edges of the leaf together, near the tip, with their hind-legs, while the female poured her eggs into the fumel thus formed, the male fertilising them as they passed. The jelly in which the eggos were laid was of sufficient firmmess tn hold the edges of the leaf together. Then moring up a little further, more eggs were laid in the same manner, the edgets of the leaf being fastened together by the hind-legs, and so on uy the leaf until it was full. 'As a rule, two briar-leaves were filled in this way, each containing about 100 eggs. The time occupied in filling one leaf was three-quarters of an hour.

Development proceeds rapidly. Within six days the embryo increases from the $2 \mathrm{~mm}$. of the egg-diameter to 9 or $10 \mathrm{~mm}$. When it leaves the leaf it is a transparent glass-like tadpole, whose only conspicuous parts are the eyes. These are rery large and of a hright metallic green colour, so that when swimming in the water all that is seen is a pair of jewel-like eyes. The newlyhatched tadpole has also a bright metallic spot between the nostrils somewhat in front of the pineal spot. This is the point which touches the surface of the water when the tadpole is in its favourite position. Whether it is a protective coloration, or some mechanical arrangement for holding the surface, Budgett could not make out.

The egr contains a great amount of yolk; the rest of the jelly-like contents of the egg becomes fluid, so that towards the end of embryonic life the larva comes to lie quite freely within a membranous capsule. The external gills appear on the third day, and reach their greatest size on the fifth, when these bright red filamentous organs extend beyond the rent. By the time the tadpoles are ready to be hatched these gills have quite disappeared, there is a median spiracle, and the lungs are shining through the transparent bodywall. Five weeks later, i.e. six weeks after the egges were laid, the tadpole is $\mathrm{S} \mathrm{cm}$. long, glossy green ahove, rosy and silvery helow, and the hind-limbs protrude. The roung frog at the close of its metamorphosis is two-thirds the length of the adult, and at this time acquires the red flanks barred with black.

The first account of the breeding of Phyllomedus? was given hy v. Thering ${ }^{1}$ concerning Ph. iteringi of Southern Brazil.

1 Ann. Jag. Nat. Hist. (5) xvii. 1886, p. 461. 
"Plyllumidusu does not lay its exgers in the water, although the larva derelops in that element, but in the open air in masses

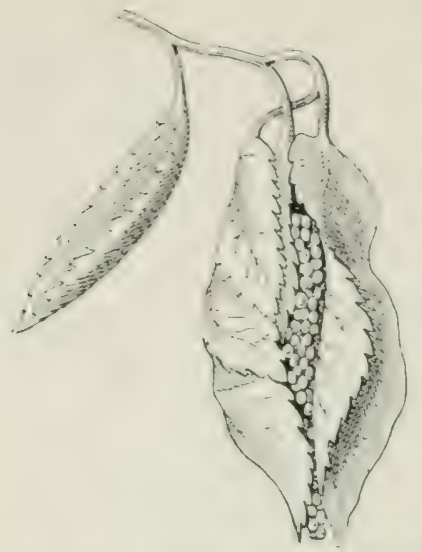

Fic. 40. - A liranch with exes of Phyllomeduse iheringi, $\times 1$, enveloped in the leares. (After v. Ihering.)

50 millim. long by $15-20$ broad, between leaves hanging over the water. Willows are frequently used for that purpose. The egg-mass contains rather large white ora, wrapped up between two or three leaves in such a way as to be completely enveloped save an inferior opening. $\mathrm{MI}$ attempts at rearing the eggs failed owing to the leaves drying up; but I am assured that the tailed larvae may be seen wriggling in the gelatinous mass. As at a later period the latter is found emptr. we must infer that the larrae drop into the water below. The eggs are found only on plants hanging over stagnant water.'

"The adult animal is a stupid creature, and will let itself be taken without attempting to escape. Their moderately loud roice resembles somewhat the sound froduced hy ruming the finger nail orer the teeth of a comb. Only during the breeding season, in the month of Tamury in Rio Grande do Sul, do these frows malie their appearance: at other times not one is to be seen, frobahly because they establish themselves high up in the trees."

Alyulychnis, with two species in Central America, is practically like IH!la: but the pupil is vertical, and the tongue is extensively free behind.

Myptimuntis differs from either by its round tongute. Which is not nicherd lehind, and is almost completely adherent, much resembling that of the Iniscoglessidate. The sacral diapophyses are liut slightly dilated. The only species, 1 . ingireps, lires in Echador, and grows to nearly three inches in length. The head is large and rough owing to the skin heing involved in the "ranial osifications. It is further freculiar in its coloration, the muler parts being chestunt-hrown insteanl of whitish. The upper parts are olive-grey or brown.

The following four genera, each represented hy one or two species 
only, much resemble each other in the curious shape of the head, which forms a flat projecting snout, used probably for digging in rotten wood in search of insects. There is a peculiar degradation in the extent of dentition of the palatal region. Diuglemer and Triprion are the only Anura which possess a longitudinal row of parasphenoid teeth. Diaglena petasate of Mexico and D. jordeni of Ecuador have, moreover, a transverse row of teeth on the palatine bones in addition to those on the vomer.

Triprion petusatus of Yucatan has parasphenoid and romerine teeth. The head is a hony casque, with strong superciliary ridges, the skin being extensively ossified. The mouth forms a flat snout, owing to the long projection of the upper over the lower jaw. The skin of the back is smooth hrown with darker spots; the under parts are uniform whitish. The male has a subgular vocal sac. Like Diaglena and Corythomantis they possess adhesive discs on the fingers and toes, and climb trees. The total length of this curious creature is 2 inches.

Corythomantis greeningi of Brazil has a similar head. The romers alone carry teeth, besides of course the maxillae. The pupil is rhomboid. The tongue, as in the two previous genera, is roundish, scarcely free. General colour above olive, with darker freckles; the sides are studded with whitish tubercles; the under parts are whitish. The male is devoid of vocal sacs. Total length 3 inches.

Pternohyla fodiens of Mexico approaches the previous three genera by the

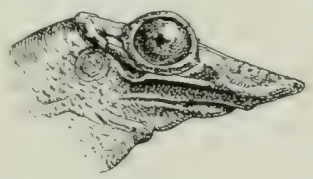

Fil. 41.-Heal of Corythomantis greeningi. $\times 1$. (After Boulenger, Cat. Batrach.) curious shape of the head and prominent upper jaw, although these features are not so exaggerated. The dentition agrees with that of Corythomantis and other normal tree-frogs. The fingers and tues are not provided with dises, in conformity with the burrowing, not climbing, habits of this creature. The next following three genera connect the Hylidae with the Crstignathidae. The sacral vertebrae are but slightly dilited.

Aris. - The adhesive discs are very small, the tympanum is indistinct. A. gryllus, the only species, inhabits the greater part of Eastern and Central North America, extending northwards into Canada. It attains a length of $1 \frac{1}{2}$ inch. The coloraion is very changeable, in adaptation to the surroundings. As 
it rule it is hrown. with a more or less retelish or arey gromultune. ornanentud with dark lwown or liackish irregular, longiturlinal patches, one of which is hordered with light green, and there

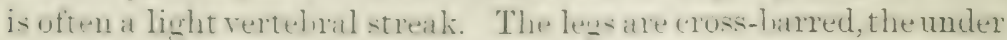
garts are whitish hrown and rellowish. The male has a sulngular vocal sac, and its num rematriahle feature is the voice, which "hesly remenhles the noise of a cricket or of certain grasshoppers.

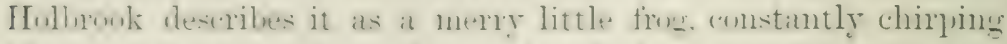
like a crieket. eren in confinenent. It freenents the horders of p.ouls. am is often fomml on the leares of alyuatic plants, rarely on the han hese of such low shruls as wrerhang or dip into the water. When distmiled it takes lone jumns and hides at the bottom of the pond. Insects are secured by leaps. It can eatily he domenticatenl. and takes foul readily from the hami. Frinkling them with wat: 1 never fails to make them mor. lively and noisy. Alpeaning in April in great numbers they are sidel to ranish early in the antunn fre hibernation. The tadpoles are metamorphosed by the end of August.

rhomplifus.- The fincers and toes are provided with very

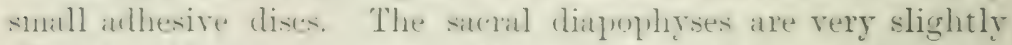
dilated. Alwat seren speciess occur in Sorth Anerica, chiefly in

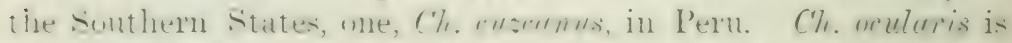
the snallest of the frog-kind known, and lives in south Carolina.

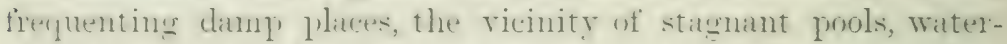
flints or low shruhs, for instance the " murtle." Myricu ceriforn. I once haul two of the-e tiny creatures leses than three-fuarters of an inch in lenth. They were very active, and terk surprisingly

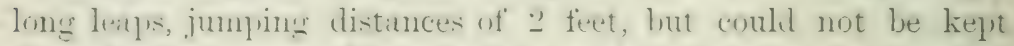
through the winter, although they tomk ninute insects readily enmesh. The head in natrow, long and puinted: the upper prats are of a rich chestnut-hrown with a hronzy gloss. The upper jaw is white: a hlack hamb extends along the sides of the head and lunly. The umler parts are rellowish white.

1\%. "routus is another inhabitant of the couth-Eastern States ; its nature refers to the dark lewwn patches on the hack

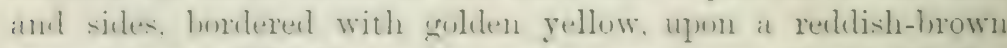

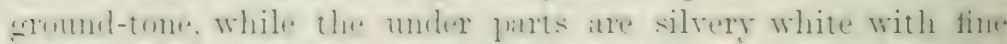
arey siots. This fires, at little more than whe inch in length. lives on land in dry plates preferably in corm-tielels, hats eo roise

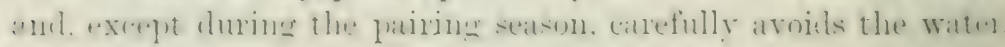


Thuropa.-The fingers and toes are free, the tips simply swolleu and not dilated into dises. Closely allied to C'horophitrs. Th. miliuris, of Brazil, the only species, has very long toes. The head is broad and flat. The upper, nearly smooth surface of the body is flesh-coloured, with brown marblings; the limbs are cross-barred; the under parts whitish, granular on the belly. The male is devoid of vocal sacs. The total length may be 2 inches. Hensel has published the following notes of this species, under the name of Hylodes cbbreviutus. The tadpoles are quite flat, their bellies forming a kind of sucking disc, so that these creatures, even before the appearance of the hind-limbs, can quickly wriggle up rertical walls of stones, provided these are covered with a little water. In correlation with this halbit, the root of the tail is not compressed laterally, but is as loroad as it is high, and the usual rertical fin is restricted to its distal third. On the proxinal portion of the tail the ventral fin is flattened and broadened out so as to form almost the continuation of the peculiar disclike belly. The anal opening is not a projecting tube, but is a flattened transverse slit.

Fam. 5. Cystignathidae.-This is one of the largest families, and also one of the least satisfactory. Its numerous members, more than 150 , exhibit such a versatility in adaptation to circumstances (there are acilatic, terrestrial, arboreal, and burrowing species), with a corresponding development or loss of anatomical characters which we should like to rely upon as taxonomic marks, that the numerous genera not only rum into each other, but also get entangled with those of other families. In fact the whole family is ill defined. It can be characterised as follows:- The shoulder-girdle is arciferous ; the sacral diapophyses are cylindrical or but slightly dilated; the metasternum has either a bony style or it forms a cartilaginous plate; the terminal phalanges, although they sometimes carry adhesive dises, are never claw-shaped.

The last statement is, of course, intended to separate the Cystignathidae from the Hylidae, of which, however, the three generit Thoroper, Chorophilus, and Acris stand on debatalle ground (cf. p. 186, Hylidae), while, on the other hand, most of the Australian genera, notably Chiroleptes, have unmistakably dilated sacral diapophyses. The difference from the P'elobatidale can in this case be one of degree only.

YOL. VIII 
The ('ystignathilate maty be said to represent the Ranidae in Notogate. Some of them can he distinguished from the true, typical fross sulely ly the areiferus type of the shouldersirdle and stermum. There is in both fomilies the same adaptive versatility. the sime amplitule in the formation of the fingertipe, the exasional slight dilatation of the sacral diapophyses, the salne range in the contignation of the omn-and neta-sternum. In fiact. young lianilate, hefore the firmisternal character is assumed, are indistinesuishalile from Crstignathidae. and the latter would turn into Ranidate if they could be induced to consolidate their sternal apparatus.

The geographical distribution of the cystignathidae is suggestive of their leing an old family. nust of whose members hatre reached a high stage of morphological development. The overwhelning majority inhalit the Yeutropical region, a few forms extending into tropical Central America and into the Antilles: the rest, some twenty species only, are confined to the Continent of Australia and to Tasmania.

The family name is rather a misnoner. It is taken from the senus C'ystignuthus, which is, wr rather was, characterised by the peculiarly lirualened lower jaw, hollowed out hy the rocal sacs: but this generic name had to give way to that of Leptudactylus, in whedience to the iften senseless rule of priority. The family is composed of three sub-families.

Sub-Fam. 1. Hemiphractinae.-Teeth are carried hy both jaws, the vonters and the palatine bones: or hy the palatines and parasphenoids in Ampludus. The vertehnae are opisthocoelous, deroid of rils, and the sacral diapophyses are not dilated. The shoulder-girdle and sternum are strictly arciferous. The omosternum is very much reduced; the metasternum forms a cartilaginous pliate. The tongue is slightly free behind. The tympanmm is distinct. Three genera, with eight species, all inhabitants of South America.

Hemiphractus. - The head is large: the upper surface of all the cranial hones alplears pitted, owing to most of the covering shin being involved in the osification. The temporal fossa is bridged over on roofed in ly the fronto-parietal amel the sflutunosits, so that the orthit is completely encircled hy bone,

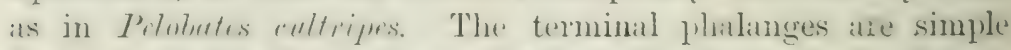
and are not dilated into disces. The teeth of the lower jaw are 
very small and numerous. The tongue is round and very small. H. seutatus, the only species, living in Ecuador and Colombia, is a frog-like creature, with a large helmet-shaped head. Total length $2 \frac{1}{2}$ inches.

Cerutohyla has the same kind of helmet-shaped head, and the orbit is likewise enclosed by bone, but the terminal phalanges are claw-shaped and carry regular adhesive dises. This genus, the five species of which live in Ecuador, bears undoubted resemblances to the Hylidae. In C. proboscidca the upper eyelid is produced into a little upright fold, as in Amphignathoctom. and some species of Tototieme and Ceratophrys among Cystignathidiae. The suout is produced into a long, compressed, bifid appendage, and the heel carries a triangular flap. In $C$. Iubcrlus the partly ossified helmet sends out a pair of diverging processes, formed by the squamosals, extending backwards and sideways from the concare and ridged interorbital spaces. The tip of the snout and the tips of the divergent horns form an equilateral triangle, and the whole head bears a striking resemblance to some of the fossil Reptiles from the Elgin Sandstone, e.g. Triccratops. Total length 3 inches.

Amphodus werheri.-The only species of this genus has been found near Bahia. It has teeth on the palatine bones and five series of small teeth on the parasphenoid, but none on the romers. The teeth of the mandible number about eleven on each side and decrease in size towards the symphysis. The tympanum is distinct; the heart-shaped tongue is free behincl. The cranial bones are only slightly pitted. The skin is smooth abore, chocolate-brown, spotted with yellow, and with a yellow band on the sides of the body beginning with the upper eyelid and encling in a broad patch above the rent. The uncler parts are yellowish white.

Sub-Fam. 2. Cystignathinae.-The upper jaw alone is provided with teeth. Tertebrae procoelous. The twenty-seven genera of this sub-family have been arranged in the following key, merely for convenient determination.

I. American genera.

A. The metasternum forms a cartilaginous plate without a narrow handle. The pupil contracts into a horizontal slit.

u. The terminal phalanges are bifurcated, $Y$-shaped, and provided with large discs; the tympanum is distinct; the omosternum is absent

Centrolene geckoideum, Ecuador. 
b. The terminal phaianges are T-shaped and carry discs. The omosternum is cartilaginous.

a. Discs divided by a dorsal groore.

With romerine teeth . Elosia, 3 species in Brazil. Without "Syrrhopus, ${ }^{1} 9$ species, South Anerica. $\beta$. Dises undivided.

With romerine teeth . . . Hylodes, p. 214.

Without , . . . . Hylopsis.

¿ Terminal phalanges sinples pointeml, or witle very small dises.

First finger opposed to the others . Pseudis, p. 213.

d. 'Terminal phalanges simple, without discs.

a. Tympanum hidden. A large, flat gland on each side of the body . . Cyclorhamphus fuliginosus, Brazil.

ß. Tympanum distinct. Head rough, entirely bony.

Trmpanum hidden or absent Calyptocephalus, p. 215. nicked, free behind. Toes webbed.

Telmatobius, 6 species in Western South America.

$\delta$. Tongue heart-shaped, free. Toes weblbed.

Ceratophrys, p. 215.

$\epsilon$. Tongue round, free behind. Toes webbed. With two tooth-like projections in the lower jaw:

Lepidobatrachus, p. 218.

§. Tongue entire, or slightly nicked, free behind. Toes free. Borborocoetes, 11 species in Western South America.

ๆ. Tongue entirely adherent. Tympanum distinct.

B. Metasternum with a bony style.

Zachaenus parvulus, Brazil.

a. Pupil horizontal.

a. Terminal phalanges T-shaped, with discs.

Tympanum distinet.

Plectromantis, 2 species in Western South America.

B. Terminal phalanges simple; tips not dilated into regular disis:

1. Tympanum distinct.

Sacral diapophyses slightly dilated.

Edalorhina, 3 species in Ecuador and Peru.

Sacral diapophyses not dilated.

Leptodactylus, p. 218.

2. Tympanum indistinct or hidden, Paludicola, p. 220.

b. Pupil vertical. 'Terminal phalanges simple and not dilated. Chili.

a. Tongue slightly nicked . Limnomedusa macroglosit.

$\beta$. Tongue entire, but free behind. Digits very long.

Hylorhina silvatica.

II. An-traliatn generat. The troninal phalinges ane simple and not dilated.

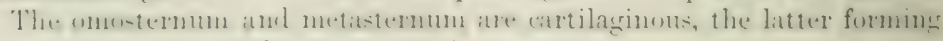
a plate, semi-osified only in Heleioporus.

$I=$ Phyllobates (part) Bibron; cf. Boulenger, P.Z.S. 1888, p. $20 \%$. 
A. Pupil contracted into a horizontal slit.

u. Omosternum rudimentary. Vomerine teeth present.

a. Tympanum distinct

ß. Tympanum hidden

b. Omosternum present. Vomerine teeth vestigial.

Phanerotis fletcheri.

Cryptotis brevis.

Crinia, 4 species.

c. First finger opposed to the others

Chiroleptes, p. 221 .

B. Pupil contracted into a vertical slit.

a. Omosternum rudimentary. Tomerine teeth absent.

b. Omostornum fully developed. Vomerine teeth present.

Hyperolia marmorata.

a. Tympanum distinct. Toes webbed.

B. Tympanum hidden. Toes webbed. Heleioporus, p. 222.

$\gamma$. Tympanum indistinct. Toes free or slightly webbed.

Limnodynastes, p. 222.

Pscudis, widely distributed over South America, consists of four species which hare the appearance of long-legged frogs. The fingers, of which the first is opposed to the others, are free; the long toes are fully webbed. The trmpanum is exposed.

$P$. puredore is absolutely aquatic, floating in pools, and is extremely shy. In life it is most heautifully coloured with lronze, bright green, and black markings above; underneath it is shiny rellow, with brown spots on the body and stripes on the thighs. Within a few minutes after death all the brilliant colours of the smooth skin of the back turn into dull uniform lnown, with indistinct darker spots. Total length of the adult from ? to $2 \frac{1}{2}$ inches. The specific nane refers to the peculian shape and monstrous size of the larva or tadpole.

One of the larvae described and figured by Parker measures $10 \frac{1}{3}$ inches in length, the head and body taking up $3 \frac{1}{3}$ inches. The spiracle lies on the left side and the hind legs are $\frac{1}{2}$ inch long, just breaking through the skin. The rent is median. The liuge tail is very thick and museular, and is furnished with a high, irregularly shaped dorsal and rentral fin, the whole organ measuring $t$ inches dorso-rentrally. Another larva, or rather tadpole, in the national collection is older, and although still very large, namely, 7 inches long, has fully developed hind-limbs 3 inches long; the fore-limbs are less than half that size, the left protrudes through the spiracle, while the right has broken through the skin. The dorsal and rentral fins of the tail have much shrunk; the whole organ, 5 inches long, is gradually tapering to a point like the tail of ordinary tadpoles. By the time that the 
tadpole is nearly ready to leave the water, its whole loulk is reduced to less than one-fifth that of the latrest tarlpole. It measures from snout to vent wnly $1 \frac{1}{3}$ inch in the 7 -inch tadpole this distance is fully 2 inches, aml the tail, deroid of fins, is reluced to 2 inches in length. Instead of the solitary left spiracle there are now two, one wn the rentral side and a little in front of the hase of each arm, the horder of each hole being continued by a peculiar semilunar fold.

Ilyluta. - The numerous slecies, nearly fifty, of this tropical Anerian senus exhibit sereral anatomical differences. The

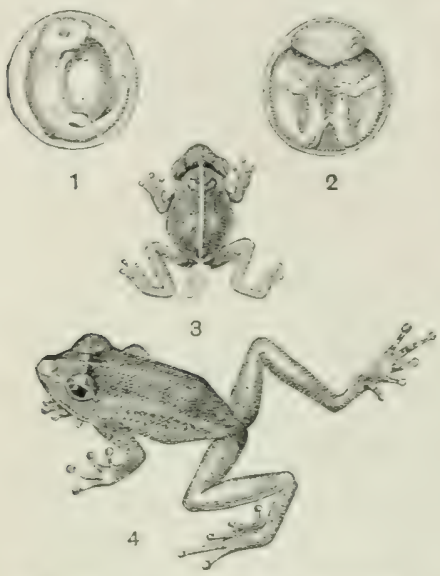

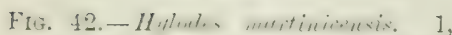
an egg with embryo about seven days old ; 2, another, twelve days olit : 3. the young Fros just hatched: all $\times \frac{3}{4} ; 4$, adult male $\times 1$. (After Peters.) tympanum is sometimes indistinct or hidden, in which case the Eustachian tubes are generally very narrow. The fingers are free, and carry dises, like the toes, which are sometimes slightly webhed. The males have a subgular rocal sac, producing a loud, or whistling, roice. The general appearance is that of land- and tree-frogs; the size is small, mostly between 1 and 2 inches.

H. martinicensis is about $1 \frac{1}{2}$ inch in length. The groundcolour is pale vellow-grey, with a large brown patch on the nape, which colour is continued over the back in the shape of more or less coherent or dissolved patches. A dark brown stripe runs along the midale of the sides. The limbs are harred with hown, the under parts are whitish. This species, known ly the rernacular name of " rouni," inhalits many of the Wrest Indian islands, "y. Inarbadoes, Martinique, Porto Rico, and Hayti. It hats lecone finnums, as it was the first instance known of a from which unlergoes its whole metamorphosis within the erg. The priring takes platee on land, in the months of May and June, when the female lays about twenty egers, which are envelopeed in a foumy mass and ghed on to a hroad leaf, on hiflden in the axillate of Iridiaceous plants. The mother aems to remain in the neighlourhoul watching the eggss, which are 
large, measuring t-5 $1 m m$. in diameter. Dr. Gundlach, a resident in Porto Rico, was one day, in the month of May, attracted by sounds like those of a young bird, and found three males and one fernale of this species sitting between two large leaves of an orange-tree. He put them all into a glass ressel and soon saw a pair in embrace. The female laid about twenty-five pale straw-coloured eggs. The embryo develops neither gills nor gill-openings, but a large well-rascularised tail, by means of which, being immersed in the watery fluid contained within the eggr, it seems to breathe. After twenty-one days the tadpole, having used up all the available yolk and fluid, and most of its own tail, bursts the egg-shell and hops away as a little frog of $5 \mathrm{~mm}$. in length, but still with a stumpy white tail, which is quite absorbed within the same day.

This species has several times made its appearance in the tropical houses of Kew Gardens. It seems to have hred and vanished again. ${ }^{1}$

Culyptocephulus is remarkable for the dermal ossification of the cranium, which has assumed the greatest possible extent. It affords a curions parallelism to Triprion and other Hylidae, which are likewise Central American forms. Only two species are known; C. greyi of Chili, and C'. testudiniceps of Panana. They are large, thoroughly aquatic creatures, 5 to 6 inches in length, with huge heads. The tadpoles grow to an enormous size. One specimen of $C^{\prime}$. gayi in the National Collection is more than 6 inches in length, the tail taking up more than halt of the total: the spiracle lies on the left side, the rent on the right, and the hind-limbs are still half enveloped in a kind of fold of the skin.

C'eratophrys is a genus of some ten toad-like species, living in South America, from Guiana to Argentina. The generic name alludes to the peculiar modification of the eyelid, which in most species is developed into a triangular, upright, but flexible appendage. The head, in conformity with the huge mouth, is very large. The tympanum is rather indistinet, sometimes quite hirdden. Several of the species have a large dorsal shield, which is produced by a thick ossification of the cutis, but is not fused with any of the vertehral processes. The male has a rocal sac. C. dorsuta s. boiei of equatorial Brazil is a monster toad, reaching

1 See Giinther, Nature, lii. 1895 , P. 643. 
a length of 6 inches. The upher evelirl is transformed into a triangular hom, whence a cutanemes rikge extends all along the side of the back. meeting that of the other sile aluse the rent. There is no osserons shielel on the latek. The tympanum is

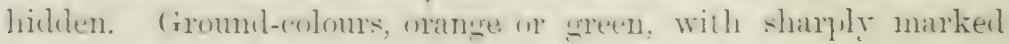
dark brown or blackish patehes.

C. curnutu, in Northern Brazil, latcis the dorsal shield, but has horned eyelids and a visilite tympanum. Its coloration renders it one of the most heautiful toarl-like creatures known. The sromul-colours are greeren, liack and lirown, with an orange-rellow stripe over the head and hack. All these colours are most pleasingly lilended and arranged in marbled pratches or stripes radiating

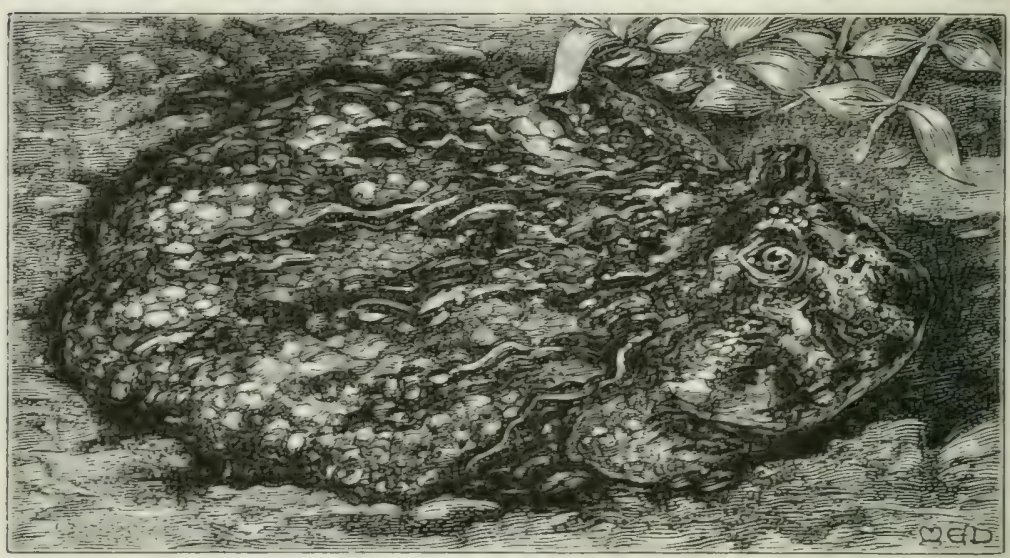

Fig. 43.-Ceratophrys' ornutu. Horned 'load. $\times \frac{\text { i. }}{4}$.

from rarions centres, as, for instance, from the eyes towards the rircumference of the mouth, the slit of which they pass, the sane line of the gattern leing continued upon the lower jaw. The whole surface maties the impression of a gay hut exquisitely banmonions carpet. The under parts are yellow, inclining to white towards the middle.

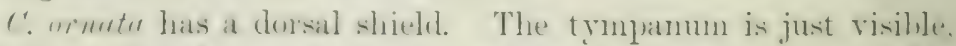

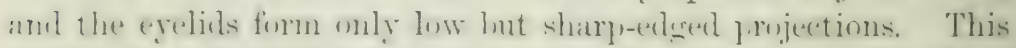

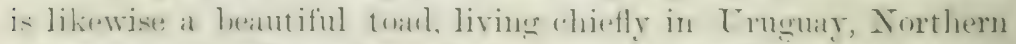
Argentina, and Paranglay, where it is universilly known as the "escher\%o," one of the simanish works signifying a toul. Its size

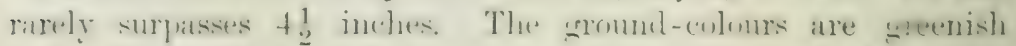

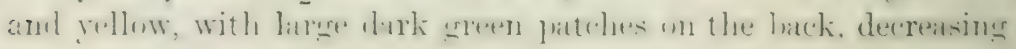


larger one, and could still lie felt through the soft body. This sane camnibal took large-sized frosis greedily, one or two for a meal. swallowing them whole and then sinking back into its lair, which it scarcely ever left, except for an occasional soaking hath in its water-plam, espercially hefore shedding its skin. It livel for many months in the sume enclosure with a pantherine

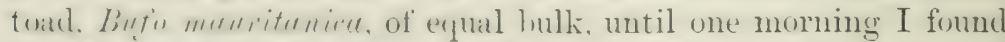
the Monocan half swallowed and almost lifeless in the month of the Anerican, whence it was rescuerl with difficulty. It canne romml aftere a tew loums, lut never fully reervered, lingering on for weeks: the skin wats (hanged to a learl-culour so far as it harl heen swallowed and partly dissolved by the gastric juices, and soon began to develop festering ulcers.

These "horned trats" milie a suluealing noise when teazed, not at all loud or strong in proportion to their size. Ill-tempered indiviluals jump at their ageressor and can inflict rather painful nips. They hiliernate during the dry season in the ground.

Lepidobatrachus.-Large teeth in the upper jaw, and two large tomth-like projections in the lower jaw near the symphysis. Voner truthless. Silcral diapenhyses mot dilated. Tongute rumbl, ame free hehind. Tympanum distinct. (rreat developnent of the memblume-bones on the head, and a weaker ossification in the skin of the hack, recalling that in reretoplerys. The eres ale chely set torgether, and the nostrils take up the most elevated portion of the head. Pupil horizontal. The two sprecies of this semus were discovered by Budgett ${ }^{\text {in the }}$ I'araguaran ('ha(0). L. "spur lives continually in mudaly pools, flouting with just the ares and nostrils alwe the surface. If disturlued it slowly sinks to the buttom, leaving no ripule. It

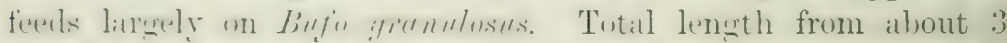
inches. The skin of the unger prarts is tuhercular, tongh, and of a dull leaden colour; the tips of the toes are horny. L. laevis is slumth ant slimy. "with the urwans of the lateral line showing rearly upon it." it feature elsewhere known to exist in lenopus. and Leptobrachinm only.

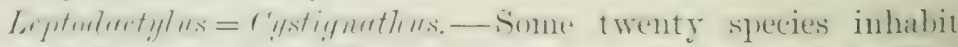
tropical Ameriat, from ('entral Mexion to Buenes Aires. The fingers and toes ane not wellederl and end mostly in points; only

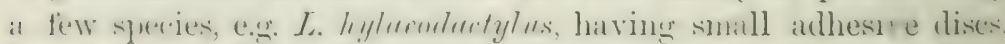


The legs are long and the general appearance is very much like that of an ordinary frog.

One of the commonest and prettiest Brazilian species is $L$. ocellatus, which is characterised hy a number of longitudinal glandular folds on the back and flanks. The colour of the upper parts is olive-brown, that of the prominent folds is yellowish white, interspersed with black spots. The under parts are yellowish white, with blackish marblings on the throat. The males have a sharp black spur on the inner carpal edge and one on the rudiment of the thumb. Total length about 4 inches.

According to Hensel ${ }^{I}$ the spawning takes places in Tio Grande do Sul after hibernation. The voice of the male is then very loud, resembling the sound made by a carpenter chopping a heam. They repair to ponds and produce a cup-shaped puddle, about 1 foot in width, by raising a wall of mud, which separates the inner water from that of the pond. The taripoles remain in this nursery until the spring-rains demolish it and set the young ones free. Drought causes the drying up of these water-pans and subsequent destruction of the brood.

L. mystacinus is another Brazilian species, about 2 inches in length. Its specific name refers to the dark lrown stripe which runs from the tip of the mouth through the eye to the tympanum. This species is thoroughly terrestrial, and nerer enters the water. It digs a cavity, the size of an ordinary tea-cup, under stones or rotten trunks, always in the neighbourhood of ponds and just so high above the water that the latter can rise up to the nest in the rainy reason. The straw-coloured eggs are laid in this carity, and are enveloped in a foamy, sticky mass, like the well-beaten white of an egg. The young tadpoles seem to live on this froth until the rains set them free. When, however, the rains delay and a drought kills the broods of other less circumspect species, these tadpoles, still provided with gills and lung tails, remain in their moist nest or withdraw further beneath the rotten stumps, huddled together in large numbers until the next rainy season.

Similar nursing habits have been recorded of $I$. allilubris, which inhabits Mexico, Cuba, and several wher West Indian islands. The same applies to L. typhonius. (rundlach found eggrs

1 Arch. Naturg. xxxiii. 1867, p. 124. 


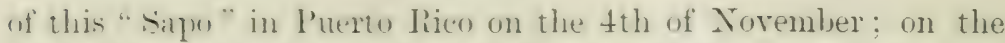
Enth the young showed the first signs of hind-limbs, on the 3rd of December of fore-limbs, and win the 7 th of the same month they began to climb out of the water.

Prolublimblu is a semi-apuatic gemus with some eighteen sprecies, langring from Mexico to Patagenia and accoss the Andes into Chili. Sonne of them have a peculiar sland on the lumbar region. (1) large, flat warts on the back. smmetimes arranged in longitulinal folds. The tres are slightly wehlied, or free, according to the more or less pronounced aquatic habits.

I'. fuscomerulutu, an inhalitant of southern Prazil, Paraguay. ami limguar; is a short-limberl frow, with spreading slenter toes

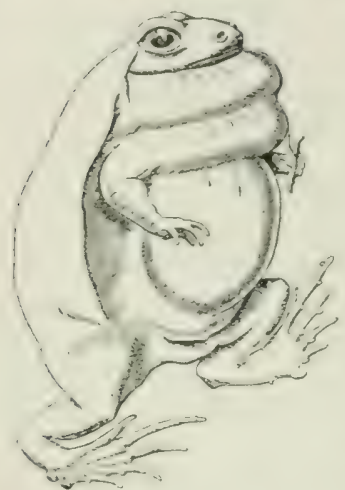

Fig. 45. - P'aludicula fiescocurvilute. 1. with varial sacs partly filled. and a small head. There are shovelshaped, black, horny tubercles on the metatarsus. The general colour is olive above, with darker markings and conHuent white-edged spots; the limbs are cross-barred; the lumbar glands are black, with a white margin in front. The male has a rocal sac. Budgett ${ }^{1}$ gives the following account of its habits:-

The peculiar ery, which is so constantly heard in the neighbourhood of shallow pools in the Paraguayan Chaco, and resembles that of a kitten, is proinced lis the alternate inflation of throat and abdomen. When fully inflated, the frog appears to be the size of a golf-ball, but, if startled, instantanemusly shrinks to one-fifth of that size, so that it seems to have vanisherl. It has also the power of rentribupising. The foud consists larepely of water-hertles. In the spawning time it was foume at night floating on the surface of prools in the distembled condition, and aring to the females in al most monmful way. (1) coming to the surfice it fills its lungs with

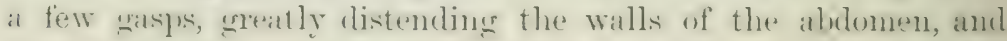
then drives the air inte the rocal sales, canting then to become

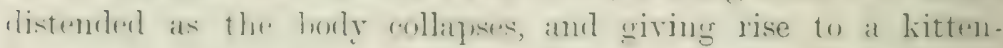
like cry.

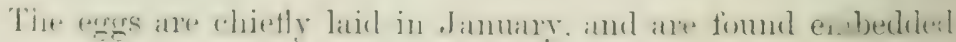
'Quurt. J. Mier. Ści. xlii. 1899 , ì. 309. 
in a frothy mass floating upon the surface of the water. The? eggs measure only $1 \mathrm{~mm}$. and are without pignent, and with extremely little yolk. The larvae become free-swimming within frum eighteen to twenty-four hours after the first segmentation. When ready for hatching they wriggle their way through the froth to the water below, and hang into it from the floating froth.

$P$. bitigonigeres s. notete, in Brazil, lacks the lumbar gland, the place of which is marked by a black spot. The upper parts art olive, with darker marblings and a dark lateral stripe. The male has a black throat and two exterual rocal sacs. Hensel fouml the eggs, in Rio Grande do Sul, in September, formiug a frothy mass of the size of a fist, Hoating between grass upon the water near the margin.

The following three genera may serve as Australian examples, especially since we are indebted to Baldwin Spencer for interesting observations made on their habits in Central Australia. ${ }^{1}$

Chiruleptes, of which six species are known, is easily reconnised by the first finger, which is opposed to the others. The sacral diapophyses are slightly dilated. The general shape is that of a thick-headed, rather stout land-frog or of a tree-frog. The tympanum is distinct, and the toes are only half webbed, or even less, except in Ch. platycephalus, in which the toes are entirely webbed and the tympanum is indistinct. This species is about 2 inches long, uniformly olive-green abore, with a few tubercles on the otherwise smooth shin. Other species rather resemble the European Natterjack in coloration.

spencer's account is as follows:- "In Central Australia C'h. platycephalus seems to prefer the hard clay pans rather than sindy creeks, as the sand-beds of the latter are too loose for the formation of the burrow. We came across the animal first when encamped by the side of a rery shallow clay pan, the Hour of which was deeply cracked with the sun's heat. Around the edge were withered shrubs of Chenopolium nitiariacem, and it was at the base of these that the black fellows looked for the burrow. In the hard-baked clay were imprints made by the frog as it burowed, and about a foot underground we came across the animal, puffed out into a spherical shape, and just filling up a ciavity, the walls of which were moist but not wet. The ground

1 Report on the IVork of the Horn Scicntific Expedition to Central Austratiu, pt. ii. "Zoology," 1896, p. 164. 
Wats so hard that it harl to he chipped away. When one side of the hurow was opremed, the fros remained perfectly still; its liwere eyelid wats drawn up over the eye and was rery opaque, wiving rise to the belief amongst the lilacks that the animal is hincl. In the sunlight, after a short tine, it oprened its eyes.

" On squeczing the buly. water was forced ont of the cloaca : this was acrumulated principally in the uninary hlader. On cutting the buly ofen it was seen that there was a certain ammunt of water in the suldeutaneons spaces, hut that the greater furtion, which caused the crreat swelling-out of the body, was contained in the loxly-cavity itself ; and it was also observed that the lungs were considerably distended and lengthened, their apices lying right in the pelvic remion. They contained air and not water, hut their onter faces were hathed with the water in the boly-cavily." The larrate am tarlpoles probalily develop with extreme rapidity, som to aestirate as very small frogs.

Hol, inmeres has a calcified metasternal plate and slightly dilitted saldal vertehrate. The two species hate a toad-like apfeitrance, owing to their stout londies, short limbs and conspicuous

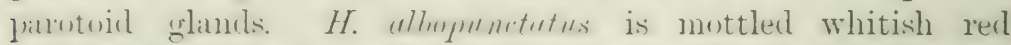
and brown above; it extends from Western into Central Australia. H. pritus is olive, with darker marblings, and is distingruisherl ha a light rertebral line. It is likewise found in Central Anstraliat, and it extends into Tictoria and New South Wrales. Fiencer found it in swarms after heary rains, the specimens heing much swollen and distended with caterpillars and beetles. They lonked as if they were simply gorging themselves with foud frepatratory to returning again to their long aestivating condition.

Limmulyurstes is me of the commonest genera in Australia. The six species have the halits and alprearance of stort frogs or smooth toarls. L. dorsolis seems to dange through the whole of Australia, from east (1) west, and looks like the European Pshluetes. The skin is smosth, hut with an elongated white slame extending from benesth the ere to the shouldere and another slandular complex on the thigh. The upuer parts are mottlecl olive-hrown, often with a light vertelnal line. The under parts are whitish, with hrown spots. The male has a vocal sace. One of the speecimens in the National collectun cou-

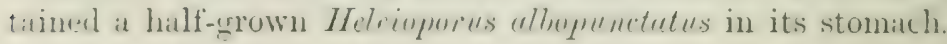


Concerning the pairing and the other habits of the Anura of Tew South Wales we have some valuable notes hr. J. J. Fletcher. ${ }^{1}$ He observes that Australian frogs spawn whenever they are ready, and when the rery irregular conditions of moisture will allow it, but that they are not all ready at the same time, if. they have no fixed period of the year. Limnotynnstes, Hylu antera, and $H$. coerule deposit their spawn in the water, in more or less irregular floating patches, which look white and frothy. The period extends from . July to. May, and is at its height in August and Septemler; but if there is a spring-drought rigorous spawning may be looked for ahout the middle of January, when heary showers are likely to occur. Crinia and several Hyla, e.g. H. cuingi, spawn at any time of the year. The egys form small submerged bunches, enclosed in a transparent jelly, attached to the blades of grass or twigs of dead branches in the water.

Pseudophryne, a genus closely resembling Cirinia, but on account of the absence of teeth in the lower jaw relegated to the Bufonidae, spawns during the Australian summer and autumn. The numerous ora of $P$. austratis and $P$. bibroni are laid separately, not in the water, lout under stones, or in the dél,ris of reed-and grass-tussocks, on the edge of a pool.

The larvae of Pscudophryne and others have often to depend upon the next following rain, sometimes waiting for months to he relased from the eggs, wherein they have so far developed. But the tadpoles, once hatched, probably lo not bury themselves: they either metamorphose or die.

The males of Mirophyes and Hyla grasp the females in the axillary region; those of Limnodynastes, Hyperolia, Crinia, and Psemdophryne throw their arms round the inguinal or lumbar region.

For some three months during the winter, commencing alwut May, the frogs, like lizards and snakes, resort to shelter mincler loys and stones, beneath which they are then to he met with in a more or less sleepy condition. During the hot and rery dry periods many bury themselves in the drying-up mud, which becomes very hard, and does not release them until the next rains. They croak during showery times of the rear. There is no evidence that any Australian species live in the high Eucalyptus-trees.

1 Proc. Linn. Soc. N.S.W. (2), iv. 1898, p. $35 \%$. 


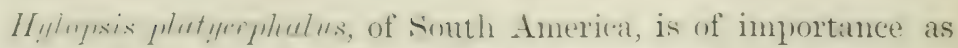
forming a link with the Inembenhryiscinat, owing to the very suatl size of the teeth in the unper jaw. There are no romerime teath. The fingers and toes are welbed, and furnished with disc. The very snall musternm and the metasternum are artilitimus. The pupil is horizontal. Total length, about or under $1 \frac{1}{2}$ inch.

Sub-Fam. 3. Dendrophryniscinae. The two Neotropical semera uf this suh-fimily are characterised hy the entire absence of terth. The tomblhess condition of the upper jaw is really the sule charater which sepratrates them from the Cystignathinate, taken as a whole. The suppression of the tympanum and of the

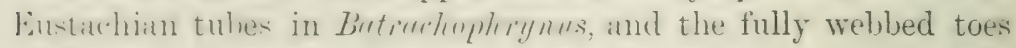
wl li. murestumus indicate complete alaiptation to aquatic life.

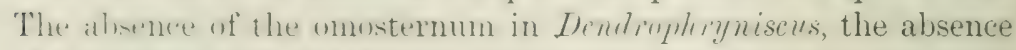
of romerine teeth, the dilited phialangeal tips, the entire and quite allherent tongue, are: all features which likewise ocenr in some of the ('yotignathinate, and therefore cannot be urged against their atfinity: Lastly, the recently discovered south American genus Mylnosis is, as pointerl ont by Werner, an intermediate link, wwing to the extremely small, scarcely risible teeth in the upper jaw.

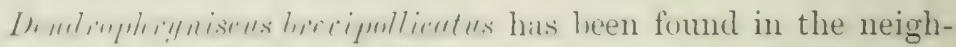

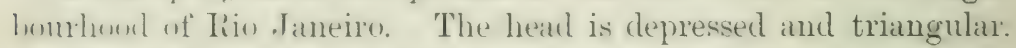
The tomple is antire, but free lehind. The tympanum is suppresent. The omosternum is absent; the metasternum forms a long lomy style. The sacral dianophyses are cylindrical. The terminal phalanges are simple. Hut carry dilaterl tips. The first finger is rulinentary. The skin is nearly smooth, redelish brown ahove, whitish below; the limbs are cross-barred.

linfimlundrignus inhabits the monntains of Peru. The head is much depeneserl and small, with the eyes directed upwards, as is usual in escentially aquatic sperejes. "The tongue is larger. circulat: and entirely adherent. The tympanum and the Enstarlitian tulues are sulplessed. The mustermum is cartilaginous. and the metastermum forms a cartilatginms plate. The sacrial diafmphyses are cylindrical. The terminal phalanges are simple, and airry no discs. The fon fingers are short; the toes are

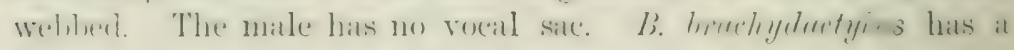


smooth skin, olive-brown above with darker spots. Li. muenstrmus, 2 inches in length, is distinguished hy its larger size, and by its completely webbed toes.

Fam. 6. Engystomatidae (Narrow-mouthed Tnads)-Firmisternia with dilated sacral diapophyses.

Sub-Fam. 1. Engystomatinae. - Without teeth in the "ly"e jan:- Although there are only about 60 species known, these have heen grouped into more than two dozen genera, many of which are represented by one or two species only. The range of this sub-family is peculiar, namely, Neotropical and Palaeotropical. Secphliophryne and Rhombophiyne are peculiar to Madagascar: Calophrynus occurs in the same island and in the Indian region: Tenobuticuches, Sphenuphiyne, Liophiryne, Jentophryne, C'ullulops and Fenorlina live in New Guinea. Breviceps, C'acosternmm and Hemisus are confined to Africa, while of Phrynomantis two species live in Africa, and the third in the Malay island of Amboina. Such freaks of distribution indicate either that many of these genera are not established upon rery valid characters, or that their respectire species are instances of convergent evolution, and do not form natural genetic groups.

Many of the members of this sub-family live upon ants and termites, and it is a well-known fact, not restricterl to the Anura, that this kind of fare has a peculiar, modifying influence upon the structure of the mouth, teeth, tongue, limbs, and various other organs. In the present case the tongue is not much affected; it is, with few exceptions, more or less oral, not nicked, but free behind: in the Indian Glyphoglossus and in Rhomboph ryn of Marlagascar onl $y$ is it modified into a rather long and groored, almost double, apparatus.

A rery common feature is the small size of the mouth and the formation of a snout, which projects beyond the upper rim of the mouth and beyond the nostrils. Such a prominent and pointed snout is well developed in Rhinoderma, Phrynisers, Calophrymus, Stereocyclops, Hypopachus and Engystoma. The mouth is rery narrow in C'acopus, Glyphleoglossus, Biericeps, Rhombephryne, and Hemisus, all creatures which seem to he confirmed eaters of ants and termites. However, it must not be supposerl that the mouth of all the genera is narrow, although this character, rather marked in Enyystoma, is now embodied in the name of the family. A peculiar development of the palatal region 
is presilhy correlated with this foul. The palate is mostly tonthless, hut its skin is freupently raised into a transterse fold, hetween or hehind the romers, and into a second fold in front of the oesophlagus: these folds are sometines rather hard and sarrated or ilenticulated. The galatine bones carry true teeth

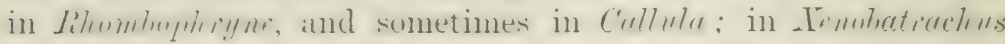
the teeth are reducet to two latere grairs. The trmpanmm is usually hidden.

The shate of the holly is generally very stout. The limbs are

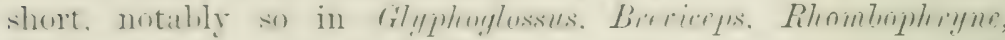

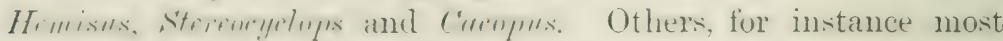

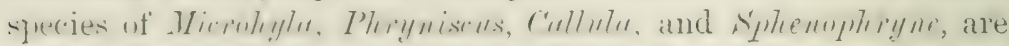
of a rery slemeler huild: amel their linnls, instead of being short and well anlapted to digging, are long and may eren he provided with trpical athesive discs. supported hy T-shapeel phalanges,

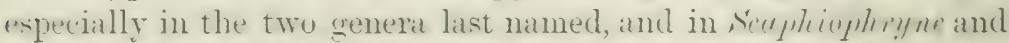
Phimminuntix. However, none of the forms provided with rliscs are known to be arboreal.

Exceptional diversity is shown in the shoulder-gircle and stermum. The omosternum oecurs only in lihinoderma and Hemisus. The metasternum is a cartilaginons plate, very large

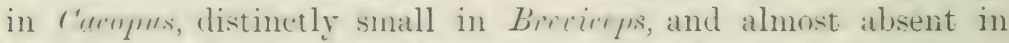
Hemisus. The precoracoids and clavicless show all stages from

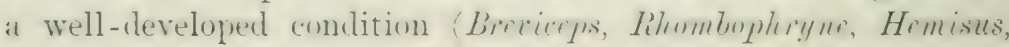

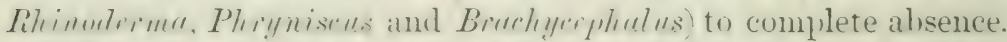
The circumstance that these hars are rery weak in Ifolono-

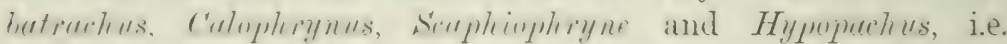
in I'alaco- and Nen-tropical genera, indicates a widespread bendency towards (omplete suppression, a feature independently aimed at both in America (Engystoma) and in the Old World.

Tntil we know something ahout the habits of the members of this much diversified sul-fanily, it is idle to comnect the various modifications with each other, and thus, hy correlation, to find out their meaning. Thuse forms which possess well-dereloped discs (1) their fingers and toes are silid nut to be arboreal. What is the true meaning of the prominent smout which is not restricted to the dirgring forms? Most of the goond digrgers hate well-elevelopeed freenateoid bars, and the coracoids are distinctly strengthened,

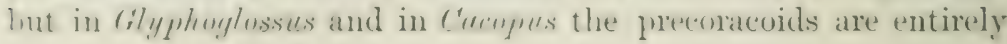


absent, and this loss is compensated for by exceptionally strong coracoids.

On the whole, those genera are to be considered as the most primitive which have undergone the ferest losses. Those with a complete shoulder-girdle, with an omo- and meta-sternum and with simple phalanges, are necessarily the older forms. One step firther back in another direction, the possession of teeth on the palate, and on the upper jaw, leads to those genera which have been separated off as Drscophisat, while teeth in the lower jaw constitute the GenYophrinisat. Lastly, the firmisternal type has necessarily been evolved from the arciferous condition, and there the two Bufonid genera Myobatrachus and Rhinophirymus, the former Australian, the latter Mexican, with their narrow and scarcely urerlapping epicoracoid cartilages, seem to form a connecting link, although their ant-eating habits, with concomitant modifications in structure, may be nothing but cases of convergent evolution.

Key to the genera:-

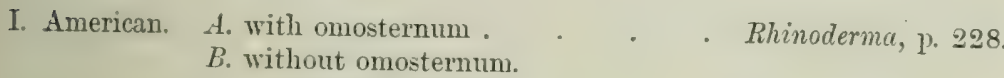

u. Pupil horizontal.

Precoracoids present.

Sacrals strongly dilated. Oreophrynella.

" moderately ,. Phryniscus, p. 230.

b. Pupil vertical.

"feebly " . Brachycephalus, p. 231.

a. Precoracoids feeble. . Hypopachus.

B. " absent. . Engystoma, p. 231.

c. Pupil round. Precoracoids

present . . Stereocyclops, p. 231.

II. Palaeotropical. u. Pupil horizontal.

a. Precoracoids present.

With palatal teeth. Madagascar.

Palate with dermal papillae. Africa.

Rhombophryne.

Breviceps, p. 232.

With palatal dermal folds. Madagasear.

Scaphiophryne.

With serrated palatal folds. Madagascar and

India. Calophrynus.

Palate smooth. New Guinea. Sphenophryne

B. Precoracoids absent. and Liophryne.

ITalacer.

Phrynella, p. 233.

New Guinea .

Africa .

Mantophryne.

Cacosternum. 
b. Pupil vertical.

a. Precoracoids present. India. Melanobutrachus.

B. Precoracoids absent.

Tongue oval. India.

Africa Hemisus, p. 232.

Tongue elliptical. India. Wicrohylu.

Tongue divided by a longitudinal furror. India. Glyphoglnssus, p. 233.

Fingers and toes with discs. Africa and Amboina. Phrynomantis. New Guinea. Callulops.

c. Pupil round. Precoracoids alsent. Tongue round. India. Callula, p. 234. Tongue long, oral, with a deep groove. New Guinen. Xenorlina.

Wotc.-Icnozatrachus ophiodon, New Guinea. Palatine bones, each with two large curved teeth. Otherwise imperfectly known.

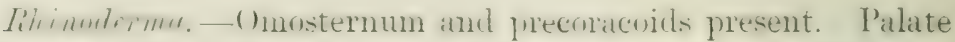
withrut textl. Tympanum inclistinct. Trmomal phalanges simple, and not dilaterl. Tomsue heart-shaned. and free behind. Pupil horizontal. Habitat, Chili.

lik. Animini, the only species, wat discovered by Darwin, during the royage of the Bumle. Its total length is only $\therefore$ cun., or little more than one inch. The slatue is crotesque, as the shin is prolongel, leyond the very small triangular mouth, into a false nose, i.t. a nose-shajed poujection, while the nostrils remain at their original place. The skin is snooth ahrove, srimmlar on the under parts, and forms a trianesular flap or spurshaperl aplyentage on the heel. A chlandular fold extends along the sirles uf the hody. The general colour is brown above, black ln. lıw, with lar.ge white patches, the latter colour leing sometimes grolominant on the throat and chest. The male has a pair of intemal vocial sars. and the use of these as nurseries for the young has made this species famous.

Eipurlit ${ }^{1}$ has sgiven an elaturate accomt of this species, which lives on the gromed in shaty wooks. Its voice somnds like a little leell, and betore taking its short jumps, it erects itself rertically ny"u the hind-limbs. The grular sac of the male opens ly two slits. one on each side of the tomane. (renerally this sac does not extend heromel the minlelle of the (-hest, hut during the breerling

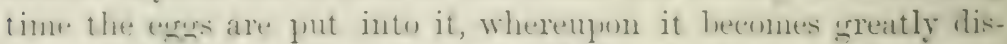

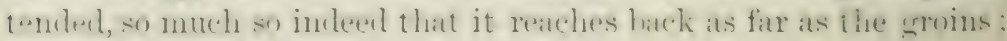

\footnotetext{
1 An. Suc. Espan. i. 1822. See also Howes, P.Z.S. 1888, 1) 231.
} 
dorsalwards around the flanks, almost to the vertebral diapophyses; rentrally and forwards it reaches the chin. The walls of the sac are of the same structure as the buccal lining, of which they are in fact continuations. They adhere, at intervals, to the cutis and to the pectoral and abdominal muscles.

The effect of the distension of the sac upon neighloouring organs is twofold. First, the viscera are pressed back within the abdomen; this disturbance is temporary and does not apply to all specimens; the feeding in.no way impeded. Secondly, a permanent change is produced in the direction of the precoracoid bars, in such a way that each bar is curved tailwards and rests with its rentral half upon the coracoid; owing to this forcible bending the clavicles do not neet each other: There is, of course, not so much space gained by this slight rearrangement of the shoulder-girdle as Espada implies, but we have here, perhaps, an illustration of direct correlation between two originally independent organs, namely, shoulder-girdle and rocal sacs. Repeated distension of the throat-bag during every breeding season, while the whole organisation of the male is in a highly excitahle condition, has pressed the clavicular bars back, or rather has staved them in, and this at first pathological and abnormal condition has at last become a fixed feature. It is to he regretted that we know next to nothing about the habits, especially the mode of breeding, of the other genera which likewise have reflected or very feeble precoracoids and clavicles. Their weakness or even complete absence must have a reason, or rather must have had a vause.

The pairing and oviposition, and the manner in which the eggs are conveyed into the gular sac, have not yet been observed. Espada examined five males with young, the number of which varied from five to fifteen. In one male with eleven embryos the 1 1. the end of the tail, and they were lying within the chest of the father, the less advanced in the farther recesses of the bag. Three of the tadpoles had already completely-formed fore- and hind-limbs, while the arms were still hidden. The least developed were still globular, a proof that the eggs are conveyed into the bag. Another male with fifteen embryos looked as if it had gorger itself with the almost fully-formed tadpoles, which measured $14 \mathrm{~mm}$. They were quite irregularly distributed, and nowhere 
attached to the walls of the bag. None of them had horny jawarmaments, and not eren the smallest specimens showed any traces of gills, resembling in this latter character those in the female brood-pouch of titutieme. The intestine of the taclpoles is short and thick, coilex up spirally and filled with yolk, certainly not with regetalble or other foreign matter. Conseyuently the entire development from the eng to the complete stump-tailed little creature is undergone within the pouch : and this, after the young have escatpenl, probalbly shrinks lack to its original size and acts as a gular vocal sac.

Phrynisis. - About ten species of this tropical American genus are known: they extend from Costa Rica to Buenos Aires. They differ not inconsiderably in various details. The tongue is elliptical, entire, and free behind. The palate is smooth. The trmpranic disc is alsent. Fingers and toes more or less webbed, smmetimes with swollen tips, without, however, forming adhesive discs. In a few species the first toe is quite indistinct. The male has a subgular vocal sac. The mouth is small, and there is a short snout. The general apluearance varies much. I', nigricens of Lruguay, ete, is stout and has rery short hind-limbs; the skin of the upper prarts is liack, spotted with white, and covered with warts. Most of the other species are slender. with larger hindlimbs and a perfectly smooth skin, the coloration of which ranges from dull uniform brown, or hlack with crimson markingse, to bright green with purple spots. The under parts are, as a rule, conspicuously coloured, a rare feature in Anura, the farourite colours being orange. rellow, or even crinson, with or without black patches.

I'hiynisr us nigricons has been observed in Paraguay by Budgett, ${ }^{1}$ who gives the following account. This is a brilliantly coloured frog of toul-like appearance, and ahout :3: $n$ m. in length. The crromel-colom is blikck, with yellow spots or patches on the ulper farts, the moler garts are liack, with scarlet. butehes, the palms of the hands amb sules of the feet are scarlet. At the breeding season both sexes utter a call-note which consists of two clear musical "rings," followed he at long desermling "trill," like that of our British cireenfinch. This frog, which at molinary times is the slowest aud boldest of frows is nuw actire and excessively

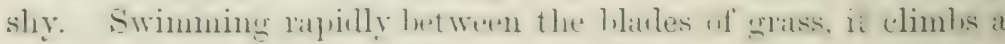


tuft, and dilating its throat, repeats its call; but if in the least disturbed, it is suddenly gone. The eggs are laid in quite temporary pools in grassy ground, and form separate globules of jelly, which float on the surface of the water, and are heavily pigmented. The development is excessively rapid. The segmentation beginning at 10 A.M., they were hatehed and wriggling about by 7 A.M. the following day. They are probably washed down into deeper pools by the retreating waters, and for this purpose the mamner in which the eggs are laid, namely, in separate globules of jelly, seems especially suited.

Biculugephalus ephippium in Brazil, the only species, is remarkable for the development of a broad dorsal shield of bone, which is fused with the processes of the second to seventh vertebrae, an ossification which strongly resembles that of several species of the likewise Brazilian Ceratophrys, a genus of the Cystignathinae.

sterencyclops is remarkable for the peculiar formation and protection of the eyeballs. The anterior portion of the sclerotic is ossified into a ring, which surrounds the transparent comea. Another peculiarity lies in the metasternum, which is so much broadened out that its cartilage is in wide contact with the posterior edge of the coracoids. The epidermis is everywhere "thickened by a chitin-like deposit." The only species, S. imeressutus, found near Rio Janeiro, is an altogether aherrant creature. Its general appearance recalls that of Pipa. The gape is large, with a slightly projecting muzzle; the limbs are so short that the upper arms and the thighs scarcely stand out from the broadened and flattened body, which is leathery brown, with a narrow white median line extending dorsally from the nose to the vent.

Engystoma, with about five species in the Southern States, Central and South America, is the type-genus of the whole family. chiefly on account of priority of name. It is fairly characteristic in so far as the mouth forms a narrow, somewhat projecting snout: the precoracoids, the clavicles, and the omosternum are ahsent, the palate is deroid of teeth, the lining of the mouth forms is dermal ridge across the palate and another in front of the oesophagus, the tympanum is hidden, the sacral diapophyser are moderately dilated, and the tongue is elliptical and free behind. The pupil is vertical. The fingers and toes are free, ending in slightly dilated or blunt tips; the terminal phalanges are simple 
and the hind-limbs are short. The male has a subgular rocal sae.

The most northern species is E. motulinense, living in the finthern Inited states. concealed under the bark of fallen trees ar in whl fences. The skin is smoth, lut forms a fold across the head. lehind the eyes. The general colour is brown, with light. whitish dots on the under parts. 'Total length 1 inch.

Biring is a south African genus with three species. The coracoicls are very strong and directed backwards, but so broadened that they form a long and strong symplyysis, touching in front that of the precoracoids, which stand transversely and are well deredoped. The metasternum is cartilaginous and decidedly small. The silcral vertebra has much dilated diapoplyses and is co-ossified with the cocegx. The general aprearance is extremely stout and short, the head heing almost drawn inte the nearly globular body, and ending in a short snout with a small mouth-opening. The tongue is long and oval, not nicked, but slightly free behind. $b$. mussumliers is athout 2 inches long, and looks like an overstuffed round hage, ont of which the short arms and legs project from the chows and knee-joints only. The tarsus is provided with a strong horny, spade-like tuhercle, which enables the creature to dig into the gromnd, and into the nests of termites, which seem to he its chief food. Peters found this species in enormous numbers, during the tropical rains, coming out of the ground, whither they withdraw anain completely for the dry season. The skin is smooth, resklish frown ahove, with darker patches: the under parts are dull white, with a large black patch on the throat.

Hemisus is another African genus, with two species, $H$. guttatum in Tatal, and $H$. sudmense in East and West Africa. This genus is so exceptional in its shoulder-girdle, that Cope separated it from all the other Anura as a sinecial sub-order Gastrechmia. The precoracoids are extremely strong, and form a hroad symphysis from which springs the long cartilaginous omosternum: the conaterids are slender, very long, and converge backwards to it namow spmphysis, and there is no metasternum. The two symplyyes are connected hy a narrow cartiliginous median har, probalily produced ly the much modified epicoracoid cartilages. However. except for the reverse development shown by the onnand meta-sternum, it is easy to connect this apparenty quite anomalous shoulder-grirlle of Hemisus with that of Breviepps. 
(cf. Fig. 5 , 5 and 6, p. 25). The sacral diapophyses are slightly dilated; the fingers and toes are free and end in points. The tongue is triangular, broader in front. The lining of the mouth forms a transverse ridge across the palate, and another in front of the oesophagus. The male has a subgular sac. The general shape is stout, the head small and ending in a pointed snout. Colour lorown above, with whitish sinots. Total length about 2 inches.

Glyphoglossus has a peculiar tongue. It is elongated, notched behind and in front, livided into two lateral halves hy a deep groove; moréorer, the tongue is not only extensively free hehind, lut also slightly so in front. The skin of the palate forms a transverse serrated ridge. The precoracoids and the omosternum are absent; the metasternum is a well-developed cartilaginous plate. The sacral diapophyses are moderately dilated: the terminal phalanges are simple. $G$. molossus, the only species, is olive-brown above, marbled on the sides: the under parts are uniformly whitish. This creature, about 2 inches in length, looks like a rommlish bag, with a ridiculous, short face. The typespecimen, still the only one known, was taken hy In. Theobald under the following circumstances:- "I had halted one day within the tidal portion of the Irawaddy delta, to enible my hoatmen to prepare their dimner. One of my servants, having cooked his rice, youred out the hot water as nsual on the ground, and some of it went down a hole that happened to lee near the spot. No sooner, howerer, had the hot water disapleaned than out scrambled in great haste a fine Grlyphoglossus, only, alas: to be transferred to a collecting jax."

Phrynella. - The tongue is heart-shaped, free behind. The paliate is smooth and toothless. The fingers and-toes end in small discs, smpported by $T$-shaped phalanges; the fingers are firee, the toes extensively wehbed. Precoracoids absent: metasternum cartilaginous. Pupil horizontal. Malay I'enimsula.

Ph. pollicaris is dark olive hrown above; an ohlique vellow line runs from the eve to the angle of the mouth; a pale rellow mark, across the forehead, through the eyes, and down the sides of the body. A dirk-centred yellow patch on the anal regiom. The limbs are banded yellow and lorown. The under parts are lnown, with paler specks, dark on the throat. Iris reil brown. The whole coloration changes considerably.

"They inhabit the hills of Perak from 3000 feet upwards, 
and live in holes in trees, which are so situated as to contain more or less rain-water. They hatre a loud flute-like, musical note, which they utter at irregular intervals, principally during the night. The form and size of the hole in which they are seem to have a sreat deal to do with the loudness of the note, as specimens when extracted from their holes have far more feeble vocal prowers than they had when in them. These frogs blow themselves out with air, and lonk more like bladders than anything else. When intlated they float on the surface of the water, and will remain motionless for a long time, with legs and arms stretched out." I

callulu.-The tongue is round, entire, and free behind. The balatine bones form an acute, sometime's toothed ridge across the palate: two dermal serrated ridges in front of the nesophagus. Fingers free, sometimes with dilated tips, supported liy $\mathrm{T}$-shaped phalinges. Precoracoids and omosternum absent; metasternum cartilaginous. P'upil round. About seren species in the Indian region.

': pulchir.-The following aceount has been extracted from Mr. S. S. Flower's observations: 2

This pretty creature inhabits most of the warm portions of the continental Indian region, from India and Ceylon to South ('hina and Malacea. The back is a rich dark hrown, divided from the vellow of the head hy a narrow hack line which extends from ere to ere and forwards to each nostril. A conspicuous yellow hand runs firm the eyes to the himl-limbs. The sides of the body and the limbs are mottled yellow and brown. The under parts are dirty luff: the throat of the male is hack. The intensity of coloming varies individually and from time to time, the contrast between the brown and yellow being occasionally very luilliant. Total length up to : inches, the male being the smaller sex.

"I have been told by hoth English and natives that this frog wats unkinown in fingatpore until some nine or ten years acen, when it was introduced hy a half-caste (why, it is noi known and that it rapidly sperad about the island. It is now well known as the 'Bullfoge hy the English in singapore, and derested for the moise it matkes at night. The roice of these rotume animals an be heard erery night aftere heary rain: it is

${ }^{1}$ S. S. Flower, I'.Z.S. 1896, 1. 910.

Ibid. p. 909. 
a deep guttural croak, ' wau-auhhhh, very strident and prolonged. The males croak while floating on the surface of the water, the single rocal sac under the mouth inflated like a glohe, and the arms and legs extended. They can hop well on land and are good swimmer's. The skin is excessively slimy : the secretion comes off profusely, and dries on the hand into a sort of white gum, with a faint aromatic smell. This gum dissolves in hot water and coagulates in cold. The general appearance of these frogs is very stout, their girth being about twice the length from snout to rent. The tongue, which is ohlong in spirit specimens, in life is very elastic, assuming, when extended, a rermiform shape and reaching about $t \mathrm{~cm}$. in length. Ther appear after sunset, crawling on old wood and feeding on white ants."

\section{Sub-Fam. 2. Dyscophinae. W With teeth in the "pper jut:}

This small group of nine genera, with scarcely more than one dozen species, all with one exception living in Madasgasear, has been separated by Boulenger from the Engrstomatinae merely on account of the presence of teeth on the upper jaw and on the romerine margin of the palatine bones. He himself remarks that C'rlluelle may be considered a toothed Hypuguchus, and Plethrduntoluylu a toothed Cullulu. These are ohvious cases of conrergent analogy. Except for the teeth, the Indian C'alluellu would be merced into the American Hypopaches, and this would present an instance of the most puzzling geographical distrihution. In the case of the other two genera, one Indian and Malayan, the other Malagasy, no such suspicion would arise, since there are many other instances of such a coincidence of distribution. There is the same diversence or unsettled condition in the modification of rarious parts in the Drscophinae as in the Engrstomatinae. The precoracnid bars are weak and curved backwards, and closely fressed against the strong coracoids, in Dyseophus, Calluella and Ilutypelis, while these elements are reduced to unossified hars, and the clavicular portions completely lost, in Plethoduntuluylu and in Ilirynumir. The omosternum is ahsent and the metasternum is small in all except Dysurnhus, in which hoth these parts are exceptionally well developerl and large, although remaining unossified. The palate of Dysophlus and C'ulluellu is provited with curious, serrated dermal folds like those which are so common in the Engystonatinae: and well-derelopred disc's m the fincers and toes, supported by $y^{*}$-shaped lhalinges, are 
possessed ly Plutypulis. Cophlylu and others. The sacral dial"mphrses are dilated. The pupil is either horizontal ar vertical. Those which are jrovided with discs to the fingers and toes ine climbers, and mostly slender and long-legued, sometimes of very mall size. for instance ('ophlylu, the budy of which is scarcely one inch in length.

The fenera can be determined hy neans of the fullowing key :-

A. Pupil vertical. Palatine teeth in long transverse series.

u. Precoracoids ossified. Tips of fingers and toes not dilated.

Sternum very large. Madagasear

Sternum small. Burmah

- Dyscophus.

- Calluella.

l. Precoracoids not ossified. Tips dilated

- Plethodontohizla.

B. Pupil lorizontal.

i. Palatine teeth in long transrerse series.

a. Precoracoids ossified. Tips dilated.

Fingers and toes free. Precoracoids entirely ossified

Mantipus.

Fingers and toes webbed at the base.

Precoracoids semi-ossified . . Platyhylu.

B. Precoracoids not ossified. Tips not dilated. Phrynocuru.

b. Palatine teeth in one or two small groups.

Precoracoids ossified. Tips dilated.

Two small groups of palatine teeth

One single group in the middle of the palate .

No teeth on the palate

- Platypelis.

Cophyla.

Anodontohyla.

Tygsenhle,s nntengili.-Madagascar: General appearance stout. with short legs and a wide mouth. Total length about 3 inches. The skin is mostly smouth, and forms a liroat ylanchular fold which extents from the eye to the groin. The upper parts are beautiful magenta red, with a purplish streak beneath the lateral folls: the unler parts are yellowish white, with minute rrey specks. Fed an pink colomrs, and the lateral folds, orrur also in most of the other members of this family, for instance in the Indian genus Calluella.

Sub-Fam. 3. Genyophryninae. - With rivy smull tieth an the unterior portion of the lower jaw.

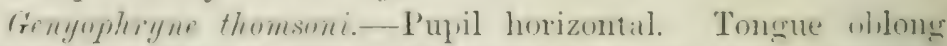
and entire. With teeth on the palatine hones, and a serrated transerse dermal ridge in front of the oesophagus. Sternum cartilaginous. I'rexoracoids absent. Sacral diapmingses mollerattely

I Boulenger, Ann. Nat. Hist. (6), iv. 1889, p. 247. 
dilated. Tympanum hidden. Head large and much depressed. Heel with a triangular dermal flap. The smooth skin is pink brown above, with hlackish marks; a light line extends on each side from the eye along the back. Under parts black. About $32 \mathrm{~mm}$. in length. Sudest Island, between New Grunea and the Lotisiade Archipelago.

Fam. 7. Ranidae.-Frogs, in the true sense, are all well diagnosed as Firmisternia, with cylindrieal sacol diapophyses. According to the presence or absence of teeth in the jaws they can be subdivided as follows:-

Sub-Fam. 1. Ceratobatrachinae, with teeth in the upper and in the lower jaws. The sole representative is the genus Cerotnbatrachus.

Sub-Fam. 2. Raninae, with teeth in the upper, but none in the lower jaw. These are the Ranidae of Boulenger in the Catalogue of Batrachia Salientia.

Sub-Fam. 3. Dendrobatinae, without teeth in the upper and lower jaws.

Sub-Fam. 1. Ceratobatrachinae.-Teeth present in both jaws. Those of the lower jaw, between 20 and 30 in number in Ccicutubutachus, the only genus, are nearly all inserted upon the articular bone; only 2 or 3 are carried by the dentary element, which, although large, enters into the formation of the upper horder of the jaw at the anterior end only. In the small extent of the share of the dentary in the formation of the edge of the lower jaw, and in its anterior "toothlike" process, Runa adspersu of Africa bears ummistakable resemblance to this genus. The tongue is deeply notched, and free behind. Pupil horizontal. Tomers furnished with teeth. Tympanum distinct and large. Precoracoids present. Omosternum and presternum with a bony style. Sacral diapophyses cylindrical. Fingers and toes free, with swollen tips. Outer metatarsals united. Male with two internal vocal sacs.

C. guentheri, Solomon Islands, the only species, has an enormous mouth and a triangular head not much smaller than the rest of the body. The skull is fumished with prominent ridges and a small curved spine at the angle of the jaws. The hind-limbs are rather short. The skin of the upper parts shows linear ridges, variously arranged; that of the belly is granular. A triangular dermal flap on the tip of the muzzle, one on the 
nlyer exlge of the evelids, others on the heel and ahore the rent. The colour ant markings are very variahle, the groundcolour is yellowish to pink, hown. grey or olive, with darkel and lighter markings. Tutal length of the males: 3 inches, of females : 1 inches. - fruply, the discoveres of this peculiar creature, remarks that "horned Fross are very nunterons in these islands, and se closely do they initate their surroundings in colom and pattern, that on one occasion I captured one by accidentally placing my hand on it when clasping a tree."

Sub-Fam. 2. Raninae.-The vertebrate are procoelous and deroid of ribs. The precoracoids are always present and ossified firom the clatricles, and are parallel with the much stronger and wsified coracoids. The omosternum usually possesses a bony style, hut in the Indian genera Sommulutiachus and Lomnophrys and in Pllyflutiomess of Ecundor it remains cartilaginous, and in colosthetus of Colombia it is absent. The metasternum also possesses a lmoy style, hut it remains cartilaginous in the

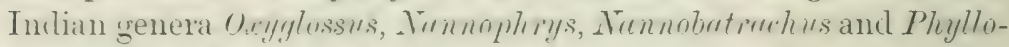
dimmus, in the last two genera rather reduced and slender, while in the Eenadorian and Colombian genera Hyliralus,

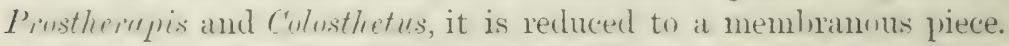
In quite a number of genera the normal number of phalanges is increased ly one owing to the intercalation of an extra phalanx hetween the terminal and the otherwise penultimate phalanx. ${ }^{1}$. This is the ease in all the species of Cassina,

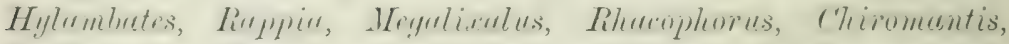

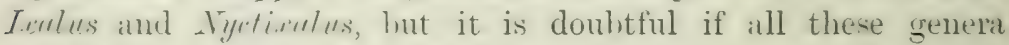
are therely more nearly related to each other than to the rest of the Iiminae. The structure of the tips of the fingers and toes exhilits more variety. The terminal phalanges are mostly simple, with slight swellings at the ends, or they are $\mathrm{Y}$ - or $\mathrm{T}$ shatped in conformity with nore or less developed adhesive discs: in the African gemus Mylumbutes only they are claw-shaped, as in the Hylidae.

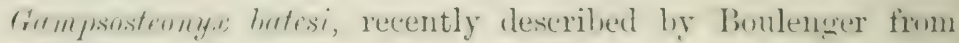
the (iahorm, shows a mique modification of the terminal phalinges of the second to the fifth toes. They are transformed into sharp and curverl (laws, like those of at cat, hui instead 
of horny sheaths, it is the bone itself which is thus shirpened and perforates the skin, an anomaly reminding us of the ribs of Triton waltli. Total length of the type-specimens, ahout 3 inches.

Adhesive discs are common, and are best developed in Rihruphorus, Ixalus, Riappia, and Hegalixalus. In the Neotropieal genera, excepting Colosthetus, the dises are very peculiar, heing provided on the upper sicle with leathery scales which are separated by a fissure. The fourth and fifth metatarsals either diverge and are connecterl hy a distinct web, or they lie close

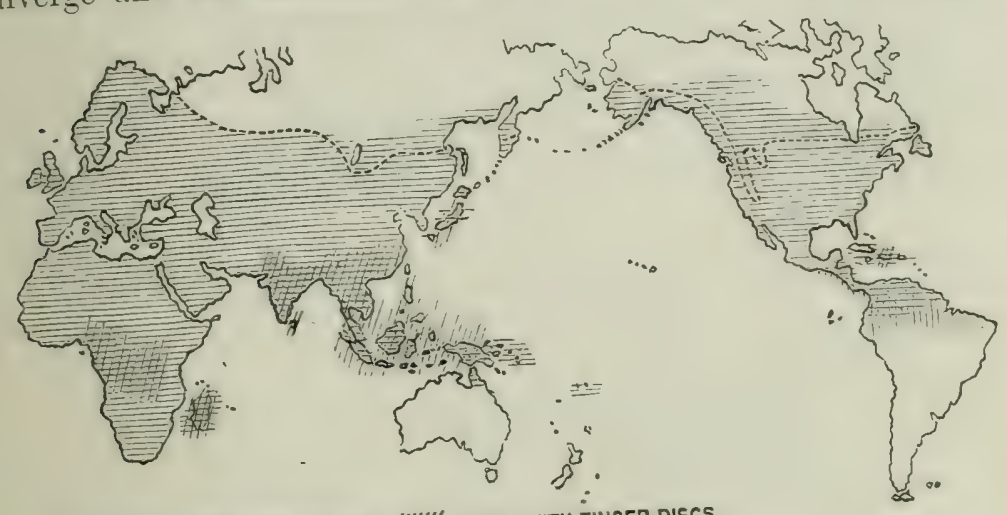

ERANIDAE, IIIIIII DENDROBATES. 'VIIII/,FORMS WITH FINGER DISCS.

FIG. 46.-Map showing distribution of the Ranidae.

together with only a groove between them, or lastly they appear externally united.

The tympanic lise is very variable, large, small or quite hidden. Tomerine teeth are present or absent. The pupil comtracts into a horizontal slit except in some Palaeotropical genera. The tongue is universally free behind, mostly deeply notched, and can be well protruded; only in the Indian Oxyglossus and in the Neotropical genera, excepting Hylixalus, its posterior margin is entire.-There are terrestrial, arboreal, and aquatic nembers in this large sub-family. The geographical distrihution of the Raninae, which comprise about twenty genera with at least some 270 species, is almost entirely Arctogaean. Tone, with the exception of three species in the P'apuan subresion, occur in the Australian region; and only fom genera, with owe or two species each, inhabit the tropical Andesian district, the 
renainder of south Anerica lueing without any Ranninae. All the species of the whole I'eriaretic resion helong to the gremus limner exceth in Eitstern Isia, where the chosely allied genus

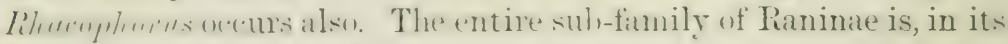
fulness and diversity of development, esentially Palateotropical.

Many of the genera, eren in the present nume liberal sense as interpretexl hy bunlerger. are hatsed mon mimportant characters, amd in veality rum inte each other. This is for instance the case with Rene and Rhacophorus.

The following tabular arrangement is merely a key for determination and does not necessialy express relationships. The presence wa alsence of romerine teeth is a character easily ascertinined, but it separates closely allied genera, for instance, Rhacophorus from Ixalus and Micrixalus from Rana.

The gerlecia with extrat, interpolated phalanges are marked *.

KEY FOR THE DETERMINATION OF THE GENERA OF RANiNAE.

I. Pupil vertical.

A. With vomerine teeth.

1. Omosternum very slender and cartilagirous. Small discs. India and Cerlon, 3 species

Nannobatrachus.

1. Omosternum with a bony style.

a. Outer metatarals webbed. Suall discs. South India, 2 species . Nyctibatrachus.

B. Outer metatarsals close together. Africa.

Fingers and toes with interpolated phalanges.

Without terminal discs. 2 species. . Cassina.*

With dises supported by claw-shaped phalanges, 10 species . . Hylambutes.*

Fingers and toes withont interpolated phalanges; without dises.

Toes welbbed - Trichobutrachus robustus,

Toes free, with sharp claws p. 271.

Gampsosteonyx hatesi, 1. 272.

B. Tithont vomerine teeth. Dises well dereloped. Outer metatarsals united. Tropical Africa and Madagascar, 7 species Megalixalus.* 
II. Pupil horizontal.

A. With vomerine teeth.

a. Outer metatarsals webbed together.

Fingers free, toes webbed . . Ranc, p. 249.

Fingers and toes more or less webbed.

Always with dises .. . . Rhacophorus, * P. 245.

Two fingers opposed to the others.

Africa . . : Chiromantis, ${ }^{*}$ p. 244.

b. Outer metatarsals united, or separated by a groove only.

Omo- and meta-sternum with a bony style . . . . Cornufer, p. 243.

Omo- and meta-sternum slender and cartilaginous,
Ceylon, 2 species
Mozambique .
Nannophrys.
Phrynopsis boulengeri.

B. Without vomerine teeth.

17. Palaeotropical.

$\alpha$. Tongue narrow and entire. No

discs. Outer metatarsals

webbed. India, 3 species . Oxyglossus.

$\beta$. Tongue oval, feebly nicked. Large

dises. Solomon Islands . Batrachylodes vertebralis.

Karin Hills . . . Phrynoderma asperum.

$\gamma$. Tongue deeply notched. Outer metatarsals united by a web.

Discs none or very small.
Africa, 3 species.
- Phrynobatrachus.
Borneo
- Oreobatrachus baluensis.

With regular discs.

Number of phalanges normal.

India, 5 species . Micrixalus.

With an extra, interpolated phalanx.

India, 18 species . Ixalus,

Two fingers opposed to the others. Karin Hillș . . Chirixalus doriae**

$\delta$. 'Tongue heart-shaped. Outer metatarsals united.

Fingers and toes free, tips blunt.

Africa, 8 species . . Arthroleptis, p. 242.

Fingers and toes more or less webbed, with regular discs.

Africa and Madagascar,

$$
23 \text { species . . Rappia.* }
$$


b. Neotropical.

Metasternum small, cartilaginous or membranous.

With dises.

1. With a pair of dermal seales on the dises.

Omosternum with a bony style.

Tongue heart-shaped.

Ecuador, 2 species. Hylixulus.

Toes free. 5 species . Phyllobates, p. 242.

Tongue entire. Ecuador'

and Colombia, 3

species . . Prostherapis.

Omosternum cartilaginous.

Ecuador

Phyllodromus pulchellus.

2. Dises without scales. Omosternum alsent.

Colombia

- Colosthetus latinasus.

Phylluteres. ${ }^{1}$ - This is one of the few Neotropical genera, and like nearly all of these has peculiar adhesive discs on the fingers and toes, each disce bearing on its upper surface two dermal scales. The tympranum is distinct. Vomerine teeth are alsent. The general appeatrance of the five species is that of tree-frogs. One species, Ph. birnlwi, yellowish ahove, dark hrown beneath, lives in Culna. The others inhabit Central Anerica and Venezuela. They seem to latre peculiar nursing halits. Ph. trinitutis of Venezuela and Trinidal carries its tadpoles on its back, on to which the young fix themselves hy means of their suckers. Nothing is known alout their lneeding hal,its, for instance whether the gromer are hatched on the bark, or, as sems more likely, if the parents (the specinen descrilied hy Boulenger 2 is a male) only sive their offinging a temporary lift in order to convey them from a chring-mp jool to a healthier place. It is remarkal) that several species of Itemdrobatinae, which inhalit the same countries, have precisely the same habits. ${ }^{3}$

Aithroleptis. Slemere and lone-limber little frogs, about one inch in length. The fingers and toes are free, very slender, and end in slightly dilated tips, the supporting phalanges heing simple. The tringanum is varialle. The skin is smooth as finely aramulated. The colours are inconspicums, lorown or grey tones ustally grevailing. Ahout ten species are known, mostly

${ }^{1}$ Boulenger has shown (Y.Z.S. 1888) that Bibron's species of Phyllobates, hitherto grouped amongst the Cystignathidae, are Ranoids, closely allied to Hylixalus and Prostherapis. The other species now form the Cystignathoid genus Syrrhopus, Cope (cf. p. 212). 2 I.Z.S. 1S95, 1. $209 . \quad$ Gf. 1. 273. 
from Continental Africa, a few from Madagascar and the islands in the Indian Ocean.

4. seychellensis-Brauer ${ }^{1}$ has discovered the mode of nursin of this frog. He found a specimen of A. seychellensis which carrieit nine tadpoles on its back, in the month of August, in the Surchelles, about 1500 feet above sea-lerel, upon an old tree-fern. 'The' little ones were already provided with long tails, the hind-limls were partly free, the fore-limbs still corered hy the skin, and they held on by their bellies; not, like the rouns of Phyllobutes. wr their "suchers." Another specimen carried young which were still further dereloped. $\mathrm{He}$ also found an old frog, near.which was lying a little heap of eggs, not enveloped in a common mass of jelly. The old frog escaped, but the eggs were taken care of in a vessel with moist sand at the bottom. By the following morning the eggs were hatched and the tadpoles were clinging by their bellies on to the walls of the glass. Braver concludes that the young, when

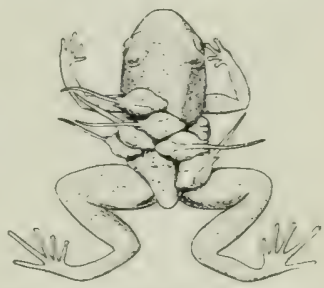

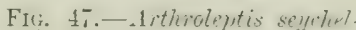
lensis, carrying Tadpoles. $\times 1$. (After Brauer.) hatched, creep on to the parents' lack, he or she waiting near the heap of egrs until the latter are ready. Curiously enough, he did not find out the sex of the nurse, nor are we told if the young are taken to the nearest water to finish their metamorphosis, or if they remain upon the parent's back until they hop off as haby-frows. The rolk is rery large. When the four limbs are alrealy dereloped, the gill-carity possesses no gills and no outer opening: and since the lungs are only just beginning to sprout, the tatprle must needs hreathe by means of its shin. The jaws have no horny coverings. The adults live on the ground between moist leaves, and eat chiefly termites.

Comuicr, with about trelre species, is an essentially AustruIIalayan and Polynesian genus, but one species, $C$. juhnstoni, has been found in the Cameroons. The fingers and toes are free, and their $T$-shaped phalanges support adhesive dises. The tympanum is distinct. The general shape is frog-like, usually with slender and rery long hind-limbs and toes, the dises of the latter being much smaller than those of the fingers. The coloration is dull, mostly bromn, more or less marhled, whitish below. The 


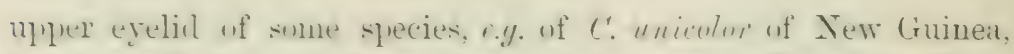
has a small tuhercle. lience the serneric name. The skin of the

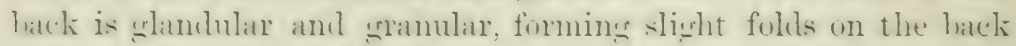
and on the sicles of the heal in some sieces. The male has one or two internal rocal sacs.

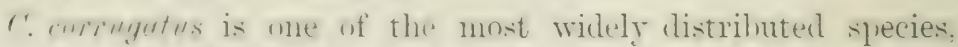

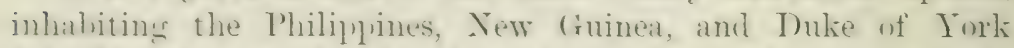
Island. The granular skin forms lomgitulinal folds on the back, one of which reaches from the eve to the shoulder. Bromish alsue with darker narkings. heluw rellowish, with or without hrown spots on the throat... Three slecies inhahit the Fiji Islands.

(If $C$. sotumunis of the siblomon Islands little is linown about the lonplation, although the large size of the egze, which measures j mm. in diameter, sugrests that the rommg underoro must or the whole of their metamorphosis within the egg.

Climmontis is distinsuished hy the jeculiar arangement of the fingers, the first and second heing opposed to the others: theil ternimal phalanges are olituse and supjort small kmolss or discs. The general shape is that of a fros with long and slencler hind-limbs. The tympanum is distinct.

$1 \%$. remmplinm, the type-species, was discorered by l'oters at Mozambinge: it is a midrlle-sized frog: alont 2 inches in lenuth, hown ahove with reddish spots on the sides: the male is devoid of rocal sacs.

$1 \%$. jutisi, a native of East Africa, differs from the preceding lys the gussesion of an internal rocal sac. C\%. rufesens = guimensis shows rery little of the typical grasping arrangement of the fincress: the two inner ones are separated from the two onter fingers ly a wite gard, hut they all lie in the same planes, are much wehled and jussess latrese dises, so that ly the latter two characters a link is formed with liburuphorus, to which the present genus is closely allied. Total lensth ahout g-2 inclues.

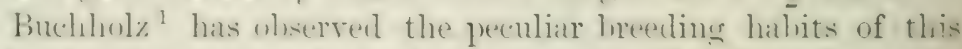
rather lares brown. and slemeler tree-from in the cameronns. In the montle of Jume he fimme on the leares of a low trees, standing in the water. a white formy mass. like the fioth of a lineken rene containing a nmmlex of newly hatched larvae and yuite

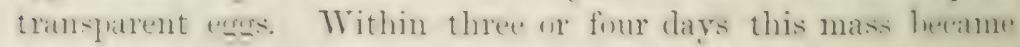


Huid, and the larvae, provided with external gills and a long tail, swam ahout in the slime. In the natural course of events the larvae are probably washed down into the water liy the rain. He found that the female deposits the eggs in the foamy mass at night, during the months of June and July, on various kinds of trees, either between the roots or in a carity formed by gluing together several leaves, sometimes 10 feet and more above the water, or near the margin. 'On one occasion the mother was seen sitting upon the foamy mass, clasping the same with its four limbs.

Rhucomhorus.- This large genus, containing more than forty species, has a curious distribution. At least one dozen species are found in Madagascar, eight or nine in Ceylon, the rest in Southern India, the Himalayas, the Malay Islands and Philippines, extending northwards through China and Southern Japan. 'Therefore this genus, with the three species of the African chiromantis, extends over the whole of the Palaeotropical region. The generic name has reference to the possession by many species of little dermal flaps, especially at the inner side of the heel, and it has nothing to do with the parachute-like use of the hambs and feet of certain species, to be mentioned presently.

The terminal phalanges are generally lifurcated, rarely uhtuse, and support well-developed adhesive discs. The fingers and toes are webbed to a variable extent. The two outer metatarsals are likewise connected by a web. The tympanmm is distinct. The general appearance is that of tree-frogs, ant many of them are green. The males have one or two intemal vocal sacs. Not all the species have dermal appendages. Iih. maximus, for instance, the largest of all, living in the Himalayan forests, has none. A heel-flap occurs in some halfdozen Indian species; and Rh. madagaseariensis has these Haps on the heels and on the elbows. Some have queer little lappet. ahove the rent, or on the edges of the arms and legs; in others the hend of the arm is fringed. The small size of these appendages, in comparison with the welss and dises, makes them practically useless so far as increase of surface is concerned, and they have most likely some other, although unknown meaning, especially the Haps over the vent. Lastly, in the majority of species the fingers are not more than half-webhed, or even less, and in a few only, the webs reach down to the discs. 


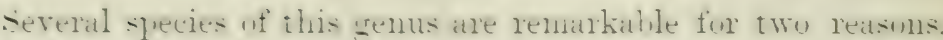
Finst. the great enlingenent of the fully-wethed hambis and feet. which are then userl at gratachutes: secombly. the mole of propagation.

Creatly exagceratel notions are howerer, entertaines alunt the furachutes. erer since Wallaces description ${ }^{1}$ of the first

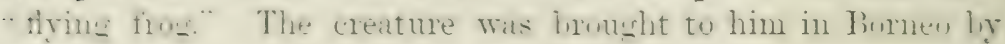

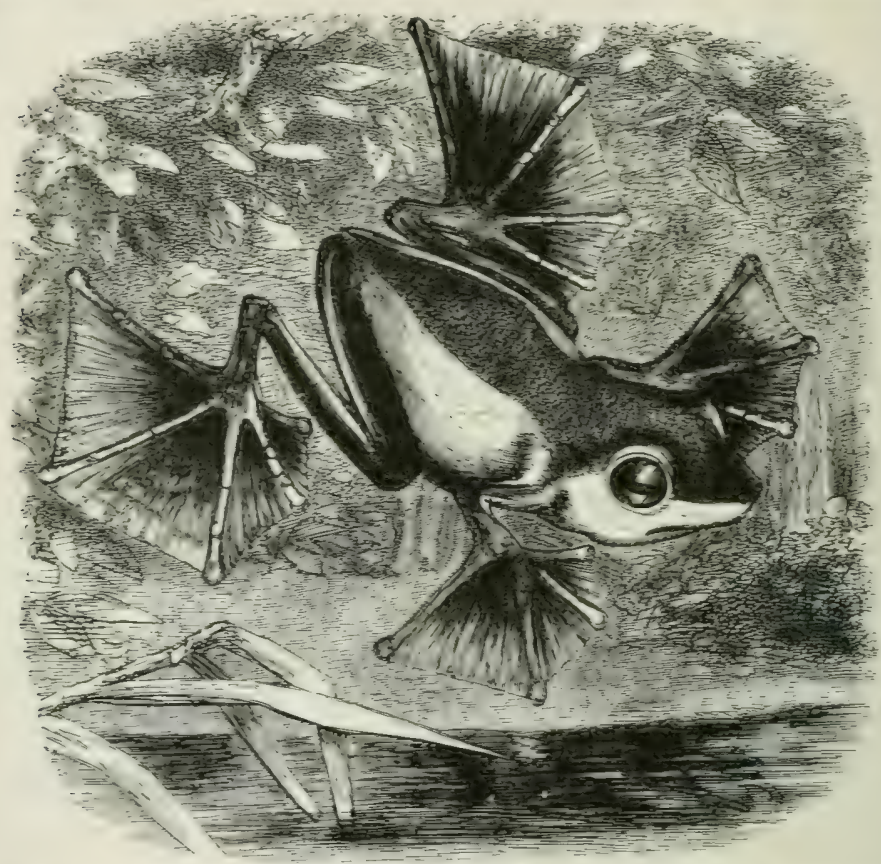

Fig. 45. - Rhatcuphures pardalis, $x$ about 1. (From Wallace, Malay Archipelago.)

at 'hinese workmin. " He assured me that he hat seen it come lown, in a santing direction. from a high trees as if it flew. The imbly was about four inches long. while the wets of eath himi-foot. when fully expramlet, corvered at surface of four sylit?"

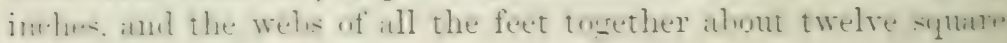
inches."

The species in question is Rh. purdalis, an inhabitant of

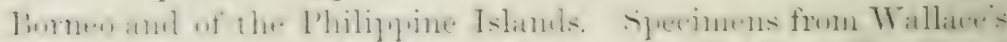

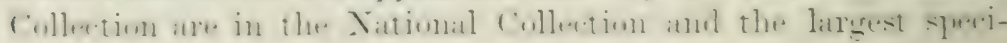


men shows the following measurements. Total length $6.5 \mathrm{~cm}$. or $2 \frac{1}{2}$ inches, not 4 inches.

Area covered by one fully-expanded hand 3.4 square $\mathrm{cm}$.

foot 6.0,

$9 \cdot 4$ square $\mathrm{cm}$.

i.e. for the four limbs 18.8 square $\mathrm{cm}$.=about 3 square inches, and not 78 square $\mathrm{cm}$. or 12 square inches. By some unfortumate oversight Wallice must have mixed up the total expanded area with that of the four hands and feet! In Brehm's Thichlobn the 78 square $\mathrm{cm}$. have increased to $81 \mathrm{~cm}$., and the artist has in the somewhat larger species $R h$. rein ardi improved mon this, and has produced a truly startling picture hy a further exaggeration based upon the figure given by Wallace.

Rh. reinwardti lives in the forests of the mountains of Java and Sumatra. It reaches 3 inches in length, and is grass-green ahove, yellow below. Younger specimens are further adorned with large blue patches on the webs of the hands and feet and behind the armpits. Besides the flap on the heel and the "urious cutaneous fringe on the forearm, suggestive of an incipient flying-membrane, the skin forms a projecting fringe on the inmer side of the fifth toe and a transverse flap alove the vent.

Of $R h$. leucomystex, Ammandale, who accompanied the Skeat Expedition to Malacea, gives the following account:- "This frog, which is called by the Malays of Lower Siam either 'Berkata l'isang' (banana-frog) or 'Berkata Rhumah' (house-frog), lays its eggs either on leaves of branches overhanging the water, or on the mud surrounding buffalo-wallows. The ova are enclosed in a round mass of yellow froth, which afterwards becomes steel-grey, about as large as a cricket-ball. Should they he placed judiciously in a position sheltered from the sun, the a alpoles may either hatch, and reach a considerable degree of levelopment, before the mass is washed into the water, or the froth may be melted almost as soon as it is formed and the eggs he curried into a pool by a shower of rain. Tery often, however, the whole mass is dried up by the heat of the sun before the rain comes. During the breeding season, which seems to occur as often as the land is flooded under the trees, for I have never seen the eggs of this frog on the bank of a river, the 
males croak londly, producing a sound which can hardly be distinguished from the chattering of the large black and rellow squirrel, Sciurus bicolor."

These arhoreal frogs have a peculiar mode of nursing the young and taking care of the exgs. Rh. menculatus of Ceylon,

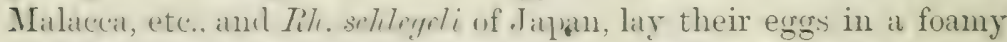
mats, the size of a fist, on the mangins of ponds, and the whole process has recently heen described hy Ikeda. He observed

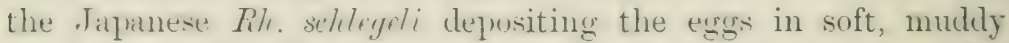
gromul corered with grass, and in wet, muddy banks of paldyfields. ponds, and similar localities near Tokyo. Sometimes they are deposited between the leaves of trees, near the gromul. The breeding season extends from the middle of April to the micldle of May. Towarls the evening the female, hearing the much smaller male on her hack, retires underground for the deposition of the exgs. The spots chosen are 10-15 cm. above the surface of the water: the female diss a spherical hole $6-9$ cm. wide. sitting thus concealed underground, the frogs assume a dark colour and the spawning takes place during the night, whereunon the parents leave the nest. The eggrs are enreloped in a white mass of jelly full of air-hubliles, the whole frothy lump looking like the well-beaten white of a hen's egg, with the yellowish eass scattered through it, and neasuring some 6 cin. in diameter. The air-bubliles are 2-:) mm. large. The froth is originally very elastic and sticky, hut it gratually sinks down, lecomes liguid and ultinately runs out of the hole. It is proAncerl in the following peculiar manner. Iluring and after the deposition of the egros the female puts her feet upon the sticky jelly, part of which arlheres and is then pulled out as at thin,

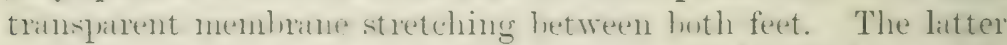
are then thrust batekwards, the membane is folded downwarts and heconnes at vesicle of 5 to 10 mm. in wilth. Iir repreated Working of the limbs the sucessively formest bubles are trodken and kntalest into fioth, which ultimately surrounds and at th. same time separates the eggs.

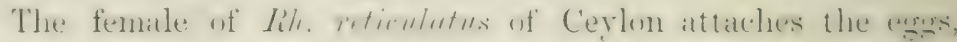
alwent twenty in numblus, to the under surface of her belly, an the skin of which the leare litthe collular impressions. What becomes of the tadpoles is not known. 
Rh. lencomystex is found in the Malay Archipelago, Farther India, and the Philippine Islands.

S.S. Flower ${ }^{1}$ found the tadpoles about Singapore, from . Tanuly to April, in small ponds and in rain-water butts. The spiracle lies on the left side, directed backwards and upwards, nearer the anus than the end of the snout. The anus opens on the right side. Exceptionally large tadpoles measured $46 \mathrm{~mm}$. in total length, the recently transformed young only $14-18 \mathrm{~mm}$.

"A cheerful little frog of most graceful build. It comes out from its hiding-places shortly before sunset, and remains aloroad all night. The males are easily found as they sit on shrubs or trees, or on the edges of the rain-water butts under the verundahs of the houses, and from time to time utter a single, rather musical, short croak. In March and April they can be found both by day and night in embrace, in the ponds. This species chinges both its colour and markings very rapidly and frequently, but dark bands across the legs can always be more or less distinguished; the lower parts are some shade or other of luff, but the principal variations of the upper part are as foiluw: pole hrunze, either uniform or with four longitudinal dark-brown or black lines; uniform, almost orange, bright bronze: chocolate, with darker mottling; pale brownish green or olive, with irregular dark spots; yellowish green, mottled with ilarker or brown." The females are considerally larger thin the males; the largest male caught was $48 \mathrm{~mm}$. from snout to vent, and the largest female $68 \mathrm{~mm}$.

Ficne.-The following combination of characters should he a sutficient diagnosis: pupil horizontal; tongue deeply notcherl and free behind; vomers with teeth; fingers free, toes webbed. fourth and fifth metatarsals diverging and webled together.

In conformity with the great number of species and the wide distribution of this genus some of the organs vary consiclerably. imleed so much so that many of these modifications have heen deemed sufficient to be of generic importance. Fortunately the species are so numerous that these characters mostly form an uninterrupted series from one extreme to the other.

The terminal phalanges are mostly simple and pointed: smmetines transversely dilated or T-shaped, according to the presence of more or less developed discs. Such discs are, for 
instance, present in the Malay species $I_{i}$. frythroen and $I_{i}$. cherl-

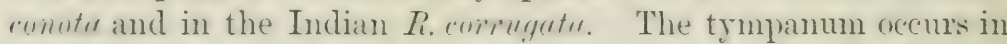
erery stage from a conspicuous, free dise to being guite hidden ly the skin. The romerine teeth either form a pair of tiny. mostly transterse rows, between the choanat, or they are arranged in two oblique series which extend heyond the hinder edges of the choanae.

The vocial sacs vary greatly. Many species, e.g. R. myilis, have nome at all. Most species have a pair of internal sacs, and in compratively few, about a dozen, these sacs hare hecome external, a feature which indicates no relationship of the species thus distinguisherd, for instance the European li. essolinter, the

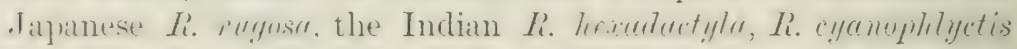

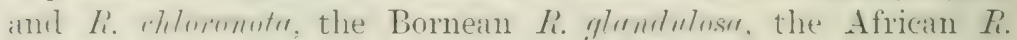

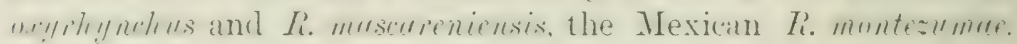

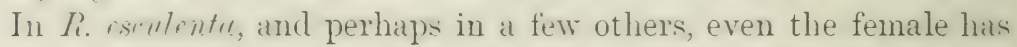
sine traces of these otherwise male organs, indicated by slitlike folds of the onter skin helow the angles of the lower jaw.

Suptial excrescences on the inner metacanpal tubercle and on the immer fingers of the male are common; they reach their sreatest develonment in the Himalayan R. lirligi, the male of which is "remarkable for the extreme thickness of its arms, the inner sides of which are studded with small conical black spines, ear henpyorted on a rounded hase produced hy a swelling of the skin. A large gatch of similar spines exists on each side of the breast." 1

sivecific glandular complexes in the shin are mostly restricted to a fair of lateral or dorso-lateral folds: they are often alsent. but a few species, e.g. Ri. glomdulusa of Borneo, R. tempural is of

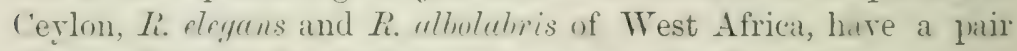
of large flat glands at the base or inner side of the arms.

All the slrecies of Rimn, except those in the Solomon Islands. spawn in the water, where the development of the tadjoles takes its (rourse. Those of some Indian species, notably fi. altirula and

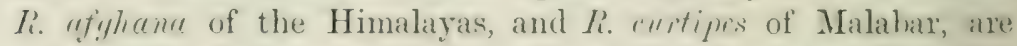
very peculiar, heing provided on either side of the shoulders with a large oval parotoid-like gland, well defined and crowled with pores; li. alticola possesses in addition an unpaired, sharply

\footnotetext{
1 Boulenger, Cat. Batrach. Salientia, p. 22.
} 
marked glandular complex on the top of the root of the tail, or rather upon the future cocesx. These complexes gradually disappear with age.

The grenus Reur, with about 140 species and sub-species, is distributed over the whole of Arctogaea so far as this is itrailable for Amphibian life, while there are only a few stragglers in Notogaea, niamely, a few species in Ecuador and in the I'eruvian or Lpper Amazon district. Tone exist in the rest of the Neotropical region, including the Antilles, and practically none in Australia; lout $R$. cefuli and $R$. purnue inhabit Tew Guinea and the northern corner of Australia, li. lirffiti the solomon Islands. A few species are restricted to Matagascar, and a few others live there and on the continent of Africa.

So far as number of species is concerned, the home of the grenus Run is the Palaentropical region; ahout one dozen (some of then with a very wide range) live in the Palaearctic sulb-region, scarcely more in the Nearctic sub-region, and a few in Central America.

I. tempinuria (the common European Brown Frog or Grassfrog:- The tympanum is distinct, two-thirds the diameter of the eye in size. The first finger is slightly longer than the second, which is shorter and weaker than the others, whilst the fourth is the longest. All the fingers are quite free. When the hindlimbs are laid forwards along the hody, the ankle-joint reaches to a point between the eye and the tip of the snout. The five toes, which are about half welibed, increase in length from the first to the fourth, while the fifth is about equal to the thircl. The sole of the foot has a small, blunt, inner metatarsal tubercle; the outer one is scarcely visille. The skin is smooth, always moist, owing to the minute mucous glands; but a series of larger glands forms a prair of folds along the upper sides of the back; heginning behind the eyes they converge slightly beyond the shoulters, liverge a little in the sacral region, and converge again towards the rent. Another, much feebler, $\wedge$-shaped ridge lies lietween the shoulders.

The male has two internal vocal sacs, which, when in use, lulge out the skin of the throat beneath the angles of the mouth like a pair of globes. It is further distinguished from the female hy the stronger muscles of the arms and by a jair of swollen parts on the inner side of the first finger. I)uring the frairing 
semsun these pads are enlarged into cushions covered with black horny rugosities.

The iris is golden, with dark specks. The coloration is, getherally speaking. loww above, with blatch-lirown irregular spots. espectidly on the sides of the hroly, and with cross-bands wn the less. The under parts of the male are white or pale yollnw. with a hluish tinge on the throat, while the female is more rellow insteal of white, inclining to orange. In both sexes the muler barts are mostly spotted with dirker colours. A large dark-hown patch, extending from hehind the eve over the tymunam tortarls the shoulder, is alwats present and has given this fimg its specitic nume. Otherwise the coloration raries consillerahly : more or less according to the locality and nature of the survomlings and to individual variation and temporary change of colour.

Some specimens are almost spotless above and of a rich huwn. or alnost yellow colour, the spots heing restricted to the siles helow the lateral folds. Others have very few spots, lut these are then arranged in two interrupted streaks on the back. The under garts, especially the flanks, may be lemon relluw insteul of whitish, and the darker markings may be alnost ahsent. Boulenger has figured a beantiful specinen, alnust orange red, with red spots and rerniculations on the yellow under surfice. I have found similar red specimens of unusually striking alpearance hetween Berlin and Spandau in a forestgivele, through which rum little streans with banks of red ferrtigimns soil. Specimens which live in wooks with rich hlick soil are often very dark, all the ligown and reklish tints being alsent. The vatriations atre, howerere, really endless, and it is difterult to find two intividuals exatrty alike even annongst al great number collected in the sane Incality. Morenrere, they dhange colour. Wranth

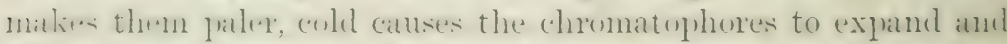

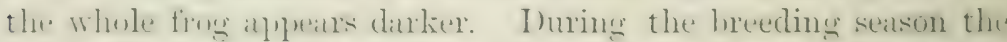
males assume a delicate hlui-h hue, expecially on the throat, hut this tiln sulickly fiules away when they ane taken ont of the

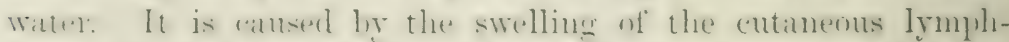

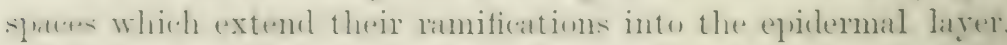
amel it is ant a question of pigmentation or of chromatophores. lute a rase of interteremee-colonrs, hue heing freguently the

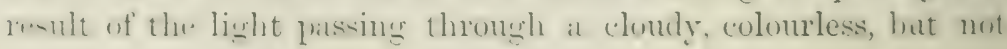


quite transparent and thin stratum, in this case the turcid epidermis.

The habits of the Grass-frog are essentially terrestrial. It spends most of its time on lind, preferably in damp places, lut local fashion permits of a great deal of freedom, as these frogs are sometimes found not only in very wet, naturally irrigated ylaces, but also in the water itself. However, the (rrass-frog when pursued rarely takes to the water for safety. It trusts to Hight, first hy a few long and fast jumps, and then to concealment by squatting down between grass, under leaves; it rarely creeps into a hole, even if there be one near. The jumps soon become shorter and shorter after a few dozen repetitions. It swims well, but cannot climb. The food, which consists chiefly of insects, snails, and woms, must be moring to excite interest; then the frog, whose favourite position is half sipuatting, half supported by the arms, erects itself, and, facing the insect, turns round upon its haunches, adjusts its position anew hy a shifting of the legs, and betrays its mental agitation hy a few rapid movements of the throat. All this time the prey is watchel intently until it moves; then there follows a jump, at Hap of the tongue and the insect is seen no more. As a rule these frogs do not crawl, they jump or hop, even whilst stalling, and this takes place at any time of the day; in fact they are rery dimmal, although they become more active towards the evening. When caught they are at first rery wild and, like all true frogs, very impetuous, committing acts of astonishing stupiciity without any apparent sense or appreciation of distance or height. The captive will not only jump off the table, whilst a toad stops at the edge and looks carefully down, but without hesitation he jumps out of the window, regardless of the height above the ground. This is due to sheer fright; he loses his heid. When at large in his native surroundings, nothing will induce him, although hotly pursued, to commit suicide ly jumping down a precipice. But all this wildness calms down wonderfully soon. The captive no longer dashes his head against the glass, he does not struggle or twist when taken up; on the contrary, he makes himself at home, watches your coming with intense expectation, and without hesitation accepts the proffered mealworm, maggot, butterfly or earthworm; in short, he shows what a jolly and intelligent fellow he really is. 
The cratsi-frug hats many more obrious enemies than perhays auy other Amphilian, and it is not eren slightly protected by any aplurecialile poisonons secretion. Nevertheless it is extremely conmmon. A whole hust of birds eat it-for instance, huzzards, harriers, and ahore all storks. Foxes, polecats, and stoats are not arerse to it, and the Grats-snalie lerives its main sustenance from it. In fact the enemies of the little frog are leginn, one of the worst heing Man. In France, Italy, and other parts of the Continent, the skimed fleshy himl-limls are turned into a by no neans disitgrevalhe ragoht, or into dainty morsels when frienl in butter and encrusted with loreal-crumls. This frow, tosether with its consin the Water-frus, also suffers from the distinction of leing one of the chief martyrs to science. Perhaps the story is true that Galvani was led to his investigations into animal magnetisn and electricity by olserving that the lews of a number of skinned frogs, strung up ly his wife upon the hinnze ralins of the halcony, jumped whenerer the scissors, which "out wif the feet, touched the other metal. Frogs have sutfered erer since. Easily procured and of a convenient size, they are used in erery hiological laboratory, and the roung student is sulumserl to he initiated into the mysteries of Tertelirate structure ly the careful dissection and study of this, the worst of all the so-called types. Next to Man there is no animal which hats been studied so minutely; and has had so many primers and text-hooks written on it, ats this frog. In spite of all this it is rery little unclerstond, thanks to its rather aberrant and far from generalised structure.

Howerer, the frog, by reatson of its fertility, holds itsown. Early in the rear, sonnetimes while there is still ice and sumw, the frogs leave their hibernating places (mostly holes in the ground, uncler nuss. or in the munt, and they becin to pair in standing or slowly flowing, mostly shallow, waters.

They are not always very careful in the selection of the stawning locality, namy of them lay their exyes in a ditch, or "Nen in the shallowest putdle, which is sure to try up, and thus to cause the destruction of the whole lommi. This carelessness is all the more surprising when there are litrge pools or lakes in the

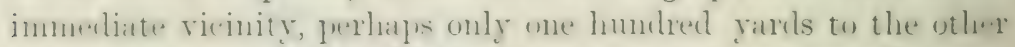

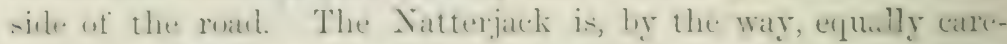
l...s. While wher toats and the tree-fross are rery circumspet. 
Both sexes can croak, and this sound is frequently produced under water; but there are no regular concerts, although miny collect in the same pond or spring, which is perhaps the only suitable place for miles around. The male puts its arms around the chest of the female, behind her arms, and the embrace is so firm that nothing will induce him to loosen his hold. The process hecomes an involuntary reflex-action, a cramp which may last for dlays, or even for weeks, if sudden cold weather sets in, until the female is ready to expel the egrgs, an act which is quick and soon over. The usual time of spawning in Middle Europe is the month of March, earlier in warm, later in cold seasons; in southern countries, February or even January, but in Norway not until May. Although the males of this species are not more numerous than the females, and therefore should be ahle to mate without much trouble, their ardour is so great that they occasionally get hold not only of the wrong kind of frogs, but of toads or even fishes, and, if taken off by force, they fasten on to anything else, a $\log$ or on to your own fingers. The eggs measure 2-3 $\mathrm{mm}$. in diameter, are black with a whitish spot on the lower pole, number from 1000 to 2000 , and sink at first to the bottom. Their gelatinous cover soon swells to a large globe more than 10 $\mathrm{cm}$. in width, and the whole mass, as large as a man's head, floats on the surface, often stained with mud and other impurities. During the cold weather which often prevails in the spring, the dark brown larvae are slow in their development; and provided with rather large branched external gills and a well-developed tail, they wriggle about in the dissolving slime for three or four weeks. Fischer Sigwart ${ }^{1}$ has timed

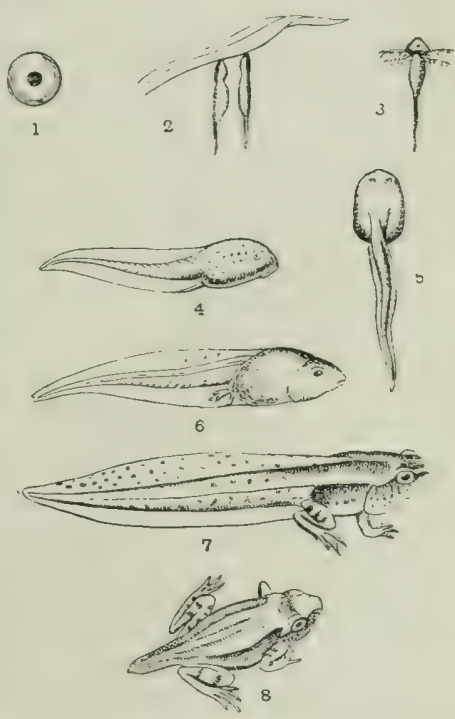

FIG. 49.-Rana tempurerin. Eight sue. cessive stages in the development from the egs to the almost complete Frog. $\times 1$. and measured them as follows. - The eggs were laid on the 10 th of 
March. On the 1 inth the larvae were $4 \mathrm{~mm}$. long and began to leave the engs. On the 19 th they measured, body 4 , tail 9 , total $1: 3 \mathrm{~mm}$; on the jth of April 10,16 , and $26 \mathrm{~mm}$. respectively. On the listh of May they were $40 \mathrm{~mm}$. long and the hind-limls "lpleared: the fore-legs hurst through on the 25th, when the tampoles hat reached their greatest length, namely to mm., the borly meanuring $15 \mathrm{~mm}$. On the :31st of May they left the Water, still provided with a rather long tail of $20 \mathrm{~mm}$., the total length heing reduced to $35 \mathrm{~mm}$. The lartac of this set dereloped munsually fint, perhaps owing to artificial conditions. The whole development is, howerer, mostly finished in three months, so that the little stump-tailed loaly-frogs swarm about well before miclsummer, and have time enough to grow to the size of $20 \mathrm{~mm}$. or $\frac{3}{4}$ inch before they begin to hibernate in October.

In higher localities and in northern countries the tadpoles are sometimes obliged to winter in the unfinished condition.

In spite of the unusually hot summer of 1899 I found plenty of tadpoles on the 10th of September in the tarns of the hills of North Wales, 1500 feet ahove the level of the sea ; while thousinds of little frogs, with and without stumpy tails, were hopping about in the surrounding bogs. The water of these tarns is always rery cool. Cold and rainy weather set in by the mindile of the month, and on the 26th the tadpoles, all rather small, measuring only :35 mm., with the four limbs developed, hut still with a loroar fin on the tail, had all settled down muler stomes at the lontom of the now very cold water, prepared for hilnernation. A few were taken home and kept in a glass ressel with water, cool, but less so than that of their native tarns. Within two days they lost the fins on their tails; before the ent of a week they left the water, and crawled on to the moss, and the tails were reduced to little stmmps. By the 10 th of ()otoher the motamorphosis was complete, the little frogs measured mly $13 \mathrm{~mm}$. in length and showed no desire to hibernate in the genial atmosphere of the greenhouse.

This species has a very wide distribution. It ranges from the west of Irelamel to the islands of Saghalin and Yezzo, being fomm werywhere in the enormous stretch of intervening comntries, mactically the whole of Central and Northern Europe and the midulle leelt of Asia. Its most northern extent is the wole of swedlen and Norway. I have found it to the east of the Three- 
fjeld, at an elevation of 4000 feet, well-nigh the snow-line. In conformity herewith it ascends the Italian Alps up to 10,000 feet. The southern limit in Europe is the Cantabrian range and the hilly province of Galicia. In the rest of the peninsula, in Italy and Lombardy, Greece and Turkey, and on the Mediterranean islands it is absent.

$R_{\text {. }}$ aralis is often confounded with $R$. temporariu, as it differs from the latter only by the following characters. The snout is rather more pointed and is narrower; the inner metatarsal tubercle is large, compressed, and hard; the dorso-lateral glandular folds are more prominent and the belly is white and immaculate; lastly, it scarcely reaches 3 inches in length, a size which is not rarely surpassed by the other species. There are also some differences in habits. $R$. (irculis prefers moist, boggy, open localities, and does not ascend beyond 2000 feet in Central Europe. It pairs as a rule later in the spring and the eggs are smaller, only $1 \frac{1}{2}-2$ mm. in diameter; they do not swell up so much, and the whole mass does not float but remains at the bottom of the shallow water. The coloration much resembles that of $R$. temporariu, and is likewise subject to much variation, except that the pale rertebral stripe is perhaps more common. This species is distributed over the whole of Central Europe, Russia, and Western Siberia, south of the 60 th degree of latitude, living side by side with $f_{\text {. }}$ temporariu. Between the rivers Elbe and Phine it becomes decidedly rare, and the latter river is practically its western boundary, while the Bararian Alps and the Dimulse form its southern limits.

fi. ryitis is still more frequently confounded with both the two former species. It differs from either by the absence of the two interual rocal sacs of the male, and by the decidedly longer hind-limbs, the tibio-tarsal joint reaching often a little beyond the tip of the snout. The imner metatarsal tubercle is as prominent as in $R$. arvalis. Total length up to 3 inches. The prevailing colour of the upper parts is rather yellow or pinkbrown with few and small blackish spots; a $\wedge$-shaped dark mark on the neck is often present, and the large dark patch on the temporal regions is always conspicuous. The under parts are white, inclining to lemon yellow on the flanks and thighs. The iris is golden yellow in its upper half, dark brown in the lower half. 
This species lads a much smaller range than the first two: from France through Midlle and southern Germany, Switzerland, and Lombarly to Hungary and freece. The specitic name refers to the puick and long leapse of this pretty, or rather delicately coloumen fires. which prefers works and wooled glens to large mpen flaces. Their voice differs much from the croak of the

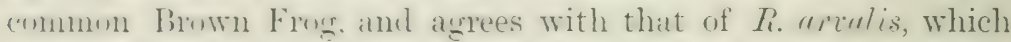
is thanschilned ly Boulenger, who has liejt them alive, as a ratpilly uttered " "(o)-(c)-co," or "cor-cor-cor." Aceording to the same

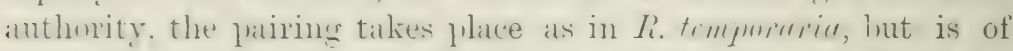
muel shorter dumation, the females nsually resurting to the water only at night and when quite ready to spawn. sprecimens in embrace are therefore seldom found in the daytime. The eggs lesemble those of $R$. trimpurmin in size, but they do not swell up so much and they do not float.

These three species of Europrean hrown frogs, difficult enough to distinguish, have of late been increased ly three more, thanks to the sagacity of Boulenger. These latter inhabit south Europe, and the males all lack the internal vocal sacs.

fi. ilwion hat a very small range, namely the north-westem portion of the Iherian peninsula, from the Tagus northwards into Gialicia, lint south of the main extension of the Cantabrian chain. The rest of the P'eninsula south of these mountains has

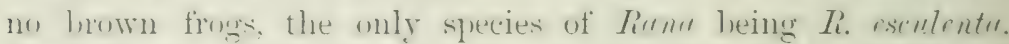
Li. ilnion is rather local. heing restricted to those hilly and mountainous districts which are well watereel. A favourite haunt is the munerous streans in the wooled prats of the serra fierez, the red, disintersated granite of which suits this little, extremely attive, and reshlish fros to perfection. The prevailing groum colour varies ancording to the district, from prale to dark rechlish (1) ordnge hrown, with red specks and lareger, dark brown spots, which in sone speecinens leerin with the $\wedge$-shaped mark hetween the shomblers. Dark spents on the flanks are very variable: the himb-linhs show the usual darker aros-hats, and the temporal

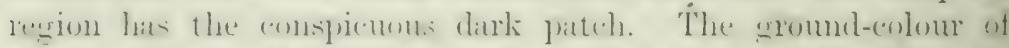
the curler parts is whitish, suffised with a pink tinge, and the throut is murh speckled with laww: the tenes are pink. The size of this pretty frog ancounts to 2 inches. The breeding time is the month of March. When catught and stuterged tisey emit it slight "co-co-co." 
R. grace inhabits Italy and the Balkan peninsula from Rusina to Morea, together with $R$. agitis, from which it is rery difficult to distinguish except that it is a little smaller, remaining helow $2 \frac{1}{2}$ inches, and is generally more uniformly pale grey brown to yellowish and pinkish brown above, with scarcely any, or only a few, small dark specks on the back and limbs. The temprral patch is likewise paler than in the other species. The flanks are spotless, their colour gradually passing into the light buff of the under parts, which are more or less marbled with grey. The iris is golden, speckled with dark brown.

R. latestei of Lombardy and Northern Italy down to Florence is the last of these closely allied frogs. Its aftinities lie with $R$. iberice and $R$. argitis. The latter and $R$. latreste $i$ although living side by side in the same locality, for instance near Turin, are said not to interbreed. The roice is a rapidly uttered "keckkeck-keck;" the length remains below $2 \frac{1}{2}$ inches. The ground colour is greyish or reddish brown with a dark brown $\wedge$-shaped mark between the shoulders, and a few red, orange, or blackish spots on the back. The flanks are without definite dark spots. The uncler parts are whitish, with a strong pink tinge, especially alnng the middle of the throat and on the chest, the paler portions being mottled with pale grey brown.

Perhaps the least unsatisfactory way of distinguishing between

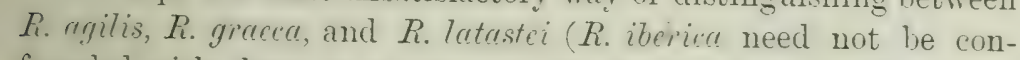
founded with them on account of its distribution) is the size of the tympinum, and its distance from the eye. The tympanum is smallest in $P$. graecu, its diameter being about half that of the eye and from $\frac{3}{4}$ to the whole of its width distant from the eye.

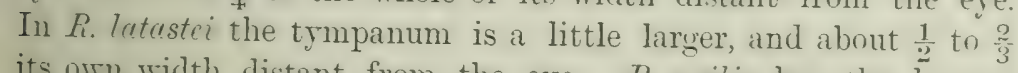
its own width distant from the eye. $R$. agilis has the largest tympanum, measuring about $\frac{3}{4}$ of the diameter of the eye, and the rlistance between the two organs amounts to only $\frac{1}{3}$ of the size of the tympanum.

Brown land-frogs of the $R$. trmpor(r)ia group are found in most countries of nearly the whole Periarctic and (1riental regions, and by the time their races and varieties hare been studied as minutely as those of Europe are now being scrutinised, the number of species will indeed be great.

R. silucution is the chief representative in North Anerica. It clissty resembles $R$. agilis, lut is smaller, only 2 inches in length, 
and possesses a pair of intermal vout sates. Its specific name refers (n) its predilection for forests of mak, annmg the dried leaves of which it conceals itself su successfully that it is discovered with ditticulty. Ri. jufunion of Eastern Asia is almost indistinguishahle from this Anesican species and fron the Furnetun Ii. agilis.

L. "gristhodun of the solomon Islands hats the wonerine teeth in two ollinge series entirely hehind the level of the choanate. The genteral shate of this linge from is stunt. the type specimen of the mate measuring $-\mathrm{s}$, that of the female $125 \mathrm{~mm}=5$ inches. The upret surface of the female is covered with small, flat warts, that of the male is much smonther. The uplerer garts are dark brown, while the under surfiace is brownish white. 'The male has two internal rocal sacs.

This species is interesting ats affording inother instance of shortened development, the whole netamorphosis being gone

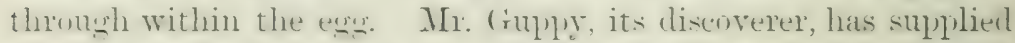
the fullowing notes: "I Iuring a descent from one of the preaks of Farm Island I stopped at a strean some 400 feet above the seal, where my native boys collected from the mojst crevices of the rucks close to the water a number of transparent gelatinous balls, rather smallex than a martile. Each of these balls container a joung frog, alwut 4 inches in length. aplarently fully develneed, with very long himd-legs and short fore-legis, no tail, and learing on the silles of the body small tufts of what seement to be hranchiate. On nyy rupturing the ball or exg in which the little animal wats clombled up the tiny frog tonk a matrvellons leaty into its existence, and disalneared before I conld (atch it. On reaching the ship an hour after, I fouml that some. of the wags which I had put in a tin had leeen ruptured on the way he the jolting and the lilerated frogs were leatping alout with great aletity. On placing sone of them in an openmonther luttle, 8 inches long. I had to fun the cover on, ats they kept leaping out."

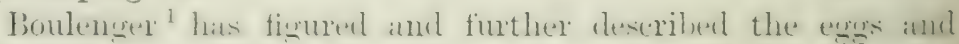
youme. The eng meatures $6 \mathrm{i}-10 \mathrm{~mm}$. in diameter, and is a transparent atpsule in which the gomme frog is eniled up in the same way

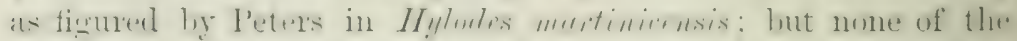

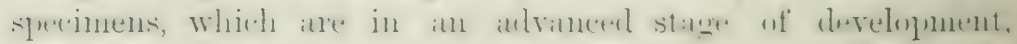
show anything of a tail. There are no gills, but on each side

1 Irans. Zool. Soc. xii. 1884, p. 51. 
of the abdomen are several regular transverse folils, the function of which is probalily that of breathing organs, like the tail of Hylocles. The tip of the snout is furnisherl with a small conical protuberance projecting slightly through the delicate envelope of the egg, and evidently used to perforate that envelope.

R. y"lpyi, likewise an inhabitant of the Solomon Islands, is a giant among frogs. It was discovered by Mr. Guppy on the Chortland Islands. The type-specimen measures $165 \mathrm{~mm} .=6 \frac{1}{2}$ inches in length! The skin of the upper parts is covered with minute warts, and forms a strong fold above the distinct, but small, tympanum. General colour dark olive brown above, dirty white below.

R. tigriun is a common species of Eastern Asia, including the Malay Islands. On account of the strength of its voice, and its size, which is said to reach 7 inches, it is callerl the "Indian Bullfrog:" Mainly aquatic, it has a strong cutaneous fringe along the outer sicle of the fifth toe. The skin of the back is thrown into longitudinal folds, and a strong fold marks the upper lorder of the tympanum. The general colour ahove is olive brown, with dark spots, often with a light rertelural line; the uncler parts are white. The male has a pair of large external vocal sacs.

li. gracitis has the same distribution, but it remains much smaller, and the toes are only half, instead of fully, webbed.

Ii. cutestiuna is now the settled name of the "Bullfrog" of Xorth America, the much more appropriate name of mugiens having been sacrificed to the fetish of priority. The tympanum is extraordinarily large, at least equal to the size of the eye, largest in the male. The first finger does not extend beyond the second ; the toes are connected by a broad web down to the ends, and there is a small inner, but no outer, metatarsal tubercle. The "luer parts are olive brown, clouded with dark brown or blackish spots: the under parts are yellowish white, often marbled with lnown, especially on the throat. The iris is reddish, with an cuter yellow ring. The male possesses two internal vocal sac's. Total length of adult specimens about 5 inches, but there are giants on record 7 inches in length, while the stretched hind-linlss measure another 9 or 10 inches. Its home extends orer the whole of the United States, East of the 
Rocky Mountains, southwards into Mexico, northwards into Canada.

According to Holbrouk the Bullfrogs are solitary in their halhits, only collecting together in the breeding season, when hundreds may be seen in the same small pond; and then the croak uttered by the males is so lond as to resemble the distant rouring of a bull, and can le heard on still evenings at a distance of half a mile. The roice is at hoarse bass " inwoon," playfully translited into "more l'un." "They cannot be said to abound, lut are found commonly enough sitting half immersed in water, or on the banks of ponds, waiting for their prey. If alimued they hup suddenly into the water, but do not conceal themselves at once, frequently skimming along the surface for sereral yards before they dive below." They are the most annatic of a!l the Forth American frogs, and Holbrook has known specimens to live in wells for years, where they could not rest a moment on solid ground above the water.

The Bullfrog is voracious, and takes alnost anything that lives or gets into his own pond-Molluscat, Crustacea, fishes and, aluve all, frogs. There is no doubt that they drag down and swallow a good many ducklings and the young of other water-fowl, hut certainly not the half-grown lirds which have a way of disalpearing from the fams wherever there are negroes and other firm-hands about. In turn the bullfrog has sufficient enemies to keep its numbers clown, in fishes, birck. otters, and snakes, and, in the South, alligators. Although easily kept and spowing comparatively tame, they ale dull, having to le kept in solitary confinement on account of their areediness, which knows no linits. Two of our specinens each

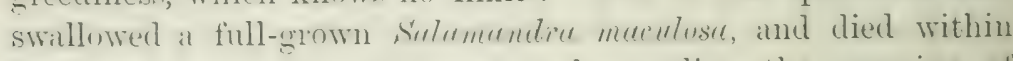
the same night, probably not understimding the meaning of the conspicunos hlek and yellow warning colours of the European.

li. rlumate! \& junlimalis, likewise an inhalditant of Eastern

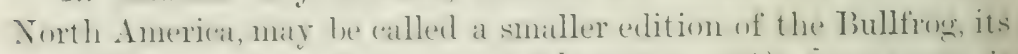

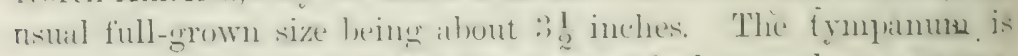
(onspicuonsy larewe, hut the toes are webled to a lesser extent. and the skin forms a glamblular fold which extends from the shoulder in it "urve to the flank. This spereden is partial 10 the neighbouhood of ruming streams: it is salin to le 
exceedingly timid, and to utter a short cry when disturbed and making its enormous leaps.

Another North American relation is R. halecines. pullustris, frequenting the neighbourhood of ponds and rirers, very lively and capable of jumping $\&$ to 10 feet. The tympanum is

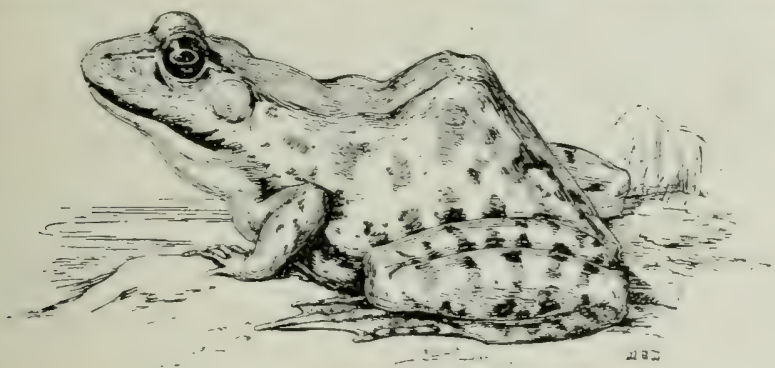

FIG. 50.-Rane clamata, $\times:$

smaller than the eye, but there is the same glandular lateral fold as in $F$. clumate. The rocal sacs are internal and decidedly small.

I. esculenta.-The common Wrater-frog of nearly the whole T'alaearctic region is closely allied to the American Water-frogs's described abore, and, like most of them, has the romerine teeth in two small oblique rows between the chomae and extending a little beyond their posterior borcler. But the males have a pair of external rocal sacs. The tympanum is clistinct, aljout twothirds the size of the eye. The first finger is slightly longer than the second. The toes are entirely webled. Besides thes usual subarticular phalangeal tubercles, the sole of the foot is provicled with two metatarsal tuhercles, the outer of which is rery small, while the inmer is much larger, although varying in siz. from a soft oval to a long, curved, shovel-shaped structure. The skin is smooth, except for a pair of prominent glandular folds. "hich extend from hehind the eye along the dorso-lateral line. The coloration varies comsileralily. The nyper parts are mosty greenish brown, with black brown spots on the back, and lareser patches on the limhs. Mnst specimens have three lighter stripes along the back, the midule one mostly green, the two latteral lronzy how and coinciding with the clanchular folds. The tympanum is brown, and there is occasionally a dark temporal patch. The posterior aspect of the thighs is invariably 
spotted with hlack and white or rellow, in olyosition to the Li. timpurmin moup, where these pilts are never spotted.

The tutal length of this species varies much. Specimens $2 \frac{1}{2}$ inches in length are certainly matme, those of $t$ inclies are musually larege, and Tomlenger has received a giant from Jamascus, which measmed 125 mm., or nearly 5 inches. The females are larger than the males.

The variations in colour are not only local but also individual, morecorer the colours are changeable. The ground-tint langes form dull hrown thengh olive to hroght green, the dark spots lexing more or less promomnced and numerous: the light verterlal line is olive-yellowish, lright green, or altogether absent.

Those which inlialit waters with plentiful vegetation, like water-lilies and other luxuriant plants. are generally prettier and mone vivilly coloured than those which live in swampss and junds with dark mul, or where the prevaling vegetation has a sombe aspect. Find and dull, warm and smmy days also influence the water-fross, and those which hare been hejt in a dark tank look very different from the bright assembly which had been put in some weeks before.

Varions attempts have heten made at suldividing $P_{i}$. samlenta of' Limnaeus into sul-species, and Boulenger las now, after the attentive study of an enomous material, arranged them in fom principal and recosmisable races. The chief differences are the relative length of the femur to the tihia and the size of the metatarsal tubercles.

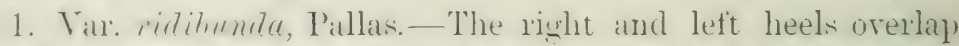
arch other when the thighs are stretched out at right andes to the rerteliral columm, and the tilia is alosely folded up anamst the thishs. When stretched forwards, the heel reaches the eye or erenthe tip of the sumt. The inmer metatarsal tubercle is ferbly developerl, very small and lilunt: the outer tubercle is absent.

That part of the thighs which is concealed hy the lens when the animal is at rest is whitish or gale ereenish, marlited with dark olive, or lerome, or wi the latter colour with or without small lingt spots. Xo thate of gellow is ever to he detereded "m that resiom, nom at the axillate on on the aroin. The rocal sars are strongly pionented with black, when inflated they are pale grey. The iris is a mixtme of black and gold. 
This form or race has the widest distrihution, namely; all orer Europe with the exception of England, the northern half of France, the Rhine countries, Demmark, and Italy. Somthwards it extends from France throngh sirain and l'ortugal into the Suhara, eastwards into Turkestan. It attirins a lareer size than the others, lut only in certain localities in varions countries where circumstances farour its development. Eastern countries 1rouluce the largest of all: those of the Tolsat are said to he rerr litwe. German phrsiological laboratories prefer those from the Dimule, from Bohemia, and from the lakes and hroal expansions. of the Spree, to specimens from other localities.

2. Tar. typiru (osulentu, Limmaeus).-The heels just meet, but (1) not overlap. The inner metatarsal tubercle is strong. comliresed, and prominent. A small outer tubercle is present. The heel reaches to the ere or a little further: the hinder surface of the thighs is "marbled with liack, usually with more or less lright rellow pigment" in the living specinens: the vonal sacs ar white or feelly pigmented. This race inclines to rather more green than the others, the males especially are often dati chass-green, with scarcely any markings. The vertelnal stripe is then yellowish, and the lateral stripes almost golden. The range extends orer the whole of Central Euroure and the kingdon of Italy. Its northern limit is the southern end of sweden. In the greater portion of Germany, Polame, and Austria it orerlaps the vill. riditumda, with which it dnes not seem to pair, owing to a difference in the time of spawning: the var. typuca heing ahout a firrinight later, and hegiming to spawn when the other has finished.

3 Viar. Irssome, camerano.-Except that the inner tulercle is stronger, while the onter one is near the ranishing point, and that the fourth toe is proportionally longer, this variety is really not clistinguishalile from the tylieal form, and Boulenger himself (onfesses that the distinction is arlitrary. The var. Tessume ser-ms to have a rather sporadic distribution. It has lieen fomel in I'iedunont and other parts of Italy, in Hungary and Transyrania, near Vienna, Halle, Upper Bavaria, on the Fhine, near Thussels, I'aris, and what is of especial interest tw us. in a few places in the eastern counties of England.

According to Boulenger's "Notes on the Edille Frog in Englitnd." " the individuals of $R$. rsmente which live in Foulnire 
Fen in Cambridgeshire, near stow Bethn, and between Thetford and sionlton in Norfolk, and are senerally supposed to hate been intrulneed from France, belong to the Italian form of var. lissmun. . It used to be found in Cambridgeshire, in Foulmire Fon, where it was discovered in 1844 : and Bell ${ }^{1}$ assures us that his father. who wats a native of cambridgeshire, had noticed the gresenere of these frogs many rears before at Whaddon and Fonlunire. where they were known from their loud croak as - Whathlon olgans' and 'I)utch nightingales.' The species was afterwarks renlisentered in Norfolk, lietween Thet ford and Scoulton, where it is now still rery ahmolant. and from inquiries made loy Iond Walsinghan, must have existed for the last serenty ( 80 , years at least. There firogs belong to the var. lessonar, and differ wilely he the much stronger inner metatarsal tubercle) from thuse fimme in a few other places in Norfolk, which are undumbedly the descemlants of a mumber imported from France and Belgium in $18: 3-5,18+1$, and 1842 , and turnerl loose in the Fens at Foulden and in the neighbourhood. . . Within the last ten years large numbers of all the three forms have been inported from linusels, Perlin, and Italy, and liberated in various localities in West currey and Hampshire. Berlin specimens of the rar. , inthem har he also leeen introduceel in Bedfordshire, and Italian ones in Oxfordshire." ?

Letring aside the question whether the so-called var. lessince is merely sporalically developed ont of the typical form, the inguiry of the gussilile origin of the English specineses of the var. fessmum is of special interest. Have they heen introduced, as has

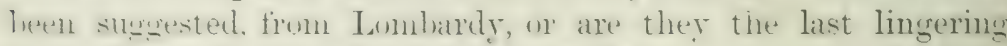
deserulants of native English frogs! The sugesestion as to their Italian origin hats naturally lost in ralue since similar specimens

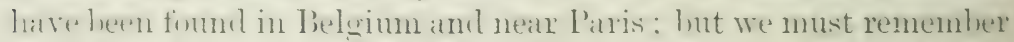
that thele axisterl considerahle intercontre between East Angliat and the monks of Lombarily. who, to mention only one instance

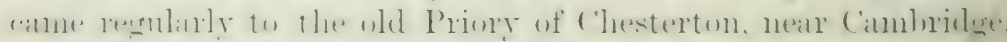

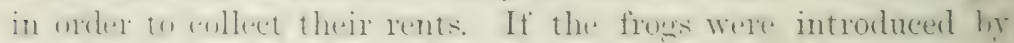

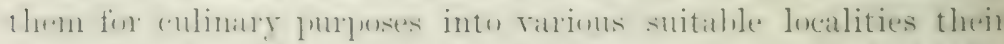

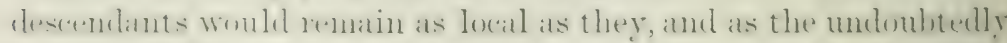

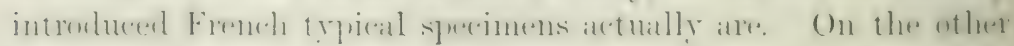

1 British lieptiles, 2nd ed. 1849, 1. 110.

"Boulenger, "Tailless Batrach. of Europe," pt. ii. p. 257, liay Socicly: 1897. 
hand, if we assume the lessonce specimens to be the last living descendants of English natives, it is inconceivalle why they should now be restricted to that eastern corner while there are hundreds of other suitable places in England and Wales which, if on the Continent, would be perfect paradises for Water-frogs. The same vegetation, the same insects, the same climate, and-an enormous advantage to the frogs-no storks.

These English specimens are "olive-brown or bronzy-hrown above, with black spots, strongly marked on the flauks, where a light longitudinal area remains unspotted; glandular folds lighter: the sides of the head and the ground colour of the flanks are sometimes green; tympanum chestnut-lorown; a pale yellow or pale green vertebral line, frequently edged with black; the ilark cross-bands on the limbs usually very irregular, sometimes absent: lower surfaces more or less profusely spotted with hlackish; iris golden. Length of a male from Stow Beclon, $64 \mathrm{~mm}$. or $2 \frac{1}{2}$ inches; of a female, $78 \mathrm{~mm}$. or 3 inches." 1

4. Tar. chinensis, Osb.-Distinguished loy short glandular folds along the back, in addition to the long dorso-lateral pair. The metatarsal tubercle is large and shovel-shaped. Distribution from Corea and Japan to Siam.

All these Water-frogs are decidedly aquatic. They make short excursions on land when their homes are dried up, but as a rule they remain in the lake, pond, river, morass, or ditch in which they were born. Their favourite resorts are the broad floating leaves of water-plants, for instance water-lilies, or a prominent stone, a tussock of grass, or the banks of their homes, where they sit motionless, basking for hours in a half-erect, alert position, watching for insects and other small fry, which are secured by a jump, and then lapped up. Sunshine is sure to bring them out, and on our approach they make straight for the water, either by one tremendous leap or with quick lounds, but without the slightest hesitation or stopling on the way. With folded arms they take a header, swim, with the arms still folded, for some distance under water, and conceal themselves in the mud, hetween stones, or in the regretation. Ire jerhaps have not seen them at all, whilst their watchful eyes aml keen ears have noticed our approach, and the poul might alpear uninhalited if we had not heard the plumping noise. If we

1 Boulenger, op. cit. $1.27 \varepsilon$. 


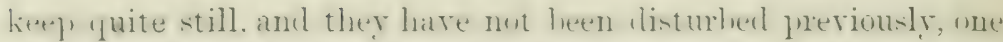
after another will wighle out of the mud, rise slowly to the

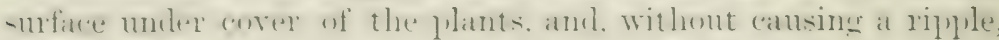

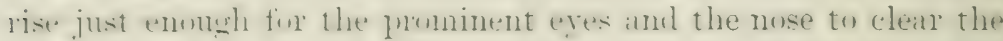

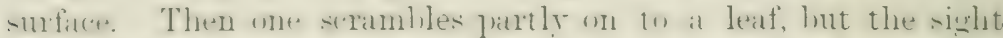
of the huge human tigure strikes him at moanny, as it certainly

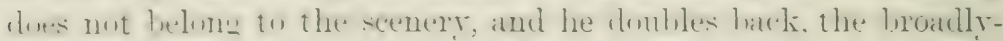
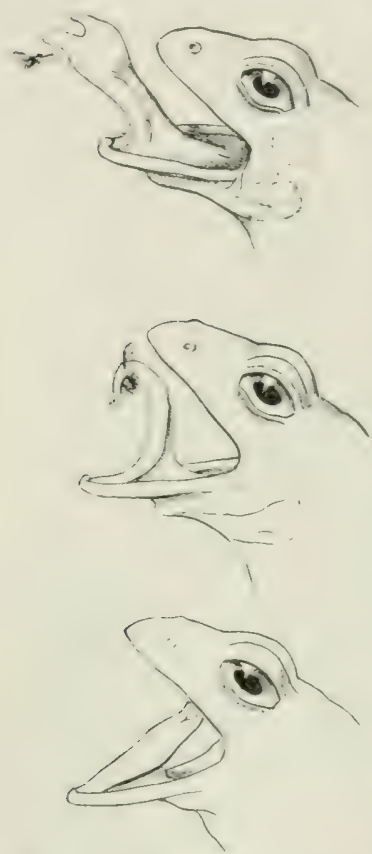

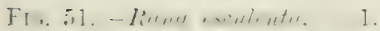

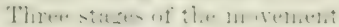
of the tintan. webbed feet making a little splash. But another appear's, jumps on to a leaf in the middle, or at the farther end of the pond, settles down, and utters a little croak, somewhat like "ooaar," and soon the whole company appear one after another, each taking up its favourite position. After all, their observing powers cannot be very great. If we ourselves keep still we may wield a rod and fish for them. There is no need of a hook, a piece of red cloth tied to the end of the line and skimmed over the water causes a lively commotion. The new bait is noticed at once, and arouses their cmiosity; sereral jump at it, and the one which swallows the bait can be lifted ont before it has time to let go. However, this is after all poor sport; the game is too eager. When a boy I have often caught them with a noose of slender wire at the enel of a long hatael roul. They den not mind the rod at all. their attention being fixed on the person; they allow the noose to he slinged orer their heads and at suhlen

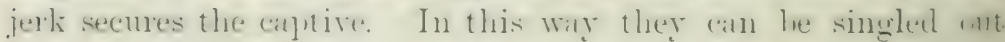
indivilually. old frows are more wary amb experienced than

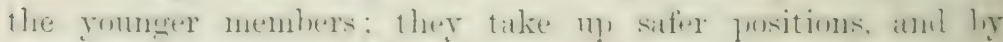
their sudden plunges give the alarm.

The males are sroat musichens, singing for sheer enjorment

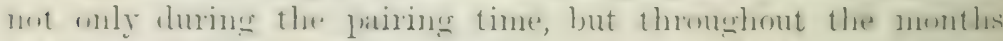

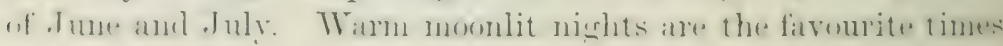


for the concert, which takes place in the water, beginuing at sunset, and continuing until the early dawn. A few individual. here and there utter a single note, "gwarr, on-arr," "sr "coarx," lut these are only preliminaries. The precentor-the complyfolk in North Germany firmly believe that in each pond one olit male holds the dignified position of choir-master-begins with it shitrp-sounding "brekeke," and this is the signal for all the other: to chime in with the same notes, varied with all sorts of other sounds, lass, tenor, and alto, each performer filling its resounding vraal sacs to bursting size, and these bags then look as if they acted as floats. When there are several hundred of these sociable creatures, the din is continuous, and may be heard more than a mile off. There can be too much of this, just as there can be too many nightingales; and a well-stocked pond in the neighbourhood may become a perfect nuisance. There are accounts of servants having been employed in the Midule Ages for the sole purpose of keeping the noise down by beating the pond.

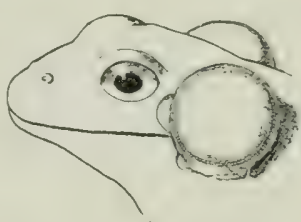
throwing stones into the water, or otherwise disturling the frogs. Sometimes more rigorous and lasting mentsures seem to have been taken: the monks exorcised them in nuler not to be disturbed in their vigils. Near the forner monastery of Chorin, in the province of Brandenburg, the frogs have still the reputation of lieeping very quiet on account of smne powerful abbot who threatened them with awful consequences if they did not forego their concerts.

The length of life which these frogs can attain is quite mnknwin. They do not reach maturity until the fourth or fifth Year, lut this is long before they stop growing, and it is mo exalgrelation to say that few, if any, frogs die of old age, since they have so many enemies. The stork is their king in the fithle, and his daily visits to his realm strike dire distres. mnongst his suljects, which soon learn to know his conspicuunis white and black garb, and seek imperfect safety at the bottom of shallow ponds and ditches, not too deep for the long-legged annl long-billed despot. Numbers are taken hy birds of prey: snikes and tortoises hunt them up in the water, and they are som bait for pike and other roracious fishes. The specific 
nimue revtrutu needs no comment, and this species is as much a matry to science as the brown (rass-frog. The destroyers of tarlpules and yomes frogs are unlimited. In their turn the firus themselves, especially the old ones, are very rapacious, and eat any living creature they can master,--insects, worms and suails, other frogs, expecially the brown lind, and the young brool of fishes.

Tiecently caught Water-frogs are wild heyond description, much more so than the Crass-frog, hut even they calm down after smue time, learn to know their keeper, and allow him to hamelle them without trying to commit suicicle by jumping on to, into, and down anything. Howerer, they do not thrive well in captivity, and it is rare that they can be induced to breed, mules: their enfurced new home affords them anple freedom, and plenty of water and fresh air.

The Water-fiogs appear in Germany rather late in the year, not hefore the middle of April, first the younger, then the adult memlnes. In Southern Europe they show themselves earlier, and still further south they do not hibernate at all. The breeding seatson lesgins in Germany towards the end of May and continues well into June, the var. ridilunda begimning mostly a fortnight earlier. The male clasps the female moler the arms, throwing its ww romnd her hreast, the muptial grey excrescences on his inner fingers pressing against her skin, the palms leing turned vutwarls. The embrace does not last long, rarely extemling orer a few days. The exgs, to the astonishing number of 5000 to 10,000 in full-grown specimens, are expelled in sereral natses, which sink down and remain at the hottom. The eng measure only $15 \mathrm{j}$ mm. and are yellowish-grey above, prale yellow below: their gelatinous cover swells to $7-5$ mm. in wirtth. The embryo escalpes on the fifth or sixth day as a very small linva, in which, however, the mouth, eyes, and beginnings of the external gills are already discernible. At the age of two weeks the sills have shrunk away, the left-sided "spiracle" is mmpleterl, and the well-tailed tarlpoles, olive brown ahore, yellowish white below, still hang with their suchers on to plants and stones, or lie at the luttom, nilllings awaty at any rotting animal matter or scraping off the green algae.

It may here lie nentimenl that sniall tadpoles of any kind

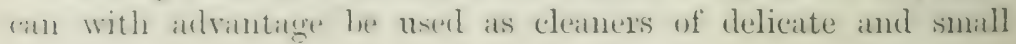


skeletons. The olject is put into a ressel, and the tadpoles. will soon nibble and rasp away all the edible portions, learing the skeletal framework beantifully cleaned. But they reguire attention lest they rasp away the cartilage.

The tadpole stage lasts three to four months: but cold, alssence of sumshine, and scarcity of food delay the metamorphosis well into the end of summer, or force them to hibernate in the unfinished condition. They are rery gregarious, and when the tallooles of sereral families combine, they make imposing shows. Iry the time that their hind-limbs begin to sprout, they frequiently combine into large shoals, and instead of always feeding they swim about in their tens of thousands, all moving in the same direction, and making almost regular evolutions. Mill-ponds with steep banks are good places for watching these peculiar habits. The tadpoles reach a considerable size, the total length areraging $2 \frac{1}{2}$ inches, or some $60 \mathrm{~mm}$. the tail taking up $\frac{2}{3}$ of the whole length. Specinens which measure nore thim 3 inches are rare. The baby-frogs hop on land while still providerl with a stumpy tail; when this is resorhed the little creature is scarcely half-an-inch long, and for the rest of the availalile season leats a rather more terrestrial life than erer after.

Ex Africa semper aliquil nuil! Quite recently Bonlenger has received a consigmment of Anura from the French Congo, amongst which were sereral new, remarkable genera, notahly Trichobutrachus and Gampsosteonyx. Both are true Raniclae. Pupil rertical, with romerine teeth. Omosternum with a hony style. The outer metatarsals are hound together. In TrichirTutiachus robustus the toes are webled, and both sexes have the Hanks and corresponding portions of the thighs corered with numerous darkly pigmented, filamentous, cutaneous excrescences; these are several millimeters in length, giving the flanks and thighs a "hairy" appearance. Mr. F. F. Laidlaw has eximined these structures. Their most remarkable feature is the presence in them of a great number of ordinary tlask-shaped cutaneous glinds, whilst such glands are scarce on the surrounding skin. They differ in no way from those seen in sections of the skin of the Common Frog. The fibrous connective tissue is dense and vilscular; the pigment-cells are nost plentiful at the hase. ('intrary to expectation no nerre-endings were found in these filaments. 
Gampsosteonyx has free toes. The terminal joints of the digits stiud out heyond the skin, and end in sharp, bony claws, like those of a cat.

Sub-Fam. 3. Dendrobatinae.-About one dozen arboreal little frogs have heen separated from the Rumina proper on accoment of the entire alsence of teeth. This mere loss of teeth, and the geographical distribution suggest that these frogs do not form a natulal group, but have been developed independently from other Rimidite, the Nentropical Dendrubates from some like-

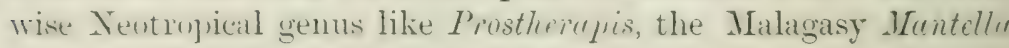
from an African form like Megalixalus.

The sacral diapophyses are cylindrical. The omo- and metat-stemum are well developerl. The fingers and toes are freet, their terminal phalanges are T-shatped and carry regular, round, alhesive cliscs. The tympanum is distinct, although sometimes, in Dendrobates, very small. The pupil is horizontal.

Dindiolutes. - The tongue is elongate, entire and free behind. The onosternum has at weak, semi-ossified style, but the metasternum remains cartilaginous. The nules have a subgulan rocal sac. Seren closely-allied species inhabit tropical Americat.

D. tincturius-This pretty little species, scarcely $1 \frac{1}{2}$ inch in length, is quite smooth, varies much in coloration, and forms local races to at certain extent. Some are quite black, others are grey above, black on the sides and under parts; or they are grey with large black patches. A fourth variety is black above with several white or pink longitudinal stripes, while the under parts are grey, spotterl with black. In others, again, the groundcolour is black, with white stripes and spots alove, marblenl below. Int this enumeration does not exhaust the list, since living specinens are sometimes much more conspicuously coloured, some being black with large patches of saturated yellow on the head and back, while the limbs are orange red and blatck. This species has a wide range, from I'anamat to Echador and to the mouth of the Anazon. It owes its sperific name to the peeculiar use mate by man of the strongly poisonous seceretion of the tiny slinels of the otherwise smooth slin. ()hler species atre dombless emplored in the same way. The poism is mainly nsenl for "dyeing" the green Amazon-parrots. This is done as follows: - Tle green and blue feathers on the lexal and necks ar other frarts, according to the fancy of the 
operator, are plucked out, and these places are ruhbed with the loison, often simply with the living frog, certainly not with its. blood, as is sometimes asserted. This operation may be repeated when the new, young feathers begin to bud. The result is that these appear yellow instead of green, and since the Brazilians, and to a certain extent the Portuguese, are rather partial to these artificially-produced freaks or "contrafeitos" as they call them, the inclustry is kept up. That the poison is also used for arrows has been mentioned on p. 38 .

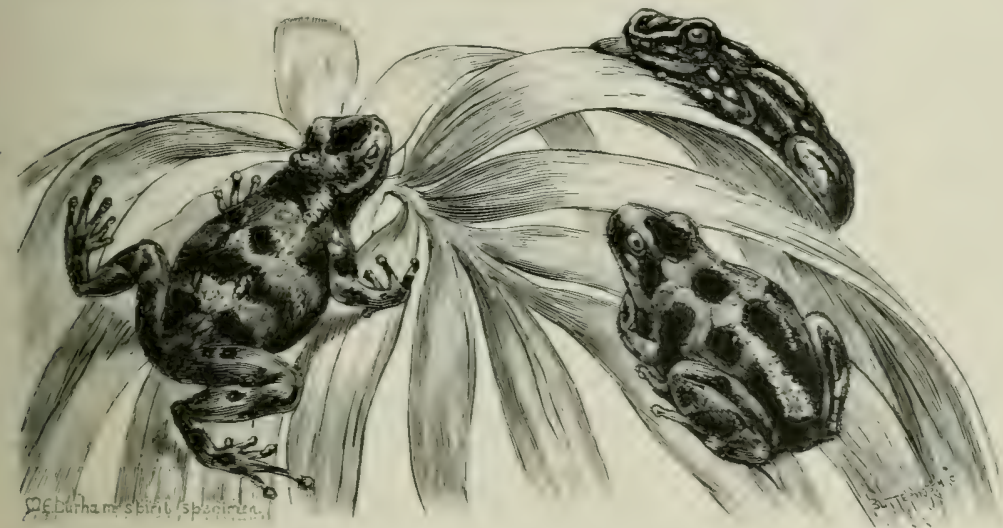

FIG. 53.-Dendrobates tinctorine, three colour-variations. $\times 1$.

1). trixittatus, chiefly in Northern Brazil, has the first finger slightly longer than the second. It likewise varies considerably in its coloration, being either quite black, or spotted with white and brown, or with a whitish forehead and several white patches on the back and hind-limbs. D. typogiaphus of Central America is rermilion red, with small dark marks on the back; the legs are black.

The various species of Dendrututes take remarkable care of their young. D. braccatus lives in Brazil in "varzeas," i.e. moist but waterless places, and carries its tadpoles on its back, to which they are attached hy a peculiar secretion. The same is saicl to be true of $D$. trivittutus, which sits down in a drying-up puddle, lets the little tadpoles, when they are only 6-7 mm. longe, fasten themselves on, and convers them to a safer locality, where the water is calculated not to evaporate before the metamorphosis is completed. 
16ritillu.- Both omu- and meta-sternum possess a hony strle. The tongue is free and distinctly mitred or cut unt behind. The skin is rery granular. Sereral species, in Madagascar, were formerly put into the sane crems as the American forms, mutil Bunlencer established the genus Irutellu for them. The crloration is strikingly pretty. Ir. mardagascariensis is a rare instance of difference in colour between the two sexes. The male is bluish hlack, with light blue spots on the belly, while the thighs and the imner sides of the legs are leautifully red. The female is deep hlack, with a light green spot at the base and in front of the limls: the rest is coloured like the male.

Curdiuglossn grurilis, quite recently discovered at the Gaboon, has likewise to be added to the Dendrobatinae, on account of the ahsence of teeth. It is a small, slender, arboreal frog, bearing an unmistakable resemblance to the other genera by its general appearance and conspicuous, contrasting coloration of black and white. 
PART II

\section{R E P T I L I A}


"Cada uno es como Dios le hizo, 5 aun peor muchas vezes."

"We are all as God made us and many eren worse."

Saxcho Paxza, Don Quixote. 


\title{
CHAPTER VII
}

\author{
REPTILIA
}

DEFINITION AND CHARACTERS-POSITION OF THE CLASS REPTILIA IN THE PHYLUM VERTEBRATA-CLASSIFICATION-SKULL ANU VERTEBRAE.

THE recent Reptiles comprise, broadly speaking, the Crocodiles, Tortoises, Lizards, and Snakes. They are the only Vertebrates which are cold-blooded, breathe by lungs, and have a median occipital condyle. Another equally sufficient diagnosis is the following:-Tetrapoda, with a median occipital condyle, with nucleated red blood-corpuscles, and with complete right and left functional aortic arches. A still shorter diagnosis is:Monocondylia with a scaly skin.

If our diagnosis is to include the fossil Reptiles we have not only to discard the characters drawn from the soft parts as unavailable, but we are forced to treat the condition of the occipital condyle with caution, since there exist, or must have existed, transitional stages between Reptiles and Amphibia and Mammals; and the winged class Pterosauria does not permit us to use the wings as a differential character for the Birds. In fitct, while the Reptilia are sufficiently separated from the Auphibia by their absolutely gastrocentrous vertebrae, it is difficult to distinguish them as a class from the Birds; hence the term SAURopsida, which is intended to indicate the close relationship of the Reptiles to the Birds in opposition to the Mammalia, and to the Ichthyopsid or Amphibia and Fishes. However, the lieptilia take up a very central position in the evolution of the main classes of the Vertebrata. On the one hand, there is not the slightest doubt that they are evolved from some branch of 
the Stegocephali, whilst on the other hand the Reptiles, probahly through some branch of the Theromorpha, have given rise to the Mammals: some other Reptilian branch, at present unknown, has blossomed out into the Birds.

\section{Principal Characters of the Reptilia.}

1. The vertebrae are gastrocentrous.

2. The skull articulates with the atlas hy one condyle, which is formed mainly by the basioccipital.

3. The mandihle consists of nany pieces and articulates with the cranium through the quadrate bones.

4. There is an auditory columellar apparatus titting into the fenestra oralis.

5. The limbs are of the tetrapodous, pentadactyle type.

6. There is an intracranial hypoglossal nerve.

7. The ribs form a true sternum.

8. The ilio-sacral connexion is post-acetalular.

9. The shin is corered ( $r$ ) with seales, but (1) neither with feathers nor with hairs; and there is a great paucity of glands.

10. Reptiles are poikilothermous.

11. The red blocd-corpuscles are nucleated, hiconvex, and oval.

12. The heart is divided into two atria and an imperfectly divided ventricle. It has no conus, but semilunar valres exist at the base of the tripartite aortic trunk.

13. The right and left aurtic arch are complete and remain functional.

14. Respiration is effected by luugs; and gills are entirely alsent, tren during embryonic life.

15. Lateral sense-organs are absent.

16. The kilners have no nephrotomes. Each kidner has one separate ureter.

17. There is always a typical cloaca.

18. The eggs are meroblastic.

19. Fertilisation is internal, and is effecterl, with the single exception of Sphenodon, by means of male copulatory organs.

201. An amnion and an allantois are formed huring direlopment.

Numbers 1, 2, 6, 7, 8, 14, 16, 18, 20 separate the Reptiles from the Amphibia. Cf. also pp. 4 and 5.

Numbers $9(b), 10,12$, and 13 separate them from the Birds anl Jammals.

Numbers 3, 8, and 11 separate them from the Mammals.

The evolution of the classification of the Reptiles hats

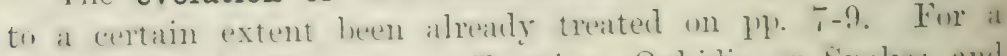

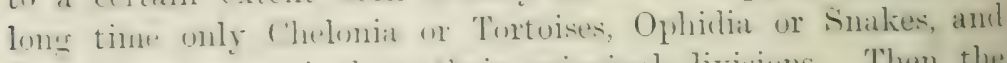
Samii were recomised as their grincipat divisions. Then the

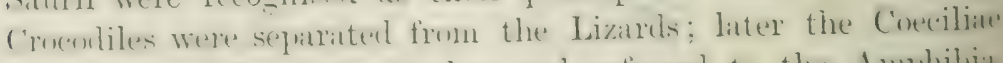

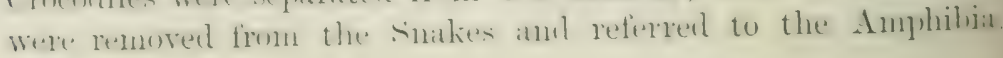


and ultimately Sphenodon was recognised as deserving a separate position, equal in rank to the other groups. Stamnius showed that the Crocodiles and Tortoises are relatively near allies in opposition to the likewise closely allied Lizards and Snalies (Sphenodon was then unkmown), and he expressed this by the term Monimostylica, or creatures with fixed quadrate bones, for the former, and Streptostylica, creatures with movable quadrates, for the latter combination. The fossil Reptiles were hardly allowed proper places in the system. In various zoological texthooks they were, or are even now, treated as inconvenient, outlying, or supernumerary members. A long time elapsed before, thanks to the labours of H. von Meyer, Owen, Huxley, Marsh, Cope, Zittel, and Seeley, it was recognised that the extinct groups form the preponderant mass of Reptiles, and that it is the recent sroups which, in spite of the bewildering number of species of Lizards and Snakes, are the comparatively few and much-reduced members of a once flourishing class. With the exception of the Lizards and Snakes, which are on the ascending branch, the modern Sphenodon, the Crocodiles and the Tortoises are a mere fraction, comprising a few survivals of richly-teveloped groups, while all the others, the overwhelming majority, have died out.

The classification adopted in this volume is as follows:-

Class Reptilia.

\section{Sub-Class I. Proreptilia. \\ II. Prosauria.}

Orders: Microsauri, Prosauri.

III. Theromorpha. Orders: Pareiasauri, Theriodontia, Anomodontia, Placodontia.

- IV. Chelonia. Orders: Athecae, Thecophora.

V. Dinosauria. Orders: Sauropoda, Theropoda, Orthopoda, Ceratopsia.

VI. Crocodilia. Orders : Pseudosuchia, Parasuchia, Eusuchia.

VII. Plesiosauria. Orders: Nothosauri, Plesiosauri.

VIII. Ichthyosauria.

IX. Pterosauria.

X. Pythonomorpha. Orders: Dolichosauri, Mosasauri.

XI. Sauria. Orders; Lacertilia, Ophidia.

The eleven principal groups are here called "sub-classes" to emphasise the undeniable fact that these Reptilian groups are of much greater morphological value than those which are most generally called "Orders" in the Mammalia, that class which we consider as the standard or model of classificatory units. The 

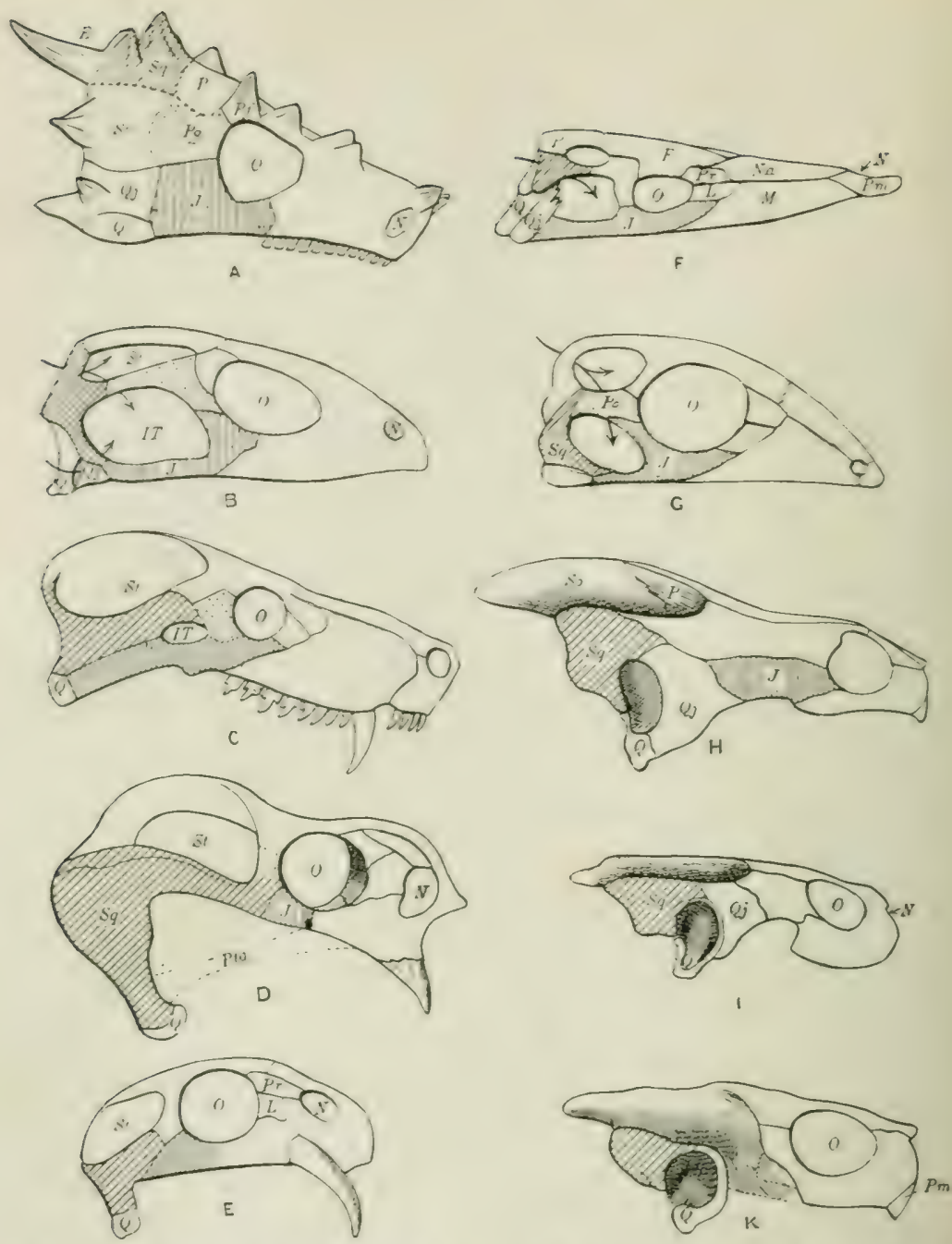

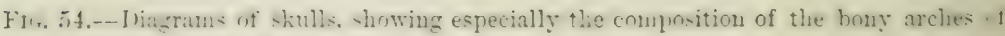
the orbito-temporal region.

A, C, D, E, Theromorphd. A, Eilginia, 1).305; C, Cynagnathus, 1. 306 ; D, Gardonia, 1). 310 ; E, Jicynodon, p. 310.

B, G, Prosauria. B, Sphenotun, 1. 294; G, Palacohalteria, p. 291.

F, Crocodili, p. 434 .

H, I, K, CHeloNia, p. 316. H, Chelydra, p. 338; I, Chrysemys, p. $346 ; \mathbf{E}$. Cistuelo, p. 361.

$E$, Epiotic; $F$, frontal ; $I T$, infratemporal fossa; $J$, jugal, shaded vertically : $L$, lacrymal; $\boldsymbol{N}$, maxillary; $\boldsymbol{N}$, wasal groove; $\boldsymbol{N}$, nasal bone; 0 , orbit: $P$, parietal ; $P o$, postorbital, dotted ; $P f$, post-frontal ; $P m$, premaxillary: $P r$, prefrontal ; $I t g$, pterygoid ; Q, quadrate; $Q j$, quadrato-jugal ; Sh, supranecipital ; $\mathbf{S}$, squamosal, shaded obliquely ; st (in B-E), supratemporal fossa ; st (in $\mathbf{A}$ ), Supratemporal bone. 

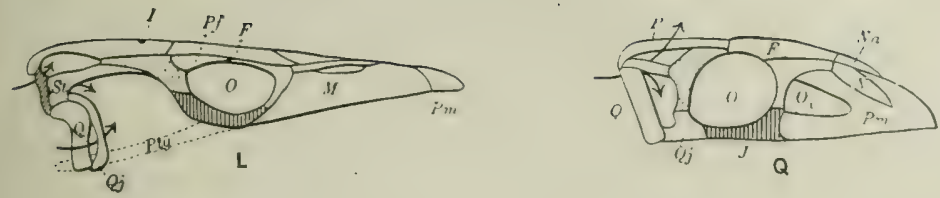

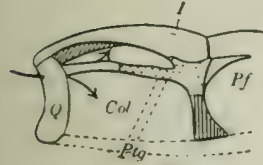

M

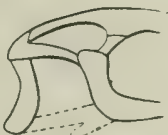

N

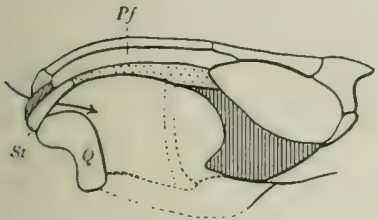

0

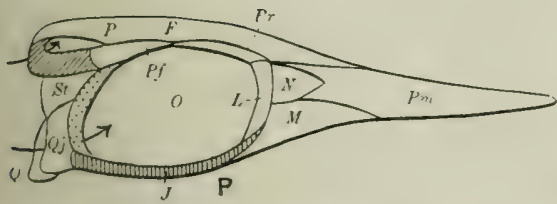

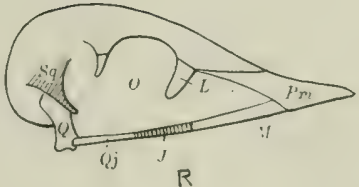
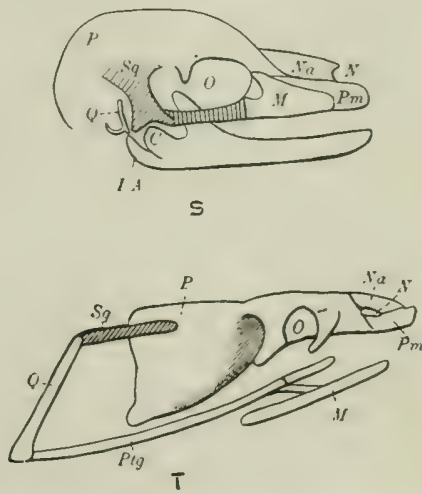

Fici. 55.-Diagrams of skulls, showing especially the composition of the bony arches of the orbito-temporal region.

L, Pтthonomorpha. Clidastes, p. 490.

M, N, 0, Lacertilid, p. 496. M, Varanus, p. $543 ;$ N, Uromastix, p. 524;0, Lacerta, p. 550.

P, ICHTHYOSAURIA, p. 479. Ichthyoscuurus, p. 483.

Q, Pterosauria, p. 484. Dimorphodon, p. 486.

$\mathbf{R}, A \vee E S$, generalised, for comparison.

S, Mammalia, generalised, for comparison.

T, OPHIDIA, p. 581.

$C$, Condyle of mandible; Col, columella cranii ; $F$, frontal ; $I$, interparietal or pineal foramen; I.A, Inner angle of mandible; $J$, jugal, shaded vertically ; $L$, lacrymal; $\boldsymbol{M}$, maxillary ; $\boldsymbol{N}$, nasal groove; $\boldsymbol{N} \boldsymbol{C}$, nasal bone; $O$, orbit ; $O_{1}$, preorbital fossa ; $P$, parietal ; $P f$, postfrontal ; $P m$, premaxillary ; $P r$, prefrontal ; $P t g$, pterygoid; $Q$, quadrate ; $Q_{j}$, quadrato-jugal ; $S_{q}$, squamosal, shaded obliquely; $S t$, supratemporal bone. 
fanilies camnot well be changed, and terms like super-families and suprer-orders are sonetimes resurted to by those who do not like to look stern facts in the face.

The sernence of the groups, although arranged as much as possible in ascemeling order, is of necessity ats mmatural as that of the majes in an atlas. The cannot ret construet a satisfactory phyletic tree of the lieptiles. The Froreptilia connect them with the Amphilia. Next follow the l'rosauria with splichodun anong the l'rosinuri ats the key to most other srumps. Then follow the Theromoryhat and it is probahle that from rarious branches of these have arisen the Chelonia, Ininosauria, Crocodilia, and Plesiosamriat. The descent of the Ichthyosamia is very problematic. The sane applies to the P'terosauria and to the Pythononorpha, hut it is possihle that they; together with the Sauria, are connected with the Prosauria.

With all reserve these hypothetical aftinities may be expressed by the following diagram:-

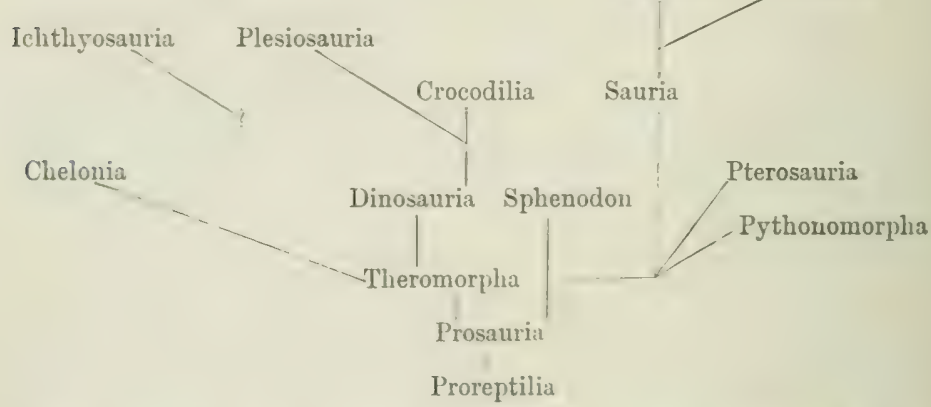

The eleren sub-classes of the Reptilia present so many improtant differences that it is not advisable to give here a further weneril account of their structure. The diagrammatic figures

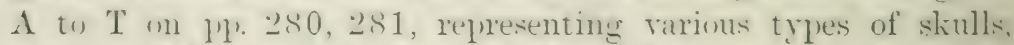
are intenclesl to explain their chief noclifications, all referable to I'roreptilian and to ertain Theromorphous conditions. One of the most innortant features is that the mamblible, which is always

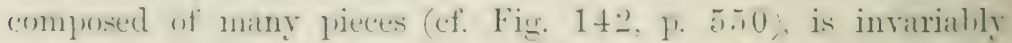
arried ly the quatrate bone. J)iaglatus of the generalised skulls of a Birel and a Mammal have hexn added for comprarison.

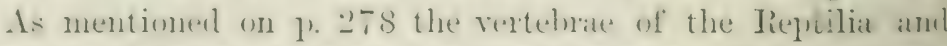
these of all where .mmivtal are gustementeress: that is to sily 
the centra or bodies of the rertebrate are formed by the pairs of interventralia, while the basiventralia are reduced, persisting
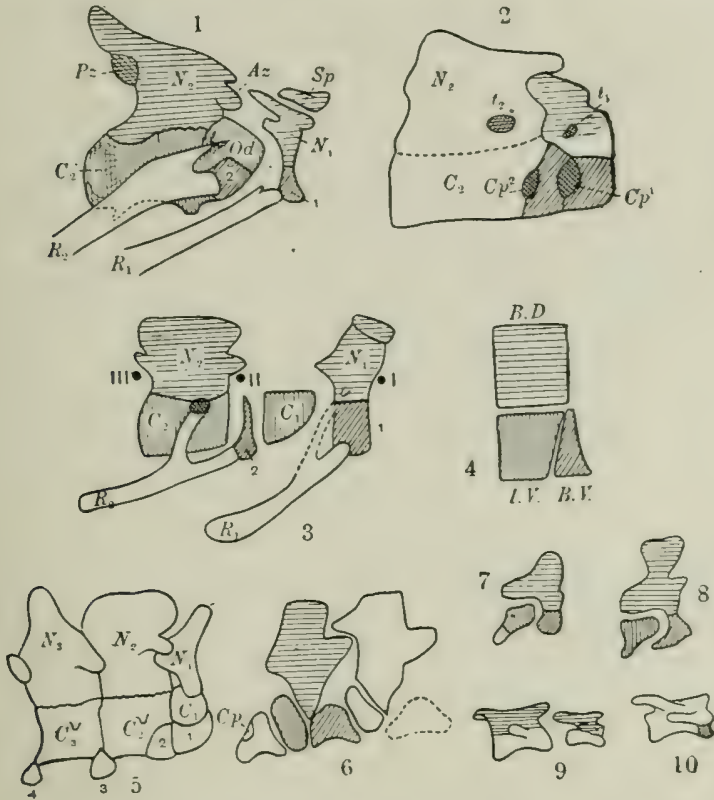

FiG. 56.-Composition of rertebrae of Reptiles, illustrated by the first and secnnd cervical vertebrae. (1) Atlas (first cervical) and axis (second) vertebra of Crocodilus. (2) Atlas and axis of Metriorhynchus, a Jurassic Crocodile. (3) Analysis of the first two cervical vertebrae of a Crocodile; 2 , second basiventral complex or "intercentrum" continued upwards into the meniscus or intervertebral pad. (4) Diagram of the fundamental composition of a Feptilian vertelura ; compare this and (6) with Fig. 1 ( 8 and 9) on p. 13. (5) The first three cervical vertebrae of Siphenolon. (6) Trunk-Fertebrae of Eryups, a Pernian Proreptile : typically temnospondylous ; $c p$, articular facet of the capitulum of a rib. (7) The complete atlas of an adult Trionyx hurum; the second basiventral (intercentrum) is attached to the posterior end of the first centrum, which, not being fused with the second centrum, is not yet an odontoid process. (8) The complete atlas of an adult Trionyx gangeticus; still typically temnospondylous. (9) The first and second cervical vertebrae of an adult Platemys. (10) The complete atlas of a Chelys fimbriata. Az, Anterior zygapophysis ; $B . D$, basidorsal ; $B . V$, basiventral ; $C_{1}, C_{2}, C_{3}$, first, second, and thircl centra, formed by the interventralia; $C p^{1}, C p^{2}$, articular facets of the capitular portions of the first and second ribs ; $I . V$, interventral $; \boldsymbol{N}_{1}, \boldsymbol{\Lambda}_{2}, \boldsymbol{N}_{3}$, first, second, and third neural arch, formed by basidorsalia $(B . D)$; $O d$, odontoid process = first centrum ; $P z$, posterior zygapophysis ; $R_{1}, R_{2}$, ribs; $S p$, detached spinous process of the first neural arch; $t_{1}, t_{2}$, tubercular attachments of the first and second ribs ; $1,2,3,4$, "intercentra " = basiventrals ; $I, I I, I I I$, position of the exit of the first, second, and third spinal nerves.

rither as so-called intercentra or wedge-bones, or as intervertelinal pads, or disappearing altogether. At the earlier stages of derelopment the gastrocentrous rertebrate behave in the 
same way as that descrilued on P. 1르 (Fig. 1), except that the interdoral elements are supuressed from the beginning. In the remaining three pairs of constituent elements of each rertehra (the hasidursalia, forming the nenral arch; the interventralia, forming the body or centrum; and the hasiventralia) remain

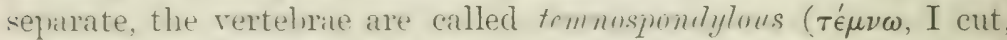
$\sigma \pi u ́ \delta v \lambda o s$, a vertelsal). If the neurat arches and the centrat are suturally uniterl or are fused with each other, the vertebrae are

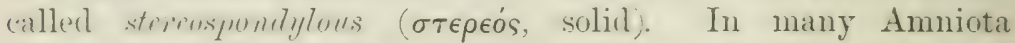
the atlas or first vertehra remains in a relatively primitive, mulnronic (omlition, and is temmosjondylous but for the usual molification that its centrum becomes attached to that of the secomel rertelura, and forms the ulontoid process of the latter. The composition of gastrocentrous vertelmae (cf. p. 282) is best illustrated by the first and second cervical rertebrae of the Crocodile (Fig. 56, 3, p. 283).

Concerning geographical distribution, even a cursory study shows that the sub-classes have conne into existence at rery different geological periods, and have each followed their own lines of dispersal. 


\title{
CHAPTER VIII
}

\author{
PROREPTILIA - PROSAURIA-THEROMORPHA
}

SUB-CLASS I.-PROREPTILIA.

Permian T'emnospondylous Reptiles with reell-developed limbs and girdles of the terrestrial type.

The two genera Eryops and Cricotus of the North-American Permian formation had until recently ${ }^{1}$ been relegated to the Stegocephali. By grouping them and their nearest allies together as Proreptilia it is intended to indicate that they are the lowest known Reptiles and that they probably link this class to the Amphibia. The superficial resemblance of their tri- or bi-partite vertebrae, and their occurrence in the Lower Permian, have caused the error of classing them with the Stegocephali, but the composition of their typically gastrocentrous vertebrae leaves no doubt as to their affinities. After all, we feel certicin that Peptiles have arisen from Stegocephalous Amphibia, and it is in the Lower Permian, exactly where these debatable creatures lived side by side with Stegocephali, undoubtedly likewise temmospondylous, that the change from Amphibia into Reptiles seems to have taken place. Both are referable to Amphibia with quadripartite vertebrae. The condition of the occipital condyles determines nothing. This greatly exaggerated character has lost in importance since we have known the condylar modifications of the Theromorpha ; moreover, C'ricotus itself seems to have possessed a single condyle. We should even expect the Proreptilia to present many Stegocephalous inheritances, for instance the condition of the shull roofed in by dermal bones, a ventral dermal armour, a very complete pectoral arch still without a sternum, and only one sacral vertebra.

1 Pril. Trans. clxxxvii. 1896, B. p. 23. 
Lntil mure genera are hetter known than they are now, it is Irenature to divide the present sub-class into orders.

$E, y(1)$, with several species in Texas and New Mexico. $E$. morymorluchlus is the most abundant and the largest species, its Troad and flattened skull measuring more than 18 inches in length and 12 in width. With the exception of the nostrils and the small orhits, the skull is entirely encased in bone, with a rough, pitted surface, but without any distinguishable sutures. The alsence of mucous canals, so common in the Stegocephali, is worthy of note. The quadrates extend olliquely outwards and backwarks, so that the joint with the mandible lies in a plane hehind the oreiput. The mandibles are devoid of a projecting

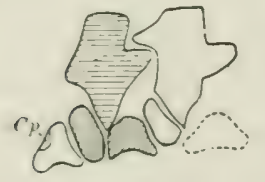

Fis, 5.7.-Trunk vertehrae of Eiryous (cf. Fig. 56, 4, p. 28:3). ('p. Articular ficcet of the capitulum of a rib. angular process. The teeth are numerous, small, and pointed. The vertebrae are typically temnospondylous, consisting each of three pairs of separately ossified pieces, which, although closely packed together, are not suturally connected. The neural arches possess high spinums processes, they articulate by short and broad zygapophyses and are, with their triangular bases, wedged in between the two ventral pieces, the posterior of which (the united interventralia) is in broader contact with the neural arch and lies behind it; the anterior piece (the united hasiventrals) appear as typical, but large, intercentra, and bear on their posterior, dorsal margin the facets for the ribs. The latter are short, but are broad at their proximal ends, which are not lifurcated: they extend their articulation from the "intercentra" "pon the short lateral processes of the neural arches. The tail is short and ends in a pointed coccrx, owing to fusion of the last vertebrae.

The puhes and ischia are heary, the former flattened and hroadened out. The limhs are of an almost ideal pentadactyloid type; strongly developed for terrestrial locomotion. The ulna lussesses a large ulecramon. The carpus consists of ten separate fieces. ulnare, intermedium, radiale, two centralia and five distal arpulia. The latter support only four metacarpals and fingers, the second finger heing completely abolished, an explanation suggested by Cope and corroborated by Emery. 
Cricotus, with several species in Texas and Illinois. C'. heteroclitus was perhaps 10 feet long and probably aquatic. The skull has a long, narrow, depressed snout, the margins overhanging those of the lower jaw ; its surface is encased in dermal bones, most of which still show sutures, so that for instance postfrontals, postorbitals, supratemporals and squamosals can be distinguished; all these are in contact with the long parietals and with the quadrato-jugal arch, covering the temporal region; but the supratemporals have a free projecting border, like the squamosals of the crocodiles. According to Cope's description the basioccipital is connected with the first vertebra by an undivided discoid " intercentrum," probably the true centrum, while the first basiventral mass, which would be, if independent, the first true intercentrum, is more probably connected with the first neural arch, thus constituting the ring of the atlas.

The vertebrae are still temnospondylous, but no longer tripartite. The neural arch is fused with the interventralia into one mass, which carries the capitula and tubercula of the ribs, while the united basiventrals still remain as separate intercentral wedges. In the tail these wedges carry chevron-bones, and are enlarged into thick almost complete dises, or rather rings, while the whole vertebral column is still perforated, as also in Eryops, by the chorda dorsalis. The tail is long. The digits are devoid of claws.

Remains of dermal armour exist on the throat in the shape of several large gular plates, while the whole belly is covered with many closely packed bony scales, which are arranged in chevron-shaped transverse rows.

Probably several other genera of American Permian and also of European Permian strata will, when better known and critically examined, have to be referred to the Proreptilia. Thus for instance the European Melosaurus may have affinities with Eryops, while Diplovertebron of Bohemia seems to be allied to Cricotus. The difficulty of division will lie with those Lower Permian Amphibia which, like Archegosaurus, Euchirosaurus, Actinodon, possess tripartite vertebrae, which at first sight are strikingly like those of Eryops. But the tail-vertebrae permit of no mistake, and since these are quadripartite in Archegosaurus, rhelydosaurus, and Sphenosaurus, these genera are safely to be clisssed with the Amphibia, unless, indeed, for mere argument's 
salke, it he assumed that the intercentral discs of Diplovertebron and Crimtes are formed by the fusion of Amphibian interdorsils with interrentrils. Anyhow, simply to state that the tripartite vertelirite of $E^{y} r_{y}$ ps are the same as those of Actinodon, would be ats convincing as saying that the English and French flags are essentially the same, both containing the same colours, but one is white, red, and blue, the other blue, white, and red. Tripartite Amphilian vertebrae are composed of basidorsals + basiventrals + interdorsals, those of Reptiles are marle up of basidorsals + hasirentrals + interventrals. (Cf. Fig. 56, 1). 283, and Fig. 1, p. 13.)

\section{SER-CLASS II.-PROS'ATRIA.}

1/nstly extinet Reptiles, with derpl!y amphiroclous lint steren-

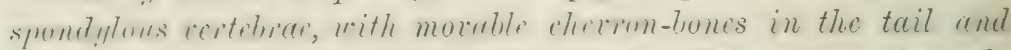

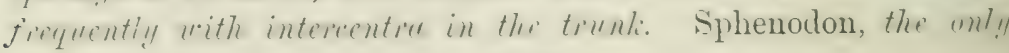
recent genus, has no copulatory organs.

\section{Order I. MICROSAURI.}

Eutimet, small Reptites, mostly reritumiferous and Prrmiun, with

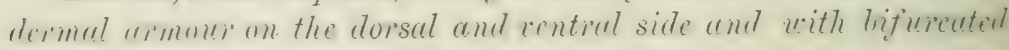
vibs.

We retain this term of Dawson's for those small, newtshaper, chiefly T'ermian reptiles, which are allied to Hylonomus, after elinination of contemporary forms like Keraterpeton and Limorlylus, which helong to the Branchiosaurian order of the Stexocephali. Intil recently all these creatures had heen classed with the Sterocephali. The Microsauri in the present restricted semse reveal themselves, howerer, as reptiles by the novable chevron-hones in their tail, their hroal neurocentral sutures, the possession of two siccal vertebrae (Petrobutis. the hifureated rils which always articulate with the centlia (most venty shown in (ipthorester), and the possession of fire fingers and toes.

Comsidering the age of these little creatures and their low jusition in the reptilian scale- in fiact, they stand alnowst as low

${ }^{1}$ Phit. Trans, clxaxvii. 1896, B. p. 23. 
as the Proreptilia-it is not to be wondered at that they still retain a number of amphibian features. The skull is encased in dermal bones as in the Stegocephali, and the dermal armour of the trunk and tail is composed of many bony, sculptured seales; which cover back, sides, and under surface. The middle rows on the back are the largest, while the scales on the belly are arranged in transverse rows, which imbricate and converge obliquely headwards. Special gular plates seem to be absent. The skull has an interparietal foramen. The jaws and the palate are furnished with small, simple teeth, and there is a large parasphenoid bone, an eminently amphibian character. The occipital condylar articulation is supposed to be donble. The centra of the vertebrae are deeply amphicoelous, elongated, and constricted in the middle, just like those of the Aistopodia and Branchiosauri. The dorsal spinous processes are strongly dereloped, and with the zygapophyses are very reptilian. Transrerse processes are absent or very short, the tubercular portions of the ribs articulating with the centra, the capitula mostly intervertebrally, in any case close to the anterior end of the centra. The tail-vertebrae possess very typical, movable chevrons, placed intervertebrally, and bear an extraordinary resemblance to those of Geckos. The ribs are long and slender, but there is no sternum. The fore- and hind-limbs are pentadactyle, in opposition to the invariably four-fingered Stegocephali. The shoulder-girdle consists of scapulae, coracoids, clavicles, cleithra, and a T-shaped interclavicle. The pelvis also resembles that of certain Stegocephali by the separately ossified, somewhat discshaped, flat ischia and pubes, which seem to have been joincd together by cartilage into one broad mass.

Hylonomus, Dawson's type of Microsauri, was found in the Coal-measures of Nova Scotia, within decayed tree-stumps. Closely alliel, if not identical, but much better known is Hyloplesion, e.g. $H$. longicostutum of the uppermost Permian of. Nyrschan in Bohemia. Total length under 4 inches; eyes with hony sclerotic rings; neck short. The truly Permian genera Dursonia, Melun"rpetun, Oithocosta, and Seeleyce are allied forms, the last scarcely one inch in length, but well preserved. Petroluates of the Triassic Lower Red Sandstone of Saxony has an arrangement of the ventral dermal armour closely resembling abdominal ribs. 


\section{Order II. PROSAURI.}

Mostly extinct, chiefly I'ermian and Triassic, terrestrial, unammoured reptiles with deeply liconcave rertebrate, numerons intercentrat and cheron-lones, fixed quadrates, complete penta-

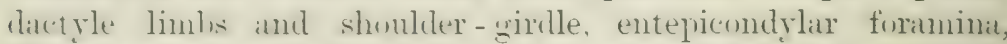
acrokdont teeth, and many small abdominal ossifications.

The Prosaturi differ from the Microsauri, with which they are chesty allienl, hy the nore alranced solidification of the vertelsate, the reduction of the tubercular portions of the ribs. the presence of an entepicondylar formen in the hunerus, and the loss of the dermal ossifications on the upper surface.

Their ancestors are the Microsari, whilst they themselves serem to be very near the root whence have sprumg most, if not all, other main hranches of the reptiles, notalily Crocodilia, Ininusauria, and siauria. In fact the l'rosanri, although apparenty few in number, seem to represent the central stem of the reptilian tree. Only one of them is still surviving, the famous Splerman, now represented hy a single sprecies in New Zealanil.

Sub-Order 1. Protorosauri-The rentral half of the pelvis seems to have formed one hroad, continuous mass of cartilage in which the pulic bones are representerl hy a pair of oval, rather disc-shaped ossifications, while the ischia are mure elongated. The pelvis conserpently still bears a great resemblance to that of the Microsaturi, and therely also to the Stegocephalous condition, but the ilium seems to he attached to more than two vertelnae. The rertebrate are deeply biconcave, perhaps even with a persistent continuous chorda. The neural arches lear high, laterally confresed spines, hut no diapophysial or lateral processes, the rils heing pliacel mostly intervertebrally and having lost their tubercular portions. The ribs are continued to about the sixth candal vertehra. Intercentral werlges exist in an unbroken series between all the vertelirate from the atlas to the tail, where they are represented by movihle cherrons. A costal sternum semins to lie alsent, unless it was quite cartilaginoms. The shouldergrirle is complete, consisting of a long interclavicle, clavicles. disc-shitped coracoids, and scilpulate: lut there are no cleithra, and no indication of precoracoids or eren motehes in the coracoids. The lore- and himl-limls are complete and prinitive, with five digits. The abdemen is potected by numerous oat-shaped litte ossificat- 
tions, which are arranged in many transverse or rather cherronshaped rows, still greatly resembling the condition prevailing in the Microsauri, except that they have sunk deeper intu the skin, being no longer directly corered by the scales. The skull, being no longer completely encased by bones, and possessing now wicle supra- and infra-temporal fossae, appears at first sight much like that of a generalised lizard, except that it possesses three very conspicuous and distinct arcarles in the temporal region : namely, the orbito-squamosal bridge across the temporal fossa, formed by the postorbital and squamosal; the arch formed by the squamosal with the postero-lateral buttress of the parietal; and the infratemporal arch or jugal bridge. The jugal itself is long, comnecting the quadrato-jugal with the maxillary and lacrymal, and sending up an ascending process to the postorbital bone, thus taking a considerable share in the formation of the orbit. The quadrato-jugal is small, apparently fused with the quatrate, which itself is firmly orerlaid by the squamosal. The quadrates are further fixed by being buttressed by the pterygoids, which rest upon short basisphenoid processes and extend far forwards, meeting the romers and separating the palatines. The premaxillae are short, the nares small and terminal, the nasal bones are large. There is a small interparietal foramen. The teeth are acrodont and pointed, forming unbroken series on the premaxillaries, maxillaries, palatines and dentaries, and there are scattered little teeth on the vomers.

Pulucohatteria longicaudata from the Lower Red Sandstone of Saxony. Total length about 18 inches, with six cervical, twenty trumk, three or four sacral, and about fifty caudal vertebrae. The teeth are ankylosed with the supporting bones. The tive fingers have $2,3,4,5,3$ phalanges respectively. For the skull see Fig. $54,(\div$, p. 280 . Telerpeton elginense from the Triassic sandstone of Scotland, and perhaps Scurosternon of the South African Karroo sandstone seem to be allied.

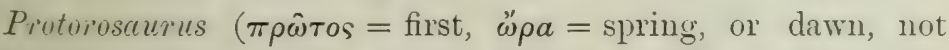
Proterusucus apparently several species, e.g. P. lincki in the Lpper Permian (marl-slate and magnesian limestone) of Thuringia and I)urham. About 4 or 5 feet long, and in its general appearance rather like a Monitor-lizard, with about eight cervical rertelrare, most of which carry slender backwardly-pointing ribs, sixteen long-ribbed trunk-vertebrae, followed by three or four 
sarcrals and mone tham thirty camdals, some of which have hifurcated spinous processes.

Sub-Order 2. Rhynchocephali.-The rentrul pelvic lunes resemble those of lizards and enclose a wile puho-ischiadic formen. There are only two salcral reptehrae. The aldominal ribs are clusely packed. each transterse set consisting of only three rodshalperl piecess instearl of miny small oat-shatped nodules. The interentrat are sometines suppressed in the trunk-region.

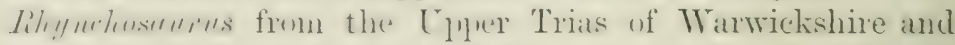

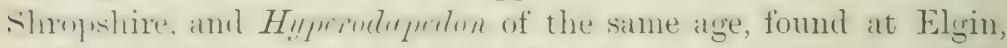
in Warwickshire, and alsu in (entral India, are ratlier large, $H$. gridnni measuring 6 feet in length. Both have a short, liruad, and stout cranimm, and emrert down. toothless premaxillae, hencer the natme Ihlymchocephali: the nares are confluent: the tereth ane nunerous and small, and are liathle to be worn down si) that the animals ultimately lite with the edges of the jaws, to which the teeth are ankylused. The premaxillaries of

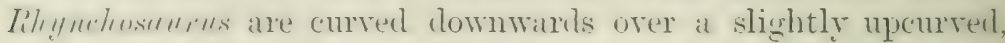
likewise trothless process of the mamdilies, which form a strong srmplycis. All the teeth are very small, alsent, or minute on the mandibles, fornins one series on the maxillae, several rows on the romers and especially on the palatines, which latter remain

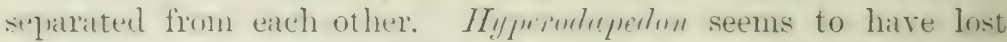
the intercentra; its vertebrae are solid, those of the neck are "pisthocoelous. The interparietal foramen is likewise abolished. The hook-shinged end of the curved-rlown premaxillate fits into a hifurcation of the mandihles in fiont of their stont symphysis. The teeth are similar to those of the other genus. Whilst these, the andiest known genera of Phynchocephali, are ahealy in virious witss rather specialised, e.g. the hooked beak and the luss of the interentra, the two following fossil genere, although of mull later ditte, namely Upler Triassic, are more closely allied in the recent Sphenodon.

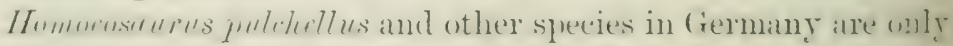
if to 8 inches long. The rertelnal columm eomsists of twentythree presacral and many caudal vertebrae. The first five cervicals are devoid of rilss. Intercentra are restricted to the neek and the anterin fortion of the tail. The mandihles are not fused together. The nares are divided by a bony septum. Barde premaxillary has one rather houd tonth. The teeth of 


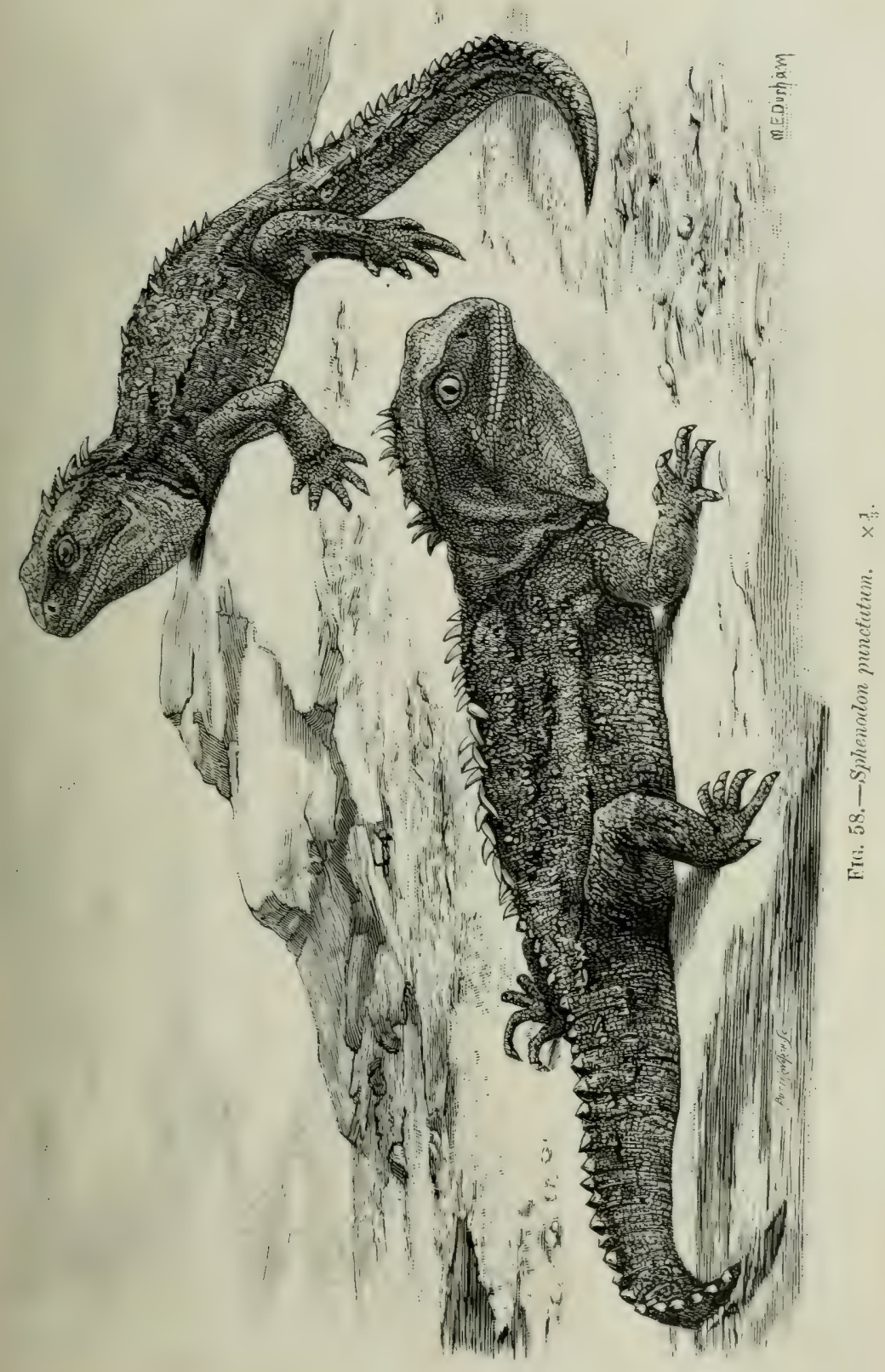


the maxillaries and mandilles are triangular, much worn fown in front. The rils are deroid of uncinate processes. C'losely allienl lout larerer is sirmennmlon of France, which has lost the myres teeth and uses the sharp marerins of the jaws instearl.

Plontusturus of (rermany and France, about is feet in length, is remarkahle for the shortness of its still pentadactyle extremities, for its short neck, and rery long tail:- an interesting parallel to what has happened in many genera of recent lizards.

Sphenodon s. Hatteria is the sole surviving nember of the whole gronu of l'rosanria, and is represented by one species only, $\therefore$ functutum, in New Zealamd. As the last living witness of lixgme ages this primitive almost ideally generalised trpe wi reptiles this "living fusil." deserves a detailed description.

Tutal length of very latre male suecimens up to two feet and a half: in general alluearance like many a stontly huilt lizard. The getneral colom of the shin is dark olive-green with small white or rellowish specks wn the siles. A series of slightly erectile spines of yellowish colon "xtemes from the top of the head to the end of the tail. hut is interrupted on the neck: they are cutaneous. corered with a thin sheatis of horn. The under smrace is covered with numerous scales, arranged in transterse rows: the rest of the body is rather granulats. The tail is thick, slightly compressed laterally. The exe is large. dark liown, with a vertical pupil.

Those who are satisfied with sulerficial resemblances still Eroup this creature with the lizards, hut it reveals itself as a frimitive reptile or I'rositurian ly the following charaters every me of which distimusushes it firm the lizarls:- The tempral rengim is lristged liy three bony arcales. The lange roners. palatines, and piterregoils form a lirual bony roof to the month: the litrge quadrates are firmly fixed hy the jotergegoids, squanowils,

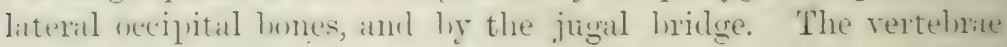
possess an mhloklien series of intercentral wedge-bones. There is an elithorate syotem of alulominal ribs. The humerus hats an

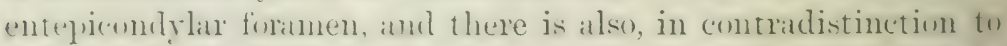
the forsil Rhynchuephatia, an ectepicombly formen for the passage of the ranlial nerve. The carpus still has the frimitive mmulwer of ten bones, all of which remain sedrate, including the interuediun. (lf suft parts are to he mentioned atowe all the

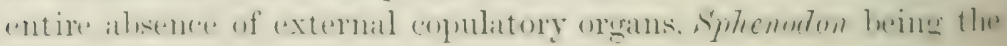


only recent reptile which is devoid of them: a most primitive condition, sutficient hy itself to separate this creature from all the other living reptiles.

The supratemporal bridge is formed by the squmumosal ambl
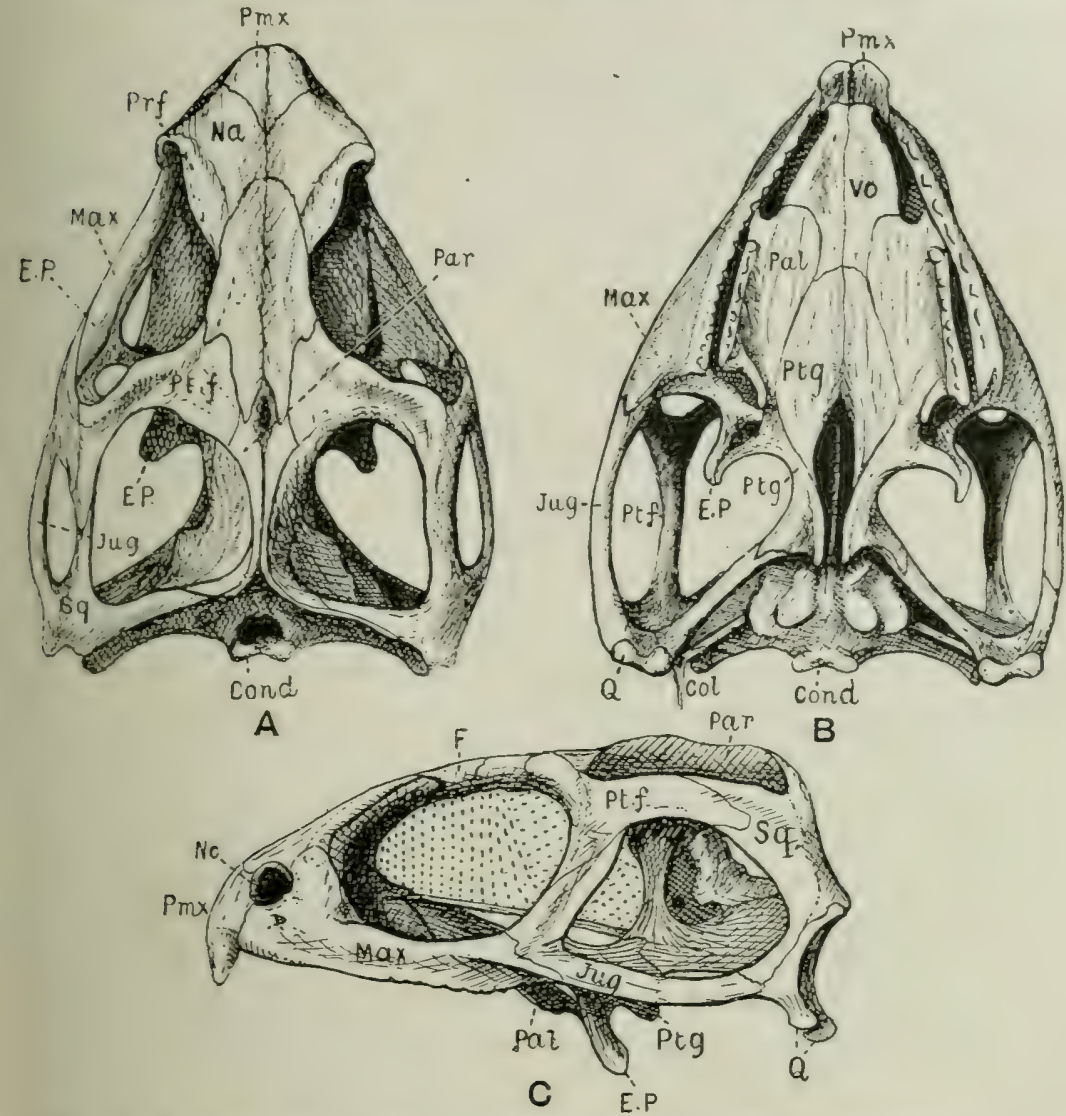

Fig. 59.-A, Dorsal; B, ventral; C, left-sided view of the skull of Sphenodon. $\times \frac{:}{2}$. $C o l$, columella auris; Cond, occipital condyle ; $E . P$, ectopterygoid ; $F$, frontal ; Jug,

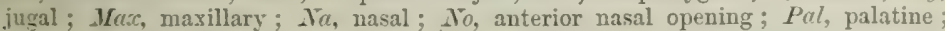
P $(r$, parietal ; Pmx, premaxillary ; Prf, prefrontal ; Pt.f, postfrontal and postorbital ; $P t g$, pterygoid or endopterygoid ; $Q$, quadrate and quadrato-jugal ; $S q$, squamosal ; Vo, vomer. See also Fig. 54, B, p. 280.

l'm:torlital (Fig. 59, C, Pt. $f^{\prime}$ ), the latter being continued forwards ani fused with the postfrontal $(A, P t \cdot f)$. The postorhital joins the ascending branch of the jugal, both together forming the lmiler borler of the orbit; this is bortered below chiefly ly 
the maxillary, which is long, while the anterior process of the jugal is much reluced. There is no pre-orlital fossa. The nares are terminal and lateral, well separated he the premaxillaries. The posterior temporal hridge is formed hy the squamosal and farietal. the hridge extending litterally orer the quadrate and enclosing a wide space hetween itself and the buttress-like expansion of the lateral oecipital bone. The space enclosed between this aripital luttress, the puadrate, and the pteryogd support uf the latter is likewise very large: it is of course the cavity of the mildle ear, and as such is crossed hy the columellar chain wf the ent. The infratemporal briclge or jugal arch is formed by the jugal. which joins the descending process of the squamosal, and lis the quadrato-jugal, which is small and finsed with the quadrate. The latter is consequently very firmly fixed.

The teeth are acroclont, ankylused in one series with the sulpurting lones, triangulat and much worn down in older specimens. Originally there seem to he several in the premaxilla, but the actult bite with the somewhat curved-down portions of the premaxillaries themselves, or with what remains of the fused lases of the original teeth, which then, together with the bone, look like one pair of large chisel-shaped incisors. The lateral edges of the palatines likewise carry teeth, those of the mandibles fit into the long slit-like space between the palatine and the maxillary teeth. Young specimens have a few small teeth on the voners, which are large, and separate the long choanae from each other. The pterygoids form an anterior symplyssis, posteriorly they rest um short processes of the basisphenoid and send short flanges to the quadrates.

The rertehral column is very primitive. The atlats is still typically temmospondylous. The first intercentrum or fused pair of hasirentrals is hoond and thick, and forms the rentral half of the atlas-ring, which articulates with the first centrum and with the second intercentrum. The irregularly shaped nemal arches remain separate from each other and from the centrum; they citrry on the dorsal sile a frair of discomected supradowals, the sorealleal poro-atlas. The second intercentrum is fused with the first and second aentrum. The second to ninth intercentrat have low median ridges or knobs, and are as a rule more firmly attacherl to the cranial ends of the centrat. Thues of the trunk are small. From the thirel or fourth candal vertehra 
backwards they appear as chevrons, articulating more with the vertebra in front than with the one behind. The bases of the right and left cherrons are frequently fused across. so that the caudal caual is completely surrounded" by bone, a feature common in Dinosaurs. Every intercentrum, be it a pair of chevrons, or an unpaired nodule, or crescent, extends dorsalwards into a fibrocartilaginous ring which surrounds the chorda. The centra of the vertebrae are deeply amphicoelous, the cavity being filled throughout life by the chorda; but the middle of the centra is solid. Most of the cautal vertebrae are transversely divicied into two parts, the posterior of which carries the greater share of the arches; they resemble in this respect those of lizards,

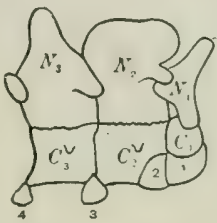

Fic. 60.-The first three cervical vertebrat of Splenutun. 1, 2, 3, 4. Intercentra : $\quad C_{1}^{\prime}-C_{0}$, eentra; $X_{1}-X_{3}$, neural arches. and the lost tail is likewise reproduced. The first three ribs are represented by bands of connective tissue. The first is attached to the side of the first intercentrum; the second arises from the second intercentrum, and forms a small tubercle on the side of the second centrum; the third behaves similarly. The vertebral arteries and lateral strands of the sympathetic nerve-chain pass through these double basal attachments of the reduced ribs. The other ribs are osseous; they possess short capitula which retain their partly intercentral attachment, while the short tubercula are carried by low processes of the centra, not of the neural arches. Already in the thoracic region both capitulum and tuberculum merge into one facet, at first dumb-bell shaperl, further towards the tail oval, gradually shifted backwards and dorsalwards upon the middle of the centrum, until the facet reaches and ultimately lies right across the neuro-central suture. The first few caudal vertebrae also possess ribs, which are however very short and fuse with the diapophyses, immediately below which lies the neuro-central suture.

The whole column consists of twenty-five presacral, two siccral, and about thirty caudal vertebrae. Some of the thoracic rils have cartilaginous uncinate processes. Three or four pairs of rulus join a typical sternum, into the antero-lateral portion of which are let in the coracoids. The stermum is raised into a low nuedian crest which fuses with the posterior branch of the 
T-shatper intercharicle. while the lateral handhes of the latter

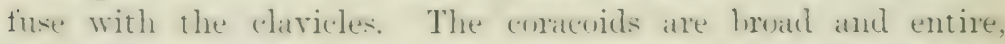
still without fenestrate or noteles indicative of precoracoirls. The pratsternum is very elalwate : it extends from the stermun (1) the puldie lunes and consists of alsut twenty-four transierse rows. anch of which is compused of a merlian and two lateral splint-lones. They are irreenlarly shated. partly with inluricatting lowhs. and are firmly attached to, in fact still comnecterl with, the derefer juntions of the cutaneous scrales of the helly. The three pairs of pelric bones are fused together at the

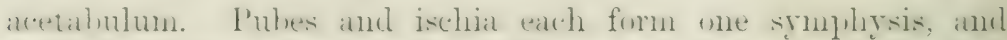
these are comnecterl with each other hy lartly ossitienl aartilage and ligunents, so that the original cordiform formene is divilenl into a pair of ovals. The lateral processes of the pulues are thick, but rery short. The ischia have postero-lateral foreseses. There is also a mustly cartilaginous, mpraired hypo-ischium.

The fore- and hind-limbs are still primitive in structure: luth prentarlactyle. The ampus ronsists of ten. sometimes eleven pieces, according to the single or doulde nature of the central elenent. The proximal series is formed ly the radiale, intermetlan, and ulnare, with a pisiform. The ulna and ralius remain selarate. The humerus has the usual ectepicondylar in allition (1) the entepicontylar formen common to all the l'rosandi and Theromorplat. The hind-limbs are typically plantigrade.

The tail is capable of regeneration, as in many lizards.

The development of this reptile has recently leen studied and described by Howes. ${ }^{1}$ who yotes the literature hearing upon the whole subject.

A groul accomnt of the occurrence and hahits of the ". Tuatera has been given ly Newnan." The Mauris call it "ruatara. "tuatete," or " thatala," the latter meaning "having spines." Formerly connmon on the main islands of Xew Zealand, they are now alparent ly restricted to some of the islets in the Bay of llentr.

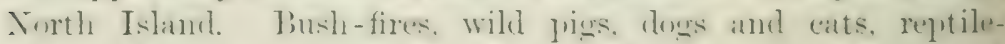
wating Manri tribes, and the andrance of eivilisation, hase swept them awaty exept on some of the small minhalited islands. difficult of acoess, where they dig hurrows, inter which they retreat at the slightest sign of danger. They sleep thang the

1 Trans. Zool. Soc, xv.

"Trans. N. Zcalanel Inst. x. 1S78, 1. 222. 
greater part of the day, are very fond of lying in the water, and they can remain below for hours without breathing. They live strictly upon animals, but these are only taken when alive and moving about. The kind of food seems to vary according to the custom or fancy of the indirichals. Sir W. L. Buller observed that some of his captives stubboruly refused to eat until (me day, rather accidentally, minnows were offered. Others eat insects and worms; those which live near the seashore not inprobably eat also crustaceans. From Norember to January they lay about ten eggs-white, hard-shelled, long aud oval-about - 8 1nm. long, in holes in the sand, where they can be warned by the sum. They are as a rule lazy in their movements. The usual pace is a slow crawl, the belly and tail trailing on the ground, but when chasing prey they lift the whole trunk off the ground. Atter ruming, or rather "wobbling" three or four rarls, they grow weary and stop. They cannot jump the smallest olsstacle.

Ton Haast ${ }^{1}$ has earefully examined their habitations on the Chicken Islands. The Tuatara excavates its own hole, and this is shared sociably ly various kinds of Petrels. The entrance to the chamber is generally $t$ or 5 inches in diameter, and the frassage leading into the inner chamber is 2 to 3 feet long, first descending and then ascending again. The chamber itself is one foot and a half long, by one foot wide and 6 inches high, lined with grass and leares. The petrel lives usually on the left side, the Tuatara on the right side of the inner chamber. Whilst rery tulerant of the bird with its egg and young, it does not allow another of its own kind to live in the same hole, which it is ready to defend by lying in such a manner that the leat is placed where the passage widens out into the chamber. On jutting one's hand or a stick into the burrow the Tuatara lites at them furiously. They can rum very fist, and defend themselves with great pluck against dog or man by biting or scratching. As soon as the sun has set they leave their holes to seek food. During the night, and especially during the pairing season, they croak or grunt.

The eggs, having been deposited during the Southern summer, frum November to .Tanuary or Februtry, in holes on a sumny and sandy spot, contain nearly ripe embryos in the following August. They are, however, not hatched until about thirteen ${ }^{1}$ Trans. N. Zeatand Inst. xiv. 1881, p. 276 : cf. also Reischek, opr. cit. xiv. p. $2 \overline{7}$. 
months old. In the meantime they seem to undergo a kind of aestivation. The nasal chambers become blocked with groliferating ephthelium. which is resorher shortly hefore hatching.

I have liept half-a-dozen specimens in a green-house for xereral years. and have come to the conchusion that they are

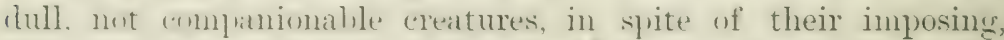
rather nolile aldeatrance when, with their heads erect, they alnoly lowk alwut with their large, quiet eyes. Each dug it. wwn hole in the hard gromel underneath and between large stones. At dusk they sat in front of the holes or walked leisurely to the pan with the earthworms which formed their principal fims. Meat they did not tonch, but they killed and chewed "1' lizards and hind-worms. Sometimes they soaked themselves fin many hours in the shatlow. Warm water. The skin is sherl in flakes. I never found them hasking in the sum, and the fineal ere, still so well develuped in these strange areatures. cansed them no distress when bright light was thrown mpm it. Ther grew tame enough not to run away when found maming alout at night, but they dis not like being handled, and they inflicted the most painful bites when taken up carelessly: The liggest, a male, wats rather quarrelsome, grunted much, and worried the others.

\section{SUB-CLASS III.THEROITORPHA.}

The Theromorphit comprise a great number of extratordinary, extince l'eptiles, which as a groul had a wide range in spacet and tine. The eadiest known aceur in the Lower Red Sandstone of Thuringia and Bohemia, and in the mistlle Permian strata of linssia. The majority have leeren found in strata transitimal hetween the I'erminal and the Triassic age, notahly in the Karros sandstone of sonth Afriea and in corresponding lerels of North Anerical. C'losely allied to them are those of the Triascic sindstone of Elgin in seotland, and of Indiat. They seenen to have dieel ont with the Muschelkalk or Mirllle I'rias.

The varions generat exhibit such a diversity of : tructure, shile. and size, and many are still so imperfectly honown, that 
any diagnosis is liahle to be faulty, eren assuning that they are a homogeneous groul. Fo avoid confusion, we chanaterise the

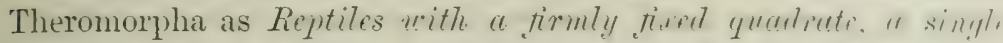
temporal arih, an interpurietel furamen, and " petris in "rhirh the pubes and ischia form one stout, ventral symphysis.

The dentition is most abnornal, and permits the division of the Theromorpha into two or three main groups. In the Pareiasauri the teeth of the upper and lower jaws form rather eren series of nearly equal size; smaller teeth are carrien hy the palatal bones. In the Theriodontia the teeth are differentiated in a truly Mammalian fashion into incisors, frominent canilies. and multicuspid or tubercular molars. Each tooth, and this applies to all Theromorpha, is implanted in a separate alveolus: Tritylutun only seems to have domble-rooted molars. The luwer canines cross in front of the upper, just as in Mammals. In Placolus, which probahly belongs to this assembly, the teeth are few in numbers, very hroad and flat, especially thuse of the palate. In Dicynorom and Gombunin the teeth are restricted to a pair of conical, sometimes rery large, tusk-like upler canines, and in Oudenodon the whole mouth is toothless.

The configuration of the shull shows two nain types. In the Pareiasauri it is completely roofed in by dermal hunes, the only holes on the surface being the nostrils, orloits, and the interparietal foramen.

The most striking feature of the second type of skull is the tendency to form an almost Mammalian zygomatic arch ly the junction of the much elongated squanosal with the jugal home, hoth abutting against a downwarl process of the postfrontal bone. The skull shows a pair of wide supratemporal foramina bordered by the parietals, squamosals, and postfrontals. The comprosition of the temporal arch varies considerably in cletail, and in cyurgnathus ciruterunutus at least there is a small hole within the arch, between the syuamosal and jugal, probably the last remmant of the otherwise absent infratemporal foranen. Except in the roofed-in skulls of Pareiasourus and Elginin there is no sej barate quadrato-jugal element. The quadrate is fimly fixed ly the orerlapping squamosal, and the whole pedicle for the suppout of the mandible is rather elongated, and either stands rertically ar slints forwards. The mandible itself is compound. The ittergoids extend backwards so as to approach or reach the 
distal portion of the fulluate; separate ectopteryogoids do not seem to he developeel. The shoulder-girdle consists on either sicte of a large scapulat, which is mostly directed ohliguely backwards, and is fused with the coracoid : a precoracoid is present or at least indicated hy a notch or foramen; it is usually fused with the other hones. At least some generat possess a T-shaperl inter-

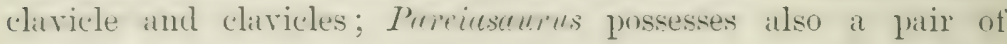
cleithra.

The pelvis is in every respect constructed upon the Mimmalian plan. The three constituent parts meet at the acetabulum, and the ventral bones, pulves and ischia, form one broid symplysis, leaving two, sometines rery small, olturator-foramina. The ilimu is attached to one to five sacral vertebrae, and since the whole pelvis slants ohliquely downwards and backwards, this sacral attachment is distinctly pre-acetabular, perhaps most markedly so in Dieynodon. The limbs are mostly stout, humerus and femur with strong crests; the feet are thoroughly plantigrade, with five fingers and toes. The details of the carpus and tarsus are not well enough known to permit of generalisation, but there is a tendency to form a heel, and to develop the cruro-tarsal joint into the chief joint of the hind feet. The rertebrae are amphicoelous, sometimes with rather thin-walled centra, so that in these cases the chorda was continuous. Intercentral weclges, (nr hasiventral elements, are frequent in the cervical and caudial regions. Most of the ribs, especially those of the neck, have it tuberculum attached to the neural arch, and a distinct capitulum which articulates either with the centrum or with the intercentrum, or lastly, if the latter is alsent, between two centra. The axis and atlas vertebrae are united.

The accipital comlyle exhibits every stage between the single merlian knob (Pereirsumps) formed almost entirely by the basioccipital hone, a triple condyle (Dicynodon) to which hoth lateral and the bisioceipital bones contribute, and at kidneyshaped or douhle condyle (cynugmuthus) from which the middle or basioccipital portion is more or less withdrawn.

Dermal bony armour reached an extratolinary development on the head of Parrisurms and Elginiu; whether other parts of the borly were protected is domlitful, hut the flattened topis of the nemal spines of Imoriusmores sugerest that they carried bony scutes. Andonninal protective ossifications are unknown. 
Many of the Theromorpha ${ }^{1}$ reached a considerable size, massive skulls of one foot in length being not uncommon. The tail was comparatively short.

The many resemblances of these strange creatures to Mimmals have naturally suggested that the Mammalia have sprung from some such Theromorpha or "beast-shaped" animals. The resemblances are chiefly the dentition, the zygomatic arch, the pelvis, the cruro-tarsal joint, the scapula which is sometimes possessed of a spine, and the occasionally double occipital condyle. The general shape of the skull of Cynognuthes is incleed strikingly like that of a Carnirorous Mammal, and the shape of the whole hody suggests rather a Mammal than a reptile: and when we have to deal with the fragmentary skulls of Trityludon (cf. 1). :309) it is, indeed, difficult to decide to which of the two classes such a creature belougs. But the Theromorpha possess a number of important characters by which they reveal themselves it once as reptiles: (1) the large and fixed quadrate bone, which is still the sole support of the lower jaw; $(\mathscr{2})$ the compound mantible, which is composed of at least an articular, dentary. angular, supra-angular, and splenial element; (3) the interparietal foramen; $(t)$ the possession of prefrontal and postfrontal hones, sometimes also postorbital, supratemporal, and quadrato-jugal bones. Of course, any of these ancestral hones may be lost, and the interparietal hole may be closed as in tortoises and crocodiles. We can also imagine that the quadrate may be relieved of its jaw-bearing function and become loosened, but this is not easy, considering the strong development of the squimoso-quadrate pedicle. Those Theromorpha in which the quadrate itself is small, whilst the squamosal reaches down, or at least approaches the mandible, as in Dicynoton and Gordoniu, are so hopelessly pledged, or specialised in other directions, that it is impossible to connect them ancestrally with Mammals.

Howerer, it is beyond reasonable question that the Mammals hare sprung from some reptilian stock (the attempts to derive

1 Cope, the inventor of this most appropriate name, soon changed it, unnecessarily, into Theromora ( $\mu \omega$ pós=sluggish), perhajes in order not to emphasise twe much their possible Mammalian aftinities; while others rashly called them Samm-Mammalia. For detailed illustrations of Theromorplat reference should he made to Owen, British Fossil Reptiles, 4to, London, 1849-55, and to numerous japers by Seeley, Phil. Trans. 178 (1887), 186 (1895), and by E. T. Newton in Phil. Truns. 184 (1893), 185 (1894). 
them from Amphibia, without the intervention of Reptiles, are as gratuitons as they have proved futile), and the Theromorhat umclouldedly comprise creatures which of all animals aplunach nearest to Minmmals, and coincide with them in most important features. But we have not yet found a single Theromorph which can claim to be a direct ancestor of Mammials. since the latter oceur alrearly in the Trias, we have to lonk for their reptilian forefathers at least in the Lower I'ermian, and this naturally excludes all the known forms. The filling up of this gap is but a question of time.

The ancestry of the Theromorpha themselves is also shroulecl in mystery. Attempts have been made to comnect

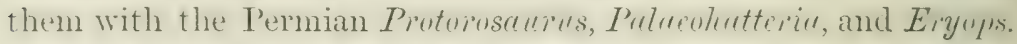
On the other hamd, some retain rarions Stegocephatous reminisrences (e\% the roofed-in condition of the skull by memlnanebones, anongst which, besicles others, supratemporals and posturbitals can be recogniserl; occurrence of cleithra in I'weirsun'ms; clistinct epiotic bones in Elyinion. Although they have died ont as a group, they have perhaps given rise to sereral side-hranches, one of which (leaving aside the question of Mammalian origin) seems to have flomrished as the Dinosamia.

We divide the Theromorpha into four orders, which are, howerer, liable to rum into each other, and it is reasonathy to be hoped that many forms may be discovered which will commect nut only these provisional orders with each other, but also with other sub-classes.

\section{Order I. PAREIASAURI.}

Cranimm completely roofed in by memblane-bones. The only forannina are the nostrils, orlits, and the interpariotal foramen. The terth alle comparatively small, and stand in even series in both jaws.

P'erierstentus, several speecies from the Karroo sandstone of sonth Africit. I'. luini wats an extremely clumsy brute, of most menth alpeatrance, standing betwenn 2 and :3 feet high, and mesume with the short tail nearly 8 feet in length. The skull is very massive, 1 is inches long and slightly broater, with a rugose, deeply pitted surface. The teeth are thickly enatnellel, serrated at the margin, with miny pointed cusjs: those 
of the romer, palatines, and pterygoids are recurved and arrangent in several longitudinal rows. There is a small incisive foramm in the premaxilla; the choanae lie within the pterygoids. The palate has a pair of large lateral vacuities. Between the stplitmosil and quadrate is a small forame'n, as in Brlentrin and splienulun. The nares are terminal, bordered behind by the nasals, and divided ly the premaxillaries. The occipital comlyle is a single knob, but the lateral oceipital hones also partake in its formation. The shoulder-girclle is strong. The scapular slants latkwards, is broad, and possesses a longitudinal spine, an almost exchsirely Mammalian character. The scapula, coracoid and precoricoid are fused together, and are united rentrally with those of the other side. There is a T-shaped interclavicle, a pair of clavicles, and a pair of slencler, long cleithra, which extend along the upper anterior margin of the scapulae. The humerus possesses enormous crests. The broad ilium is attacherl to two, or perhaps three, sacral ribs. The acetahulum is closecl. The pubes and ischia are united into one broad miass of hone, and the obturator-foramina seem to he just large enough to permit of the lassage of the nerre. Both fore-and hind-imbs are plantigrade and five-toed. The tibia articulates with one large bone, which is supposed to represent the mited astragalus and calcaneum, the latter being without an inclication of a liuminent heel, although there is a tendency to derelop the crurotarsal into the chief joint. The number of rertebrae amounts to eighteen presacrals, eight to ten of which are cervicals. There are two or three sacral and about twenty-four mostly shortened catulal rertebrae. The latter possess intercentral wedges and cherron-liones; wedges occur also between the cervical and some thoracic vertebrae. Some of the posterior cerrical rilis are ver'y peculiur-straight, broadened out, turned backwards, pitrtly overlitpled hy one another, and 18 inches long, recalling the first two ribs of the crocodiles. Sternum and abdominal ribs are unlinown.

Elyinim mirubilis.-The skull(Fig. 54, A, p. 2S0) - nothinge else is known-indicates one of the most remarkille reptiles hitherto found on this side of the Atlantic. It was discorered in the lied simnlstone of Elgin (Lower Triats). The skull reminds us in it. general shape and by its spikes and horns of the little Anerican Intanoir? lizard, Phrynosomm. The length of the cranimu is almut 6 inclies, the distance between the tips of the two lingest 
horns measures 9 inches. The teeth are small and resemble those of an Iymann in their shapre and finely serrated edges, indicating herlivorous hathits, hut there are also several rows of smaller teeth on the palate, the configuration of which is nut unlike that of Splenodon. The top and sides of the skull, "xcept the interparietal foranem, the orloits, and mostrils, are conpletely encised hy rugase, pitted, dermal bones, most of them with strange, horn-like sprikes. In the encatsentent of the temploral region can be discernerl a postfrontal, parietal and sillatnusil, a conically projecting epiotic, a pustorlital and supratfompral, a jugal and a qualrato-jugal, which latter almost (nmpletely covers the qualrate hone. The interparietal foramen lies fir forwals, ahnest on a level with the orlits. The nostrils are terminal. surromuled hy the shert natsals, the maxillaries and the premaxillaries, which latter divide them.

\section{Order II. THERIODONTIA.}

The cranium is not roofed in, but shows a pair of large smpratemporal fossae, hordered leelow hy the zygoma, which is formed mainly by the symanoso-jugal bridge, and is shut off firm the orlhit he the postfrontal joining the briche. The teeth are difterentiaterl into incisors, canines, and nolars (Fig. it, (', 1). 280). The lower canines close in front of the upper.

Cynognathus, Karroo formation of South Africa. C. craterountus hats at skull ahout 16 inches long, lonking like that of a ferocious Carnivore; there are four incisors, huge canines, and nine molins, the latter with serrated elges and anterior

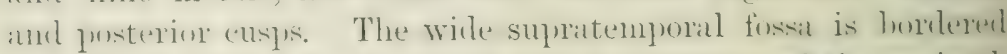
and chased hehind hy the hroad lateral extension of the parietal. which joins a similar extension of the squamosal bone. The latter is very long, extending to the postfrontal and to it lume. which, lumbering the orhit posteriorly, is either an upward branch of the jugal, or a postorbital bone; the latter inter-

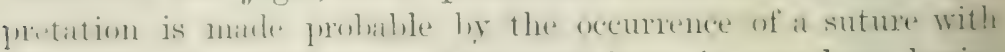

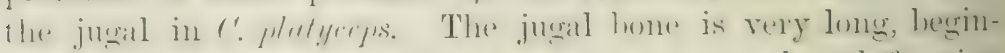

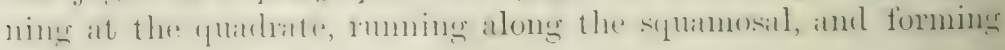
the lower border of the orbit.

The number of vertebrae is large, there being as many at 1wenty-nine presilctils, six of which helong to the cervical region. 
The atlas is fused with the axis: most of the thoracic rils articulate partly upon the intercentra. The lumbar ribs are rery peculiar; they are much expanderl horizontally, and orerlitp each other, forming thereby intercostal foramina. The linat ilium is attached to three or four sacral ribs. The acetilunlum is closed. The ventral side of the pelvis shows a broad symphysis and has a frair of obturator-foramina. The scapula is large, directed backwards, and shows a distinct, very Mammalinn spine; it is fused with the coracoid and precoracoid.

The occipital condyle of $C$ plotyreps is kidney-shayed, with the concavity directed upwards; in C. brryi it is seprarated into two distinet knobs, the middle, basioecipital portion being apparently wanting. The mandible prossesses a long coronoid process which ascends ohliquely into the temporal fossa.

Aclurosaurus, Lycosaurus, Galesaurus, and many others, likewise of the Karroo formation. In the first gems the splenial bones help to form the symphysis of the lower jaw ; teeth are also found on the palate, in opposition to Lyposenirs. This has a skull 6 inches in length; the dental formula on either side is $i . \frac{4}{3}, c . \frac{1}{1}, m . \frac{5}{5}$; the molars are slender, conical, and recurvect. Gulcsurus seems to have been rather small, the low, triangular shull measuring only 2 to 3 inches in length, with fom or fire sharply pointed incisors, prominent canines and four or five small multicuspic or deeply serrated little molars.

Encuthiodon, with several species from the Karroo formation, is of umcertain systematic position, only imperfect skulls being known. The animals nust have been large and bulky, the skiulls being very massive and at least one foot in length. The prenaxillaries and the maxillaries are toothless, their alveolar borlers forming cutting, prominent edges. The sime applies to the very strong lower jaw; but there is a pair of tooth-lilie stout projections in the upuer and lower jaws in the place of canine teeth. True, enamelled, small, aluarently conical or low and perhaps blunt teeth oceur on either sile in one or three longitudinal series upon the palate, and in corresponding positions wn the inner sicles of the two halres of the lower jaw. It is doubtful if the upper teeth are carried by the palatines or ly the hroadened inner flanges of the maxillaries. The choanae seem to lie between the pteryoicls and the palatines, incompletels rooled in hy rentral extensions of the latter towards the midale line. 


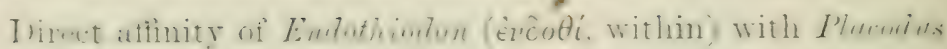

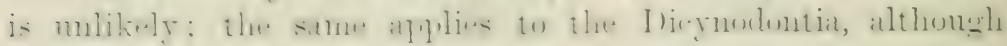
the restriction of the teeth to the palate seems to point as

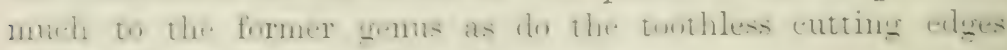
of the jaws to the forms like Oudenodon.

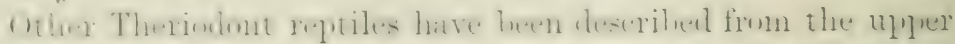

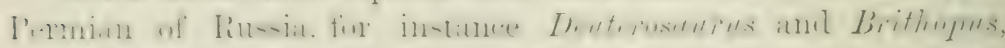

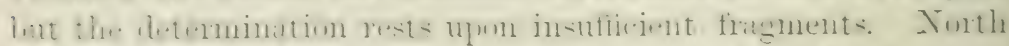

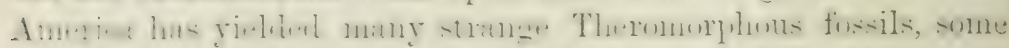

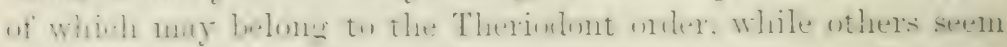

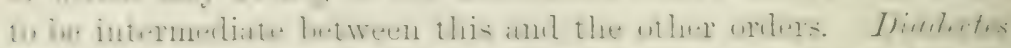

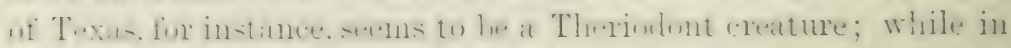

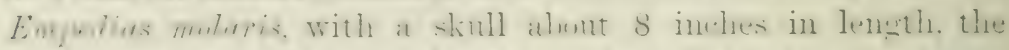

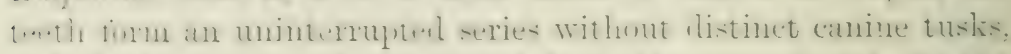

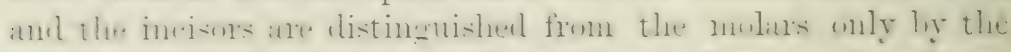

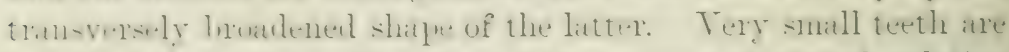

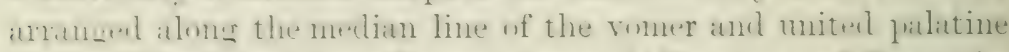

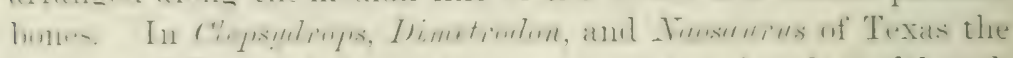

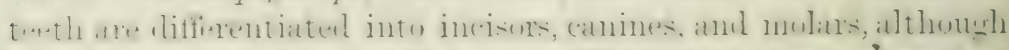
nut on remularly as in the tyluat Therimlunt forms described

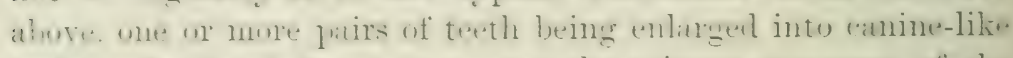
tuske. In the litter two genera the spimms poresese of the

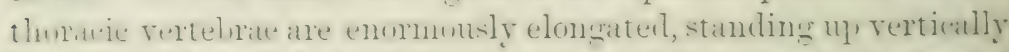

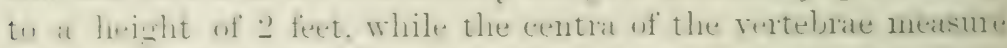

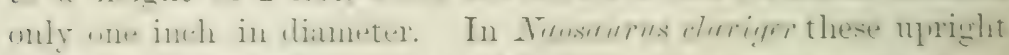

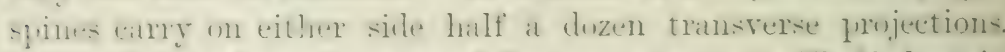

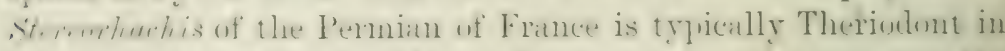

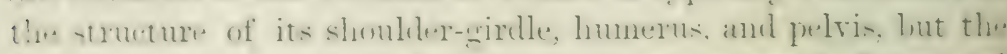

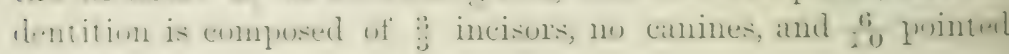
mulars.

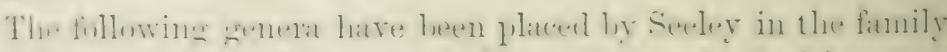

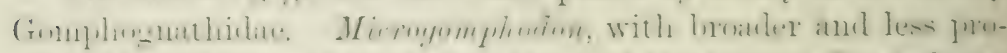

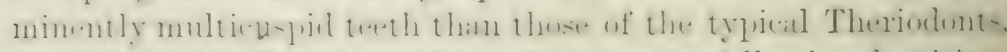

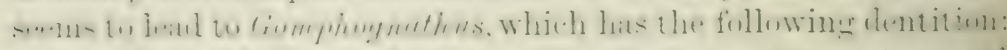
$\therefore 3, \cdots \frac{1}{1}, m \cdot \frac{1}{1} \frac{2}{2}$ with at long diatema between the canines and

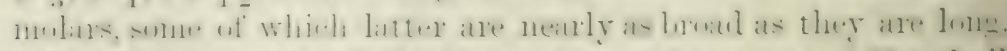

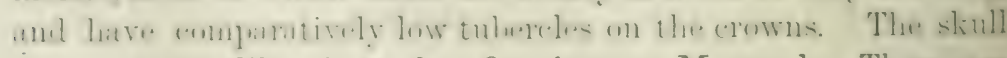
is remarkably like that of a Carnirorous Mammal. There are

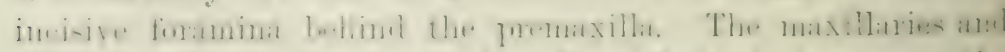

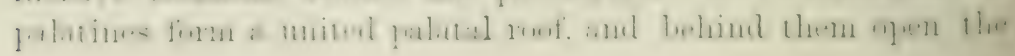


(homate. The occipital condyle is kidney-shaped. The mimrihle: is most extraordinary, approaching that of the Nammalinn, especially the Marsupial trpe, except that it is still (onupusent of sereral pieces. The articular facet for the mandible is mane l,y an outward or lateral projection, while the lulli of the posterior half of the jaw projects inwards like a loroul thange, muloubtedly recalling the so-called inner inverted angle of the Marsupial jaw. The coronoid process is large and extends fir into the temporal fossa. Nearly the whole sheleton of Mirrogompthodon is known; the lumbar rilss are broadened and overlap as in C'ynoynathus, and the mandilule is typically compound, so that there is no doubt ahout the affinities of this genus with the Theriodontia. It throws light upon frumplum!nuthus and the three likewise South African genera Dirdimulon, Trimerhiodon and Tritylodon, which are all known from imperfect skulls only. Their teeth are restricted to the jatws, the nular's have flat, multituberculax crowns and bear an extraordininy resemblance to those of Mammals. Some of the mulurs of Tritylurlun are said even to possess two ronts, but this point. "hisolutely unique in Teptiles, lut common in Mammals, is not certain. The few upper incisors of Trityloclon are rather lange, chist-shaped, and extend like those of the Torlent-type lack into the maxillaries; canines are absent, learing a cliastema.

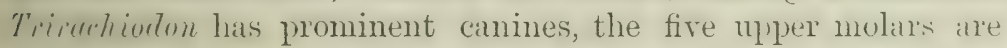
multitubercular, rather flat, and much broadex transversely than in the longitudinal direction. Still, even these creatures, with skulls of the size of that of a small fox, possessed distinct plefrmital and postfrontal bones, and are, at least in this respect. typical Reptiles.

\section{Order III. ANOMIODONTIA.}

The cranium is not roofed in. The pedicle for the suspension of the lower jaw is much elongated, slants slightly forwardi, and is complosed of the long quadrate, which is laterally overgrom ly the squanosal bone. The teeth are restricted to a pair of strong. tusk-like canines, or they are altogether absent. The mareins of the upper and especially those of the lower jaw ane trenchant, and were possilly furnished with a thich horuy armature like those of tortoises. 
Mirynutun, with many sprecies from the Kinroo formation of sumth Africa, reached formidible dimensions. The thick, curverl skinll is in size and ontline not unlike that of a large lion, hesnce

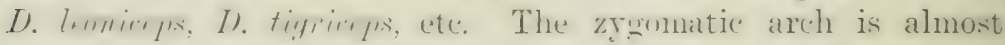
mammalian, except that the posterior lommlary of the orhit is formed hy a distinct justrontal hume. The nostrils are lateral. The canine tusks (Fig. 54, E, p. 280) are very large. The chanate open helind the rhombuid roner and hetween the separaterl palatine lunes, which are posteriorly confluent with the medially mited pteryonils. The latter send out flat extensions, alonge the lateral sicle of the palatines: these extensions reach the mitxillaries and probahly represent the ectopteryogids. The oceipital contyle is clistinn ty triple, heing entully composed of the basi- and latero-occipital bones.

The three bones of the shmuliler-girclle meet at the glenoid fissia ; the scapula has the indication of a spine. The pelvis is sisut, attacherl to four or ive rertebrae, converting the latter into a rery Mammalian-like sacrum, the jusition of which lies distinctly in front of the acetahulum. The latter is closed, annlmsed by the three pelvic bones. The pubes and ischia are fused togethex, learing only a rery small ohturator-foramen. The linhs are liluntigrate and pentallactyle, very stout; the humerus and femur have enormous crests.

Imblomlun, of which several species have been described, is so much like Dirymomlon, exceph for the complete alisence of teeth. that it has been sugresterl that these skulls belong to females of this genns. This rim is strengthenerl lig the fact that tusklike connines exist. or are alsent in sone of the sprecies which

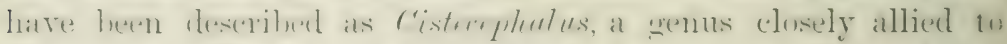

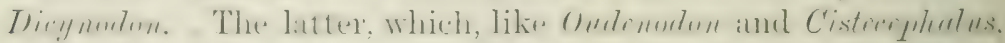

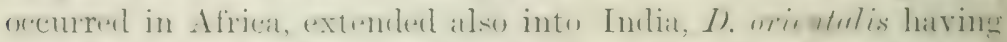
been fommel in the l'anchet formation of liengal, of transitional

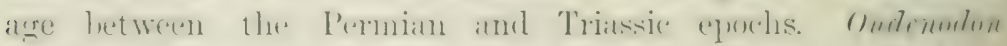

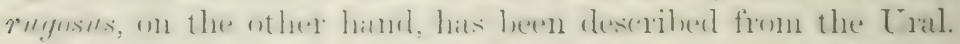

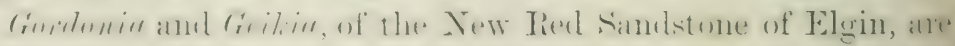
known from their skulls only. lut these are so well preserved that there is me dould almut their elese relationshipe to the

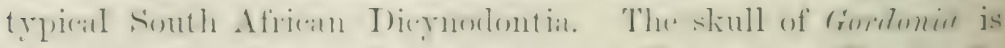

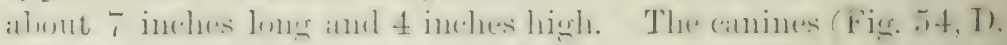

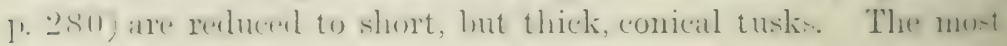


remarkable feature is the rery elongated squanoso-jugal arch, which arises moreorer from the dorsil end of the long squamoso-qumliate pedicle. The two wide and long temporal fossae are dorsally divided by narrow parietal crests. There is a distinct interparietal hone, and the usual interparietal formen. The chomate are united and lie within the palatines, which themselves are uniterl; the large lateral palatal foramina are otherwise enclosed liy the pterrgoids; quadrates, and laterally by the squamoso-jugal arch.

\section{Order IV. PLACODONTIA.}

These are the latest and last members of the Theromorpha. unfortunately known from skulls only, from the Muschelkalk w Middle Trias of (remmany and Russia. The skull of Plaroulus gigas is about one foot long, rather high and triangular owing to the lateral expansion of the temporal arches, which diverge posteriorly. The squamoso-jugal arch is very broad, and most of the posterior border of the orbit is formed ly the large postorlitil hone. The maxillary bone seems to extend back to beyond the level of the orbits. The choanae lie behind the premaxillaries. The palatines and pterygoids are fused in the midelle line, forming a broad hony palate, which, owing to the hroad. posteriorly extended wings of the pterygoids, much resembles that of the crocodiles. The tecth are rery remarkalile. There are two or three stout, conical, or chisel-like teeth in each premaxillary bone, and three to five lroad and flat maxillary teeth: three pairs of liuge, broad, and guite flat teeth are crowded together and fill up the whole romerine and palatine portion of the palate. These crushing teeth indicate that Placomis probahlylived upon hard-shelled molluses, and this would he in conformity with its occurrence in the Muschelkalk, which is a strictly marine deposit and full of shells. Another closely allied genus is C'yurimmlus, one species of which is known from Russia. The terth are fewer in number and not so large as those of Plucoulis. 


\title{
CHAPTER IX
}

\author{
CHELONIA - ATHECAE-THECOPHORA
}

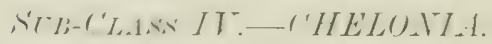

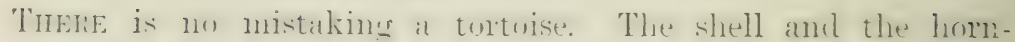

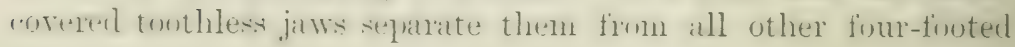
creatures.

They may he descrilest as terextrial or aymatic, gentadactyle lentiles, with walking limls or with paldles: rils with capitulat lurtions only, two sacral rertelsate, humerus with entepiconrlylar

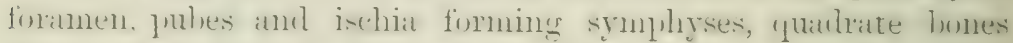
fixed, jaws without weth. hut with rotting homeg sheaths.

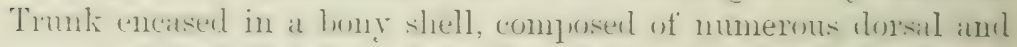

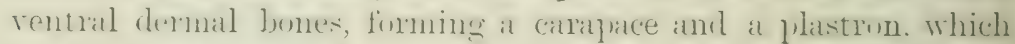
maty or maty met lee coremel with horny shielils. (') pulatory

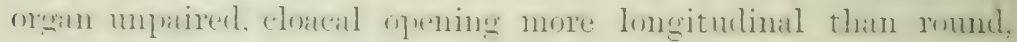
never transverse. Oviparous.

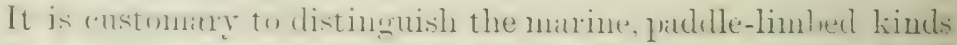
as I'urtles, the others as Land-and Water-tortoises.

'Tortoises oceur already in the Trias. They reached their.

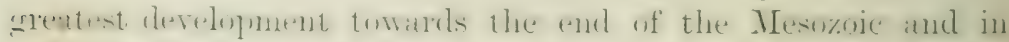
the earlier Tertiary periods. They are now comparatively reduced in the number of families and genera, although thry are still represented by about 200 speeies. The sub-class as a

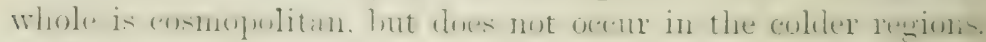

Their origin is quite unknown. Of recent groups only 1 he

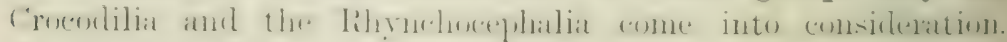
Combination of these groups with the Chelonia lends to smm. mnknown forms whence also the Theromorpha have arisin.

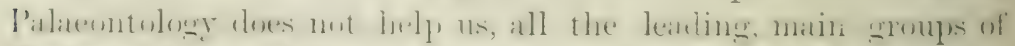

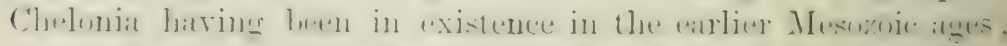


ancl Palaeozoic Chelonia are still unknown. The cinn, hnteres. to a certain extent, reconstruct an ideal primordial Chelonian by assigning to it all the ancestral characters actually 13 -inctent in recent and fossil kinds, and by reducing to simplex comlitions those features which we know to be more or less exagrelated specialisations. It is reasonable to assume that originally each metimere, except those of the anterior half of the neck and the josterior half of the tail, carried a transterse series of itermal plites, covered with horny shields, while the trumk, acoroling to the greater bulk of the body, increased in size, converging toward; the root of the neck and tail. By concentration, resluction of the number, and increase in the size of some of the remaining pliates and shields, the skull assumed its characteristic hox-like shalpe, the neck and tail hecoming at the same time free. Chelnnia are without dount descendants of terrestrial, or at least stulianuatic reptiles, and the marine paddled forms sulsesuently developed from terrestrial kinds.

Classification of Chelonia.-After many vicissitules it was recomised that the Chelonia cunnot naturally he diviled arcurling to the modification of their feet. The Thosirnomes Were clearly separated from the rest hy stannius in 18 it. Cope, in 1870 , was the first to emphasise the important chatrater of the mole in which the neck is either bent sick wank.s. (I'LELIODIL ) or withdrawn in an S-shaped curve in at rertical

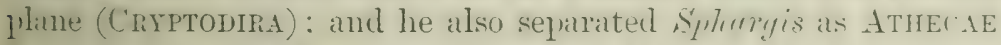
fwn all the other Chelonians, for which Dollo in 18.86 propiosed the term Thecopiona. The division of the latter into reconnisible families, based upon reliable, chietly inter'nal. skeletial. characters, has been effected by Boulenger' ${ }^{1}$ and his classitication has been adopted in the present rolume, after intercalittion of the more important fossil forms. The relationships between these various families may perhaps be indicated as follows:-

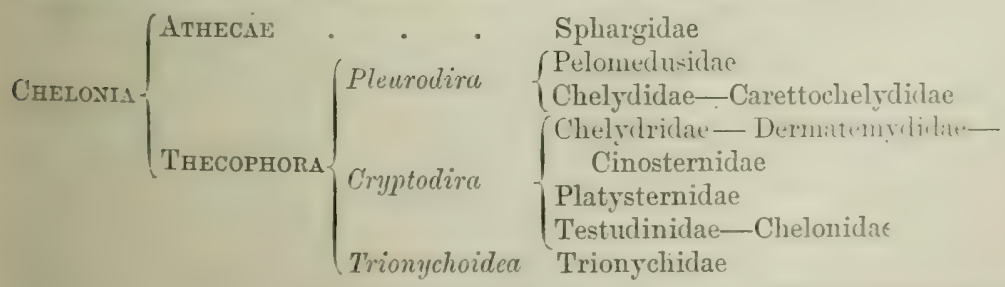

${ }^{1}$ Cat. Chelonians, Brit. MLus. 1889. 
The guiding taxomomic characters are fully mentioned at the hearl of the different fanilies, and are mostly intermal. The following " lexp." adapterl from Boulenger, and based unon exterinal charaters is preferable for practical purposes.

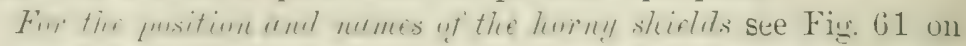
p. 315 .

Shell corered with horny shields

Digits distinct, with 5 or 4 claws.

- Pectoral shields separated from the marginals by inframarginals.

Tail long and crested. Plastron small and cruciform. North America . . Chelydridae, p. 338. Tail long, covered with rings of shields.

Plastron large. Indo-China Platysternidae, p. 345.

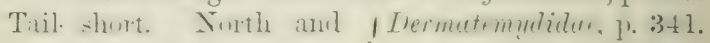
Central America - Cinosternidae, p. 342.

Pectoral shields in contact with the marginals.

Plastmal shiehd 11 or l:, without an intergular.

Neck retractile in an S-shaped

rertical curve . . Testudinidae, 1). 345.

Plastral shields 13, an intergular being present.

Neck bending sideways under (Chelydidae, p. 399. the shell

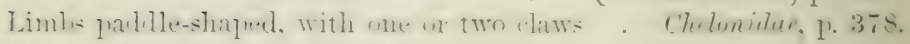
Shell without horny shields, corered with soft, leathery skin.

Digits distinct, broadly webbed, but with only

three claws

Trionychoidea, p. 404 .

Limbs paddle-sliaped.

Shell composed of regular series of

bony plates. Two claws . Carettochelydidae, p. 404.

Shell composed of very many small plates arranged lik. mosaic. No claws . . Sphargidae, p. 333.

The vertebrae are, sumetines in the various regions of the

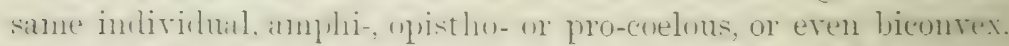

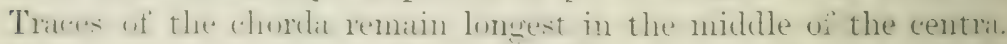

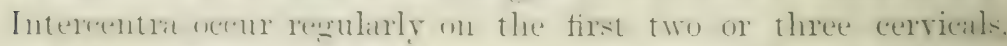

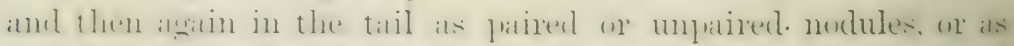
short chevrons. The latter occasionally fuse with the calmlu!

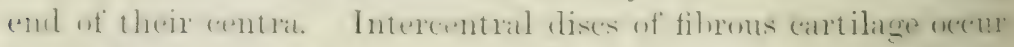
regularly in the neck and tail. The ribs develop originally in the same transverse level with these dises, and frequently the anterion thoracie vertelnate retain this intereentral or intervertehral gwsitim throughout life. Farther hatek they often show a graulual change from the intercentral to a more central and ultinately 
remarkable to a purely neural attachment. In all the Chelonia the ribs are devoid of the tubercular portion.

The cervical vertebrae have no ribs, except mere traces in the shape of small nodules. On the tail the ribs are often large, and, when fused with their neural supports, look like transverse processes; the whole arrangement exactly resembles that of Crocodilia. The first pair of thoracic ribs, those borne loy the

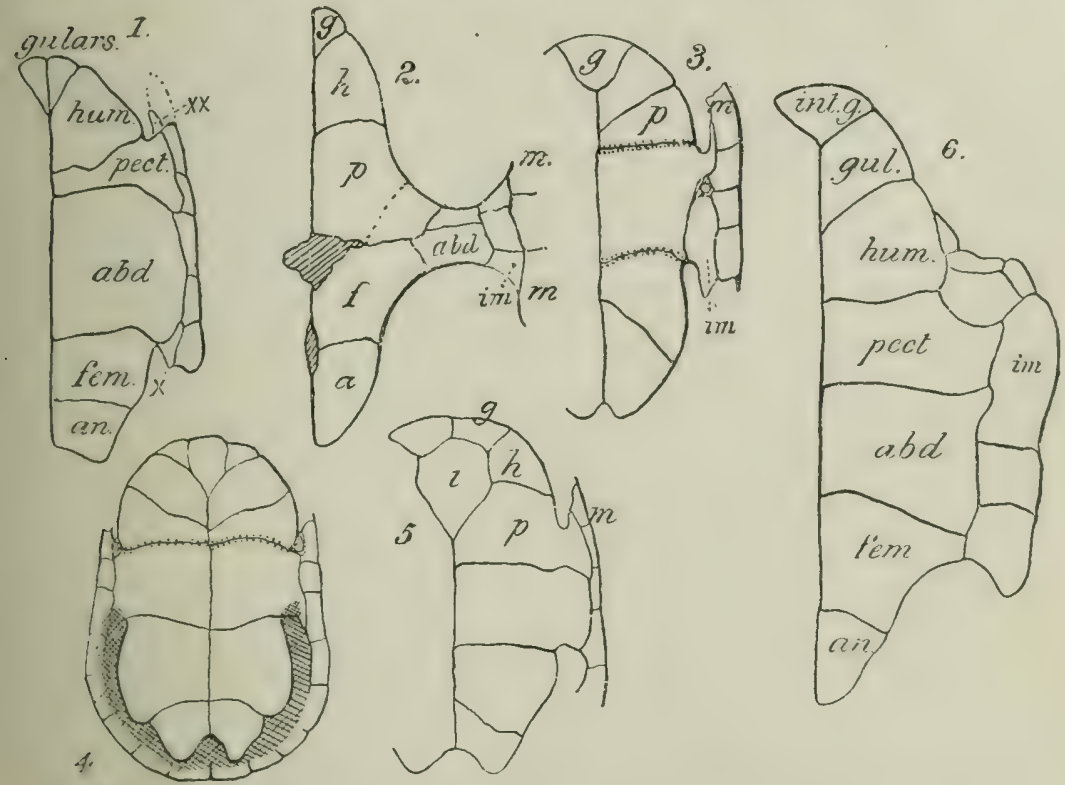

Fig, 61.-Various plastra and their horny shields. 1, Testudo iberce; 2, Macroclemmys temmincki; 3, Cinosternum odoratum; 4, Stemothaerus nigricans; 5 , Chelodina longicollis; 6 , Chelone mydas. a or an, Anal shield; $a b d$, abdominal shield; $f$ or $f e m$, femoral ; $g$ or gul, gular, unpaired in Fig. $3 ; h$ or $h u m$, humeral shield ; $i$ or int.g, intergular ; $i m$, infra-marginals ; $m$, marginals ; $p$ or pect, pectoral ; $x$, in Fig. 1 , inguinal shield constituting, with the axillary $x x$, the last trace of inframarginals.

ninth vertebra, are peculiar. They arise from the anterior portion of the centrum, are much reduced, sometimes to mere theads of bone, and lean against the anterior rim of the second pair of rils, in many cases without reaching the carapace. The next following ribs, those of the tenth to the sixteenth vertebra, are intimately involved in the formation of the first to serenth costal plates. The rils of the two sacral vertebrae sometimes l'main quite distinct throughout life, just touching the uprer 
ends of the iliac lones: : hut since these find a much more effective silngult in the shell, the distal encls of the sacral vertelsate fure with the eighth, or sircalled last. piar of costal plates.

The neural arch of the ninth rertebra rests upon its centrums but the nemral arches of the other trunk-rertebrate.

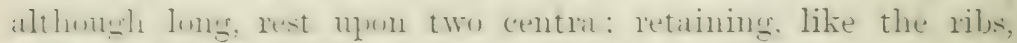
their original intereentral pusitinn; and in most cases the nemorentral sutures remain thrombont life. The atlas and the lat cervical vertehat deserve special attention. In many

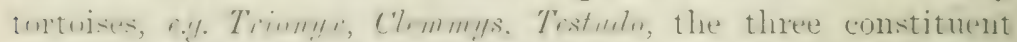
fiats of the atlits: namely, the nemal atch, the centrum, and the interentrum or first pair of united basirentralia, dn not ankyluse lut remain lowely comnected: and the first eentrum. insteml of fomming an orlontoid process remains movalily attateded to the second centrun, although it sometinnes carries, and fuses with, the second intercentral piece. In other tortoises, e.g.

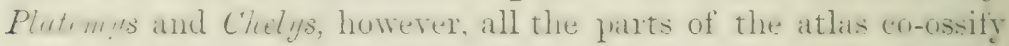
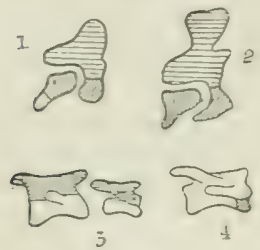

FIG, 62,-1, The complete athe of at aluit Tinu hurum. The second basi-

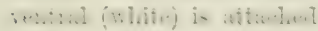
to the posterior end of the first centrum, which, not being fused with the second rentrum. is mot ret an

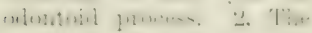
complete atlas of an alult

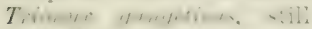

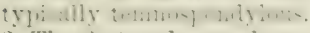
3 , The first and second cer-

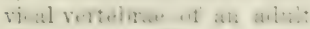

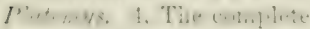
atlas of a Chelys finbriate. and form a complete, solid vertebra which articulates by a concaro-convex joint with the centrum of the second vertelir:. The normal number of cerrical rertebrae is eight in all Chelonians. The tirst ininal nerve issmes letween oceiput and atlas. all the others hehind the neural arches nit their vertehrae. The last, or eighth cervical, owing to the retractility of the neck, forms elaborate joints; its centre fits with a knob into a cup of the ninth, and its post-zrgapophyses form broad. curved articulating concatre fiacets for the recteptien of the anterior greatrongyes of the fixed uinth vertebra. In the Triongelistare

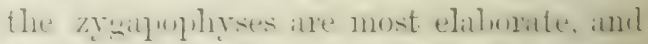
they alune articulıte with the ninth r...'tebra, while the centra do not join, but

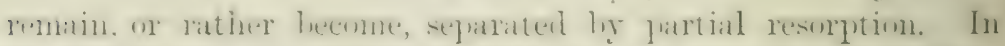

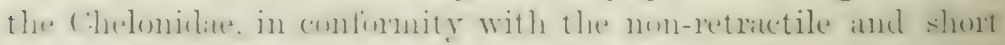
neck, all the cervical joints are much reduced.

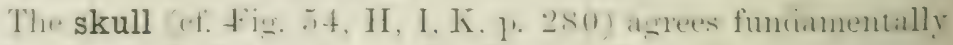

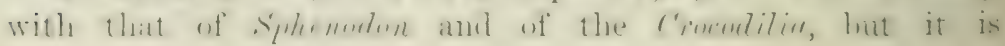


characterised by several special features. There are no ectnpterygoids or ossa transversa; no lacrymal hones, no interparietal or pineal formen; the romer is mpaired and the nasal hones are mostly alsent, unless they are fused with the prefrontals. The premaxillae are very small. The single romert forms a septum between the choanae; and these are, except in Sphuryis, ventrally roofed over lyy wings sent out by the palatines. The latter form a continuous bony roof to the mouth with the iterryoids, and these diverge.posteriorly, being connected suturally with the quadrates, lateral and basi-occipital bones, and with the umpaired basi-sphenoid, which appears between the basi-

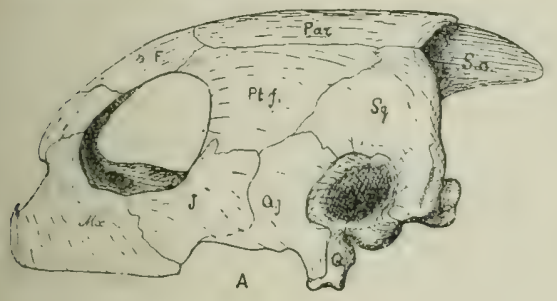

Fig. 63.-Skull of Chelone myclas. A, from the left side; in $\mathbf{B}$, the postfrontal and squamosal bones have been removed, and the broad expansions of the jugal, quadratojugal, parietal, and quadrate bones have been reduced in order to reduce the skull to more primitive conditions. $F$, Frontal ; $J$, jugal ; L.o, lateral occipital ; $M x$, maxillary ; Op, opisthotic; $P$ al, palatine; Par, parietal ; Prf, prefrontal; Pro, pro-otic ; Pt.f, postfrontal ; $P t g$, pterygoid ; Q, quadrate ; $Q j$, quadrato-jugal ; S.o, supra-occi-

pital ; $S q$, squamosal.

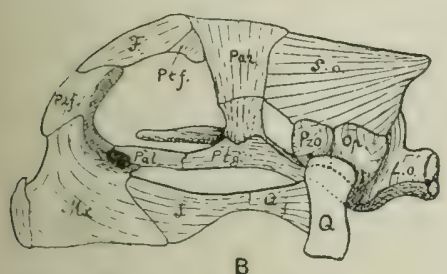

occipital and the diverging pterygoids, but is in most cases to a sreat extent overlapped ly the latter. The occipital condyle is distinctly triple; the basi-occipital sometimes helps to horler the firamen magnum. The supra-occipital sends out a long rertical bate, directed backwards and generally projecting far over the neck, for the attachment of the powerful cranio-cervical muscles. Thie quadrate is rery peculiar. Firnly attached, and hemmed in on nearly all sides by the neighbouring bones, it stands nearly vertically and forms a broad articulating surface for the mandihle. Its posterior side shows either a transverse, horizontal grouve, in which lies the columella auris, or the groove is transformed into it mue or less closed canal. Moreover, the hinder lateral mirgin "ff the ymadrate forms most of the tympanic frame; its margins beinge curved backwards, leaving in the Cryptodira, howerer, is 
wide notch behind; in the P'leurodira this gart of the putulate is transformed into a trmmet, the wille rim of which, forming a connlete ring, arries the tympanic memlinue. The tympanic cavity thus formerl often learls into a de+le recess which exteurls beneath the splanmosal towards the opisthotic and hears some resemblance to the intricate tympraic recesses which pervale that region of the Crocodilian shull.

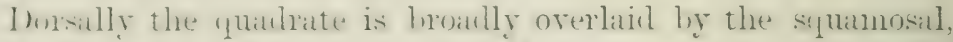
which fresuently forms an arch with the parietal. Anteriorly

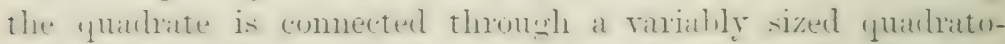
jugal with the jugal ; and this, ly joining the maxilla and postfromtal. helps normally to form the josterior rim of the orlit. All the lones which border the temporal fossat vary much in extent in the alfferent wroups of Chelonit. The extremes are

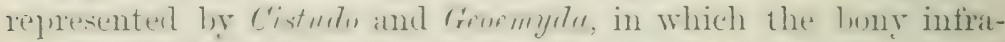
temperal arreh is alsent, owing to the loss of the quadrato-jugal; and on the other hamel by the Chelonidae amd hy sthorigis, in which the whole temporial resion is covered over by an arlditional "fitse crimial" roof. This rouf is produced chietly by liateral wing-like expansions of the parietal and pustfrontal lones, which neet the likewise much expranted jugal, puindrato-jugal,

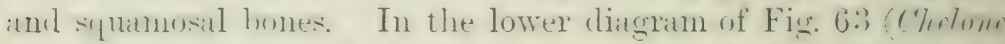

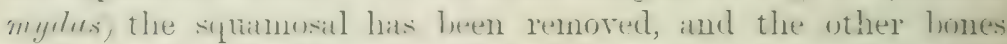
latre been resheed to their numul, or rather primitive conditions, firr eomprarion with the external riew of the complete skull of the sinne aninnal. The lower diagram shows also the comnexion of the ptergonid with a dexcementing process of the parietal ; this columu, paired of contrese, nsilally contains a separate bone, the epipterygoid, the portion between Ptg and Par.

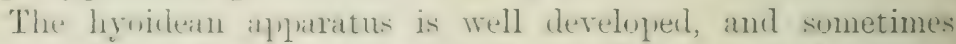

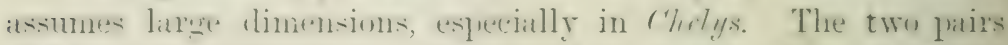
of "horns" ane the first and secend branchial arches. whilst the

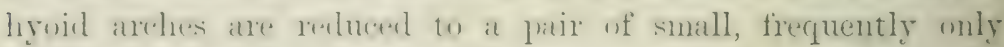

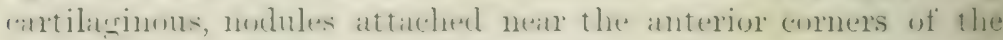

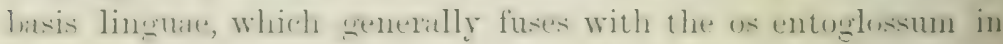
the tip of the tongue.

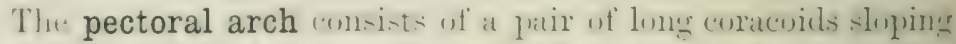

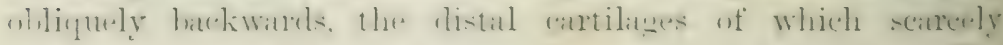
touch each other in the middle line, and the scapulae. Th. mitner and of the seapulat fropuenty tomethes the inside of the 
first costal plate, protected by a cartilaginous part. Titir the glenoid cavity arises a long process (PC in Fig. 65), plicced transversely and approaching its fellow. The distal end is connected with that of the coracoid by a fibro-cartilaginous hancl. The homology of this scapular process is not quite clear. The hand just mentioned farours the idea that the process represents the precoracoid, but its being an outgrowth from the scapulia suggests that it is merely the much enlarged acromion. It certainly does not represent the clavicle, which forms part of the plastron: and this is net in contact with the shoulder-girdle at all.

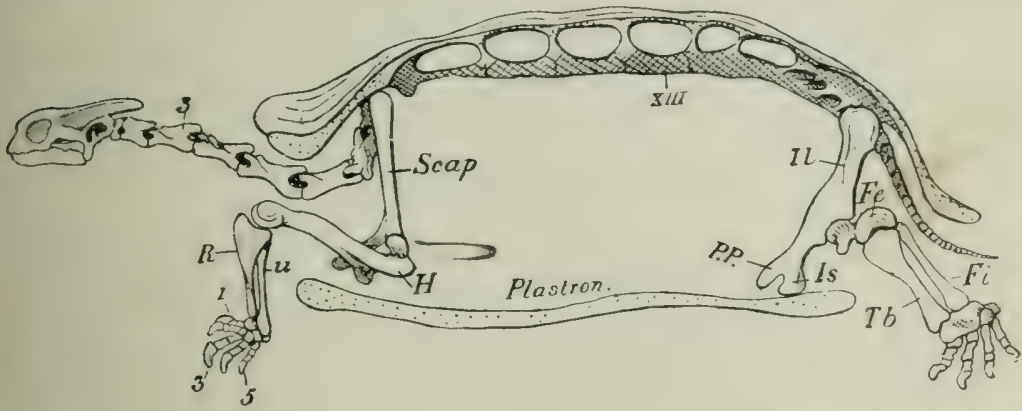

FiG. 64.-Diagram of the skeleton of Testudo elephantopus, after removal of the left half of the carapace. The plastron is roughly indicated by a section through the middle line. $F$, Femur, foreshortened ; $F i$, fibula ; $H$, humerus ; $I l$, ilium; $I s$, ischium ; $P . P$., pubis ; $R$, radius ; $\boldsymbol{S c a p}$, scapula ; $\boldsymbol{T} b$, tibia ; $\iota$, ulna ; 3 , third cervical vertebra; $1,3,5$, first, third, and fifth fingers ; $x I I$, thirteenth (fifth thoracic) vertebra.

The pelvis is strong. Ilium, pubis, and ischium meet at the acetabulum. The dorsal end of the ilium is generally hroadencil, and is attached to one or both sacral rertebrae, but it is also in contact with the superimposed last costal plate. This additimal comexion often becomes predominant and the sacral verteline are partly or completely relieved of the iliac surnort, fusing in this case more or less with the costal plates. The pules have strong lateral processes, directed obliquely formarts and downwards. The pulses and the ischia, which latter are much smaller, form lroad symphyses, and these are comnected with each other hy a longitudinal cartilaginous hand irhelone, Triony, ; or the commecting bridge is broad and yuite ossified "Trstur(1i), forming in the latter case two roundish obturatorfirmunil. Cartilage frequently remains at the anterion end of 


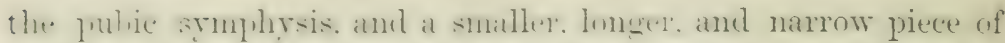

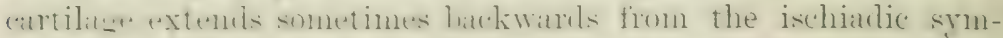

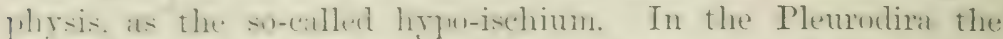
emols of the iliat. and these of the lateral processes of the pubes. are mulh Bmonlement and timly ankylused with the posterior costal plates and with the xiphiplastron respectively.

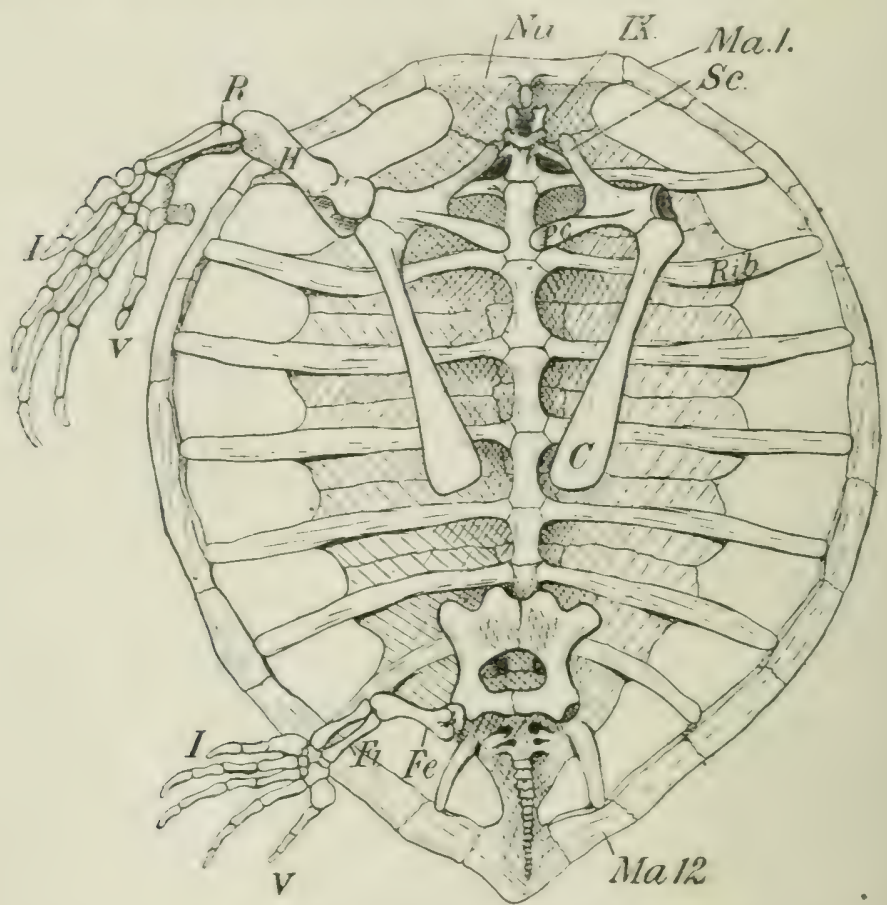

FIG. 65. - Ventral riew of the bony shell of Chclone mydas, the Green Turtle, after removal of the plastron (Fig. 66). The costal plates are marked by cross lines to distinguish them from the ribs. $C$, coracoid ; $F$ e, fenur; $F$, fibula ; $I I$, humerus :

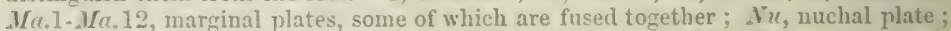
$P C$, "precoracoill"; $l$, radius ; $S c$, senpula ; $1, r$, first and fifth digits ; $I X$, Ninth vertebra or first thoracic.

The limbs are trpically pentadactyle and complete, and are

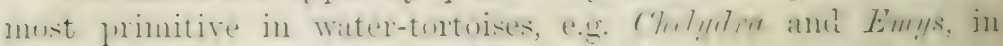

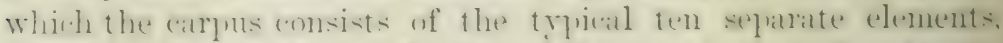
includine the pisifurue. In Testudn the centrale is fused with the intermentium. and the first three distal carpals are also fused

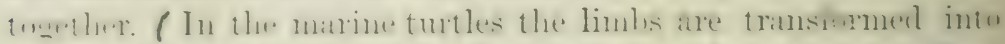

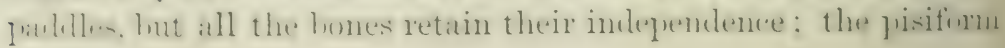


and the first metacarpal are enlarged and flattened, thereby giving additional width to the paddle. The tarsus remains less primitive; the centrale and the proximal elements have a tendency to fuse together, most completely in land-tortoises; the fifth distal carpal is enlarged, and stands out hook-like from the rest. The number of the phalanges of the fingers and toes varies slightly. It is noteworthy that none of the Chelonia possess more than three phalanges. The three middle fingers and toes have mostly three phalanges; the pollex and hallux have always two; the number of phalanges of the fifth finger varies from three to one, of the fifth toe from two to none. The greatest reduction occurs in Testudo and its allied genera of typical land-tortoises, Humupus, Pyxis, and Cirixys, the formulir for the fingers being $2,2,2,2,2$ or 1 , and $2,2,2,2,0$

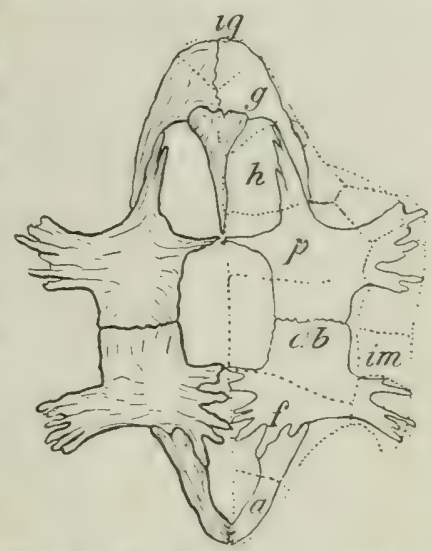

FIG. 66. - The hones composing the plastron of Chelune imydes. On the right sile the position of the covering horny shields ${ }^{1}$ is indicated by dotted lines. a, Anal horny shield; $a b$, aldominal ; $f$, femoral ; $g$, gular ; $h$, humeral ; ig, intergular ; im, infra-marginals ; $p$, pectoral.

for the toes. In Pelomedusc all the fingrers possess two phalanges only; owing to fusion of the first and second phalanges with each other.

The shell, which is the most characteristic feature of the Chelonia, consists of the dorsal "carapace" and the ventral "liastron." Each is composed of a considerable number of bony plates which arise as ossifications of nearly the whole thickness of the cutis, only a thin layer of subcutaneous connective tissue remaining soft and lining the inside of the shell. We restrict ourselves to a description of the shell of the Thecophora, leaving the discussion of the peculiar shell of Sphaigis to p. $336 \mathrm{f}$. Tery yumb turtoises are still soft, and the plates which are beginning to assify are not yet suturally united. The plastron (Figs. 66 and 67 ) comsists of the paired epj-, hyo-, hypo-, and xiphi-plastral pliten, and the umpaired endo-plastral plate. The latter is homo-

"It shroild be noterl that the horny pieces of the carapace are termed "shields" and the bony pieces "plates."

VOL. VIII 
longus with the interclaricle, the epi-plastra are homologous with the clavicles of other Refites, while the other pieces are genetically derived from, and are further modifications of. the su-called almbminal rils of the Crocudilia and I'rosamia. These plastral plates are nerer in cirect contact with the
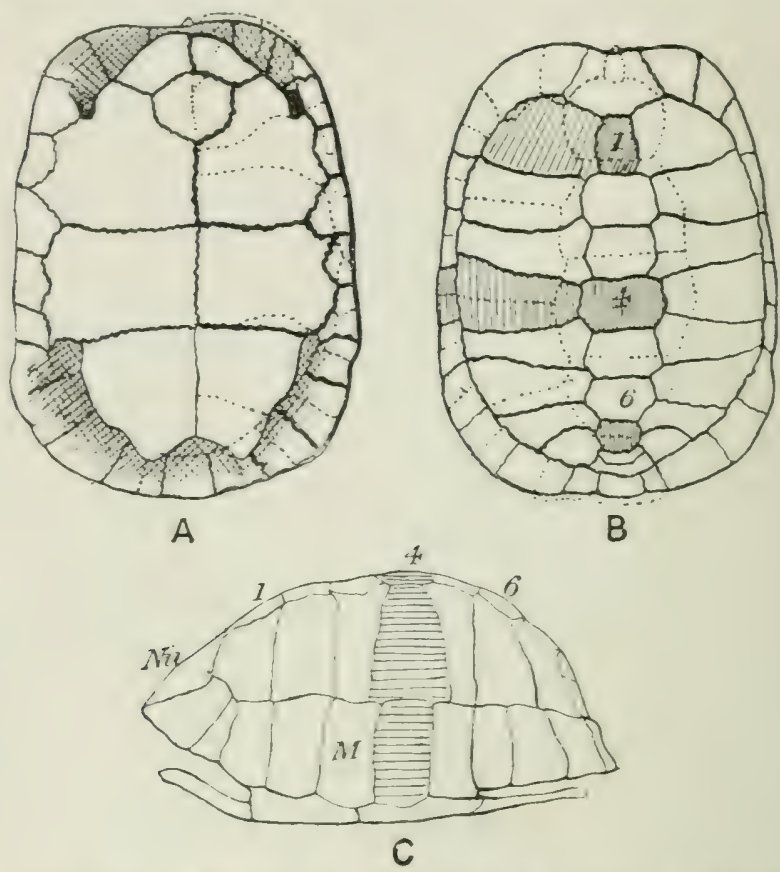

FIG. 67.-Bony shell of Tizturtio itrin. A, Ventral: B, Inrsal; C, left-sile riew. In $B$, and on the right half of $A$, the position of the horny shields is indicated by dotted lines. The underlying bony plates are marked by strong lines. Iq $\mathbf{B}$ the Ist weurial aud costal plates, the 4 th neural. costal, and 6th marciual liates, am? the 7 th neural plate are shaded. $1,4,6$, First, fourth, and sixth neural plate; $\boldsymbol{M}$, in $\mathbf{C}$, fifth left marginal plate; $N u$, nuchal plate.

shoulder-girdle or with any other parts of the internal skeleton. In the young of all tortoises, and in the adult of the Chelonidite and Trionychiclate, the several plastral plates enclose litro. imesularly-shated fontanelles. These are more or less filled uy in the other gromps; and in the Testudinidae especially the whole plastron forms one continuous mass. The navel is sitnated hetween the hyo- and hypo-plastrals. Both these pairs are bruader than the others, and are connected with the caralate liy 
means of several marginals. The comnecting region is called the bridge. In several tortoises, e.g. Emys, the connexion with the marginals is formed by ligaments only and remains movalile. In others, transverse, more or less perfect hinges are formel across the plastron. A rather imperfect joint between the hypo- and xiphi-plastrals develops with age in Testudo ibrre. In c'istudo and Cyclemys a very effective hinge lies below the hyo- and hypo-plastrals, just in front of the bridge; and the anterior and posterior lobes of the plastron can be closed
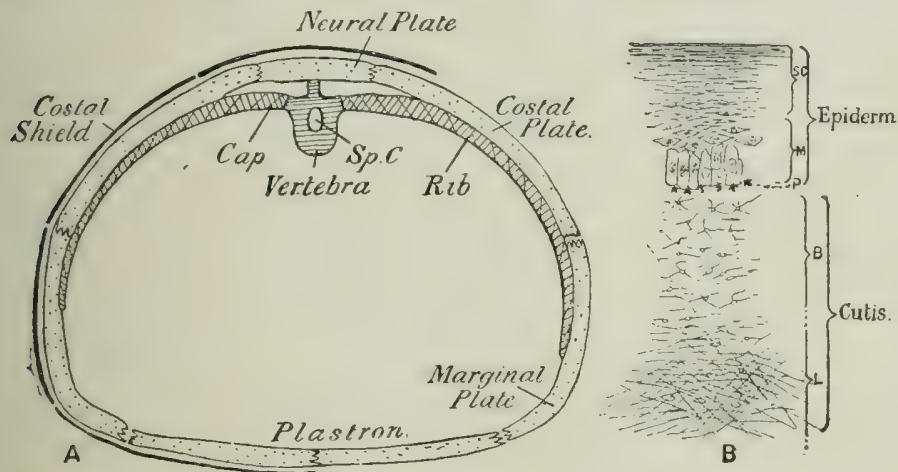

FIG. 68. -A, Diagrammatic transverse section through the shell of Testudo, On the right side the horny shields have been removed, on the left are shown the neural, costal, marginal, and pectoral shields. The bony dermal plates are dotted. Cap, Capitular portion of rib ; Sp.C, position of spinal cord. B, Vertical section through part of the shell, magnified and diagrammatic. B, Bony layer of the cutis; L, leathery layer of the cutis ; $\mathbf{M}$, cells of the Malpighian layer ; $\mathbf{P}$, star-shaped pigment-cells; sc, stratum corneum, composing the horny shields.

against the inner rim of the box, fitting tightly in Cistudo. In Pyxis the front lobe only is movable.

The carapace is composed of one median series, a right and left lateral series of costal plates, and a series of marginals which surround the whole. The median series consists of one large nuchal pliate, normally eight neurals and one to three supracaudal plates. The characteristic feature of the neural plates is that they are firmly fused with the broadened neural spinous processes of the underlying vertebrae. The nuchal plate lies in frout of the first thoracic or ninth vertebra; it overlies the last cervical vertebrae, with the eighth of which it is connected by ligament only; lut the posterior corner of the plate often fuses with the spine of the ninth vertebra. In the Chelydriclae, and still 
more in the Trionychidae, the nuchal sends out a fair of long ril-like processes, which either extend to letow some of the neighlouring marginils, or their ends overlap those of the ribs of the second thoracic vertelura (e.s. Trimmyr), or, lastly, they

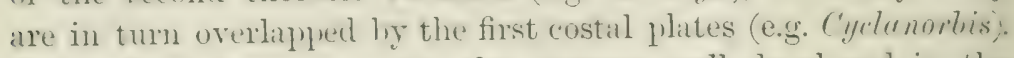
such rib-like procesoses are also present, well developerl in the roung, shorter in the adult, in the I)ermatemydidae and Cinostemilite. It is possible that the nuchal plate represents the fused nemral of the eighth and the costal plates of the ninth verteliate. An indication of the compomel nature of the nuchal naty le found in the fact that two muchats have been described

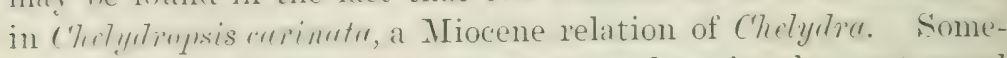
what smilar moditications have taken place in the post-sacral region. The one to three supracaudal plates are, namely, nemmls which have lost their comnexion with, or perhaps hare nerer heen fuserl with, the spinous processes of the novalle tailvertelinat. The number of neural plates is mostly eight, hut there are sometimes inctividually nine or ten, the gradual suppression taking place first in the sacral region. When such a plite is supluessed the neighloming contal plates usually close up and meet in the median line. In cistudo, for instance, there are only seven nomal neurals, the eighth pair of costals neet, and the original eighth neural is transformed into a supracaulal. In cinosternmm the sixth to eighth costals meet, separating the one supracaulal wilely from the remaining five neurals. The meeting of the last pair of costals, with co-ordinate recluction of the nemals to seren, is almost universal in the Plemodira : aml this temlency is carried out to an extreme in the Brazilian Pletemys and in the Anstratian Chelwline and its allies, in which all the costals meet in the middle line, and the nemals are emmpletely smpressed. Every stage intermediate between complete nembals (strmotheress) and interrupted, vestigial, and vanishel nenrals, is still represented ly some genus. This pur. cess takes plate independently, both in Anerica and in Australiat and is mee of the most reently introdnced modifications.

The costal plate's arise, like the nemals, independently in the

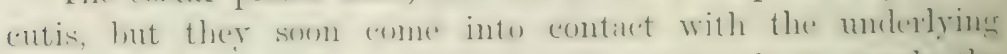

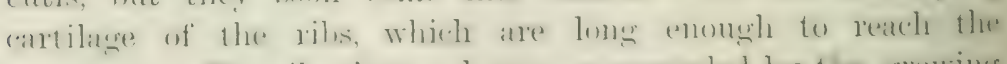

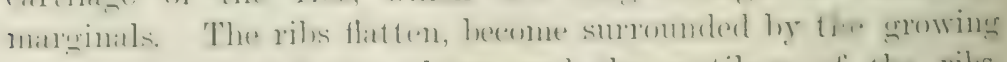
membane-lume of the flates, and the cantilage of the ribs. 
instead of ossifying, undergoes a process of calcification. T'timately this is more or less absorbed, its place is taken l,y the dermal bone, which forms so to speak a cast of the rib, preserving in many cases the shape of the ranished rib, only, the capitular portions of which remain unaflected. The number of costal plates is very constant, namely eight on each sicle, but some fossils have nine or ten, and there are still individnal rariations in recent forms, indicative of that number. In a large Chiysemys concinnu I. find the last pair of costals clearly composed of at least two pairs, and this same specimen has nine distinct neural plates.

The marginal plates are originally paired, almost always eleven pairs, very rarely ten or twelve; in unpaired posterior plate, the pygal, is always present, and is probably the result of fusion. In the Chelonidae large fenestrae remain between the costal and marginal plates, only covered by leathery unossified cutis, and of course by the horny shields. In the Indian fresh-water genus Butagui similar windows are gradually fillerl up) with age, and the horny shields become extremely thin and almost confluent. On the other hand, in Testudo polyphemus, the bony shell, always rery thin, becomes still thinner with age and finally fenestrated by absorption.

Great reduction has taken place in the carapace of the Trionychidice. The American species of Triony, have only seven pairs of costal plates; in Cyclunorlis the nemrals are reduced to two. The whole dorsal shell is much smaller than the hody, and marginal plates are absent or merely restigial. It is doubtful if the ossifications in the posterior half of the marginal flap of some genera are homologous with true marginals.

Extemally the whole shell is covered, except in the Trionyrhidue, in shluargis and C'arettochelys, with horny, epidermal shields. These are phylogenetically older than the dermal plates, and they do not correspond with them either in numbers or in position, although there exists a general resemblance in their arangement. On the plastron we distinguish an unpaired or paired gular, and a pair of gular, humeral, pectoral, ablominal, femoril, and anal shields (Fig. 66). Sometimes there are also intergulars, paired in Macioclemmys and chelys, umpaired in l'helome: in many of the Pleurodira an umpaired intergular lies behind the gulars. 
The caralpace of most Chelonians is covered with five neural, four pairs of costal and twelve prairs of matrinal shirlds, the last of which often forms an unpared pyoal. In front of the first neural lies the nuchal shiehl, very varialile in size, often absent. The Chelydrilate, Thernatemydilate, Platysternidie, and Cinosternidae forsess moreover sereral inframarginals, intercalated on the hridge hetwern the maryinal and some of the plastral shields. In many of the ot her fanilies these inframarcinals are restricted to the anterior and posterion comers of the hridge, as the sro-called axillaries and inguinals. mostly small and varialile. Lastly, Moromlommys has several small supramarginals.

There are consequently eleven longitudinal rows of shields in all: ly elinination of the supra- and infra-marginals they are renlucerl to seren rows. It is ahsolutely certain that the number of transverse rows also was originally much greater than it is now. The mole of reluction of the number of the nemal

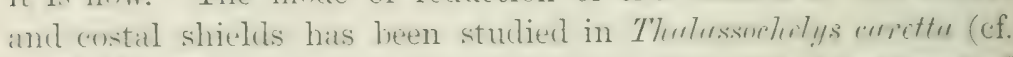
1. 3.s.) The accompanying illustration (Fig. (69) shows some of the main stages actually olserved in the reduction of these shields. The (hief joint is that certinin shields are sipueezed ont, or sulpfressed ly their enlarging neighloms. The ultimate result is the formation of fewer, but laiger shields.

Fitch shied grows individually as follows. Every year, or rather luring every perimlically recurring period of growth, the areat of the Malpighian layer belonging to each shieh increasts 1n-ripherally in size, and at the same time produces a new layer of horn. The original little shield, with which the tortoise is horn. remains for years. often thronghout life, as the so-called "areola : it increases in thiokness owing to the new layer of horn adelen from lelow, and prepipherally the increase in size is indicated ly the overdapling ondentric rings. Eath ring represents a year's crowth, at leats in tortuises which live in temperate zones, where

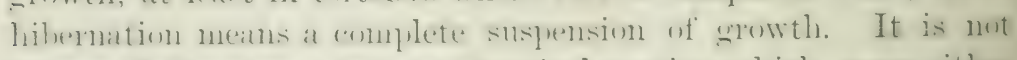

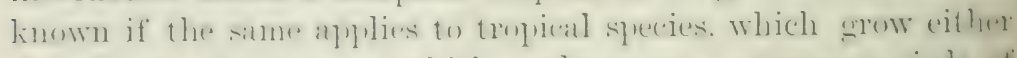

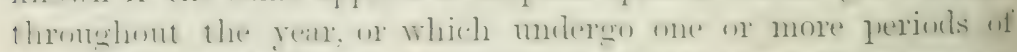

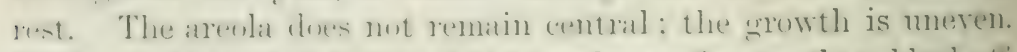

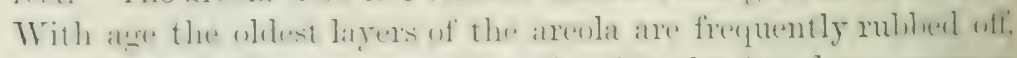

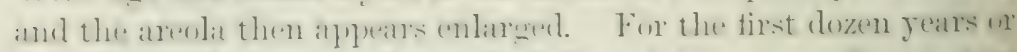

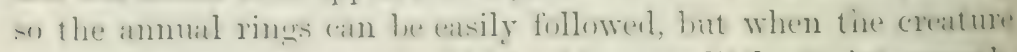

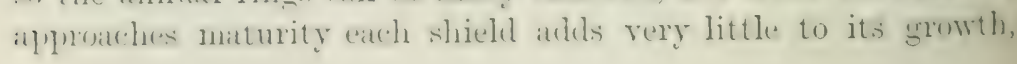



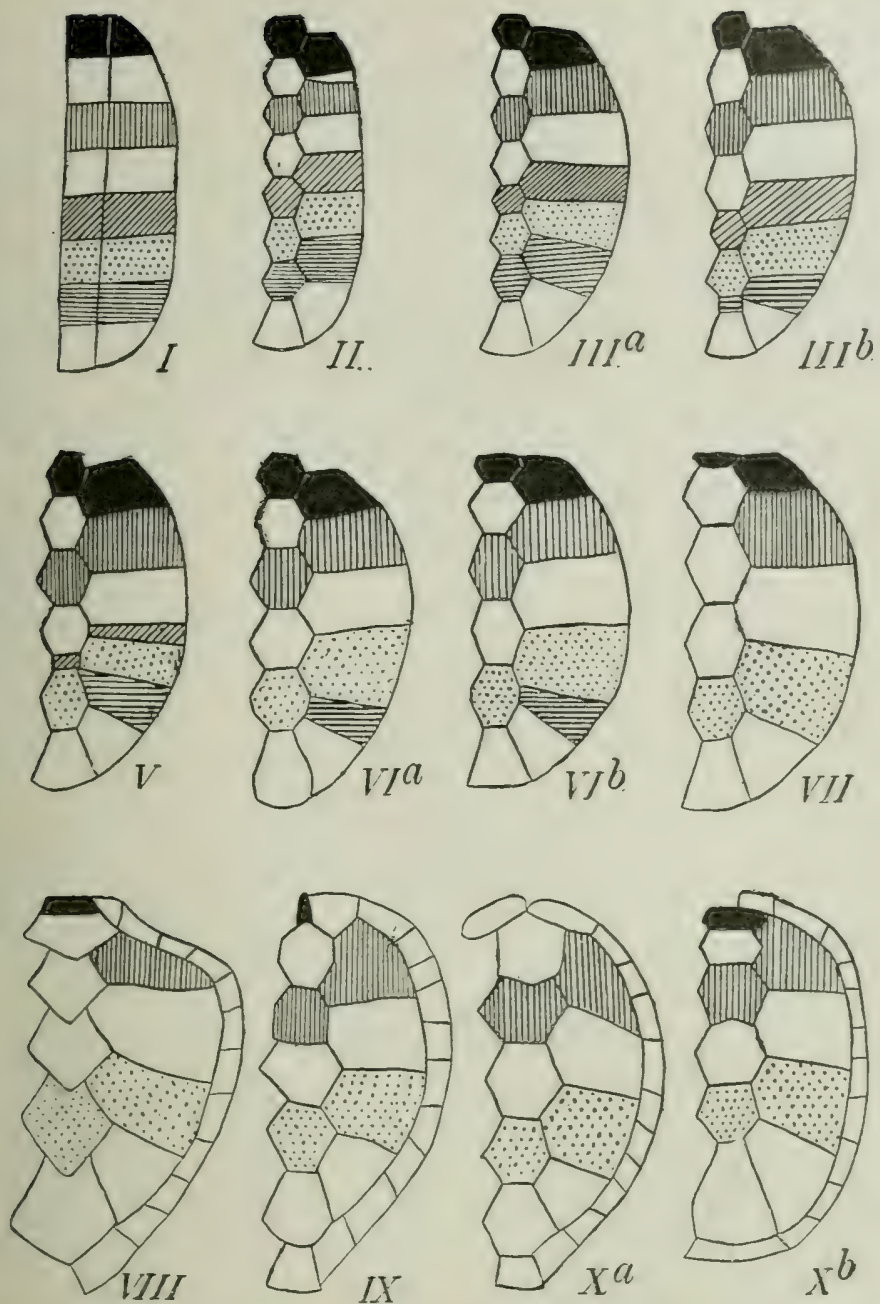

Fi: 69.-Diagrams illustrating the progressive reduction of the horny shiehts in various Chelonians. The shields, the fate of which it is desired to follow, are indicated by distinctive shading. I. Hypothetical, primitive stage. Eight neural (including the nuchal) and eight costal shields. Both neurals and costals lie in the same transverse planes. II.-VII. Successire stages in the reduction and suppression of rarious shields, observed in specimens of Thalassochelys, the normal condition of which is represented by VIr. VIII. Six neurals and only four costals. The normal condition of Chelone. IX. The nuchal shield has become very small and the resulting gap has been filled up by an enlargement of the first pair of marginals. This is the normal condition of most Cryptodirous tortoises. $\mathrm{X}$. The first marginals meet in front and the nuchal is either suppressed $(\mathrm{X} a), e . g$. in several species of Testudo, or it is surrounded by the marginals $(\mathbf{X} b), e . g$. in Sternothcernes. (From Willey's Zool. Results, 1899.) 
and the rings become very fine, crowded and irregular. Only by careful counting and comparison of the rings on the costals, martinals, and plastrals, can a reliable average be arrived at. In some tortoises, e... (hrysimys, the whole outer layer of the shields peels off periodically: only a thin smooth layer like mica or tracingpaper remains, of course without any indication of rings. The pignent is formed in the Malpighian layer, but it frequently diffuses into the horny shields themselves, notably in Chelon imbrimtu, which yields the beautiful "tortoise-shell." The colour of the pirment is either black, rellow, or red, with resulting combinations. The green colour, often so beautiful in babyspecimens of $C h$ ryssmys, is optical, produced, according to Agassiz, hy a network of black pigment, spreal orer a layer of yellow oil.

Horny scales, sometimes forming spines, and covering a nodule of dermal ossification, are also common on other parts of the skin, especially on the limbs of land-tortoises, and also on the tail of Chelydim. Sometimes the end of the tail is protected by a clawlike nail, for instance in Pyris. In some of the gigantic landtortoises, and in Cheloni mydn's, this nail assumes large dimensions. and sereral of the terminal caudal rertelorae are fused together into a regular urostyle. In some subfossil specimens of Mauritian tortoises, these ankylosed complexes are 12 cm. long and more than $5 \mathrm{~cm}$. broad!

Pefore leaving the description of the shell, it is worth while to draw attention to the enormous correlative changes in other organs produced hy this case. Nearly the whole organism has heen altered. The hard, firm caraluace has partly rendered the supporting functions of the vertelnal (nhmun mnecessary or impossible. In many tortoises, especially in the large land-fortoises, the rertehrate and the capitulier protions of the rils are reduced to mexe bony outlines: the reduction wo thin paper-like bony lanellate proceeds with agre. The iliar luaes find a better support in the costal plates: the contact with the sacral rihs is given up, and these rils fust: fartly with the costal plittes, or they are alsortrexl. The whole. mass of muccles of the trunk is ampletely lost in the region of the shell, hut traces of them exist in yomng specimens. Neck, limbs, and tail can in most asses be withdrawn and hidden in the shell. When this is not pussilile it is due to secondiry changess. The neck is withdrawn oither hy leing tucked away 
sideways (Pleurodira ${ }^{1}$ ), or by being bent in an S-shaped curve in a rertical plane. In a left-sided profile-view of the animal, the head represents the tail of the $\mathrm{S}$. The neck is withdratw lyy long muscles, which are inserted into the rentral side of the middle of the neck, and extend in the shape of vertical ribbons far back into the shell, arising from the centra of some of the middle or even more posterior thoracic vertebrae.

Lastly, a few remarks on the partial regeneration, or the mending of injuries to the shell. If part of the horny corering is badly bruised, torn off, or rubbed through, or if part of the shell is crushed, the underlying portion of the bony plate becomes necrotic, and the horny covering also dies so far as its Malpighian layer is destroyed. Soon, howerer, the uninjured Malpighian cells, around the margin of the wound, multiply, srow into and beneath the injured portion of the bone, and form a new horny layer, casting off the necrotic portion. After several months the deficiency is patched up; new bone has grown in the deeper remaining strata of the cutis, and the outside is covered by a continuous horny layer, without, however, reproducing the original concentric moulding of the shields. In badly crushed shells sometimes ahmost one-third of the whole shell is thus cast off and mended within one or two years. The regeneration of the forcibly stripped-off shields of Chelone imbricate is described on p. 386. Bitten-off tails and limbs, rather frequent occurrences in water-tortoises, are of course not reproducerl, but the wounds are healed and covered again with scaly skin.

Sense-organs.-The EYE is by far the best developed senseorgan. It is comparatively small. The pupil is round. The iris is mostly dark in terrestrial forms, while in water-tortoises it is often brightly coloured, for instance pale yellow in Chelurinu, greenish and mottled with black, pale grey, brown. etc., in ririous species of Chryscmys. Cistudo presents a curious sexual dimorphism; the males have red, the females brown, eyes. The sclerotic wall contains a ring of numerous small ossified plates. There is no trace of a pecten. The eye is protucted externally by the two lids and the nictitating membrame. In some water-tortoises, notably in Chelocino, the lower lid is transparent. Lacrymal and Harderian glands are present.

$1 \pi \lambda \epsilon u \rho o ́ v$, side ; $\delta \epsilon \iota p \eta ́$, neck. 
The sExsE OF HEARIN is aplarently not rery acute, although tortoises and turtles are frightened hy noise, and can distinguish somuls: otherwise they would hate no voice, which is very tiny and piping in most tortoises during the fairing season. In most Water-tortoises the trun anic memlurane is thin and quite exposed; in linul-tortoises it is often thick and corered by the ordinary skin; lastly, in Chelome the tympanic carity is fillerl with a plug of the munch-thickened skin. possibly in adaptation to the waterpressure when these creatures dive to considerable depths. The usinular dhain is mostly reduced to a long, bony, columellar rod.

The sExis of smeli is well developed. All Chelonians canefully suell their food, in the air as well as under water. The indivilual predilection shown he many sprecies for different kinds of animal and regetable food,- - since they are, for instance, alble 11 distinguish between the various sorts of cablage, cauliflower, surnuts, etc..- - proves that they possess a consilerable anount of smell and taste.

Tortoises have a fine sense of touch: even the slightest tap on the shell is noticed, and the skin of the soft parts is extremely sensitive. Tickling of the sides of the tail, or of the hincler surfice of a thigh, froduces ricliculous scratching actions of the same or of the opposite foot.

The digestive apparatus is simple. Only a few peculiarities. neerl he nentioned. The tongue is mostly hoad and soft: it

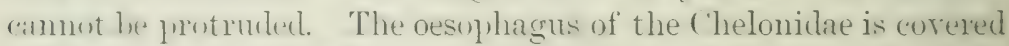
with many anical projections juinting towards the stomach. The latter is simple. exent in spllorgis. The intestine is deroid of a andun, hat the difference between the small intestine and the rectum is rery marked and often abrupt. The cloasea is rery

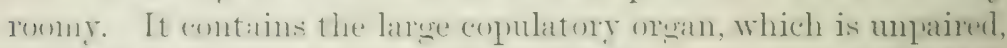
srooved on its dersal sirle, and is altogether constructerl like that

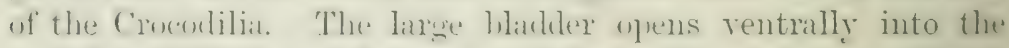

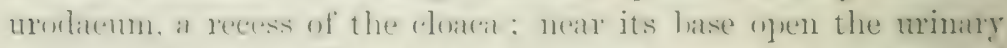
anul genital durets. Many water-tortoises forsess also a pair of litiral thin-walled siles, the so-called anal sales, dorso-lateral diverticular of the walls of the momlatsun. These saces, which have highly vil-1nlarised walls, ane incessantly filled and emptiml with water thromeh the vest, and alet as impertant respinatery oreans: When such a water-tortoise, for instance an Limys on at C\%mmlys, is suldenly talien out of the water, it syuirts out a 
stream of this water, which is not, as is generally supposed, the urine from the bladder.

The mole of respiration is interesting. The lungs are very complicated, highly-developed, spongy structures. Ther are attached by their whole dorsal surface to the imner lining of the shell. As they cannot expand through their own initiative, and since the shell has made costal and abdominal expansion impossible, the tortoise has to resort to other means of producing the necessary vacuum. This is done partly by the neck and the limbs, which act like pistons in being drawn in and out; purtly by the greatly developed hyoidean apparatus, by which, when the neck is stretched out, the throat is alternately inflated and emptied, the air being swallowed, or pumped into the Iungs. Additional respiration, besides that of the anal sacs mentioned above, is effected in rarious aquatic tortoises by slightly rascularised recesses of the pharyngeal region. Most Chelonians (an exist for a very long time without breathing; sulky individuals ramain for hours or days under water. Cistudo cam shut itself up for an equally long time. Nevertheless this and other landtortoises easily get drowned.

All Chelonians lay white eggs, round or oral, according to their kind, but the shape of the eggs of one set sometimes varies within the greatest limits. The shell varies from a parchmentlike, flexible, searcely calcareous cover to a hard, well-polished case. As a rule the egrs, imbedted in the ground, are hatcher ifter a few months, but in some of the northern kinds, e.g. Eimys "riviculuris, the hatching is deferred until the next spring, the embryo's development being arrested during the winter. How such eggs, buried a few inches only below the surface, withstancl the often very severe North German and Russian winter is a mystery. Whilst the plastron is generally flat, it is more or less concave in the males of many species, notally in Testudo, Cistudo, and Emys.

The general conclusions which can be drawn from the present geographical distribution of the Chelonia are as few and unsatisfitctory as those applying to the Crocodilia, since all the main sproups of Chelonians, and many more extinct fimilies, vecurred together in loygone ages in the same countries, for instance in Europe. The marine forms are naturally cosmopolitan, but the Testudinidue are likewise cosmopolitan, except in the Australian 
region. The Chelydritue, now restricted to North and Central America, occurred formerly also in Europe. The Plemrodira, in Mesozoic times plentiful in Europe, India, and North America, are now restricted to suth America, Australia, and Africa; the

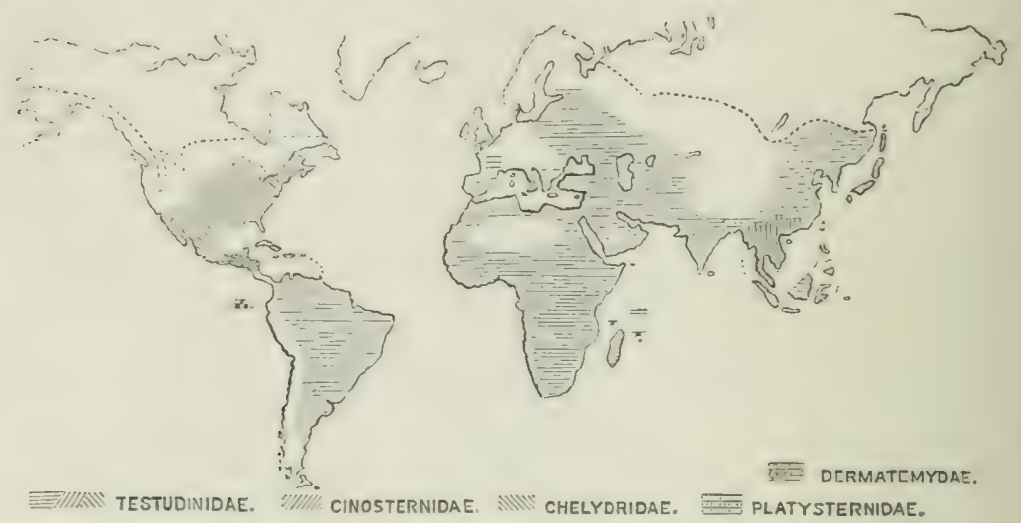

FIG. 70.-Geographical distribution of Cryptodirous tortoises.

I'enmminsidne to Africa, Matagascar, and South America: the Ghelydilue to south Amerien and Australia. In the latter country all the Chelonians helong to the Chelydidae. The Trimmrhenter, occurring since the Cretaceous epoch in North Americal, in Early and Mid-Tertiary times in Europe, are now restricted to
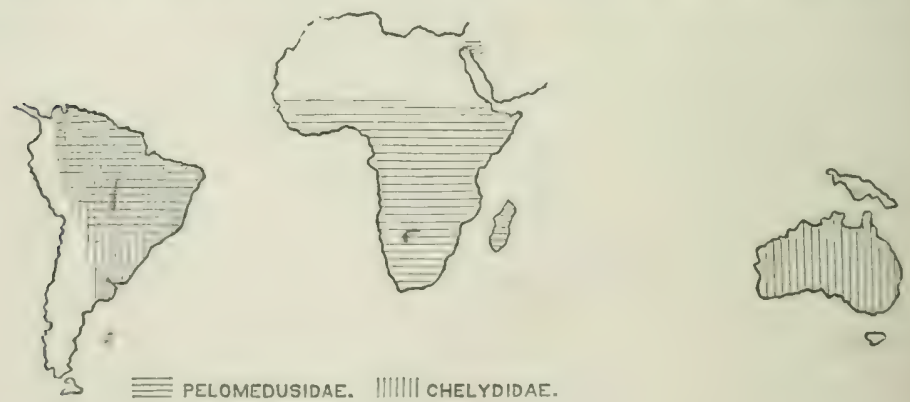

FIG. 71.-Geographical distribution of Pleurodirous tortoises.

North Anerica, Asia, and Africal. The comutry richest in ('helonians is Americal : North and central Anerica together possessing repuentatives of all the families except the Plemrotina, and these we linow to have died out there. The Dermatemydidar, 
Cinostcrnidac, and Chelydridae are now restricted to the Nearctic sub-region (including Central America). Poorest in genera and species, all of them Chelydidae, is the Australian region, where no fossils of other families have yet been discovered. Europe, with its
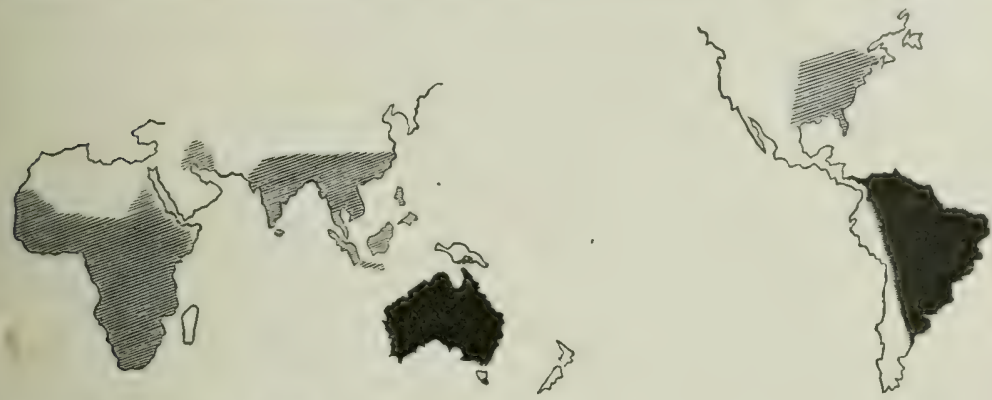

FER TRIONYCHIDAE.

CHELYDIDAE.

FIG. 72.-Geographical distribution of Trionychidae and Chelydidae.

few Testudinidae, does not come into consideration; Asia has at least Testudinidae and Trionychidae, and in addition the solitary Plutystemum in Indo-China, representative of a family whose affinities with the Chelydridae again proclaim the validity of the Periarctic region.

\section{Order I. ATHECAE.}

The vertebrae and ribs are not fused with, but are free from, the carapace, which consists of numerous small polygonal plates and is coceral with leathery shin without any equidermal shields. The limbs are transformed into paddles. The nect is not retrutile. Mrarine.

Fam. Sphargidae-Sphurgis s. Dermatochelys coniucea, the Leathery Turtle or Luth, is the only recent species and is the langest of all recent Chelonians. The biggest specimen in the national collection is about six feet and a half long, from the nose to the end of the shell, which latter is about four feet long; such a specimen may weigh half a ton. Agrassiz, howerer, salys that he has seen some "weighing over a ton." The general colour is dark lrown, either uniform or with yeliow spots. The Leathery Turtle has a wide clistribution, ranging orer all the intertropical seas, but it is rare everywhere; least so perhaps in the 
Trestern Atlantic from Florida to Brazil and in the Indian Ocean. Acomding to Agassiz it lneeds regularly erery year in the spring wn the Bahamas, on the Tortugas, and on the coast of Brazil, depusiting its many egress on the sandy shore like other turtles. Accidentally it visits the mothern const up to Loug

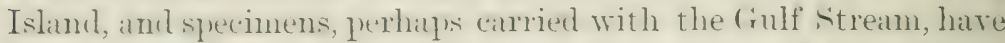
been cancht on the coasts of Europe, for instance off' Irorsetshire. One wals cancht near Nantes in 17.29 , and is sild to have malde
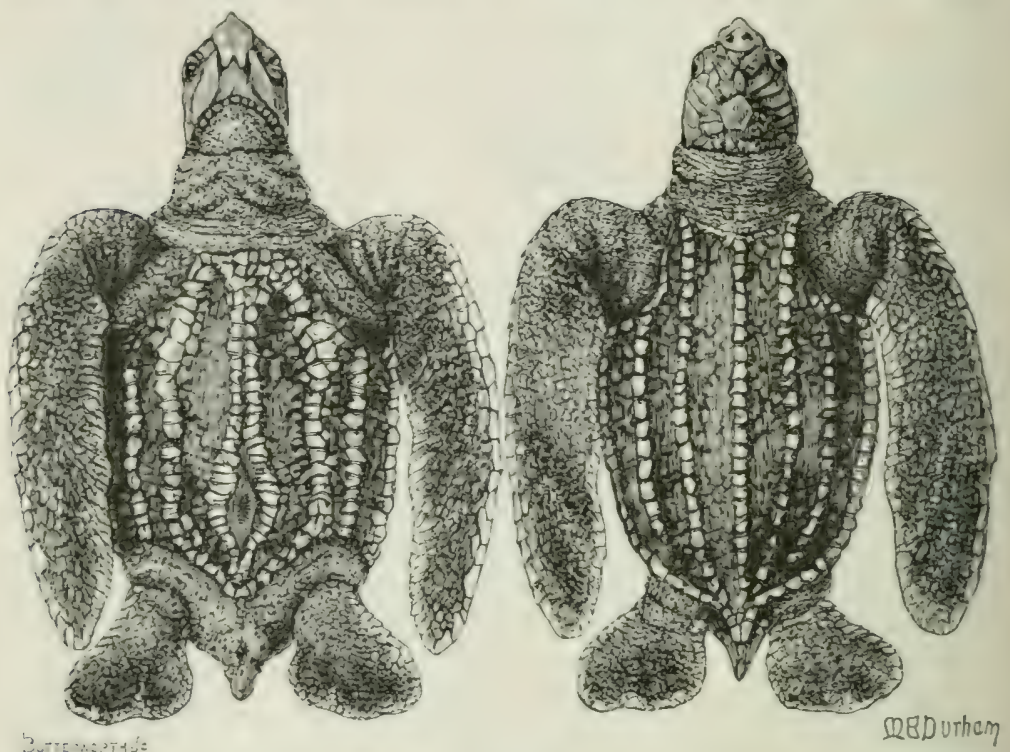

Zurrinatis=

FIG. 73. - Sphargis coriacen, the "Leathery Turtle," young specimens, rentral and dorsal views. $\times 1$.

a terrilite noise when lreing killed. This is perhalps the reason

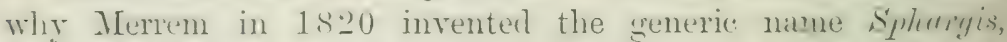
suphosed to he lerived from $\sigma \phi a p a y e ́ w$ (I malie a noise). It hias also been recorded from the Mediterranean. It seems to be entirely camivorous, living upun Molluses, Crustacea, and fisls. The flesh is supposed to he unwholesome. It is a rery curions

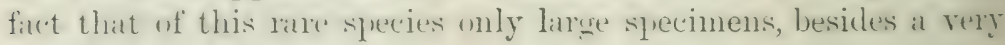
fiew halis-turters, ane linown or preserved in collections, while individuals of intermediate size, say from four inclese to thee feret in length, hatre never leeen recurded. If it were sut for the firet that ther are still known to breed, it would look as if the 
species were dying out. Perhaps they are rery shre, lemting a pelagic life, diving at the least sign of dauger, and coming nean the land only for the sake of breeding.

The structure of Splurigis is so peculiar in many respects that it deserves a somewhat full account. The neuro-centrill sutures persist on all the rertebrae. The eight cerricals are short. All the ten trunk-rertebrae carry ribs, and these, with the exception of the last, articulate between the centra and with the nemral arches; the first and tenth. ribs are short, the other's are long and flattened, but not broad, with wide spaces between them. The tail is short, although it consists of about twenty rertebrae; these are devoid of chevrons.

The skull superficially resembles that of Chelone, chietly owing to the completely roofed-in temporal region. The supraoccipital crest is rather short, covered completely by the parietals, the pusterior margin of which is rounded off instead of forming, as in the Chelonidae, a long projecting triangular crest with the supraoecipital. The parietals are in broad contact with the postfrontals, posteriorly they are just reached ly the squamosals. The quadrato-jugal is small, separated from the pust-froutal ly the meeting of the squamosal with the jugal. The quadrute is notched behind, and it separates the opisthotic from the squamosal. The basisphenoid is large and hroad, extending far forwards so as to separate the pterygoids widely from each other except in their anterior portions, which, instead of sending a lateral arm to the jugal and maxillary, as in Chetune, are widely separated from these bones by the palatines. The choanae lie on either side of the anterior half of the romer, and are not roofed over by ventral vomero-palatine wings.

The limbs and their girdles are essentially like those of the Chelonidae, but are not derivalile from them. The most remiarkible feature is the shell. The dorsal and rentral halres are directly continuous, forming one unbroken case all round, which is composed of many humbeds of little bony plates, irregulatrly jolygonal, fitting closely into each other with their sutural etges, and giving the shell a beatiful mosaic appearance. On the dorsal side are a median row and three pairs of lateral rows of larger plates, aud these form seren lougitudinal blunt ridges which all converge towards the triangularly pointed tail-end of the shell. The ridges are not so much produced liy thichened 
or spine-like enlges of the pliates, but hy the right and left halves of the plates being actually lent at an angle. This is most conspicuous at the silles of the shell where it passes into the rentral portion. The latter has two pairs of lateral and one median ridge. The whole shell has consequently twelve ridges. The mosaic plates are deeply imbedded in the cutis, being externally as well as internally covered or lined with deuse leathery skin. The eprderm is thin, and shows no indications of horny scales. In young specinems the whole shell is soft and rery imperfectly ossified, litter on it is quite rigid, although comparatively thin. It is nowhere in contact with the internal skeleton, except by a nuchal hone, which hy a descending process articulates with the neural arch of the eighth cervical vertebra.

The aftinities of the sphargilae and their position in the system are still debatable. Whilst some authorities, c.\%. Cope, Inollo, and Bonlenger look upon Sphurgis as the sole remmant of a prinitive group in opposition to all the other recent Chelonia, Batur considered it the most specialised descendant of the Chelonidace. Dames acreed with him. Tan Bemmelen has moditied this view in so far as he regards Sphorgis as the most specialisud Chelonian, but comsiders the differences between it and the Chelonislate great enough to conclucle that hoth spharicilae and Chelonidae represent two independent, partly parallel, branches which liave arisen from two different groups of terrestrial tortoisess. Case, from the study of Protustegu and other fossil forms, tends towarls Baur's view. He helieres that splunges is the culninating form of a branch which through Psephopheress and with Eusphergis has sprung from some creature like Lyfulumm, which at the same time is the startingpoint of amother branch which culminates in the genera

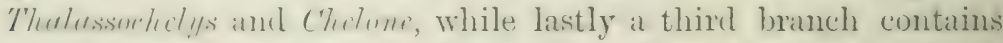

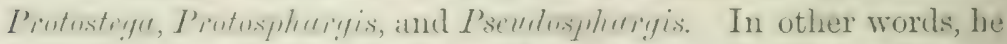
consilfers them all cheloniclate. If he is right we have of course

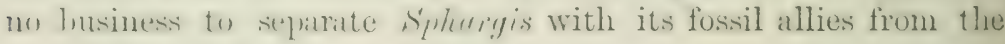
rest of the Chelonia as "Athecae."

However, Case has not proved his point. It is easy enough (1) molerstand that the chatraters of the cranimu and platstron

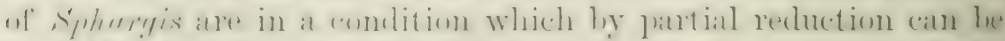
derived from that of typinal chelonislate. The struce re of the 
cervical rertebrae, the absence of the marginal plates and the peculiar articulation of the nuchal with the last cervical rertelirit can be explained as convergent analogies, just like the paddles of C'aiettochelys. But the shell of Splirrigis is fundamentally difterent from and not homologous with that of the others. Cope was therefore quite justified in distinguishing the Sphargilate as "Athecae" in opposition to the others which Dollo later" on, hy contrast, named "Thecophora." Unfortunate names, since both groups are undeniably in possession of a $\theta \dot{j} \kappa \eta$ or shell. Both authors meant, however, by Theca the epidermal shields, but even this distinction is rendered invalid by c'urefturhelys.

The most reasonable explanation has been suggested by Hay. ${ }^{1}$ The mosaic polygonal components of the shell of Spharyis arte, so to speak, an earlier generation of osteodermal plates than the later generation of longer and broader bony plates which in the Thecophora come into contact, and fuse with, the neural arches and ribs. The osteoderms of Spherryis helong to the sime category as the dermal ossifications in the scutes of Crocodilia, whilst the plates of the carapace and plastron of the Thecophora belong to the category of the abdominal rihs. Spluargis has the first kind in its peculiar shell, the second kind in the deepeet lying plastron and in its neural plate. But it has lost, or perhaps had never developed, the horny shields. The only difficulty is, however, the presence of a plastron and of a typicial neural plate in Sphargis. This difficulty is not rery serions. The plastron is a very old institution. It occurs together with the more superficial osteoderms in Caiman, and the nuchal plate may he the oldest of all dorsals. Wre can scarcely imagine that the direct ancestors of Sphargis had dereloped both kinds of shells, and that comparatively recently the inner shell of the carapace was lost, leaving only the nuchal plate. Fossils do not support such an assumption. Undoubted ancestral forms of Sphlurgis are very rare. Psephophoms of the Oligocene and Miocene of Europe had a continuous mosaic shell much resembling that of Sphargis: Ensphargis is represented by a well-preserved skull from the London clay. Then follows a wide gap until we come to Psephoderma of the Phaetic, or Upper Trias of Bavaria; the large fragment of whose dorsal shell is composed of about 200 mosaic pieces. If this fragment really formed part of the shell 
of a Chelonian, its age would spreak greatly in farour of the Athecae being a rery primitive and independent group.

\section{Order II. THECOPHORA.}

Thoracic vertebrae and ribs united with a series of median or newral and a paired series of lateral or costal plates. Parietals

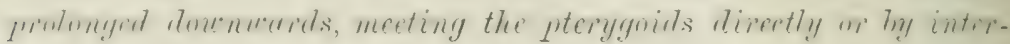
position of an epipterygoid.

Sub-Order 1. Cryptodira. - The carrpues is curepren with

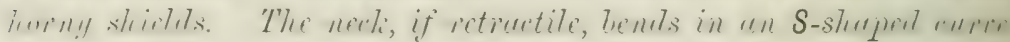
in a vertical plane. The pelvis is not fused with the shell.

Fam. 1. Chelydridae.-The plastron is small and (cross-shat perl (Fig. $61,2,1,815)$ : the hridge is rery narrow, and the displaced alutoninal shields are widely separated from the marginals by a few irregularly shaped inframarginals. The tail is long. The limbs, neck, and head are so stout that they camnot be completely withdrawn into the shell. Sum with a powerful hooked beak. American; only two genera, each with one species.

The tempral region is ronfed very incompletely and only anteriurly hy the expanded parietals and postfrontals, which form a long suture. The plastron consists of nine bony plates, a small entoplatstrom being present; there are lacmua in the midhle line. the plates meeting imperfectly, and the horny alodominal shields are likewise seprarated by soft skin. The caraprace has a muchal with long rib-like processes which underlie the marginals; the neural plates form a continuous series. There are twenty-three marginal plates. The puhic and ischiarlic symplyses remain setparate, enclosing one large heart-shaped foramen. The fire tingers and toes are wehbed and are protected hy claws except the outer toe, the nail of which is usually suppressed.

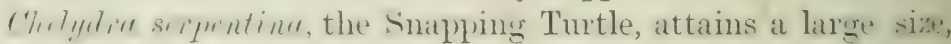
namely, a shell-length of more than one foot, and a total length from the nose to the tip of the tail of more than three fint. Its range extends from the Canadian lalies east of the liorky Yountains, through the United States and Central America. The caraprace of young specimens has three rery marked siries of lieds, which gradually disalplear with age, until in rery all individuals the shell becomes quite smonth. The skin is rery warty. eprecially on the neck, and there is a pair of minute: 
barbels on the chin. The tail carries three series of origrinally triangular horny crests, which with age are transformed into blunt knobs. The general colour of this rather ugly creature is olive, mottled with dark brown above and with yellowish below.

According to Holbrook the Snapping Turtle is found in stagnant pools, or in streams where the waters are of slugrish motion. Generally they prefer deep water, and live at the bottom of rivers: at times, however, they approach the surface, ahore. which they elevate the tip of their pointed snout, all other parts heing concealed: and in this way they float slowly with the current, but if disturbed they descend speedily to the bottom. They are extremely voracious, feeding on fish, reptiles, or any animal sulistance that falls in their way. They take the hook readily, whatever may be the bait, though most attracted hy pieces of fish; in this way many are caught for the market. It is, howerer, necessily to have strong hooks and tackle, otherwise they would be broken, for the animal puts forth great strength in his struggles to escape, both with his firm jaws and by bringing his anterior extremities across the line. When caught they always give out an odour of musk, which in rery old animals is sometimes disagreeably strong.

Occasinnally the snapping Turtle leaves the water, and is seen on the banks of rivers or in meadows, eren at a distance from its accustomed element. On land his motions are awkward; he walks slowly, with his head, neck, and long tail extended, elevating himself on his legs like the Alligator, which at that time he greatly resemhles in his motions; like the Alligator also, after having walked a short distance, he falls down to rest for a few moments, and then proceeds on his journey. In (aptivity they prefer dark places, and are exceedingly ferocious: they will seize upon and bite sererely anything that is offered them, and their grasp upon the object with their strong jaws is most tenacious.

The Snapping Turtles, or "Snappers," are feared on account of the ferocious bites which they inflict, and they are hated lecause of the destruction of raluable fish and water-fowl. They in turn atone for this damage by being eaten, especially the younger half-grown individuals, the flesh of the older ones being tow much tainted with the odour of musk. The round eggs, which are laid to the number of twenty to thirty in the summer 
in the Northern States almut June, are likewise gool to eat. The first anet of the roung creature on leaving the shell is said to les snaplying and biting. In captivity they are often very sulky, and refuse food stublumbly for many months, perhajs for a whole year, and alparently without much ham to themselves, since they lie puietly in the distant corner of the tank, now and then slowly rising to the surface to breathe. Fresh-water algae grow on the shell and in the mud which settles on it, and since this

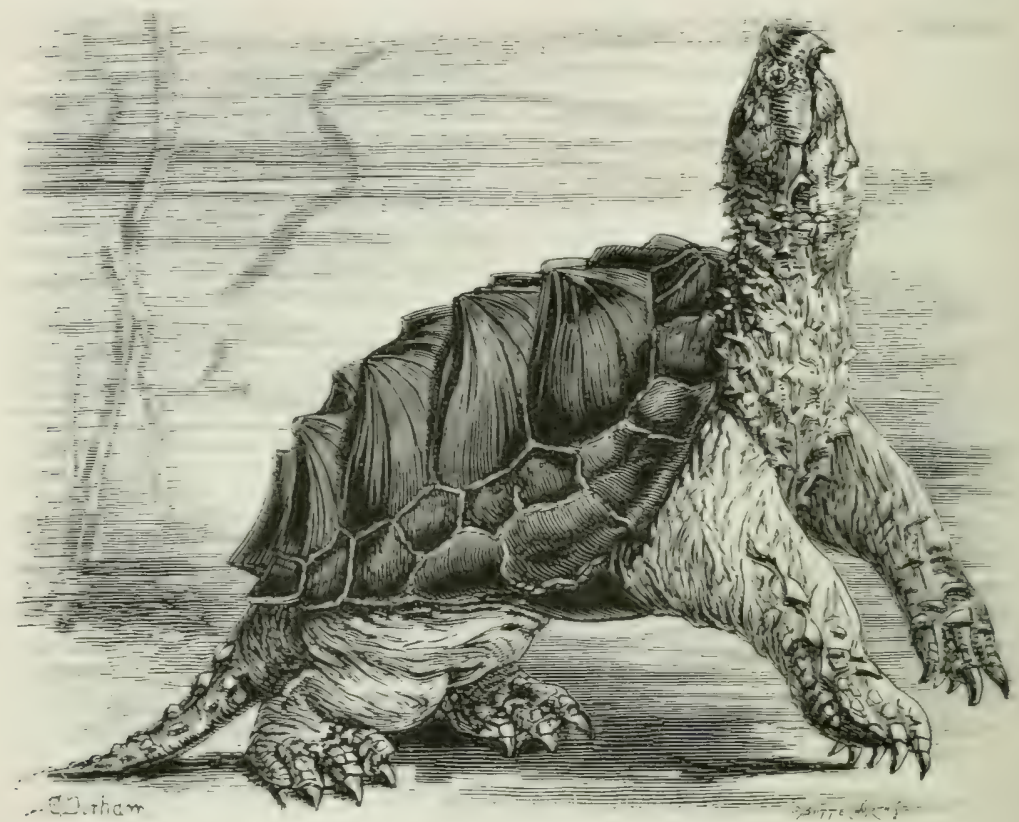

EIG, 74.-Macroclemmys temmincki, "Alligator Turle," $\times \frac{1}{1 .}$

litppens also in the wild state, they are rendered as inconspictous ats wh rotten logs. In order to attract fishes they protrude a jair of worm-like, pale pink filaments from the tip of the tongue.

Werrowlomm!|s trmminelie, the "Alligaton' Turtle." - In size and gerneral alpeatrance much like the other snaplying Turtle, but the dersal shields have each a strong and prominent lieel, and these three series increatse in size with age. The rostal shields are segaraterl from the matrinals ly an additional series of alont four smprantuarginals, well shown in the illustration. The shields of 
the cross-shaped plastron are subject to much individual variation, small shields being frequently intercalated, or rather retimed, between the usual ones, especially between the pectorals and abdominals, in the gular region, and on the narrow bridge, where the inframarginals number one to three or eren more. This species inhabits, broadly speaking, the whole basin of the Mississippi and Missouri rivers.

This beast is as vicious as the other Snapping Turtle. According to Agassiz it does not withdraw its head and limbs on the approach of danger, but resorts to more active defence. It raises itself upon the legs and tail, highest behind, opens the mouth widely, and throwing out the head yuickly as fir as the long neck will allow, snaps the jaws forcibly upon the assailant, at the same time throwing the boly forward so jowerfully as often to come down to the ground when it has missed its olject.

It lives mostly in the water, hut makes considerable journeys orerland. Both in the water and on dry land the limbs move nearly perpendicularly, and the body is raised high. On dry land a considerahle part of the weight of the body is horne liy. the long, strong tail.

They are as ferocious as the willest beast of prey, lut the slowness of their motions, their inalility to repeat the attack immediately, their awhwardness in attempting to recorer their balance when they have missed their object, their haggard lonk, and the hideous appearance of their galping mouth, constitute at such times a picture as ludicrous as it is fearful and revolting. Their strength is truly wouderful. I have seen a large specimen bite off a piece of a plank more than an inch thick. They take hold of a stick with such tenacity that they may be carried for at considerable distance suspended to it free ahove the ground. Fishes and young ducks are their ordinary prey. They lay from twenty to forty or more round eggs only about the size of a small walnut in holes which they dig in sloping banks not far from the water" (Agassiz).

Fam. 2. Dermatemydidae. - The pectoral shields are widely separated from the marginals by inframarginals, the gular shields are very small or ahsent, and the tail is extremely short. Only two or three genera, with three or four species in Central America.

The plastron is composed of nine plates. In Dirmatemys muxi it is large, firmly joined to the carapace, covered with 
eleven or more shiehis, and there are four infianarginals: in

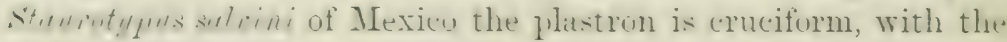
anterion lobe movilile. corvered with seren wr more shields, accordin th the fusion of the anal shiehls and the presence or ahsenct. uf the gulars: there are unly two inframarginals. The pulic and ishliatic symphyses remain separate: the tempral fissa remains wilely open, the potfrontuls scarcely tonching the parietals.

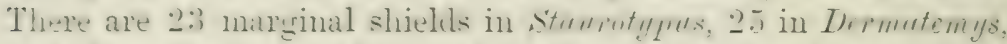
im huling the unpairest nuchal. The muchal plate has a pair of rib-like precestes like those of the chelvitricke, lut some of the funtering costal plates. sometines only one prair, neet in the mithle line, orerlyiug or sunprting the corresponding neural ylates. The shell of these aruatic tortuises is rather flat. more

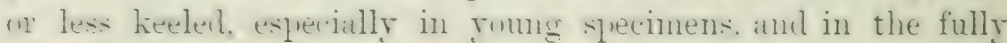
adult condition is about one foot in length.

Fam. 3. Cinosternidae. repesented hy the single genu-

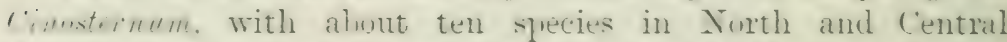
Anerica, and one in (ruiana. C'lnsely allied to the two grevious. fandilies, with which it arrees lis the sepraration of the pulic am? ischialic symphyses, the presence of an ento-plitistal plate; the lustession of infranarginal shields Fis. 61, 3. 1, 31.7, the witely "yen tempral fossite. am the rib-like pair of provesses to the nuchal plate. It agrees with the Inermatemriliate in the interrup,ion of the neural plates ly the meeting of sereral pairs of the costal plites. There are 22: narwinal slikelds : fire or foum shielsh, accomling to the presence on absence of the gular on the flitson, and in solnt species these plitstral shields become, with ate, more and none sepratrated from each ot leer hy soft skin see Fin. -5 . The -lutpe and size of the plastron differ considerably

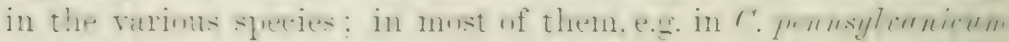
and $C$. leucostomum, but not in $C$. odoratum, the anterior and lustorior loles arre morahle. with transverse soft hinges, so that the aninal (an completely chese its shell. The skin of the lews and ne $\mathrm{k}$ is so bagey and lonee that these gatts slip in. the skin molling ntt: when the creature withlraws inte its shell. They liy only a few-fiwn thee to five-elliptical ens. which have a shining, glazed, and thick, but very brittle shell.

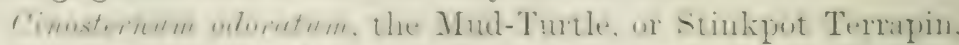

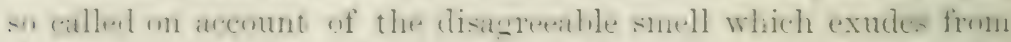

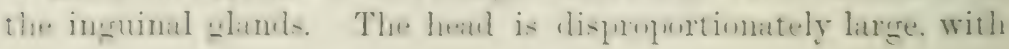


the snout rather compressed laterally, and pointed underneath, with several short barbels. The neck is long and slender. The carapace of the young is keeled, each of the neural shields being

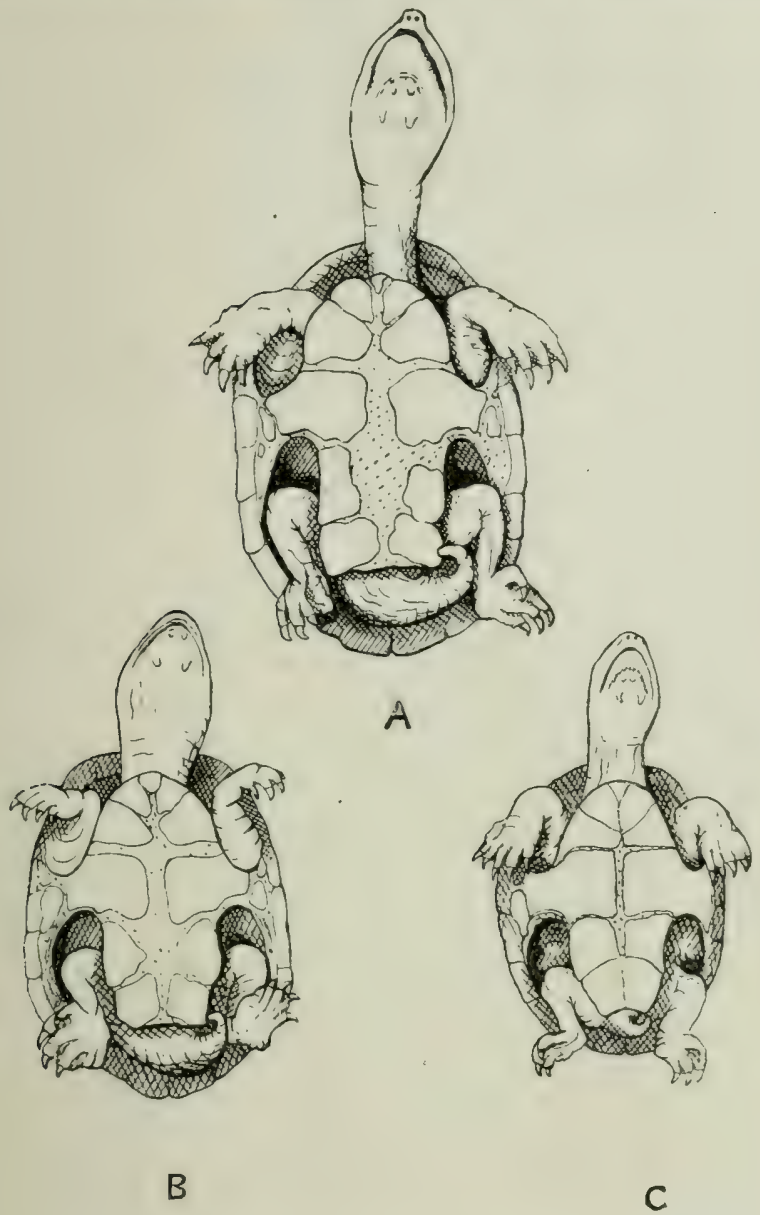

EIG. 75.-Cinosternum odoratum, young specimens, $\times \frac{9}{3}$. $\mathbf{A}$ and $\mathbf{B}$, males; $\mathbf{C}$, female.

raised in the middle line; but in full-grown specimens the shell hecomes quite smooth and rounded. The horny shields of the plastron are relatively largest in the young, but they soon leave ever-increasing spaces between them, which are then filled with soft skin only, which thinly covers the underlying bone. The 
fure-and hind-limbs, especially the latter, are extensively webled, and are providenl with five short claws. The general colum of the shell is horny hrown, either uniform or with darker spots or streaks. The neck and limbs are mottled hrown. The only ornmental colnuring is a fair of clear yellow hroal lines on earch side of the head, and a sinnilar streak om each side of the lower jaw: () n the ehin and upuer throat are two pairs of small tentacles. The tail of the male is of about the length of the himl-limbs: while that of the female is so short that its tip scarcely reaches herond the hinder margin of the caralpace. Length of the shell of full-grown specimens hetween four and five inches. Very romg specimens have a rather droll appearance. wwing to the long and slemeler neck with the large hetul, and the humpy back.

This sprecies is ammonm in the eastern half of North Anerica, from Camala to Texas. It is mainly anuatic, and is one of the dullest and shyest sprecies. My uwn specimens spend most of their time in the water, invariahly in the darkest corners, pereferably muler a stone or a lowe, and they do mot leare their hilling places until dark. in search of worms, meat, and all sorts of animal food. For months I could never induce them to take food from a stick, or even to eat in my presence, and it was not until after many weeks that one of them at last protruled it: hearl far enumgh to exhibit the vellow stripes. Then taken out of the water they draw in their heads, just allowing the vicioms little eres to he visible, and opening the sharpertged mouth writely to bite leliberately and furiously at the unwary finger. Some spent the winter in the water, in the greenhouses, feeding as usual, others arept on lind, hiding under moss, half buried in the soil. where they slept for sereral months, but with interruptions in order to sonk and to drink. Then spring is well adranced they lorefer the water for the-ir regular sojourn. Some which had been sent ores from New York arrived in a deploralily driesl-up condition, the skin heing quite flably and shrivelled. but after a few hours sobling they came round, and increased considerathly in weight, the limbs and nexk beconning turgid.

6. fennsylionicum of Eastern North Anerica has a larerer, more oval plastron. The heal is not so strikingly large as in the other species and, like the neck, is lrown with yellowish flots, and often has streaks on the sides. The tail of the male ents in at 
nail-like horny point. The lobes of the plastron are well hinged in the adult.

C. leucostomum of Central America is larger, with a shell-length of six inches. The plastron is not at all cruciform, but has a lroad bridge, and fills the box, moreover it has an anterior and a posterior hinge, so that the box can lie completely closed. Hence the vernacular name of the Box-Terrapin.

Fam. 4. Platysternidae, represented by the single species I'lutysternum megacephalakm in Burma, Sian, and Sonthern C'hina.

The pectoral shields are widely separated from the maryinals ly inframarginals, the plastron is large, ollong, not cruciform, and the tail is long.

The plastron consists of nine plates, and is covered with six jail's of shields, the most anterior of which are the hroarl gulars. The nuchal plate has no rib-like processes. The neurals form a continnous series, and there are twenty-three marginal scutes. The temporal fossae are completely roofed over, owing to the long sut ures formed by the parietals with the postfrontals, moreorer the postfromtals expand laterally so much that they posteriorly come into hroad contact with the quadrato-jugals and squamosals, anteriorly with the maxillaries, so that the jugals are completely surrounded hy bones, and are shut off from the orlits and from the temporal fossae. This is a unique arrangement, fomm nowhere else in Tortoises. The pulic and ischiadic symphyses are comnected with each other by ligaments only.

The general appearance of this water-tortoise is rather curions, since the carapace is much depressed, looking, especially in younger specimens, as if it had been crushed in. The head, prorided with rery strong hooked jaws, is strikingly heary and lirge, and is covered above with one single large shield. The tail is longer than the shell, which, in full-grown specimens, rearches about six inches in length; it is, throughout its length, corered with rings of squarish shields. A large specimen measures $1 \pm$ inches in total length, of which only five fall to the shell.

Fam. 5. Testudinidae. - The shell is always covered with well-dereloped horny shields. Those which form the plastral lridge are in direct contact with the marginals. The plastron is composed of nine bones. The digits have four or fire claws. The neck is completely retractile. The skull is deroid of parietosquamosal arches. 
This lare family is cosmopolitan, with the exception of the Anstralian and the aljoining Austro-Malayan countries. It contains gentra which form a continnous gradation between ahsolutely terrestrial and thoroughly aquatic tortoises; and many are truly amphihious. As a general rule the typically terrestrial kincls have a more curved or arched shell, the digits are short, the egas are nore oval or round, and they are chiefly herbivorous: the esentially arpuatic kinds have a flatter or depressed shell, weblinel feet, with longer, often slender claws, the eggs are nore cylindrical, and they live on animal diet. About 20 genera, with mure than 110 slecies, are recognised by Bonlenger, but their esential chatraters are nearly all internal, and therefore uf no avail for the determination of live or entire specimens.

(1/insm!ys-One of the most typical and widely distributed senera of American Terrapins or water-tortoises. The carapace is Hatt: the plintron is puite immovable, with a strongly dereloped hridice. Feet well wehbed. Tail short. skull with a broad, omplete. lateral. temporal arch. Ahout one dozen species, mostly in the eastern half of the Inited states, hut the whole genus rangres from Canada to Argentina.

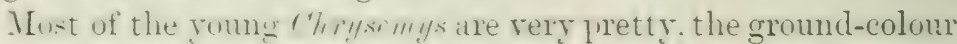
of the upler shields heing green, variegated with yellowish-brown or hlackish markings. which often form expuisitely delicate

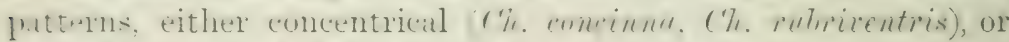
nume longitulinal $(1 \%$. degmes. or alparently quite irregular.

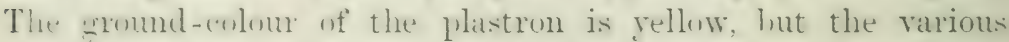

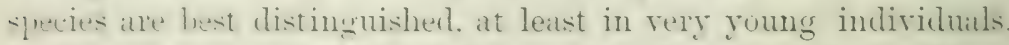
ly the arangenent of the dark hrown spots and patches. There ane, for instance. sereral pairs of lould lateral and sereral median

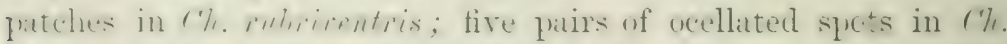
dequns: mly snall median patches, where four plistral shields

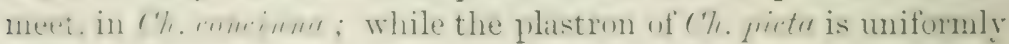
yellow.

These water-tortwises are rery lively and shy, most so perhatps

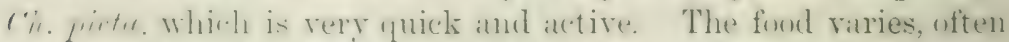

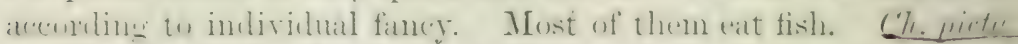
is latrtial te inserts. lunt it also takes woms. Some of my specinems refused nueat for a long time, hut ultinatedy they lecantes so fornd of it and of worms that they came out of the gromet to take the foud from the tingers: these in the Zoologiceal 
(rardens of London have developed a taste for biscuits. One of my largest Ch. concinna fasted deliberately for eight months, refusing worms, insects, meat, and frogs, only occasionally sniffing at the food, until it was tempted with whitebait, which it took greedily. It refused, however, smelts and pieces of soles, hut after another month it condescended to take meat regularly. Very young individuals live chiefly on flies, which they watch for near the surface of the water; and they are fond of smooth caterpillars, maggots, the larvae of humble-bees, and similar soft creatures. They all spend most of their time in the water, preferably floating near the surface, hidden between weeds; and they are fond of basking. Some of them spend the night in the water, lying motionless on the bottom, with heads and limbs turned in. Others prefer hiding under moss. Those species, which, like $C h$. concinne and $C h$. picte, are common in the North, are of course perfectly hardy. For the winter they dig themselves holes in the banks near the water, and they do not come cut again until the spring is well advanced. The eggs are hardshelled, mostly long and oval, and they are hatched before the end of the summer. The larger species of Terrapin are eaten.

(1). pict" (Fig. 76), the "Painted Terrapin," of the Eastern Lnited States, e.g. of New York and Long Island, is easily recognised by the much depressed shell, which is absolutely smooth. and without a trace of a keel. The colour above is dark olive-brown or blackish, with broad yellow bands across the anterior ends of the neural and costal shields. Three or four of these transverse bands are very conspicuous. The marginals are red, with more or less concentric black and yellow markings. The pretty red colour, with some black stripes, extends over the bridge, but the plastron itself is uniformly yellow. The soft parts are likewise prettily marked, the ground-colour is black-brown, with delicate lright rellow and red stripes on the sides of the neck, limbs, and tail. l'he stripes are originally yellow, but they develop an orange or recl line in the middle, so that each red stripe is ultimately narrowly edged with yellow; or the yellow and red stripes alternate, for instance on the tail, which is short, narrow, and pointed. The head is further adorned with a pair of conspicuous bright yellow patches behind the eyes, and a smaller pair on the occiput. The black and yellow stripes run across the gape of the mouth, some of the lines even looking as if they had been 
painted across. The nuchal shield is elongated and very narrow; it: anterior edge and that of the neighbouring marginals are finely serraterl. Tery youne individuals are at once recognised by the forminent lungitudinal median stripe of loright orange extending wre the nuchal and neural shields: the yellow transwerse bands are still ahsent : they appear when the longitudinal line ranishes.

The "l'ainted "Terrapin" is one of the few species of which, thankis to L. Agasiz. (onplete chata of growth from the new
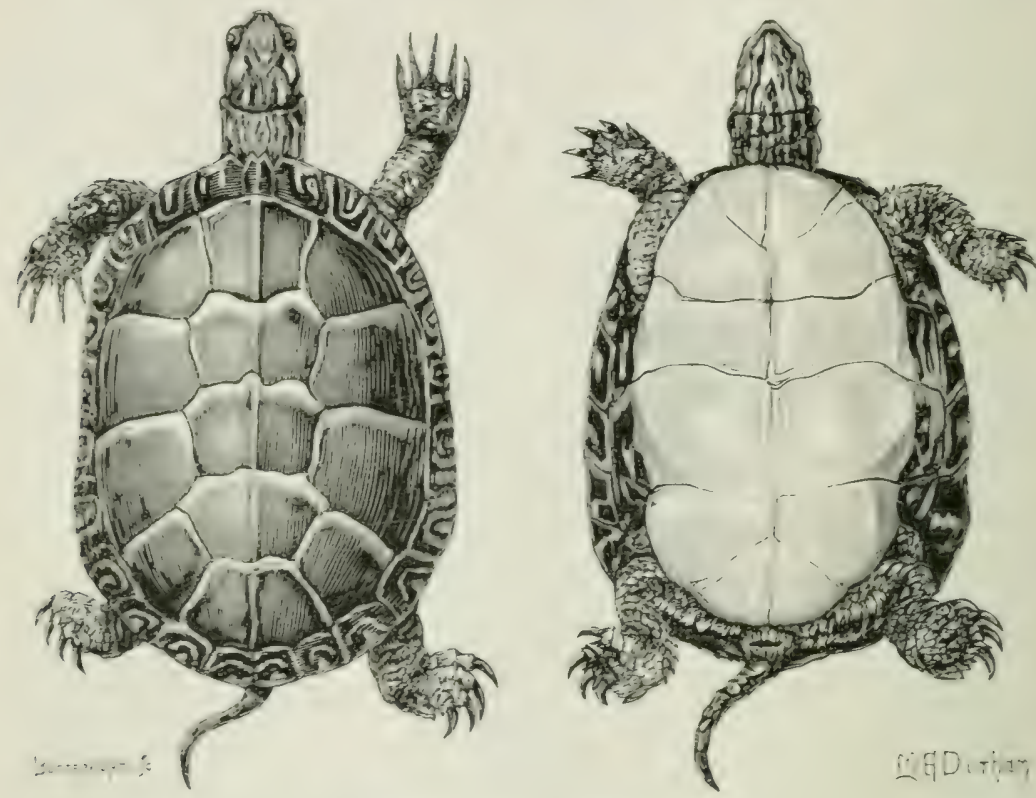

Fic. 76.-Chrysemys picta, "Painted Terrapin." $\times \frac{1}{2}$.

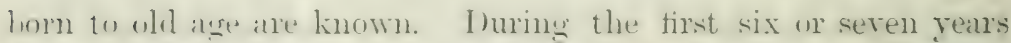
the rite of growth is so uniform that numerous specimens collected at the sane time are reatily arrangerl in sets of the sime age, simply ly the differences they show in their size. The sucressive lines of arowth on the shields indicate the number of vears. After the seventh rear the age is much more difficult to distinguish in those tortoises, which, like $1 \%$. prictu, have a furferetly smoroth epidernis. This smoothmess is due to the fact that dhe shielels molereso a process of moulting. An uplet quite

1 Contributions to the .liet. Hist. of the U.S. 1., Boston, 1857. 
transparent layer of each shield peels off completely like a pieces of mica. I have been able to confirm Agassiz' statement on C $\%$. concinne in their third and fourth springs, and on a number of adult $C \%$. picta. The latter were not allowed to hibernate, heing kept in a warm tank; they peeled completely during the late autumn, and then the red and yellow colours underlying the newly formed shields appeared very vividly; others moult at midsummer.

Growth of Ch. picta, after Agassiz.

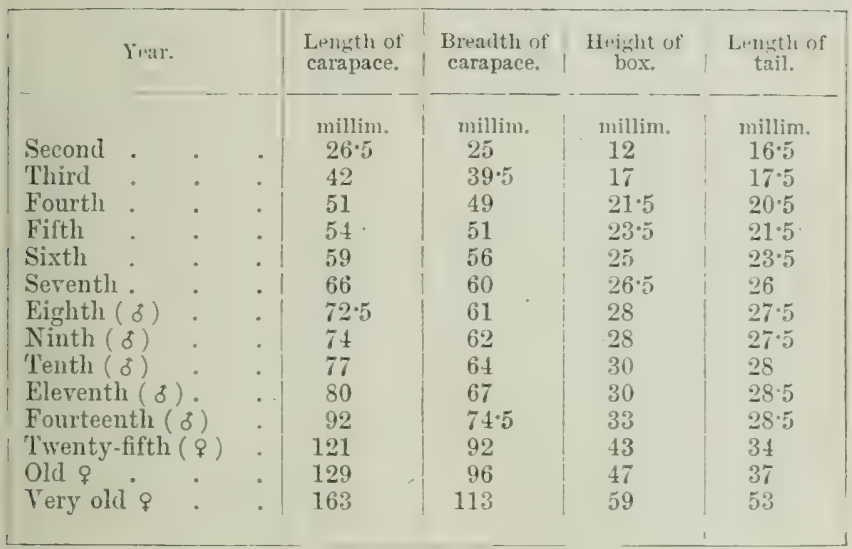

The size of the eggs varies considerably, from 26 by 17 to :30 by 16 millimeters; sometimes they are perfectly round, $17 \mathrm{~mm}$. in diameter.

C\%. concinnu.-The specific character by which this Terrapin may be easily recognised is a pair of orange-red broad streaks, which extend from above the eye to the sides of the neck. The general colour is olive-brown above, variegated with yellowish dark-edged lines, which, together with numerous rugosities, radiate from the middle field of each shield. The plastron is yellow, often with blackish symmetrical patches, and sometimes these become confluent and preponderant. Tery young specinens are extremely pretty, the ground-colour of the carapace being green, each shield with darker, somewhat concentric markings, most conspicuous and regular on the upper surface of the marginals, where the marks of the adjoining shields form one pattern-system across the dividing lines. The plastron is either uniform yellow or has a few pairs of blackish spots 
which stand so clusely together that they form ahnost median patches.

The caraflace is ronerh. The horny shiehds become very thin with atre. The anterior margin of the small nuchal and the neirhlouring marginals is fainty serratent. The posterin marninals form slight notches or indentations between their elges. The plastron is almost square behind. The erlges of the

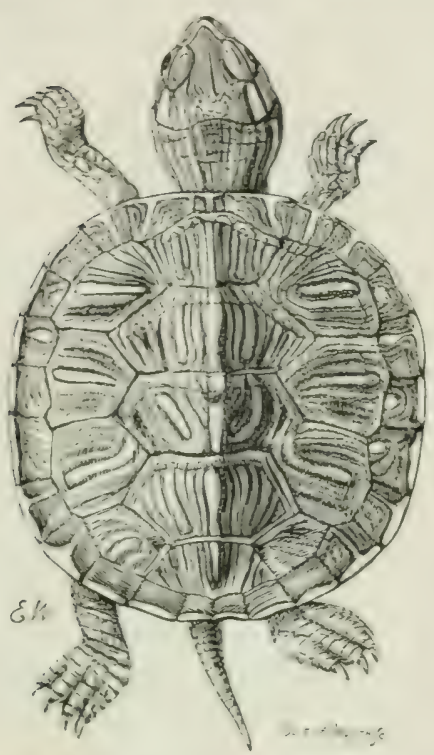

Frg. 77.-Chrusemus concinne, in its third summer. $\times 1$.

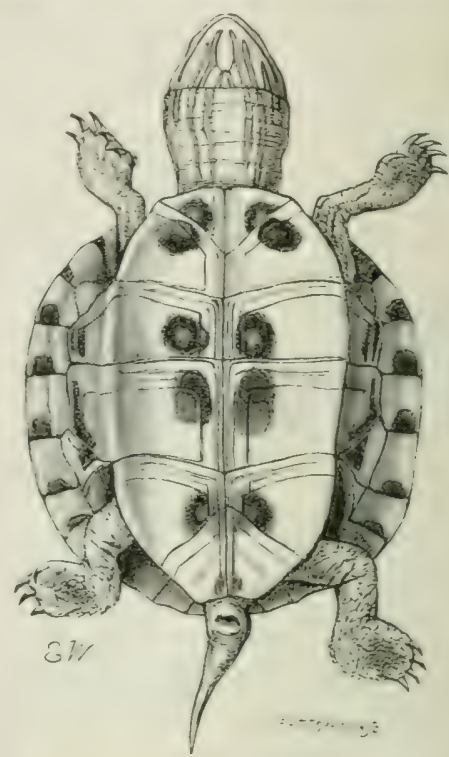

FIG. 78.-Chrysemys concinue, in its third summer. $\times 1$.

jaws are nearly smooth, without hook and receiving-notch. The tail is short.

This species inhalits the Sonth-Eastern states of North Aneriea, from Missmuri and North carolina to the cinlf of Mexico. Very lare female specimens have a shell sixteen inches

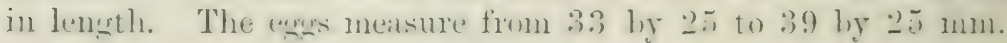
or about $1 \frac{1}{2}$ inch in the long diameter.

fimys. The platstron is moxally united to the carapare liy liganent, and in the atult has a slightly flexihle hinge across the minlile, hedween the hyo- and hypo-platstral plates and the prectomal

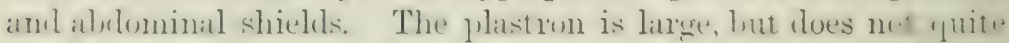

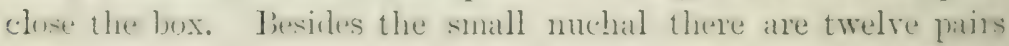


of marginal shields. The head is covered with smooth skin; the temporal arch is complete. The limbs are extensively wehbed. The tail of the very young is nearly as long as the shell, but it becomes relatively shorter with age, being reducerl in the males to about two-thirds, in the females to half the length of the shell. Only two species are found in Europe, the other, E. blandingi, in Canada and north-eastern U.S.A.

E. orbicularis s. europaea s. lutaria, the European Pondtortoise.-The shape and coloration of the shell change likewist much with age. In the very young the shell is round, and the shields are rough and slightly leeled, uniform dark brown ahove, black below, with a yellow spot on each marginal and plastral shield. When half grown the dorsal shields hecome quite smooth, and are striated or spotted, with yellow upon a dirti sround. The head, limbs, and tail are dark, with yellow or light hrown spots and small dots. In rery old specimens all these rellow markis disappear on the shell, which then becomes uniform hrown or almost black. The coloration is sulject to much local and individual variation, and there are two main tyres, the spotted and the radiate. It is difficult to say which of the two is the prettier. One male which I canght in the Alentejo was rery beautiful. The shell was almost llack with a greenish shine when in the water, and had many bright yellow and whitish spots. In the radiate type the yellow is sometimes preponderant, so that each shield hecomes a study of delicately painted yellow, lorown, and blackish lines radiating from the rentre. This variety seems to prevail in the south of Spain, lecidedly so in the Marismas, also in Northern Italy, whence most of the European markets are supplied. The largest shell in the British Museum is $19 \mathrm{~cm} .=7 \frac{1}{2}$ inches long. Fischer sigwart receired one from Naples which was about ? inches long, and this seems to have been kept as a pet, since its shell latd been gilt. Specimens about 5 inches in length may be consiclered as fully adult. There are very few reliable olservations on the growth of individuals. One of F. Sigwart's grew in eleven years only about $2.5 \mathrm{~cm} .=1$ inch, when its shell wis $13.4 \mathrm{~cm} .=5 \frac{1}{4}$ inches long - total weight of the tortoise $4 ? 1$ srammes, about $1 \mathrm{lb}$. One of my own grew from 1.1 to $1: 3^{\circ 2} \mathrm{~cm}$. shell-length, and 8.3 to 10.6 cm. in width within eight years, lit this was one of the specimens which, living in a greenhouse, 
did $11 n$ liblemate. This European poml-tortoise is now restricted (1) Fumberm and Midelle Europe, extemling eastwards towards St. P'etershure and into Asia Minor, southwards into Algeria. Formerly it hate a much wider sange, having been foumd in post-nlatial deporits in sonthern sweden, Demmark, the Netherlanks, and in Ealst Anglia. sprecinems have been found in lhe leat of the fens of Norfolk and (ambridgeshire, contempurary with hones of the Bearer, Rine-fleer, and Pelican. The sitne applies to North (iemmany, where its gratual disalpeanance from the western and central parts is olvious. Exerete in (entral France it is now practically unknown to the we-t of the Eilhe river. The comntry between the Elhe and Oder

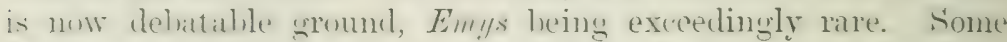
fifty rears age this seems to have heen different, to judge from the filct that finduers were rather fond of lieeping a tortoise in the wilter-tronghs of the cattle to lieep the water free from worns and other innpurities. Hence arrse a silly superstitious eustonn. It Wits comsilereel explatly comelucive to the health of the pigs to keepl' a tortoise in the foul tub into which all the dish-rvater and kitchen-lefuse its jotato-peets, som milk, etc.,-were collected before the mess was given to the pigs.

1 sprecinen is still occasimally canght in the Havel and Spree rivers. I myself have heard of one or two in the backWaters of the Gele near Frankfurt, hut they are vinishing, and it is diflienlt to sily exactly why. The miversal lowering of the water-level whing to hetter drainage camnot quite account for it, since there are thousands of suitalile ponds, swamps, and backWater's left. In l'oland and in biastern P'russia the tortoise is still common.

This creatme lives on a strictly animal diet. Wurms, insects, frogn, fishes form its main sustenance. Fishes are regularly stalked. The tortoise watches its opportmity, slowly it halt crawls, half swins along the bottom, rises imperceptibly liy a few gentle movements of the willely sperarl-out wehhed feet, then opens its sharl "utting jaws wile, and makes a grab at the belly of the fish. Frons are most ansily stalkerl when they sit upon a floating leat. The tortoise rises from below, and wten waits with the nostrils and eyes just alove the water and close to the frog. After a while it sinks, and rises again, this time atually tosoling the

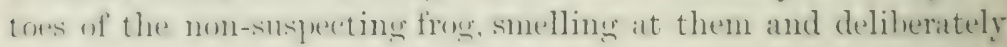




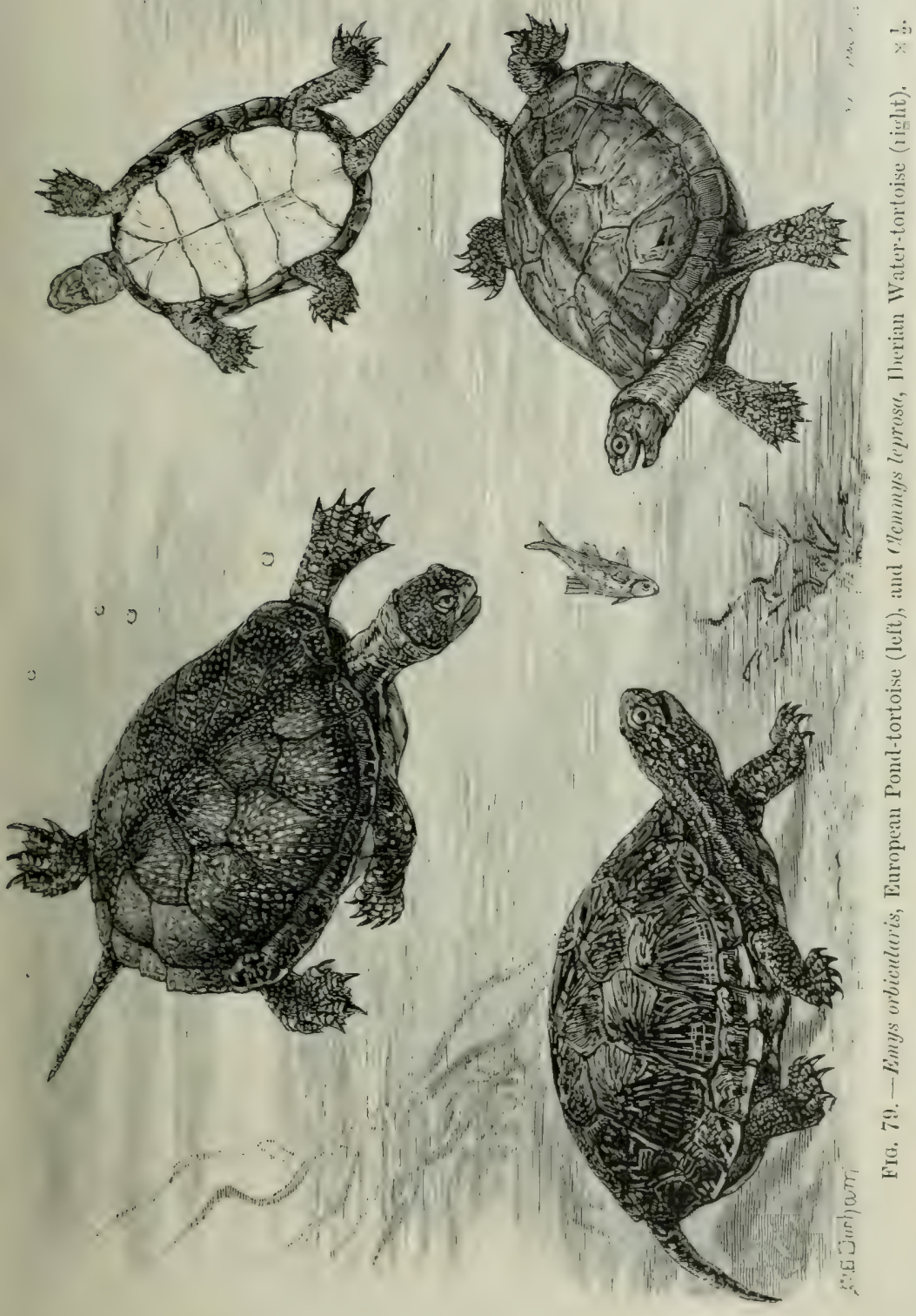


hiting with a sileward tum of the heat. What the jaws hatre

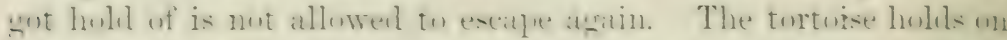

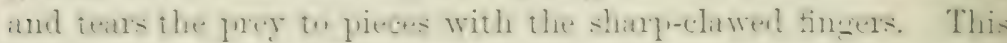
takes a long time, only the scraped-off' flesh and the intestine-

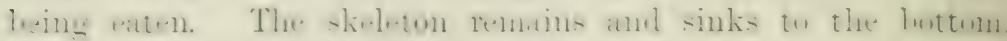
while in the case of at tish. the air-hlubher thats away on the

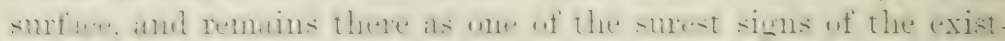
ence of tortoises in that locality. The bones are cleaned with

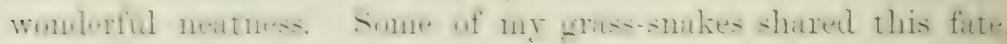

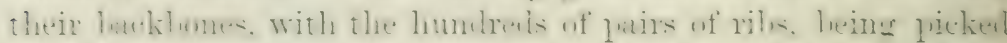

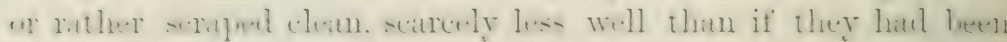
prepared for a museum.

As a rule the prey must be in motion to be seized, unless the

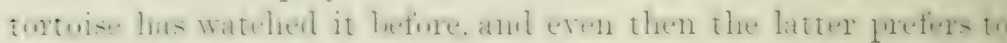

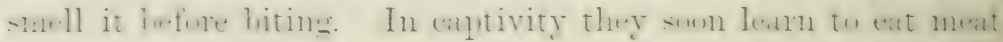
and they become rery tame, but in their native haunts they ar. rximmely chy and cautions. Fomi uf hasking num a stone on wn the lanks. with the four limbs snawling, or with the himi-

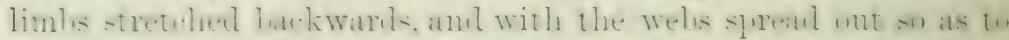

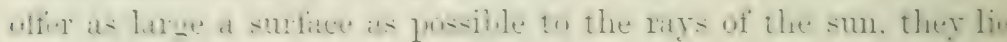

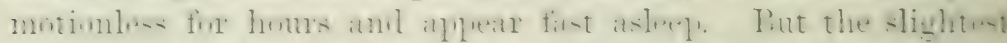

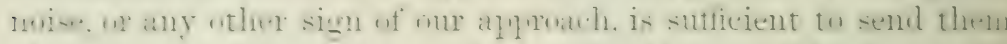
flumping inte the water. and to make them sentle alonge with

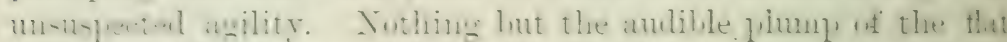

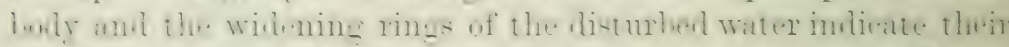

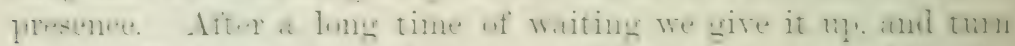

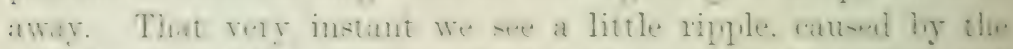

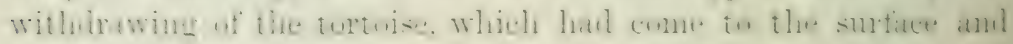

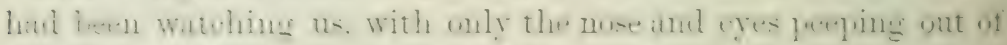

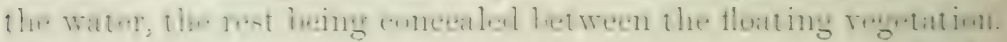
Apparently they camnot see us well with their eyes still um?.r.

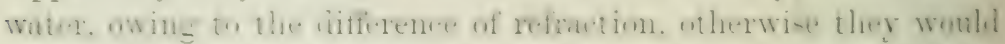
not peep out and then at once turn back. It is certainly not for the want of air, since they can remain below for many humwithout breathing.

Although they generally feed in the water, they come on luw when tame and lumgry enough to take the offered food. Somm-

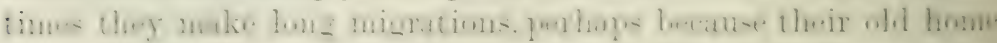
is chied up or does not yield food enough. They hibernate duin

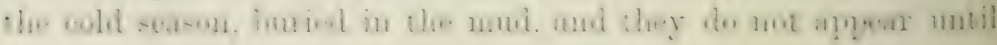


the spring is well adranced. I)uring the pairing seasm, wh warn spring nights, they enit short piping sumds, and when thes have fomml each other, the couple swim ahout together. The white. hard-shelled, long, oral eggs, areraging 2.5 to $1 . \overline{1}$ mu. and about ten in number, are laid on land. This is a very laturious and curious business. The female having selectrat a suitalle spot, not loose sand, but rather hard suil free from ${ }_{1}$ lats and other clense regetation, prepares the gromed hy moistening it from the blatder and the aual water-sars. Then it stiffens the tail and bores a hole with it, moring the tail but not the hour. The lind-limls then scoop out the hole, the lumal feet moring alternately and healing up the soil on the sile, until the hole is alwut tire inches deel, that is as far as the himl les will reach. The eys are latil at the hottom in one laterer, divirled and distributed lig the fert. Lastly, the soil is put in agatin. and the tortuin.e. liy refreatedly raising its body and falling down, stannps the sirl firm and that, roughens the sumface a little with its claws, and leatres the nest to its fate. Yothing lout an accident leads to it: niswovery. The young are hatched, accorling to lncality and the kind of seiason, either in the same autumn or not until the next spring. Eges laid in a garlen at Kieft, in Fussia, were hatchent eleven months later. This implies hibernation of the enlnge within the egrg, amel this is probalily the nsual comrse of erents: resembling the conditions of the develoment of sylicminten ict. 1. 299. The pretty little creatures, scarcely larerer than a shillinpiece, are exceedingly difficult to rear. They require a tanlwith rren vegetation, stones to bask on and to hide under, and alsi dry ground and moss for a change. They eat flies, tiny wrms, tadpoles, etc., greedily enough, but for some occult revisuns they do less well than many another kind of waterturtuive. Miss Durham has, however, succeeded in rearing one, which is now in its fourth year; the shell is 2 inches long, mi: exch shield shows three annual rings around the areolix. Tlis s lecimen spent the winters in an unheited roum unter nus: n', in the water.

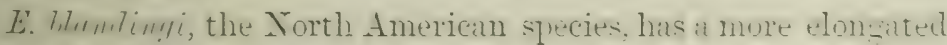
and desidelly hicher carapace than its smaller Eumpean relation.

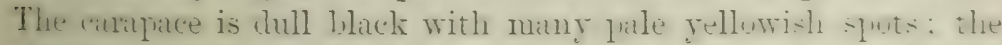
flition is yellow, with a latere lark patch on the mater and himber "wn? of each shield. The head is dark brown abore, bright 
rellow helow and wn the throat, a contrast which gives this tortuise at striking alpeatrance. This spectes is extremely roracious,

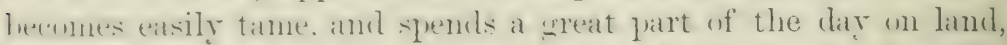

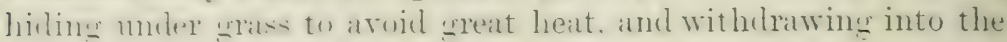
water for the night.

Clemmys. - The plastron is immovably united with the caralatere and is levoil of any transverse hinge. The skull has a complete hmy tempural anch. This gemus, consisting of eight

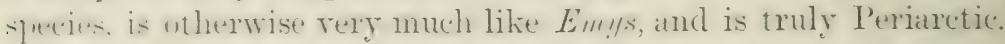

C'. Teprosa s. sigris (Fig. 79).-The upper jaw has a median nuth the the reception of the unturned point of the lower fiar:

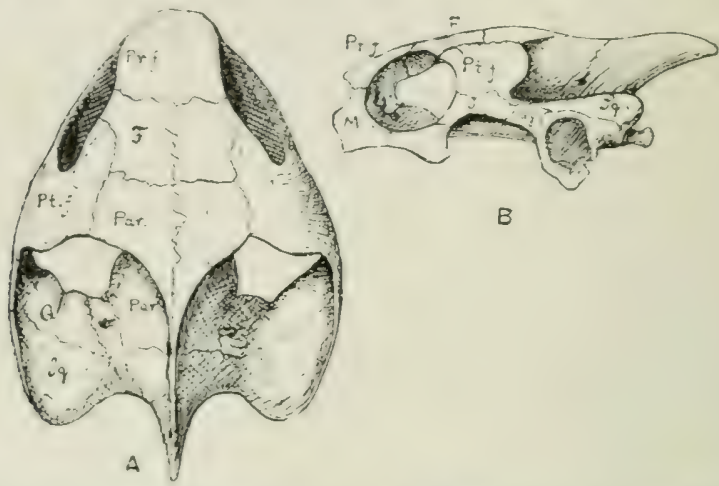

Fici. so. - Skull of Clemmys Teprosa. $\times \frac{3}{2} . \quad A$, dorsal view ; $B$, from the left side ; $F$, frontal ; $J$, jugal ; $\boldsymbol{M}$, waxillary ; $P a r$, parietal ; Pr.f, prefrontal ; $P t . f$, postfrontal, Q, quadrate, $Q j$, quadrato-jurgal; $S q$, squamosal.

Whe rotting edges of the powerful beak are smooth. The shell is flat and long-oval, nowhere serrated. The plastron does not quite fill the imx. In the young the shell is nearly rombl, and the lmmy shichels form three series of keels, of which the lateral pair disilneatr early; the shields are olive-brown, each with an orange spot ar streak: the plastron is dark brown, with a yellowish maryin. The adult lowks very different. The shell lats become much more oval, with the greatest width behind the bridge. The lonw shielis are smonth, and in elelerly specintens are without any trace of the original comnective rings of growth. The greneral colom of the shell is uniform grale olive-grey, inclining to yelhw "ill the plistron. The gromel-colour of the soft parts is olivegrey. lut the sides of the head are adorned with orangre-red or ?ollow marks, the patch between the eye and ear and three or 
four stripes on the neck being especially conspicuous. The linnlis hare pale yellowish streaks. All these markings are, howerer. subject to much individual variation. While, for instance, the half-grown creatures are distinctly agreeahly coloured, often with a rich brown, nicely sculptured shell, and with conspicuous mange and rellow marks on the skin, the rery old ones becone rather ugly, the prevailing colour varying more and nore into dull uniform pale olive-grey.

The "Iberian Water-tortoise" is typical of the Iherian I'eninsula, and extends through Moroce and Algeria far into North-TVestern Africa. Unknown to the north of the Cantalnian range, lecidedly scarcer than its cousin Emys in the unthern half of the Peninsula, it becomes common in the south. In the Alemtejo, in the lower parts of Andalucia and in Morocen, there is scarcely a pool, stream, or river in which it is not found, feeding on anc living thing it can master, although fishes and frogs are its principal pres. When the streams and wateromes run dry, during the hot and dry season, the tortoises crowd together into the remaining pools, which soon becone stagniant and filthr. But even these harens of refuge are not of lasting avail. They are soon cleared of anything edihle, and the stinking water becomes dirtier and hotter day by day. Tltinately the turtuises leave the pool to hide under ledges of rocks, where they aestivate for months. This life in the mudly, slimy pools renders these tortoises peculiarly liable to the attacks of a certain fresh-water alga, which enters through the cracks in the horny shields and then flowrishes in the Malpighian layer, and even in the underlying bone itself. This becomes gangrenous in fatches, anl the whole shell assumes a leprous appearance, hence the slecitic name of trpiost. Everything combines in farour wit this ilestructive little alga. The tortoise, corered with mud. batsis in the hot sun, the horny shields become hrittle and crack. often perling off in thin flakes. But those happy individuals which inhalit permanent rivers, or pools which do not dry ul, ares. and remain, as clean as other water-tortoises.

C. lipros has a most disagreeable, offensive smell, something like concentrated essence of fish, due to the secretion of a pair of large glauds situated beneath the skin of the inguinal region, and opening behind the bridge. Freshly caught specimens :tink horribly, but when they have lecome accustomed to heing 
handled, they no longer void these glands. They always withdraw into the witter for the night, and the cold season is spent in the mul. Their time of propatgation is still somewhat doubtful. Very young tortoises are net with in the P'eninsula in Matrch, when they are alleaty in the riress. Those which I imported in the summer and antumn invariahly dueg their nests and laicl their long, orinl egges (2) to :3:) mm. long') in the month of Nowember: pairing laving taken place some two or three monthis flrevinuly. The mole of making the nest is exactly the same as that dercribed for Eim!s. As most of my specimens were liept in a wrenhouse with a permanent current of warm water through their tanks, they never hibernated, nor did they jass through in torpird time in the smmmer, but they showed an irresistible lore for the hot-water pipes, hudilling together ly the dozen, so that the pijes hat to be screened off to prevent the creatures fom setting lumt. Until this precantion was taken, they heated themselve's so much that the shields and even the loones of the plastron were injured. The artificial wimm temperature and the complete suppression of seasonal rest hat no hat influence, most of the tortoises living with moliminished appetite for more than twelle gears, but the sexual period became disturbed, pairin! ocemring ultimately at all times of the gear. The eagremess of the mates, howerer, had a peculiar eril secondinry influence upon the females. The male tries to fasten on to its mate hy biting intu the collatr-like fold of the neck into which the head is withdrawn. and this repeated irritation produces sores and swellings. which latter in their turn perent the female from wiping the "res with the hack of the fore-limlss, a hal)it common to most, if not all. tortoises. Cltimately the eyes fester, and the tortoise. hecoming practically hind, falls ofl its feed, leaves the water, which makes matters worse, and is very difficult to cure.

In other respects they are very hardy, and they stand alchinatisation in England perfectly. Some, thriving in a deep ancreted pond, pased through the very severe winters of serchal rears ago, hiding in the mul helow the ice, and alpreared in the spring in perferet health. They cant also successfully prass the winter under moss and a heap of loose garden-rubbish.

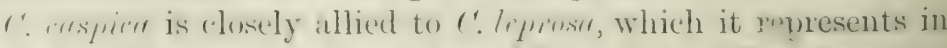
the Balkan Peninsulat and in Asia Minor. It differs firom the south-western species chicfly hy having the entting edges of the 
upper jaw finely denticulated, and by its prettier coloration, eatch shield being ommented with yellowish streaks which form a kind of $\infty$ on the costals, and a ring on the marginuls. The plastron is black in the young, with yellow and black patches in the adult. The hend and sides of the neck are striped with yellow lines, narrowly edged with black, and the rest of the sott parts is mirhled dark olive and yellow. A few other sprecies occur in China, Japan, and North America.

Climm!s insculpta, one of the American species, ranging from Traine to I'ennsylyaia and New Jersey, is easily recognised ly the peculiar reddish-brown and brick-dust colour of the soft narts. The strongly keeled, posteriorly emarginate carapace is recklish hrown, with raliating yellow lines. Each shield is clelicately sculptured. The plastron, which is notched behind, is sellow, with a large black patch on the outer corner of each shield. Length of a full-grown specimen $S$ inches. They frequent the rivers and ponds, lut are also very fond of leaving the water, sometimes remaining for months in dry places.

Mentuculemmys of North America, with three species only, is chesely allied to C'lemmys, from which it difter's chietly by the very broad alveolar surface of the upper jaw, and hy the more forward position of the entoplastron, this being placed anteriorly to the humero-pectoral suture. We mention this senus since one of its species. M. tormpin, is so extensively eaten in the Eistern Inited States. The shell is oral, slightly enarginate behind, whtusely carinated along the mirllle line. The ulnere parts of the shell are brown or greenish, with dark concentric lines; the marginals are yellow below, each with a ring of dark grey, and forming a peeuliarly up-turned rim. The plastron is gullowish, either with concentric stripes and dusky lines or uniform yellow. But it is the colom of the soft parts which gires this otherwise inll-lnoking creature its delicately pretty apleanance. The skin is, namely, greenish white with countless small black dots. 'The males remain much smaller than the females, and have the conrentric stripes more pronounced. This species, the choicest of the edible Terrapins, frequents the salt marshes of the east coust uf Torth America, from Phode Island to the Grulf of Mexico, being most abundant around Charleston.

The following is a condensed account of an article which appertred in the New York Sun, 18th September 1S9s, the data 
of which were suppliet by the manawer of the terrapin-farm at Deanlien, Georsia. The continued hunting and the unfailing demand for them are making them rery scarce, so that enterprising men have estahlished terrapin-firms or "crawls" for the kexpring and hrexting of terrapins. The "crawls" in question are near the river. The larger is : $: 10$ hy 60 feet, and is diviled into there compartments for three sizes. The smaller "crawl" is for the babies, and is 100 by 8 feet. Through both " cramls" puns a ditch comnerted with the river and making a circuit of the farm. The bottom of the "crawls" is on a level with the low tide, and is eorered with a laver of mud alout six inches deel. Inte this the terrapins hurrow in the winter. The average fopulation of terrapins is abuut 40,000 , one halt "bulls" and the other half "heifers." The latter are much better eating, and grow to a much larger size, namely, eight inches on the plastron, while the "bulls" rarely grow vrer fire inches long. When a female reaches six to eight inches it is malled a "count." Those hetween five-and-a-half to six inches long are known as "two-for-threes," while those from fire to fireand-a-half inches are known as "halves." They are fed "xchusively on shrimps and cralss on account of the flarour. alloumh they will eat alnost anything. The 40.000 consume on an avelage twenty hushels of crustaceans a dity. They are quite indifferent to cold. The manager saw some placed in a hlock of ice and frozen fitst to it; after four or five days they were chopped out, thawed, and were soon as lively as ever. The statement that it takes these terrapins only seren years to attain full commeredial growth is surprising. and is problahly an underestimate. It the end of the large " "arwl" is a board to enathe

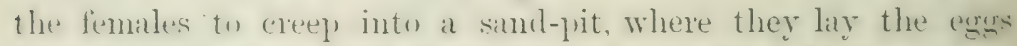
fronn April to onne, eight to twelve forming a set. It is necessiny

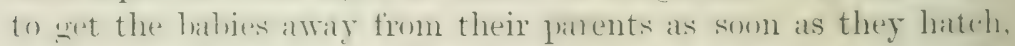
whe they will he eaten. The yomig must mot le exposed to the cold. The old ones have a large amount of curiosity. The best. waly of ratching them is for two men to go ont in a luat with it mot. They row carefully along unt il they come to a likely spot. Then one man raps sereral times shinply on the boat with a stick, and if there are any terrapin alwut they will come to the

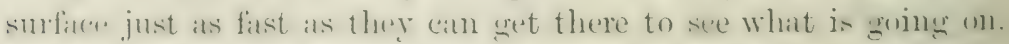

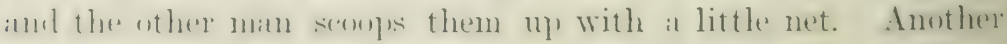


way, used in the salt marshes, is for the negroes to go tranning through the mud and water. If they pass any terrajin these will rise out of the mud to see what the disturlance is. The' captives are then fattened in the "crawl." When the men gon in to feed them they whistle, and terrapin from all orer the "crawl," thousands of them, come swimming through the water, piling over each other in their efforts to get close to the mim with the shrimps and crabs.

Cistudu.-The plastron, without forming a bridge, is commected with the carapace by ligaments, and is divided into two nurable lohes, the transrerse hinge being so perfect that the bux can be completely closed after head, legs, and tail have been withdrawn. The nuchal shield is very small; the first four neurals are large and broad, the fifth much broader than long. There are twelve pairs of marginal shields. The carapace is high and arched. The digits are almost completely free. The tail is rery short. The skull is without a bony temporal arch, the qualrato-jugal and the jugal being absent. Only two species, in North America.

C. curolinu of the Eastern United States is a very interesting species. Closely allied by its internal structure to the watertortoises, it has become absolutely terrestrial; and the shape of the head, the convex shell which is coloured black and yellow or orange-lorown, and the short webless fingers are all terrestrial features. But the rather long toes, provided with long and sharp' cliws, the broad and that feet, enlarged by a broad fold of skin on the outer margin, the long oval eggs, the smooth corering of the hearl, and the preponderant animal diet, still proclaim the ayuatic relatiouship of this tortoise. It is in fact a genus which has changed habits and features from aquatic to terrestrial life. The head is covered with a smooth skin, and the upper beak, esperially in old specimens, is strongly and broadly hooked. The eyes if the males are red, those of the females are brown. The plastron of the males is concave, that of the females is flat. Large females reach a length of nearly six inches. The roung are nearly round, with high, arched back and prominent keels. The keels of the middle line remain a long time, but they gralnally flatten down with age, being prominent only at their posterion ents. Fach dorsal shield is originally nicely sculpturest, with a well-marked areola and concentric rings: Very old individuals 
become munch flatter on the top of the shell, but the sides rematin steep. st that the whole shell romghly resembles a somewhit

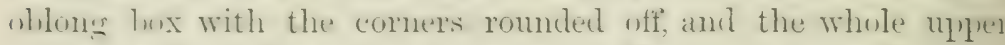
surfice ruhbed down yuite smooth. The variations of colour are almost andless, and they oceur in the same localities. I have a number of all ages from Lomg I-land, near New Tork. The half-grown are heantifully reslitish or orange-brown with

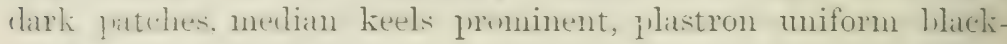
brown. In others the dark-brown prevails over the lighter mathings, which are rellower and nore spotted or dotted than jutcleni. Sonne of the oldest, with quite smonth shells, are: blaks. with small. round, light yellow spots. Others are vermi-

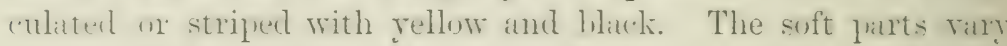
to the same extent, some showing on the neck a beautiful intricate pattern of yellow, retilish and hrown, while in otherthese colnurs are arranged nore or less in longitudinal stripes.

There "Pox-tortuises" are often caurht in the states and liept as pets in the wartens, and their owners mark them he cuttintheir initials into the plastron. These marks heal up and widen in time like letters eut into the bark of a tree. One of my - yeerintens, certainly a very old one to julge from his homker luak. luetectly smenth and flat shell, and from the condition wi the matrinals, which have the elgees rubled down guite smontl:

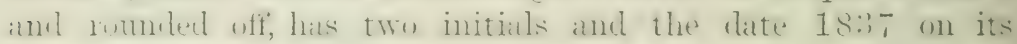
plastron. Of course there is 110 proof that the date had been cut in that year, more than sixty-three jears ago, but it was chne a ling time age. The sars on thrie parts of the shell which twmeh the gromel are almost effaced, and the letters and figmes have hecome somewhat distorterl owing to the usuil

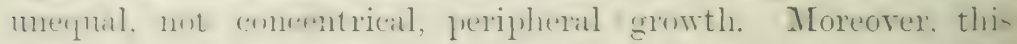
fortoise must have been alrearly arlult, although wot quite fully „2rown, since the markis are lange and were evidently put in such at size and pusition as to fit the arailable slace. I maly mention that this reond tortuise was, when I got it, not kept in confinment, but had been picked up at large.

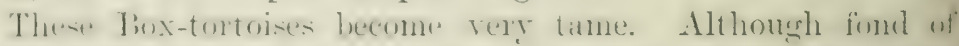
hrinking quantities of water in long and slowly repeated dranghts. the de not go into the water. and if they fall in accilentally they are lialle to get drowned. They enjoy a mixed diet, lum

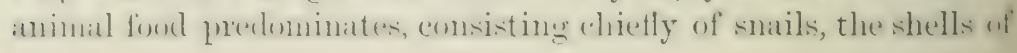


which are passed, slugs, earthworms, maggots, and soft caterpillars. 'Their fondness for slugs is all the more remarkahle sinces scarcelyany other Vertebrate eats these slimy, sticky molluses; but a Boxtortoise will make a meal of two or more fat specimens of the hlack slug stion, and it will eat dozens of small slugs. It first deliberately smells the prey, turns the head sidewards and gives a hite, whereupon first the intestines and then the rest are eaten. The slime is later on scraped off with the forelimbs, or the head is rubbed against the grass. The favourite time of feeding is towards dusk or in the early dewy morning, and they are especially lively during a soft, warm rain. They also relish various kinds of fungi and fruit, for instance halfrotten bananas. Close olsservation of their habits gives us inclications as to how the change from carnivorous to herbivorous halits may have taken place. Accidentally many a blade of gr:lss is bitten off and swallowed together with the molluses, also hiti of rotten wood and moss, and their excrements are often full of such more or less digested matter. They are not very fond of hasking, although they love warmth, creeping into the grass, where they make a shallow form liy moving the shell backwards and forwards. During the cooler nights they frequently retire into a hole or under a log of wood. They require to hibernate. If lept in a warm house they become restless in the autumn, refuse ford, lrink and feed again after some weeks, but are liahle to die during the winter. If they can find a cool place they bury themselves and sleep for several months. If left out of doors they dig into the ground, creep into a hole, at the hottom of which they half bury themselves, or they hicle under a heap of carrlen-rubbish well out of the reach of frost. Warm April days bring them out, and the first requirement is a drink.

When walling about in search of food they assume a curious attitude, with the shell well above the ground, the long neck stretched out and raised high. Their temper raries individually. Some hecome tame readily and lose all shyness, and creep up to their friend to take food from his fingers. Others are decidedly shy and sulky, withdrawing with a hiss into the shell, which in some specimens shuts almost hermetically all round, and they do not come out until all imaginary danger is past. One of $11 \mathrm{y}$ miles sulked thus for several months, at least we never saw anything of it except the closed shell, but it did not starve itself. 
Propagation tathes place in the smmmer, the long oval harrlshelled eggs being laid in June and July.

The TrPI Al LAND-Tortorses are easily recognised hy their feet. The digits are short, have not more than two joints, and are without any trace of wels: the metacarlals are scarcely longer than momi. The hind-feet are cluh-forted. The skin on the anterior side of the fore-limbs is corered with strong horny scales. fremuently with dermal ossifications. The plastron is uniterl suturally hy a lroad ludidge with the usually strungly arched carapace. The skull has complete postorlital am

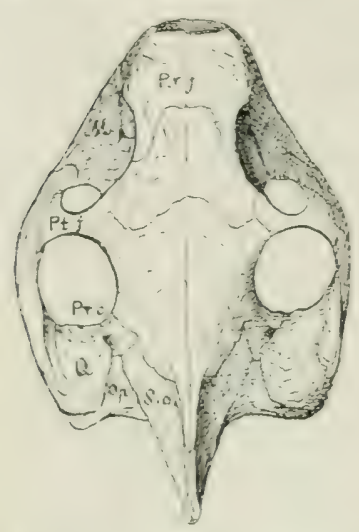

Fig. S1. - Skull of Testudo mivitas. de pluentropes, from the Galapagos Islands. $\times \frac{1}{2}$. H, matxillary: " $\%$, (1) thotir: Prit prefroutal:

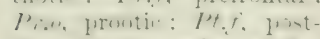
froutal : $\because$ qualrate : S. slima-encipital. temporal arches. The top of the head is covered with shields. The tail is short. There are only a few recent genera, modifications of the central and typical genus Tcstudo. The latter is cosmopolitan in the warmer temperate and tropical regions, except in the Australian and Austro-Malayan countries.

Cinyxis (Fig. 82) with a few species in Tropical Africa from the Gambia and from Abyssinia to the Equator is remarkable for the unique modification of its carapace, the posterior portion of which is movable, the hinge passing between the serenth and eighth marginal and the fourth and fifth costal plittes. extemally hehind the serenth mirrginal and the second costal shields. In the middle of the back the hinge is imlertect, the prits being merely flexible enomgh to permit the justerior half of the hox to he cheed. The head is corered with shields.

1'. Inllirm, of Northern Tropical Atrien, has a small nuchal

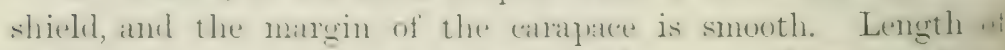

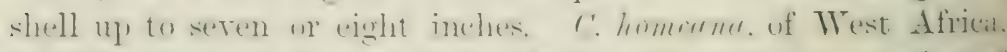
has likewise a suatl nuchal shicels, hut the posteriox purtion of

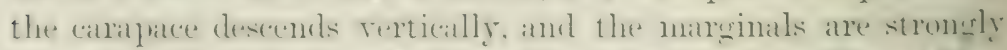

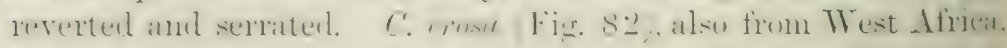
lats no nuchal shield: the marginals are reverted and somated. Int the pesterion part of the caraprace is sloping, and the anterion 
portion of the plastron is strongly forked in front, and projects heyond the anterior border of the carapace. This peculiar creature reaches a length of nine inches. When withdrawn within the shell, which is closed behind and depressed in front, with the jagged edges of the plastron and the anterior marginals protecting the drawn-in head, it has a rery quaint appearance. It lives entirely on fruit and other regetable matter, and is saicl to prefer to lie in the water, while $C$. bellianc is supposed to be entirely terrestrial.

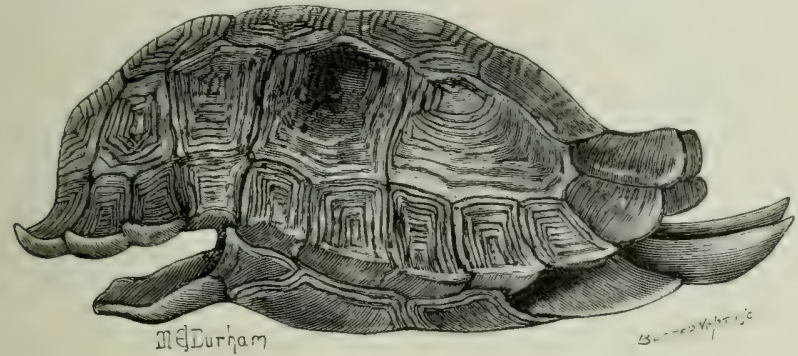

Fig. S2.- rinyxis erose. $\times \frac{1}{3}$.

Pyxis arachnoides, of Madagascar, a small land-tortoise, only four inches in length, has an immovable carapace, but the front lobe of the plastron is hinged.

Testudo.-The plastron is immovable, except that in old individuals of some species, e.g. $T$. ibera, the hinder lobe develops a transverse flexible hinge. They have existed since the Oligocene of North America and Europe; and are now represented by nearly forty species in all the tropical and warmer temperate countries excepting the Austro-Malayan and Australian region. Typically terrestrial, herbivorous and frugivorous, although occasionally varying their diet with worms, molluscs, and insects. The eggs are hard-shelled, mostly less oval than those of the aquatic and seni-aquatic tortoises. The males generally remain smaller than the females, have a slightly longer tail, and have a concave instead of a flat plastron. Most land-tortoises hibernate in the ground during the cool and cold seasons, or they aestivate during the hot and dry months of tropical countries, hut this is not an invariable rule.

T. Irece, the common "Greek Tortoise." The shell is rery convex, without keels, and has a smooth, not serrated margin. 
The nuchal shield is narrow. The titth or last neural shield is much invarter than the other's. The supracautal is usually divided in the median line, su that this is really the last pair of matrinals. The plastrom is notchenl helind: the axillary amb inguinal shichls are small. The scales on the anterior surface of the fore-limbs are small, and form from half-a-dozen to ten loneitulinal rows. The hinder surface of the thigh is quite smooth. The tip of the tail ents in a conical, homy spur. The eolorattion of the shell varies somewhat, lut the gromel-colom is yellow, each shichl with a dark hown centre and irregulat: gatches or confluent spots towards the marsin. The plastron liats an irregular, hoad biack burder. The soft parts are greyvellowish. Somme specinens are rather pale, almost lemen yellow with little black: others incline towards orange with more or less hlack. The midlle tields of the shields of youme specinems are gramular, although this area is rubbed smonth with ates: hut the rest shows clearly matiel concentric lines of growth. The ejes are dark, with a brown or bluish tinge, sonetines inclining to dirk spey in very old speceimens.

Full-grown fenules hate a shell six inches in length. This spercies inhabits the northern half of the Ballian I'eninsula, parts of Asia Minor and Syria, Italy, and most of the islands of the Menliteramean, from the (irecian Archipelago to the Balearie: Islands.

T. ibera is closely allied to $T$. gracea, from which it differs (hiefly in the following pwints. The last prair of marginal

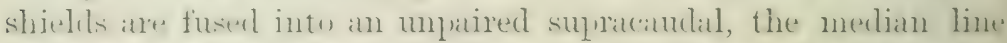
of divisom heing almost obliteraterl. The fifth neural shelil i-

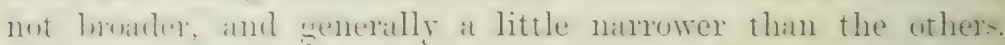
The posterion lolue of the plistrom develoges with age a transterse

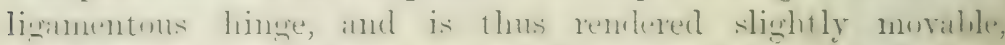

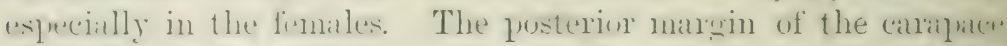

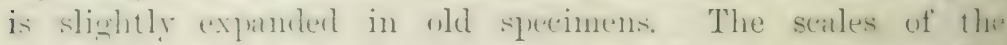
form-limb ate linge and imbricating, and form only fom or tive

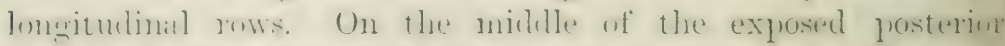

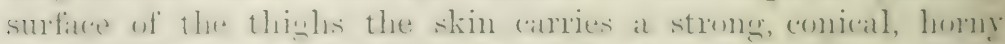

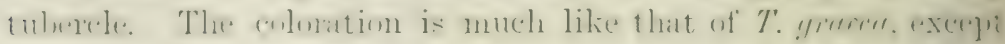
that the yellow of the young inclines to pale olive. Fume specimens are uniform brownish. This species reaches a mult

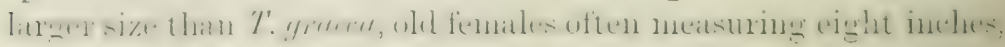


rarely more than nine inches in length. Its home is Mroroceo and Asia Minor, extending into Persia. It also oceurs in certain jarts of Southern Andalucia, where it breeds regularly, for instance, in the sandy pine-forests of the Marismas, near the month of the (ruadalyuirir. Whether it has been introduced from Moriscur), (1) is indigenous, is an open question. Its specific name refer's to its Iberian home.

T. marginate is worth mentioning, since it is the Greek tortrise, although not that of the European marliets, which are supplied by the other two species. T'. murginutu is restricted to (ireece proper, where it is the only land-tortoise. It is less

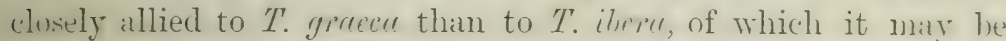
called an exaggerated form. The posterior nnargin of the carapace is much expanded or flanged, and serrated. The smpratcauclat is undivided, the posterior lobe of the plastron is movible, hut the large conical spur on the thights is alsent. The dorsal shields of adult specinens are hlack with a small rellowish patch: the rentral shields are yellowish, each with a large black triangular patch. The British Musem possesses in shell $2 \mathrm{~s} \mathrm{~cm} .=11$ inches in length.

The habits of these Moorish and Greek tortoises are very much alike, and since they enjoy the distinction of frepuently leing liejt as jets in gardens, where they are allowed to lowk after thenselves, a great many incilental and odd olservations hare leecin made on them. They are exsentially vegetahle feeders, but their taste raries individually and with the season, also ac(orcing to the regetation of the comntry they halpyen to come from. Irost of them enjoy juicy plants, for instance, lettuce ancl athlate: the flowers of the dandelion attract them not medely ly their hright colour; clover is also a farourite food, and an enclusure of grass-land with clover in it is son cleated of thr latter: grass is also taken, in default of anything better. Some of my specimens gradually bite large holes into comols and ? mmplins: and in Horoceo I found them in the autumn teeling "untirely on the terribly astringent green fruits of the drate

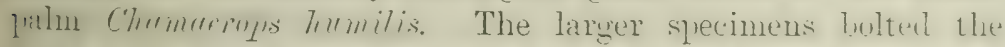
frulit with the stones, passing the latter. In chese calptirity they often learn to take and to like lnead smaked in milk or witer. They drink slowly and at length, hut scarcely erer when thery have succulent food. There is one thing which they to 
not eat. namely: "black beetles," although they are warranted to do so by the men who hawk them in the streets. Worms, slugs, ete: are often nentioned as part of their occasional diet, but I ann nut aware that any of the hundreds which I have watcherl hatre take'n such creatures, in spite of every opportunity. Their habits are very regular. They learn to know the geomaphy of their domain thoroughly, and the spot selected for sterpine will he resorted to orer and over again, be it unlerneath some broad leaves, under a bushy fir-tree, between a chust.r. uf wallthwers, or between some tussocks, or eren in an almost bare corner, the attractions of which are not at all whinns. Although their mental capacities camnot possibly be callext hrilliant, they soon learn to distinguish between different: persons, and they will come up to be feul hut their memory for lucalities is surprising. Here is only one instance. A tortoise which had heen put into an onthouse for hibermation was six months later taken to its usual large enclosure, and in the afternom it tucked itself away on the top of a mound undex precisely the same low bush where it used to sleep during the previous antumn. It could not see that spot from where it had leeen put down, and it did not meander about during the day, hut after having enjoyed the warm sun it made straight for its faromite place. Dr. (rirtamer of St. Gallen in Switzerland testifies to their appreciation of music. When the town-band hesin to play on the square aljoining his garden, all his tortuises (rept as fast as possible towards the fence and remained there nutionless with heads and necks erect. When the piece was finisherl they moved about, but when the next number benaln they were again spellbomul. This he has observed, not. (ni one lint on many occasions. That they can hear, although their ears are not visible, but covered ly the orlinary skin, is mbinms anmoln from the fact that during the pairing season they emit feeble piping sounds.

They are extremely fomd of basking in the hot sum, sometines allowing themselves to be almost baked in it, but then "train at other times they seem to be anxions to seek the shade. They rise litte and go to herl early, heing absolutely dimmal. In the summer they leare their quarters when the sum is well 111, unk king for a sumng spot to graze. Then they lie still and

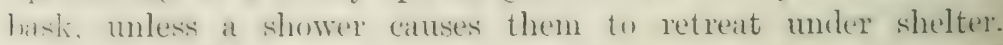


After some hours' rest they feed again, and in the afternoon, long before sumset, they go to bed. Some winters in Endinn are of course much more severe than any which these tortoises experience in their native comtries. Still they manage to survive them, provided they find a place which they can burrow into, deep enough to be out of the reach of frost: and if there is a heap of mould, rotting weeds, and leaves, they are probably safe. Sometimes they are restless, coming out again in unusually mild winters without, howerer, taking food. If they appear too early in the spring, they run the risk of terrilile colds on prolonged wet and cold days, but in the autumn they are hardier, and can stand several degrees of dry frost.

The pairing season begins in May, hut lasts far into the summex. In Morocco I found them pairing as late as the month of September. The preliminaries extend orer many dirys. The male becomes unusually active, makes a piping sound, runs after the female, draws in its head, and knocks with its shell against that of the female. This is repeated many times, until the female is excited enough to raise itself upon its hind-limbs. The eggs, only two to four in number, are laid several weeks later, and are buried in the gromd. They are roundish-oval, hard-shelled, and vary according to the size of the female. Those of $T$. groter measure on the arerage 30 by $24 \mathrm{~mm}$; those of a large specimen of $T$. ilu' 32 to 36 by $30 \mathrm{~mm}$. The newly-hatched little creatures are still quite flexible, and apparently soon bury themselves before lreginning their active life in the ensuing spring.

The age which these tortoises can reach is quite unknown. but there are reliahle data of inclivicuals having been kept for many years. Rumpf ${ }^{1}$ kept two $T$. yrece in his garden at Frankfort-on-the-Main, and let them hibernate in a box with hay in the cellar. One lived $3:)$, the other 23 reals. The most fanous specimen of $T$. ither is "Gilhert Trhite's Tortoise," which had been liept for more than 40 years hefore it came into his possession. It used to bury itself in November and to come out in April. It died in 1794 , having reached an age of fifty-four $1^{\prime l}$ u.s an unknown number of years, since there is no recort of its size when it came to England. The same applies to every other specimen which has been, and is heing, observed as a pet. MI

1 Zool. Garten. 1892, p. 260. VOL. VIII

2 Natural History of Selborne. 
latrgest MIorocen temale, which has a shell 7 inches long, shows at leist 25 concentric rines of wrowth on the shields; the last half-elozen rings are very narrow, while some of those of the central alrea latre been rublied clown. This creature is not imfmobalily :30 years old. A small female, which is only $5 \frac{1}{4}$ inches long has alreany 14 rings on its still perfect shields. Lastly, a little me, only $t$ inches long, shows 7 rings. They grow fastest when they are about ( to $T$ inches long, and they then seem to be at their printe. White's tortoise, now enshrined in the National collection, was umsually latre, the shell measuring at (mil.. or neirly 10 inches: around the much-enlaresed, rubbedduwn alreslat of eath shiell are ahout 30 very narrow rings.

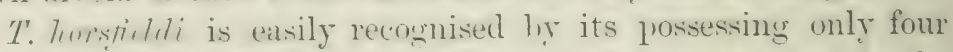
ditws wh the fore- and hind-limlss. It is closely allied to the slecies last mentioned, which it seems to represent in the sindy districts of Transcaspia and the Kirghiz steplyes to Afghanistan.

T. digmus, the "Starred Tortoise" of the southern half of India and Ceylon, is easily recomnised ly the very convex caraface withont a nuchal shield, and by the heautiful markings of the other shielsts, each of which has a yellow areola, whence ratiate rellow streaks mon a black ground. Mroreover, the dorsal shields often form hmmis. It reaches the lemeth of one font. Olil specinens lose the leantiful vellow rallation, owing to a considerable amount of peeling off of the horny layers.

The hahits have heen carefully watched by Captain Thomas Huttom, who gives the following aceount. The tortoises live in the grassy jungle at the hatse of the hills, hat ow ing to their colour being si hemelet with the rocky nature of the sround, they are with difliculty distinguished. Mroreorer, they remain concenlerl heneath slmuls or arass during the heat of the diey. In the rainy season they are most active, wandering about all diy, fereling and frating. At the alpromeh of the cold weather they seleret at sheltereel spot and conceal themselves ly thrusting their shell into sme thick tult of griss, rematining there in a sort of lethargic, but not torpid, inactivity until the hot season, it which time they remain concealed only during the heat of the day, coming ont about sunset to feed.

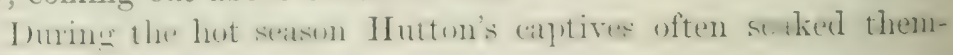
3. J.Asiat. Soc. Bengal, vi. 1837, p. 689. 
selves in water, and they drank a great deal. Connlation lasted about ten minutes; the females received the miales from the end of June to the midlle of October. On the 11 th it Norember a female dug a pit at the root of a tuft of grass, hitring previonsly watered the spot, then digging with the hind-linus alternately, and continuing to water the soil. In two hours she hat male a hole six inches deep and four wide; she then laid four pure white eggs, each about $1 \frac{3}{4}$ inches or $45 \mathrm{~mm}$. long, and filled the hole agrain with the prepared mud, pressing it well in with the feet and with the weight of the hody. The whrile operation took four hours. From December to the begimning of Fetruary these tortoises were listless, they then took water and some lucerne, but did not come out again until the middle of April. well in the hot season. Buth males and females mrestled in a curious way. One confronted the other, with the heal and forelimls drawn into the shell, and with the hind-linbs plantel fimly on the ground, and in this manner shoring against each wher in any narrow space. Sometimes, if one succeecled in llacing its shell beneath the other, he tilted his adrersary orer on his back, from which position he had great difficulty in recovering himself.

T. Pmlyplemis, the "Ciopher Tortoise" of the south-eastern States of North America, is one of the few American species. It is characterised by the shape of the front lobe of the plastron, which is bent upwards, and extends beyond the carajace. The nuchal shield is present, not narrow: the supracaudal is undirided. The shell is much depressed, and Hattened along the vertelual region, with rounded margins. The fore-limls are armed with rery strong cliaws. The general culour is rery dark lrww abore, inclining to black: brownish yellow lelow. with liackish patches. The length of the shell is about one foot, I eren eighteen inches.

The Gopher is interesting for its habits, which are dercriluel ly Agassiz, schnee, and others. Its domicile consists of an excavation, the mouth of which is just sufticient to aumit the animal, the burrow running in an oldique direction to the lefoth of alont four feet. The whole passage is sometines more than two yards long. It expands from the entrance, and enuls in a rminy space, sometimes with a few branches of fir trees which larve been dragged in either for food or as a lining. The lourrow 
is inhalited ly one pair only. When the dew is on the grass, or after rain. they emerge in search of fook, which consists of Erass, sucenlent veretables, fruit, ete. Ther also eat the gum that exules from trees, esprecially the resin of the pine. The eng- are lial in . Tunte, not in their lomicile, hut in a separate "arity near the entrance : a set consists of five egass, almost romnd, and rery litrere, namely, $40 \mathrm{~mm}$., or more than one inch and a half in clianeter. To capture the (iophere al detp hole is dug at the mouth of their home, into which they fall as they emerge for foml. In fiouthern Texas and neighlouring garts of Mexico they are represented hy a smaller and lighter colomed species.

T. Anlmlotu, widely spreat orer Tropical South America, whence it is often brought over as a curiosity, reaches a large size, sprecinens nearly two feet in length being not uncommon. The shell is flat on the top, and is very elongated, without a muchal, hut with an undivided supracaudal shield. The carafuce is very dark hrown or black, each shiels with a rellow or orange centre; the plastron is hrown and yellow, the dark colour heing mostly confined to the middle portion. The sromed-colour of the shin of the limhs is blackish, hut the scales are orange or red. The head is yellow and black. This species inhaloits the forests, and lives chiefly on the fruits of trees; in captirity they are said to talke breal soiked in milk or water, lemons, apples, banamas, cablage, gourds, and also meat, at least the males.

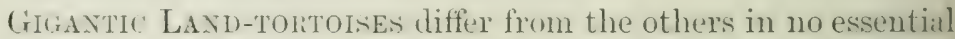
points excest their large size. The term gigntitic is, howerer, applied to many of them hy courtesy only, since they do mot exceed the dimensions of large Turtles. A truly gigantic species. T. whlos, hats left its remains in the Sivalik Hills of late Mincene or early l'liocene dite. The skull is between seren and dight inches long, and is well preserved, hut the corrertness of the dimensions of the specinen, as it now stands, restored in the National collection, is ngen to doult. The shell was probalily not more than six feet long. Miocene and P'lincene Europe was alsu inhahiterl by latre tortoises, with shells ahout four feet long, e.g. T. preprigniom, whose lwny plates are one inch thick: others have heren foumd in Nortle America. Such large tortoises are now restricted to two widely sepratated regions of the world, namely the Galapatges Islands (which have received their name from these creatures, grelipurgn leeing one of the Spanish terms for 
tortoise), and the islands in the Western Indian Ocean, nanely the Mascarenes (Bourbon, Mamritius, and Rodriguez), the Comoros, Aldabra, the Amirantes, and the Seychelles. When they hecame extinct in Madagascar is not known, but $T$. greculintirri was a rery large species of apparently very recent date. Of the other islands the Comoros only were inhalited by man, the other's were deroid of any but small and harmless Mammals. It was on these peaceful islands that large tortoises lived in incredible numbers, and, like the Dodo of Mauritius and the Solitaire of Rodrignez, grew to a size far beyond that of their less farourably plicert continental relations. The same applies to the tortoires of the Galafagos Islands. I'lenty of food, a congenial equable climate, and alisence of enemies enabled them to enjoy existence to the fullest extent. There was nothing for them to do hut to thrive, to feed, to propagate, to grow, and to rary. At least there was nothing to check variation within reasonalle limits. Scattered orer the many islands, they were prevented from inter-hreeding, and thus it has come to pass that not only every groul of islands, lut in the case of the Galapagos almost every island, has or had its own particular lind, be these called varieties, races, forms, or species.

There are four features of special interest. First, these tortoises grow to a large size, and there are no small species on any of these islands. Secondly, they vary much individually. Thirdly, each island or group of islands has developed its own lind. Lastly, there is the widely spread tendency to reduce the thicknes. of the bony plates of the carapace, in spite of its size. In some cases, notably $T$. rosmani of Rodriguez, the bony shell is reduced to aplarently the utmost limit compatible with mechanical wafety. The horny shields are, or were, howerer', well developed, sometimes much more so than in other recent land-tortoises. Whatever were the original reasons for the development of a strong shell in tortoises, they cannot have prevailed in these islands.

Trhere did all these tortoises come from, and how did they get to these oceanic islands? Accidental tramsport or migration are out of the question. Land-tortoises are drowned within a few hours. Moreover, there are none of their lind on the continents of Africa, Asia, and South America, although they had a much wider distribution in past geological ages. Consequently we have to assume that they are descenclants of tortoises once pryulating the land which, except the islands, lies now below 
the western Indian ocean. The existence of this, "Lemuria" or "Gomlwana." came to an end in Mid-Tertiary times. The large tortoises on the remaining continents diend out-in any case they ure ginne, while those which lived un, or retreated to, what became the present islands, survived and flourished.

The turtoises were not left in peace with the adrent of man, who fom that they were good to eat. They were first exterminated on the Mascarene Islands. In 1759 four small resiel: were specially appointed for the service of bringings tortuis from Iindrign: to Mamitius: one ressel carried a (aryo of 6000 ; and altogether more than $: 30,000$ were imported inti Mamritius within the space of eighteen months. Dr. Giinther very properly remarks that many of these tortuises must have heen small-sized specimens, and that many of them were probably

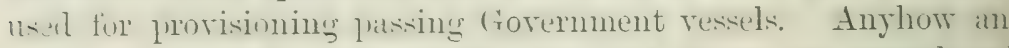
inter-insular trattic was carried on, and there are records of sinerflums tortoises having heen turned loose, at the end of the voyage, in distant islands, even in Java. Importation and exchange of choice specincens, hy way of presents, seems also to have tiken place. All this makes it now actually imposible to trate the original halbitat of the few surviving specimens with anything like certainty. At the beginning of this century the latre tortoises had heen nearly cleared off most of the islands. and at the present time only the south island of Aldabra enjoythe reputation of still posiesing some really incligenous tortoises. The few survirors on the other islands are said to have been introIncerl. The small stock at Aldaliza is now under Gorermunent protection. Liepresentatives of varions species will linger on for a little time to come, when they are kept as jets on some tropical islands, lut those which have been loromght to Emrope are of comrite doomed.

We can mention only a few of the large tortoises which hare lecome famous, not to say historical. I fascinating résumi of the whole complicated fulestion has heen given ly by. Giinther. ${ }^{1}$

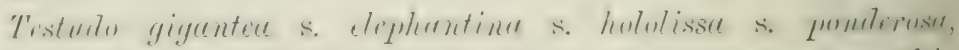
miginally confined to the North Island of Aldabra, where this

1 Presidential Address. Proc. Linn. Soc. 1898. See also Güuther, Gigantic Land-Tortoises, Brit. Mus. London, 1877; Gadow, Trans. Zool. Soc. xiii. 1894,

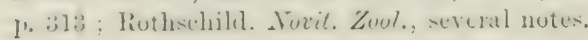


kind has been completely exterminated, is now still to be found in the Seychelles in considerable numbers, introluced there lis planters, and kept in a state of semi-domestication. A very liarge specimen was received by the Hon. Walter Riuthechild, at Tring, in 1893. In 1897 its shell measured $40 \frac{1}{4}$ inches in length, $52 \frac{1}{4}$ orer the curve, and 50 inches across the curve transrersely; it weighed $358 \mathrm{llks}$. The measurements taken in previous years are unfortumately not free from mistakes. "Whenever the temperature was orer $60^{\circ} \mathrm{F}$. this tortoise had a fre rum of 350 acres of grass park, and when the temperature showed permanently below $5 \mathrm{~S}^{\circ}$, it was kept in an orchicl house from September to June. Then at liberty in the park it lived entirely on grass, but in the hothouse it fed on carrots, cablage, lettuce, and several other vegetables" : it was also rer's fond of rotten fruit. To this species belongs the large tortuise which has been living at st. Helena for more than the last hunched years.

T. Anuctini is the species of the Sunth Island of Aldabra. Voeltzliow, in 1895 , succeeded in carrring off seven specimens. He gives the following description:- The island is an atoll, cut through in three places, with a greatest length of about trenty miles. The chief hindrance in the search for the tortoises is the impenetrability of the island. The soil consists entirely of shar' water-worn corals, with their points upermost, while the whole is corered with such thick masses of low scrub, that a way has to be cut with an axe, so that an extented search orer a large areit is cut of the question. To land on the outsicle is dangerous, on account of the heary surf; while landing from the inside of the atrill is much hindered by the dense thickets of mangrove trees. As drinking water, and that rery bad, is only found in one flace, rainwater has to he collected from the natural hollows, and camried along in tanks. Thousands of mosquitues prevent one remaining orer night in those places which the tortoises freyuent. Then at last, when one has discorered, liy a stroke of luck, one of these creatures, in the thick scrul, where they hicle during the heit of the day, the real hard work begins, namely, the conveyance of the beast. Six reached Europe alive, two of them were sent to Frankfort, and the four others to Hamburg. Mr. Iisthschild received a male of $T$. Aructini, which, until its recent death, was the largest living tortoise known. The length 
uf its shell wats ij inches, on $6-1$, inches orer the curve : total weight 560 lbs. This specimen. had a chequered career. Althomoh its mininal home must hate been the Aldatha atoll, it hath heen known for many years on Eirnont Island, one of the ('hatgrs Islants. Acompling to tratitions. it hat been there sunte 150 rears, but the first settlement on that islanil was

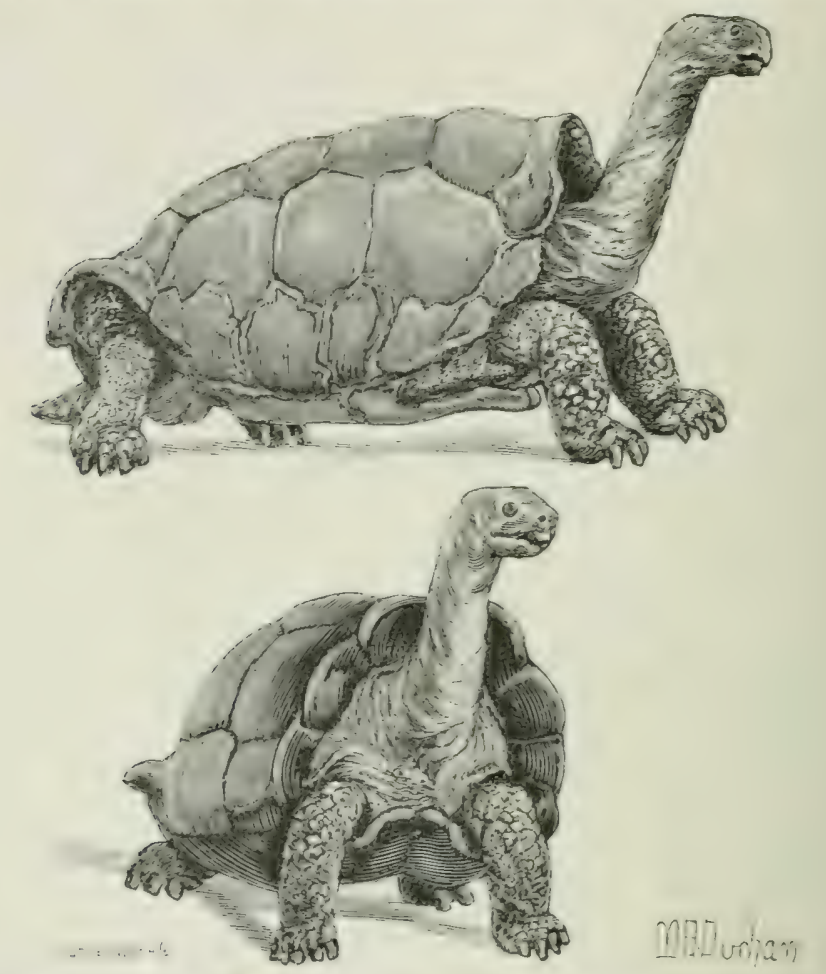

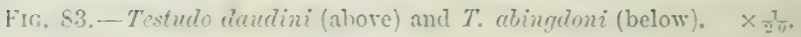

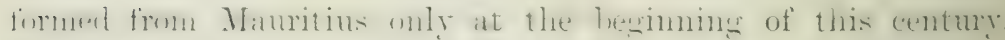
The owner of the tortoise, MI. Antelme, took it to Mamitius, whence it came to England. On the Egmont Island it used to bury itself for six months in the ground without eating anything.

T. sumeirei.-This kind is supposed to have been the species

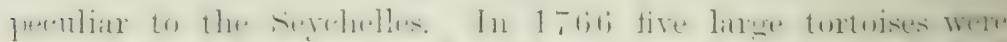

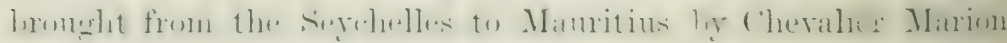
de T'resne. Of these only three were alive in 1898, two in 
Maturitius and one in London: the latter specimen soon died in the Zoological Gardens. One of the two survirors, the last of their race, is famous. It was kept at Port Louis, and when Mauritius became a British possession in 1810 , the tortoise was especially mentioned and taken over. It still lives there in the grounds of the barracks of the garrison. Accorting to the proverbial oldest inhabitants it had in 1810 already reached its present size, namely, a shell-length of about 40 inches with a greatest circumference of 259 cin. $=8$ feet 6 inches. Total weight 160 kilo=about 358 lbs. When walking it stands $635 \mathrm{~cm} .=25.1$ inches high, with the plastron about 15 ('in. or 6 inches above the ground, and it can then carry with tast two full-grown men on its back. This old male is now nearly blind, but is otherwise of regular habits and in good health. Although it hats been known for nearly 150 years it had to wait for its scientific name until the year 1892.

Another famous individual is the Colombo tortoise. It is supposed to have come to Colombo from the Serchelles in 1798. It died in 1897 . To judge from photogralls, this specinen, a male, may possibly belong to $T$ '. sumcirei, in spite of the ver' Hat shell, which is $53 \frac{1}{2}$ inches in length.

Leaving aside the remains of sub-fossil tortoises, $c \cdot y$. the thinshelled $T$. cosmatri of Rodriguez, and several kinds which have been dug out in the Mare-atux-songes of Mauritius, one of which had a markedly forked and prolonged anterior plastral lolie. rather resembling that of the Pliocene Siralik T', attus, we now turn to the tortoises of the Galapagos Islauls. They existed in enormous numbers towards the end of the serenteenth century. when Dampier visited those islands. Hundreds were exported and scattered early in the nineteenth century. When the islands became a penal settlement of Ecuador, the introduction of cunricts and pigs proved detrimental to them, but Darwin founcl them still present in 1835 on most of the islands. His clatssical account of these old giants is to be found in the Troymye of the Brugle. They lived on the succulent cactus plants, leares of trees, herries, and a kind of Usnen, a lichen pendant from the trees. They collected regularly at certain pools and springs, leading to which were regular well-trodden paths, formed by the coming and going of the tortoises. He calculated that they could walk a distance of about four miles in one day. Inuring 
the time of propagation the males enit a hoarse bark, which can

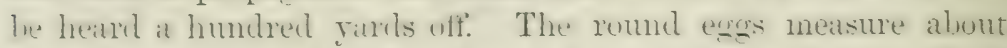
is (nil. or 2) inches in dianeter, and are laid in the montl of October, about oue dozen making a set.

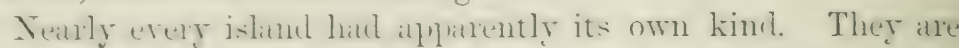
all remankinlle for their small head and the length of their neck. whinh is decidently longer and nume slender than that of the Eirstem tortuises. The most peculiar lowking are or were T.

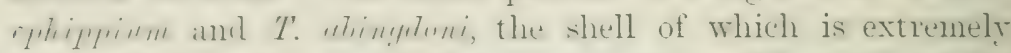
thin. with latre latume in the astenus plates. The protile of the shell is somewhat suldle-shatped, with the horny shields partly (monatre and turned upwards at the siles. The general colom of

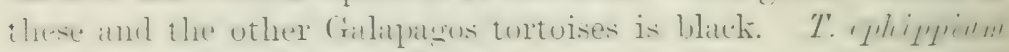
still survives on Duncan Island. Of T. eleppentopus s, vicine

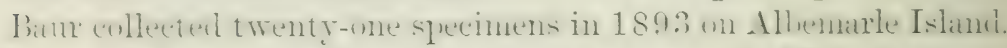
sone of them are still complatatively young, only 1 li inches long.

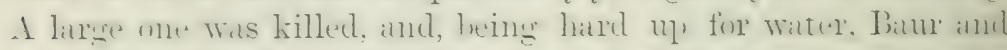
his complanimos dank the tive culs full of thud contained in the

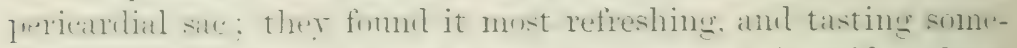
what like the white of an egg. One monster is said to hàve mesumel 5 in inches over the curve, with a skull $7 \cdot 12$ inches in length. Mrr. Rothschild received one of this kind alive- $\mathrm{a}$

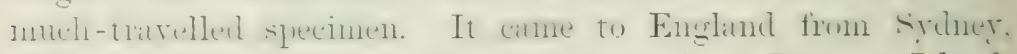
whether it had been brought in 1880 from Rotuma Island.

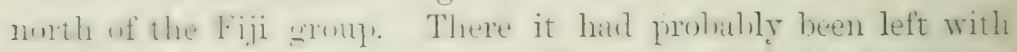
whers ly faptain l'orter, who, on his voyage from the Galaplaters in 1 s lo distributer serelal poung tortoises from his stock

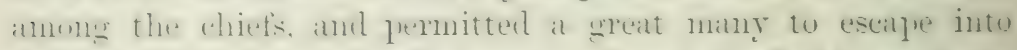

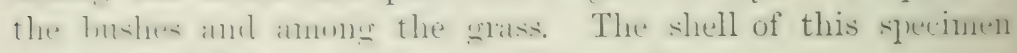

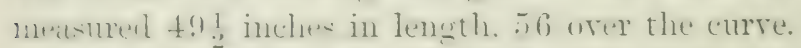

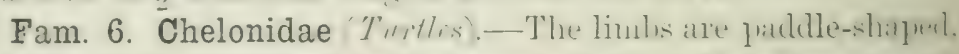

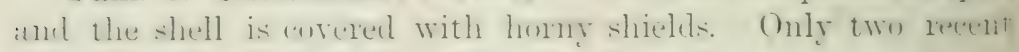
stenera, with three species, widely distributent in the seats.

The mek is slont and incmingledely retractile. The temperal

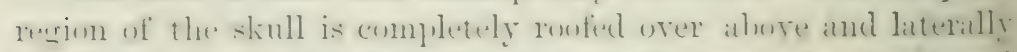

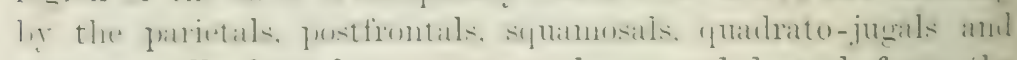
jugals. All these bones are much expanded, and form the

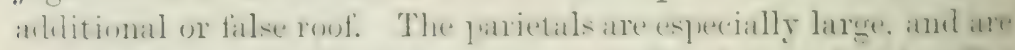

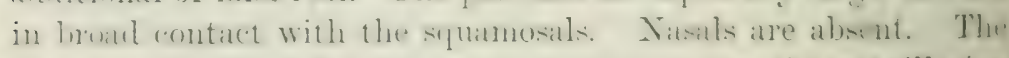
nares are horlered ly the small furmaxillaries, the mavillario. 
and the prefrontals. The choanae are enclosed by the palatines, which are separated by the romer, and are posteriorly in bruad contact with the pterygoids. The latter are comnected with descending processes of the parietals by epipterygoids. The foramen magnum is bounded not only by the supra-occipital and the lateral occipitals, but also by the basi-occipital. For the slieleton see Fig. 65,1 . 320. The pul,ic and ischiadic symphyses are connected hy a narrow cartilaginous band. The pulis has a large, hroad, lateral process, but the ischium is devoid of such a process.

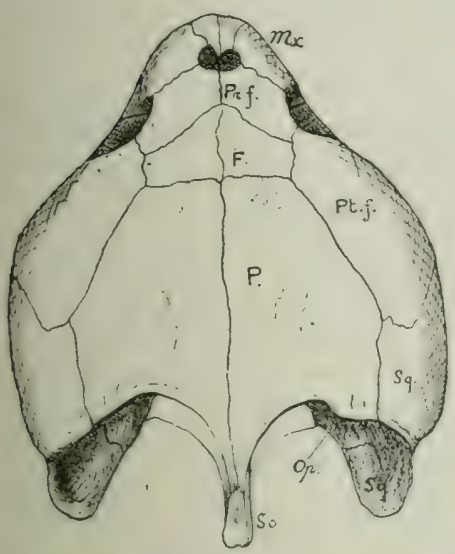

A

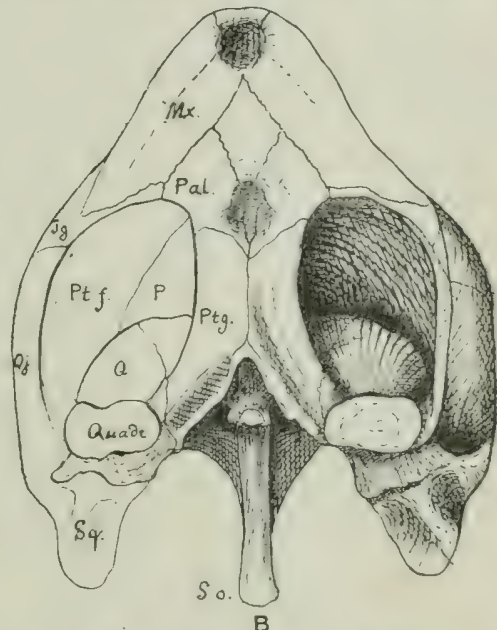

B

FIG. 84.- Skull of Thatassochelys caretta; cf. also Fig. 63, p. 31\%. A, Dorsal view ; $B$, ventral view; $\boldsymbol{F}$, frontal; $J_{g}$, jugal; $\boldsymbol{I} x$, maxillary ; $O p$, opisthotic ; $P$, parietal ; Pcl, palatine ; $P r . f$, prefrontal ; $P t . f$, postfrontal ; Ptg, pterygoid ; $Q$, quadrate; Quadr, articular surface of quadrate; $Q j$, quadrato-jugal ; S.O, supraoccipital ; $S q$, squamosal.

The praddles of the fore- and hind-limbs are produced by an dongation of the metacarpal and metatarsal bones and of most of the phalanges, and these have no condyles; most of the carpal and tarsal elements are flattened, and additional width is given to the hands by the much enlarged pisiform bone. The number of phalanges of the five fingers is $2,3,3,2,2$; that of the fire toes, $2,3,3,3,2$.

The carapace is heart-shaped and rery flat. The nuchal plate lats no rih-like processes. The eight neurals form a continuous series, and the short tail is covered by two or three prgal plates lesides the unpaired last marginal. The number of all the 
marcinals is 2.), sonetines 25 inclividually. The plastron (Fig. (66. 1). $: 21$ ) is comprosed of the usial nine plates, which, however, remain entirely free from the marginals, and are only loosely connecterl with each uther, enching a rery large unossified sprece. The lumy shielis covering the plastron number $1: 3$, and there is a series of alout o infranimginals (Fig. $(41,6, p .315$ ), There ane nurmally 12 jairs of marginal shielels, a muchal, 5 neural, and 5 or 7 costal shields. Whilst the number of

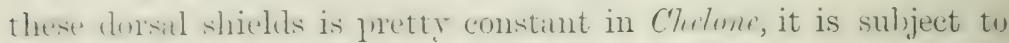

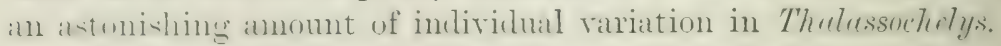

The Chelonidae are a highly specialised offshoot of the

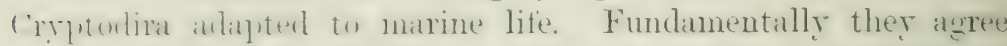
mon with the Testudinidae paraluxical as this may aplear at firs sinht. There is nothing prinitive almot then except the (-mmplete series of inframarginal shiehls. Fossil forerunners of marine turtle-like (reatures appear in the Cplper Jurassic deposits uf Europe and North Anerical. The numerous genera have heen

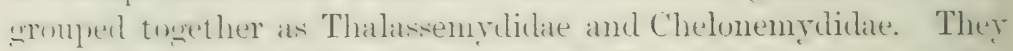
are nume or less intermediate hetween Cheloniclate and Emys-like

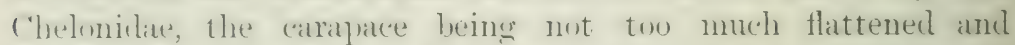
hrmalemel ont, the fontanelles letween the ribs are mostly small. 1he plastral innes are still hroul, enches a smaller ussified spare,

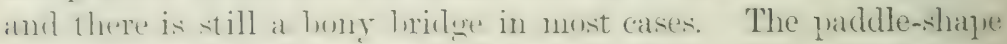
of the limbs is less pomouncell, and sometines only indicated. In sinne forms. especially Lyfulmm, from the L'per Cretaceous and Eocence of Corth Aneriea and Eurone, the anterior portion of the

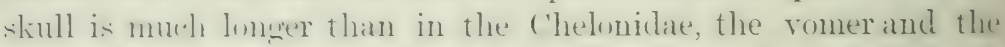
forentaxillaries are elongaterl, and the anterior pertion of the ronot of the mouth, with the corresponding parts of the lower jaw:

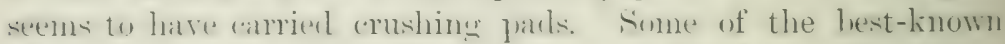

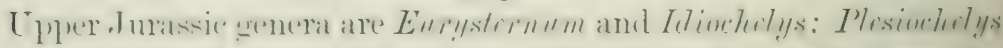

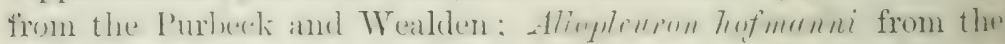

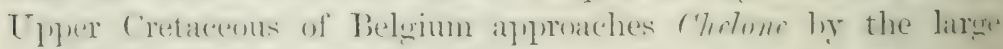
fontanelles hetwen the small marginal and the short costal plates. True ('helminlate are very rare and imperfect in the Misl-Tertiary strata, but both recent generat seem to have existed since Pliocene times.

The few rexent ('heloniclia are entirely marine, going on land mly in order to deposit their eages in the sands of underpuenterl shores. Their distrihution, in conformity with their ocennic life, 
is almost cosmopolitan within the warmer zones, but not a few find their way far into the temperate seas. They are all eagerly hunted by man either for food or for the sake of the tortoiseshell.

Chelone- With only four pairs of costal shields. Carapace with large persisting fontanelles between the costal and marginal plates. Two species.

C'h. mydus (the " (rreen or Edihle Turtle") has when adult a neirly smooth shell, all the shields being juxtaposed, fitting closely into each other, and becoming quite smooth with age. The neural shields of younger specimens have a feetle keel. The twenty-five shields which surround the carapace form a smooth, or but indistinctly serrated rim. The head is corered with one pair of prefrontal shields, the others are small. The horny heaks of the upper and lower jaws have denticulated outer edges, those of the upler jaw having two pairs of strong denticulated ridges. The limbs have generally only one claw, namely on the first digit. This claw, although sometimes curred and thick, and more than an inch in length, is blunt. The general colour is olive or hrown above, with yellowish spots or blotches; the under parts are pale yellowish. This species attains a large size, with a length of shell of nearly four feet, but the usual length of full-grown specimens is three feet, and these weigh, when in goud condition, more than three hundredweight. Their home is in the Atlantic, Indian, and Pacific Oceans, hut there are certain regions in which they are more common than in others. Famous centres are the Island of Ascension, the West Indies, and the coast of Mosquito, at least for commercial purposes. As they require sindy, easily accessible beaches for the deposition of their eggs, they congregate in certain parts of the world more than in others, and being strictly regetable feeders, ther are naturally bound to the coasts, although they are sometinies met with far ont at sea. Their chief food consists of algae, and of Zostera morina, the edible "Dulce," which grows plentifully in the lagoons of the coast of Florida. When they have eaten their fill, they are said to chop off more of these plints, and roll them, together with the adherent mud, into balls of the size of a head, and these balls, receding with the tide, are followed by the Turtles.

Whilst in the water they are caught in various ways, with 
nets or harpoons. In sone parts of the world the natives follow them in a haat, and when they esuy a turtle crawling along the bottom, a mam, attacherl to a ropes clives in, clasps it, and is hrought up hy his compranions together with lis prey. Turtles are fomd of hasking asleep, fluating on the surface, and they are then harponned from a stealthily apluraching hoat. The most original morle of catching them is that used hy the natives of Tomess straits, Mandargatsar, and C'ulat. The turtle-fishers go out

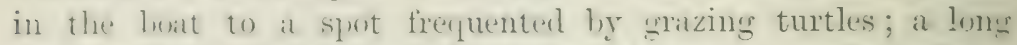
string is ties to the tail of a fish, Eirhoris, a memher of the

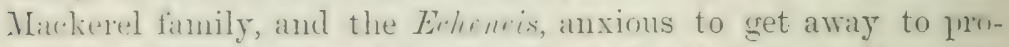
tertioe shelter, makes for a turtle, and attaches itself to the turtes platitrom ly means of the large sucking apparatus on the top of its hearl and neck-renion. The men are gruided ly the string, and the turtle is gently colaxed up towards the surfice or finlowed into shallow water, where it is either harpooned or diverl fin. It is corious that this use of the Erferne is exists in such widely separated parts of the world, the natives of which canmot have any linowlerdge of each other. These modes of catching turtles are sortsman-like, lut the sreatest and most wanton destruction is practised at their breeding places. In conformity with the wile distribution of these creatures, the time of lireenting is not the sanne erergwhere. In the Wrest Indian renim, and in the straits of Malacear, it falls within the period of April to June; on the coast of West Africa it occurs from

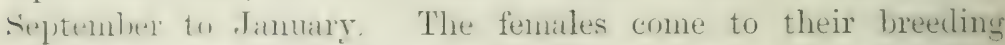
1lices firm at ax, recommoitre the leach carefully, are extremely wary and shy, taking alarm at the slightest disturbance, and at lit<t ratwl on land. Trell ont of the reatch of the ticle the female

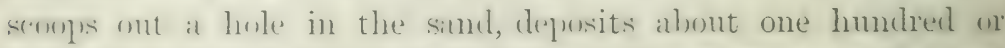

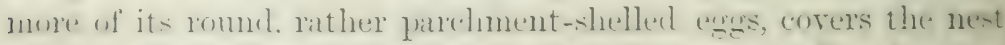

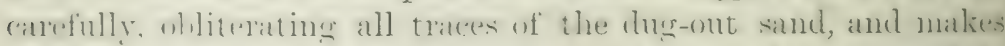
again for the seat hy anotleer route. It least they are satel to make a sort of circuitous route so that nobody can tell th:

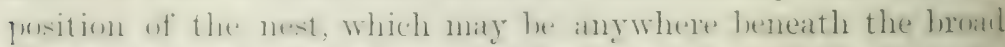

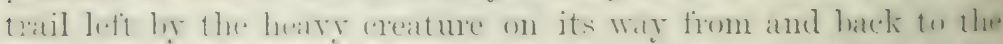

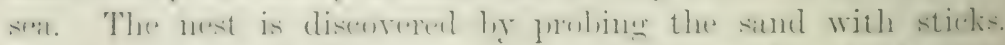

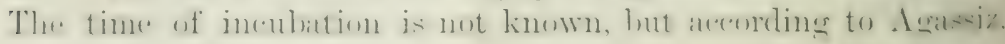
lasts at least seven weeks.

The "turning" of turtles is a cruel and wanton operatimn. 


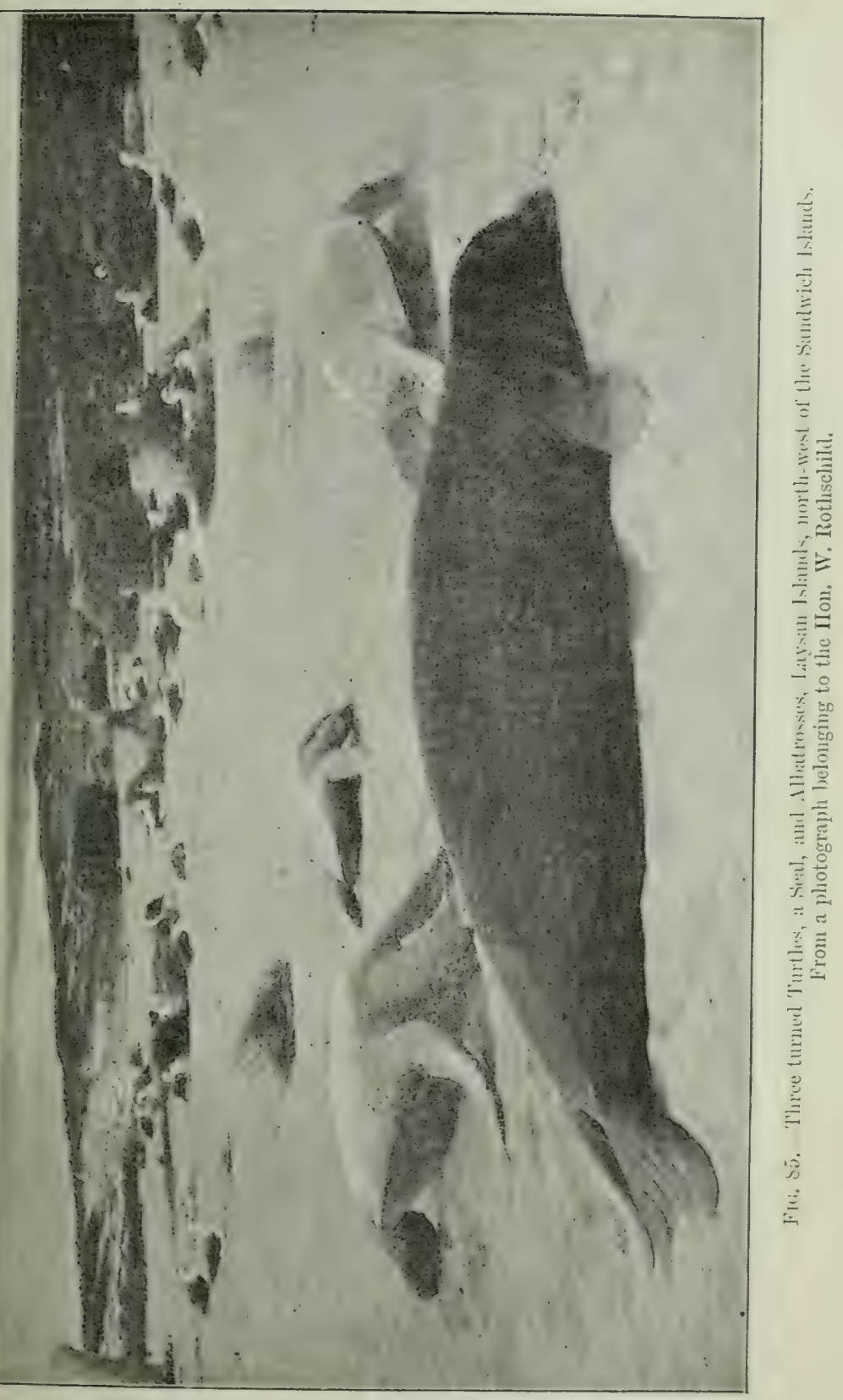


since frefuenty many mure are turnerl wrer and left to prerish than ane titken away. Men lying in ambush watch the beast,

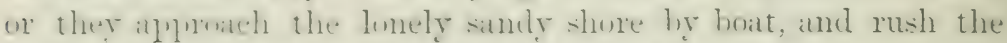
helpless coratures when these are surpurisen in sufticient numlers. It takes sereral nen to lift a full-wrown specimen. It is there-

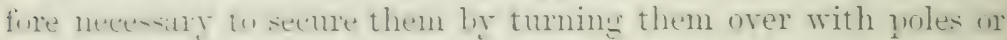

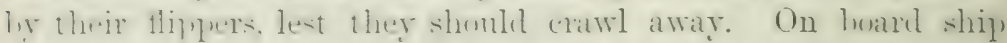
they are either jut inte tanks ar tied with ropes on deck. corered

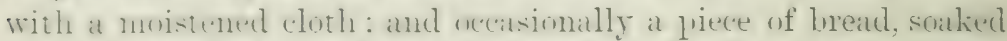
in seatwater. is thrust into the parched mouth. In London they are kejt in large tanks, wfen in comsilerable numbers, hut sine

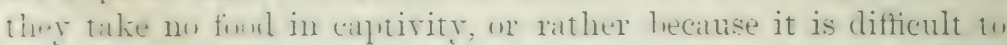
-mbly them with the right sont, they are not liept long. After the leaml hats been (ut wif, the borly is suspended for a day or two, in ordere to drain it of the liloor. It is not only the meat and the fat which are uset for the making of the famous soupr, lnt alsu the thick and dense layer of sulucutaneous tissue which lines the insicle of the shell.

Tennent descrilues a rerolting spectacle exhilited in the nuarkets of . Tatfina. in Ceylon. The flesh of the turtles is sold pieceneal liy the Tannil fishermen, while the animals are still alive. It certain seasons, says the same authority, the the- of turte on the south-west coast of Ceylon is usuably arrideil as poismons, hut sone lamentable instances are recorded of neglect of this, and conseyuent sickness, followed hy coma and deatl. In the finlf of Mimalar specimens are frequently fomm hetween four and fire feet in length: and on one vecasion, in riding along the seashore north of l'utlam, he sia a man in charce of sinne sheepr. resting under the shacle of a turtle shell. which he had erected on sticks to protect him from the sum. In commexion with this curions sight, Temment quotes delians

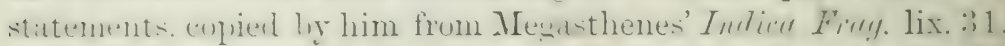
that in the Inclian ocean turtles oceur which meatsure fiftern ells. si that not a fiew prengle may find ample shelter beneath a single shell.

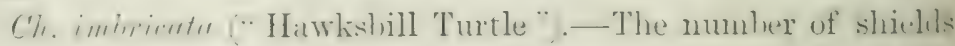
covering the carapace is the same as in Ch. mydas, but they

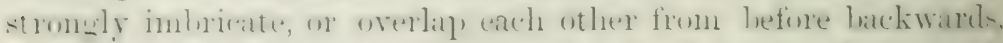

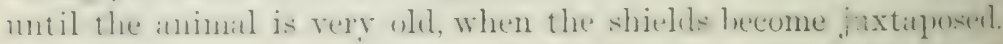

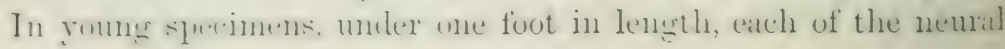


and costal shields is strongly keelerl, the three rows of keels converging towards the posterior end of the shell. The nemral series of keels is almost continnous, and remains longest, eren in half-grown specimens. The twelve pairs of marginal shields form at first a strongly serrated sharp edge; the serrations disilplpent sractually on the front portion, but remain on the posterior half of the shell. The horny cover's of the jaws form a hooked beak, with sharp but smooth or feebly denticulated margins. The fore-

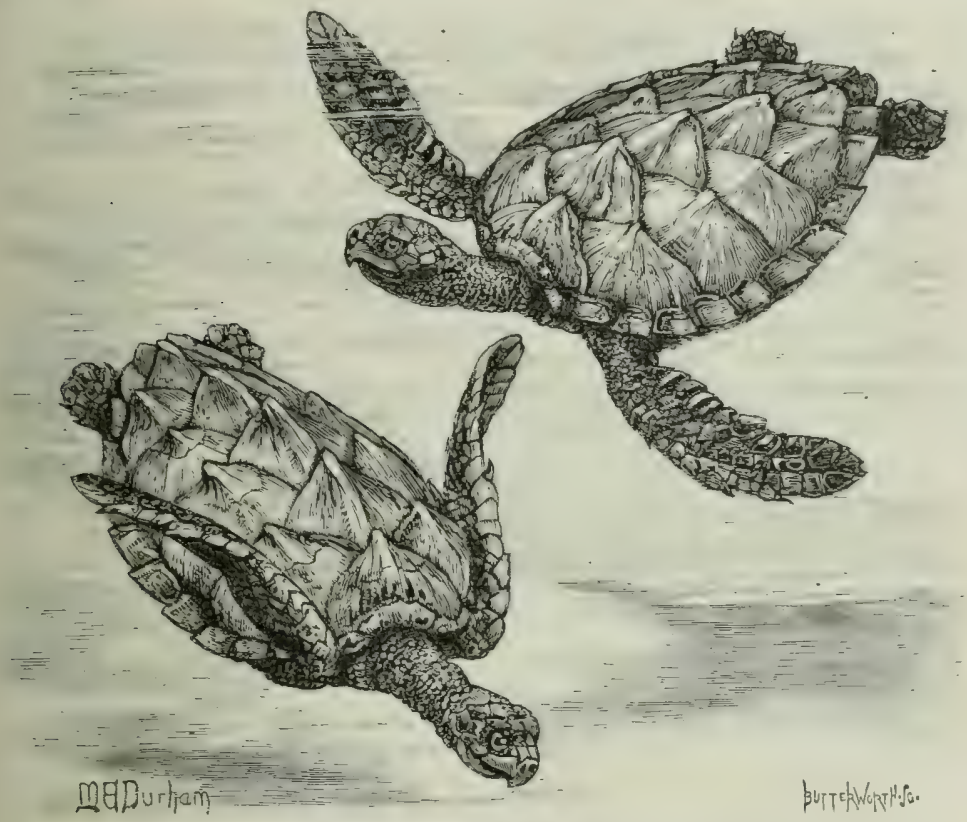

FIG. 86. -Chelone imbricata ("Hawlisbill Turtle"), young. $\times \frac{1}{2}$.

and hind-flippers have two claws. The young are pale brown above, blackish below; the shell of the adult is beautifully marhled with yellow on a rich dark-brown ground; the plastrom is yellow. The shields and scales of the head and limbs are ditrk brown, with yellow margins. The top of the head is covered by a linrge unpaired frontal and a pair of prefrontal or interorluital shields. This Turtle does not reach the size of the sreen or eclille kind; the liurgest shell on record is in the Nitional Collection, and measures $85 \mathrm{~cm} .=34$ inches in length. They range over all the tropical and sulhtropical seas. They are aprarently strictly car- 
nirorous, living upun fish and molluses, the shells of which ther crumch. Although not caten, they are much persecuted on accomit of their shells, the horny shields of which are the "tortoise-shell

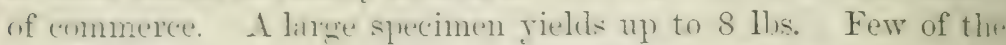
shielils are. howerer, thick enongh to le manufiactured into the laresere articies which art and fashion delight in, lut if heated in wil, or builech. they can be wetherl together under pressure, and be siven any desirel shape. In genuine articles of Oriental manufitcture these welds can generally lee detected, or their cominomm nature is indicated by the lecautiful pattern, which is ton regular in the initations now common. Even the shavings and learings can le welled and moulded into latroe pieces. The sripuing of the shields has heen itescribed ly sir E. Tement. "If taken from the animal after death and decomposition, the crlour of the shell becomes clouded and milky, and hence the crutel expredient is resorted to of seizing the turtles as they repriti 'to the shrme to derosit their eress, and suspending them over fires till heat makes the plates on the dorsal shields start from the bome of the cirapace, after which the creature is permitted to escape to the water. It Celebes, where the finest tortoise-shell is exported to China, the natives lill the turtles by blows on the head, and immerse the sledl in hoiling water to detach the shields. Inry heiat is only resirted to hy the unskilful, who frequently destroy the tortuse-sledl in the operation." The cruel process descrituen ahove is resurted to "for economy s salke," the Singhalese believing that such maltrented turtles resenterate the shields, to he caught and shipned acting. Since none of them are actually re-anght in the mutilaterl condition, this is looked upon as a proof of the colrectness of the treatment. It is more likely that they die.

New shields can le reproduced only if the unlerlying Mal-

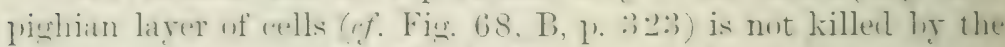

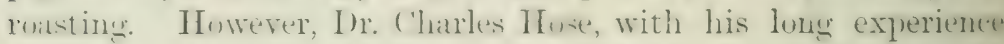
in lonmen, is positive that numerns individuals are there canght whirh hate imperfectly menterl shells the shields of which do not imbricate, are thin, and almost worthless.

It is commonly believed that the same indiviluals retmin arain and again to the same sunt for layng. This is very likely the rase. Tement mentions that in the reatr 1806 a Hawkshill was taken near Hambangtotte. Which ione a ring

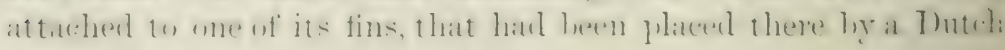


officer thirty years before, with a view of estahlishing the fact of these recurring visits to the same beach. The same homing instinct has been observed in some females of the Green Turtle, which, having been brought from the Tortugas Keys to Key West off the south end of Florida, escaped, and were, a few days later, re-caught at the Tortugas. On the other hand, experiments made with turtles at Ascension are said to have had no result.

Thulassochclys, with five pairs of costal shields. The carapace is completely ossified in the adult, leaving no fontanelles between the ribs and the marginals.

Th. curettc (the "Loggerhead Turtle").- The shields of the carapace imbricate only in young specimens, in the adult they become smooth and juxtaposed. The margin is serrated posteriorly. The carapace of the young has three strong keels. The intergular shield is very small or absent. The marginals, including the nuchal, usually number 2.3 , rarely 25. The large hear is armed with hooked jaws, the crushing surface of the horny upper beak has a median prominent ridge. The top of the head has a pair of shields in front of the unpaired frontal. The flippers of the young have claws on the first and second digits; in the adult usually only that of the first digit remains. The general colour of the shell is uniform brown above, yellowish below. Very young specimens are uniform dark brown or blackish above and below.

Large individuals have a shell about three feet and a half in length. The Loggerhead is carnivorous, and is commercially of no value. Its habits seem to be the same as those of the other Turtles, but it has a much wider distribution. Besides all the tropical and intertropical seas, it inhabits the Mediterranean, and is an accidental visitor to the western coasts of Europe, especially Portugal and the Bay of Biscay. It has been caught several times on the coast of Belgium, and an old female containing 1150 eggs was captured in 1894 on the Dutch coast. In 1861 one was caught near Penman, on the coast of Banfishire, and a second in the completely land-locked Loch Lomond. ${ }^{1}$ It has been more frequently recorded from the coast of Devon and Cornwall.

The most interesting feature of the Loggerhead is the 
astonishing varialility in the number of the horny shields of the carapace. The normal number of shields of the carapace, learing out the marginals and counting the nuchal as the first neural, is 6 neurals and 5 pairs of costals, in all 16 . The sreatest number of dorsil shields olsserved is 8 neurals and 8 pail's of (nstals, in all 2) 4 . Many of the intermediate combinations have hexn ohserverl, there being, for instance, specinens with \& nemals and $16,14,1:), 12$, or 11 costals, the latter not leing always in pairs, hut mergual on the right and left sides: or there are $T$ neuruls with 20 to 16 costals, or 6 nemrals with $20,19,18,17$, or 16 costals. The interesting fact in connexim with these variations is, moreover, that some of the shiehls are much smaller than the others, sometimes mere vestiges in all starges of gradual smpresession, and that the almormalities are murh more common in habies and snuall specimens than in alults. The importance of these "orthogenetic " variations has been discussed on p. 326 .

Sub-Order 2. Pleurodira. - Treli trenting laterally and turlied

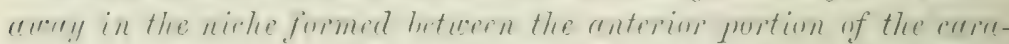

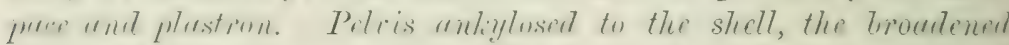

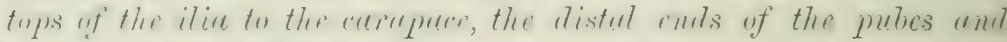
ischica to the plastron.

Freshwiter tortuises, almost entirely camivorous, inhabiting Funth Americat, Austrulial, Africa, and Madagasear. Fossil forms are known from the Jurassic epoch onwards.

Owing to the strong connexion of the iliac bones with the custal plates the saccum has become practically abolisherl, the salcral ribs being restuced to one pair (the posterior of the original two jairs) w heing ahsent. The centra of the cerrical vertelara articulate ly ('up and ball joints. The formation of the trmporal rexion of the skull varies considerahly in the three families, some genera lacking the complete zrgomatic arch, while wher's have a narrow parieto-syuamosal areh bridging over the tempral fossit, or the latter is completely roofed over by the laterally expambed parietal, which meets the jugal and quadratojugal. The quallate is always trumpet-shatped ; the rime of the tympmun is complete, hut the posterior part of the trumpet rentins open. The hatsisphenoid, pterygoirls, and palatines form a lirand and flat goof to the month. The vomer is large, and separates the pralitines in the Chelycliclae: it is very much 
reduced or absent in the Pelomedusidae, in which the palatines meet. All the Chelydidae, except C'helys, have nasal bones which remain distinct from the prefrontals. The choanae lie in front of the palatines, dirided by the romer when this is fresent, but they are not roofed in ventrally.

The ilia are solidly ankylosed in the adult with the neighhouring costal plates, mostly with the last two pairs, sometines also with the prgal plate. The lateral processes of the pulues fuse with the xiphiplastra. The ischia are also attached to the same plastral elements.

The carapace is flat and completely ossified. The nuchal plate is alwars conspicuous, much larger than the neurals, ant these are often reduced by being encroached upon ly the eight pairs of costal plates, which then meet in the dorsal line. In sternothoris all the eight neurals are present and form a continuous row. In most of the other genera they are reducen to seven, the last heing squeezed ont. In Rhinemys they are reduced to the second, third and fourth and an isolated fifth, and in Hyliospis they are all gone. The pygal plute is always, eren in Strimothuerus, separated from the last neural by the eighth grair of costals. The marginals number 2:3, lut in c'riettuctelys only 21.

The carapace is corered with horny shields, except in C'uicttechelys. The nuchal is absent in the Pelomedusidae and in a few Chelydidae (Elsey" and a few species of Emyduru). In Hyllomedusu the nuchal is shut in by the anterior marcinals, sinulating a sixth neural. The plastron is composed of the usual nine elements, but the Pelomedusidae possess an aclitional prair, the meso-plastra, inserted between the hyo- and hypo-pliastra. The bridge is strong, connected with the carapace by suture. In Stcruthuress the front lohe of the plastron is movable. The intergular shield is always present; it is terminal, forming part of the front margin, except in Chelortinu, where this shield, although large, is shut in behind the ggulars (cf. Fig. 61, 4 and 5, 1). 315).

Although the Pleurodira are a peculiarly specialised group, we of the oldest Chelonian fossils known seems to helong to them. Pingunochrlys, represented l,y a complete shell, nearly 2 feet long, has been found in the Upper Keuper. Sindstone of Wirtemlerg. Plesiochelys, of the Tpper Jurassic of Switzerland, law eight neural and three supracaudal plates, hut is without the 


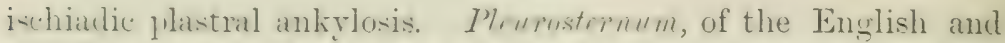
Continental I'urbeck lreds, has meso-plisstral plates like the recent P'elonedusidite. Illinucholys, of the Cambidge Greensand, has a limal parieto-postrontal roof, and larwe nasal bones. Forms like Prularmmis, now restricted to Sonth Anerica, occur in the Eocene of Europe. One of the most aberrant Chelonians is. Minlonie, from the I'listocene of Oneensland and from Lorl

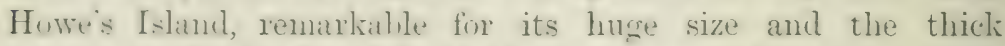
amome on the head and tail; the hearl especially carries large pairen projections, one pair of which extends horizontally like powerful homs, recalling the queer Theromorphous Elyinir.

The divide the recent I'lenurodira into three fanilies, of which

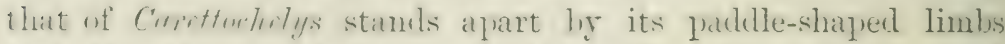
and the absence of homy shields. The I'elomedusidae and Chelyclidae are closely allied. The former are not Austrilian, and are extermally distinguisher by the ahsence of a nuchal shield.

Fam. 1. Pelomedusidae.-Neck completely retractile within the shell. Carapace without a nuchal shield. The plastron is composed of eleven plites, there leing besides the umpaired endoflastron a pair of meso-plastra, situaterl letween the hyo-and hypo-plastra; lut these meso-plastra meet in the midllie line in strmuthuress only, while in Pomlicurmis and Pelumelnsu they are restricted to small pieces on the bridge, widely separated from each other hy the usual hyo- and hypo-plastral suture. A nuchial shield is alsent; there are twenty-four marginal and thirteen platstral shields, inclusive of the conspicuons intergular. The temproul fosia is widely open, except in Pulurmis, where it is fratly roofed in $\mathrm{by}$ the meeting of the much-expanded quarlato-jugll with the pratal. The palatine bones are in median contiat, not sepraraterl by the romer. Nasal bones being alsent. the large prefrontals neet in the miclde line. The second cervical vertebra is biconvex.

This family is now represented hy only three gencra, witl abont fifteren speries in Ifrica, Maudagassar, and fonth Americal.

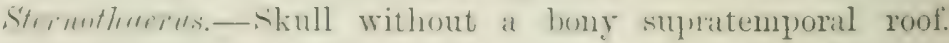
Mesio-plastra latrese extrulling right across the plastron. Anterior lobe of the plastron novalile, the hinge passing between the hyor- and meso-plastral flates, and between the pectoral amb abdominal shields. Fore-and himl-liness with tive short digits and claws. Several speries in tropical and southern Africa, and 
in Madagascar. S. depliunus in Trest Africa, from the (rambia to Angola, is the largest species, with a shell nearly one foot in length.

Pilomelusu._Skull with a slender parieto-squamosal arch. Meso-plastra small and lateral. Plastron without a hinge. Fore- and hind-limbs with fire rery short digits and five claws. 'Top of the head with one pair of shields between the eyes, and with a large interparietal and a pair of parietals behind.

I'. galeatu, the only species, occurs in Madagascar and nearly the whole of Africa south of the Sahara, from the Cape to Aloyssinia, and in the Sinaitic peninsula. The shell, less than one foot in length, is much depressed and is obtusely heeled; brown abore with black spots; brownish-yellow below. The short and broad head is coloured like the rest, without ornamentation. In Sonaliland this species sleeps hidden on land during the dry seasons, fion July to the end of Septemler, and from January to March, and appears at once after the rains have set in.

Putucnemis. - With a supratemporal roof formed by the junction of the parietal with the quadrato-jugal. Meso-plastra small and lateral. Fore- and hind-limbs broadly wehled, with tive and four claws respectively. The fore-arms and the onter edges of the hind-feet with sereral conspicuous shields, hence the generic name. Head with an interparietal, two parietals, and a narrow umpaired shield between the eyes. The tail is rery short. The carapace is flat and broad, strongly serrated on the posterior margin. Chin with one or two short barbels. SeveraI species in South Arnerica, chiefly in the basin of the Amazon, and one in Madagascar.

P. expensa. - Very common in Tropical South America, east of the Andes. The female, which is much larger than the male, has a shell nearly three feet in length. Olive-lrown above with darker patches; yellowish below. With a few yellow siots above and behind the eyes, and on the parietal region. The "Arrau" turtle is of great commercial importance on account of the eggs, which are periodically collected in enormous yuantities, chiefly for the oil. This is either eaten, like the eggs themselves, or used for burning in lamps, or as an addition t) tar. The turtles are likewise eaten by man and beast. Thousands of the little creatures are snapped up by Jabiru strulis, alliggators, and fishes; the adults fall an easy prey 
to the prowling jaguar. which turns them orer on to their backs and neatly cleans out the flesh with its sharp and powerful claws.

Fertilisation takes platee in the water, the excs are depositer

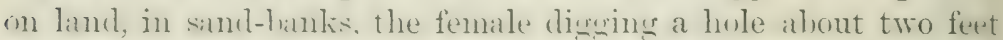
deen and ("orering un the munerous soft-shelled exgs with samd. The time of deposition is the early hours of the morning, but the seasm depends upn the lexinning of the principal rains, since the romng are liatehed shortly lefore the torrential rains. This seasm differs comsiderally in the various countries. The hatching takes about forty dars: the exess are conseruently laid in the Anazon comntries during the months of Septemler to November, in the Orinoen district in March. This species lives in the prouls of the immlated forests, and when these are dried II), the animals retire into the rivers themselves. Their food consists mainly of the fruit dropping lown from the trees.

Bates, in his delightful book. T\%, Luturalist on the Tider - Lmmsn, gives the following lively and exhaustive accomt of his experience with these turtles:-

"I accompranied Cardozo in many wanderings on the Solimoes, during which we risited the 'pratias' (sand islands), the turtle fools in the forests, and the by-streams and liakes of the great desert rivel. His olject was mainly to superintend the business of aigging up turtle egges on the sandhanlis, having been elected commandint for the Jear liy the muncipal council of Egal, of the 'praia real' of Shimuni, the one lying nearest to Ega. There are fom of these roval praias within the Ega district, a distance of 1.0 miles from the town, all of which are risiterl ammully ly the Egat people for the purpose of collecting egres and extrating wil from their yolks. Each has its commameler. whose husiness is 10 make arrangements for securing to every

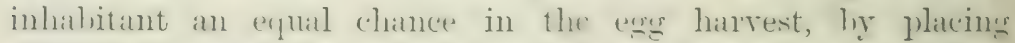
sentinels to proteret the turtles whilst liying, and so forth. The

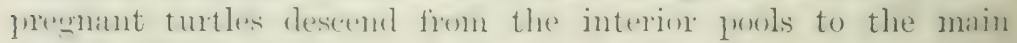
river in ouly and August, before the outlets dry up, and there

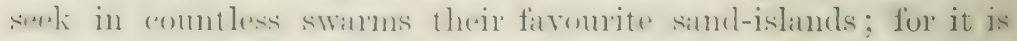
mly it few pratias that an selecterl hy them out of the great. mmber existing. The youmg animals remain in the pouls thromghout the dry season. These hreding places of turtles then lie 20 to 30 or more feet above the level of the river; 
and are accessible only by cutting roads through the dense forest.

. Tre found the two sentinels lodged in a comer of the prailit. where it commences at the foot of the towering forest-wall of the island, having built for themselves a little rancho with poles and palm-leares. Great precautions are obliged to be taken to avoid disturbing the sensitive turtles, who, previous to crawling ashore to lay, assemble in great shoals off the sand-hank. The men, during this time, take care not to show themselves, and warn off any fisherman who wishes to pass neir the plice.

"I rose from my hammock by darlight, shivering with cold: a praia, on account of the great radiation of heat in the night from the sand, being towards the dawn the coldest place that can be found in this elimate. Cardozo and the men were already up watching the turtles. The sentinels had erected for this purpose a stage ahout fifty feet high, on a tall tree near their station, the ascent to which was hy a roughly made ladder of wooly lianas. They are enalied, ly ohserving the turtles from their watch-tower, to ascertain the date of successive deposits of egres, and thus gruide the commandant in fixing the time for the general invitation to the Ega people.

"The turtles lay their eggs by night, leaving the water, when nothing disturlss them, in rast crowds, and crawling to the central and highest part of the praia. These places are, of course, the last to go under water when, in unusually wet seasons, the river rises before the eggs are hatched liy the lieat of the sand. ... The hours between midnight and dawn are the busiest. The turtles exavate with their broal webhed pars deen holes in the fine sand; the first-comer, in each case, maling a $1^{\text {it }}$ about three feet deep, laying its eggs (about 120 in number), and covering them with sand; the next making its deposit at the top of that of its predecessor, and so on mitil every pit is full. The whole body of turtles frequenting a maia does not finish laying in less than fourteen or fifteen days, even when there is no interruption. When all have clome, the area (called by the Brazilians 'taboleiro') orer which they have excatrated is distinguishable from the rest of the praia only by signs of the sand having been a little disturbed.

"I nounted the sentinel's stage just in time to see the turtles reireating to the water on the opposite side of the sincl-bank, 
after having latil their eres. The sight was well worth the

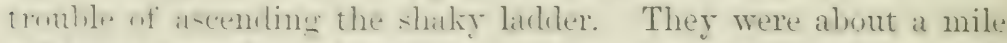

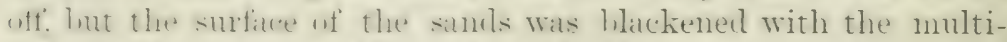
tmes which were withling twwats the river: the margin of the frata was rather sterp. and they all seemed to tumble head fir-t drom the derelivity into the water. . . Placirds were lustem nly wh the church ilours at Ega, amouncing that the exartion on Shimmi would commence on the 17th of Octolser, and m Candil. sixty miles helow Shimumi, on the 25th. By the numbing wi the $17 \mathrm{th}_{1}$ sone 400 jeroms were assembled on the hundirs of the simblank. each fimily having erected a mule tringurary shed of proles and palm-leaves to protect themselve- frum the sm and rain. Larre crpper kettles to preprare the wil. and humberls of real earthenware jars, were scattered about on the sand.

The excaration of the talnoleiro, enllecting the egges, and purifying the oil, occupied four days. All was done on a

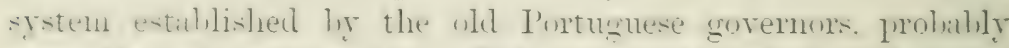
none than at century agev. The commandant first tom down the natues of all the masters of householis, with the number of

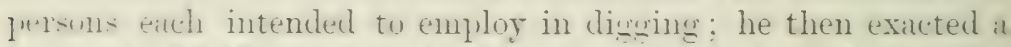

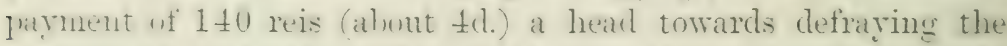
"xpens of sentinels. The whole were then allowed to go to the tabmleiro. They ranged themselves romed the circle, each fersin armed with a padille, to he useel as a spade, and then all intwn simultanenty to dis on a signal being given - the roll of irum:-iy weler of the commandant. It was an animating sight to helublil the wile circle of rival diggers throwing up

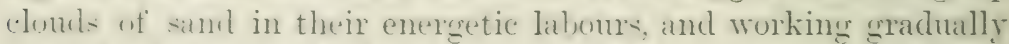
towark the centre of the ring. A little rest was taken during the great heat of minl-ilay, and in the evening the egges were cirried to the huts in haskets. Fy the emol of the serombl day

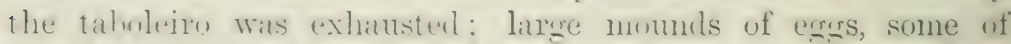
them fonm to fire feet in height, were then seen he the side of each lunt, the produce of the labour of the family.

"In the hurry of digning, some of the deeprer nests are passed

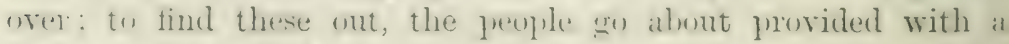

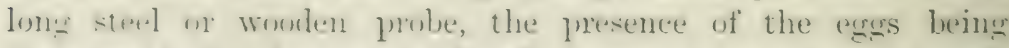
discroveralle by the eatse with which the spit enters the samd. When nu more erges are to be fomml, the matshing process begins. 
The egge, it may be here mentioned, has a flexible or leathery shell; it is quite round, and somewhat larger than a hen's e-s. The whole heap is thrown into an emptr canoe and mashecl with wooden prongs; but sometimes naked Indians and children jump into the mass and tread it down, besmearing themselve: with yolk, and making about as filthy a scene as can well he imagined. This being finished, water is poured into the canoe. and the fatty mass is then left for a few hours to be heated ly the sun, on which the oil separates and rises to the surface. The Hoating oil is afterwards slimmed off with long spoons, made ly tying large mussel-shells to the end of rods, and purified over the fire in copper kettles.

The destruction of turtle eggs every year by these pruceedinges is enormous. At least 6000 jars, holling each three frallons of the oil, are exported amnually from the Tpper Amazons and the Madeira to Para, where it is nsed for lighting, firing fish, and other purposes. It mar be fairly estimated that 2000 more jarfuls are consumed by the inhabitants of the villages on the river. Now, it takes twelve basketfuls of eggs, wi about 6000 , by the wasteful process followed, to make one jar of oil. The total number of eggs annully destroyed amounts, therefore, to $t S$ millions. As each turtle lays aliout 120 , it follows that the yearly ofispring of $\$ 00,000$ turtles is thus annihilated. A vast number, nevertheless, remain muletected: and these would probably be sufticient to keep the tirrtle population of these rivers up to the mark, if the people diul nut follow the wasteful practice of lying in wait for the newly-liatched roung, and collecting them by thousands for ating; their tender flesh, and the remains of rolk in their utrails, being considered a great delicacy. The chief natural themies of the turtle are rultures and alligators, which derour the newly-hatched soung as they descend in shoals to the water. These must have destrored an immensely greater number hefore the European settlers began to appropriate the egss than they do now. It is almost doubtful if this natural persecution dia unt act as effectively in checking the increase of the turtle as the artificial destruction now does. If we are to believe the tradition of the Indians, howerer, it had not this result: for they sil that formerly the waters teemed as thickly with imiles as the air does now with mosquitoes. The universal 
minion of the settlers on the Linere Amazon is, that the turtle hits very seratly decreatsed in numbers, and is still ammully decreasing.

"The frincipal olject of another experlition was to search (xotain prols in the forest for young turtle. We started from

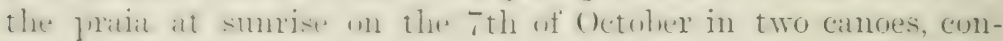
taining twenty-thres lersons, ninetern of whom were Indians. The juml conerenl an atreat uf almut four or five acres, and was 1.hely lummed in by the forest. which, in picturesque variety

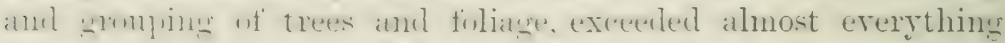
I had yet witnessed. The margins for some distance were swanny and cortrenl with large tufts of tine grass. The frool

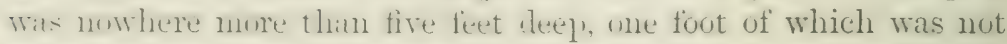
mater, but extremely fine and soft mud.

"S'ardezo and I spent an hour gadellings alont. The Indians sermed to think that netting the amimals, as Cardozo proposed king.. Was not lawful sourt, and wished tirst to have an hour or twis ohldishiomed pratetice with their weanons. I was astonished at the skill which they displayed in shooting turtles from little

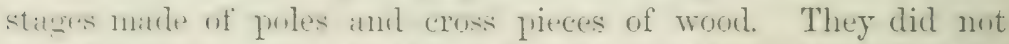
wait for their conning to the surface to hreathe, hut watched for the slight nowements in the water which revealed their presence underneath. These little tracts on the water are called the sirin: the instant one was perceiven an arrow flew from the lum of the netarest man, ant never failed to pierce the shell of the sulnument aninat. Thlen the turtle was rery distant of (onuse the ain land to he titlen at a considerahle elevation, but

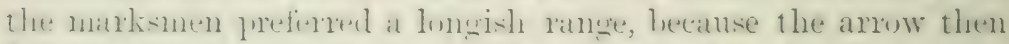
fill nore gerpemelicularly wn the shell, and entered it more deeply.

The arrow need in turth-shenting has a strong lancet-shajeel

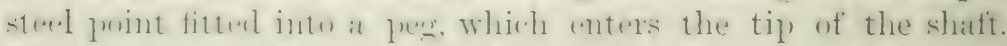
The fun is seculend to the shaft hy twine, heing sone thirty or

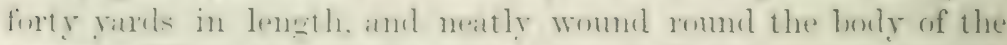

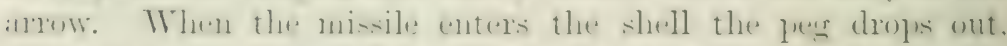

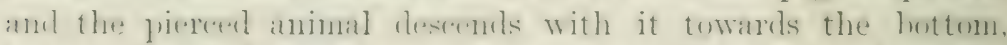
loving the slaft thating on the surfiue. This being deme the cluptinan fouldles in his ranoe lo the place, and gently draws 13.. aninal ly the twine, humoming it hy giving it the rein when it plunges, unt it is lowengh atwin noar the surface, when 
he strikes it with a second arrow. With the increased hold given by the two cords he has then no difficulty in landing his game.

"By mid-day the men had shot about a score of nearly fullgrown turtles. Cardozo then gave orders to spread the net. .

Three boat loads, or about eighty, were secured in about twenty minutes. They were then taken ashore and each one secured by the men tying the legs with thongs of bast.

"When the canoes had been twice filled we desisted after a very hard day's work. Nearly all the animals were young ones, chiefly, according to the statement of Pedro, from three to ten Jears of age; they varied from 6 to 18 inches in length, and were very fat. Cardozo and I lived almost exclusively on them for several months afterwards. Roasted in the shell they form a most appetising dish. These younger turtles never migrate with their elders on the sinking of the waters, but remain in the tepid pools, fattening on fullen fruits, and, according to the natives, on the fine nutritious mud. We captured a few full-grown mother turtles, which were known at once by the horny skin of their breast plates being worn, telling of their having crawled on the sand to lay eggs the previous year. They had evidently made a mistake in not leaving the prool at the proper time, for they were full of eggs, which, we were told, they would, before the season was over, scatter in despair orer the swamp. The also found several male turtles, or capitaris, as they are called by the natives. These are immensely less numerous than the females, and are distinguishable by their much smaller size, more circular shape, and the greater length and thickness of their tails. Their flesh is considered unwholesome, especially to sick people having external signs of inflammation."

The most recent account of these water tortoises is that published by Dr. Goeldi from the MS. of Joăo Martins da Silva Continho, a former resident at Mancios on the Middle Amazon. The "Tartaruga" (the Portuguese name for turtles) live from January to July in the inundated, quiet backwater's of the forestregion, feeding upon the various seeds of palms as these ripen and (trop successively; rarely, and only when hard up, they are carnivorous. The creatures hide under water below the trees, when they are espied by the Indians, who dive down to a depth of wwenty and more feet to catch them in their arms. The 
civiliserl Intlians use a steel-pointed lance of hard wood, al:out 10 feet in length. A string comects the proint with the shat aromed which it is womel. When stuck into the tortoise the Shaft and puint part: the string is either tied to the luat or to a little that of light womkl. In wther districts an anrow with at string is employed.

In An-n-t. when the water subsiles, the tortoises return tn the rivers. and the entrance of the lagoon is closed with nets. A number of lonats with long proles drive them with much noise towarls the entrance. On their way to the rivers the tortoises always on m-strean, and this is called the "arribacais das tartarugas," the ascent of the turtles. The fishermen post them-

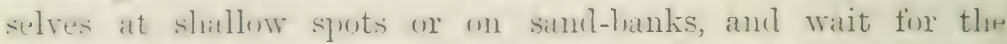

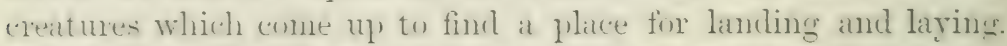
The arrows employed are called smoment is at thing which can lie disjointerl; they are alont 4 feet long, and consist of a gminn or internoulinu of word 9 inches lomg with a one- or two-harhed steel fuint. and the shaft into which the gumn tits loosely. The

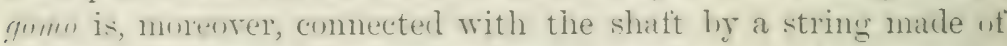

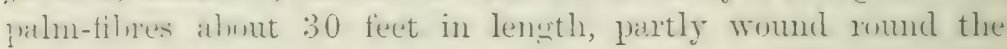
shaft, which ultimately acts as a float.

The latring takes place from the end of September into Octoluer. Sinne of the parents seren to recommoitre on land for a few days. As a rule only females do this, and the natives say that they are led hy a "mestra." The laying takes pliace arly in the morning. The number of females is so great that they riften block the way of the boats, and natie a great noise hy knocking atginst their neighbours'shells. Eateh digs a hole

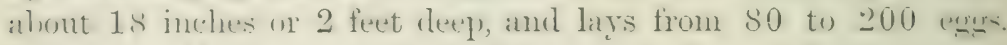

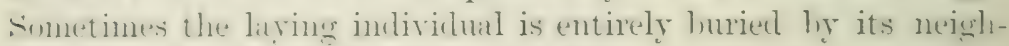
bours which are scraping their own holes.

In some districts the eggs are wanted for "manteiga"

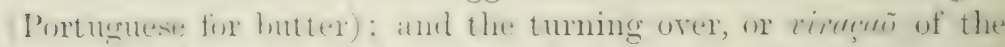
tortuises dakes plince later. In other districts they are callght

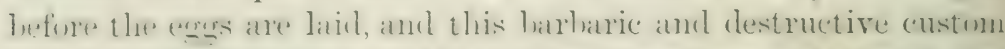

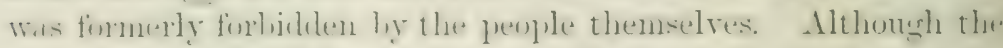

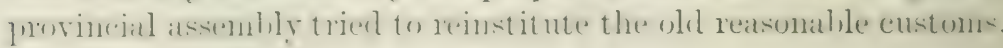
the inspectors are often got over by bribery.

There are two ways of extrating the oil firm the res. Th

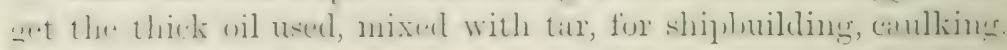


etc., the eggs are heaped up for five days and then worked. The fluid oil for lighting is male from fresh egrgs, which are jut int, a boat and then trampled out with the feet. The oil is dratw off' into large earthen jar's and put on the fire. 'Then it is rilpinly. cooled. The best oil, used for frying fish, is that which is ginuril from the roasted tortuises themselves. Fresh regs are either fried or taken with sugar, or mixerl with manioci-flour and water. The young, which are hatched in Janumy, are likewist eaten fried, or they are preserved in the fat of the parents.

An arerage tortoise yiehls 5 lhs of fat, ersting on the spot two milreis. The whole full-prown animiel, of one yart in length. costs the same, and its meat is sufficient to sustain a fimily of six people for three days. To make 24 ils. of wil reunires 3000 eggrs. Two or three tortoises wonld yield the sime amomnt from their fat. Conseruently the destruction of the exgs causes an enormons waste, and is after all the loast econonical procolure. In the year $1719,192,000$ Hs. were exponted from the Alto Amazones, representing $24,000,000$ eggs. In 1700 there were still plenty of tortoises 50 leagues ahore the mouth of the Para river. Now there is no assembly of more than fifteen tortoises to he found anywhere within :300 leagues from Para to the mouth of the Rio Negro. On the Fin Marleira. from the mouth to the first cataract, 186 leagues clistance, there are now only two regular nesting localities. The upler sulinues and the Rio Tapura are still rich. Tear Egar are regular tortoise-ponds, called "curral," which rield sufficient supuort to thrir owners; the animals are fect with manioca-flour and leguminous plants.

Fam. 2. Chelydidae.- The neck bends under the margin of the carapace, but remains partly exposed. The nuchal shield is alssent except in two Northern Anstralian species. There are twelve pairs of marginal shields. The plastron is composed of nine plates, and is covered with thirteen shields, one of which is the conspicuous intergular. The temporal region of the skull shows great diversity. It is quite open in Cheludinu, covered in by broad expansions of the parietal bontes in Platemys, Emyitmin. and Elseya, or bridged orer hy a parieto-squamosal arch, which is very slender in Phincmys, strong in Chelys and Hyntiospis. The palatine hones are separated hy the romer ; the nasals are varial,le. mostly presert, but the prefrontals are always small, and sepurated 


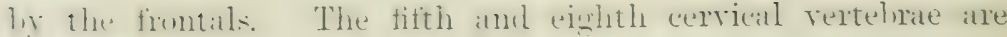
biconvex.

This fimily, still represented ly nearly thirty species, which

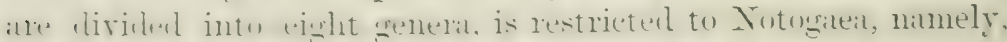
South America and Australia.

Chilys fimlinintu, the " Matamatal," the only species of this
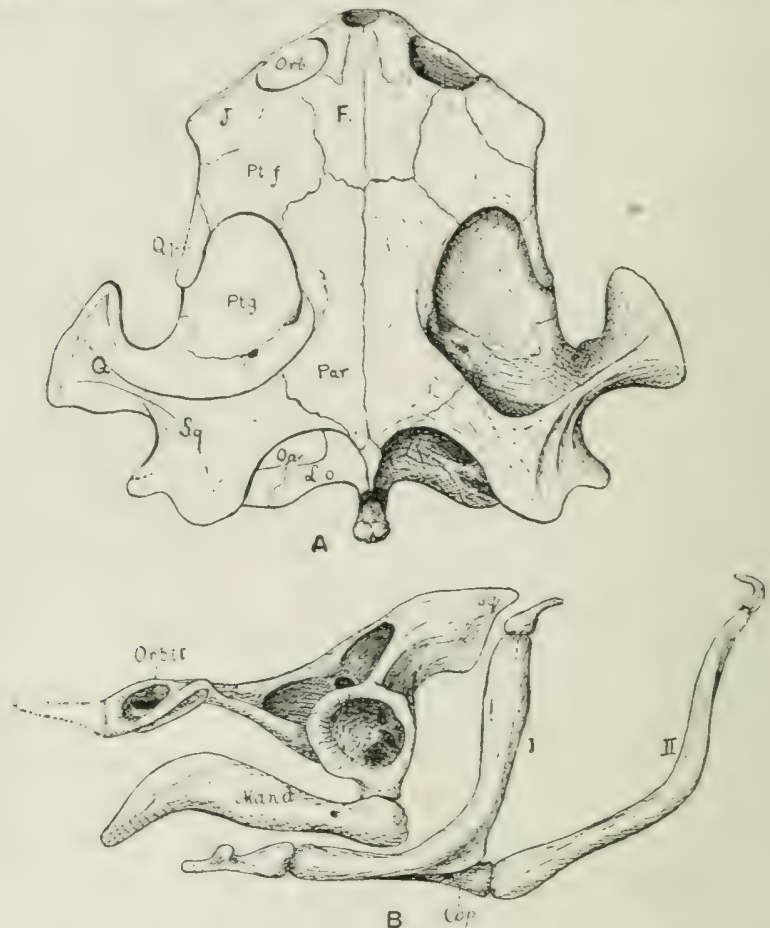

FIG. 8\%. - Skull of Chelys fimbriata. $\quad \times 1 . \quad$ A, Dorsal view of skull ; B, side riew of skull and hyoid apparatus. Cop, copular piece ; $F$, froutal ; $J$, jugal ; L.o, lateral occipital ; IA $a$ d, mandible ; $O p$, opisthotic ; Orb, orbit ; Par, parietal ; P't. $f$, postfrontal ; $P t g$, pterygoid ; $Q$, quadrate ; $Q j$, Quadrato-jugal ; $S q$, squamosal ; I, II, First and second loranchial arch.

genus, inhathits the rivers of Guiana and Northern Brazil. Besides

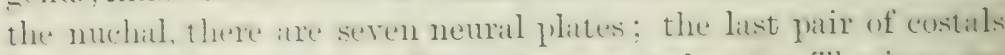
form a metian sutume. Nasial bones are ahsent. The jaws ane

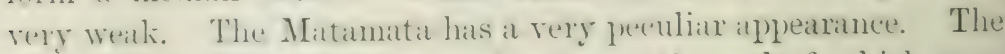

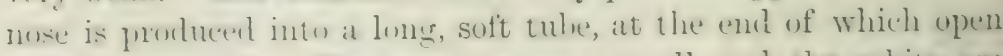
the ting nostrils. The eres are very smatl, and the orbits are placed rery near the anterior end of the shull, while the parietal 
region is broad and much elongated (Fig. 87, 1) 400). The quadrates are drawn out into trumpet-shaped tubes. The hyoil apparatus is very large, with enormous anterior and posterior horns. The head and neck are as long as or even longer than the carapace, which is covered with thick, lumpy shields. The skin of the thick neck, of the sides and under parts of the head, is produced into many soft arborescent excrescences or fimlrive, those of the chin and throat and the large ear-flaps being movalble at will, and probably used to attract fishes and other prey. The tail is very short. The fore- and hind-limbs are webbed, the former

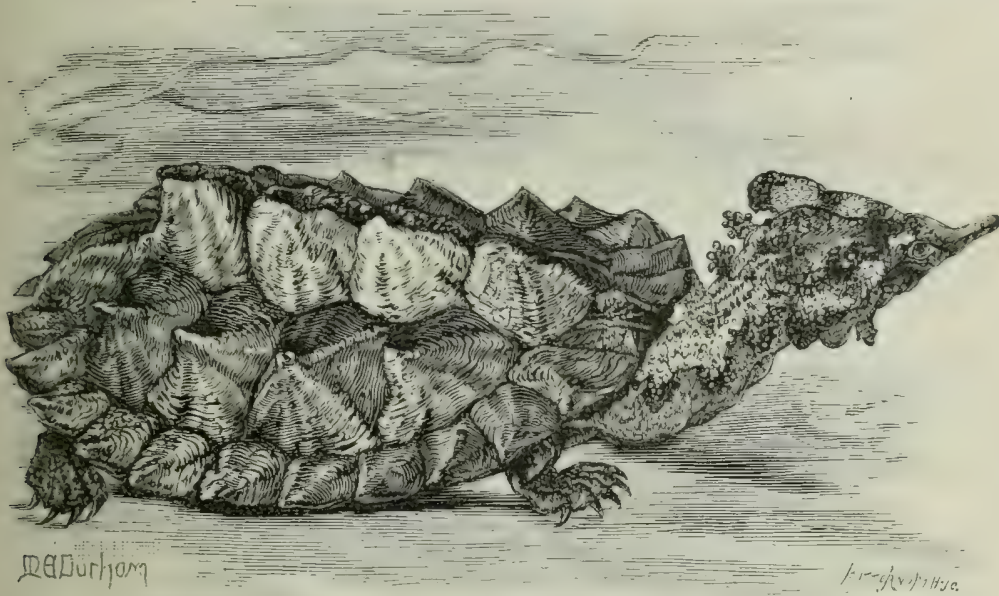

FIG. 88. Chelys fimbriata ("Matamata"). $\quad \times \frac{1}{10}$.

with five, the latter with four claws. Old specimens, which reach a total length of three feet, are uniformly dark brown, and look like a log covered with rough bark. The young are far less ugly, with black and yellow spots on the shell, and with dark stripes along the neck.

Very little is known about the habits of this peculiar creature. It is siid to lie submerged in the water, waiting for fishes, frogs, or tadpoles, which are attracted by the playing motions of its cutaneous excrescences. The jaws being so weak, and being covered with a partly soft lip-like skin, it is probable that they are not used for seizing the prey, but that the latter is engulferl into the mouth with the inrush of water into the throat. 
That this cam be wilened enormonsly is indicated loy the greatly developed hyoid apparatus.

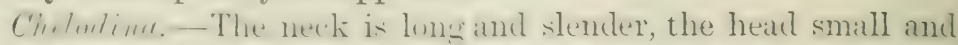
smonth. The nuchal is torninal: the intergular is large. The nemal flates atre completely smplresed, all the eight pairs of costal plates neerting in the milllle line. The shell is very liat. Anterior and pusterior limls entirely wehled, and with only four claws. The tail is very short. Three species in Australia, one in New Guinea.

Ch. longicollis reaches a shell-length of ten inches. It inhaluits southern Australia. The illustrations malie a detailed leseription unnecessiry. The colom of the dorsal shield is unifumbly dark rich bown. while the shields of the muler surface are rellow, with hroal dark hrown lines along the

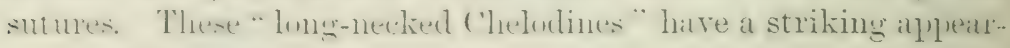
ance, when they swim or creep about, with the neck either stretcherl mut stratght or bent horizuntally in an S-shapre. The whole creature lowhis neat and elegant: the iris is pale rellow,

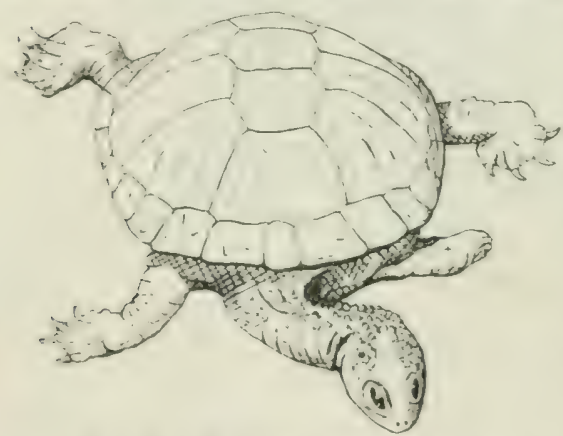

FIG. 89.-Chelodina longicollis. $\times \frac{1}{3}$. and gives the eye a very intelligent expression: They keep well in captivity, provided they are given the choice of land and water. My own prefer to spend most of the day on land, preferably under the ledire of a stone, or perched mpon the stone itself if the latter is in the shade, and not too much exposed to view. There they he motionlese, with the neck neatly tucked nuder

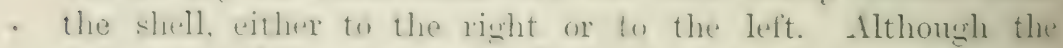

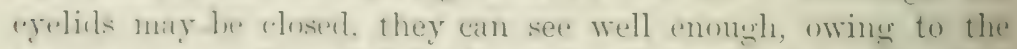
transparent comblition of the lower lid. They feed in the water

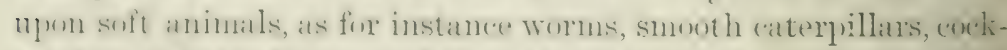
roathes or little frogs: and they also take meat readily, provided this is mosed alont. The food is invarially taken with a quick

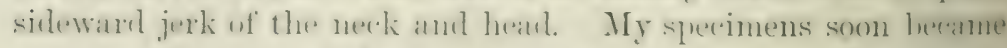
so tame that they left the water, and ran up to me with the necks stretched to their full length, then snatching the lit of 
food, and retiring into the pond to swallow it. When left tw themselves they are rather nocturnal in their feeding halit:

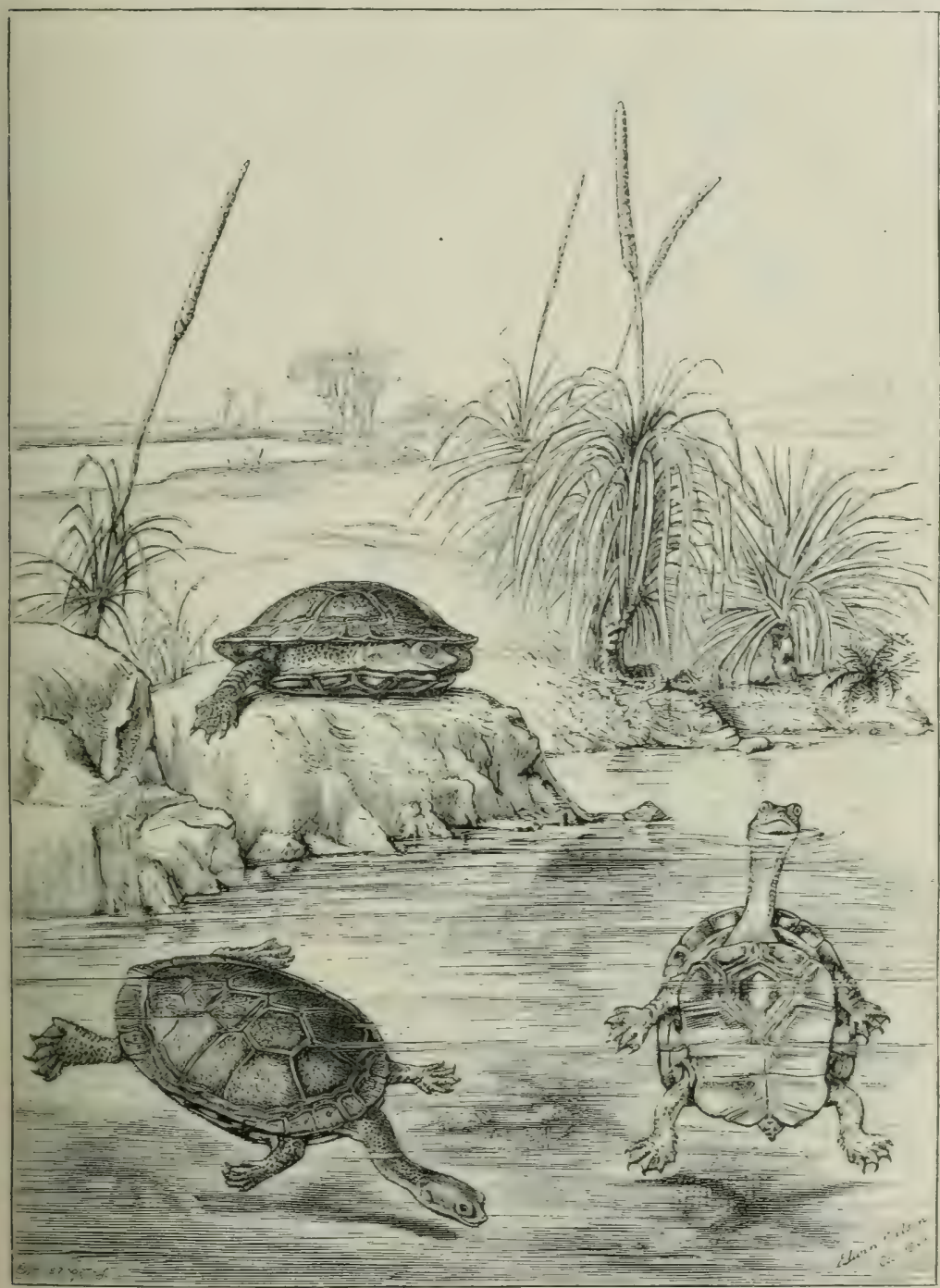

FIG. 90.-Chelodina longicollis (Australian long-necked Chelodines). $\times \frac{1}{4}$.

Now and then they tuck themselves away for weeks without feeding, for instance when they go through a regular term of 
axtivation in the smmmel. The last winter they spent buried

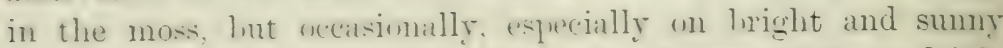
dals. they went intu ihe water for a fiew hours, chiefly to drink. but sometimes also to take a little food.

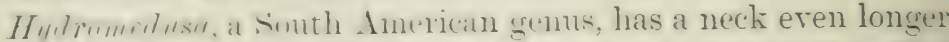

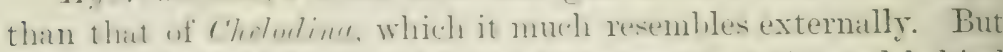

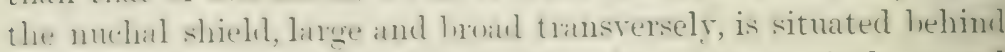
the anterior narrinals, looking therefore like a sixth neural shivl. The nesural plates form a contimums row, only the last laile of costal plates meeting in the midulle line. $H$. trofifere

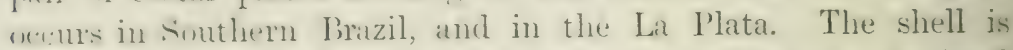
dark hrown aluse: rellowish, with lark sjots, helow: the hear

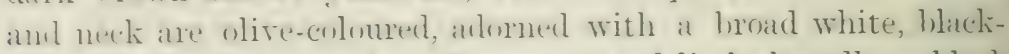

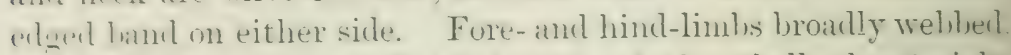
anul with four claws. Total length of the shell ahout eight inches.

Fam. 3. Carettochelydidae.-The shell is coreren with soft shin instarl of hurny shields. The limbs are transformed intu lanlilles. with thongated diegits, and hatre only two claws. The neck is shut, and mot retractile. In other respects the sheletom, nut-

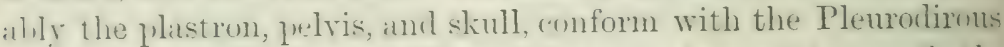

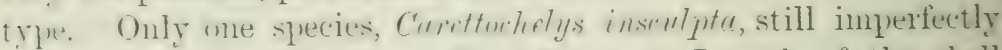
known, finm the Fly River, New Grunea. Length of the sinell wi the omly complete specimen abunt 18 inches. This peculiar (reatures serens to stand in the sane relation to the typicial I'lemrolina, as do the Cheloniclae to the Testudinidate, except for the complete reduction of the homy shiels upon the shell, revalling in this respect Spluargis and Trionyx.

Sub-Order 3. Trionychoidea. The shell is very tait, oral. or almust romed, and is covered with soft, leathery skin instearl of with homy shelds. The limbs are hroadly welbed, amb only

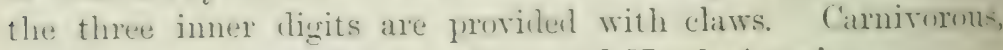
found in the rivers of Asia, Africa, and North America.

The heat and neck are complectely retractile, bencling hy a

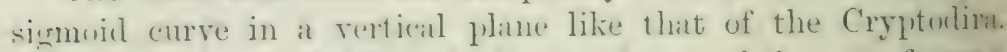
The jaws ale comeraled hy soft, lip-like thaps, and the nuse forms a soft short proboscis. The ar is hirlone The skull, Fig. 91, is flat, with three lon:s pusteriol procesese formed ly the supratreripital alowe, and the symamosals on either side. The whole temporal region forms a wide, shalluw fossal, without any indicat- 
tion of being arched or bridged over. The premaxilla is extremely small, unpaired, not even reaching the nasal carity or the vomer. The maxillaries are correspondingly enlarged, surrounding the choanae, which are separated by the narrow vomer. The palatines form a median suture, and are joined behind by the long basisphenoid, which separates the long pterygoids from each other. The quadrate is trumpet-shaped, with a posterior notch for the stapes. The zygomatic arch is complete, and is formed by the quadrato-jugal and the jugal; the latter joins the maxillary and postfrontal, mostly reaching the orbit; in some cases it also just meets the parietal, thereby adding to the strength of the postorbital arch. The prefrontals are large; nasals are absent. The mandible is remarkable for the great derelopment of the coronoid process.
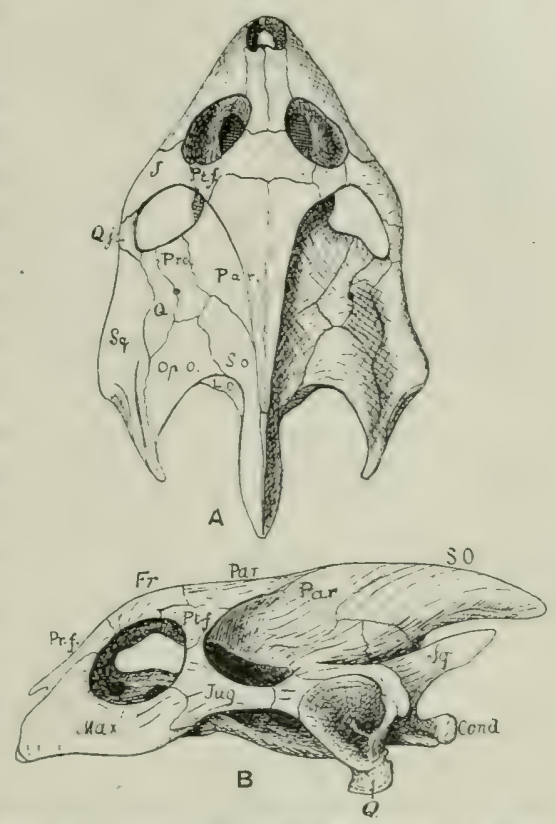

FIG. 91.-Skull of Triunyix hurum. 1, Frnm above; $B$, from the left side; Cond, occipital coudyle : $F r$, frontal : $J$, Ju'y, jugal : $L . \cdots$ lateral oceipital; .Mu, maxillary: U,..", opisthotic ; Par, parietal ; P'r,f, prefrontal; Pro, prootic: P't.t, postfrontal : (', qualrate: " $j$. quairato-jugal: $\therefore$ ", supra-occipital ; $\$$ q, squamosal.

The pubic and ischiadic lones enclose a large heart-shaped formmen, and are free from the plastron; the ilia are attached mily to the sacral ribs. The carapace is peculiar in so far as it is very incomplete peripherally, the ribs extending consideratily beyond the costal plites, nor are they joined by marginal plates, which are absent, unless they are represented by a few small ossifications imbedded in the posterior marginal flap of the clise (E'myntu of India). The rim of the disc is alwars formed hy a hrrizontal, cutaneous, very flexible thap. All the dorsal plates hitre a rough upper surface, rermiculated or ruguse, as usual with such dermal bones, which have lost nost of or all their lomy covering, and have sunk more deeply into the skin. The 
muchal plate has usually a pair of rib-like processes. The neurals form a contimuns series, excetet in the African Cyclonortis, in which they are much reducel in size, and seprated hy the custal plates.

The jlistron is imperfect, all its constituent nine elements heing mly loosely commecterl with each other, and there remains a whis mellian vacuity letween the lateral elements. Most of then plistral lunes are redued to splints, which, instead of menting ly rewlar sutures, lowsely interligitate with their

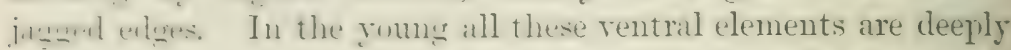
imbedded in the soft, leathery skin, and they do not at all

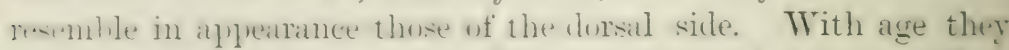
develup mun their ventral surface stronger and denser ossificafinns. Which nltimately hrouden out, sometimes beyoud the mirinal molerying home, and assune the characteristic remi(1) laterl surface-alphealmance. This is undouldedly a jocess of exustosis, a step towards reviral of that armour which had been mun he refluced ancestrally. To anpreciate this condition, it is at least sligrestive that these mul-tortoises, when kept in the usual laml-hotomed tunks, invarially lecome sore, the shin wearing through where the inferded plastral hones touch the gromol. Thas what is crammed into the short life of a.captive individual. is in the natural contrese of events spread orer many generations. wherely it has ceased to he patholocical, and has becone a comparatively new, tertiary, but regular feature.

It is mot "Ipen in much douht that the characteristic features of the Triomschosileat are not prinitite lont secondiary. This is imlinated liy the whole structure and hehariour of the carapree amil plastron. The softening of the whole shell, the loss of the homy shirels the seduction of the claws, are the direct and almost unaroidable results of life in muddy waters.

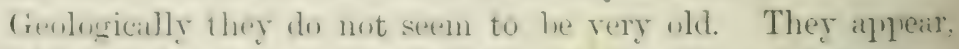

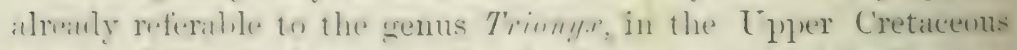
strata of North Amerioa. In the Lower and Tiddle Tertiory atratit many species existed in North America and in Europe. amel it is of great importance that in these species the costal

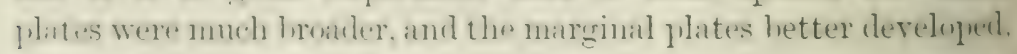
than in the recent forms. Now their half-dozen senera, with alwme twenty-four species are confined to Nortin Americal. the tropical and warmer parts of Asia, and the Mraliyy 
Islands, and to Africa from the Nile to the Senegal and to the Congo.

The habits of Trionychoidea have found few observers. Accorlto L. Agassiz, ${ }^{1}$ they live in the muddy bottom of shallow waters, burying themselves in the soft mud, with only the head, or a small part of it, exposed. They breathe without moving the body, by raising up the long neck and carrying the leathery snout above water. When moving through the water they strike horizontally with both pairs of limbs, alternating, however, the right and left; but when they start suddenly, the front limbs are seen moving together towards the tip of the snout, and then striking simultaneously backward with great power. As the shield does not project forward, the fore-limbs usually move beyond the shield, and as its outer edge is sharp, and the feet are broad, their webs reach above as well as below the plane of that edge, so that the water is driven partly over and partly under it. When they move along the bottom, the limbs still more horizontally, the webs striking against the water, and the inner toes, those with the claws, against the bottom. They also bury themselves horizontally, becoming covered by only a thin layer of mud. They readily resort to the shell for protection. The neck and head are withdrawn entirely, the loose skin rolling off from the greater part of the neck; and the skin of the legs also slips off, as far as the elbows and knees. In confinement they exhibit great quickness; their movements are abrupt and unsteady, except when they swim rapidly in one direction. They then dart their long and slender neck quickly forwards or sideways and upwards, as snakes do, and bite in the same way, striking suddenly. Their temper is bad or even ferocious, and large specimens are quite dangerous.

Their food consists of all sorts of aquatic animals, fish, frogs, and molluses, for instance Anodonta and Paludina. According to the different diet, many species develop a peculiar kind of dimorphism, a reasonable explanation of which has been given by Boulenger. In the young the horny coverings of the jaws are sharp, with cutting edges, and in those specimens which keep to a diet of fish and other soft creatures, the jaws remain in the same condition. But in those which take to living upon molluses, the hard shells of which they have to crush, the horny edges are

1 Contributions to the Natural Hisiory of the U.S.A., vol. i. 1857, p. 333. 
worn down; and hroald thick, homy, crushing pads are developed in their steat. the sulpurting parts of the jaws hecoming more milswive. The masticatory muscles are likewise enlarged, and a tuhercle growis nom the lower lwoler of the jugal bone, whence arises part of the masseter muscle.

The euses are roumb, thick-shelled, but very lirittle; they are Iain in the sand alore the level of the water, and this is the chief occasion on which these tortoises creep on land.

Trimul.-The plastron has nu suecial cutaneous valves for the concealunent of the himl-limbs. This is the principal gemus, with the greatest munher of serecies and the widest distrihution. the lattex conceling with that of the whole family. The uplece suntiue of the sledl of young specinnens frepuently forms numerous longitulinal ridges or series of little homy tubercles which disappear with age.

T. firm, the commonest "Soft-shellexl Turtle" of the Lnited States. Olive ahore with seatteresl, small. round, black spots: romng with anical, spine-like tulereles, expecially on the nuchat

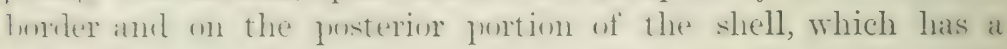

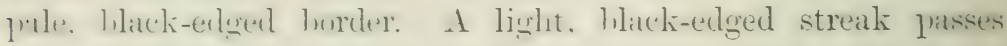
fluromb the ere and joins its fellow on the snout. The limbs are olive hrown. spotterl and marliled with black. The muler garts of the shell are white. Very large specimens have a shell is inches in length anrl 1 i inches wille. Holbrook gives the following account of its habits :-

"A voracious, carnivorous creature. They reside most constantly in the water. swim with rapility and choose for their retreat holes moler the lanks of rirers, or moler rocks : and not unfrequently the trunk of some huge forest tree, fallen into the strean, aftinds them shelter. Sometimes they leare the water and conceal thenselres in the munt: I haw frecuently seen them thus buried to the depth of 2 or 3 inches, leaving wrly a small loreathing luble for the long neck and narrow heal. which is occasionally thrust out, but most commonly it is retracted so that one would pass near without observing their lublitation: and if serne, it mi-ht easily he mistaken for the

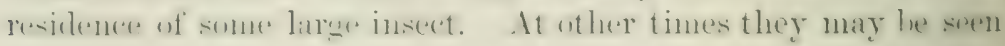
in numbers on rocks in shallow water, basking in the stu. alpharently aslerel. They hite sererely when provoled, darting forward with erreat velocity the long neek and head, and mot 
unfrequently spring upward at the same time and make a loud hiss. In the month of May the females seek samdy places along the banks of the waters they inhabit to liry their eyss, generally about sixty in number; and it is remarkable that, thongh their motions are slow and difficult on dry land, yet at this seasum they sometimes mount hillocks several feet high. The flesh

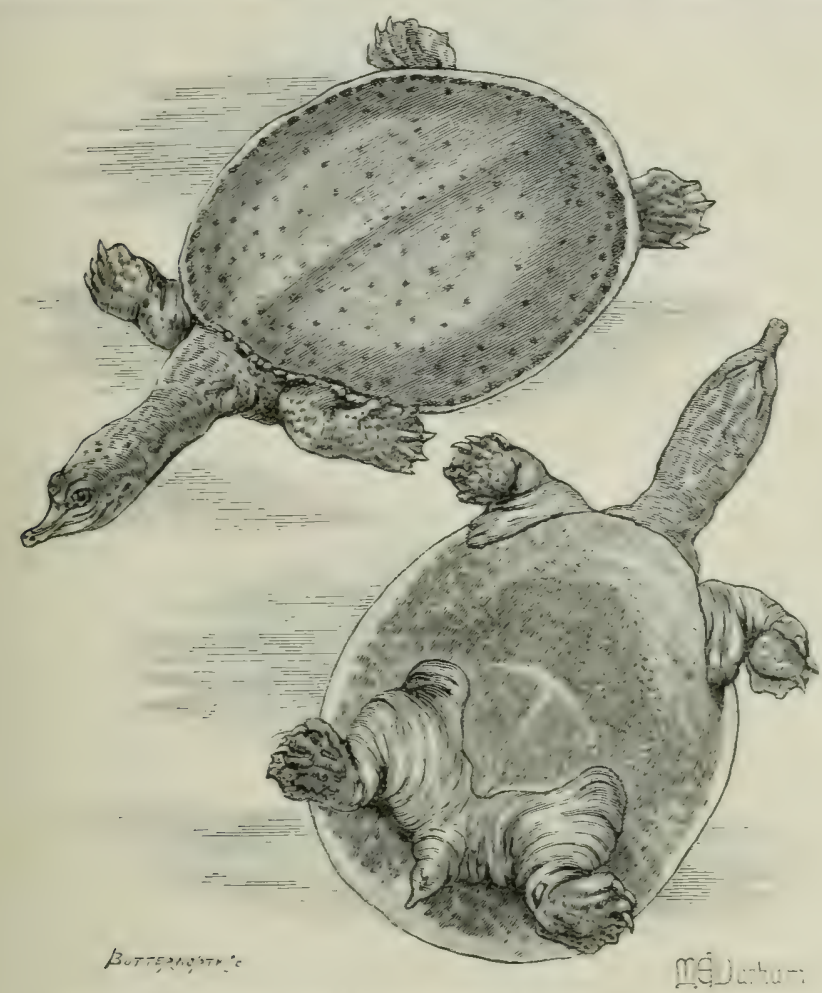

Fic. 92.-Trimate ferm, (Anerican Soft-shelled Turtle'. $\quad{ }_{1}^{1}$

affords the most delicate fool, surpassing that even of the (ireen Turtle. The geographical distribution is interesting. It inhahits the Savanniah as well as all those river's that 'munt? into the northern horclers of the Crulf of Mexico; it ascencls "1]' the broad Mississippi, and is found in all its trilutaries, eren (1) the rery fout of the Rocky Momntains: it aloumls in the chain of great northern lakes both ahove and helow the Falls of Niagara, and is common in the Mohawk, a tributary of the 
Hudson river: hut it is not found in any other Atlantic stream leetween that and the Savamnale river, a distance of nearly 800 miles."

T. triunguis, the only African species, ranging from the Senegal and Congo into the Nile-system, but occurring also in srria, is prexhaps the larest of all Trionychidae, reaching a sluell-length of almost 3 feet. The adults are olive-brownish

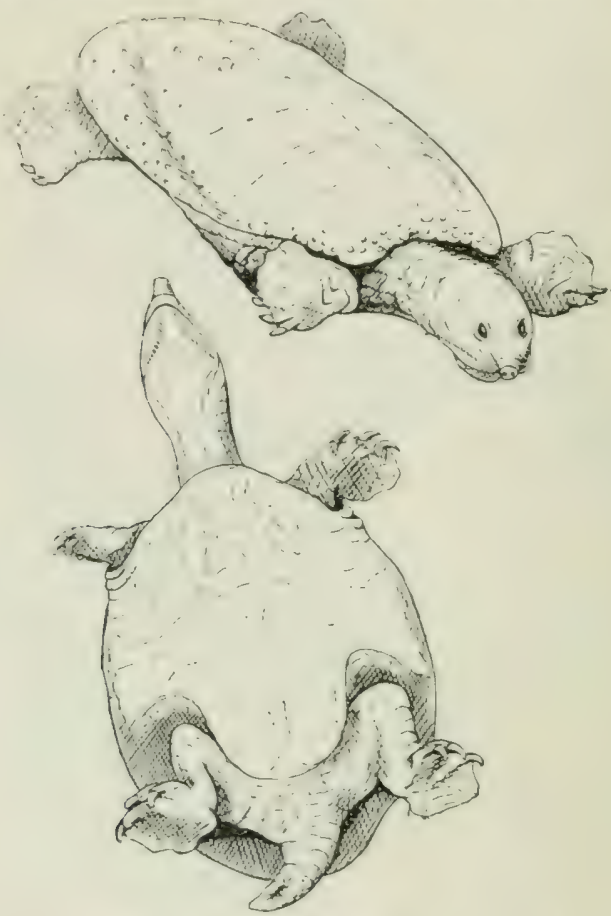

FIG. 93.-Trionyx gangeticus (young). $\times \frac{2}{3}$.

above, the throat and under parts of the shell with round, white spots separated by a dark network. The young have whitish specks and spots.

T'. yongrticus and T'. hurum are the principal Indian species. The former is the larger of the two, with a shell of more than 2 feet in length: olive above, the young with fine black vermiculations: head with a hatck longitudinal streak from between the eyes to the nape, intersected hy two or three chevron-shaped blacki streaks: under parts yellowish. T'. Turum is olive brown above 
and below, in rounger specimens with conspicuous, large, rellow spots on the sides of the head. The young are ornannented with

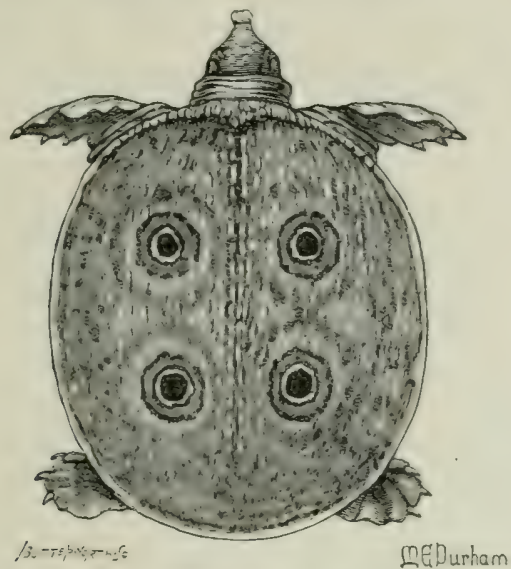

FIG. 94.-Trionyx formose (young). $\quad \times 1$.

two or three pairs of large round spots on the back, and the same applies to the heautiful roung of the Burmese, T. formosu.

The three genera, Cyctoderma and Cyctanortis of Tropical Africa, and Emyde of India, have a pair of cutaneous femoral ralves or flaps on the plastron, beneath which the hind-limlss are withdrawn. 


\title{
CHAPTER X
}

\author{
DINOSAURIA - CROCODILIA
}

\section{SOB-CLASS T.-DINOSAURIA.}

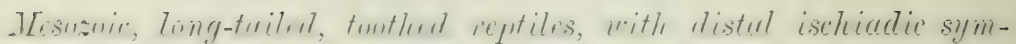
physis, terrestrial limbs, large fixed quadrate bones and bifurcated ribs.

THE Iningsints begin and end with the Mesozoic epoch, and hare a world-wide distribution. The name, "terrible Reptiles." refers to the sigantic proportions which mans of then attained, not a fow of them surpatsing in size and shape the fantastic pictures of the dragns of our falles. Although these creatures canne to an end millions of years before the first man-like beings "lpreared, it is reasonal, le to suppose that the widely-spread myths of thasms are hasted upon the accidentally disclosed skeletons of these monsters.

The skull is built after a plan which may be derived from a combination of the Crocorlilian and Iihynchocephalian shulls, lnt the detail varies consideralily in the many and much diversifient members of this large sub-class. There is

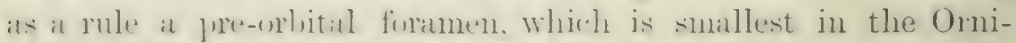
thoporta. The orite is completely encircled by bones, and

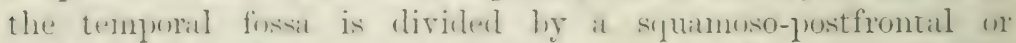

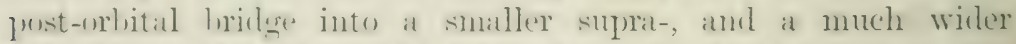
infratemporal jortion. the latter being hordered below hy the jural and quadrator-jugal, and this is firmly commected with the

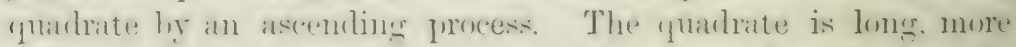
ar less vertial in position, slanting either forwates or lackwarts,

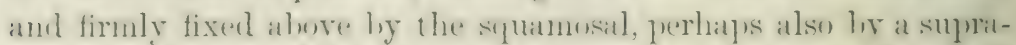

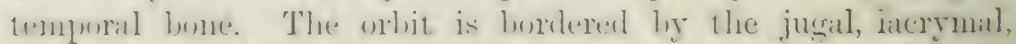
pre-and pust-frontals. The interparietal formen seems to be 
abolished. Teeth, mostly alveolar and laterally comrressed, are restricted to the dentary, maxillary, and premaxillary bones. In the Orthopoda the latter carry no teeth, or these are restricted to the lateral portion, leaving a wide diastema. This toothless part plays upon a peculiar crescent-shaped bone, the so-called predentary, which rests loosely upon the anterior ends of the mandibular rami, which latter do not as a rule form an nsseons symphysis. The Ceratopsia possess in addition a similar upper toothless piece, the prerostral, a kind of pre-premaxilla. The morphological value of these extra pieces is quite olsscure; they were in all probability provided with thick, horny pards. The bones of the roof of the mouth recall in their arrangement that prevailing in the Phynchocephalia and the Parasuchia. There are two pairs of large vacuities; one between the maxillae, ectopterygoids and palatines; the other between the latter, the maxillae and the usually small or slender vomers. The pterygoids are perhaps the largest bones, and form a rather long symphysis: laterally and behind they abut against the quadrate, anteriorly against the ectopterygoids and the palatines, which latter they sometimes separate. A peculiar feature of some skulls, c.y. Cerctoscutrus and Triceratops is the great size of the groove in which the large hypophysis of the brain is lodged.

The vertebrae are very variable, amphicoelous, opisthocoelous, nearly plain, with a slight concavity behind, or occasionally procoelous in the anterior region of the tail. Besides the usual pre- and post-zygapophyses many Sauropoda and Theropoda possess on the posterior trunk-vertebrae additional joints, effected liy a rertical wedge, the hyposphene, which extends backwards from between the post-zygapophyses and fits into a notch between and below the anterior zygapophyses of the next following rertebra. These additional articulations are analogous to the zygosphenes and zygantra of snakes and iguanas, except that in these Sauria the wedges are formed on the opposite, namely the anterior ends of the vertebrae. The vertebrae of the neck and trunk are devoid of intercentra, but those of the tail carry long chevron-bones. The number of sacral vertebrae is generally increased to four or five. The ribs have well-dereloped capitulit and tubereula, and the former have the tendency to shift from the centra or from their parapophysial processes on to the usually much elongated diapophyses of the neural arches. This arrange- 
ment. recalling the C'rocodilian condition, results in an increased capacity of the dursal furtim of the houly-arity. Interrertelnal articulation wi the ribs lanes not oceur except smetimes in the

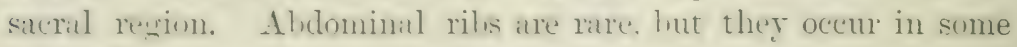
of the 'Theropoda, e.g. in Compsognathus.

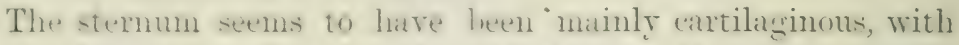

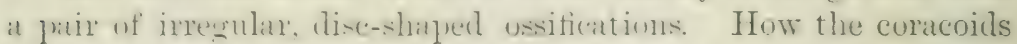
Were attacherl is unkmown: tluy alle small, senerally with a fimamen. hut the satprulate are always rery stromg and slant barkwarels. Clavieles and interelavicles serem to he alsent.

The fire-limbs are as a jule jowertul, although often much shorter than the himi-limbs. which are then enormonsly developed. and in many generat of two of the main eroups show

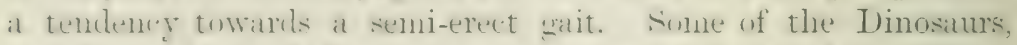

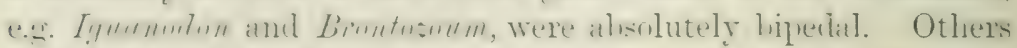

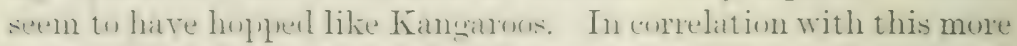

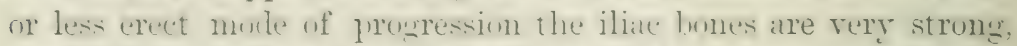
much elonsated hurizontally, and attardere to more than three, nften to fire or eren more, verteluate. The pulic lumes show two main types. Each consists either af a simglestrung shaft, which is

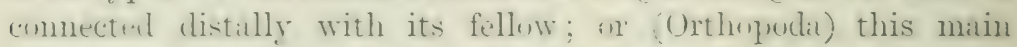
shaft semels out, helow its point of contact with the ischium, a lomer foucess, the su-called pust-pulis. which is directed downwarrls and hackwarls. In the latter case it runs parallel and in chese contact with the ischimu. Such lifurcated pubic

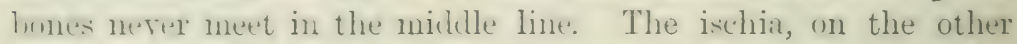
haturl, are always commected with tarch other, mot so much hy fusion as by syndesmosis.

The himb-limbs exhilit all statses frum a simple. plantigrate

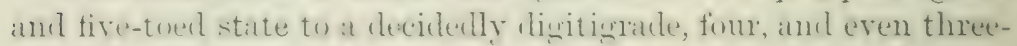
torel allangement. Many genera exhilit the tembeney to forman intertatril juint, a feattue elsewhere known in hircls only, where it is typiral and universal. The astratgalus semels up an ascending guxess which temels to fuse with the anterior atseret of the dis:al

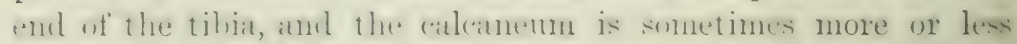

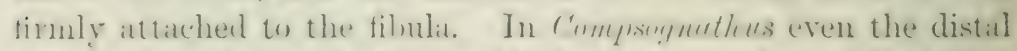

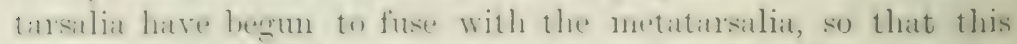
reptile at least hats a typical intertarsil juint. The femml is remathithle fin the frepuent poscesion of a "fomrth" arochanter

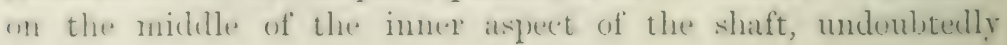


for the insertion of the long candi-femoral or long adductor muscle.

Many Dinosaurs possess hollow instead of solid bones. The rertebrae have large cavities in the Sauropoda, notahly in Brontuseurus; in many Theropoda, e.g. Coclurus, Anchisourus, Comprognathus, the limb-bones and the vertebrae are hollow, the latter being reduced to thin-walled shells with a few inner partitions, the bones being at the same time much swollen and enlarged. In the Ornithopoda the vertebrace are solid, but the limb-bones are hollow. The reason of this hollowing out is not easily found. Undoubtedly it results in a saving of material and weight, whilst at the same time, without loss of strength, the surfaces for the attachment of the necessarily powerful muscles are increased. But Compsognathus is a small, Brontozoum a gigantic, creature. On the other hand, the bones of the huge Stegosauri are solid. Most probably these cavities were, as in birds, filled with air-sacs ultimately in communication with the lungs; and it is by no means a baseless suggestion of Haeckel's that the Dinosaurs were warmhlooded. Their mode of propagation can only be guessed at from the circumstance that a rather well-preserved specinen of Compognathus contains in its abdomen what nua possibly be an embryo. There is nothing against the assumption that the Dinosaurs were viviparous; on the contrary, it seems more natural than that, for instance, an Atlentoseumes of more than 100 feet in length and many tons in weight, should have laid eggs.

Some of the herbivorous Dinosaurs, namely, the Stegosauri and the Ceratopsia, had a dermal armour of variable extent; the plates were loosely imbedded in the skin, and reiched their greatest size along the middle of the back and tail, and these crested plates were probahly covered with horny scutes, olviously weapons of defence. The Ceratopsia were armed with a pair of huge pointed horns on the head, and a smaller one on the nose (see Fig. 102, p. 430). It is difficult to guess the use of the reapons of these terrestrial monsters, unless they were employed against the equally large carnivorous Dinosan's or in the combats for the possession of their chaming mates.

About the ancestry of the Dinosaurs we know nothing except that their affinities lie with the Crocodilia; but it is impossible to derive either from the other. The oldest forms, in the 
present state of om knowledge-those which hare left their three-twed spoors in the Trias of connecticut-were already much spredialisen hy having attinimed to an upright bipedal gait, while the simuroula, which except for their wigantic size are the most generalised, are of compratively recent diate, none of them being

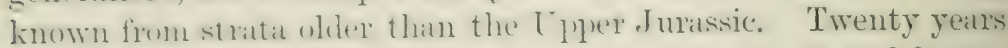
anow. mil the discoreries of numeroms kinds in the Lnited States, omr knmwlentge of the while group was rery limited. There is a whilly spreat notion that the lirkls have sprumg from some Dinositurian steck. Huxley was the first to show clearly that birls were an offishont of the regtiles, and he said of the Dinosams,

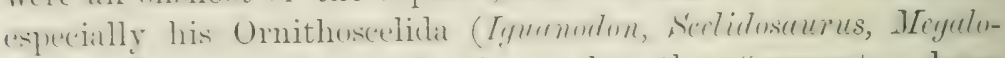

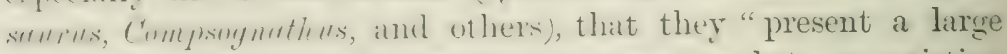
series of molifications intermediate in structure between existing reptiles and Ares." Iban proved to his own satisfaction that we Latre 10 lowe for the ancestors of the Ratitale among the herloivorum I linosiurs, especially the Oruithuotous forms, whilst the Carinatile are descemlants of the liatitate. Howerer, even he had to give up this absolutely unwarrantable view.

It is eatsy to select a considerable number of characters anonest the various I)inosaurs which also oceur in bircls, and some of these have until a recent date heen considered as peculiar to birks. For instance, the double, hifurcated pubic bones of the (1)thopulia: the increased number of vertedrate to which the horizontally elongater ilia are attached, expecially in the forms with an "lu'ght gait, ant the hiperal feature itself; the possession of an ascemeling pocess of the astragalus and its fusion with the

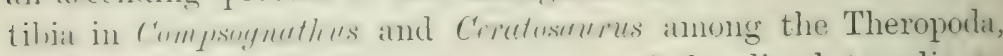
and in Ornithomimes; the attachment of the distal tarsalia to

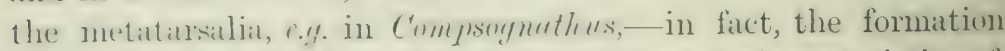
uf an intertarsal joint, a feature otherwise characteristic of, and preculier to, lireds; the frempent resluction of the fifth metatinsal bone; the hackwart position of the hallux and the proximal reduction of its metatarisal in Compreynuthes; the alongation and partial fusion of the functional metatarsals in

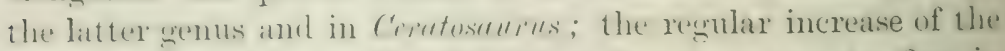
phalingeal numbers of the first fonr toes from two to fire in matny of the Oronthopula: -in short, the great resemblances letween the fiet of some of the Ininosanus and those of the lirets. Inwerer striking these argmuents are, they are instancess of con- 
rergent analogies. The upright walk, which has been assmued and improved upon independently by members of hoth Theroporla and Orthopoda, has produced the same, or nearly the sime modifications in them as in the birds.

It is easy to show that these features are mere coincidences. The oldest bird known is Archacoptery. from the Upper Oolite of Bavaria. Consequently all those Dinosaurs, which are of the same and of later date, have to be excluded from the supposed ancestry, and they happen to be those in which (as in C'erctosutrus, Comprognathus, Oinithomimus, Iguchuton) the resemblances are greatest. There remains only Anchismurus of the Upper Trias, more or less contemporary with the Brontoroum, which left its three-toed footprints (Archacoptery ic has four well-dereloped toes) with Zanclodun. Moreover, the most hird-like foot is either that of the Theropoda, which, like Anchiscurus and Zunclodon, differ from birds by the formation of the pelvis, or of some of the latest Ornithopoda. What, then, is the good of selecting a number of bird-like features from members of Dinosaurs which we are bound to class in different groups, and which existed, some in the lower, others in the middle, or eren in the latest Mesozoic periods?

Lastly, the advocates of the Dinosaurian ancestry of birds cannot have fully appreciated the enormous differences hetween the wing of Aichacoptery, and the fore-limb of any Dinosam with the most arian resemblances in the hind-limbs. The forelimbs of these reptiles are modified in a direction diametrically opposed to that from which a bird-like wing could be developed. The skull presents another difticulty, and here again C'ompsognathus, a contemporary of Aichacoptery, comes perhaps nearest to that of al generalised bird's skull. The ancestors of the birds must have (ombined the following characters:- Of not later than MinColitic age, with bifurcated pubic bones, four functional toes, elungated metatarsals, complete clavicles, premaxillary teeth, and frete, not firmly fixed quadrate bones. But such creatures are not Dinosaurs.

We divide the enormous number of Dinosaurs according to the formation of the jelvis, that of the hind-limbs, and the dentition, into four orders. 


\section{Order I. SAUROPODA.}

Pritics simple, with symphysis. Piemaxillae with tecth. Plantigiale.

The teeth are mostly spatulate, laterally compressed, with

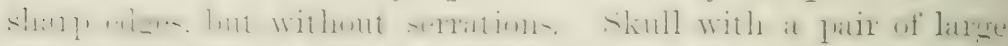

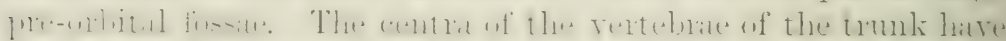

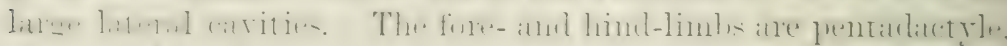

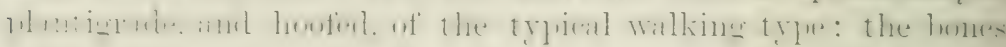
of the limbs are stout and solid; the femur is devoid of an inner distal or fourth trochanter. The carpal and tarsal bones are fri..

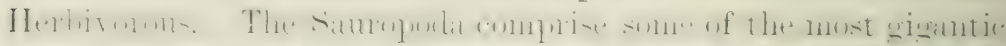

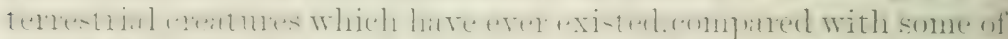

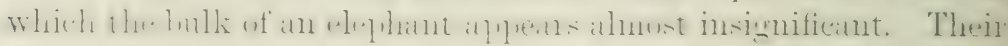

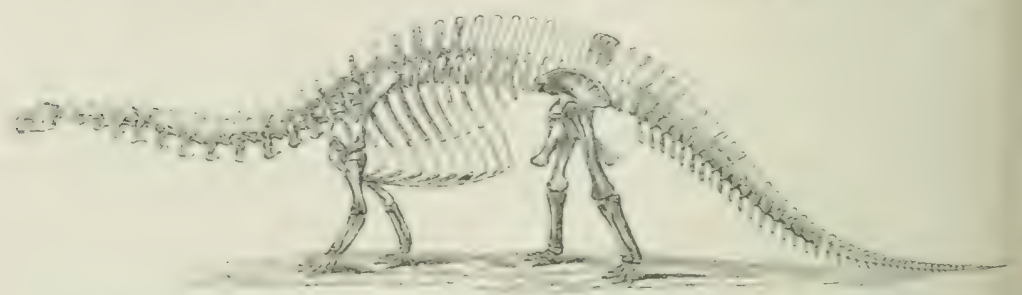

Fig. 95. - Skeleton of Brontosaurus excelsus. $\times \frac{1}{1}$. (After Marsh.)

1"ance in time extemis from the [aner Oolite into the Cretacents,

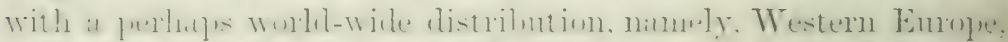

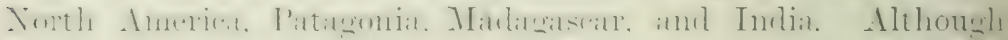
they are, except for their size, the least specialised of all Dinosaurs, none of the Samropoda hitherto discorered are old enough to claim to be the ancestors of the other Dinosaurs.

Brontosurrus cxcelsus of the Upper Jurassic of Wroming was a giant at least 60 feet long and about 10 feet high. The hearl

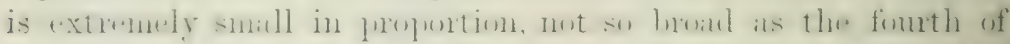
the thirteen vertebrae of the long and flexible neck. 'The'

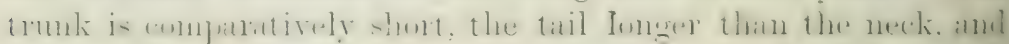
provided with numerous chevron-bones. Mlost of the rertebrite

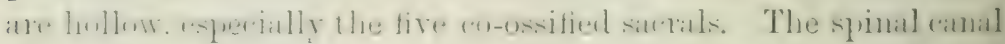
of the sacral region is very wide, indicating a strong sicral swelling in molmonity with the huge posterior timls. The

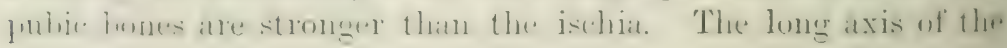


former stands almost rertically like that of elephants, and the knee is scarcely bent in the erect position. The shoulder-ciritle consists of long scapulae, hroar at the hase and small, almost square and perforated coracoids, which latter fit into a pair of partly ossified plates representing the sternum.

Atlantosaurus immanis of the Upper Jurassic of Wyoming and Colorado, is supposed to have been 115. feet long, perhaps the biggest and bulkiest of all animals, the femur measuring more than is feet in length and 2 in wicth at the upper end.

Inirusurums giondis, of the Lpper Juratsice of ITyoming, with allied forms in the I'mrlece and Wealden of England, reached a length of 30 feet;

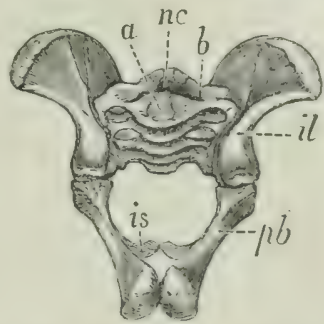

FIc. 96.-Front vitw of the yelvis of Moroscurus grandis. $\times \frac{1}{30}$. (After Marsh.) ", First sacral rertelura: h, "transverse procees" (rilh) of first sacral ; il. ilium ; $i s$ ischimu ; ne. neumal canal : $1^{\prime \prime}$, pulis, in gencral alpuranance resemhling Brontosoums, but the sacrum consists of four rertebrae only, and the ischia are bent backwards in their distal halves, so that their symphysis is formet by the shafts instead of by their ends.

Ornithopis and Cotiosanrus, likewise huge creatures, from the English Trealden and from the Great Oolite respectively, are rither imperfectly hnown, although several species of each. under many generic synonyms, have been described.

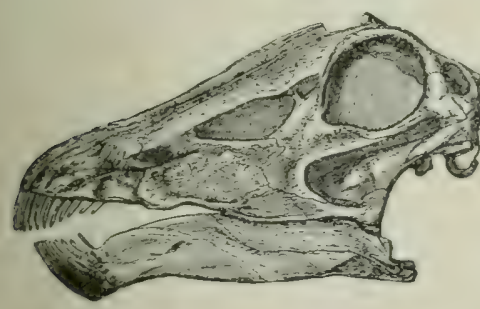

Fra. 97.-Skull of Diplodocus longus. $\times \frac{1}{12}$. (After Marsh.)

Diplodocus longus, of the Upper Jurassic of Colorado and Wyoming, is almost completely known. More than 40 feet long, it had a head in its general outlines not unlike that of a horse, the skull being about two feet long. The outer nasal openings are confluent, elongated, and lie far back on the top of the skull. There is a pair of large antorbital, and a pair of smaller litrymal fosite. The teeth, long and slender, are restricted to the anterior portion of the mouth, with many successors, which, decreasing in size, lie on the inner or lingual side of the functional tooth, like the cartridges in a repeating rifle. The 
functional teeth themselses are implatuted in socliets. The

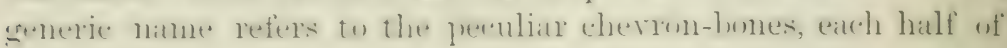
which diverges into an anterior and a posterior branch.

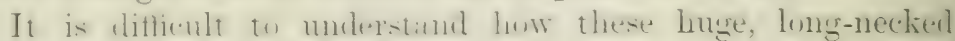

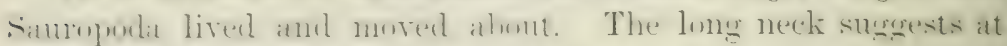
first sight premlanjuls hathits. lint the teeth, lather feethe in

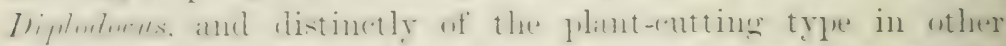

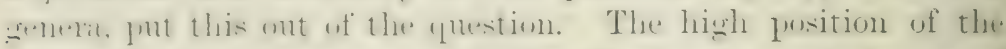

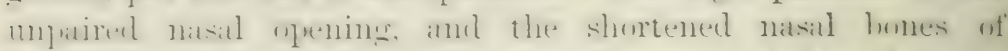

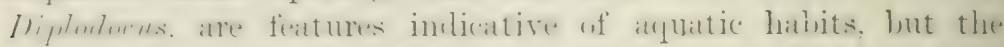

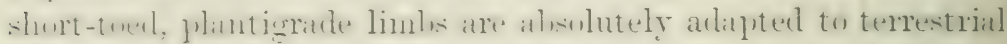
lifi. and wr cannot well assmute that streh enormous lorutes as

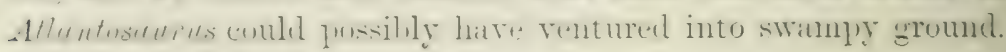

\section{Order II. THEROPODA.}

Pubies simple, with symphysis. Premaxillae with teeth. Digitigrade. Carnivorous.

The teeth ane frinted, rentureel. laterally compressed and serrated. The nasal openings are large, lateral, and nearly

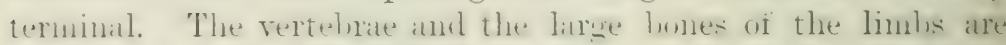
lowlow. The fore-limbs are comsicherilly shorter that the hindlimbs, which are distinctly digitigrade, many of the species latring a fronouncerlly uprisht gait. The proximal tarsiliat show a temeleney to fuse with the tibia, and the astragalus has solnetintes an ascending pocess, by which the fusion with the tihia is strengthenet. The first and fifth metatarsals are

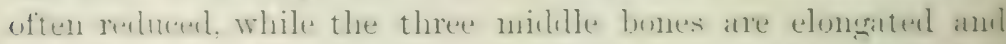
sometinus even fused with each other, so that the whole foun as-munes a striking resemblanee on that of lirds. The terminal phalanges atre frotecterl hy curred clatws. Owing to

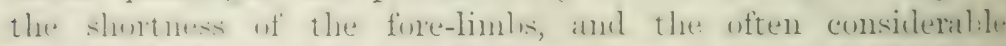
length of the hind-limbs, which are strongly bent at the knew

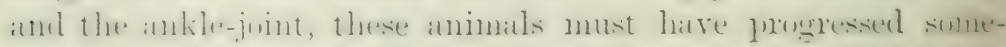
what like clumsy kangaroos.

The Theropoda, of which a great number of genera are nuw

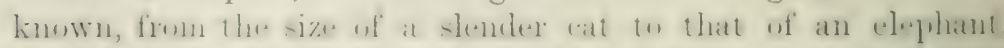

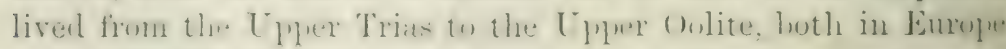
and in North America.

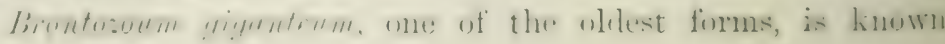


from its foot-spoors only, which, together with other three-toed spoors in the sandstone of the Connecticut valley, were originally deseribed and figured by Hitchcock as Ornithichnites (" $\chi^{\prime \nu o s}=$ track, or spoor). Some of these imprints are more than a foot in length, the right and left spoors following alternately at a chistance of from four to six feet. In sume cases the long trailing tail has left a furrow behind, and the large tracks are accompanied or crossed by much smaller, and even by quite tiny tracks, otherwise similar, and undoubtedly made by the young.

Anchiscurus, from the same locality, was still Sauropodous, in so far as the metatarsals are still free, with two, three, four, and five phalanges on the first four toes, but the fifth metatarsal is reduced, carrying a vestige of only one phalanx, and the proximal tarsal bones are fused with the tibia and fibula respectively. Total length some seven feet, of which about four belong to the tail.

Zanclodon, from the Keuper of

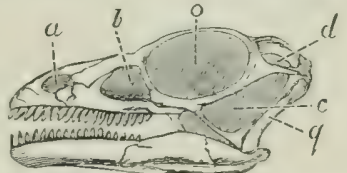

FIG. 98.-Skull of Anchiscurus cuelurus. $\times \frac{1}{4}$. (After Marsh.) a, Nasal fossa ; $b$, antorhital. $c$, infra-temporal, $d$, supratemporal, and $o$, orbital fossa ; $q$, quadrate bone.

Wiirtemberg, ahout ten feet long, with pentadactyle hands and feet. Ischia stronger than the pubic bones, which are distally much broadened. The femur is nearly three feet long, and possesses a fourth trochanter. The astragalus has an ascending process, and is fused with the tibia. The toes are short, strong, and clawed. The shoulder-girdle and fore-limb are strong, the latter well adapted to grasping. The teeth are much compressed laterally, with sharp, finely serrated edges. Several allied genera hare been described from the Cpper Trias of Frauce and England: others from corresponding strata of India and South Africa.

Megalosaums, from the Trias to the Wealden in England and France, with other species in Colorado and India, reached a considerable size, larger than that of any other Theropocti, the scapula of Mr. Tuctilundi being nearly three feet long, and the fenur still longer. The hind-limbs are twice as long as the fore-limbs. The cerrical rertebrae are short, the neck being much shorter than the tail. Hands with five fingers, feet with four toes. Pubic bones long and slender, with a lroad symphysis. With well-developed abdominal ribs, resembling those of crocodiles. 


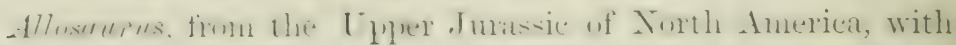

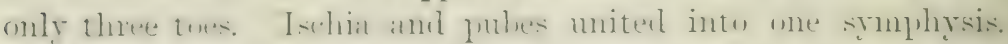
Anterior extremities very short. Sacrum consisting of four

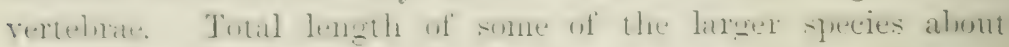
twenty feet.

Ceratosanirus nasicornis, from the Upper Jurassic of Colorado,

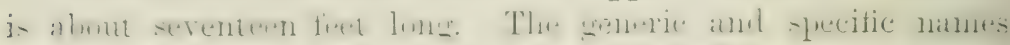
refer to the nasal bones, which are raised into an unpaired

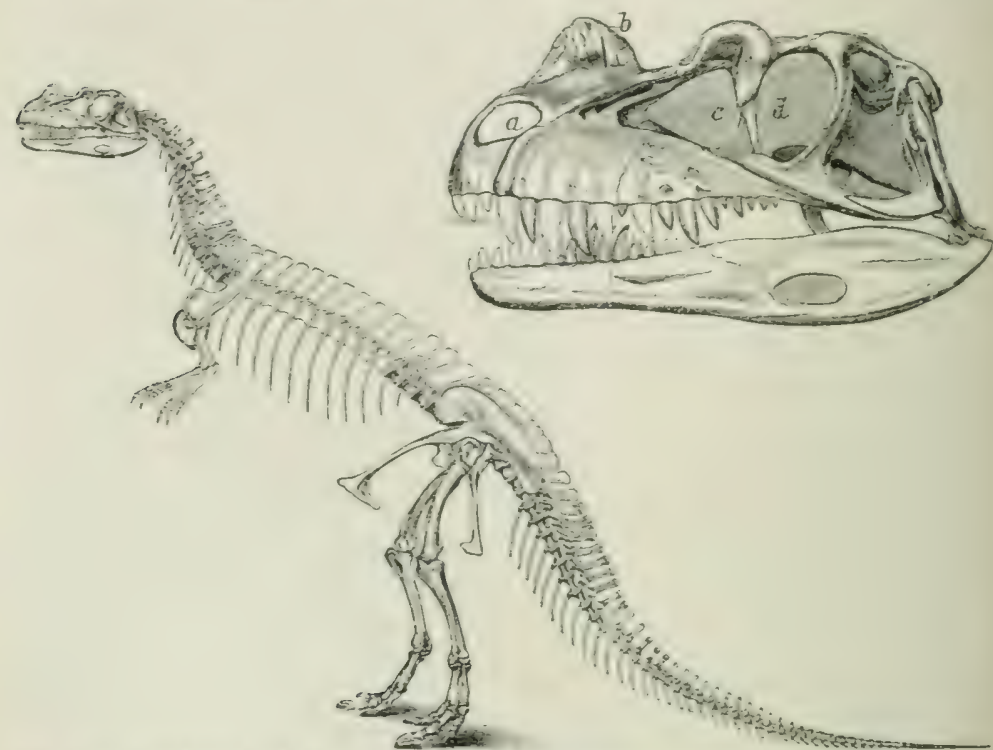

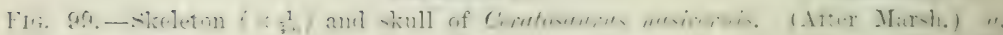
Nasal cavity ; $b$, bony horu-supporting excrescence ; $c$, pre-orbital fossa ; $d$, orbital fossa.

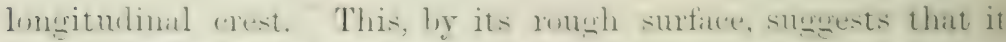
was corered by a horny sheath, or carried a horn. The large. skull, alunt two feet in length, is armed with strong, slighty

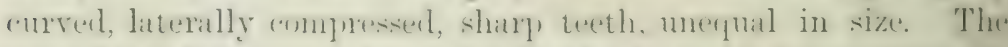

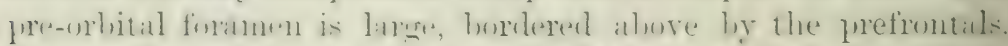
which are raisel inte pominent knols. The supratengmal fimanina are extremely small, the lateral fomminat very latro. The quadrate slants backwards. The sacrum consists of tir.

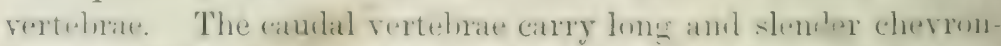
lomes. The pulnes and ischia are lomes and slemeler. anch forming

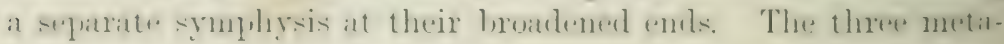


tarsils are elongated and fused with each other. There seems to have been some dermal armour in the shipe of osseons pliates. which extended in one series from the occiput over the necki

Coclurus gracilis, of the Upper Jurassic of Wyoming, and closely allied forms in the Wrealden of England, are remarkahle for the premmaticity of the centra and processes of their rertebrate, the bony parts of which are restricted to thin, hollowedout shells, so that the whole skeleton must have heen very light. Computed length of these inperfectly preserved creatures about five feet.

Hullopus rictor, of the Lpper . Turassic of Colorato. Interior extremities rery short, with only four fingers; pusterior limbs rery long and sleuder, especially the tibia; the much elongated metatalsils are separate, the first absent, the fifth much rectuced, so that the foot is tridactyle; the calcanemu projects like a heel. The ilimm is attached to two sacral vertebrae only; the pubes are slender, forming a narrow symphysis, while that of the ischia is broad. Most of the bones of this creature, which probahly progressed by hops, are hollow. Total length about three feet, the length of the hind-limbs being alwnt nine inches.

Comproynathus lengipes, of the T'per Imassic of Pararial, is (ne of the smallest of all the Dinosalus. It is most remarkiable un account of its almost bird-like feet. The fibula is much thinner and sonewhat shorter than the tibia; the latter is closely attached to, although not fused with the proximal tarsal hones, while the distal tarsals are fused with the united and much elongated second, third, and forrth metatarsals; the fifth is restucer to a short bone near the intertarsal joint; while the first is represented loy its distal portion only, which is stowed away on the hinder aspect of the middle of the second metatarsal, and carries two phalanges. The three middle toes (rmsist of three, four, and four phalanges respectively. Thilst the whole hind-limb is typically avian, the pelvis is quite different; the pubic bones are simple, slender, and directed forwards, forming a symphysis with their whole distal halies, and broadening out distally into a horizontal procetsis directed towards the symphysis, which is likewise formed by the fusion of the inner surfaces of the thin and rather flat ischia. The fore-limbs are only half the size of the hind-limbs. The neck consists of about ten verteluate, mostly with long and 
fointerl ribs. Tail long with well-ileveloped cherrons. The skull is long and pointed, compused of thin hones, which have lust most of the surures: with lirree lateral, temporal, and pre-orbital, but withut supratemporal, foranina. Premaxillate. maxilite, and mandilite with numerous slender and rather long conical, alveolar teeth.

\section{Order III. ORTHOPODA.}

Each pubic bone consists of an anterior or pre-pubic and a posterior or post-pubic branch, neither of which forms a symphysis. Premaxillae without teeth. With a premandibular predentary piece. Herbivorous.

The so-called pre-puhis is homologous with the pubis of most recent reptiles, and with the pectineal process of birds, while the "pust-pubis" is homologous with the processus lateralis of (helonims and Samians, and with the "pubis" of birds. The right and left halves of the pul,is remain willely asunder ventrally. In many cases the post-pubis, always directed obliquely backwards, lies closely against the shaft of the ischium, which always forms a clistal symlesmosis, or a symphysis, with its fellow. The forelimbs are usually very short, provided with five or four short and strong fingers. The hind-limbs are long and strong, mostly with three, sometimes with four functional short toes, either plantigrade (Steiosalri) or digitigrade (Olinthopoda). Femur with an inner distal, or fourth, trochanter. The dentition is of the herbivorous type, restricted to the dentaries of the mandible and to the maxillary hones, leaving the whole or the greater part of the premaxillaries free. The additional "predentary" piece of the mamlihle is possibly a calcified, hut originally horny, pad. The teeth are greatly compressed laterally, and finely sermated, but are much ground down hy use; several rows of successional teeth lie on the inner or linental side. The skull is strongly built, with large anterior nisial openings; pre-orbital formina very small or absent; orbits (ompletely encircled hy bones; supratemporal

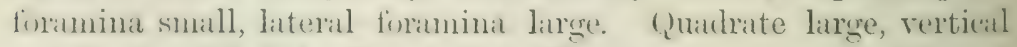
or slinting slightly forwaris. The verteluate are solid, not lubluw ; sacrum consisting of four, five, or more vertelone; rilss hifurcated, the cappitulat anriest either hy the centra, or inoverl up' to the diapuphyses of the nemal arches: chevon-hones numer- 
ous, and frequently long, especially on the anterior half of the long and heavy tail.

Orthopoda occur from the Lias to the Upper Cretaccons, both in Europe and in North America. The name Orthoporlit, invented by Cope in 1866 , is appropriate for obvious reasons: it comprises the Stegosauri and Ornithopoda of Marsh (1881). The latter term is not very fortunately chosen, considering that the whole hind-limb of the Theropodous Compsognathes is fur more ornithic than that of any three-toed Ornithopoda, in which the tarsalia rarely fuse with the tibia and never with the metatarsals. To apply the term Ornithopoda to the whole order is quite unjustifiable, unless it is meant to apply to the strikingly bird-like configuration of the pelvis.

Sub-Order 1. Stegosauri._-The fore- and hind-feet are plantigriade, or nearly so, the metapodials being but little elongater, with more than three functional digits. The bones of the limbs are solid. The ribs of the trunk are bifurcated, and are carried by the diapophyses of the neural arches. The body, especially the back, is protected by dermal bony plates, which are not connecterl with the internal skeleton.

Scelidosaurus harrisoni. One nearly complete skeleton, about 11 feet in length, from the Lias of Lyme Regis. About twentyfour pre-sacral vertebrae, of which six or seven belong to the neck, four sacral and about forty caudal vertebrae. Four fingers, four tnes, with $2,3,4,5$ phalanges, the fifth metapodials being quite restigial; the hallux and pollex are very short, so that the foot at least is functionally tridactyle. The tarsal bones remain separate. The head is rery small. Two rows of ridged bony plites extend from the neck orer the back, and converge into one row upon the long tail; smaller plates, arranged in many rows, seem to have protected the sides and under parts. Hylueosuurus and Polaranthus of the English Wealden are allied forms.

Strgosaurus, with several species from the Upper Jurassic of Colorado and Wyoming, and others, e.g. S. armatus ( = ()mustrurus), from the Kimmeridge Clay of Wiltshire in England. The head is relatively very small, and the brain is surpassed several times in thichness by the huge sacral swelling of the spinal cort. Teeth numerous and small. All the cervical and trunk-rertebrate carry lifurcated ribs, those of the trunk being carried entirely by the rery high neural arches. The fore-limbs are only about half 


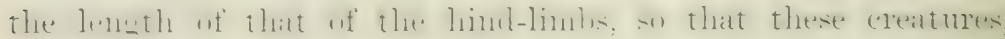
which were undoubtedly quadrupedal, must have had a very

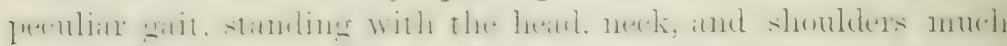
lower than the arched back and pelric region. The ulna has a

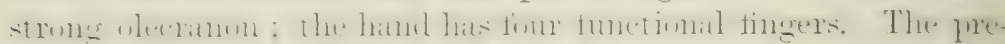

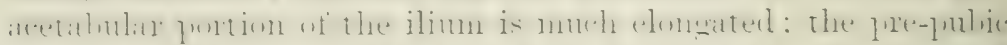

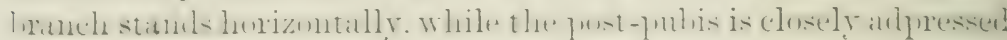
to the ischium. The astragalus is fused with the tibia, the calcaneum with the fibula. The foot has only three short toes,

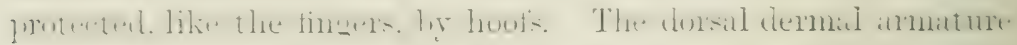

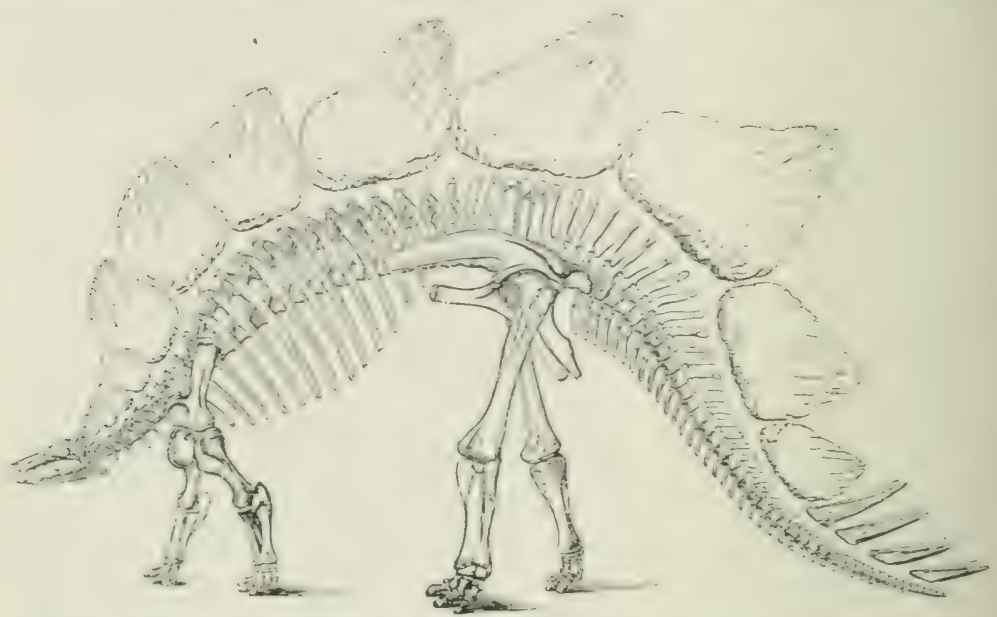

FIG. 100. -Skeleton and dermal armour of Stcgosaurnes ungulatus. $\dot{x} \frac{1}{60}$. (After Marsh.

consists of very high, crest-like plates. S. ungulatus of North

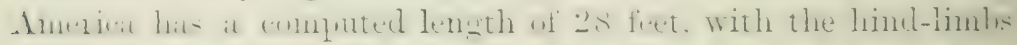

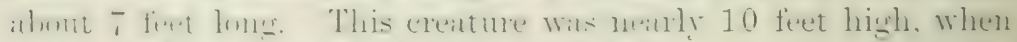

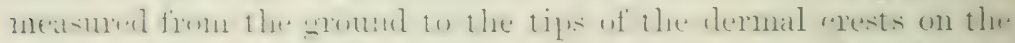

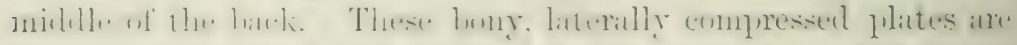

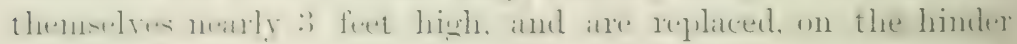
portion of the tail, by several pairs of pointed spikes aboun 2 feet in length.

Sub-Order 2. Ornithopoda.--The himl-linlss are distinedl?

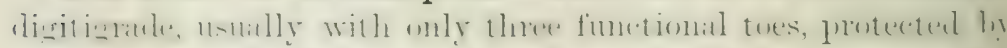
claws. The long bones are hollow. Femur with a long fourtl trochanter. Without dermal armour-plates.

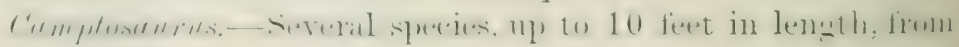


the Upper Jurassic and the Wealden of North Anerica and England. Five fingers, with 2, 3, 3, 3, 2 phalanges and foum toes, with 2, 3, 4,5 phalanges, but the hallux is much shortenert and does not touch the hard ground; astragalus and calcanemu separate.

Laosaurus of Colorado is a smaller form, intermediate in structure between the former genus and $H_{y}$ psilophombu forci from the Wealden of the Isle of Wight. A small creature, less tham 5 feet in length. Four fingers, with 2, 3, 4, 2 phalanges; fifth metacarpal vestigial. Four toes with $2,3,4$, is phalangen and long claws. Astragalus and calcanem separate. Pust-pulic rery slender. Eich premaxillary with five pointed alveolar teeth, leaving a wide median diastema; maxillaries with eleren, dentaries with ten laterally compressed blade-like teeth.

Iguanodon from the Wealden of England, Felgium, and Germany. Apparently two species, $I$. muntelli, alout 16 feet, I. bernissartensis nearly 30 feet long. The premaxilla is quite toothless; the teeth of the maxillate and mandihles stand in close series, implanted in alveolae; they are spatulate, laterally compressed, with finely serrated edges, and slightly curved, the lorrer outwards, the upper inwards, and bear a general resemblance to those of Iymana, hence the generic name. There is only one functional set of teeth, and these are much worn down by use, but in such a way that, owing to the different curvature of the oplosed teeth, the worn-down crowns form cutting, and at the sane time crushing, almost triturating surfaces, inclicaţing that these animals lived upon herbs. The gait of these creatures was upright, as shown by their spoors; the long ahnost vertical ischia, which form a padded symphysis, only slightly raised above the ground, suggest that this symphyis was used as a true sitting support, the animal resting upon it, the hind-limbs and the long tail. The latter, to juclge from the long cherrons and the high neural spinous processes, must hate been furnished with strong muscles. The whole tail was undoulbteclly used as a balance during the upright position. Many of the tendons of the dorsal spinal muscles on the back and "lyper halt of the tail are ossified. The post-pubie branches are rery slender, distally much reduced, and, except at the obturator-formen, separited from the ischia; the pre-pubes are very strong and broad. The femur has a fourth trcelanter, a feature which 
induced the unfortmate late Paul Allirecht to declare that Inmmuntun was a reptilian Indek! The tarsal hones are separate. The metatarsals and tores are resluced to three, with 3,4, i) phalanges respectively, the first heing a mere styliform restige. The anterior linbs are likewise very puwerful, but are much shorter: the hands are alitpted for grasping, possibly for defence and offence as indicated by the pollex, which, althongh short, i. transformed into a formidalile spur-like weapon, firmly fixed at a right angle to the other fonm fingers, the phalanges of which number 3, 3. : 4 : the second and third fingers were protecterl

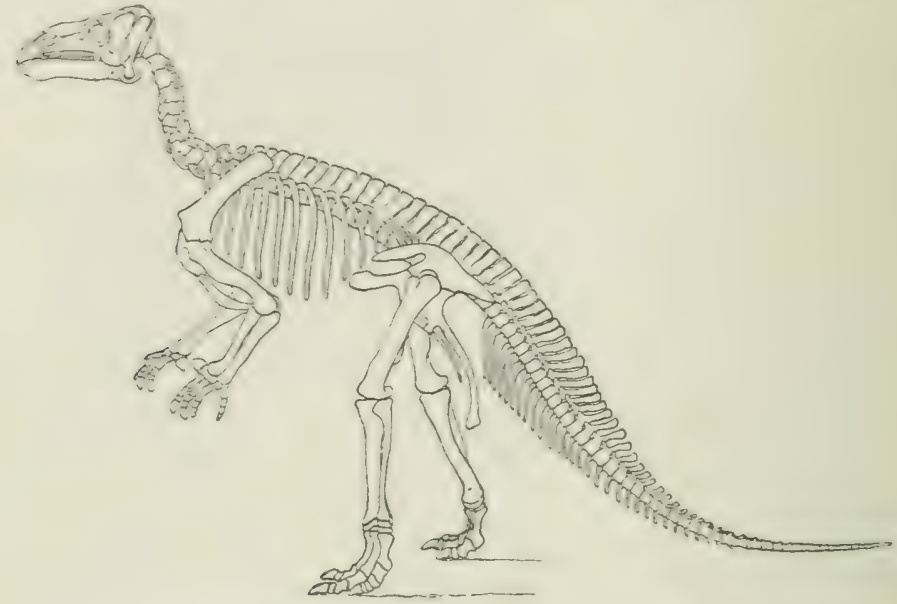

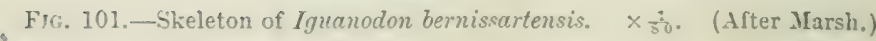

h, honf-like natils, the fifth fincer is teethe, and stands somewhat allart. The whole vertelnal colmun consists of nore than eighty rertehrate, of which ten are cervical. eighteen thoracic and humhar, while five or six are fused into the sacrum. The cerrical rertehrate are opisthocoelents, and carry short ribs, except the atlas, which pussesses two separate suphia-dorsil pieces, which fill the gap between it and the occiput.

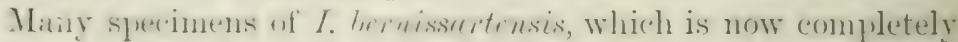
knwwn, inchuling even the hyoid bones. were discosered in 1578, in the Inelgian colliery of Pernissart, leetween Mons and Tournai, rluee to the French froutior. The lones were in a fault or crack, filled with clay of Wrablen age, alonet one thousand feet hedow the present seatelevel, and there almot thirty Ienanodons, all 
apparently adult, had become embedded. Five of them are now mounted in one of the public galleries of the Brussels MIusemm, of which these perfect monsters form one of the chief attrations. Having proved to be such a valuable find, they were claimed hy the Government, on the ground that Ignanodons were not included in the license of the Coal Mining Company. The finct that not only $I$. hemissartensis, but also a few specimens of I. mantelli, already known from England, where the large form likewise occurs, were found in the same place, makes the specific differences somewhat doubtful; they are perhalss sexual.

Clouscurus of the uppermost Cretaceous strata of Wyoming, is one of the latest of Dinosaurs. It is nearly allied to Iymunmonm, but has only three functional fingers, the fifth being alsent, whilst the pollex is very short.

Hudrosmurus s. Dictunius of the same level as the preceding genus in North America, apparently also in the Middle and Tpper Chalk of England and Belgimm, has a most peculiar spoon-shaped bill, the premaxilla and the predental bone lieing spratulate and quite toothless. The teeth in the upper and lower jaws are numerous and small, and whilst one set of teeth is being ground down, the several successional series are aheady functional. H. mirulitis has in all about 2000 teeth; the total length of the skeleton is 38 feet, of which nearly 4 feet are taken up by the skull; in other respects this genus is allied to Iguanodon.

Ornithomimus, of the Upper Cretaceous of Colorado, is known only from its fore- and hind-limbs. The fore-limbs are short, with three fingers. The hind-limbs are rery long and strikingly bircl-like. The metatarsals, of which only the second, third, and fourth are developed, are much elongated; the proximal half of the third is pushed back between the second and fourth, and imperfectly fused with them, exactly as in roung hirds. The astragalus has a long ascending process, and is fused with the tibia. The fibula is very slender, distally much reduced; the calcaneum is represented by a tiny nodule; the terminal phalanges end in pointed claws. O. grantis must have reached a considerable size, to judge from its mildle metatarsal, which is $60 \mathrm{~cm}$. or 2 feet long. Until more is known of these extraordinary creatures, nothing definite can be said aljout their affinities. They may perhaps belong to the Theropoda. 


\section{Order IV. CERATOPSIA.}

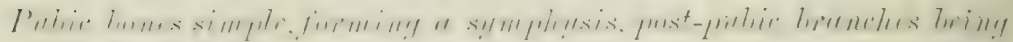
absint. The mandible ererries a toothless "pre-dental," and the fused premaxillaries carry a similar", toothless, "rostral" bone.

The teeth of the upper and lower jaws are alveolar, and have two roots. The fore-limbs are little shorter than the hind-

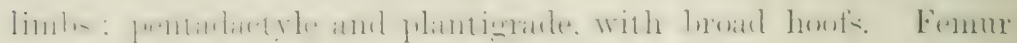
without a fourth trochanter. Limb-bones solicl. The skull is

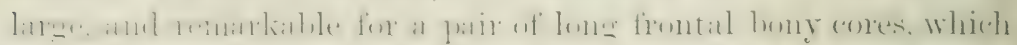

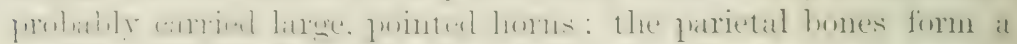

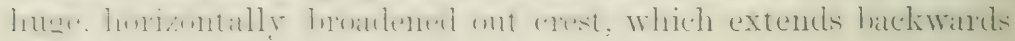

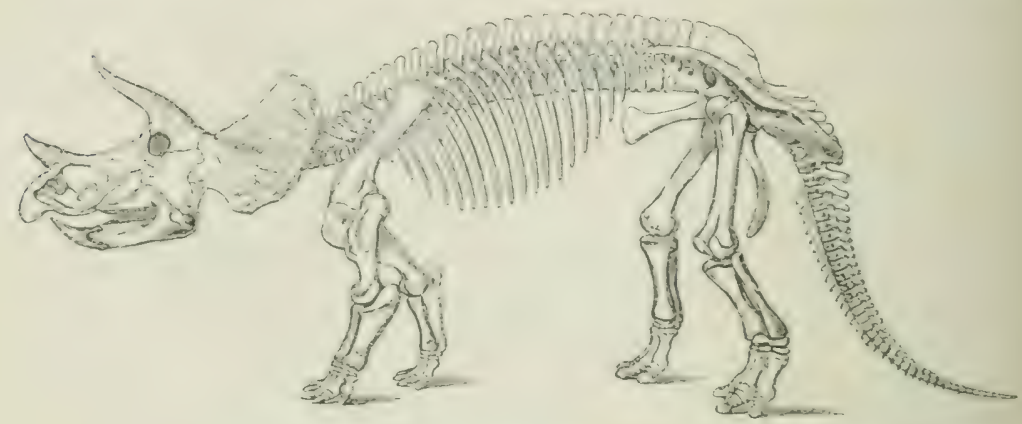

Fici. 102.-Skeleton of Triccutops prorsus. $\times \frac{t}{10}$. (After Marsh.)

over the neck. Upon this cranial neck-shield follow small

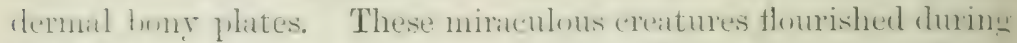

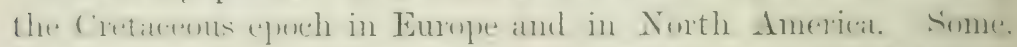

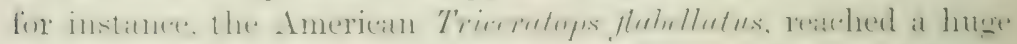
size, its skull alone measuring more than 5 feet in length.

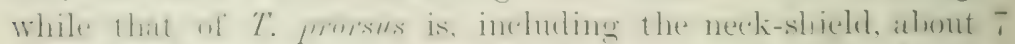
leet longe. The total lemeth of this momster, the batck of which

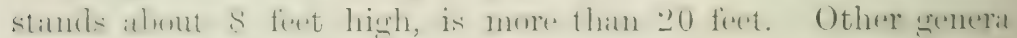
seem to have a well-developed dermal armour, c.y. Nodosaur'm: of the Niddle Cretaceous period of Wyoming.

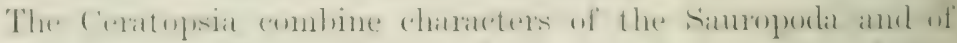

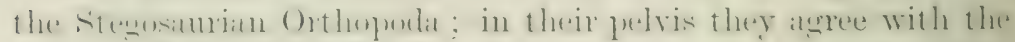

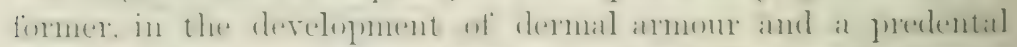
home they actere with the latter. while they differ from either ly the possession of a rostral element. 


\section{SUB-CLASS VI.-CROCODILIA.}

If we had to deal only with the recent Coucolilia the tiolluming would the an all sufficient diagnosis : - Fon, fomtert, lon!y-

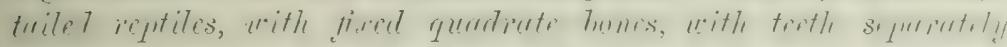
implanted in alveolac and restrieted to the upper and lover jitus.

To define Crocodilia in general and to distinguish them finm

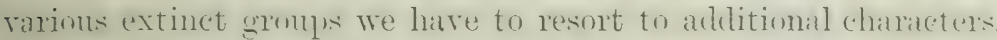
The rerteluate are sulid : the rils of the neck and thurax possess a distinct capitulum and tuberculum; there is a series of luose,
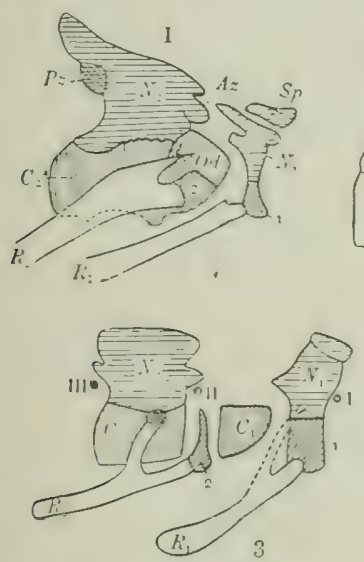

$+\frac{L}{\text { L.V. R.V. }}$
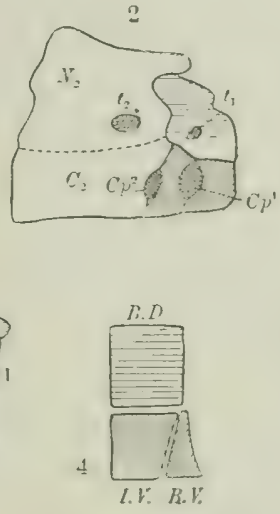

FIG. 103.-1, Atlas and axis of Crocodilus. 2, Atlas and axis of Metriorhynchus, a Jura- ic Crocolile, see 1). 439. 3, Analysis of the first two cervical rertehnate of at Cromeile. t, Iniaram of the funtamental composition of a lientilian or athere Amniotic, typically gastrocentrous vertel,ra. Az, Anterior zygaloullysis ; $L . L$, basidorsal ; $\boldsymbol{B} . \mathrm{T}$, basiventral ; $C_{1}, C_{2}$, first and second centra, formed by the

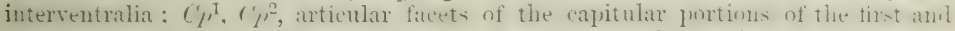
second ribs; $I . T$, interventral $; \Lambda_{1}, \Lambda_{2}$, first and second neural arch, formed by

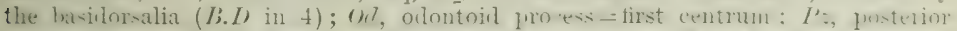

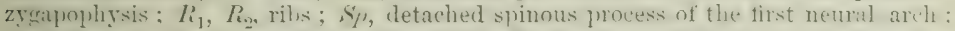

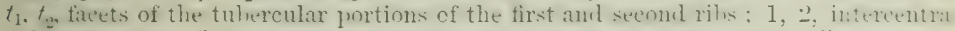
=basiventralia ; " (in 3), second basirentral "complex or intercentrum," continued upwards as a meniscus or intervertebral pad; $I, I I, I I I$, position of the exit of the first, second, and third spinal nerves.

compound abdoninal ribs; the humerus is dexoid of an ent"picondylar formen; the iliac bones are broadened ont ant attached to two sacral vertebrae; the pubic bones are simple, not lifiurated, and neither they nor the ischia are ventrally uniterl. The skull ahways has a strong, bony, quadrato-jugal arch. The possession of a longitudinal cloacal opening and of 
an anterior or rentral single copulatery argan can of contre le asserted of recent forms only.

In spite of these many chatraters common to all Crocolilial, it is rery difficult to separate the latter from the Dinosaturia, the only absolute ditterence lying in the ventral pelvic bones. It is therefore must sugerestive that the fore-linbs of the Mesozoic cromelilia are su much shorter and weaker than their hindlimblis a discrepuney which is not lessened before the Tertiary "push. The Mesozoje Crocodilia were almost entirely marine: the strungly-ilevelogerl ankle-joint (indicaterl already by such carly forms as Actusumes and Mrystrimsurus) must have been inheriterl from some terrestrial group, with oligitignade temelencies and shortened himb-limbs. All this points to some Theropodous

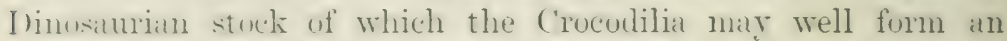
itpratice fiuther-dereloped hranch. Loss of the pulbic and ischiarlic ventral srmphysis is nut a serions modification. So firr as moklern repitiles are concerned only the Chelonia and Syllementon are related to the Crocuctilia, whilst Monitors and "ther lizards resemble them unly superficially. We divide them into three Orders.

\section{Order I. PSEUDOSUCHIA.}

The few members of this preculiar gromp of reptiles are all restricted to the Kenper or variegated marls, although they seem to hase hat a wide distribution, sume having been foun.: in Cinnany, whers in New Mexico. They perhaps form a! carly sile-liranch of the ateneralised Crocodilian stock, which died out with the Jurassic age.

The skull is distinctly short and pointed. The premaxillaries are rery small and are dorsally separated from each other ly the large nasis, which also keep the maxillae widely asimeler. The mestrils are latero-terminal, hordereel chiefly ly the nasals, below ly the premaxilate and part of the maxillae. The whit

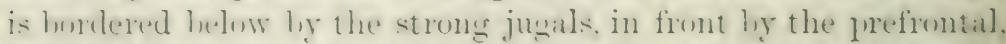
almse liy at supuaterbital and a sinall pustfontal, behind ly a gustorlital, whirth, firmly commerted with the jugal and squamosil, sluti off a supratemunal foranem. There is also a lateral

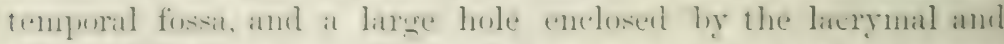
the maxillary lones. The teeth are restricted to the anterion 
lalf of the jaws. The neck, back, and tail are coveresl by two rows of large and broad, closely-jointed bony plates; smaller plates protect the sides and the ventral surface. The vertebrae are still unknown.

Aitosaurus ferratus of the Upper Keuper near Stuttgart is the best known. One of the greatest treasures of the Stuttgart Mruseum is a slab of sandstone, about 2 square yards in size, upon which lie huddled together twenty-four individuals of various sizes, the largest measuring $86 \mathrm{~cm}$. or 2 feet 10 inches. They are in a beautiful state of preservation, and many of them are in the most life-like attitudes, just as if a mass of sand had fallen upon them and crushed them down, and as if they were struggling to get out.

Erpetosuchus and Ornithosuchus of the Elgin sandstone seem to be allied forms.

\section{Order II. PARASUCHIA.}

As the name implies, a collateral branch of the true Crocodilia. They are, like the Psendosuchia, restricted to the Keuper formation. The rertebrae are mostly biconcave, sometimes with nearly plain, scarcely concave, central joints. The premaxillae are very long and powerful. The nostrils lie far back, rather near the orhits, on the top of the snout, within the anterior half of each nasal and almost above the choanae. The latter are sitnited in front of the palatine bones and are divided by a backwarlly clirected process of the vomer, which is plainly visible on the roof of the mouth. The palatines and pterygoids leave a wide median space between them. The pterygoids are narrow and have three processes, the antero-lateral of which joins the palatines and the maxillary bones (there being no separate ectopterygoid), the inner joins the basi-occipital, and the posterolateral the quadrate.

The orlit is surrounded by the frontal, prefrontal, lacrymal, postorlital and postfrontal, while the strong jugal is excluded. The temporal region shows a lateral and a dorsal foramen; the latter opens backwards and alove the occiput, being hordered in front by the parietal, laterally by the squamoso-occipital bridge.

The vertebrie are amphicoelous. The first and second VoL. VIII 
vertelurate are devorid of rils: the cerricals and first thoracics carry separate cippitular aml tuherenlar processes for the attachment of the rihs. while the rils of the rest of the trunk are

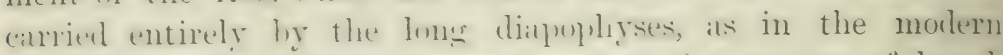
crocombiles. The dermil armom ansists of two rows of broad,

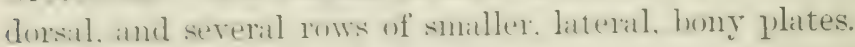

Jirlulum is hy fin the lest-known genus, with several species in Fimtl fiermatny and Sirth Anerical, some of which reached a length of 10 feet, without ventral armour. The closely allierl

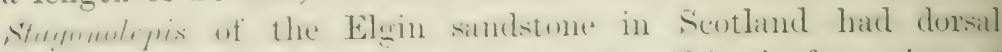
and ventral armonr. Other generat in the Triatsic formations of India and North America.

\section{Order III. EUSUCHIA.}

Crumblilia in the stricter sense. The premaxilhe are shont and always encluse the nostrils. The chomale lie hehind the palat

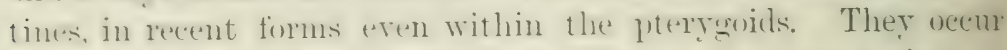
fion the Liassic or Lower ourasic period to the present time.

The direct ancestors of the Eusuchia are still unknown.

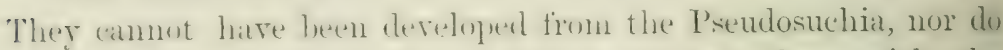
we know internediate starges which comnect them with the Parasuchia. The nostrils, situated within the premaxillaries, always lies in front of the nitsals, althomgh these sometimes extend forwarks and form a bury internatsal septum fusing with the ustial cartilaginous septum. The chomale, insteat of opening

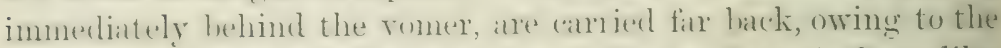
formation of a secondiny beny palate. In the Jurasicic Crocodiles this ronf is forment he the meeting of the palatine hones in the metios-ventral line, and the chomate open inmediately behine?

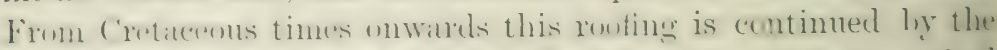
forergobils. which likewise form at median suture: and the uniterl choanae (which may, or may not, be divided by a thin bony septum; are pusherl towards the pusterior ent of the potergaids.

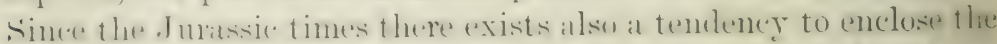

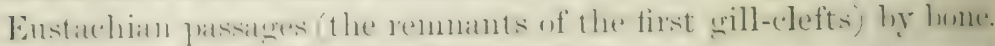

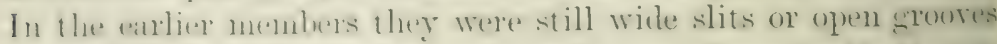

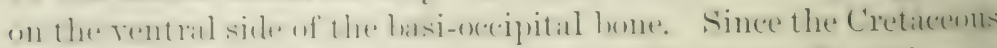

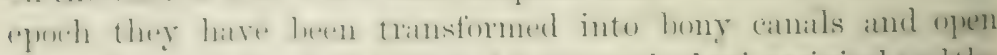
thronghene median hole, sitnated het ween the bats-oceipital and he 
basisphenoid, immediately behind the posterior symphysis of the dorsal portion of the pterygoids, which latter almost completely cover the basisphenoid. The romer is not visille (except in Caiman niger), being covered by the rentral junction of the palatines and maxillaries. The broad, lateral wings of the pterygoids are connected ly separate bones, the ectopterygoils = transpalatines = transverse bones, with the maxillaries, and in recent forms also with the jugals. Thus an extensive, rery firm hony palate is produced; and the.large palatal foramina, between the palatines, maxillaries, ectopterygoids and pterygoids, are closed ly the same dense mucous membrane which cover the whole roof of the mouth.

The opisthotic and epi-otic bones fuse early with the litteral and with the supra-occipital bones; only the pro-otic remains longer as a separate element, perforated anteriorly by a large hole for the exit of the third branch of the trigeminal nerve. The basisphenoid is scarcely risible, being covered by the piterygoids. The presphenoid is large, continued formards and mpwards into the usually cartilaginous interorbital septum. Tear the anterior and upper margin of the presphenoid is a large notch on either side for the passage of the optic nerve, the three eye-muscle nerves and the first branch of the trigeminal nerve. There are no separate orbito-sphenoids, their place being taken hy membrane or cartilage in continuation with the interorbital septum, but the alisphenoids are large, abutting upwards against the frontals. Each prefrontal sends down a vertical process which joins the palatine of its side.

The configuration of the snout varies much. There are tro parallel lines of development since the Jurassic epoch, namely, long-snouted creatures, of which two still survive as (ururiulis and Trumistoma, and more broad and short-snouted members like the rest of the Crocodiles and Alligators. In opposition to the Parasuchia the elongation of the snout is effected by the maxillaries. The length of the nasals varies much, mostly in conformity with that of the maxillaries. As a rule they reach the premaxillaries but not always the nasal groove. In Curiulis they are short, far separated from the premaxillaries by the maxillaries, which meet in the dorso-median line. The orbit is horlered by the frontals, which at an early age fuse into an unjaired piece, and by the prefrontal, lacrymal, jugal, and postfrontal. 


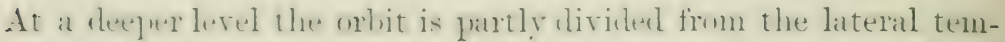
fwral fiss: ly a strones column which is formed ly the meeting of

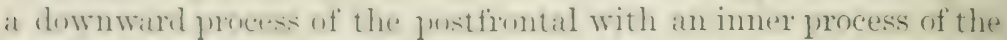

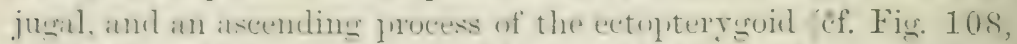
p. 4is. This arrangenent adds ansiderahly to the strength of the skull. The lateral temporal forsit is hordered in firnt ly

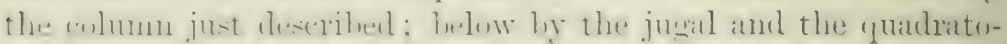
juenl. Which is tirmly werleger in hetween the jugal and quadrate;

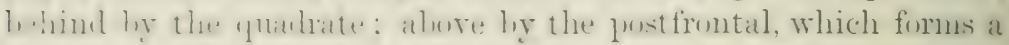

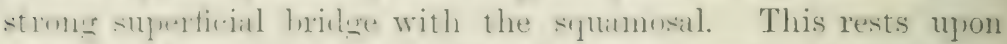
and when finses with the quallate and an intervening thansterse wing-like extenaion of the literal occipital bone. Tiy this

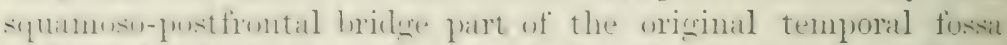

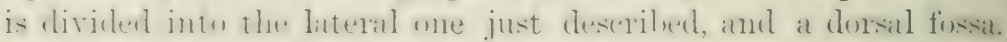

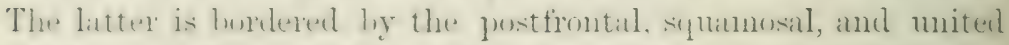
parietals. 'This dorsal temporal fossa is consequently not hommlirgons with that of the l'arasuchia, a vestige of which is luwever furesent in many, expecially in yomes skulls of Crocodiles. in the shale of a narrow passige which extemls hackwards from the dorsil fosit, bribed orer by the junction of the parietal with the squamosal, and bordered below by the occipitals.

The size of the mper tenumal fossite stands in an inverse. ratio to that of the lateral foscate. In the older Eusuchia the

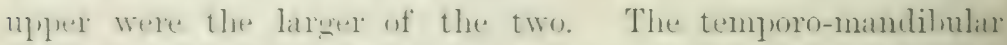
muscle which lifts or shuts the lower jaw arises from the walls

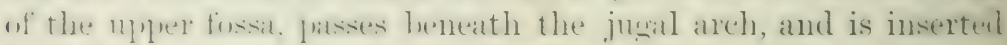

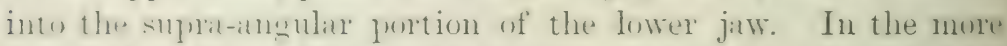

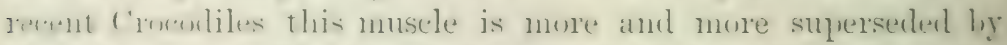
the perygo-mandibular musche, which, arising chedly from the

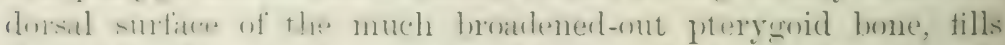

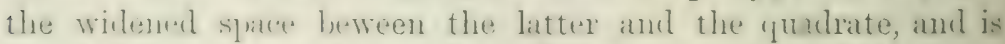
inserterl into the muter surface of the os anderlitie of the lowes

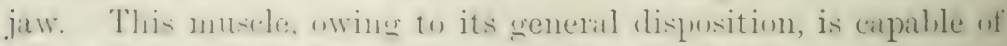

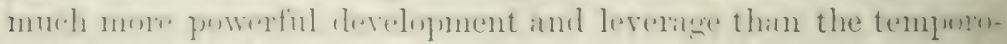

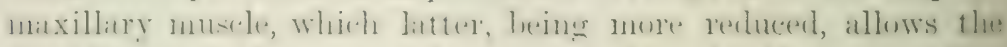

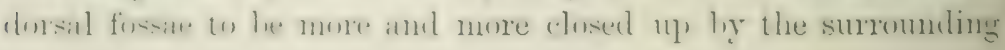
bones.

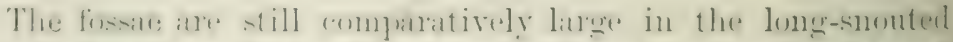

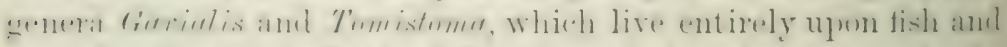
scarcely chew their fiend. Whilst these holes aluost completely 
disappear in some of the Alligators, namely in the broal- and short-snouted members, which, having a varied diet, taken from every available group of the animal kingdom, chew their prey.

The quadrate extends obliquely backwards, and is immovably wedged in and partly fused with the quadrato-jugal, the squamosal, and the lateral occipital wings. Between the latter and the quadrate remains a slit-like canal, well visible from behind, through which passes the continuation into the mandible of the columellar or ossicular chain of the auditory apparatus. Intricate passages, used as additional enlargements of the space of the mildle ear, perrade the proximal portions of the quadrate and the roof of the cranium beneath the parietal bridges mentioned above, the two sides communicating with each other. The supra-occipital bone is visible from behind; its top is corered and partly fused with a continuation of the parietals, which are, like the frontals, fused into an unpaired mass. The occipital condyle is formed entirely ly the basi-occipital bone, so far as the articulating facet is concerned, but it is supported on either side by a lamella from the lateral occipitals.

The two halves of the lower jaw form a smphysis of very variable length. Each half is composed of six bones. (1) The articulare, perforated in its upper, posterior, immer comer by a camal for the reception of the siphonium, a narrow tube of connective tissue, which comnects the carities of the middle ear with the large empty space enclosed within the lower jaw; (2) the angulare: (3) the dentary, which alone carries the teeth; (4) the splenial, a long splint-like bone on the surface of the imner or median side of the jaw, of variable length; (5) the operculare, the comnterpart of the splenial on the outer side: (6) the supra-andulare, which forms the dorsal horder of the lower jaw between the dentary and the angulare.

The teeth, which are more or less conical or compressed laterally, are deeply implanted in separate sockets. They are often shed throughout life, the successors lying on the median side, and with their caps partly fitting into the wide, open roots of the teeth to be expelled. The number of teeth in the premaxilla is universally five on either side in recent forms, lut in a fixw speries, e.g. Crocodilus nituticus and C purosus, the second pair is lost with naturity and is not replaced. In the broad-snonterl 
linds, esperially in the Alligators, most of the upper teeth overlap laterally thuse of the lower jaw. In must species of cromolitus. the orerlapping is less marked and the teeth partly interlock, but the fourth mambiluliar touth, senerally the strongest and longest, is received into a laterial notch at the junction of the premaxillary ani maxillary. Frequently those of the longer lower terth which tit into pits of the upler jaw. Eratually transform the pits into holes by continued gressure upon the hone, and in old sureintens the tip of the lower tonth may even perforate and stand out above the skin of the snout.

The vertelnate are solid. lint remmants of the notochord persist fin a long tine in the niliblle of the centra. These are still anplicuretous in the Turasic Ensuchia, and there were probahly consileriblite intervertehral portions of the notochord. From the Lower Chalk onwards the rertelurae are procolous, with the exception of the first caulal vertelira. which has a knoh at pither end. so that naturally the posterior of the two sacral vertelnate is opisthocoelous. This peculiar formation of the first amblal is probubly correlated with the flexibility of the tail.

Cartilaginous intercentral rings, pads or menisci, occur renulary throughout the vertehral column, unless they are almlisherl by fusion of adjoining vertebrate. It is most instructive to follow the attachment of the ribs in one and the same individual. The position of the capitulum, rertically helow the tulereulum in the neck, changes in the thorax into one in which the appitulum lies anterior to the tuberculum and in the sane horizontal pline with it. Moreover, whilst on the cervical vertelnate the appitulum is carried hy the centrum (enclosing with the tuberculum a trpical transverse canal for the rertehal artery, etc.). further lack it moves its point of attachment uywark lying right unon the newo-central suture on the tenth and elerentli rateliate. From the twelfth vertebra backwards both mipitulum and tulerenlum are carried hy the transverse process or diapnpluysis of the nexural arch. The rils of the five or six lumbar vertelorate are merely vestigial or ahsent. The rils of the two sacral vertellate are very stont, fusing in the adult with both centrum and neural arch. Some of the anterior canclal vertebrate also carry ribs, attached across the neuro-rentral suture; long lnfore maturity they fuse with their vertelorae, and then look like transwerse procesies. Mrot of the caulal rertehrae carry also a 
pair of chevron-bones, and these are continuous with the intercentral rings of cartilage.

The atlas and the epistropheus or axis are of supreme interest. Crocodiles are, in fact, the only animals in which these two vertebrae retain all their constituent hard parts in an almost mdisturbed primitive condition (Fig. 103, 1-4). The basal piece of the atlas-ring, the first basiventral or intercentrum, carries a pair of long rilss attached by their capitular portions. A small huob near the dorsal edge of the rib occurs in many specimens, and is the last remmant of the tubercular portion. The latter was still complete in Jurassic Crocodiles, for instance in Metriowyneh us (Fig. 103, 2, $t_{1}$ ). The first centrum joins that of the second rertebra as its so-called olontoid process, not directly, however, but by the intercalation of the complete second basiventral, represented by a cartilaginous dise, and by a large unpaired pyramidal piece (Fig. 10:3, 3, ). This, serially homologous with the rentral half of the atlas-ring, is the second basiventral intercentrum, wedged in from below between the odontoid process and the second centrum, with which it soon fuses. Moreover, it canries the capitulum of the second rib $\left(2, C_{p}{ }^{2}\right)$, the tuberculum of which is articulated with a facet of the second neural arch in Jurassic Eusuchia $\left(t_{2}\right)$. In recent Crocodiles this tubercular portion is much reduced, and, curiously enough, is attached to a knob which belongs to the odontoid piece or first centrum. This shifting explains the apparently anomalous condition that "the atlas of the Crocodiles carries two pairs of ribs, the second rertelura none." To complete the account of the atlas we have to mention the separate unpaired piece which lies upon the two neural arches. It is the detached neural spine, and not the remmant of a "pro-atlas."

The first and second ribs $\left(R_{1}\right.$ and $\left.R_{2}\right)$, at least in the recent forms, are very long and are quite movable. Those of the next five cervical vertebrae are firmly fixed, short, and adze-shaped. The eighth and ninth are again long, and make the transition to the thoracic ribs, which are mostly eight in number, some with uncinate processes. Then follow several shorter or floating ribs, mostly two or three pairs. The next following three presacral vertebrae carry no ribs. The two sacral and the caudal ribs have already been mentioned.

As a rule the vertebral column of recent Crocodiles, Alligators, 
and Gavials is composed of twenty-six precaudal vertebrae (nimely, nine cerrical, fifteen thoracic and lumbar, two sacral), and about thirty-four to firty or more caudal vertelorae. Individual variations, induling lep-sided attachment of the iliac bones, are by no means uncommon.

The stemum remains cartilasinous. It consists of an anterior rhomheid fortion, which carries the coracoids and two pairs of rils, and a posterior longer and narrower protion formed by the menlian fusion of the next following tive or six ribs. Posteriorly the stemum hifurcates, each half carrying two or three rils, of which the list sometimes loses its proximal comexion, and thus alplears as a xiphisternal process. Ventrally, upon the anterion lart of the sternum lies the longiturinal, originally paired, "pisternum. The shoulder-girdle consists of the coracoids and the scipulate, which fuse with each other into one bony piece rme each silte. I pre-coracoid is inclicated in fossil forms hy a notch in the coracoid.

The sprace hetween the pristerior end of the sternum and the:

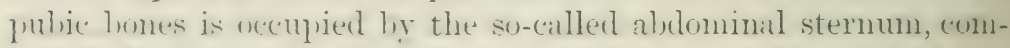
losed of seren lairs of ositications, resting upon the rentral sicte "if the rectus aldominis muscle. Each pair consists of two chely alproed pieces. while the right and left remain separate in the median line. The last pair is much stronger than the rest, is mure

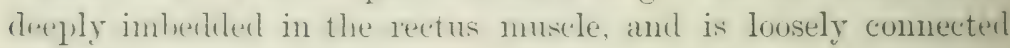
with the anterior margin of the two "pubic" bones.

The linhs are hult upon the typical terrestrial pentaclactyle

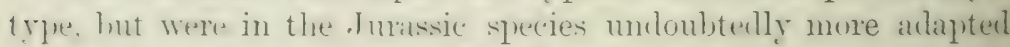
(1) swimning lecomotion. The fore-limbs were anspicnously shorter aml smaller than the hind-limbs, and it is only since Tertiary times that the difference has decreased to a greit extent. Ulna and radius remain separate. The proximal row of canplat homes consists now of the ulnare and radiale, buth strong and distinctly alomgated. On the onter sicle, hetween ulna and ulnare, lies a pisiform bone. Upon the rarliale follows a componund bone, often inperfectly ossifiexl towards the median side, and comsisting of the first distal "arpal, the "entrale, anul the internedimm. The third, fourth. and fifth carpals are fused into one mass. The second distil carpal remains separate. All fire fingers are present and well dereloped. The number of phalanges of the prollex is 1 wo, of 
the others three, four, four and three respectirely. During the embryonic development the number of phalanges of the fourth and fifth finger increases temporarily, to as many as seren on the fourth, to five or six on the fifth fiuger. Before the young animal is hatched the numbers are reduced again, chiefly by fusion of adjoining phalanges. This hyperphalangeal condition, typical of Plesiosauri, Ichthyosauri, Cetacea, and sereral other absolutely aquatic animals, naturally suggests the descent of the present Crocodiles from more essentially aquatic ancestors, lut hitherto no trace of supernumerary phalanges has been found in any Jurassic Eusuchia, nor in the Parasuchia and P'reudosuchia.

The composition of the pelvis is difncult to understand. It consists in the adult stage of three separate bones, of which two only partake in the formation of the acetabulum. The lroad ilium sends out two processes; the posterior and stronger articulates with the ischium, which sends out a short and stout process towards the anterior process of the ilium, enclosing a foramen. This process contains a separate centre of ossification, jossibly homologous with the true pubis, while each club-shaped home, loosely attached to it and directed forwards, generally called the pulbis of the Crocodiles, would then be equivilent to an epipubis. Neither the "pubes" nor the ischia form a ventral median symphysis.

The femur is deroid of a prominent immer trochanter. Tibia and filula are of almost equal strength. The tarsal elements are, in the adult, reduced by fusion to five hones. The fitulare is transformed into a typically projecting, heel-shaped calcaneum, while the intermedium is fused with the tibiale into a lnoad astragalus. The first, second, and third distal tarsalia are much reduced towards the inner side, and form one wedge-shaped, partly curtilaginons mass. The fourth tarsale lies between the fibulare and the fourth metatarsal, while the fifth tarsale is houk-shaped incl loosely attached to the outer side of the fourth. It has lost its metatarsal and the rest of the fifth finger. Finbryos are liyperphalangeal, the fourth toe leveloping six phalanges, and there are traces of the fifth toe. The numbers are ultimately recheed to 2, 3, 4, 4,0 on the five toes. The fumth toe remains without a claw.

Skin. - The epidermal horny layer is not shed periodically nor in pieces; the wear and tear is made gool imperceptilly. The 
scales, which cover the whole body, have a hard, horny, waterprof covering, lut between them the skin is soft. Each scale of the sides belly, and tail, and especially those of the lower jaw, shows a little dut or pit. At this spot the epidermis is not cornified or thickened, and a nerve with sensory corpuseles ends beneath the hottom of the pit. Sometimes these pits are filled with diburs of cells, and on the lower jaw, expecially on the chin, these organs, instead of forming pits, are raised into little wartlike prominences.

The scutes or dermal portions of the scales consist of thickenesl. cutaneous connective tisine, and are more or less extensively usified, thus forning a juper dermal armour. In most rexent Crocodilia the amour is restricted to the lack, with ueasimal osseons plates on the throat, as in Osteulaemus; regular althongh thin ossifications in the ventral scutes oceur in the Camins only. The Crocodile and Alligator skins of commerce comsist entirely of the tamnel cutis, minus the epidemis and the horny corerings of the scutes. In some fossil generia the ventral armonr was extensively ileveloped, expecially in Telcosentus, in sonne genera to the exclusion of clorsal ossifications. The arnom of the recent forms consists, so far as the large seutes are concerned, of a considerable number of scutes, which are arranger in transverse rows, ach row corresponding with one skeletal segment of the trunk proper. Mustly there is a destached Cluster of scutes on the hack of the neck. On the trumk some of the sentes are larere and nore crested than others, and form in their totality a variable number of longitudinal rows. The merlian pair is genemally the most comspicuons on the back. Sinne of the more lateral rows of keseded scutes converge more and more towards the tail, the imner rows drop out imperceptibly, and two lateral rows combine on the milllle of the tai? into an unpaired seriss of vertical hlales. These are no longer lomy, int show mone strongly dereloped horny sheaths; they are very flexille, and transforn the tail into an effective propelling organ.

Most of the langer sentes amb the uplere surfice of the bones of the skiull have a peruliar gnawed-ont, almost honeyeombed appearane, ats is usual whererer most of the eutis itself is transforment into lwome or en-tssifies with underlying lone. while the mpermust layers and the horny layer of the epidermis are much reduced and thinned out. 
All the recent Crocodilia possess two pairs of skin-glands, hoth secreting musk. One pair is situated on the throat, on the inner. side of the right and left half of the lower jaw. The opening of the gland, risible from below (see the figure of c'moutilus niloticus, p. 461), is slit-like, and leads into a pocket, which in large specimens is of the size of a walnut; the bag is filled with a smeary pale brownish substance, a concentrated essence of musk, nuch prized by natives. The secretion is most active during the rutting time, when the glands are partly everted. $\Pi_{y}$ young Crocodiles and Alligators often turned them inside ont, like the finger of a glove, when they were taken up and held ly force. The other pair lies within the lips of the cloacal slit, and is not visille from the outside. The use of these strongly scented organs, which are possessed by hoth sexes, is obriously hedonic. The sexes are probably able to follow and find each other, thanks to the streak of scented water left behind each indiridual.

The tongue is flat and thick, attached by its whole undersurfice, so that it can be elevated but not protruded. It fills the whole space between the two halves of the lower jaw hehind their symphysis. The dorsal surface shows numerous irregular polygonal fields, in the middle of most of which opens the dnet of a large mucous gland. Tactile and gustatory corpuscles are scattered orer the surface in the shape of tiny wartlike elevations. The hinder margin of the tongue is raised into a transverse fold, which, by meeting a similar fold from the palate, the relum palatinum, can shut off the mouth completely from the deep and wide carity of the throat, which leads of course into the gullet. I)orsally the choanae open into this carity; and since the narial passages are transformed into long tubes, completely surrounded by lone, Crocodiles can lie submerged in the water, with only the nostrils exposed and with the mouth open, and breathe without water entering the windpipe. The opening of the latter, the glottis, is a longitudinal slit, protected by the laryngeal cartilages, opened and closed by muscles. There is also a pair of memliranous folls within the glottis, which serve as vocal cords. Tentrally below the larynx lies the cartilayinous, broad, shield-shaped hyoid; on the sides are attached the short hyoid horns. The trachea is long, consists of about sixty or more complete cartilaginous rings, and divides into two short bronchi, likewise protected by complete rings. The trachea is depressed ; its transrerse diameter decreases 
from the gluttis backwards. The lungs have attained a high denree of efficiency. Fiach luns is an oval sac, and is transformed into a complicated system of tuhes, at the end of which are the (anntless honeyeomb-like respiratory cells, the whole lung being slongy. The main bronchus is continned straight down to the josterior encl of the lumg, and semels off during its course regular seromelary loronchi, and these send off tertiary bronchi. The whole arrangenent is rery regular, the tubes coming off like rows

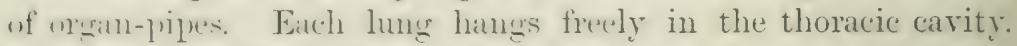
Desiles its ventral attachment by its arteries, veins, and the irmulnus, it is connected ly lonse tissue with the liver and the pericartial septum. Each half of the thoracie cavity is partitioned off' from the aldominal carity by a strong transterse mesenteric linnellat. The partition between the lums and the stomach is at lirst sinple, it then cliviles, to encluse the liver; the anterior partition passing hetween liver and lung to the inner surface of the sternum: the posterior lanella letween the liver and the stominch. Foth meet on the ventral surface of the liver, and ares continued into or attached to the peculiar "diaphragmatic" muscle. This is coveret by the internal rectus muscle of the alulumen, arising from the last gatir of alulominal ribs near the pulice lones: it is imnervated ly a lianch of the last precrumal nerve, and extends as a broad but thin muscular sheath (always within and uncomnerest with the ahdominal wall) to the rentral posterior vein of the liver; thence it is continued as an apmenusis. together with the peritoneal lamella mentionest anse, un the inner surface of the sternum. Contraction of this simgular muscle indireetly wilens the fulnomary cavity, ame thereby dimetly aids inspiration. It ants conseruently like the

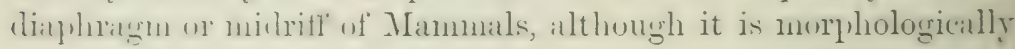
an entirely different muscle.

The stomach is snaller than one ningt expect from the filct that large ('rocouliles can eat up nearly a whole man; lut a great deal of their pory is stowed away pedininarily in the wide gullet mutil the rapill, juwerful digestion, which dissolves every bone, makes room in the stomach. This consists of a wide, some-

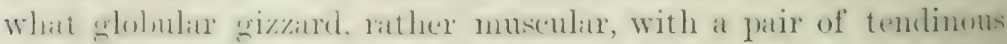

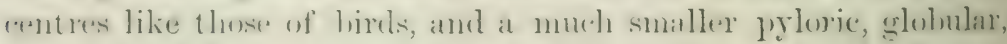

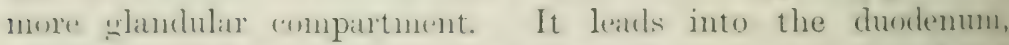

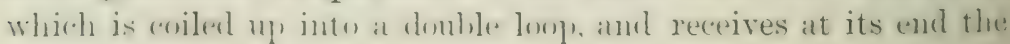


hepatic and pancreatic ducts. The small intestine is narrow, and is stowed away in a few irregular coils; the rectum is wicle a caecum is absent.

The cloaca is peculiar. The coprodaeum and urodieum, cf. 1. 498, are confluent, and form a wide, oval bag, closed in front and hehind by strong sphincters, and it acts normally as a minary receptacle. In the dorsal wall open the two ureters; a little towards the sides, and rentrally, open the two oviducts, on the right and left, near the base of the clitoris. Then follows a transverse, soft, muscular fold, which shuts off this cavity from the proctodaem or outermost chamber. In the latter is stowed away the rather large copulatory organ. It arises out of the medio-rentral wall of the cloaca, and has a cleep, longitulinal groove on its morphologically dorsal side for the conduction of the sperma, the vasa deferentia opening near its basal end. On either side of the root of this organ, in both sexes alike, opens a peritoneal canal, wide enough in large specimens to pass a goose-quill. The outer opening of the cloaca forms a longitudinal slit; within it, dorso-laterally, are the openings of the two anal musk-glands.

The kidneys are much lobed. The testes are long and ural: the oraries are much elongated and Hat; and the egges contained therein in great numbers are extremely small, except those which ripen during the time of propagation.

The vascular system has attained the highest state of derelopment of all reptiles. The heart is practically quadrilocular, the partition between the right and left ventricle being (wouplete; but there is still a small communication, the formen Iauizzae, which lies in the middle of the wall cominon to hoth aortae, where they leave their respective rentricles. The left aurtic arch conveys all the arterialised blood out of the left ventricle, and supplies head, neck, trunk, and tail. The right aortic arch, coming from the right ventricle, supplies venous hood, mixed with what little arterial blood it receives through the foramen Panizzae, to most of the riscera. On a level with the stomach both descending aortic arches are still comnectecl with each other; the left aorta supplies most of the gut : the right, the trunk and the kidneys.

The outer ear lies in a recess, dorwally urerhung ly the litteral edge of the bony squamoso-postfrontal lridge; and this 


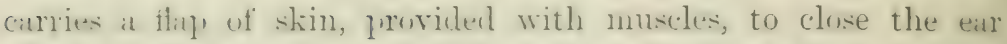
tighty. The trmplanic membrane is risible at the hottom of the lexess: shinines thrmes it is jart of that cartilage which is honulusums with the mallens of the anditory osicular chain: the ontwarel extension of the latter on its way to the mamdihle.

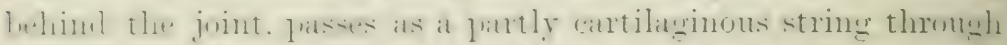
the slit-like hrole which is visible at the lack of the skinll, between the quadrate and the latero-occipital wing.

The eyes have. lusiles the lower and uner lid, a third, the

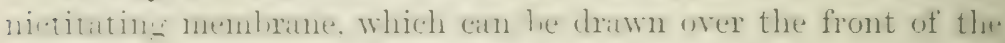
exeball. In the upper lid lies a cup-shaped bony plate of varialle size. The jupil contracts into a vertical slit. The iris is greenish.

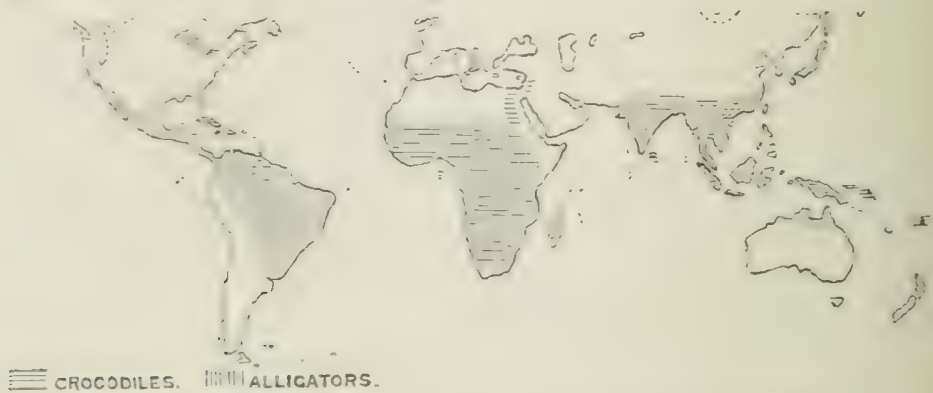

FIG. 104.-Map to illustrate the present distribution of Crocodilia.

The $1+\cdots+n t$ geographical distribution of the rarious kinds of

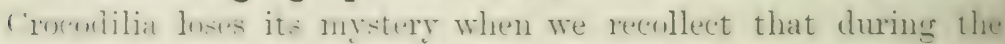

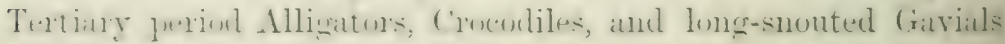

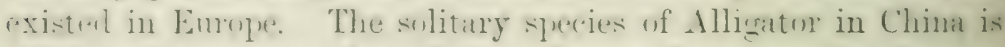
the lats living reminder of their former Periaretic distribution. The proup, taken as a whole, is otherwise now intertropical, Crocorliles alone inhaliting the I'alaten-tropical resion, together with long-snouted forms in the Oriental sub-region, while Alligatuss and Camans, with a few Croculites, live in Anerica.

They are all rapacious, doing much damage by their irrdatory hahits, and are fiere and sulky in temper. Jut the

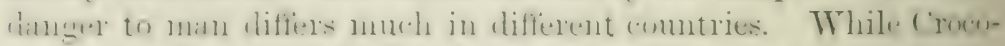
diles are hreated in some localities. they are in others consilered

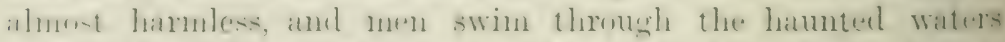
withunt lexitation. It serens as if certain oll and wily inclividuals turn into man-eaters, just like tigers and lions. 
Their home is the water, in which they pass the night, their time of hunting. The prey is either patiently watched or stalked, and nothing falls amiss. Water-lirds are seized ly the beast, which rises imperceptibly from below. Some species are said to make use of their powerful tails for hitting the victim and even jerking it into the month. The strength of their jaws is enormous, and they do not let go what they have seizerl, muless, in the case of a man, he has the presence of mind and the opportunity to dig his fingers into the monster's eves whilst being dragged down.

In the morning they crawl on to sandbanks, or on to logs of wood, which they chosely resemble, in order to bask, mostly in such a position that on the slightest alarm they can plunge into the water. For this reason they frepuently make a half circle before they settle down to rest, with the heads turned towards the river. There they bask all day long, alparently fast asleep, often with gaping mouths. But their sense of hearing and of sight is sharp, and they learn from experience, old individuals being by far the most wary. Commercially the skins are now of considerahle value. The flesh is white, and is tolerable eating but for the combination of fishy and musky odour, which, although faint, is not to everybody's liking.

All the species have a voice, a kind of loud, short bark or croak, heard at night and when angered. The female lays several dozen or event three score white, oval, hard-shelled eggs in the sand, well out of the reach of moisture; and some species construct an elaborate kind of nest. The mother watches it, takes care of and fights for her offspring, numbers of which fall an easy prey to large storks, fishes, and to the stronger members of their own kind.

In the cooler countries they hibernate in the ground: and in hot countries, which are subject to drought, some kinds aestivate in the lardened mud; or they migrate. When during a prolonged drought on the island of Marajó, at the mouth of the Amazon, the swamps and lakes were dried up, the Alligators migrated towards the nearest rivers, and many perished in the attempt. On one farm were found 8500 dead, and at the end of Lake Arary more than 4000 . Such occurrences in hrgone times may perhaps explain the masses of bones found here and there in a fossil state. 
The age to which croemdiles can live is quite herond calculation. They are capralile of propargation long lefore they are anything like half-grown, nayle at an age of little more than ten rears: then they continue to grow perhaps for more than one hundred years, until they die.

It. is customary to divide the Eusuchia, most of which are extincl.intw a longirostral amel a lnevirostral section. In the former

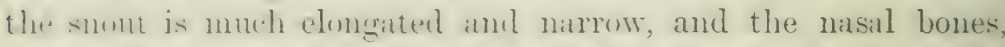
althom they are sometines very longe, do not reach the natsal cromse. The mandihular symphysis is repr long, and is formed not wnly lis the dentary hut also hy the splenial bones. In the herimstral sextion the snont is shorter, sometimes hroart and rommlerl ofi, and the nasal lones ane supposed to reach the nasial

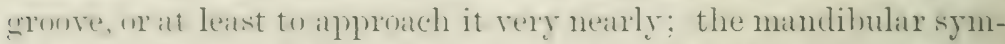
physis is forment by the dentaries only. But these distinctions are quite arhitrary, and there exist all kinds of intermediate

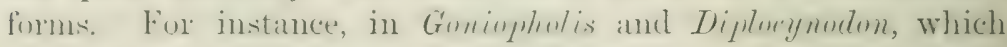
are buth unclouldetlly near allies of the recent Crocodiles and Alligators, the natsal bones are considerably removed from the

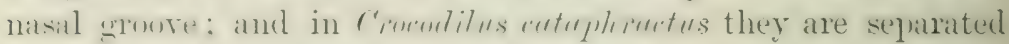
eren from the premaxilla ly the medio-dorsal suture of the maxillaties. Again, in fonchumblis the mandibular symphysis is so long that it comprises part of the splenial bones. Both typically long-and short-smouted forms oceur alreaty in the Inper (olite, lut in the Lower Jurassic age only long-snouted linds seem to have existed. The latter cammot easily lie connected with birmlon, one of the l'arasuchia, on account of the position of the nostrils; the mere shortening of the long premaxillaries of bormten would not transfer its distinctly painesl nostrils to the anterion end of the premaxilla. To acroment for the position of the nasal groove in the Eusuchiat, we have to go back to a primitive condition, such as that of

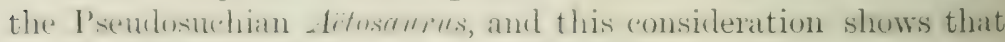
the Parasuchia and Eusuchia are collateral branches.

The Eusuchia have been split into many families. Zitt.l. for instance, divides them into ten, some of them on insuflicient grommks since there are ton many intermeliate forms : and nome. sometimes quite mexperterl, morlifications are still being fouml.

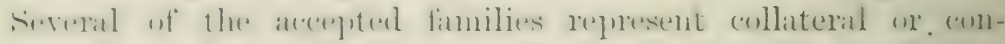
verent lines of derelopment. There is the sime tendemey to 


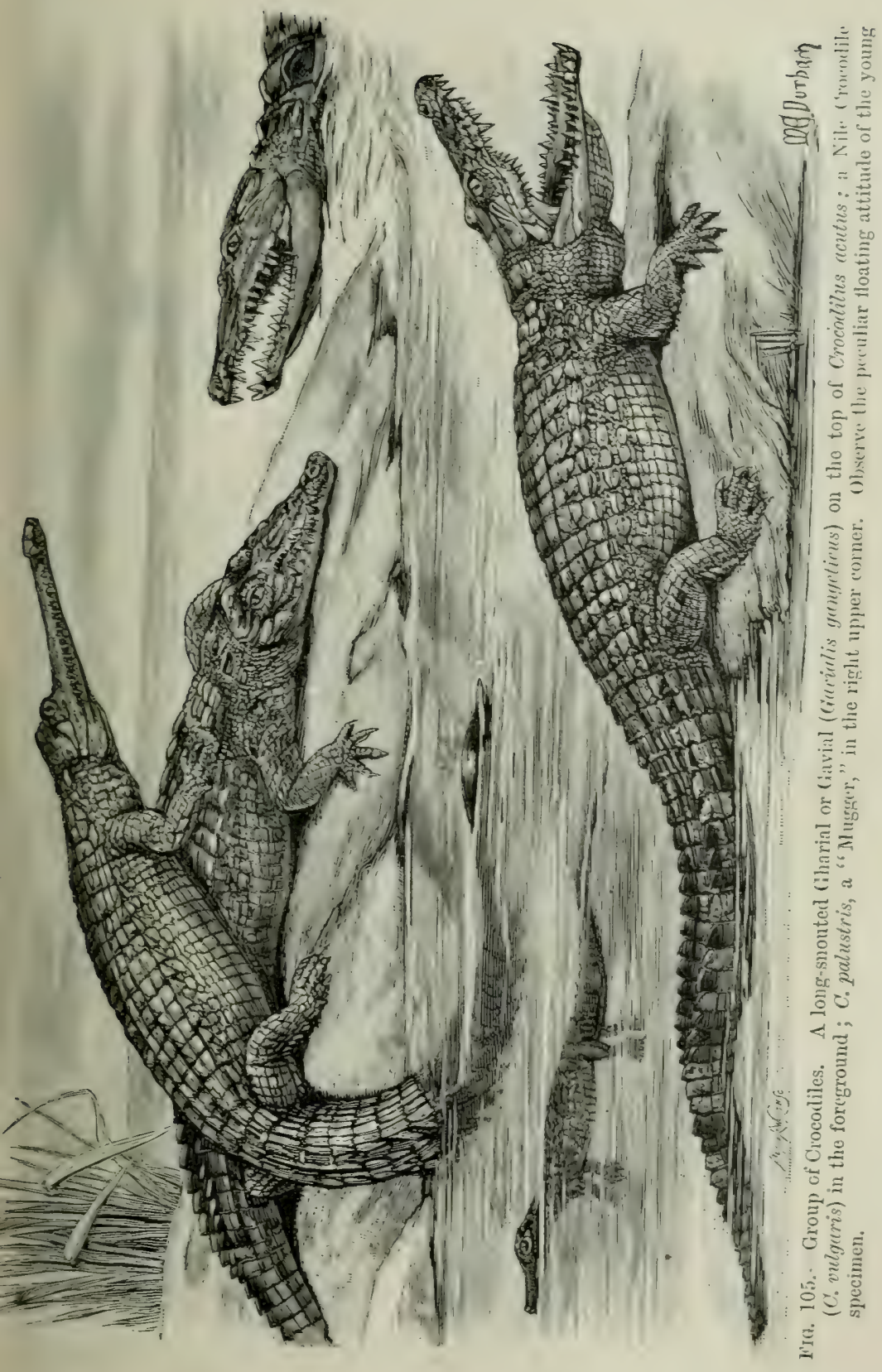

VOL. VIII 
transfer the chomale firther back, owing to the formation of a solid secondary roofing in of the month, to tiansform the

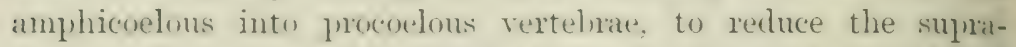
tempural foramina, and tu whtain a better elevelopnent of the dorsal armour, whilst thit m the verutral sicle is sradually reduced. Lastly, there is a tendency towards a shortening and lroadening of the smont, a conclition which has reached its culmination in the Alligators, while the Gavials are survivals of another hanch. The notches in the premixilla, for the reception of some of the lower terth, have also been acyuired independently. Although the recent crocodilia cammot now, as has been pointed ont ly Jinnlenger, lu separaterl into different families, no valid diagnoses lexing gusibles owing to the existence of Tomistomm, their phylogeny shows them to helomeg to at least two heterogeneous groups.

\section{Key to The GenekA of ReCExt Crocodilia.}

I. Snout very long and slender. The mandibular symphysis extends at least to the fifteenth tooth, and is pratly formerl liy the splenial lomes.

11. Nitsal homes reor small, and willely separated from the premaxillaries

Gavialis gangeticus, p. 451 .

b. Nasal bones long, in contact with the premaxillaries.

Tomistoma schlegeti, p. 453.

II. Sumut not slemler, lut triangular or rounded off. The mandilular symflivis does not reach leyoud the cighth tooth, and deses not reach the splenial bones.

u. Fonth mandilular tooth fitting into a noteh in the upper jaw:

1. Without a bony nasal septum . - Crocodilus, p. 454 .

2 . Nasal bones dividing the nasal groove. Osteolaemus, p. 466 .

b. Fourth mandibular tooth fitting into a pit in the upper jaw.

1. Without a bony nasal septum . . Caiman, p. 471.

2. Nasal bones dividing the nasal groove . Alligator, p. 466 .

Fam. 1. Teleosauridae, in the Lias and Oolite of Emroln:

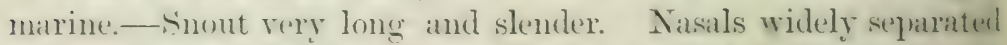
from the yommaillate hy the maxillaries. Chom at the prosterior end of the palatines. In front of the eye a small sub-lacrymal foranen. Supratemporal foramina large. Tertelmate amplicombons. Interior limbs scarcely half as long as the gusterior latir. The dermal anmone comsists of two rows of hroul srutes on the back, while the belly is protected ly a shield uf numerous hony scutes, which are comnected with aich other hy sutures. Tereth numerous and rather slender. Creneral alpeatrance like that of Gavials. 
Teleoseurus of the Middle and Lpper Oolite in Englimul and France. Snout very slender. Nasals narrow and short. The under side is protected by a beautifully finished armour, consisting of a square breast-shield of four rows of lony scutes, and at larger, long, oval shield on the belly, with about six longitudinal and seventeen transverse rows of scutes.

Irystriosaurus, of the Upper Lias in France and Ciermany. reached a length of 15 feet, and is characterised by an additional series of keeled but smaller eaudal plates rumning parallel with the middle pairs, which are neatly sutured together.

Fam. 2. Metriorhynchidae, in the Upper Oolite of Europe: marine.-Nasals broad posteriorly, sometimes extending with a pointed wedge very near the premaxillae. Without sul-hacrymul foramina. Eres with a ring of ossifications in the sclerotic. Dermal armour unknown. Tertebrae and choanae like those of the previous family. ICtrimingnchus and Gensanres.

Fam. 3. Macrorhynchidae, in the freshwater deposits of the Purbeck, Wealden, and Greensand of Europe. Suout long and slender. The nasals are narrow, and so elongated that they meet a similar long extension of the premaxillaries. Choanae between the palatines and pterygoids. Tertebrae amphicoelous. Dermal armour consisting of two imbricating dorsal and eight ventral rows, e.g. Pholidoscurus of the English Trealden.

Fam. 4. Gavialidae. - Snout long and slender. The choanae are situated entirely within the pterygoids. Tertebrae procoeluus. Members of this family make their first appearance in the littoral marine deposits of the $\mathrm{L}_{\mathrm{P}}$ per ('halk of Europe and North America; others are common in tertiary, marine, and freshwater deposits, whilst only two genera and species occur now in the Oriental sub-region.

Thordcuscurus in the Upper Chalk of New Jersey and France and Belgium is intermediate between Garialis and T'omistomu. The prefrontal bones are very small, while the lacrymals are very long and surround the nasals posteriorly. The nasals themselves are slender, and reach the posterior likewise long and narrow prolongations of the premaxillaries.

Gurialis. - The snout is extremely long and slender. The mandibular symphysis is so long that it comprises a great portion of the splenial bones, and extends backwards almost to the level of the last teeth and to the palatal foramina. The nasal 
homes are very short, and are separated from the premaxillaries he the long suture of the maxillaries. Alout twenty-eight upper. and twenty-five lower teeth on each side.

(i. ynufftirus. the only recent species, is essentially Indian, inhaliting chiefly the basins of the (ramges, Brahmaputra, and Jndus: it necurs also in the Mahanadi of Orissat and in

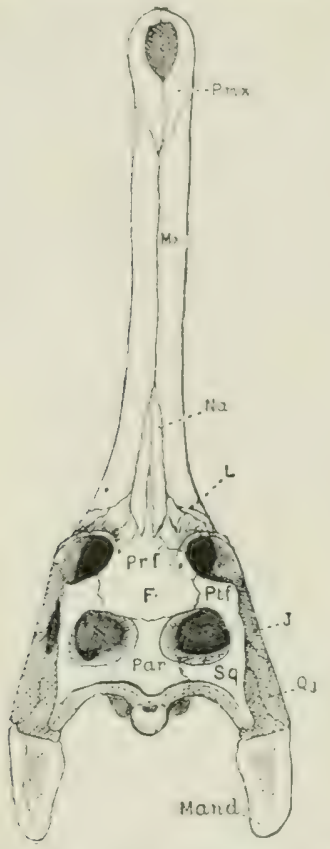

FIG. 106. - Skull of Garialis ganwe tires (the Gharial). I. $F$, frontal ; $J$, jugal ; $L$, lacrymal; Munel, mandible ; IVx, maxillary ; Ne, nasal;

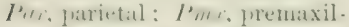
liry: I'if, prefroutal ; $I$ '/ $/$, postfrontal; Qi, quadratojugal ; sq, squamosal. Arakan, but does not live in the Irrawaddy, nor in the Narbada, Kistna, and farther south. In spite of its great size, which reaches 20 feet or even more, it is harmless, and lives entirely upon fish; hence its Hindustani name, gharial, meaning fish-eater. of which the generic name is a corruption.

The nuchal and dorsal scutes form a continuous shield, but there are two small postoccipital scutes. Generial colour, dark olive-brown above; the young are paler, with dark markings. The male is remarkable for several peculiarities. The nose is very much swollen, and can be inflated like a bag when the nostrils are closed. In connexion herewith, probably produced by the recoil of the air in the long narial passages towards the choanae or posterior nares, there is a pair of hollow globular swellings, in large specimens: of the size of a goose's egg. The shell of these gloles is formed hy the dorsal wings of the palatine bones above the floor of the choanae, and thes extemel formarls (o) the right and left of the ethmoid almost to the rertical downward process of the prefrontals.

Althomgh the fillatial is common enough, we know next to nothing about its hahits, and in zoological gardens it is rather rare. A. Anderion ${ }^{1}$ has, lowever, mate the following observittions. Forty enges were dus out of the sand, where they were 
lying in two tiers, twenty below and twenty ahore, with a fint of sand between. The young ran with amazing rapidity the moment they were hatched. Some of them actually lit his fingers before he had time to remove the shell from their hodier: The length of these new-born creatures was 15 to 16 inches, 9 of which belonged to the long and slender tail.

several fossil species have been described from the Pliocene deposits of the Sivalik Hills of India; and in the same district weurred the closely allied fihumphosuchus circssidens, which reached the gigantic length of about 50 feet !

Tomistoma.-The general configuration of the skull and snout is that of Gurialis, but the nasal hones are long and reach the premaxillaries, although not the nasal groove, thereby seprating the maxillaries. The first and fourth mandihular teeth fit into notches of the upper jaw, while most of the others fit into pits hetween the teeth of the upper jaw. About twenty upper and eighteen lower teeth on each side.

T. schleycli, the only species, reaches a length of 15 feet: it inhabits the rivers and swamps of Borneo, Mralacea, and Sumatra. Fossil specimens of Tomistumm. have heen found in the Miocene of Malta and Sardinia. Gerciulusuchers of the Miocene of Hungary is closely allied.

Fam. 5. Atoposauridae.-The few memhers of this family, Atuposmurus, Alligutorium, and Alligutorellus, lived in the L'pper Oulitic period of France, and were small, about one foot in length. The rertebrae are amphicoelous. The nasal groore is divided hy a prolongation of the nasal bones. The head is short, and in its general shape rather like that of a lizard.

Fam. 6. Goniopholidae, in the Purbeck and Trealden of Europe and the corresponding level of North America. The vertebrae are amphicoelous. The choanae are still elongated but are situated between the palatines and pterrgoids. The prendxillaries are rather large, and each sends a broad triangular process between the nasal and maxillary. The nasals are broad and are well separated from the nasal groove. The splenials help to form the mandibular symphysis.

(anniopholis. - The general configuration of the skull is rather like that of Crocodilus vulgaris. There is a pair of deep notches in the npper jaw for the reception of the lower canine teeth. $G$. simus and G. crossidens in Englind and continental Europe, and 
others in Colorado, were large-sized Crocodiles, some with a skull 2 feet in length. The dermal armour consisted of a pair of dorsil rows, a thoracic and an ablominal shield, composed as in the Telensauridae of six to eight longitudinal sutured rows.

Fam. 7. Crocodilidae.-Peximing in the L perind of Europe and North America, many forms of Crocodiles, Alligators, and Caimans existed in the Tertiary yeriod in America, Europe, and India ; persisting in Europe until the Plistocene. The vertebrate are procoelous. The choanae are completely surrounded hy the piteryoroids. The nasals reach the nasal groove, except in Couculilus cortuphorntus. The orbits are larger than the small supratemporal fossae, and always continuous superficially with the lateral temporal fossae, the jostfronto-jugal bridge not reaching the surface. The dorsal armour consists of more than one puir of longitudinal rows, while the rentral armour is much reduced in thickness or absent.

Ihiplurynumlun.--Common in the Oligocene and Miocene of Europe, e.g. D. hustingsiar. The skull resembles that of the Alligators, but has a pair of lateral notches in the premaxilla for the reception of the thirl, and sometimes also of the fourth mandibular tooth. The ventral armour is still rather strong.

Cimmilus. - The fourth mandibular tooth tits, as a rule, into a notch in the upuer jaw. The other teeth are more or less interlocked with those of the other jaw. The fifth upper tooth is the lingest. The nasil homes form the posterior horder of the nasal groore, but do not extend into it as a septum. The hony scutes of the dorsal shield are keeled, and stand closely together. being rarely united hy suture; and they form from four to six principal rows.

Crocodiles have occurred since the Lpper Chalk in Europe: many speecies existed in the T'ertiary epoch in Europe and North Anerica, decreasing in numbers in the l'liocene and disappearing with the beginning of the Plistocene. Ahout ten recent species are known, and these have now a somewhat scattered distribution: natnely, three species in Afriea, one of them extencling into Syria; three in tropical America and the West Indian Islamis; the rest in the Malay, Imlian, and North Australian rountries.

(. pulustis. The "Mugger" of India. The premaxillomaxillary suture is transverse, as in the Alligators. The adults 
retain the five teeth in each half of the premaxilla. The mandibular symphysis is short, extending only to the level of the fourth or ifth tooth. The snout is stout, rather broal; the top of the head is rough but without any ridges. The upper and lower jaw each contain nineteen teeth on either side. The nuchal scutes, six in number, are packed closely together, the four biggest forming a square. Four smaller scutes are arranged in a curved line on the occiput. The dorsal shield is composed of four, sometimes of six rows of larger scutes, of which the central pair is the broadest. The fingers are webbed at the base; the outer toes are broadly webbed, and the outer edge of the hind-limbs is turned into a serrated fringe. The general colour of the upper parts is dark olivebrown; the young are pale, with black spots. The length of twelve feet is considered a fair arerage size for a large specimen.

This, the "Marsh Crocodile," has

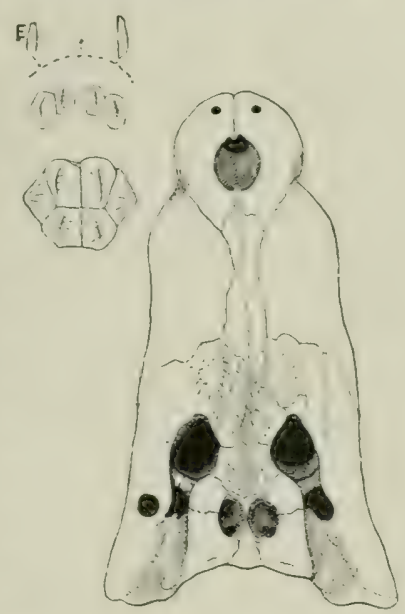

FIG. 107.-Dorsal view of the skull of Crocodilus palustris. $\times \frac{1}{3}$. The arrangement of the nuchal scutes is shown in the upier left-hand corner ; $E$, position of the ear-Hap.

a wide distribution. It inhabits the rivers, ponds, tanks, and marshes of India and Ceylon, extending eastwards through Burma and Malacea into most of the Malay islands, westwards into Beluchistan. This species is frequently renerated by the Hindoos, and is kept in a kind of domesticated condition, attended by fakirs. One of the most famous erocodile ponds, the so-called "mugger-peer," lies in an oasis of the sandy stretches to the north-west of Karachi. A. L. Adams has described a visit to this pond. ${ }^{1}$

"The greater pond is about 300 rards in circumference, and "ontains many little grassy islands, on which the majority of the ('rocodiles were then basking; some were asleep on its slimy siles, others half submerged in the muddy water, while now and then al huge monster would raise himself upon his diminutive legs, and waddling for a few paces, fall flat on his helly. Young ones,

1 Wanderings of a Naturalist in India, Edinburgh, $186 \%$. 
from a fowt in length and upwards, lam nimbly along the margin uf the pombl, disilnearing suldenly in the turbid waters ats soon ats we alpureateherl. The largest croconlile lives in a longr narrow tank sepratrated from the others. The fakirs, and natives who worship in the neighloming temples, have painted his forehead red; they venerate the old monster, making a. salaam to his majesty whenerer he shows himself ahove water. A hamdsome roming belonches. Whose occupation it was to feed the animals, informet us that this sprecinnem wats upwards of 200 years old. and that he way of a "tit-hit he was in the hahit of derouring the voune erowdiles. During our visit this enormous brute Wats atseep on the hank of his dwelling-place. and setmed yuite indifferent to our presence, although we cane within a fout of him, and erenatempted to arouse him hy rubbing his nose with

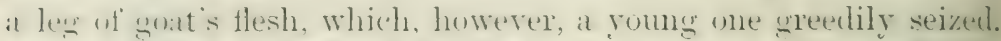
Gur attendant tried in vain to excite their ferocity, but heromd a feeble attempt to snap their trenchant teeth, the animals showed no disposition to attack us.

"A pony was wading about in the pond and feeding on the grassy hillocks, but the crocodiles took no notice of him.

"The crocodiles dig deer in the same, meler the neighbouring date-tretses, and there deposit their exges. Quantities of decidums terth, of varions sizes, were strewn along the sling sides of the pond.

"Strangers are expected to stand treat, not only lye the falkirs and natives, whe gain a livelihoud hy hanging about the pomel and showing the monsters, hat eren the crocodiles themselves seem to anticipate a feast, and on the arrival of a party cone. wht in munsul munhers. Acondingly, we hat a goat slinghtered. during which oleration the houtes seemed to rouse themselves.

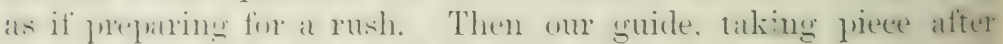
piece of the flesh, dasheel it on the bank, uttering a low growling somml, at which the whole tank lecame in motion, and crocordiles, of whose existence we hatrl heen hefore jenorant, splas hed thromeh the shallow water's strughling which would seize the prize. The shore was literally covered with sealy monster. snapping their jaws at one another."

Sir J. Emerson 'Tennent ${ }^{1}$ has had many opportunities of studying the hathits of the Marsh crocolile. Aceorumes to him 
it is essentially cowarlly in its instincts, and hastens to conceal itself on the approach of man. One of these creatures, which was overtaken in the jungle by a gentleman riding on horselack, Hed to a shallow pool, and thrusting its head into the mud till it covered up its eyes, remained motionless, in profound confidence of perfect concealment.

"There is a popular belief that the crocodile is exceedingly sensitive to tickling, and that it will relax its hold of a man if he can only contrive to reach and rub with his hand the softer parts of its under side. An inciclent of some reality in this piece of folk-lore came under my own obserration. One morning . . . we came suddenly upon a crocodile asleep under some bushes of the buffalo-thorn, several hundred yards from the water. The terror of the poor wretch was extreme when it awoke and found itself discovered and completely surromded. It was a hideous creature, upwards of 10 feet long. . . . It started to its feet and turned round in a circle, hissing and clanking its bony jaws, with its ugly green eye intently fixed upon us. On being struck with a stick, it lay perfectly quiet and apparently dead. I'resently it looked cumningly round, and made a rush towards the water, but on a second blow it lay again motionless and feigning death. We tried to rouse it, but without effect; pulled its tail, slapped its lack, struck its hard scales, and teased it in every way, but all in vain: nothing would induce it to move till, accidentally, my son, then a boy of twelve years old, tickled it gently under the arm, and in an instant it drew the limb close to its side and turned to aroid a repetition of the expreriment. Again it was tonched under the other arm, and the same emotion was exhibited, the great monster twisting ahout like an infant to avoid being tickled."

In the dry season, when the tanks become exhausted, the Marsh Crocodiles have occasionally been encountered in the jungle, wandering in search of water. During a severe drought, jn 1844 , they deserted a tank near Kornegalle, and trarersed the town during the night, on their way to another reservoir in the suburb; two or three fell into the wells; others, in their trepidation, laid egres in the street, and some were found entangled in garden fences and killed.

fienerally, however, during the extreme drought, when unahle to procure their arlinary food from the drying up of the 
waterconses, they hury themselves in the mud and remain in a state of torpor till released by the recurrence of rains.

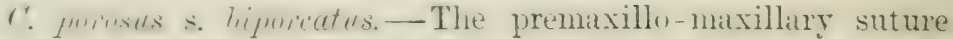
wh the pallate dene not form a transterse line, but is W-shaped,

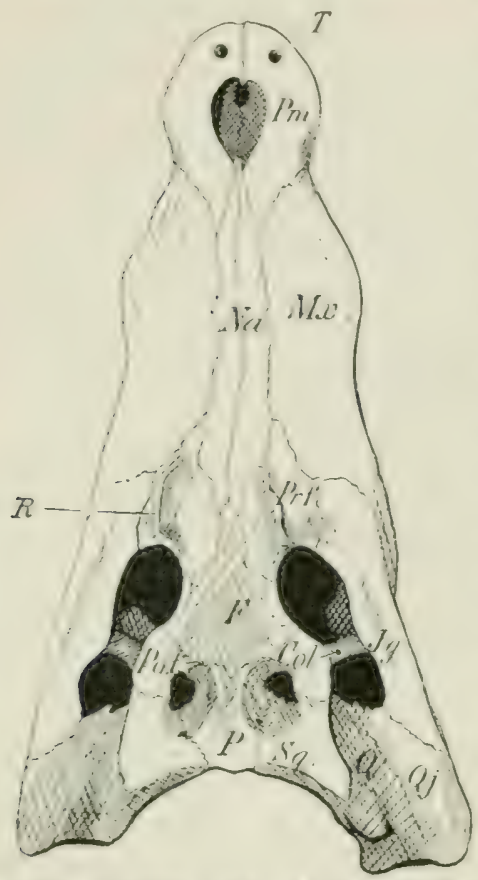

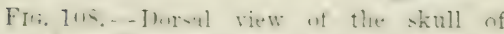

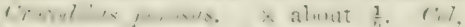
linteme whinetins the guntfontal with

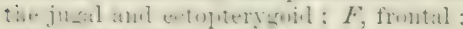
$J_{\%}$, jugal ; $M: c$, maxillary ; $\mathcal{L} a$, nasal ; $P$, parietal ; $P$ m, premaxilla ; Pof, post-

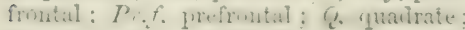
$Q j$, quadrato-jugal ; $R$, the characteristic sidge on the prefrontal bone; $S_{\%}$, squa mosal ; $T$, perforations in the premaxilla

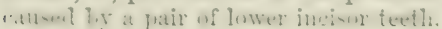
and extends backwards as in the rest of the species of Crocodiles to be described. This Indian species is easily recognised by the prominent longitudinal ridge which extends in front of each eye, over the prefrontal bones, and by the absence of sub-occipital scutes. The nuchal scutes consist of four large ones, which form a square, and one or tro smaller scutes on each side. The dorsal shield contains four to eight principal longitudinal rows. The digits, webs, and the serrated fringe of the legs are like those of $C$. palustris. The head and snout, however, are distinctly longer, and more slender in proportion, and the adult has only four teeth in each premaxilla. The terentral colour is dark olivelnwwn. Vomm specimens, as twatl, are much paler and are spotted with black.

This species attains a much larger size than the Marsh rrocodile. Specimens of 15 to 20 feet in length are not

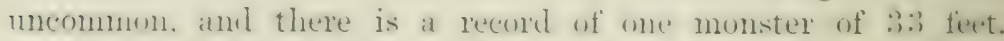
Comsentuenty this is, both in luble and length, molouldedly the

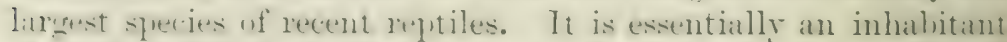
uf tidil waters of estuaries. frepuently entering salt water and

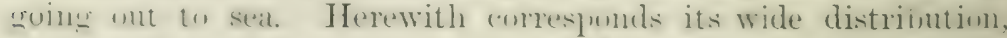
namely. The whole coitst of the ciulf of liengal, extending to 
Southern China, and across the Malay Archipelago to the northern coasts of Australia. Eastwards it ranges to the Solomon Islands and even to Fiji. Curiously enough, it does not seem to occur on the west coast of India.

According to Tennent it is ready to assail man when pressed by hunger, and the same authority mentions the following serio-comic incident. A man was fishing, seated on the branch of a tree overhanging the water, and to shelter himself from the drizzling rain he covered his head and shoulders with a bag folded into a shape common with the natives. While in this attitude, a leopard sprang upon him from the jungle, but missing its aim, seized the bag and not the man, and fell with it into the river. Here a crocolile, which harl been eyeing the angler in despair, seized the leopard as it fell, and sank with it to the bottom.

I have had some personal experience in the bringing up of the young of this species. Two dozen of them had come from Ceylon when quite young, only one foot long. At first they were very shy, and huddled together in their tank, but they took food greedily-strips of fish and, later on, sheep's heart. When frightened they emitted peculiar, high-pitched, halfcroaking sounds. Some of them snapped at the finger when touched; others were of a more gentle disposition; the shy ones were undoubtedly the most vicious. Within one year they grew to 18 or 20 inches, and added much to their bulk. Then they were transferred to a deeper and larger tank in a greenhouse, in which they could roam about at liberty. In the daytime they dozed on the margins of their pond, mostly in such a position that, at the slightest alarm, they could plunge back into the water. The strongest specimen left the tank entirely, and took up its favourite place for basking on the stump of a tree, to reach which it had to climb up a rough wall of stones. After three years, several had grown to the length of three and a half, and even four feet, and had by this time hecome formidable pets. Although handled frequently; they never became tame, the only change in their behaviour being that, instead of rushing off in a fright, and hiding for half an lour at the bottom of the tank, they became more vicious and confident, making for and snapping at the hand which fed them. The nights were spent regularly in the water, either floating 
with just the nostrils exposed, or in search of food, frogs being their farourite pres, while their main sustenance consisted of "lights," with an occasional mouse, or a piece of solid meat hy way of an mutit. Small pieces were holterl. The tough "lights," nandy lung with the windpipe and hlond-ressels, were causes of sreat 'platrels. Two or three would get hold of a lump of this kind, tearing at it, and twisting and rolling orer in opposite directions. The supply of warn water cane through a stout lige of renl incliatuliber, and this was an irresistible attraction to the crocoliles. On many a morning the tube was fomol twisterl into a knot, one of the creatures having spent hours in chewing it and in trying to wench it off. In order to aid direstim they swallowed frelibles. The most farourable temprature of the water was $85 \mathrm{~F}$ : if below $75 \circ \mathrm{F}$. they refused to eat. hut a continued exposure to $60^{\circ} \mathrm{F}$. did not hurt them. When the temperature rose above $95 \mathrm{~F}$. they left the

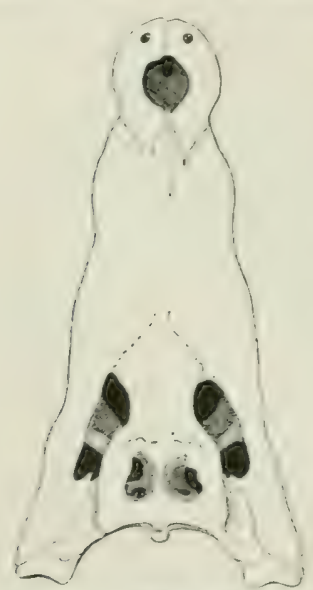

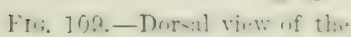
skull of a very old specimen of Crocudilus niloticus, in which lumet of th.. lomy -nture are wisliterateil, about io. water, although means had to be taken to prevent them from lying on the hot-water pipes.

C. niloticus s. vulgaris.-The premaxillo-maxillary suture on the palate is W-shaped. The nasal bones form only a small part of the posterior border of the nasal groove. There are eighteen or nineteen upper and fifteen lower teeth on each side. In old specimens some of the anterior nandibular teeth perforate the frenaxillate, as imlicated in Fig. 109, and they eren pierce throush the integrument so as to be visible from above. The

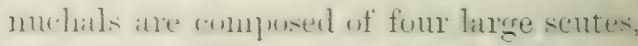
with a smaller one on each side anrl smetimes wre lohinil, and there is a row of smaller pieces acruss the acciput. Th. dorsal shield contains six to eight principa] longitudinal rows. The fingers are webbed at the base; th. outer toes are very broadly webbed; and there is a serraterl fringe on the outer sille of the len. The genteral coldene of the adult is dark olive-brown; the young are paler, with black sunts and remiculations. The muler parts are yellowish white. 
The Nile Crocodile is essentially African, ranging from the Senegal to the Cape and to Egypt. It is also very common in Madagascar. Nothing is known about its occurrence in Arabia, but a few specimens of rather small size seem still to exist in Syria, in the Wadi Zerka, an eastern tributary of the Jordan.

Even in historical times the Crocodile must have been very common in lower Egypt, to judge from the number of mummies preserved by the old Egyptians. Now it is practically exterminated, and there are scarcely any left below Wadi Halfa.

Such a conspicuous and dangerous creature has naturally always enjoyed notoriety. It is well described in one of the oldest writings of the world, the Book of Job. "Canst thou draw out leviathan with an hook? or his tongue with a cord which thou lettest down?... His scales are his pride, shut up together as with a close seal. One is so near to another, that no air ean come between them. They are joined one to another, they stick together, that they cannot be sundered. . . . Lay thine hand upon him, remember the battle, do no more." Bows and arrows, spears and clubs, are of little arail against such a 
monster; the dragging out of a hooked, full-grown specimen requires many men and is a formidable task. Of course tirearms have changed all this, and its invulneralility to bullets is nonsense. It is true that a bullet sent into the heal is generally ineffective, since it is a hunclred to one that the bullet does not hit the small hrain, and eren if it does, the creature sinks to the bottom and is lost to riew until decomposition sets in and the gases developing in the body cause it to float.

Herolotus has quaint stories about these crococliles and their worship. Amongst other stories he mentions that the bird Timhilus, supposed to be the Ilurianus aryyptins, a kind of I'over, slipsi into the gaping mouth to pick off the leeches which infest the reptile's gums. "In Egypt it is called Champsa, but the Ionians call them кокобрí resemblance to the lizards which live on their garten walls."

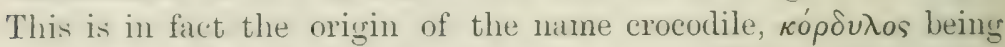
the ancient Greek for lizard and newt. With reduplication

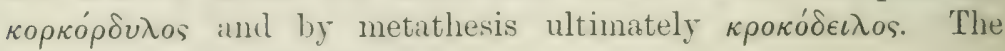
Arabic name is ledschun.

The story about the Plover seems to be true. These bircls are sometines seen sitting upon basking crocodiles, and since the latter are in the habit of resting, perhaps half asleep, with the mouth wide open, it is possible that these agile lirds do pick their teeth, and that they, heing also very watchful, by their own cry of warning and by fluttering off on the approach of dinger, give the alarm to the crocodiles and thus benefit them in more than one way.

But the expully old story ahout the Ichneminon or Mongoose is an ille invention. Mongooses are partial to egoss, hut they certainly prefer those of hens and other birds to those of the crocodile, which are far too hard and strong to be brolien hy such a little animil. Moreorer, as we shall see presently, the eggs are far too well concealed.

The best account of the habits of these crocodiles is the cre given recently hy Voeltzkow, who has spent a long time in Madigascan to collect material for the study of their derelopment.

He says that $C$. niloticus is not only the most common reptile, hut perhaps the nost common rertehate in Maligascint.

1 Sitzber. Ak. Bertin. 1891, 1) 115; 1893, p. 347. 
It occurs in every pool and river in great numbers, especially upon the sandbanks of the Betsihola River, where one may sep more than one hundred within one hour's paddling down strealn. The largest specimen measured hy Voeltzkow was $1: 3$ feet long; the largest in the National Collection is a little less than 1:i feet.

The crocodiles are caught in various ways. The simplest apparatus consists of two pointed sticks, which are fastenterl crosswise within the bait to which is attached a rope, and this is made fast on the bank of the river or lake. The animal, when it has once swallowed this spiked bait, keeps its jaws firmly closed, so that it can be dragged out of the water. Another methou is more reliable. A long and strong rope is made into an easily slipping noose, with an opening of about 18 inches. The bait is attached to the upper part of the nouse, while the lower portion is kept open by a springy branch, the whole thing being so balanced that it will float upright. When a crocodile seizes the bait, which it does with a side jerk of the head, the branch falls ont of the noose and the liatter closes around the upper or lower jaw.

These crocodiles dig long subterranean passages of 30 to $\neq 0$ feet in length; the passage opens in the bank below the level of the water, and gradually ascending ends in a somewhat wider compartment, which allows the creature to turn round. Two or three air-holes are pierced through the ceiling of the hurrow, in which bones and other remains of food are often found, su that the natives' belief, that the crocodiles retire into these chambers in order to devour their prey in undisturbed secrecy, appears rery probable. When suddenly disturbed or frightened they take to these lairs, and since their position is clearly marked by the air-holes, the natives block the passage and then dig the animal out from above.

Eggs are laid, in Madagascar, from the end of August to the end of September; the number of one set raries from twenty to thirty. They are deposited in a nest. This is in the ground, mostly in white sand, and consists of a hollow 18 inches to 2 feet deep. The walls are rather vertical, but near the bottom they are undermined, and here the eggs are placed. The centre of the pit being somewhat higher, the eggs roll by themselves into the undermined peripheral region. The laying takes place 
during the night, mostly a little luefore dayloreak. After one half of the eggs has been laid, they are covered up with simil, wheremun the other half is depresited. Then the hole is

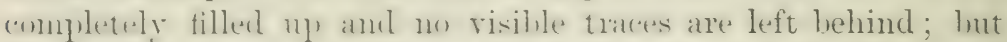
the molher sleeps num the nest and thus leats to its discovery. The gusition of the nest is so chesen that it cammot be reatehed

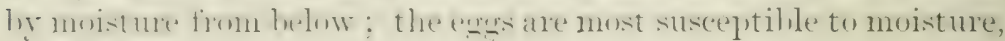
a very slight amount of which causes them to turn bad.

The shape of the eggs of one and the same clutch varies

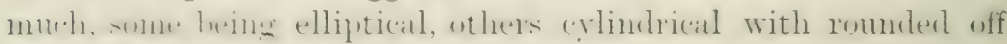
ends. Their size varies from 5.5 to $9 \mathrm{~cm}$. in length, and 4 to in. in wilth. The shell is white and glessy, thich and haml, e.ther romehly granular or smootl. They are hatehed in about twelve weeks.

Voeltzkow feels certain that the mother returns to the nest at the proper time in arter (1) dig the roung ones out and to conduct them to the water. To test this story he had a nest smromulerl with a fence: the mother returnerl sereral times and glatrty destroved the fence, which was then replaced hy a stronger one. One disy, when the young had heen hatched, the nest wats fimmol to be tilled with sand, the shells and one deat little crocontile heing at the bottom of the hole. The mother had dug a deep ditch heduw the fence, hut had not succeded in reaching the

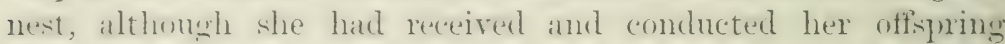
away. As a rule, when the young are hatched, the sand and the shells are fomml to lee scrolperl ont of the nest. The mother is

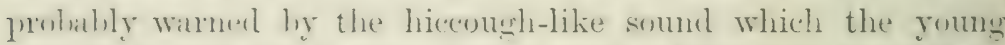
enit while still within the unhroken shell. Vueltzkow heart them piping from the other end of his romen, the egges leing corered with a layer of simul two feet high. The somd: were heard when lee walkerl gast the nest, or knocked against the hox. I'osilily the young hear the mother when she retires to the nest

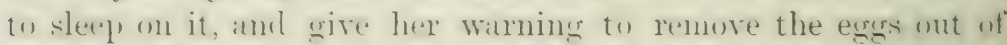
the growe. Inowerer, they do not lireak the shell until several days later.

The hatrhing is not cansed hy the rainy season, since it tork phare a fortuight before the first showers. The "egrg-tonth" of the

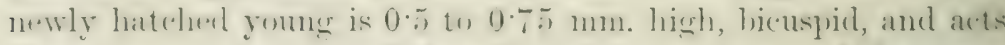

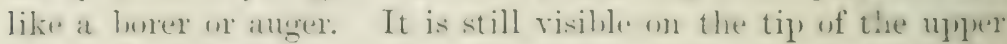
jaw, in front of the mose, when the creature is two weeks old. The 
newly hatched crocodile is of an astonishing size, so that it is rather puzzling to understand how it was stowed away in the egy. For instance, an egg of $8 \mathrm{~cm}$. length and $5 \mathrm{~cm}$. width, sends forth a crocodile $28 \mathrm{~cm}$. or 11 inches in length. Even at this early age they snap at the finger.

The egg is covered by a hard shell, within which is a thicker outer and a thinner inner membrane. The "white" is jelly-like, sometimes of a greenish tinge, and is so consistent that it will not flow. The yolk is round, and so large that it nearly reaches the shell-membrane in the short diameter. The yolk itself is surrounded by a very thin but strong membrane.

The embryo begins to develop long before the egg is laid. When laid the germ is about $4 \mathrm{~mm}$. long and shows about twelve somites. The cephalic bend begins at the end of the second week, the tail grows longer and the embryo becomes curled up. At the end of the third week it measures $10 \mathrm{~mm}$. in a straight line from brain to rent. The limbs begin to bud in the fourth week. With the sixth week the final shape hegins to reveal itself, and is completed at the age of eight weeks; but a third month is necessary to ripen the embryo.

C. cataphractus is the Common Crocodile of West Africa, from the Senegal to the Congo. In opposition to C'. niloticus it does not enter brackish water. It is easily recognised by the very slender suout, which rather resembles that of the Gavial; but the mandibular symphysis, although extending to the level of the eighth tooth, does not reach the splenial bones. The premaxillo-maxillary suture on the palate is not transverse, but extends backwards. In conformity with the length of the snout the maxillaries meet in the dorso-medial line behind the nasal opening, thus excluding the nasals from the latter. The nuchal scutes consist of two large pairs, almost in contact with the dorsals, six of which form the principal longitudinal rows. The gular and ventral scutes ossify in the adult, hence the specific name. The fingers and toes are slightly webbed. General colour above, dark olive-brown; yellowish below. The young are olive with large black spots.

The natires of the Lower Congo catch the crocodiles with two pointed sticks tied together cross-wise, surrounded with entrails lyy way of a bait. The whole is fastened to a pole or a strong rope and thrown into the river; and a narrow line, with a float VOL. VIII. 
attacherl to the cross-sticks, inclicates the whereabouts of the crocodile when it has taken the bait and has sunk to the bottom.

('. juln nstoni, of Northern Australia and Northern Queensland, and $C$. intermedius, of the Orinolio, are allied to $C$. catceplereetus, at least so far as the (nnfiguration of the bones of the slender and long snout is concemed. The former is small, scarcely

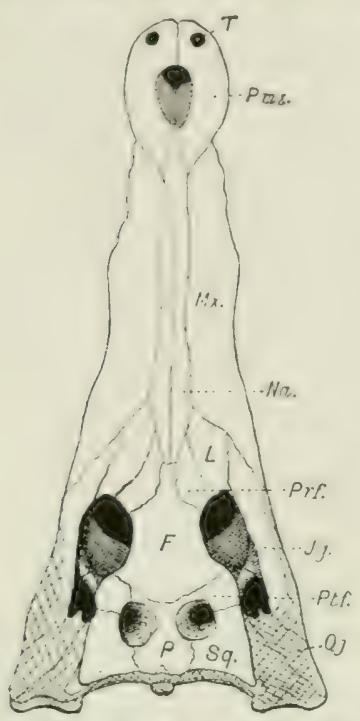

FIG. 111.-Dorsal view of the skull of timondilusumericunes. $\times \frac{3}{8}$. F. Frontal ; Jy, jueril ; L, lacrynal ; Mr. maxillary: Wo, nasal ;

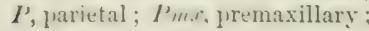
Prf, prefrontal ; Ptf, postfrontal ;, i, qualirato-jugal : S $q$, syuamosal ; $T$, tooth-perforatim.

scutes is also common. Largest size ahout 12 feet long.

Ostevluemus tetiospis s. firmtutus.- The only species of this gemuri inhalits the rivers of the west coast of Africa, from Sierrat Leone to the Ogowai. It differs from C'momdilus chiefly by the bony septum of the masal groove, produced hy forward extension of the nasal bones. The snout is rather short and stout; the "1pler surfice very rugove and deeply pitted, but without rilges. The gular and ventral sontes are ossified, hence the generic name. Total length about 5 feet.

- Mlignter.- The fomth mandibular tonth fits into a pit in 
the upper jaw, and this pit is in some adult specimens transformed into a hole, the tip of the tooth appearing on the ulper surface through the perforation. Most of the other teeth of the lower jaw are overlapped by those of the upper jaw. The number. of teeth on either side amounts to serenteen to twenty in the upper and eighteen to twenty in the lower jaw. The nasal bones form not only the posterior border of the nasal groove, lut they divide the latter by a median bony septum. The dorsal shield is formed by six or eight longitudinal series of keeled bony scutes, which, although standing close together, do not articulate with each other. Ossification of the gular and rentral scutes is absent or very slight.

Alligators occur in the fluviatile deposits of the age of the Upper Chalk in Europe, where they did not die out until the Pliocene age; they are now restricted to two species, one in the Southern States of North America, the other in China.

A. mississippiensis. - The much-depressed and broadly rounded suout bears some resemblance to that of a pike, hence the now discarcled specifis name of lucius. The neck is protected by two pairs of large scutes, which form a square, interrupted in the middle line, with a pair of small scutes in front and another behind. Of the eighteen transverse dorsal rows of scutes eight are broad and prominent. The fingers are about half webbed, the outer toes about two-thirds webbed. The general colour is greenish black or dark brown above, yellowish below. Young specimens have yellowish cross-bands on a darker brown ground.

The Alligator's northern limit is the mouth of the river Neuss in North Carolina, $35^{\circ} \mathrm{N}$. lat. From this point they abound near the mouths of all the creeks and rivers as far south as the Rio Grande, ascending the Mississippi to the entrance of the Red River in $33^{\circ} 50^{\prime} \mathrm{N}$. lat.

The habits and the embryology of the American Alligator have been described by S. F. Clarke, ${ }^{1}$ who gives the following vivid and minute account:-

"Usually one finds them in the waters of the smaller streams and ponds, lying with only the tip of the nose and the eyes exposed, or lying on an exposed place on the bank where the grass and other plants are beaten down, and the black, rich mud of the river bank is sinoothed by the repeated movements of the

1 J. Morphol. v. 1891, p. 181. 
alligators in almbing uy and down. There they hask in the sunlight until disturbed by the hunter or the desire for fond. When aroused they make for the buttom, and I late never waiterl long enrum to see one return unless he were ricorously stimulated with a long pole. They frequently dig a care for

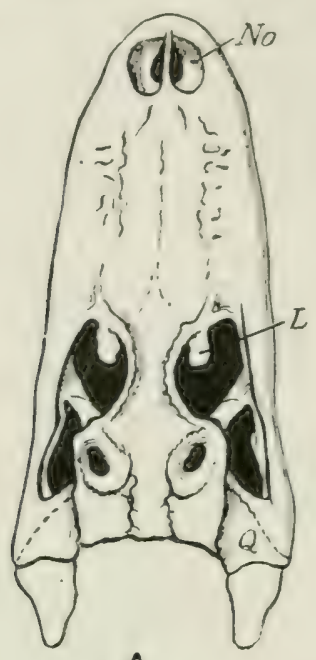

A.

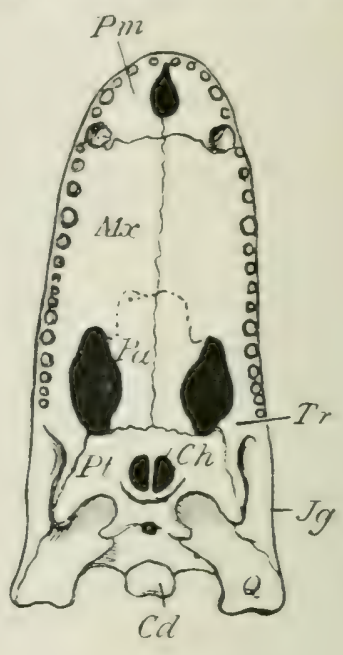

B.

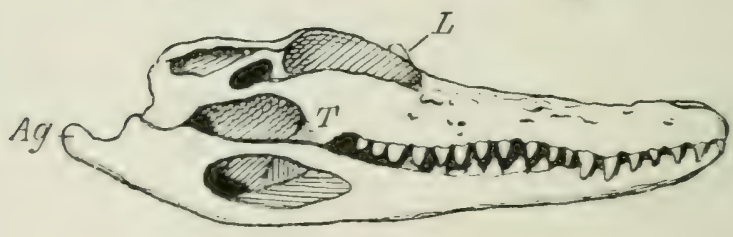

C

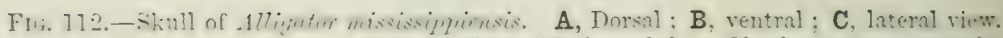
$\mathrm{Aq}$, Angular bone of mandible; $\mathrm{Cl}$, occipital condyle; $\mathrm{Ch}$, chnamae or posterior narial openings - the median small hole behind them indicates the position of the opening of the Eustachian tubes; $J g$, jugal ; $L$, lacrymal ; $I I x$, maxillary ; No, nostrils; $P a$, palatine ; $P m$, premaxillary ; $P t$, pterygoid ; $Q$, quadrate ; $T, T r$, transverse bone or ectopterygoid.

themeelves in the bottom of the pond or stream, or in the hank lneneath the water. Oltentimes one can start them ont of the are hy using a gule, hut if very olstinate. the hunters dig them out with spades.

"As the water dererases in the streams and pronts with the smmmer heat, the alligators travel on the larger hodies of water. 
During the breeding season, from the end of May to the begiming of July, the males are very active, wandering ahout to varions ponds and rivers in search of the females. Fierce battles are said to take place during this time between the excited males; and the mutilated specimens that one sees are weighty evidence for the truth of this assertion. . . . It is in the breeding season also that their bellowing is mostly heard, and more in the night than during the day. I have frequently heard them, while lying in the swamps at night, when they were in ponds fully a mile distant.

"The largest specimen I saw measured 12 feet in length: and none of the many hunters and other matives of Florida I have met have seen any longer than $1: 3$ feet. All the hunters agree that it is only the males that acquire the great size: no one had erer seen a female that measured orer $s$ feet, and the majority are not over seven.

"The male has a heavier, more powerful head, and during the loreeding season especially is more brilliantly coloured. The more brilliant colour occurs in patches aud streaks on the sides of the head and hody; it is generally a light yellow, or even whitish, and on one large male I saw a fairly bright red spot over each eye.

"The alligators are rapidly diminishing in numbers under the stimulus of the high prices offered to the hunters for their hides. Both Whites and Indians make increasing war upon them. Several thousand skins were brought into the little station of Fort Pierce in 1890. The pioneers and settlers always destroy the nests and eggs, because the alligators eat their pigs; and the cleamed eggs and young alligators are sold by humdreds in the curio shops farther north. As their numbers diminish in Florida it is noticed that the Moccasin snakes increase. In Lonisiana also the alligators are disappearing; and there the musk-rats are at the same time increasing, and are doing much damage by hurrowing in the levees along the Mississippi. While the alligator can make a very stout fight, I have never seen one offer fight if there was any chance of retreat. They never offered to molest us, even when we waded through the ponds where they were.

"The nest of the alligator is very large, and is built by the female. A great quantity of dead leaves and twigs, together with 
much of the fincly divided humus underlying them, is scraped together into a low momd alonut :s feet high; this varies considerably in its other dinemsions, being in some instances s feet in dianeter at the lase. The nests are huilt on the bank of a stream or prool, and the female digs a care moler water in the bank close to the nest. ('areful examination of the largent nest found showed a rout wi a neighlouring galnetto-tree, nearly an inch in diameter, rumning through it at ahunt a font alove the ground: there were also bouts of a grape vine growing near, which extended nearly throming the nest. This furnishes strong sulport to the statement of many of the lounters, that the nests are used for more than one seison. I could get no eridence whatever that the nests are used more than once a year.

"The "ugs are laid near the tol' of the nest, within 8 inches of the surface, are four or five layers deep, and have no regular arrangenent ox miform position of their axes in relation to the nest. The number of erges to a nest varies from twenty to thirty, and arerages twenty-eight; the maximm found was forty-seren.

The egas are white, elliptical, and vary in length from 50 to 90 1mm. or 2 to: $: \frac{1}{2}$ inches, and in the shorter diameter from 28 to 4.5 mnn. (ienerally there is only slight variation in the exuss of me nest, but occasionally a nest is found in which most of the exges are alout the average size. while from two to five are rery much smaller.

"The shell is much rougher than that of a hen's egg, and much thicker. The shell membrane consists of an onter and an inner layer; in lwth of which the filores are arranged spirally ahout the egg, but at right angles to one another.

"The white of the ergs has the consistency of a rery thick jelly, is rery clear and transparent, and is so firm that the whole

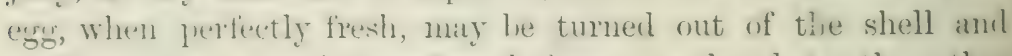
shell memblrane, and transferresl from one hamel to the other without heaking, and with hut slight change of form. The white lies mostly at either end of the shell, but extends also in at thin laver hetwern the yolk and the sides of the shell. The roilk

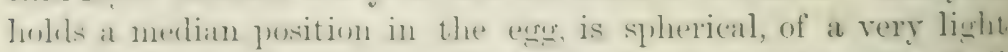
fale follow, and so latror that it alunest touches the shell memlirane about the midline."

Aecording on Mollores the youms as som as they are disencratrenl from the shell seek the water and shift for themselves, 
the parents taking no eare of them, though they may remain for some weeks in the same locality. In the spring and early summer months, and during the time of incubation, and especially on clondy clays or in the evening, alligators make a great noise; their croak is not unlike that of the bullfrog, but louder and less prolonged. On the approach of winter they select holes in the ground, where they remain torpid until spring. In this stite of libernation many are dug out by the negroes, who esteem the tail as an article of food.

A. sinensis. - The first intimation of the existence of a Crocodilian in the Yang-tse-kiang was made by swinhoe in 1870 , but it was not until nine years later that Faurel ${ }^{1}$ described the creature as $A$. sinensis. The same gentleman gave also an exhanstive accomt of the former records of this species in Chinese literature. According to Boulenger its nearest ally is A. mississippiensis, but it approaches the Caimans by the presence of ossifications in the ventral shields, which ossifications are, howerer, wide apart from each other. There are three pairs of large nuchal scutes in contact in the median line, besides smaller scutes in front of the nuchals and behind the occiput. The dorsal shield contains six rows of larger scutes. The fingers are not webbed. The general colom is greenish black above, speckled with yellow; greyish helow. Total length only about six feet.

C'aiman.-The five species of this gemus, confined to Central America or to the East Andesian parts of South America, resemble the Alligators in most features, but differ from them in the following points. The nasals, although horrlering the nasal groove, do not form a bony nasal septum. The supratemporal fossae are very small; or closed $u p$, as in C'. trigonutus and $C$. julpetrosus of Guiana. The rentral armour is composed of overlapping bony scutes, each of which is formed of two parts united by a suture.

C. sclerops has the widest distribution, from Southern Mexico to the northern half of Argentina. The upper evelid is rugose, although only incompletely ossified, and is often more or less jroduced into a small horn. C. niger has flat upper eyelids.

According to Bates, Cainans exist in myriads in the waters of the Upper Amazons. One species, Cr. trigonatus, the Jucaré-

1 J. China Asiat. Soc. xiii. 1879, pp. 1-36, with Figs. 
fingre of the natives, reareleses only six feet in length and has a slenter muzzle and a hiak-batnderl tail. Another species,

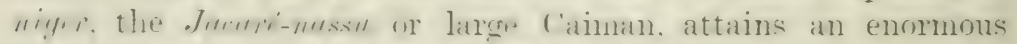
lulk amb a length of 20 feet. They misrate ammully, retreating to the flomed forests in the wet reason aud descending to the main rivers in the dry season. 


\section{CHAPT'ER XI}

PIESIOSAURIA - ICHTHYOSAURIA - PTEROSAUIIA-PYTHONOMORPITA

$$
\text { SEB-CLASS TII.-PLESIOSATRIA. }
$$

Mesozoic aquentic reptiles, with two puirs of pentuductyle limbs, firmly fiaxd quadrute hones, single temporat arders, numerous alveolar teeth, and ribs which articulate only with the centra of the biconcave vertebrae.

Tre Plesiosamria comprise the Mesosami, Nothosauri, and P'lesiosami in an ascending order of derelopnent, which concerns especially the changes from a semi-terrestrial to an alsolutely arpuatic life; - elongation of the neck with corresponding shortening of the tail, and the gradual transformation of the limbs into hyperphalangeal paddles.

The skull varies considerably in length. Seen from alhove it shows the nostrils, orbits, very large supratenuoral foramina, and the interparietal hole. The mostrils lie rather far back, in front of the orbits, between the elongated premaxillaries, short nasals, and the usually large maxillaries. The ortits are rather small, bordered behind by the postfrontals and postorbitals, which two bones fuse together in the Plesiosauri. The temporal bridge is long, and is formed by the junction of the two bones just mentioned with the squamosal mass, which overlaps the greater portion of the quadrate, and perhaps contains the quidrato-jugal. The dorsal branch of the squamosal joins a corresponding diverging branch of the parietal, and completely shuts off the pusterior region of the supratemporal foramen. The interparietal hole is small and placed far back. The palate possesses a row of teeth on the pterygoids in Lariosaurus. The choanae open separately leetween the vomers and maxillaries. The pterygoids are very long: posteriorly they join the quadrates, anteriorly they extend 
right up to the roners. separating the palatines from each other therely. Palatal vacuities are alsent in Tothosompus; small and wral. letween the palitines, piterrgoirls, ectopterygoids and maxillaries in Luriosurus : still smaller in the Plesiosauri.

The rertebrate are mosty licuncare, in the Triassic genera still jerforated hy the chorda. while in many I'lesiosauri the centra are solinl. with almost plane articulating surfaces. The nemal arehes are usually firmly sutured, or yuite fused with the centrat. Intercentrat ale alsent. except as cherrons in the tail. Althmoh the cervical and some of the thomacic ribs of the Triassic semera latre typical cappitula and tubereula, they articulate exchuscly upon the centrat. and not unom the neural arches also. The number of cervical vertebrae amounts to nine in

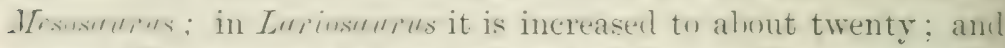
in some I'lesiosaturi to hetween thirty and forty. The cervical ribs alre very short, but they increase srarlually towards the thorax. which is well protected hy lomg and strong ribs, which decrease again very gralually, heing still long in the lumbar recrion. There is, fornerly speating, no sacrum, lecanse the one to fom sacral rils remain quite separate. The tail is still long in Lurisurus, consisting of ahout forty much shortened rertebrate; considerahly shorter than the neck in most of the Plesiosauri. A stermun is aisent, but the belly is protected by many stromg abluminal rils, crowded together, and consisting each of a median and two pairs of lateral pieces.

The shoulder-girdle is very strong, composed of scapulite, very stroms colacoids, claricles, and an interclavicle. The precoracuids are indicated ly a process and a notch in the Triassic: genera: in the later forms they are abolished. The coracoirls alwaty neet in the median line, and often produce a strong symphrsis. The scapulate fuscess a rery promint nt and litroe acronial process, upun which rest the dorsil or lateral ends of the ditricles. In some l'lesisami the shomleler-girclle has underone an ahsolutely mique morlification. The correct interlere-

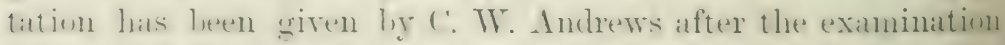

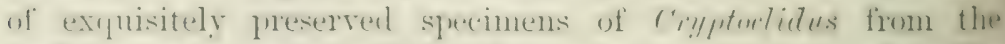
Cxford elaty of the Mimble ondite, near Peterboromgh. The

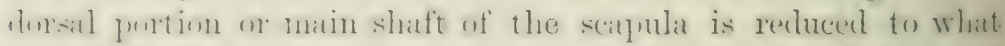
now lowkis like a dorsor-litteral precess, while the broad acromial process is muth elongateml, and lies in Plisiosentus upon the 
ventral surface of the clavicle; the latter and the irregularly T-shaped interclavicle being, however, still visible from below. In Cryptoctidus the two acromial processes meet each other and form a long ventral symphysis, which meets that of the much-enlarged coracoids, the latter enclosing with the scapulae a pair of roundish foramina. The clavicles are not visible from below; they rest upon the dorsal surface of the scapular symphysis, and the interclavicle seems to he suppressed. Young Cryptoctidus (Fig. 113, B) and various species of Plesiosaurus show intermediate conditions.

This unique arrangement is correlated with the enormous

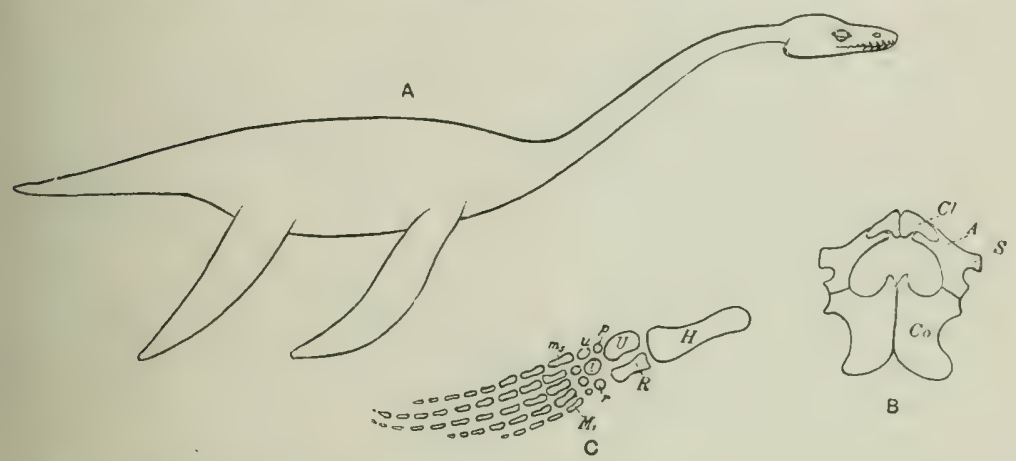

FIG. 113. - A, Restored outlines of a Plesiosaurus, $\times{ }_{3}^{1} \frac{1}{0} ; \mathrm{B}$, dorsal view of the pectoral arch of an immature Cryptoclidus; from the middle Oolite; $\mathbf{C}$, fore-limb of a P'lesiosaurus, from the Lias. $A$, Acromial process of scapula; $\mathrm{Cl}$, clavicle; $\mathrm{Co}$, coracoid ; $H$, humerus ; $i$, carpale intermedium; $M_{1}$ to $m_{5}$, first to fifth metacarpals; $p$, pisiform bone ; $R$, radius ; $r$, radial carpal ; $S$, scapula ; $U$, ulna ; $u$, ulnar carpal.

derelopment of the fore-limbs, although nothing of the kind has taken place in the Ichthyosauri, which have similar large paldles. The limbs exhibit considerable differences in the virious groups of Plesiosauria, lut they are all pentadactyle. In the uldest, the Mesosauri and Nothosauri, the limbs are still of the terrestrial type, although fitted for swimming: the chief hones are still slender and elongated, and none of the five fingers and toes have more than five phalanges, the usual number of which seems to be $2,3,4,5,3$ for the first to fifth digits respectively. In the Plesiosauri the limbs are transformed into long hyperphalangeal paddles, unfit for progression on land, rather like those of the Ichthyosauria, with much 
shortened radius and ulna, tilia and filula; lut the phalanges, which increate to ahout ten. are alwars longer than hroad, and there is no inclication of an increatse of the number of fingrers, ar of adilitimal. lateral, phalanx-like nodules. The pelvis is very

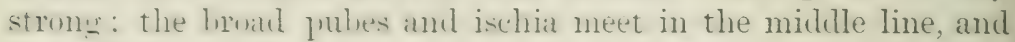
they either enclose one wide undiviled foramen, or the two srmphysial jurtions meet. and there are then two obturatorfiraminia. The pules are generally much larger, especially lmater. than the ischial and althongh frartaking in the firmation of the acetihulum. they do not articulate with the ilia, at least not in Plesiosauri. The ilia are always small; in I'lesiosumi attached to only one or two satcral ribs: to three or four in the Triassic genera.

Ichthyosauri and l'lesiosauri were comlined as "Enaliosauria" hy Conyleare. Owen recunised their fundamental difterences,

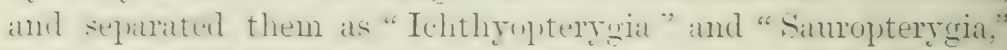
accorting to the structure of the limlss. Tre now know that the pruldes of the Ichthycsauri hear hut a superficial resemblance to the fins of fishes, and are fimlanentally referahle to the fentadactyle type, as are the paddles of the Plesiosauri. althugh the latter retian more of the typical features of repitilian limls. It was soon recrognised that the Nothosani are allied to the Plesiosauri. lut the Mesosauri cuntil then vignely arouped with the Rhynchocephalia. or linked with I'roturusauri as I'roganusumia) have only recently received their proper place in the srstem as members of the Plesiosamiat. which we divide into two main groups.

\section{Order I. NOTHOSAURI.}

The limbs ate of the terrestrial trine: the fire digits hatre the numal number of phalanges, which to not exceed five. The bones of the limbs are slender; the humerus has an entepicondylar foramen.

Fam. 1. Mesosauridae.-The neck contains ahout tert vertelsate. The verteliate are deeply biconcare, perforated liy the chorda dorsalis. Sacral vertehrae four in number. Clavicles strong: interclavicle very small. Mesosaierus, the only genus. with one sprecies, . Ir. temnidens, ahout one foot in length, was found in

${ }_{1}^{1}$ Boulenger, Trans. Zool. Soc. xiv. 1898 (read Nov, 1893). $\quad 2$ vóbos=spurious. 
South Africa, probably in Triassic sandstone. Very similar specimens are known from São Paolo in Brazil.

Fam. 2. Nothosauridae.-With sixteen to twenty-one cervical and three to five sacral vertebrae. The vertebrae are biconcave. The clavicles are strong; the interclavicle is much reduced. Coracoids with distinct acromial processes.

Nothoscurus mirabilis, of the Muschelkalk of Cermany. Total length about ten feet. Length of head about one foot. The teeth are very irregular: About five slender, long teeth are implanted in each side of the premaxilla, with wide spaces between them, similar to those of the symphysial portion of the lower jaw. Those of the maxillaries are numerous and small, except two large pairs in the anterior portion, on a level between the orbits and nostrils. The upper and lower teeth overlap, or cross each other. The palate of the long and slender skull is quite bony, without anterior palatal or infra-orbital vacuities.

Lariosaurus balsami, about one foot in length, from the fresh-water deposits of the Upper Trias in Lombardy. Neck with about twenty, tail with about forty vertehrae. Head comparatively shorter; more triangular than in Nothoscurus; palate with small infra-orbital vacuities. The number of the phalanges of the fingers and toes is apparently $2,3,4,4,3$ and $2,3,4,5,4$.

Anarosanrus pumilio, of the Muschelkalk, near Magdeburg, and Neusticosaurus and Simosanrus of the same geological age, are allied forms.

\section{Order II. PLESIOSAURI.}

The limbs are transformed into hyperphalangeal paddles. The clavicles are small, and are overlapped ventrally by the strongly developed acromial processes of the scapulae. The vertebrae are slightly biconcave or plane. The neck consists of at least twenty vertebrae; those of the thoracic region have long transverse processes; the sacral vertebrae are mostly reduced to two or one. Very large, massive animals.

Fam. 1. Pliosauridae.--Ahout twenty cervical vertebrae, with proximally bifureated ribs. The scapulae do not meet ventrally; they enclose with the coracoids a single large foramen, and are fused with the clavicles. Plioscurus, the principal genus, contains several species of gigantic size; for instance, $P$. granctis, of the Kimmeridge clay, Upper Oolite, of England, has a sliull 
nearly j feet long and 2 feet lroad, armed with many enormous conical teeth, some of which reach one foot in length, inclusive of the long collar and rout-portion. The neck is rather short, owing to the much condensed, disc-shaped centris of the vertebrae. Total length of this species about 30 feet. Other species in England and continental Europe as far as Ruscia.

Fam. 2. Plesiosauridae. - The neck is very long, and consists uf fron twenty-eight to forty vertebrae. The scapulae do not meet ventrally, hut the spmphysial portion of the coracoids meets the clavicles and the interclavicle, the pectoral areh thus enclosing two foramina. Chief genus 1 l'esiusmins, with many species. The heat is comparatively small, the neck very long, the tail short, although consisting of from thirty to forty vertebrae. The thirr digit (Fig. 11:, (') is the longest, and possesses nine or ten phalanges. The ablominal ribs are very strong, and reach from the pectoral to the pelvic girdle. Riange from the Lower Trias to the Lower Oolite, chietly European. I'. dolichudirus and P. conyberri, the latter reaching a total length of more than 15 feet, from the Lower Lias, especially at Lyme Regis.

Fam. 3. Elasmosauridae.-The neck is extremely long, possessing from thirty-five to serenty-two rertehrae, with single-headed, not hifurcated, rils. The scapulae meet ventrally, and enclose with the very broad coracoids two foramina. The tail is short. The pisiform bone articulates with the humerus. Otherwise much resembling the Plesiosamidae. Principal genus C'imoliasumes, with many synonyms, and many species from the Middle Oolite to the Cluer Chalk: cosmopolitan distribution, e.e. C. contulpigiensis, uf the Greensand and Tlyer Chatk: C. trumenterieus, of the Kin-

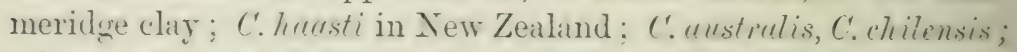
others in North America. C'rypturlintus of the Middle and Tlyer' Oolite of Eurofes. Eilusmosuri'us, of the UPper Cretaceous formattion in Kansas, with a computed tutul length of 45 feet, of which 22 belong to the neck, with its serenty-two rertelorae.

\section{SUB-C'LASS VIII.-ICHTHYOSAURIA.}

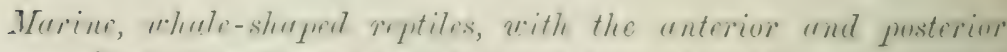

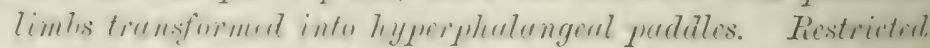
to the Mesozoic age from the Trias to the Upper. Chalk.

The skull is long, owing to the elongaterl slender snout, which 
is formed mainly by the premaxillary bones. The nostrils lie far back, in front of the orbits, and are bordered by the long nasals, the premaxillaries, a small part of the maxillaries, and posteriorly by the large lacrymal bones. The eyes are large, and are strengthened by a sclerotic ring composed of many elosely orerlitpping bones. The orbits are very large, and are directed sideways so as to be scarcely visible from above. They are formed above by the long prefrontals, which join the postfrontals; behind by the long postorbitals; below by the long and slender jugals; in front by the lacrymals and prefrontals. The postorbito-temporal region of the skull is short but high, and, with the exception of the supratemporal foramen, is entirely closed in by bones, namely, the quadrato-jugals, supratemporals, and squamosals. The litter, with the parietals and large postfrontals, surround the supratemporal foramina. The parietals and the small frontals enclose the parietal foramen. The whole temporal arch consequently recalls much that of the Pareiasauri and Stegocephali, chiefly owing to the presence of conspicuous supratemporal and postorbital bones, which, together with the quadrato-jugal, close in the whole side without any indication of a lateral or infratemporal foramen. The postorbital completely separates the jugal fiom the quadrato-jugal, and this almost hides the quadrate. The occipital condyle is single. The lateral occipitals and the supra-occipital bones retain their sutures. The pro-otic and opisthotic bones remain separate. The latter lie between the basi- and lateral occipitals, the squamosal, quadrate, and pterygoid. The pterygoids, which posteriorly touch the quadrato-jugals, basi-occipitals, opisthotics, and basisphenoid, are very long and remain widely separated from each other; in the space between them appears the long ensiform presphenoid. Anteriorly they are connected through the ectopterygoids with the maxillae, and touch the palatines. These are likewise narrow and slender, but touch each other in the middle line, and contain the wellseparated, slit-like choanae, laterally to which lie the elongated, rather narrow, palatal vacuities. The vomers are mostly not visible; when they appear on the surface they are long and narrow, and enclose the choanae between them and the palatines.

The teeth are pointed, conical and thickly covered with enamel, which in transverse sections forms vertical ridges, recalling 
the folls of the Labyrinthodonts. The teeth have open roots, and are not implanted in separate alveoli, but lie in long gronses of the premaxillaries, maxillaries, and dentals.

The vertelorate are mumeroms, up to 150 , two-thirds of which belong to the tail. The centra are deeply liconcave and short, not (n)-ossified with the neural arches, which have therefore often lorken louse. The atlas much resembles the other cervical vertebrae in su firr as its centrum is concave in front and scarcely ankylused with that of the secomel. Its basiventrals, equiralent to the ventral half of the atlas-ring of other reptiles, thus become an mpaired intercentral wedge, hetween the first centrum and the hasis of the cranimm; the nemal arches rest upon the centrum, lint renain sejarate from each other, or at least diverge dorsally. The atlis canries no ribs. Intercentril occur also between the second and thind rertelorie; they reatpleat in the tail as cherronlwnes. All the other vertebrie carry ribs, which gradually increase in length towaris the trunk and decrease again equally sradually on the tail. In the neck and trunk they have separate capitula and tubercula, which articulate upon short knobs of the centra: towards the tail these shift farther and farther towards the ventral side, and ultimately linite. Although the ribs of the trunk are so long, there is no trace of a sternum, but there are many " "hblominal rils" crowded together, each consisting of a middle and a pair of lateral pieces.

The sumlder-rirdle is very complete, but the pieces remain separate, or at least do mot co-ossify; it consists of a T-shaped interclaricle, clavicles, broal coracoids touching each other in the midille line, and short scapulae. The existence of small separate precomatcoids is doultful. The pelvis is much reduced; the small ilium is quite unennected with any rertebrae; the small puhes aml ischiat form no symphyses. The fore-and hind-limbs are very sinilitr to each other: the posterior are, however, much smaller. Juth are transformed into highly specialised padtles. It is af the grentest importance, as an inclication that the Ichthyosiumi are desend:ants of a terrestrial stuck, and have been modified into what they are owing to having taken to marine life. that in the oldest nembers known, the padrlle-like structure of the linhts was less arlvancerl than in the later species. In Mirnstrills of the Muschelkalk of Europe the ulnit and ratius are still distinctly longer than broal, and they encluse a sprace 
between them. They articulate with three carpal bones, the ulnire, intermedium, and radiale, while a small pisiform bone lies on the outer side, between the ulnare and the outer distal carlal bone. In Irththyosaurus, from the Liassic period onwards, the ulna and radius are much shortened, broader than long, and touch each other without any intervening space; the pisiform element is enlargerl. Lastly in Ophthalmoserums of the Middle Oolite (hut not in contemporary species of Ichthyosourus) the uhna and raclius are still more reduced, and the pisiform has moved up to the humerus, so that the latter articulates with three bones.

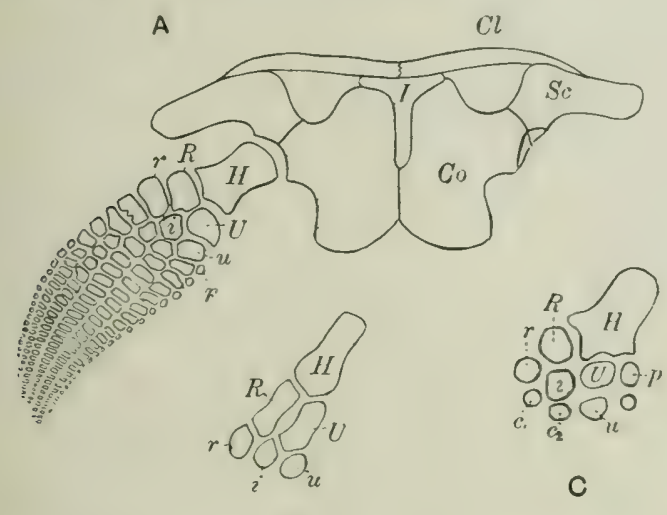

B

FIG. 114.-A, Ventral view of the shoulder-gircile and right tore-limb of an Irhthyosmurus, from the Lias; B, part of the fore-limb of a Afixosaurus, from the Trias ; C, part of the fore-limb of an Ophthalmosaurus, from the Chalk. $c_{1}, c_{2}$, first and second centrale carpi ; $\mathrm{Cl}$, clavicle ; $\mathrm{Co}$, coracoid ; $H$, humerus ; $I$, interclavicle ; $i$, intermedium carpi ; $p$, pisiform; $R$, radius ; $r$, radial carpal ; $S c$, scapula; $U$, rilna ; $u$, ulnar carpal.

Other important features of these paddles are not only the much-increased number of phalanges (sometimes up to twenty or more), but also the increase of digits to six or more, produced apparently by a splitting of the third finger into two series, and by the development of additional rows of phalanx-like bones on the onter and inner margins of the paddle. This increase of fingers exists, for instance, in Ichthyosaurus communis, hut not in I. tenuirostris. Owing to this peculiar derelopment of paddles the constituent bones are extremely numerous, and from the radius and ulna downwards they are all closely packed, and have assumed a polygonal, often hexagonal, shape, dwindling to more or voL. VIII 
less flittened nodules towards the ends of the digits. These carpal and phalangeal hones are common objects in anateurs collections: they fit tosether ly the short angular ficcets, while the two Hat and hrouler surfaces are those of the dorsal and ventral sides.

The Ichthrysiturs lived unom fishes and cuttlefish, as is indicutenl hy their dentition and the shape of the snout, and proved by the enprolites. most of which are full of fragments of bones and sanmid scales of fishers, and of the heals and shells of euttletish: the liarerer of these true copurolites literally "petrified dung,", in conmolite-herls, contain also an alumdance of other fossils, such as Ammonites, Terebratulite, molluses and fish-remains; they are several inches long, and many of them show on the outside riug-like impressions, undoulstedly caused by a spiral valve of the intestinit canal. In conformity with their absolutely aquatic life the Ichthrosaurs were viviparous. Several well-preserved adult specimens liare been found, which contain the sheletons of one or more rather large young within the hody, in exactly the position in which such fretal creatures would lie, namely, with the hear in the pelvic region of the mother, while the rest of the boly stretches along the verteliral columm towards the chest. The suggestion that these young Ichthyosaurs have been swallowed hy their camilial elders is too idle to require serious refutation.

Until within a few years Ichthyosaurs were always restored with a smonth and even hack, but several well-preserved specimens have cone to light in Wrirtemberg which show the complete contour of the animals, with a long, somewhat jagged fin on the middle of the bark. Since then not a few specimens in various collections have on closer examination revealed the same feature, except, of course, those in which the ontlines of the fin had been chisellerl away in order to "improve" the lonk of the slat). The fins were undoulitedly of the "adipose" lind:raised folds of the skin. The latter is now known to have been covered, at least at the hases of the dorsal fins, with hard little scales, probably osteoderms.

Many sperimens are beatifully preserved, others present a very peculiar appearance. They look, namely, like long rolls of ality, and nohody but an expert would suspect an hihthyoserrins within such a log. The explanation is simple. The deat 
creature was rolled about by the waves of the surf on the Iiassic muddy beach until it was wrapped in a mantle of cliy and then imbedded on the shore.

The distribution of Ichthyosaurs in time and space is wille. The earliest are found in the Middle Trias; in the Lias they are very common, fairly frequent in the Oolites, dying out with the Cretaceous epoch. They have left no descendants, heing far too specialised, and their origin is quite unknown. Mirosmurns, the oldest genus, occurred in Europe, and has also been found in the Triassic strata of Spitsbergen. Ichthyoscurus, the chief genus, is known from the Liassic, Oolite, and C'retaceous strata of Europe, a famous place being Lyme Regis: and also from the Cretaceous

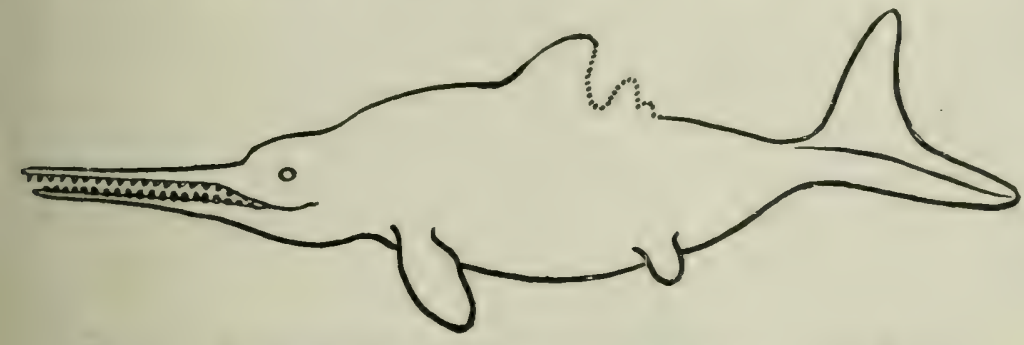

Fig. 115. - Restored outlines of 1chthyosaurus quadriscissus. (After Fraas.)

strata of Queensland and New Zealand. The Jurassic of Wyoming has yielded Baptanodon.

\section{Order ICHTHYOSAURI.}

The few genera are easily recognised.

IFirosaurus, Triassic, with radius and ulna still elongater, a longitudinal space occurring between them. Both jaws with numerous uniform teeth.

Ichthyosurus, with much shortened radius and ulna; both jaws with uniform series of teeth. Many species are known, some with four to five, others with several additional and incomplete rows of fingers and toes. I. trigonodon of the Lias in Wiirtemberg seems to have reached the size of $: 30$ feet, the vertebrae showing a diameter of 9 inches, while the skull is 6 feet long. I. communis and I. tenuirustris are common in the English Lias. The long-snouted $I$. campyloulon, with large, spaced teeth, occurs in the Gault of Cambridge, Dover, and France; and 
there are many others. Ophetholmosomens, of the Eyper Oolitic and ('retaceons formations of Englanul, hat very small vestigial teeth.

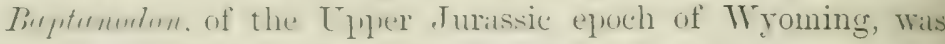
toothless, and was one of the six-toed forms.

\section{SUB-CLASS IX-P'T'EROSAURIA.}

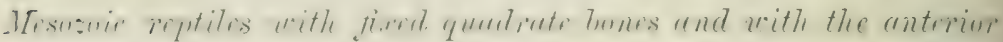
limbs transformed into wings, the enormously elongated ulnwi finger carrying a patagium.

The skull hears a superficial resemblance to that of Birds. It articulates with the neck hy a single condyle, at nearly a right angle. The interparietal foramen is absent, lut there are five pairs of foranina on the surface of the skull, namely, the nostrils; orhits, supra- and infra-temporal and pre-orlital foramina. Most of the constituent bones of the cranimu fuse with each other, and the composition of the various arches is therefore difficult to make ont with certainty. The premaxillaries are fused together,aml extend dorsally backwarts hetween the nasals, which themselves diverge towards the prefrontals. The nostrils are bordered chiefly by the maxillaries, nasals, and prefrontals. The orbits are very linge, mostly shut off in front from the pre-orbital foramina ly a lridge, which is formerl by descending processes of the prefrontals and ascending processes of the jugal. Abore and behind, the orbits are bordered by the frontals, postfrontals, and posibly the puatrato-jugals. The whole temporal region is shortened from hefore hatkwarks, but heightened dorso-rentrally, and the whole temporal fossa is divided into a supra- and infratompral portion by the junction of the postfrontal with the squanosil, the latter joining the parietal, thus elosing the supratemporal fonst hehind. This is conspicuous only in the older forms, e.g. Inimerphentun, but is very small in Pteroductylus, and quite almisherl in Itrouman. The infratemporal fossa is a narrow slit, slinting olliquely upwards and backwards, between the quadrate and the quatrato-jugal. A foramen of this kind oceurs Msewhere mly in the Rhynchocephalia. The quadrate is long, fimly fixed, and slants so far forwards that the mandibular joint lies on a level beluw the midlle of the orhit. The pterygoids articulate with strong and long processes of the basisplenoid, tonch the quadrate posteriorly, enclose an interpterygoid racuity, 
and extend forwards as slender bones to the romer, sepurrating the palatines. The choanae are enclosed by the romer, palatines, and maxillaries, and they lie in dorsal recesses above the level of the roof of the mouth. The teeth are alreolar, pointerl, of variable size, and restricted to the jaws: in the Pteranodonts they are absent.

The brain is known from the natural cast of Secophouguatlus. and shows some remarkably bird-like features, especially the wilth of the hemisplieres, which touch the well-dereloped cerebellum, while the optic lobes lie on the sides of the cerehellum. with a pair of appentices, the so-called floceuli, elsewhere known in birds only.

The caudal rertebrae are still amphicoelous, while the presacral vertebrae are procoelous. Abdominal ribs are few in number and are very thin. The true ribs possess capitula and tubercula; those of the neck are very short and directed backwards; in the thoracic region they are long, and some are attached to a broad sternum with a keel and a median anterior process, on the sides of which latter articulate the coracoids. Precoracoids and clavicles are absent. The scapulae are long, sabre-shaped, and turned back as

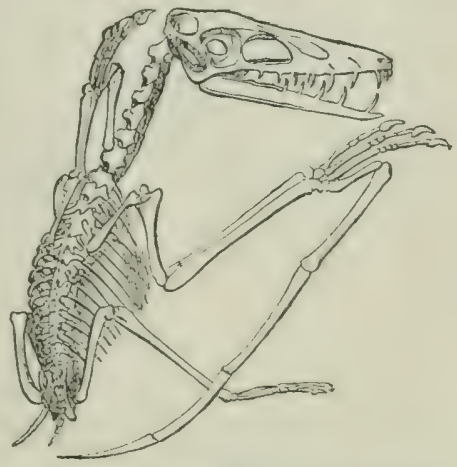

FIG. 116. -Pterodactylus crassirostris. $\times \frac{1}{3}$. (From Geilie.) in lirds: in I'teranodon they show the mique modification of articulating with special processes of the neural arches of several ankylosed thoracic vertebrae.

The hand possesses only four fingers; the four phalanges of the ulnar finger are very much elongated for the support of the patagium; the other fingers remain short and are provided with little claws. The ilia are expanded horizontally, and are firmly attached to from three to six vertebrae, which mostly fuse togrether into a sacrum. The rentral half of the pelvis consists of a patir of hroad bones, which contain a small obturator-foramen: they form a rentral symphysis, and are usually fused with the ilium. These hones represent the conjoint ischia and pubes, while the so-called pubes, a pair of flat and club-shaped bones, are excluded 
from the acestabulum. The whole arrangement resembles that of the Crocoulilian pelvis. The himl-limls are loird-like in so far as the filutiae are reslued to splints. and attached to the proximal halves of the long anil slencler tiliae. The feet contain five sepratate tous with rather long metatarials and short claws. Many of the bones are hollow.

The I'terusiuria have no relittionship with the bircts, in spite of the number of alplarently striking resemhlances (ey choanae, fre-orlital forminina. brain, scapulat. filula. (crvical vertelnate), which are however, coincidences, cases of convergence, in conformity with the aerial life. The totally different plan of the wings is sufficient to show this. On the other hand, the real aftinities of this group of flying reptiles are unknown. The' turn "u, "fully tlectgerl " in the Lower Lias, and they reach their lighest specialisation in the Cluee ('retaceons epoch, with which they have died out. In fact we do not know any forms through which to connect them with other extinct reptiles. The skinl shows some Iihynchocephalian features: the pelvis, Crocolilian features: and this combination points lack a long way.

\section{Order PTEROSAURI.}

Sub-Order 1. Pterodactyli, with alveolar teeth in the upper and luwer jaws. Inperfect remains, inpressions of phalanges of the long patagial fingrer, are known from the Rhatic of Wiirtcmlers. The oldest well-known genus is Jimurplintan, Lower Lias of Lyne Regis. D. mucrmys-Total length between : and 4 feet, of which the large light skull takes up ahout? inche's, and the long thin tiil ahout 2 feet. The patangial finger is alout 20 inches, the whole wing about $2 \mathrm{~S}$ inches long.

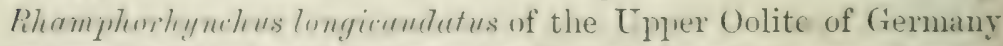
is remarkible for the long slender teeth, which are directed firwarks and separated by wide spraces from each other. The nine or ten cervical vertelirae are elongated. R. phyllurus of the same geolorical ase has left impressions of the flying membrants. They extend from the whole length of the wing and the silles of the trunk to the thigh as far as the knee, and from the inside of the himcl-limlss to the tail. The end of the tail carries it spatulate membrane. Allied is ornithocheres, with many species in the English Wealden and Greensand. I'tern- 
The nustrils ane dorsal. hordered hy the premaxillae, nasals, jrefrontals, and maxillaries. The quadrato-jural arch is incomplete. and the ondit is posterionly conthent with the infratemporal fussil. lont a suphatempural space is shut off by the single arch, which is eompused of the pestfontill. sulumosil, and suprattempral. The latter is interposerl between, and comects the smatmosil and quatrate with the latero-posterior liranch of the

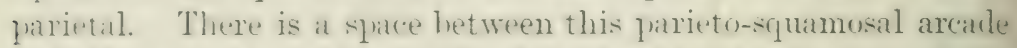
and the epi-stice, which is fused with the lateml wing of the lateral oreipital home. The formen masnum is bordered ly the two smpra-necipital, lateral nceipital, and the unpaired hasimeipital hones: the comlyle is triple. The fuadrate is movalles. articulating with the suluanosal and laterally expanded epi-otic: There is no buny comnexion of the quallate with the jugal, which is restricterl to its anterior half, and attached to the maxillary and lacrymal. The quadrato-jugal is absent as a separate lone: it is probalily fused with the anterior surface of the puadrate, as indicaterl ly a jerforation of the quallate, resemlling in this

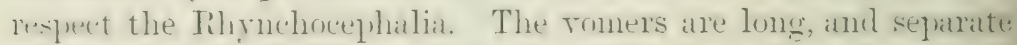
the elongated choanate from each other. The palatines separate the voners fimn the ptergendes, which enclose a long median varuity and ale not commecterl with the qualrates. The teeth are animal, and stand near the inner matrin of the jaws upon littl: luminences, with which they fuse. Some genera have teeth upon the pterygroids also.

The verteblate are rery numerous and are mostly procoelous. They are nutewortly for the posession of an adhitional anterion and a posterior pair of articulating processes on the neuril arehes, homblumus with the zyco-phenes and zyamentra of

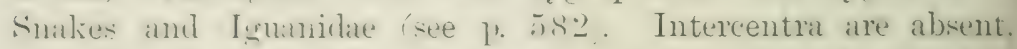
except in the tail. The ribs have nu tulerenla, and articulate with the centra of the vertebrae to which they belong.

The peretural areh is strong. The scapulate are short and hroal ;

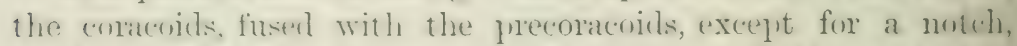
are flat and hroul, and nuent ventrally: pusteriorly they articulate upun the anterior narein of the flat sternum, to the litteral matrin of which are attacherd several rils. ('lavicles and interditricle seem to he alsent. Aldominal ribs are likewise alsent.

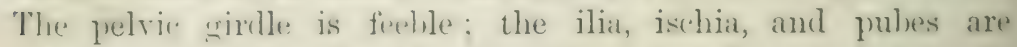
lorisely comected with each other, the pairs of rentral elements 
meeting also in the middle line. The ilia are loosely attached to two vertebrae in the Dolichosauri; in the Mosasauri they have lost this connexion. Both anterior and posterior limbs are transformed into pentadactyle paddles, with much shortened and broadened bones of the arms and legs. The digits are to a certain extent hyperphalangeal, since several of them possess five phalanges.

The Pythonomorpha are undoubtedly allied to the Sauria, but they are certainly not their ancestors, since typical Autosauri occur in the Lower Chalk; nor are the Snakes their descendants, in spite of many convergent resemblances. Tre consider them to be the marine collateral branch of the Samria, which rapidly developed highly specialised, often very large forms, restricted to the Cretaceous epoch, with a wide, cosmopolitan distribution.

\section{Order I. DOLICHOSAURI.}

This older group is characterised by the sutural sympliysial connexion of the two mandibles and by the possession of two sacral vertelorae. The body is snake-like. Plemrodont. Dolichosturus longicollis of the Lower Chalk of Kent and sussex; total length about 3 feet, with about seventeen cerricil vertelirae and pleurodont teeth. Acteosaurus of Istria ; anterior extremities distinctly shorter than the posterior pair: tail long. Vertebrae, like those of Dolichosanims, with zygosphenes. Pliupluterarpus of the Tpper Chalk of Holland has a slender interclavicle; the rertebrae are without zygosphenes, but those of the cerrical region possess a downwardly directed long hypapophysial process with a separately ossified epiphysis.

\section{Order II. MOSASAURI.}

The two halves of the lower jaw are connected by ligament and are therefore movable as in Snakes. There are no sacral vertebrae, the pelvis having lost its connexion with the rertebral column. The formation of the limbs into paddles is more pronounced than in the Dolichosauri.

Mosusrurus, the chief genus, so called from Mosa, the Latin name of the river Maas, with sevelal species from the L'per Cretaceous strata of the Netherlands, England, and North 
Anericia. Y. monpri, from Belgium, with a skull ahout 4 feet in length. armerl with many large, curved, acrodont teeth. The vertebal (whmm ansists of ahont one humbed caudal and thirtyfin precantal rertebrate, of which seven are cervical, without zyouspheses. The total length of the trpe-sinecimen is estimated at 25 feet.

IMrtwenges of Nortl Anerica and New Zealand, and various when North American gentrat. also contained species of large size.

Limlun.- Premaxilla without teeth, the others nearly smooth instean of leing ridered. With a very wide distrilution in the Challe of Europe, North Anerica, and New Zealand. I. hunmm,irmsis of New Zealand seems to have been the giant amomest these monstrous marine creatures; its total length has been computed from imperfect fragments at 100 feet.

Ilidustis, of the Lpper Cretaceous of North America and Europe, althungh not so mascive, comprises the most elongated forns. The cervical vertebrat possess long median hypapophyses with separate epiphrses; most of the rertebrae are much elongater and have well-dereloped zygosphenes. C. tortor had a skull nearly two feet and a half long. 


\section{CHAPTER XII}

SAURIA - AUTOSAURI OR LACERTILIA-LIZARDS

SUB-CLASS XI.-SAURIA.

firptiles with morable quadrate bunes, with a tiunsweise, ritfinul, cloacal opening, near the posterior lateral comers of which

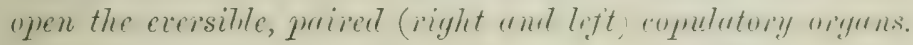

ThE Sauria, which comprise the Actostcli or Lacertilia in the wider sense and the OpHidi or snakes, are the most recently developed groups of Reptiles. No fossils are knomn from strata earlier than those of the Cretaceous epoch. Their origin has probably to be looked for among the Prosauria, of which Sphenodon, ef. p. 294, is the only surviving member. The Sauria have attained their great development within the Tertiary period. They, both Autosauri and Ophidia, are now the two dominant Reptilian groups, and ther have, so to speak, a future before them, being apparently still on the increase in numbers and species, but certainly not in size.

\section{Order I. AUTOSAURI or LACERTILIA-LIZARDS.}

Sirnriuns which hare the right and left halces of the mandilides 1 connected by a sutural symphysis.

The orerwhelming majority possess well-developed limbs, movable eyelids and cutaneous scales, corered by the mostly: thin and horny epidermis. But there are many kinds of Autosauri, especially those belonging to the degraded, burrowing fumilies, which have lost not only one or both pairs of limbs, but even the limb-girdles, while the eyes have becone concealed beneath the skin, and in some cases the scales have been lost, or reducerl 
10 mere restiges. Morenter in some of these burrowing and limbless forms the quadrate bones have become more or less immovable.

Te divile the Autosami inte three sub-orders:-I. (ieckosfs, 1. 5u2: II. LACEITAE, 1' 513: III. CHAMAELEONTES, 1. 567 , with about 270, 1500, and 50 species respectively.

The Anturami are of great interest, since they exhibit a creat. almost enclless variety in shape, size, and structure in direct adaptation to their surroundings. Most of these modifications are restricted to the external organs, or rather to those which come inte direet contact with the onter world, namely the skin, the limlss, the tail, or the tongue. The majority of the Antusinri are terrestrial. lut there are also semi-aquatic forms. There are climbing: swiftly rmming, and even flying forms, while uhers lead a suliterranean life like earthworms. Mrost of them live on animal food, varying from tiny insects and worns to Pirts and Mammals, while others live upon regetable diet. Acording to this diet, the teeth and the whole digestive trat are molified. The intestine is relatively short in the cirnirurous, long in the herlirorous species. But swiftness, the alluaratus necessary for clinbing runming, and digging, the nerhanisn of the tongue, the armament and the muscles of the firws hence monlifications of the cranial arches, etc.), stand also in comediation with the lind of foud and with the way in which it has to be procured.

I very interesting stuly of the influence of the clinate and the nature of the country upon Rieptiles has been mate by boettgen. with especial reference to the Transcaspiam desertrenion. The winter is there short, hut very severe, and there is a consideralle anomit of snowfall, while the summer is intolerably hut. The spring arrives suddenly. Lilies and tuijes, which have heren asleed' for nine or ten months, sprout towards the end of Folnuary, and a carpet of flowers cosers the gromil for a short time. Then everything shrivels up during the rainless and fieree heat of the summer, and the antummal storns of dust and sand kill of the last remmants of regetation. There are no trees, and even prickly shrubs are rare. Instead of hroal leates the plints have srass-like blades or needles. The little shruls do not form coherent pitches, but they are scattered 
about, and around the roots of each shrub the wind accumulates little maunds of sand and dust, a place of retreat for roclents. lizards, snakes, and even for the female tortoises. Cr. Rardle's "law of the steppe" is in full force;-there is little change of forms in a wide district, but all these forms are peculiar, and they congregate socially in great numbers. Most characteristit. are those kinds of Geckos which, like Terotosinems, ef. 1. 507, hare become inhabitants of sand instead of climbers of rocks and trees; rarious hinds of Phiynocephelus, of. p. 5.21, and Trencess griseus; the four desert-species of Lacertidae are brownish-grey or sandy rellow, with conspicuous stripes or spots. Of snakes are to be mentioned Eryx joculus, digging in the sand, and about ten other non-poisonous snakes. Trupidonotus is, of course, restricted to permanently watery places, where they can get frogs and fishes. Of poisonous snakes there is the Colra and Echis arenicole. Of Amphibia only Bufn riridis and Fonu csculente rar. ridibundu exist in suitable places, but there are neither Tree-frogs nor Newts.

Characteristic features of these inhabitants of the desert are the following:-

1. Velocity. The Lizards are slender. The Sand-snake, Teplrumetopon, is whip-like; even the Cobra has a relatively narrower and longer tail than the Indian specimens, although the number of the rertebrae and of the scales is the same. All the desert-suakes are remarkable for the great number of their ventral shields, two hundred and more.

2. Hard, scaly covering, for instance in Agema, Echis, Gymnuductylus, Tercutoscincus; the latter with its fish-like scales is exceptional among Geckos, resembling the likewise deserticolous Geckolepis and Homopholis of Africa.

3. Capacity for digging in the sand in order to escape great cold, or burning heat. All the Lizards and the Tortoise, Tistudo horgfieldi, have strong claws. The snakes Typhlups and Eryx dig with their specially modified snouts, and their tails are very short and blunt. The Sand-riper, Echis, has the scales of the back arranged in rery oblique rows, so that it cam heap sand upon its body by wriggling, shaking, and up-and-down motions of the body. The Agamoid Phiynocephalus does this by means of lateral folds of the skin.

4. Arrangements for running on sand. The lizard Eiemies 


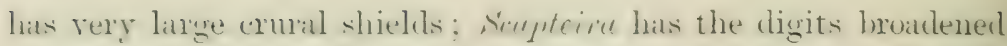

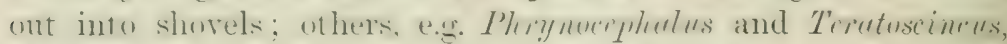
have long latteral fringes on the digits, a very rare arrangement

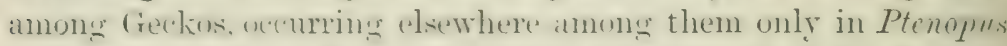
and stemelertylus. Which are likewise inhahitants of the desert.

‥ Protection asainst the everlasting, ubiquitous sand. In the diswing sleedes the nostrils are directed upwards instead of forwark: in must of the snakes they are protected iy complicaterl valves, "r they are reduced to small pin-holes. The eres

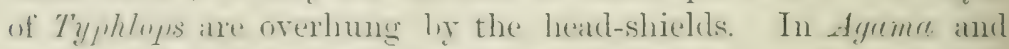

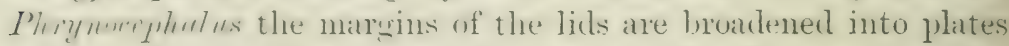
and are furnisherl with peculiar scales. In Terotuseineus the mprer lid is enlarged. The lizard stulum has the lower lid much enlinged, with a transparent window in it, so that the eye can lie closed without inperding sight, an arrangement carried to the

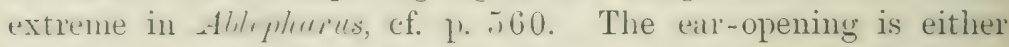
small, or protecterl hy fringres of scales, or it is abolished, c.y. in Plurynocephalus.

6. Coloration. Pure green is quite absent, even in Bufo ririlis and in lione exrulentu, since there is no green in that country, at least not of long duration. White, with grey and black spots, oceurs only in the nocturnal Geckos. Tellow, buwnish, reddish colours are common, in adiptation to the samd. The advantages of the carmine-red, and of the blue spots of Plirymephlulus, and the yellow or bright red under surface of its tail, are unknown. Striation is of frequent occurrence anong the lizards and snakes, probably in adaptation to the dry grass heaped up around the scattered shrubs.

Concerning the varions organic systems of the Autosami only some of the mure injortant features may here he mentioned.

Skeleton.-The rertehae are procoelous, with the exception of most of the (rechones, in which they are amphicoelous. Soabled intercentrat, in the shape of mpatired nodules or wedges, persist between most of the cervical vertebrae. In the tail these werlges, the remuluts of the hasiventralia, are generally fresent, frequently in the shape of cherron-hones sometimes they luse with the centrat of the rertehrae; occasionally the axial or central portion of these basiventrals persists as a sort of filnous disc, which may ralcify seprarately, and is interposed letween the candial and of the centrum and the articulating 
knob. The caudal vertebrae of the Geckones and of most Lacertae are liable to break across, like those of sthemenn. They are enabled to do this owing to a transverse split, which makes its appearance with the ossification of the vertelyal bodies and extends later into and across the nemral arch and the various lateral processes. The split is ultimately referable to a transverse septum of cartilage, wrongly callect chordal cartilage, which develops in the shell of the body of the vertebra, destroys the chorda, and extends peripherally. The cells of this septum retain throughout life their jurenile quasi-embryonic character. When the tail is broken off-and this always happens at such a septum-the cells of the remaining half reproduce a new tail. The latter is, however, in reality a sham tail, since neither new centra nor arches, but only a non-segmented rod or tube of fibro-cartilage is produced by this process of regeneration. Reproduction of centra is precluded by the previous nomal reduction of the chorda, around which alone proper bony centra could be formed. The regenerated tail is, howerer, inrested with new muscles, and with skin, but the scales often differ considerably from those of the normal organ. Boulenger ${ }^{1}$ has found that the new or aberrant scaling is in some cases in reversion to an ancestral form. This is, for instance, the case in Pscudopus, and in the Tejoid genus Gymnophthalmus; to a certain extent also in Geckos and Slinks. On the other hand, Lacertidae, Gerrhosauridae, and also Anguidae reproduce a caudal scaling true to their type. Injured or broken-off tails are often reproduced double, or even trifid; sometimes an additional little tail grows out from an injured spot, anywhere on the side of the old remaining but mended tail.

The rils of the trunk articulate by their capitula only, while the reduced tubercula are attached to their rertebrae by ligaments. In the tail the capitular portion is much reduced, while the tuberculum is much stronger and lies behind, no longer above, the capitulum, fusing sometimes directly with the centrum. The ribs of the poststernal region of Geckos and Chameleons are very long, and meet each other in the midille line, forming thin cartilaginous hoops.

The limbs are of the typical pentadactyloid type. The distal tarsalia are often fused with the metatarsals, so that the chief 
lending of the fout is effecterl ly truly intertursal joints. The

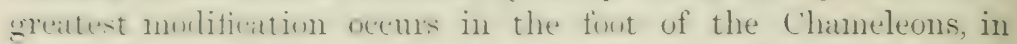
which the froxinal tarsitia are reslucet in number, and form a globe for the articulation with the tibia and fibula.

The shomlder-girdle and sternum nuth resemble that of sphenoAnn in their annleteness. The coracoils articulate with the sternum: the precoracoids and the hasal prarts of the scatpulate uften semel con sereral processes tomards thuse of the other side, so that serelal fenestrac are formed. The claricles are complete, hut are absent in the chaneleons. The interclaricle is mostly T-shipend. I fresternum is alsent, but the sternum proper is well ileveloned. uften forming a rhmboid plate, nsually cartiliginums, wften divering lackwards into xiphisternal processes.

The pelvis is attached to two vertebrae by means of several rils.: The ischium and puhis form symphyses. The pubis carries a well-developed lateral process, and the obturator-nerve pierces the sluat of the pubis. Epipulic and hypo-ischial cartilages are of frequent occurrence.

The hroid apparatus consists of a median, styliform rod, which extends forwards into the tongue: it is often bifid behind. The unpaired piece carries two pairs of horns. The posterior of these, the first pair of branchial arches, exteucls hackwards along the gullet, and is very long if the tongue is very slender and protractile. The anterior jair, the hyoid arches, consists of two pieces on either sile, one short and directed forwards, the other long, connected with the former at a sharp angle and continued upwards to the sides of the skull, often in direct continuity with the columellar chain of the ear.

The molifications of the skull concern chiefly the composition of the temporal arrehes, see Figs. 5i, M, I, O, 1. 281. The quadrate lonte is movialle, but it has become fixed in various dergruled fimilies, where the skull shows a great reduction and concentration: the postorbital and temporal arches, the interorhital septum, and with it the columellae cranii are lost. The columellat cranii of the Chaneleons, which is generally stated (1) he alsient, is really present, although in a much reduced state, and is partly imbedien in the interorbital septum. The occipital condyle has become bifid in Amphisbaenidae.

liurrowing and living in sand are often correlated with partial or complete reduction or loss of the limbs and their 
girdles. This loss of limbs is as a rule correlated with an elongation of the trunk, not always at the expense of the tail, which in such cases is much shortened. The restiges of the hind-limbs come to lie as near the vent as possible. This rerluction of the limbs occurred in several families which are not directly related to each other. Moreover, it does not occur in all the members of the family, not always in those of the same genus, and there is a considerable amount of individual variation. In most cases of reduction the fore-limbs disappear before, or are smaller than, the hind-limbs. In the Amphisbaenidae (cf. Chirotes, p. 566), and in the Tejidae the reverse takes place. In extreme cases the reduction is so complete that even the pectoral girdle has disappeared, leaving scarcely any trace, e.g. in Dibamus, p. 564.

The skin is normally covered with scales, which are formed liy the cutis and have a horny epidermal coating. The latter, thin and transparent, is shed periodically, peeling off in flakes, except in Anguis and perhaps other smake-shaped creatures, which shed the skin in one piece. In the Amphisbaenidae the scales have practically disappeared. When well developed the scales are prominent, and imbricate or overlap with their free posterior edges; but in many cases the scales are not "scale-like" at all, only like little tubercles, which give the skin a granular appearance. Frequently, for instance in the Scincidae and Anguidae, all the scales contain "osteoderms," or ossified portions of the cutis, and encase the whole body and tail. In other families, e.g. Lacertidae, such osteoderms are restricted to the scales or shields on the head, where they come into contact and fuse with the underlying cranial bones, and moreover roof in the supratemporal fossa.

The skin of the Autosauri is entirely devoid of glands. The femoral and pre-anal pores of many families, occurring especially in the males, are probably not glands. They are arranged in rows on the under surface of the thighs and in front of the anal opening. Each of these organs perforates a scale and leads into a tubular invagination, which is lined with epidermal cells, the proliferation of which produces a horny yellowish déris, and this fills the tube and appears above the surface in the shape of a little cone. The use of this "excretion" is unknown; it is possibly hedonic. 
Most Autosauri are capalile of changing colour. In most of them this faculty is restricted to the assumption of paler or darker tints owing to the shifting of the colouring matter contained in the ehromatophores. In uthers new, often rivid colours are the result. The medhanism is lescribed in detail in the chameleon on pp. 570 and 574.

I'inment is deposited either directly in the upper strata of the cutis, just helow the Malpighian layer, or it is contained in chromatophores. The latter are imbedded in the deeper layers of the cutis, and send out norahle contractile processes, in which their pignenterl protoplitsm is conveyed towards or away from the surface. The only colours a valable are black, red, gellow, and white, with their comblinations of grey and lowwn. The white pigment consists of guanin-salts. Bhe and green are structural colours, not due to pigment. The sime can no longer be sail of the Ophidiat, since Boulenger has olserved acciclentally that green Tree-snakes (e.g. Mryoulis) give the alcohol in which they are liept the colour of green Chartrense.

Digestive organs.--The tongue is rery variahly developed, amel affords gool taxommic characters. It is always furnisherl with many tactile, or with gustatory, corpuscles. When the tongue is very long and narrow it is generally forked, and in these cases, for instance in the Varanilae, is almost entirely used as a sensory organ. In others, especially where it is lroad, it assists in catching the food, and in the chameleons it has attained a most elaborate development (see p. 569).

Salivary slands are restricted to hahial glands. In Heloderme those of the lower jaw are transformed into poison-glands, an analugy to what prevalis in the prisonous suakes. The intestinal canal is longest in the herlivorous forms; the rectum sometimes possesses a short blind sac or caecum.

The cloaca of the sauria is somewhat molified; instear? of the Coproslacum, Lroulatum, and Proctodatem forming three successive chambers. the urodaem is practically reduced to its dorsal half, forming it dursial recess between the two other chambers. The coproditeum is constricted into several successive rhambers, and is always well shut off from the urolaemm ly a strung splineter. The uroditem receives the urinary excretions, which are mostly chalky white and are rather consistent insteal of leeiner fluid. The right and left oriduets also opren into it. The vasa 
(leferentia open into the dorso-lateral portions of the walls of the urodaeum, but the sperma is conducted by folds of the lining of this chamber towards the bases of the copulatory organs, which, although arising from the lateral and posterior corners of the cloaca, where uro- and procto-daeum meet, are stowed away outside the cloaca. These organs are always paired. The proctodaeum or outermost cloacal chamber is shallow. Its inner opening is round and is furnished with a sphincter, but it is surrounded and covered by lips of the outer skin, which form a transverse slit. This is due to the peculiar arrangement of the copulatory organs.

Each organ consists of a tuhe of erectile tissue, aud can he everted like the finger of a glove. To the apex of the tulse is attached a long retractor muscle, which arises from the rentrolateral surfaces of the caudal vertelmae and extends a considerable distance lack. When at rest and withdrawn the organs form slight conical, longitudinal swellings on either side of the root of the tail, an external feature by which male specimens can generally be distinguisher. Only one organ is inserted at one time.

The majority of Autosauri lay eggs, surrounded ly a white or yellowish shell, which is either hard, for instance in Geckos, in Lecerta 'viridis and I. agilis, or parchment-like, e.g. in Chameleons and in L. viripara. Eggs with a thin and soft shell sometimes exhibit the paradoxical feature of increasing in size after they have been laid. This is explained by the growth of the embryo, which stretches the shell and does not merely live upon the white and yellow contents of the egg itself, but also takes in air and moisture. Many Lizards do not lay their eggrs until they contain ripe embryos, which hurst the shell shortly after deposition. Some, for instance Lacerta vivipura, Anguis fiagitis, and Chrmacleo pumilus, are practically viviparous. The embryos, especially those which are enclosed in hard-shelled eugs, are provided with a sharp, calcareous "egrg-tooth" on the top of the snout.

The lungs are thin-walled saes, sometimes provided with lateral ex-sacculations, and these reach their greatest development in the Chameleons. The breathing is effected by the motion of the rils. Inflatalle sacs on the throat, or on the sides of the neck, for ornamental or sexual purposes, oceur in various families. The lungs of much-elongated, snake-shaped Lizards are generally 
asrmmetrical: the risht heins rechued in Amphishaenidae: the left in other cases.

Serveral Intosuluri, for instance the Geckos, Psommortomes, and various other Lacertidae have a weak roice.

The Fat-bodies are nusterious oreans which are situated beneath the shin, and extend from the insumal region forwards alnis the sentral sides of the leelly. They are often of considerahle dinemsions: larpest in the spring. in hoth sexes, at the time of fropmation. Their colour is greyish-white or gellow, uwing to the squat accumulation of fat in the meshes of the conne tive tiscue which ampuses the frame-work of these organs. An artery enters them. lreaks up into capillaries, and these comline to form an efferent vein. After the time of proprasation these organs are reduced to grey or reddish Haps, consisting mainly of very viscular connective tissue. (r. Wr. Butler ${ }^{1}$ has written a lom jajer on their morphology. The same author" has investigaterl the "sul-divisions of the hodr-cavity in Lizards, Crocodiles, and Birks." with reference to peritoneal diaphragmatic structures.

The geographical distribution of the Autosauri teaches few, hut important lessons. We hare to restrict ourselves to the principal families, leaving out those which are small and have a linited distribution: also those which, like the few Anelytrupidate in Africa and in Mexico, are not natural groups.

The frechones, which are probathly the oldest of modern Autosinri, are practically cosmopolitan, being absent only in the (w) and in the cooler temperate regions. They are common even in orennic Islands, for instance in New Zealand and in the Sandwich Islinds. Although not at all aquatic, they are particularly tit to be transported acciclentally on or in the trunks of thoating trees, to which they aling firmly, and they can exist without food for months. I once received a little Sonth American crecko in perfect health from a grocer, who found it in at well-closed wouden lox containing canned meat, two months after delivery of the box in Cambridge.

The Sincinclate, likewise an old fimily, are eyually cosmopolitan, but althourh many exist in the is aumb of the I'acific they do not or.ur in New Zealand. Many of the genera have a very wide distrihution: for instance, L!! fostmun, with its one humdred and sixty ar more species, oceurs in the Anstrilian and P'aliken-
${ }^{1}$ P.Z.S. 1889, 1. 602 .
2 P.Z.S. 1889 , p. 452. 
tropical regions, and also in North and Central America, not extending, howerer, into South America. Muluri, with more than sixty species, occurs in the Palaeotropical and the Nerotropical regions. Whether these and other widely-distributed genera are all natural is another question.

The Agamidae, Varanidae, Lacertidae, and the Chamaeleontes are restricted to the Old World. The Agamidae and Taranidat: have the widest distribution, occurring in the whole of the Old Trorld with the notable exeeption of Madagasear and New Zealand. The Lacertidae are Palaearctic and I'alaeotropical, leing however absent in Madagascar, and, broadly speaking, not extending eastwards beyond Wallace's line. It is a most suggestive fact that most of those families of Reptiles, and even of other Tertel)rates which have a wide distribution and are aplurently debarred from transgressing Wallace's line, are also alsent from Madagascar.

The Chameleons are essentially African, with their centre of greatest ahundance and development in Madagascar, only one or two species occurring in Socotra, Southern Arabia, and in C'er'nn and Southerm India. If they existed, or could he shown to have existed, on the rarious islands in the Indian Ocean, for instance in Mauritius and the Seychelles, the Chameleons would be an excellent illustration of the former existence of a direct land-connexion between Southern India and Southern Africa.

The Iguanidae are essentially American, with the remarkable exceptions of Chulurorton and Hoplurus in Madlagascar, and Bruchylophus in the Fiji and Friendly Islands. This peculiar distribution finds some analogies in that of Dendrobatinae (1). $272)$, certain Boinae (1.601), and Centetes and Solenodon among Insectivora. An Iguana (I. europucu) has, howerer, been described from the Eocene of France and England. The supposed relationship of the Iguanidae with the Agamidae makes the problem only more puzzling, since Agamidae are absent in Madagascar. If we have recourse to the Zonuridae, which are confined to Africa and Madagascar, and are supposed to be intermediate hetween Anguidae and Iguanidae, then we may have ultimately to conclude that the Malagasy Iguanoid genera and the American Iguanidae are a case of convergent evolution.

The Amphisbaenidae are distributed over America, including the West Indies, Africa exclusive of Madagascar, and the 
Mediterranean countries. This is very juzzling, considering that these suliterranean, helpless creatures positively cannot travel.

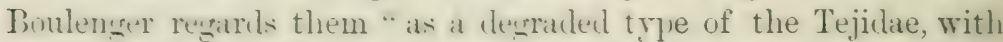
which they are to some extent connected hy Chalcides and its allies," i.e. genera with reduced limbs, ef. p. 562.

Howerer, this sulpused relationship with a strictly American fanily does not explain the occurrence of Amphishatenidae in Africa. Either they are not a matural group, or they had, as alrealy degrabded. limbless creatures, a much wider range: and this would imply their heing a very old family, perhays as old as we suppose the Coecilians to be.

Anguidite occur in North and South America, in Europe ancl the Mediterranean parts of Torth Africa, and in Trans(rangetic India. Their older relations, the Zonuriclae, inhabit Africa and Madagascar.

Marlagiscar is consequently devoid of Agamidae, Taranidae, Licertilat. Anguidae, and Amphisbaenidae, while it possesses, beside- the cosmopolitan Sincidate and reckones, only Chameleons, Crerhosituridae, and Zonurielite- - all three essentially African families.-and a few Iguanidate. This means that the Autosaurian famma of Madacascar is intimately related to that of Africa, am that it possesses only old families so far as Sauria are concerned. But since this sreat island was separated from its continent not earlier than in Mid-Tertiary times, it follows that most of these "old" families are comparatively recent.

Australia posserves only Agamidate and Taraniclae hesides the uhipuitoms (reckos and skinks. IBesides the latter two families it has nothing in common either with Madlugascar an analogy with the Anura or with America. The Autosituri conseguently do not support the illea of a Notogatea, of. 1) 7t. This again inclicates the complaratively recent ane of Autosamian families. The marked dinterence which exists lretween the Old and the New Wurlal points to the same conclusion. On the other hand, the Autosauri support the idea that the l'alacotropical region is lut the trepical and therefore richer continuation of the now impoverished Palaearctic sub-region.

Sub-Order 1. Geckones. - The tylical Geckos are chatr-

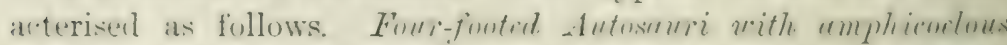

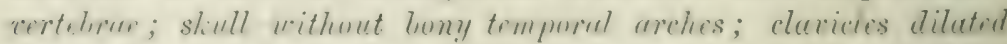
and with a perforetion neter the wntral end; parietal bones 
scparate; eyes (with few exceptions) withont morelle lids; plempolont; tongue fleshy and broud, stightly niched anteriorly, and capable of protrusion.

This definition does not apply to a few forms. In the Eublepharinue the vertebrae have advanced to the procoelous condition, and the parietals are fused together, while the eyes are provided with typical, movable lids. In the Uroplutinar the clavicles are not dilated, and the nasals are fused into one bone. The Geckos seem to be not only a very independent hut also a very old branch of Saurians. Although fossil representatives are unknown, the resemblance of their vertelirae to those of the Palaeozoic Microsauri is at least remarkahle. They are now practically cosmopolitan within the warmer zones, being found in

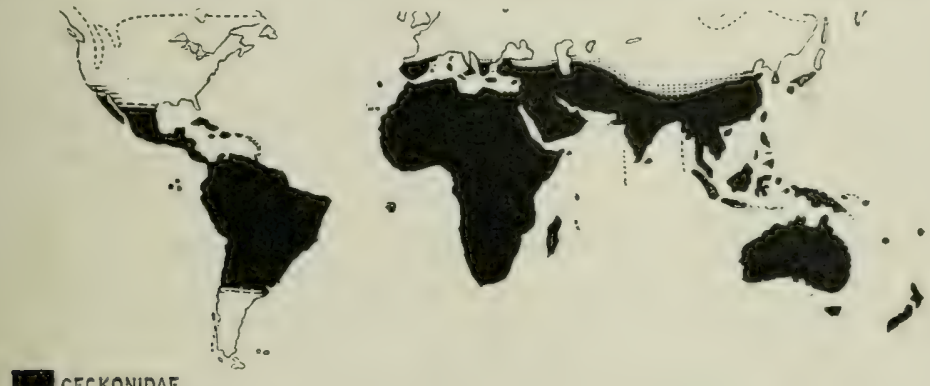

CECKONIDAE

FIG. 118.-Map showing the distribution of Geckonidae.

abundance in all intertropical countries and islands, eren in New Zealand. Ahout two hundred and serenty species are known, which have heen suhdivided into about fifty genera. The generic difierences are trivial with few exceptions, and refer mostly to the structure of the digits.

The more important features of the rertehral column are the absence of axial joints and the persistence and life-long growth of the chorda dorsalis. Each vertehral centrum consists of a cartilaginous tuhe, more or less calcified or ossified, with a narrow waist and a cartilaginous septum in the middle. In the tail this septum, which is only slightly invaded by ossification, coincides exactly with the line of transverse division of the vertebrae into an anterior and a posterior half. This is the level where the tail brealis off and whence it is renewed. Between every two successive centra lies an intercentrum, broalest ventrally, crescent- 


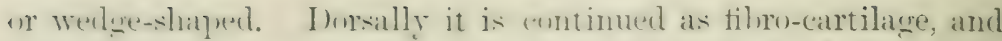
the whole ring acts as an articular pad instead of the joint. Cherron-bones are common in the tail.

The ribs are bifurcated, lut the tulereular portion is frequently retheesl. The post-thoracice rils are usually very slender, and so long that they meet each other in the middle line, in this case hearing an extrambinary resemblinace to the so-called "abdominal ribs" of other reptiles.

The lony frame of the skull is stumler. There is a complete

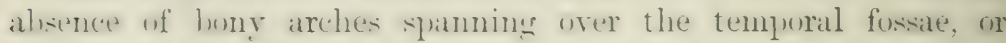

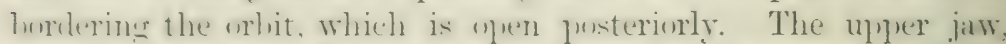
owing to the slemter and flexille nature of the respective lones, is movalle upon the rest of the skull: in this respect not unlike the mpere jaw of a duck. The lentition is pleurodont and the teeth art minute. The eres of the trobal ciechos are preculiar. Ther are covered with an absilutely namsparent skin, shateel like a watch-ghas. heneath whith the ere mores freely; while the true myer and lower lids are reduced to tiny folds. The corering "Watch-glass" is probahly a molification of the nictitatinger memTrane. In the Eublepharinate. howerer. and in the few species

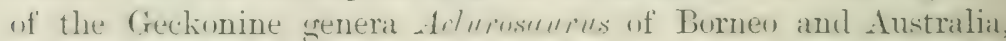
and I'tempers of south Africa, the nplee and lower liels are present and movalile. The pupil contracts mostly into a rertical slit, "xcept in the few diumal kinkls, e.g. Pletsume, of the islanels in the Indian ocean, and the Afrisan Lyguntertylus.

Another peruliarity of at least many Gechos is the extritorlinary develonment of the molu-lymphatic sacs of the ear, which, lesing filled with the chalk-like otoconia or otolithice crystals. perfimate the skull, and are stowed away in the shape of

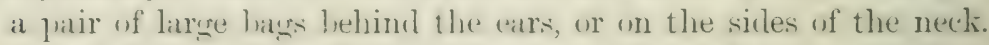

The skin exhibits consiclerable variety. It is mostly soft alore, with little gramular tuluercles, sometimes containing small dermal osifications or calcifications. The latter are most develuperl on the head, where they occasionally fuse with the molerlying lones. A few species of Torntula possess supuriorbital lunes, independent remmants of such osteolems. The ventral surface is generally coreresl with small imbricating scales. but in some senera, e.s. Ifommplutis, such scales oceur also on the dursal surface, rearehing their lisghest developunent in

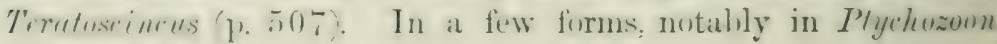


(1). 512), the skin of the sides of the hody and tail is producert into a series of lobes and flaps, the object of which seems to assist adhesion. Maur, perhals the majority of feckos, have athesive digits, hy means of which some kinds are enabled to climb absolutely smooth and vertical surfaces, for instance a windowpane; or, what is more startling, they ruu along the smooth, white-washed ceiling. lack downwards. The aplaratus is complicated in its minute detail, lut is very simple in principle. The adhesion is effected neither ly sticky matter, nor in the way described in the Anura ( $1.18 \%$ ), but by small and numerous vacua. The under surface of each digit is furnished with many transverse lamellae. The pressing down of the foot upon a smooth surface

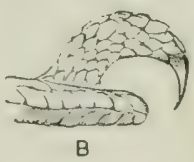
causes the lamellae to spread asunder and to drive out the air; partial retraction lets them return to their original position by virtue of their elasticity; and little racua are produced. Each lamella is further beset with tiny hair-like excrescences, which secure adpression to even the slightest irregularity of surface and at the same time enhance the elasticity of the park. The arrangement of the lamelline and pads differs much in the various genera. For instance, the lamellae are either hroad and entire, or they are divided into two parallel rows, with or without lateral hairy fringes; or the under surface of the digits is granular, hut strongly fringed: or the lamellate are restricted to the dilated tips of the digits, etc. The fingers and toes are mostly furnished with sharp, curverl daws, and these are in many cases retractile hetween some of the lamellae, or into a special sheath. Those Geckos which live on samdy, barren ground are as a rule devoid of adhesive pals, the digits being narrow. The typically padded, achesive digits cause a peculiar sensation when a Gecko hangs on to one's finger, and this feeling has perhaps given rise to the erroneous notion of stickiness.

The tail exhibits many kinds of shape and size. Mostly 
"ylimbical and tapering to a point, it is leat-like in Gymnudertylus plutures of Australia: provided with many lobes, and used as a parachute in the Malay Ptyduzoun. In Liphrurus msper of Eatstern Australia the tail is quite short, much shorter than the linhs, nuth swollen at the hase, and very thin towards the end. whith carries a round knul. The tail of all Gechos is very brittle and can le quickly regenerated, except the long rat-like tail of the I'ersian - fymmon. In many other desert-forms the tail is lung, slender, and laterally compressed, acting in such cases like that of desert-forms among the Lizards.

Many (ieckos have a voice, mostly rather feelble, and sounding like a soft "click" or "chick" produced hy our tongue. Repetition of this somml resemhles in smme species the word "gecko." They lay egs rather glolular, or lut slightly oval, hard-shelled. and white, mostly two in number. Timblinus deguns of Tew Zealand is said to be viviparous. The males are generally larger than the fenales, and they are further distinguished in the possession of femoral or pre-anal pores.

All rechor feed upon animals, chiefly upon insects, lunt the larger forms take anything thes can master. With few exceptims they are nocturnal, which, however, lues not prevent them from accasionally baling themselves in the sun. They are capalle of changing colour, but since their ground-colour is almust universally grey, rellow, wr hrown, the range of the coluurchanges is restricted to the adoption of clarker or lighter hues. The skin is shed in flakes and eaten.

(ieckiss are alisolutely harmless; they cannot even inflict painful hites. However, in many countries they are feared as much or even more than the mont poisonous suakes. In the south of sirain and l'ortugal, for instance, where Geckoss are plentiful in and outside the lomses, and are consegriently olyjects of chily observation, the "usyen" is considered a clrealfully poismons creature. They hecome very tame, or rather contioling in their remplar halits, provided they are not molested. If andht-amil they have many enemies among other lizards aml smakes-the only safety of these defenceless and mostly small creatures lies in their tail, which, heing extremely brittle, is left in the rlaws or jaws of the purster. The remaining stump son problueses a new tail, in shate and size like the old one, lut with a difterent and simpler scaling. I knew of several specimens of 
the Portuguese Platydactylus facetamus, which, having lost their tails in the act of being caught, were kept in a box for six weeks without food. On their arrival in England they haul each grown a new stump nearly half an inch long!

Fam. Geckonidae. Sub-Fam. 1. Geckoninae.-Tertelurae amphicoelous; parietal bones separate; clavicles dilated ancl perforated. Hereto belong the overwhelming majority of Geckos, only a few of which can be mentioned.

Teratoscineus scincus.-This most peculiar creature, about six inches in length, inhabits the steppes of Turkestan and neighhouring desert-regions of Persia. It is a thorough desert-form. The digits are devoid of adhesive lamellae, lut are gramular inferiorly and strongly fringed laterally, an arrangement which is rire among Geckos, practically restricted to it with Ptcnopus and Stenodactylus, which are likewise deserticolous. This is a beautiful illustration of adaptation to the surroundings. A Grecko, instead of elimbing rocks and trees, has lost the climbing alpraratus, or has transformed parts of it for running upon loose sand. The body is covered with imbricating, rather large and smooth scales. The tail is round at the base, compressed in its posterior half, covered below and on the sides with scales like those of the body, but on the upper side with a series of large, transverse, nail-like plates. By rubhing these plates upon each other, this Gecko produces a shrill, cricket-like noise, sitting at night in front of his house, perhaps in order to attract grasshoplers. The noise is made by both sexes.

Ptenopus, a Gecko of Damara Land, likewise adapted to desertlife, produces a similar chirping noise by its throat.

Phyllodactylus is a genus of world-wide distribution, occurring in tropical America, Africa, Madagasear, and Australia, extending to the Norfolk Islands and to Lord Howe's Islaud. One speeies, Ph. europaeus, occurs on the islands in the Western Mediterranean. The digits are furnished with transverse lamellae, the greater number of which are broken up into small scales forming three longitudinal series. The ends of the digits are dilated, with two large plates inferiorly, separated hy a longitudinal groove into which the claw is retracted. The upper parts of the body are covered with juxtaposed scales intermixed with larger tubercles. The aldominal scales are small and imbricating. The cylindrical, tapering tail is slightly prehensile, covered with 
small scalles arranged in verticils. This species is elevoil of femoral w amal pores. Cieneral colour aluere erey-lirown. with darker and lighter markings: a dark streak on the side of the heat, grasing through the ere. Under parts whitish. Thial length ul tn: inches. The engs are ahnost romol. measuring S.7 by $7 \mathrm{~mm}$.

II, millurtylus. likewise a wilely distrihuted genus, with many speries. The digits are dilated. inferiorly with two rows of

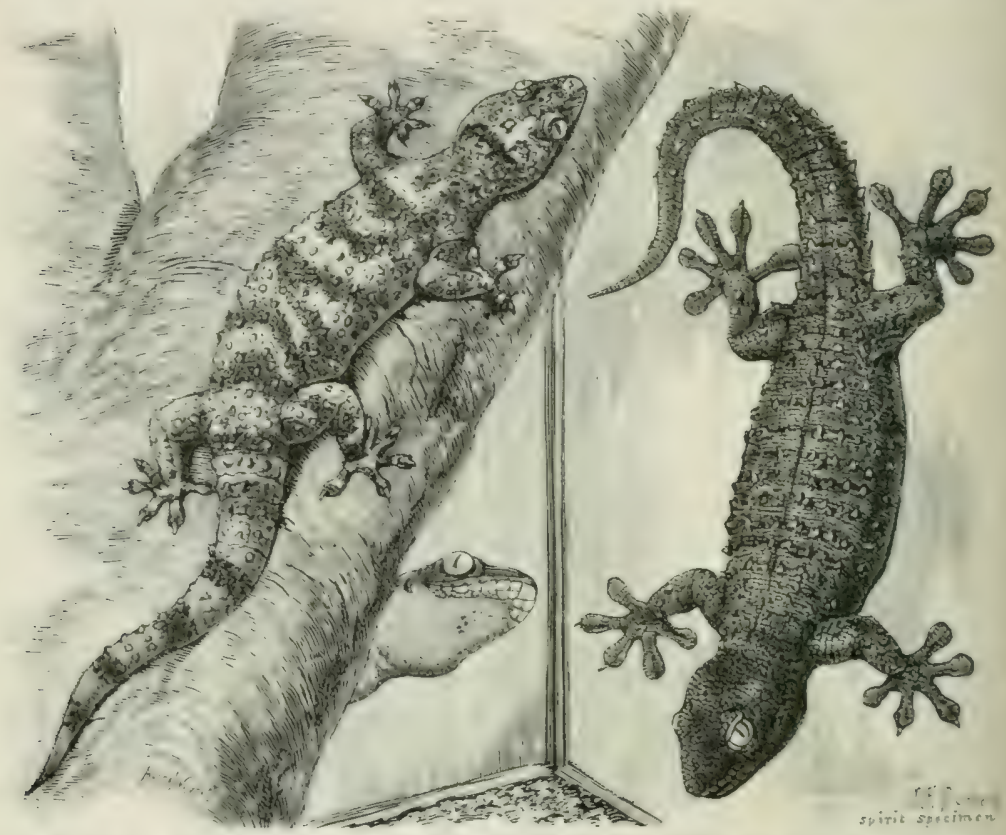

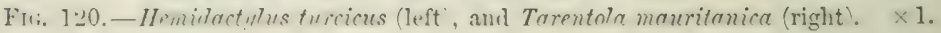

lamellate: the clawed joints are slemder, bent at as angle, and rising from within the extremity of the dilated portion. II. tureirus. hetween :3 and 4 inches long.-The mpler parts of the louly are (a)ered with minute granules, mixed with larwer tuhereles. The alulominal scales are small and slichtly imbricating. The male has several pre-anal pores. The tail is concred above with minute scales aud tubercles, below with a series of lareg tramsersely dilated plates. The general colour is white irelew; lowwn aluse. with darker spots, and with white sperelis m many of the tubereles. This species extemels from 
Southern Portugal and Spain to Karachi. Like I'hyllumlurtylus and rarious other kinds of Geckos, the body is semi-transiarent : so much so indeed that the white eggs shimmer through the luxly in certain lights.

T'erentole manitunieas. Platydactylus fucetunus. - The digits are strongly dilated, with undivided lamellae helow, and a that, nail-like scute on their upper surface near the tip. Only the third and fourth digits are clawed. Femoral or pre-anal pures are absent. The upper parts are covered with scales and granules, and bear several longitudinal row of strongly keeled, lirge tuhercles; the under parts have hexagonal scales. General colour ahove greyish-brown, with darker or lighter markings: with a dark streak through the eye. Total length of large males about 6 inches. This species is one of the commonest Gechos in the Southern Mediterranean countries. In Portugal it extends northwards to the Douro. It has been introduced hy ships into the ports of Cette, Toulon, and Marseilles. It is easily liept in captivity, like most Geckos incleed, provicled they are supplied with a variety of insect-food, water in the shape of dropss, and suitahle places to hide in. A female, which I had received from Algiers in a little tin box, with a lump of meat (presumally its food!), laid two eggs six weels after its arrival. This was towards the end of April. Towards the end of Jume in the same year it again laid two eggs, measuring $13 \times 10 \mathrm{~mm}$. Another specimen laid in June in two successive rear. These and other Geckos live rery well in a greenhouse, or in a large glass eage. They change colour most alaptively. They hunt preferably at night for insects, which are stalked and then suldenly rushed at. Drops of water are taken by a lapluing motion of the tongue. For sleeping-places they selected bits of hollow bamboo, but these had to be vacated when some treefrogs crept into them for the daytime, and the Geckos took to some curved pieces of bark, on the under side of which they slept, with their backs downwards. This is, hy the way, a favourite position of rest of most Geckos. But Stenuductylus guttutus of Egypt lies flat on its belly, tucks the fore-feet uncler and inwards like a cat, rests the head upon them, and stretches the hind-limbs out backwards. The little Geckos are rather intelligent. They take no notice of a finger put against the other side of the glass to which they haplen. to cling; but 
when the hand is put inside their cage aml approaches them tou near, they diart off sublenly. Then driven into a corner they wriggle aml way their tails, or even raise the latter, perhaps as an invitation to srasp it, in which case it would of course break off. Then caurht, they enit feeble sommes, and attempt to hite with the mouth willely oren. During the moultinis, which tokes place at least twice a year, in the spring and in the autumn, the skin pees off in flakes: if, as haplyens sometimes, the skin upwn the lanellae is not stripled off neatly, these refuse: to act, and the creature cannot climb until all the old skin has been rubbed off.

In their native haunts they are rery regular in their halits. Farmurite resorts of theirs are old olive trees or oak trees, the rolgh and cracked bark of which affords excellent places for hisling in. Hollow trees are of course preferred. Not a single specimen is seen during the early hours of the morning or in the firemon: lut when the sun has hecome loroiling hot, and our own shatow grasses orer the stem of a tree, we hecome aware of Hitting little shatows which jerk over its surface. These are Geckos which hat leen lasking, motionless: very dark arey, ahmot hlackish, just like the culour of the grey hark upon which the last wet seats:n's moss has heen seorched to a hlack cinder. It is difticult to espy a Geckon whilst it is glued on to such a tree. Only the little healy eyes hetruy it, watching you carefully: Nothing alpears more easy than to catch that motionless thing. Yom jut mut your hand and it is gone: like a flash it has moved a fort higher up, or down, to the right or to the left, just where you least expected it to gn, and there it cliness on motionless as before. It does nut seren to run: it whiles along, dowging over to the other side of the stem and latck again. There is system in its motions, since, taking a last lejourely lowk around, it gently disalpears in a rent or luble. Towards the erening, or when the shadows become longer, the Gechos hecome lively. One after another aplears on the surface, unwn the tree, or at the entrance of the cave, and they all unve almut in their peculiar rushing jerks. Spiders, flies, mosquitues, moths, form the principal diet, and the huntins grese on well into the night. Where a gector has heen seen once it is sure to reaplyear the next diay at the same hour. Thuse which take u], their alwule insile a house hecone almost domesticated. They are strange sights when hunting for flios, 
running up and down the papered walls; lut we fairly asspl when they come to the upper corner, calmly hend oser, and with the next jerk slide along the white-washed ceiling. We are accustomed to flies performing such feats, but at animals five inches long, supple and fat, we are inclined to draw the line. However, that is the way of Geckos, and-he it confessed-the more we ponder over the mechanism of their fingers and toes, the less we comprehend how such little racua can supjort or suspend such heavy creatures from a dry and often porous surface.

Geclio.-The digits are strongly dilated with undivided lamellae. All, except the pollex and hallux, have a very short compressed terminal phalanx with a retractile claw. Males with femoral or pre-anal pores. This Eastern genus inclucles some of the largest of all Geckos.

G. stentor of the Malay countries reaches a length of 15 inches. G. verticillutus s. verus s. guttritus ranges from Eastern Bengal to China and through the Indian archipelago. It grows to alout one foot in length. The head is large; the lack is covered with small granules and ahout a dozen rows of large tubercles. The tail, when intact, and the helly are covered with scales, those of the tail being arranged in transverse rows, several of which make up distinct rings. The upper parts of the budy are grey or yellowish with red spots and rermiculations. According to Theobald ${ }^{1}$ it lays about eight hard-shelled white egges as big as a musket-ball, cementing them to trees, rocks, or secluded buildings. The cry is "touk-tay," several times repeated, and ending in a long-drawn out, diminuendo, guttural rumble. This animal does not confine itself to insects, but eats young rats also. Dr. Mason has seen it devour smaller species of house-lizards, and Theobald has seen it seize a bat flying round the room, and devour it.

Tennent ${ }^{2}$ tells the following story about one of these creatures : "In an officer's quarter in the fort of Colombo, a Gecko had heen taught to come daily to the dinner-table, and always made its appearance along with the dessert. The family were alosent for some months, during which the house underwent extensive repairs, the roof having been raised, the walls stuccoed, and the

${ }^{1}$ F. Mason's Burma, London, 1882.

2 Sketcher of the Nat. Hist. of Ceylon, London, 1861. 
colings whitenet. It was naturally sumised that so loner a

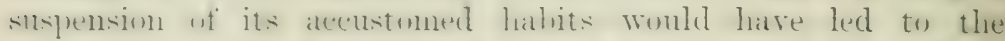

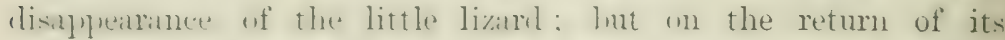
old friends, it made its entrance as usual at their first dinner the instant the eloth was removed."

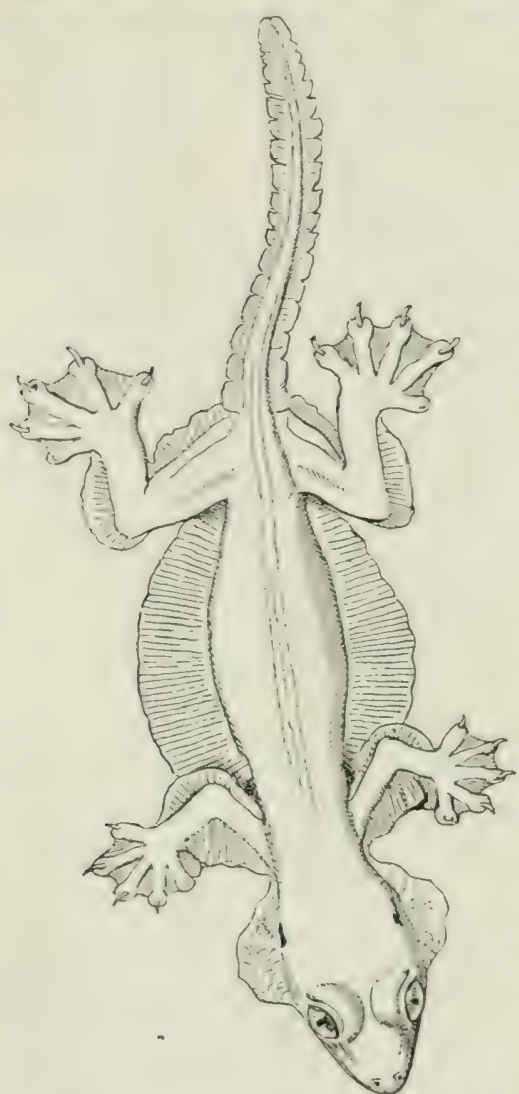

FIG. 121. - Plychozoon homalocephalum. $\times \frac{2}{3}$.

Ptych,ozoon. - The digits have the same structure as described in the genus Gecko, but they are entirely webbed. The extraordinary feature of Ptychozoon is the membranous expansions on the sides of the head, body, limbs, and tail, which are said to act as parachutes. P. homalocephalum, the ouly species, inhabits the Malay Islands and the Malay Peninsula. It reaches it length of 8 inches. A specimen obtained by F. H. Bauer in Java, in the month of November, laid two eggs a few days after its capture. One young was hatched in the middle of the following Nay, and two days later auother came out of the second egg. The characteristic folds of the skin were already elearly discernible.

Sub-Fam. 2. Eublepharinae. - Differing from the true Geckos by their frocolous rertebrae and the fusion of the two parietal homs into one. The erelists are not relucel, hut remain functional. This sul-fanily is undonlitedly a heterogenenus assembly, as indicated by the very scattered distribution of its few species (about seven, in India. West Africa, and C'ntral America.

Sub-Fam. 3. Uroplatinae, complused of a few speces of the genuss Tropletes in Mildigascar. The distinctive characters of 
these otherwise typical Geckos are the fusion of the uasal lones into one, the small size of the interclavicle, and the non-dilaterl shape of the clavicles.

Neither the Eublepharinae nor the Troplatinae are more nearly related to other Autosauri than are the other Geckos. They are modifications within the sub-order of the Geckones.

Sub-Order 2. Lacertae--Autosauri with prococluns, sotid vertebrae, and with the rentral portions of the elarides not dilated.

Cope, ${ }^{1}$ discarding outer appearances as deceptive in the classification of the Lacertae, laid stress upon internal characters, notably the presence or absence of osteoderms, the formation of the skull, and the structure of the tongue. Bonlenger" has followed and improved upon Cope's arrangement, and has elaborated the classification, which, heing used hy himself in the three rolumes of the Catalogue of Lizards in the British MIuseum, has also been followed in the present work, with slight alterations in the order of treatment of the families. For our present purpose we diagnose the families as follows, giving preference to such characters as are most easily ascertained:-

\section{Synopsis of the Families of Lacertae.}

Fam. 1. Agamidae.

Fam. 2. Iguanidae.

Fam. 3. Xenosauridae.

Fam. 4. Zonuridae.

Fam. 5. Anguidae.

Fan. 6. Helodermatidae.
Acrodont. Tongue broad and thick. No osteoderms. Old World, p. 515.

Pleurodont. Tongue short and thick. No osteoderms. America, Madagascar, Fiji Islands, p. 528.

Pleurodont, solid teeth. Anterior part of tongue retractile. Osteoderms on the body. Mexico, p. 536.

Pleurodont. Tongue short, not retractile. With osteoderms at least upon the skull, where they roof in the supratemporal fossae. African sub-region, p. 536.

Pleurodont, solid teeth. Anterior part of tongue emarginate, retractile into the posterior portion. Osteoderms on body and head, roofing over the supratemporal fossae. Limbs mostly reduced. America, Europe, India, p. 537.

Pleurodont, lower teeth grooved, with poisonglands. Tongue bifid. Osteoderms tiny. Postfronto-squamosal arch absent, p. 540.

${ }^{1}$ P. Ac. Plitad. 1864, p. 224, and P. Amer. Ass. xix. 1871, p. 236.

${ }^{2}$ Ann. Nat. Hist. (5) xiv. 1884, p. 117. 
Fam. - Lanthanotidae.

Fam. 8. Varanidae.

Fam. 9. Xantusiidae.

Fam. 10. Tejidae.

Fam. 11. Lacertidae.

- Fam. 13. Scincidae.
Pleurodont. Tongue short and bifid. Pustfronto-squamosal arch absent. No osteoderm. Borneo, p. 541.

Pleurodont. Tongue very long, bifid, smouth, very protractile. No osteoderms. Postorbital and temporal arches incomplete. Old Worlt, p. $5+2$.

Pleurodont. Tongue very short and scaly. No osteoderms. Supratemporal fossa roofed over by the cranial bones. No morable eyelirls. Central America and Cuba, p. 547.

Teeth solid, almost acrodont. Tongue long, deeply bifid, with papillae. No osteoderms. Limbs sometimes reduced. America, p. 547.

Pleurodont. Tongue long, bifid, with papilla. or folds. With osteoderms on the hear. Supratemporal fossae roofed over by the cranial bones. Old World, p. 549.

Fam. 12. Gerrhosauridae. Pleurodont. Tongue long, with papillae, bu feebly nicked. With osteoderms on the head and body, roofing over the supratemporal fossae. African sub-region, p. 559.

Pleurodont. Tongue scaly, feebly nicked. Osteoderms on the head and body. Limbs often reduced. Cosmopolitan, p. 559.

The folluwine five "fimblies" are much olergated in cunformity with their usually subterranean life, see p. 496 :-

Fam. 14. Anelytropidae. Without limbs. Body covered with stalu. Mexico and Africa, p. 564.

Fam. 15. Dibamidae.

Fastr. 16: Anicllirlite:

Vermiform, limbless body covered with scale., without osteorlerms. Australasia and Nicular. Islands, p. 564 .

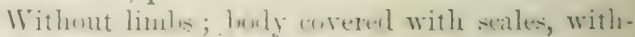
out osteoderms. California, p. 564.

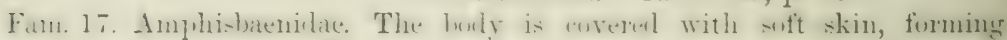
numerous rings with mere vestiges of scile. Without limbs, except Chirotes with fumclawed fore-limbs, p. 565.

Fam. 18. Pygopodidae. Snake-shaped, with scales. Fore-limbs absent, hind-limbs appearing as a pair of scaly thars. Australia, p. 567.

These equteen "fomilies" uf the Lacertate fall into four main eroujs. Tre maturally assume that the presence of ostenderms atmel

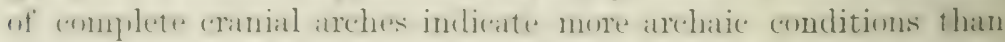

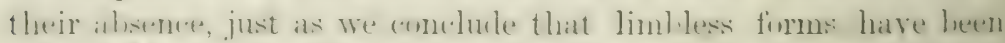
evolvenl from ereatures with fully dereleped limbs. We arranger the four groups with their families as follows :- 
Group I. Zonuridae and Anguidae assume a central position, with Igruanidate and Agamidae as two parallel families of highest development. Aniellidae as the most degraded forms. Helodermatidae and Lanthanotidae as rather primitive and solitary survivals.

Agamidae Iguanidae

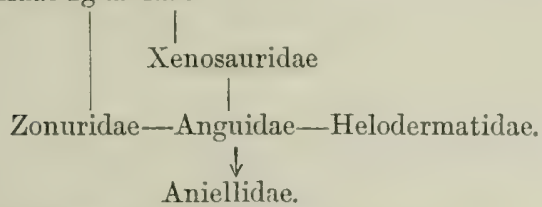

Group II. Xantusiidae-Tejidae-Amphisbaenidae.

Group III. Scincidae-Germosamidae-Lacertidae-Here also Anelytropidae and perhaps also Dibamidae as degraded Scincoids.

Group IT. Taranidae, which are in many respects the most highly developed of all.

Pygopodidae are of obscure relationship.

Fam. 1. Agamidae.-Acrodont, Old-TWorlel Lizards, with a hroad and short tongue. The teeth are usually differentiated

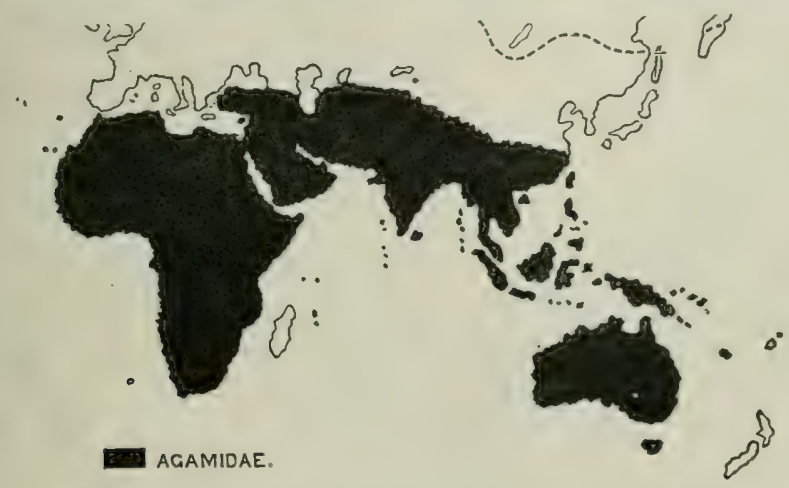

FIG. 122.-Mrap showing the distribution of the Agamidae.

into incisors, canines, and molars. The orbit is closed posteriorly; the temporal fossa is bridged over by an arch which is formed chiefly by the squamosal and the well-developed jugal; the postorbital mostly remaining small, and the postfrontal and supratemporal bones being either absent or not present as separate elements. The limbs are well developed. The eye, provided with complete eyelids, is distinctly small and has a round pupil. The skin is devoid of osteoderms, although large and numerous spines are often present, especially on the head and on the tail. The Agamidae, of which alout two hundred species, arranged 
in about thirty genera, are known, exhibit a great diversity of mostly that-lmolied, terrestrial and more laterally compressed, arloreal forms. The majority are insectivorous, a few Agamas latre a mixed diet. while fromustice and sme others are chiefly. if not entimely, frugivorous and herbivorous. They are an exclusively Old-Worle family, avoiding the comber parts of the

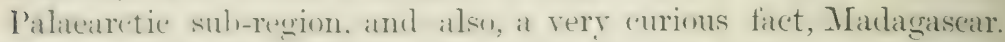
The majority live in Australia and in the Indian and Malay countries, complatatively fiow in Africa, dhiefly the genus Agume.

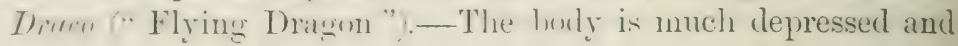

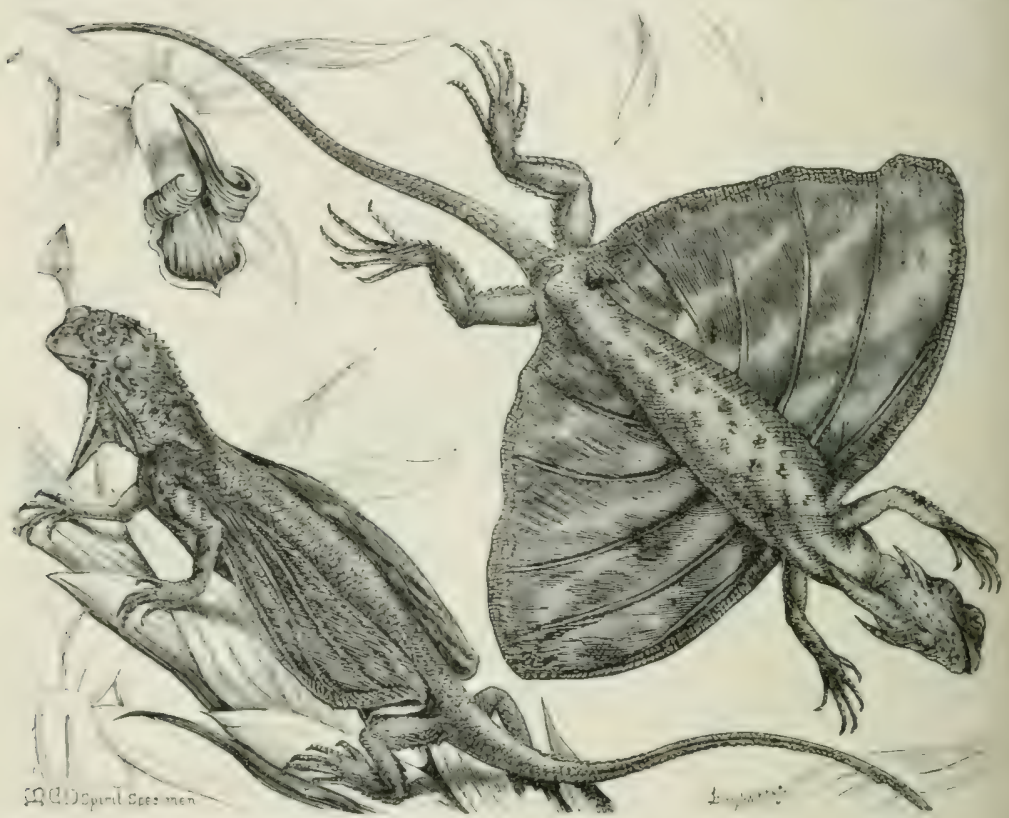

Fis, 123.-Draco rolans, $\times \frac{?}{3}$.

the sides extend as a jair of large wing-like memloranes, which are sulpunted hy tive or six of the much-elongated posterior ribs, and man le folded up like at fan. On the throat are three pointed aplemelages, at short we on eithere side and a long one in the mindlle. The tail is rery long and slender, luat not brittle. Alout 1 wonty spereses of this extratorlinary genus inhabit the varions Into-Malayan (nuntries; one, D). Alussumiri, oceurs in Madras. I). roldus of the Malaty P'ninsula, Sumatrat, Java, and Borneo is about 10 inches long, is of which are taken up hy the tail. The 
male has a small nuchal crest. The upuer parts of this pretty creature have a metallic sheen, with small dark spots and undulating cross-bands upon the rich brown ground-colour. The wings are orange with black markings. The gular sac of the male is orange, that of the female is blue.

The "Flying Dragons" use their wings as parachutes, lut their sailing powers are said to be very moderate. Certainly they do not fly by moving the wings, lut when at rest upon a hranch, anidst. the luxurious regetation and in the immediate neighhourhood of gorgeously coloured flowers, which partly conceal them by their likeness, they greatly resemble butterflies, especially since they have the habit of opening and folding their pretty wings.

C'cratophoru.-This exclusively Ceylonese genus is remarkalle for a flexihle, erect, and pointed appendage which arises from the top of the snout; it is best dereloped in the males, restigial or absent in the females. Gular appendages are ahisent. The trunk is crestless, slightly compressed, and covered with partly keeled scales. The tail is slender and very long, abont two-thirds of the total length of the animal. The general colour is olive-hrown, with irregular darker markings and with light streaks on the head and thighs. $C$. studdarti and $C$. tennenti are ahout 10 inches long, the former without, the latter with, little scales upon the rostral appendage.

Lyirocephalus, with $L$. scututus (Fig 124) of Ceylon as the only species, is remarkahle for its Chameleon-like appearance. A splendid case of convergent evolution, but most improbahly of mimicry. The tympanum is quite hidden. The head is raised into a pair of sharp bony edges. On the top of the nose is a thick globular lump, recalling the genus Cerutophore; and also various Malagasy Chameleons. The back and sides are covered with very small granular scales, intermixed with sereral rows of enlarged scales as in Chameleo pumilus, and there is a serrated crest along the back from neck to tail. The under parts are covered with large keeled scales with sharp points directed backwards, especially on the tail. The whole body is laterally compressed. The pollex and the fifth toe are strongly opposed to the other digits. The general colour is greenish above, whitish below. Total length about one foot.

Calotes, with many species in India and in the Malay Islands, is distinguished by a crest on the neck and back. Many of the males have il gular sac. The tail is extremely long. These lizards are remarkable for their changes of colour. 
1: rersimble ranges from Af hamistan through the whole of Intial to southern ('hina, amel attains a length of 14 inches, 11 of which are taken uy ly the tail. It possesses no grular sac, hut has a well-develneted crest. The whole body and tail are covered

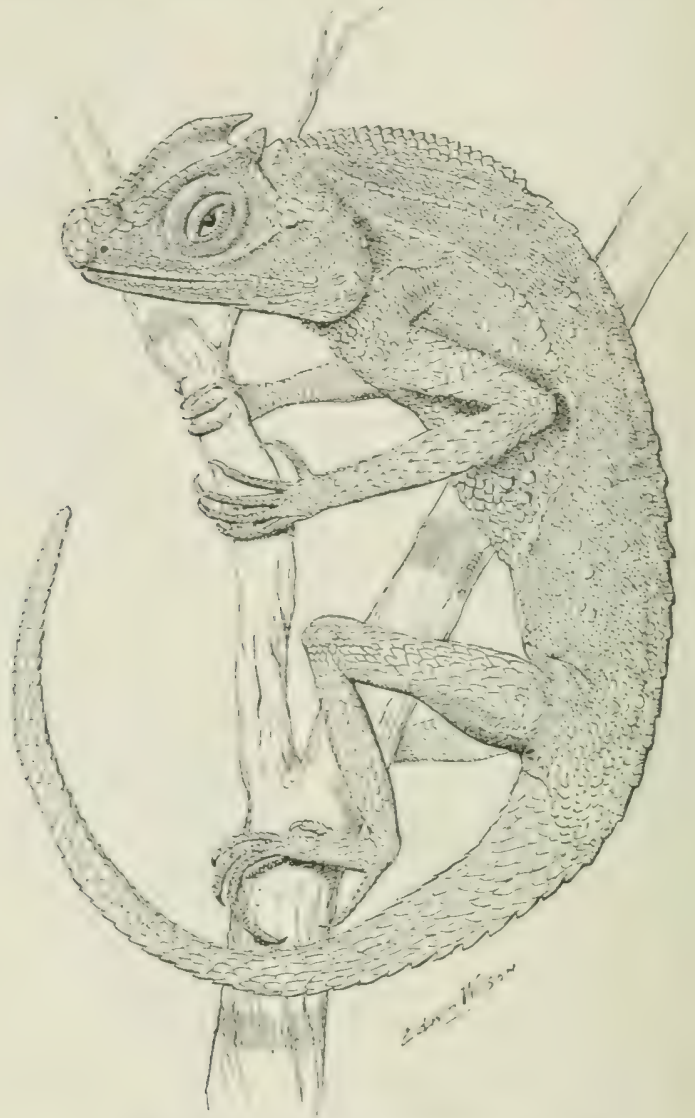

Fig. 124.-Lyriocephalus scutatus. $\times \frac{2}{3}$.

with strongly liecled scales. When the lizard is irritated, or swallowing its ford, the heasl and neck herome brilliant real, whilst the usually hownish tint of the boty is converted into pale yellow. Mr. Annandale hats fitwoured me with the following olservations

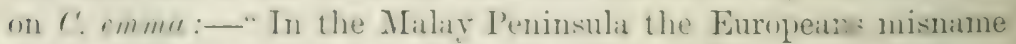
this lizard ('hamelegy. The colour-ehames appear to be hrought about hy emotions, althuush the lizard is often darker towards 
erening than it is at mid-day. The males are very pugnacions, and change colour as they fight. At the time of comrtship a curious performance is gone through hy the male, the female remaining concealed in the foliage hard hr. He chooses some convenient station, such as a banana leaf or the top of a fence, and adrances slowly towards the female. His colour is then pale rellowish flesh-colour, with a conspricuous dark spot on each of the gular pouches, which are extended to their utmost. He stands. upright, raising the fore part of the body as high as possible, and nodding his head solemnly up and down. As he does so, the mouth is rapidly and repeatedly opened and shut, hut no sound is emitted. When he is driven away, caught or killed, the diurk spot disappears entirely from the neck. If one male is captured, another takes his place within a few hours."

C. ophiomachus of Southern India and Ceylon reaches 2 feet in length, has a fold of skin in front of each shonlder, and is generally known as the "blood-sucker" on acconnt of the red colour displayed during excitenent on the head and neck.

C. mystaceus, chiefly in Burma and Siam, but also in the Ticobar Islands and in Cerlon, has a small gular sac and an ollique folk in front of each shoulder. The sprecific name semes to refer to the yellomish lips. Mason ${ }^{1}$ gives the following vivid account of it:-

"This is a very common species in gardens in Toung-ngoo. A pair made their home in the mango trees near my study window: The female blundered into the house a few days ago, but I found her a rery mattractive animal of a unifom earthbrown colour. The male, howerer, is sometimes a beanty. He may be ofteu seen jerking his head up and down, with the head, pouch, and whole frout of the body a glowing ultramarine blue, contrasting beautifully with the reddish brown of the hinder part of the body and tail. From the nose to the shoulders, helow the eye, is a broad white band, which is interrupted by three reddishbrown patches, in line with the white band, before reaching the uniform reddish brown of the hinder part of the body. Occasionally the white band below the eye assumes a brownish colour, and the animal appears to have a brown band down each side. He does not always, however, appear in this gay dress. While I am writing, I see him coming down the trunk of one of the trees

1 Burma, its People and Productions, London, 1882. 
in a very fated gurment. His shin suggests a bright calien after it has heen washed. whose colours succumb to soap. The bue is there. but it is no lemerer the bright blue of resterday. It has changed to a dull light indign colour. He runs across the srass to the foot of another tree, and stops on the bare grommit at its hase. where for a minute or nore he bites with great enery at a strugeling grasshoprer, and while thus exercising himself the hlue fatles ont from his ludy altogether, and his whole buly takes the colour of the brown earth on which he stankls. Ifter tarrying a minute ar two he ran up the other tree, and the dull light blue colour seemed to return to him."

- Lommer with many species in Afriea and Asia : some in SouthEastern Eumpe. The houly is somemhat depressed. There is a tihli acms the throat ant a pit wn either side: the presence of a gular sac is variable. A dorsal crest is absent or but feebly developed. The males have pre-anal pores.

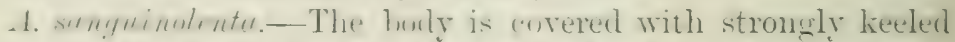
and printed scales. (On the sides of the head are a few spine-like sales. The eatr-opening is partly conceated hy a fringe of spinous scales. The males have a gular pouch. This is a typical inhlialitant of the deserts amb steples of Turkestan. Zander ${ }^{1}$ has ohserved the halits and many changes of colour of this lizard. The usut garh is earthy lom ahore, with somewhat darker and rathes indistinct markings. The uncler parts are whitish. Sonetimes the creature changes to dirty white, at other times into blickish on grey hown. Bluish-red stripes may appear on the sides of the buly: hlue lines benin to show on the throat, and nltinately the whole helly, mininally white, maly become ultrinomine blue. When the general tone hapens to be sulphurous yellow. hise often nilpears on the tail and limbs. Brick red illyears on four longitulinal ruws of patches on the sides of the lwoly. Sommetines the whole animal assumes a vinous tinge, or it is at first greenish hefore turning into hlue. The change berins on the tail and limbs, extends over the head, and at lemgth reaches the back. Tiesl appears in both sexes, more frequenty in the fenale; blue almost entirely in the male. Sunlight and warnth only intensify the colours. dilaptiwe coloration, besides the usual sandy garh, has not been observed. The lizards live on soil which is hateed as hard as breks, or in

1 Zool. Garlen. 1895, 1. 232. 
cavities of old walls, provided there is regetation. They reyuire vegetable food, besides insects, grazing on grass, and having a fondness also for IVesembryonthemum enrtiform. Tery large males reach a total length of one foot. They are pugnacious, especially during the time of breeding. The male inflates its gular sac into the size of a walnut, stands up upon its four limbs, with its head slightly lowered and turned to one side. Then it darts upon the foe which it has been eyeing for some time.

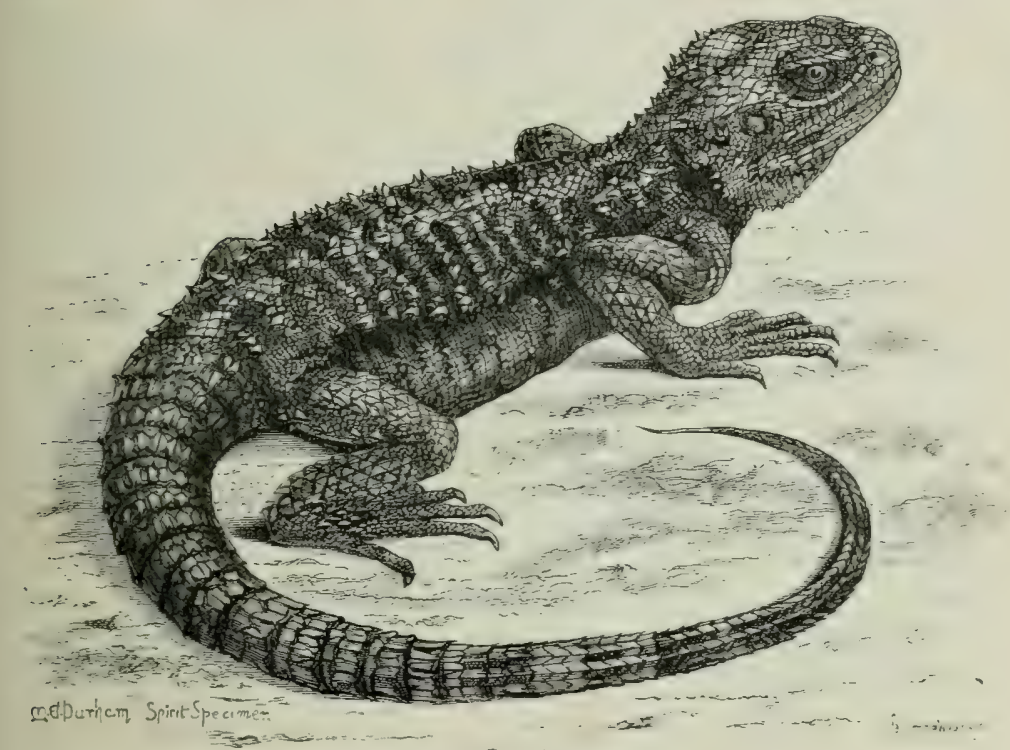

FIG. 125. - A gana stellio. $\times \frac{1}{2}$.

A. stellio is the commonest Agama in Egypt, Asia Minor, and in some of the Grecian Islands, where the Greeks still call it korkordilos, just as they did in the time of old Herodotus. The Arabic name is hardun. This lizard is easily recognised ly the irregular folds on the neck, which are beset with spinous horny scales. It grows to a length of 15 inches. The general colour is brown, with dark patches on the back. Then basking they become almost black; in the breecling season the male assumes red tints on the head and neck.

Phrynocephalus.-This is a typical Aganoid of the steppes and deserts of Asia. The head is short and thick, the ear is 
hidden. The boly is depressed. devoid of a dorsal crest: on the throat is a transverse fold but no sac.

1. Zanter ${ }^{1}$ has male interesting observations upon the habits of several species.

Ph. hetioscopus lives on hard stretches of soil, which are alsonlutely bare of veretation, the soil heing haked as hard as a pared rual. The lizimls live on any insects they can get hold of. chielly. howerer. unom minime ants. When chased they run with short jorks. (atrying the tail high or rolled up).

I\%. interserfulloris accurs, in Transcaspia, on the shiftings. lowse sambl. It runs so fitst that one scarcely sees anything lut its shadow. The tail is rolled upwards. With short jerks it suldenly ohanges its direction. strogs hehind a few blatles of

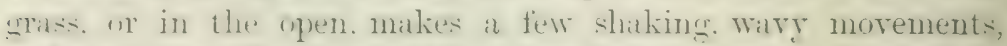
aml corers inclt lightly with saml. Shortly after that the top of the haul allyeats the mains of sind rolling off between the strong sumaliary ridges, and the little creature, only alout :) inches long, peeps out of its temporary hiding-place.

I\%. Inystwers, whicht inhabits Transcasplia and parts of sonthern Fonsia, often finces its argressor, raising itself mon its

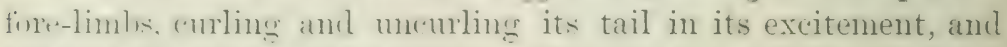
holline its momth wirlely olen. The creature. which attains a length of a inches, inchusive of the long tail, then assumes at matidly changerl aspect. The thas of skin at the corners of the mouth swell up into a half-noon-shaped transverse plate, the hinder surface of which is corered hy the outer skin, while the front is a continuation of the rosy lining of the mouth, which therehy aplears hugely enlarged. When biting it hangs firmly on to the finger. This frightening attitude is interesting, since it occurs in a much more developed condition in the following genus.

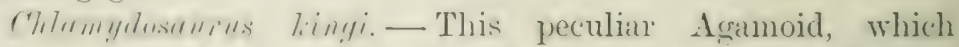
inhabits (Puenensland and Northern and North-Western Australia, is easily reconised hy the latre frill-shayed dermal expansion on either side of the neck. The two halves are confluent on the throat. The whole frill can he erected, and is worked by the much-elonsated arehes or horns of the hyoid apparatus, which extend into the flins of slin, somewhat like the rils of an umbrella. The suecially modified hyoidean muscles spread ont 
and fold the frill. When this curious creature is pursued it folds the frill and rums in a semi-erect position upon its hinclimbs, with its fore-limbs hanging down. Howerer, it cannot lie'e' up this peculiar gait for long, and it then suddenly turns to hary, frequently at the root of a tree, which it can climh with ease. When standing at bay it spreads out the shield to its full extent, in the middle of which appears the widely opened mouth, which is red inside and armed with powerful teeth. Altowether this

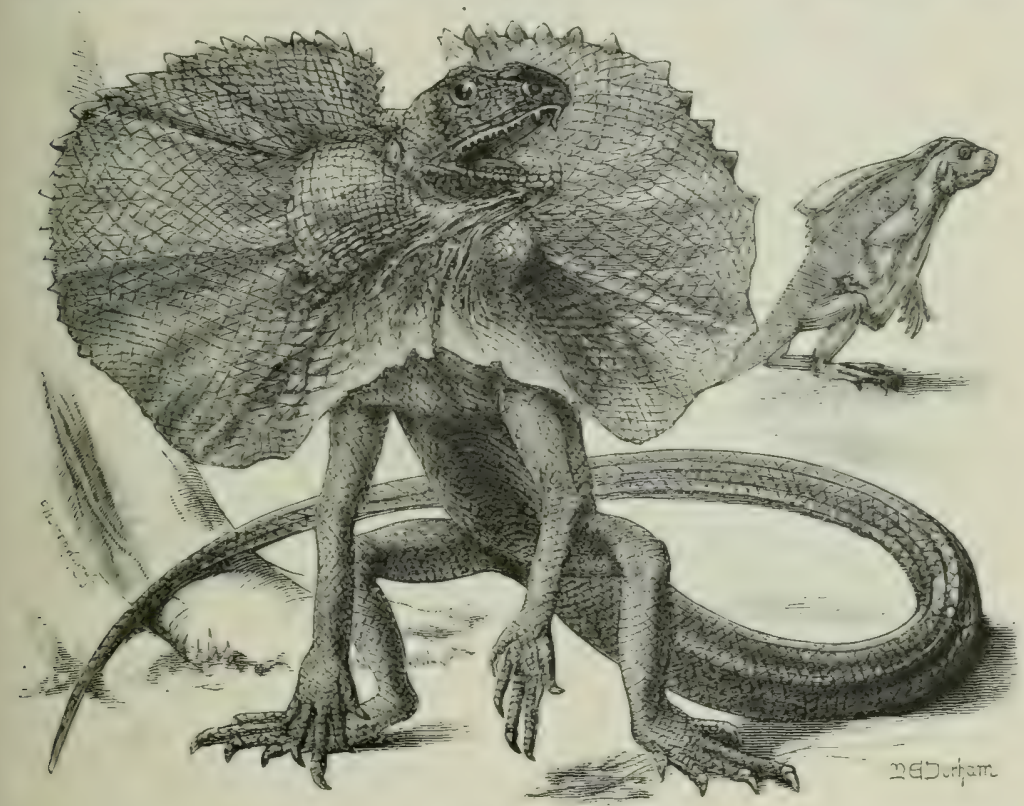

FrG. 126.-Chlamydosaurus kingi. $\times \frac{1}{1}$.

lizard presents a formidable aspect, and is an enemy not to be respised, considering that it is strougly built and grows to nearly $\therefore$ feet in length. For a further account of the habits and of the mechanism of the frill see De Vis. ${ }^{1}$

Physignuthus.- This is a water-loring genus, inhahiting wellwatered districts with luxurious regetation in Australia, I'itpuasia, Siam, and Cochin China. The body and the very long tail are laterally compressed and furnished with a low, serrated crest. I'h. Tesueuri of Queensland reaches a length of about $1 \mathrm{~s}$ inches. The general colour is dark olive ahove, with darker and lighter

${ }^{1}$ P. Linn. Soc. N.S.W. viii. 1883, 1) 300. 


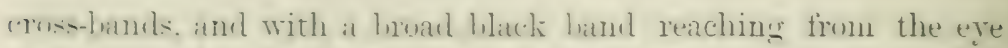

- to the shoulin.r. The unler parts are prele olive, with small black

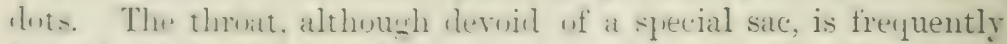

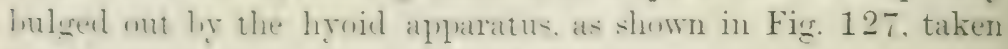
from a specimen in the Zoological Gardens in London.

Trmmastir is a trpical desert-form, inhabiting the dry and sindy trate of Jurth Afrima, Aralia, Syria, Persia, and SorthWestern Imlia. The senus is easily recosnised by the short and thick tail. which is covereel with whorls of large spinous scales,

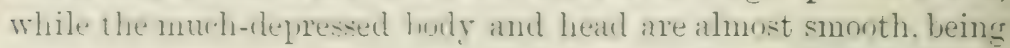

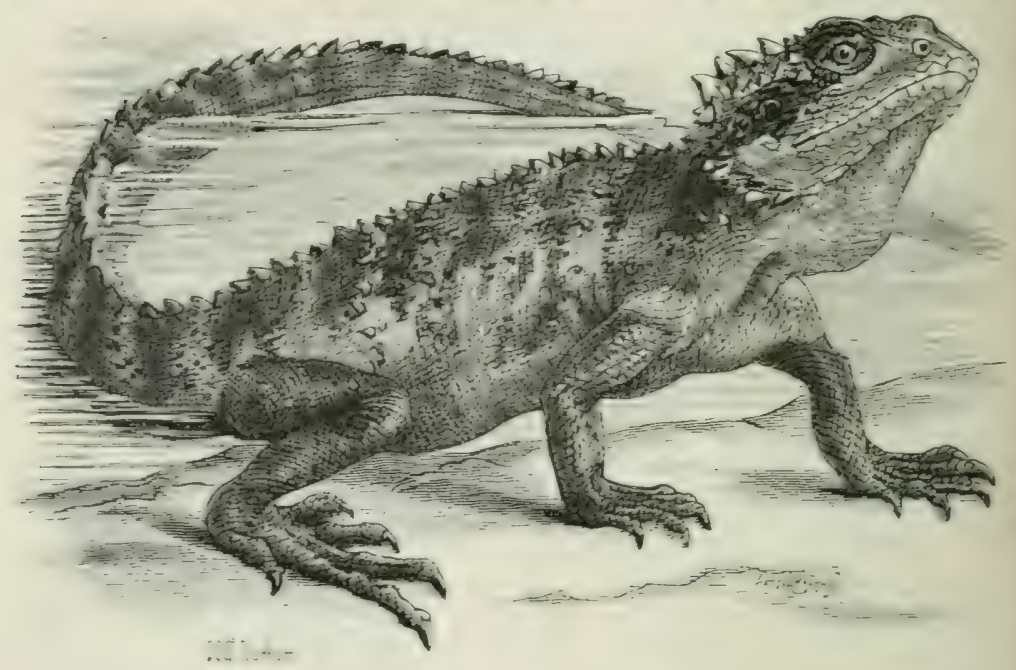

FIG. 127.-Ihysignathus lesueuri. $\quad \times \frac{1}{1}$.

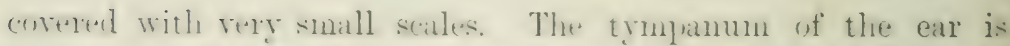
quite expmed. The incisurs are latree uniting in the alult inte whe or two prits of latere cutting teethe sepratrated fron the molars

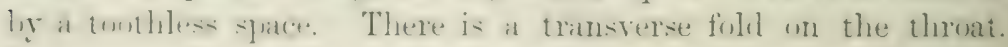
Pre-anal and femoral pores are well dereloped.

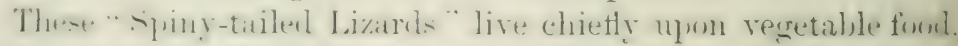
loaves gatse and fruit. hut they bary this diet with insects, at Jeast in atplivity, where they hexpmes rather partial to mealworns. Ther are aholutely terestrial and diumal, preferring samly flares. where they hask or rather roust themselves in the sun: for tine night, at the approach of rain, or on dull and rhilly days ther retire intw their hurrows. which they dig in 
the sand or in the hard ground, mless they hide in the crackis of rocks. They have a regular mania for digging with their strong limbs and short, curved claws. Although they love a great amount of heat, and become stiff when cooled down to about $16^{\circ} \mathrm{C}=60 \mathrm{~F}$, they can stand several degrees of dry frost without injury. During the cold season they hibernate. The spiny tail is used for defence. The lizard lies as a rule in such a position in its hole that the tail blocks the narrow passage; when touched with the hand it deals out jerky side-hlows with the tail. The bite is deliberate and very painful.

$U$. herduchi is a native of North-Western India and Beluchistan, occurring especially in Sindh and Rajputana, for instance near Delhi and Agra. This species is of a delicate sandy colour, with dark dots or vermiculations, interspersed, occasionally, with pale blue specks. The under parts are whitish on the tail with a greenish hue. A distinctive and obvious mark is a large hackish patch on the anterior side of the thigh. Total length up to one foot.

I have several times received consignments of the Indian Spiny-tailed Lizard through the kinduess of friends, hut I must confess that they are far less easily kept lham one is led to believe from certain exaggerated accounts. They are lovely, most interesting, and surprisingly tame creatures. 'I received one lot in the month of Jume. They made hurrows in the dry soil, basked in the sun and on the grassy sods of their roony cage, and showed great curiosity. When approached, they at first scrambled off or sank down flat, shut their eyes and feigned death. They then opened their tiny yellow eyes a little, while others peeped out of their retreats to see if all was safe, or attracted by some noise. Soon they became so tame that they crawled over my hand. But the difficulty consisted in feeding them. They greedily lapped up drops of water. Their lung consisted of the indigestible parts of some species of Equisetum or Mare's titil, mixed with fragments of beetles and ants. Lettuce, cablage, cauliflower, grass, the flowers of red and white clover, Mare's tail, wheat, rice, and Indian corn were offered, but they only took a few blades of grass and the hard Indian corn, besides mealworms. This is all the more astonishing since other specimens are knowu to partake freely of herbaceous food. None of them survived the late autumn, and most of them succumbed to a disease 
known as intussusception of the sut. They certainly could not complain of the want of heat since the brittom of their cage wats kept fermanenty warm hy a lamp, and in the autumn they invariably slept in the warmest part of the soil, aroiding the cool regions which would hatre given them a chance of hibernating.

Another ansignment arriven in the month of February. Tone of them ate anything on surviverl the early summer.

$U$. neanthinums and $U$. spinipes are common in Algeria,

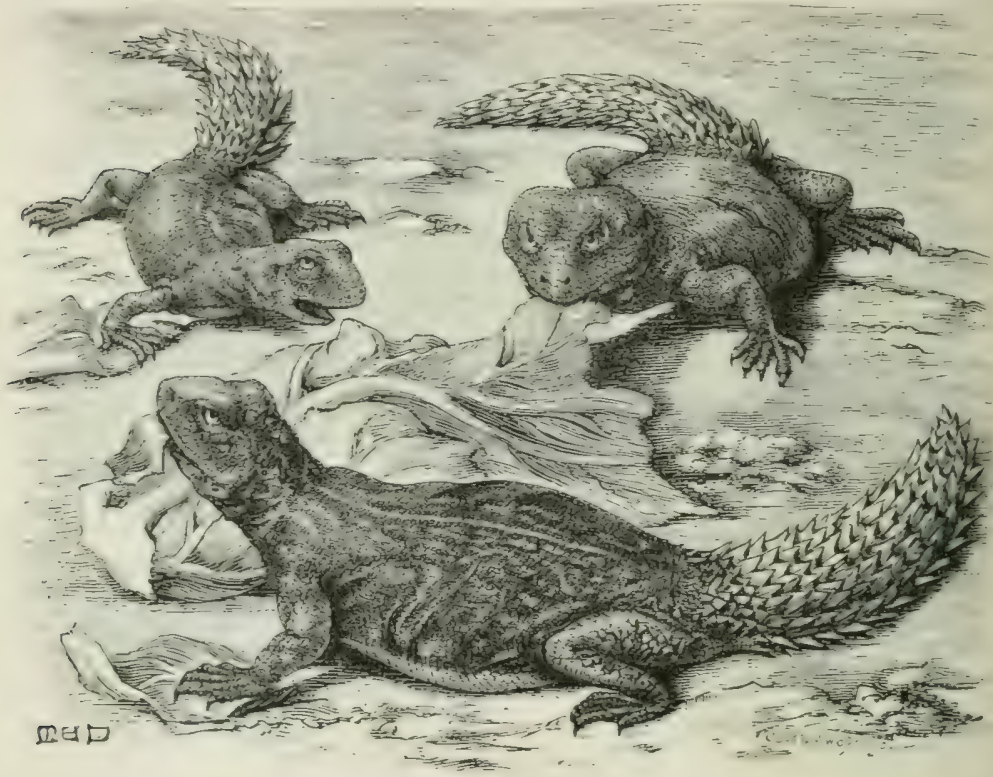

Fig. 128.-Uromastix acanthinurus. $\times \frac{1}{1}$.

Tunis, and Erynt, where they prefer sandy and ro.ty localities. Their Aratic name is Ihal. In Algeria they are sometimes abllen " livands des palmiers," perhalys hecause they eat dates,

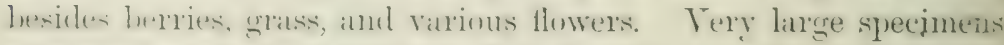
attain a lemeth of 18 inches. Like the other species of tromasti. they have no voice. The African species can change colour to a sreat extent. At a low temperature they are mostly intey ar Irownish blatk aluse, dirty white below. When it is warmer they dhane of linhter shates of hrown or even to orange vellow

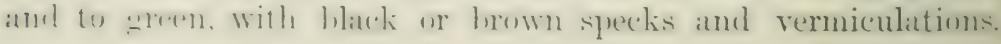


A young specimen of $U$. acunthinurus has beeu observed t" grow within twelve months from 90 to $150 \mathrm{~mm}$. in length.

Moloch.-The mouth of this peculiar-looking creature is very small ; the lateral teeth of the upper-jaw are implanted horizontally and directed inwards. The body is much depressed, and, like the short tail and head, is covered with small seales or tubercles intermixed with large spines. 1 . horidus, the only species, inhabits the sandy districts of Western and Southern Australia. Nothing is known about its habits except that it seems to live upon ants. Its extremely rough skin is, according to an aceidental observation by Dr. Willey, highly hygroscopic. H: happened to put a live specimen into a shallow dish with water.

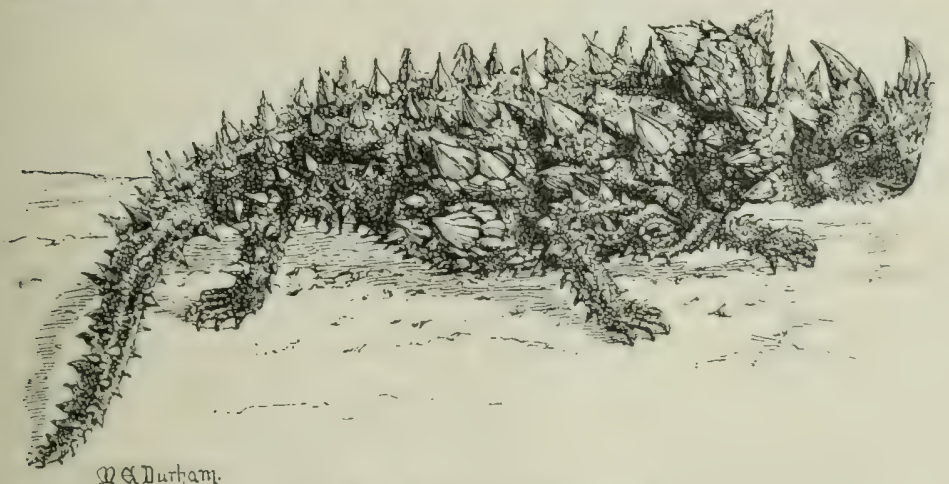

FIG. 129. - Moloch horridus. $\times \frac{2}{5}$.

when, to his surprise, the water was sucked up as by hlottingpaper.

Liolepis. - The body is depressed, without a crest, and is covered with minute granular scales. The tail is long, and has small keeled scales. There is a strong transverse gular fold, and a fold along the side of the body. The tympanum is distinct. Femoral, but no pre-anal, pores are present.

L. belli, the only species, about 18 inches long when full grown, is a native of South-Eastern Asia. The general colour is brownish, with pale black-edged spots along the back: the silles are marked with black and orange vertical bars; the under parts are orange, variegated with blue. Annandale remarks that this is perhaps the commonest lizard on the balren stretches of sind in Lower Siam, especially near the coast. It is exceedingly active and timid. Though its colour is hrilliant, the green and 
grey eye-like spots which ornament its lack, and the orange and purple stripes on its sides, are not conspicuons amidst the natural surroundings, the former harmonising with the shadows cast upon the sand by the seanty vergetation which it supports, and the latter being more or less concealed by the folds into which the skin that coreers the ribs naturally falls. When the male is morhly hambled and is mathle to use its powerful jaws, it flattens its buly in such a way that the stripes become most (omspicmons. The female is mathe to do this with such effect, at her rils do not seem to be so mohile and her colours are less hright. Liolepis lives in holes in the sround, which often go down vertically for more than 2 feet before there is a bend in their contre. Each hurrow generally contains a pair of these lizaris, which, accorting to the natives, are strictly monogamous.

Fam. 2. Iguanidae.-I'leurodont lizards with a short and thick, non-frotratetile tomene: almost entirely Anerican, with the

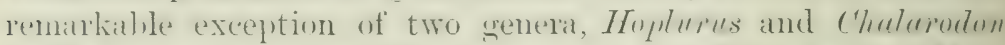

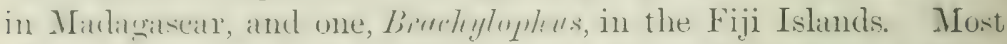
of the Intanidate are insectivorous, hut some of the most striking

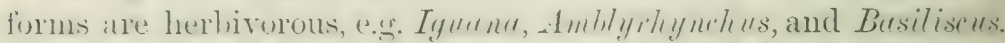
In their general structure the Ignaniclate closely resemble the Aganilate, from which they differ chiefly hy the pleurodont dentitim. The orbit is sumenuded hy hone, and the temporal fossa is hridged wer hy an arch which is formed by the junction of the splamosial chiefly with thr postortital, the jugal taking as a rule less share in the arrh. I termal ossifications are absent on the body.

There are about three humbed different species, which have bers grouped into about tifty genera, representing arboreal, terestrial, hurrowing, semi-iaguatic forms, and even one semimarine species. Their external aplyearance varies consequently within wide limits.

Auntis is clistinguished by the partial dilatation on the middle phalanges, whith carry a series of transverse adhesive lamellate. In its general shitpe 4 unlis resembles slenderly built and longtailed Lacertiblae, which it may he said to represent in tropical and sub-tropical Ameriea, inclusive of the West Indian Islands. The males hatres a large grular appendiege, which ean be distended ly the hyoil twmes. Anotis is an expert dimber, living in trees, or rushing alout on fences or walls of houses in seareh of insects; 
most species can change colour to a great extent. More than it hundred species are known, of which we mention only one, rery common in the Southern United States.

A. curolinensis of the South-Eastern United States and of Cuba is beautiful golden green on the whole upper surface; the gular sac becomes rermilion when inflated; when flaceid, it is white with occasional red lines and spots. The under parts are white. In cold weather and in confinement this little lizard, which is scarcely 6 inches in length, appears dark brown, sometimes with a white line along the back. The changes of colour are very sudden. They are thoroughly arboreal, leaping from leaf to leaf like Tree-frogs.
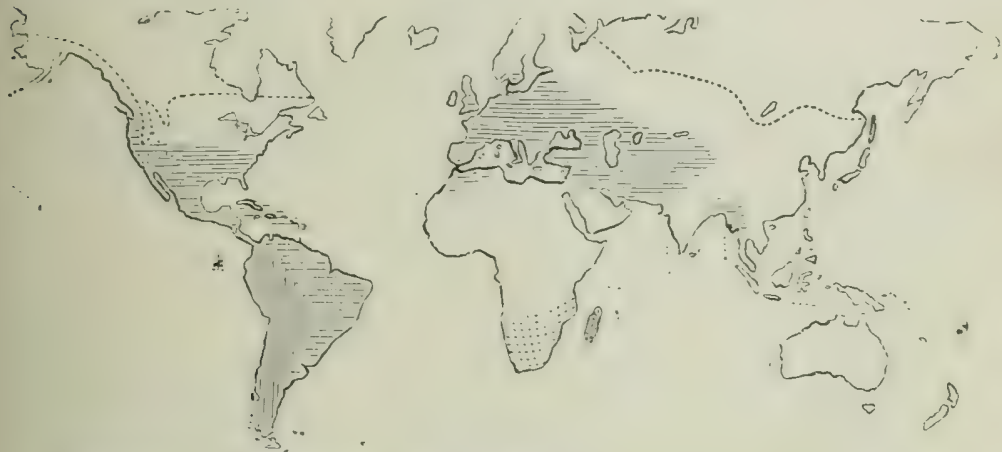

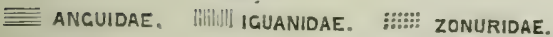

FIG. 130.-Map showing the distribution of Anguidae, Iguanidae, and Zonuridae.

In Anolis, Polychrus, Hoplurus, Chalurodon, Liosaurus, and at few others, the posterior ribs are much elongated and imbedded in the abdominal muscles, often reaching the medioventral line, a feature elsewhere known in the Geckos only.

Polychrus.-The body is laterally compressed, covered with small scales, but devoid of crests. The digits are likewise compressed, with keeled lamellae on the under surface and with four large scales at the base of each claw. Both sexes have femoral pores. The male possesses a small gular sac. I few species in Tropical America.

P. marmoratus in South America, where it is often called the Chameleon on account of its power of changing colour. The tail is nearly three times as long as the head and body, and is covered with keeled scales. The general colour of this arboreal creature, 
which reaches a length of 18 inches. is inreen, but the hues are very varialle, and within a short tine the creature can change into dull hrown. with or without hlackish spouts and lands, or with whitish spots and hlatk lines on the head and other parts of the body.

Busitixns is remarkible for the high and erectile crests which are develnged on the latk and tail of the males. The toes are borterat on the onter side with small lobes. The limbs are long, the hind-limhs when stretched furwards reaching the tip

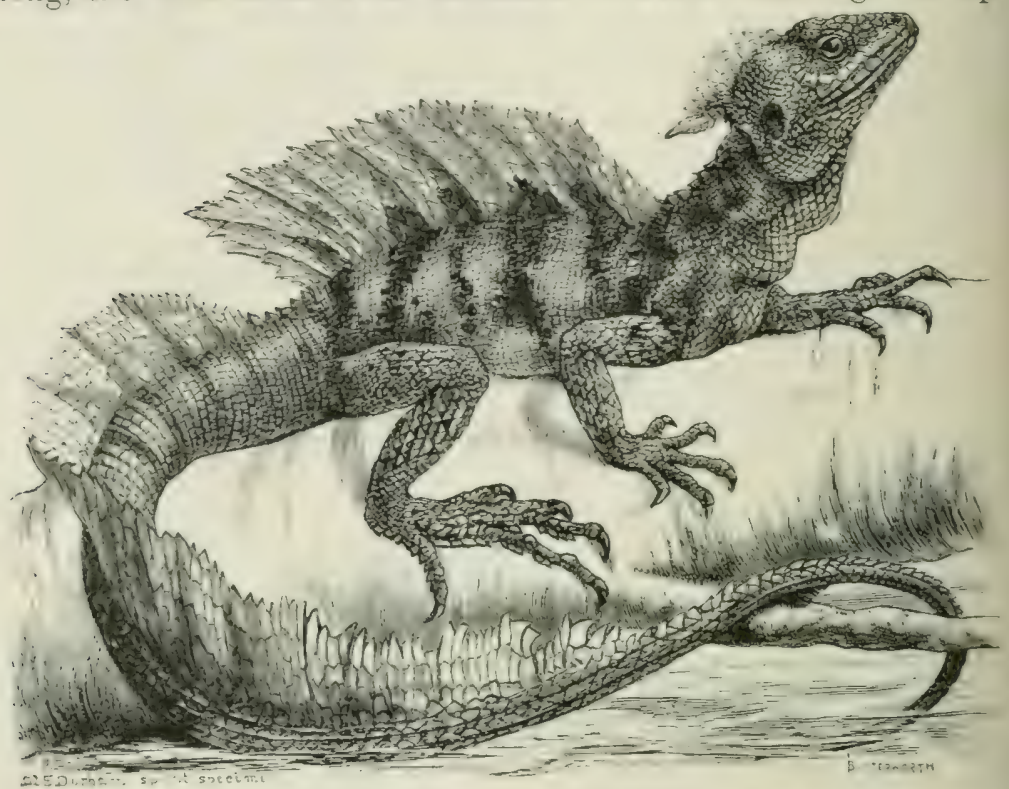

FIG. 131.-Basitiscus americanus (male). $\times \mathbf{4}_{4}^{1}$.

of the snout. Several species in Central America and the adjoining countries to the south.

B. amirionns reaches the considerable length of nearly 3 feet. The male has a crest on the top of the head, and this is produced lakckwarks into a leathery lohe. The hack is adomed with a very high crest; the folds and dark-coloured marks in which give, in the accomplanying illustration, the impression that the arest is suppentert ly spines. The long tail carries a similar crest. The generil colour of the "Tasilise" is green and hrown with dark cross-hars on the hark. The crest of the male is said to lee resl. The se creatures are very common amislst the 
luxuriant regetation on the banks of the rivers of the Tierra Caliente of Mexico and in Guatemala. They lie upon the branches of trees, preferring those which overhang the water, into which they plunge at the slightest alarm. The high. crests, being restricted to the male sex, are not essential to their swimming; they propel themselves by rapid strokes of the fore-limbs, letting the long rudder-like tail drag behind. The eggs, measuring 20 by $13 \mathrm{~mm}$., are laid in April or May, and are hidden in a hole at the base of a tree. About one dozen make a set, and they are said to be hatched within a rery short time. Owing to their being strictly herbivorous, these pretty and striking-looking creatures do not enclure captivity in Europe, unless indeed their particular food can be procured.

Iyuctur.-The body and tail are laterally compressed and are corered with very small scales, while thos on the top of the head are large. The neck and back carry a high crest, which is composed of separate, laterally compressed, soft spines. A similar but lower crest borders the anterior edge of the large gular sac, which is not dilatable. The lateral teeth are remarkable for their finely serrated or denticulated anterior and posterior edges. Both sexes have long rows of femoral pores. Only two species in Tropical America, alsolutely herbivorous. Their delicate flesh is much esteemed as food.

I. tuberulutu (Fig. 132), of South and Central America and the West Indies, reaches a length of 5 to 6 feet. The general colour of the upper parts is a mixture of green and blackish, frequently speckled with white or yellow, and there is usually a pale band in front of each arm. The flanks are marked with dark, lightedged bars. The under parts are pale greenish or whitish. The Iguanas live in the trees, and when there is danger they jump into the water whatever the height of the tree, coming down with violence. In going up some of the narrow, unfrequented creeks in the Mosquito country, according to Napier Bell, ${ }^{1}$ the royager often encounters quite a shower of falling Iguanas, and runs some risk of getting his neck broken. Large specimens, 6 feet long, weigh perhaps 30 lbs. They burrow deep horizontal holes in the sloping side of a bank. About two dozen eggs, nearly 2 inches long, are laid in a hole, where they are hatched in tne month of May. 
Iguinas are often hrought to the markets, either lashed lengthwise to a lianch of the tree on which the specimen happened to les surprised, on tient un with the long tendons of their own toes.

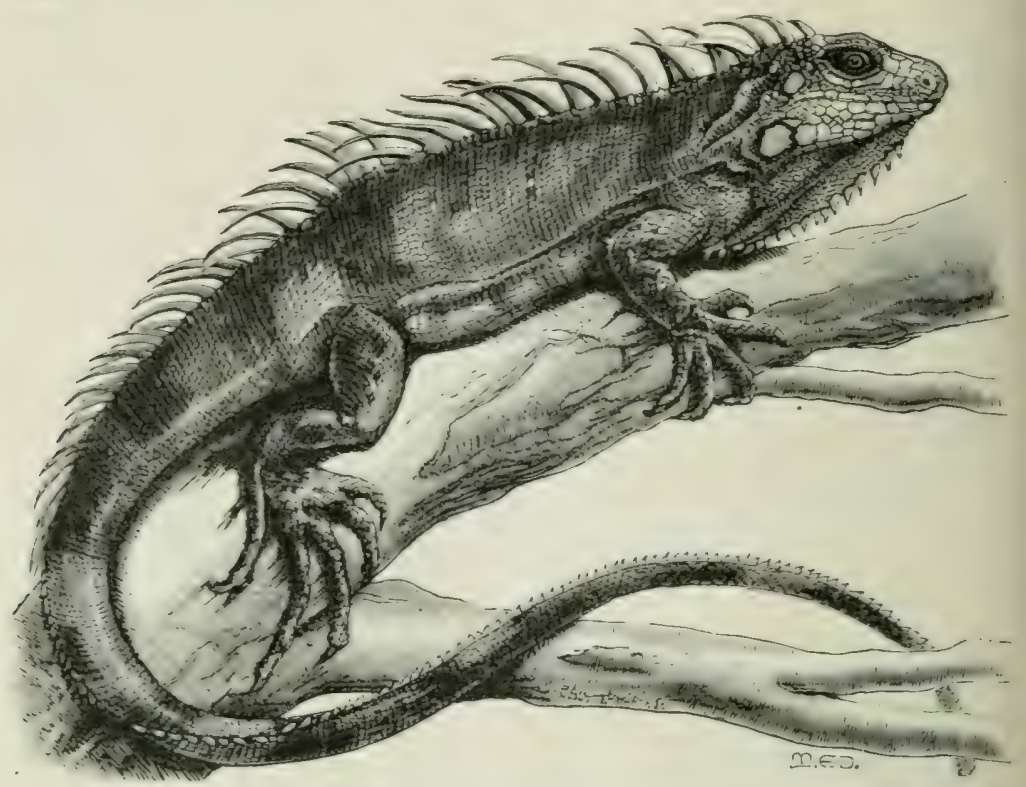

FIG. 132. -Iguana tuberculata. $\times \frac{1}{5}$.

IT topmerous armutas of Hayti is closely allied to Iguana, lut the male lias three conical horn-like scales on its head. The anderal colone of the whole animal, which grows to more than one yard in length, is dull black.

The following two gerera, earh containing one species only. are restricted to the (ralaparos Islands. I)arwin ${ }^{1}$ gives a long and vividly written account of their habits.

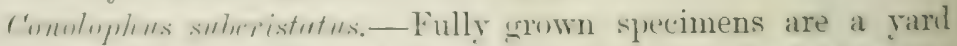
lone. Their shatue is stunt, the head and fore part of the lordy aplearing esperially heary. The heal is covered, or rather paved. with lange coblile-stone-like scales. On the neck is a low crest. of recurved spines, while the median line of the back appears simply serrated. All the teeth are tribulate. A cular sac is absent. The columation is striking. The head is lemon-yellow: 
the back is red, merging into dark brown on the flanks. The helly is dark yellow with a tinge of reddish brown.

This lizard was found by Darwin on some of the Galapagos Islands. On James' Island it was so common that the party found it difficult to pitch their tent, on account of the gromul being undermined los the many burrows of the reptiles. They feed during the daytime upon the succulent cactus and the leares of various trees. The perfectly harmless creatures are, or were, eaten by the inhabitants.

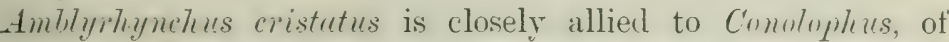
which it may be said to be an aquatic modification. The top of the blunt head is covered with low, conical, broad-loased scales. Orer the neck, hack, and tail extends a continuous crest of low, recurred, spins scales. All the teeth are trilubate. The hody and even more so the tail are laterally compressed. The general colour is dark hrown ahove, paler and inclining to whitish below. Tounger specimens have pale grey spots and hlackish cross-bands on the back and sides. Total length up to 4 feet. The remarkable feature of this Iguanoid is its semi-marine life. It inhabits the rocky and sandy strips of coast of most of the Galapagos Islands, feeding upon certain kinds of algae, which it has to dive for, since these plants grow below tide-marks.

Phrynosoma ("Horned Toads").- The body of these little creatures is much flattened and broadened, devoid of a dorsal crest, but corered with larger and smaller, strongly heeled scales. The head is bordered posteriorly by conspicuous osseous spines. The under parts are covered with small, very regular scales. Both sexes have a long row of pores on the under surface of the thighs. The general colour of the upper parts is a mixture of yellow, grey, brown, and black, the larger spiny scales causing the animal to look as if it were sprinkled with the dried husks of seeds, for instance those of Buckwheat. The object is concealment, by close adaptation to the arid, sandy localities which are the home of "Horned Toads." About one dozen species inhabit the western half of the United States and Central America. All the species are viviparous, almost the only instance among Iguanidae.

Ph. cornutum has five spikes on each side of the head: one postorbital, three temporal, and one occipital, the latter being by far the largest. The sides of the lower jaw project in the shape 
of prominent lengess and are protected liy a series of small spines. The ventral sule's are lievled. The under parts are yellowish, frequently with a few brown spots. This species,

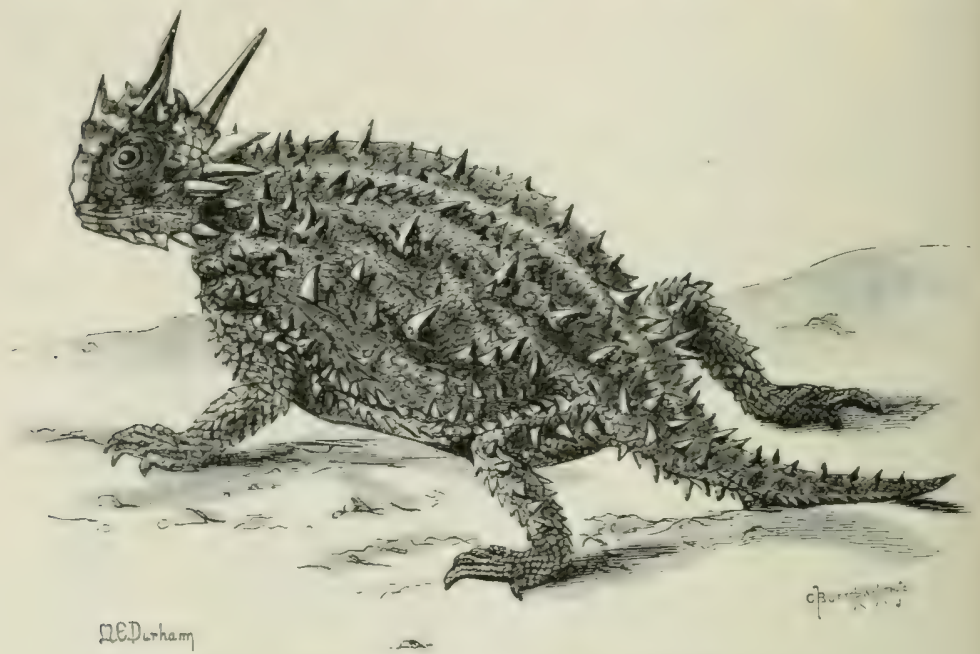

Fig. 133.-Phrynosome cornutum ("Horned Toad"). $\quad \times 1$.

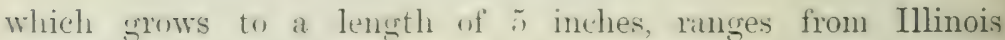
through Kansas and Texas to Northern Mexico.

$P \%$. curonutum, an inhalitant of California, has an additional smaller spine between the two large occipitals. The scales of the belly are quite smooth.

These freculiar-lowing and interesting creatures recall some of the extinct Ininosaurs in the curions configuration of their head: small miniatures indeed. In order to be kept in gool health, and to lwe observed properly, they require, above all, wamth, sunshine to hask in, sind to burrow in, and proper food. The latter consists of all kinds of small insects, the necessary variety of which is best procured ly making sweepings with a butterfly-net in a meatow. They take green-flies, house-tlies, ants, smooth caterpillans, small moths, meal-worms, wood-lice, rete. The foos is snaplexel up very quickly by a flash of the tongue, which can lee turned ont, almost like that of a frog, but only to the extent of half an inch. Water in the shape of dew, or drops is alsolutely neressary. When in gool condition, they defaecate regularly every alternate day. They love to bask in 
the broiling sun, heating themselves well through; and in the afternoon, long hefore sunset, when the sand is warmed up to $40^{\circ} \mathrm{C}$., or ferer-heat, they prepare to go to bed. For this they select a dry and soft spot, and within a few minutes manage to dig themselves in flat, literally sinking into the sand by pushing themselves forwards, and by shorelling the sand upon their backs with peculiar motions of the fringed sides of their that bodies. Sometimes the spines of the head remain sticking out, looking like dry thorns scattered orer the sand. To prevent the

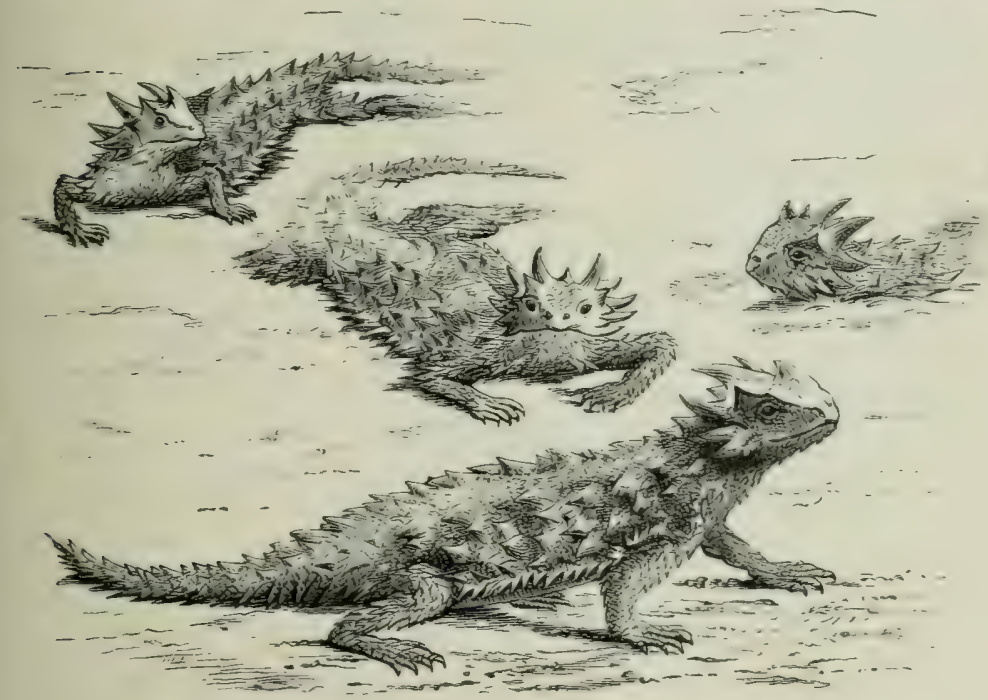

FIG. 131.-Phrynosoma coronatum ("Horned Toad"). $\times 1$.

latter from getting into the nostrils, these are provided with closely-fitting valves. Thus they remain concealed during the night, and not until the sun is well up do they leave their hiding-place, first peeping out, and then raising their head and neck, letting the sand roll off between the spines. Still half concealed, the back covered with little pebbles, seeds, or bits of dry leaves, they wait for a long time before they feel lively enough to sally forth. Although mostly slow and deliberate in their movements, stalking about with arched lack, and raised upon the fore-limbs, they can run fast enough for a few yards before they stop again and nod in a ridiculous way. When they see themselves observed, they shut their eyes and slowly sink 
down. On cool and dull days they do not appear at all, and during part of the cooler season they require artificial heat until they are ready to hibernate. Unless they are allowed to hihernate, they will keep on feeding through the winter, but in that case are sure to die in the following spring.

Fam. 3. Xenosauridae, with Homsmrus giunt is in Southern Mexion as the sole species, seems to comnect the Ignanidae with the Anguilae. Accorting to Boulenger, its affinity to the former is shown ly the T-shaped interclaricle, the alosence of symmetrical bony shields on the head and of osteodermal plates on the borly. Aninity to the Anguidae is indicated first by the short tongue, which has a narrow, fethly incised, retractile interior part, cosered with flat patpillate: secondly, by the teeth, which. insteat of heing hollow at the base, are solid: lastly, by the palatine bones, which are widely separated.

I. grandis, scarcely one foot in length. The body is depressed, covered above with minute gramules and tuhercles, below with smooth scales. A distinct fold of skin extends from the axillat to the groin, recalling the more strongly developed lateral fold of some of the Anguidae.

Fam. 4. Zonuridae.-This family, comprising four genera with alout one dozen species in South and Tropical Africa, and in Madagascar, likewise seems to connect Iguanidae and Anguidiae. It is clistinguished from the former by demal ossifications, which roof over the supratemporal fossa; from the latter by the tongue, the hollow teeth, and, in Zommins at least, by the occurrence of dermal ossifications on the trunk and tail. The tongue is short, villose, scarcely protbactile, entire, or but feebly nicked at the tip. The Zonuridae may therefore be defined as

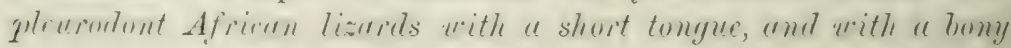
roof to the supratemporal fossae.

Zonurus.-The whole heat, hack, and tail are covered with bony scales, the horny covering of which forms very sharp spikes, especially on the tail. The body is depressed. The ear-opening is large. Sunth Africa, in dry and rocky localities; one species, Z. tropidosternum, in Madagascar.

Z. gigmntens s. dertinun, with strong spikes on the occiput, neck, and tiil. General colour yellowish brown. Total length about 15 inches.

Chumuesunre of South Africa closely approaches the An- 
guidae by its snake-shaped body, extremely long tail, and restigial limbs. In $C h$. aenca both pairs of limbs are still present and pentadactyle, but are very small; in $C '$. (ninguina the limbs are reduced to little styliform stumps: and in Ch. maciolepis they are altogether absent. The scales of the bolly and

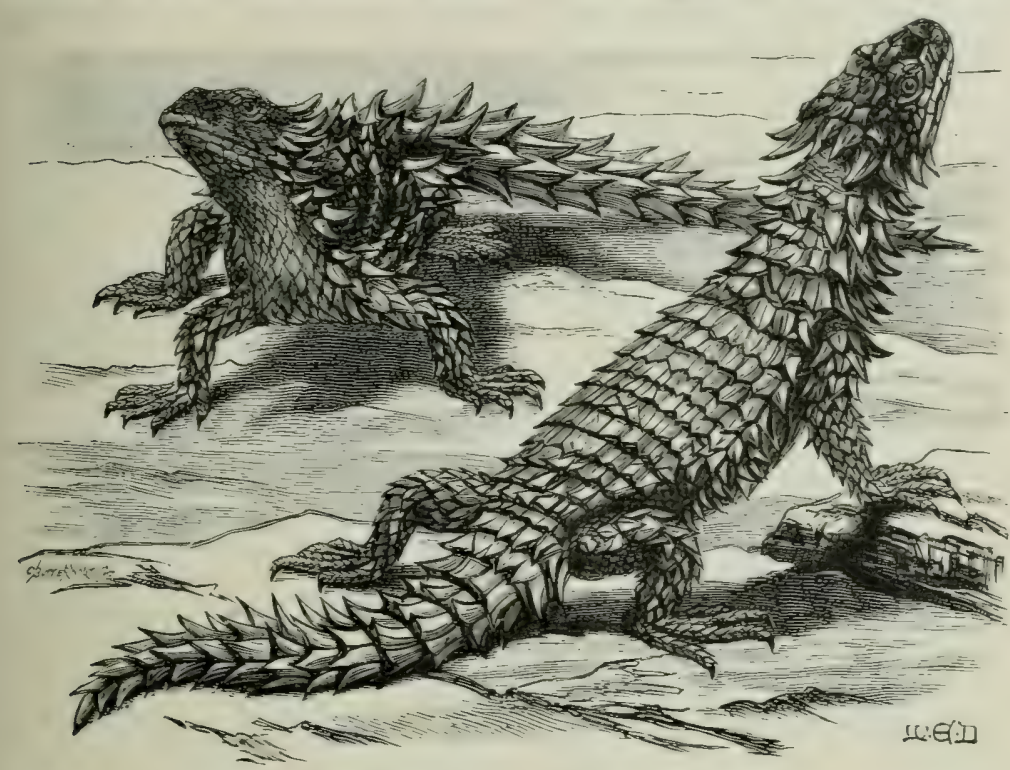

FIG. 135.-Zonurus giganteus, $\times \frac{1}{4}$.

tail are strongly keeled and imbricating, but are devoid of dermal ossifications. Total length up to 2 feet.

Fam. 5. Anguidae.-Pleurodont lizards with osteoderms, and with the tongue composed of two distinct portions, of which the anterior is thin, emarginate, extensible, and retractile into the posterior thicker portion. The supratemporal fossi is roofed in by dermal bones. The whole body is protected hy hony plates underlying the imbricating scales. The teeth vary much in shape, but they are always solid, the new teeth not growing into the base of the old ones, but between them. The limbs are in a very unstable condition, there being in the family a general tendency to reduce and lose the limbs. The shoulder- and pelvic-girdle however remain, although sometimes merely restigial. The tail is long, very brittle, and easily reproduced. All the Anguidae are strictly terrestrial, and live on animal diet. 
Some fuynis, at least, are viviparous. The distribution of the seren crenera, with some forty species, is rery scattered. The majority, chiefly Grrolumotus, inhalit Central America, a few occur farther north and south-two, Anguis freqpitis and Pseudopus pallusi in Eurnpe, and one in the Hinalayas and in Burmah.

Criflomotus has a pair of dexp longitudinal folds, each of which extemis from the region of the neck along the side of the lumly towarts the tail. The frum limls are well developed and puritarlactyle. The teeth are conical. Many species, mostly in Central Anerica. $F_{r}$. cormlins has the widest range, extending from cista Iical to Vancouver. It is also one of the largest speries reaching a lemgth of more than one foot. The tail is nearly twice as long as the rest of the hoty. General colour above brown with hlackish hars and spots, especially on the more yellowish flanks: under parts whitish with a greenish tinces, ofter with hrown spots arranged in longitudinal rows.

Opllisanils s. Psendopus is closely allierl to the previous genus. heing possessed of the same hind of cleep lateral folds: the limbs are. however. reduced to a pair of tiny spikes, half concealed at the sides of the anal cleft. The teeth are conical, and in the adult have somewhat flattened crowns. The hody and tail are very loug and snake-like, hut the hearl is that of a typical Lizard.

(1) "puss s. Psemlopus prollasi, the (rlass-inake of the Balkan l'eninsula, South Russia, Asia Minor, and Moroceo, grows to more than one yard in length, of which about two-thirds belong to the tail. The seneral colour is brown ahove, paler below: Yumer specinens are olive-grey with dark hrown cross-lands on the hack. O. yruilis inhabits the Eastern Himalayas and Burmah, the others live in North America.

The "Cilas--inake" inhahits bushy localities, where it can hide under the fallen leaves and in the sand; it camnot climl, and arwils the water. Its movements resemble those of a smake, lut are far less graceful, owing to the stiff armour in which the whole hody is encased. The food consists chiefly of snails, the shells of which are crushed, and of mice, but nothing contes amiss which can he mastered, namely insects, wolms, small lizards, young lirds, and vipers. The prey, when caunht, is rapilly twisted roumd and round, or shaken until it is gillly or stunned, whereupon the Glass-sinake proceeds to chew it with its powerful jaws, and then to swallow it in pieces. 
Although it can bite so well, it never does so when caught, lut resorts to the much more disagreeable defence of twisting itself around one's hand and arm, and besmearing them with its disgustingly stinking excrements. Those who have olserved Glass-snakes praise their tameness, and the intelligent waty in which they hunt about in search of their food. They lay egrss under moss and leaves, and the young seem to require many years to grow up.

Anguis, with only one species, A. fragitis, the "Slow-worm" or" "Blind-worm," is devoid of a lateral fold. Limbs are entirely absent. The whole body is covered with smooth roundish

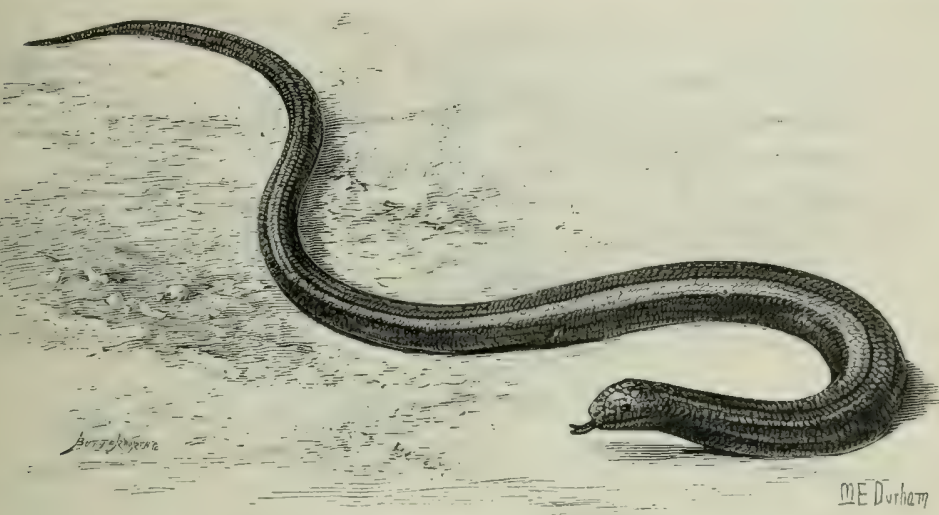

FIG. 136.-Anguis fragilis (the Slow-worm). $\quad \times \frac{1}{2}$.

scales, with a substratum of dermal ossifications. The teeth are curved backwards, fang-shaped, and have a very faint longitudinal groove on their anterior surface. The ear-opening is very minute, more or less hidden hy surrounding scales. The eyes are perfectly well developed, provided with movable lids, and it does not speak well for the power of observation of most people that this creature should generally be known as the "Blind-worm." The whole skin is shiny, metallic, quite smooth, brown above, blackish below. But the coloration is subject to much individual variation. Old specimens are sometimes adorned with blue specks. 'The very young are exquisitely beautiful, the upper surface being silvery white, with a median and two more lateral lines of deep black; the under parts are black. The iris is yellowish red. Very large specimens measure more than one 
foot in length, more than half of which belongs to the tail. One in the British Museum is $425 \mathrm{~mm} .=17$ inches long.

The slow-worm is viriparous, i.e. the young are fully developed, and hurst the trinsparent, soft, yellowish eggs immediately after these are laid. This takes place in the months of Ausust or reptemher, about one dozen making a litter. The little (reatures are at first alout one inch and a half long, and as thin as an wdinary match. They eat the smallest of spiclers and delicate insects: later on earth-worms, which they bite int, and then suck out hetore devouring them. Then six wexks uld and well fed they are ahout :) inches long, but it is at least four or five years before they are mature. The little ones carefully aroid the hot sunshine, and the adults are likewise rather partial to the shade, although strictly diumal. Their chief food consists of earth-worms and snails. For the night they retire under moss. leaves, stones, or into the cromud. In the autumm the Slow-worms dig passages or burrows, which often serve as the winter-yuarters of many specimens, as if there were no other place availahle, or rather as if the spot. selected were by far the best with regard to safetr, dryness, and warmth.

Fam. 6. Helodermatidae.-Pleurodont, poisonuus lizards of North America. The teeth are fanc-like, recurved, with slightly swollen hases, rather loosely attached to the inner edge of the jaws. Each tooth has a groove on its anterior and posterior surface, and a series of labial glands which secrete the poison open near the lases of the teeth of the lower jaw. The skull has strong postorlital hut no jostfronto-syuamosal arches. The pre- and jost-frontals are in contact, separating the frontal from the orhit: the fremaxillaries are fused into one; the nasals and frontals remain selatrate. The limls are short, hut stroug and well developed. The tongue is villose, with an anterior smooth jortion, which is hifid and protractile, resembling the tongue of the Anguirlate and of Anirllt. The skin of the upper surface is sranular, with many irregular bony tuhercles, which give it an ngly warty look. The under parts are covered with flat scales.'

Helorimu, the only genus, with H. horrilum in Mexico and II. suspertum in New Nexico and Arizona, reaches alonut 2 feet

${ }^{1}$ For further anatomieal le.tails se. Shufeddt. P.Z.S. 1890, 1. 148: Boulenger, P.Z.S. 1891, 1. 109 ; and Stewart, P.Z.S. 1891, p. 119. 
in length. The animal, stout, depressed, thick-tailed, looks rather repulsive when it squats down in its usual lethargic way. The whole skin is blackish brown and yellow or orange, these two "warning" colours being distributed unevenly, except on the thick, peculiarly-shaped tail, where they are arranged in alternate rings. The specific differences are rather imaginary. The New Mexican form is supposed to he more orange and yellow than black, with a somewhat smoother skin and with shorter toes and tail.

The "Gila Monster" inbalits dry localities, spends most of

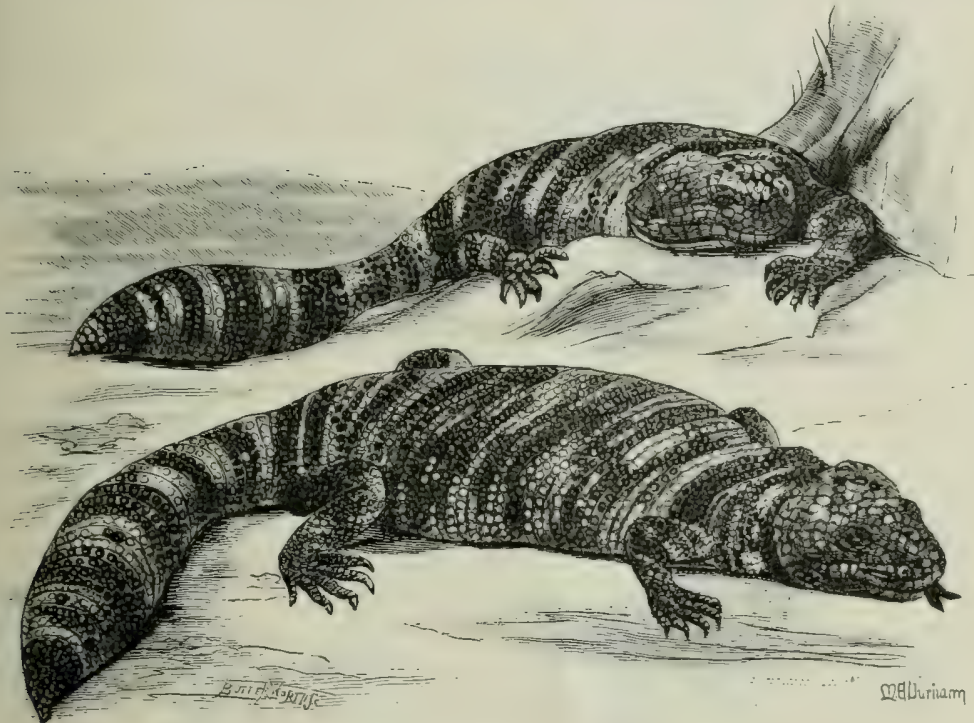

Fig. 137.-Heloderma suspectum (the Gila Monster). $\quad \times \frac{1}{3}$.

the daytime in concealment between the roots of trees, and crawls about in the evening in search of worms, centipedes, frogs, and the eggrs of large lizards. Frogs are probably paralysed or killed ly the bite which, although not so dangerous as that of poisonous snakes, is effective enough to produce severe symptoms even on man, and a few cases of death of people who had been litten are on record. In captivity they are very partial to eggs, which they break and then lap up. During the dry and hot season they aestivate.

Fam. 7. Lanthanotidae. - Lanthanotus borncensis, of which only two specimens are known, one in the Vienna Museum, the 
other in the Sarawak Museum, was described by Steindachner as the type of a distinct family, near the Helodermatidae. Boulenger, ${ }^{1}$ after examination of the Sarawak specimen by means of a sciagraph, has come to the conclusion "that the aftinity of Lanthanotus to the Helodernatidae is fully confirmed." The teeth of Lanthanotus show, however, no traces of grooves; poison-glands are probably absent, and there are no osteoderns. The skin is covered with wart-like tubercles, each with a horny, peeled scale. The eres are very small, the ears are concealed. The general colour is rerlish brow above, rellowish, with brownish bands, helow. Total lenestl ahout one foot, a little more than half of which belongs to the roundish tail.

Fam. 8. Varanidae. - Pleurudunt Old-THomld Lizards, with a

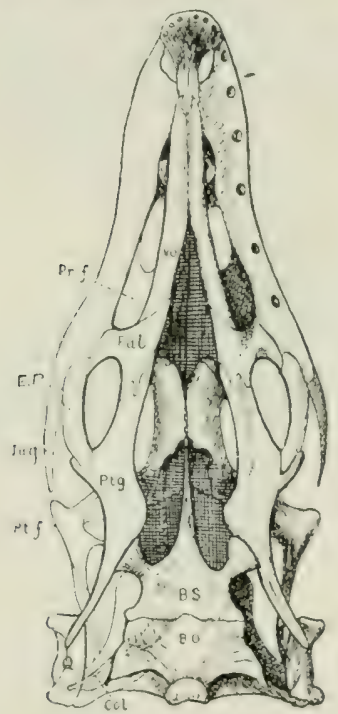

A

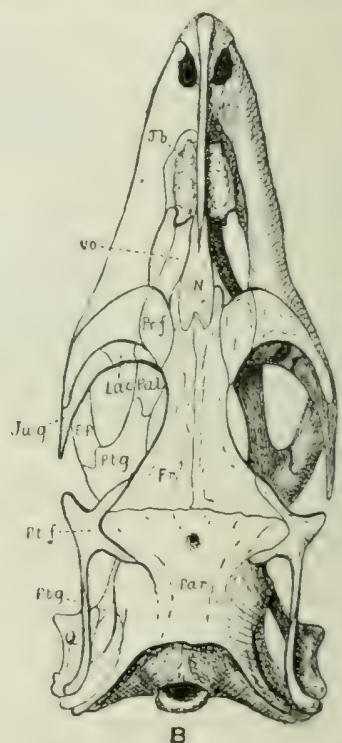

B

FIG. 138.-A, Ventral, B, dorsal view of the skull of laranus grisens. $\times 1 . \quad$ B.O. Basioccipital ; B.S, basisphenoid; Col, columella auris or stapedial rorl; E.l', ectopterygoid ; $F r$, frontal ; $J u g$, jugal ; Lac, lacrymal ; $N$, nasals ; $P$ 'al, palatine ; $P^{\prime}(e r$, parietals ; $P^{2} r, f$, prefrontal ; $P^{\prime} t, f$, postfrontal, fused with postorbital ; $P l g$, pterygoid (endopterygoid) ; Q, qualrate ; Tb, turbinal ; Vo, vomer.

long, deply hifid and protioctili smooth tongue. They reach a laree size, and the neck is relatively much longer than that of wher lizards. The limbs are well developed. The skin is 1 P.Y.S. 1899, p. 596. 
covered with rery small juxtaposed scales and tubercles alove, while the rentral scales are squarish and arranged in transterse rows. Osteoderms are entirely alsent. The tail is very long, often laterally compressed. The teeth are large and printenl, dilated at the base. The premaxilla is unpaired and dirsally extends backwards to the likewise unpaired nasal. There is at pair of small supra-orbital bones, easily lost during maceration. The orbit is open behind, the jugal being short and not meeting the postfrontal; the postorbital forms a slenter arch with the supratemporal. The romers are long and diverge posteriorly. The palatines, pterygoids, and ectopterygoids enclose on either side an oval infra - orbital foramen. The Varanidae contain only one genus, Toranus, with nearly thirty species in Africa, Southern Asia, and Australia, but not in Madagascar.

Varanus. - The name of "Monitor" bestowed

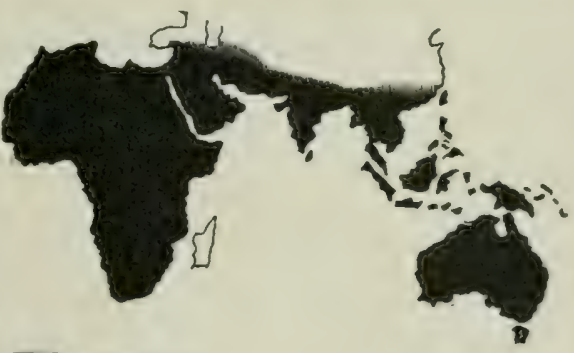

VARANIDAE.

FIG. 139._Map showing the distribution of the Varanidae.

upon these creatures has a curious origin, owing to a ricliculous etymological mistake. The Arabic term for Lizard is "Ouaran": this has been wrongly taken to mean warning lizard, hence the Latin Monitor, one of the many synonyms of this senus, e.g. Hydrosaurus and Psammosumps. Many of the "Mronitors" are semi-aquatic, others inhal,it dry, sandy districts, while others are at home in well-wooded localities. They are all rapacious, taking whatever animals they can master according to their size, which in some species amounts to 6 or 7 feet.

$T$. niloticus inhabits the whole of Africa, except the northwestern part. It reaches a length of more than 5 feet. The colour of the adult is brownish or greenish grey above, with darker reticulations and yellowish ocellated spots on the back and linls. The under parts are yellowish with blackish cross-bands. The groundcolour of the young is black above with yellow lines on the head and neck, and with yellow spots on the back and limhs; the tail has black and yellow bars.

V. sulvator ranges from Nepal to Cerlon, Cape Tork, and 
Southern China, inclusive of the Malay Islands and the Philippines. This is the largest species, specimens of $T$ feet in length heing on recort. The general colour is dark brown or hackish aluse, with rellow spots or ocelli. The snout and chin have transterse hlack lines on a lighter ground. A hlack band, hordered with yellow, extends from the eye along the side of the neck. The under parts are yellow.

Mr. Annamlale has faroured me with the following observa-

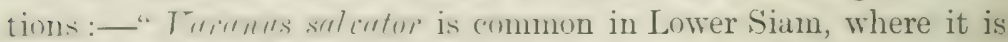
expally at home on lamel. in water, and amoner the branches of trexs. The ens are litil in hollow tree-trunks. When in the water the lizard swims leneath the surface, the legs heing closely applied to the sides, and the tail functioning hoth as oar and as ruller. Their food is rery varied. In the states of Patalung and sinerora, in which the Simese practise a form of tree-lurial, these great lizards are accused, probahly with justice, of eating the thesh of the corpses in the airial coftins. I have disturbed a large Monitor devouring the boly of one of its own species, which hat evidently been deal for sime days. Another, which was (hatsed by some men, drophed from its mouth a small flying stumirel (Simputerus): a thire, which I dissected, had lately swallowed at small tortoise, the hard shell of which had been iroken into innumerable framuents. The stomachs of several others contained nothing hut dung-heetles, for which Varanus may often he seen hunting, turning over the dung of elephants and huffiloes with its fore-feet. The Malay name of these lizards is Biawak."

According to Mason and Theobald ${ }^{1}$ all the Varanidae and their ersess are highly esteened for food, and are sought for in hollow trees with the aid of dogs. If not wanted at once, the wretched creature has its fore-feet hent over its back, a few of its toes are broken and the sinews drawn out and tied into a knot, rendering the animal helpless. The Karens, who are extraragantly fond of the flesh, steal up the tree with a noose at the end of a hambur, and often none them while leaping for the water, or catch them in a boat which is hrought under the tree. The head, the natives say, is renomous, and they discard it altogether, but the flesh of the other prorts, which smells most odiously, is deemed preferable to that of fowls.

${ }^{1}$ Burma, its Pcople and Productions, London, 1882. 
Sir J. G. Tennent ${ }^{1}$ gives the following account of $T$. salvator:-

"The 'Kathara-goya' of the singhalese is partial to matry ground, and when disturhed upon land will take refuge in the nearest water. From the somewhat eruptive appearance of the vellow blotches on its scales, a closely allied species, similarly spotted, obtained the name of Innitwi comthematicus, and it is curious that the native appellation of this one, hubrim, is suggestive of the same idea. The Singhalese, on a strictly homoeopathic principle, helieve that its fat, externally alulied, is a cure for cutaneous disorders, but that taken inwardy it is poisonous. The skilfulness of the Singhalese in their preparation of poisons and their addiction to using them are unfortunately nutorions traits in the character of the rural population. Anomgst these rreparations the one which above all others excites the utmost dread, from the number of murders attributed to its anency, is the potent firluriotel, a term which Europreans sometimes corrupt into colipe-tel, implying that the renom is olvained from the hooded-snake; whereas it professes to be extracted from the Kabara-goya.

"In the preparation of this mosterious compound, the unfortunate Kabara-goya is forced to take a frainfully prominent part. The receipt, as written down hy a Kandran, was sent to me from Kornegalle hy Mr. Morris, the civil ofticer of that district: and in dramatic arrangement it far outdoes the cauldron of Macheth's witches. The ingredients are extracterl from renomous suakes hy making incisions in the head of these reptiles and suspending them orer a basin to collect the poison as it flows. To this, arsenic and other drugs are added, and the whole is hoiled in a human skull, with the aid of three Kahara-yoyas, which are tiel on three sides of the fire, with their heads directed towarls it, and tormented hy whips to make them hiss so that the fire may blaze. The froth from their lips is then aduled to the hoiling mixture, and so soon as an oily scum rises to the surface, the hahara-tel is complete. Before commencing the operation of preparing the poison, a cock has to le sacrificed to the demons.

This ugly lizard is itself regarded with such aversion ly the Singhalese that if one enter a house or wall over the rout, it is regarderl as an onen of ill-fortme, sickness, or death: and in

1 Sketches of the Nat. Hist. of Ceylon, London, 1861.

VOL. VIII 


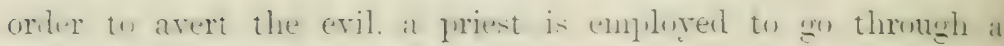
rhythmical incantation."

Captain linlinam, remowned ats a hunter of tigers on font in

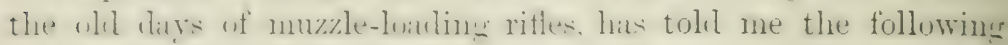
unigue une to which these large lizards are jut hy ingenious.

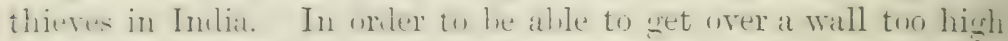
for dimbing without assistanee, the the proviles himself with it

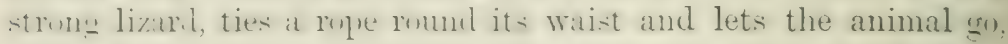
when it at once scales the mud wall by its strong and shar claws, and jumps down on the other side. The weight of the

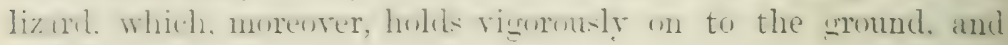

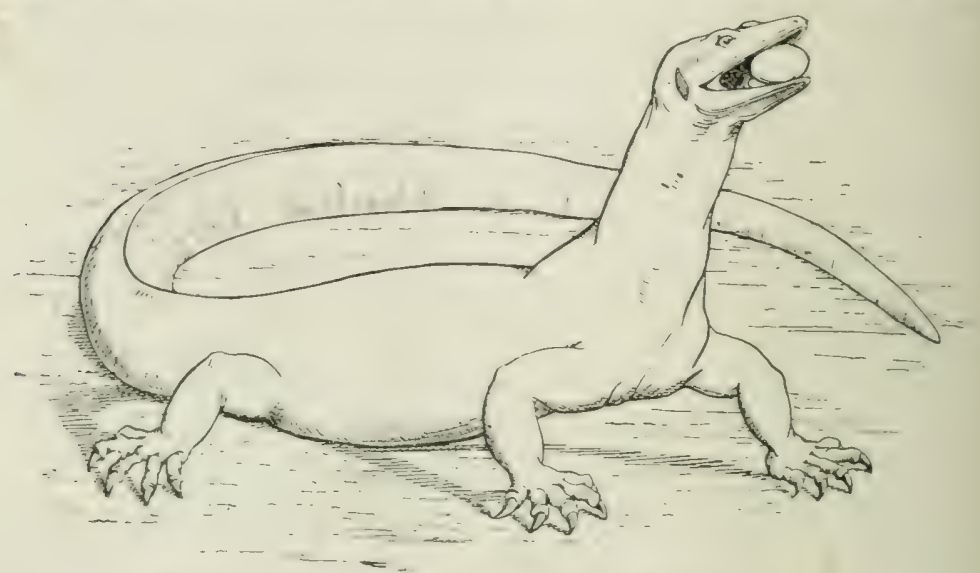

FIG. 140.- Varanus sulvator swallowing a Fowl's egg. $\quad \times \frac{1}{3}$.

the friction of the roge on the top of the wall, are sufticient to help the man over!

It is a sight. never finling in its attration to the visitors of the Zorrelogical Gardens in Lomdun, to see one of the lig Monitors fed with an eggr. The lizard knows the treat well that is in store for it. It raises itself up high in expectation, then

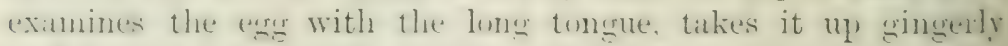
and swallows it entire, crushing it hy the contratetion of the muscles of its gullet. On one occasion it was given a rotten (...- which hurst in its mouth. and the lizard refused for a lonstime to take another.

$V$ gouldi is common in Australia and in New Guinea. It reaches a length of about 4 feet. Its colour is lorown abow 
with yellow spots on the back and limbs, and with yellow rings on the tail. Two yellow streaks separated by a black land extend from the temples along the side of the neck. The unler parts are yellowish, sometimes with black spots.

Fam. 9. Xantusiidae. - Three Central American, or TrestIndian genera, with less than half-a-dozen species. Plourortont with a short tongue and with the supreatemporal fosse roufed arer by lone. The tongue is scarcely extensible, with oblique overlapping folds which converge towards the median line, and with scale-like imbricate papillae towards the tip. The skull possesses complete postorbital and postfronto-squamosal arches, the latter meeting the parietals and roofing over the supratemporal fossa. The palatines are in contact with each other, and there are 10 infra-orbital fossae. There are no osteoderms; the bouly is covered above with small granular scales, below with larger scales. The eyes are devoid of movable lids. The tympanum is exposed. Femoral pores are present. Limbs and tail well develoyed. Xantusice and Lepidophyma.

Fam. 10. Tejidae.-American Lizards with a long and bifid tongue. The greater portion of the tongue is corered with scale-like papillae; the anterior forked and pointed ends are smooth. The teeth are solid and implanted almost upon the edge of the jaw, being therefore intermediate letween the acrodont and pleurodont condition. The shape of the posterior teeth shows several modifications; they are conical or tricuspid, or molar-like in the adult Tejus; in Dircuent they are transformed into large, oval crushers. The palatines are in contact anteriorly. The infra-orlital fossae are surrounded by the palatine, pterygoid, and ectopterygoid bones, the maxillary being excluded from the fossa, as in Tarunus (see Fig. 138, p. 542). The skull has no supra-temporal arch. Osteoderms are absent; the body is covered with small scales, or the shin is simply granular above; the under surface is covered with larger scales, generally arranged in transverse rows.

This large family, which comprises nearly forty genera with more than a hundred species, exhibits great diversity of form. Some are inhabitants of forests and are arboreal, while others are strictly terrestrial, preferring hot and sandy plains, or they dwell below the surface and are transformed into almost limbless and blind-worm-shaped creatures. The range of the family extends over the whole of the South American continent, over the Irest 
Indian Islands, and through (entral Anerica into the warmer parts of the United States.

T'upinambis ("Teju").-The skin of the back is smooth, corvered with small scales; with latrge scales on the top of the heat. The skin on the neck is gencrally thrown into two irremular transterse folds. The long and namow tongue is capable "f heing telescoper intw a sheath at its hase. The lateral teeth are (ompressed and tricuspid in the young, but the later generations of teeth have obtuse crowns in the adult. T. tognatin is

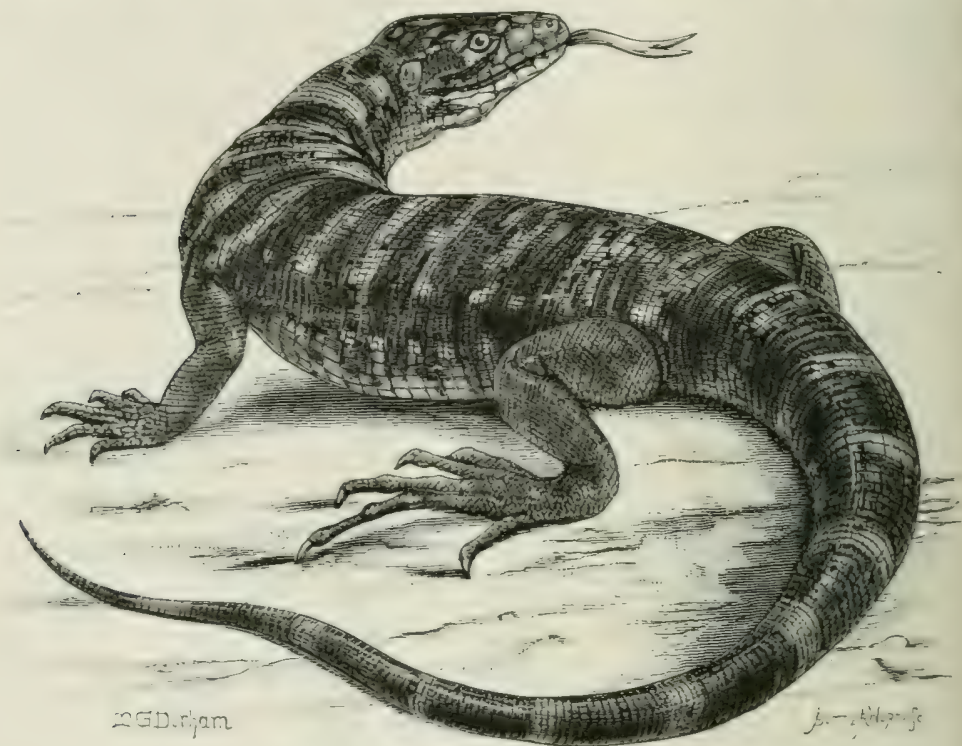

F1G. 111.-Tupinambis nigropunctatus. $\quad \times \frac{1}{6 .}$

the largest member of the whole fimily ; it reaches a length of a ritrl, nust of which, howerer, helongs to the tail. The general inhour is hluish liack, with pale or whit ish-yellow spots on the hack, flanks, and tail, combining into more or less transversely arranged bands. The limbs are black, with many and tiny yellow dots. The momul-colour of the muler parts is reddish yellow, with

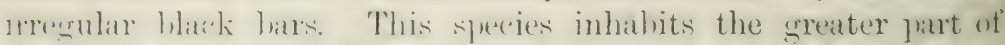

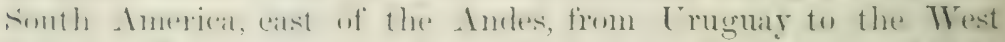

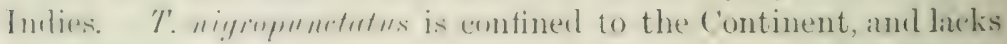

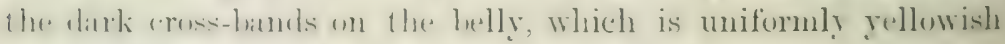
or speckled with black. 
The "Tejus" frequent forests and plantations, and are carnivorous. Their strength and swiftness enable then to catch all kinds of animals, from insects and worms to frugs. snakes, mice, and birds. As they take chickens and eggs from the farms they are considered noxious, and they are frequently hunted down with dogs for the sake of their flesh, which is regardecl as good to eat. They defend themselves with lashing strokes of their long tail and with their powerful jaws. They retire into burrows, and they deposit their hard-shelled egigs in the ground. In captivity they can easily be kept on meat.

Dracaenu grianensis of the Guianas and the basin of the Amazon has the lateral teeth transformed into regular large molars, with broad and rounded crowns. The tail is strongly compressed, with a double, denticulated keel. It seems to be semi-aquatic, and, to judge from the teeth, herbivorous.

Ameire and Cnemidophorus, with many species chiefly in tropical America, have laterally compressed bi- or tri-cuspid teeth. The skin forms a double fold on the neck, and is corered on the upper surface of the body with rery small scales; those on the ventral surface are large, and arranged in regular rows. MIost of the species are small, under one foot in length, and are extremely pretty, very active, timid, and mainly insectivorous.

C. Sertineatus is one of the few species of Cnemidophorus which inhabits the southern half of North America. Likie all its relations it has the appearance of an ordinary lizard (Lacerte). The head is dark brown. A purple or brownish band extends orer the back and tail, bordered on either side with three golden-yellow longitudinal lines. The flanks are brown, the under parts bluish white. The iris is golden, and the inner margins of the lids are hordered with a narrow band of loright yellow. This species is a very fast rumer, and frequents dry and sandy places. Its total length amounts to about 10 inches.

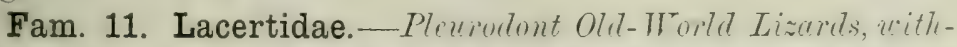
out ostenterms on the body, and with the supretempural regions roofed over by osteoderms.

The limbs are always well dereloped, and have five fingers and five toes, always provided with sharp claws. The slin corering the head forms large shields, mixed with small scales: most of which, especially the shields, contain dermal ossitications. These frequently fuse with the underlying bones of the top of 
the skull. The latter is always well marked off from the neck. The pustorlital arch is complete. The temporal region is comfletely rofed wer liy lomes dorsilly, chiefly owing to the size of
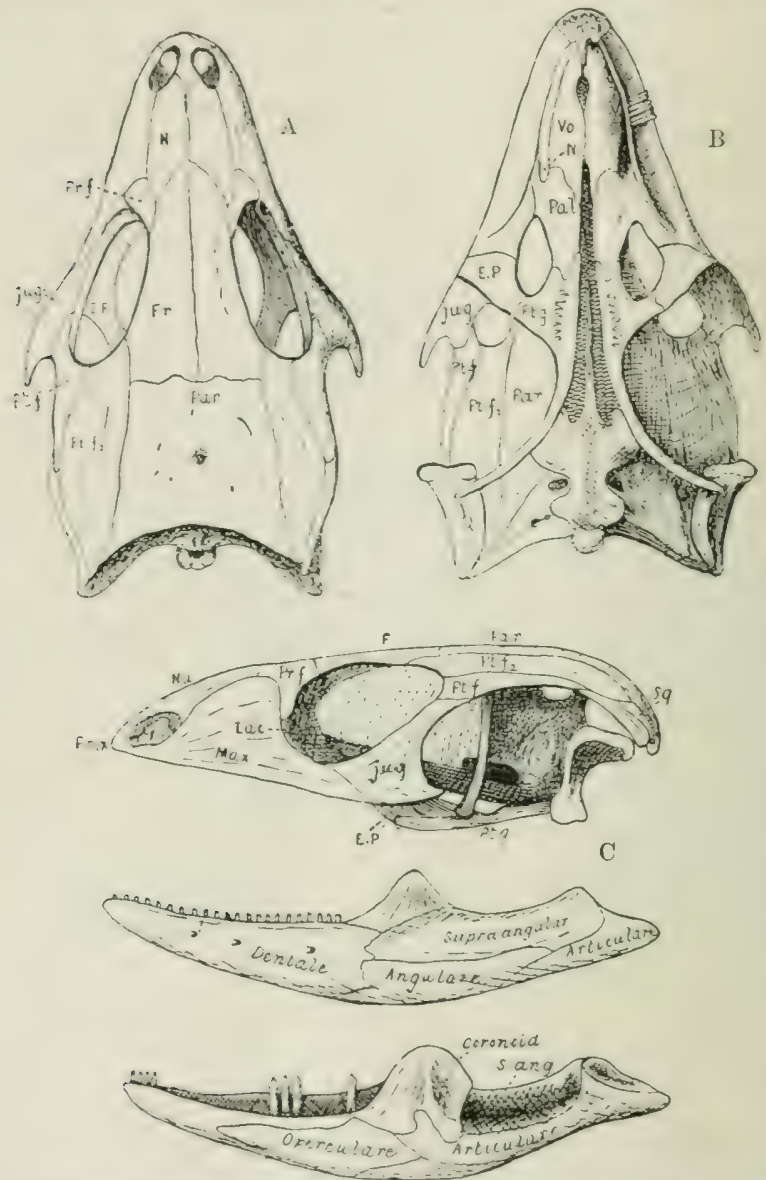

FIG. 142.-Skull and lower jaw of Lacertu vimilis. A, Dorsal view; $\mathbf{B}$, ventral view ; C, from the left side; $\mathbf{D}$, right lialf of the lower jaw, from the inner side, with some of the pleurodont teeth. E. $I^{\prime}$, Ectopterygoid ; $F, F r$, frontal ; jug, jugal ; Lac,

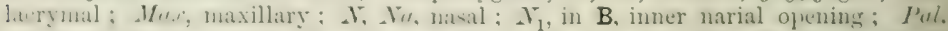
palatine ; $I^{\prime}\left(u r\right.$, parietal ; $I^{\prime} m x$, premaxillary ; Pr.f, prefrontal ; $P t_{t} f$, postorbital : $P t . f_{2}$, postfrontal ; $I \prime g$, pterygoid ; Q, quadrate ; $S .(\ell n g$, supra-angular ; $S \mathcal{q}$, squamosal ; Vo, vomer.

the postfrontal (Fis. 1+2, pt. $_{2}$, which fills the space between the parietal and the spmamoso-postorlital bridge, thus aholishing the

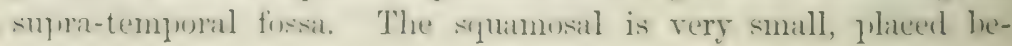


tween the postfrontal $\left(j t_{f}\right)$, the lateral occipital and the supuratemporal. The large jugal and the quadrate are not connected with each other. The columella cranii is well developed. The infra-orbital fossae are surrounded by the palatines, pterygoids, ectopterygoids, and maxillaries. The palatines and pterywoids remain separated in the middle line. The pterygoids frequently carry little teeth. The other teeth are typically pleurodont, hollow, slightly curved, and bi- or tri-cuspid.

The skin covering the body, the legs, and the tail is levoid of usteoderms. The scales on the dorsal surface vary much in size, from large, strongly keeled scales to tiny granulations. Those of the rentral surface are large, broader than long, and are frequently arranged in regular transverse and longitudinal rows. The tail, generally long and pointed, is very brittle. All the sense-organs are well developed. The tympanum is exposed. The tongue is deeply bifurcated, narrow, flat, and covered with scale-like papillae.

Various Lacertidae, especially some of those grenera which live and dig in the sand, have a transparent disc in the middle of the lower eyelid, so that they can see while the eye itself is protected. This is for instance the case in some specimens of the Indian and African Eremius. In the Indian grenus Cubritu the transparent disc is very large, and in Ophiops, which inhabits sandy stretches from North Africa to India, the lower eyelirl is fused with the rim of the much-reduced upper lid, and forms a large transparent window.

The Lacertidae or True Lizards comprise nearly twenty genera, with about one hundred species, and are typical of the Old World, being found in Europe, Asia, and Africa, but not in Madagascar nor in the Australian region. They are most abundant in Africa. Their northern limit coincides fairly closely with the linit of the permanently frozen under-ground. This is indicated in the map' (Fig. 14:3) ly the dotted line. All the Lacertidae live upon animal food, chiefly insects, and after them worms and snails; but the langer lizards take what they can master, frequently other lizards, and even younger members of their own kind. Many of them love sugrar, which they lick, and all require water. They are all terrestrial, preferring, according to their kind, such localities as yield them their particular food. Sunshine and warmth make a 
marrellous change in the same individual, which on dull, rainy. or cold ditys lies in its hole. or shows mly sluggish movements. Their sense of locality is great. or mather each individual inhahit. one plate, of which it knows erery now and corner, cramny, tree, and bush. It has its favourite hole to sleep in, a stone, the hranch of a tree. or a wall to hask upon, and when disturled or chatsent it makes with merring swiftness for a safe spot to retire into. The same lizard, when once driven away from its own Incilitr; seturs to lose all its presence of mind, fiomulers almut. amol is compraratively easily caungt. Most lizards are extremely curions, although shy, and this state of their mind can

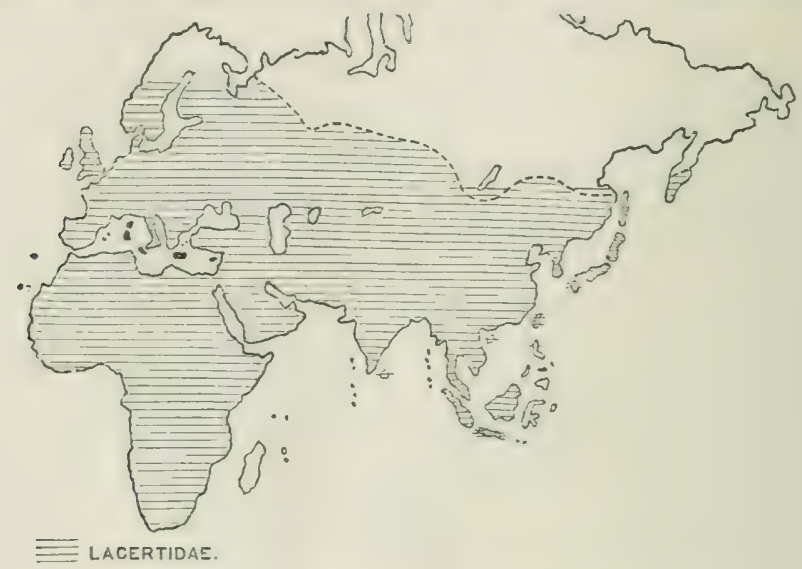

FIG. 143. - Map showing the distribution of the Lacertidae.

be male use of hy three who want to catch them without injury. and almote all without getting the aninal minus the hittle tail. This sufe way of catching lizarls consists in taking a thin roul with a running noose of thread at the end, in drawing the latter over the lizard's head, and then raising it. The little creature drese not nind the rou in the least: on the contrary, it watches it carefully, and often malkes for the thread. The hurs in simtlem Italy have impored mon and simplified this mole of

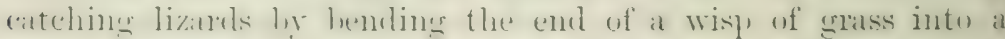
monse, and corering the litter orer with a thin film of salivat The shing filne, like a soalp-hulhle, is sure to excite the curiosity of the creature. The late T'rofesere Eimere refers to this practice

1 Organic Exolution. Translation, London, 1890. 
as carried out by the children of two thousand years ago, and he sagaciously explains that the beantiful statne of the so-called Apollo Sauroctonos represents a boy who is in the act of noosing the little lizard on the tree.

Lacertu. A row of enlarged scales forms a distinct collan across the rentral half of the neck, in front of the chest. The scales on the back are much smaller than those on the tail, which is long, roumd, and pointed. The digits have smooth, tuhercular lamellize on the under surface. Femoral pores are well market. This genus, with about twenty species, ranges through Europe. Northern and Western Asia, and Africa north of the Equator.

L. vivipure, the Common English Lizard, has a rery wide range, through Northern and Central Europe and Siberia to the Amoor comntry and the Island of Saghalien. It oceurs throughout Great Britain, even in Ireland, where it is the only species of reptile, occurring, for instance, in the county of Neath and in the south-eastern counties, $6 \%$. Waterford. It does not oceur south of the Pyrenees or south of the Alps. The suprit-ocular and the supraciliary scales are in contact with each other, not heing separated hy a series of little granules. Normally there is a single postnasal and a single anterior loreal shield. The rentral scales are arranged in six or eight lonsitudinal series, of which the second series on each side from the median ventral line is the largest. The coloration of this species is subject to much variation. The general colour of the adult is brown or reddish above, with small darker and lighter spots; many specimens have a blackish rertebral streak and a dark lateral band edgerl with yellow. The under parts are orange to red in the male. with conspicuous hlack spots; yellow or pale orange in the female, either without or with scanty black spots. The newlyborn specimens are almost black. The males are slightly smaller than the females; males of a total length of 6 inches, and females 7 inches long, may lue considered rather large specimens.

This lizard is, as the specific name implies, viviparous, if. the six to twelve young burst the eges immediately after they have been laid; sometimes the mother has to retard the lavins, in which ease the young are born free. The female does not make a nest, but simply deposits her offspring on the gromed and leaves the young to their firte. For the first few dirs the little ones, which scarcely measure three-quarters of an inch in 
length, remain almost motionless between leaves or in cracks of the gromed, and they do not take any food. They grow, how"rer, yuickly, living upon the remains of the yolk which has siplued into their boly. Their first fond consists of Aphides and similar tiny insects.

The (ommon Lizart prefers moist localities and is rery hardy. It extends northwards to Archangel, and in the Alps it ascends to nearly 10,000 feet abore the level of the sea. However, on the alpurach of the cold stason, in the month of October, it withlraws into its winter quarters, frequently in company with many of its own kind.

L. mgitis, the Sand-Lizard, has nearly the same wide range as $L$. ilifun" except that it does not go so far north and does not extend eastwards beyond Central sibria. It is absent in Irelind and scotland, while in England it is restricted to the southern half.

The characters which distinguish the sand-Lizard from $I$. irifun are few; although the majority of the specimens of either lind are very distinct in their coloration, and $L$. ayilis is strictly oripharnus, depositing its exgs in the ground, under leares, in herilys of weeds and similar places. The Sand-Lizard has usually a single postnasal and two superposed anterior loreals, the three shields forming a triangle. The temples are covered with flat scales, two or three of which are enlarged and in contact with the parietals, but there is no tympanic scale.

The coloration is subject to much variation, local as well as intividual. As a rule the Samb-Lizard gives the impression of heing striped longitudinally, the striation heing caused by row "ff clark aml white spots and patches along the sides of the hack, flinkis, and titil. In the male a more or less pronomeed green, in the fente hrown aud grey are the prevaling gromel-colours. A typically colnured male during the breeding season is yrass-

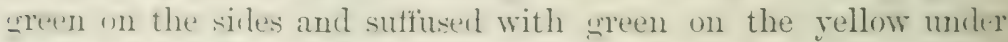
fiarts: the sirles are dotted with hlack, with whitish eye-spots. The mimler parts are spotted with liack. The achlt female is

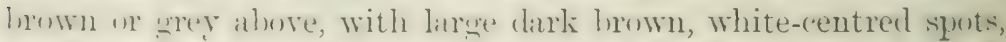
which are arranged in threes rows on eatch sicle. The under parts

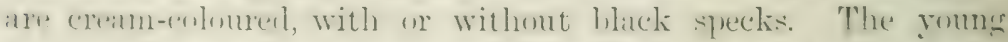

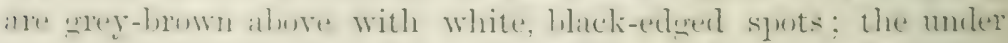
louts are whitish. Total lemeth of the adult uly to s inches. 
The male is a little smaller than the female lut has a relatively longer tail, a little less than half the total length.

The Sand-Lizard is easily kept in captivity, and lives for rears if allowed a variety of food and proper places to hihernate in. It pairs in the spring, in England in May or June; the white, parchment-like eggs, numbering five to eight, are hatched in the following July or August.

L. viridis, the Green Lizard, inhabits Southern and Midhle Europe and South-Trestern Asia. The general colour of this beautiful lizard is emerald-green alove, changing into greenish yellow on the flanks and into yellow on the belly. The throat, especially in the males during the breeding season, is blue. The upper parts are frequently speckled with black. The young are brown or green above with one or two yellowish lateral stripes, which persist in some adult females. There are usually two superposed postnasal shields. The semilumar collin on the neck is well pronounced, and there is usually a distinct gular fold. The tail is often rery long, especially in the males, sometimes nearly three-quarters of the tutal length, which in very large males reaches 16 or 17 inches. The females do not quite reach this length.

The Green or Emerald-Lizard prefers rocky localities, from the sea-level, as for instance in Jersey, up to a height of several thousand feet. It is extremely swift and can climb trees, which it sometimes resorts to when chased. When hard pressed it takes tremendous leaps down to the ground, marvellously enough without injury to body or tail, which latter is otherwise very brittle. They pair in the spring or early summer after much fighting between the males; the egrss, to the number of about ten, are whitish and are deposited a month later. The young are hatched after another four weeks.

This beautiful lizard does not keel well in captivity, although it becomes very tame; it eats meal-worms, suails, earth-worms, and insects, especially buttertlies, but it sickens after the first winter even if it has been allowed to hibernate.

In Portugal and Spain $L$. viritis is represented by a slightly different kind, L. schreiberi, the chief interest of which lies in the fact that it approaches $L$. ocellute in several respects. The occipital shield is large and is usually broater than the interparietal. The dorsal scales are smaller, aud there are eight well- 
develepterl rows of rentral scalles. Insteal of being uniformly grens, the uper parts are usully spotterl and remiculated with hlack: sometimes, especially in the females, the black spots have a white ocellus in the centre. The nuler jats are yellowish, with w withut black spots. The throat is blue. The roung lowk rery different. They are ulive-hown ahove with large rellow, or hluish-white. black-erliged ocelli on the side of the head and body.

Uther forms, perhals of suh-specific rank, approaching $L$. w..Mnt, orcur in the Balkan I'eninsula, where. for instance in Inalnatial, the typical L. viritis attains its most beatiful derelopment.

L. conllot", the Ereel Lizard, inhahits Spain and I'ortugal.

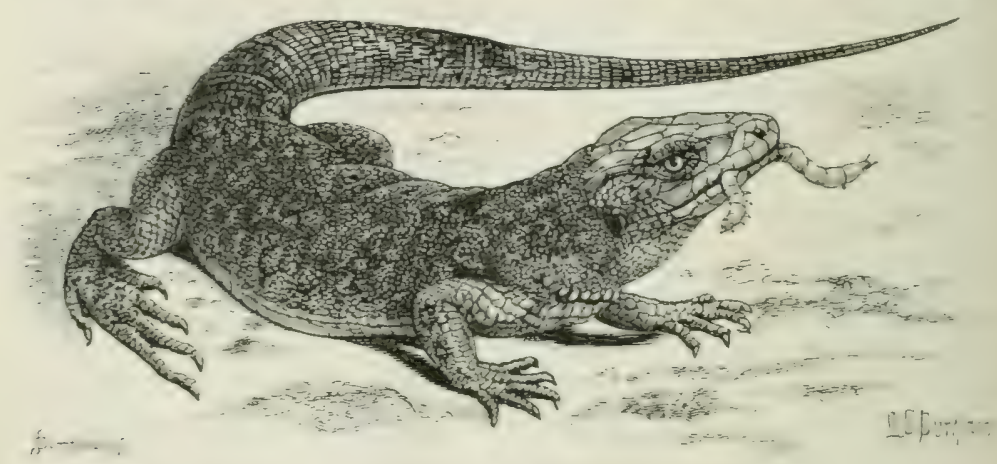

Fir. 144. - Lacerta ocellata (the Eyed Lizard). $\quad \times \frac{1}{3}$.

extemeng northwarls into the south of France and into the Tivierit, southwards into Morneen and Algeria: these southerm forms (L. pater and $L$. tangitana) approach $L$. viridis. The Evenl Lizard is green or dark olive above, with hlack or vellowish duts. Which are sontetines comblined into a kind of network pattern. The moler parts are uniformly greenish yellow. The

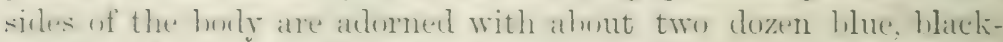

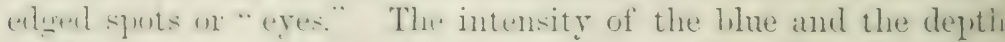

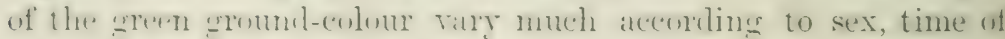

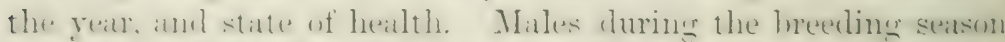
are nust luatutiful and lorilliant. The aceipital shield is lomal:

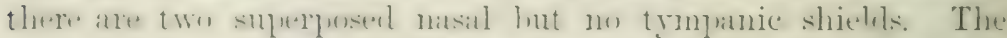

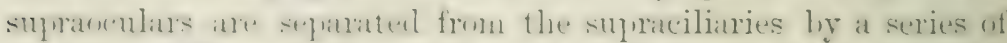

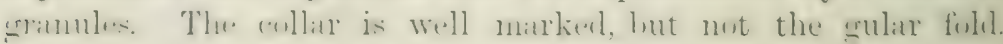


The dorsal scales are minute and granular; the rentral shields are arranged in eight or ten longitudinal rows.

The "Eyed Lizard" reaches a considerable size, especially the males, which develop a very strong and thick head, and are much more robust and powerful than the more slender females. Old males reach a length of 2 feet, two-thirds of which length belong to the tail; but the latter varies much, even if it has never been broken and renewed.

The Eyed Lizard keeps extremely well in captivity, and in this respect is unlike the Green Lizard. A case has heen recorded of its living thirteen years. This species is rery intelligent. Although at first ferociously wild and biting furiously, these lizards soon become tame and take food regularly. One of my own, a half-grown male from Northern Spain, about one foot in length, made its home in a little niche of the greenhouse-wall, whence it emerged regularly to take the offered food from my hand. It soon knew the whole place thoroughly, making use of the creepers whilst scaling up to its retreat, jumping over certain gaps, descending to the ground at certain spots, basking on certain stones, invariably in the same methodical way. In the month of October it retires into the ground on the coolest side of the greenhouse, and although the latter is well warmed, the lizard remains invisihle until the next Felruary or March, when on some fine day it is rediscovered basking upon exactly the same stone where it had been seen five months hefore. The only drawback in commexion with keeping this kind of lizard in company with other creatures is their voraciousness; since large, fully adult specimens attack and eat any other small lizard, slow-worm, or' snake they can find. They also take mice. The eggs are often deposited in hollow trees.

L. muralis, the Wall-Lizard, is very common in Southern Europe, Asia Minor, and Northern Africa. Northward it extends into Belgium and into South Germany. In the Iberian Peninsula it ascends up to 5000 or 6000 feet above the level of the sea. This graceful little creature, with an average length of 6 to 8 inches, is easily recognised by the series of granules letween the supraocular and supraciliary scales and usually liy having only six rows of ventral scales. The great variety in coloration has given rise to the establishment of many races, varieties, and sulb-species. In the typical forms the npper parts are brown or 
grerish, with hlackish spots w streaks, sometines with a lugnzy greenish sheen. The unler parts ar white, rellow, pink, or reel,

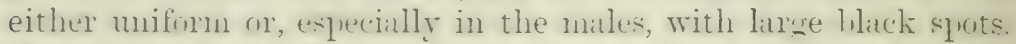
The lateral rows of rentral shields are frepuently blue. The colour-varieties are almost endless. One of the most noteworthy is that describent ats var. corrulen br Eimer; this, confined to the Faragline linckis near (ilpu, is liackish ahore, like the rock. aml silphire-blue below. sinilarly coloured specinens, rar. liffindi, oceur on some of the rocky islets of the Tialearic Isles.

The Wall-Lizard deserves its name, since in the Mediterranean comntries there is scarcely a wall on which these active lizards do mi hask or run up and down, often heal clownwards, in search of insects. They are oviparous. The hibernation is short and not very deep, since these lizards can sometimes be seen batsing an sumy winter days hefore their regular appearance in the early spring.

P'summolromus, with a few species in South-Testern Eurole. notahly in the Iberian I'eninsula and in North-Western Africa, has no distinct semilunar collar, hut hats a short fold in front of each arm. The back is covered with large, rhombice, strongly keeted and imbricating scales. The lateral scales pass gradually into the ventrals, which are smooth and arranged in six longitudinal rows.

I'. lispunicus is bronzy brown above, with small black and white specks. and with one or two longitudinal streaks on each sirle. The under parts are.white. Total length alout 5 inches. Althomgh also fomm inlant, this species prefers sandy dunes, studded with prickly and scanty regetation. It runs very fitst and cligs itself rupidly into the sand when pursued. When candut it either utters a faint cry like "tsi-tsi", or it feigns death. The prairing takes place in June; half-it-dozen egess are laid abmut eighteen days later, deeply imberded in the warm sand, and they are hatched in eight weeks. The exges are sain? to grow after they have been laid from $1: 3$ hy $T$ mm. to 17 20 by $10-11 \mathrm{~mm}$. The newly hatched little creatures numature almut 2 inches in length, more than half of which belongs to the tail.

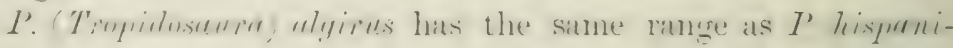
cus, but grows to 10 inches in length, and is much more ${ }^{1}$ Fiseher, Zool. Garten. 1884, 1. 38. 
beatifully coloured. The upper parts are broms larwn with one or two golden, dark-edged, lateral streaks; the under liart: are whitish; the male has one or more blue-eyed spots abort each shoulder.

Accuthudactylus is distinguished hy the laterally fringed ligits. This genus ranges throughout Northern Africa to the Punjab. One species, $A$. vulgriris, extends into Spain and Portugal. The dorsal scales are sinall and almost smooth, lut those on the tail are strongly keeled; the rentrals are nuch broader than long, and are arranged in eight to ten rows. The fringes on the digits are but feebly dereloped in the shape of lateral denticulations. The adults are grey-brown with faint longitudinal stripes, and with more conspicuous black and pale spots; in the breeding season larger blue-eyed spots apyear on the sides near the limbs. The tail is often pink, especially on the under surface. Total length about 7 inches.

Fam. 12. Gerrhosauridae.-Pleurodont African Lacertidae with osteoderms on the head and body.

This family is intermediate between the Lacerticlae and the Scincidae. The tongue is constructed like that of the Lacertidae, but is only feebly nicked anteriorly. Dermal ossifications roof orer the temporal region, and femoral pores are present. On the other hand, the osteoderms, which cover the whole body, are in their structure and arrangement typically Scincoid. The tail is long and fragile. A lateral fold is usually present. The limbs are sometimes reduced to useless stumps. The few genera and species of this family are strictly confined to the African sub-region, being found in the whole of Africa south of the Sahara, and in Madagascar.

Gerihosumps, with a strongly developed lateral fold and complete limbs, occurs in Africa. G. flarigularis, of South Africa, has a total length about one foot.

Tretrectuctylus, of South Africa, has also a strong lateral fold, but the limbs are either very short and pentadactyle ( $T$ '. s'ls), or tetradactyle, or they are minute pointed stumps, as in $T$. africanus.

Fam. 13. Scincidae-Pleurodont lizurds with strongly developed osteoderms on head and hody, with rery fetely nicked. scaly tongue, with complete cranial arches, and with separated premaxillaries. 
The tempural rexion is onvereal over, as in the Lacertidae, with strungly develupred. Jwny, dermal ossifications. Similar asteoterms unlerlie the scales which cover the hoxly and tail. The tongue is relatively short, nut forlied hehind, and but very ferthy nicked at the tip'; it is covered with scale-like prapllate. Femoral pores are absent.

All the skinks prefer dry, sandy around, in which they not mily lnurow, hut move quickly about, either for frotection or in search of their animal food. In connexion with this sandluring and at least temporary sulterranean life stands the fredilent relustion of the limbs. Every stage from the fully developed and functional pentadactyle limb to complete alsence of limb is represented. There are species within the same arenus with five, four, three, or two fingers or tues. There are -kinks without fort-linhls, hut with restigial hind-linnls, and iri, rish. The interesting puint is that these reductions do wut indicate relatimship within the fanily, hut have happened imlegenlently: They are impressive illustrations of convergent retrosersive erolution.

All, flures, wirlely distributed in the Old World, has the hwer erelir transformed into a transparent cover, which is fuser with the rim of the resheed uner lid, exactly as in the Lacertine genus Opliops.

All the sincialate seem to he vivilarnms, some of them, e.s. Trunhysurms, in the strict sense of the word, since the hard or parchment-like egg-shell has been dispensed with.

The family contains alout four humberl species, which have leen arranged in nearly thirty genera, many of then on fanciful -rmunds. The fomily is asmopolitan, but reaches its greatest cliversity in numbers and forms in the tropical parts of the old Worlel, expecially in the Australian region, inclusive of the islanuls of the Pareific. Americal, notahly south Ameriea, hats the smallest number.

T'arhysomens, with one sleecies, T', rmgusus, inhahits the whole of the Australian continent. It is easily reconnised by the laree and rough scales, and the short and hroat stump-like tail. It is dark lonwa alore with yollowish irrenular matrings: the umbles parts atre yellowish, matriel with hrown. - Embryos of this species have yollow transverse bands on the back, but these often facle away before birth. The creature is strictly vivi- 
parous, the egg-meminame leing very thin, and the two or three emlirys are ripened in uterus-like clilatations of the ovilum.s. The period of gestation is about three months, and the hirth takes place, in South Australia, about April. Accorcling to Fischer ${ }^{1}$ this species, which is often in the market, is easily kept. It reduires warmth, sand and stones for basking, and water, in which it soaks itself preparatory to the shedding of the skin, which takes place half-id-dozen times in the rear. and is a sluw process, requiring eight, to ten dars. The fond consist. chietly of worms, lizarils, and snakes, but meat, callinge, anml lettuce are also taken. The total length is about one foot.

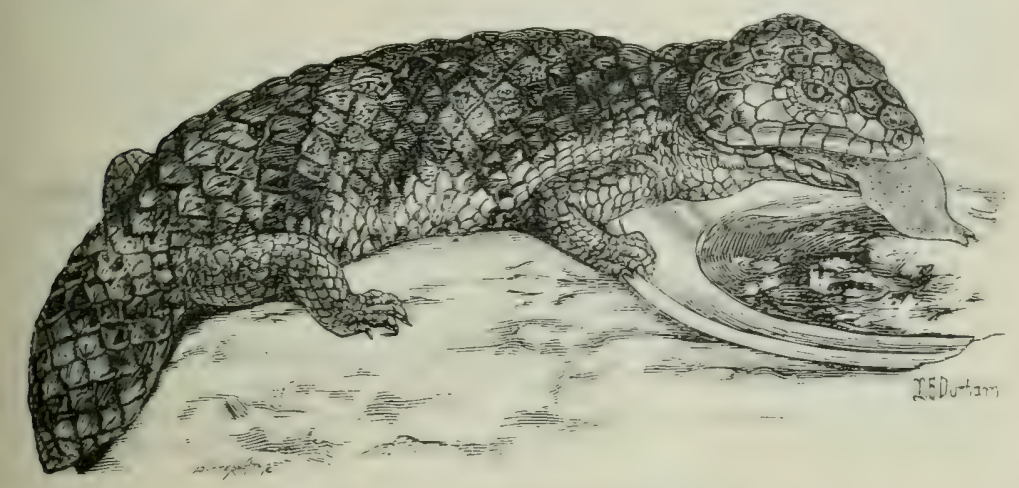

FIG. 145.--Trachysaurus mugosus. $\quad \times \frac{1}{3}$.

Cyeloctes s. Tilique, of Australia, Tusmania, and the Malay Islauds, has stout lateral teeth with spherical crowns. The imbricating, cycloid scales of the body and the rather short but pointed tail are quite smooth and shing. C. gigas, of New Guinea and the Moluccas, reaches a length of nearly 2 feet. The general colour is brownish yellow, with broad, dark bands across the body and tail.

Sirurus, of North Africa, Arabia, Persia, and sindh, has pentadactyle limbs, with laterally serrated digits. The eyelids are well developed, but the ear is hidden under scaly flaps. $S$. uffirinalis, of the Sahara and of Egrpt, grows to ahout $\&$ inches in length. The snout is peculiarly shaped, cuneiforn. The eyes are very small. The scales of the holy are perfectly smooth: the sides of the helly are somewhat angular. The

1 Zool. Gart. 18s2, p. 206.

TOL. VIII 
whole shalpe of the creature, the sates, and the digits an atipiterl to hurrowing and muving quickly through the lonse saml. The seneral culour is rellowish or brownish alowe, each *arle with small lorown and whitish slots: the under parts ure mitorn whitish. The young are yuite beantiful, heing uniform

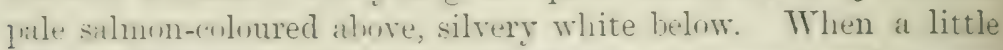
where vellow spots appear on the tlinks and grey bands across the lack. These skinks live in the aholutely dry rechlishrellow sand of the desert, in which they may almost he said to sirin about, so swift and easy are their movements. They live

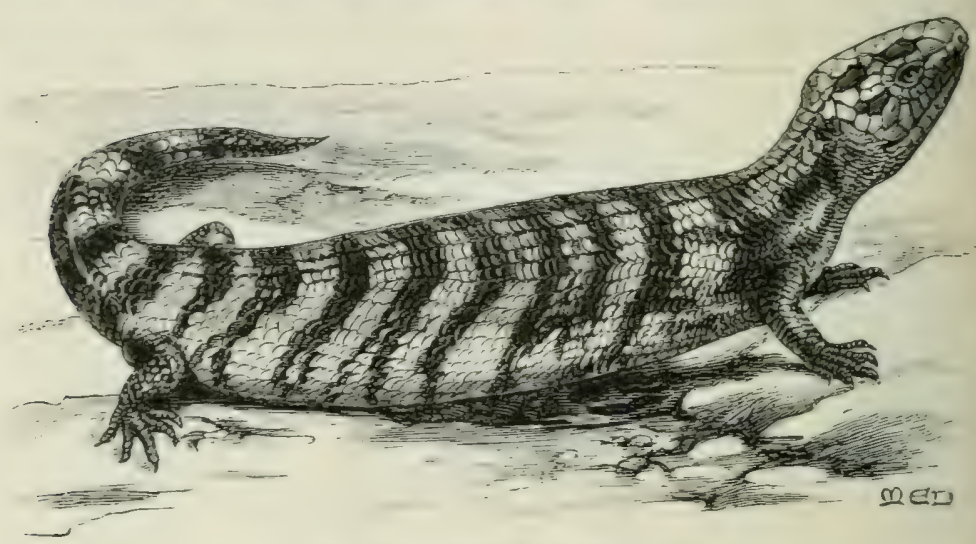

Fia. 116.-Cyclodus gigas, $\times \frac{1}{4}$.

on instects, while in their turn they are eaten hy snakes, and above all by the Varcanus lizards.

Of Mrrtwin with almut forty species, in the whole of Africa, Southern A.ia, and in Tropical Anerica, we mention only $M$.

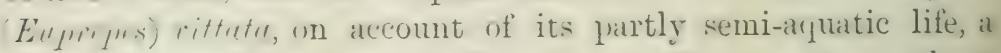
very rare condition anong scincidate. This creature, ahout T inches long when full srown, freduents damp localities in Tunis and Alerria, where the French call it "Poisson de sable."

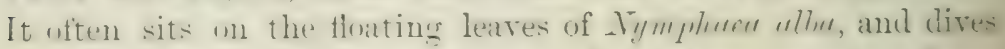
into the water in wrler to escatpe. Its proprer element is, how-ver, the samd, and for the night it retires under stones. The

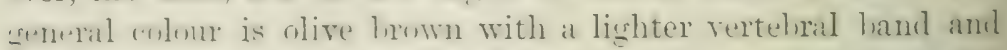
two natruw whitish lines wn each sile, smnetimes edged with black. The under parts are yellowish or greenish white.

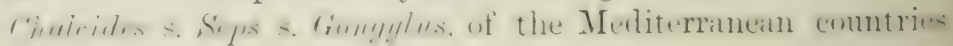


also occurs in South-Western Asia. The lower eyelid hats at tramsparent dise. The body is much elongated, and is corerext with smooth shiny scales. The limbs are rery short, or reduced to mere vestiges.

Ch. occllatus, of the Southern Mediterranean countries, occurring also in Malta and Sardinia, reaches about 10 inches in length. The snout is conical, the ear-opening a small slit or hole. The limbs have five fingers and toes. The under parts are uniform silvery white, but the colour of the upper parts is very variable, mostly olive brown with black spots and irregular cross-bars, or with dark and light spots; sometimes uniform bronzy brown with a light upper and a black lateral band. This Skink seems to have no fixed abode, but digs itself into the sand wherever it wants to hide. The skin is not shed in flakes, but, as in most Skinks, it peels off by a process of gradual desquamation. Fischer's specimens paired towards the end of December. The gestation lasted 56 days, when nine young were born, which measured about $75 \mathrm{~mm}$. or 3 inches; when three weeks old they had increased to nearly double this length.

Ch. lineutus, of Spain and Portugal, and of the South of France, like Ch. triductylus of Italy and North-TTest Africa, has nnly three fingers and toes. The fore-limbs are only alout one quarter of an inch in length in large specimens of 10 inches total length; the hind-limbs are a little longer. The general colour is bronzy olive or hrown ahove, in the former species with nine or eleven darker longitudinal streaks; miform, and with an even number of streaks in the latter species. C $h$. bectriugue, of spain and Portugal, has mostly five fingers and toes, and the limbs are relatively longer in this smaller species; hut it is a question if these and other species of this genus are not to a great extent simply individual variations, since the reduction of the limbs and toes seems to be a very recent feature. $C h$. yuentheri, of Palestine, otherwise in every respect like ('/\%. tridactylus, but reaching a length of more than 14 inches, has the limbs reduced to tiny conical stumps without a trace of separate digits.

I have caught Seps accidentally under stones or pieces of bark in sandy districts. On the western coast of Galicia and Portugil, close to the sea, they frequent the gorse-bushes, on which they can be seen basking, provided they are alynoached 


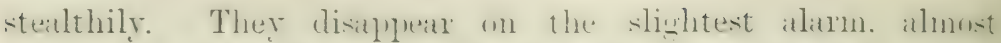
swimming, as it were. with great awility throwgh the mirkly worer, and then hilling and wrigeling through the loose simel between the roots.

The following five "families" are composed of degraded forms of various descent. Most of them lead a burrowing, suhteranean life, in alatitation to which the hody has hecome snatis-slitperl or worn-like. The fore-limbs are entirely alsent. except in Chirotes; the hind-limbs are absent, or reduced to smatl thats: the girlles atre reduced correspondingly. The skull is ilevidel of posturbital, postfrontr-st pamosil, supratemporal, and fucil arches. The qualrate lume is mostly inmovable. The eyes and ears are concealed, except in the Pygopodidae.

Fam. 14. Anelytropidae.- In artiticial assemlily of a few

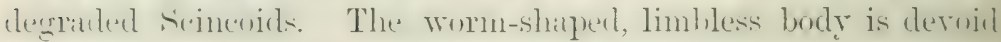
of usteolerms. The tongue is short, slightly nicked anteriorly; and covered with imbricating papillate. Columellate cranii are

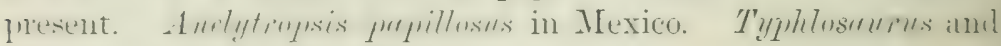
Feylinia in South and West Africa.

Fam. 15. Dibamidae, consisting of the genus Dibumus, with

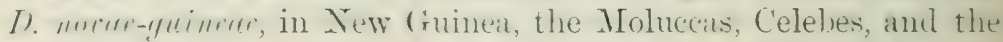
Nicolbar Islands. The tongue is arrow-shaped, undivided in front, covered with curved papillae. Columellae cranii are ahsent. The vermiform boly is covered with eycloid imbricatius scalles without osteoderms. The limbs and even their arches are alsent, lut in the males the hind-limbs are represented by a pair of flaps. Total length of the animal about 6 inches.

Fam. 16. Aniellidae. - The gemus Anidlu comprises a few small worm- or snake-shapeel species in California, which seem (1) lu decrated forms of Anguirlare. The eyes and ears are concraled, limbs are entirely alsent, the body and tail are covereal with soft, imbricating, nome or less hexagonal seales. The tmome is villose, smooth, and hifiel anterionly. The teeth are relatively large, few in numbers, recurved, with short swollen bases. The

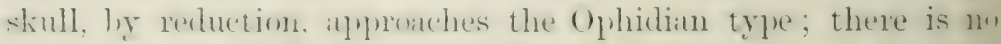
columellat cranii, the fusturhital areh is liganentons, the premaxillary is single, the latsils and fromtals rematin sepanate. the

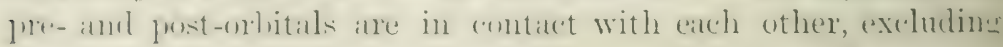
the frontal from the orbit.

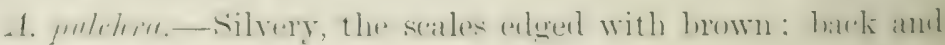


tail with a narrow, brown, median line. Total length, 7 to 8 inches.

Fam. 17. Amphisbaenidae-Worm-shaped lizarls with the soft skin forming mumerous rings, each of which is divided into many little squares, the restiges of scales which are otherwise restricted to the heald. The eves and ears are concealed. Limbs are absent except in Chirotes, which has short four-clawed forelimls. The pectoral arch, and still more so the pelvic arch, are reduced to minute restiges. The tail is rery short. The skull is surall, compact, and strongly ossifierl, in adaptation to the hurrowing life, and is deroid of postmbital and postfiontusquamosal arches and of columellae. The texth are either acrodont

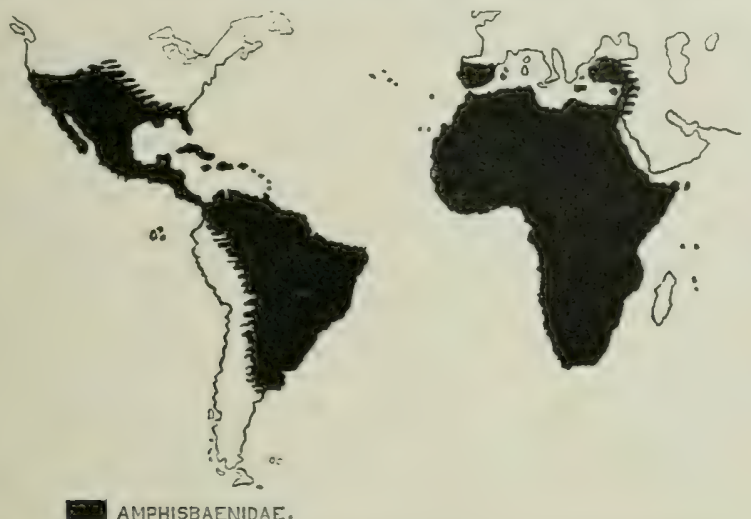

FIG. 147.-MIap showing the distribution of Amplisbaenidae.

or plemodont. The tongue is slightly elmigaterl, corererl with scale-like papillate, and lifurcates into two long and narrow smooth points.

The Amphishonas lead an entirely sulterranean, hurrowing life, like earth-worms. They are frequently fimud in ants' nests (11 in mamure-heaps. Their progression is rery worm-like, their ammulated soft skin enabling them to make almost peristaltic motions and to more backwarls as well as forwards. They crawl in a straight line, with slight rertical waves, not, like other linbless lizards or snakes, by lateral unlulations. The font consists of worms and small insects. Aliout one duzen greneria with nore than sixty species are known, most of which inhalit the witrmer parts of America, the Trest Indies, and Africa. Four inhabit Mediterranean countries. 
If the tonsule and the dentition lie taken as indications of relationship, the Amplishatenidate mat perhaps he considered as derraded descentants of Ignunidate, a family which contains varinus limbless, burrowing. worm-shaped forms. But it is also grosilile that the Amphishatidae are not a natural group. This consileration apllies with nost force to the genera Amphis7nnme and Alumps, the vitrious species of which oceur in America and in Africa.

Chimotrs comalirulatus, the only species of the genus, is the only Amphishatenicl which still pussesses fore-limls. These are short, stmit, plided close behind the head, and are provided with four-clitwed digits. This species occurs in Mexico and California. is brownish or flesh-coloured, and reaches a length of ahout 8 inches.

Amphistmenn, with nearly thirty species, in Tropicul America and Africal. On account of the short rounded-off head and the almost equally blunt tail these creatures are called by the natives "colnas de dous cabezas," i.f snakes with two heads, or they are known as "mats das formigas," i.e. mothers of ants, hecause of their predilection for taking up their quarters in the nests of ants or termites. The scientific name refers of course to their capalility of morine forwards and backwards a a $\mu \phi i s$, at both emils, and $\beta a i v \omega$, walk).

A. fuliginus!!, "ne of the commonest species in South America and in the Test Indies, is cherpered black and white. The shin of the body has ahout two hundred rings, the tail about thirty. Total length between rne and two feet. A more or less distinct forl extends along each side of the body from the neck tr the tail, at the level where the dorsal scales originally joined the ventral scales.

Blanus is the only genus of the Mediterranean province. B. cinereus, of Portugal, spain south of the Cantabrian range. Inoroco, aud Algeria, reaches a length of 10 inches, but such large specimens are rather rare. The general colour of the living animal is pink with a hrownish tinge and with minute grey specks. The lateral lines or folds are well marked, and a stronger transverse fold is placed hehind the head. The lody show: from one humbed and ten to one humber and twenty-fiv. rincs, the tail from twenty to twenty-two: each hodig-ring contains almat thirty little syuares or remmants of scales. There are a few pre-anal pores. 
I have sometimes found this species in I'ortugal whilst diguing for earth-worms in manure-heaps and similar moist places, where they lead the same life as the worms except that they live ulon them and upon insects. When kept dry they become very thin and shrunken, but when put back into moist soil they again beeome turgid and supple within a short time. Those which I hatre kept in glass jars filled with rich mould throve very well, living upon the tiny insects and worms which infest such conlost soil; they dug long tortuous chamnels, in which they mored forwards and sometimes backwards, but they never came to the surface.

Fam. 18. Pygopodidae.-Pleurodont, snake-shaped lizards, without fore-limbs, but with the hind-limbs appearing as a pair of scaly flaps.

The shoulder-girdle is much reduced. The hind-limbs, although rery small and hidden within the scaly, almost finlike flips, still possess five toes. The ischium appears externally as a small spur on either side of the anal cleft. The eyes are levoid of movable lids, remaining open and unprotected; the pupil is vertical. The ear is either concealed or exposed. The tongue is fleshy, slightly forked and extensible. The lody is covered with roundish imbricating scales. The tail is very long and brittle. The few genera of this undoubtedly natural family of unknown relationship contain in all about ten species, restricted entirely, to Australia, Tasmania, and perhaps New Guinea. Next to nothing is known about their habits, except that some of them eat other lizards.

Pygupls lepidopus is distrihuted over the whole of Australia. It reaches a total length of about 2 feet, 16 inches of which belong to the tail. General colour coppery grey above, sometimes with several longitudinal series of dark spots.

Lialis burtoni of nearly the same size and equally wide distribution has the hind-limbs reduced to extremely small, scarcely visible, narrow appendages.

Sub-Order 3. Chamaeleontes.-Acroctont Old-II vild Sirurims with a laterally compressed body, prehensile tail, and well-developed limbs with the digits arranged in opposing, grospring, bundles of two and three respectively.

The Chameleons are an essentially African family. Ahout half of the fifty species known inhabit Madagascar, the others 
the African continent. Onw. the commum Chanelenn, is Nonth Afriman, extemline intw Andilucia: two others oceur in sonth Arabia and Socotra, and mly one in Southern India and Ceylon.

This sub-order is well distinguisherl from all other Saturians lig sereral. musty unique, rharacters. The tongue is club-shaperl and axtrenely projectile, to a length entail to that of the boty.

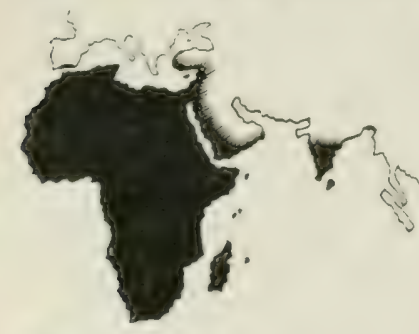

CHAMAELEONTIDAE.

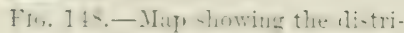
bution of Chameleons. The head is usually described as forming a casque, with prominent crests and tubercles. There is no tympanum and no tympanic cavity. The parietal bones, united into one, extend backwards far beyond the occiput, and the tip of this projection is met by a much-elongated supratemporal bone, which, partly fuserl with the sfuamosal, hellss tn enclose a huge supratemporal fossa. The latter is widely ogers behima. The postfronto-stulmosal areh and the potorlital arch are strmes. The jugal is wislely stolaraterl from the dualrate: the latter stands vertically and is mot renched by the pterregirl. There is no columella cranii. The pre- and post-frontals witen join to form a supra-orlital ruif. The natsals are rery small and are exchuled from the nares, which are lorilered entirely liy the enlarred prefrontals and hy che maxillaries. The premaxillaries are small and carry no

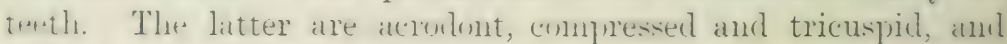
are restricted to the inaxillaries and mandibles.

The linhs are peculiar. Not mly are they relatively long and very slmuler, lut two digits are lermanenty opposed to the other three. On the hatul the first three fingers form an inner humble "Ilymal to the wuter, or fourth and tifth fingers. On the fint the inner lommle is formed hy the first and second, the onter ly the wher toes. The shoulder-sirlle is of the ordinary samian tyje. hut thele are no clavicles and no interclavicle. The costal stermum is well aleveloperl: the rils pusterion to there which meet the

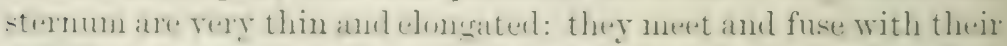
didlows in the menlio-rentral line. These hoopss are not connerted

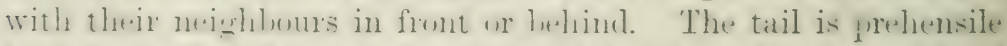

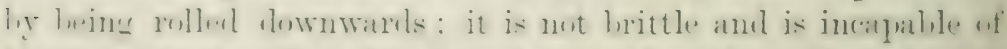

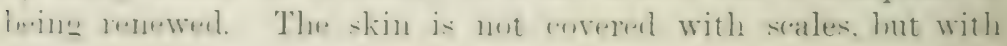


granules. The eyes are rery remarkathe. The eyelalls themselves are large, but the eyelids are united into one fold with a small central opening. However, when the Chamelen is aslete the margins of this opening sometimes hecome more slit.like. The right and left eye can be, and are incessantly, norvert separately from each other, and the creature squints terribly. Each eyeball, together with the pin-liole eyelid, is rolled up and down, backwards and forwards, independently of the other eye. This is a unique feature, but it also occurs in people who squint badly. The question " What, and how, do these creatures see?" is therefore quite idle, especially since in reptiles binocular vision does not exist at all and, consequently, caunot be disturbed by squinting.

The tongue has attained an extraordinary development. The tongue properi (Fig. 152) is club-shaped, and is covered with a sticky secretion. The base or root of the tongue is very
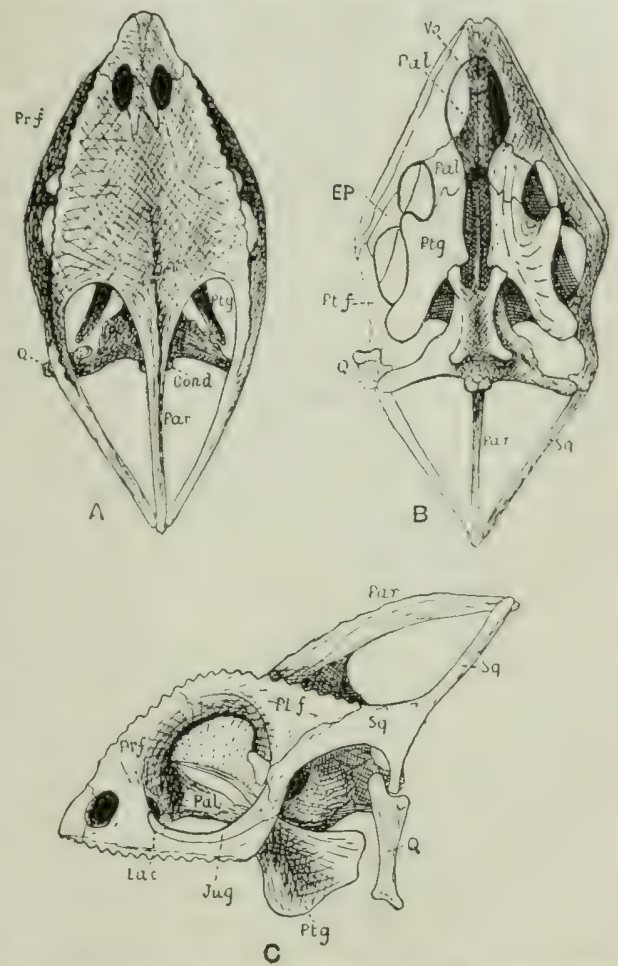

Fig, 149.-A, Dorsil, B, ventral, and C, lateral view of the skull of Chemenferen velguris. $\times 1$. C'oned, occipital condyle ; $E P$, ectopterygoid ; Jug, jugal ;

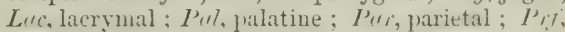
prefrontal ; $P t . f$, postfrontal ; Ptg, pterygoid ; Q, quadrate; $S_{q}$, squamosal ; Vo, vomer.

narrow, composed of extremely elastic fibres, and is supuorted by a much-elongated copular piece of the hyoid. The elastic part of the tongue is, so to speak, telescoped orer the style-shaped copula, and the whole apparatus is kept in a contracted state like a spring in a tube.

A lair of wide, very elastic blood-ressels and special elastic bands extend from the lase into the thick end of the tongue. 


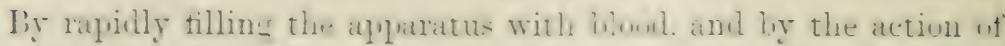

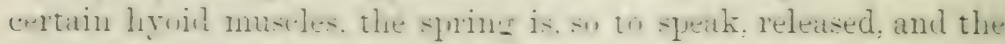
monentum sained by the thich and heary lub-shaped tongutepoper Jrojects it far ont of the munth. The stirky eud of the club shapes itself into an unher and a lower thep. which grartly envelop the

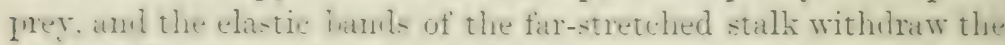

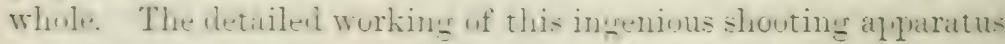
is nut ency to follow. An wdinary full-crown Chaneleon can shoot a fly at the distance of 7 or $S$ inches. The whole ferformance is rery quick, lasting less than one second. When the de-ired whject is rery near. only -2 or 3 inches off. the Chanelem hats a certain ilticulty in shouting its prey. The tongue is at first gut wo slowly, tentatively, the following jerk is fertile, and it serms as if the appratratus refuses to wonk unles: it is allowed to shoot out with full force.

Anther renarkible and yuite groverbial feature of Chaneleons is their changing of colour. This is hy no neans restriched to Chantemins. which indeed are rivalled in this respect by rariuns wher lizards, for instance ly the Indian Asamoid Conlotis and hy the American Ameiva.

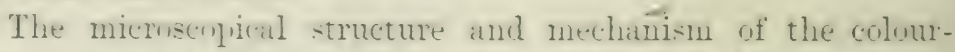

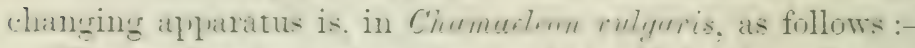

The epilermis is colourless, and the Malpighian laver is not furtionlarly lumlifien except that in it are inheduled sone iridecent cells. with very ninute wary striation on their surface. The entis contains in its leathery tissue a sreat number of small and clocely lawket cells, filled with strongly refractive cranules. chiefly manine-rystals. These cause the white colour hy diffuse reflection of lirect light. The cells nearer the surfice are chareen with oil-ilroge and algear rellow. Large chromatophores are imbehlen in the white granular nass, nust of then with hlachishlirnwn, whers with reidish pirment. the sranules of which arm shifterl up and down. towarils and away from the surface of thr. cutis. in ramified hanches of the chromatophores. When thes. hranches are contracted the pirnnent is convered back into the hullous basal portion of the chrmatophores and the skin aplears yellow or white. When all the gimnent is shifted towards the surface of the cutis. the animal lowks dark. sometimes bivek. In intemenliate conditions the light is changed into green ly diffration through the yollowish uple-1 stratia and ly the finely 
striated iridescent cells of the Malpighian layer. Those prarts inn which the chromatophores do not send pigment apletar as yelluw spots. The chromatophores are to a great extent under cuntrul of the will of the Chameleon, but external stimuli, as heat and cold and other reflex actions, also play a great part in their movements.

For further information on this subject see Briicke, ${ }^{1}$ P. Bert ${ }^{2}$ Pouchet, ${ }^{3}$ Thilenius, ${ }^{4}$ and lastly Keller, ${ }^{5}$ who has written a very long but rather confused account.

The process of moulting is curious. When the Chameleon is in good health the whole process is accomplished within a few hours. The skin to be cast off becomes loose and assumes a

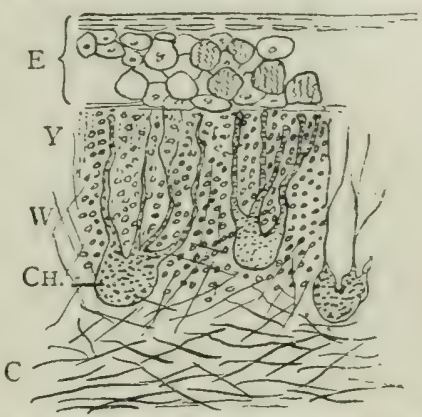

FIG. 150.-Diagrammatic sectinn through the skin of a Chameleon. Highly magnified. $C$, deeper portion of the cutis; $\mathrm{Ch}$, three chromatophores, in varions stages of contraction. fillel with hlack, brown, or retklish pigment; $E$, epidermis; $W$, white layer of granules; $Y$, yellow layer of cells.

blistered appearance. Sometimes the creature looks as if it were wrapped up in white, semi-transparent tissue paper. By rubbing against stones, or between the twigs of trees, the skin comes off in large flakes, first on the lips, then on the contorted body, and last on the under surface of the hands and feet. During a rapinl and successful moult the changes of colour go on as usual in the new skin. Sometimes large thakes of the old shin remain adherent for datss, especially on the top of the head. The moulting takes place sereral times in one year. One of my Ch. vulgaris moulted in January and September, and then not until June of the next following year. A $C h$. pumilus moulterl in the months of May, October, and March.

When they know themselves to be discorered, Chameleoris: make themselves as thin as possible by compressing the boly or rather the belly. This is done by means of the peculiarly elongated abdominal ribs described above. The whole body is then put into such a position that, hy presenting only its narrow edge to the enemy, it has become as little risible ats

1 Denk. Ak. IVicn. iv. 1852.

2 C. R. Ass. Franc. lxxx. 1876, No. 21.

3 J. de l'anat. physiol. viii. 1872, p. 401.

+ Morphol. Arbeit. vii. 1897, p. 515. 5 Arch. Physiol. 1xi. 1895, p. 123. 
fusilile. Ai the sane tine the Chaneleon turns romed upon its twis. sn that the litter connes to stimel letween the olserver inn itsown lunly, which may therely le conpletely hidulen. When ancly, the creature either present: it: broatest surface, swayng tw the rinlt and leftor it blows itself un and hisses. The lungs

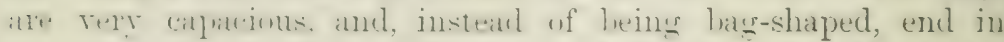

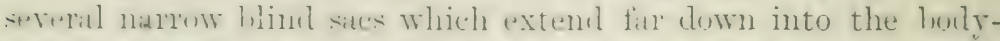
("itrity. $s$ that nut whly the chest but the whole body can lie blown up.

The usual mode of propagation is by means of eggs, but a few species allied to $C h$. pumilus are viviparous. The time of inculation and of gestation is long. Fur instance, the prairing of

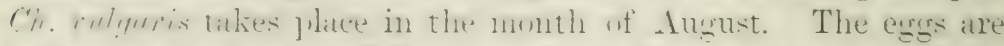
laibl in the list week of Octuber, ahout fifty to sixty days later.

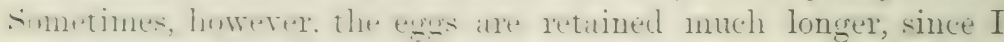

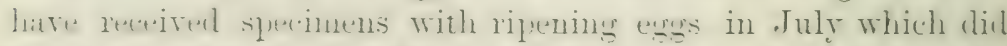

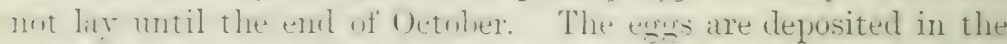
sromed and ane not hateherl until the following Februars or Marr.h. i. almut $1: 30$ dars later. The new-lorn little creatures

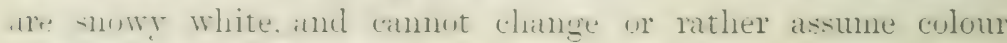
until after the second week.

All Chameleons are insectivorous and require enormous Inintities of forml. which nust lee alive to be taken. Most of

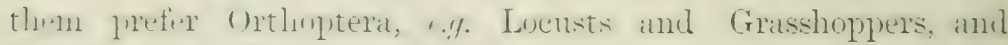

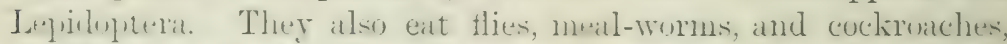
lint their tastes differ not only individually lut also temporarily.

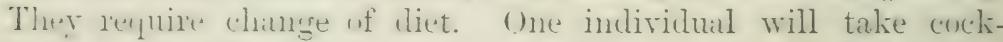
rathes croplily, whilst another of the sane kind will rather starre itwelf than tonch one. The sanne alplies to meal-worms. It is a great lut common mistake to sulpose that Chamelenms (1, nut renuire water. () n the contriry they drink resenlarly and

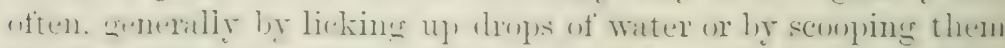
uf, with their lips shoving the susut along the elores of wet leaves. It is not too much to say that most. Chameleons are short-liven in calptivity on acomut of the want of water. Thuse which are sold by the dealers are grenerally in a parched monlition. Fininkling the twigs on leates of their catge with

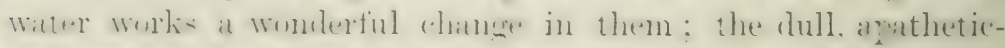

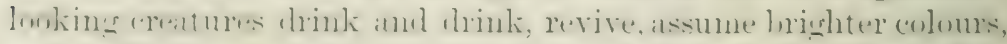
and will som talir fomel. whing they have mutil then refused 
obstinately. Once I have even seen a Chameleon, when put into the greenhouse, make straight for a tank and actually drink in gulps.

After they have fattened themselve's in the antumn, ('hannleons, at least those of North Africa, withdraw to hibernitu in the ground. But nothing is known about how, when, and where they do this, nor is it hown if tropical species aestivite during the dry season.

Chameleons are notoriously difticult to keep successfully, whereby we do not mean the keeping for three to six months. This is easy enough, since it takes them several months to die of starvation. The difficulty is to keep them through the winter. To enable them to do this, it is alsolutely necessary to fatten them up during the summer and autumn. Otherwise, although kept in a warm place, they are liable to lose their appetite in the autumn, when they hecome restless, probalily with the desire to hihernate. Those few inclividuals which set orer this critical period, say during the month of Octoler, and do not refuse food, are probably safe. Thut those are clowned which refuse to eat meal-worms or cockroaches or such food as can be procured easily during the winter.

The origin of the Chameleons is unknown. They form only one family, Chamaeleontidae, with between fifty and sixty species, which, with a few exceptions, belong to the genus chumuelemn.

Ch. vulyaris is the Common Chameleon of North Africa, Syria, and Asia Minor. It occurs also in a few parts of Southem Andalncia, for instance near Jerez, and near Nerja, to the east of Malaga, where it has possibly been introduced. A series of conical, slightly enlarged granules forms a little crest on the median line of the throat. A whitish line, which does not change colour, extend. from the chin to the vent. The rest of the skin, with the exception of a median dorsal series of slightly enlarged tubercles on part of the back, is composed of small granules. A small but distinct lobe of leathery skin extends along either side of the occiput towards the posterior end of the median parietal crest. Deal or spirit-specimens are usually pale yellow; living ones are greenish, usually with differently colonred patches on the sides. Exceptionally large males reach a total length of about 9 inches, females reach the length of perhisls a foot, but alout half of the total length belongs to the tail. 
It is innosilule to say what is the anlene of this Chameleon, since the sane specinen nay whthin a few hays aplyear in half-itdozen different sarts, not comtine minon combinations of colour. After it hats been watched for sereral months, when all its fusililities seem to he exhatustert. it will frobahly surprise ns. la a totally new comlination. Sot erery specinnen changes alike: some lieel the sime appearance for a long time, others change often: some are prartial to specks, others to large patches.

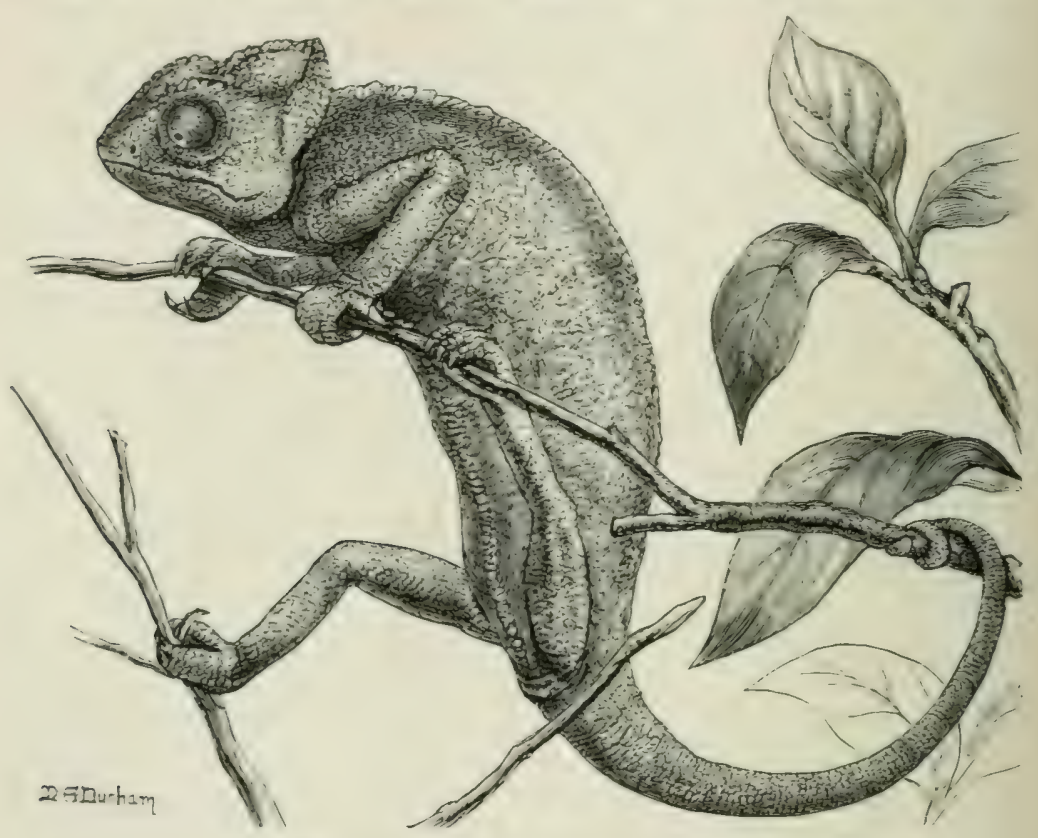

FIG. 151.-Chanacloon velyaris. $\times$ ?

In the group of Chameleons shown in Fig. 152 several of

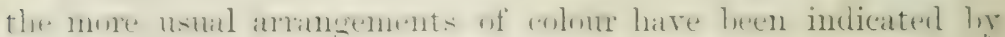
stippling and various kinds of cross-hatching.

A represents the usual coloration at night. The whole

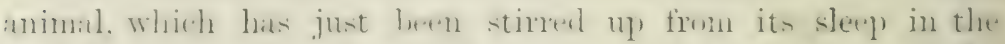

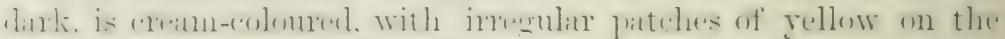
head, the back, the sides of the body, the legs, and the tail.

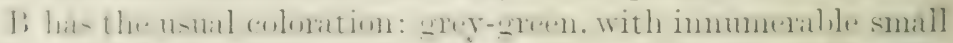

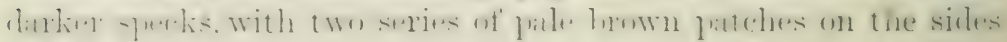
of the loody, and with one patch on the recrion of the ear. 


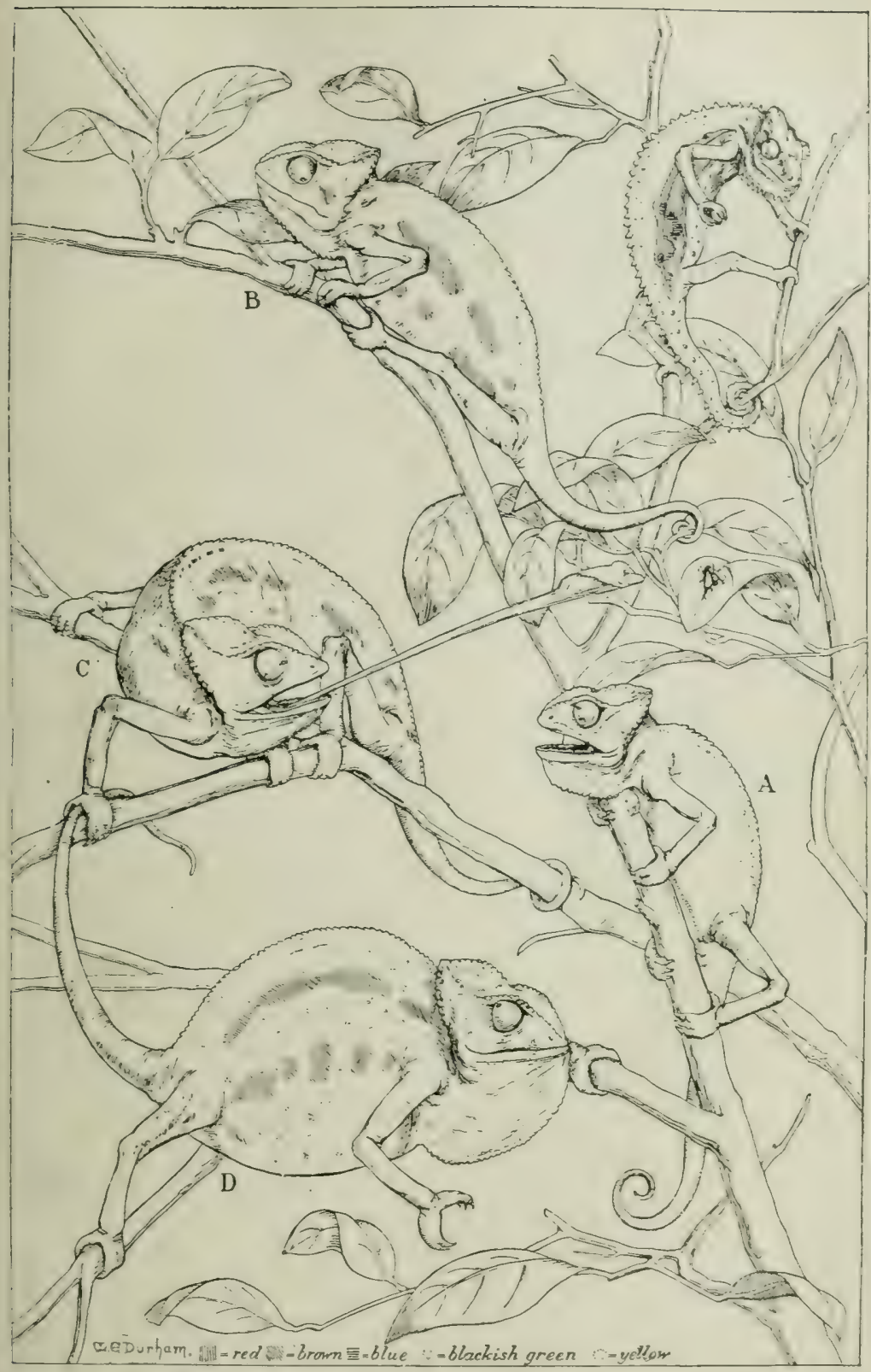

FIG. 152.-Showing changes of colour in Chameleons. A to D, Chamacleon vulgaris (see p. 574). Chamaeleon pumilus in the right upper corner. 
$\mathrm{C}$ is the same specimen in an excited frame of mind; it is represented in the aret of shouting a fly. The light hawn

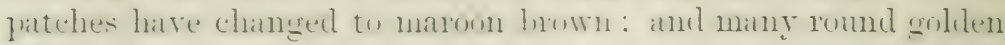
yellow spots have appeared on the green parts.

D shows a specimen, coloured like C, within a few seconds after it has heen fut into an angry numbl. in the present case hy having its tail spueezed. The whole buly is blown cut. the thick tongue causes the throat to hulge out, and all the yellow spots have become blackish green.

Matny smatl slowts scattered over the body are usually a sign of antere. One of the specinnens described alove was, when fint

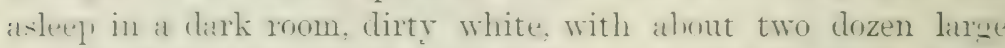
and small romm spots of a rich yellow on each sicle of its bocty. Then a lighted lanne was lrought into the rom without in any way disturling the animal. Within sixteen minutes the vellow slut - had ramished completely: the whole body and tail haul linenne suffused with greenish yellow, which sratually tumed to gale yellowish green, and those parts which in Fig. B are palle hrown, were just distinguishalile as pale yellowish-white regions. The Chameleon was found to lee fiast asleep, and it kept this (n)loration dluring the rest of the evening. Other specimens letelares on sinilar occasions in the sane way, hut the greatest interest is attached to the fict that frequenty only that side of the hoily "greened up" which haprened to he exposed to the light, whilst the opposite side remained whitish. These changes are not alsolutely unconscions; they are, after all, uncler the control of the creature. In order to test the possilility of direct action of the light, I have taken the precaution of throwing the light of a candle only upon the boxly, whilst the head was liept in clarkness. No changes of colour took place whilst the animal was asleet, lut when a little lichlt was allowed to sweep across the chised eye, this soon leesaln to twitch, and although the creature did not open the eye, the usual changes of colour began to take place. When the light was remored, the animal som re-itsumed its whitish appeatrance. Artificially coloured light, for instance green, red, or hlue glass or pater, has apparently no influence upon the changes of colome. The Chameleons hehave as they woulel behave moles ordinity conditions. Ilirect aml hot sumshine howerer causes then to darken, sometines to turn unifom inll biak except fin the white median ventral 
line. Occasionally I found one of the specimens described ahore deep maroon brown, with dozens of round orange spots. Iilue and red do not seem to be within the range of Ch. vulgaris, but the combinations of green, yellow, brown, black, and white, with their various shades, are almost endless. Sometimes the C'hauneleons do not turn pale during the night, but remain more or less dull green, with or without brownish patches. Adaptation to their immediate surroundings takes place to a very moderate degree only, but as a rule they are brightest, especially in their green tints, when they are allowed to sit amongst green foliage. The introduction of a branch with fresh leaves generally has a brightening effect upon those which have previously been confined in a cage with dry twigs only. Cold does not necessarily make them pale, but they appear duller, and the changes take place more slowly. After all, Linnaeus has summed up the little we really know about the causes of these changes, in the following terse sentence: "Tivus varios colores assumit secundum animi passiones, calorem et frigus."

Chameleons are not very amiable. When taken up they blow themselves out or they bite painfully, and it is a long time before they are tame enough not to go through various antics of anger when one approaches them. When taken in the hand they produce a peculiar faint grunting noise, which, however, can be better felt than heard. They quarrel much amongst each other; and the males, during the pairing season, are particularly ill-tempered. Each individual selects its own particular branch to sleep on, if possible a horizontal one, upon which it crouches down lengthwise, with the head and belly resting upon the branch. The tail generally makes a turn round another branch, and the four legs, grasping some supporting branch, are put into any, sometimes into an almost incredibly, awkward position. Although they climb about a good deal during the daytime, they generally resort to their accustomed sleeping branch, and they defend this vigorously against wouldbe intruders.

Chameleons are most deliberate in their morements, sometimes provokingly slow. Each arm and foot leaves the firmly grasped branch with great hesitation, and makes with equal deliberation for some other foothold. It does not matter if the thigh appears almost twisted out of its joint. The creature will VOL. VIII 
remain in the most uncomfortalle position, forgetting, one might think, to put one or more of its linbs down, but keeping them instead in the air.

It is most interesting to watch them stalking their prey. sulpose we have introduced some lutterflies into their romy cage, which is furnished with living plants and with plenty of twigs. The Chameleons, hitherto quite motionless, ferhalys hasking with flattened-out bodies so as to catch as many of the sun's rays as prssible, become at once lively. One of them makes for a hutterfly which has settled in the farther upler corner of the cage. With musually fast motions the Chameleon stilts along and across the hranches and all seems to (a) well, until he discorers that the end of the branch is still $S$ inches from the prey, and he knows perfectly well that 7 inches are the utmost limit to a shot with his tongue. He pauses to think, jerhaps with two limbs in the air, but stability is secured hr a judicious turn of the tail. After he has solved the fuzzle, he retraces his steps to the base of the branch, climbs up the main stem, creeps along the next branch above, and when arrived at the 7 inch distance, he shoots the butterfly with unerring aim. The capacity of the mouth and throat is astonishing. A full-grown Chameleon will catch, chew, and swallow the largest moth, for instance a Sphine ligustri. When large, the prey is chewed, but the wings and legs are swallowed with the rest. Occasionally these parts are bitten off, especially the prickly long legs of large locusts.

In water Chameleons are quite helpless. Sometimes they inflate themselves, hut they always topple orer on to the side, and the movements of their limbs are absolutely without any definite purpose.

When the erges are ripe, and this happens with the Common Chameleon alout the end of October, the female refuses to take ford, and leconnes restless. One of my specimens searched ahout probing the gromul for alwout a week before she dug at hole in some more solid soil. This took two days. In the evening I fomm her sitting in the hole to the midulle of her hody. On the following morning she was still there, but busy filling the hole with soil and covering it with dry laves. A few expes were lying abmut outsicle, two of which at least I saw her taking up ly the hamd and futting them on the 
nest, which was found to contain some thirty soft-shelled eggs closely packed upon each other. During the whole process she was rery snappr, and hissed much when approached. After that she crept into the twigs as usual, but refused to eat, romited at once the artificially introduced food, became restless on the sixth day, crawling about at the bottom of the cage, and died on the following day. This is the usual fate, almost without exception, of females after they have deposited their exgs in captivity. The great number of eggs and their deposition naturally exhausts them, and they probably want to hibernate at once. The eggs, which are yellowish, long-oval, about half an inch long and covered with a parchment-like shell, are very difficult to rear, chiefly on account of the difficulty of regulating the moisture. They shrink up when too dry, and they are very liable to become mouldy. According to Fischer ${ }^{1}$ the eggs can be hatched in a large flowerpot with a layer of horse-droppings at the bottom, then a layer of 6 inches of slightly moist soil, then the eggs, then another 6 inches of loose soil, with a glass plate covering the top, securing at the same time rentilation. In this way he succeeded in hatching several sets of eggs after $12 \tilde{y}$ and 133 days respectively.

$C \%$. calcaratus, the Indian Chameleon, is found in the southern half of the Peninsula and in Cerlon, but it is far from common. It much resembles C' $/$. vulgaris, but the male is distinguished br a tarsal process or "spur," corered with skin, on the immer side of the foot.

Ch. pumilus, the Dwarf Chameleon of South Africa, reaches a total length of 5 to 6 inches. It has a well-marked, serrated gular crest, which extends from the chin to the end of the neck. The chest and belly are without a toothed line, but a strongly serrated series extends from the occiput orer the back and tail (see the right upper corner of Fig. 152 on p. 575 ). A row of enlarged tubercles or scales extends along the sides of the hody. The greneral colour is green, with a large and long patch of brickred on the sides; small dots and spots of intense red are scattered over various parts of the body. The changes of colour are rather limited. At night the Dwarf Chameleon does not turn pale, but generally keeps its colour. When they are rery well the green is quite saturated, and the large red patch on the side is

\footnotetext{
1 Fischer, Zool. Gart. 1882, 1. 4.
} 
interrupterl by several hue sprits. Then they are angry or mhitly the red turns inte dirty lrown, and the green becomes quite lull. Simetines the whole aninal turns dull hlack.

This pretty little species is relatively harly, being, as a native of Sonth Africa, accustoned to cold nights. It does well in an whinary temperate seenhouse, where it will live for several rears: proviled it has an ample supply of thes and meal-worms. It is viviparous, the young being frobably born in the month of March or April.

(\%). Difutus, of Madagascar, shows an extraordinary difference lietwern the sexes. The male reaches the great length of 1i inches, and derelops two lous rostral processes, which extend forwards liegond the snout; these processes are formed of denve connective tissue, which ossifies in the adult, and they are covered with scaly skin.

(\%. Mrisoni, likewise of Madagascar, is the giant amongst Chameleons, reaching a total length of 2 feet. The male has two large rostral processes which diverge upwards and outwards.

Birmksin, with sereral species in Madagascar, may be mentioned on account of its stunted appearance. The tail is much shorter than the body and scarcely prehensile: the scales on the soles are spinous. Total length only about 3 inches.

lihamplemenn, of tropical continental Africa, with several species, is likewise remarkable for the stunted and dwarfed appearance, and for the peculiar claws, each of which is furnished with a second cusp which is directed downwards. The tail is much shorter than the body. The total length of Ph. spectrum of the Camaroons is about 3 inches. 


\title{
CHAPTER XIII
}

\author{
SAURIA, continued-OPHIDIA-SNAKES
}

\section{Order II. OPHIDIA-SNAKES.}

Saurians which have the right und left hatres of the lower jow connected by an elastic band.

The Snakes are the most highly specialised branch of the Sauria, from which they do not differ in any fundamental characters. The chief modifications consist in the absence of the limbs ancl limb-girdles (a feature intimately correlated with the muchelongated body), and in the swallowing apparatus. The reduction of the limbs and the elongation of the body also occurs in many Lacertilia; in several of the older families of Snakes (r.\%. Typhlopidae and Boidae) vestiges of the hind-limbs and even of the pelvis are still in existence. Even the peculiar suspensorial apparatus of the lower jaw approaches that of the Lacertilia in the burrowing Ilysiidae and in Xenopeltis.

In the majority of the Snakes the quadrate is very loosely suspended from the squamosal (l)y some authorities homologised with the supratemporal bone of other reptiles), and this again is loosely attached to the lateral parietal region of the skull, placed horizontally, and elongated so far backwards that the vertically placed quadrate lies in a plane behind the skull. In most Snakes the elongated pterygoids are loosely attached to the inner side of the distal end of the quadrates, and they also often touch the mandibles. The whole palatal apparatus is movably attached to the skull, except in some burrowing families. The right and left pterygoids and palatines are willely separated from each other: The pterygoids and maxillaries, connected by the ectopterygoids, are absent, owing to reduction, in the Typhlo- 
pidae and Glauconiidae only. The premaxilla is unpaired and small, and is rarely furnished with teeth. The latter are always sharp and recurved, and are lodged in sockets upon the edge of the sulporting bone, with which they become firmly ankylosed. There is a perpetual succession of teeth. In the majority of Snakes teeth are carried ly the maxillaries, palatines, pterygoids, and dentaries, rarely by the premaxillaries. The palatal teeth are restricted to the palatines in Oligulun, Dasypeltis, and Atractaspis only.

Peculiar modifications prevail in the poisonous Snakes. Those maxillary teeth which are at their base in connexion with the openings of poison-glands (modified upper labial (ylinds), either have a furrow on the anterior side (Proteroglyphi if the anterior teeth are groored, e.y. the Cobras; Opistho. (1) pha if some of the posterior teeth are groored), or the groore is converterl into a canal, as in the Solenoglypha or Viperidae. The special modification of the maxillaries of the vipers with their long poison-fangs is described on pp. 587 and 637.

The orlit is generally closed behind ly the postfrontal. Quadrato-jugal, postfronto-squamosal, and other arches are alsent, so that the temporal fossa is quite open (see Fig. 156, p. 59 \%, and Fig. 155, 1. 596). The occipital condyle is distinctly triple. The mandibles are composed of sereral bones, but the coronoid is alsent in the Xenopeltidae, Colubriclae, Amblycephalidate, and Tiperidae; it is large in the Boidae, reduced to a nodule in the Ilysiidae.

The parietals are always fused into a large umpaired bone. which senerilly forms a sharp crest and partly overlaps the wecipitals; there is no interparietal or pineal formen.

The rerteliral column consists of many, often nearly three humbed vertelorae, and these sheletal segments currespond in number with those of the rentral and transverse scales of the skin. The vertebrate are procoelous; in atdition to the anterior and posterior zyganophyses they have a prir of accessory articulations on the neural arches, dorsally to the zygapophyses; - the "zygantrum" carried by the posterior end of the nemal arches, its articular surfaces looking upwards : and the "zygosphene" carried by the anterior end and looking downwarts. Suci, accessory articulations oceur also in a few Lizards, e.q. Ignamidale. The vertehrae of many Snakes have muaired vertical, blade-lilie 
haemapophyses on their centra for the more effective attachment of the muscles. All the vertebrae, except the atlas, carry rils. These articulate by their capitular portions only, and are rery movable in a head- and tail-ward direction. The ribs being long, and fitting with their ventral ends into the connective tissue of the sides of the rentral transverse scales, are the principal agents in pushing the body forwards, the posterior edges of these scales being sharp and imbricating.

The skin is covered with scales, absolutely devoid of osteoderms. When the scales are enlarged ther are called shields. The keel, a common feature, is caused by a slight ridge of the cutaneous part of the scale. The whole skin is covered with a thin layer of horny epidermis, which is shed frequently: at least several times in one year; the shedding begins at the lips, and the whole outer skin is turned inside out from head to tail, retaining every minute detail of the cutaneous scales: eren the watch-glass-like covering of the eyes is preservecl.

The eyes are peculiar in so far as they possess no lids. The latter are still present in a restigial condition in the emlryo, but their place is taken by what is probably a modification of the nictitating membrane, which is drawn over the eye and covered with a single transparent scale of the horny shin, like a watch-glass. The eyes themselves are not morable. The "tears" which of course cannot appear on the outside, are drained off into the nasal cavities by the naso-lacrymal ducts.

The ear is likewise peculiar. There is a long columellar rod with a fibrous or cartilaginous pad at the outer end, which plays against the middle of the shaft of the quadrate, an arrangennent which, we must assume, produces a thundering noise in the internal ear, since every motion of the quadrate during the act of swallowing conveys the vibrations directly to the fenestrat ovalis. The tympanic cavity, the Eustachian tubes, and the tympanum are abolished, and no external traces of the ear are visible. However, in spite of all this, Snakes can hear rery well.

The nose is rell developed, and many Snalies, for instance the Crass-Snake, are guided to their prey as much by the sense of smell as by the eyes and ears. The tongue is slender, rery protractile and bifid, always moist, and furnished with many sensory corpuscles. It acts entirely as an additional sense-organ, hence the incessant play of the tongue of a snake which wants 
to investigate anything. In spite of the protractility of the tongue, the hyoid alparatus is rery small: the hyoid arches themselves are remluced to mere restiges near the base of the first and only branchial arches. which are thread-like and extend backwards down the throat.

The trachea is very long, and opens far forwards in the mouth; it can be slightly protruded between the two Jalves of the lower jaw sis ats not to be lilocket during the act of swallowing. This is a lalwrions grocess. The snake, having got holl of its prey with its teeth, generally shifts it into the must (omvenient pusition, in order to swallow the head first. One half of the mamlitile is then pushed forwards, then the other lialf: the recurved teeth affurd the necessary hold, and the snalie, little by little, llaws its mouth-carity, and later on itself, wer the jrey. In fact, it literally gets outside it. Sometimes with a large rictin this process may last for hours: the whole month and head hecome pianfully distended and the veins swollen almust to bursting. The snake pushes the prey against a stone or other obstacle, rests awhile quite exhausted, and hegins afresh. At liast the lunk of the prey has passed the mouth, the skin of the neck is stretched to the utmost, the scales being separated by wide interstices, the rilss work spasmodically, the rictim is fresied into the shape of a sausage, and the deed is done. In orrler to assist deglutition there is a great amount of salivation, lut the often-heard story that snakes cover their prey with silival lefore they swallow it, is a firble, or based upon faulty olserration, snakes sometimes leing forced to disgorge the half-swalluwed jury, which, in such a case, is covered with slime. One of my tame snaties had swallowed a frog on my talle when a frient entereel the rom. The snake was frightened, jumper on to the sromm, striking it with its full belly, and therely. lowting the frow, which sifueaked loudy, whereupon the snatie reversed its medhuism and the frog hopped away, none the worse for its terrible experience.

In exrelation with the elongated narrow space of the bodyarity the lungs are nut equally dereloperl, the left heing much smaller than the righte. The batter is a rery thin-walled, hollow hats, and the posterior half or third scarcely contains ans of the

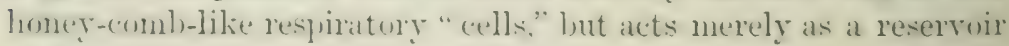
of air. 
The cloacal arrangement is essentially the same as that of the Lacertilia, but Snakes possess no urinary bladder. The copulatory organs are stowed away beneath the skin in recerses of the posterior lateral corners of the shallow cloacal restibulum. Each organ is grenerally bifurcated at the free end, and furnished with little spike-shaped, hut scarcely horny, excrescences. On each side of the outer cloacal chamber, in both sexes, lies a roundish gland with an offensive, strongly-scented secretion; that of various Boas smells disagreeably sweet and musky. The majority of Snakes lay eggs, but most of the Tiperidae and the thoroughly aquatic kinds, besicles a few ter-

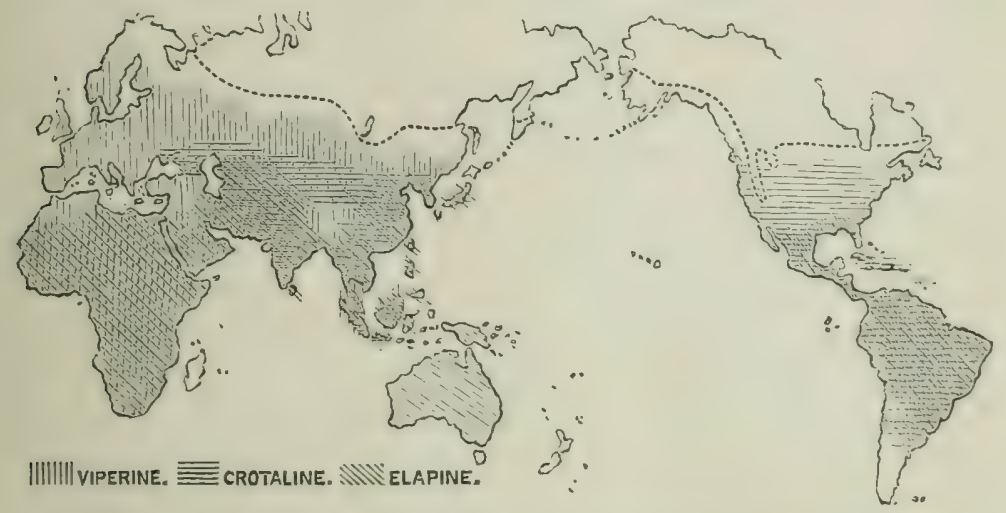

FIG. 153.-Nap showing the distribution of dangerously poisonous snakes.

restrial forms, are viviparous. The egg-shells are like parchment, with very little or no calcareous deposit, so that they are always soft; many embryos are, howerer, provided with a little "egg-tooth" on the tip of the snout.

Snakes are intelligent creatures; some become quite alfectionate in captivity, but most of them are of a morose disposition, and do not care for company.

The geographical distribution of snakes has been dealt with in cletail in commexion with the various families. Infortunately rery few fossils are lnown. One of the oldest is Pulucoptis, of the London clay (Lower Eocene). Remains of Elipine and of inmocuons Colubrine snakes have been found in the Lower Miocene of Germany: Crotaline forms are known from the Miocene of Turkey and North America. All the Plistocene 
remains belong to recent genera. There are indications that the Oplicliat are a relatively young luanch of Reptilia, essentially of Tertiary date, but the foundations of the distribution of most of the older families were laid in Miocene times. The older families, notully those which still possess vestiges of hind-limbs ar of the pelris, are circuntropical, e.g. Typhlopidae, Boidae. The few survivors of the Glatuconidate are likewise circumtropical, with the exception of Australia. The Ilysiidae occur in Sonth-Eastem Asia and in tropical Sonth America; their offisoot the Lropeltidae are restricted to India and Ceylon. The Colubridate and even many of their sub-families are cosmopolitun. It is quite possible that the Opisthoglypha and Proteroglylia are not natural groups, but that their respective conditions hare been developerl on various occasions and in different countries. The same applies more strongly to the Tiperitie, a further development of the Opisthoglyphous type. To jurlge from their distribution, the Crotaline snakes were posilly dereloped in the Palaearctic sub-region; they spread all over Anerica, but they were debarred from entering either Australia or Africa. The Vipericlae, on the other hand, are restricted entirely to the Palaeotropical region and to the Palatarctic suls-region. The fact that no separating belt of water existed for them between Europe and Africa, indicates their being the most recently developed of poisonous snakes. Matlatiscar is the only large comntry which, hesides snakeless Tew Zealami, enjoys a total alsence of poismous snakes of any kind, while the Oriental is the only sul-region which suffers from the juesence of numerous species of every sub-family of proisonous Elapine, Crotaline, and Viperine snakes.

sinnli-l'misun.-Many Snakes, belonging to different families, are proisonous, and unfortunately there is no external character, easily ascertained, by which every poisonous snake can be distinguished firm a hamnless hind. If the head is very broad, this is probalily due to the pair of poison-glands on the sides of the hearl; lut many harmless snakes can flatten and broaden their heals in a suspicious way, and, what is much worse, numy of the most poisonous snakes, for instance the Cobras, have a hearl as smouth and as sleek-looking as the Grass- or RingSnilie, the most latrmless of species. It so happens that, with a fir exeeptions, for instance among the Crotalines and Vipers, no 
badly poisonous snake has loreal shields, i.e. a pair of shielels intercalated between the nasals and the preoculars, but this character is obviously no good for any practical purposes. Therefore, unless you know a snake well enough when you see it, leave it alone, because a mistake may be fatal.

The poison is secreted in modified upper labial glands, or in a pair of large glands which are the homologues of the parotid salivary glands of other animals. ${ }^{1}$ A duct passes from the gland forwards along the side of the upper jaw. Just in front of the fang it doubles on itself, so as to open by a small papillat on the anterior wall of the sheath of nucous membrane which embraces the base of the tooth like a pocket. As mentioned before (p. 582), the poison is conveyed either along a furrow on the anterior side of the tooth, or the growing substance of the tooth partly converts the furrow into a canal which opens only near the end of the tooth. This is a perfectly derilish contrixance, ensuring the conveyance of the poison into the rery deepest part of the wound. The Elapinae have relatively short. fings, while those of the Vipers, and especially those of the Crotaline snakes, are much longer, sometimes measuring nearly an inch in length. The most formidable apparatus is that of the Tiperidae, since in them the maxillaries, each provided with only one acting fang, and without any other teeth behind, can he erected. The mechanism is explained in Fig. 154 and Fig. 179 (p. 647, The apparatus of the upper jaw is so constructed that the pushing forwards of the horizontal pterygoid bar will, by acting on the ectopterygoid, rotate and erect the short maxillary. The pulling forwards is effected by contraction of the sphenopterygoid muscle, which arises far forwards from the hasal orbito-sphenoid region, and is inserted on to the inner dorsal surface of the pterygoid. The principal closing muscles of the mouth are the temporo-masseteric muscles (Fig. 179, T.a. and T.p.) and the inner and outer pterygoid muscles, which latter arise from the outer surface of the pterygoid bone, or from the maxillary, and are inserted on to the articular region of the mandible.

A strong ligament arises from the squamoso-quadrate junction, and spreads fan-shaped upon the connective tissue

1 For a detailed anatomical account, see West, J. Limn. Soc. xxy. 1895, 1) 419 ; xxvi. 1898, p. 517 ; and xxviii. 1900. 
will of the poison-gland: the anterior and posterior ends of the gland are held by another strong land, which stretches from the maxillat to the mandihular joint. The whole is so arranged that the acts of opening the jaws (by the digastric muscles) and the erection of the fang-bearing maxillaries are enough to mechanically squeeze the contents out of the poison-gland. A
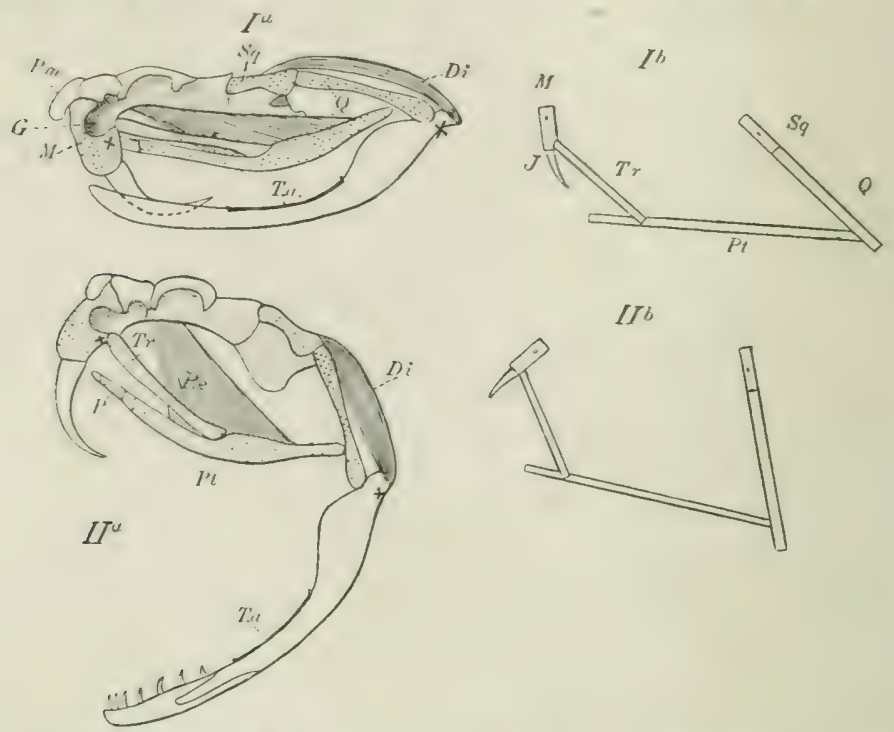

$I T b$

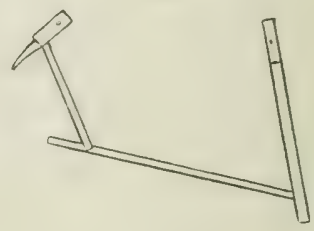

FIG. 154. - Explanation of the biting mechanism of a rattlesnake. Ia and $1 b$, position of the apparatus when the mouth is shut. IIa and $I I b$, position of the apparatus when the mouth is opened widely; the spheno-pterygoid muscle $\left(l^{\prime} \cdot c\right)$ is

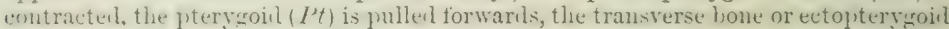
$(T r)$ pushes the maxillary $(I /)$, rotates it and thereby causes the poison-fang $(J)$ to assume an erect position. Di, Digastric muscle, contraction of which lowers, or opens, the lower jaw; $G$, the groove or pit eharacteristic of the Crotaline snakes; $J$, poison-fang; $I$, maxillary; $P$, palatine ; $P$.e, spheno-pterygoid muscle ; $P$, premaxillary; $P t$, pterygoid ; $Q$, quadrate ; $S q$, squamosal; $T . \varkappa$, insertion of the anterior temporal muscle, by contraction of which the mouth is shut; cf. Fig. 179 (p. 647) ; $T r$, transversum or ectopterygoid ; $\mathrm{X}$, origin and insertion of a muscle and a strong ligament, contraction of which draws the maxillary and its tooth back into the position of rest and assists in shutting the mouth.

portion of the anterior temporal muscle is attached to the capsule of the poison-gland.

An excellent account of the nature and of the effect of the venom of Snakes has been written by Charles J. Martin. ${ }^{1}$ The following condensed account has been abstracterl from it:- "The poison is a clear, pale yellow, or straw-coloured fluid,

2 Cliflord Allbutt's System of Medicine, vol. ii. London, 1896, 1. 809. 
which reacts acid, and contains about 30 per cent of solids, lut this raries much according to the state of concentration. MIost venoms are tasteless, but Cobra poison is said to be disargreealily bitter. Dried venom keeps indefinitely, and dissolves reulily in water. It keeps also in glycerine. It contains albuninous bodies in solution. The renom is, in fact, a pure solution of two or more poisonous proteids, which are the active agrents, with a small quantity of an organic acid or colouring matter. The renom is destroyed by reagents which precipitate proteids in an insoluble form, or which destroy them, e.g. silver nitrate or permanganate of potash. Hypochlorites have the same effect. Carbolic acid and caustic potash destroy it only after a day or two.

"The venom is generally introduced into the subcutaneous tissue, whence it reaches the general circulation by absorption through the lymph and blood-vessels. When introduced directly into a vein, the effects are instantaneous. It is absorbed by the conjunctiva, but, excepting Cobra poison, not by the mouth or alimentary canal, provided there be no hollow teeth or no abrasions. The venom of the various kinds of Snakes acts differently.

"The symptoms of Cobra poison. Burning pain, followed by sleepiness, and weakness in the legs after half an hour. Then profuse salivation, paralysis of the tongue and larynx, and inability to speak. Vomiting. Incapability of movement. The patient seems to be conscious, but is unable to express himself. The breathing becomes difficult. The heart's action is quickened. The pupil remains contracted and reacts to light. At length breathing ceases, with or without convulsions, and the heart slowly stops. Should the patient survive, he returns rapilly to complete health.

"The symptoms of Rattle-snake poison. The painful wound is speedily discoloured and swollen. Constitutional symptoms appear as a rule in less than fifteen minutes: prostration, staggering, cold sweats, vomiting, feeble and quick pulse, dilatation of the pupil, and slight mental disturbance. In this state the patient may die in about twelve hours. If he recuvers from the depression, the local symptoms begin to play a much more important part than in Cobra poisoning: great swelling and discoloration extending up the $\operatorname{limb}$ and trunk, rise of 
temperature and repeated syncope, and laboured respiration. Death may occur in this stage. The local haemorrhagic extravasation frequently suppurates, or becomes gangrenous, and from this the patient may die eren weelis afterwards. Recovery is sudden, and within a few hour's the patient becomes bright and intelligent.

"Srmptoms of bite from the European Viper. Local burning pain; the bitten limb soon swells and is discoloured. Great prostration, romiting, and cold, clammy perspiration follow within one to three hours. The pulse is very feeble, with slight difficulty in breathing, and restlessness. In severe cases the pulse may hecome imperceptille, the extremities may become cold, and the patient may pass into coma. In from twelve to twenty-four hours these serere constitutional symptoms usually pass off, but in the meantime the swelling and discoloration have spread enormously. Within a few days recovery usually occurs somewhat suddenly, but death may occur from the severe depression, or from the secondary effects of suppuration.

"Symptoms of bite from the Daboia or Tipera russelli. These resemble the effects of Rattle-snake poison, but sanious discharges from the rectum, etc, are an additional and prominent feature. The recovering patient suffers from haemorrhagic extravasations in various organs, besides from the lungs, nose, month, and bowels. Kidney haemorrhage and albuminuria is a constant srmptom. The pupil is always dilated and insensitive to light.

"Symptoms of bite of Australian Elapine snakes. Pain and local swelling. The first constitutional symptoms appear in fifteen minutes to two hours. First faintness, and an irresistible desire to sleep. Then alarming prostration and vomiting. The pulse is extremely feeble and thread-like, and uncountable. The limbs are cold, and the skin is blanched. Respiration becomes shallow with the increasing coma. Sensation is blunted. The lupil is widely dilated, and insensible to light. There is sometimes passing of hlood. If the patient survives the coma, recovery is complete and as a rule rapid, without secondary symptoms. The Australian venom and that of all viperine snakes, perhaps also that of the Cobra, if introduced rapidly into the circulation, occasions extensive intravascular clotting. If the venom is slowly absorbed, the blood loses its coagulability, 
owing to the breaking down of the red blood-corpuscles, most so with vipers, less with Australian snakes, least so with the Colura. The Cobra venom is supposed to extinguish the functions of the various nerve-centres of the cerebro-spinal system, the paralysation extending from below upwards, and it has a special aftinity for the respiratory centre. The toxicity or relative strength of the Cobra renom has been calculated to be sixteen times that of the European Viper. Snakes can poison each other, even those of the same kind.

"Treatment.-Apply a ligature above, not on the top of the situation of the bite; twist the string tightly with a stick. Then make a free incision into the wound. Sucking out is dangerous! Then bandage the limb downwards, progressing towards the wound; repeat this several times. Direct application into the widened wound of calcium hypochlorite, i.e. bleaching powder, is very good, or of a 1 per cent solution of permanganate of potash, or Condy's fluid. Amputation of the finger is the best remedy of all if a large snake has bitten it. Do not keep the ligature longer than half an hour. Then let the circulation return, and apply the ligature again. In any case, do not keep the ligature on for more than one hour for fear of gangrene.

"Internal remedics. - The administration of enormous doses of alcohol is to be condemned strongly : small stimulating doses are good, but stimulation can be more effectirely produced by ammonia or strychnia. Hypodermic injection of strychnine, in some cases as much as one to two grains (but not into a rein :) has in some cases had good results; but injection of ammonia, instead of doing any good, has disastrous sloughing results. There is only one fairly reliable treatment, that by serum therapentics, the injection of considerable quantities of serum of animals which have been partially immunised by repeated doses of snake-renom. Unfortunately this treatment will not often be available."

Sereral well-known Mammals and Birds are immune by nature against snake-venom, but most of them avoid heing hitten. Some birds induce the snake to strike and bite frequently into their spread-out wings. Such more or less common creatures are the Mongoose, the Hedgehog, and the Pig, the Secretary bird, the Honey Buzzard, the Stork and probably other snake-eaters. 
Classification of Ophidia.-Inuméril and Bibron ${ }^{1}$ divided Snities according to their teeth into Opotérodonts, Aglyphodonts, Solenoglypha, Proteroglypha, and Opisthoglypha.

J. E. Cray 2 divided Snakes into two sub-orders: Viperina and ('olubrinia. Griinther ${ }^{3}$ distinguished between Ophidii colulnifimmes, $\mathrm{O}$. coluhniformes venenusi (Elapidae and Hydrophidae) and 0 . viperiformes. Copre ${ }^{4}$ laid stress upon the modifications of the sifuamosal, ectopterygoid, and endopterygoid bones, and also nym the condition of the restigial limbs. He dirided the snakes into Scolecophidia (Trphlopidae), Catodonta, Tortricina, Asineat the harmless snakes without liml-restiges), Proteroglypha, and Solenoglypha.

Bunlenger" has accepted Cope's principles, and, mainly by comlining the Asinea with the Proteroglypha as Colubridae, has produced a logically conceived system, ly far the best hitherto inoposed. It has been followed in the present work. Boulenger's phylogenetic system stands as follows:-

5 Uropeltidae : $7 a \mathrm{C}$. Opisthoglypha $76 \mathrm{C}$. Proteroglypha

9 Viperidae

I. No ectopterygoid; pteryoid not extending to quadrate or to mandible; no supratemporal (squamosal); prefrontal forming a suture with nasal; coronoid present; vestiges of pelvis.

Maxillary rertical, loosely attached, toothed; mandible edentulous ; a single pelvic bone. Typhlopidae, p. 593.

Maxillary bordering mouth, forming a suture with premaxillary, prefrontal, and frontal, toothless; lower jaw toothed; pubis and ischium present, latter forming a symphysis. Glanconiidae, p. 594.

II. Ectopterygoid present; both jaws toothed.

A. Coronoid present; prefrontal in contact with nasal.

1. Vestiges of hind-limbs; supratemporal (squamosal) present.

Squamosal large, suspending quadrate. Boidce, p. 596.

Squamosal small, intercalated in the cranial wall. Ilysizdae, p. 594.

2. No vestiges of limbs; squamosal absent. Uropeltidae, p. 595.

\footnotetext{
1 Erpeetologie générale, Suites à Buffon, vol. vii. Paris, 1852.

"Catalogue of Snakes, British Museum, London, 1849.

3 Reptiles of British India, Ray Society, 1864.

4. Ac. Philad. 1864, p. 230.

5 Catalogue of Snakes, British Muscum, London, 1893-1896.
} 
B. Coronoid absent; squamosal present.

1. Maxillary horizontal; pterygoid reaching quadrate or mandible. Prefrontal bone in contact with nasal. Tenopeltidce, p. 605.

Prefrontal not in contact with nasal. Colubridae, j). 606.

2. Maxillary horizontal; pterygoid not reaching quadrate or mandible. Amblycephalidae, p. 637.

3. Maxillary vertically erectile, perpendicularly to ectopterygoid; pterygoid reaching quadrate or mandible. Tipericlae, p. 637.

For ordinary practical purposes this symopis is useless, lyeine hased entirely upon anatomical characters, not all tasily ascertained. The following characterisation of fanilies may therefore be preferred:-

Eres restigial; no teeth in the lower jaw ; without enlarget rentral scales. Typhlopidae.

Eves vestigial; teeth restricted to the luwer jaw : without enlarged ventral scales. Glauconitidae.

Eyes very small; head not distinct; ventral seales scarcely enlarged; tail extremely short, ending obtusely and covered with peculiar scales. Uropeltidae.

Trith restiges of the hind-limbs aplearing as claw-ilie spurs on tarle sirle of the rent; rentral scales transversely enlarged; eyes functional, free.

Ventral scales scarcely enlarged. Ilysizdae.

Ventral scales transversely enlarged. Boidae.

Writh a pair of poison-fangs in the front part of the mouth, arried hy the otherwise tootliless, much shortened, and vertically erectile maxillaries; ventral scales transversely enlarged; eyes free. Viperidue.

All the remaining Snakes combine the following characters: the maxillaries are typical, not separately movable, horizontal, with a series of teeth. $^{1}$ The mandible is toothed but has no coronoid bone. There are no vestiges of limbs or of their girlles. The eyes are free.

Dentary movably attached to the tip of the articular bone of the mandible; skin beautifully iridescent. Ienopeltidae.

Without a mental groove; the encls of the piterygoids are free, not reatehing the quadrates. Amblycephalidae.

With a metian longitudinal groore letween the shields of the ching the squamosal is horizontally elongated, movable; the pterygoid reaches the quadrate. Colubridae.

Fam. 1. Typhlopidae.-Burrowing snikes which hare the whole body corered with uniform cycloid scales, and with the tecth restricted to the small and transversely placed maxillary bones. The pterygoids do not extend backwards to the quatrates, and there are no endopteryoids. The quadrates slant obliquely forwards, and are attached directly to the pro-

1 Except Oligodon, Dasypeltis and Atractaspis (see p. 582), in which palatal teeth are restricted to the palatines. 


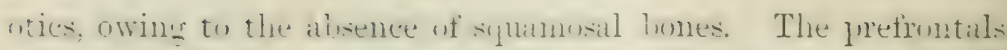
are in lateral contatct with the nitsils. There are restiges of the felvis, reslucent to a single lme wn each sicle. The eyes are hidden by shields of the skin.

The Typhlopidiate, mainly comprest of the genus Typhlops, with abme we humberl species, are undmutedly the last living descendants of formerly cosmnolitan, rather archatic, snakes, which in adaptation to their hurrowing lite and insectivorous diet have mulergone deratation. They are still widely distrihuted in all tropical and sul-trofical comntries, sune on the solitary Christnias Islaml. hut unt in New Zealand. One species, T. rermiculuris, inhahits the Balkin l'eninsula and couth-Trest Asia. It is brown above, yellowish below, and reaches a length of ahout 10 inches. The tail is extremely short and ends in a lorny spine. T'. limminus is widely clistributed in sonthern Asia, the Malay Islands, the islands in the Indian Ocean and in Southern Africa.

Fam. 2. Glauconiidae.-In inost respects resembling the Trphlopidae, but the maxillaries retain their normal position and Ire tumthless, teeth being restricted to the lower jaw, which is stout and short. The pelvic girdle and the hind-limbs show the least reluction found in any recent Snaties: in the pelvis the ilia, pubes, and ischia can still be distinguished, the last even retaining their srmphrsis; there are also restiges of femurs. Alont thirty species, nearly all 1:elonging to the genus Glumeniu, are found in sumth-Trestern Asia, Africa, and the warmer parts of America, including the West Indies.

Fam. 3. Ilysiidae.-The scales of the cylindrical body are smooth and sinall, those on the rentral side are scarcely larger. The tail is extremely short and blunt. The head is very small, not distinct from the neck. The gape of the mouth is rery natrow: Teeth are carried ly the manclibles, the pterygoids, falatines, maxillaries, and one or two or more by the premaxillate. The endopteryouids are short. An important cranial feature is the short gulluhates, which stand rather vertically and are connetterl with the artuinu by the syumosals: these are very small and are firmly wedered in between the uppere ends of the

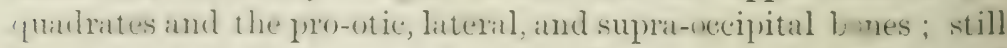
forming part of the cranial wall. Testiges of the pelvis and bind-linls are very incomplete, and terminte in claw-like spurs, 
protruding between the scales on either side of the vent. The eyes are very small, and are either free or corered liy transparent shields. The few, scarcely half-a-dozen, sinecies are fimnd in south America (Mysia) and in Ceylon, the Malay Tslands, and Indo-China.

Ilysiu (Tortrix) seytule, the Coral-Snake of Tropical south Anerica, is a heautiful coral-red with black rings. On accomnt of its beanty, perfectly harmless nature, and for "cooling purposes," this snake, which grows to nearly a yard in length, is smmetimes worn as a necklace by native laclies. All the Ilysiiclae lead a partly burrowing life, live chiefly upon worms, insects, and little Typhlopidae, and are viviparous.

Fam. 4. Uropeltidae-Burrowing snakes of Ceylon and southern India, with a short and rigid cylindrical boly and a very short tail, which ends in a large peculiar shield, often obliquely truncated. The scales of the body are smooth, and are little larger on the belly; the coloration is mostly, very heautiful. The eyes are very small.

The Uropeltidae are somewhat intermediate between the Ilysiidae, Glauconiidae, and Boidae. The pterygoids do not reach the quadrates; but ectopterygoids are present; the quadrates are very small and directly attached to the skull, squamosals being absent. Teeth are carried by the mandibles and by the maxillaries, which are normal in their position. There are no restiges of hind-limbs or of the pelvis. The Uropeltidae, of which about forty species are known, are viviparous, burrow in the ground, and frequent damp localities, preferring mountain-forests. The use of the characteristic tail-shield is not clear; perhaps it issists these rather rigid creatures in digging, by being pressed against the ground.

Cropeltis.-The tail is obliquely truncated, ending in a roundish, flat shield.

$U$. grandis s. philippinus.- The latter name seems to have misled W. Marshall ${ }^{1}$ into including the Philippine Islands in the range of the family, a mistake which is sure to be propagated. The species, the only one of the grenus, is confined to Ceylon; it is blackish above, yellow below, frequently with small yellow spots above and brown spots on the muler surface. It grows to about 18 inches in length. 
Phinophis.-The tail-shield is convex and the snout is

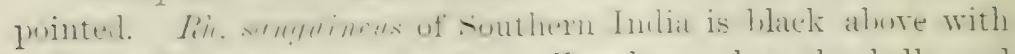

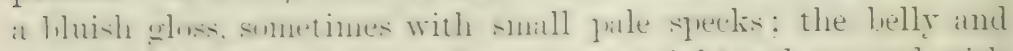

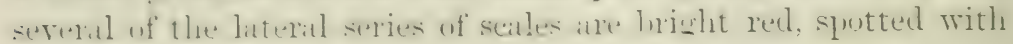
black. The tail-shield is black and red.

Fam. 5. Boidae. - Typical snakes. usmally litre, and with vestiges of pelvis and himb-linbs, appearing externally as claw-

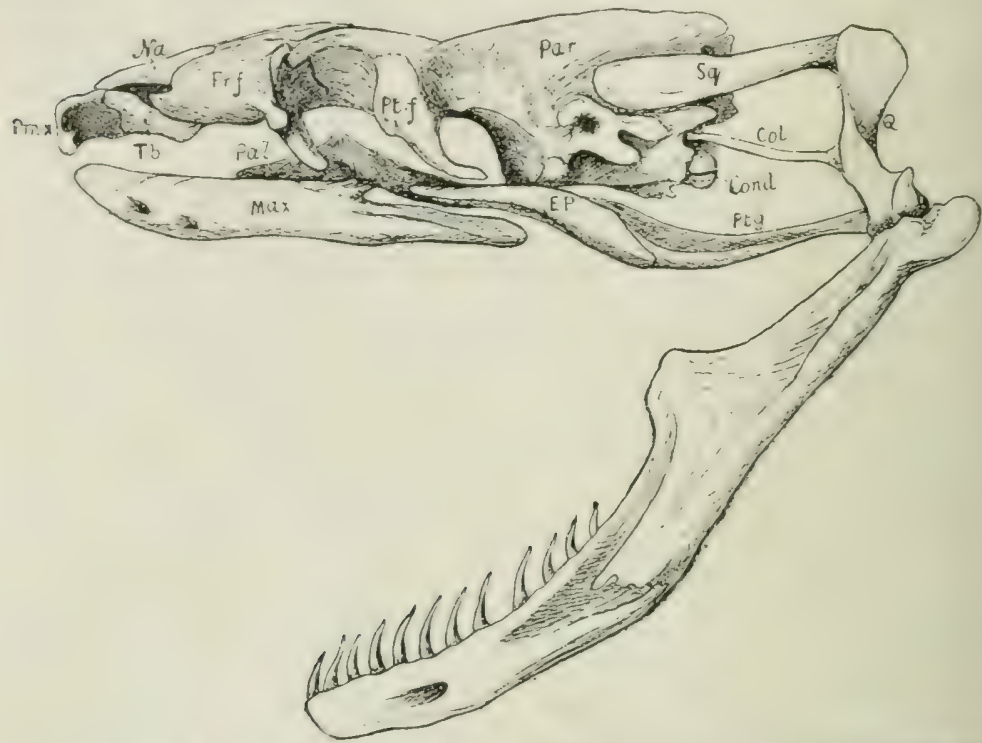

Frg. 155.-Skull of Eunectes murinus. $\quad \times 1$. The teeth on the maxillary, palatine, and pterygoid have been omitted. Col, Columella auris; Cond, occipital contyle; E. $P^{2}$. and E.I'ly. ectopterygoid or transverse bone; $F$, frontal ; Mand, mandible; Ifox, maxillary ; V $\left(\right.$, nasal ; Pal, palatine; $P^{\prime}(e r$, parietal ; Pmx, premaxillary

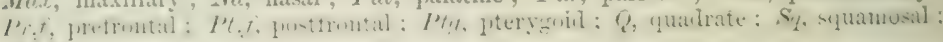
Ti. turbinal.

like slums on earhe siste of the rent. The scales of the uplere surface ane nstally small and sumoth, while those of the rentral surfice form one lirend sories an the belly, and one or two rows (nit the tail. The quardrate is carried hy the horizontally elongated

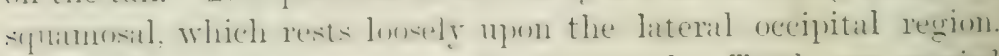
The jerefrontal is in contant with the natsal. Teeth are carrienl by the mandibles, the petergutes palatines, maxillaries, and, in the lythminate. ly the premaxillaries also. For furtlor details see Figs. 155, 156 .

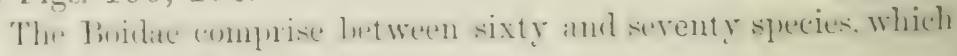


hare been grouped into many gentat, on mimportant chatraters referring to the scales and shields of the heal. It is dominfinl it they are natural groups, a consideration which detracts much frum their value in the study of geosrathical distributim. Even the two sub-families are not free from this remuach. The range of the family is world-wide, builate ocemring in all tropical and sub-tropical countries, including islands, except New Zealand. A few species live in South-Eastern Eurupe
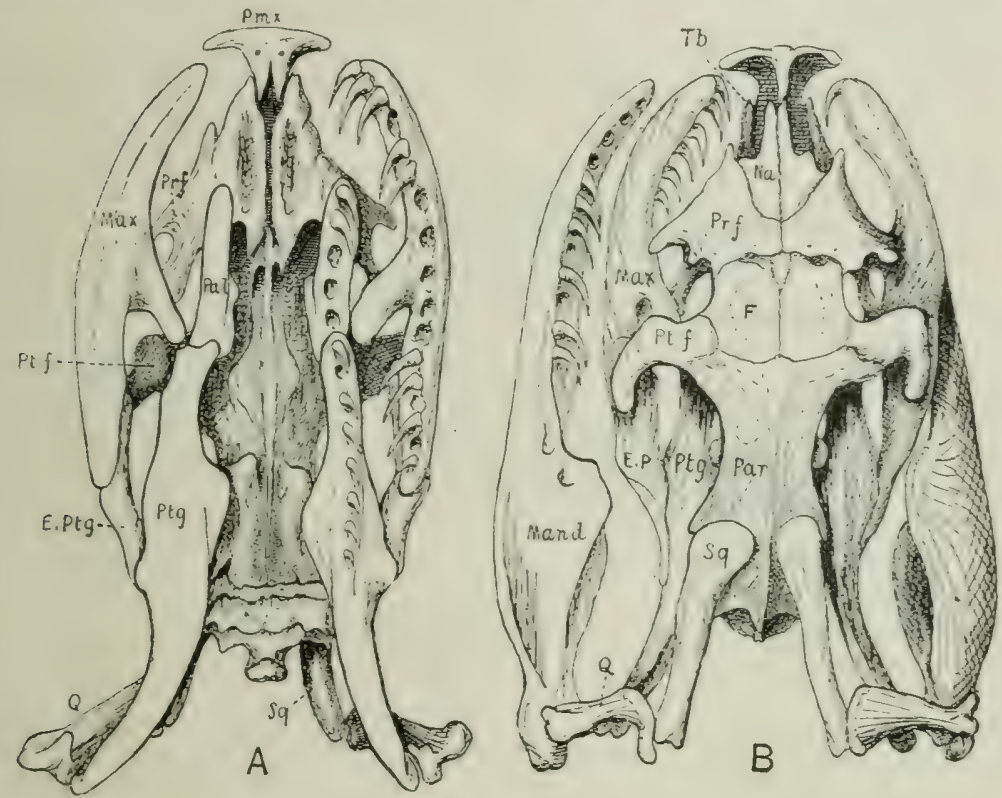

FIG. 156.-A, Ventral, B, dorsal, riew of the sliull of Eunectes murinus. Lettering as in Fig. 155。 $\times 1$.

(Eryir) and in North-Tresteru Americi. They mostly prefer mooled districts, especially forests: climbing trees, assisted by the short and partly prehensile tail. Others are semi-ayuatic. and a few live in sandy localities. They are all rapracious, and ly preference feed on warm-blooded creatures, which they constrict by coils of the body in order to hold, kill, and crush the victim before swallowing it. Exaggerated notions are entertained about their swallowing capacity. It is ofwious that a larce snake, 20 feet long, half a foot thick, and weighing several hundred pounds, can crush a tiger, a stils, or even a 
cow: hut common sense tells ns where to llatw the line when it enmes to the swallowing of the furer. Snall game, although of a bulk aglarenty far tom hieg for the snake, is so crushed and mancled that it is turnerl into the shitpe of a sansage prepraratory in the long grocess of swallowing. The Boidae lay eges, and some species inculnate theme or rither the female coils herself romil them for the sake of protection. No aplyecialile anoment of extra walluth is develenget. Tnfortunitely the olservations of one of the hest cases on recoril ${ }^{1}$ were conclucted so imperfectly that they are of little ralue.

Sub-Fam. 1. Pythoninae.- With a lair of supra-orbital lumes. intercalated letween the prefrontal, frontal, and postfrontal lumes. The sul-caulal scales are mosty in two rows. The premaxilla often carries a few small teeth.

The Pythoninae, comprising about twenty species, are restrietel to the I'alientropical and Australian regions, with the sole exception of Loxocemus bicolor in Southern Mexico.

I'uthon. the principal genus, has teeth on the premaxillat. The rutral, eath of the anterior uprer lahials, and some of the lower lahial shields, contain a deepr probahly sensort, pit. The maxillary and mandilular teeth are long. but decrease from lnefore lackwards. The heal is distinct from the neck, and is covered with symmetricul shields or with small scales. The scales of the body are small and. smooth. The tail is short and prelensile: letow with two rows of scales. The pupil of the ere is rertical. The range of the genus extends over the

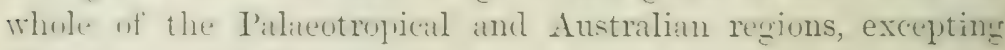
Madagascar and New Zealand.

I. spritutes the "C"arpet snake" of Anstralia and New Guinea. is motly leantifully malkerl. lut is sulject to much variation in colone. The mere typical sprecinens are hlack above, each scale with a yellowish dut. with rellow spots or combinations of deots. more or less arranged in rows. The muler parts are rellow. It rearhes a length of alwut two pards: and spends a great part ot its time in trees.

I' refirmlutus is the commonest sleecies in Indr-C'hina and in

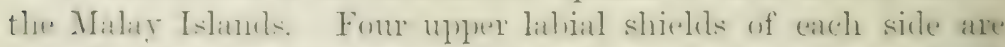

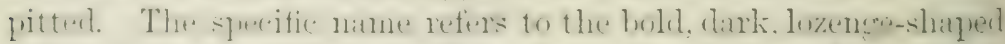

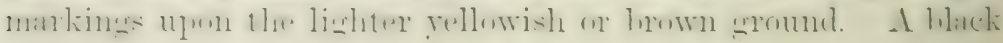


line extends over the head from the nose to the neck, and another on each side from the eye to the angle of the mouth. The under parts are mostly yellowish, with small lirown sputs on the sides.

This is one of the largest species of Python, some specimens leing known which measured about 30 feet in length.

As a sample of folk-lore connected with this momstrous snake the following Burmese fable has been recorded by Mason:-

"According to a Karen legend all the poisonous serpents ilerive their virulence from the Python, which, though innocuous now: was originally the only one that was venomous. In those days

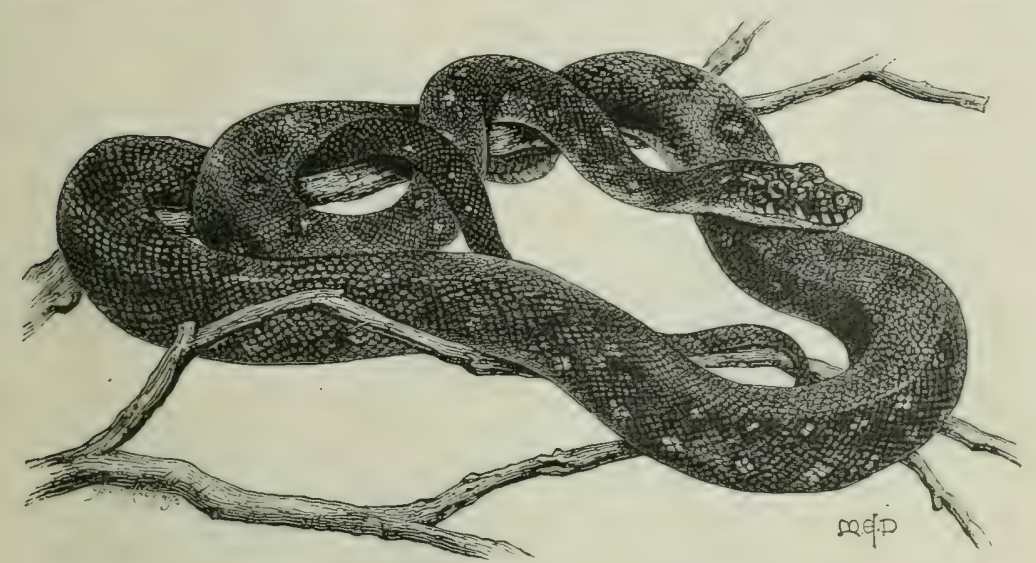

Fig. 157.-Python spilotes (the Carpet Suake). $\quad \frac{1}{5}$.

he was perfectly white, but having secluced away a man's wife, Aunt Eu (Eve), he made her, while she was in his den, weave figures on his skin in the forms which are now seen. At that time, if he bit the footstep of a man in the road, such was the virulence of his poison that the man diecl, how far soever that man might have passed from the bitten track. The I'ython had not, however, an ocular demonstration of the fact, so he silil to the Crow: 'Crow, go and see whether people die or not when I bite the foot-track.' The Crow went to the neighhourhood of a Faren cabin, and found the people, as is their custom at funerals, laughing, singing, dancing, jumping, and beating clrums. He therefore returned to the Python, and told him that so far from

1 Burma, its Pcople and Productions, London, 1882. 


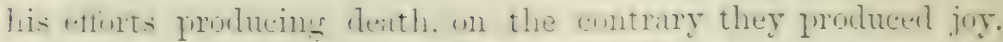
The I'ython wats an ancry when le leart this that he ascencled

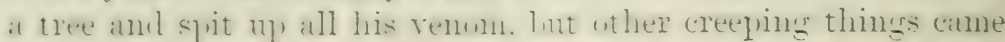
and swallowed it and pengle die of their malignaney to this day. The tree. therefine. fron which the I'ythom slat lip his renom lecane dearly, and its juice is userl to this day for the purpose of poisuning amms. The l'ython male the other creatures gunnixe not to lite without prorocation. The Cobra sitil: "If

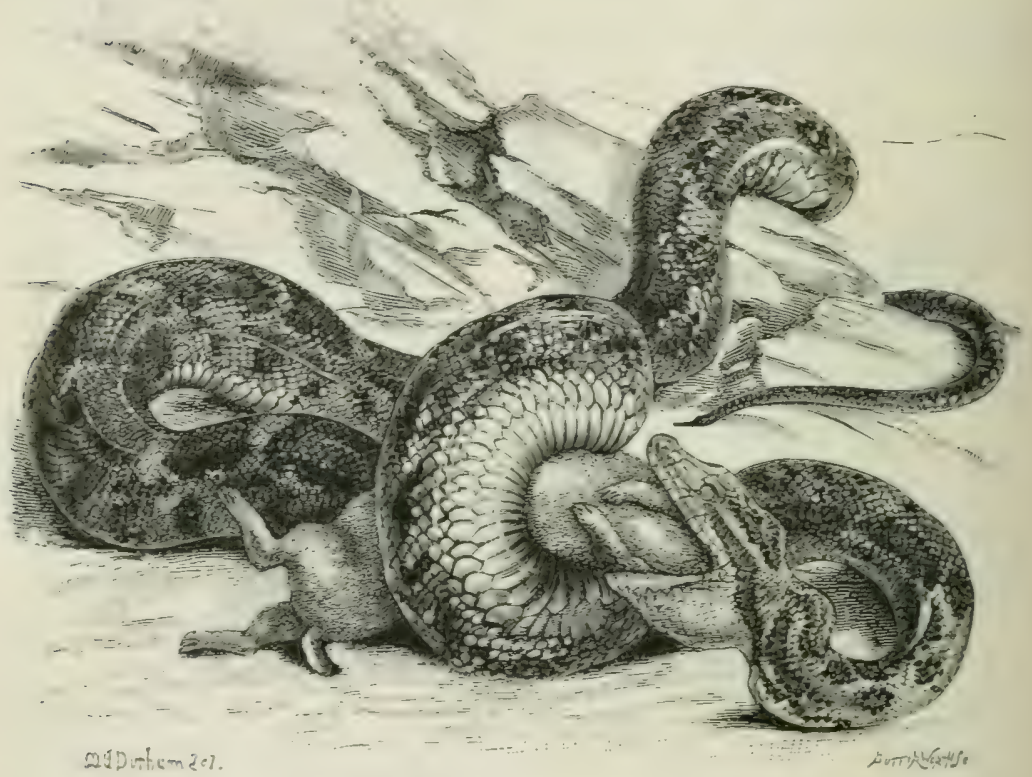

FIo. 158.-Python molurus. $\times \frac{1}{T_{0}}$.

there lie transeresion sis as to dazzle my eyes, to make my tears fall seren times in one dity, I will hite:' So said the Tiger 'whose lite the Karens esteenn ats virulent as a serpent's) and others and they were allowerl to retain their foison. But the Water snake and Fros satil they womlil lite with or without cause as they likel: so the l'ython drowe thene inte the water. where their poison melted away and their bite became harmless."

$P$. molurus is the species of India and Ceylon, ranging,

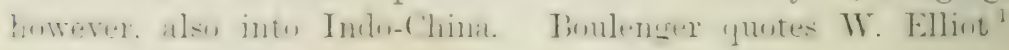


as the authority for the statement that this species grows to the length of 30 feet. Only two prairs of unier lahials are pitted. The general colour above is greyish or yellowish lnown with a dorsal series of large redhish-brown, hlack-edgerl patches imul on the siles of the body with a series of smaller spots with light centres. On the head is a lance-shaped marking; a lirown stripe passes from the eje backwards. The under parts are yellowish.

$P$. sebce and $P$. regius are African species. The former has two pairs of upper labials pitted, the latter four pairs. $P$. selue is generally pale brown above with dark hrown, black-edged cross-bars, which are usually connected by a sinuous dark stripe along each side of the back. The upper surface of the tail has a light stripe between two black stripes. The belly is spotted and dotted with dark brown. $P$. sebce ranges over the whole of Tropical and Southern Africa, perhaps with the exception of Eastem Africa. P. iegius of West Africa is leautifully marked, and may be recognised by the dark brown, black-edged hand along the back, sending down triangular or $Y$-shajed processes on the sides, which are pale brown. This dorsal band encloses a light streak on the neck and another on the tail. The belly is yellowish.

These African Pythons grow to a length of about 15 feet, but slecimens so large as this are not often net with. The negroes of certain parts of the coast of Guinea are said to worship them and to keep them in special temples, where they are regularly attended to. Their food consists chiefly of small Mammals, notably rats, and of Birds. A couple of these snakes paired in the Zoological Gardens of London in the month of June. The female laid nearly one hundred eggs in the following January, and incubated them until April, when the embryos were foum to be still unripe.

Sub-Fam. 2. Boinae. - Tithout supra-orlital bones. The premaxilla is toothless. The subcaudal scales form mostly a single row.

The Boinae comprise between forty and fifty species. Mrost of them are American, but the genus Erye inhabits North Africa, Greece, and South-WVesteru Asia; the genus Emygrus inhahits New Grinea and many of the Pacific Islands, for instance New Britain (Neu Pommern), the Solomon, Loyalty and Fiji Island's, 


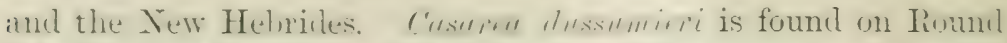
Island near Mauritius : and two species of bion and one of Coralius represent the Bublate in Matlasascatr. while all the others live in Central and South America.

Bum.-The maxillary and mandihular teeth gradually decrease in size. The scales of the uples jurts of the lody and tail are smonth and very small. The rostral shield is enlarged. The mostrils are placed leetween two or three nasals, and these are

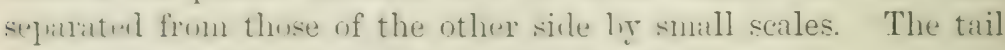
is short and prehensile. The pupil is rertical.

Ii. must,intur, of Sunth Americal, has the hearl covered with small sates, one of the pre-oculars treing enlarged. The ere is seprated from the labials ly several series of tiny scales. The gemeral colour is a delicate "pale lirown above, with fifteen to twenty dark brown cross-bar's widening on each side, and, if connecterl ly a rark ilurso-lateral streak, enclusing large elongatte owal suts. . O On each sicle is a series of large dark brown spot: with light centres, most of which alternate with the cross-hars. On the tail the markings becone much larger, brick-red, edgeet with likek, aml seprotated by narrow; yellowish interspaces."

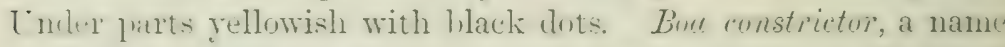
:prilien in popular parlance to many species, reaches a lengrth of inme than 10 feet: the larrest specinen in the British Musem mensures exactly 11 feet. A few other species inhabit Central

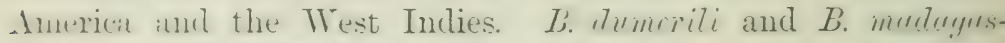

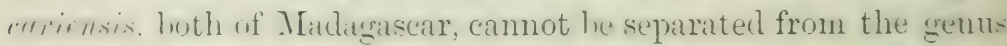
Bou.

A. D. Bartlett ${ }^{1}$ has described the following incident:-

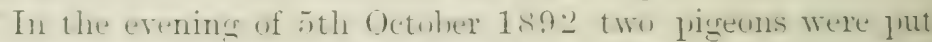

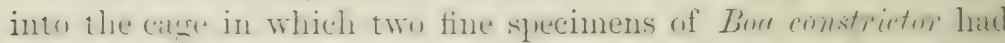
leen living on friendly terms sines the lesinning of the reatr. The lareer snalke seized one of the pigeons and the leeper lett

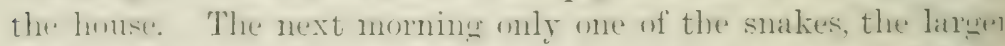
specinen, was risible, and fum its enormonsly extemled boly it was erident that it bul swallowed its complnnion, which was

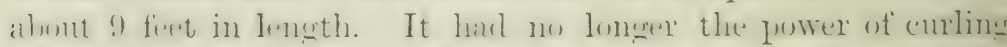
its.lf romm, hut remained extonded mearly to its full length in a sraight lime, and appearesl to he at least threes times ic normal (ircunference. It wats alnost painful to see the ristenterl skin. 
which had separated the scales all over the midille of the lwoly. By 2 nd November, twenty-eight days later, the snake hirl not only digested its companion but had regained its appetite as well as its normal size, and it immediately swallowerl a jigeon 1,4 into its den."

This peculiar case is not one of ordinary camilualism. It is rather an unintentional acciclent. When two suakes happen trot holk of the same animal (in the present case a pigeon) and herin to swallow it, the action of swallowing hecomes alnost mechanical, the snakes continuing to push their jaws orer the prey-which in the case of a bird or mammal thes cannot taste, nor can they see it-so long as they feel something in the mouth. After the original prey has been mastered, it is the turn of the opposite

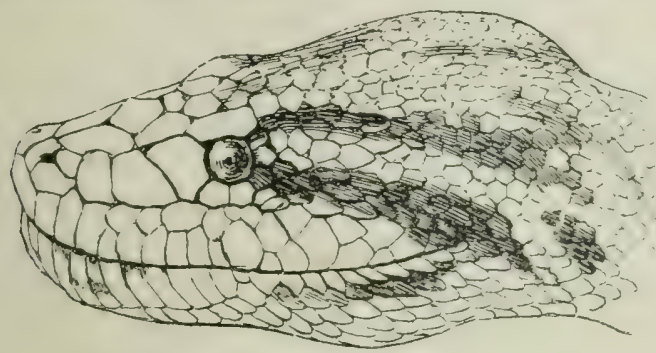

FIG. 159.-Head of Eunectes murinus. $\quad \times 1$.

snake's head, and if the weaker snake does not give war it is swallowed by its stronger mate. Grass-Snakes will swallow several frogs if these are tied together in a string, and other snakes do the same with mice. There are instances on recorrl in which a Python swallowed its blanket, which, being absolutely indigestible, caused its death.

C'rstree, the "Round-Island Snake," differs from Bur chietty l, the rough and strongly keeled scales, and by the relatively. much longer tail.

Eunectes murinus, the "Anaconda," is an aquatic Boa. It differs from this genus mainly by the inner of the three nasal shields being in contact with that of the other sick (see Fig. 159 ), and by the absence of the little scales between the eye and the labials; the snout is, moreorer, corered with shields insteal of small scales. The pupil of the eye is nomally rertical, hut it had contracted into a round pinhole in the dead but still fresh 


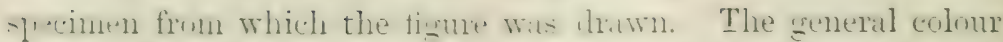
is diak olive-hrown, with laree oval liack spots arranged in two mone o: less alternating rows along the back, and with smaller

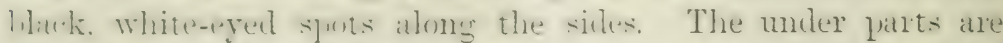
whitish, sunteel with hatck. The unger parts of this and of miny wher dark-colonred sprecies of buidate are often shiny, with an iriclescent lustre.

The Anacomlit combines an arimeal with an ayuatic life. a linn of existence eminently in harmony with the well-watered, dunse firests of Tropical sonth Anerion. which are the home of this. the latrost of all modern snakes. It is said to attain a 1+meth of as much as :3:) feret. There is no inherent impossihility in such statements, lut the criant specinens seem to have a knack of keeping out of the naturalist's way.

The Anacombla feets chiedy "lwom Pirds and Mammals, which it cotches either on land, mostly during the night-time, or in the water. For the latter primpre it lies sulmerged in the rivers or Hoats alout leisurely; only the head heing alove the surface, and anything suitahle is attacked. In other localities the snake, if $\therefore$ inclined, estallishes itself unon the lnanches of a tree which werhangs the water, or the track of the same. These aruatic Snakes seem to be viviparous.

En, has the head not listinct from the neck and covered entirely with snall scales. Those of the boly are likewise small, and are either smoth or leedenl. The tail is very short. The anterior maxilary and mandilular teeth are lonser than the lusterion teeth. These snakes, mont of which are less than $\therefore$ fiet in leneth, inhahit the sandy districts of North Africa, Aralia, and south-Western Asia, extenting into Central Asia. 1) slectes, $E$. jurntus, extents into Greece and the Innian

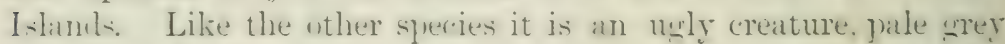
or yellowish alore, with dirker pitches and spots. The moler parts are whitish. The scales are snouth on the front half of the hody, hecoming keeterl further hasek and on the tail. Total length under 2 feet. The pupil is rertical.

Acending to Zander" and Werner " this snake lives in sandy

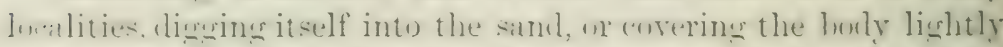
with sand and leaving only the eres am numbils free. Tly whole buly is very flathy, and preseses itself into any irrenulatity of the

1 Zool. Giart. 1895, p. 330.

- Ibid. 1S96, 1. 85 . 
ground over which the snake creeps. Some specinems live on lizards, others prefer mice. The prey is caught ly the heanl, and further secured ly several turns of the body of the calpur, whose tail is then turned forwards, round the head of the victin. s. as to form a kind of knot.

Not less striking than their agility is their jealnusy, which is so strong that a snake will occasionally leave the monse which it has just strangled in order to seize another snale's: mouse. Sometimes sereral snakes fight for the sane mouse. coiled together into one inextricable lump so that the mouse itself is yuite invisible. The snakes polie their heads almont in search of the hidden prey, and every attempt of une of the smalies to free itself, causes the other's to squeeze it firmer and firmer, thinking apparently that the motion was caused by the lost prey.

Occasionally one of Wrerner's captives caught sereral mice in succession. With these it crawled into a connex, dropled the mice, and then proceeded quietly to swallow one after another. After a fortnight the whole repast was digested, and the snake was ready for more.

Fam. 6. Xenopeltidae.-The single species, Tenopeltis uniculo', of South-Eastern Asia, including the Malay Islands, has heen raised to the dignity of family-rank on account of the following combination of characters. The prefrontal hones are still in contact with the nasals as in the previous families, but the coronoid bones of the mandibles are absent as in the remaining families. The mhole suspensorial apparatus and the lower jaw itself are peculiar. The lentary bone is morally attached to the end of the much-elongated articular hone, the movability being enhanced by the alssence of the coronoid element. ${ }^{1}$ The quadrate is short and thick, and is carried hr the short ame broal squamosal, which lies flat against the skull, resemhling in this respect that of some of the Ilysidae. Boulenger rightly considers Irnupeltis to be in various ways internediate between this family, the Boidae and the Colubridate. The heal is small and not distinct from the neck. The eyes are small and hare a vertical pupil. The body is cylindrical, corered alowe with

1 The same arrangement oceurs in the Colubrine genus Polyodontophis, with about ten species in South-Eastern Asia, Madagascar, the Comoro Islands, and in Central America. 
smonth black or brown and highly irilescent scales, hence the generic name. The rentral scales are white and transversely eularsed as in the majority of smakes. The tail is short, lut not stunterl, measuring abut \pm inches in full-srown specinens of a total length of 3 feet.

Fam. 7. Colubridae.-This funily comprises those snakes silumt nine-tenths if all recent sfecies) which combine the finllowing chanacters:- - ectopterrgoids are present: the syuanosals are lowely attached to the skull, and carry the quadrates, which we not reached ly the pterygoids: the prefrontals are not in mntact with the nasals: the maxillaries are horizontal and form the greater protion of the upner jaws: the mandibles lack the coronoid process or element: both jaws are toothed.

The lest arrangement of this emmous cosmopolitan family with terrestrial, arboreal, and aquatic forms, is that by Boulenger, who, adopting Iuméril's terms, has divided them into three parallel series.

A. Aglypha.-All the teeth are solid and not grooved.

I. (1)isthonlyphlu.-One or more of the justerior maxillary teeth are grooved.

C. I'rutomglypler.-The anterior maxillary teeth are grooved or "perforated."

The Aglypha are harmless, non-poisonous. Most of the (1)isthoglyphat are poisonous, although few of them are clangrermsly so. The l'moteroglypha, which comprise the "Cobras" and their allies, are deadly poisonous.

\section{Series A. AGLYPHA.}

Sub-Fam. 1. Acrochordinae.-The postfrontal hones, besicles burlering the orbits josteriorly, are extended forwards so as to firm the upuer lorder of the orlits, separating the latter from the frontals. The few genera and species of this sub-fanily are mostly anuatic, inhaliting rivers, or estuaries with larackish water, and they have leeen known to swim far out into the sea. The holy is coveren with small, freruently gramular scales: in the typically aquatic forms the body is slinhtly compressed laterally, and the rentral scales are scarcely lareser than the others. Most

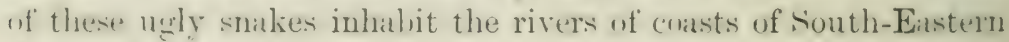

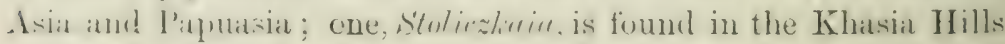


of Torth-Eastern India; another, Toffupsin, lives fir fron its smposed allies, on the Isthmus of Darien, Centrid Antericil.

Acrochordus javanicus has no ventral shields. The head is Hilt, covered with small granules, with the eyes and mostrilis wh the upuer surface. The general colour is dull olive-hrown. linhter and spotted beneath. The food consists of tishes. Tutal length up to 4 feet.

Cheraylines girunulutus ranges from the coast of Matras to New Gruinea. The body and tail are compressed, and form a rentrial fold, covered with tiny scales like the rest of the buly. General colour grey above, yellow below.

Sub-Fam. 2. Colubrinae.-The postfrontal bones are restricted to the posterior border of the orbits. The maxillary and dentary bones carry teeth on their whole length. The scales are usually imbricating. This sub-family contains the orerwhelming majority of snakes, about 1000 species, all of them harmless so far as poison is concerned. None of them reiteh a sreat size, species of 6 or 7 feet in length being rare, e.g. Zumenis mucosus, but a few species of the Indian genus Zuncys $\therefore C^{\prime}\left(1 r^{\prime}\right)$ phutur grow to 10 feet. Most of the Colubrine smakes are oriparous, but some, e.g. C'oronella, are viviparous. Some are aquatic, or semi-aquatic, others are absolutely arboreal, others again prefer dry, sandy, or rocky localities, according to their fool. The distribution of the sub-family is cosmopolitan, finding its natural limits only in the permanently frozen under-ground, a condition which makes hibernation impossible. Most of them love warmth and like to bask, although many are not fond of the hroiling sun. In the temperate regions they hilernate. As a rule they are intelligent and some of them become even affectionate.

Tiupidonutus. - The teeth form closely set series on the whole length of the maxillaries, palatines, pterygoids, and the greater l,ortion of the dentaries. The premaxilla is toothless. The teeth of the maxillaries gradually increase in length, the posterior teeth being the longest. The pupil is round. There is a pair of internasal shields. The scales covering the holy have each an apical, sensory pit, are mostly lieeled, and are arranged in longitudinal series. The rentral shielils are broad; the sulcaudals form two rows. This genus, with more than seventy species, has a wide range, practically orer the whole world with the exception of New Zealand and the sonthern half of Australia. 
T. natrix, the common Grass-Snake, has a divided, or double, anal shield. The strombly keelerl sales of the body form ninetern rows. There are momally seren mpere labials, the third and fourth of which lunder the ere. The nsual colom of the Grass-

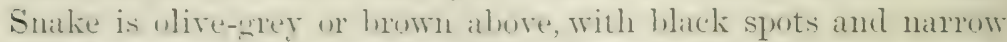
crosithands. The labials are white on rellowish, with black sutures. The belly is checkered blatck aud white, more or less suffused with grey. There are sereral colnur-varieties. The trpical or northern form has a white, rellow, or orange collar;

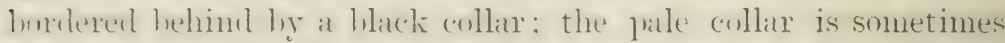
faint on alsent. The second variety, rather common in spain and Portugal, although not the only form in the P'eninsula, has no collar whaterer, and these specimens are sometimes almosi uniformly grey-green abore. The third variety, common in Sunth-Eastern Eurne and in Asia Ninor, has a well-marked ("olliar and a yellowish streak along each sicte of the back. But there are also almost black specimens.

The usual length of an achlt female Cirass-Snake is about 3 feet, but very exceptional cases of more than 6 feet are on riand: the males are smaller and more slenderly built. The ringe extends over the whole of Mildle Europe, Algeria, Test and Central Asia. It does not, however, occur in Ireland or sentlami. Its morthern limit is the sunthern part of Sweden.

The Crass-snalie grefers moist, grassy localities, with the neighlomrhood of water, chietly on accomnt of the food, which comsists entirely of tishes aml Amphibia, notahly of frogs: tree-frogs are preferred to anything else' eaten, but mice are never taken.

The Grass-Snake can climb trees or rather shrubs and is an aceomplished swimner, often spending much of its time in water for fishing purposes. The fish is caught hy the belly and then generilly swallowed on land. The fratss-inakes apleat in the spring and disalprear in the alutumn to hibernate in the grenum. They pair. in England, in the month of May or Jume.

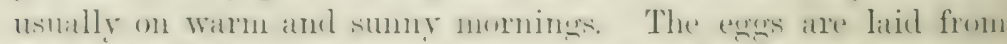
July to the end of Angust, mosty in rich renetalle soil, in

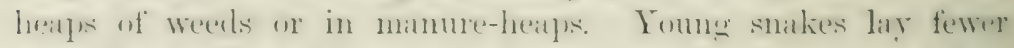

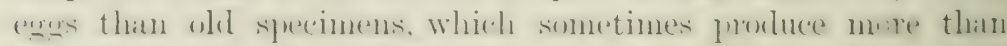
three dezen at a time. The enges are solt, whitish rellow, abment one inch longe, and sonn stick together, so that the whele chump 
can be taken up at once. As a rule the new-laid eggs do not contain any visible sign of the embryo, but it ofter hallyens that the snake has to delay oriposition, and then the enulnyos are more or less advanced. This is especially the case with revently caught specimens. The young are hatched in the late summer or in the autumm, and seem to live at first upon soft insects anil worms. Curiously enough they are easily drowned when they fall into the water, even in a shallow tank. My tame snalies have often laid eggs between the stones in the greenhonse: the roung throre well upon unknown fool, but most of them met their fate in the water. When they are a few weeks oli they are strong enough to take baby-frogs.

The Grass-Snake becomes very tane, learns to distinguish between different people, allows itself to be handled withont hissing or without roiding the obnoxiously smelling contents of its cloaca and anal glands, will in time take the offered ford from the hand, and will even crawl up the arm or sleere and coil itself up contentedly. One of the finest specimens, quite green, without a trace of a collar, and with brownish-red eyes, I caught in the Guadiand, where it had been fishing in minstream. It swam towards the lank, dived, and hid itself at the hottom hetween rocks. This snake, a female, becane very tame. It never hibermated, shed its skin regularly every few months. ancl grew within nine years from 35 inches to 4.2 inches in length.

The Grass-Snake is perfectly harmless: although hissing, aud striking out furiously with its head, it never bites, not eren when it is severely handled. Its only defence consists of the awful contents of the cloaca and the anal slands, the secretion of which smells of concentrated essence of garlic mixed with other inclescribable odours. The wildest specimens I have erer met with inhabited a swamp with a little stream to the north of Oporto close to the coast. To my utter surprise some of them actually made for me, swimming aloug rapillly with the learl erect, about 6 inches above the water, and dirting forwarks with widely opened jaws, but they did not bite. These and other kinds of allied snakes require to drink much and often. Occasiomally they drink milk when this is offerenl them, but that they suck the udiers of row or the breasts of women in an idle fable. 
T. riprinds.-The scales are stromely keeled and form twentywhe to twenty-three lomgitudinal rows. The third and fourth labials Im reler the eve. The anal shield is divided. The eyes and nostrils are directerl upwarks instearl of sidewards, in adaptation to the essentially anuatic halits of this suecies, which lives upon fishes and Amphihia. The general colnur is arey to reddish brown, with a hlark ziozay hand alomg the hack and a lateral series of hitck, rellow-ered spots. The helly is rellow or red, checkered with black.

The Tiperine snake bears a general resemblance to the wonmon rifrex. It inhalits France, Italy, Spain and Portugal.

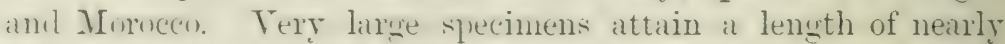
$\therefore$ feet, hut the ordinary size of adults is 2 feet. This snake spemis most of its time in the water, but it is often found on

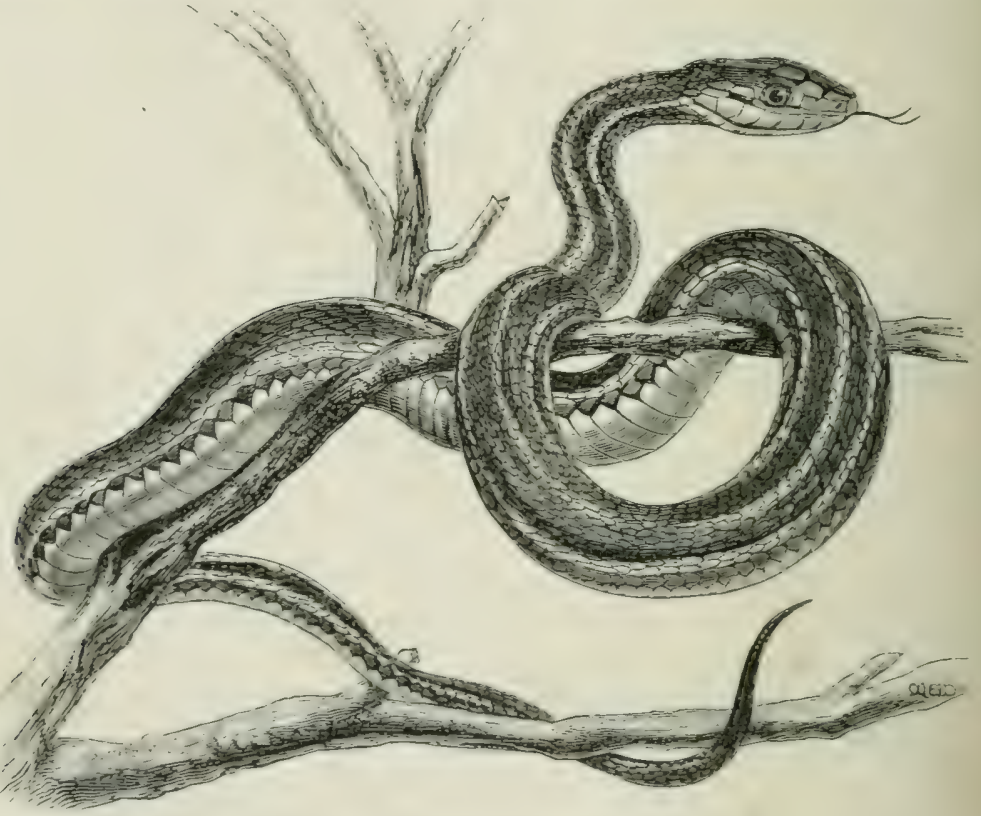

FIG. 160.-Tropiatonotus sirtalis. $\quad \times \frac{1}{2}$.

land, basking on the top of a low wall or on a low shrub. It is exerenlingly ammon in sprin and Portugal, where it inhalit: almost every ditch, any standing water or slow river. In the Alentejo. when during the ranless and hot smmer the small 
rivers have nearly dried up, these snakes collect in great quantities in the remaining stagnant and muldy pools, aml as the stoch of suitable fish grets exhausted, are often reduced to a cleplorably emaciated condition. By the month of August they have become so thoroughly aquatic that they camot he kept alive in dry surroundings for twenty-four hours. Those which I collected generally died, apparently from some kind of cutaneous suffocation, during the night following their capture. Taken under other conditions they are very easily kept and tamed.

I once caught a Viperine Snake in a ditch whilst it was swallowing an eel of nearly its own length. Both were separated, and then put into a small hag together with other creatures, and no more attention was paid to them for several hours. When I opened the bag again, the snake, mulisturled lyy my incessant walking about, was again husily engaged in trying to get outside that same eel :

$T$. sirtalis (Fig. 160) is one of the almost endless varieties of what is now known by the name T. ordinatus, of North and Central America.

T. tesselatus is closely allied to T. vipcrinus, which it represents in South Germany, Italy, South-Eastern Europe, and Asia; but the scales form only nineteen rows, and the fourth, or fourth and fitth labials, horder the eye. The usual coloux is olive-grey with thatk little spots, and with a dark cherron-shaped band behind the occiput. The lower parts are yellow or red checkered with black, hence the specific name.

Zumenis.-The maxillary teeth are not closely packed; they increase slightly in size backwards, and the last two are often a little larger and separated from the rest by a diastema. The mandibular teeth rather decrease in size from before backwarts, inversely with the upper teeth. The scales are smooth with apical pits; the sub-caudals form two rows. The eye is larene, and has a round pupil. The range of this genus, with about thirty species, extends over the whole of the Periarctic regrion.

Z. (Ptyus) mucosus (Fig. 161), the Rat Snake of Inclia, extenting frum Transcaspia to Java, is a very common species, often seen in nenaceries. Its general colour is brown alove, often with hick cross-bands on the hinder part of the borly and tail. The under gurts are yellowish. The fourth and fifth lahisls border the eye. 
The scales on the body form only seventeen rows. Another feature of this species is the prominent ridge of the back-bone not only in half-starved hut in well-conditioned specinens.

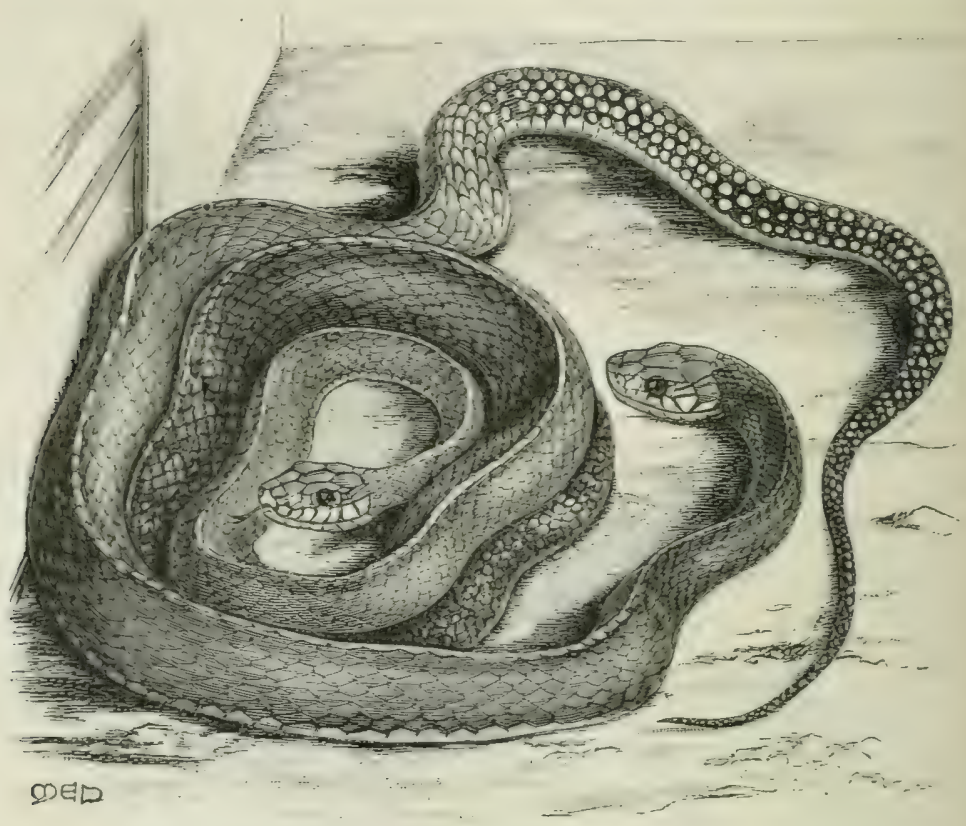

Fic. 161. -Zamenis mucosus (Rat Suake). $\times \frac{1}{5}$.

The liat sinalie erows to a length of more than 7 feet, and is as ill-tempered as most species of this genus.

Z. gemonensis s. viridiflarus inhabits France, Italy, the Balkan Peninsula, and Asia Minor. Its coloration is rery variable. In general it is either green above and yellow below, hence the aldropriate nane rifiliflares, or the grommi-

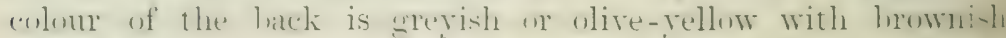
spots. Which form nume on less longitulinal rows on the trumli

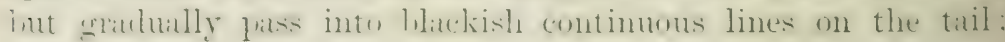

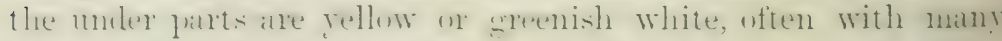

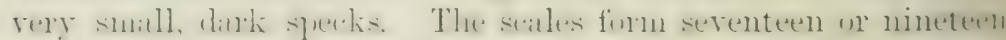
rows; the anal shield is divided. There are two small post-

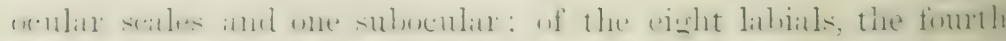
and fifth border the eye. This species is rery lively, attacks 
and bites furiously, climbs well, and when suspended from branches can protrude half of its length in a horizontal direction. It eats any lind of Reptile, Bird, or Mammal it can master : small animals are swallowed directly, rats and moles are first killed by constrictions. Large specimens reach perhaps 6 feet in length.

Z. hipporpis is the representative species in the Iberian Ieninsula and in North-Western Africa. It is rarely more than $t$ feet long, and is very pretty, the gromul-colour being redlish or olive-yellow with a row of large, dark lrown, yellow-edged spots along the back. Two rows of smaller spots adorn the sicles; where the dark spots are large, the pale ground-colour is restricted to forming rings around the spots, producing a pretty iplearance. The under parts are yellow or orange, with black spots. On the head is a dark, pale-erlgerl patch in the shape of a horse-shoe, a feature alluded to by the specific name. Structural characters are the possession of a row of little subocular scales, which completely separate the eye from the labials, the ilonlile anal shield, and the small and snooth scales on the body, which form generally as many as twenty-seven rows.

Z. constrictor.-The American Black Snake. The scales are smonth, and arranged in seventeen rows; the anal shield is clivicter. The general colour above is uniform bluish-black; helow skaty, tinged with blue; the chin and throat are silvery white, sometimes with a black spot. Large specimens attain a total length of 6 feet.

Hollnook gives the following exhaustive account of this srecies, about which many sensational stories are current even in would-be scientific periodicals :-

The "Black Snake" is one of the commonest of North American species. It is extremely active, climling with facility, and ruming with great rapidity, whence it is not uncommonly callerl the "liacer." It frequents shady places, covered with thick shruls, on the margins of water. It feeds on mice, toark, (1) snall birds; and, as it is an excellent climber, is frequently seen on trees in search of hirls' nests. It is a bold and daring ser'jent, enters barns and out-houses without fear, and has leeen linown to destroy young chickens. Its specific name

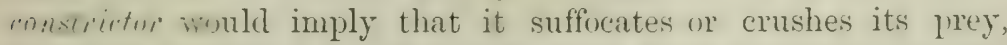
lut this according to Hollurook is at least dombeful. In the 
breeding seascin it is extremely irascible, and will frepuently attack jersons passing at a distance of sereral steps: the tail then quivers with rage, making a quick viluating motion, which in forests and annong deal leares somuls not unlike the RattleSinkie: it now elerates the hearl one or two feet from the grouml, and darts mon its adversary: luckily its bite is harmless, and not more painful than the scratch of a pin.

"It will even descend from trees to attack its enemy if teazed, yet it does not twine itself around the legs, as is commonly supposed.

"The same power of charming its prey has been attributed to the Black as to the Rattle-Snalie, and with still less appearance of reasin: for this is a nimble animal, and can pursue it: lrey, while the Rattle-Snake must lie in wait for his. It is reminkible that the hirds most (ommonly found 'charmed' are the Cat-lind (Turtus cormlinensis) or red-winged Black-bird (Lit. ins flewnireus). These hirds choose thick and shaty places on the mitrins of streans for their residence, and generally huild their nests on such shruls as the alder; the latter hird not unfretuently talies the preciution to select such bushes as are on small islanck, or such as have their roots surrounded ly water, and thus their home is more secure. Now the Black snake chnoses precisely the sane localities, knowing probahly the haunts of its prey. The seruent hexins the war by hesieging the nest: the old birk, aware of its intention, attacks it with Huttering and uncertin motions, accompanied by a plaintive cry of clistress, and is then satul to he 'charmed.' The snake is at list either driven off', or it calptures the young and not unfrequently the old bird too.

"Sinnetiness the old bird, ly her cries, calls in the assistance of her neighlours to drive away the agrasesor. I hatre seen

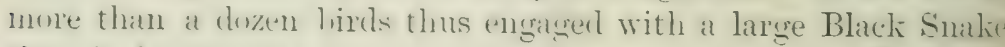

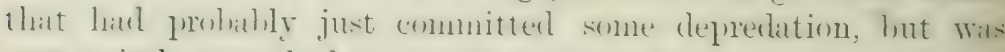

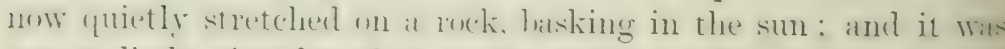
not a little singrular that lirds of rery different senera. anil these sedilum seen towether, all unitul in this warfate against a

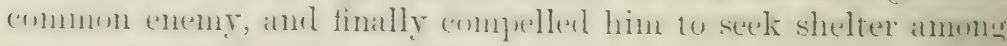
some low, thick shrubs, by the violence of their assault."

Zurnys, with ahout half-ithlozen spectes in south-Eastern Asia, is closely allied to Zamenis. Z. carinatus, of the Malay 
Islands, grows to 10 feet in length: it is consequently one of the largest harmless Colubrine snakes. The scales firm mily sixteen to eighteen rows. The sub-cauclals are douhle. The general colour above is dark olive, passing intu greenish hrom

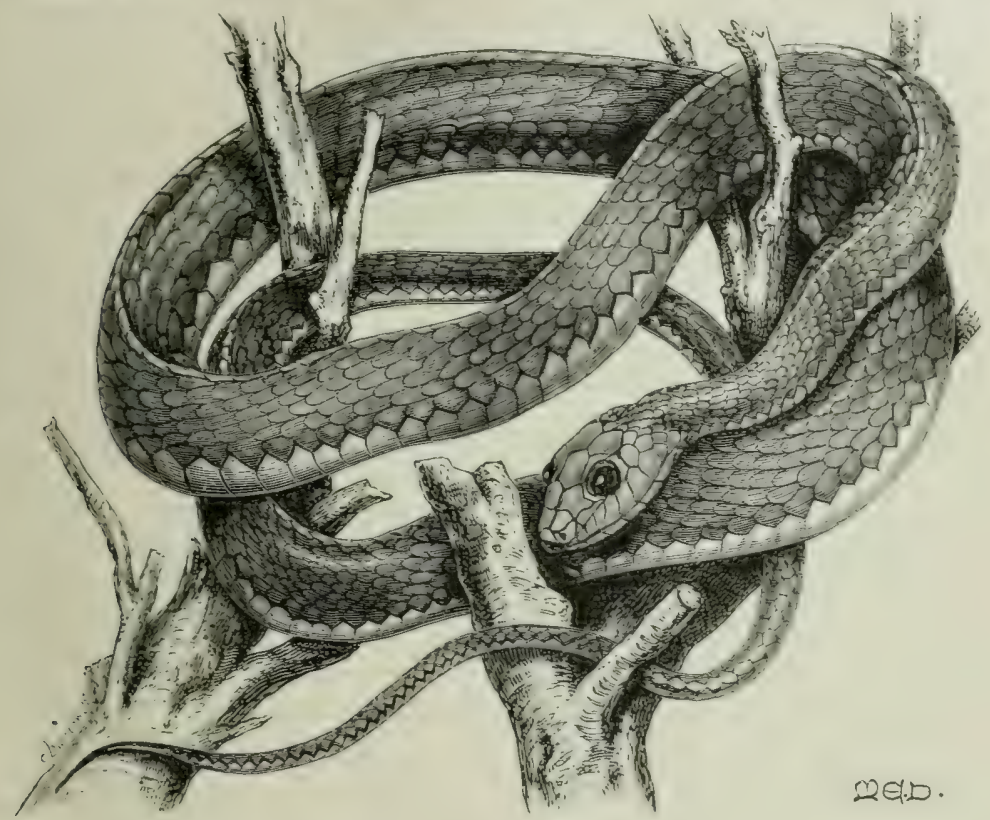

FIG. 162. -Zuocys carinatus. $\times \frac{1}{4}$.

firther iack. The under parts are rellowish: black and yelluw posteriorly. The fifth and sixth labials border the eye.

Coluber.-The maxiliary teeth are of equal size, but the nnterior mandibular teeth are the longest. The head is distinct firm the neck. The nasals are distinct: not fused with the loreals. The eye is rather large, with a round pupil. The scales, smooth or keeled, have apical pits: the ventrals are rounderl or angulate laterally: the sub-caudals are double. They all lity eys and constrict their food. Nearly fifty species in the Periarctic region.

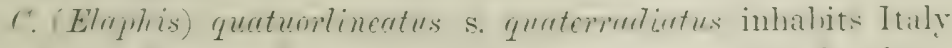
and Souch-Eastern Eurne. It occurs also in the Sontherm Tyrul. The scales of this large snake. which grows to nearly 6 feet in length, are aranger in twenty-five row and are ferly 
keelell. The anul is divileal. Allult specimens have a yellowishhrown ground-colour with a pair of lilack streals on each sile of the back. A black line extends from the eye to the angle of the month: the moler farts are rellow, mostly closely spottent with luwn. This snake is snoul-temunered, and heeps well in "atptivity. They live on spurrows. mice, lizards, etc, and are very

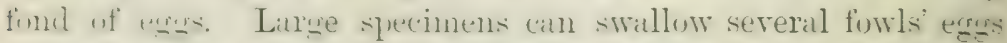
in succesion: the arusher remains of the shells are later dis-

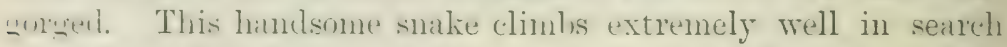
wi hirls and their exgs, and it is not aftail of the water. The lwa is camblyt either with the teeth or he a rapid twist of the tail: in any case, the prey is always stringulated ly the constriction of coils thrown round it. A sparrow thus secured is litmrally passed through the moring coils along the smake's lonly into a lusition convenient for swallowing. Hungry snakes ratch and secure several hircls or mice hefore eating then. My wWn specinens became almost affect innately tane, never attempterl to bite, and took food from the hand.

I. lingurminus is smaller, hut is one of the handsomest smalies ut Sintlern Italy, simth-Eastern Europe, and Asia Minor. It is chosely allied to the previonsly lescriber species. The moundcolour is pale brown with a dorsal series of dark brown or rmhlish. hlack-erlged, traniverse spots, and a lateral alternating stries of maller lulack spots, or with two dark hrown, liachmelsen stripes burlering a yellowish vertelmal stripe: usually with a firkesl hatch matrk on the occiput and nape. The moler parts are white, chechered with hlack, sometimes with the latter colour prevailing.

C. Alomerer us s arsculngui is the Atesculap-Snake, for which the

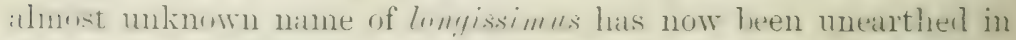
deference to the fetish of priority. This snake is of an extremely craceful and slenter builel, with a very long tail. Its home is the sonth of France, Italy, and Sulth-Eastern Europe. It oceure sponalinally in the Trrol, for instance near Bozen, in Anstria, at

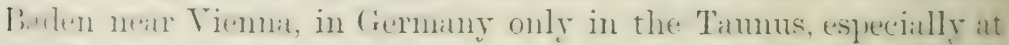
$\therefore$ hlantenhal, which has received its nane from the frequent

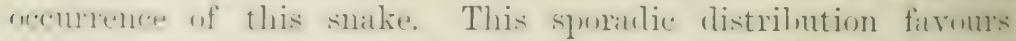

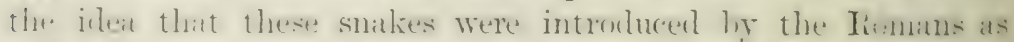
inmates of the temples erented to descolapins at such watering-

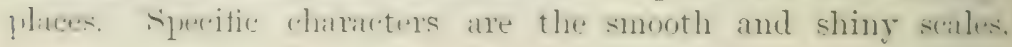


which are arranged in twenty-one to twenty-three rows, the distinctly angulate rentrals and the double anal and sul-(atudirls: the fourth and fifth of the upper liblials horder the ere, which has a round pupil. The coloration is very variable, as a rule ulivehrom above with a dark streak hehind the ere: the mprer lips and a triangular patch on the temples are yellow; the under prarts are uniform pale yellow. Some specimens are prale golden lrown; others are very dark, almost hlack; while some have four darker stripes along the body, and lastly whitish specks occur on the nuler surface. Large Aesculap snakes grow to a length of 5 feet. Their food consists chietly of mice. They hecome very tame, although many of them at first hite furionsly. Their clinhling capacities are astonishing, the snaties heing able to scale high and rertical walls provided there is the slightest " foothold." sume of my specimens escaped in the room and were at last: found near the ceiling, resting on the rods of the curtains, ul' the folds of which they had managed to wriggle. Bonlenger kept one for many years in a glass cage, where the snake entwined himself round the branches of a stick and allowed us to talie him with the stick out of its socket and to inspect him. Buing kept in an inhabited rom, the snake did not exactly hilermate, creeping into the moss at the bottom of the cage : but it refused to feed, and remained in a rather drowsy condition coilenl up on its farourite stand. During the pairing season they frefuently resort to the water, at Schlangenbad at least; the few egres are deposited under dry moss or in dry, lecayed woud, and are hatched in about six rreeks.

C. (Flinechis) seclaris has the smooth scales disposed in twenty-seren rows. The snout is strongly projecting, and has a V-shaped dark mark on the top: a black streak runs through the ere, and another black spot lies below the eve. Foung sperinens are pale brown with a series of dark $H$-shaped marks wn the lack, suggesting a ladder, hence the specific name. In the adult these marks are replaced hy a pair of hrown stripes running along the back; the under parts are always uniform rellow. Total length about :3 feet. This snalie is restricted to the Iherian Peninsula and to the south of France. Most specinens are rery ill-temperer. The young live upon locusts and smali lizarls, the old eat mice and small lirds. In captivity they also take dead animals - a rare habit with snakes. 


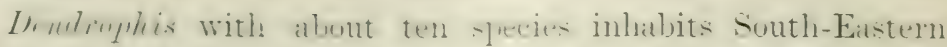

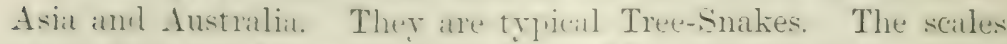
are lieeded, and form only thiteter or fifteen rows: those of the vertehal row are enlareed: the ventrals have a fair of suturelike lateral keets aml a motch on each side. arrantrements which are of weat assistance in climbing the snakes being alle to slicle up the lanncless of trees in alnust straight lines insteal of having to twist and undulate their way up.

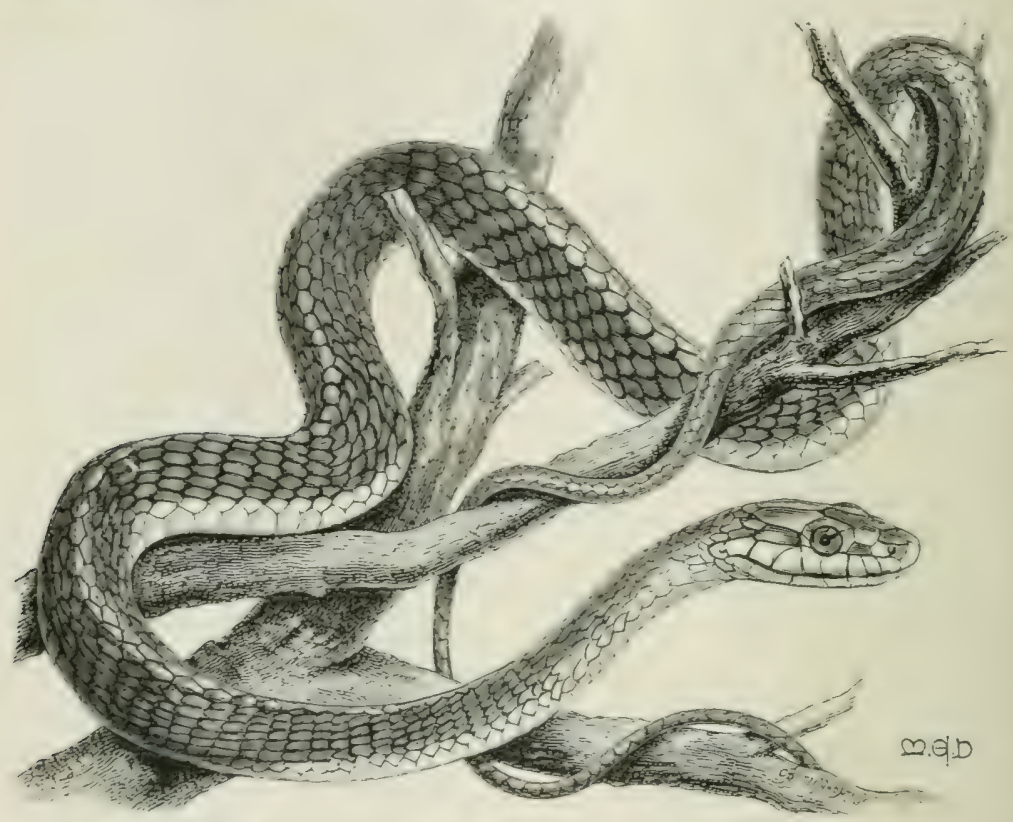

FIG. 163.-Thendrophis punctulatus. $\quad \times \frac{1}{2}$.

D. punctulatus, of Northern and Eastern Australia, is olive-

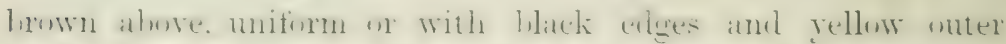
lursters to the scates. The mpere lijes the throat and anterion ventrals, are yellowish. Total length up to 6 feet.

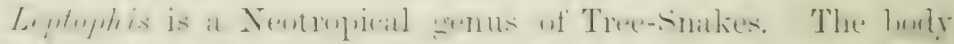

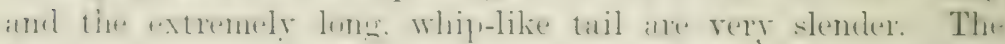
head is very distinct from the neck; the eye is large, with a round pupil. The scales form thirteen or fifteen rows: the ventrals atre sonelimes anculatte lattrally: the sub-catulals are?

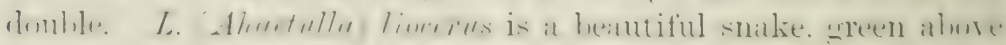


with a golden lustre, while the under parts are rellww or white. The total length of this species amounts to 6 feet, the tail then being nearly 2 feet long. These graceful Tree-sinakes live upun small reptiles and birds and their egres. When shatien wnt af at tree or frightened off they let themselves fall down from (w) siclerable heights, coiling bouly and tail like a watch-sprius.

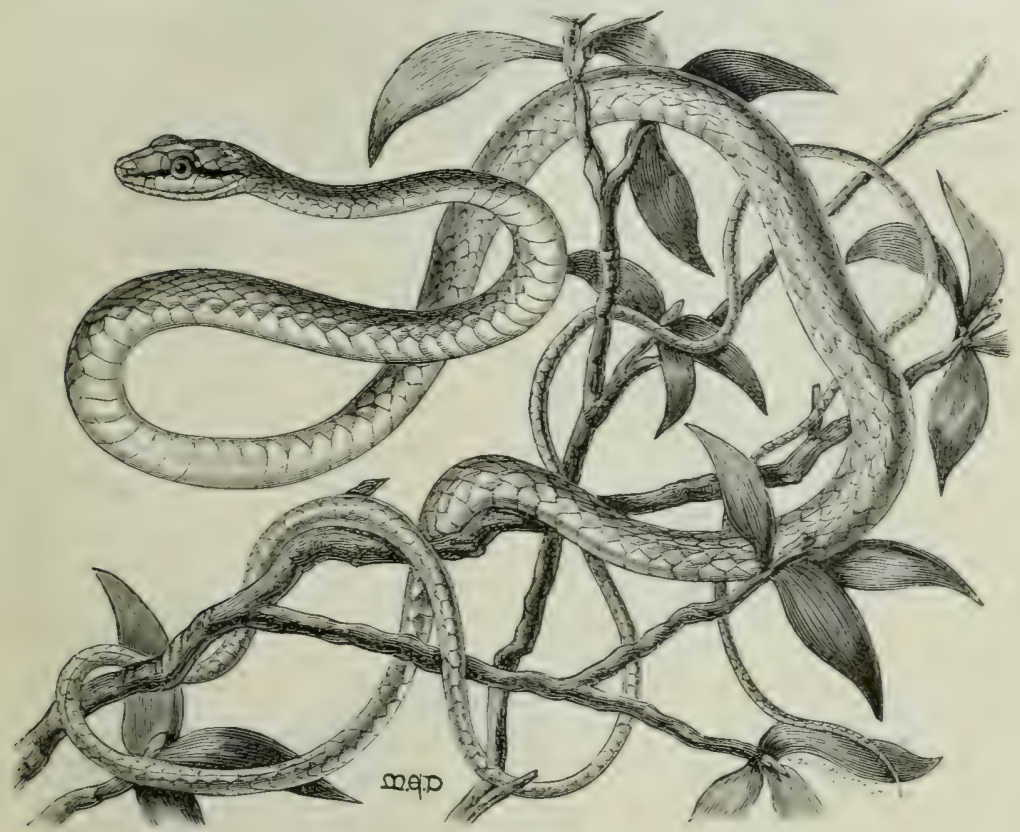

FIG. 161.-Leptophis liocerns. $\quad \times \frac{1}{1}$.

and alighting on the ground upon the spiral. which lireatis the fall.

Commelle.-The teeth are nearly all of equal size aml form continuous series. The scales are smooth aml hare apical pits: the sul-caudals are domhle. The head is scarcely olistinct from the neck. The pupil is round. This genus, with nearly twenty species, is widely distributed except in the Australian resion, the northern half of Asia. and sinth Anericat. Te can mention only the two European species one of which orens in England.

C. austriace S. laevis, the Smooth Snake. The scales are arranged in nineteen rows. Mostly the third and fourth 


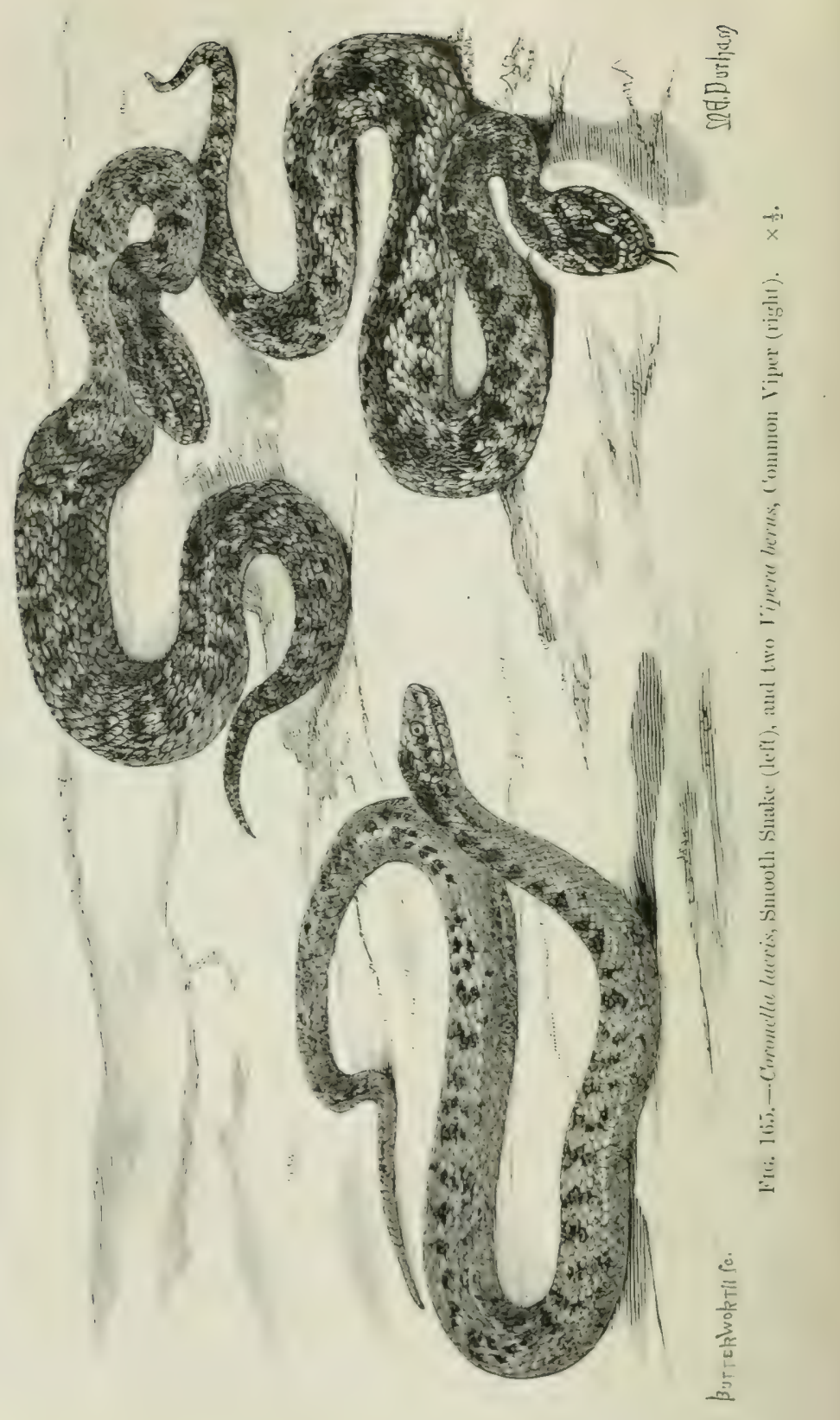


labials border the eye. The anal shield in diviled. The general colour is hrown or reddish ahove, often with one or two lighter stripes, with small dark lorown or red spents: two dark hrown al red stripes on the nape, usually confluent with a large dirk fatch on the occiput; a dark streak extends from the nustril thrus s the eye to the angle of the mouth. The uncler farts are reil. orange, lrown, grey or blackish, either uniform or specklect with lilack and white. The coloration is, however, sul,ject to much rariation, and some specimens strikingly resemile some of the Common Viper, which is also very variable in its colcration. The resemblance is enhanced when the smooth suake lroatens it: heal hy widening the jaws, as it is in the habit of doing. Two such similarly coloured specimens are reluesented in Fis. 165. On closer inspection the differences are creat enough. the harmless snake having smooth scales. and the top of the hetat being covered with large shields: while the Tiner has keelent scales, the top of the heal being covered mostly with scales. a rertical (not round) pupil, and, morenrer, when attachech, usually coils itself into a spiral dise with the head standing out in the mildle, realy to strike. Howerer, these two species are sonuttimes mistaken for each other.-The smooth snake preters lizards as food to anything else, hut it also takes mice. The prey is hunted chiefly in the late aftemonn and in the evening, and is constricted hy the coils of the snake. When canght or eren when handled after months of captivity, the sunonth sinake lites deliberately and firmly, selecting a suitalile slot, for instance a finger, opens the mouth willely and alnust chews the sput. The lite is of course quite harmless, and scarcely clraws blood, few of these snakes attaining a length of more than 2 fert. The $y$ are viriparous, bringing forth about half-ia-tozen young at at time. The range of the smouth Snake extends over the weater lat of temperate Europe, from England and the Iherian l'eninsulit to Berlin, and south-eastwards to Asia Minor. In Englind it ocems in a few counties only, for instance in Hampshire and in Dorsetshire.

C. givmelier, of the south of Frunce, Italy. the Iherian l'eninsula and Xorth-Trestern Africa. much resmbles the English Sinooth Suake, from which it differs in a few loints only. The scales are arranged in trenty-nne. ranely in nineteen, lnms:

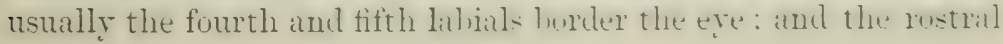




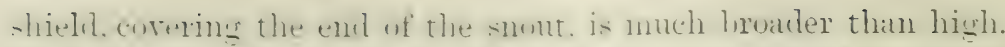

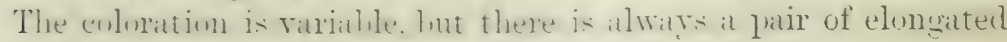
blackish spots or a U-shaped mark on the nape.

Sub-Fam. 3. Rhachiodontinae. With mly a few teeth on the funterion lart of the maxillinies. wn the palatines and dentaries Sume of the vertellate in the rewion of the lower neck

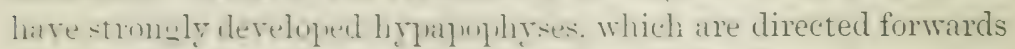
and piepte the oesiphagus. Ther are used for filing through or

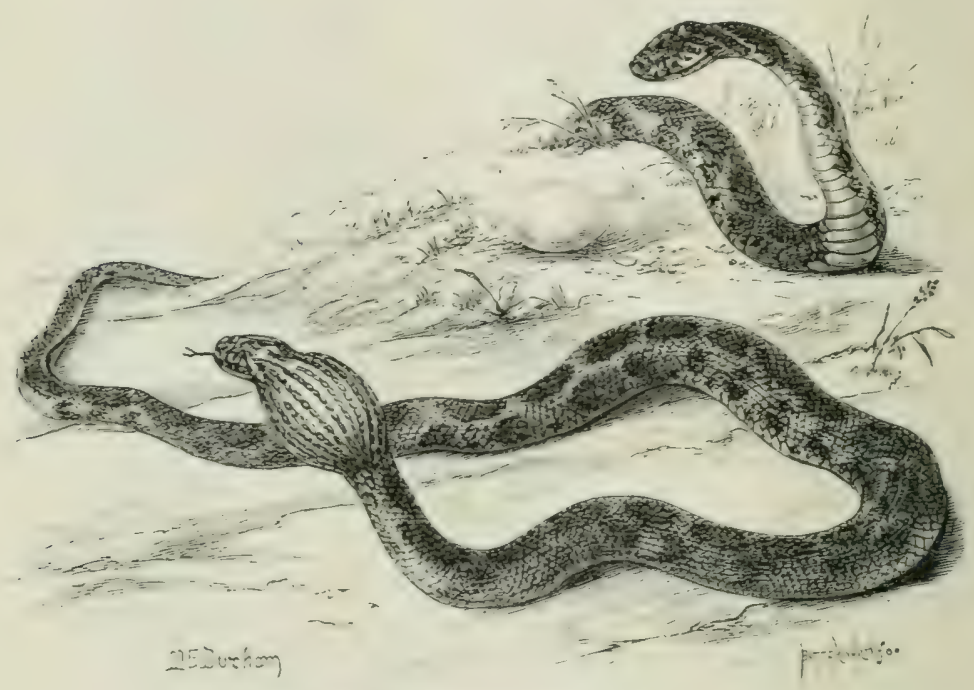

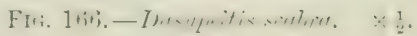

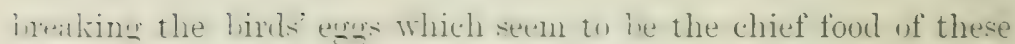
snakies.

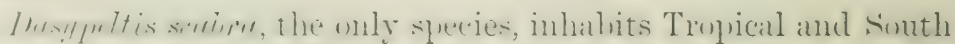
drinat althomph it reaches sarcely more than two feet and at

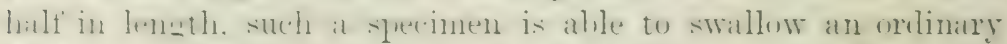

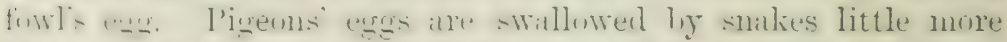
thatn un, fint in length, which setems at first sight quite im-

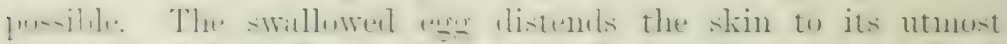

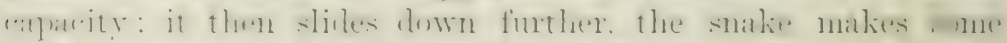

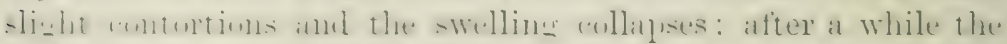

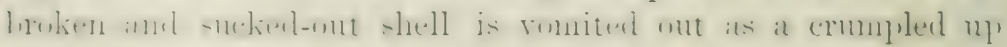


mass. Miss Durham has illustrated this curious frocess in a series of drawings. ${ }^{1}$

\section{Series B. OPISTHOGLYPHA.}

One, or a few, of the posterior maxilliry teeth have a groove or furrow in front, which conducts the secretion of the enlarged upper labial glands. Apparently all these snakes are more or less poisonous, paralysing their prey before or cluring the act of leghtition. So far as man is concerned they are rather harmless, since the poison is not very strong, not available in large quantities, and above all because the small poison-teeth stand so far back that the snakes cannot easily inflict wounds with them.

The Opisthoglypha are of considerable morphological interest, since they connect the Colubridae with the Viperidae, the characteristic poisonous apparatus of which seems to have been derived from that of the Opisthoglypha by the reduction or shortening of the anterior portion of the maxillaries and the harmless teeth, so that the posterior or poison-fangs come to the front.

The Opisthoglypha comprise about three hundred species and are cosmopolitan, including Madagascar but excepting New Zealank. They contain truly terrestrial, arboreal, and thoroughly aquatic forms.

Sub-Fam. 1. Dipsadomorphinae.-The nostrils are lateral amd the dentition is well developed. Long-tailed, terrestrial, and arboreal forms. Most of the arboreal species are green above, often with white or yellow longitudinal bands, while the under parts are white or yellow. They feed chiefly upon lizards, birds and their eggs.

Dipsadomorphus s. Dipsas (part).-Typical, very long-bodied and long-tailed Tree-Snakes, with a vertical pupil. The median or vertelial row of smooth scales is enlarged: the hroal ventral scales are bent at an obtuse angle on the siles, the resulting ridge assisting in climling. The sub-caudals are arranged in two rows. Ten to fourteen maxillary teeth are followed by two or three enlarged, grooved fangs.

D. trigonatus, of India, grows to one yard in length. Tullowish olive or pale grey above, with a white, black-edged 
zigzatg band along the bakk or with a seriess of white, blache-ediged spots.

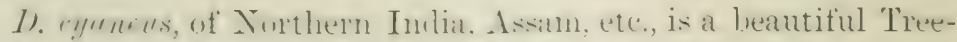
Snake, steen abore, with the slin letween the sciales black.

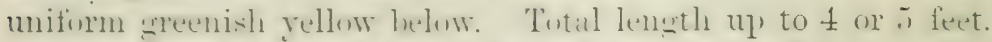

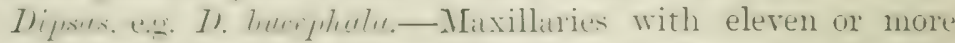
teetli. l'teryonils towthless. Inuly strongly compressed, with

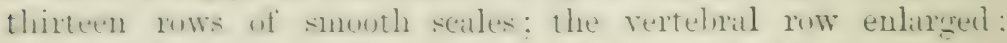
sul-eamials dumble: tail very long. Tropical sonth Americat.

Leptornathus with many species in Central and South America, like Dipsas, but with teeth on the pterygoids.

rinloultis--Terrestrial and dimual. with a romd pupil. The row of small maxillary teeth is followed hy ane or two much

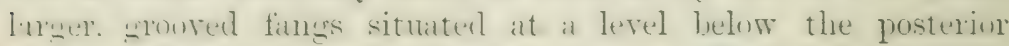
lmoles of the eye. The first half-it-lozen mandihular teeth are

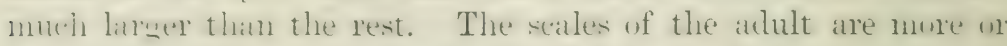

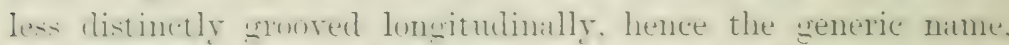

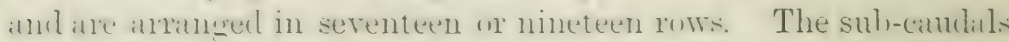
forme two rows: the rentrals ane rounded off laterally. Two species in the Mediterranean anntries and in sonth-Westerm Asia.

C. monspessulanu s. lacertina is one of the largest snakes in Eurnge. reathing a length of 6 feet. of which the tail takes up 18 inches. Olive-brown or yellowish or reddish abore, freduently with small, dark, lightedged spots. The silles are wften liakish, with whitish sprecks. The under parts are rellowish white, with or without lowwish markings. sinne sincinens are rely green, with a chll hiackish neck. Une of the syerifie manes of this terrestrial snake is the latinised form of Inntpellier: the other refers to the shape of the heat, which is

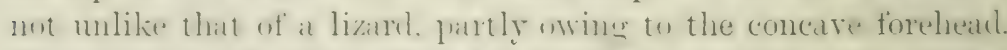
This sperejes inhalits rather hy localities studled with shruls.

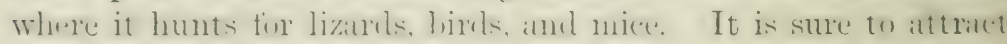

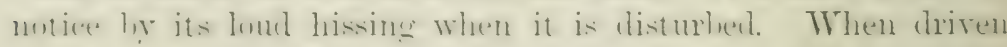

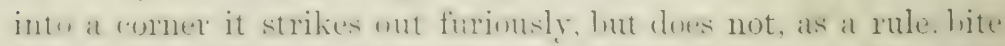

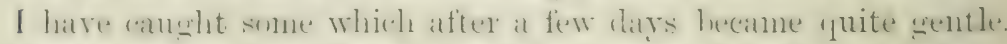

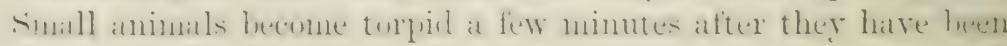
bitten.

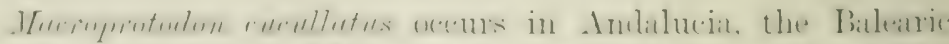

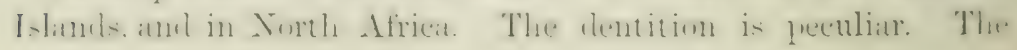


fourth and fifth maxillary teeth are enlarged, followed hy an interspace, then follow several small teeth, and lastly the two enlarged, grooved teeth. The sixth mandibular tooth is rery long, separated by a space from the much smaller posterior teeth. The general colour of this sand-loring snake is pale brown or grey above with small spots or streaks on the trunk, and with a large black patch behind the liead extending orer the sides of the neck, hence the specific name. The under parts are bright red or vellowish, sometimes spotted with black. Total length under '- f'eet.

Sub-Fam. 2. Elachistodontinae. - With only a few teeth on the posterior part of, the maxillary and dentary hones, and on the palatines and pterygoids. Some of the vertebrae in the thoracic region have much-developed unpaired hypapophrses, which are directed forwards and pierce the clorsal wall of the grullet. In this respect Elach istoctun vestermunni, of Bengal, the only species, hears it striking resemblance to the South Africin Aglyphodont Dosypeltis (see 1. (620), and it is prolualle that this apparently very rare Indian snake also smallows egrss. It is brown above, with a yellowish vertehral stripe; yellowish helow.

Sub-Fam. 3. Homalopsinae. - The nostrils of these alsolutely aquatic and viviparous snalies are valrular, and are situated on the upper surface of the snout. The eyes are small with vertical pupils. The two dozen species, mostly very ugly, inhabit the rivers and estuaries of the East Indies from Bengal to North Australia. Some species have rery small and narrow rentral scales, recalling the Hytrophinae, or the hurrowing snakes, none of which use their ventral scales for locomotory purposes.

Hommlopsis buceatu, Cerberus rhynehops and Hypsidhine, e.g. H. ylumber, have well-developed rentral scales; the other scales of the first two genera are keeled, thuse of the third are smooth. In Hipistes the whole heal is covered with very small scales: all the scales of the body are smooth except the very narrow rentrals, which have double keels. $H$. hydrinus, of Simn and the Malaty Peninsula, has a compressed body, and in its general appearance much resembles the Hydrophinae. It lives, like its allies, upon fishes, and it swims far out into the sea.

\section{Series C. PROTEROGLYPHA.}

The anterior maxillary teeth are deeply groored, or so folded VOL. VIII 
as to appear hollow or prerfurated. Behind these enlarged poison-fimgs the maxilla carries a series of smaller, solid teeth: hence the term " proteroglyphous." which means that the anterior teeth are grorved, in oppusition to "opisthoglyphous." Both series have been developed independently.

The I'roteruslyphat are all extremely poisonous, mostly rivifarous, and widely distriluted orer the whole of the Anstralian, Palitentropical and Sentropical regions, with the exception of Mithdaticar and New Zealand; they extend northwards into the warner parts of North Anerica, and they also

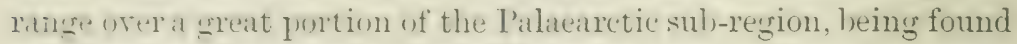
in Nonth Afrieat and sumb-TWestern Asia. They form two matural sul-families: Elitpinate. with cylindrical tails, and Hydrophinae or Sea-Snakes, with laterally compressed tails.

Sub-Fam. 1. Elapinae.-The tail is crlintrical. The Elapinate complite nearly 150 species, which have been grouped into a
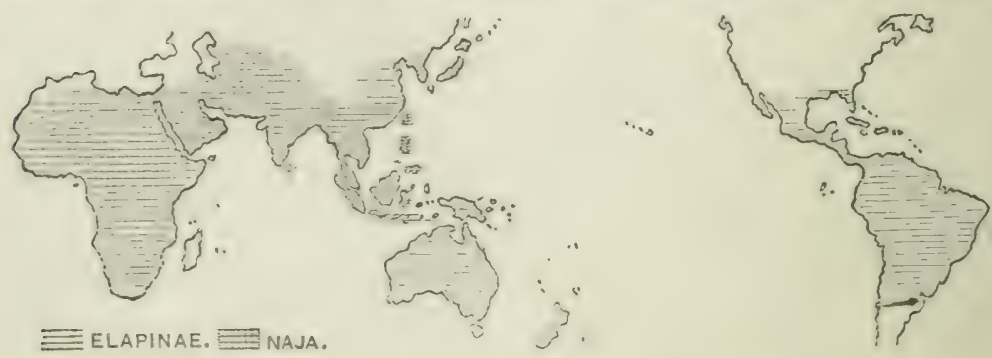

FIG. 167.-Map showing the distribution of the Elapine Snakes.

gre it number of, mostly sonewhat imaginary, genera. In Australia they constitute the great majority of Snakes, there heing hesides the deally Elatpinate only a few I'ythoms amb Truhlopinlate, and reery few Coluhrinae.

Sirju. - The pair of large and grooved poison-fangs are splatrated hy an intersplace fion one to three small. faintly gronved teeth near the posterior end of the maxillaries. The scales are smonth and without pits, and are arranged in fiftex'n to twenty-fise obligne rows on the trunk, althomgh more necur in the resion of the neck: the vertebral row is not enlarged. The hearl is lut slightly distinet from the neck. Fach nosidil lies between two nasials and the internasal. The suld-caudals form two rows. The punil is romd. The neck-resion can he explanderl 
into a hood by the spreading and moving headwards of the rihs. Several species in Southern Asia and in Africa.

I. tripudiuns (the "Cobra").-The coloration varites much. The typical form is yellowish to dark brown with a blitck and white spectacle-mark on the dorsal side of the hood, and with a large black and white spot on each side of the correspondins uncler surface. Other specimens are uniform pale brown to blackish grey, without any markings on the lood. The cobra is

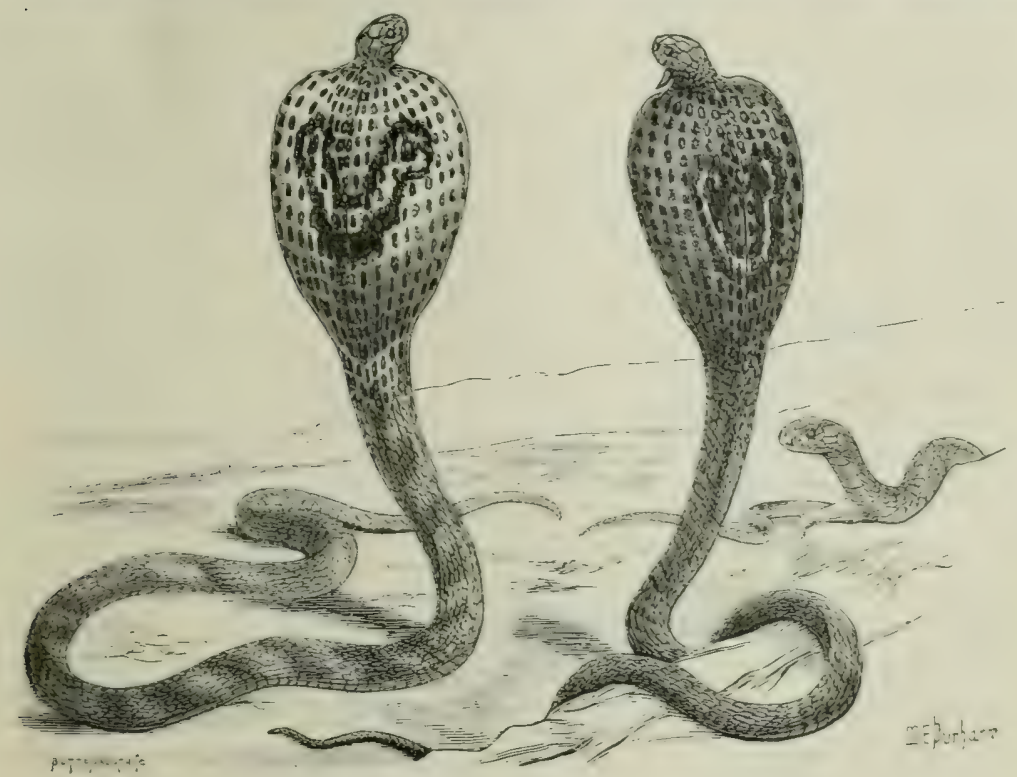

Fig. 168.-Naja tripudians (the Cobra). $\quad \times \frac{1}{5}$.

widely distributed, from Transcaspia to China and to the Maluy Islauds; in the Himalayas it ascends to about 3000 feet abore the level of the sea. Very large specimens are said to attain more than 6 feet in length, but a cobra of 5 feet, inclusive of the tail of 9 inches, is considered large. The colma prefers platces which afford it a convenient hole to retire into: for instance, deserted hills of termites, ruins, heaps of stones and stacks of wood, and it has the disargreeable habit, like the harmless Tat-snake, Zrimenis mucusus, of making itself at home in inhalited houses, probably attracted by the rats. Its chief food consists of small Vertebrates;-frogs, lizards, rats, occasionally fishes and 
small hirds. It drinks much, and hunts chiefly in the late afternom and in the evening. althongh it possesses a round fupil. It avoils hot sunshine. Many olservations show that the colnats live in gairs, otherwise they de not take nuch notice

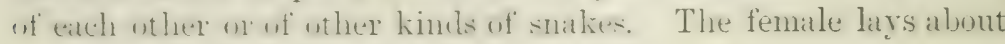
a dozen soft-shelled eggs as large as those of pigeons.

This cobrr is used by Indian conjurers. The "dance" is the halit of these malkes of ereting themselves, when agitated, upon the himber thim ar quater of their lenoth, whilst they

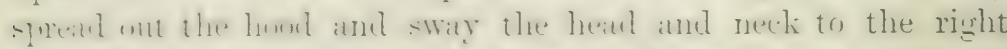
and left, always in an attitule realy for striking. They are docile and by nature not vicious. Most of the performing (nilnas hate their teeth drawn, and they then linw well that they camnot bite. They only strike at the hand, just as

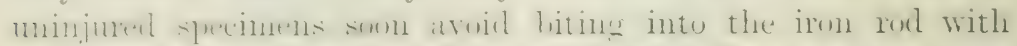
whinh they alle liftel ul in menateries. The drawing of the teeth is an operation which has to be repeated, since reserve-teeth soon take the place of the lost pair.

I camnot refrain from relating an abstract of a ridiculous

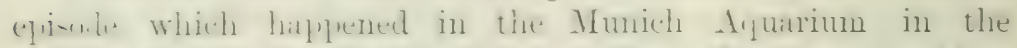

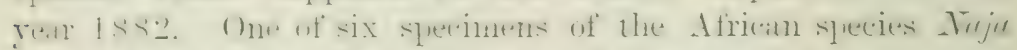

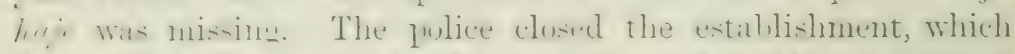

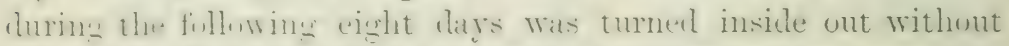
any where thict than that two other, himmless, snalies were dis-

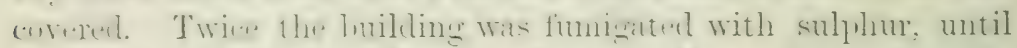

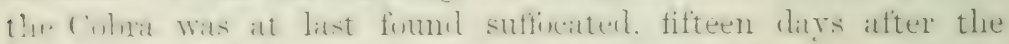
1, ...inning of the stanch. This snake cansent the owner of the Aquarium a loss of nearly $£ 1500$. But the cruel joke was,

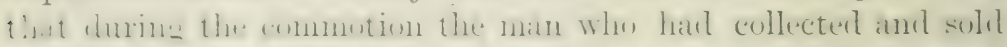

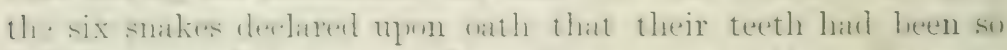

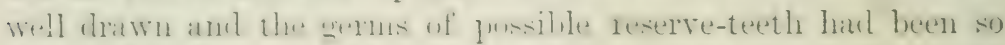

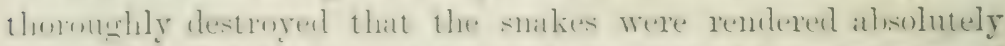
harmlen. Inut le was not helieveil. in spite of a commission of

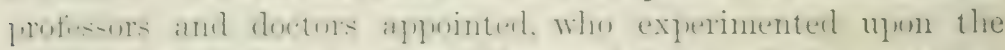

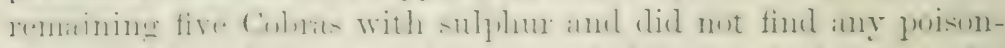

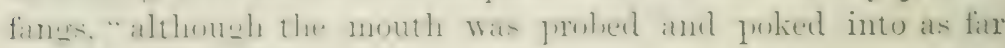
down as the larynx."

Coloras have quite a number of enemies. Peafowl and

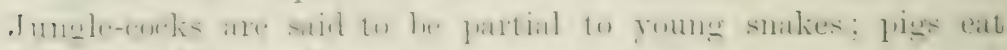

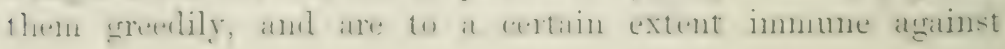


their bite. The same applies, according to the most recent observations, to the famous Mongoos. Sir E. Temnent, in his Lutural History of C'cylon, quoted several times in the lwesent book, makes the following remarks about the immunity of this little creature:

"I have found universally that the natives of Ceylon attach no credit to the European story of the MLongoos (Herpustes grisrus. resorting to some plant, which no one has yet succeeded in irlentifying, as an antidote against the bite of the venomous serpents on which it preys. There is no doulut that, in its conflicts with the cobra and other poisonous snakes, which it attacks with as little hesitation as the harmless ones, it may be seen occasionally to retreat, and even to retire into the jungle, and, it is added, to eat some regetable. . . A number of plants, such as the Oplii-

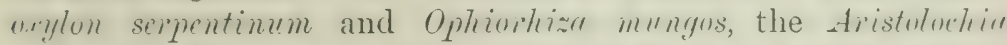
inlice, the rimose octundria, and others, have each been asserterl to he the Ichneumon's specific. . . . If the Ichnemnon were inspired hy that comage which would result from the consciousuess of security, it would be so indifferent to the bite of the serpent, that we might conclude that, both in its approaches and its assiult, it would be utterly careless as to the precise mode of attick. Such, however, is far from being the case; and next to its andacity, nothing can be more surprising than the adroitness with which it escapes the spring of the snake under a due sense of dinger, and the cumning with which it makes its arrangenents to leap upon the back and fasten its teeth in the head of the colma. It is this display of instinctive ingenuity that Lucan celel rates where he paints the Ichneumon diverting the attention of the Asp by the motion of his bushy tail, and then seizing it in the midst of its confusion. See Pharsalia, lib. iv. verses 729-734."

There is a widespread belief in the efficacy of "Snakestones," which are generally pieces of charred bone, well polished, occasionally pieces of chalk or some similar porous substance, which, if pressed upon the bleeding wound, are supposed to absorb the poison. Snake-charmers profess to prepare such "stones," and to preserve the composition as a secret. The manufacture is a lucrative trade. The Boers bought them, imported from India, at high prices. Mr. Selous saw one, or heard of one, that was kept as an heirloom. Snake-stones are 
also male, and usen, in Mexico, of charred hartshorn; they are called "piedras ponsonas."

The use of the Suake-stone, called " l'amboo-Kaloo," has probahly leen communicated to the singhalese by the itinerant snake-chamers who resort to the island from the cuast of Coromandel.

Althnuh sir E. Tennent describes several instances of the sucessful application of snake-stones as well authenticated, he has never hinself heen an eye-witness. Although two cases have lexen fully described, they do not at all exchule the possihility, nay the probalility, that the Tamils imposed upon the Europeans in order to sell the snake-stones.

". No ilunht the snake-stones, owing to their porous nature, artherest to the bleeding wound, hecame saturated with blood, and them fell off. Tery likely, in calse of a poisonous lite, some of the renom wotill he sucked ul too, hut we do not know if those makes were still in the prosession of their poison-fungs. I'ronerly conducted experiments with snake-stones have proved as little efficacious as the application of dry cup.

"Themetically snake-stones as yuick ahsoritent agents of the linel with the poison are good; they will certainly prevent sone of the poison from entering the system, but that would at best, be a partial eure only.

"In March 1854 a friend of mine was riding, with some "ther civil ofticers of the (rovermment, along a jungle path in the vicinity of Bintemes, when he saw one of two Tamils, who were aldnumbling the party, suchenly dart into the forest and return, holding in buth hands a Colna de capello, which he had seizel hy the head and tail. He called to his compranion for assistance to pliace it in their corered basket, lut in doing this, he hambled it sn inexpertly that it seized him ly the fireger, and retainerl its hold for a few secomels. as if mahle to retract its fims. The bloml flowed, amel intense pain splueared to follow almust inmentiately: hut with all experlition the friend of the sufferer unlil his waist-cluth, and tork from it two snalie-stones, eath of the size of a small almomel. intensely blate and highly pulisherl. though of an extremely light substance. These he alplied, one to eareh wouml inflicterl by the teeth of the serpent, to which they attached themselves alosely: the hood that oozed from the bites being rapilly imbibed ly the porous texture of 
the article applied. The stones adhered tenacion:ly for three or four minutes, the wounded man's companion in the meanwhile rubbing his arm downwards from the shoulders towirts the fingrers. At length the snake-stones dropped off of their own accord; the suffering of the man appeared to subside; he twisted his fingers till the joints cracked, and went on his way without concern. Whilst this had been going on, another Indian of the party, who had come up, took from his bag a small piece of white wood, which resembled a root, and passed it gently near the head of the cobra, which the latter immediately inclined close to the ground; he then lifted the snake without hesitation, and coiled it into a circle at the bottom of his basket. The root by which he professed to be enabled to perform this operation with safety he called the "Naya-thalic kialanga" (the root of the snake-plant), protected by which he professed his ability to approach any reptile with impunity."

The following narrative, communicated to Sir E. Tenment by H. E. Rerne, of the Department of Public Works, Colombo, seems to exclude the possibility of deception:-

"A suake-charmer came to my bungalow in 1854 , requesting me to allow him to show me his snakes dancing. As I had frequently seen them, I told him I would give him a rupee if he would accompany me to the jungle and catch a cobrat that I knew frequented the place. He was willing, and as I was anxious to test the truth of the chamm, I counted his tame snakes, and put a watch over them until I returned with him. Before going I examined the man, and satisfied myself he had no snake about his person. When we arrived at the spot, he pliyed on a small pipe, and after persevering for some time, out came a large cobra from an ant-hill, which I knew it occupiecl. On seeing the man it tried to escipe, hut he caught it ly the tail and kept swinging it round until we reached the bungalow: He then made it clance, but before long it bit him above the knee. He immediately bandaged the leg abore the bite, and applied a snake-stone to the wound to extract the poison. He was in great pain for a few minutes, but after that it gradually went away, the stone falling off just hefore he was relieved. When he recovered he held a cloth up, which the snake flew at, nnel canght its fungs in it; while in that position, the man passed his hamd up its back, and having seized it by the throat, 
he extracterl the fangs in $m y$ fresence and gave them to me. He then squeezed ont the proison on to a leaf. It was a clear oily sulstance, and when ruhlued on the hand produced a fine lither. I carcfully watched the whole operation, which was also witnessed ly my clerk and two or three other persons."

I. haije is the common hooded cobrat of Africa, the "Aspis," so called on atcumt of its shield ar hood-the "spy-Slange" of the Foers. As a rule the spectacle-marks on the neck are absent wr inclistinct, the seneral colour raries much, either brown above, yelluwish leeneath, with or without hrown spots: or dark brown aluse with yellowish spots, lark hrown lieneath; or blackish alrove and leneath. The name spy-slange. meaning spitting Snake, refers to the halit which this and other African Cobras have of letting the poison drup from the mouth like saliva when they are excited. This is not a larticularly economical habit, nor is it of the slightest use to the snake.

A. (Ophiophagus s. Hamadryas) bungarus s. elaps is the " Hamadryad " or "Snake-eating Colma" on "King Cobra." It has a well dilatable hood; the very variable coloration is yellowish to black, with or without an olive gloss. Many specinens have more or less distinct dark cross-bands or rings armunt the indy. while others are olive ahore with liach-edged scales and others again are rery dark ahove and beneath. The distinctive, specitic character is the small number of scales, these furming only fifteen rows on the middle of the body, nineteen or twenty-one on the dilatahle neck. There is a pair of large occipital shields behind the parietals.

This snake reaches the length, enormous for a poisonous snalie, of 12 feet or more. Its size and rery poisonous nature malie it the curse of the jungle. It ranges from India to South ('hina, and to the Philippines. The food seems to consis entirely of other snakes.

St futlun hutmmhutes is another hooded snake in South Africa, where it is linown as the "Pinghals," i.e. banded neck. It differs from ling by the absence of small teeth on the maxillarien hehind the fangs, and ly the strongly keeled scales, which furm nincteen rows. The general colour is black above variegated with yellow w pale brown: the under parts are also black, often with we or two whitish hands across the lower portion of the neck. 
The Rer. G. Fisk ${ }^{1}$ mentions the case of two young "Ringhals," of 10 and 9 inches in length, having been attacked and partly devoured by a mouse, supposed to be Dendromys melimotis, which

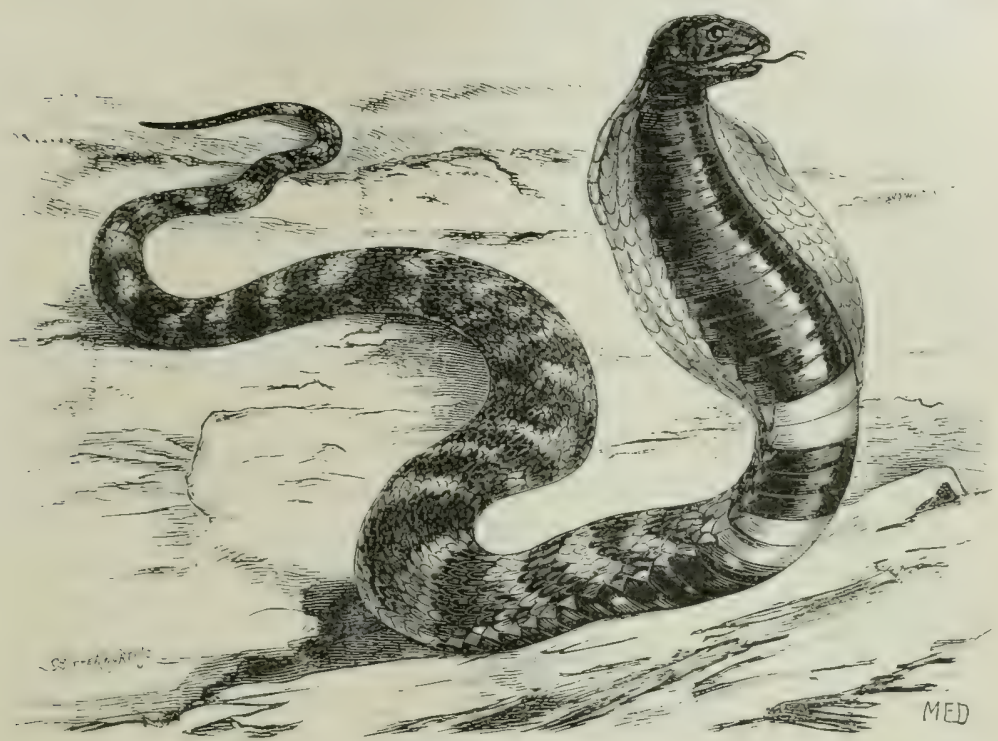

FIc, 169.-Sepedon haemachates (the "Ringhals"). $\quad \times \frac{1}{5}$.

was put with the snakes in a band-box. On the habits of the Ringhals see Symonds. ${ }^{2}$

Bungurus.-The scales are smooth, and form thirteen to seventeen rows. The spine is very prominent, and the median row of scales which covers the ridge is much enlarged. There is no dilatable hood. In other respects Bungarus is closely allied to $\Lambda^{\top}$ aja ; about half-a-dozen species, in South-Eastern Asia.

b. fusciutus reaches a length of 5 feet. The general colour is bright yellow, alternating with blackish rings.

B. coeruleus s. candidus is the dreaded "Krait," oceurring in the whole of the Indian sub-region. It is dark brown or bluish black with narrow cross-bars or white specks, or it is alternately barred brown and yellow; the under parts are uniform white. Total length rarely 4 feet.

The "Krait" seems to cause more deaths in India than any uther snake, since it is very common, especially in Bengal and in 1 P.Z.S. 1887, p. 340.

2 P.Z.S. 1887, p. 489. 
Southern India, and often creens into the houses. It lives chietly on rats, lizards, and snakes.

Collophis. With only thirteen row of smooth scales. The head is small, not distinct fion the neck. The small eye has a round pupil. The short tail hats two rentral rows of scales. The whole horly is cylinclrical. Sereral small species, one or two feet in length. in Sunth-Eistern Asia. r. muclellandi in India and Indo-china is reddish brown above, yellow below, with rexplar, ryuidistant, liack, light-exlged cross-bands or rings. Total length up to 2 feet.

Imolinglis differs from Collophis mainly ly the enormously derelnged proison-glands which, insteal of heing restricted to the heat. exteme along the anterior thirel of the hody, gradually thickenings and terminating in front of the heart with clubshilpel emis. Owing to the extension of these glands, which "an lin felt through the skin as thickenings at the end of the first third of the hody, the heart has been shifted farther hack than in any other snake. Sereral species in Indo-China and in the Malay Islands, 1). intestincelis with many colourrariations.

Anstralial sufters from an abundance of Elapine snakes, of which we will mention only the three commonest.

Pscudcchis e.g. Ps. porphyriaceus, the "Black Snake" of Anstralia. hats serenteen rows of smooth scales on the bouly, a few nene wh the neek, which howerer is not, or is only slightly; chilated. I few of the sul-cautal scalles are undivided, the rest are priver. 'The head is distinct from the neck: the pupil is round. Total length up to 5 or 6 feet. The general colour abore is black, with the outer row of scales red at the base: the ventral sonles are mel with black edges. The females are cenemally more lnown than lilack, and are therefore ometimes

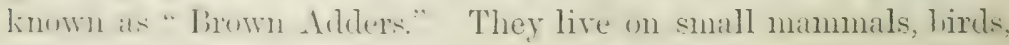
lizards and other snakes.

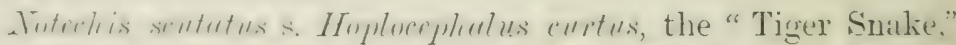
has rather small eyes with romel pupils. The leat is distinct from the cylintrical lumly, which is covereel with fifteen to nineteen rows of smonth scalles. The sult-candals are single. The heat of this varbibly colomed snalie is mostly lolack, the hody olive brown with dark aross-bands: towards the tail the colorat ion hecomes more uniformly blackish. The under parts are pale 
yellow. The range of this rery common suake extends over Tasmania and Australia.

Acunthophis anturcticus, the "Death Adcler," is masily reursnised hy the peculiar tail, the end of which is laterally compresect. beset with a few rows of enlarged imbricating scales, and terminates in a thin horny spine. The heal is distinct from the neck, and flat; the eye has a rertical pupil. The short and thick body is corered with trenty-one or twenty-three rows of keeled scales. The anterior caudals are single, the posterior double. The colours of the upper parts are a mixture of brown, reddish and yellow, with dark cross-bands. The helly is pale yellow, often spotted with lrown or black. The end of the tail is jellow, redulish lnown or hlack. The total length of this stout and unly viviparous creature remains uncler :3 feet. It is widely distrihuted from South Australia to the Molnceas. The use of the peculiar tail rery probably consists in attracting or fixing the attention of small animals; the snake, lying coiled up on a dry and -anly spot, slightly raising and vibrating the tip of the tail.

Elaps is an entirely American genns, with many species, most of which are extrenty prettily colouren, red and biack in alternate lins leing a farourite pattern. The maxillaries carry no teeth lehind the poison-fangs. The scales of the hody are smooth and form fifteen rows. The tail is short. The small eye has mostly a rertical pupil. The head is very small, not distinct frum the neck. The squamosal and quadrate bones are short, and the silpe of the mouth is so linited that these beautiful snakes, althmuh possessing strong poison, are practically hammless to man. One of the prettiest is E. corallinus of the forests of Trupical sonth Americal and the Lesser Antilles. The whole houly, ahove and helow, is alomed with about twenty deep black rings, which are edged with yellow and again separated hy red rings equalling in width the black ones. Sometines the red ring are dotted with black, and the black dots may form alditional rings letween the red and the rellow. Total length under 3 feet.

Sub-Fam. 2. Hydrophinae (Sea-Snalies).-The tail is strongly compressed, sometimes the hody also. All the seales are sunall, and there are often no enlarged ventrals. The eyes are small, with romd pupils. All these snakes are very poisonous and live in the sea, often at considerable distances from the land, 
with the exception of one sleeries of Distira, D. sempori, which is confinesl to the land-locked fre-hwater Lake Taal at Luzon in the Philiphines. They live on fish, and range from the I'ersian (inlf to (entral Anerica. In conformity with their absolutely apuatic life they are riviparons, and they die when kept ont of the water fire any length of tine. Alout fifty species are known.

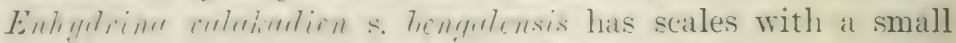
thinercle wreel. which is stronger in the males: the rentrals are rerr small. forning a sarcely enlarged stries. The maxillaries

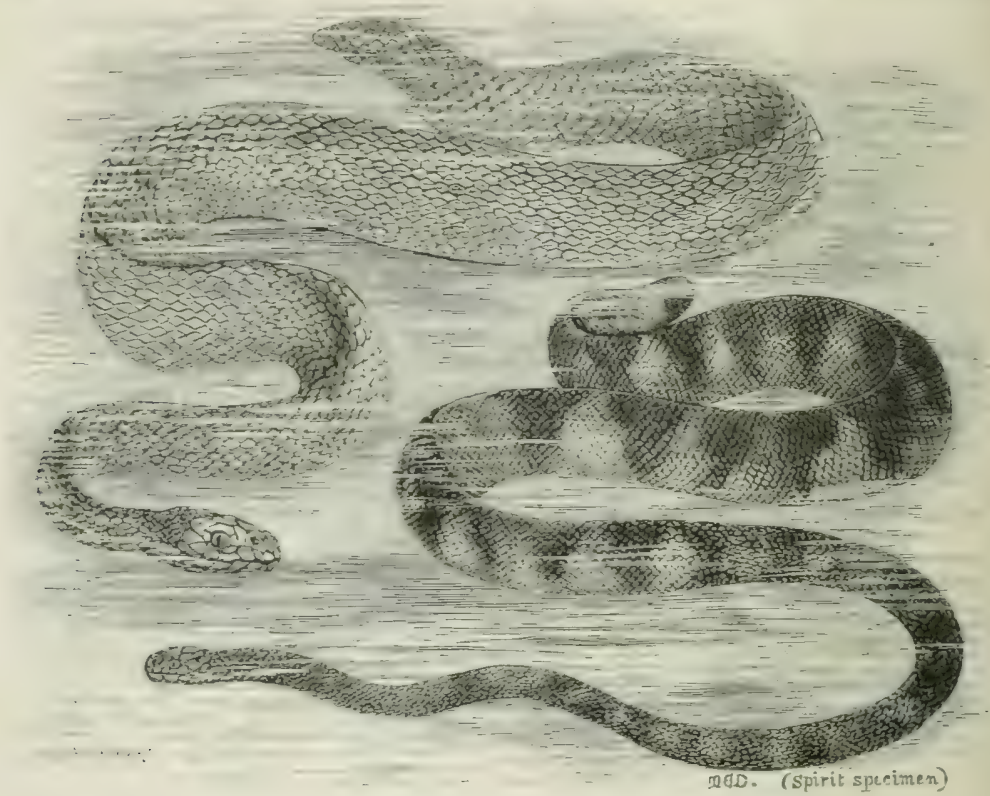

FIG. 170.-Enhydrince valakadien (left upper figure) and Hydrophis wbscura (right lower figure). $\times \frac{1}{4}$.

rarry two or mole small srooved teeth in addition to the poisonfincs. The hack is olive or dark grey, with liack transverse hambs, which are most distinct in the young. The under parts are white. This sqeedes ranges from Persia to the Malay Islands.

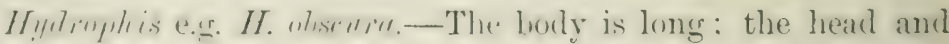
neck are very slenter, the holy becoming much thicker farther back. The small teeth hehind the poison-fangs are not grooverl. The ventral scales are very small, the others are keeled, strongly so 
in the males. The general coloration of this sea-sualie, which reaches about one yard in length, is dark olive-green allwe with yellowish cross-lar's, which form complete rings romel the slendere part of the houly. Other specimens are pale olive. with dinls cross-hands. This species occurs in the Bay of Bemgal and the Malay Archipelago.

As a rule Sea-Snakes are not found in mid-ocean. After leaving Cerlon, the steamer meets them again in the sitraits of Mirlaceal. Those which ocem near the south coast of Jalan, e.s. Distiva cyanocincta, are found there only in the summer, and are probably carried there by the south-west monsoon.

Acomding to semper the gravid female visits the shores of low islancls, there to give birth to its roming letween the rocks. and she remains with her offspring for some time. Semper

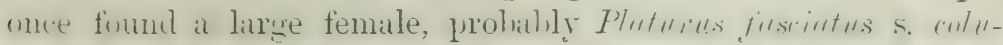
Trinus. coiled up amomgst rocks, and hetwern the folds were at least twenty young, each already about 2 feet long.

Ionlenger ${ }^{1}$ has witten an interesting popular account of Sea-Snakes.

Fam. 8. Amblycephalidae. - Some thirty suecies of Nentricical and Oriental Snakes have heen separated from the ('oluhidate on acenunt of the pteryoids, which are widelyseparated firm the qualrates. the posterior ends of the pteryogids not reaching herond the lerel of the oceipital condyle. This condition can be ascertained when the nouth is opened widely. The prefrontals are not in contact with the natsils. The squamosils are reduced to prullike restiges. Externally the Annlycephahidat are easily distinguished from the colubrilate liy the alsence of a longitulinal melian mental groove. The heal is thick, rery distinct from the neck, and gives these ham less smakes a " poisomous" il]pearance. The pupil is vertical.

Amblycephalus, e.g. A. monticola-Maxillaries short, with only five or six teeth. Sub-caudals in two rows. Body comfresiel, corereal with fifteen rows of scaless. South-Eastern -1-ial.

Fam. 9. Viperidae. - The maxillaries are rery short. muraly attached to the prefrontals and ectopteryouils, so that they can te erected tugether with the large poison-fings, which (lesides ressre-tecth) are the only maxillary teeth. The frefrontals are not in contact with the nasils. The signamosals are very lousely 
attached. For further details se Fin. 180 . The poison-fangs are perforated, havins a wide hole on the anterior side at the base, in connexion with the linge proisun-sland: the hole leads into a camal, which onens gratually as at semi-canal on the anterior surfice of the distal thirel or quarter of the tooth. As msual in guismons snakes, sereral reserve-teeth are stowed away behind the acting fance. When the latter is hrolien off or has served its tine it is cast of at the lase, and the next reserve tooth takes its place. The smply uf reserve-terth is indefinite, half-finished teeth down to mere germs constantly growing.

All the Viperidae are very poisonous, and all, except the Atrican Atrmaturis, are viviparms. They include terrestrial,

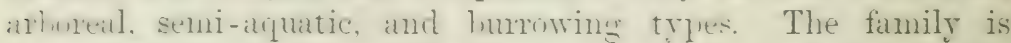
asmonulitan. exceptinge Matugastar and the whole of the Anstralian region: it is divilent intu Vipers and Pit-Tipers.

Sub-Fam. 1. Viperinae Tilers.-There is no sensory

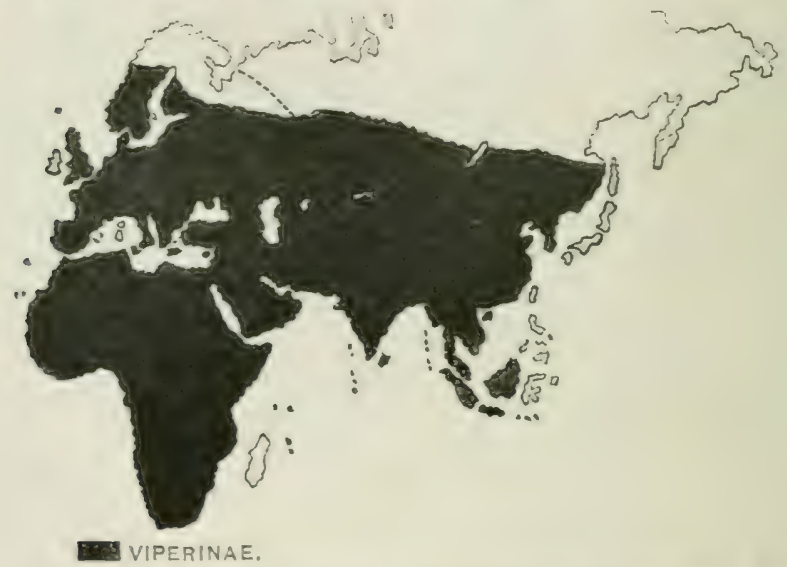

FiG. 171.- Hap showing the distribution of the Sub-Family Viperinae. Corsica and Sardinia should be black in the map.

extermal pit hetween the ere and the nose and the maxilling is unt hollowed ont ahove. The Tigers ate alsolutely restricted to

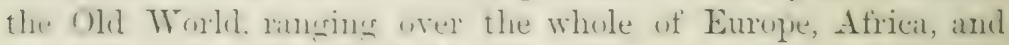
Asiat, with the exeptim in Manligasiar : their northern extension is linited mily ly the permanenty frozen condition of the undergromul. Xine -enera with ahunt forty species are known.

Cousus with a few species in Africa and dzemiops fece in Ulper Jumah are the only ripers which have the head covered 
with large symmetrical shields, while in the other etererit the head-shields are broken up into scales or small shields. C'nusus thombeatus is very common in Africa, from the Grimbia to the Cilpe. It reaches a length of a little more than 2 f'eet. I'ale? (olive-brown above, usually with a dorsal series of large rhomlic or $V$-shalped dark brown, sometimes white-erlged spots, and with a ditrk arrow-shaped mark on the occiput; under parts yellowish white or grey.

bitis s. Echidna.-Very much like Tipera, but the nasal

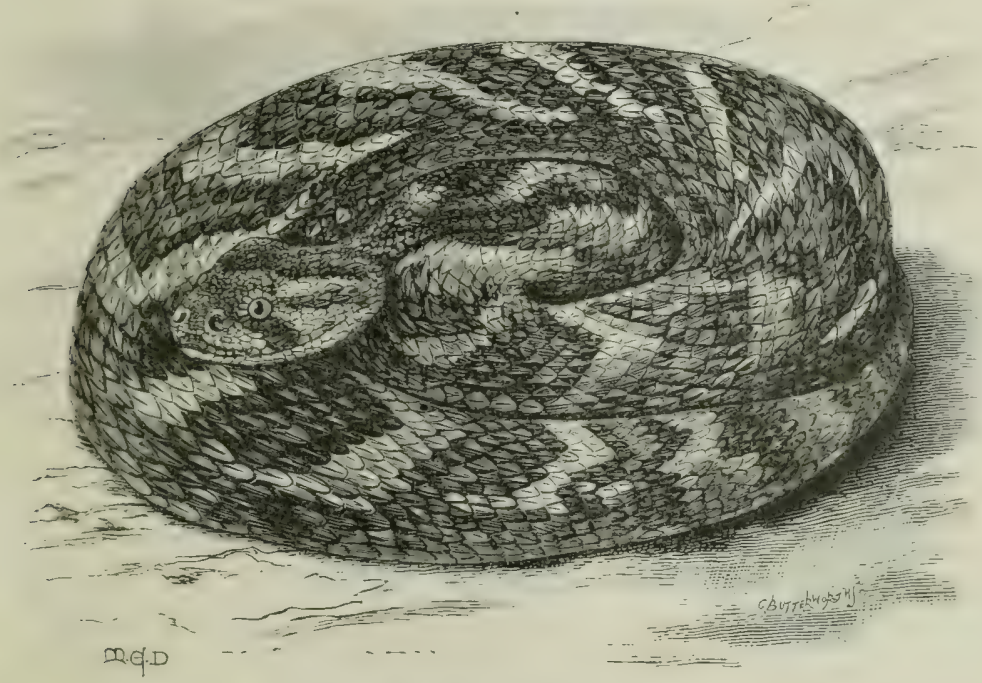

FIG. 172.-Bitis arietans (Puff Arder). $\times 1$.

shields are separated from the rostral by small scales, and the pustfontal hone is rery liurge. Several species in Africi.

The head is rery distinct from the neck, chiefly owing to the litre poison-glands and to its being, like the boly, much depressed. The small 'ye has a rertical pupil, and is separated from the labials ly a series of small scales. The scales are keeled, and form many, from twenty-nine to forty-one, rows; the tail is rery short, with two rows of scales below.

In is. wrictuns, the "Puff Adder," the nostrils are directed upwarks. This ugly hrute is yellowish to orange hrown ahove with regrular, cherron-shaped dark bars or other markings, helping 
to conceal the creature when it is lying on sandy and stony ground; the under parts are yellowish white. The Puff Adler reaches a length of 4 , or rery rarely is teet, ranging all over Africia, except the north coast, and extending into Southern Arahia. It is rely slow; ami trusts to mot being discovered when

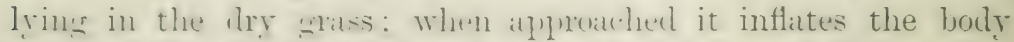
and hises lombly with a juffing somul, watches the enemy with raised and rhatrateristically lent head and neck: hut it bites only when atully tomeherl or attatched. The effect of the bite

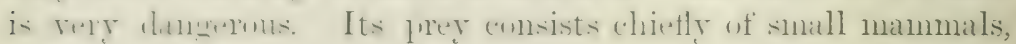
which are hunted during the night.

B. (Echidna) nasicornis, of Tropical West Africa, has two or

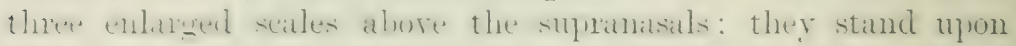
erectile tissue so as to form horn-like elevations. This "Nose-

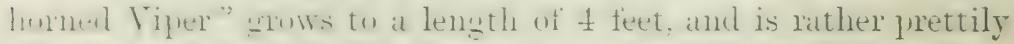

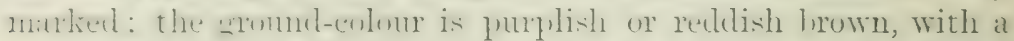

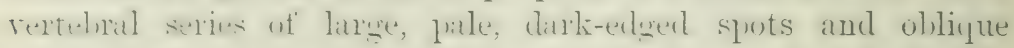
renses. The youme are at hirth as much as one foot in length, and are very tastefully coloured.

Cercestes and Eclis prefer to burrow in sand. The lateral seales are smatler than the dorsals, and arranged oliliguely with serritenl ketels, sis that the snalies can corer themselves with sind by lateral shovelling motions of the sides of the body.

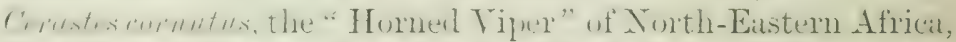
fion Aleria to Alathia, extending also into l'alestine, has the silke of the ventral scalles lent angularly, with an whtuse lieel on either sile. Aluse ench ere stamels a large homy, spiliy scalle. The mlles palts ane pale yellowish brown, mosty with dark

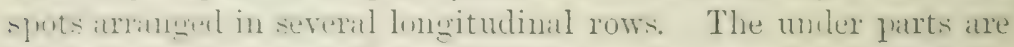
white. 'This, or perhaps C'. viperce, which has $n 0$ horns, is

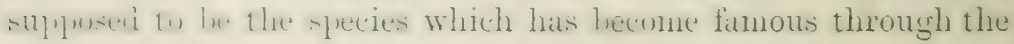
suicicle of Cleopatra.

Alunt twenty years aten at munler of "Horned Vipers" were

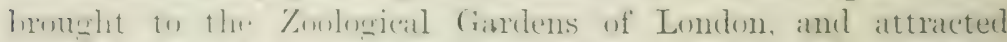
attention ly their monsually long horms. It was foumel that

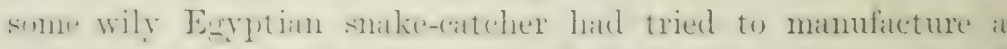

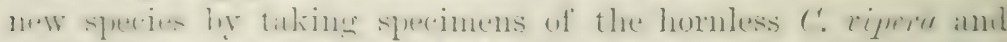
inserting a lair of hemphoges spines, fushing them apwards through the mouth.

The " Horned Vinere" attains a length of two feet and a half. 
In the daytime it is invisible, being huried in the sand with only the eyes, nostrils, and the "horns" appearing abure the surface.

Tiperd.-The head is distinct from the neck, and is corered with small scales and a few larger shields. The eye is seprarated from the labials by scales; the nasals are in contact with the rustral shield or separated by one naso-rostral shield. 'The scales on the boly are strongly keeled; they are in two rows on the short tiil. This gemus with about ten species ringes over Europe, Asia, and the greater part of Africa.

T. Terns, the Common European Viper (see Fig. 165, 1). 620). The snout is not turned up at the end; between the small head-

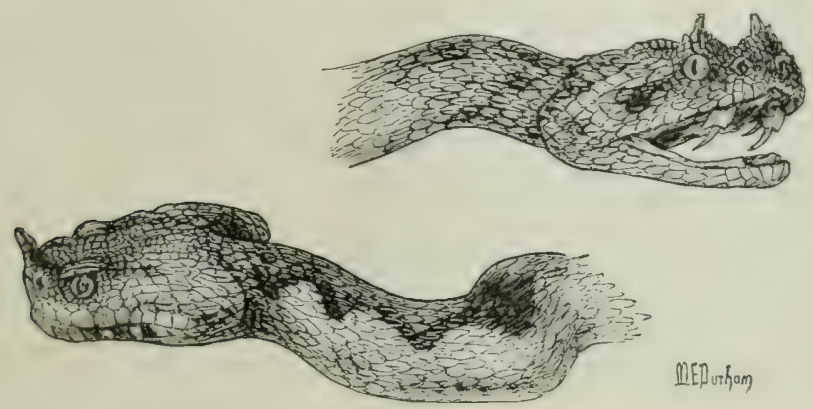

FIG. 173.-Cercastes cornutus, the "Horned Viper" (right), and Vipera ammodytes, the "European Nose-horned Viper" (left). $\times 1$.

scales there is generally a pair of well-developed parietal and frontil shields. The scales of the trunk form twenty-one rows. The culoration is very variable, there being grey, brown, red, or black sprecimens in the same country, and the much-spoken-of black zigzag line along the back is so often indistinct that it is a character not to be relied upon. Csually the grey, yellowish, olive, hrown or red ground-colour is set off by a dark zigzag band along the spine, and hy a series of lateral spots; an oblique or St. Andrew's cross or two diverging bold strealis of dark brown (Ir black are ustally present on the back of the head, and there is a dark streak behind the eye. The under parts are grey, hown, or black, miform or speckled; the end of the tail is usually yellow or rect. According to Boulenger, who is making a special study of the individual rariations of Vipers (concerning colour, scaling, number of vertebrie, etc.), some specimens are entirely VOL. VIII 
Wlack in the males through extension of the black markings, in the females through darkening of the ground-colour. Males are usually distinguishable from females by darker, deep black markings and lighter sround-colour. The females are mostly larger than the males. The litrigest specimen in the British Mnsem measures $700 \mathrm{~mm}=28$ inches, but a riper $2-$ feet long may lie considered a very litrge specimen. The Common Viper has a wide range, from Wales to sathatien Island, and from Caithness to the north of Spain. It ascends the Alys to a consideralle altitude, up to 6000 feet. J. Blum has published an elaborate statistical accomnt of the Viper in (iemany, unfortmately confining himself strictly to the pulitical frontiers.

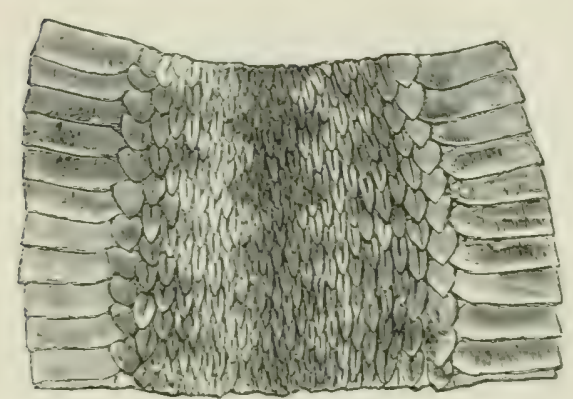

FrG. 174. - Skin of Tiper. $\times 1 . \quad$ (From White's History of Selborne.) According to the map attached to his work, the Viper is common all over Germany with the exception of South-Western and parts of Middle Germany. It is absent in Alsace, the Bavarian Palatinate, Rhenish Prussia, Hesse, the northern half of Baden, Würtemberg, and Franconia, countries which, speaking broadly, have a Warm subsoil. composed of Red Sandstone and Basaltic formation. As a rule the Viluer prefers heaths, moors, and mixed wools with sumy slopes. Brambles, clumps of nettles, hedges, the ediges of little colises, lieaps of stones, are farourite places of retreat, afforling shelter, holes, and the vicinity of mice, which form its chief sustenance. At harvest-time it is often found in comfields. and it frepuently hicles in the sheares. Vipers are fond of hasking on certain spots, on the top of a stone, the stump of a tree, or a patch of sand: a shower of rain or even passing clouls drive them back into their holes. They are eminently noturnal, when they regularly "heat" their district, hiting and paralying their prey before swallowing it. A fire limbled at night is sure to draw ripers near: the same applies to other vipers, for instance (irestes, which appears in perplexing

\section{IVerbreitung der Kreuzotter in Doutschland. Frankfurt a. M. 1888.}


numbers at the camp-fire. They cannot climb, and they aroid going into water. The pairing takes place as a rule from Mirch to MIay, a number of individuals, mostly males, collecting around the females, and forming entangled lumps of suakes; parturition takes place in the following July and August. In exceptionilly warm winters they have been known to pair in December, having left their winter-quarters. They hibernate for about six months, more or less according to the climate, congregating in great numbers, sometimes in dozens. With very rare exceptions Vipers do not take food in captivity, but prefer starving themselves to death. The bite is as a rule not fatal. The seriousness of the case depends of course upon many circumstances, as for instance the state of concentration of the venom, the position and depth of the bite, and last hut not least upon the general condition of health of the victim. General depression aggravated hy nervousness, weakness of the bitten limb, occasional breaking wit of the wound, are of frequent and protracted occurrence. (See also p. 590.)

$V$. aspis is a more southern and western European Viper, necurring from France to the Tyrol, and in Italy. The snout is slightly turned up at the end, and still more so in $V$. latrestei of Spain and T'ortugal. In $T$. cmmodytes, of South-Eastern Europe, the raised portion is produced into a soft, scaly appendiage (see the lower figure on 1.641). Vipers are sometines umpleasantly common in certain localities. This was for instance the cise at the drill-ground near Metz, and the military anthorities paid a price for each viper delivered to them. The supuly of the latter increased to an alaming extent until the German authorities discovered that a regular trade had been estallished across the frontier, and that the French Lorrainers were importing vipers briskly.

$V$. vusselli, the "Daboia" or Russell's Viper, is one of the scources of Intia, Ceylon, Burma, and Siam. The scales form about thirty rows on the body. The upper surface of the head is covered with small, imbricating, usually keoled seales. The general colour is pale hrown ahove with three longitudinal series of hlask, light-edged rings, which sometimes encircle reddish spots. The muler parts are yellowish white, uniform, or with small crescentic black spots. Total length up to ahout 5 feet. The poisoning symptoms are described on p. 590. 


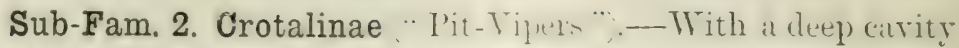
or pit hetwern the eye and the more, lumbed in the hollowedout maxillary hone. This pit is linen with a moditied continua-

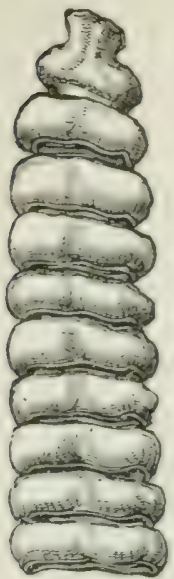
tion of the epidemis, and is amply supplied with branches from the trigeminal nerve. It is lindoubtedly sensory, but we do not know its function. A good anatomical account of this organ has been given by West. ${ }^{1}$ Some of the Pit-Vipers have a rattle at the end of the tail; these are the Rattle-Snakes. The rattle is composed of a number of horny bells which fit into each other. 'The oldest or terminal bell is in reality the horny covering of the tip of the tail, and with each moult or shedding of the skin the youngest bell becomes loose, but is held by the new covering which has been developed in the meantime. There is thus produced an ever-increasing number of loosely-jointed bells, Fig. 175.-Rattle of

Rat tle-Sinake. (From White's History of Selborne.) but now and then most or all the bells break oft, probably when they are worn out, and a new set is gradually dereloped. Rattles with a dozen bells are, for instance, very rare. They naturally inclease in lulk with the age of the snatie, but the number of joints is no indication of the suake's agre.

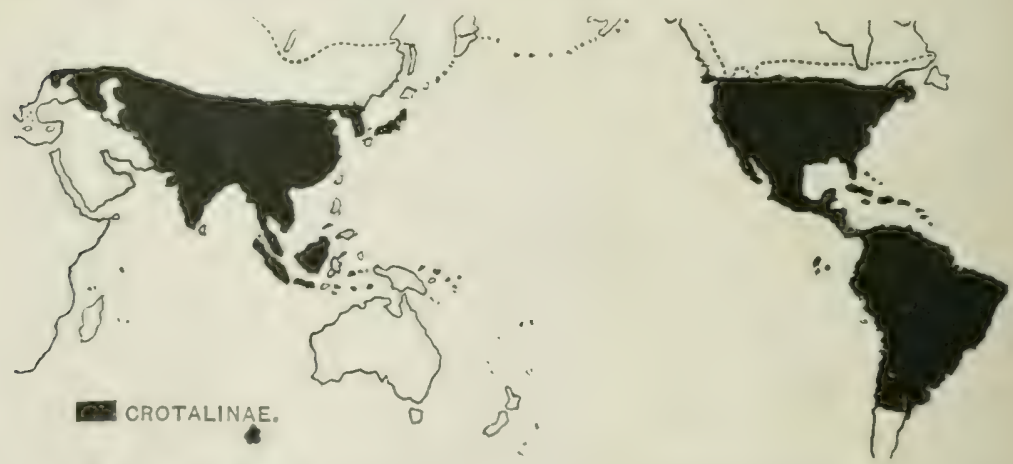

FIG. 176.-Map showing the distribution of the Sub-Family Crotalinac.

T'it-Tigers hase a very while di-tribution. They are divided

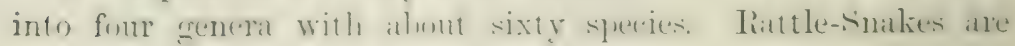
1.J. Limn. Soc, xxviii. 
restricted to Americar, but other l'it-Tipers wern in North and South America and in the southern half of Asia.

Ancistrocton.-Without a rattle. The upper surface of the head is coverenl with nine large shields, lut the internatsils and fuefiontals are sometimes broken up into scales. The scales w the henly have apical, sensory pits. Hhent ten species, smue in Central and North America, other's in the caspian district ( 1. halys), in the Himalayas (A. himmlnymuss), in ('eylon, Java, ete.

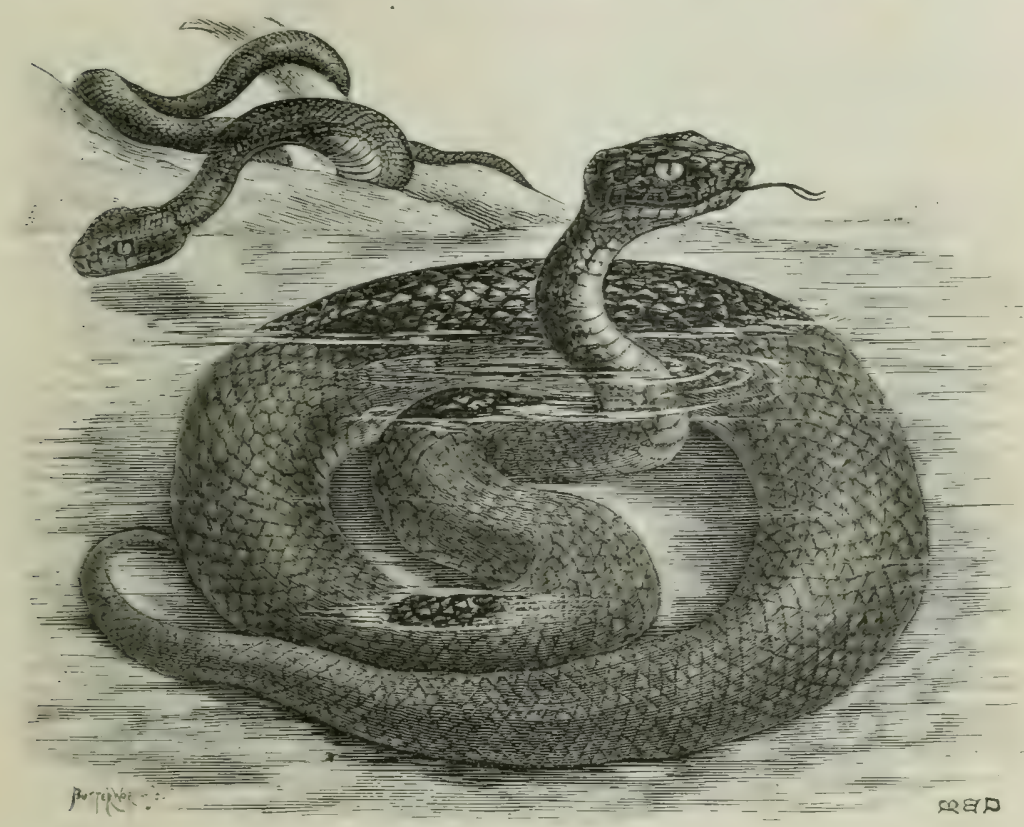

FIG. 17T.-Ancistrodon piscivorus (Water-Viper). $\times \frac{1}{4}$.

4. piscimms s. Trigunnephalus rom-hris (part), the "WaterViper," inhabits North America from Carolina and Intiana to Florida and Texas. The general colour is reddish to lark hrown, with darker cross-bands or with C-shaped markings; it dark, light-edsed hand extends from the eye to the angle of the month. The under parts are rellowish, spotted with black, wr the latter is the prevailing colour. Total length up to 5 feet. The Water-Tiper is semi-aquatic and lives chiefly on fishes, but it also eats other snakes and various Amphibia, Rirks, and Mammals. This snake is very cood-humoured in captivity, and becomes 
easily tame. A gentleman in Terlin, rather too much addicted to making pets of poisonous snakes, hat a pair which propragated regularly. When I was a boy he invited me to feed the young Water-Tiper's with fishes cut into strips, and I enjosed this immensely until he warned me not to touch the mother, which might bite strangers.

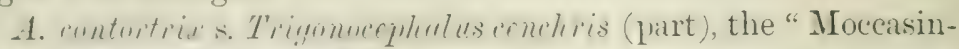
Snake" or "Copper-hetad," is one of the few joisonous snakes

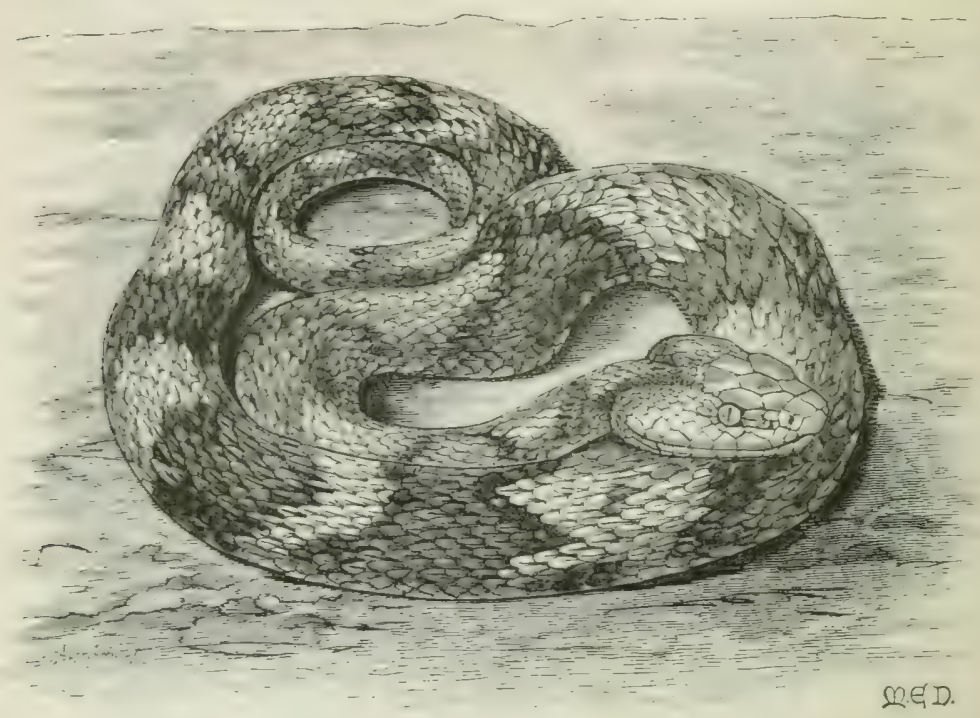

FlG. 17. - Ancistimben cumtutrir (Moccasin-Snake or Copper-hear). $\times \frac{1}{4}$.

which gossess a Ioreal shield, i.e. a shiehd intercalated letween the pre-nculars and the nasals: helow it lies the pit. The general colour is gellowish to pink or pale brown, with dark hown or red cross-bars or triangular marks. The under surface is yellowish or redilish, speckled with grey or hrown, and with a lateral series of latre blackish spots. Total length of full-grown specinems about one yard. The Moceasin-Snake ranges from Massarelowetes and Kansals to Northern Florida and Texas. It prefer's swampy localities or meanluws with high grass, where it hunts for small Mammals and Birds.

Lardersis.- Withut a rattle. The uplet surface of the inear is covered with very small shields or with sales. About forty 
species in South-Eastern Asia and in Central and South America.

I. (Bothiops s. Craspedocephulus) lanccolatus inhabits nearly the whole of South America, extending into Mexico and the Lower Antilles, e.g. Martinique, Guadaloupe, and sinnta Lucia, where it is known as the "Fer-de-Lance," and is the curse of the sugar-plantations on account of its being so rery common and so deally poisonous. The Mongoose was introduced as a jossille antagonist, but, the little Indian Mammal wisely left the dingerous reptile alone, and has in some places estahlisherl himself as another pest-as a destroyer of poultry. The Fer-rle-

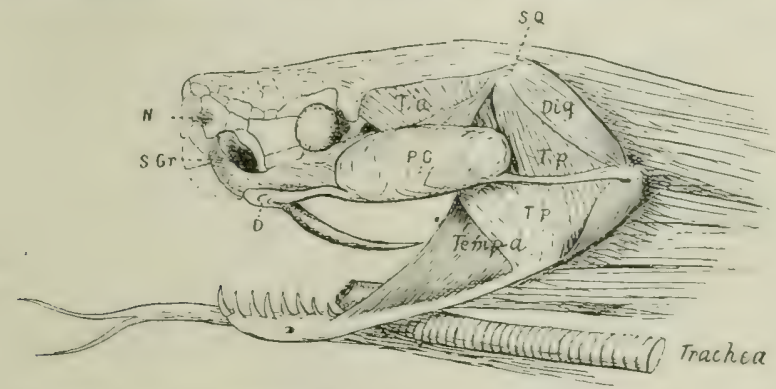

FIG. 179.-Head of Lachesis lanceolatus after removal of the skin. $\quad \times 1 . \quad$, Duct, bent upon itself, from the poison-gland into the tooth; Dig, digastric muscle or opener of the jaw; $N$, nostril ; $P . G$, poison-gland; $S$. Gr, sensory groove or pit; $S . Q$, point of junction of the squamosal and quadrate; T.a, Temp.a, anterior, and $T \cdot p$, posterior, temporal muscle.

Lance grows to a length of 6 feet, estahlishes itself everywherein swamps, plantations, forests, in the plains and in the hillsand is very prolific, producing, according to its size, dozens of young which are 10 inches long, very active and snappy.

L. ('rimeresurus) gramineus s. viridis, to mention one Asiatic species, grows to less than 3 feet in length, is luight green above, sometimes with faint blackish bars: green, yellow, or whitish below, and with a light streak along the outer row of scales. The end of the tail is usually bright red. This beautiful snake has a prehensile tail and is arboreal. Its range extends over the whole of India, to Hong-Kong and to Timor, and even into the Andaman and Nicobar Islands.

Sistrums. - With a rattle. The upper surface of the head is covered with nine large shields. A few species in North America east of the Rocky Mountains, e.g. S. miliarius. 
Crotalus. - With a rattle. The upper surface of the head is

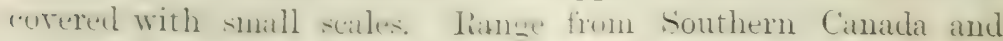
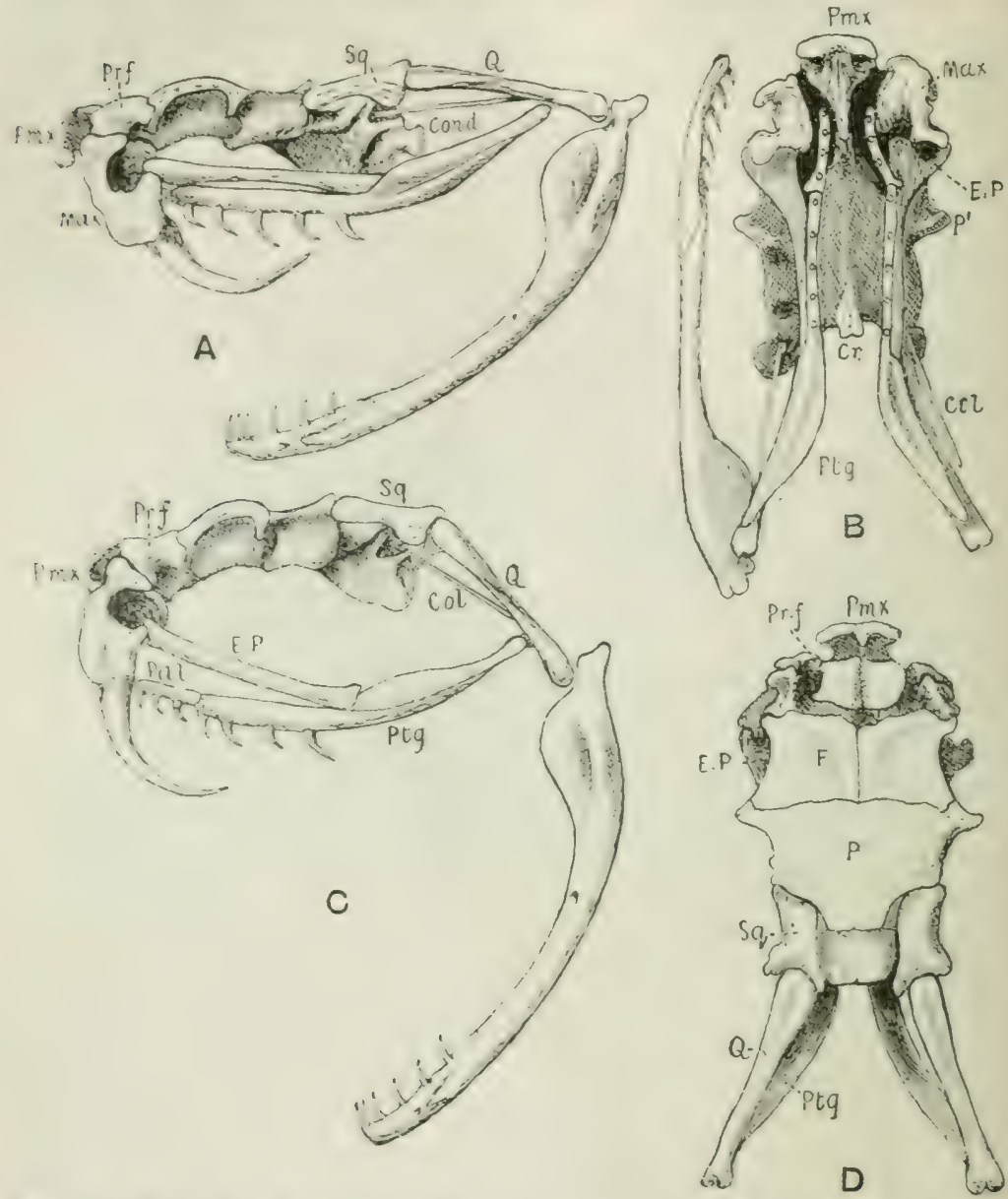

FIG. 180.-Skull of a lattle-Snake, Crotalus durissus. $\times 1$. A, Lateral view, jars slightly opened; B, rentral view; C, lateral view, the jaws opened fully in the position of striking; D, dorsal view. Compare this with the diagrammatic figures on p. 588, where the mechanism has been explained. Col, Columella auris; Cond.

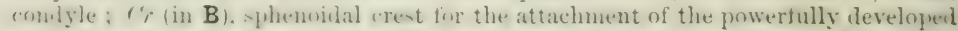
ventral cranio-cervical muscles ; $E_{.} I^{\prime}$, ectopterygoid or transverse bone ; $\boldsymbol{F}$, frontal ; $M\left(\boldsymbol{M} x\right.$, maxillary ; $I$, parietal ; $P^{\prime}$, post-orbital process ; $P$ al, palatine ; $P m x$, premaxillary ; $P^{\prime} f$, prefrontal ; $P t g$, endopterygoid ; Q, quadrate ; $S q$, squamosal.

Fritish Cohmulia to Northern Argentina, but not in the West Indian Islands. About ten, mostly closely-allied species. 
The effect of the poison of Rattle-Snakes has heen discussed on p. 589.

C. horridus is the common Rattle-Snake of the Lnited states: ('. confluentus is the species in Western and $C$. nuirsus the common species in South-Eastem North America. Tory lince? Iiattle-Nuilies, C'. durissus, attain a length of is feet, other's nut often more than five. They prey chiefly upon small Mammals, hunting for them at night. In the daytime they are also ahout, manly in order to bask. Although they ocensionally take to the water in pursuit of their prey, they dislike lexing wetted hy rain, withdrawing then into their holes, apmornoiating as a rule those of ground-squirrels, rats, and Prairiedens. The often-repeated story abont Rattle-Snakes living in neighhourly friendship in the holes of I'rairie-dogs, together with the little Irairie-nws, is an exaggeration. We do not know how many of the original inmates are eaten. Pairing takes place in the spring. During the cold months they hilernate unler ground, often in considerable numbers.

Pattle-rnalies have few enemies besides man and pigs. The latter kill and eat them wherever they can. The rattle is decidedly useful to the suake as an instrument of warning off any aproaching posibile enemy, since no suake likes to lite unless in self-efences or in order to kill its prey. The noise of the rattle is very lout in dry weather, much duller on clammy days; it is a shrill sound like that of a rattling alamm-clock, ant a well-conditioned snake in a roon can make conversation well-nigh impossible, and can leep on rattling for half an hour or longer. The rattle is kept in such rapid lateral vibrations that it shows only a blurred image, the rattle standing with its broader sides rertically, not horizontally. They endure calitivity for many years, and hecome tame enough not to hiss and to rattle whenever they are approached.

C. horridus is grey-brown above, usually with a rusty vertehral stripe and with $\mathrm{V}$ - or $\mathbf{M}$-shaped blackish cross-luands; the under surface is yellowish; the end of the tail is blackish. The supra-ocular shields are smooth and much narrower than the scilly space between them, and there is only one pair of internasals.

C. durissus s. ademantrus differs from the previous species chiefly by possessing two pains of internasals; and the dark 
markings on the body form a hank-one gattern of rhombs with linhter centres and yellowish ediges. This is the largest species of Rattle-Snake, reaching a length of $S$ feet.

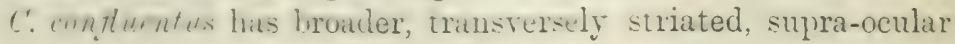

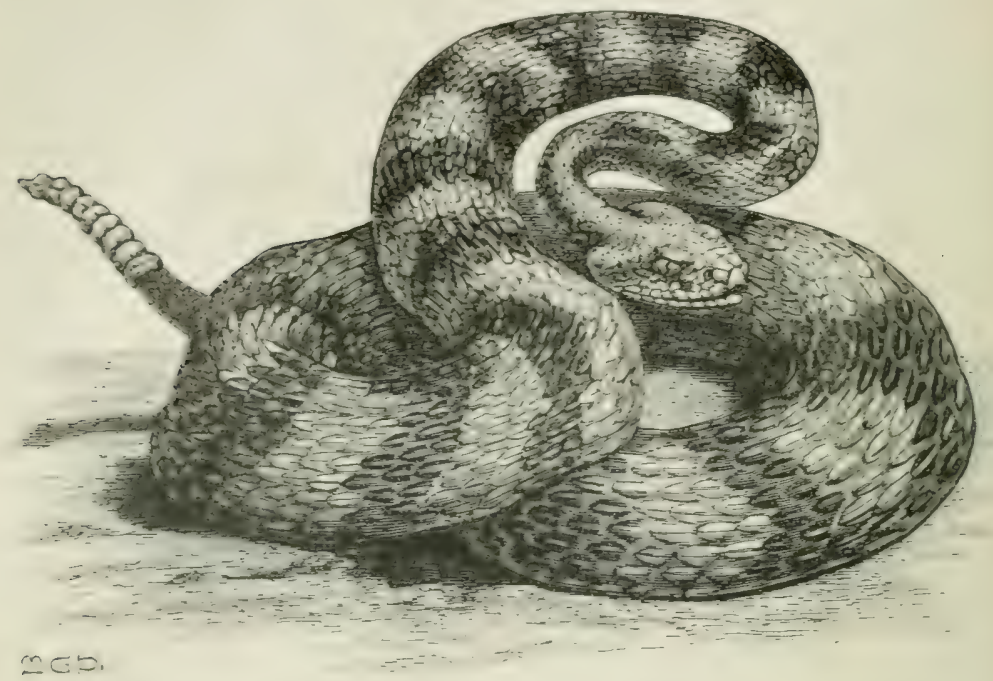

FIG. 1S1.-Crotalus durissus s. adamanteus (Rattle-Snake). $\times \frac{1}{4}$

shielik. The specific name refers to the continuous series of large brown or red rhomboidal spots on the back.

Utrrinions ranges from Arizona to Argentina, and is the only species of Tiattle-Snake in south America. It differs from the wthers ly having a pair of frefrontal shields behind the pair of internasals. 


\section{INDEX}

Every reference is to the page: woris in italics are names of genera or species ; figures in italics indicate that the reference relates to systematic position ; figures in thick type refer to an illustration; $f .=$ and in following page or pages ; $n_{0}=$ note.

Abdominal armour, of Cricotus, 287 ; of Microsauri, 289; of Prosauri, 290

Abdominal ribs, of Rhynchocephali, 292, 298 ; of Dinosauria, 414; of Megalosceurus, 421

Aberrant scaling of Lacertilia, 495

Ablepharus, 560 ; eyelids, 494

Acunthodactylus vulgaris, 559

Accuthophis intarcticus, 635

Acentrons vertebrae, i.e. those without a centrum or body, 4

Acris, 186, 189; A. gryllus, 207 f.

Acrochordinae, 606

1 crochordus javanicus, 607

Acteosurus, 489

Actinodon, 83 ; 287,288

Adams, visit to the Mfugger-peer, $455 \mathrm{f}$.

Adaptive characters of Anura, 142

Adhesive apparatus, of tadpoles, 57, 57 ; of Tree-frogs, 187; of Thorope, 209 ; of finger-dises of Raninae, 239; of Geckos, 505,505

Aeluroseurus, $30 \%$

Aestivation, of Crocodiles, 457 ; of T'ortoises, $357,365,404$

Aetosaurus, 432; Ae.ferratus, 433, 448

Agalychuis, 189, 206

Ayama, 520; A. sanguinolenta, 520;A. stellio, 521,521

Agamidae, $513,515 \mathrm{f}$.

Agamura, tail, 506

Agassiz, on habits of Alligator Turtle, 341 ; of Trionyx, 407

Age of Chelonia, how to estimate, 326 ; great age attained by Tortoises, 369,376 , 377 ; see also Growth, rate of

Aglossa, $139,140,143 \mathrm{f}$; distribution, 143

Aglypha, 592, $606 \mathrm{f}$.

Ahuetulla s. Leptophis, 618,619

Aistoporles, 81
Aldabra, gigantic tortoises of, $373 \mathrm{f} ., 375$

Algae, destructive to shell of tortoises, 357

Allantois, an embryonic outgrowth from the posterior part of the gut, acting as a respiratory organ, 278

Alligator, 450,466 f. ; A. mississippiensis, 467 f.; skull, 468 ; nesting, $469 ;$ A. sinensis, 471

Alligator Turtle, 340

Alloplearon hofmanni, 380

Alloscurus, 422

Alpine, Newt, 126 ; Salamander, 119

Altitude, high, in which Anura have been found, 181

Alytes, 157 f. ; A. cisternasi, $160 ; A$. obstetricans, 15S; urino-genital organs, 49

Amblycephalidae, 592, 593, 637

Amblycephalus monticola, 637

Amblyrhynchus, 528 ; A. cristatus, 533

A mblystoma, skull, 17, 94, 96, 109, $110 \mathrm{f}$., 112 ; A. jeffersonianum, 111; A. mavortium, 115 ; A. opacum, 110; A. persimile, 111; A. prenctatum, 110 ; A. talpoideum, $110 ;$ A. tigrinum, 111 f. ; metamorphosis of, $112 \mathrm{f}$.

Amblystomatinae, 102, 109

A meiva, 549

Amnion, a membrane round the embryo, 278

Amphibia, 3 f.; definition, 5 ; systematic position, 5 ; numbers of species, 4

Amphicondylous, i.e. the occipital part of the skull articulates with the neck by a right and a left knob, 4

Amphignathodon, $185 ;$ A. guentheri, $1 S 8$

Amphignathodontinae, 139,188

Amphisbaena, 566 ; A. fuliginosa, 566

Amphisbaenidae, 514, $565 \mathrm{f}$.

Amphirma, 88, 96 ; A. means s. tridactyla, 100,101 
Amphinmidae, 94, 97

Amphodus, 210; A. wucheri, 211

Anacouda, 603, 603

Anaides $=$ Autolicx (q.v.), $10 \%$

Anal sacs of Chelonia, used as additional respiratory organs, 330

Anarosaumes memilio, 4i

Anchisaurus, 415, 417, 421; skull of A. coclurus, 421

Ancistrolon, $645 ; A$. contortrix, 646,646 ; A. halys, 675 ; A. himalayanus, 645 ; 1. piscivortes, 645,645

Anderson, on nest of Gavialis, 452

Anilrews, on $A$ mblystoma, 110

Andrias schenchacri, 81

Anelytropiclae, 514, 564

Anelytropsis papillosus, 56-4

Anguidae, 513, 537 f. ; distribution, 501, 529

Anguis fragilis, 539, 539

Aniella pulchra, $\overline{6} 64$

Aniellidae, 514, 564

Ammandale, on habits of Calotes, 518 ; of Liolepis, 527 ; of Rhacophorus, 247 ; of Faranus salcator, 541

Anodonta, as food of Trionyx, 407

Anolontohyla, $\approx 36$

Anolis, $5: 28$; A. caralinensis, 5.29

Anomodontia, 309

Anura, 7 ; characters, 138 ; classification, 139 f., 141 ; phylogenetic tree of, 142

Anus, asymmetrical position of, 60

Apoda, 84 f. ; aflinities, 88 ; distribution, 89 ; eyes, 86 ; skin, 87 ; skull, 84,85 ; spermatozoa, 87 ; tentacular apparatus, 88 ; vertebrae, 86 ; visceral arches, 86 Archaeopteryx, 417

Archegostument, vertebrae, 13, 82, 287

Arcifera, of Cope, 140 ; of Boulenger, 140

Arciferous, type of shoulder-girdle, 24, 25

Arion, slug, eaten by tortoises, 363

Arrau-turtle (Pollocnemis), $391 \mathrm{f}$.

Arteria cutanea magna, 14t; A. sacralis of Anura, 144

Arthroleptis, 241, 242; 1. seychellensis, 243,243

A scaphuse, 153

Asterophrys, 161

Athewae, 333, definition of name, 337

Atlentosaurus, 415,$419 ;$ A. immanis, 419,420

Atlas and Axis, i.e. first and second cervical vertebrae; of Cryptobranchus, 13; of Crocodilia, 283; of Chelonia, 283, 316; of Sphenodon, 283, 294; atlas fused with axis, 307

Atoposauridae, 453

Atractaspis, 638 ; dentition, $593 \mathrm{n}$.

Atria, the thin-walled receptive parts (auricles) of the heart

Auditory columellar apparatus, of Amphibia, 24; of Anura, 29
Australian, Anura, spawning time and habits of. 201 ; Lacertilia, 502

Autodax, 96, 104, 107; A.lugubris, 107; A. iecanus, 107

Autosauri, $491 \mathrm{f}$.

Axis : sce Atlas

Axolotl, 65, 112 f., 112 ; Neoteny of, 65, 112

A zemions feae, $63 \mathrm{~S}$

Balancers of Amphibia, 45

Baptanodon, 483, 484

Barfurth, oll absorption of 'Tadpole's tail, 61

Bartlett, on Boa constrictor, 602 ; on Pipa, 152

Basiliscus, 528, 530; B. americanus, 530, 530

Bates, on habits of Podocinemis, $392 \mathrm{f}$.

Batrachomyia, fly infesting Bufonidae, 177

Batrachophrynus, 224; B. macrostomus, 225 ; B. brachydactylus, 224

Datrachopsis, 161

Butrachoseps, 96, 104

Butrachylodes, 241

Batrachyperus, 96 ; B. sinensis, 103

Baur, on Sphargis, 336

Bdellophis, 90

Bedriaga, on Axolotl, 114; synopsis of Urodelous Larvae, $59 \mathrm{n}$.

Bell, J., on classification, 8

Bell, Napier, on habits of Iguana, 531

Beloulon, 305, 434, 448

Bemmelen, on Sphargis, 336

Berg, on Spelerpes fuscus, 106

Bert, quoted, $571 \mathrm{n}$.

-Bidder's organ, 49, 52

Biedermann, on change of colour in IIyla, 35

Birls not related to Dinosaurs, $416 \mathrm{f}$.

Bitis arietans, 639, 639; B. nasicornis, 640

Black Snake, of Australia, 634; of North America, 613

Blainville, de, on classification, 7

Blanus cinercus, 566

Blood, shape of red corpuscles, 4 ; tem. perature, $67 \mathrm{f}$.

Bloorl-sucker $=$ Calotes ophiomachus, 519

Blum, quoted, $642 \mathrm{n}$.

Boa, 602; B. constrictor, 602; B. dumerili, $602 ;$ B. madagascariensis, 603

Boettger, on influence of climateaud country upon reptiles, $492 \mathrm{f}$.

Boidae, 592, 536 f. ; skull, 596, 597

Boinae, $601 \mathrm{f}$.

Lombinator, 154 f, 155 ; habits, 156 fo ; tadpoles, 157 ; abnormal vertebrae, 22 ; shoulder-girdle, 25 ; urino-genital organs, $49 ; B$. igneus, 154,$155 ; B$. pachypus, 155

Bothrops, 6.77 
Boulenger, classification of Amphibia Caudata, 9 ; on vertebrae of Pelobates, 20 ; on vertebrae of Bombinator, 22 ; number of phalanges in Anura, 27 ; on poison of Amphibia 36 ; on rocal sacs, 48 ; on modes of fecundation and nursing habits, 54,56 ; synopsis of Tadpoles, $59 \mathrm{n}$. ; on tadpoles of Rana opisthodon, 260; on classification of Anura, 140, 141; on Pipa, 152; on Scaphiopus solitarius, 165 ; on Alligator sinensis, 471; on Lanthanotus, 542; on aberrant scaling, 495 ; on Heloderma, $540 \mathrm{n}$. ; on classitication of Snakes, 592 ; on Sea-Suakes, 637 ; on Sphargis, 336

Boulengerula, 90

Box-Tortoises, 362, 364, 365

Brachial plexus, of Anura, 39

Brachycephalus, 226, 227; B. ephippium, 231

Brachylophus, distribution, 501.59S

Brain, of Scaphognathus, 485 ; small size of, in Dinosaurs, 425

Branchial arches, of Urodela, 16 ; of Anura, 42

Branchiosauri, 80

Branchosaums, skull, 80 ; B. salamandroides, $S O$

Brauer, on development of Aporla, 92 ; on nursing habits of Arthroleptis, 213

Breeding of Axolotl, 113

lirericeps, shoulder-girdle, 25, 225, 226, $22 \%, 232$; B. mossambicus, 232

Brithopus, $30 \mathrm{~S}$

Bronguiart, on classification, 7

Brontosaurus, 415, 418; 1 . excelsus, 418

Brontozoun , 415, $417 ;$ B. giganterm, 420

Brood-pouches, of Anura, 151, 248; of Hyla goeldii, 198; of Nototrema, 202 ; of Rhinoterna, 228

Brookesix, 580

Brown Adder, 634

Brown Frog, Common, 251 f., 255

Brïcke, quoted, 571

Buchholz, on Chiromantis, 244 $\mathrm{f}$.

Budgett, on breeding habits of Phyllomedusa, 204; on Paludicola, 220; on Lepridobatrachus, 218; quick development of Phryniscus, 231; on Buyo marimes, 179

Bufo, sacral vertebra, 22 ; shoulder-girdle, 25 ; urino-genital organs, 49 ; devclopment of adhesive apparatus, 5 7 ; $B$. agua, $17 S ; B$.americanus, $17 S$; B. calamita, 1S1f.; B. ceratophrys, 179 ; B. empusus and $\boldsymbol{B}$. peltocephalus, dermal ossifications, $179 ; B$. jerboa, $166 ; B$. lentiginosus, $17 \mathcal{S}, 179$; map of distribution, 167, 168,169 f. ; B. marinus, $178 ; 13$. mauritanica s. pantherina, 1S4; $\boldsymbol{B}$. melanostictus, 1\%7, 179; 13. quercinus, $1 \tau S ; \boldsymbol{B}$. variabilis $=$ viridis, $180 ; \boldsymbol{B}$. viridis, 180 f., $493 ;$ B. vulgaris, $170 \mathrm{f}$., 172 ; large-sized specimens, 171 ; immured in buildings, $17 \pm$; diseases, 176 ; distribution, 177

Bufonidae, 139, 166 f. ; distribution, 167 ; affinities, 166

Bufoniformes, 139

Bullfrog, of America, Rance catesbiana. 261 ; of India, Callula pulchra, 234; Rana tigrina, 261

Bungarus coeruleus s. candidus, $633 ; B$. fasciatus, 633

Butler, on fat-bodies, 500

Cabrita, 551

Cacopus, shoulder-girdle, 25, 225, 226, 298

Cacosternum, 225, 22\%

Caiman, 450, 4i1; vomer, 435 ; C.niger, 471, 472; C. palpebrosus, 471;C. sclerops, 471; C. trigonatus, 471, 4\%:

Calcareous deposits in the skin of Amphibia, 31, 34

Calliphora silvatice, fly infesting $B u f o$, 176

Callophis macclellandi, 634

Calluella, 235, 936

Callula, 226, 298, .234; C. pulchra, habits of, $234 \mathrm{f}$.

Callulops, 225, 228

Calophrymus, 225, 227

Calotes, $51 \tau$; C. emmu, 518 ; C.mystaceres, 519; C. ophiomachus, 519 ; C. versicolor, 518

Calyptocephalus, 179, 212, 815

Camptoscurerus, $426^{\circ}$

Capitosaurus, 83

Carapace, 321 f., 319, 320, 322, 323 ; posterior portion movalule in Cinyxis, 364,365 ; carapace of tortoises, erolution of, 337 ; composition of, 324 f.; reduction of component elements, 325 ; reduction in thichness, 373 ; correlative changes, 328 ; of Sphargis, $335 \mathrm{f}$.; of Chelone, 379; of Testudo, 322 ; of Pleurodira, 389 ; reduction in Trionychidae, 325 ; fenestration, 325 ; with linge in Cinyxis, 364, 365

Cardioglosse, $2 \pi_{4}$

Carettochelydidae, 313, 31'

Carettochelys, 337, 359, 390 ; C. insculpta, 404; absence of horny shields, 325

Carpet Snake, 598, 599

Carpus (see also Limbs), of Eryops, 2S6: of Sphenodon, 294; of Chelonia, 320, 320 ; of Eusuchia, 440

Cascrere, 603

Case, on Sphargis, 336

Cassina, 240

Causus, 63S; C. rhombeatus, 639

Centrolene yeckoidenim, 211

Cercestes cornutus, $6: 40,641$ 
Ceratobatrachidae, 141

Ceratobatrachinae, $139,23 \% \mathrm{f}$.

Ceratobatrachus guentheri, 23\%

Cercatohyla, 211

Ceratophora, 517 ; C. stocldarti, 517; C. tennenti, 517

Ceratophrys, 212, 215 f. ; C. comuta, 216 ; C. dorsata, $215 ;$ C. ornata, 216, 217

Ceratopsia, 430

Ceratosaume, $113,416, \pm 17$; C. nasicornis, 422,422

Cerberns, vhynchons, GD5

Cetiosanines, 41:

Chalurodoit, 5:S; geographical distribution of, 501

Chalcides, 562; Ch. bealivigae, 565; Ch. guentheri, $563 ; C h$. lineatus, 563; Ch. ocellatus, 563; Ch. tridactylus, 563

Chamalcon, 5\%3; Ch. bifidus, 580; Ch. culcaratus, 579: Ch. parsoni, 580; Ch. pumilus, 579, 575; Ch. vulguris, 573, 574,575

Chamaeleontes, $56 \%$ f.; distribution, 568 ; skull, 568, 569 ; tongue, $569 \mathrm{f.}$; colourchauging mechanism, $570,571,573 \mathrm{f}$; eggs, 572

Chamaeleontidae, $573 \mathrm{f}$.

Chamaerops humilis, dates of, eaten by Testudo, 367

Chameleon, misnamed Calotes, 518 ; misnameri Polychrus, 529

Chauvin, Marie von, on Axolotl, 113; on Selamandra atre, 120

Chelodina, suppression of neural plates, 324 ; intergular shields, $389, \quad 315$; skull, 399 ; Ch. longicollis, 402 f., 403

Chelone, skull, 317; skeleton, 320 ; plastron, 321 ; shields, 327 ; intergular shields, 325 ; Ch. mydtes, $3 S 1$ f.; various modes of fishing, etc., 382, $383 ; \mathrm{C}$. imbricuta, 384, 385

Chelonemydidae, 380

Cluelonia, 312 ; number of species, 312 ; allinities of, 312 ; classification, 313 ; key to living families, 314 ; plastron, nnmes of the lrorny shields, 315,321 , 325 ; vertebrae, 314 f., 316 ; skull, $280,317,356,364,379,400,405$; skeleton of Testudo, 319; of Chelone, 320; pectoral areh, 318 ; pelvis, 819 ; plastron, bones of, 322 ; limbs, 320 ; bony shell, 321 f., 322,323 ; evolution of, 337 ; cvolution of the loorny shields, 326 f., 327 ; regeneration, 329 ; senseorgans, 329 ; digestive apparatus, 330 ; respiration, 331 ; growth of Chryssemys, 349

Cliclonidae, $313,314,3 \% S \mathrm{f}$; aftinities of, 350

Chelydidae, $318,314,399$; distribution, 332,333

Chelyclosuzusus, $\mathcal{S}: 28 \pi$
Chelyelra, 328; Ch: serpentine, 338

Chelydridae, 313, 314, 338; distribution of, 332

Chelydropsis, nuchal plates, 324

Chelys fimbriate, 400; skull, 400, 401; intergular shields, 325

Chersydrus grumulatus, 607

Chioglossa, 96, 115; Ch. lusitanica, 121

Chiriaculus, $\approx 41$

Chiroleptes, 209, 213, 221; Ch. platycephalus, 221

Chiromantis, 238, 241, 24f; Ch: petersi, $244 ; \mathrm{Ch}$. xerampeline, 244

Chirotes, $564 ; \mathrm{Ch}$. canaliculatus, 566

Chirotherium, 83

Chlamyclosaurus kingi, 522, 523

Chomae, or inner nasal openings, $\mathbf{4 7}$

Chorda dorsalis, the axial rod between the gut and the spinal cord, around which the vertebrae are formed, 12

Chorophilus, 186, 189; Ch. ornatus, g0S

Chromatophores, 35

Chrysemys, costal plates of, 325; green colour of, 328,346 f.; colour of iris, $329 ; C \%$. concinna, $346,349,350 ; C \%$. clegans, 346 ; Ch. pictu, 346, 34\%, 348 ; Ch. mbriventris, 346

Chthonerpeton, 87, 90

Cimoliasaurus, 478; $C$. australis, 47s ; $:$ cantabrigiensis, 478; C. chilensis, 47S: C. hausti, 478

Cinosternidae, 313, 314, 342 ; distribution, 332

Cinosternum, 342 f. ; arraugement of neural plates, 324 ; C. leucostomum, 3.42, $344 ; C$. odloratum, 342, $343 ;$ C. pennsyluanicum, 340, 344

Cinyxis belliana, 365 ; C. erosa, $36 \%, 365$; C. homeana, 364

Cistecephalus, 310

Cistudo, arrangement of neural plates, 324; C. cerolina, 361 f., 364 ; colour of iris, 329

Claoscutrus, 429

Clarke, on lialits and development of Alligator, 467

Classification of Amphibia, historical account, $7 \mathrm{f}$.

Clawed Toad (.Tenopus), $146 \mathrm{f}$.

Claws or nails of Amphihia, 32

Cleitlma = the pair of additional clavicles ; of Stegocephali, 79 ; of P'arciascums, 304,305

Clemmys, 356 f.; C. caspica, 358; C. insculpte, 359 ; C. leprosa, 356 f., 353 ; sliull, 356

C'lepsydrops, sos

Clidrastes tortor, 490

Cloaca, of Chelonia, 330 ; of Crocodiles, 145 ; of Lacertilia, 498

C'nemidophorus, 5.49; C. sexlineatus, 549

Cobra, 627,627 
Coccyx, s. Os coccygeum, of Auura, 20, 21, 22

Cuecilia, $\$ 9$

Coecilidae, $S 9 \mathrm{f}$; distribution of, 89

Coelopeltis, 624; C. monspessulana s. lacertina, 6:4

Coelurus, $415 ;$ C. gracitis, 423

Colombo, gigantic tortoise of, 377

Coloration, waruing colours of Amphibia, 3S, 156; protective, of Amphibia, 191, 238,252 ; of deserticolous reptiles, 494 Colosthetus, 238, 24?

Colour, changes of, in Anura; 35 ; in Calotes, 518, 519, 520 ; in Gechos, 509 ; in Lacertilia, 498 ; mechanism of chang. ing, in Chameleous, 570,571

Coluber, $615 \mathrm{f}$; $C$. aesculapii = flarescens $=$ longissimus, $616 \mathrm{f}$; C.leopardinus, 616 ; C. (Rhinechis) scalaris, 617

Colubridae, $593,606 \mathrm{f}$.

Colubrinae, $60 \% \mathrm{f}$.

Columella cranii, $496,550,551$

Columellar auditory chain, of Amphibia, 4 ; of Anura, 29 ; of Crocodiles, 416 ; of Lizards, 496

Comoro Islands, Tortoises of, 373

Compsurnathus, 415, 416, 417; C. longipes, 423,425

Condyle, occipital, of Theromorpha, 302 ; exaggerated importance of its character, 285

Conolophus subcristatus, 532

Conus arteriosus, continuation of the heart beyond the ventricles so far as it contains ralves, 6

Cope, on classification of Amphibia, 9 ; of Anura, 140, 141 ; on Siren, 136; on hand-skeleton of Eryops, 286; on Sphargis, 336 ; classification of Lacertae, 513 ; classitication of Suakes, 592

Cophophryne, 167,168

Cuphyla, 236

Copper-head, 646, 646

Copulatory organs, of Lacertilia, 499 ; absent in Sphenodon, 294; of Chelonia, 330 ; of Snakes, 585

Coqui, 214

Coronella, 619; C: austriaca s. laeris, 619 , 620 ; C'. girondica, 6:21

Cormufer, 341,$243 ; C$. commgatus, 244 ; C. johnstoni, 243; C. solomonis, 344; C. unicolor, 244

Corythomantis, 1S9, 20\%; C. greeningi, 207

Costal plates of Chelonia, 324 f., 322,323

Craspedocephalus, 647

Crested Newt, 125, 125

Cricotus, 285, $285 ; C$. heteroclitus, 287

Crinia, 213; spawning, 223

Crocoulilia, 431 f. ; skeleton, 431 f. ; skull, 280, $43 \pm$ f.; atlas and axis, 283, 431, 439; aftinities, 432 ; teeth, 437 ; skiu, 442 ; dermal armour, $44^{2}$; skin glands, 443 ; tongue, 443 ; respiratory organs, 444 ; "diaphragm," 414 ; digestive organs, 444 ; cloaca, 445 ; heart, 415 ; ear, 445 ; eye, 446 ; geographical listribution, 446,446 ; voice, 447 ; habits, 447 ; propagation, 447 ; classification, 448

Crocodilidae, 454

Crocudilus, 450,454 fo; teeth, 437 ; skin glands, 443 ; $C$. acutus, 446,$449 ; C$. americanus, 466; skull, $466 ; C$. biporcatus = porosus, $45 \mathrm{~S}$; rate of growth, $459 ; C$. catapleractus, $465 ; C$. intermedius, $466 ; C$. johnstoni, $466 ; C$. niloticus = vulgaris, $460 \mathrm{f.,4} 449,461$; habits, 462 f.; C. palustris, 449, 454; skull, 455 ; C. porosus, 458 ; skull, 458 ; C. vulgaris, $449,460 \mathrm{f}$.

Crotalinae, 644

Crotalus, 6.4S; rattle of, $644 ; C$. adamanteus, 6399, 650; C. confluentus, 649 , $650 ; C$. durissus, 648, 649, 650; C. horridus, 649; C. terrificus, 650

Cryptobranchus, 81, 96, 99; fossil, 84 ; C. alleghaniensis, 97; C. japonicus, 98, 99

Cryptoclidus,-shoulder-girdle, 474, 475, 475

Cryptodira, 313,338

Cryptopsophis, $89 ;$ C. maltiplicutus, 9:

Cryptotis, 215

Cutis, of Amphibia, $33 \mathrm{f}$.

Cyamodus, 311

Cyclanorbis, 411; nuchal plate, 324

Cycloderma. 411

Cyclodus s. Tilique, 501; C. giges, 561, 562

Cyclorhamplius, 212

Cynognathus, 301, 302, 303; C. berryi, 30\%; C. crateronotus, $306 ; C . p$ latyceps, $30 \%$

Cystignathidae, 139, 209 f. ; distribution, 161

Cystignathinae, 139, $211 \mathrm{f}$.

Cystignathus $=$ Leptodactylus, 210, 21S

$\mathrm{Dab}=$ Uromastix, 5i6, 526

Daboia, 643

Dactylethra; see Tenopus, $1766^{\circ} \mathrm{f}$.

Darwin, on Conolophus, 532 n.; on tortoises of Galapagos Islands, 377

Dasypeltis scabra, 622, 622 ; dentition, $593 \mathrm{n}$.

Davison, on breeding of Amplizma, 101

Daresonia, 289

Death Aduler, 6.35

Denburgh, van, on 1 utodax, 107

Dendrobates, 272; D. braccatus, 273; I). tinctorius, 2\%2, 273; 1 . trivittatus, 2\% 3 ; D. typographus, 273 ; various uses of its poison, 38 
Dendrobatinae, $139,23 \%, 2 \tau \sim$ fo ; distribution, 239

Dendrophis, 618; D. punctulatus, 61S, 618

Dendrophryniscinae, 139,224

Dendrophryniscus brevipollicutus, 2024

Dentition, of suakes, 582, 592, 593; see also 'Teeth

Dermal armour, of Cricotus, 287 ; of Miero. sauri, 259: of Prosauri, 290; of 'Theromorpha, 302; of Chelonia, 321 f.. 337 : of Dinosauria, $\$ 15$; of Psendosuchia. 433; of Parasuchia, 431; of Crocodiles, 44:2

Dermal ossification in Anura, 179, 190, 210

Dirmatemydiclae, $313,314,341$; distribution of, 332

bermatemys menci, 341,342

Dermatochelys coriacen, 333 f., 334

Demophis, 39,23 ; 12. thomensis, 93

Deserticolous reptiles, 493 if.

Desmognathinae. 10.'

Desmagnathus, (10, 10?: 1). fuscus, 10?, 103

Dinlerosaums, itis

Development, of Antura, 56 f., 57 ; of horny teeth, 58 ; of - Apoda, 92 ; of Crnculilus, 465 : of Alligutor, 467

Diculectes, 3US

Dierlemodon, 309

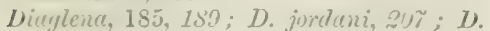
petasata, $20 \%$

Diaphragm, of Anura, 144; of crocodiles, 444

Diapophyses (the lateral or "transverse" processes of the netual arches) of Anura, 138,141

Dibatuidae, 51\%, 56:4

Dibrmas norae-guinede, 56:4

Dicamptodon, 96; ; I). cusutus, 109

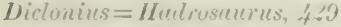

Dicynoulon, 301, 302, 303, 310; skull. $280 ; D$. leoniceps, 310; 1). oricntalis. $310 ;$ D. timpiceps, 310

Digestive apparatus, of Chelonia, 330 ; of erocouliles, 444 ; of Lacertilia, 495

Digits = Fingers and Toes, Number of iligits in Urotlela, 15, 16; in Anura. 26 ; terminal plialanges, 26 ; number of joints, 27 ; adlhesi:e dises, 27 ; variability in numbers, 56:3; dicrits of Eryons, 286: of Crocorliles, 4\$1; of Plesiosauri, 475 ; of Geckos, 505

Dimetruden, $30 S^{\circ}$

Dimorphodon mecronyx, 486

Dinosauria. $41 z^{\prime}$; aflinities of, 415 ; analogies with Birds, 416

Jriplocynodon, 448 ; 1). hastingsiae, 454

Jiplendocus longus, 410 fo ; skull, 419

Jiplenertebrim, ..8\%, 288

Dipsadomorphinae, $6 \cdot 2 \cdot 3 \mathrm{f}$.
Dipsatemorphus, 623; D. cyanens, 624; D. trigoncetus, 623

Dipsas bucephala, 6?74

Discoglossidae, 139, $152 \mathrm{f}$.

Discoglossus, urino-genital organs, 49, 153; D. pictus, $153 \mathrm{f}$.

Dissorophes multicinctus, $\therefore$ :

Distira cyunecineta, 637 ; D. semperi, 636

Distribution, geographical; see Maps

Dolichosauri, 459

Dulichosuurus longicollis, 489

Dolichosome longissimum, 81

Jolinph is intestinalis, 634

Dollo, on Sylhargis, 336

Diacaena, 547 ; D. gumensis, 549

Dirco, 510; 1). dussumieri, 510; $D$. rolans, 516,516

Duméril, 7,139 ; and Bibron, on classification of Snakes, 592

Dwarf Chameleon, 5rt

Dyscophinae, 189 , 2:35 f.

Dyscuphers, 236; D. antongiti, 236

Echeneis remora, used for turtle fishing, 382

Echidna s, Bitis, 689, 639

Ëchis, 6.j0; E. arenicola, deserticolous, 493

Eitaluine, 212

Ear, of Chelonia, 330 ; of Crocodiles, $445 \mathrm{f}$. ; of Snakes, 583

Ear-opening of deserticolous reptiles, 494

Eggs of Amphilsia, 53; mode of deposition in Amphibia, 54-56; of Ichthyopthis, 91; and spermatophore of Triton viridescens, 128 ; nursing and taking care of, 55 ; by 1'ipa, 151 ; by Alyles, 159 ; by Rhacophomes reticulatus, 248; by Nototrema, 188, 202; by Ampsi. inathodon, 1SS; by Hyla goeldii, 198, 198 ; by Leptodectylus mystacinus, 219 ; by Rhinoderme, 2DS; by Rhacophornes, 2.ts; by Desingyinathes fuscus, 103. 103; number of: in Bufo vulgaris, 175 ; in Bufo virilis, 181; in Hyla arborea, 193 ; in Rana esculenta, 270

Eggs of Reptilia: Sphenudon, 299 ; Chelonia, 331; 'Testudo yraeca, $369 ; T$. iberce, 369 ; $T$. elegans, 371; T. poly. phemus, 372; Emys orbicularis, 355 ; Clemmys leprora, 358 ; Chelone mydas, 382: Thulassochelys caretla, 387 ; Pollochemis conunse, 393 f., 398 ; Triony. 105: mode of laying ly kimys, 355 ; by Pulocnemis, 393 ; used commercially; $39+\mathrm{f}$. ; enormous destruction of, 395 , 399 ; Crocodilus, 463, 464 f.; Alligutur, 470; eggs and nest of Gmialis. 452; Iacertilia, 499 ; increasing in size after deposition, 199 : Geckos, 506, 508, 509, 511: Terentole, 509; Lacerta viridis, 555 ; Chameleons, 572 
Egg-sac, of Salamandrella, 110

Egg-tooth, of Lacertilia, 499

Eimer, on habits of Lacerta, 552 ; on $L$. coerulea, 558

Elachistodon westermanni, 6:5

Elachistodontinae, 625

Elaphis s. Coluber, $615 \mathrm{f}$.

Elapinae, 6*' $0^{\prime}$

Elaps corallimes, 635

Elasmosauridae, 478

Elesmosaumes, 4\%

Elginia, 301, 304; E. mirabilis, skull, 280. $30 \tilde{5}$

Elosie, 212

Elseye, 3S9, 399

Emerald Lizard, 555

Emery, on haud-skeleton of Eryops, 286

Empedias molaris, 308

Emyela, 411

Eimyelura, 389, 399

Einys, 350 f.; E. blandingi, 355 ; $\boldsymbol{E}$. europaed $=$ orbicularis, $351 \mathrm{f},, 353$

Enaliosauri, $4 \pi 6$

Endothiodon, 307

Engystoma, 227, 231; E. carolinense, 23:-

Engy'strmatidae, 139, $225 \mathrm{f}$.

Engystomatinae, 139, $025 \mathrm{f}$.

Entyystomops, 166, $16 S$

Enhydrina valakadien s. bengalensis, 636, 636

Exyggres, 601

Evsphargis, 336, 33т

Epichordal type of vertebrae, 20, 145

Epictermis, of Anphibia, 31 f. ; senseorgans in, 33

Eivuisetum, eaten by Cromastix, 525

Eremias, 551 ; deserticolous, 493

Erpetosuchus, 433

Eryops, 285, QS6; trunk-vertebrae, 286, 288. 301 ; E. megacephalus, 286

Eryx, 604; E. jaculus, 604; deserticolous, 493

Escuerzo $=$ Ceratophrys, $\mathbf{2 1 6}$

Espada, on Plinoderma, 228

Eublepharinae, 512

Euchiroscurus, 83,287

Eunectes murinus, 603, 603

Eireprepes vittata, $56 ?$

Eiuproctus $=$ Triton, 130

Eurysternum, 380

Eustachian tubes, of Anura, 29 ; or Pelo. batidae, 161; of Aglossa, 143

Eusuchiu, 434

Eye, of Apoda, 86 ; of Chelonia, 329 ; of deserticolous reptiles, 494 ; of Chameleons, 569 ; of Sinakes, 583

Eyed Lizard, 556,556

Eyelid, of Geckos, 504, 512 ; transparent in Chelncline, 329; lower, transparent in Lacertidae, 551 ; in Scincidae, 560
Fasting, of C'hrysemys, 347

Fat-bodies, of Amphibia, 49, 52 ; of Lacertilia, 500

Fecundation, various modes of, in Amphibia, 54; in Apoda, 8i

Fer-de-Lance, $64 \pi$

Ferreiro = Hyla faber, $196 \mathrm{f}$.

Feylinia, 5644

Fingers, number of, in Urodela, 15 : number of joints in Anura, 26, 27: terminal modifications of, in Anura, 26 ; mechanism of adhesive dises in $\mathrm{Hylidae}$, 187

Fire Salamander, 115

Firmisternal, type of shoulder-girdle, 24, 25

Firmisternia, of Cope, 140 ; of Boulenger, 140

Fischer-Sigwart, on growth of Alytes, 159 f. ; on growth of $B u f o, 175$; on gesta. tion of Chalcictes, 563

Fletcher, on spawning of Australian frogs. 201,223

Flower, S. S., on habits of Rhacophorns, 249; Phrymella pollicaris, 233; Callule pulchere, 234

Flying Dragon, 510

Flying Frog, Rhacophores, 245 f., 246

Foot, tridactyle, in Hallopus, 423 ; birdlike in Compsognathus, 423

Fore-limb, of Urotela, 15 ; of Anura, 26 ; of Proreptilia, 286 ; of Microsauri, 289 ; of Prosauri, 290, 298; of 'Theromorpha, 302 ; of Chelonia, 320 ; of Dinosauria. $414,423,425,427$; of Crocodilia, 440 ; of Plesiosauria, 475; of Ichthyosauria, 481 ; of Pterosauria, 485; of Pythouomorpha, 489 ; of Lacertilia, 497

Gage, on Triton viridescens, 129

Galapagos Islands, tortoises of, $372,377 \mathrm{f}$.

Galesaums, 30\%

Gicimpsosteonyx, 271; G. batesi, 238, 240

Gasco, on spawning of newts, 124

Gastrechmia, 140, 141, 23:

Gastrocentrous vertebrae, defined, 282

Gaupp, on frogs' respiration, $47 \mathrm{n}$.

Gavialidae, $451 \mathrm{f}$.

Garialis, 435, 4362, 451; G. gangeticus, 452 ; skull, 449, 452

Gavialosuchus, 453

Gecko, 511; G. stentor, 511; G. verus $=$ guttatus =verticillatus, 511

Geckolepis, deserticolous, 493

Geckones, $502 \mathrm{f}$; ; distribution, 500, 503 ; adhesive apparatus, 505,505 ; voice, 506 ; reproduction of tail, 506 ; eyelids, 504,512

Geckonidae, 50 \% f.

Geckoninae, $50 \% \mathrm{f}$.

Gegenbaur, on classification, 9

Gegenophis, 87, 90 


\section{Geilia, 310}

Genital organs, of Amphibia, 45 f., 49

Genyophryne, 236; G. thomsoni, 236

Genyophrynidae, 141

Genyophryninae, 139, 236

Geographical distribution, principles of, 69 f. ; regions and sub-regions, $7 \pm \mathrm{f}$. (for details see also Maps); of Apocla, 89 ; of Urodela. 95, 96 ; of Anura, 143. 161, 167, 185, 239; of Chelonia, $331 \mathrm{f}$., 332,333 ; of Crocodilia, 446 ; of Lacertilia, 500 f., 515, 529, 543, 552. 565,568 ; of Snakes, 585

Geomolge, 96

Geosaurits, 451

Geotriton, 97

Geotrypetes, $S 9$

Gerrizonotus, 53S ; G. coeruleus, 538

Gerrhosauridae, 514, 559

Gerrhosaums tlavigularis, 559

Gharial, 45:; see also Gavialis

Gigantic 'Tortoises, $3 \approx \sim \mathrm{f}$.

Gila Monster, $5: 1$

Gills, detinition, 40 : derelopment of, 11 , 43 ; retention of, 40 ; external and internal, $43 \mathrm{f}$. ; operculum of, $4 \pm$; of Nototrema, 203

Gill-clefts, 42; of Urodela, 42 ; of Anura, 42

Girtanner, on musical appreciation of tortoises, 368

Glass-Snake, 538

Glanconia, 594

Glauconiidae, 592, 594

Glyphoglossus, 225, 226, 22S, 233; $G$. molossus, 233

Goeldi, on Hyla faber, 197 ; on habits of Polocnemis expansa, $397 \mathrm{f}$.

Gomphognathus, 30S, 309

Gonduanosurus, 83

Gongylus, 56?

Goniopholidae, 453

Goniopholis, 448, $453 ; G$. crassidens, 453 ; (i. simus, 453

Gordonia, 301, 303, 310; skull, 280

Grass-Frog, 251 f., 255

Grass-Snake, GUS t.

Greek Tortgise, $365 \mathrm{f}$.

Green Lizard, 555

Green 'Toal, 180

Green, or Edible, Turtle, $381 \mathrm{f}$.

Groenberg, on Pipa, 149

Growth, rate of, in Testuclo ibera, 370 : Chrysemys picta, 349 ; Emys orbicularis, 351,355

Gular shields of Chelonia, 315

Gundlach, on Leptodrctylus, 219

Giinther, 140 ; on gigantic Tortoises, 374 ; on classitication of sinakes, 592

Gutzeit, on horny teeth of Tarlpoles, $\mathbf{5 8}$

Gimmolactylus, tail, 506, 51: 512; deserticolouts, 493
Gymuphiona, $\mathcal{S}_{4} \mathbf{f}$.

Giymnnphis, 90

Gymmophthalmas, aberrant scaling, 495

Haast, on havits of Sphenodon, 299

Inalrosaums mirabilis, 4209

Haeckel, on classitication, 9

Hallopus victor, $4: 3$

Hamalryal, 63.

Hand-skeleton, excalation of second tinger in Eryops, 286

Haptoglossu, $96^{\circ}$

Hardun $=$ Algama stellio, 5:21

Hatteria-see Sphenolon, $293 \mathrm{f}$.

Hawksbill-Turtle, $3 S 4 \mathrm{f}$.

Hay, on Sphargis, $33 \overline{7}$

Heariug of Chelouia, 330

Heart, modification of, in Iungless Am. phibia, 47

Heulonic glands ( $\dot{\eta} \delta \nu^{\prime} \dot{\eta}$, lust), 143

Ueleioporis, 213, 22.2; $H$. albopunctatus: $2.2 ;$; 11 . pictus, 222

Helix virgata, eaten by Hyla cnerulea, 200

Heloderma horridum, 540; $H$. suspectum, 540,541

Helodermatidae, $513,5.40 \mathrm{f}$.

Hemidactylus turcicus, 5US, 508

Hemiphractiuae, $139,210 \mathrm{f}$.

Hemiphractus, 210

Hemisus, 225, 226, 228, 232; shouldergirdle. $25 ; H$. guttatum, 232; $H$. sudanense. 232

Hensel, on Bufo marinus, 179 ; on tadpoles of Thorope, 209; on nest-buildiug ot Leptoductylus, 219

Herodotus, on Crocodiles, 462

Herpele, 30

Heipestes grisens (Mongoos), 629

Hihernation, temperature of blood cluring, 65 ; of Tortoises, $3 \pm 7,349,35 \pm, 358$, $360,363,365,369,376$; of Crocodiles. 447

Hinckley, on tadpoles of Hyla versicolor, 195

Hiud-limbs, of Urodela, 15; of Anura. 27 ; of Prosauria, 289; of Theromorpla, 302,305 ; of Chelonia, 321 ; of Dinosauria, 414, $423,425,427,429$; of Crocodilia, 440 : of Plesiosauria, 476 ; of Ichthyosauria, 480 ; of Pterosauria, 486 ; of Lacertilia, 497 ; of Ophiclia, 593, 594. 596

Hipistes hydrinus, 625

Holbrook, on the Black Snake, 613; on habits of Alligator, $470 \mathrm{f}$.

Holoblastic egrs; the whole mass of the egg unclergoes the process of cleavage, 53

Homalopsinae, 6:55

Homalopsis brecata, 6.75

Homing of turtles, instances of, 386 
Homoeosaums pulchellus, 292

Homopholis, deserticolous, 493

Homothermous, defined, 65

Hoplocephalus curtus, 634

Iloplurus, 598; geographical distribution, 501

Horned Toad=Ceratophriys, 215 f., 216, 217

Horned Viper, 640, 641

Horny nail, on tail of Chelonia, 328

Horny scales, of Chelonia, 328

Horny shields, of Chelonia, 314, 315, 322 , $323,326 \mathrm{f}$, 327 ; their growth, 326

Horny teeth, of Anura, 58

Hose, on reproduction of tortoise-shell, 386 Howes, on development of Sphenodon, 298

Humerus of Sphenodon, 294

Hutton, on Starred Tortoise, $370 \mathrm{f}$.

Huxley, on classification, 9

IIyulraspis, 389 ; skull, 399

Hydromedusa, 389, 404; $\mathrm{H}$. tectifera, 404

Hydrophinae, 635

IIydrophis obscura, 636, 636

Hydrosaurus, 543

Hyla, 189 f. ; H. arborea, 190 f., 190 ; var, meridionalis, 191; var. savignyi= japonien, 191 ; H. aureu, 201 f. ; spawning, $201 ; H$. carolinensis s. lateralis, 194; $H$. coerulea, 198 f., 199 ; spawning, $223 ; H$. dasynotus and $H$. nigromaculata, dermal ossifications of, 190 ; $H$. eloingi, 201; spawning, $223 ; H$. faber, peculiar mursing habits, $196 \mathrm{f}$; H. femoralis, 194; 11 . goeldii, 198, 198 ; female with eggs, 198; H. maxima, 136 ; H. nebulosa s. luteola, 197 ; nestbuilding, 198 ; H. polytaenia, $19 S ; H$. squirella, 194; $H$. vasta, $195 ; H$. iersicolor, $194 \mathrm{f}$.

Hylaeformes, 139

IIylaeobatrachus croyi, $\$ 3$

IIylaeosaurus, 4:5

Hylambates, 238, 240

Hylella, 186, 189, 203

Hyliclae, 139, 185 f.; distribution, 185, 186; mechanism of elimbing, 187 ; map of distribution, 185 ; distribution, $186^{\circ}$

Hylinae, $139,189 \mathrm{f}$.

Hylixulus, 238, 24?

Hylodes, 212; II. martinicensis, $214 \mathrm{f}$, $214 ; H$. abbreviatus $=$ Thoropa miliaris, 209

IIylonomus, 288, 289

Hyloplesion longicostatum, 2S9

Hylopsis; 212; H. platycephalus, 20't

IIylorhine, \&12

IIymenochinus, 143, 144, 149

Hymnbius, 96, 109

Hyoid apparatus, of Urorlela, 16 ; Anura, 31; of Chelonia, 318 ; of Chelys, 400 ; of Lacertilia, 496
IIyperodapedon gordoni, 292

Hyperotia, 213; spawning, 223

Hyperphalangeal limbs, of Eusuchia, 111 ; of Ichthyosauri, 480

Hypogeophis, 87, 89, 92; $I$. ulternans, $92 ; 11$. rostratus, 9?

Hypopachus, 226, 227, 235

Hypsilophodon foxi, 497

Hypsinhina plumbea, 6:5

Iberian Water-tortoise, $357 \mathrm{f}$.

Ichthyodea, distribution of, 95

Ichthyophis, skull, 85, 88, $\$ 9$ f:, $91 ; I$. glutinose, 90, 91; I. monochrous, 90

Ichthyopsida, 5,277

Ichthyopterygia, 476

Ichthyosauri, $4 \$ 3 \mathrm{f}$.

Ichthyosauria, 478 f.; skull, 281, 479 ; vertebrae, 480 ; limbs, 481 ; shouldergirdle, 481

Ichthyoscurus, 4S3; I. communis, 483 ; I. campylodon, 483; I. quadriscissus, 483 ; I. tenuirostris, 483; I.trigonodon, 483

Illiochelys, 380

Iguane, 306, 528,531; I. tuberculata, 531 Iguanidae, 513, 5.28 f., distribution, 501, 529

Iguanodon, 416, 417, 427; I. bernissartensis, 4NS, 428 ; 1. mantelli, 427

Ihering, on breeding habits of Phyllomedusa, 205 f., 206

Ikeda, on nursing habits of Rhacophorus, 248

Ilysia, 595

Ilysiidae, 592. 594

Inframarginal shields, 326, 315

Intergular shields of Chelonia, 325,315

Iris, colour of, in Chelonia, 329

Ixalus, 238, 241

Jaw, lower, of Salamandra, 17 ; of Urodela, 18; of Anura, 30

Keller, quoted, $571 \mathrm{n}$.

heraterpeton, 81,$288 ; \pi$. crassum, 81

Kidueys of Amphibia, 48 f., 49

Klinckowstroem, on Pipa, 149

Kollmann, on Neoteny, 64

Krait, 633

Labial glands of Heloderma, 498

Labyrinthodon, 83

Labyrinthodonta, 82

Lacerta, 553 ; L. agilis, 554; L. muralis, 557 ; L. ocellata, 556 f., 556 ; L. pater, 556 ; L. schreiberi, $555 ; L$. tangitana, 556 ; L. viridis, 555 ; skull, 550 ; $L$. vivipara, 55.3

Lacertae, $513 \mathrm{f}$.

Lacerticlae, 514,549 f.; skull, 550 ; distribution, 552 
Lacertilia, 491 f. ; skeleton, 494 f. ; skin, 497 ; change of colour, 495

Lachesis gramineus, $6.47 ; L$. lanceolatus, 646,647

Land-tortoises, $364 \mathrm{f}$.

Lanthanotidae, $514,541 \mathrm{f}$.

Lanthanotus bomeensis, 541

Laosaurus, 4;i

Laviosanrus, 473, 474; L. balsami, 4ĩ

Larvae, of Ichthyophis, 91 ; of Hypogeoph is, 92; of Amblystoma, 112 ; of Triton walli, 131

Latreille, on classification, 7,8

Laurenti, on classification, 7

Leathery 'T'urtle = Sphaigis, 333 f., 334

Lechriodonta, distribution of, 95 ; defined, 10.2

Lepidobatrachus, 21:, 218

Lepidophyma, 5 . 4

Lepospondylous, defined, 79

Leptobrachium, $161 ; L$. carinense, 166

Leptodactylus, ¿12, 218 f.; L. albilabris, 219 ; L. mystacinus, 219 ; L. ocellatus, 219 ; L. typhonius, $219 \mathrm{f}$.

Leptognathus, 62't

Leptophis, 61S; L. liocerus, 61S, 619

Leslie, on Ienopnes, 146

Lenckart, on classitication, 8

Leydig's duct, defined, 48, 49

Lialis burtoni, 56 ir

Limbs, of Amphibia, 26, 27 ; Stegocephali, 79, 83; Eryops, 286; Microsauri, 259 ; Prosauri, 291; sphenodon, 29s; Theromorpla, 302 ; Pareiasauri, 305 ; Chelonia, 320, 319, 320; Sphurgis, 335: Chelonidae, 379; Dinosauria. 414 f., 418, 420; Compsornathus, 423; Stegosauri, 426 f. ; Igucenodon, 428 , 428 ; Eusuchia, 440 ; Plesiosauria, 475,475 ; Lariosaurus, 477 ; Ichthyosauria, 480; Pterosauria, 485, 485 ; Lacertilia, 495 : Geckones, 505 ; Chameleons, 568 ; reduction of, in Lacertilia. 497 ; in Ophidia, 593, 594, 596

Limnodynastes, 213, 222 ; spawniug, 223

Limnomeduse, ¿212

Limneus, on classification, 7

Lioulon hanmuriensis, fitu

Liolepis belli, 527

Liopelma, 153 ; L. hochstetteri, 160

Limphryne, 225,22 i

Liosuarus, 509

Lissamphibia, $S_{7} \mathrm{f}$.

Lizard, Common English, 55.3 ; Emerald, 555 ; Eyed, 556, 556 ; Green, 555; Sand, 554 ; Wall, $55 \%$

Lizaris, $491 \mathrm{f}$.

Locality, sense of, in 'Iortoises, 368, 387

Loggerheal T'urtle, $35 \%$; individual varieties of shields, 327,388

Longevity, of Testudo deudini, $376 ; T$. graeca, $369 ; T$. ibera, $369 ; T$. sumeirei, 377

Loxocemus bicolor, $59 \mathrm{~S}$

Inxomma, $\$ 3$

Lucilia bufonirora, thy infesting $B u f o, 176$

Lungs, definition, 40 ; suppression of, 46 ; of Aglossa, 144; of Lacertilia, 499

Luth, or Leathery Turtle, 333 f., 334

Lycuseuris, 307

Lygusoma, distribution, 501

Lympl-spaces, in the cutis of Anura, 31

Lyriocephalus scutatus, 517, 518

Lytoloma, 336, 380

Mabuia, 562 ; distribution, 501 ; eyelids, 494: M. vittetta. 56:

Macroclemmys, 326; M, temmincki, $340 \mathrm{f.}$ 340

Hacroprotodon cucullatus, 624

Macrorhyuchilae, 4051

Madagascar, Lacertilia of, 502

Malacoclemmys terrapin, ,is.) f. : (n) mercial breeding-farms, 360

Iralpighiau, body, 49 ; stratum, 32

IIammalian attinities of Theromorpha, 303 , 309

1.unculus, 96, 103, 106; 1. quadridigitatus. 106

Iandible, composition of, in Crocodiles, 437 ; very Mammalian in Gomphogna. thus, 309

Iantella, 274

Mantophryne, 225, 227

Maps showing geographical distribution, of Coeciliidae, 89 ; Urodela, 95 ; Aglossa, 143 : Cystignathidae, Discoglossidae, Pelobatidae, 161 ; Bufouidae, 167 ; Hylidae, 185 ; Ranidae, 239 ; Chelydiclae, 332, 333; Chelydridae, 332 ; Cinosternidae, 332 ; Dermatemylidae, 332 ; Pelomedusidae, 332 ; Platysterniclae, 332 ; Trionychidae, 333 ; Crocolilia, 446 ; Geckonidae, 503 ; A gamiliae, 515 ; Anguidie, 529; Iguanidae, 529 ; Zonuridae, 529; Varanidae, 543 ; Lacertidae, 552 ; Amphisbaenidae, 565 ; Chamaleontes, 568 ; Snakes, clangerously poisonous, 585 ; Elapinae, 626 ; Crotalinae, 644 ; Viperinae, 638

Marbled Newt. $1 \approx 6$

Marginal plates of Chelonia, 325, 322, 323

Marginal shields, $326^{\circ}$

Marsh, ou Axolotl, 115

Narsh Crocouile, 455

Marshall, on distribution of Uropeltidae, 595

Mascarene Islands, tortoises of, $373 \mathrm{f}$.

Mason, on habits of Calotes, 519; on Pytlion legends, 599 ; on. Tar:mus, 541

Mastadonsaumus, 8.3

Matamata $=$ Chelys fimbriata, 400, 401

Mauritius, gigautic tortoises, 373 f., 376 
Mecorionta, distribution of, 95 ; defined, 102

Megalixalus, 238, 240

Megalophrys, 161; tadpole, 60

Megalosaurus, 416 ; M. bucklandi, 421

Megalotriton, 83

Melanerpeton, 81,289

Melanobatrachus, 226, „2S

Melosaurus, 287

Menobranchus lateralis, 13:

Menopoma, 97

Mento-Meckelian cartilages, 30

Meroblastic eggs; part of the egg only undergoes the process of cleavage, 53

Merrem, on classification, 8

Mesosauridae, $4 \pi 6$

Mesosanme, 476 ; 1 . tenuidens, $4 \pi 6$

Metamorphosis of Tadpoles, $56 \mathrm{f}$.

Metasterum of Anura, 26, 25 ; taxonomic value, 141 ; definition, 26

Metatarsalia of Theropoda, 420

Ietopias, 83

Metopoceros cornutus, 532

Metriorhynchidae, 451

Metriorhynchus, atlas and axis, 283, 431, 451

Metzdorff, on Axolotl, 113

Micriaculus, 241

Microgomphodon, 30 S, 309

Microhyla, 298

Microsauri, $2 S \mathcal{S}$

Midwife-toad, 158

Kimosa (plant), 629

Hidania, 390

Mixophyes, 213; sprawning, 213

Mixosqunus, limbs, 480, 481, 483

Wolge-see Triton, 1:2

Woloch horiclus, 5i\%, $\mathbf{5 2 7}$

Mongoos and Cobra, 629

Monitor, 543

Worosaumes grandis, 419; pelvis, 419

Mosasauri, $489 \mathrm{f}$.

Mosusumis, 4S9; M. comperi, 490

Ioult of Geckos, 510 ; of Chameleons, 571 ; of Snakes, 583

Mud-diver, 165

II ul-turtle, 342

Mugger, 454

Miiller, J., on classification, 8

Millerian inct, 49, 51

Musical appreciation of 'Tortoises, 368

Myobatrachus, 166, 167, 16s; . I. gouldi, $194,227,236^{\circ}$

Mystriosaurus, 432, 451

Nails or claws of Amphibia, 32

ATaja, 626; $\mathrm{T}$. bungurus s, elaps, 6.9.2; 1. haje, 628, 632; $\boldsymbol{N}$. tripudians, 627, 627

Niunnobatrachus, 238,240

Nicosaumes clariger, $30 \mathrm{~S}$

Natterjack, 181
Saultinus elegans, 506

Neck, mode of withdrawing in Chelonia, $328 \mathrm{f}$.

Nectes, 166, 168; $N$. subasper, 169

Nectophryne, $166,16 S ; \Lambda$. afra, $109 ; \Lambda$. tuberculosa, 169; $N$. guentheri, 169; 1. hosei, 169; $\mathbf{1}$. misera, 169

Lecturus, pelvis, 15, 96, 132; 1 . maculatus, 13?

Neoteny, 63 f. ; definel, 64

Nephrostomes, 48, 49

Nephrums asper, tail, 506

Nerves, spinal, of Amphibia, 38 ; cranial, 39

Nest, of Crocolilus, 463 ; of Garialis, 452

Neural plates, of Clielonia, 323 f., 322, 323 ; suppression of plates, 324 ; in Pleurodira, 389 ; of Dermatemys, 342

Nensticosaurus, $4 \pi$ \%

Newt, Common, 127; Crested, 125, 125 ; Marbled, 1:6 ; Spotted, 12\%

Newton, E. T., on fossil Reptiles, 303 n.

Nile Crocodile, 461

Nodosanrus, 430

Nose-horned Viper, 640

Notaden, 166, $169 ; \boldsymbol{N}^{\mathrm{r}}$. bennetti, $16 \%$

Notechis scutatus, 634

Nothosauri, $476 \mathrm{f}$.

Nothosamidie, $47 \%$

Nothosaums, 474; $\Lambda$. mirabilis, 4iy

Notocentrous vertebrae, defined, 19

Notochord $=$ Chorda dorsalis, $q \cdot v$.

Nototrema, 1S9; $\mathbf{L}$. cormutum, 203; $\mathbf{N}$. marsupiatum, $202 ; \mathrm{N}$. oriferm, 202; peculiar gills of embryos, $203 ; \Lambda$. pygmaeum, 202; 1 . testudineum, 202

Nuchal plate of Chelonia, $323 \mathrm{f}$; ; of Pleurodira, 389

Nuchal shield of Chelonia, 326, 327 ; of Pleurodira, 389, 399

Nuptial excrescences of Anura, 33

Nursing, habits, of Arthrolept is seychellensis, 243 ; of Chiromantis rufescens, 244 ; of Pihacophorus, 248; of Rhinodema, $22 \mathrm{~S}$ f. ; of Pipa, 151 ; of Hyla faber, $196 \mathrm{f}$. ; of $H$. nebulosa, 198 ; of $H$. goeldii, 198 ; of Nototrema, 203; of Phyllomedusa, 204 f. ; of Leptodactylus, 219 f. ; of eggs by Desmognathus, 103, 103; by A utoclax, $10 \mathrm{~s}$

Nyctibatrachus, 240

Nyctimantis rugiceps, 199,206

Nyctixalus, 238

Occipital condyle, of Reptilia, 278; exaggerated importance of, 285 ; of Theromorpha, 302 ; of Pareiasauri, 305 ; of Cynognathus, 307 ; of Crateronotus, 307 ; of Dicynodon, 310 ; of Eusuchia, 437 ; of Amphisbaenidae, 496

Odontaglossa, 140

Oligodon, dentition, 593 м. 
Omoscumus = Stegosaurus, $4: 35$

Omosternum of Auura, 25 ; taxonomic value, 111

Onychodactylus, 96; 0. japonicus, 109

Operculum of gills, 44

Ophiderpeton, 81

Ophidia, 491, $581 \mathrm{f}$.

Ophiophagus, 63:'

Ophiops, 551

Ophioxylon (plant), 629

uphisaurus, 535; 0. apus, 53S; 0. gracilis, 535

Ophthalmosaurus, limbs, 481, 481, 484

Opisthocoelous, definition, 12

Opisthoglossa, 110

Opisthoglypha, 592, $606 \mathrm{f} ., 6: 33 \mathrm{f}$.

Oppel, on classitication, 7

Oreobatrachus, 241

Oreophrynella, 2:2

Ornithocheinus, 456

Ornithomimus, $417 ; 0$. grandis, $; 09$

Oruithopoda, 425, 4:6

Ornithopsis, 419

Ornithoscelicla, 410

() rnithosuchus, 433

Orthocosta, 288, ¿39

Orthopoda, 4:4

Ossifications, lermal, in Anura, 31, 34179. $190,210,211$

Osteoderms=ossifications in the slin, of Sphargis, 337; of Caiman, 337; of Lizards, $504,513,514$

Osteolaemus, $450 ; 0$. tetrospis, 466

Ouarau, 543

Oudenodon, $301 ; 0$. rugosus, 310

Ovary, 49

Oviduct, 49, 51

Owen, on fossil Reptiles, 303 п.

Oxydactyla, 140

Oxyglossus, 239, 241

Pachytriton, 96, 115; I'. brevipes, 132

Painted Terrapin, 347,348 ; rate of growth, 349

Palacobatrachus, vertebral column, 22, 145

Pelueohatteria longicundate, 291; skull, 280,304

P'aludicnla, resembles Engystomops, 166 , 21:2,20; P. fuscomaculata, 220; 1 . bitigonigera, 221

Paludina, as food of Triony $x, 40 \overrightarrow{7}$

Parasternum = the sum total of the Abdominal ribs, q. $x^{*}$; of Sphenodon, 298 ; of Crocodilia, 440 ; of Ichthyosauria, 480

Parasuchia, 433

Pareiasauri, 301, 302, 304

Pareiasanns baini, 304

Parrots, feathers dyed with poison of Dendrobates, 272

Pelobates, variation of vertebrae, 19 ; sacral vertebra, 22, $161 \mathrm{f}$, : I'. juscus,
102; P. cultripes, 163,$164 ; P$. syriacus, 16 '

Pelobatidae, 139,160 f. ; distribution, 161 Peloclytes, 161, 165; P. punctatus, 165; $P$. crucasicus, $16^{\circ} 6^{\circ}$

Pelomedusa galeata, 391.

Pelomedusidae, 313,31 ; d distribution, 332, 390 f.

Pelosuurus, SI

Pelvic, plexus of Anura, 39

Pelvis, of Urodela, 15; of Anura, 22, 27 ; of Eryojs, 286; of Microsauri, 289; of Sphenodon, 298; of Theromorpha, 302 ; of Pareiasauri, 305 ; of Cynognathus, 307 ; of Vicynodon, 310 ; of Chelonia, $319,319,320$; of Pleurolira, 388, 389 ; of Dinosauria, 414; of Eusuchia, 411 ; of Plesiosauria, 476 ; of Ichthyosamria, 180 ; of Pterosauria, 485 ; of Pythonomorpha, 489 ; of Lacertilia, 496

Perennibranchiata, 8,9 ; not a natural group, 65

Petrels living with Sphenodon, 299

P'otrobates, 285, 289

Phalanges, number of, in Uroulela, 15 ; in Anura, 26, 27, 238; in Stegocephali, 79 ; in Palceohutteria, 291 ; in Chelonia, 320, 321: in Chelone, 379; in Scelidosaurus, 425; in Camptosanrus, 427; in Laoscurus, 427 ; in Iguenodon, 428 ; in Eusuchia, 141 ; in Plesiosauria 475; in Lariosaurus, 477 ; in Ichthyosauria, 481, 481; in Pterosauria, 485, 485 : shape in Anura, 138 ; peculiar in Pipa, 151

Phaneroglossa, 152

Phanéroglosses, 139

Phanerotis, 913

Phisalix, on poison of Anphibia, 37

Pholilosaurus, 451

Phractamphibia, is f.

Phrymaglosses, 139

Phrynella, 23y; Ph. pollicaris, 233

Phryniscus, 226, 22\%, 230; $12 /$. nigricans, 2.30

Phrynobatrachus, 241

Phrynocara, 235, 236

Phrynocephalus, 5:1; deserticolous, 493 ; coloration, $49 \pm$; $P$. helioscopus, $5: 2$; $P h$. interscupularis, $5: 22 ; P h$. mystaceus, 522

Phrynoderma, 241

Phrynomantis, 226, g2S

Phrynopsis, 241

Phrymosoma, 305, 53.3; Ph. coronatum, 534,$535 ; 1 \%$. cornutum, 533, 534

Phyllebates. 249; Plh. bicolor, 242; Ph. trinitatis, 240

Phyllodactylus, 507 ; Ph. europaeus, 50 \%

Pluyllodromes, 238, 24:

Phyllomelusa, 189, 203 i. ; Ph. bicolor, 203; Ph. rlacnicolor, S03; Ph.hypochon- 
drialis, breeding habits and development, 204 ; $P h$. iheringi, 205 ; breeding habits, 206

Phylogeny, of Amphibia, 66 ; of Anura, 142 f. ; of Reptilia, 282 ; of Lacertilia, 515 ; of Opliclia, 592

Physignathus tesueuri, 523, 524

Pigment in the skin, 34

Pipa, 143, 144, 149 f., 150

Pit-Vipers, 644

Placodontia, 311

Placodus, 301 ; P. gigas, 311

Plastron, of Chelonia, 315, 321, 321 ; provided with hinges, 323 ; sexual characters of, 331 ; movable in Emys, 350 ; of Chelonidae, 321, 321, 322, 380 ; of Pelomedusidae, 390 ; of Chelydidae, 399 ; of Trionychoidea, 406

Platecarpus, 490

Platemys, suppression of neural plates, 324 ; skull, 399

Plathanier $=$ Iennpus, $146 \mathrm{f}$.

Platume fasciatus s. colubrinus, 63y

Platydactyla, 140

Platydactylus facetanus, 509, 508

Platyhylu, 236

Platypelis, 235, 236

Platystemidae. $314,326,345$

Platysternum megacephalum, 345

Plectromantis, 212

Plesiochelys, 380, 389

Plesiosaturi, $4 \% \approx \mathrm{f}$.

Plesiosauria, 473 f. ; vertebrae, 474

Plesiosauridae, 478

Plesiosaurus, 475, 478; P. conybeari, 478; $P$. dotichodirus, 478

Plethodon, 94, 96, 104, 106; P. erythronotus, 10\%; P. glutinosus, 106

Plethodontinae, 102, 103.

Plethodontohyla, 235, 236

Pleurodira, $313,388 \mathrm{f}$.

Pleurosaurus, 294

Pleurosternum, 390

Plioplatecarpus, 489

Pliosauridae, $4 \pi 7$

Pliosaurus grandis, $47 y$

Plover, Egyptian, and Crocodile, 462

Podoenemis, 390,391 ; $P$.expansa, 391 f.; Bates, on habits of, $392 \mathrm{f}$.

Poikilothermous, defined, 67

Poison, of Amphibia, 37, 38; peculiar use of, 272

Poison-apparatus, of Heloderma, 540 ; of Snakes, $586 \mathrm{f}$.

Polacanthus, 425

Polychrus marmoratus, 529

Polyodontophis, 605 n.

Portschinsky, on parasitic flies, $177 \mathrm{n}$.

Postpubis, of Dinosaurs, 414, 424, 426

Pouchet, quoted, 571

Predentary bone, of Dinosaur, 424

Prehallux, of Anura, 28
Prepubis, of Dinosaurs, 414, 424, 426

Proganochelys, 389

Proganosauria, 476

Proreptilia, 255

Prosauri, 290

Prosauria, «SS

Prosthercuis, 24\%

Protection of Amphibia by poison, 38

Proteidae, 94, 96, 13\% f.

Proteroglossa, 140

Proteroglypha, 625

Proteus, 96 ; $P^{3}$. anguinus, 133, 134

Protorosauri, 290, 304

Protorosunims linchi, 291

Protosphargis, 336

Protostega, 336

Protriton, 80,81

$P$ sammodromus hispanicus, 558; $P$.algirus, 558

Psammosaurus, 543

Psephoderma, 337

Psephophorus, 336, 337

Pseudechis porphyriaceres, 634

Pseudis, 21\%, 213; P. paradoxa, $213 \mathrm{f}$

Pseudobranchus, 96 ; $P$. striatus, 137

Pseudocentrois, defined, 79

Pseudophryne, 166, 167, 16S; spawning, $223 ; P$. austratis, $168 ; P$.bitroni, $16 S$

Pseudopus, aberrant scaling, $495 ; l$. pallasi, 535

Psendosphargis, 336

Pseudosuchia, 432

Ptenopus, 507; deserticolous, 494

Pteranodon longiceps, 487

Pteranodontes, $4 S \%$

Ptemohyla, 179, 189; 1 . fodiens, 207

Pterodactyli, 486

Pterodactylus longirostris, 4S\%; P. spectabilis, $48 \mathrm{y}$

Pterosauri, 486

Pterosauria, $484 \mathrm{f}$.

Ptyas = Zamenis, 611

Ptychozoon, tail, $506 ; P$. homalocephalum, 512,512 ; adhesive apparatus, 505

Pubis, of Dinosaurs, 414, 424, 426

Pulf Adder, 639, 639

Pygopodidae, 514, 56ry

Pygopus lepidopus, 567

Python, 59S; $P$. molumes, 600, 600; $P$. regins $=P$. sebce, $601 ; P$. reticulatus, 598 ; P. spilotes, 598, 599

Pythoninae, $598 \mathrm{f}$.

Pythonomorpha, $49 \% \mathrm{f}$.

Pyxis arachnoides, 365

Raclde's "law of the steppe," 493

Pana, 241, 249 f. ; sacral vertebrae, 22 ; shoulder-girdle, 25 ; urino-genital organs, 49 ; Tadpoles' horny teeth, 58 ; rocal sacs, 250 ; nuptial excrescences, 250 ; large glandular complexes, 250 ; distribution, 251 ; species with finger-discs, 
$250 ; R$. afghana, $250 ; R$. agilis, $25 \%$; $R$. albolabris, $250 ; R$. alticola, $250 ; R$. arralis, 257; R. catesbiana, 201; $R$. chalconota, $250 ; R$. chloronota. $250: R$. clemata, 262,$263 ; R$. corrugata, 250 : R. curtipes, $250 ;$ R. cyanophlyctis, 250 ; $R$. elegans, $250 ; R$. erythraea, $\approx 50 ; R$. esculenta, 203 ; mechanism of tongue, 268 ; vocal sacs, 269; var. chinensis, 20\%; var. lessonae, 265 ; var. ridibunda. 264 ; var, typica, 265 ; R. fontinalis, $262 ; R$. glandulosa, 250; $R$. gracilis, 261; R. graec, 259 ; R. guрнууі, 261; R. halecina, 263 ; R. hexalactyla, 250 ; R. iberica, $255 ;$ R. latastei, $259 ; R$. liebigi, $250 ; R$. mascariensis, $250 ; R$. montezumae, 250 ; R. mugiens, 261; R. opisthodon, $260 ; R$. oxymynchus, 250: R. nugosa, 250;R. silvatica, $259 ; R$. temporalis, 250 ; R. tempararia, $251 \mathrm{f}$., $255 ; R$. tigrina, 261

Ranidae, $139,237 \mathrm{f}$.

Runidens, 90; R. sibiricus, 109

Paniformes, 139, 140

Raninae, 139, $\sim 3 \%$, $23 S$ f. ; distribution, 239

Rappia, 241

Rat Suake, 611,612

Rattle of Rattle-Suake, 644

Rattle-Suake, 6 ' 4 f., 648,650

Reduction of limbs, in Urodela, 16 ; in Lacertilia, 497

Regeneration, in Amphibia, $66 \mathrm{f}$. ; of tail in Sphenorlon, 298; of shell in Chelonia, 329 ; of horny shields in Chelonia, 329 , 386 : of tail in Lacertilia, 195 ; of tail in Geckos, 506

Regions, geographical, $7 \pm \mathrm{f}$.

Reproduction of Tortoise-shell, 386

Reptilia, defined, $27 \mathbf{7}$; principal clıaracters of, 278 ; classitication of, 279 ; diagram of attinities of principal groups, 2S2; aftinities to Mammalia, 303, 309

Respiration, mode of, in Chelonia, 331 ; assisted by anal sacs, 3:30

Respiratory organs, of Amphibia, $\$ 0$

Rhachiodontinae, 6?3

Phacophorus, 151, 1S6, 238, 241, 241, $246 ; R h$. lexcomystax, 247; tarlpoles, $249 ; R h$. maculatus, nesting, $248 ; R h$. madagascariensis, 245: 11\%. maximus, $245 ;$ Rh. pardalis, 24h, 246; Rh. reinuaralti, $24 \pi$; $R h$. reticulatus, 248 ; Rh. sclilegeli, nesting, 248

Rhempholeon spectrum, 580

Rhamphorhynchus longicaudatus, 486 ; Rh. phyilurus, 4\$SC; Rh. muensteri, 487

Thamphosuches crassidens, 453

likinatrema, 89

Khinemys, 389, 399

Rhinochelys, 390
Rhinoderma, 226, 22\%, 22S; Rh. darwini, $2.25 \mathrm{f}$.

Rhinophis, 91 ; Rh. sanguineus, 596

Rhimophrynus, 166, $16 S$; Rh. dorsalis, 185,227

Phinophrys, 167

Rhombophryne, 225, 22\%

Rhynchocephali, 292

Rhynchoscurus, 992

Rhytidostens, 83

Ribs, of Urodela, 14: of Auura, 21 ; of Microsauri, 288; of Sphenodon, 297; of Theromorpha, 302 ; of Cynognathus, 307 ; of Microgomphodon, 309; of Chelonia, $315,320,324$; of Dinosauria. 413; of Crocodilia, 438; of Parasuchia. 434; of Eusuchia, 439; of Lacertilia, 495 ; of Geckoues, 504 ; much elongated in certain Iguaniclae, 529; meeting ventrally in Chameleons, 568

Ridewood, on hyoid apparatus of Anura, 31

Ringhals, 632,633

Ritter and Miller, on A A todax, 107

Robinson, on peculiar use of Farcenus, $5 \pm 0^{\circ}$

Rodriguez, gigantic tortoises, 374

Rostral bone of Ceratopsia, $\$ 30$

Round Island snake, 603

Sacral vertebrae of Anura, 21, 22

Salamandra, 115 f.; trunk-vertebra, 14 ; skull, 17 ; lower jaw, 17 ; distribution, 96,115 f. ; S. atra, 119 f. ; S. caucasica, 121; S. maculosa, $115 \mathrm{f}$.

Salamandrella, 96,102 ; S. koyserlingi, 109 ; S. schrenki, egg-sac, 110

Salamandridae, 94,102

Salemandrina, 96, 115; - S. perspicillata, 122 ; skull, 17

Salamandrinae, 102, 115

Sarasin, P. and F., 10 ; on Coeciliae, SS ; on Ichthyophis, 90

Sauria, $491 \mathrm{f}$.

Surichnites salamandroides, $\$ 3$

Sauropoda, $41 S$

Sauropsida, 5, 27

Sauropterygia, 476

Saurosternum, 291

Scales of Apoda, 87

Scaling, aberrant, 495

Scaphiophryme, 225, 226, 227

Scaphiopus, 161, 16:; S. solitarius, 165

Scapteira, deserticolous, 494

Seapula, attached to thoracic vertebrae, 487

Scelielosaurus, 416: S. harrisoni, $4: 35$

Schenchzer, on Homo diluvii test is, 84

Schlegel, on Cryptobrauchus, 100

Schuberg, on mechanism of finger-dises of Hylitae, 187

Schwalbe, on Salamandra atra, 120

Scincidae, $514,559 \mathrm{f}$. 
Scincus officinalis, 561

Sciurus bicolor, squirrel, 248

Scolecomorphus, 90

Sea Snakes, 635

Seeley, on fossil Reptiles, $303 \mathrm{n}$.

Seeleya, S1, 2S9

Segmental duct, 49

Sense-organs, of Chelonia, 329 f, ; of Crocodiles, $445 \mathrm{f}$.

Sepedon hatemachates, 632, 633

Seps, 562

Seychelles, gigantic tortoises of, 373

Shell of Chelonia, 321 f., $319,320,321$, $322,323,327$; partial regeneration of, 329 ; correlated changes, 328

Shields, horny, of Chelonia, 322, 323, 325 f., 327 ; evolution of, 326 f. individual variation in, 326,327 periodical peeling of, 328

Shoulder-girdle, of Urodela, 14; of Anura, $24,25,138$ f.; arciferous, 24, 25, 138 ; firmisternal, 24, 25, 138; of Aglossa, 144; of Microsauri, 289; of Protorosauri, 290; of Theromorpha, 302; of Pareiasauri, 305; of Dicynodon, 310 ; of Chelonia, 318, 319, 320 ; of Dinosauria, 414 ; of Eusuchia, 440; of Plesiosauria, 474; of Cryptoclidus, 475 ; of Ichthyosauria, 480, 481 ; of Pterosauria, 485; of Pterchodon, 487; of Pythonomorpha, 488; of Lacertilia, 496

Shufeldt, on Axoiotl, 114; on Heloderma, $540 \mathrm{n}$.

Simoseurus, 477

Siphonops, 86, 87, 90

Siredon (Axolotl), 112

Siren, 96 ; S. lacertina, 136, 136

Sirenidae, 94, 96, 136

Sistrurus miliarius, 647

Skeleton, figured, of Testuclo, $\mathbf{3 1 9}$; of Chelone, 320 ; of Brontosaurus, 418 ; of Ceratosaurus, 422 ; of Stegosaurus, 426 ; of Iguanodon, 428; of Triceratops, 430 ; of Pterodactylies, 485

Skin, of larval Amphibia, 31 ; shedding of, 32 ; glands, 32 ; pigment, 34 ; change of colour, 35; poison, 36 ; of Apoda, 87; of $P i p a, 149$; forms receptacles for eggs, 151, 248; of Eusuchia, $441 \mathrm{f}$.

Skin-glands, of Crocodiles, 443 ; of Lacertilia, 497 ; of Geckones, 504 ; of Snakes, 583

Skull, of Urodela, $16 \mathrm{f}, 17$; of Amblystoma, 17; of Salamandrina, 17; of Salamandra, 17 ; of Anura, $28 \mathrm{f}$; ; of Apoda, 84, 85

Skull, of Reptilia, 280, 281:-of Proreptilia : Cricotus, 287; Eryops, 286 :- of Microsauri, 289:- of Protorosauri, 280 ; Palacolutteria, 280, 291 :- of Rhynchocephali (Sphenodon), 280, 295, 295 :of Theromorpha, 280, 301, 303 ;
Elginia, 280, 305 f. ; Cynognatteres, 280, 306 ; Gordonia, 280, 310 ; Dicynodon, 280, 310 ; Theriodontia, 306; Mammalian resemblances, $308 \mathrm{f}$; Lycoseum 307 ; Endothiodon, 307; Gomphognathus, 308 : Anomodontia, 309, 280 ; Ouderiodon, 310 ; Placodus, 311:- of Mammalia, generalised, 281 :- of Chelonia, 316 f., 280; Sphargis, 335 ; Chelyảridae, 280, 338; Chelydra, 280, 338 ; Chelonidae, 317, 378, 379; Chelone, 317, 378; Thalussochelys, 379 ; Clemmys, 356 ; Testudo, 364; Chelys, 400,344; Trionyx, 405, 404; Chrysemys, 280,316 ; C'istudo, 280, 361: Pleurodira, 388, 400 ; Pelomedusidae, 390 ; Chelydidae, 399, 400 ; Trionychoidea, 401. 405 :- of Dinosauria, 412 fo, 422; Anchisuums, 421; Ceratosaurne, 422 ; Diploilocus, 419 :- of Crocodilia, 280 ; Pseuclosuchia, 432; Parasuchia, 433 ; Eusuchia, 434 f. ; Garialis, 452 ; Crocodilus americanns, 466; C. niloticus, 460 ; C. pulustris, 455 ; C. porosus, 458: Alligator, 468:- of Plesiosaturia, 473 ; Nothosanerus, 477:- of Ichthyosauria, 479; Ichthyosanme, 281 :- of Pterosauria, 484 ; Dimorzhodon, 281 :of Pythonomorpha, 488; Clidastes, 281 :- of Lacertilia, 281; Gecliones, 504 ; Agamidae, 281, 515; Uromastix, 281; Iguanidae, 528; Anguidae, 537 ; Helodermatidae, 540; Varanidae, 281 , 542, 543 ; Varanus, 281 ; Tejidae, 547 ; Lacertilae, 281, 550, 550; Lacerta, 281 ; Scincidae, 559 ; Amphisbaenidae, 565 ; Chamaeleontes, 568, 569 :- of Ophidia, 281, 596, 597, 588 ; Eunectes, 596, 597 ; Crotalus, 588

Slow-worm, 539, 539

SIngs eaten by tortoises, 363

Smell, sense of, of Chelonia, 330

Smith, the, = Hyla faber, peculiar nursing habits. $196 \mathrm{f}$.

Smooth Snake, 619, 620

Snakes, 581 f. ; skull, 581 f. ; 281,588 , 596, 597 f. ; vertebrae, 582 ; general anatomical structure, 583 f.; geographical distribution, 585 f., 585 ; classification, $592 \mathrm{f}$.

Snake-charming, 631

Snake-poison, $586 \mathrm{f}$.

Snake-stones, $629 \mathrm{f}$.

Snapping Turtle, $388 \mathrm{f}$.

Soft-shelled Turtle. 408

Sound produced by rubbing of scales of Teratoscincus, 507

Spade-foot, 162

Spelerpes, 94, 96, 97, 103, 104, 106 ; S. altamazonicus 104; s. bilineatus, 104; $S$. fuscus, 104, 105; tongue, 106 ; $S$. infuscatus, $104 ; S$. lineolus, $104 ; S$. 
parripes, $104 ;$; porphyriticus, $105 ; S$. salmoneus, $105 ; S$. subpalmutus, 104 ; S. uniformis, 104

Spencer, on habits of Chiroleptes, $221 \mathrm{f}$.

Spermatophores, 53, 128

Spermatozoa of Amphibia, $52 \mathrm{f}$.

Sphargidae, $313,31 \%, 333$ f. : attinities, 336 ; morphology of shell, 337

Sphargis coriacea, $333 \mathrm{f} ., 334$; absence of horny shielils, 325

Sphenoilon, 28S, 290, 305, 306, 432; S. menctatum, 293, 294; skull, 295; cervical vertebrae, 297 ; haljits, $298 \mathrm{i}$.

Siphenophryne, 225, 23?

sphenosantus, S?, 287

Spiny-tailed Lizard, 52.4 f.

Spiracle, derelopment, 45

Spotterl Newt, $13 \gamma$

Spy-Slange, (6.3:3

st. Helena, gigantic tortoises introduced, 375

Stagonolepis, 434

Stannius, 8, 139: on vertebrae of Pelobates, 20

Stanrotypus sulvini, 342

Stegocephali, 78 f.; St. Lepospondyli, 80 f.; st. Temnospondyli, $S 1 \mathrm{f}$.; St. Stereospondyli, 83 f.; vertelorae, 78 f. ; shoulder-girlle, 79 ; dermal armour, 79

Stegosauri, 4:5.5

Slegosanmes armatus, 425; S. unyulatus, 426,426

Slensdactylus, deserticolous, 494 ; sleeping attitude, 509

Slereocyclops, 227, 231; S. incrassatus, $\therefore 1$

Stercorhachis, sOS

Stereospondylius vertebrae, defined, 284

Sternothaerns, 321, 389, 390; S. derbicnus, 341; shields of, $\mathbf{3 2 7}$

Sternum, of Urodela, 15 ; of Anura, 25 ; taxonomic value, 111,142 ; of Spleenzollon, 297 f. ; Protorosauri, 290 ; Dinosauria, 414 : Eusuchia, 440

Stewart, quoted, on Ileloderma, $540 \mathrm{~m}$.

Stinkpot Terrapin, 342

Suboceipital (first spinal nerve) of Anura, 144

Subregions, geograplical $7 \pm \mathrm{f}$.

Syrrhopus, 212

Systomata, 139

Tarlpoles, horny teeth of, 58 f. : of Ifegalnphrys, 59,60 ; absorption of tail, 61 f.; of Jenopus, 147, 118; of Bombinator, 157; of Alytes, 159 ; of IIyla arborea, 193; of $\mathrm{H}$. versicolor, 185; of Jufo rivilis, 181; of 13 . culemite, 183 : of 1 B. velgaris, 176 : of Thuropa miliaris, 209; of P'seudis prerculure, 213; of Hyledes martinicensis, 214; of Rhinuderma dervini, "229; of
Arthroleptis seychellensis, 243; of Rana temperaria, 255; of $R$. opisthocton, 260; of $R$. esculenta, 270

Tail, of Anura, 2I, 24; its absorption, 61 : of Chelonia, 328; of Geckos, rarious shapes, 506 ; reproduction of, 506

Tarentola mauritanica, 508, $509 \mathrm{f}$.

Tarsus (see also Limbs), of Chelonia, 319, 320,321 ; of Dinosauria, $416,418,420$, $421,423,426$; of 'Theropoda, 420 ; of Compsognathus, 423; of Iguanodon. 425

Teeth, of Anura, 30, 138, 139 ; substitutes for, 30, 58, 218, 237; of Apoda, 86 ; of Phyncliosanrus, 292; of Homoeosaurus, 292; of Rhyuchocephali, 292; of Sphenodon, 296; of Theromorpha, 301; of Elginie, 306, 280; of Cynognathus, 306. 280 ; of Lycosaurus, 307 ; of Galesaurus, 307; of Endothiodon, 307; of Empalias, 30s; of Stereorhachis, 308; of Gomphognathus, 308; of Tritylndon, 309 ; Nammalian resemblances, 309 ; of Anomodontia, 309 ; of Dicynoulon, 280. 310 ; of Gordonia, 280; of Placodus. 311 ; of Sauropoda, $418 \mathrm{f}, 419$; of Theropoda, 420 f., 422 ; of Orthopoda, 124 f.; of Eusuchia, 437 ; of Ichthyosauri, 479 ; of Snakes, 582

Tejidne, $514,54 \tau \mathrm{f}$.

'Тејu, 5.45, 548

Teleosanridae, 450

Teleosuzurus, 451

Telerpeton elyinense, 291

Temnospondylous vertebrae, defined, 284

Temperature of blood, $67 \mathrm{f}$. ; of water for Crocodiles, 460

Tennent, on immunity of Cobras, $629 \mathrm{f}$. ; on turtles at Ceylon, 384, 386; on habits of Cincodilus palustris, $456 \mathrm{f}$. ; on habits of C. porosus, 459 ; on peculiar use of Iteranus, 545; on habits of Gecko, 511

Tentacular apparatus of Apoda, 45, 86, 88 Tephrometopon, 493

Teratoscincus, deserticolous, 493 ; eye, 494 ; T. scineus, $51 \%$ i

'T'errapin, 35.' f.

'Testis, 49

Testudinilae, $313,314,345$ : distribution. 332

Testuitr, 365 ; skeleton, 322,323 ; shielils of, $327 ; T$. abingdoni, 376,$378 ; T$. atles, $37.2,377 ; T$. daudini, 375,376 : $T$. deguns, 370 fo; $T$. elephantina, 3\% 4; $T$. elephantopus, 3\%S; $T$. ephippium. $37 S ; T$. giganter, $3 \% 4 ; T$. graeca, 375 t. ; habits, 367 ; eggs, 369 ; great age. $369 ; T$. grandiulieri, $373 ; T$. hersielli, $3 \% 0 ; T$. iherce, 366 ; age attained, 369 ; ritte of growth, $370 ; T$. marginata, $367 ; T$, perpigniana, $372 ; T$. poly- 
phemus, 371 f. ; $T$. sumeirei, 376; $T$. vosmaeri, 373,377

Tetradactylus, 559; T. africanus, 559; T. seps, 559

Tetrapola, Creclner's name for "four. footed "creatures in opposition to the tishes, which have fins, 4,11

Thalassemsdidae, 380

Thalassochelys caretta, individual variation of slields, $326,327,38 \%$; skull, 379

Thecophora, definition of term, 337, 338

Theobald, on Varanus, 544

Theriodontia, 306

Theromorpha, 300, 301 ; skull, 280, 301 ; their affinity to Manmals, $303 \mathrm{f}$, 309

Theropoda, 420

Thilenius, quoted, $571 \mathrm{n}$.

Thoracosaurus, 451

Thorius, 96, 103; Th. jennatulus, 103

Thoropa, 186, 189; Th. miliaris, 209

Tiger Snake, 634

Tiliqua s. Cyclodus. 561

Toes, number of, in Urodela, 16 ; in Aunra, 28 ; of Geckos, structure, 505, 505

Tomistoma, 435, 436, 450; T. schlegeli, 453

Tongue, of Amphibia, nerve-supply, 39 ; shape of, in Anura, 47; of Spelerpes, 106 ; absent in Aglossa, 145; of Rana esculenta, 268 ; of Crocodiles, 443 ; of -Lacertilia, 498; of Chameleons, 569 f.

Tortoise, Greek, 365 f. ; habits, 367 f. ; Morocean, 366 ; habits, $367 \mathrm{f}$; Starred, $3 \% 0$ f. ; Gopher, 371 f. ; Gigantic LandTortoises, $3 \pi 2 \mathrm{f}$.

Tortoises $=$ Chelonia, $312 \mathrm{f}$.

Tortoise-shell of commerce, 386

'T'rachea, of Crocodiles, 443

Trachysaurus, 560, 560; T. rugosus, 560, 561

Tree-frogs, $185 \mathrm{f}$ : : change of colour, 35

Trematosaurus, 80, 83

Tricercetops, $413 ; T$. prorsus, 430,$430 ; T$. Habellatus, 430

Trichobatrachus, 240; T. robustus, 27 I

Trigonocephalus cenchris, 645, 645, 64t, 646

Trimerorhachis, 82

Trionychidae, 313 ; distribution, 333

Trionychoidea, $313,314,404 \mathrm{fo}$; habits, 407

Trionyx, nuchal plate, 324; skull, 405; plastron, 406; number of costal plates, $325 ; T$. ferox, 408, 409; $T$. formosa, 411, 411; $T$. gangeticus, 410 , 410; T. hurem, 410; T. trinnguis, 410

Triprion, $179,185,189 ; T$. petasatus, 207

Trirhachiodon, 309

Triton, 122 f., 96, 115, 125, 128, 131 ; fossil. 83 ; snermatophores, $53 ; T$. alpestris, 123,$126 ; T$. asper, 123,$130 ; T$. blasii, 126; T. boseai, 123, 127; T. cristatus, $122,125.125 ; T$, hagenmuelleri, 123; T. hetreticus, $12 \% ; T$. italicus, $12 \gamma$; T. marmoratus, 122,126 ; T. montadoni, $12 \%$; $T$. montenus, 123 , 130 ; T. palmatus, 107; T. poireti, $123 ; T$. punctatus $=$ vulyuris, $12 \gamma ; T$. pyrenceus, 130; T. myrhogaster, 123 , $128 ; T$. mesconii, 123,$130 ; T$. sinensis, $123,12 S ; T$. taeniatus =vulgaris, 127 ; T. torosus, 123, 12S; T. riridescens, $123,12 S$; egg, $128 ; T$. vittatus, 122 , $12 S ; T$. vulgaris, 123, 127; T. walli, $123,130,131$

Tritylodon, 301, 309

Tropidonotus, 607; T. natrix, $60 S$ f. ; $T$. ordinatus, $611 ; T$. sirtalis, 610,611 . T. tesselatus, 611

Tropielosaura, 558

Tupinambis, $548 ; T$. tegnixin, $548 ; 1$. nigropunctatus, $548, \mathbf{5 4 8}$

Turtles, $37 \$$ f. ; skull, 317,379 ; skeleton. 320 ; plastron, 321 ; on Laysan Islauds, 383 ; Green or Edible, 381 f.; Hawksbill, 384,385

Tylototriton, 96, 115 ; T. andersoni, 130 ; T. verrucosus, 132

Tympanic cavity, reduction of, in Anura, 30 ; in Ophidia, 583

Tympanum of Aglossa, 143

Typhlomolge, $96 ; T$. rathbuni, 135

Typhlonectes, 87, 90; T. compressicanda, 93

Typhlopidae, $592,593 \mathrm{f}$.

Typhlops, 91; T. braminus, 594; T. vermicularis, 594

Typhlosaurus, 564

Typhlotriton, 94, 96, $102 ;$ T. spelceus, 10.3

Urueotyphlus, 86, 89

Ureter, 48 f., 49

Urino-genital organs, 48 f., 49

Urocordylus, 81,288

Urodaeum of Chelonia, 330

Urodela, $94 \mathrm{f}$. ; geographical distribution, 96

Uromastix; 524; U. accenthinumes, 5:6, $526 ; U$. hardwicki, 595

Uropeltidae, $59: 595$

Uropeltis, 595 ; U. grandis, 595

Uroplates, 512

Uroplatinae, 512

Urostyle, of Autra, 23 ; of Chelonia, 328

Varanillae, 514, 542 f.; skull, 542 ; distribution, 543

Tarannes, $543 ; V$.gouldi, $546 ; \mathrm{V}$.griseus, skull, 542; $V$. niloticus, $543 ; \quad V$. sulvator, 543 f.. 546

Vas deferens, 48 f., 49

Vertebrae, procoelous, definition, 19, 138 ; 
acentrous, i.e. without a centre or body, 4 ; amphicoelons, defined, 12; of Urodela, 11 ; gastrocentrous, defined, 2S2 ; lepospondylous, 5 ; defined, 78 ; notocentrous, 4 ; defined, 19 ; opisthocoelous, defined, 12, 13S; pseudocentrous, 4. 75 ; stereospondylous, defined, 79 , 281 ; temnospondylous, 13 ; defined, 79 , 281: derelopment of-in Urodela, 12, 13 ; in Anura, 19; of trunk of Salamanelra, 14; epicliordal, 20 ; sacral, of Anura 22; shifting forwards of sacral attachment of ilium, 23 ; of Reptilia, composition of, 283, 288; trunk-

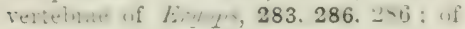
Cricotus, 2S7; of Microsauri, 289; of Sphenodon, 294, 296, 297 ; atlas and axis of Sphenolon, 283; of Theromorpha, 302 ; of Pareiasauri, 305 ; atlas fused with axis in Cynognathus, 307; of Dimetrodon, with peculiar processes, 30s; of Chelonia, $31 \pm \mathrm{f}$; atlas of Triony.c, 283 ; of Chelys, 283 ; of Dinosauria, 413 ; hollow in Dinosaurs, 415 , 120; of Eusuchia $438 \mathrm{f}$ : ; atlas and axis of Crococlilus, 283; of Metriorhynchus, 283 ; of Pterosauria, 485 ; of Ichthyosauria, 480 ; of Pythonomorpha, 485; of Lacertilia, 494 ; of Geckones, 503 ; of Snakes, 582

Tertebral column, instance of greatest shortening, 144; of Urodela, 11, 13 ; of Stegocephali, 78 ; of Anura, 18 f., 21, 22 ; Pulacobatrachus, 22 ; Pipa, 22, 143; IIymenochinss, 22, 143; Bombinator, 22 ; Tenopus, 21, 143; of Apoda, 86; number of vertebrae of Protorosuzurus,

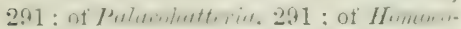
seurus, 292; of Sphenodon, 297; of Cynognathus, 306 ; of Iguanodon, 428 ; of Eu-whisa, 110: of Pl-cisauria, 4it: of Elasmosauriclae, 478

Vesiculae seminales, 49,51

Viper, Common, 641 f., 620, 642

Tipera, 6.11; T". ammalytes, 641, 643; V. aspis, 643; I. bernes, 641.642, 620; I. Iatastei, 643 ; I. russelli, 643

Viperidae, 592, 593, 637
Viperinae, $63 S$

Viperine Snake, 610

Vis, de, on Chlamyulosaurus, 523

Viviparous, Chameleon, 572; Lacertilia, 499 ; Geckos, 506

Vocal sacs, 47 f. ; of Paludicola, 220 ; of Rhinalerma, used as brood-pouches, 228

Voeltzkow, on nesting of Crocodiles, $462 \mathrm{f}$. ; on Testudo daudini, 375

Voice, 47

Wagler, 8

Wallace, on Rhacouhorus, $216 \mathrm{f}$.

Wall-Lizard, 55\%

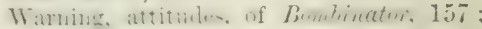
colours, 38, 116, 156; of Heloderma, 541

Water-Viper, 6ł5, 645

Weismanu, on Arolotl, 64, 114

Werner, ou Eryx, 604

White's aged 'Tortoise, 369

Wilder, on Desmognathus, 103

\section{Tentusio, 547}

Xantusiidae, 514, 547

Tenobatrachus, $225 ; \boldsymbol{I}$. ophiodon, 228

Xenopeltidae, 593, 605

Tenopeltis unicolor, 605

Ienopus, 143 ; distribution, 143, 144, 146 f. : I. calcaratus, $146 ; 1$. lacris, $146 \mathrm{f}$., $147 ;$ I. muelleri, 146

Tenorhina, 228

Tenosauridae, 513,536

Tenosaurus grandis, 536

\section{Zachaenus, 212}

Zamenis constrictor, 613 ; Z. gemonensis s.

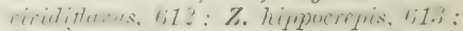
Z. mucosus, 611,612

Zanclodon, 417, 421

Zituler. on liahits of 1 iroma. 520 : of Phrymocephalus, 522 ; of Eryx, 604

Zaocys carinatus, 614,615

Zatachys, $\mathcal{S}_{2}$

Zeller, on spermatophores, 53 ; on Proteus, 134

Zonuridae, 513, 536

Zonumus derbianus s, giganteus, 536, 537

END OF VOL. VIII 


\title{
THE CAMBRIDGE NATURAL HISTORY
}

\author{
Edited by S. F. Harmer, Sc.D., F.R.S., Fellow of King's College, \\ Cambridge, Superintendent of the University Museum of Zoology; \\ and A. E. Shipley, M.A., Fellow of Christ's College, Cambridge, \\ University Lecturer on the Morphology of Invertebrates.
}

\section{To be completed in Ten Volumes. 8vo. Price 17s. net each}

Intended in all respects to be a Standard Natural History accurate enough to be of use to the Student, and at the same time popular enough for the general reader who desires trustworthy information as to the structure and habits of all members of the Animal Kingdom, from the Protozoa to the Irammals. The Volumes are fully illustrated by original figures drawn where possible from nature. When complete the Series is one which should be indispensable in all Libraries, whether public or private.

\section{WORMS, LEECHES, ETC.}

\section{VOLUME II *}

Flat Worms. By F. W. GaMble, M.Sc. Vict., Owens College.-Nemertines. By Miss L. SHeldon, Newnham College, Cambridge.-Thread-worms, etc. By A. E. Shiplex, I.A., Fellow of Christ's College, Cambridge.-Rotifers. By Marcus Hartog, M.A. Trinity College, Cambridge, D.Sc. Lond., Professor of Natural History in the Queen's College, Cork.-Polychaet Worms. By W. Blaxland Bexhasi, D.Sc. Lond., Hon. M.A. Oxon., Professor of Biology in the University of Otago.-Earth-worms and Leeches. By F. E. BEDdArd, M.A. Oxon., F.R.S., Prosector to the Zoological Society, London.-Gephyrea, etc. By A. E. Shiplex, M.A., Fellow of Christ's College, Cambridge.Polyzoa. By S. F. HArmer, M. A., F.R.S., Fellow of King's College, Cambridge.

CAMIBRIDGE REVIEW.--"Several of the groups treated of in this volume are unknown by sight even, to the general reader, and possess no popular name whatsoever; and as only a few insignificant details are known of the habits of the animals composing them, their treatment in the volume before us has necessarily been to a large extent anatomical. This circumstance renders the book of especial value to students, more particularly as in some cases the articles on the groups in question are the first comprehensive ones dealing with their respective subjects. . . . IIost of the articles are of a very high order of merit-taken as a whole, it may be said that they are by far the best which have as yet been published. . . . We may say with contidence that the same amount of information, within the same compass, is to be had in no other zoological work."

NATURAL SCIENCE.- "This second volume of the Cambridge Natural History is certain to prove a most welcome addition to English Zoologieal literature. It deals with a series of animal groups, all deeply interesting to the specialist in morphology; some important from their economic relations to other living things, others in their life-histories rivalling the marvels of fairy-tales. And the style in which they are here treated is also interesting; history and the early observations of the older writers lend their charm; accounts of habits and mode of occurrence, of life, in a word, from the cradle to the grave, are given in ample detail, accompanied by full references to modern and current literature. The whole is admirably illustrated." 


\section{S H E L L S}

VOLUME III

\section{Molluscs and Brachiopods.}

By the Rer. A.H. Contr. M.A., A. E. SHILt.Y, M.A., and F. R. C. Rerm. M.A. TIMES- "There are rery mant, not only anong educated an interest in science, lut even anoing specialists. who will peorle who alk redsonahle compass and hamly fum containing a trustworth treleme a work of Farious defrartments of Natural History. in a trustworthy treatment of til. competent to deal with. the late-t results of men who are familiar with. an

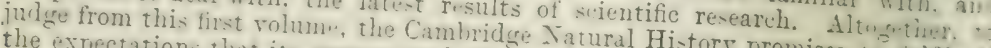
the exrectation. that its pro-jw.tus holls out atural History promises to tulfi! wl

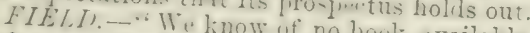

such a vast fund of infurutiun ou a railable to the general rearl.r which affor is

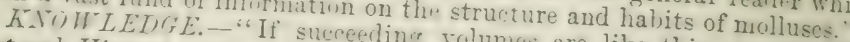

Natural History will rank as one of the finw-t work this one, the Cumbring. as one of the fine-t works on natural history $6 \cdots \cdot \mathrm{r}$

ATHEY.EY Y. - "The series certainly ond not to be restricted in i

tion to lecturers and sturlents only: and, if the fortheomintricted in its cirmia.

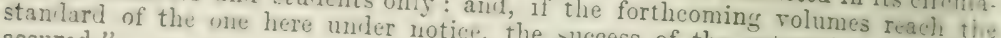
rotice, the success of the enterprise shoulil ie

\section{INSECTS AND CENTIPEDES}

VOLUALE V

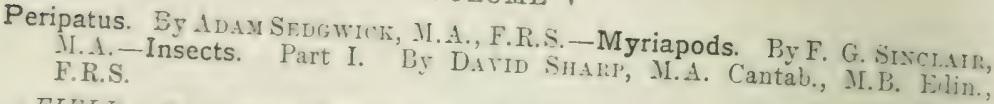

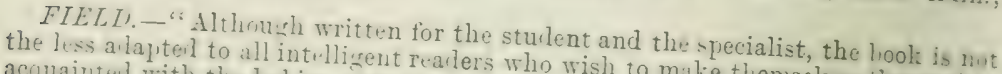
acinaintel with the habits, structures who wish to make themselres thorough!y of which it trwats. To :uch it cannot and the molern classification of th aninals

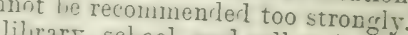

lossess this work, which is of the litars, sclool, and college in the country shonl i

P'F. liAPIAEI WEI of the lin liest elucational value.

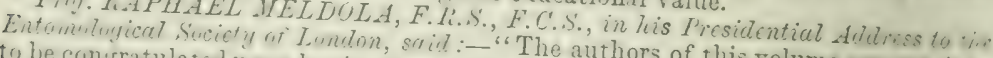
to be consratulatel uron having furnished such a thors of this rolume are certainity

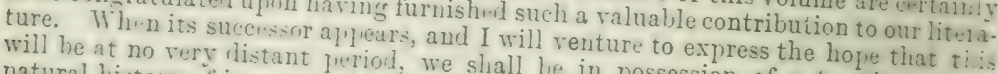
natural history of inswets whir.h, from the roint of riossion of a treatise on the confre mont farourahly with any sine glont of riew of the general real.r. wiil

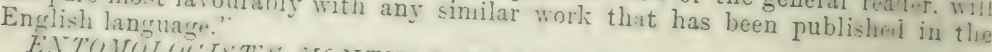

work will he fouml indispens beyon l the narrowing inflicen... of exw who seck to exteud their gen ral knowlerige

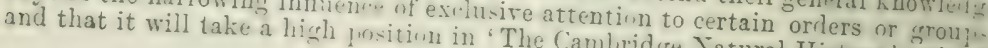

\section{INSECTS-PART II}

\section{Hymenoptera continm? Tubulifera Lepidoptera, Diptera, Aphanipter By David Sinir, F.R.S.}

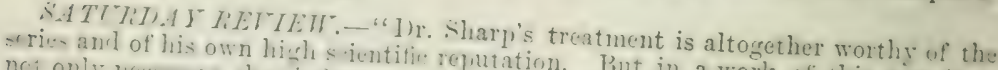

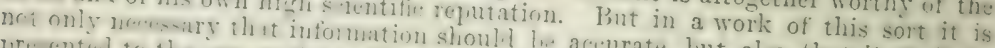

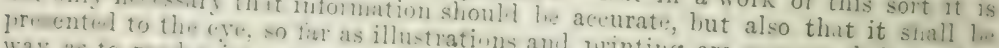

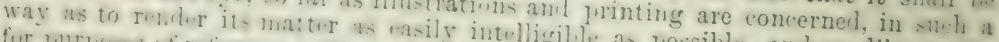

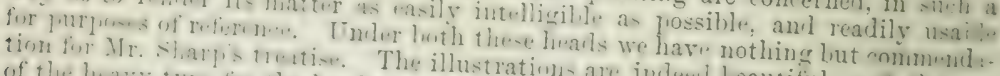

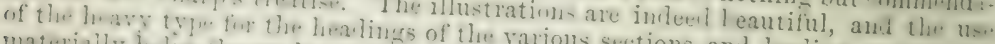

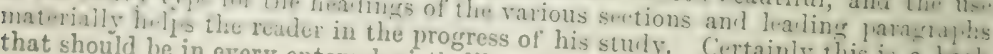
that should be in every entomologist's library." stuly. Certainly this is a hook 
DAILY NEIVS.- "It would be hard to say too much in praise of this most admirable volume. It is too often the case that scientific books are written in a dull and uninteresting style. The reader will find nothing of that kind to complain of here. The descriptions are clear, the illustrations are excellent: while, as in the previous volumes of the series, printing and paper are all that could be desired."

$S P E A K E R$. - "Amateur naturalists will find the volume of the createst possible assistance, while serious workers will welcome it as an extremely convenient handbook, in which the latest results of original research at home and abroad are clearly and succinctly summarised. No book so comprehensive and of such ralue has appeared since Westwood's Classification marked an epoch in the literature of entomology sixty years ago."

LITEI IAURE. - "We may confidently expect it will take a similar position to that which Westwood's Introduction has so long occupied. . . A An immense amount of well-selected matter, much of which is by no means easy of access, has been brought together and made available for instant reference by an index extending over twenty-four pages, in double columns."

\section{AMPHIBIA AND REPTILES}

VOLUME VIII

By H. GADow, M.A., F.R.S.

[Ready.

\section{BIRDS}

\section{VOLUME IX}

By A. H. Evans, M.A., Clare College, Cambridge. With numerous Illustrations by G. E. LODGE.

IBIS.- "Nr. Evans has produced a book full of concentrated essence of infurmation on birds, especially as regards their outer structure and habits, and one that we can cordially recommend as a work of reference to all students of ornithology."

NATURE NOTES.- "We venture to predict that, of the ten volumes of which this excellent series is planned to consist, none will secure a wider popularity than Ir. Erans's treatise on birds. Strange as it may appear, among the many books on birds that have appeared of late years, we do not recall any that covers the same ground. ... We are grateful to the author for the nine of valuable information which he has crowded between his two covers."

SCIE ${ }^{\prime} C E$ GOSSIP. - "General readers will find this work most useful in obtaining a proper understanding of birds, and will be assisted by the effective diagram of a hawk in the introduction, showing the recognised names of every part of the exterior appearance. The expressions used in naming the various portions are fully explained on the adjoining page. As we have already said, the illustrations are admirable. The book is a useful addition to any library, as it treats of nearly every known kind of bird throughout the world."

NATURALISTS" JOURNAL.— "As a descriptive handbook the student can have no better. : . We have no hesitation in saying every ornithologist ought to

SATURDAY REVIEW.- "The expert and the novice alike must be at once delighted by the accuracy and the beauty of the illustrations. . . . It is astonishing to note the mass of information the author has been able to bring together. . $\therefore$ With a little practice any observant person would soon learn by the help of this volume to track down any bird very nearly to its ultimate place in classification."

LITERATURE. - "The classification-in the main that of Dr. Hans Gadow-is admirable. . . The general account prefixed to the Orders and Sub-Orders is excellent; the illustrations, drawn for the greater part hy Mr. Lodge, are admirably characteristic. In a serviceable introduction the author has shortly dealt with feathers, colour, moult, structure, and the leading facts of migration. The book, as a whole, is a reflection of conscientious and accurate labour. . . The accuracy of the work is beyond all challenge."

$S P E A K E R$. - "It is safe to conclude that all working ornithologists will place this volume on their shelves within easy reach, and not far from Newton's 'Dictionary of Birds'; and we have great pleasure in recommending it to all who take an intelligent interest in birds and bird-life as an admirable introduction and guide to the study of the subject. . . The illustrations by Mr. G. E. Lodge are admirable. All reach a very high level of excellence, and for a few no praise can be too high." 


\section{COMIPLETE LIST OF SERIES}

To be completed in Ten Volumes. Svo. 17s. net each.

\section{VOLUME I}

Protozoa. Mancte HArtur, M.A., Trinity College (Professor of Tatural History in

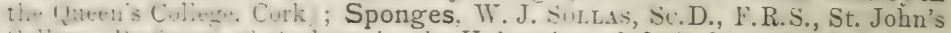

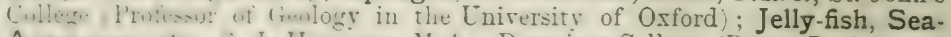
Anemones, etc. S. I. Hik-1)s, II.A., Downing College (Beyer Professor of

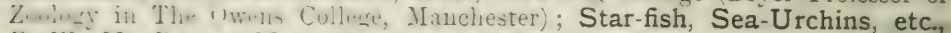
E. W. Macbrinm. M.1., st. John's Collecre (Professor of Zoolog5, IIcGill University, Montreal).

\section{VOLUME II}

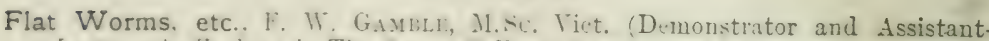

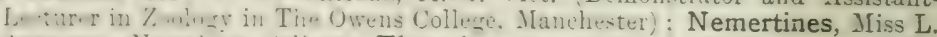

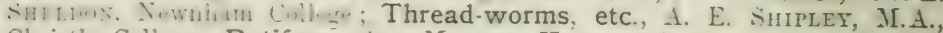
Christ's College; Rotifers, etc., Marcus Hartog, M.A., Trinity College,

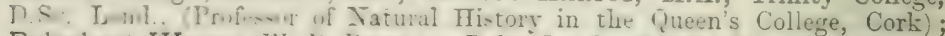
Polychaet Worms. WV. M. limxns, D.Sc. Lond.. F.R.S., Hon. M.A. Oxon.,

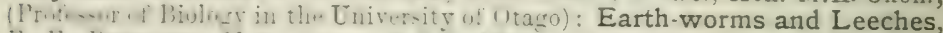

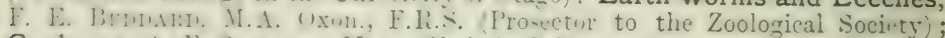
Gephyrea. A. E. SHALI, M.A., Christ 's Colle ge; Polyzoa, S. F. HA MEr, J.A., F.R.S., King's College.

[Ready.

\section{VOLUMIE III}

Molluscs. A. H. Cinnt, M.A., Kin's cillece: Brachiopods (Recent), A. E. SHII: M. MI.A. 'hrist' = Cullege; Brachiopods (Fossil), F. R. C. IIEED, M.A., 'Trinity College.

\section{TOLUIE IV}

[Ready.

Spiders, Mites, etc., C. Waretrius, M.A., Christ's Cullecre (Zoolorist to the Popal

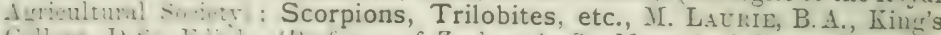

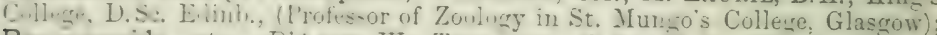
Pycrogonids, etc., D'Al:or W. Trmmpsos, C.IF, M.A., Trinity Collexe

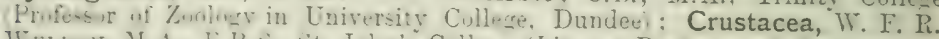
Wentws, M.A., F.R.s., St. John's College (Linacre Prolessor of Comprative Anatomy in the University of Oxford).

\section{VOLUME V}

Peripatus, A. Snm,wrok II A., F.R.S., Trinity Cull-ge; Centipedes, etc., F. G.

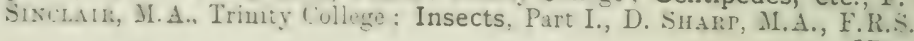

\section{VOLUME VI}

[Rcady.

Insects, Part II., D. SHAlp, M.A., F.R.S.

[Ready.

\section{VOLUME VII}

Balanoglossus. etc., S. F. H inmin, Sr..., F.I.S., King's Colle a ; Ascidians and Amphioxus. W. A. Inemus, D.si. Taml. F.R.S. (Propson of Xatural

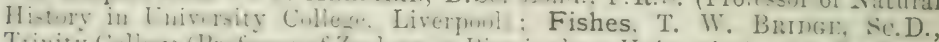

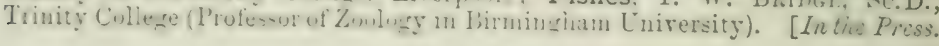

\section{VOLUME VIII}

Amphibia and Reptiles. H. G.IDw. M.1.. I.R.S., Fing's Cullege.

[Riculy.

$$
\text { VOLUME IX }
$$

Birds, A. H. Evaxs, M.A., Clare College

[Ready.

\section{VOLUME $\mathrm{X}$}

Mammals, F. E. BFinisin, II.A. WxuH., F.li.S. (Prostctor to the Zoological Society).

$$
\text { MACMILLAN AND CO., LTD., LONDON. }
$$




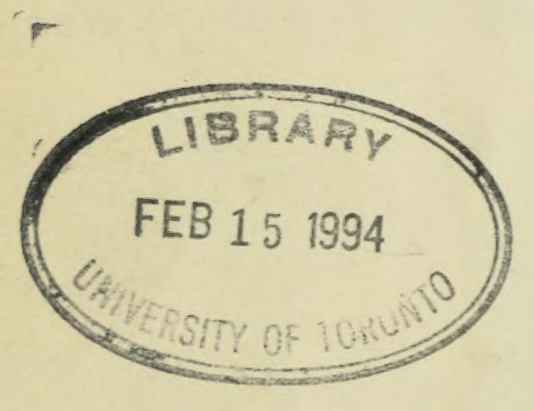



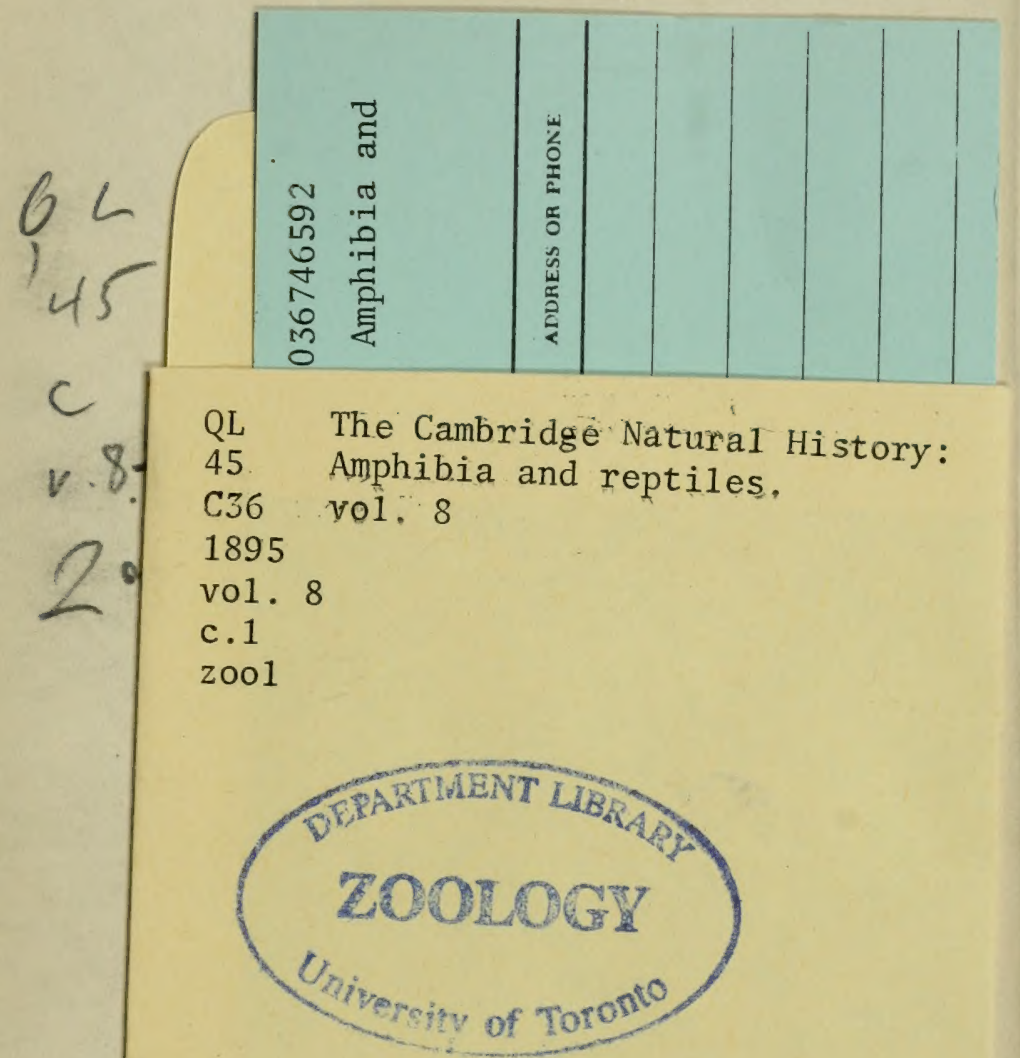
